\title{
Metamorphosen in inneren Räumen
}

Video- und Performancearbeiten der Künstlerin Ulrike Rosenbach 

Meike Rotermund

Metamorphosen in inneren Räumen

This work is licensed under the Creative Commons License 3.0 "by-nd", allowing you to download, distribute and print the document in a few copies for private or educational use, given that the document stays unchanged and the creator is mentioned.

You are not allowed to sell copies of the free version.

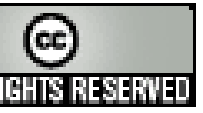


erschienen im Universitätsverlag Göttingen 2012 
Meike Rotermund

Metamorphosen in inneren Räumen

Video- und Performancearbeiten der Künstlerin Ulrike Rosenbach

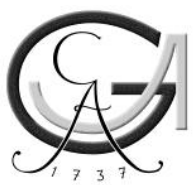

Universitätsverlag Göttingen 2012 


\section{Bibliographische Information der Deutschen Nationalbibliothek}

Die Deutsche Nationalbibliothek verzeichnet diese Publikation in der Deutschen Nationalbibliographie; detaillierte bibliographische Daten sind im Internet über $<$ http://dnb.ddb.de $>$ abrufbar.

Autorenkontakt

Meike Rotermund

E-Mail: mrotermund@gmx.de

Dieses Buch ist auch als freie Onlineversion über die Homepage des Verlags sowie über den OPAC der Niedersächsischen Staats- und Universitätsbibliothek (http://www.sub.uni-goettingen.de) erreichbar und darf gelesen, heruntergeladen sowie als Privatkopie ausgedruckt werden. Es gelten die Lizenzbestimmungen der Onlineversion. Es ist nicht gestattet, Kopien oder gedruckte Fassungen der freien Onlineversion zu veräußern.

Satz und Layout: Alice von Berg; Derzi Csongor

Umschlaggestaltung: Franziska Lorenz

(C) 2012 Universitätsverlag Göttingen

http:/ / univerlag.uni-goettingen.de

ISBN: 978-3-86395-051-4 


\section{Inhaltsverzeichnis}

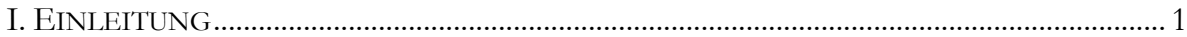

II. ZUGÄNGE

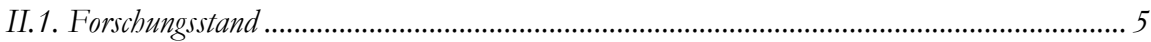

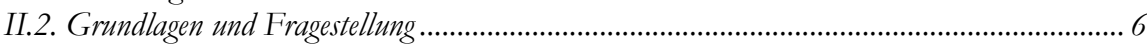

II.2.1. Videotapes - ein kurzlebiges Medium mit Gestaltungsmöglichkeiten............................. 6

II.2.2. Closed Circuit - Das eigene Bild kontrollieren ................................................................11

II.2.3. Multimediainstallationen - In den Raum eingebundene Sichtweisen ...........................12

II.2.4. Aktionskunst - Strategien künstlerischer Intervention im Leben ..................................12

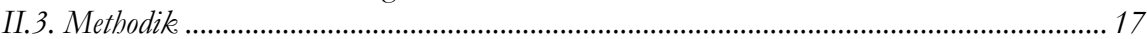

II.3.1. Herausforderungen prozesshafter Kunstformen..........................................................18

II.3.2. Anleihen aus der Filmanalyse ........................................................................................... 19

II.3.2.1 Begrifflichkeiten und Untersuchungsverfahren ......................................................19

II.3.2.2 Übertragbarkeit dieser Verfahren auf künstlerische Videotapes ............................24

II.3.3. Kunstwissenschaftliche Methoden ..................................................................................2

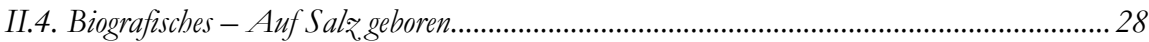

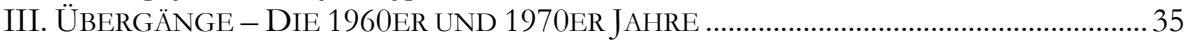

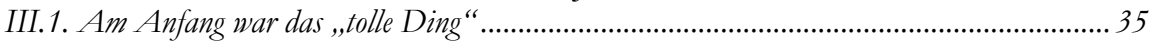

III.1.1. Joseph Beuys und die Ausbildung an der Kunstakademie in Düsseldorf...................41

III.1.2. Politische und künstlerische Aufbrüche ........................................................................46

III.1.3. Vom Objekt zur Aktion: Erste Arbeiten als freischaffende Künstlerin .......................52

III.1.4. Erste Video-Live-Aktionen .............................................................................................. 54

III.2. Die Kunstszene im Rheinland in den 1960er und frühen 1970er Jahren ..........................63 63

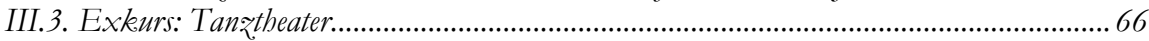

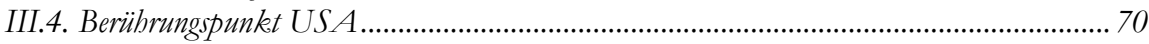

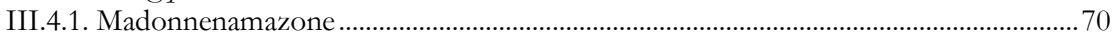

III.4.2. Exkurs: Destruktive Tendenzen in der Kunst.................................................................73

III.4.3. Begegnungen mit amerikanischen Künstlern .................................................................77

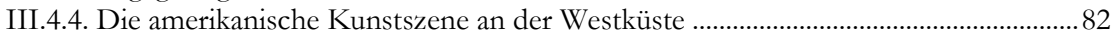

III.4.4.1 Judy Chicagos und Miriam Shapiros Feminist Art Programm.............................. 84

III.4.4.2 Im Licht der Venus .............................................................................................. 91

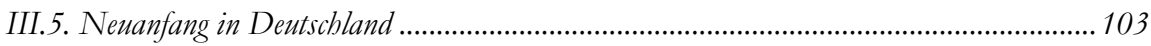

III.5.1. Die Schule für kreativen Feminismus .........................................................................103

III.5.2. Fotografische Arbeiten für die Zeitschrift „Emma“........................................................105

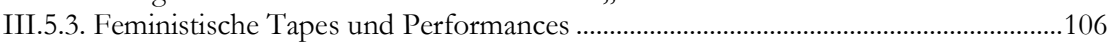

III.5.4. Exkurs: Mythos, Symbol, Metapher und Ritual .............................................................113

III.5.4.1 Ritual: Funktion und Wirkung ...........................................................................114

III.5.4.2 Ritualität in der zeitgenössischen Kunst ...........................................................117

III.5.4.3 Rituale in den Aktionen von Ulrike Rosenbach ...............................................120

III.5.5. Die documenta 6 im Jahr 1977 in Kassel ....................................................................124

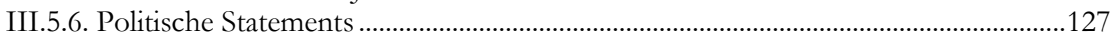

III.5.7. Erste Grenzgänge ................................................................................................ 141

III.6. Kleine nicht-narrative Schleifen: Die Ikonographie der Werke der 1970er Jahre ............. 149

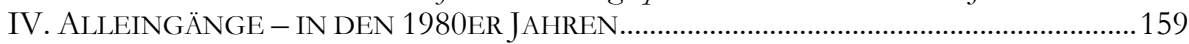

IV.1. Die Dekade der 1980er Jahre im Kontext der Politik und Kultur................................ 159 
IV.2. Werkekomplex: Mutter-Tochter-Beqiehungen ………................................................... 162

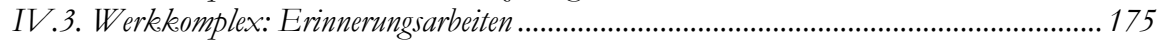

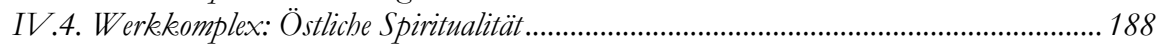

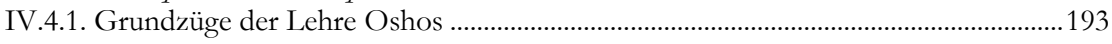

IV.4.2. Einflüsse auf das künstlerische Werk Ulrike Rosenbachs ........................................195

IV.4.3. Tanzend die Mitte finden............................................................................................220

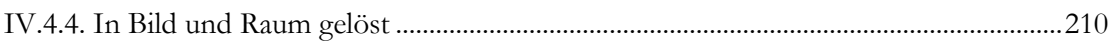

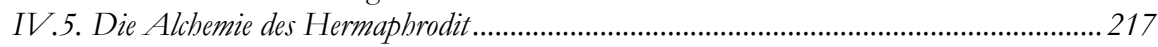

IV.5.1. Werkuntersuchung: Begegnung mit Ewa und Adam ................................................22

IV.5.1.1 Die Ideenwelt der Alchemie ................................................................................224

IV.5.1.2 Die Deutung der Alchemie im Werk C.G. Jungs..................................................227

IV.5.1.3 Dem Traum Bilder geben .........................................................................................22

IV .5.1.4 Schmelzprozesse im Werk von Ulrike Rosenbach ..............................................233

IV.5.2. Werkuntersuchung: Die Eulenspieglerin ....................................................................2.236

IV.5.2.1 Das Videotape „Die Eulenspieglerin“ .....................................................................240

IV.5.2.2 Beschreibung des Tapes .................................................................................... 241

IV.5.2.3 Formale und inhaltliche Analyse des Tapes .......................................................2. 253

IV.5.2.4 Analyseergebnisse ..............................................................................................2. 275

IV.5.3. Werkuntersuchung: „Or-Phelia - Ein Transformationsstück“...................................227

IV.5.3.1 Beschreibung des Tapes .........................................................................................22

IV.5.3.2 Ein steter Bildfluss - formale Aspekte...................................................................2.28

IV.5.3.3 Eine Geburt an der Schwelle des Todes - inhaltliche Aspekte..........................286

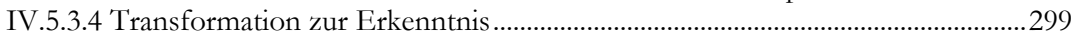

IV.5.4. Werkuntersuchung: Wie ein Phönix aus der Asche........................................................302

IV.6. Tanzende Körperzeichen im Raum - Charakteristisches der Arbeiten der 1980er......... 305

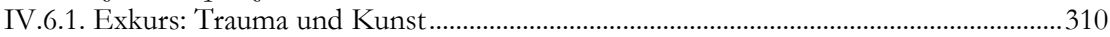

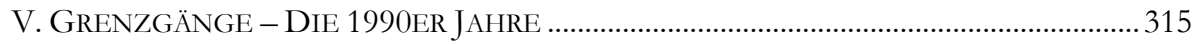

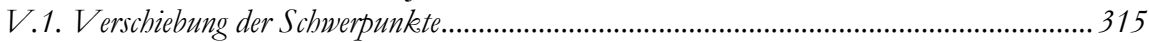

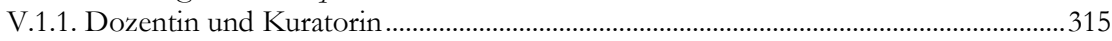

V.1.2. Das Körpertraining als Bestandteil der künstlerischen Ausbildung..............................317

V.2. Werkuntersuchung des Videotapes „OSho-Samadhi“ “................................................... 320

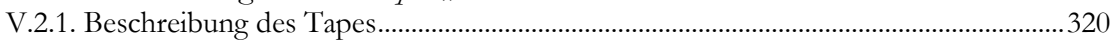

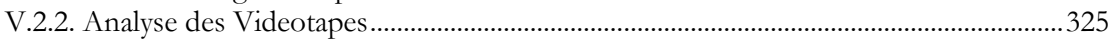

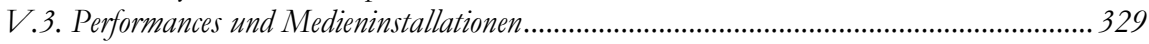

V.3.1. Werkuntersuchung: Herzpendel - Energetisches Phänomen........................................332

V.3.2. Werkuntersuchung: Requiem für eine Eiche ................................................................335

V.3.3. Werkuntersuchung: Die Schlacht der Bäume ................................................................338

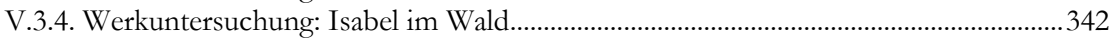

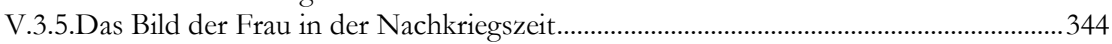

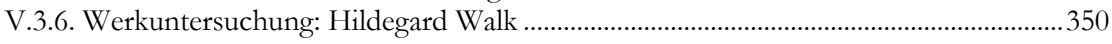

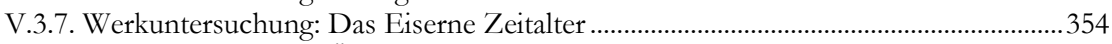

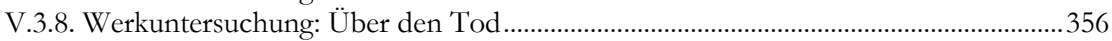

V.3.9. Wiedergeboren: Im Palast der neugeborenen Kinder.....................................................366

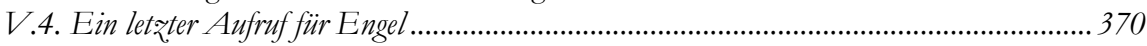

V.4.1.Exkurs: Engel - Mittler zwischen den Seinsebenen......................................................374

V.4.2. Der Performancezyklus „Über die Engel“...........................................................................378

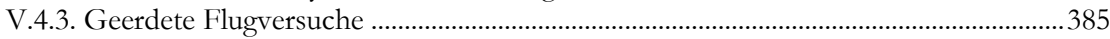

V.5. Skulpturales aus Licht und Energie - Die Ikonographie der 1990er............................. 387

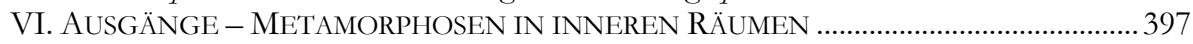

VI.1. Eine klare Sprache der Bilder ....................................................................................... 398 


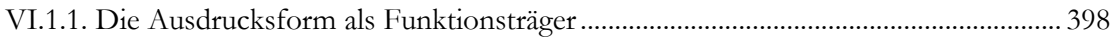

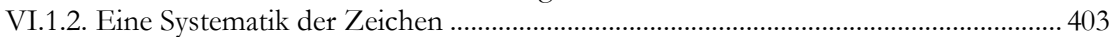

V1.2. Der Körper als elementarer Ausdrucksträger ............................................................... 414

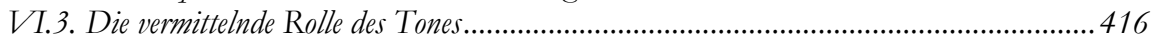

VI.4. Die Form spiegelt den Inhalt - Fazit und Ausblick ......................................................4 418

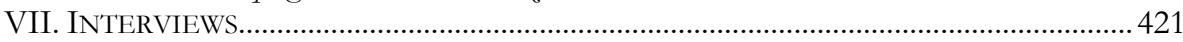

VII.1. Auszüge aus einem Gespräch mit Ulrike Rosenbach .................................................. 421

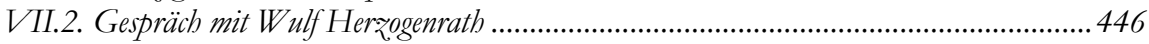

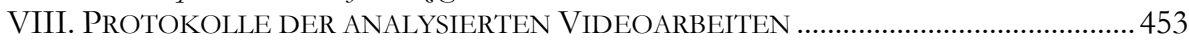

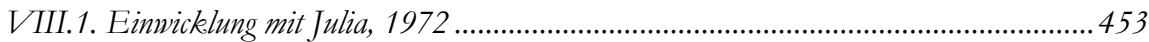

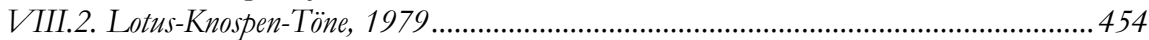

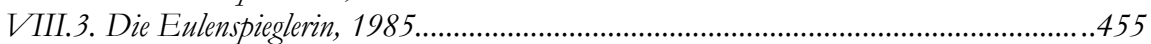

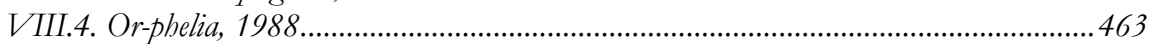

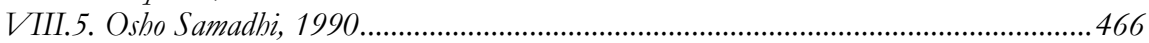

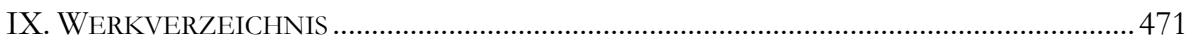

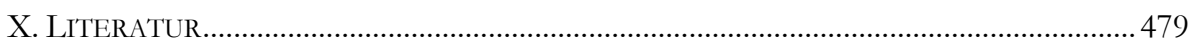

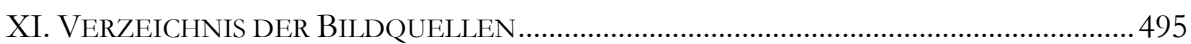



„Im Angelpunkt zwischen dem, was einmal war, und dem, was einmal sein könnte, liegt der lange Moment der

Erkenntnis, dass die Vergangenheit keine

Schicksalsfalle sondern ein Vermächtnis ist. "

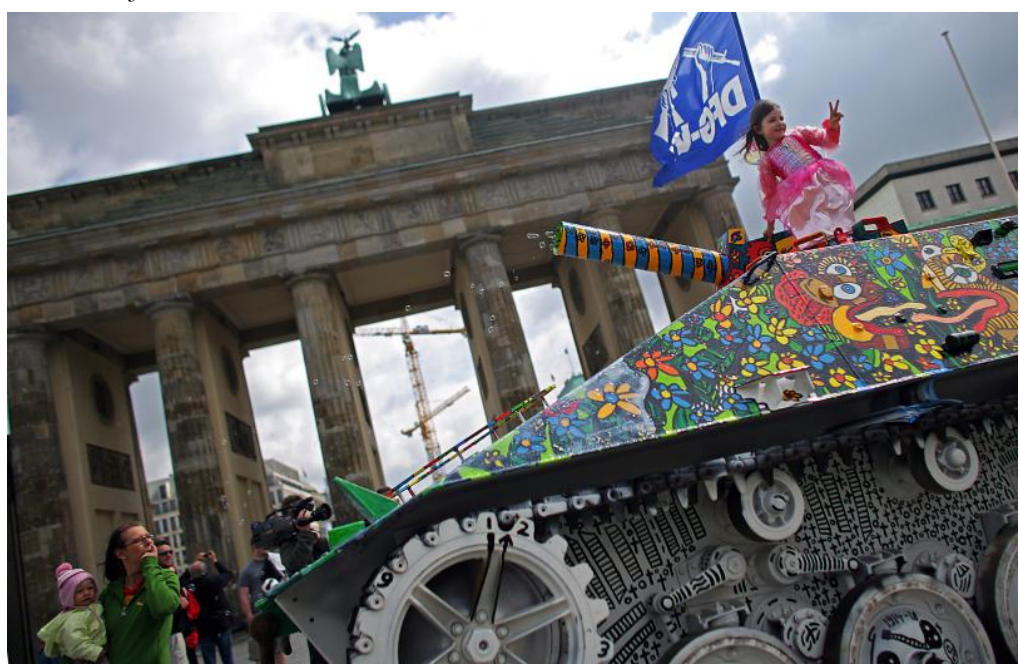

Abb.1: Friedenspanzer vor dem Brandenburger Tor - Aktion von Ulrike Rosenbach und Michael Fischer am 8. Mai 2007

\section{Einleitung}

Am 8. Mai 2007, anlässlich des 62. Jahrestages der bedingungslosen Kapitulation Deutschlands im Zweiten Weltkrieg und der damit verbundenen Befreiung von der vorangegangenen zwölfjährigen Diktatur der Nationalsozialisten wie auch des Endes des Krieges in Deutschland, gab es vor dem Brandenburger Tor in Berlin eine Kunstaktion der Künstlerin Ulrike Rosenbach gemeinsam mit dem Künstler Michael Fischer. Mit einem bunt bemalten Friedenspanzer erinnerten die beiden Künstler an dem geschichtsträchtigen Ort an das historische Datum. Während Michael Fischer das ehemalige Kriegsgerät mit buntfarbigen Figurendarstellungen, die Szenen aus dem Leben zeigen, übermalt hatte, konnte man durch ein Guckloch in das Innere des Panzers schauen, in dem auf einem Monitor eine Videocollage von Ulrike Rosenbach zu sehen war. Ein - inszeniertes - Foto der Aktion zeigt zudem ein kleines Mädchen in einem rosafarbenen Kleid, das auf dem Panzer steht.

Auf sinnfällige Weise verdichtet sich in dieser Friedensaktion das, was sich im Verlauf der intensiven Betrachtung der Werke als Grundthema des künstlerischen

$1 \quad$ Minnich 1994, S. $117 f$ 
Wirkens Rosenbachs herauskristallisiert: Die Auseinandersetzung mit den Folgen von Diktatur, Totalitarismus und Krieg und deren Spuren auf einer seelischen und psychischen Ebene. So wie in der Friedensaktion die Waffe durch die farbige Bemalung mit einer neuen, konstruktiven Aussage überzogen wurde, ist auch das künstlerische Wirken Rosenbachs durch den Aspekt steter Umwandlungen gekennzeichnet. Bewegung und Veränderung kennzeichnen dabei auch die beiden Kunstformen, die das Werk Rosenbachs bestimmen. Denn die Künstlerin schuf in den vergangenen Jahrzehnten ein facettenreiches künstlerisches Werk, das sich an der Schnittstelle zwischen Aktions- und Videokunst ansiedelt, wobei gerade die eingebundene Videotechnik gekennzeichnet ist durch das Charakteristikum des kontinuierlichen elektronischen Bildflusses.

Im Jahr 2006 gab es - auf fünf deutsche Museen verteilt - eine umfangreiche Retrospektive, die einen Überblick vermittelte über inzwischen vier Jahrzehnte Videokunst. Gewürdigt wurde auf diese Weise die prozessuale Kunstform, die sich seit den 1960er Jahren als eine neue Gattung der bildenden Kunst stetig weiter entwickelte und seit einiger Zeit im Zuge der technologischen Innovationen unter dem Begriff „Medienkunst“ ${ }^{\text {“2 }}$ subsumiert wird. Fast ebenso lange wie die Videokunst die Welten der bildenden wie auch der darstellenden Künste bereichert, ist Ulrike Rosenbach $\left({ }^{* 1943)}\right.$ künstlerisch tätig. Die Beuysschülerin war in Deutschland eine der ersten, die Anfang der 1970er Jahre das damals avantgardistische elektronische Medium als Ausdrucksträger in ihren Kunstwerken nutzte.

Die beiden Kunstformen Aktion und Videoarbeit werden im Mittelpunkt dieser Untersuchung stehen. Doch greift Ulrike Rosenbachs künstlerisches Schaffen weiter. Eine Fülle an Fotografien und zahllose Zeichnungen, deren Konvolut stetig wächst, ergänzen das CEuvre der Künstlerin, das ein - aus einer Fülle von Beiträgen herausgegriffener - Lexikonartikel wie folgt knapp zusammenfasst:

\section{„Grundlegender feministischer Ansat:. Vermittelt dabei die Situation von Frau in unse- rer Zeit und Gesellschaft oft durch mythologische und historische Stoffe. Die Befreiung der Fran wird zum Akt avantgardistischer Praxis mit autobiografischem Ausgangs- punkt. Ulrike Rosenbach gilt als Pionierin der Videokunst in Deutschland." "3}

Der Blick auf das Werk der Künstlerin wird in dieser Aussage - wie in zahlreichen anderen Publikationen auch - durch die Perspektive auf die feministisch geprägten Arbeiten Rosenbachs der 1970er Jahre bestimmt. Dies ist jedoch eine einseitige Sichtweise, die dem komplexen Werk, das im Verlauf der Jahrzehnte grundlegende Wandlungen vollzog, nicht gerecht wird, wie gezeigt werden wird.

Während sich in der Vergangenheit zahllose Katalogbeiträge und Aufsätze mit Arbeiten der Künstlerin punktuell beschäftigten, erschien 2005 ein umfangreicher und bebilderter Band, der Rosenbachs künstlerisches Wirken in umfassenderer

2 Vgl. Kapitel II.3.

3 Rühl 1999, S. 197 
Weise würdigt. Im Geleitwort zu diesem Buch wies der Kunsthistoriker Wulf Herzogenrath, der das Wirken der Künstlerin seit ihren Anfängen begleitet, auf die oben angerissene Verschiebung der Perspektive:

„Die Themen der eigenen Existenz und Rolle in der Kunst, die Frage nach den Inhalten der Kunst und die Zuspitzung dieser Problemfelder auf das Spezifische der Arbeit als Künstlerin, als Mutter, als Frau und Feministin bestimmen die ersten Jahrzehnte von Rosenbachs Arbeit - ein Faktum, das die Wabrnehmung der künstlerischen Substanz. des Werkes einerseits verstärkte, andererseits aber auch verstellte. Denn mit den ersten subtilen Zeichnungen und Objekten - etwa den Hauben -, besonders aber den frühesten Live-Aktionen lenkt sie die Aufmerksamkeit auf die feministischen Inhalte ibrer Arbeit, was dazu führte, das deren formale, künstlerische Qualität mit ihrer Minimalisierung der Mittel oftmals auf Grund des emanzipatorischen, gesellschaftspolitischen Gehaltes übersehen wurde. Dies führte dazu, dass Rosenbachs Werk auch beute noch nicht den bohen Stellenwert innerbalb der Kunstentwicklung der 1970er-Jahre einnimmt, der ibm gebübrt."

Diesen Gedanken verfolgt auch diese Untersuchung weiter, die ihren Schwerpunkt auf formale Aspekte und die ikonographischen Hintergründe im Werk der Künstlerin legt. Daneben wird das CEuvre in einen kulturhistorischen Kontext gestellt vor dem Hintergrund, dass Aktionskunst, in der Künstlerinnen und Künstler in der zweiten Hälfte des 20. Jahrhunderts nach neuen künstlerischen Ausdrucksformen suchen, immer eine ganz besondere Form der Kommunikation ist:

„Eine Kunst, die aus Aktionen bestand, bedeutete, daß Kunst ungegenständlich und darstellend zugleich sein konnte, daß sie das Primat des Körpers gleichzeitig als metaphorischen Inhalt und als konkrete Darstellungsform vorbringen konnte. Diese Kunst hat das metonymische Verhältnis des Austauschs zwischen Betrachter und Kunstwerk klar zum Ausdruck gebracht. Aber sie hat dieses Verhältnis auch verändert, indem sie ein agierendes Subjekt in einem realen Austausch mit einem anderen agierenden Subjekt darstellt: Kurz gesagt, Aktionskunst zeigt zwei Menschen, die einander Bedeutung vermitteln, ganz gleich wie kompliziert die Kommunikationsform auch sein mag. Denn wenn Aktionen zu Kunst werden, geht es immer um Kommunikation zwischen Menschen."

Aktion und Videotape fungieren als direkte Mittel der Kommunikation, für die Ulrike Rosenbach ihre eigene bildhafte Sprache findet. Dabei durchzieht die Werke der Künstlerin gleich einem roten Faden eine grundsätzliche Botschaft: Denn fast alle Werke thematisieren Aspekte der „Befreiung“ oder auch „Heilung“. Doch ist dieses elementare Anliegen in ganz unterschiedliche Formen und Aussagen gekleidet, präsentiert sich dem Betrachtenden in immer wieder neuem Gewand. Die-

\footnotetext{
Herzogenrath in: Glüher 2005, S. 7

Stiles in: Kat. Los Angeles 1998, S. 228
} 
se vielfältigen Erscheinungsweisen werden im Folgenden in chronologischer Reihenfolge in Augenschein genommen, nachdem Forschungsstand und Methodik umrissen sind. 


\section{Zugänge}

\section{II.1. Forschungsstand}

Seit Ende der 1990er Jahre haben sich Kunstwissenschaftlerinnen und Kunstwissenschaftler verstärkt der wissenschaftlichen Aufarbeitung der während der vergangenen vier Jahrzehnte entstandenen Video- respektive Medienkunst zugewandt. So ist in kurzer Zeit eine Fülle an Literatur erschienen mit ganz unterschiedlichen Schwerpunkten. Die Vielfalt entspannt sich von philosophischen Ansätzen, die auf einer abstrahierten Ebene über die prozessualen Kunsterscheinungen reflektieren, über Untersuchungen, die sich der Thematik unter medienwissenschaftlichen Fragestellungen nähern, bis hin zu auf die Arbeiten eines einzelnen Künstlers inhaltlich fokussierenden Untersuchungen. Analysen, die sich den Werken aus einer methodisch-formalen Perspektive nähern, sind dabei allerdings selten. Zudem sind in dieser Zeit verschiedene öffentliche Netzwerke entstanden, die es sich zum Ziel gesetzt haben, die Geschichte dieser Kunstform zu rekonstruieren. ${ }^{6}$ Auch haben verschiedene Institutionen, wie das Zentrum für Kunst und Medientechnologie (ZKM) in Karlsruhe oder das Museum Ludwig in Köln diese noch junge Kunstform in den Mittelpunkt ihrer Forschungen und Archivierung gestellt und große Ausstellungen zur Medienkunst und Retrospektiven einzelner Medienkünstler zogen die Aufmerksamkeit der Öffentlichkeit auf sich. ${ }^{7}$

Wenngleich die historische Aufarbeitung der Videokunst - beziehungsweise der inzwischen so genannten Medienkunst - mit großer Geschwindigkeit voranschreitet, hat sich für eine systematische Analyse dieser audiovisuellen und synästhetischen Kunstform bisher noch keine klare Methodik herauskristallisiert. Vielmehr greifen die einzelnen Autoren - je nach Fragestellung - auf den Pool inzwischen entwickelter Methoden zurück. Dabei zeigt sich allerdings, dass die Untersuchungen dieser schwer fassbaren, prozessualen Arbeiten zum Teil recht ungenau ausfallen und viel Raum für Legenden- und Mythenbildung lassen, die vielleicht aber auch einen Aspekt dieser flüchtigen Kunstformen ausmachen.

Zahllose Ausstellungen mit Videokunst wurden in den vergangenen vier Jahrzehnten weltweit gezeigt. Werke der Künstlerin Ulrike Rosenbach waren allein in über 200 Gruppen- und Einzelausstellungen vertreten. Im Rahmen dieser öffentlichen Präsentationen ihrer Werke sind im Laufe der Zeit zahlreiche Publikationen erschienen, in denen punktuell einzelne Arbeiten oder Werke aus einem bestimm-

6 Zu nennen sind hier unter anderem das „Medienkunstnetz“ und andere Datenbanken zur Videokunst.

7 Wie zum Beispiel die 2007 an fünf Orten gleichzeitig gezeigte Werkschau unter dem Titel „40 Jahre Videokunst“. 
ten Zeitabschnitt untersucht wurden. Zudem ist im Jahr 2005 ein umfangreicher und bebilderter Band erschienen, der das vielfältige Werk der Künstlerin umfassender erschließt. ${ }^{8}$

\section{II.2. Grundlagen und Fragestellung}

Diese Arbeit ist aufgeteilt in fünf Abschnitte, von denen sich die drei diesem ersten methodischen Teil folgenden in chronologischer Abfolge dem Werk der Künstlerin zuwenden. Am Ende jedes dieser chronologischen Kapitel finden sich die Erkenntnisse über die Werke des jeweils vorgestellten Jahrzehntes zusammengefasst. Im abschließenden Kapitel dieser Werkuntersuchung werden die Ergebnisse und das Fazit formuliert.

Das künstlerische Werk von Ulrike Rosenbach besteht - neben Zeichnungen, Fotografien und Objekten - zum Großteil aus Videotapes, MultimediaInstallationen und Performances. Die drei zuletzt benannten Formen werden anders als die statischen Kunstformen der Zeichnung, der Fotografie und der Objektkunst - zu den prozesshaften Kunstformen gezählt, bei denen mittels Bewegung und auch Ton in der Zeit agiert und im Zusammenspiel gleich mehrerer Zeichensysteme Bedeutung erzeugt wird. Die Komplexität der auf diese Weise vermittelten Vielfalt an Information stellt eine Analyse vor besondere Herausforderungen. Doch bevor im Anschluss ein vertiefter Blick auf die besonderen Herausforderungen geworfen werden soll, die die Untersuchung dieser Arbeiten mit sich bringt, soll zunächst ein Blick auf das Spezifische dieser drei audiovisuellen Kunstformen geworfen werden, die im Mittelpunkt der folgenden Untersuchung stehen werden.

\section{II.2.1. Videotapes - ein kurzlebiges Medium mit Gestaltungsmöglichkeiten}

„Video" kommt aus dem Lateinischen und bedeutet „ich sehe“. Aber abweichend vom Namen wird bei der Rezeption eines Videobandes nicht nur der Sehsinn sondern auch der Hörsinn angesprochen, besteht die Videoaufzeichnung doch in der Regel aus Bild und Ton. Ist doch ein Mikrofon in die Videokamera integriert und der Originalton wird bei der Aufnahme synchron zum Bild aufgezeichnet. Mit der Tonebene beziehungsweise dem synästhetischen Zusammenspiel von bewegtem Bild und Ton wurde von Video-Künstlern und -Künstlerinnen in ihren Arbeiten in vielfältiger Weise experimentiert.

Aus technischer Sicht sind Videotapes elektromagnetische Speichermedien, die audiovisuelle Informationen bis in die 1990er Jahre in analoger Form, seitdem

8 Dieser von Gerhard Glüher herausgegebene Band bietet im Anhang auch eine umfangreiche Literaturliste zu den vorangegangenen Publikationen. Dieser Band erwies sich für diese zu diesem Zeitpunkt bereits fortgeschrittene Arbeit besonders auch durch das zahlreiche Bildmaterial und weitere genaue Beschreibungen von einzelnen Performances als sehr fruchtbar und die dort zu findende Dokumentation und die formulierten Thesen bereicherten diese Untersuchung. 
auch in digitaler Form, sichern. Diese audiovisuelle Information ist mittels entsprechender Wiedergabegeräte abrufbar. Man benötigt einen passenden Videorekorder, einen entsprechenden Monitor, einen Lautsprechers sowie eine vorhandene Stromzufuhr. Seit Sony 1965 den Portapak auf den Markt brachte und damit die Videotechnik Amateuren - und damit verbunden auch bildenden Künstlern zugänglich war - hat sich die Technik stetig gewandelt. ${ }^{9}$

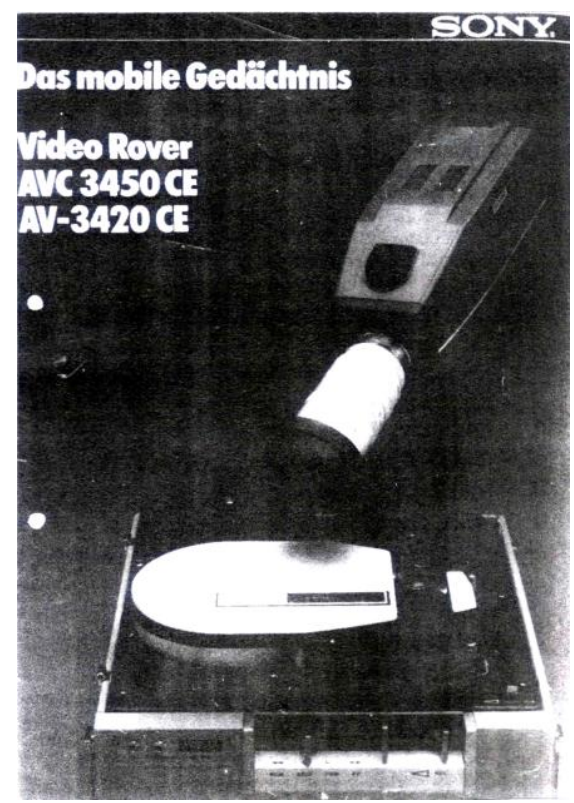

Abb. 2: Werbung für den Sony Portapak

Während der Jahrzehnte ist die analoge Videotechnik mit der digitalen Technologie zum elektronischen Multimedia verschmolzen, so dass audiovisuelle Information, die in der Vergangenheit auf analogem Magnetband gespeichert wurde, inzwischen auch in digitaler Form auf „Digital Video Discs“ - kurz DVD - gespeichert werden können. Bedeutsam ist - nicht nur aus restauratorischer Sicht - die Haltbarkeit dieser elektronischen Speichermedien. So hat Magnetband eine „Lebensdauer" von höchstens 30 Jahren, bevor die Metallpartikel, die die Information kodieren, beginnen, sich von dem Kunststoffträger zu lösen. Wie lange CD's und DVD's ihre Informationen zuverlässig speichern werden, ist bei dieser jungen Technologie noch nicht geklärt, aber der Zeitraum dürfte nicht länger als bei Videotapes, eher kürzer als bei diesen sein. Hinzu kommt der Aspekt der Hardware,

9 Amerikanische Künstler hatten bereits in den frühen 1960er Jahren die Möglichkeit mit professioneller Fernsehtechnik zu experimentieren. Die Geschichte der Videokunst wird aber in der Regel mit Nam June Paiks Aufführung seiner mit dem Sony-Portapak aufgezeichneten Dokumentation einer Taxifahrt durch New York 1965 verknüpft. 
der technischen Geräte, die die Wiedergabe und damit die Rezeption der künstlerischen Videotapes erst ermöglichen. Bei den rasanten Generationswechseln der Technologien im Bereich der Neuen Medien ist die Kompatibilität der unterschiedlichen Systeme bereits mehrfach verloren gegangen und damit die Abspielbarkeit alter analoger Bänder nicht mehr gegeben, selbst wenn der Informationsträger noch intakt ist, wenn die entsprechende Hardware nicht mehr funktioniert oder gar existiert.

Es lässt sich zusammenfassen, dass das Videotape ein relativ kurzlebiges Speichermedium ist, so muss die audiovisuelle Information in bestimmten Abständen auf aktuelle Informationsträger übertragen werden, soll das jeweilige Kunstwerk dauerhaft erhalten werden. ${ }^{10}$

Ein Blick auf die Bildebene einer Videoaufnahme zeigt, dass die Wiedergabe des bewegten elektronischen Bildes auf dem Phänomen der Suggestion von Bewegung im älteren mechanischen Medium des Filmes fußt. Ein Film, das sind aus der technischen Perspektive in schneller Folge hintereinander gezeigte einzelne Bilder, die sich erst im Auge oder besser Gehirn des Betrachtenden zu einem flieBenden Bewegungseindruck zusammensetzen. Es ist das physiologische Phänomen des Nachbildeffektes, das diesen Eindruck ermöglicht. ${ }^{11}$ Ab zwölf Bildern, die pro Sekunde gezeigt werden, funktioniert dieser suggerierte Bildfluss. Der Film arbeitet in der Regel mit 24 Bildern, die sich im Verlauf einer Sekunde auf der Leinwand ablösen. ${ }^{12}$

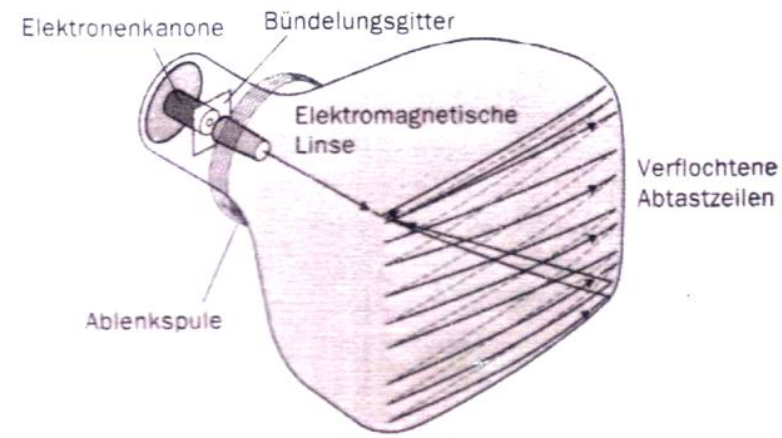

Abb. 3: Schematische Darstellung der Kathodenstrablröhre

10 Ein Thema, mit dem sich Kunsthistoriker inzwischen verstärkt beschäftigen zumal seit Entstehung der ersten Bänder manche Werke schon wieder verloren gegangen sind. (Vgl. z.B. Projekte im ZKM) Zudem stellt sich bei dieser reproduzierbaren Kunstform die Frage nach der Originalität.

11 Mit einem so genannten Daumenkino ist dieses Prinzip gut nachzuvollziehen.

12 Monaco 1995, S. 89f; dabei werden die 24 Einzelbilder nochmal durch eine Blende verdoppelt in 48 Bilder. 
Die elektronische Bildwiedergabe geht einen Schritt weiter. Die mit der Kamera aufgenommene und elektromagnetisch gespeicherte Information wird hier kodiert in Form elektrischer Impulse an den Bildschirm weitergegeben. Im Unterschied zum Film, der mit aneinandergereihten vollständigen Einzelbildern arbeitet, ist hier jedes der Einzelbilder zudem in Bildpunkte zerlegt. Ein Fernsehbildschirm im normierten Format 3:4, das bis in die 1990er Jahre üblich war, bevor das 9:16 Format eingeführt wurde, setzt sich aus circa einer halben Million Bildpunkten so genannten Pixel - zusammen. Dabei unterscheidet sich die Auflösung des Bildes je nach Fernsehnorm. Die europäische Norm (PAL) verwendet zum Beispiel 625 Zeilen mit jeweils 833 Pixeln. ${ }^{13}$ In dem gläsernen Körper des Bildschirmes befindet sich eine Kathodenstrahlröhre, deren Elektronenstrahl den beschichteten Bildschirm in sehr hoher Geschwindigkeit systematisch abtastet. Entsprechend der Kodierung animiert der Strahl in jeder Zeile nacheinander die Punkte. Auf diese Weise leuchtet jeweils nur ein einziger kleiner Punkt der Fläche, nicht die ganze Fläche, wie es dem Betrachtenden erscheint. Der Eindruck des Gesamtbildes wie des Bildflusses setzt sich aufgrund der Trägheit der visuellen Wahrnehmung im Gehirn des Betrachtenden zusammen. ${ }^{14}$ Ein elektronisches Bild ist damit eine Licht- oder Energiespur. ${ }^{15}$

In den Anfängen der Videotechnologie stand zunächst eine schwarzweiße Bildtechnik, die aber im Profibereich bereits in den 1960er Jahren und im Amateurbereich spätestens ab den 1980er Jahren durch die Farbaufzeichnung abgelöst wurde. Vom fotochemischen Film setzt sich die elektromagnetische Bildaufzeichnung zudem durch ganz besondere Eigenschaften ab. Die Bilderzeugung mittels des Kathodenstrahls lässt sich manipulieren.

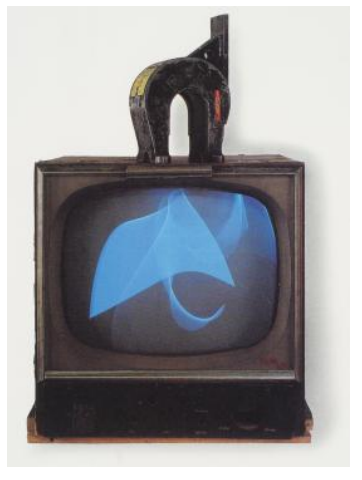

Abb. 4: Nam June Paik: Magnet-TV, 1963

13 Willim 1989, S. 19

14 Monaco 1995, S.156f

15 Dies Prinzip ist auch auf die LCD-Bildschirme zu übertragen, nur dass hier die Animation des einzelnen Punktes mittels elektronischer Impulse wirkt. 
So lässt sich nicht nur der Elektronenstrahl während der Bilderzeugung manipulieren. Der Musiker und Künstler Nam June Paik (1932-2006) zeigte bereits erste künstlerisch-technische Experimente mit der Kathodenstrahlröhre im Jahr 1963 in der Ausstellung „Exposition of Music“ in der Galerie Parnass in Wuppertal. AuBerdem sind eine Vielzahl an Varianten der Bildverknüpfung sowie der Bildmischung in dieser elektronischen Technologie erzeugbar. Dabei haben sich die Möglichkeiten der elektronischen Bildbearbeitung während der vergangenen vier Jahrzehnte in großen technischen Sprüngen weiterentwickelt und an den diese begleitenden ästhetischen Entwicklungssprüngen waren auch Videokünstler maßgeblich beteiligt. ${ }^{16}$ So hat zum Beispiel der auch als "Vater der Videokunst" bezeichnete Nam June Paik bereits ab Mitte der 1960er Jahre die Eigenschaften des elektronischen Bildes erkundet und Anfang der 1970er Jahre hat der Künstler zusammen mit dem Techniker Shuya Abe einen analogen Bildmanipulator, den so genannten Paik-Abe-Synthesizer, entwickelt, mit dem Bilder vervielfacht und verzerrt werden konnten. Effekte, die für die weitere Videoästhetik prägend waren und die das Band „Global Groove“ aus dem Jahr 1973 dokumentiert. ${ }^{17}$

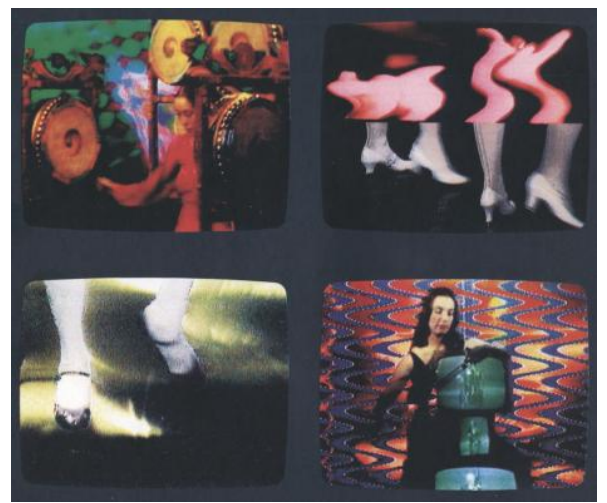

Abb.5-8: Nam June Paik: Global Groove, 1973, 4 Videostills

16 Nam June Paik entwickelte bereits 1968/69 zusammen mit dem Techniker Shuya Abe einen ersten elektronischen Bildwandler, der in Anlehnung an den Klangsynthesizer als Paik-AbeSynthesizer in die Literatur einging. Dieses Technik wurde dann in einer Variante von 1972 verbessert.

17 Das Tape „Global Groove“ entstand 1973. „This is a glimpse of a video landscape of tomorrow when you will be able to switch on any TV station on the earth and TV guides will be as fat as the Manhattan telephone book." (»Hier bekommen Sie einen Einblick in eine neue Welt, in der Sie jeden Fernsehsender der Welt einschalten können und die Fernsehzeitschrift so dick wie das Telefonbuch von Manhatten sein wird.«) Dieses Statement am Anfang des Videotapes steht für sein gestalterisches Prinzip und seine Botschaft: die Vision eines weltweiten Channel-Zapping heute wahr geworden - wird von Paik 1973 in dem Video vorweggenommen. Es liefert das Lebensgefühl zur Theorie Marshall McLuhans vom kommenden "global village«, der weltweiten Kommunikation im »globalen Dorf«. 
Möglich war bei der Magnetbandaufzeichnung bereits in den späten 1960er Jahren im Bereich der Profitechnik das Übereinanderlegen von Aufnahmen, der Einsatz von vielfältigen Masken und Filtern, der so genannte Bluebox-Effekt, bei dem eine Farbe eines Bildes - meist Blau, woher auch der Name des technischen Kniffs rührt - durch andere Bildinformationen ersetzt wird. Zudem konnten unter anderem bereits Farben, Kontraste und Helligkeiten elektronisch verändert werden. Mit diesen Möglichkeiten haben Künstlerinnen und Künstler, wie auch Techniker gerade in den 1960er und 1970er Jahren experimentiert. Der zunächst vom älteren Medium Film übernommenen Bildsprache fügten sie im Zuge einer kritischen und experimentellen Auseinandersetzung mit der Bildsprache und deren Codes sukzessive neue, avantgardistische Ausdrucksformen hinzu. Entsprechend der sich wandelnden technischen Gegebenheiten entwickelten sich avantgardistische Ausdrucksformen, die sich unter dem Begriff „Videoästhetik“ summieren lassen, eine Ästhetik, die jedoch steten Wandlungen unterliegt. ${ }^{18}$ So ist inzwischen die Vision Nam June Paiks, die dieser im Jahr 1965 anlässlich der öffentlichen Vorführung des ersten künstlerischen Videotapes, das er mit einem Sony Portapak gedreht hatte, Wirklichkeit geworden. Wenn er damals seinen Wunsch äußerte, dass die Kathodenstrahlröhre zum Pinsel der zeitgenössischen Künstler werden möge, dann ist mit den heutigen digitalen Bildbearbeitungsmöglichkeiten genau diese Utopie zur elektronischen Realität geworden. Mit der entsprechenden Hard- und Software, die inzwischen nicht nur erschwinglich, sondern auch handhabbar geworden ist, lassen sich elektronische Bilder am heimischen Schreibtisch generieren, manipulieren und inzwischen auch animieren.

Wie dargelegt speichert eine Videoaufzeichnung neben dem Bild aber auch gleichzeitig den Ton in elektronischer Form. So kann auf Video ein relativ authentischer Ton des Geschehens gleichzeitig mit der Bildaufzeichnung eingefangen werden, während die Tonspur beim Film getrennt aufgenommen beziehungsweise sogar erst nachträglich erzeugt wird. Dabei bleibt die Möglichkeit der Nachbearbeitung auch bei Videotonaufnahmen weiterhin offen.

So steht aus der technischen Perspektive die Videotechnik mit ihrer fließenden elektronischen Aufzeichnungsweise der Musik näher als dem fotochemischen Film. Und so erklärt es sich vielleicht auch, dass viele der Videokünstler der ersten und zweiten Generation, wie zum Beispiel Nam June Paik oder auch das Künstlerpaar Woody und Steina Vasulka, aus der Musik kommen.

\section{II.2.2. Closed Circuit - Das eigene Bild kontrollieren}

Die Videotechnik hat neben den erwähnten Charakteristika noch eine wesentliche Besonderheit, die sie vom Film unterscheidet: Videoaufnahmen können genau wie

18 Als die Videotechnik in die bildende Kunst einzog, hatte der Film bereits in seiner wechselvollen Geschichte - vom Stummfilm über den Tonfilm zum Farbfilm - seine eigene Sprache, auf der Grundlage unterschiedlicher Montagetechniken entwickelt (vgl. Monaco 1995, S. 151-228) 
Filmaufnahmen Aktionen und Prozesse wiedergeben, dies allerdings zeitgleich, ohne verzögernden Entwicklungsprozess. ${ }^{19}$ Damit ist die Technologie für Künstler besonders geeignet zur Dokumentation von Soloaktionen. In den Anfängen der Technologie experimentierten verschiedene Künstler genau mit diesem so genannten Closed-Circuit. Kann der oder die Agierende bei einer Videoaufnahme doch durch die Möglichkeit des so genannten Closed-Circuit, bei dem die aktuelle Aufnahme parallel auf einem Monitor erscheint, die Aufzeichnung gleichzeitig kontrollieren. ${ }^{20}$ Auch Ulrike Rosenbach nutzte diese Möglichkeit der Selbstaufzeichung für ihre künstlerischen Tapes in den 1970er Jahren, wie noch ausführlich dargelegt werden wird. Zudem wob sie die Videotechnologie in ihre Aktionen ein und entwickelte damit ihre spezifische Form der Videoperformance.

\section{II.2.3. Multimediainstallationen - In den Raum eingebundene Sichtweisen}

In den räumlichen, multimedialen Installationen finden sich im Cuvre Ulrike Rosenbachs künstlerische Videotapes als Ein- oder auch Mehrkanalarbeiten eingebunden. Wenn das Monitorbild in der Regel ein Querformat bildet, wird es in diesen Präsentationszusammenhängen auch gelegentlich ins Hochformat gedreht. ${ }^{21}$ Ein Format, das allerdings ungewöhnlich ist für die durch das Querformat konditionierten Sehgewohnheiten. In dem durch die Monitormaße vorgegebenen Bildraum im Verhältnis 3:4 bewegen sich die hinter die Scheibe projizierten Bildsequenzen. Als elektronisch generierte Lichtspuren bleiben sie flüchtig und nicht greifbar auf den im Raum angeordneten Bildschirmen oder Leinwänden, auf die sie gebeamt werden. ${ }^{22}$ Einige dieser komplexen, multimedialen Environments boten zudem den Rahmen für die Aktionen der Künstlerin. Und damit betritt die dritte Kunstform, die im Mittelpunkt des künstlerischen Wirkens Ulrike Rosenbachs steht, die Bühne: die Aktion.

\section{II.2.4. Aktionskunst - Strategien künstlerischer Intervention im Leben}

\section{„Im Begriff Aktion spiegelt sich eine Strategie entschlossener künstlerischer Intervention im öffentlichen Leben. "23}

19 Video reizte in den späten 1960er Jahren neben Super Acht und 16 mm Film zudem bildende Künstler in der Funktion als Dokumentationsmedium, zum Beispiel zur Aufzeichung ihrer Aktionen.

20 Dieser Kontrollaspekt ist der Videotechnik übrigens mit in die Wiege gelegt worden. Ist Video doch ursprünglich für militärische und überwachende Zwecke entwickelt worden und findet sich ja auch häufig im Alltag unter anderem in Form der Videoüberwachung wieder.

21 Vgl. „Hildegard Walk“, Kap. V.3.6.

22 Die Monitore liegen in den Video-Installationen Rosenbachs am Boden, stehen auf Sockeln, sind übereinander, nebeneinander, gegenüber gestellt - oder sind auch eingefügt in ein Environment statischer Bedeutungsträger aus unterschiedlichen Materialien.

23 Stiles in: Kat. Los Angeles 1998, S. 237 
Die Kunsthistorikerin Karin Thomas beschreibt ausführlicher, dass sich unter dem Oberbegriff der „Aktion“ unterschiedlichste Formen einer Kunst sammeln, die unmittelbar einen künstlerischen Denkprozess mit Hilfe theatralischer Mittel präsentiert, um durch die überraschende Pointe des improvisierten Geschehens das Leben selbst oder auch die Aktualität einer Problematik mit größtmöglicher Eindringlichkeit zu demonstrieren. ${ }^{24}$

So sind zur Aktionskunst bereits die während der Jahre des Ersten Weltkriegs entstandenen skurrilen Dada-Aktionen genauso wie das Actionpainting der 1950er Jahre zu zählen. Auch gehören dazu die Happenings und die Fluxusaktionen der 1960 er Jahre, sowie die Kunstform der Performance, die in den 1970ern entstand. Die frühe Geschichte der Aktionskunst in den 1950er Jahren ist geknüpft an die Namen der beiden amerikanischen Künstler Allan Kaprow (*1927) und John Cage (1911-1992):

„In Allan Kaprows (...) Aktivitäten entdeckt man etwas, was sich tatsächlich ereignet hat. Etwas Bestimmtes ist geschehen. Jemand, wie Kaprow wiederholt betont, tut einfach etwas. Und die Tatsache, daß jemand etwas tut - daß jemand etwas tun kann - daß etwas geschieht und nicht nichts - ist äußerst beachtenswert. Diese Tatsache zeichnet Aktionskünstler aus. Aktionskünstler wirken als Kommissuren, denen die Aufgabe zukommt, Bedeutung und Bild, daß jemand etwas tut, zu vermitteln. Aus diesem Grund gelten Performance-Künstler als so gefährlich. Sie behaupten, etwas könne getan werden, und dann sorgen sie dafür, dass es geschieht. Menschen, die dafür sorgen können, dass etwas geschieht, stellen ein potentielles Problem für normatives Verhalten und normative Werte dar. Aktionskunst ist Handeln. Aktivitäten sind Anschaunngsunterricht im ,Handeln: Dafür zu sorgen, daß etwas geschieht, ist die intentionale, kausale Essenz. eines machtvollen politischen Aktes. Indem man dafür sorgt, dass etwas geschieht, überlebt man. Aber über das nack.te Überleben hinaus entsteht daraus vielleicht der Glaube, obne den Leben praktisch unmöglich ist. Ein Glaube an und für sich selbst. Denn um zu überleben, handeln Individuen voller Glauben und mit dem Gefühl der Verantwortung für andere, mit denen sie sich zu gemeinsamem Handeln verpflichtet haben. "25

In einer legendären ersten Aktion im amerikanischen „Black Mountain College“ im Jahr 1952 verbanden eine Reihe damaliger Avantgardekünstler bildende Kunst, Musik, Theater und Tanz und brachen damit die Grenzen zwischen diesen Künsten auf. Diese Künstler gehörten neben dem Amerikaner George Macunias (19311978) und anderen zu einer Gruppe, die in ihren neodadaistisch geprägten Aktionen anstrebten eine „unspezialisierte Form von Kreativität“ zu erzeugen, und die sich unter dem Namen „Fluxus“ - vom Lateinischen „Fließen“ abgeleitet - zusammen fanden. Bei den „Fluxuskonzerten“, deren Ablauf einer Partitur folgte,

24 Thomas 1986, S. 9

25 Stiles in: Kat. Los Angeles 1998, S. 283 
die wie in der Musik eine gewisse Verarbeitung eines Konzeptes in improvisatorischer Weise gestaltete, lag ein wesentliches Augenmerk auf dem Ton: ${ }^{26}$

„Dabei wird in Zertrümmerungsaktionen von Klavieren und Geigen nach dem dadaistischen Antikunst-Vorbild einerseits mit dem traditionellen Klangrepertoire der Musike gebrochen, zum anderen entnimmt man solchen Klangereignissen gleichzeitig auch ein noch unverbrauchtes konkretes akustisches Material, das bislang nicht als Klang, sondern als Lärm galt, weil es außerhalb konventioneller Tonsysteme liegt." ${ }^{27}$

Auch John Cage hat in seiner Einzelaktion „3 44'“، diesen Gedanken in origineller Form umgesetzt. Bei der Aufführung dieser „Komposition“ trugen den Ton nicht Musiker oder erklingende Instrumente bei. Diese blieben entgegen der Erwartungen des Publikums stumm. Dagegen bildete die zufällige Geräuschkulisse das Werk. Damit hat der Künstler nicht nur die Konventionen eines Konzertes auf den Kopf gestellt, sondern zudem mit den Mechanismen der Wahrnehmung gespielt. Das sonst als störend Empfundene wurde in der Aktion - dieses anerkennend - in den Mittelpunkt der Aufmerksamkeit gestellt. Fluxus unterlief die Vorstellung, dass Kunstproduktion ein transformierender Vorgang sein müsse. Vielmehr deuteten die Fluxuskünstler auf die Dinge, die bereits existierten. Die amerikanischen Fluxuskünstler feierten 1962 das Festum Fluxorum in Wiesbaden zusammen mit europäischen Kollegen und in den kommenden Jahren fanden zahlreiche Fluxusaktionen in Deutschland statt. Auch Nam June Paik, der seit Mitte der 1960er Jahre in Deutschland lebte, gehörte zu dieser Künstlergruppe, wie auch der deutsche Bildhauer Joseph Beuys (1921-1986), dessen „unaufhaltsamer Aufstieg" sich im Sog von Fluxus vollzog. ${ }^{28}$

Während bei den Fluxuskonzerten eine Trennung zwischen Akteur(en) und Publikum bestand, ist ein Happening als ein improvisiertes Aktionsgeschehen im Sinne einer Collage aus Ereignissen vorzustellen, das keine fortlaufende Handlung hat, bei dem spontane Reaktionen von Künstler und Publikum jederzeit möglich sind und bei dem Alltagsgegenstände unterschiedlichster Herkunft zu selbständigen Akteuren werden können. ${ }^{29}$

Davon wiederum abgrenzend beschreibt Karin Thomas die Kunstform der Performance, einer besonders facettenreiche Form der Aktionskunst, die in den 1970er Jahren entstand und sich bis heute weiterentwickelt hat, wie folgt:

26 Thomas 1986, S. 14

27 Thomas 1986, S. 244

28 Lucie-Smith 1999, S. 289

29 Thomas 1986, S. $14 \mathrm{f}$ 
Aktionskunst der siebziger Jahre, bei der der Künstler im Gegensatz. zu den voran gegangenen Happening- und Fluxusaktionen obne jegliche Publikumsbeteiligung allein agiert und auf bestimmte struk.turelle Zusammenhänge des Lebens hinweist. "30

Im Laufe der vergangenen Jahrzehnte hat sich ein umfangreicher theoretischer Diskurs zur Performance gebildet, bei der das künstlerische Phänomen aus unterschiedlichen Blickwinkeln umkreist wird. ${ }^{31}$ Gemeinsam ist allen diesen Betrachtungsweisen die Betonung einer großen Nähe von Kunst und Leben, die sich bei der Performance finden lassen. Auch kann Performance als ein effektives Mittel der künstlerischen Kommunikation aufgefasst werden. Wichtig scheint zudem der Aspekt des Transformatorischen einer Performance, deren Durchführung für den Künstler einen Lern- wie auch Heilungsprozess umfassen kann. Dabei ist der Körper das wesentliche performative Ausdrucksmittel. Mit diesem Medium kommuniziert der Künstler seine Botschaft auf sehr direkte Weise. Über Bewegungen, Gebärden, Gesten, Mimik und häufig auch Sprache, Musik oder Gesang teilt er sich mit und tritt mit dem Publikum in Verbindung.

Dabei kommt dem Zuschauer in der Performancekunst eine besondere Rolle zu. Zwar ist dieser, anders als bei einem Happening, nicht direkt in die Handlung einbezogen, doch kommt es auch hier auf einer energetischen Ebene zur Interaktion zwischen Publikum und agierendem Künstler. Performance funktioniert also nur mit Publikum. Zudem sind es die Zuschauer, die im Nachhinein über das einmalige Ereignis berichten und somit Zeugnis von dem Geschehen ablegen. ${ }^{32}$ Doch bleibt zu bedenken:

„Performance lebt einzig und allein in der Gegenwart. Performance kann nicht gespeichert, aufgezeichnet, dokumentiert oder anderweitig in den Kreislauf der Darstellung von Darstellung einbezogen werden: sobald dies geschieht, wird sie qu etwas anderem als Performance. In dem Maße wie Performance versucht, in die Ökonomie der Reproduktion einzutreten, verrät und schmälert sie das Versprechen ibrer eigenen Ontologie. Das Wesen der Performance ... entsteht erst durch ibr Verschwinden. ""33

Auffällig ist, dass in den jungen Kunstformen der Videokunst wie auch der happening und Performance Art verhältnismäßig viele Künstlerinnen vertreten sind und das bereits seit den 1960er Jahre. So waren zum Beispiel Carolee Schneemann (*1939) und Yoko Ono (*1933) bereits in diesem Jahrzehnt als Performerinnen aktiv. Auch Musikerinnen wie Meredith Monk oder Laurie Anderson entdeckten in den 1970er Jahren die Performance als Kunstform für sich. Während Männer im Bereich der Aktionskunst zwar zunächst dominant waren, haben Frauen in dieser Kunstform neue, spezifische Themen eingebracht. So erhielt die Kunstform

30 Thomas 1986, S. 20

$31 \quad$ Vgl. z.B. Pollock 1987

32 Vgl. Kapitel II.3.1.

33 Stiles in: Kat. Los Angeles 1998, S. 235, siehe auch Phelan 1993, S. 146 
der Performance viele ihrer Bedeutungen durch die Art und Weise wie Künstlerinnen entschieden, diese zu verwenden. ${ }^{34}$ Künstlerinnen führten zum Beispiel den Aspekt der Autobiografie, des Charakters und der „Personae“ in das Feld der Performance ein und ihre künstlerischen Umsetzungen veränderten die Substanz und die Richtung des Mediums in Richtung der so genannten „personal Performance“. ${ }^{35} \mathrm{Im}$ Rahmen der sich zunächst in den 1960er Jahren in den USA formierenden emanzipatorischen Frauenbewegung, entdeckten Künstlerinnen schließlich auf der ganzen Welt sich, ihre Erfahrungen, ihre Geschichte auch als Thema ihrer Kunst neu. Dabei suchten die Künstlerinnen nicht nur ihre eigene Geschichte, sondern auch eine kollektive Vergangenheit der Frau zu rekonstruieren. Video und interaktive Systeme wurden zu Mitteln, um den Spuren der persönlichen Geschichte zu folgen. Eine Erfahrung, die ihr einen Hinweis auf ihren eigentümlichen Platz innerhalb des kulturellen Kontextes gegeben habe, wie die amerikanische Künstlerin Lynn Hershman (*1941) beschreibt. Gerade die Kunstform der Performance bot ein ideales Medium für feministische Statements, die sich auf die Gültigkeit des ,persönlichen Wirrwarr" beziehen, wie Moira Roth hervorhob. ${ }^{36}$

Die rasche Entwicklung feministischer Gedanken und Aktivitäten in den 1970er und 1980er Jahren brachte zahlreiche Zugänge sowohl zur feministischen Performance als auch zur feministischen Theorie mit sich. ${ }^{37}$ Dabei hatten drei Aspekte besonderen Einfluss auf die feministische Performancekunst: zum einen der Wert der persönlichen Erfahrung, zum anderen die Demokratisierung des Prozesses sowie die Erkenntnis, das Persönliche als das Politische zu benennen. ${ }^{38}$

\footnotetext{
Roth 1983, S. 11

Roth 1983, S. 11

Roth 1983, S. 14

Carlson 1996, S. 144

38 Roth/ Lacy in: Lennox 1982, S. 163-165; Jill Dovan, eine erste Theoretikerin der feministischen Performance, unterteilt aus der Sicht der Performancetheorie grundsätzlich in drei Gruppierungen des Feminismus: in den liberalen, den kulturellen - beziehungsweise radikalen - und den materialistischen Feminismus. Der liberale Feminismus zeigte eine enge Verbindung zu verschiedenen Typen der politischen Aktion der 1960er Jahre. Er versuchte Aufmerksamkeit zu erwecken für Ungerechtigkeiten und sexuelle Ungleichheit und suchte nach gleichen Bedingungen, Rechten und Schutz für alle Menschen unabhängig vom Geschlecht. Der kulturelle Feminismus versuchte - im Anschluss daran - eine Idee einer weiblichen Kultur zu definieren und zu unterhalten, die getrennt und verschieden sein sollte von der Kultur der Männer. Die daraus entwickelte so genannte essentialistische Position zeigte Formen einer kulturellen, mythologischen oder autobiographischen Performance. Gesucht wurde von den Künstlerinnen eine authentische weibliche Performance und eine spezifische theatrale Sprache, die in der Lage ist, weibliche Wahrnehmungen mitzuteilen. Anders als der liberale Universalismus oder der kulturelle Essentialismus sieht der materialistische Feminismus schließlich das Geschlecht als kulturell konstruiert an in einem Netz aus Machtbeziehungen. Die materialistische Position unterstreicht die Bedeutung der Rolle der Klasse und der Geschichte bei der Unterdrückung der Frau. (Vgl. Carlson 1996, S. 144-146)
} 
Ulrike Rosenbach ordnete sich in den 1970er Jahren durch ihre Aussagen und künstlerischen Werke explizit einem feministischen Spektrum zu. An welcher Stelle die Arbeiten der Künstlerin sich in diesem Kontext positionieren lassen, wird im Folgenden genauer untersucht werden. Im Mittelpunkt wird aber die Fragestellung stehen, was die spezifischen Inhalte der Kunstwerke der Künstlerin sind - ihrer Aktionen, Videoarbeiten und Installationen - und wie sich dieses umfassende künstlerische Werk im kunsthistorischen Kontext positionieren lässt.

Um diesen Aspekten auf den Grund gehen zu können, stellen sich jedoch zunächst methodische Fragen. Handelt es sich doch bei der Mehrzahl der künstlerischen Werke Ulrike Rosenbachs um prozesshafte Kunstformen, für deren kunstwissenschaftliche Untersuchung es noch kein kanonisiertes methodisches Instrumentarium gibt. Wenngleich seit über 40 Jahren Medienkunstwerke existieren und sie auch als Performance Art und Videokunst Eingang in die Kunstgeschichte gefunden haben, stellen sie an eine wissenschaftliche Betrachtung gleich mehrere Herausforderungen, die im Folgenden kurz umrissen werden sollen.

\section{II.3. Methodik}

„[Dem Kunsthistoriker (d.Verf.)] ist die Aufgabe gestellt, die Totalität der Kunst in allen ibren erst heute erkennbaren Erscheinungsformen zu umfassen und in ein neues $G e$ samtbild zu integrieren. "39

Denn der Kunstbegriff hat sich im Verlauf des vergangenen Jahrhunderts stark verändert. Die tradierten Gattungen der bildenden Kunst - Malerei, Grafik, Bildhauerei, Architektur - wurden ergänzt und aufgebrochen um fotografische und filmische Arbeiten, Installationen, Klangkunstwerke, kinetische Arbeiten, Aktionen oder auch elektronische Kunst. Für diese häufig prozessualen Kunstformen, die sich mit den Bereichen der darstellenden Künste - Theater, Tanz, Musik überschneiden, hat sich inzwischen die übergreifende Bezeichnung „Medienkunst" etabliert, ein Begriff den Haberl wie folgt erläutert:

„Medienkunst ist gleich vielen anderen Bezeichungen der Kunstgeschichte des 20. Jahrbunderts ein einmal eingeführtes Gebrauchswort, das weniger definiert als vielmehr bestimmte neue Handlungsfelder der Kunst zu umschreiben sucht. Ausgehend von konzeptiven und aktionistischen Erscheinungsformen der Kunst nach 1945 trat eine zunehmend technologisch orientierte Avantgarde von KünstlerInnen auf den Plan, die bis heute mit den sogenannten Neuen Medien wie Fotografie, Film, Licht, Klang, Video und Computeranimation als Mittel der Inszenierung von individuell spezifischen Wahrnehmungsräumen experimentiert. Im Mittelpunkt dieser transmedialen Experimente stebt der Mensch und seine Verhaltensformen, der eigene Körper und seine Beziehung zur materi-

39 Kultermann 1990, S. 240 


\section{ellen wie immateriellen Umwelt. Daher schließt Medienkunst die historisch gewachsenen} Handlungsfelder des Aktionismus und der Performance mit ein. "

Dieser inzwischen für die umrissene Vielfalt an Ausdrucksformen in der Kunstwelt eingebürgerte Begriff bleibt allerdings missverständlich, wird doch jede Kunst medial vermittelt und ist damit Medienkunst. So scheint die Summierung als prozesshafte Kunstformen treffender, ist doch das Besondere all dieser Werke, dass sie sich innerhalb der Zeit entspannen. ${ }^{41}$

Der zusätzlichen Dimension der Zeit, der Ergänzung der visuellen Ebene durch eine Tonebene und der Synästhesie von auditiven und visuellen Reizen gilt es in der wissenschaftlichen Analyse von Aktionen und Videotapes mit einem passenden Instrumentarium zu begegnen.

\section{II.3.1. Herausforderungen prozesshafter Kunstformen}

Vor besondere Herausforderungen stellen die formale und inhaltliche Analyse künstlerische Aktionen aufgrund deren originären Charakters. Sind die ephemeren Aktionen doch nur das eine Mal und dann nicht mehr direkt zu rezipieren. Handelt es sich bei diesen Werken - anders als bei einem wiederholt gezeigten Theaterstück - doch um eine meist nur einmalige Aufführung. Video-, Film- oder Tonbandaufnahmen sind - wenn vorhanden - hilfreiche Zeugnisse, die dazu beitragen können, das Werk für eine Analyse zu rekonstruieren. Doch bleiben es Vermittlungsmittel, die das ursprüngliche Werk bereits transformieren. Zudem können Fotografien einer Aktion, Augenzeugenberichte, Kritiken oder auch Notizen wie Aussagen des Künstlers selbst weitere Sekundärquellen sein, die einen Eindruck vermitteln und zur Rekonstruktion der künstlerischen Aktion beitragen können. Dieser Charakter der Einmaligkeit zeigte sich auch im Rahmen dieser Untersuchung als ein Problem, finden sich doch im Werk der Künstlerin Ulrike Rosenbach gleich mehrere Dutzend Performances, die während der vergangenen drei Jahrzehnte aufgeführt, nicht mehr direkt rezipiert werden konnten. So konnte für die Untersuchung nur auf Sekundärquellen, wie eigene Beschreibungen der Künstlerin, Zeitungsberichte oder Katalogkritiken zurückgegriffen werden, ergänzt um eine ganze Reihe von Videoaufzeichnungen, hat die Künstlerin doch sehr darauf geachtet, ihre Aktionen und Performances in audiovisueller Form zu

40 Haberl in: Kat. Saarbrücken 2000, o.S.

41 Allerdings ergibt sich hier eine Begriffsüberschneidung mit der so genannten Prozesskunst oder „processual art", einer Kunstform der 1960er und 1970er Jahre, die den Akt des kreativen Schaffens selbst zur Kunst erklärte. Sie betont in ihrem Arbeitsvorgang den Entstehungsprozess stärker als das Endprodukt und thematisiert somit die Erscheinungen eines Veränderungsvorganges. Damit wäre Prozesskunst auch zu den prozesshaften Kunstformen zu rechnen. 
dokumentieren. ${ }^{42}$ Doch bleibt in der Regel nur ein fragmentarischer Eindruck übermittelt.

In Bezug auf künstlerische Videotapes ist die Untersuchungssituation eine andere als bei Live-Performances. Eines ihrer formalen Charakteristika ist ja genau die Wiederholbarkeit der Rezeption, die für eine eingehende Analyse grundlegend ist. ${ }^{43}$ Wie ist aber nun das Gesehene und Gehörte eines künstlerischen Videotapes zu erfassen? Wie lässt sich der Bildfluss, der Ton und die synästhetische Wirkung für eine Analyse zergliedern? Wie können formale und inhaltliche Strukturen erschlossen und untersucht werden? Dies alles gilt es zu berücksichtigen, bevor sich dem einzelnen Bildmotiv - dem traditionellen Gegenstand der Kunstwissenschaft - zugewandt werden kann. Dafür wird ein Instrumentarium gesucht, das geübt ist, im Umgang mit bewegten Bildern. Hier liegt die Filmanalyse nahe. Diese für den Film inzwischen erprobte Untersuchungsmethode audiovisueller Texte soll im Folgenden zunächst vorgestellt werden, um dann auf ihre Übertragbarkeit bei der Untersuchung künstlerischer Videotapes überprüft zu werden.

\section{II.3.2. Anleiben aus der Filmanalyse}

\section{II.3.2.1 Begrifflichkeiten und Untersuchungsverfahren}

Für das audiovisuelle Medium des Filmes wurde eine eigene Terminologie entwickelt. In seinem „Grundbuch“ hat Wolfgang Gast eine kompakte Einführung in Begriffe und Methoden der Filmanalyse gegeben, in der er sich auf die Standardwerke zu diesem Thema von Faulstich, Hickethier, Kandorfer, Kuchenbuch, Monaco, Paech oder auch Wolff bezieht. ${ }^{44}$ Film wird bei Gast als komplexer audiovisueller Text verstanden, der in ein Feld der Medienkommunikation eingebunden ist und bestimmten Bedingungen der Produktion, Postproduktion, Rezeption und

42 Vgl. Kuni 2006, S. 11; dabei waren jedoch Videodokumentationen von Aktionen nur eingeschränkt zugänglich. Einen Einblick in die Werke boten jedoch auch die überarbeiteten Videotapes, in denen die Performanceaufzeichnungen weiter im Medium des Videotapes verarbeitet wurden.

43 Ulrike Rosenbach gehört zu den KünstlerInnen, die sich sehr früh und gewissenhaft um eine gute und langfristige Archivierung der elektronischen Aufnahmen gekümmert haben. (Vgl. Kuni 2006, S. 11) Damit taucht an dieser Stelle die Frage der Originalität bei dieser Kunstform auf. Zudem ist es wichtig, das relativ schnelle Verfallsdatum der Videokunst auf der technischen Seite zu betonen. Wie kurz dargelegt halten die Bänder mit der elektromagnetisch gespeicherten Information nur eine kurze Zeit und müssen konservatorisch intensiv gewartet werden (entsprechendes Klima, mindestens einmaliges Umspulen pro Jahr u.Ä.). Trotzdem sind Bänder aus den Anfängen dieser Kunstform inzwischen nicht mehr abspielbar, sei es mangels Hardware oder wegen des Zerfalls der Software und die Werke damit bereits verlorengeganen. Im Vergleich zu einem mehrere hundert Jahre alten Gemälde sind einige Jahrzehnte alte Videoarbeiten also ein nur kurzer Zeitraum der direkten Überlieferung.

44 Vgl. Gast 1993, S. 61-63 
Wirkung unterliegt. Erst eine spezifische Fachsprache mache diese komplexe BildTon-Collage beschreibbar:

„Ein Film ist ein großer, komplexer Text, der für die Zuschauer das Rezeptionstempo in der Regel vorschreibt, durch Mise en scène und Montage die Wahrnehmung organisiert und trotz seiner komplizierten Zeichenstruktur meist als organische Einheit verstanden wird. Das alles zusammen macht es schwierig, ihn angemessen zu analysieren. Er muß daher in methodisch bearbeitbare Elemente zerlegt werden, welche die jeweilige Analyseeinheit bilden." 45

Den Gedanken der Zerlegung in bearbeitbare Elemente aufgreifend, bietet es sich an, aus dem filmischen Text die so genannten Einstellungen herauszugreifen. Als eine Einstellung ist jene Einheit definiert, die durch zwei Schnitte oder Blenden begrenzt ist und einen einheitlichen Kamerablick aufweist. Im Verlauf einer Analyse kann es zudem hilfreich sein, eine Einstellung zur detaillierteren Betrachtung in noch kleinere Einheiten bis zum Standbild zu zergliedern. Eine Reihe von Einstellungen, die eine inhaltlich-thematisch sinnvolle Einheit bilden, werden mit dem Begriff der Filmsequenz zusammengefasst. ${ }^{46}$

In Bezug auf die Größe des aufgenommenen, beziehungsweise gezeigten, Ausschnittes wird in acht unterschiedliche Einstellungsgrößen unterschieden, die von Weit (W) über Total (T), Halbtotal (HT), Halbnah (HN), Amerikanisch (A), Nah $(\mathrm{N}), \operatorname{Groß}(\mathrm{G})$ bis zum Detail (D) reichen.

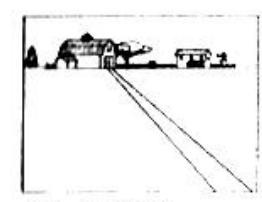

Weit (W)

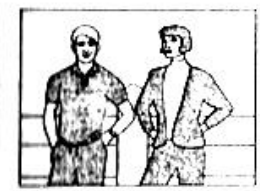

Amerikanisch (Am)

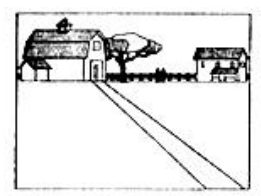

Total (T)

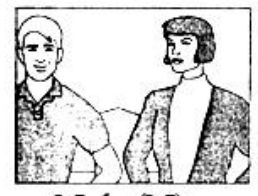

$\mathrm{Nah}(\mathrm{N})$

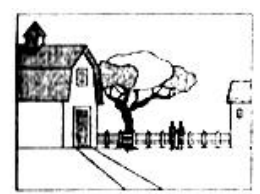

Halbtotal (HT)

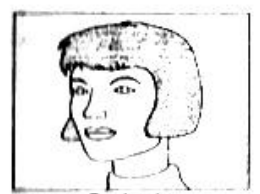

Groß (G)

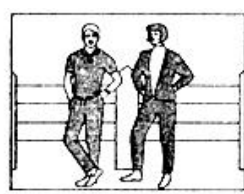

Halbnah (HN)

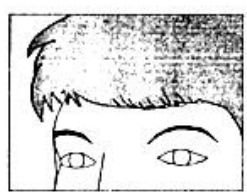

Detail (D)

Abb. 9: Einstellungsgrößen

Zudem ist die so genannte Perspektive ein wesentliches Gestaltungsmittel eines Films und damit auch ein Mittel der Wahrnehmungslenkung. Als Grundformen werden in diesem Bereich unterschieden: die Normalsicht, die Froschperspektive oder Untersicht sowie die Vogelperspektive oder Aufsicht. Diese visuellen Codes

45 Gast 1993, S. 53

46 Gast 1993, S. 53 
geben nicht nur den Blick des Filmemachers auf das Dargestellte wieder, sondern geben dem Gezeigten zudem eine unterschiedliche Qualität, sowie sie dem Zuschauer eine bestimmte Wahrnehmungsperspektive zuweisen. ${ }^{47}$

Auch bildet ein filmischer Text in der Regel Bewegung ab. Hierbei kann in zwei Bewegungsformen unterschieden werden: die Bewegung der dargestellten Figuren und Gegenstände - auch Objektbewegung genannt - und die Bewegung der Kamera selbst. Bei der Kamerabewegung werden unterschieden der feste Kamerastand, der Schwenk, die Kamerafahrt, der Zoom, der einer Veränderung der Brennweite entspricht, und die so genannte „subjektive Kamera“ - eine unruhige Handkamera, die die Bewegungen des Aufnehmenden mitmacht. Die Objektbewegungen werden nach den zwei unterschiedlichen Achsverhältnissen unterteilt quer oder in Verlängerung zur Kameraachse. Hinzu kommt in der Montage der Achssprung - auch als Schuss-Gegenschuss-Verfahren bezeichnet - als Stilmittel. Unter die zahlreichen visuellen Codes, die die Bildkomposition eines Films ausmachen, ist neben der Beleuchtung des weiteren die Mise en Scène zu rechnen, die die bildkompositorische Inszenierung eines Filmes beschreibt und mit Kategorien der offenen und geschlossenen Form und den verschiedenen Bilddimensionen arbeitet. ${ }^{48}$

Neben der hier vorgestellten Auswahl an visuellen Kategorien - die um weitere Aspekte zu erweitern sind - wirken im Film zudem auditive Elemente. Setzt sich der audiovisuelle Text doch aus dem Zusammenspiel der drei Zeichensysteme Bild, Sprache und Ton zusammen. Sie werden in der Filmrezeption als Einheit empfunden, und die drei simultan rezipierten Systeme können in komplizierten Beziehungen zu einander stehen, die es analytisch zu klären gilt. Unterschieden wird bei der Verwendung akustischer Zeichen im Film grundsätzlich in On- und Off-Ton. Während beim On (the screen)-Ton, die Quelle des Tones im Bild sichtbar ist, ist diese es beim Off-Ton nicht. Zu den filmischen Gestaltungsmitteln gehört zudem die Möglichkeit der Einheit von Wort und Bild oder einer so genannten Wort-Bild-Schere. ${ }^{49}$ Neben der Sprache ist die Musik das wichtigste Element des Zeichensystems „Ton“. Funktionen einer musikalischen Ummalung können zum Beispiel sein: den Handlungsablauf des Filmes und die Gefühle seiner Hauptfiguren zu illustrieren beziehungsweise zu kommentieren, Raum und Zeit zu etablieren, die Rezipienten des Filmes zu emotionalisieren oder auch den Film zu strukturieren. ${ }^{50}$ Nicht zu vergessen ist die Kategorie der Geräusche.

„Nahezu jeder Versuch, die Filmsprache systematisch zu gliedern und präzise zu beschreiben, bedient sich sprachwissenschaftlicher, bäufig auch semiotischer Begriffe, was si-

47 Zur symbolischen Form der Perspektive vgl. auch Panofsky 1978

48 Vgl. Gast 1993, S. 27-34

49 Außerdem hat Kracauer in seiner Filmtheorie ein Beschreibungsmodell entwickelt, das Synchronismus/ Asynchronismus und Parallelismus wie den Kontrapunkt zusammensetzt.

50 Zudem dient Musik der Filmwerbung und Kanonisierung. (vgl. Monaco 1995, S. 122f) 


\section{cherlich mit den Parallelen, Überschneidungen und Entsprechungen von Bild- und Wort- sprache zu tun hat." "F1}

Im Zusammenhang der Beschreibung einer „Filmsprache“ erwähnt Gast das Begriffspaar der Konnotation und der Denotation. Während die direkte Bedeutung eines Wortes, Satzes oder Textes denotativ sei, gehe die konnotative Aussage über diesen unmittelbaren Zusammenhang hinaus. Die Konnotation umfasst damit das über das Benannte hinaus Mitgemeinte, seine zusätzlichen Sinnebenen. Aufgrund der Analogie von Signifikant - dem Bezeichnenden - und dem Signifikat - dem Bezeichneten - trägt ein Filmbild eine sehr starke denotative Bedeutung in sich. Man glaubt, dass „,das Bild ist, was es abbildet “52. Daneben ist es aber immer auch mehr. Die symbolische Aufladung eines Bildes mit konnotativer Bedeutung kann sich aus verschiedensten Quellen speisen und durch die Verknüpfung einzelner Einstellungen - dem so genannten Schnitt oder der Montage - erst erzeugt wie verstärkt werden.

Der Begriff der Montage benennt in allgemeinster Form die Verknüpfung von mindestens zwei Einstellungen eines Filmes durch Schnitt oder Blende. Die Mon-

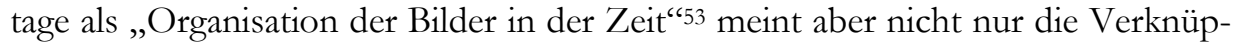
fungen einzelner Einstellungen, sondern zudem die Verknüpfungen ganzer Filmsequenzen. Schnitt und Blende als teilende - beziehungsweise zusammenfügende - Instrumente des Filmes sorgen für einen Fortlauf der Handlung sowie sie den Rhythmus des Filmes festlegen. Dabei haben die beiden Formen Blende und Schnitt unterschiedliche Interpunktionsqualitäten. Das Aneinandermontieren zweier Einstellungen unterschiedlichen Inhalts wird als harter Schnitt bezeichnet. Dieses Gestaltungsmittel macht die Gliederung für den Zuschauer erkennbar. Das Stilmittel des so genannten weichen Schnittes, der gleiche Einstellungen aneinanderfügt, fördert die Illusion von Realitätsabbildung, in dem er vergessen lässt, dass geschnitten wurde. Die so genannte Blende lenkt die Aufmerksamkeit des Zuschauers auf den Anfang und das Ende einer kleineren oder größeren Einheit eines Filmes. Zudem können unterschiedliche Formen von Trickblenden nur bestimmte Ausschnitte der gesamten Bildschirmfläche zeigen oder auch aufeinander folgende Einstellungen fließend miteinander verknüpfen. Mit diesen grundlegenden Gestaltungsmitteln können die verschiedenen Ein-stellungen in der zeitlichen Folge aneinander gefügt werden im Rahmen der so genannten Postproduktion. ${ }^{54}$

Gast 1993, S. 38

Gast 1993, S. 39

Zitat des französischen Filmwissenschaftlers André Bazin, in: Gast 1993, S. 40

54 Kuchenbuch unterscheidet sieben Grundtypen der Montage, die er drei Obergruppen zuordnet: Zu der ersten Gruppe der so genannten narrativen Montageformen zählt er die szenische, die eine Augenzeugenperspektive vermittelt, und die erzählende Montage, die wie eine erzählte Erinnerung strukturiert ist. Zur zweiten Gruppe der deskriptiven Formen gehört die beschreibende Montage, bei der die Beschreibung von Schauplätzen im Vordergrund steht. Zur dritten Gruppe der metonymischen Montageformen rechnet der Filmtheoretiker die metonymische , 
In den Ausführungen über die filmischen Gestaltungsmittel und Codes wurde von einer Filmsprache gesprochen, die den Rückgriff auf linguistische Ansätze nahe legt. Doch bleibt zu berücksichtigen, dass Film keine durch einheitliche grammatikalische Regeln geprägte Sprache ist und frei bleibt für kommunikative Experimente. In diesem Zusammenhang gibt auch Gast zu bedenken:

„Aber so bäufig auch linguistische Kategorien in die Filmanalyse einfließen - bei genauerer Betrachtung wird schnell deutlich, daß der Film „keine Sprache", aber ,wie eine Sprache" (Monaco) ist, so daß zwar linguistische Annäherungen häufig sinnvoll sind, aber die Anwendung streng linguistischer Konzepte (sowie streng rhetorischer Methoden) führt schon bald nicht weiter. Daher wurde in den 60er Jahren ein allgemeiner zeichentheoretischer, semiotischer Ansatz, berangezogen, der die einzelnen „Sprachen “ (Sprache, Film usw.) als Kommunikationssysteme begreift, die strukturelle Übereinstimmungen, aber auch Differenzen zeigen. Von hier aus läßt sich die Filmsprache dann auch sinnvoll in die Bereiche „Zeichen" und „Syntax" gliedern. "55

Und in Bezug auf eine Analyse eines Filmes merkt der Filmtheoretiker an:

„Um der Zeichenstruktur eines Filmes gerecht zu werden, ist es nötig, ibn sowohl als ganzen (Makroanalyse) als auch, zumindest exemplarisch, an ausgewählten, für die jeweilige Fragestellung relevanten Einstellungen bzw. einzelnen Sequenzen im Detail (Mikroanalyse) zu untersuchen." 56

So schlägt Gast zunächst das Erstellen eines Sequenzplanes vor, der zur Verfeinerung um einen Zeitplan ergänzt und dem eine parallel laufende Kommentarspalte beigefügt werden kann. Wenn eine solche Auflistung nicht aufschlussreich genug sei, bietet sich ein ausdifferenziertes Filmprotokoll an, in das der Film transkribiert werde mit Spalten für Bildbeschreibung, Kamera, Sprache, Sprecher, Ton, Zeit. Gegebenenfalls sei dieses nicht für den gesamten Film - weil sehr aufwändig sondern nur für einzelne Einstellungen oder Sequenzen eines Filmes anzufertigen. Und Gast fasst zusammen:

„In diesem Sinne haben die oben vorgestellten Einheiten und Hilfsmittel der Filmanalyse wirklich Hilfscharakter. Sie sollen im Rahmen einer problemorientierten Fragestellung, eines inhaltlich bestimmten Erkenntnisinteresses - belfen, den Film in seinen wichtigsten

die unter einem abstrakten Oberbegriff verschiedene Bereiche verklammert, die vergleichende, das pointierte Aneinanderschneiden zweier filmischer Einstellungen und die symbolische, bei der symbolische Einstellungen eingeschnitten werden, sowie die assoziative Montage, deren Einstellungen durch die Intention zusammengehalten werden. (Kuchenbuch 1978, S. 39f, vgl. Gast, S. 41-44)

55 Gast 1993, S. 38

56 Gast 1993, S. 53 


\section{Dimensionen erst einmal angemessen zu beschreiben und in kleinen Schritten zu analy- sieren." 57}

Für eine auf eine solche formale Analyse folgende inhaltliche Filminterpretation benennt Faulstich dann die folgenden sechs qualitativen Methoden: den strukturalistischen Zugriff, die biografische Filminterpretation, die literatur-bzw. filmhistorische, die soziologische, die psychologisch-psychoanalytische sowie den genrespezifischen Interpretationansatz. Gast merkt dazu an, dass je nach Fragestellung eine Kombination verschiedener Analysemethoden sinnvoll sein kann, um auch der Mehrdimensionalität eines Filmes gerecht zu werden. ${ }^{58}$

\section{II.3.2.2 Übertragbarkeit dieser Verfahren auf künstlerische Videotapes}

Film wie auch Video sind filmische, audiovisuelle Texte, was eine Übertragbarkeit der Methoden nahe legt. Sie unterscheiden sich jedoch - unter anderem - durch ihre technischen Voraussetzungen, formalen Strukturen sowie unterschiedliche Rezeptionsweisen. Die technischen Gegebenheiten in beiden Medien brachten bis zur digitalen Revolution in den 1990er Jahren - grundsätzlich abweichende Gestaltungsmöglichkeiten mit sich. Seitdem haben verstärkt elektronische Effekte durch multimediale Verfahren Eingang in das Medium des Filmes gefunden. So haben die sich stetig weiter wandelnden Möglichkeiten der elektronischen Bildbearbeitung die Filmästhetik im Laufe der Zeit immer weiter modifiziert. Dabei hat das elektronische Videobild genuine Eigenschaften hat, die es von seinem Vorgänger - dem Filmbild - abgrenzen. Ist doch die Zerlegung der Aufnahme in Bildpunkte die Voraussetzung einer elektronischen Speicherung und Wiedergabe, wodurch die Informationsmenge klar bestimmbar ist. Hinzu kommt die Möglichkeit der künstlichen Generierung elektronischer Bilder mittels ganz unterschiedlicher analoger und seit den 1980er Jahren auch digitaler Effekte.

Bei der Magnetbandaufzeichnung lassen sich bereits mit analoger Technik leicht mehrere Aufnahmen gleichzeitig übereinander legen. Ein Bildmischeffekt, der beim Film rein technisch auf zwei Bildschichten reduziert ist, das sonst kein Projektionslicht mehr durch die Aufnahmen dringen kann. Zudem können durch unterschiedliche analoge elektronische Effekte Videoaufnahmen in vielfältiger Weise verfremdet werden. Hier finden sich zum Beispiel die Möglichkeiten der Veränderung der Farben und Helligkeiten oder auch der Solarisation. Mit der Standardtechnik professioneller Studios konnten bereits in den 1960er Jahren mittels einiger elektronischer Trickblenden verschiedene Bilder ineinander gefügt werden. Zudem bot die Technik bereits damals die Möglichkeit per Knopfdruck Buchstaben oder Schriftzüge in eine Aufnahme einzublenden. Zu den analogen Effekten zählt auch der so genannte „Blueboxeffekt“, mit dem eine bestimmte

57 Gast 1993, S. 55

58 Gast 1993, S. 57 
Farbe einer Aufnahme durch ein anderes Bild ersetzt werden kann. So zeigt sich für das elektronische Bild, dass ein Zerlegen der Motive, ein Übereinanderlegen und Ineinanderfügen wie auch ein Verbinden durch Blenden charakteristisch ist. Damit lässt sich das Zusammenfügen mehrerer Bilder als spezifische Eigenschaft elektronischer Bilder herausstellen.

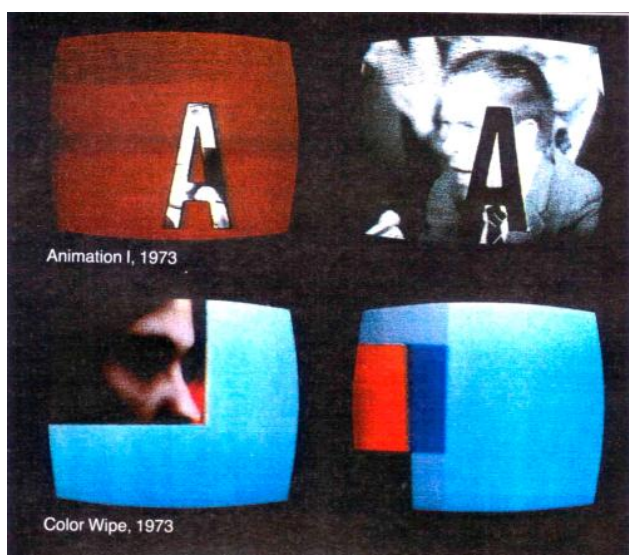

Abb. 10: Keith Sonnier: Animation I und Color Wipe, 4 Videostills , 1973

Parallel zur Entwicklung analoger elektronischer Bildeffekte entwickelte sich in den 1980er Jahren die Technologie zur digitalen Bildmanipulation wie auch zur Generierung künstlicher Bilder fort. Durch die Vernetzung der Videotechnik mit digitalen Technologien ist schließlich der Zugriff und damit auch die Manipulation jedes einzelnen Bildpunktes möglich geworden und die Verfahren der Bildbearbeitung werden immer weiter perfektioniert. Mit zunehmenden Speicherkapazitäten ist schließlich seit spätestens Mitte der 1990er Jahre auch die Animation der künstlichen Bilder kein Problem mehr. Damit sind filmische Aufnahmen nicht mehr allein Abbilder einer gegebenenfalls inszenierten Wirklichkeit, sondern können komplexe Bildgewebe sein, die erst im Innern elektronischer Schaltsysteme entstanden sind.

Da das filmsprachliche Gestaltungsmittel des Schnittes im Video hinter einer durch fließende Übergänge medieneigenen Blendenästhetik zurücktritt, ist es schwierig in einem Video eine Einstellung zu erfassen. Umgekehrt können sehr schnelle Schnittfolgen die elektronische Bildsprache prägen. Auch finden sich elektronische Effekte, die es ermöglichen das Gesamtbild in unterschiedliche Einheiten zu zergliedern und vieles mehr. Um diese Phänomene im Rahmen einer analytischen Untersuchung zu erkennen und damit beschreiben zu können, gilt es diese unterschiedlichen Effekte und Begriffe zu benutzen. Für die Analyse sind damit die oben vorgestellten Begrifflichkeiten des Filmes zu modifizieren und um das videospezifische Fachvokabular zu erweitern. 
Aber es bleibt noch ein weiterer Unterschied, der eine Übertragung erschwert. Beziehen sich die Interpretationsansätze der Filmanalyse doch auf narrative Arbeiten. Doch haben bildende Künstler, die mit dem Medium Video experimentierten, neue audiovisuelle Ausdrucksformen kreiert, die abweichen von den narrativen Strukturen des Filmes. Wenn bereits im Experimentalfilm konditionierte Genres und konventionelle Formen und Inhalte des Spielfilmes aufgebrochen wurden, so ist der experimentelle Charakter bei künstlerischen Videotapes noch stärker ausgeprägt. Zu berücksichtigen bleibt im Rahmen einer Analyse künstlerischer Videotapes zudem der grundsätzlich andere Kontext der Rezeption in einem Museum oder einer Galerie, als dieser zum Beispiel bei einem Spielfilm in einem Kino gegeben ist. ${ }^{59}$

Aus den Feldern Film und Video wurden an dieser Stelle einzelne Aspekte herausgegriffen, um die komplexe Thematik zu umreißen. Gegebenenfalls werden weitere relevante Aspekte im Verlauf der einzelnen Untersuchungen thematisiert werden. ${ }^{60}$ Bleibt an dieser Stelle zusammenzufassen, dass das Instrumentarium der Filmanalyse in modifizierter Form auf die Untersuchung künstlerischer Videotapes anwendbar ist, und dass diese Methode im Verlauf der Arbeit auch mehrfach exemplarisch praktiziert werden wird. Den Auftakt übernimmt dabei die filmanalytische Untersuchung des allerersten Tapes der Künstlerin „Einwicklung mit Julia“. ${ }^{61}$ Es folgt später die exemplarische Analyse des Tapes „Lotus-KnospenTöne", das Ende der 1970er Jahre entstanden ist. ${ }^{62}$ Schließlich wird sich mit der Analyse der beiden Tapes „Die Eulenspieglerin“ und „Or-Phelia“ zwei komplexen videographischen Hauptwerken der Künstlerin aus der Mitte der 1980er Jahre zu-

59 Fragen, die sich stellen sind unter anderem: Wo und wie wird ein künstlerisches Videotape gezeigt? Ist es in einer Galerie, einer Ausstellung oder vielleicht auf einem Festival zu sehen? Auch finden sich Ansätze, Tapes im Fernsehen einem Massenpublikum zu zeigen. Erscheint das Tape auf einem kleinen Monitor oder großformatig an die Wand projiziert? Gibt es in der Situation Sitzgelegenheiten, auf denen man es sich bequem machen kann? Ist der Ton des Tapes eingeschaltet oder die Arbeit in der jeweiligen Präsentation auf die Bildebene reduziert? Auch bleibt die Frage, ob ein Zuschauer wirklich das ganze Tape ansieht. Ist es doch - auch nach 40 Jahren Videokunst - immer noch ungewohnt, sich auf den zeitlichen Aspekt dieses Mediums einzulassen. Zudem lässt sich unter anderem die Frage anschließen, ob ein einmaliges Anschauen reicht, um den Inhalt zu erfassen, oder ob nicht ein mehrfaches Anschauen für ein Verständnis notwendig ist.

$60 \mathrm{Zu}$ methodischen Schwierigkeiten und Verfahren bei der Analyse von Videokunst vgl. Schubiger 2003, S. 11-25. Auch Schubiger kommt zu dem Schluss, dass die sprachliche Beschreibung eines Tapes eine notwendige und legitimes Instrument der kunstwissenschaftlichen Methoden im Bereich der Videokunst sei. (Schubiger 2003, S.20)

61 Vgl. Kap. III.1.

62 Vgl. Kap. IV.4. 
gewandt. ${ }^{63}$ Den Abschluss der Untersuchungen von Einzelbändern bildet dann der Blick auf das Band „Osho-Samadhi““ aus den frühen 1990er Jahren. ${ }^{64}$

\section{II.3.3. Kunstwissenschaftliche Methoden}

Im Laufe der Jahrhunderte hat die wissenschaftliche Disziplin der Kunstgeschichte ihre Kunstauslegungstheorie Schritt für Schritt erweitert und modifiziert und dabei ein umfangreiches Repertoire an Methoden zur Bild- und Werkanalyse zusammengetragen. ${ }^{65}$ Dazu gehört unter anderem die Methode der sich mit Stil und Form befassenden Ikonographie, deren Anliegen die Erforschung, Beschreibung und Deutung der Bildgegenstände ist. Sie wird erweitert durch die Ikonologie. Diese Methode, deren Begriff der italienische Gelehrte Cesare Ripa ( 15601620/25) erstmals 1613 anwandte, wurde von dem Kunst- und Kulturhistoriker Aby Warburg (1866-1929) im 20. Jahrhundert erweitert, der Kunst als kulturelles Erinnerungsorgan auffasste. Die Ikonologie legt ihren Schwerpunkt auf die Auslegung der Inhalte und fügt ein Kunstwerk in seinen individuellen Kulturhintergrund ein. Dazu nutzt sie alle verfügbaren Quellen - wie zum Beispiel historische, literarische, religiöse und mythologische Zeugnisse -, um ein so genanntes Programm zusammenzustellen, das nicht nur die offenbaren und geheimen Absichten in sich einschließt, sondern ganz besonders auch den Symbolgehalt des Werkes versucht zu enthüllen. In diesem Zusammenhang können auch psychologische oder auch semiotische Fragestellungen eine Rolle spielen. ${ }^{66}$

Im Rahmen dieser Arbeit wird aus dem kunstwissenschaftlichen Methodenpool neben kulturhistorischen auch auf ikonographische sowie ikonologische Ansätze zurückgegriffen. Auch soll die Frage nach biographischen Bezügen nicht ausgeklammert werden, verweist die Künstlerin doch selbst auf eine spezifisch „autobiographische Phase“ in ihrem frühen Werk, sowie auch die Kunsthistorikerin Karin Thomas das Ouevre der Künstlerin in ihrem Überblickswerk „Kunst in Deutschland seit 1945“ unter das Kapitel „Spurensuche und Selbstdarstellungen“.

63 Vgl. Kap. IV.5.2. und IV.5.3. Die Protokolle zu allen Werken finden sich im Anhang unter Kap. VIII.

64 Vgl. Kap. V.2.; Am 22. August 2011 teilte mir Ulrike Rosenbach per E-mail mit: „Aus copyrightrechtlichen Gründen gehört „Osho Samadhi“ seit 2005 nicht mehr in mein Werk."

65 Während die Kunstgeschichte mit den Schriften von Vasari (1551-1574) im 16. Jahrhundert den Anfang nahm als eine individuelle „Künstlergeschichte“, wuchs sie zu einer historischen Wissenschaft weiter, die sich den Entwicklungszusammenhängen zuwandte.

66 Vgl. Kultermann 1996 und Lurker 1991; die Semiotik ist die allgemeine Lehre von den Zeichen, Zeichensystemen und Zeichenprozessen. 
Mit diesem Blick auf die Biographie wird nun zur Chronologie des künstlerischen Werkes übergeleitet.

\section{II.4. Biografisches - Auf Salz geboren}

Ulrike Rosenbach wurde im Jahr 1943 in Bad Salzdetfurth geboren. ${ }^{67}$ Der Name des Geburtsortes weist schon auf den dortigen Salzabbau, der viele Jahrhunderte zurückreicht und der Ort ist bis heute durch seine Salinen geprägt. ${ }^{68}$ In einem Interview hob die Künstlerin die für sie besondere symbolische Bedeutung des Salzes hervor, das auch in vielen ihrer Performances ein grundlegendes Material bildet:

\section{„Ich bin im wabrsten Sinne des Wortes auf Salz geboren; unter dem Haus meiner El- tern im Harz ist ein Kalibergwerk. Mittags wird dort unterirdisch gesprengt, und die Häuser tragen Risse davon... "69}

Zur Generation der Kriegskinder gehörend, teilt die Künstlerin zudem ähnliche traumatische Erfahrungen wie viele andere Menschen dieser Generation ${ }^{70} \mathrm{Ihr}$ Vater sei im Krieg Bomberflieger gewesen und die Künstlerin beschrieb ihr Elternhaus als sehr autoritär geprägt und nationalsozialistisch eingestellt. Auch habe ihr Vater seine Nazivergangenheit später nicht aufgearbeitet und ihr Verhältnis zu ihm sei schwierig gewesen, wie die Künstlerin im Rückblick erklärte. ${ }^{71}$

In ihrer Jugend habe sie viel gelesen. Ihre Großeltern hätten eine große Bibliothek gehabt und sie habe schon als junges Mädchen viel Sport getrieben, erinnerte sie sich. ${ }^{72}$ Nach dem Abitur begann sie 1964 an der Düsseldorfer Akademie zu studieren. An der renommierten Kunstakademie wurde in der Akademietradition gelehrt. ${ }^{73}$ Die Kunstakademie hatte der Tradition folgend jeweils eigene Abteilungen für Malerei, Bildhauerei, Architektur und die graphischen Künste. Die junge Kunststudentin entschied sich für die Bildhauerei und begann das Studium der bildenden Kunst und der Kunsterziehung für das Lehramt an höheren Schulen,

67 Der Ort wurde 1194 erstmals als Detfurth urkundlich erwähnt und bereits damals sollen dort Salzsieder ansässig gewesen sein.

68 Im Jahr 1992 wurde der Salzabbau in Bad Salzdetfurth allerdings eingestellt.

69 Rosenbach in: Du 1981, S.42

70 Mit der Aufarbeitung der durch die traumatischen Kriegserfahrungen geprägten Leben dieser Generation haben sich verschiedene Publikationen beschäftigt, die erst in den vergangenen Jahren erschienen sind. (Vgl. z.B. Lorenz, Hilke: Kriegskinder: Das Schicksal einer Generation (2005), Die vergessene Generation: Die Kriegskinder brechen ihr Schweigen (Serie Piper) von Sabine Bode von Piper (2005) oder auch Kriegskinder: Wie die Wunden unserer Vergangenheit heilen von Gertrud Ennulat (2008)

71 Richter 2000, S.119

72 Vgl. Gespräch mit Ulrike Rosenbach 2001

73 Die Kunstkritikerin Gislind Nabakowski, die an der Düsseldorfer Akademie ab 1965 studierte, kritisierte das Lehrangebot im Rückblick als unpolitisch, unzeitgemäß und mangelhaft. (Vgl. Nabakowski in: Kat. Berlin 1977, S.92) 
in der im selben Jahr eingerichteten Probeklasse von Karl Bobek (1925-1992). In dieses Studium war auch eine intensive Auseinandersetzung mit der Kunstgeschichte eingeschlossen. Karl Bobek unterrichtete an der Düsseldorfer Akademie seit 1963 Bildhauerei für das künstlerische Lehramt. ${ }^{74}$ Im Gespräch erinnerte sich Ulrike Rosenbach an ihre Beweggründe ihr Kunststudium zu beginnen:

„Ich wollte ursprünglich eigentlich Bühnenbildnerin werden. Aber das ging nicht in Düsseldorf, weil es Bühnenbild dort nur in der Malerei gab. Doch ich wollte in die Plastik, denn das Bühnenbild war für mich eine plastische Angelegenheit. Ich war immer plastisch interessiert. So bin ich in die Plastik gegangen, weil es vom Bühnenbild her nicht funktionierte und dafür hätte ich auch noch eine Lehre machen müssen als Schreiner. Ich hatte gerade mein Abitur gemacht und keine Lust auf eine handwerkliche Lehre. Mit dem Abitur, da hätte ich natürlich auch Bühnenbild studieren können, aber ich wollte wirklich nicht malen. Ich wollte Plastik machen. Zeichnen war für mich dann im Studium auch erstmal ein Riesenproblem. Wir mussten soviel zeichnen, dass mir die Obren weggeflogen sind. Jeden Tag Aktzeichnen. So habe ich Zeichnen gelernt. Wir wurden so getriezt zum Zeichnen, das kann man sich nicht vorstellen. "75

Den Schwerpunkt der Bildhauerei weiterverfolgend studierte sie im Anschluss an die Probeklasse für zwei Semester Stahlbildhauerei bei Norbert Kricke (19221984). Der seit 1964 an der Düsseldorfer Akademie lehrende Bildhauer war einer der ersten deutschen Künstler, die nach dem Zweiten Weltkrieg auch international Anerkennung fanden. ${ }^{76}$ Bei dem für seine abstrakten, raumgreifenden Stahlskulpturen bekannten Bildhauer hat auch Ulrike Rosenbach überwiegend mit Metall gearbeitet. ${ }^{77}$ Neben verschiedenen geschweißten Arbeiten, seien in diesen ersten Semestern auch Werke aus gewalztem Stahlblech entstanden, erinnerte sich die Künstlerin. Im Jahr 1966 heiratete Ulrike Rosenbach. ${ }^{78}$ Während ihrer Schwangerschaft erlaubte Norbert Kricke seiner Studentin nicht, bei der künstlerischen Arbeit mit Materialien in Berührung zu kommen, die für das Kind schädlich sein könnten. So musste sie die Klasse des Bildhauers verlassen und wechselte noch 1966 - wie sie selbst in einem Interview sagte - aus „,pragmatischen Gründen“ ${ }^{679}$ in

74 Karl Bobek hält in seinen Werken grundsätzlich an der klassischen Tradition der dreidimensionalen, von einem inneren plastischen Kern her belebten und gestalteten Figur fest, auch wenn seine theoretischen Äußerungen anders lauten. In Rosenbachs frühen Zeichnungen zeigte sich der Einfluss des klassisch figurativen Stil des ersten Lehrers Karl Bobek, an dem sich der spätere Lehrer Joseph Beuys stieß.

75 Rosenbach im Gespräch 2001; Kap. VII.1.

76 Richter 2000, S. 118

77 Arbeiten von Norbert Kricke waren auf der d1 und d2 ausgestellt.

78 So taucht die Künstlerin in Publikationen zwischen 1966 und 1970 wiederholt unter ihrem Doppelnamen als Ulrike Nolden-Rosenbach auf, wie zum Beispiel bei der „between“, die zwischen dem 5.9.- 18.10.1970 in der Düsseldorfer Kunsthalle stattfand. (Buschmann 2002, S. 289)

79 Rosenbach im Gespräch mit Petra Richter am 29.8.1994 in: Richter 2000, S. 301 
die Klasse von Joseph Beuys (1921-1986), deren Raum auf demselben Flur lag wie ihre alte Klasse. ${ }^{80}$

Bei Beuys, der von 1961 bis 1972 an der Akademie unterrichtete, lernte sie eine neue künstlerische Arbeitsweise kennen und der Lehrer unterstützte die junge Mutter in ihrer künstlerischen Auseinandersetzung mit ihrer Mutterrolle, hatte die Studentin doch noch 1966 ihre Tochter Julia zur Welt gebracht.

Während ihrer Ausbildung stand der Künstlerin ein eigenes Atelier außerhalb der Akademie zur Verfügung, in dem sie überwiegend tätig war. Neben der Akademie war das Creamcheese ein wichtiger Düsseldorfer Künstlertreffpunkt. ${ }^{81}$ Sie engagierte sich in diesen durch das Erwachen von Studentenbewegung und ,auBerparlamentarischer Opposition" APO geprägten Jahren politisch in verschiedenen studentischen Organisationen. ${ }^{82}$ Im Jahr 1969 machte Ulrike Rosenbach ihr Diplom bei Joseph Beuys und wurde anschließend seine Meisterschülerin. 1970 legte sie dann auch ihr erstes Staatsexamen für das Lehramt ab. Parallel zu ihrem Referendariat und der Lehrtätigkeit, die sie bis 1975 fortführte, begann sie als freischaffende Künstlerin zu wirken. Fasziniert von den Möglichkeiten der Videotechnik, die sie über die Werke zeitgenössischer amerikanischer Künstler kennenlernte, kaufte sie sich 1971 bereits ihre erste Videokamera. Im Jahr 1972 wurden ihre Objektarbeiten nicht nur erstmals in einer Einzelausstellung ausgestellt - die Galerie Ernst in Hannover zeigte ihre Werke - auch führte sie ihre erste öffentliche künstlerische Aktion in Düsseldorf auf. Nach ihrem Studienabschluss war die junge Künstlerin mit ihren künstlerischen Arbeiten nicht nur national, sondern auch international auf Ausstellungen vertreten, so zum Beispiel im Jahr 1973 im Gallery House in London oder auf der von der amerikanischen Feministin und Kunstkritikerin Lucy Lippard (*1937) kuratierten Wanderausstellung „C. 7500“, die sehr erfolgreich durch die USA tourte. ${ }^{83}$

Über eine Gruppe von Studentinnen an der Düsseldorfer Akademie, die sich mit Frauenthemen beschäftigten, hatte Ulrike Rosenbach die Amerikanerin Leslie Labowitz (*1943 oder 1946) kennengelernt, die seit 1972 bei Joseph Beuys studierte und zuvor in Los Angeles bei der amerikanischen Künstlerin und Feministin Judy Chicago studiert hatte. ${ }^{84}$ Über Leslie Labowitz hatte sich auch der Kontakt zu Lucy Lippard ergeben. In den USA war zu diesem Zeitpunkt - anders als in Deutschland, wo sich die Frauenbewegung gerade erst zu formieren begann - bereits eine intensive Entwicklung einer neuen feministischen Kunst im Gange, die das Interesse der jungen Künstlerin fand.

\footnotetext{
80 Richter 2000, S. 118

81 Hier führten unterschiedliche Künstler auch Aktionen und Performances auf. (Vgl. Caianiello 2005)

82 So war sie unter anderem Sprecherin im allgemeinen Studentenausschuss (Asta).

83 Vgl. Kap. III.1.1.

84 Roth 1983, S. 28; mehr zu Labowitz in: Chadwick 1991, S. 342f; vgl. Kap. III.1.2.
} 
Zudem waren die amerikanischen Künstler John Baldessari und Vito Acconci, die sich zeitweilig zu Ausstellungen in Düsseldorf und Köln aufhielten, auf die deutsche Künstlerin aufmerksam geworden, wodurch sich neben dem Kontakt in den Westen der USA auch ein Kontakt zur quirligen New Yorker Kunstszene entwickelte. So reiste Ulrike Rosenbach in den Jahren 1973 und 74 zu verschiedenen Arbeitsaufenthalten in die USA. Im Rahmen einer dieser Reisen führte sie 1974 in dem bekannten Künstlertreffpunkt „112 Greenstreet“ auch eine ihrer Videoperformances auf. ${ }^{85}$

Parallel dazu agierte Ulrike Rosenbach in den frühen 1970er Jahren in der rheinischen Kunstszene. Hier arbeitete sie als Assistentin des WDR-Redakteurs Gerry Schum (1938-1973) in dessen „Videogalerie“ mit, einem ehrgeizigen Projekt des Fernsehmannes, das aus der so genannten „Fernsehgalerie“ hervorgegangen war, in der Gerry Schum versucht hatte, avantgardistische Kunstformen (wie z.B. die Land Art) über das Massenmedium des Fernsehens der Öffentlichkeit zu präsentieren. Für Ulrike Rosenbach eine gute Gelegenheit die vielfältigen Möglichkeiten der professionellen elektromagnetischen Bildaufzeichnung kennenzulernen. Zudem fand Ulrike Rosenbach in diesen Jahren in der Bonner Galeristin Ingrid Oppenheim eine engagierte Förderin.

In dieser Zeit traf sie auch auf Klaus vom Bruch (*1952), mit dem sie in den folgenden Jahren neben einer mehrjährigen Partnerschaft eine intensive künstlerische Auseinandersetzung verband. ${ }^{86}$ Im Jahr 1975 ging sie auf Einladung des Künstlers John Baldessari, der damals in Valencia lehrte, mit ihrer Tochter und ihrem Lebensgefährten nach Kalifornien. Die drei zogen nach Los Angeles und Ulrike Rosenbach unterrichtete für ein Jahr am „California Institute of Arts“ in Valencia, an dem sie einen Lehrauftrag für feministische Kunst und Videokunst angenommen hatte.

Wie erwähnt, hatte die Künstlerin bereits in Düsseldorf Kontakte zur westamerikanischen Frauenszene geknüpft. Vor Ort lernte sie die Protagonistinnen unter anderem Miriam Shapiro - persönlich kennen und Ulrike Rosenbach war in der dortigen feministischen Kunstszene aktiv, die unter anderem durch das erst kurz zuvor ins Leben gerufene „Womens-Building“ - ein damals einzigartiges Kunstprojekt, um einen öffentlichen Raum für Kunst von Frauen zu schaffen geprägt war. ${ }^{87}$ In der amerikanischen Frauenbewegung waren Kunst und politisches Engagement enger aneinander geknüpft als in Europa, und hier lernte die junge Künstlerin auch die so genannten „Consciousness-Raising-Groups“ kennen. Diese Selbsterfahrungsgruppen bildeten eine wichtige Erfahrung für die Künstlerin, und waren Vorbild für die Gründung ihrer „Schule für kreativen Feminis-

$85 \mathrm{Zu}$ „Isolation is transparent“ vgl. Kap. III.1.4.

86 Ulrike Rosenbach dankt ihm für seine Assistenz in den Jahren 1975-1981 in: Glüher 2005.

87 Vgl. Kap. III.4.4.1 
mus“, die Ulrike Rosenbach im Jahr 1977 in Köln ins Leben rief. ${ }^{88}$ Kehrte die Künstlerin doch nach dem einen Jahr in den USA wieder nach Deutschland zurück und mietete nun in Köln ein Atelier. Die Stadt am Rhein war damals die deutsche Kunstmetropole, hatte ein weltoffenes Flair und viele auch internationale Künstler machten dort zu dieser Zeit Station. ${ }^{89}$ Ulrike Rosenbach engagierte sich intensiv in der inzwischen in der Großstadt wachsenden Frauenszene und beschäftigte sich in ihren künstlerischen Projekten weiterhin intensiv mit feministischen Themen. Für eine Weile arbeitete sie bei der - von der ebenfalls in Köln ansässigen Alice Schwarzer - neu gegründeten Frauenzeitschrift „Emma“ mit, beteiligte sich engagiert an den Anti-Pornographie-Aktionen einer Gruppe Kölner Frauen und gehörte im Jahr 1979 zu den Mitbegründerinnen des ersten Frauenkulturzentrums in Köln. ${ }^{90}$

Daneben führte die inzwischen international anerkannte Künstlerin ihre feministisch motivierten Videoperformances an ganz unterschiedlichen Orten in Europa auf: in den Niederlanden, Österreich, Italien, Frankreich. Bereits 1975 war sie zur Biennale des Jeunes nach Paris eingeladen worden. Im Jahr 1977 bekam sie ein Arbeitsstipendium in Florenz. Im selben Jahr war eine Auswahl ihrer Arbeiten auf der documenta 6 in Kassel zu sehen und sie wurde im Jahr 1979 zur Biennale nach Sydney eingeladen. Neben anderen Stationen war die Künstlerin 1980 in Toronto und 1981 in Zagreb zu Gast. Auch wurde sie ab Ende der 1970er Jahre zu verschiedenen Lehraufträgen an unterschiedliche Kunsthochschulen gerufen.

Mit anderen Kölner Künstlern - wie Klaus vom Bruch und Marcel Odenbach, später auch Rune Mields, die 1981 bei den kurze Zeit existierenden „Videorebellen“ mitwirkte - beginnt sie Mitte der 1970er Jahre ein „Alternatives Fernsehen“ in Anlehnung an amerikanische Vorbilder aufzubauen. In Amerika hatten sich bereits Ende der 1960er Jahre Projekte gegründet, die das monopolisierte Massenmedium versuchten zu demokratisieren. Doch kam es bei dem Projekt der Gruppe deutscher Künstler kaum zu einer Zusammenarbeit mit dem öffentlichen Fernsehen und die Gruppe löste sich bald wieder auf. Ulrike Rosenbach sagt über das Projekt „Alternative TV“ zurückblickend:

„Es war eine Idee in einer Zeit, in der es in Deutschland privates Fernseben noch nicht gab. Es war die Idee, der eintönigen Ästhetik und Thematik der offiziellen Fernsehsender etwas entgegenzusetzen, das anspruchsvoller war als Unterhaltung, experimenteller und von Künstlern geschaffen. Es war gemeint als eine kritische Antwort auf den Output der deutschen Fernseblandschaft. Praktisch haben wir unsere eigenen Videoproduktionen als ATV-Produktionen gekennzeichnet. Wir haben außerdem illegal privat gesendet, aus unserem Studio heraus in die Nachbarschaft und wir haben zu Videovorführungen

\footnotetext{
88 Vgl. Kap. III.5.1.

89 Vgl. Kap. III.2.

90 Vgl. Kap. III.5.2.
} 
in unser Studio eingeladen. Es war also kein großes Ding, sondern eher der Gedanke an ein gutes privates Kulturfernsehen. " 1

Im Jahr 1981 löste Ulrike Rosenbach dann ihre „Schule für kreativen Feminismus" auf. Ein Schritt der zudem verbunden war mit der Abwendung von der politischen Frauenszene.

Nachdem ihre Mutter und ihre Großmutter kurz nacheinander gestorben waren, ging Ulrike Rosenbach 1982 erneut für einen längeren Zeitraum in die USA, wo sie sich, nach eigenen Aussagen, intensiv mit der fernöstlichen Naturmystik und besonders dem Zen-Buddhismus beschäftigte. Und die beiden Verluste ihrer weiblichen Verwandten scheinen die Künstlerin tief getroffen zu haben. ${ }^{92}$ Die Erfahrung des Todes ,,ihrer Mütter“", wie sie beide zusammenfasst, beschrieb sie später einmal so:

„Zwei Jahre hatte ich das Gefühl, ich gehe in die Unterwelt und sehe zeitweise gar kein Licht mehr. Es war eine sehr tiefe Erfahrung, die ich mit anderen geteilt habe. Die kannten das aus Todeserfahrungen mit engen Verwandten, die sebr identifikatorisch ablaufen, wie der Tod einer Mutter." "M3

Zurück in Deutschland hatte die Künstlerin dann Lehraufträge in Berlin und München. 1987 ist sie erneut auf der documenta 8 vertreten. Und im Jahr 1989 wird die Künstlerin an die neu gegründete Hochschule für Künste in Saarbrücken für den Bereich Neue Medien berufen. Sie übernimmt dort das Rektorat von 1990 bis 1993. Seitdem lehrt sie dort als Professorin. ${ }^{94}$ Nachdem sie zunächst in der Nähe von Saarbrücken auf dem Land lebte, zog sie später wieder in die Nähe von Köln. Von dort aus pendelt sie nun zu ihrem Arbeitsort.

Die Lehrtätigkeit prägt ihr Wirken seit den 1990er Jahren und sie hebt selbst hervor, dass sie die Lehre als wichtigen Teil ihres künstlerischen Werkes versteht. ${ }^{95}$ Neben eigenen künstlerischen Arbeiten, in diesem Jahrzehnt hauptsächlich Installationen, hat Ulrike Rosenbach in dieser Zeit zahlreiche Projekte und Ausstellungen mit ihren Studierenden auf die Beine gestellt. Doch auch eine große öffentliche Auftragsarbeit wurde an die Künstlerin herangetragen. Sie gestaltete die Videoinstallation „Das Bild der Frau in der Nachkriegszeit“ zur Eröffnung des Hauses der Geschichte in Bonn.

Seit Beginn des neuen Jahrhunderts wurde das künstlerische Werk von Ulrike Rosenbach mit einer ganzen Reihe von Preisen und Ausstellungen ausgezeichnet.

91 http//:www.medienkunstnetz.de/werke/atv-studio/. (Letzter Zugriff 3.8.2011)

92 In einem Interview hob die Künstlerin die wichtige Rolle und Unterstützung durch ihre Mutter hervor. (EMMA 1978, Nr.4, S.17)

93 Rosenbach im Gespräch mit Renate Petzinger am 17. September 1995 in Kat. Dortmund 1995, o.S.

94 Inzwischen lehrt sie dort nicht mehr, da sie seit 2009 im Ruhestand ist.

95 Vgl. Kap. V.1. 
So erhielt die Künstlerin unter anderem 2001 die August-Macke Medaille der Stadt Bonn verliehen, wie auch der renommierte Gabriele-Münter-Preis im Jahr 2003. Mit diesen Auszeichnungen hat ihr unermüdliches künstlerisches Wirken in jüngster Zeit eine entsprechende öffentliche Würdigung erfahren. 


\title{
III. Übergänge - Die 1960er und 1970er Jahre
}

\author{
III.1. Am Anfang war das „tolle Ding“
}

Mit einer Schwarzweiß-Videokamera - einem Philips Video System VPL 61 C begann Ulrike Rosenbach 1972 ihre ersten Videotapes zu drehen. ${ }^{96}$ Die Kamera hatte keinen eigenen Sucher, vielmehr fungierte der an das Aufnahmegerät angeschlossene Fernsehmonitor als Kontrollbildschirm, auf dem die Künstlerin ihre eigene Aktion vor der Kamera direkt beobachten konnte. In dieser Weise entstand 1972 auch das Tape „Einwicklung mit Julia“:

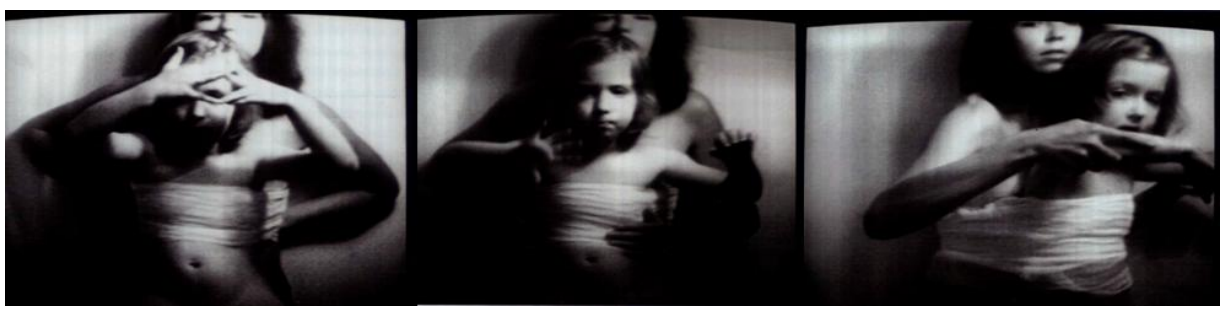

Abb. 11-13: Einwicklung mit Julia, 3 Videostills 1972

Dem Schwarzweißtape ist ein rund 15 Sekunden langer Vorspann vorangestellt. Auf hellem Grund steht dort in schwarzen Buchstaben der Schriftart „Courier“, die demnach anscheinend mit einer Schreibmaschine getippt sind: „Ulrike Rosenbach / Einwicklung mit / Julia / 6' 1972“. Nach einem harten Schnitt ist dann eine Nahaufnahme zu sehen, die die Künstlerin mit ihrer Tochter auf dem Schoß zeigt. Die beiden Körper sind der Kamera frontal zugewandt und das kleine Mädchen im Vordergrund, von dem auf dem Bildschirm Kopf, Arme und Rumpf zu sehen sind, ist in der Aufnahme ganz nackt, während der Oberkörper der Mutter im Hintergrund von dem Körper der Tochter verdeckt wird. Es ist jedoch an der auf beiden Seiten hinter dem Kind seitlich herausragenden Hüfte der Mutter zu erkennen, dass diese einen schwarzen Slip trägt und so nicht völlig nackt der Kamera gegenüber getreten ist. Der Kopf der Künstlerin ist in dem gewählten Bildausschnitt knapp bis zur Augenpartie zu sehen, der obere Gesichtsteil vom Bildschirmrand überschnitten. Mutter und Kind sitzen mit dem Rücken vor einer weiBen Wand, auf der sich die Körperschatten als dunkle Silhouetten abzeichnen. Die Künstlerin hält mit ihren unter den Achseln der Tochter hindurch greifenden

96 Die Firma Sony hatte 1971 erstmals eine Kassettentechnik für Video auf den Markt gebracht, was den Umgang mit dem Medium sehr erleichterte. 
Händen zunächst deren Brustpartie fest. Begleitet wird diese erste Bildsequenz auf der Tonebene von einem bedrohlich wirkenden Geräusch. Es erinnert entfernt an ein tiefes Atemgeräusch, mehr jedoch an starken Wind oder auch ein metallisches Scharren.

Dann greift die Mutter mit ihrer linken Hand über den rechten Bildrand heraus, und, als die Hand kurz darauf wieder im Bildfeld erscheint, hält diese eine weiße Mullbinde. Diese Binde rollt die Akteurin nun ab und umwickelt zunächst die obere Brustpartie ihrer Tochter mit der weißen Stoffpartie. Nachdem das Kind einmal fest umwickelt ist, führt die Mutter die Binde von links nach rechts auch hinter ihrem eigenen Rücken entlang und umwickelt auf diese Weise mehrfach ihren eigenen Körper gemeinsam mit dem des Mädchens auf ihrem Schoß. Bei diesem Vorgang hebt das Mädchen jedes mal hilfreich die Arme, wenn die Hände der Mutter die Mullbinde vor deren Brust vorbeiführen und lässt diese im Anschluss wieder sinken. Als die erste Binde aufgebraucht ist, greift die Akteurin eine zweite Rolle - wieder mit der linken Hand - und setzt damit die Einwicklung der beiden Körper fort. Auf diese Weise wird zunächst die obere Brustpartie des Kindes und der hinter ihm sitzenden Mutter dick umwickelt, bevor dann die Umwicklung langsam nach unten an den Oberkörpern entlang fortgesetzt wird. Insgesamt fünf weiße Mullbinden wickelt die Künstlerin auf diese Weise um die beiden Körper. Diese kontinuierlich fortgesetzte Handlung wird durchgängig von dem oben beschriebenen Geräusch begleitet.

Als der Oberkörper des Mädchens bis unter den Bauchnabel mit der Mullbinde umwickelt ist, setzt auf der Tonebene ein melodiöser Klang oder auch leiser Gesang ein. Die Künstlerin greift ihrer Tochter daraufhin wieder mit den Händen unter den Schultern durch und rückt sich mit dem Kind auf dem Schoß gemeinsam ins Dreiviertelprofil. Dann hebt sie die Arme ihrer Tochter zusammen mit den ihren in die Höhe, so dass der Blick frei wird auf den breiten weißen Verband, der die beiden Körper nun ummantelt und die beiden hintereinander sitzenden, aneinander gepressten Oberkörper eng aneinander bindet. Die Künstlerin guckt dazu kurz selbstbewusst in die Kamera, bevor das Tape abrupt aufhört.

Das sechsminütige Band zeigt die Künstlerin Ulrike Rosenbach mit ihrer fünfjährigen Tochter Julia auf dem Schoß, während die Mutter sich und das Kind, wie beschrieben, Schicht um Schicht mit weißen Mullbinden einwickelt. Das Schwarzweißtape zeigt dabei eine durchgehende feste Einstellung. Kein nachträglicher Schnitt unterbricht den Ablauf. Als Ton ist ein beunruhigendes, intensives, rasselndes Atemgeräusch zu hören, es gibt keinen gesprochenen Text in dem Tape zu hören.

Dieser Akt des Einwickelns kann im übertragenen Sinne als ein wieder ,an sich binden" interpretiert werden oder auch allgemeiner als ein Zeichen der Verbundenheit. In dieser Weise interpretierte die amerikanische Kunstkritikerin Lucy Lippard das Tape in den 1970er Jahren als ein ,umgekehrtes Geburtsstück“. Die Künstlerin pflanze, laut Lippard, in diesem Videotape ihr bei der Geburt von ihr 
getrenntes Kind wieder an ihr Ich an, wobei die verbindende Mullbinde auch als wiederhergestellte Nabelschnur gedeutet werden könne. ${ }^{97}$ Gerhard Glüher hingegen widersprach jüngst der Interpretation dieses Werkes als Verarbeitung einer Verlusterfahrung, betonte stattdessen den Aspekt der Körperarbeit:98

„Die beiden Körper scheinen in der Schlusssequenzz von Einwicklung mit Julia wie ein einziger, wobei das banale Verbandsmaterial bei diesem Gestaltwandel Initiator und formgebender Bestandteil ist. Die durchgehend rubig gehaltenen Atemgeräusche evozieren Geborgenheit, die Symbolik des Kokons, die eingepuppte Haut der Larve, in der ein Schmetterling heranreift. Die Aktion ist daher kein dramatischer Akt, sondern eher ein beiläufiges künstlerisches Geschehen, das als grundlegende Basisarbeit mit dem Körper als plastischem Material zu verstehen ist. Die Deutung des Videotapes etwa im Sinne eines Leidens über den Verlust der Tochter oder einer Ursebnsucht nach immer währender Mutterschaft wäre eine Überinterpretation." "99

Dieses kurze Videotape, das eine kurze Performance aufzeichnet, ist programmatisch sowohl für die Form als auch die Inhalte der frühen Videotapes Rosenbachs, die, wie die Zeitzeugin und Galeristin Ingrid Oppenheim charakterisierte in den 1970 er Jahren „so frisch und poetisch“" wirkten. ${ }^{100}$
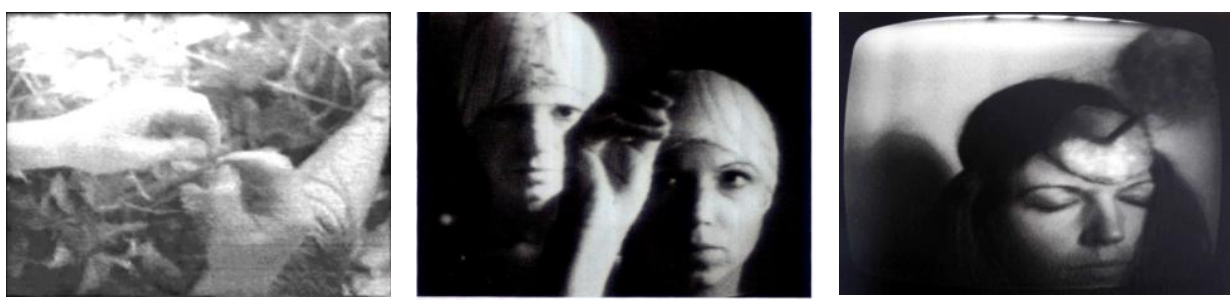

Abb. 14-16: Videostills aus das Brennesseltape, 1972, Zeichenhaube und Eine Scheibe berühren, 1973

Zu dieser Gruppe der frühen Tapes sind zudem das Band „Bindenmaske“, „Eine Scheibe berühren“, das „Brennesseltape“, „Eine Frau ist eine Frau“ und „Der Muff und das Mädchen“, die alle 1972 entstanden, zu zählen, wie auch die „Zeichenhaube“, „Mon Petit Chou“, das „Kohltape“ und „Der Mann sei das Haupt der Frau“, die im folgenden Jahr gedreht wurden.

\footnotetext{
97 Lippard in: Rosenbach 1982, S.125

98 „Kurzzeitig könnte die Idee aufkommen, die Künstlerin verarbeite in dieser Aktion eine Verlusterfahrung - praktisch den Wunsch nach einer immer währenden Schwangerschaft, wie es in Lippards Zitat bereits angeklungen ist. Doch diese Hypothese hält nicht Stand, denn in späteren Aktionen wird ganz bewußt die Reife, das Erwachsenwerden und das Loslassen des Kindes thematisiert." (Glüher 2005, S. 149)

99 Glüher 2005, S.149

100 Oppenheim in: Rosenbach 1982, S. 128
} 
Die in den Bändern behandelten Themen kreisen um die Rolle der Frau, reflektieren Fragen der Identität, beleuchten Haltungen und Beziehungen. Gezeigt werden jeweils einfache Abläufe, reduziert auf eine klar umrissene Aktion, die ohne Schnitt in einer festen Einstellung über mehrere Minuten aufgenommen werden. Häufig wiederholt sich die Handlung vor der Kamera, wie in „Bindenmaske“ oder auch „Mon Petit Chou“, die beide ein allmähliches Verhüllen des Kopfes zeigen. Während in der „Bindenmaske“ die Künstlerin mit einer Mullbinde umwickelt, sind es bei „Mon Petit Chou“ Kohlblätter, die sich sich um den Kopf und mit einem Band fixiert. Die französische Wendung „mon petit chou!“ bedeutet übersetzt „mein Liebling“, wobei das französische „chou“ im Deutschen „Kohl“ heißt. Ulrike Rosenbach verwandelt in der Performance ihren eigenen Kopf in einen ,chou“, verhüllt ihr Angesicht, ihre Identität hinter den Kohlblättern.
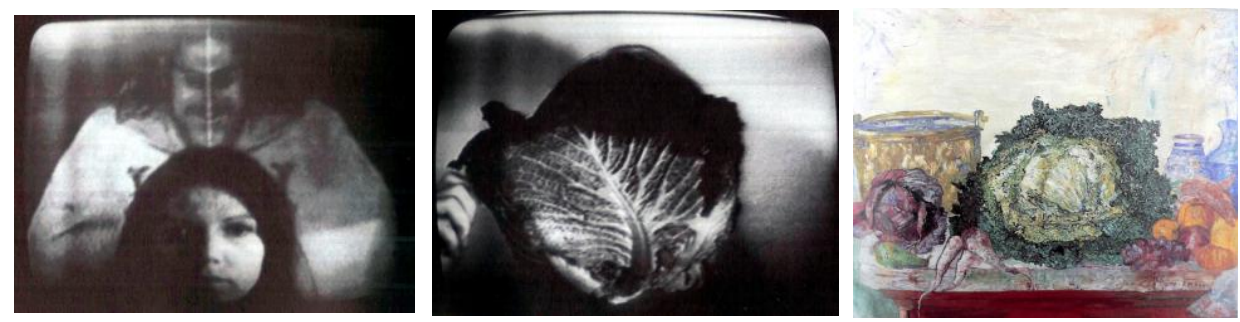

Abb.17-19: Videostills aus Der Mann sei das Haupt der Frau, 1973 und das Kobltape und James Ensor: Le Chou frisé, 1894

Damit macht die Künstlerin in ihrem porträtierenden Tape etwas Umgekehrtes, wie der belgische Maler James Ensor (1860-1949) in einem Gemälde, die ein Stilleben mit Wirsingkohl („Le chou friséc) zeigt. ${ }^{101}$ Das farbige Bild aus dem Jahr 1894 findet sich im Museum Folkwang in Essen und es scheint fast, dass der realistisch gezeichnete Kohlkopf ein Gesicht trägt. Und so heißt es im Katalog zu dem Werk, dass der Künstler in seinen Malereien die Dinge selbst handeln lasse, und es fast so scheine, als sei die magisch anmutende Szene auf dem Küchentisch mit dem Wirsingkohl mittendrin ein Selbstbildnis Ensors. ${ }^{102}$

Im Unterschied zu den meist rund fünf bis zehn Minuten langen Tapes ist das 60-minütige „Brennesseltape“ auf der Bildebene ebenfalls durch eine sich stetig wiederholende Handlung gekennzeichnet. Zu sehen ist hier in einer festen Einstellung, wie die Hände der Künstlerin Brennesselpflanzen, die am Boden ausgebreitet sind, zerpflücken. Dabei unterhält sie sich mit ihrer Tochter. Der narrative Dialog von Mutter und Kind begleitet die stete Handlung aus dem Off. Hier ermuntert die Mutter das Kind das Märchen von den sieben Schwänen nachzuer-

101 James Ensor, Le Chou frisé, Öl auf Leinwand, 80 x 100 cm, Museum Folkwang, Essen

102 Költzsch 2002, S. $121 \mathrm{f}$ 
zählen, was die Tochter auch tut. So erfährt der Zuhörer, während aus dem Brennesselberg ein Hemd aus Pflanzenfasern geknüpft wird, wie die sieben Prinzenbrüder in Schwäne verwandelt werden und von ihrer Schwester nur erlöst werden können, wenn sie ihnen sieben selbst gefertigte Hemden aus Brennesseln überwirft.

In dem Band „Eine Scheibe berühren“ wird mit den Eigenschaften des Mediums des Fernsehers gespielt, nimmt die Künstlerin hier doch mit ihrer Stirn über einen wattierten Taster Kontakt auf zum Kameraobjektiv, respektive der Bildschirmscheibe von innen auf. Auch in dem Tape „Der Mann sei das Haupt der Frau“" wird der Titel bildlich umgesetzt, in dem der Kopf eines herab guckenden bärtigen Mannes als lebensgroßes Foto über das Haupt der Künstlerin gefügt ist. ${ }^{103}$ Als Ton erklingt dazu der sehr langsam gesprochene Wortlaut als sich wiederholende Schleife. „Der Mann sei das Haupt der Frau“ ist ein Pauluszitat, das der christliche Apostel in seinem ersten Brief an die Korinther schrieb. ${ }^{104}$

Wie in diesem Tape wird auch in der „Zeichenhaube“ zum einen mit einer Verdopplung auf der Bildebene gearbeitet - das Porträt der Künstlerin erscheint fast identisch als Fotografie und in der Videoaufnahme nebeneinander, zudem zeichnet die Künstlerin während der Aufnahme mit schwarzem Stift die Umrisse der Hauben auf die Bildschirmoberfläche, denn die Künstlerin trägt ein weißes Tuch um ihren Kopf, das ihre Haare bedeckt. Mit dieser ungewöhnlichen Erscheinungsweise erinnert sie an mittelalterliche Heiligendarstellungen wie auch an Porträts aus der frühen Neuzeit. ${ }^{105}$
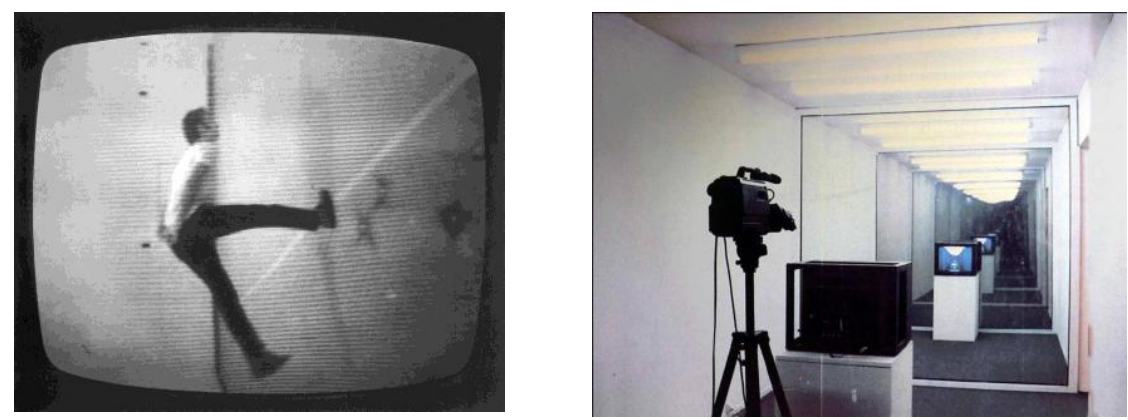

Abb.20-21: Bruce Nauman: Slow Angle Walk (Beckett Walk), Videostill, 1968 und Dan Graham: Two Viewing Rooms, 1975

$1031973, \mathrm{~s} / \mathrm{w}, 8^{\prime}$

104 Neues Testament (NT) 1 Kor 11, 3 außerdem auch in NT 5 Eph. 23

105 Siehe hierzu zum Beispiel das Brustbild im Dreiviertelprofil nach rechts blickend von Gerrit Dou (1613-1675), Alte Frau mit Kerze, Wallraf-Richartz Museum, Köln. Auch das Bildnis einer Frau der Familie Hofer, ca. 1470, Schwäbische Schule des 15. Jahrhunderts (NG 722), National Gallery, London. In ihrer „Verkleidung“ erinnert die Künstlerin in ihrem Doppelporträt auch an „Das Mädchen mit dem Perlenohrring“ von Jan Vermeer. 
In Deutschland war die Videotechnik in den Anfängen der 1970er Jahre noch etwas ganz Neues. ${ }^{106}$ Und die junge Künstlerin drehte damit zwar Filme, machte aber weder Film noch Fernsehen im geläufigen Sinne, sondern nutzte die Videotechnik als künstlerisches Ausdrucksmittel. Dabei reflektierte Ulrike Rosenbach die dem Medium innewohnenden Möglichkeiten und erkundete eigene Ausdrucksformen. Von Einfluss waren für ihre künstlerische Entwicklung - wie sie selbst im Gespräch hervorhob - die Arbeiten der in New York aktiven amerikanischen Avantgarde-Künstler, die bereits Ende der 1960er Jahre erste experimentelle Videotapes gedreht hatten. ${ }^{107}$ Der amerikanische Künstler Bruce Nauman (*1941) hatte zum Beispiel mit dem elektronischen Medium seine Bewegungen im Raum erkundet und die physikalischen Gesetze mittels Video förmlich auf den Kopf gestellt. Dan Graham (*1942) hingegen experimentierte mit den Möglichkeiten des Closed Circuit und entwickelte interaktive Aktionsräume.

Ein häufig zu findender Topos der Videokunst der frühen 1970er Jahre war zudem die so genannte Soloperformance, die mit einer fest installierten Kamera im Studio aufgezeichnet wurde. Über den angeschlossenen Monitor konnte die Aktion direkt überwacht werden und die Kamera bildete den direkten Ansprechpartner, die Zeuge der Aktion war. So konnten die Künstler in ihren Tapes gleichzeitig Schauspieler, Kameramann und Regisseur sein, wie es auch in den Arbeiten von Ulrike Rosenbach zu finden ist. 108

Werke dieser amerikanischen Künstler, die unter anderem auch weiterhin mit fotografischem Schwarzweißfilm arbeiteten ${ }^{109}$, lernte Rosenbach in der Ausstellung ,prospect 71“ kennen, die 1971 in Düsseldorf gezeigt wurde. Die dortige Kunsthalle veranstaltete seit Ende der 60er Jahre ein Pendant zum seit 1967 stattfindenden Kölner Kunstmarkt. ${ }^{110}$ In diesen mit „pprospect“ betitelten Ausstellungen zeigten deutsche und internationale Galerien der Avantgarde ein breites Spektrum aktueller Kunst. Die ,prospect $71^{\text {“ }}$ trug den programmatischen Titel „projection“ und versammelte Fotografien, Diaprojektionen, Filme und Videotapes von insgesamt 75 Künstlerinnen und Künstlern unter einem Dach: Dabei waren u.a. Arbeiten von Künstlern wie Vito Acconci, John Baldessari, Joseph Beuys, Dan Graham, Les Levine, Bruce Nauman, Claes Oldenburg, Dennis Oppenheim, Günther Uecker, Wolf Vostell, Andy Warhol und William Wegman. ${ }^{111}$

106 Vgl. dazu auch das Interview Herzogenrath 2003 im Kapitel VII.2.

107 Gespräch Rosenbach 2001 in Kapitel VII.1.

108 Hanhardt in: Kat. Berlin 2004, S. 42

109 Dabei wurden unterschiedliche Formate genutzt, sowohl 8 oder auch $16 \mathrm{~mm}$.

110 Vgl. Kapitel III.2.

111 Allerdings waren nicht die heute für ihre Videotapes bekannten amerikanischen Künstler dort mit Videos vertreten. Die meisten von ihnen, bis auf Barry Le Va und Lawrence Weiner, zeigten 8 oder $16 \mathrm{~mm}$ Filme. Vielmehr waren es laut Katalog Beuys und sein Schüler Claus Böhmler sowie Klaus Rinke und Ulrich Rückriem, die Niederländer Stanley Brown und Jan Dibbets, das 
Ulrike Rosenbach erinnert sich an die erste Begegnung mit dem neuen technischen Medium in der Ausstellung:

„Die ersten Videotapes, die ich sah, wurden auf der Ausstellung ,prospect 71' in der Düsseldorfer Kunsthalle gezeigt. Sie waren von amerikanischen Künstlern, und nachdem ich mir in einigen Gesprächen technische Informationen eingeholt hatte, war eins für mich klar: diese Möglichkeiten von Aufnahme, Speicherung und Wiedergabe laufender Bilder war das, was ich für meine Arbeit brauchte. Ein System obne aufwendige Entwicklungsverfahren, bei dem ich obne jede technische Hilfe produzieren konnte, obne komplizierte Entwicklung und die zeitraubende Suche nach einem Filmschneidetisch - das war für mich Video. Es war das ,Tolle Ding', mit dem man sich sofort vor der Kamera, kontrollieren, im Monitor überprüfen, das aufgenommene Stück sehen konnte - wie eine Zeichnung, ein Bild, derselbe Arbeitsgang; das war es, was mich an Video interessierte. "112

Das Kennenlernen der Videotechnik in der Ausstellung bildete somit eine Art Initialzündung für Rosenbachs eigene Experimente mit dem damals noch ganz jungen Medium. Die Künstlerin kaufte sich im Anschluss ihre erste eigene Videokamera und mit diesem Gerät entstanden die beschriebenen Tapes, eine Reihe technisch einfacher Bänder, die geprägt sind von einer intensiven Bildsprache.

\section{III.1.1. Joseph Beuys und die Ausbildung an der Kunstakademie in Düsseldorf}

Ulrike Rosenbach ist 29 Jahre alt, als sie die Videotechnik für sich als künstlerisches Ausdrucksmittel entdeckt. Hinter ihr liegt zu diesem Zeitpunkt eine teils traditionell akademische, teils - gekoppelt an die Person von Joseph Beuys, unkonventionelle Ausbildung an der Düsseldorfer Akademie, die zu den renommiertesten Kunstakademien Deutschlands gehörte. ${ }^{113}$ Trotz des guten Rufes der staatlichen Akademie bezeichnete die Kunstkritikerin Gieslind Nabakowski, die zusammen mit Ulrike Rosenbach ab 1965 an der staatlichen Ausbildungsinstitution studierte, im Rückblick das damalige Lehrangebot als unpolitisch, unzeitgemäß und mangelhaft. ${ }^{114}$ Mit dem Wirken des charismatischen Künstlers und Lehrers Joseph Beuys, der im Jahr 1962 einem Ruf als Professor für Bildhauerei an die

englische Künstlerpaar Gilbert und George sowie Mario Merz aus Italien die hier experimentelle Videos zeigten. (Vgl. Fischer/Harten/Strelow 1971)

112 Rosenbach in: Herzogenrath 1982, S. 99

113 Beuys brachte nicht nur die Studenten „durcheinander“, sondern auch die traditionellen Lehrinhalte des Akademieunterrichtes, die Lehrmethoden und die konventionelle Definition der Lehrerrolle. So gingen Beuys künstlerische und pädagogische Vorstellungen viel Weiter, als sie für die Akademieleitung akzeptabel waren: Beuys stellte radikal die traditionellen Lehrinhalte des Akademieunterrichts, die Lehrmethoden und die konventionelle Definition der Lehrerrolle in Frage. (Richter 2000, S. 35)

114 Nabakowski in: Kat. Berlin 1977, S. 92; Petra Richter charakterisiert den Weg zur Neugestaltung der Akademien im Nachkriegsdeutschland als „eine Gratwanderung zwischen Tradition und Innovation." 
Akademie gefolgt war, änderte sich in der zweiten Hälfte der 1960er Jahre die Situation jedoch zumindest in dessen Umfeld. ${ }^{115}$ Die Kunsthistorikerin Karin Thomas fasste Beuys' künstlerisches Wirken in dieser Zeit wie folgt zusammen:

„Leisteten die frühen Zeichnungen, Objekte und Aktionen von Joseph Beuys Gedächt-
nisarbeit an der Geschichte und der eigenen Biographie durch Rückgriff auf archetypische
Begriffe und Lebensmodelle, um aus der Stummbeit der Kriegsnachwirkung berauszufin-
den und die Ausstrablung geistiger Kraftelder gegen den sich ausbreitenden Materialis-
mus der Wirtschaftswnderära in Gang zu bringen, so nehmen die Aktionen und En-
vironments der 70 er Jahre in einem Miteinander von Lebre und Demonstration Werk-
stattcharakter an und erbalten konkrete Zeit-und Ortsbezüge. "116

Während Joseph Beuys zu Beginn seiner Lehrtätigkeit die Schwerpunkte seines Unterrichts auf das Zeichnen nach Vorbild, also Aktstudien, Zeichnen nach Gegenständen und der Natur, sowie dem plastischen Gestalten mit den klassischen Bildhauermaterialien wie Holz, Ton und Gips gelegt hatte, änderte sich dies Mitte der 1960er Jahre. Neben der handwerklich künstlerischen Arbeit traten nun diskursiv-reflektorische Auseinandersetzungen in Form von Ringgesprächen in seiner Lehrtätigkeit in den Vordergrund. Dabei ging der Künstler mit dem von ihm entwickelten Ansatz einer plastischen Theorie weit über die traditionelle Auffassung von Bildhauerei hinaus. Er entwickelte im Laufe der Zeit seine Idee einer „sozialen Plastik“, die im Denken die elementare Stufe der bildnerischen Gestaltung sah:

„Im Gegensatz, zum konventionellen Verständnis von Plastik berog Beuys das schöpferische Gestaltungsprinzip nicht nur auf sichtbare, materielle Werke, sondern ebenso auf unsichtbare Skulpturen im gedanklichen Bereich wie die »Soziale Skulptur». Die Erweiterung des Kunstbegriffs hatte das Arbeiten mit vorgefundenen Gegenständen, Materialien und Werkstoffen sowie die Integration politischer Aspekte zur Folge. "117

Beuys - nach dessen Überzeugung Kunst und Kreativität die einzigen revolutionären und evolutionären Kräfte waren - erweiterte damit den Kunstbegriff. Die Kunst wurde von ihm zum Lebensprinzip erhoben und als Voraussetzung für die Entwicklung des freien Menschen beschrieben nach der Formel: „Kunst gleich Kreativität gleich menschliche Freiheit."“118

115 Beuys hatte selbst von 1946 bis 1953 an der Düsseldorfer Akademie bei Ewald Mataré studiert. Seine Berufung an die Düsseldorfer Akademie war umstritten gewesen, besonders sein ehemaliger Lehrer hatte sich gegen ihn ausgesprochen.

116 Thomas 2002, S. 280

117 Richter 2000, S. 46

118 Richter 2000, S. 39. Beuys richtete auf der d5 1972, die starkt vom Klima der 68-Bewegung mitgeprägt war, ein Infobüro ein, indem er über 100 Tage lang dem Publikum seine Vorstellungen zur sozialen Plastik als gesellschaftliche Evolution und auf soziale Wirkung abzielende Handlung erläuterte. 
Auf dieser Basis entwickelte sich die Düsseldorfer Akademie während Beuys Lehrtätigkeit - bis zu seiner Entlassung 1972 - zu einem Experimentierfeld für neue künstlerische Ausdrucksformen. Dabei agierte die Beuys-Klasse zunehmend an allen Konventionen vorbei und nahm eine deutliche Sonderrolle an der Akademie ein. In einem Spiegel-Artikel im Jahr 1969 beschrieb ein Journalist die Beuyschen interdisziplinären Lehrmethoden:

„Statt seine Schüler nur im Gebrauch von Ton und Marmor zu unterweisen, duldet der als Bildhauer angestellte Dozent auch Komponisten und Poeten in seiner Klasse. "19

Die Bildhauerin Inge Mahn, die damals der Klasse angehörte, stellte im Rückblick fest: „Die Klasse strahlte etwas Besonderes aus.“120

Um von Joseph Beuys in seine Klasse aufgenommen zu werden, musste ihm die Studentin Ulrike Rosenbach ihre bei Norbert Kricke gefertigten Stahlarbeiten vorlegen, die jedoch nur bedingt auf Beuys' Einverständnis stießen. Im Rückblick sagt Ulrike Rosenbach dazu:

„Schweißen war ihm zu unorganisch. Er meinte, dass könne man auch schrauben. Ihm war wichtig, dass der Arbeitsprozess sichtbar und nachvollziehbar bleibt. Das Prozessuale zu erhalten, war für ihn als Aktionist selbstverständlich. "121

Die Kritik des neuen Lehrers umsetzend begann Ulrike Rosenbach das Metall kalt zu schmieden. Beuys lehnte jedoch auch diesen Ansatz ab, da bei dem starren Material Eisen die Formen nicht herauskamen. Er habe ihr schließlich vorgeschlagen es zu schmieden, bis es springe. „Damit habe ich dann angefangen, das war die erste Arbeit" ${ }^{\prime 122}$, erinnert sich die Künstlerin und beschreibt weiter ihren Lehrer:

„Beuys hatte hohe Ansprüche. Er selbst war immer da, schon morgens früh. Einmal die Woche wurde gezeichnet und einmal in der Woche korrigierte er die Arbeiten. Er erwartete dabei, dass die StudentInnen anwesend waren. "23

Die Künstlerin beschreibt diese Besprechungen als „messerscharfe Korrekturen“.124 Während ihres Studiums war das Verhältnis zwischen Rosenbach und

119 Der Spiegel 1969, Nr. 51, S. 170

120 Inge Mahn im Gespräch mit Petra Richter 28.12.93, In der Beuys-Klasse waren zu diesem Zeitpunkt u.a. Jörg Immendorff, Norbert Tadeusz, Blinky Palermo (d.i. Peter Heisterkamp, gest. 1977), Reiner Ruthenbeck, Katharina Sieverding, Peter Dürr, Jonas Hafner, T.H. Wolfs, Claus Böhmler, Hans Rogalla, Imi Knoebel, Imi Giese (gest. 1974), Anatol Herzfeld, Klaus Stein, Alexander Jordan, Christof Kohlhöfer, Ursula Reuter-Christiansen, Artur Dannhäuser, Inge Mahn, Gieslind Nabakowski, Stephan Runge, Johannes Stüttgen, Gerda Hühn, Karin Kulleschitz (später Genoux), Wolfgang Genoux. (Richter 2000, S. 97)

121 Rosenbach im Gespräch mit Petra Richter am 29.8.1994, in: Richter 2000, S. 301

122 Beuys war Plastiker, so ging es dem Künstler darum, das Material grundlegend neu zu bearbeiten. (Vgl. Richter 2000, S. 301)

123 Rosenbach im Interview 2001, Kap. VII.1.; vgl. auch Richter 2000, S. 301

124 Richter 2000, S. 302 
Beuys angespannt. So empfand die junge Frau anscheinend großen Respekt und auch eine gewisse Scheu und sogar Angst vor dem charismatischen Lehrer:

„Er hatte eine sehr starke Ausstrablung, mir war häufig sehr unbehaglich in seiner Nä-

he. Seine Erscheinung war sehr herausfordernd, man konnte ihm nichts vormachen. "225

Diese Konstellation verhinderte wohl auch, dass die junge Künstlerin zunächst einen Zugang fand zu der von Beuys vertretenen Idee der Überwindung des tradierten Kunstbegriffes. Dieser blieb ihr nach eigener Einschätzung in den 1970er Jahren weitgehend verschlossen. Rückblickend stellte die Künstlerin in einem Interview Ende der 1990er Jahre fest:

„Damals hatte ich das nicht verstanden... Dass Kunst und Leben sich vermischen, eins sind. Heute ist das für mich das Wichtigste, was ich aus der Zeit mit Beuys mitgenommen habe. Wie sehr mich Beuys' Vorstellungen von Kunst und Leben beeinflusst haben, ist mir erst in den letzten Jahren so richtig bewusst geworden. Bewys hat viel bei mir ausgelöst und das habe ich weiterentwickelt. "226

Daneben war die Beziehung zwischen Schülerin und Lehrer auch durch Missverständnisse geprägt. Die junge Künstlerin fühlte sich von Beuys durch Aussprüche wie „Ihr Frauen seid als Mütter wichtig“ in eine traditionelle weibliche Rolle gedrängt, die ihr nicht genügte. Sie habe Beuys so verstanden, dass er Frau als Synonym für Mutter, die nur biologisch nicht aber kulturell schöpferisch sei, verstand. ${ }^{127}$ Für Beuys war die Frau jedoch neutral „erst einmal Mensch, genau wie der Mann“.128 Explizit hob der Künstler in seinen Aussagen die Bedeutung der Frauen in Kunst und Gesellschaft hervor:
„Die Frau muss heute eine ganz, wichtige Rolle spielen. Feminismus - das ist ja noch keine hohe Form, ist aber doch in der Stoßrichtung zu unterstützen. Nur sollte man wünschen, dass die Frauen in einer umfassenderen Weise über ibre Wünsche, Stellung, Möglichkeiten und Energie nachdenken als immer nur im Gegensatz zum Mann. "129

Als junge Mutter arbeitete Ulrike Rosenbach bei Beuys auf dessen Anregung mehrere Semester an so genannten „Spielobjekten“, wie zum Beispiel Blumen aus Blei. ${ }^{130}$

\footnotetext{
${ }^{125}$ Rosenbach in Richter 2000, S. 119. Richter mutmaßt, dass sich in der Beziehung vielleicht das Verhältnis zu ihrem Vater widerspiegelt. Die junge Frau fühlte sich der Übermacht seiner Persönlichkeit ausgeliefert. In ihrer Beziehung zu Beuys spiegelte sich wohl das schwierige Verhältnis der Künstlerin zu ihrem Vater wider.

${ }^{126}$ Rosenbach in: Richter 2000, S. 121

${ }^{127}$ Richter 2000, S. $120 \mathrm{f}$

${ }^{128}$ Beuys im Gespräch mit von Waberer 1979, S. 202. (In: Richter 2000, S. 120)

${ }^{129}$ Beuys im Gespräch mit von Waberer 1979, S. 202 (In: Richter 2000, S. 120)

130 Blumen aus Blei 1969/70, abgebildet in: Glüher 2006, S.132
} 

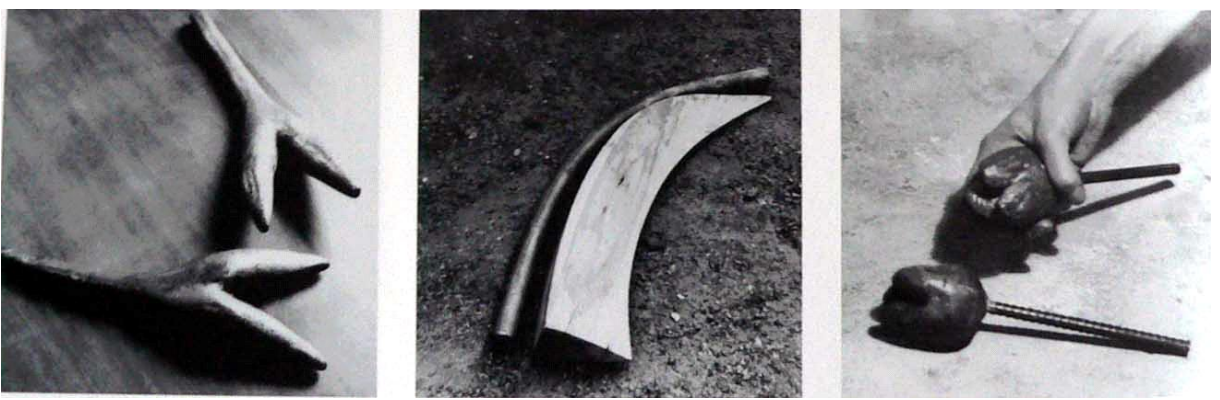

Abb. 22-24: Spielobjekte, 1967, Blei und Holr.

Die so genannten Spielobjekte waren Dinge, die ein Kind gar nicht gebrauchen konnte. Denn diese Objekte waren entweder aus einem für ein Kind unangemessenen Material - wie zum Beispiel Blei - oder passten in der Größe nicht. Den Sinn dieser Themenstellung schätzte die Künstlerin im Rückblick positiv ein:

„Mich als Mutter einzubinden, das war für ihn ein ganzheitliches Konzept. Damals hatte ich das nicht verstanden. " 31

Im Laufe der Semester nahm durch die wachsende Zahl der bei Beuys' Studierenden die räumliche Enge in der Akademie zu. Doch hatte Ulrike Rosenbach die Möglichkeit sich in ihr eigenes Atelier - eine alte Fabrikhalle - zurückziehen zu können, um dort ungestört zu arbeiten. Ihre Tochter war bei der künstlerischen Arbeit häufig zugegen. Trotzdem blieb die Akademie wichtiger Begegnungspunkt, so wie sich zudem Ende der 1960er Jahre das Lokal „Creamcheese“, das 1967 eröffnet worden war, zu einem bedeutenden Künstler- und Intellektuellentreffpunkt entwickelte. ${ }^{132}$

131 Rosenbach in: Richter 2000, S. 302

132 Zu den 1970er Jahren schrieb Stiles in: Kat. Los Angeles 1998, S. 241: „Gleichzeitig setzten soziale Bewegungen von der Bürgerrechtsbewegung bis zum Feminismus neue Maßstäbe für Identitätspolitik, Multikulturalismus und Postkolonialismus, die sich n den 70er Jahren voll entfalteten und von sich behaupten konnten, einen historischen Paradigmenwechsel sowie den Anbruch der „Postmoderne“ ausgelöst zu haben. Doch der Vietnamkrieg versetzte dieser turbulenten Zeit den Todesstoß. (...) Als die 70er Jahre zu Ende gingen war dies nicht nur das Ende eines Jahrzehnts, sondern der unrühmliche Abschluss einer traumatischen Ära von Kampf und Verfall. Der immaterielle Schmerz dieser Zeit fand seine perfekte und selbstzerstörerische Verkörperung in dem materiellen, sichtbaren Zeichen der Sicherheitsnadel, die sich junge Punks durch die Haut stachen." 


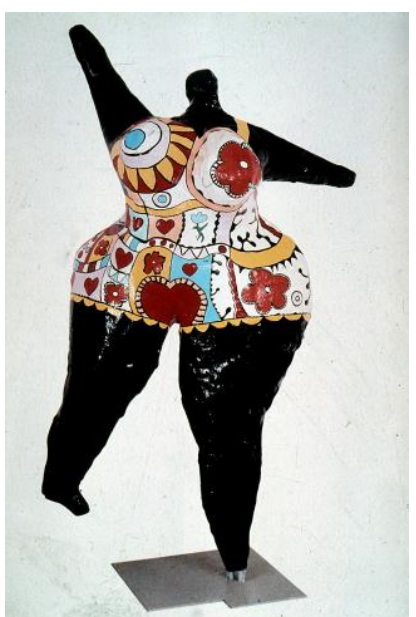

Abb. 25: Niki de Saint Phalle: Schwarze Nana, 1968-69

Zu ihrer Abschlussarbeit wurde die Studentin durch die „Nanas“ der Künstlerin Niki de Saint Phalle inspiriert. Die Figuren aus bunt bemaltem Polyester wurden im Jahr 1969 in Düsseldorf gezeigt ${ }^{133}$. So experimentierte die Studentin auch mit dem Material Polyester und fertigte auch ihre figürliche Abschlussskulptur, zwei Knie, die aus einer Wand herausragten, aus Kunststoff. ${ }^{134}$ Bei der Wahl des Materials sei die Giftigkeit der Zweikomponentenkunststoffe noch nicht bekannt gewesen, erinnert sich die Künstlerin zudem. Im Jahr 1969 wurde Ulrike Rosenbach zur Meisterschülerin von Joseph Beuys ernannt und war so nach ihrem ersten Staatsexamen für das künstlerische Lehrfach an Höheren Schulen noch weiter in der Klasse aktiv. In den folgenden Jahren bis 1975 unterrichtete sie zudem neben ihrer Arbeit als freischaffende Künstlerin als Kunsterzieherin und Lehramtsanwärterin an Düsseldorfer Gymnasien.

\section{III.1.2. Politische und künstlerische Aufbrüche}

In den westlichen Ländern formierten sich während der 1960er Jahren studentische Protestbewegungen. Ihren Ausgang nahm diese Studentenbewegung zunächst in den USA. In Kalifornien bildete sich eine Opposition gegen den Vietnamkrieg und die Civil-Rights-Bewegung formierte sich dort mit neuen Demonstrationsformen - wie den so genannten „Teach Ins“. Die Protestwelle in den USA, die teilweise kulturrevolutionäre Züge trug, griff bald auf Westeuropa über. ${ }^{135}$ In der Bundesrepublik formierte sich das kritische Bewusstsein gegenüber der gesell-

133 Spiegel 1969, Nr. 5, S. 104f: Dort hießen die Schlagzeilen „Nanas an die Macht“ und „Die Männer sind am Ende. Jetzt kommen die Frauen dran."

134 Rosenbach im Gespräch 2001; vgl. Kapitel VII.1.

135 Vgl. Geiss 1988 
schaftlichen und politischen Situation an den Hochschulen als „Außerparlamentarische Opposition“ (APO). Die APO protestierte unter anderem gegen den Krieg in Vietnam, gegen die Notstandsgesetze der großen Koalition und für eine Reform der Hochschulen. Als in Berlin am 2. Juni 1967 gegen den Besuch des persischen Schahs demonstriert wurde, kam am Rande dieser Demonstrationen der Student Benno Ohnesorg durch den Schuss eines Polizisten ums Leben. Der Tod löste an zahlreichen Universitäten in der gesamten Bundesrepublik Empörung und Proteste aus, und - wenngleich die Zentren der deutschen Studentenbewegung in Berlin, Frankfurt oder auch Tübingen lagen - wurde auch in Düsseldorf auf den Vorfall reagiert. Die Studierenden setzten sich experimentell mit den gesellschaftlichen Gegebenheiten auseinander, wie auch mit der Frage nach sozialen Realitäten wie auch der Rolle und Funktion, die der Kunst in der Gesellschaft zukommt. ${ }^{136}$ Joseph Beuys gründete als Konsequenz aus den Ereignissen am 22. Juni 1967 in Düsseldorf die „Deutsche Studentenpartei“ (DSP). Allerdings blieben die Aktivitäten der DSP auf die Akademie beschränkt und innerhalb der außerparlamentarischen Bewegung Ende der 60er Jahre hatte Beuys und seine Partei mit kaum 300 Mitgliedern keine Bedeutung. Beuys bezeichnete die DSP im Sinne der Theorie der sozialen Plastik allerdings als sein größtes Kunstwerk. ${ }^{137}$

Neben und mit ihrer intensiven künstlerischen Arbeit engagierte sich auch Ulrike Rosenbach in der Studentenbewegung, war Ende der 1960er Jahre zweite Asta-Vorsitzende, zusammen mit Peter Dürr und zudem in Beuys Deutscher Studenten Partei (DSP) Mitglied. ${ }^{138}$ Doch entwickelte sich der Schwerpunkt ihres politischen Interesses zusehends um Frauenthemen, ein Interesse, das die Künstlerin auch in verschiedenen ihrer Arbeiten dieser Jahre zum Ausdruck bringt. So entstanden bereits im Jahr 1969 erste plastische Werke, die sich explizit mit dem Thema Frausein auseinandersetzten: Ulrike Rosenbach fertigte eine Reihe so genannter „Hauben- und Kragenobjekte“ - raumgreifende fantasievolle Kopfbedeckungen und Halskrausen aus über Drahtgestellen gespanntem Stoff oder anderen Materialien wie zum Beispiel Federn.

Kegelförmig oder wie gebogene Hörner ragen die Formen in den Raum, und der Kunsthistoriker Wulf Herzogenrath beschrieb diese luftigen Objekte einmal als „skulpturelleVerlängerungen des Körpers“. ${ }^{139}$ Eine der Hauben war sogar aus einem Eisblock gefertigt, der in das formgebende Drahtgestell eingeschrieben war. Eine Fotografie zeigt die Eishaube, die im Laufe der Zeit schmolz und allein den metallenen Rahmen wie eine Wasserpfütze zurück lies.

\footnotetext{
136 Richter 2000, S. 97F; auch Gieseke 1996, S. $157 \mathrm{f}$

137 Gieseke 1996, S. $157 \mathrm{f}$

138 Richter 2000, S. 302; Gislind Nabakowski war ab 1967 in Studentenbewegung aktiv.

139 Herzogenrath in: Rosenbach 1982, S. 109
} 

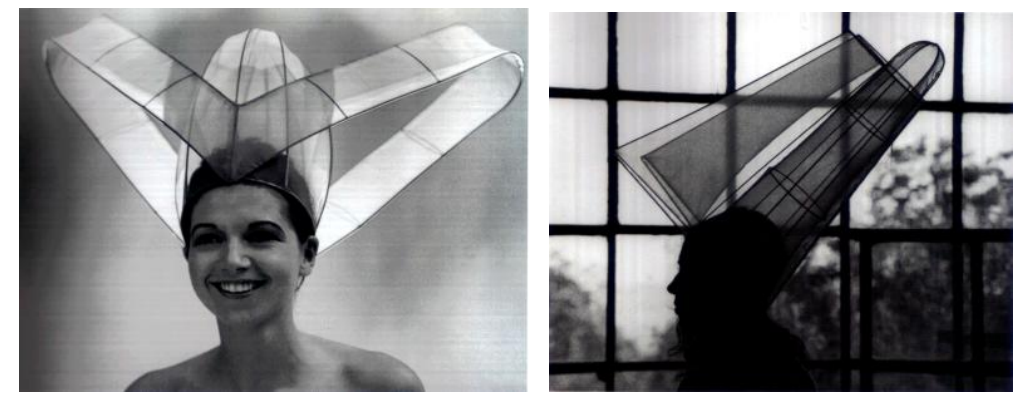

Abb.26-27: Haubenobjekte, 1971

Die Haube war im Mittelalter das Zeichen einer Frau, dass diese vermählt war. So sagt man ja auch heute noch, wenn eine Frau heiratet, dass sie „unter die Haube gekommen“ sei. Neben der weiblichen Haube, die Ulrike Rosenbach inspirierte, wird die Kopfbedeckung des Hutes von Männern wie Frauen getragen und ist bereits in der mittelalterlichen Malerei als Kennzeichen zu finden. ${ }^{140}$ So weist Elisabeth Heller Winter darauf, dass der Kennzeichenwert des Hutes seit jeher eine wichtige Rolle für seine Verwendung gespielt habe. ${ }^{141}$ Bestimmte Kopfbedeckungen seien für unterschiedliche Gruppen zum Zeichen geworden. Und sie führt aus:

„Da es sich dabei im Gegensatz. zu Gesten, Statuten oder Worten um ein unmittelbar abbildbares Symbol handelt gewinnt es eine praktische Bedeutung für die bildende Kunst." "42

Weiter weist sie auf die Funktion des Hutes als Würdezeichen auf mittelalterlichen Malereien, wie auch Hutschmuck und die Art diesen zu tragen in Malereien, Abzeichen politischer oder religiöser Gesinnung oder auch privater Empfindungen wie der Liebe oder Trauer sein könnten. ${ }^{143}$ Irene Adelmann hebt in dem Katalog zur Ausstellung „Art-Hats“, in der im Jahr 1983 das Thema Hut als künstlerisches Objekt reflektiert wurde, auf die unterschiedliche soziologische Funktion des Hutes bei Männern und Frauen hervor:

„Die Freiheit war früher vielleicht ein Privileg der Herren und der Hut nicht selten auch ein Zeichen der Herrschaft und Hoheit. "144

140 Hauben finden sich übrigens häufig als Kopfbedeckungen für Frauen in der mittelalterlichen Malerei, wie auch in den Bildern der viktorianischen Künstler des 19. Jahrhunderts, die sich genau mit historischen Kostümen beschäftigten. (Vgl. Strong 1978, S.101)

141 Joseph Beuys trug übrigens auch immer einen Hut.

142 Heller-Winter in: Ley 2000, S.10

143 Heller-Winter in: Ley 2000, S.10f

144 Adelmann 1983, S. 11; Der Katalog behandelt die Thematik des Hutes in der Kunst, wurde doch diese Kopfbedeckung von vielen Künstlern als Objekt genützt. Rosenbachs eigene fanta- 
Dagegen habe eine Kopfbedeckung bei Frauen in der Vergangenheit eine andere Funktion besessen:

„Die Frauen wurden, unter die Haube gebracht'. Die Haube als Symbol der Unfreibeit, der Unterstellung unter den Mann bei der Heirat. Es wäre grotesk gewesen und hätte auch der Demut widersprochen, hätte die Frau die Haube vor einem ,Höheren ' abgelegt. Aus diesem Grund hat sich der Gruß mit der Kopfbedeckung bei der Frau nicht eingebürgert." "145

Die traditionelle Form der Frauenhaube nimmt Rosenbach in ihren raumgreifenden Objekten aus Draht und Stoff auf und variiert sie spielerisch. Dabei finden sich Vorbilder in historischen Kostümbüchern, die Pate gestanden haben könnten für Rosenbachs künstlerische Kreationen.
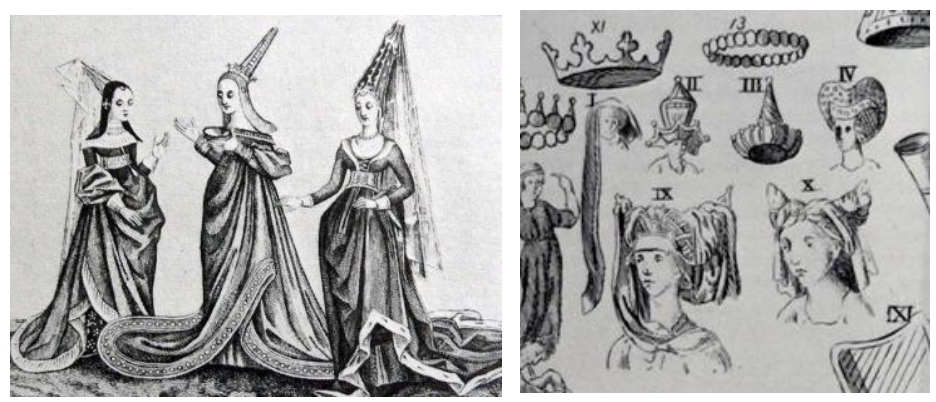

Abb. 28-29: Damen von Rang des 15. und 16. Jh. und Horda Angel-cynnan (Detail)

In Strutt's „Dress and Habits“ finden sich zum Beispiel historische Kopfbedeckungen, die denen Rosenbachs auf erstaunliche Weise ähneln. Seien es die fantasievollen „Hauben“ der hochgestellten Damen des 14. und 15. Jahrhunderts oder auch Kopfbedeckungen zu Kostümen aus späteren Zeiten. ${ }^{146}$

Die Künstlerin reflektiert die alte Kleidungstradition in ihren fantasievollen Kopfbedeckungen und wandelt dabei deren Funktion, in dem sie bei der Gestaltung das Verhüllende gegen das Markierende austauscht und aus der besitzanzeigenden

sievolle Kreationen heben sich dabei aus der Menge der versammelten Arbeiten durch die besonders fantasievolle Umsetzung ab.

145 Adelmann 1983, S. 11

146 Vgl. Strong 1978; Und auch bei anderen Künstlern finden sich ähnliche Körperobjekte, wie zum Beispiel bei Rebecca Horn, die 1970/72 bei ihrer Einhorn-Aktion eine spitz zulaufende kegelförmige Kopfbedeckung trägt. Außerdem ist es interessant, dass in diesen Jahren in der internationalen Kunstszene auch mit Haartrachten experimentiert wurde. So fotografierte der afrikanische Fotograf J.D.'Okhai Ojeikere in seiner Serie „Hairstyles et Hairgears“ aus dem Jahr 1974 zum Beispiel unterschiedlichste Haartrachten, die in Afrika ein Statussymbol sind. In den Fotografien lässt sich der skulpturale Charakter dieses Kopfschmuckes gut erkennen. (Vgl. Kat. Kassel 2006, S. 96f) 
Haube einen markanten, raumgreifenden Kopfputz macht. ${ }^{147}$ So sagte Ulrike Rosenbach selbst über ihre Hauben-Werke:

„The hauben combine male and female shapes in original forms, which when placed on my head enable me to transcend the conventional erotic context to contemporary women." "48

Dabei ist die Künstlerin selbst das Modell für ihre Haubenobjekte. Mehrere Fotoserien, die diese Objektarbeiten dokumentieren, zeigen die junge Frau selbstbewusst in die Kamera blickend. ${ }^{149}$ Die Künstlerin ist zu dem Zeitpunkt, als die Hauben- und Kragenobjekte entstehen, noch verheiratet. Im Gespräch mit Amine Haase stellte sie rückblickend auf diese Zeit fest:

„Frauenprobleme habe ich eigentlich schon mit den Objektarbeiten von 1969 angesprochen, gesehen aus einer privaten Krise. Damals hatte ich starke Identifikationsprobleme mit meiner künstlerischen Arbeit. Ich fragte mich, warum ich das eigentlich mache, und für wen. Diese Anlaßfrage steht ja wohl immer an der Problemschwelle, ob man nun Künstler wird oder nicht. Ich Kam schnell auf meine Situation als Frau, die Frage wie ich als Frau und Künstlerin klarkomme. Mein Verbältnis daqu als Ehefrau und als Mutter. Schon damals habe ich mich dafür interessiert, was Frauen in der Kunst gemacht haben - außer als Modell zu dienen. "150

Mit ihrem Interesse für die durch Diskriminierung gekennzeichnete Situation der Frau stand die junge Künstlerin nicht alleine. Zu Beginn der 1970er Jahre begannen sich auch in Europa Frauengruppen mit feministischem Ansatz zu bilden. Allerdings war die Resonanz auf einen Aufruf Ulrike Rosenbachs zur Gründung einer Frauengruppe an die Studentinnen der Düsseldorfer Akademie gering, wie die Künstlerin im Rückblick zusammenfasst:

„1972 habe ich an der Düsseldorfer Akademie versucht, einen Frauengruppen-Kontext zu schaffen. Nur vier Kunststudentinnen waren bereit, über ibre Rolle als Frau und Künstlerin überhaupt nachzudenken. "151

Bei den vier Frauen handelte es sich neben Ulrike Rosenbach um Maria Fisahn, Claudia Andre und Leslie Labowitz. Und besonders die Begegnung mit Leslie Labowitz (*1946) trug Früchte. Die Amerikanerin studierte von 1972 bis 1977 - angezogen durch das Wirken von Joseph Beuys - an der Düsseldorfer Akademie.

147 So findet sich in den Haubenobjekten auch ein deutlicher Gegensatz zu der Darstellung der Künstlerin in ihren Videobändern aus dem Anfang der 1970er Jahre. Hier hat sie sich mehrfach unter einer Haube oder auch anderem Material verhüllt inszeniert.

148 Rosenbach in: Avalanche Summer/Fall 1973, S. 66

149 Die Fotografien nahm Ute Klophaus auf.

150 Rosenbach im Gespräch mit Amine Haase in: Haase 1981, S. 125

151 Rosenbach im Gespräch mit Amine Haase in: Haase 1981, S. 125 
Zuvor hatte sie in Los Angeles bei Judy Chicago $\left({ }^{* 1939)}\right.$ studiert. 152 Judy Chicago zählt zu den Vorkämpferinnen für feministische Kunst in den USA. ${ }^{153}$ Bei ihr hatte Leslie Labowitz, die schon in dieser Zeit einen stark politischen Ansatz in ihrer Aktionskunst verfolgte, bereits Anfang der siebziger Jahre Erfahrungen mit feministischer Performancearbeit gemacht und wichtige Erfahrungen mit diesem künstlerischen Ausdrucksmittel gesammelt. Dieses grundlegende Wissen konnte sie an die Düsseldorfer Frauen weitergeben. ${ }^{154}$ Über die engagierte Amerikanerin ergaben sich zudem für Ulrike Rosenbach konkrete Kontakte zu den Feministinnen in den USA. So trat sie unter anderem mit der amerikanischen Kunstkritikerin Lucy Lippard (*1937) in Verbindung, die zu dieser Zeit ein „Adressboard for International Women Artists" in New York gegründet hatte. Diese Liste war schließlich die Basis für die Organisation der Wanderausstellung „C. 7500“, die Werke von insgesamt 25 amerikanischen und europäischen Künstlerinnen versammelte und 1973 in einer ganzen Reihe von Collegegalerien der Vereinigten Staaten zu sehen war. ${ }^{155}$ Ulrike Rosenbachs Hauben-(Fotos) waren bei dieser feministischen Werkschau dabei. Über dieses Forum erreichten die Arbeiten der jungen deutschen Künstlerin bereits zu Beginn ihrer Karriere eine breite internationale Öffentlichkeit. Außerdem hielt sich die Künstlerin ab Anfang der 1970er Jahre zu verschiedenen Arbeitsaufenthalten in den USA auf.

Und nicht nur in den USA waren Arbeiten Ulrike Rosenbachs zu sehen, auch in London konnte sie 1973 ausstellen. In den Pausen zwischen den großen Ausstellungen bot die Düsseldorfer Kunsthalle unter Leitung von Jürgen Harten in ihrem Haus jungen Künstlern der ansässigen Akademie ein öffentliches Forum für Gruppenwerkschauen unter dem sprechenden Titel „between“. Die vier Frauen beteiligten sich gemeinsam an der between 7, die vom 2. bis 6. Mai 1973 in der Düsseldorfer Kunsthalle zu sehen war. ${ }^{156}$, ,Wir stellten einen Videofilm und narrative Fotoarbeiten zum Thema Menstruation aus und ich zog mir die Feindschaft

152 Roth 1983, S. 28; Mehr zu Labowitz in: Chadwick 1990, S. $342 \mathrm{ff}$

153 Vgl. auch Kapitel III.4.4.1

154 Die Studentin von Beuys verfolgte in ihrer Kunst einen explizit politischen Ansatz. Von ihr ist zum Beispiel die Aktion „Paragraph 218“, die im Jahr 1975 in Bonn vor dem Rathaus aufgeführt wurde. 1977 ging Labowitz zurück in die USA und begann in Los Angeles mit der Künstlerin Suzanne Lacy zu arbeiten. In den Werken von Suzanne Lacy bildet die Unterdrückung der Frau das Grundthema. Die Performance „Three weeks in May“ machten die beiden Künstlerinnen später zusammen, sie ist ein radikaler Angriff auf die Medien, die Frauen in bestimmte Rollen zwingen.

155 Unter anderem im Mai 1974 auch im Warehouse in Earlham Street. (Pollock/Parker 1987, S. 76)

156 Die ,,between 7 - Yes Sir, That's my Baby“ fand vom 2.- 6.5.1973 in Düsseldorf statt und hatte fast 90 Teilnehmer, darunter u.a. Ulrike Rosenbach, Katharina Sieverding, Michael Buthe. Die Ausstellung wurde im Gallery House in London unter dem Titel „Some 260 miles from here: Art from the Rhein-Ruhr Germany 1973“" vom 14.5. bis 20.6.1973 gezeigt.

(Buschmann 2002, S. 290) 


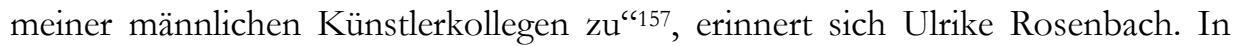
der Ausstellung stellten fast 90 Künstler aus, darunter neben Ulrike Rosenbach auch Katharina Sieverding oder Michael Buthe. Die Schau wurde kurz darauf unter dem Titel „Some 260 miles from here: Art from the Rhein-Ruhr Germany 1973 “ vom 14.5. bis 20.6.1973 auch im Gallery House in London gezeigt. ${ }^{158} \mathrm{Au}-$ Berdem hatte die Künstlerin bereits im Jahr 1972 ihre erste Einzelausstellung in der Galerie Ernst in Hannover gehabt. Die Galerie Ernst bot in diesen Jahren jungen Künstlern ein Forum, zum Beispiel wurden hier auch Arbeiten von Dieter Roth gezeigt. $\mathrm{Zu}$ sehen waren in Hannover Zeichnungen, Haubenobjekte und auch erste Videos der Künstlerin.

\section{III.1.3. Vom Objekt zur Aktion: Erste Arbeiten als freischaffende Künstlerin}

Die Hauben- und Kragenobjekte bilden einen ersten Emanzipationspunkt im Werk Rosenbachs. Die Künstlerin findet in ihren originellen Stoffobjekten für sich eine individuelle Ausdrucksform und löst sich damit auch von der traditionellen Bildhauerei. Zudem öffnet sich die junge Künstlerin damit für Formen der Aktionskunst, die sie während ihres Studiums noch für sich abgelehnt hatte:

„Anfangs stand für mich fest, dass ich keine Aktionen machen wollte. Es hat mich derartig gequält, Beuys' Aktionen zu sehen, ich war hinterher immer psychisch fertig. Mir lief der Schweiß nur so den Rücken runter. Ich habe immer in der letaten Reibe gestanden denn ich habe die Nähe nicht ertragen. Ich bin häufig rausgelaufen und wieder reingekommen. Ich war total erregt, es war etwas Manisches. "159

Nun findet Ulrike Rosenbach über ihre Rolle als „Fotomodell“ für ihre Objekte einen eigenen Zugang zur körperbezogenen Performancekunst. Bereits in den Hauben- und Kragenobjekten, die Wulf Herzogenrath auch als „Bewegungsfolgen des Körpers als plastische Arbeiten“ 160 auffasste, kündigte sich der folgende Schritt in der künstlerischen Entwicklung Rosenbachs an. Die Künstlerin selbst beschrieb die Einbeziehung des Bewegungsaspektes in Zusammenhang mit ihren Haubenobjekten:

„I like art that is coming after complicated experience. I am against the simplifying in art, because it is only a technique, a styled method is isolation. Life is complicated and an

\footnotetext{
157 Rosenbach in: Beckers 1998, S. 141

158 Zuvor hatte Ulrike Rosenbach 1970 bereits an der „between 5“ teilgenommen. In der Sektion Gebrauchsobjekte/Spielsachen war sie laut Ausstellungsliste mit einem Gebrauchsobjekt vertreten gewesen. Die ,between 5“ fand vom 9.-18.10.1970 statt. Am 11. und 18. gab es dort Konzerte von der Elektronikband Kraftwerk. (Buschmann 2002, S. 289f)

159 Rosenbach in: Richter 2000, S. 121

160 Herzogenrath in: Rosenbach 1982, S. 109
} 
art that is simplifying it, is just a complicated lie. Only complicated movements are still complex. Closed surfaces hide the movements that happen. "161

Das starre Objekt wird in dieser Phase überwunden und der bewegte, handelnde Körper, der sich in einem Prozess in einem Raum befindet, tritt in den Mittelpunkt ihres Werkes. Sowohl in ihren Videotapes als auch in ihren Aktionen setzt die Künstlerin ihren Körper als Medium ein.

Mit ihrer ersten Performance trat Ulrike Rosenbach 1973 - ebenfalls im Rahmen der „between 7 “ Ausstellung der Düsseldorfer Kunsthalle - an die Öffentlichkeit:162 „Naturkreisaktion“ hieß das Werk, das die Künstlerin im Freien aufführte.

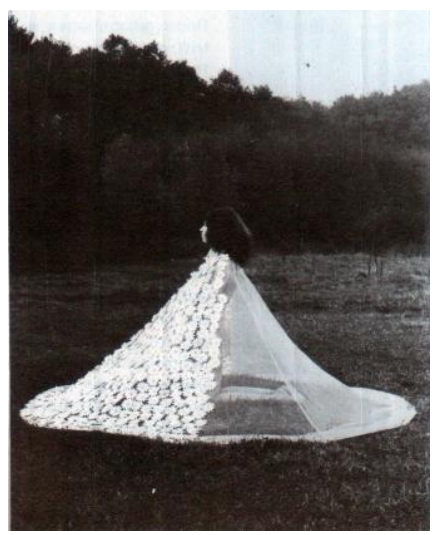

Abb. 30: Naturkreisaktion, 1973

Die Künstlerin kniete bei dieser Aktion zunächst in einem weiten runden Netzumhang, der vorne mit Margeriten besetzt war, auf einer Wiese. In ihren kegelförmigen Mantel hatte sie einen Korb mit Vögeln genommen, die sie darin frei fliegen ließ. Das netzartige Gewand wird somit vorübergehend zum Gehege für die Tiere. Während der Aktion entstieg die Künstlerin dann dem Mantelzelt, wodurch sich auch den Vögeln eine Öffnung bietet, um ins Freie fliegen zu können.

In der Aktion finden sich die Frau wie die Vögel - letztere als Symbol der lebendigen Natur wie auch der Seele zu verstehen - zunächst in einem kegelförmigen Netz gefangen, das zwar mit Blumen dekorativ geschmückt ist, aber eine Fortbewegung verhindert. Eine Inszenierung, die in treffender weiblicher Bildsprache zeige, in welcher Weise Frauen und Natur in der Gesellschaft gesehen würden,

161 Rosenbach in: Flashart, No. 44-45, April 1974; Im Gespräch wies sie darauf hin, dass das Sichtbarmachen des Prozesses von Beuys angeregt worden sei. (Vgl. Kap. VII.1.)

162 Die Performance führte Rosenbach auch bei der Ausstellung „Some 260 miles from here“ im "Gallery House“ in London auf. 
III. Übergänge

wie Lucy Lippard die Aktion kommentierte. ${ }^{163}$ Erst als die Akteurin handelt und dem sie umgebenden Mantelzelt entsteigt, bietet sich auch für die Vögel eine Öffnung, um ins Freie zu fliegen.

Die Künstlerin sagte selbst über ihre erste öffentliche Performance:

„Für mich war diese Aktion ein logischer Schritt vom Objektemachen zum Benutzen der Objekte, eine Aktion, die es mir ermöglichte, eine vorhandene Ausstellungsästhetik zu durchbrechen, die mir immer absurd vorgekommen war. Denn schließlich spielten sich die wichtigsten inneren Vorgänge beim $A r b$ e $i$ te $n$ an den Objekten ab, und ich fand es sehr befreiend, Gedanken und Gefühle, die während des Arbeitsprozesses aufkamen, mitteilen zu können. "164

Der Schwerpunkt verschiebt sich an diesem Punkt im Werk vom Zeigen des fertigen Objektes zum Aufzeigen einer prozesshaften Aktion, die dann auch wiederum mittels Video aufgezeichnet - konserviert und wiederholbar - werden konnte.

An diese erste Kunstaktion schloss sich eine zweite noch im selben Jahr an, bei der die Künstlerin Video und Performance innerhalb einer Liveaufführung zusammenführte. Auf dem Kölner Kunstmarkt 1973 kam es zu einer Begegnung zwischen dem Musiker Konrad Schnitzler und Ulrike Rosenbach, woraus sich spontan ein improvisiertes „Videokonzert“ entwickelte.

\section{III.1.4. Erste Video-Live-Aktionen}

Der Kölner Kunstmarkt fand im Herbst 1973 statt. ${ }^{165}$ Dort fand Ulrike Rosenbach zu einer neuen Arbeitsweise, die in den folgenden Jahren wichtig für sie werden sollte. Während die Künstlerin die Videotechnik bisher dazu genutzt hatte, Performancetapes in ihrem Atelier aufzuzeichnen oder aber - wie bei der oben beschriebenen „Naturkreisaktion“ - die jeweilige Aktion vor Ort auf Video zu dokumentieren, kommt ihr hier nun bei einem Auftritt des Berliner Musikers Konrad Schnitzler der Gedanke für eine erste von der Künstlerin selbst so benannte „Video-live-Aktion“. Bei diesem synchronen Zusammenspiel von direkter Videowiedergabe und Live-Aktion haben die Zuschauenden zwei unterschiedliche visuelle Eindrücke zu verarbeiten: Zum einen die im Raum stattfindende reale Aktion und zum anderen die elektronischen Bilder, die über die Videokamera live auf Fernsehmonitore übertragen wurden. ${ }^{166}$

Die elektronische Musik Schnitzlers - mit Synthesizer und E-Orgel erzeugt hatte Ulrike Rosenbach spontan gefallen: „Sie schien mir gut angelegt an das elektronische Medium und rief in mir intensive Bildvorstellungen für mein elekt-

\footnotetext{
163 Lippard in: Rosenbach 1982, S. 124

164 Rosenbach 1982, S. 95

165 Vgl. Kapitel III.2.

166 Rosenbach 1982, S. 105
} 
ronisches Medium, Video, hervor,"167 erinnerte sie sich. Nach einem Gespräch mit dem Musiker noch am gleichen Abend verabredeten die beiden eine gemeinsame Aktion am kommenden Tag. Den gemeinsamen Auftritt am folgenden Abend beschrieb die Künstlerin wie folgt:

„... er vor seinem „Soundaltar", dem Aufbau mit vier Revoxtonbandgeräten, Sythesizerer (sic) und elektronischer Orgel. Ich hatte meine Schwarz-weiß-Kamera vor mir, daneben die Video-Halbzollmaschine und dem Publikum zugewandt stand mein Fernsehmonitor auf der Bühne. (...) Außer meiner Kamera war mein wichtigstes Instrument eine Fotolampe mit $200 \mathrm{~W}$ att, die ich an einem Griff meistens in der Hand bielt und zu den leise anfahrenden Tönen der Musik von Schnitzler bewegte, die sich wie ein anfahrender Zug anbörte. Meine Kamera stand auf einem Stativ und, die Lampe in der linken, die Stativführung mit der rechten Hand, begann ich mein Gesicht und meinen Körper ,abzutasten", mein Bild ständig im Monitor kontrollierend. Auf Armlänge von der Kamera entfernt hatte ich alle Hände voll qu tun, um Schärfen und Blenden der Kamera qu bedienen und mit der Lampe auszuleuchten. In totaler Konzentration fübrte ich das Kamerabild über meinen Kopf. Die Bewegungen, langsam und intensiv, wurden detailliert über den Monitor an das Publikum weitergegeben. Es konnte so meine Bewegungen viel genauer verfolgen als in der direkten Anschaunng meiner Person auf der Bühne. "168

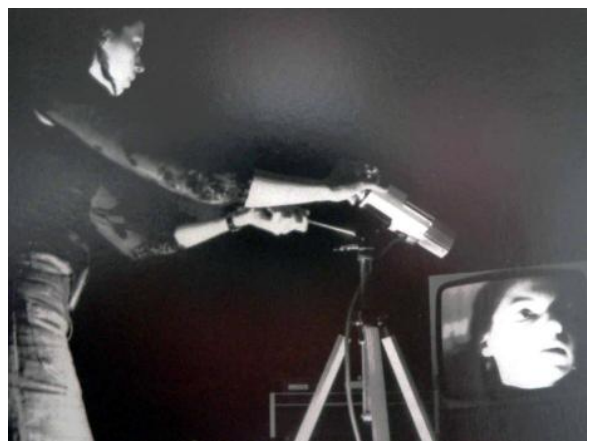

Abb. 31: Videoliveaktion mit Konrad Schniţler auf dem Kölner Kunstmarkt, 1973

Das bei der Aktion aufgezeichnete Videoband „Videokonzert - Improvisation“ gibt die sich stetig verändernde Bildsequenz synchron zu den fließenden elektronischen Klängen wieder. Eine weitere Videoliveaktion, die Ulrike Rosenbach und Konrad Schnitzler gemeinsam gestalteten, fand am 20.10.1974 in den erweiterten Galerieräumen von Ingrid Oppenheim statt. ${ }^{169}$ Das Livetape, das dabei ent-

\footnotetext{
167 Rosenbach 1982, S. 97

168 Rosenbach 1982, S. 97

169 Das Oppenheimstudio befand sich in der Lindenstraße 20 in Köln.
} 
stand $^{170}$, wurde später mit dem ersten Videokonzertband zusammen geschnitten. ${ }^{171}$

Bei Rosenbachs „Videokonzerten“ - deren Name an den Begriff der Fluxuskonzerte erinnert - bildet der Ton eine wichtige Basis des Kunstwerkes. Ulrike Rosenbach erkannte von Beginn ihrer Arbeit mit Video die Bedeutung der auditiven Ebene und nutzte dieses Element gestalterisch in ihren Werken. Charakteristisch sind in ihren Tapes einerseits fließende Klänge, andererseits der Einsatz von Rhythmus, eine kompositorische Konstante, die sich bereits in ihren ersten Tapes zeigte. Sei es der gleichmäßige Atemrhythmus in „Einwicklung mit Julia", sei es das sich stetig wiederholende, den Rhythmus des Countrysongs im Hintergrund aufnehmende Schlagen der Hand auf den eigenen Oberschenkel in „Sorry, Mister".
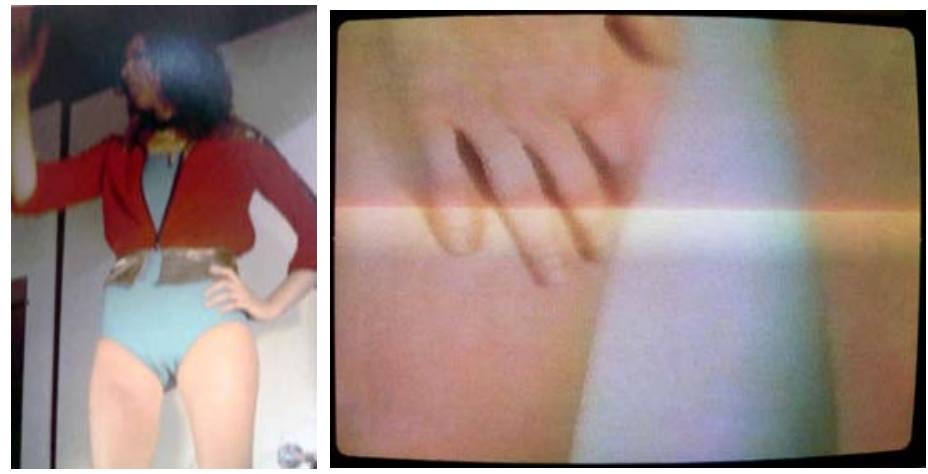

Abb. 32-33: Sorry Mister, Foto der Aktion und Videostill, 1973

In dem 14-minütigen Farbtape, das 1974 entstand, fängt das Standbild in Großaufnahme die Oberschenkel der Künstlerin ein. Mit ihrer rechten Hand schlägt sie sich in rythmischer Folge auf die Innenseite ihres rechten Oberschenkels und die Haut verfärbt sich an der Schlagstelle allmählich Rotblau. Neben dem durch das Schlagen entstehenden Rhythmus ist der im Original rund zweieinhalbminütige Song der amerikanischen Sängerin Brenda Lee mittels mehrerer Soundschleifen auf 14 Minuten gestreckt worden. So beginnt der eindringliche Gesang, in dem die Sängerin ihre Torheit bedauert, immer wieder von neuem, so wie auch das Schlagen sich fortsetzt. ${ }^{172}$

170 Videoconzert II: Inselmusik 1974, $12 \mathrm{~min} \mathrm{s/w}$

171 Daraus entstand das Tape „Inselmusik“. Das Tape wurde im gleichen Jahr noch in 112 Greene Street gezeigt, einem New Yorker Künstlertreffpunkt.

172 Der Text des Songs aus dem Jahr 1960, der in dem Tape gleich mehrfach wiederholt wird, lautet wie folgt: „I'm sorry, so sorry/ That I was such a fool/ I didn't know/ Love could be so cruel/ Oh, oh, oh, oh/ Uh-oh/ Oh, yes/ You tell me mistakes/ Are part of being young/ But that don't right/ The wrong that's been done [Gesprochen mit Chor:] (I'm sorry) I'm sorry/ (So sorry) So sorry/ Please accept my apology/ But love is blind/ And I was to blind to see/ Oh, oh, 
Der Kunsthistoriker Wulf Herzogenrath betonte in einem Interview ebenfalls die Bedeutung des Sounds in Rosenbachs Werken. Der Kunsthistoriker spricht von der Faszination des Klanges in ihren Tapes, des Einsatzes von oftmals kleinen Tonschleifen, die sofort eine ganz bestimmte Atmosphäre schaffen. ${ }^{173}$ Häufig arbeitete die Künstlerin für die Soundtracks der späteren Werke auch weiterhin mit Musikern zusammen. Mehrfach zum Beispiel mit der Band von Konrad Schnitzler „Tangerine Dream“, oder aber auch mit anderen befreundeten Musikern.

Diese Affinität zur Musik findet sich häufig bei Künstlern, die mit dem elektronischen Zeitmedium Video arbeiten. Zu nennen sind hier besonders die bekannten Videokünstler Nam June Paik, Woody und Steina Vasulka oder auch die Amerikanerin Laurie Anderson. Sie alle haben ihre Wurzeln in der Musik, vornehmlich der elektronischen. ${ }^{174}$ Beide Zeitmedien - Musik und Video - verbindet ihre fließende Struktur. Und so reizte viele der audiovisuellen Künstler in den 1970er Jahren Erfahrungen aus dem akustischen Bereich auf den optischen, elektronischen Bildfluss zu übertragen. So experimentierte Nam June Paik mit seinem Videosynthesizer, die Vasulkas richteten sich ihr eigenes Videostudio ein und experimentieren mit elektronischen Effekten.

Ulrike Rosenbach ist allerdings keine Musikerin und die bildende Künstlerin beschränkt sich auch auf die einfache ihr zu diesem Zeitpunkt zur Verfügung stehende Videotechnik, mit deren Hilfe es ihr aber gelingt, Bild und Ton zu einprägsamen Kompositionen zusammen zu fügen.

Der amerikanische Schauspieler und damalige Videoaktivist Willoughby Sharp (*1936), der mit Joseph Beuys befreundet war und das Videokonzert von Ulrike Rosenbach auf dem Kölner Kunstmarkt erlebt hatte, lud die Künstlerin im folgenden Jahr nach New York ein. ${ }^{175}$ Dort konnte sie in dem bekannten Künstlertreffpunkt „112 Greene Street“ eine weitere Performance aufführen. In der dort gezeigten Aktion „Isolation is transparent“" wob Rosenbach, wie schon zuvor beim Kölner Videokonzert, eine Liveaufzeichnung der Aktion in ihre Performance ein.

Bei der Aktion „Isolation is transparent“176 war der große Aufführungsraum durch eine milchig-transparente Folienwand in zwei Hälften aufgeteilt. In dem ei-

oh, oh/ Uh-oh/ Oh, yes / You tell me mistakes/ Are part of being young/ But that don't right/ The wrong that's been done/ Oh, oh, oh, oh/ Uh-oh/ Oh, yes/ I'm sorry, so sorry/ Please accept my apology/ But love was blind/ And I was too blind to see (Sorry)

173 Interview mit Herzogenrath vom 4.3.2003, Kap. VII.2.

174 Die Nähe von Musik und Energiefluss zeigt sich in Bandnamen, wie „Kraftwerk“ oder auch dem „Electric Light Orchestra“, die in den 1980er Jahren sehr viel Erfolg hatten.

175 Willoughby Sharp war mit Videoarbeiten beim „Projekt 74“ vertreten (Vito Acconci, Videoview, 30 min., sw).

176 Die Aktion fand am Sonntag, 20. Oktober 1974 ab 20.30 Uhr noch einmal im Oppenheim Studio in Köln statt. Der Ton stammte von Konrad Schnitzler. 
nen Raumteil befand sich die Akteurin, die sich allmählich in ein an den Wänden festgenageltes Seilgebinde verknotete. ${ }^{177}$ Die Performance weist eine gewisse formale Ähnlichkeit auf mit der Aktion „Ablutions“, die Judy Chicago mit drei weiteren Frauen - Suzanne Lacy, Sandra Orgel und Aviva Rahmani - 1972 aufführte. Hier wurde eine der Frauen zunächst an einen Stuhl gebunden und dann mit Seilen an alle anderen Dinge im Raum geknüpft. ${ }^{178}$
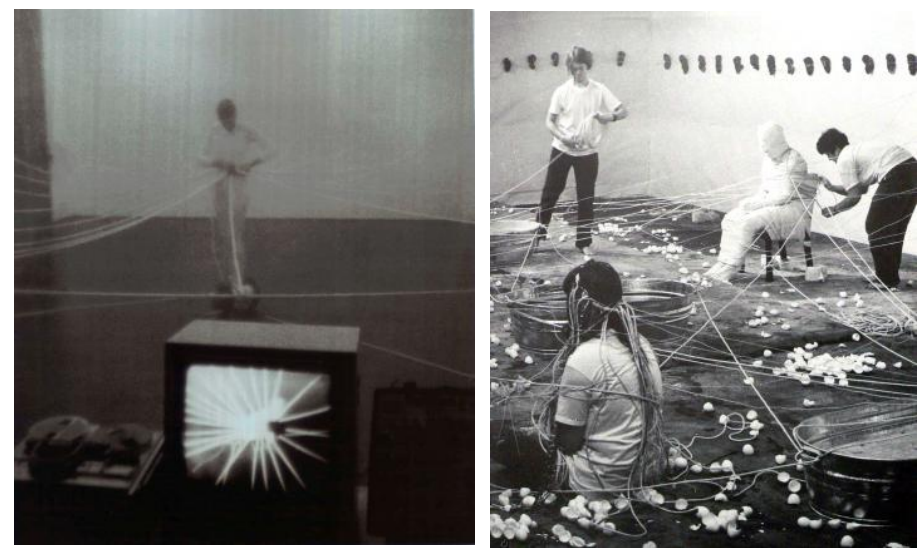

Abb. 34-35: Isolation is transparent, Aktionsfoto, 1974 und Judy Chicago und Suzanne Lacy: Ablutions, Aktionsfoto, 1972

In Ulrike Rosenbachs Aktion wurde die Handlung von einer an der Decke hängenden Kamera aufgenommen. Die Zuschauer in der anderen Raumhälfte konnten nun die Aktion einerseits direkt, jedoch verschwommen durch die milchige Folie beobachten, andererseits die klaren Bilder auf dem vor der Folie aufgestellten Monitor anschauen. Damit wurde durch den Einsatz der Technik in dieser Performance eine zweite Beobachtungsperspektive hinzugefügt: Der Blick von oben auf das Geschehen. Wenn beim Videokonzert die zweite Perspektive - das Bild auf dem Monitor - an das Geschehen heranzoomte, bot hier die Videoaufzeichnung einen Überblick über das System.

Interpretiert man die Folie als eine äußere Haut oder Membran, erlaubt die Videotechnik in diesem Stück einen klaren Blick ins Innere des geschlossenen Raumes oder Systemes, in dessen Mitte die Protagonistin verstrickt ist. Zu der ruhigen und stetigen Bewegung der Künstlerin im Raum hörte man einen unruhig vibrierenden Ton. ${ }^{179}$

177 In der ersten Aktion trug die Künstlerin einen schwarzen, netzartigen Body, womit die Aussage noch gedoppelt wurde, konnte man doch bis auf ihre Haut blicken. (zu „Hirngespinsten“ und „Verweigerung des männlichen Beobachterblickes“ (vgl. Glüher 2005, S. 24). In der zweiten Aufführung der Aktion trug sie dann einen neutraleren weißen Body.

178 Broud/Garrard 1994, S.168

179 Der Ton war von Konrad Schnitzler aufgenommen worden. 
„Es geht um das plastische Innen und Außen und die unterschiedlichen Standorte, die die verschiedenen Bilder sichtbar machen“, interpretierte die Künstlerin selbst ihr Anliegen. Doch lassen sich noch weitere Interpretationsansätze finden. Ist doch die Akteurin in dieser Performanceanordnung durch die Plane von den Zuschauern abgeschnitten beziehungsweise wird durch diese teilweise verdeckt. Das Sein im Inneren wird erst - vermittelt durch die Videotechnik - den Zuschauern sichtbar gemacht. So fasst in äußerst anschaulicher Sprache die Künstlerin in dieser Videoperformance ein Gefühl des Abgekapseltseins, des Verstricktseins in ein geschlossenes System in Bilder. Damit wendet sich die Künstlerin in dieser Performance einem neuen Thema zu, das latent in vielen ihrer weiteren Arbeiten mitschwingt: Geht es doch um mittels der Videotechnik vollzogene Artikulationen innerer Zustände, die explizit ins Bild gesetzt und auch zu Gehör gebracht werden.

Bei einer weiteren wichtigen Ausstellung moderner Kunst, die im Jahr 1974 in Köln ausgerichtet wurde, waren Ulrike Rosenbachs Werke ebenfalls vertreten. Aus Anlass eines Jubiläums der renommierten Sammlungen des WallrafRichartz Museums wurde von einem fünfköpfigen Team eine Ausstellung auf die Beine gestellt, deren Blick sich ausschließlich auf die noch ganz junge Kunst der 1970er Jahre konzentrierte ${ }^{180}$ : „Projekt $74^{“}$ wurde die Werkschau betitelt, an der 115 internationale Künstlerinnen und Künstler - zum Beispiel auch Vito Acconci und Willoughby Sharp - teilnahmen, und die aktuelle künstlerische Tendenzen herausarbeitete. Der Kunsthistoriker Wulf Herzogenrath wirkte an dem Projekt kuratorisch mit: ${ }^{181}$

„Ab Januar 1973 war ich im Kölnischen Kunstverein Direktor und es kam dieses „Projekt 74", die Ausstellung „Kunst bleibt Kunst" zum angeblich 150-jäbrigen Jubiläum des Wallraf-Richartz. Museums - das ja eigentlich gar nicht so alt ist. Es stand eine Menge Geld zur V erfügung für eine große, aktuelle Ausstellung. Diese war auch als Kampfausstellung zwischen den beiden Documenten 72 und 77 gedacht. Köln wollte zeigen, dass es viel besser sei. So war die Ausstellung als eine Art documenta gemeint. Da habe ich gesagt okay, find ich spannend - und als Kunstverein war ich ja sowieso mit dabei. Ich mache die große Videoabteilung, mit ein paar Installationen und mit einer großen Videobandabteilung. Eine solche gab es zum erstenmal überhaupt in einer Ausstellung in Deutschland. Außerdem gab es dort ein Arbeitsfeld, einen richtigen Workshop. Dafür hatte ich das Lijnbaanzentrum eingeladen aus Rotterdam. Sie kamen mit

180 Zum Team gehörten Evelyn Weiss (Kustos der Abteilung 20. Jahrhundert im Wallraf-Richartz Museum und Betreuerin der Sammlung Ludwig), Wulf Herzogenrath (Leiter des Kölnischen Kunstvereins), Horst Keller (Direktor des Wallraf-Richartz Museums), Manfred Schneckenburger (Direktor Kunsthalle Köln), Albert Schug (Direktor der Kunst- und Museumsbibliothek) und Dieter Ronte (Referent in der Generaldirektion der Museen der Stadt Köln) (Vgl. Kat. Köln 1974, S. 10)

181 Kat. Köln 1974, S. 8 
drei Mann und ibrer ganzen Technik, die sie damals schon besaßen, für zweieinhalb Monate nach Köln, um dort mit Künstlern Neues zu realisieren. Es waren hier Vito Acconci oder auch Hans Brelow aktiv, der davor noch nie etwas mit Video gemacht hatte und danach auch kaum wieder. Die Rotterdamer haben einfach etwas gemacht mit denen und dann erschienen auch ein paar Bänder, und da war Ulrike dabei, die natürlich vorher mit Konrad Schnitzler die Auftritte mit Video gemacht hatte. Bei „Projekt 74 “ war sie als Kölnerin dann zum ersten Mal auf einer internationalen Plattform. "182
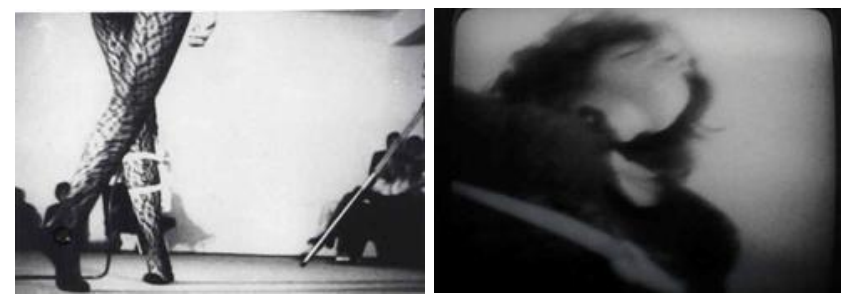

Abb. 36-37: Der innere Widerstand sind meine Füße, Aktionsfoto und Videostill, 1974

Ulrike Rosenbachs Videoperformance „Projekt Kinem“ wurde am 23. Juli 1974 im Rahmen des „Projektes 74“ im Kölner Kunstverein aufgeführt. Das Wort „Kinem“ ist vom griechischen ,kinein“ abgeleitet, was „bewegen“ bedeutet. Ein „Kinem“ beschreibt zudem die kleinste Einheit nicht verbaler Kommunikation, womit zum Beispiel ein Kopfnicken gemeint sein kann. Umberto Eco benennt in seiner Einführung in die Semiologie auch das Einzelbild im filmischen Fluss als „Kinem“. 183

In der von Musik begleiteten Live-Aktion befestigte Ulrike Rosenbach innerhalb eines kreisförmigen Environments, auf dessen äußerer Grenze sie sich bewegte, die Kamera an ihrem Körper, genauer an ihrem rechten Bein mit einem nach oben gerichteten Objektiv. Damit lotete sie in der Videoperformance, die

182 Interview Herzogenrath vom 4.3.2003; das Lijnbaancentrum hatte 1973 die erste Videoausstellung in Europa veranstaltet und war technisch auf einem aktuellen Stand. Bereits 1969 hatte in der Howard Wise Gallery in New York eine umfassende Schau zur damaligen Videokunst stattgefunden unter dem Titel „TV as a creative medium“.

183 Eco sieht das Filmbild als selbst nicht bedeutungstragendes Minimalelement (entsprechend des Lautes), das im Verlauf des Filmes zum „Kinemorphem“ mit zeitlicher Bedeutung - der Einstellung - integriert wird: „Ray Birdswhistell hat schon ein System der konventionellen Notierung der gestischen Notierungen entwickelt und unterscheidet Codes je nach den Zonen, in denen er seine Untersuchungen durchgeführt hat. Er hat sogar vorgeschlagen, das kleinste isolierbare und mit unterscheidendem Wert ausgestattete Bewegungsteilchen „Kinem“ (als Klasse aller möglichen Kine) zu nennen, und er hat durch Kommutationsproben die Existenz größerer semantischer Einheiten festgestellt, in denen die Kombination zweier oder mehrerer Kine eine Bedeutungseinheit veranlassen, die er Kinemorph nennt (dessen allgemeine Klasse das „Kinemorphem" darstellt)." (Eco 1991, S. 254f) 
den Untertitel trug „Der innere Widerstand sind meine Füße“, neben der Einbeziehung von Bewegung eine weitere Perspektive aus: den Blick von unten. ${ }^{184}$ Die Künstlerin selbst beschrieb die Aktion wie folgt:

„Im Mittelpunkt des Kreises, in dem bei der Sioux-Mandala der Lebensbaum stebt, ist die Videoapparatur auf ein Stativ montiert. Oben darauf steht in Augenhöhe ein kleiner Videomonitor. Durch einen Motorantrieb wird der Monitor ständig in Bewegung gehalten. Langsam dreht er sich vom Ostpunkt des Kreissegmentes zum Westpunk.t. Von der Mitte führt ein Videokabel zu einer kleinen Kamera, die an meinem rechten Bein unter dem Knie befestigt ist. Im Rhythmus eines schwingenden Musikstückes bewege ich mich auf der markierten Kreislinie. Ich gehe darauf hin und her, von Osten nach Westen und zurück für etwa eine ganze Stunde. Der schwingende Rhythmus der Töne überträgt sich auf meinen Gang, auf die Bewegung meiner Füße. Ich füble mich wie auf einer horizontalen Schaukel. Die Videokamera an meinem Bein nimmt meinen Körper von unten auf und überträgt das Bild auf den im Zentrum sich drehenden Monitor. Die Aufnahmen vermitteln einen Blick von unten, wie den der Erde, die die über sie Gehenden beobachtet." "185

Die am Körper befestigte und damit bewegte Kamera gibt Bilder aus einer ungewohnten Perspektive an den Monitor im Zentrum. Damit spielen auch in dieser Performance wieder zwei Ebenen zusammen: Der direkte Eindruck des Zuschauers der im Dreiviertelkreis Schreitenden. Das Bild der im Rhythmus schwingenden Akteurin wird ergänzt durch die elektronischen Aufnahmen, die an den im Zentrum stehenden Monitor übertragen werden, so dass beide Eindrücke gleichzeitig beim Betrachtenden ankommen.

Dabei findet sich auch in dieser Performance, wie bereits in der vorangegangenen „Naturkreisaktion“, ein Rückgriff auf rituelle Zeichen. Hier konkret eine Mandala der Sioux-Indianer, das die Künstlerin in modifizierter Form zitiert. ${ }^{186}$

184 Auch die österreichische Künstlerin Valie EXPORT befestigte in ihren Aktionen Kameras am eigenen Körper, wie zum Beispiel eine Super Acht Kamera in der Aktion „Adjungierte Dislokation“. Dadurch wurden die Künstlerin und das Filmbild „Mitwirkende im selben metafilmischen Prozess“. (Kat. Berlin 2003) Auch beschäftigte sie sich mit Körperhaltungen als Ausdruck innerer Zustände. (Neusüss 1979, S. 252-255) Im Rahmen des Projekt '74-Ausstellung zeigte sie die Performance „Raumsehen und Raumhören“. In dieser Aufführung geht es um das Erfahren und Erfassen von Raum durch Ton- und Körperbewegungen. (Vgl. Stoschek in: Frieling/Herzogenrath 2006, S. 140f)

185 Rosenbach 1982, S. 101

186 Das Wort Mandala kommt aus dem Sanskrit und bezeichnet in den indischen Religionen ein mystisches Kreis- oder Vieleckbild, das als Hilfsmittel zur Meditation eingesetzt wird. (Der Begriff findet sich auch für eine bildliche Darstellung als Symbol der Selbstfindung bei C.G. Jung.) Auch werden rituelle Darstellungen der Indianer so bezeichnet, die auch als Medizinräder bekannt sind. Die Medizinräder waren Kreise aus Steinen, die auf den Boden gelegt wurden und einen Durchmesser von bis zu 65 Metern hatten. Innerhalb dieses Kreises fanden sich verschiedenen, ebenfalls aus Steinen gelegte Symbole. Mithilfe eines solchen Kreises konnte einem Indianer das Wissen um seine Medizin zuteil werden. 
Wenn im Original das Mandala oder auch Medizinrad aus Steinen gebildet ist, malt die Künstlerin die Form auf den Boden. Anstelle des bei den Sioux symbolisch dargestellten Baum im Mittelpunkt des Medizinrades, steht in der Aktionsanordnung Rosenbachs dort der Videomonitor aufgebaut, um den die Künstlerin stetig die Richtung wechselnd wandert.

Einen Zugang gefunden zu den spirituellen Zeichen der amerikanischen Indianer hatte die Künstlerin über ihren Kontakt mit Lucy Lippard, die sich intensiv mit den Kulturen und Ritualen der amerikanischen Ureinwohner auseinandersetzte. In den Anschauungen der Sioux - fußend auf einem Verständnis vom Einssein des Menschen mit der Natur und dem Kosmos - haben alle Seinsprozesse eine zyklische Natur. Dieses zirkuläre Konzept ist in ihren Symbolen, wie dem Medizinrad, und Ritualen zu finden. Der Kreis entspricht ihrem Weg, die Harmonie des Lebens auszudrücken:

„Everything the Power of the World does is done in a circle. The sky is round and I have heard that the earth is round like a ball and so are all the stars. The wind, in its greatest power, whirls. Birds make their nests in circles, for theirs is the same religion as ours. The sun comes forth and goes down again in a circle. The moon does the same and both are round. Even the seasons form a great circle in their changing and always come back again to where they were. The life of a man is a circle from childhood to childhood. And so it is in everything where power moves. "87

Der Bezug auf ein archaisches Zeichensystem als Symbol des Natürlichen wird in der Aktion gekoppelt mit der Videotechnik, die die Bewegungen aufzeichnet, damit kontrolliert und beschränkt:

„Die Aktion bewegt sich in der Ambivalenz der Bedeutung der Sioux-Mandala als Lebensprinzip und des freibeitsraubenden Angebundenseins an einen technischen Apparat, der meinen Körper und mich dirigiert wie den Lauf der Tiere in einer Zirkusmanege. "188

Die Bereiche Natur und Kultur werden in diesem kommunikativen Akt, in dem das Bild verdoppelt und damit durch die Technik erweitert wird, zusammengeführt. Dabei hebt die Künstlerin den Aspekt des Gefangenseins, Gebundenseins an die Technik in ihrer Aussage hervor. Stellt man den Aspekt der Fesselung durch die Elektronik in den Mittelpunkt zeigt sich eine Nähe der Rolle der Akteurin zum Verknotetsein in der Aktion „Isolation is transparent“. Andererseits bietet die Videotechnik für die Künstlerin die Freiheit neue Sinneseindrücke zu gewinnen, neue Perspektiven zu erkunden.

187 Zitiert nach dem Ogalala Sioux Black Elk (1863-1950) unter http//:www.powersource.com/ cocinc/articles/wisdom.htm (5.1.2008)

188 Rosenbach 1982, S. 101 


\section{III.2. Die Kunstszene im Rheinland in den 1960er und frühen 1970er Jahren}

Die angerissenen Beispiele haben bereits gezeigt, dass die Städte Köln und Düsseldorf Ende der 60er und Anfang der 1970er Jahre ein buntes Pflaster waren für zeitgenössische künstlerische Aktivitäten. Neben den Metropolen New York und Los Angeles entwickelte sich Köln in dieser Zeit zu einem Zentrum der künstlerischen Avantgarde und wurde, wie Wulf Herzogenrath formulierte, in den 1970er Jahren zur Video-Stadt. ${ }^{189}$

Zahlreiche international anerkannte Künstler lebten in diesen Jahren in der Stadt am Rhein: Zum Beispiel waren der Musiker und Medienkünstler Nam June Paik oder auch der Happening-Künstler Wolf Vostell (1932-98) hier vorübergehend ansässig und künstlerisch tätig. ${ }^{190}$ Zudem hatte sich im Laufe der 1960er Jahre eine illustre Galerieszene entwickelt: ${ }^{191}$

„Die Galerie von Ingrid Oppenheim im Galeriehaus in der Lindenstraße war einer der unkonventionellsten Kölner Kunstorte jener Zeit. Hier gründete sie mit dem ,Oppenheim Studio" auch eine der weltweit ersten Videogalerien. " 192

Ingrid Oppenheim (1924-1986) stellte besonders junge deutsche Künstler aus der quirligen Köln-Düsseldorfer Szene aus, Pioniere einer gesellschaftskritischen und multimedialen Bildproduktion. Sie alle einte der Protest gegen das KunstEstablishment und den tradierten Kunstbegriff. Ulrike Rosenbach lernte die aufgeschlossene Galeristin 1973 kennen und fand in ihr eine engagierte Förderin. ${ }^{193}$

Daneben spielte in Köln der Westdeutsche Rundfunk (WDR), eine der größten Rundfunkstationen Europas mit Hauptsitz in der Stadt, mit seiner Aufgeschlossenheit gegenüber und Kooperation mit modernen musikalischen und auch

189 Herzogenrath 1994, S. 280; der Kunsthistoriker ging sogar so weit in einem Aufsatz zu titeln: „Die Geschichte der Videokunst begann in Köln“.

190 Anfang der 60er Jahre waren Paik und Vostell die ersten, die noch vor der New Yorker Avantgarde Fernsehen als künstlerisches Medium entdecken. Paik geht 1964 nach New York.

191 Stünke in: Heubach, 1986, S. 533; Neben Köln gab es auch in der nahegelegenen Hauptstadt Bonn ein reiches kulturelles Angebot mit mehreren Galerien, wie u.a. der Galerie Magers, die für Rosenbach wichtig war. In Wuppertal fand sich zudem auch die Galerie Parnass in der bereits 1963 die in Avantgardekreisen vielbeachtete Ausstellung „Exposition of Music - Electronic Television“ zu sehen gewesen war. Der Koreaner Nam June Paik zeigte hier erstmals manipulierte Fernsehgeräte als Kunstobjekte.

192 Siehe Ankündigung zur Ausstellung „Sich selbst bei Laune halten“ Kunst der 70er aus der Schenkung Ingrid Oppenheim. Ingrid Oppenheim gab 1980 ihre Sammlung von Künstlervideos an das Kunstmuseum Bonn.

193 Ingrid Oppenheim in: Rosenbach 1982, S. 127; Ausstellung von Rosenbach im Studio Oppenheim 1975 
bildnerischen Experimenten eine wichtige Rolle bei der Herausbildung und Förderung neuer Kunstströmungen. Wulf Herzogenrath urteilt im Rückblick:

„Keine der deutschen Städte hat es aber verstanden, Medien- und Kulturbereich miteinander zu verbinden. Das ist in den 60er Jabren nur dem WDR gelungen, der damals eine immense Anziehungskraft für avantgardistische Strömungen entwickelt hat. " "94

Köln bildete zudem in den 1960er Jahren einen Anlaufpunkt für den amerikanischen Modern Dance. Zahlreiche Kompanien aus Übersee gaben hier Gastspiele ihrer aktuellen Inszenierungen. Zudem war die Stadt bereits zu Beginn der 1960er Jahre international als Metropole der Fotografie anerkannt gewesen. ${ }^{195}$ Einen ganz wesentlichen Anziehungspunkt für die Kunstszene bot außerdem der jährlich stattfindende Kunstmarkt. Der erste dieser international besuchten Kunstmärkte wurde von Hein Stünke und dem Galeristen Rudolf Zwirner im Jahr 1967 ins Leben gerufen. Die Idee, die dem Kunstmarkt zugrunde lag, war eine Messe aktueller Kunst zu initiieren. Zahlreiche Galerien versammelten sich unter einem Dach versammelt, um gemeinsam die zeitgenössische Kunst zu präsentieren. Den ersten Kunstmarkt, der noch im Kölner Gürzenich stattfand, hielten 18 Galerieinhaber ab, im folgenden Jahr waren es schon 20 Teilnehmer. ${ }^{196}$ Von den ersten Märkten ging eine starke Belebung des Handels für die junge Kunst aus und so übernahm die Kölner Idee eine Vorbildfunktion. Andere Städte zogen nach, wie zum Beispiel Düsseldorf mit seinen „Prospect"“-Ausstellungen. Diese fanden ab 1968 statt, und kopierten das Prinzip des Kunstmarktes in leicht abgewandelter Form, um zeitgenössischen Künstlern ein öffentliches Forum für ihre Arbeiten zu bieten. Während bei der Kölner Kunstmesse der Schwerpunkt auf dem Verkauf der Kunstwerke lag, ergab sich in Düsseldorf eine Kunstausstellung modernster Kunst. Auf dem ersten „Prospect“ profilierten sich zum Beispiel 16 überwiegend internationale Galerien mit radikalen, zumeist nur schwer verkäuflichen Novitäten. ${ }^{197}$

Beide Kunstforen spielen in der Entwicklung der Künstlerin Ulrike Rosenbach eine wichtige Rolle, lernte sie doch - wie bereits oben erwähnt - auf der Prospect '71 die Videotechnik erstmals kennen. Auf dem im Herbst 1973 stattfindenden Kölner Kunstmarkt entdeckte Ulrike Rosenbach - wie beschrieben - ihre neue Arbeitsweise der Video-Live-Performance.

In Düsseldorf wurde die Kunstszene in den 60er Jahren maßgeblich durch die dort ansässige Kunstakademie geprägt. ${ }^{198}$ An der staatlichen Akademie war zu die-

194 Herzogenrath 1994, S. 280

195 Stünke in: Heubach 1986, S. 530

196 Spiegel 40, 1967, S. 158; Spiegel 43, 1968, S. 216

197 Vgl. Spiegel, Nr. 39, 1968, S. 181

198 Bereits Ende der 50er Jahre hatten hier die Künstler Heinz Mack, Günter Uecker und Otto Piene die „Zero-Gruppe“ gebildet. Mit ihren spektakulären Lichtaktionen, die international rezi- 
ser Zeit Joseph Beuys die schillerndste Figur. Auch war die Düsseldorfer Kunstszene durch Aktionen der Studenten geprägt, wie zum Beispiel die „LIDL Akademie“, die Anfang der 1970er Jahre von Studenten aus Protest gegen die beschränkenden Hochschulgesetze ins Leben gerufen wurde. Außerdem gab es ab 1967 das legendäre Creamcheese, in dem viele Künstler ein und ausgingen und auch verschiedene Kunstaktionen stattfanden. ${ }^{199}$

Außerdem eröffnete der WDR Redakteur Gerry Schum (1938-1973) 1969 in Zusammenarbeit mit dem öffentlichen Fernsehen in Düsseldorf seine Fernsehgalerie, mit der er versuchte avantgardistische Kunstformen (wie z.B. die Land Art) im Fernsehen der Öffentlichkeit zu präsentieren. ${ }^{200}$ Als dieser ehrgeizige Versuch scheiterte, funktionierte der ambitionierte Filmmann das Projekt 1971 zusammen mit seiner Lebensgefährtin Ursula Wevers in eine Videogalerie um. ${ }^{201}$ Ulrike Rosenbach war eine Weile Assistentin bei Schum, und hat in der intensiven Zusammenarbeit mit dem Medienmann wertvolle Kenntnisse über die Video- und Fernsehtechnik erworben.

Neben privaten Galerien und Kunstvereinen öffneten sich in den 1970er Jahren weitere öffentliche Institutionen der noch ganz jungen Videokunst. So zum Beispiel das Folkwang Museum in Essen, dessen damaliger Direktor Paul Vogt modernen Entwicklungen gegenüber sehr aufgeschlossen war. Wulf Herzogenrath, der in den Jahren 1971 und 1972 als Kunsthistoriker Mitarbeiter am dortigen Museum Folkwang war, erkannte das innovative Potenzial der neuen Kunstform und beschäftigte sich als einer der ersten Kunstwissenschaftler in Deutschland mit diesem neuen künstlerischen Medium. Dieses Interesse prägte dann auch seine Aktivitäten als Direktor des Kölnischen Kunstvereins (1973-1989), wo in den kommenden 1970er und 1980er Jahren wichtige Ausstellungen zur Videokunst stattfinden sollten.

piert wurden, opponierte das Trio gegen den ihrer Meinung nach abgeflachten Abstrakten Expressionismus. (Thomas 1986, S. 236)

199 So zeigten zum Beispiel Joseph Beuys und Anatol Herzfeld mit Ulrich Meister, Joachim Duckwitz und Johannes Stüttgen am 23. Januar 1969 die gemeinsame öffentliche 90-minütige Aktion: „Der Tisch“ im Düsseldorfer Creamcheese in Düsseldorf. (Vgl. Kirves 1986); vgl. auch Caianiello 2005

200 Gegründet worden war die Fernsehgalerie in Berlin bereits 1968.

201 Die umfangreiche Sammlung Schums wird nach seinem Tod 1973 bis heute von Ursula Wevers, Schums Witwe, betreut. Wevers gründete schließlich auch 1976 die „Zentrale Einrichtung für Film und Video" an der Düsseldorfer Kunstakademie und läutete damit als erste die Videoära an bundesdeutschen Kunsthochschulen ein.(Vgl. Herzogenrath 1982, S. 47-67 und S. 92) 


\section{III.3. Exkurs: Tanztheater}

Auch das Tanztheater lotete in diesen Jahren neue Ausdrucksformen aus. Kontakte ergaben sich hier für Ulrike Rosenbach zu amerikanischen Tänzerinnen wie Yvonne Rainer oder Trisha Brown. Aber auch das Tanztheater von Pina Bausch (*1940), die als bedeutendste europäische Modern Dance Choreographin gilt und die ab 1969 im Folkwangstudio in Essen inszenierte, bevor sie von Arno Wüstenhöfer nach Wuppertal engagiert wurde, war befruchtend für die Performancearbeit der Künstlerin. ${ }^{202}$ In der Tradition des Ausdruckstanzes revolutionierte die Choreographin aus dem Rheinland das moderne Tanztheater und zog mit ihren eigenwilligen Inszenierungen internationale Aufmerksamkeit auf sich. ${ }^{203}$ In ihren Gruppeninszenierungen reflektiert sie immer wieder Tanz und Bewegung kritisch und auf das Notwendige reduziert. Pina Bauschs Tanzstücke handeln von Menschen und ihren Lebensgeschichten. Es sind die Heimatlosigkeit des Menschen, seine Kommunikations- und Beziehungslosigkeit, die Einsamkeit oder auch der Kampf der Geschlechter, die sie in Szene setzt. Themen, mit denen sie in den 1970 er bis 1980er Jahren den Nerv der Zeit traf.

202 Gespräch 2001, Kap. VII.1.

203 Müller 1979, S. 24; Pina Bausch wurde von Kurt Jooss 1961 an das von ihm neu gegründete Folkwang-Ballett geholt. Nach Abschluss ihres Studiums 1959 in der Tanzabteilung der Folkwangschule unter Leitung des Choreographen hatte sie verschiedene Gastspiele und Stipendien in den USA wahrgenommen, bevor sie wieder nach Essen kam. Im Folkwang-Ballett arbeitete Pina Bausch intensiv mit dem Choreographen und Tänzer Jean Cébron zusammen und seit 1967 schuf sie dort eigene Choreographien. In den Jahren 1969 bis 1973 war sie künstlerische Leiterin des Folkwang-Tanzstudios sowie Dozentin an der Folkwanghochschule. Ab 1973 leitet die Choreographin das Wuppertaler Tanztheater. Neben ihrer Tätigkeit als Tänzerin, Choreographin und Pädagogin in Deutschland wurde sie zu zahlreichen Gastengagements im Ausland eingeladen. (Vgl. Schlicher 1987, S. 267) 


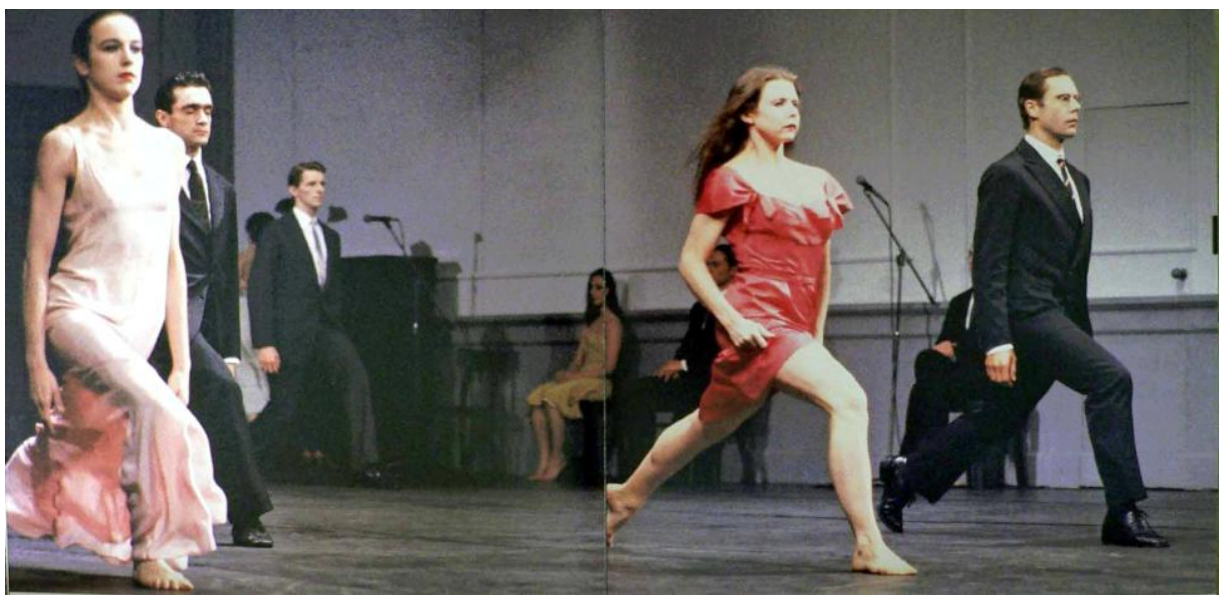

Abb. 38: Szenenfoto aus „Kontakthof" von Pina Bausch

Für die revolutionäre Tänzerin ist Tanzen alles, was Menschen mit Körper, Gestik und Stimme ausdrücken. „Wo fängt Tanz an?“ ist die Frage, die sie in ihren Choreographien auf der Schwelle zwischen Schauspiel und Tanztheater immer wieder stellt. „Was die Menschen bewegt, weniger wie Menschen sich bewegen“ kennzeichnet Pina Bauschs Haltung zu dieser Frage in ihrer Arbeit. Und so wachsen ihre Stücke, in denen die Choreographin mehrere Dimensionen parallel erkundet, auch nicht von vorn nach hinten, sondern von innen nach außen und das Fragmentarische durchdringt im Laufe der Zeit alle Ebenen. ${ }^{204}$ Die dadurch entstehenden Brüche innerhalb der Dynamik der Stücke werden bewusst forciert. Kompromisslos und offen eingesetzt, dienen sie zur Vermittlung von Inhalten und zur Darstellung ihres Tanz- und Körperverständnisses.

Die Stücke der Choreographin entwickeln eine poetisch zeitlose Dimension, indem es ihr gelingt, die oft biografisch gefärbten Improvisationsangebote ihrer Tänzer in großer Form zu organisieren und über das primär Private zu einer künstlerischen Darstellung zu stilisieren. In den Gruppeninszenierungen ihres körperbezogenen Tanztheaters, berücksichtigt Pina Bausch die kompositorischen Faktoren des Tanzes: Energie, Form, Raum, Rhythmus, deren Polyphonie sie beherrscht. So schafft sie eine Ausgewogenheit zwischen Freiheit und Disziplin in der Arbeit ihrer Tänzer. Dabei strebt ihr Schaffen zu Genauigkeit und Einfachheit. Die Bewegungen konzentrieren sich dabei auf einzelne Körperteile. Diese vollziehen unabhängig voneinander ihre Bewegungen und so bleibt das Bild eines zerstörten Körpers mit dem Willen zur Aktion. Viele Handlungen der Tänzer spielen zudem mit Tabus, mit intimen Bewegungen, die nicht schicklich sind. ${ }^{205}$ In

204 Schlicher 1987, S. 116-118
205 Schlicher 1987, S. $145-150$ 
dieser Form weist die Bewegungssprache der Choreographin auf einen körpergeschichtlichen Kontext: auf die Bedingungen, mit denen Bewegungen gewachsen sind, auf ihre gesellschaftliche, zivilisationsgeschichtliche wie individuelle Herkunft und Funktion. Ihr bekanntes Stück „Kontakthof“ wurde am 9. Dezember 1978 an den Wuppertaler Bühnen uraufgeführt:
„Das Einüben von Normen, deren Inhaltsleere, die Verbinderungen zwischenmensch- licher Kommunikation konzentrieren sich vor allem in den frühen Stücken auf das Ver- bältnis von Mann und Frau. (...) Den Umgang der Partner, auch der Tanzpartner auf der Bühne, zeigt sie als von brutalen und auch rücksichtslosen Gesten bestimmt, als ein sich ständiges gegenseitiges Verletzen als einen existentiellen Kampf ums Überleben der Reste an Liebe und Zärtlichkeit, die jeder noch besitzt. Die Suche nach Geborgenheit und gegenseitigem Halt verunglückt mit derselben Konstanz, mit der sie immer wieder unternommen wird. Streichelnde Hände fassen ins Leere, die Umarmung rutscht am Partner ab, Kontaktangebote oder-aufforderungen werden entweder nicht beachtet oder erweisen sich als Scheinangebote, die im Ernstfall ängstlich wieder zurückgenommen wer- den. Die Forderungen und Angebote werden dabei oft mit gleichbleibender Rigidität ab- gewiesen, beim ersten wie beim zehnten Mal einer Annäherung. "206

Pina Bausch fängt in dem Stück alltägliche Situationen in einprägsamen Bildern ein, enttarnt Gefühlszustände in Haltungen, Gesten und Worten. Sie nimmt Begriffe aus unserer Alltagssprache wörtlich, setzt diese in Körperbilder um. Der Choreographin geht es darum Gesamthaltungen - Körperhaltungen und Körperverhalten - zu begreifen, sowie deren gesellschaftliche Relevanz und Bedingtheit zu hinterfragen. Das Misstrauen allem Fest-Stehendem und Gesichertem gegenüber lässt Pina Bausch die Vorgänge in ihren Stücken so lange wiederholen, bis das Nicht-Stimmige auffällt. Und an die Stelle der quasi unfreiwilligen Abbildung tritt die bewusste Ausstellung, die Sichtbarmachung körperbezogener Zwänge und Selbstzwänge. ${ }^{207}$ Die bespielten Theaterräume und Bühnen werden in den Stücken zu vielschichtigen Landschaften:
„Die Räume zu Pina Bauschs Stücken sind begebbar in dem Sinne, dass man das eige- ne Leben nochmals durchschreiten kann. Sie sind dramatisch, obne dass noch ein Drama in ibnen stattände. Verblieben sind in ibnen einzig die Frage nach dem Leben und den Lebenden." 208

Damit sind die Tanzversuche auch Selbsterkundungen, ohne dass sie - wie im vorangegangenen deutschen Ausdruckstanz - zu einer narzisstischen Konzentration auf das Ich führen. Das Außersichsein und das Überschreiten des eigenen Mikrokosmos, ohne die eigene Identität aufzugeben, vermitteln sich in den Stücken Pina

\footnotetext{
206 Schlicher 1987, S. 125

207 Schlicher 1987, S. 129 und 150

208 Schlicher 1987, S. 139
} 
Bauschs' als Enderfahrungen auf dem Weg zu einem neuen Tanz- und Körperverständnis. Die individuelle Selbstfindung verliert ihre geschlechtsspezifische Orientierung und die Emanzipation wird schließlich zum gemeinsamen Anliegen aller. ${ }^{209}$ Die Deutung ihrer Stücke überlässt die Meisterin der Desillusion und Demaskierung dem Zuschauer, seiner Sicht- und Erfahrungsweise:

„Ich habe noch nie gemeint: so ist das. Ich habe mir oft was ganz anderes gedacht, was ganz anderes gemeint, aber auch nicht nur das. Das ist einfach die Art und Weise, wie man reinguck.t. Aber das einseitige Denken, das man da reininterpretiert, das stimmt nicht." 210

Auch wenn ein direkter Vergleich zwischen den Performances Rosenbachs und den Choreographien Bauschs an dieser Stelle nicht möglich ist, fällt doch die Arbeit mit Wiederholungen bei beiden auf, wie auch die Reduzierung auf minimale Bewegungsabläufe. Zudem finden sich bei den beiden Künstlerinnen Parallelen zum Beispiel in der Auffassung von Körperlichkeit und dem Ausdruck von Emotionen, was im Folgenden noch deutlicher werden wird. 


\section{III.4. Berührungspunkt USA}

\section{III.4.1. Madonnenamazone}

Bei der 9. Biennale des Jeunes in Paris, die im Oktober 1975 im Musée d'Art Moderne stattfand, war auch Ulrike Rosenbach vertreten. Die Pariser Biennale bot damals jungen Künstlerinnen und Künstlern ein Forum für ihre Werke. Neben Rosenbach waren als deutsche Kollegen auf dieser internationalen Schau auch Rebecca Horn, Barbara und Michael Leisgen und Anna Oppermann mit Arbeiten vertreten. ${ }^{211}$ Damit fanden sich verhältnismäßig viele Vertreterinnen aus der Bundesrepublik bei der Ausstellung und zeitgenössische Berichterstatter wiesen insgesamt auf den „Vormarsch der Frauen“ bei dieser Veranstaltung hin, war der Anteil von rund 20 Prozent Künstlerinnen doch höher als in den Jahren zuvor. ${ }^{212}$

Ulrike Rosenbach zeigte zur Biennale-Eröffnung als Uraufführung ihre Videoperformance „Glauben sie nicht, dass ich eine Amazone bin", mit der sie deutlich Position als feministische Künstlerin bezog und auch überregional Aufmerksamkeit erregte. ${ }^{213}$ Der Verlauf der rund zehnminütigen Videoperformance lässt sich wie folgt beschreiben: Ein Pfeil trifft zischend auf die Darstellung der „Madonna im Rosenhag“" des Malers Stefan Lochner (1400-1451). Die Reproduktion des mittelalterlichen Gemäldes ist auf eine runde Zielscheibe geklebt. ${ }^{214}$ Der Pfeil bohrt sich in das unnahbar schöne, demütige Marienbildnis. Ein zweiter folgt, darauf ein dritter. Insgesamt fünfzehn Pfeile treffen in kurzer Folge auf das Bild. Abgeschossen werden die Pfeile von einer jungen Frau im eng anliegenden weißen Trikotanzug, die einen großen Bogen führt. Ernst und konzentriert blickt die Künstlerin auf die große Scheibe mit der Frauendarstellung, zielt mit den Pfeilen aber nur auf das Madonnengesicht, nicht auf den Körper der Madonna.

211 Puvogel in: Aachener Volkszeitung, 18.10 .1975

212 Ein Ziel der amerikanischen Frauenbewegung um die Kritikerin Lucy Lippard war es den Frauenanteil bei Kunstausstellungen zu erhöhen und für Künstlerinnen öffentliche Foren zu schaffen. So waren zum Beispiel 98 der insgesamt 123 Teilnehmer dieser Biennale Künstler. (Spiegel 40/1975, S. 201)

213 Diese Arbeit bildet bis heute ein Kernstück feministischer Kunst und findet sich in zahllosen Sammelwerken kommentiert.

214 Stefan Lochner malte 1451 das Original, das sich im Wallraf-Richartz-Museum in Köln befindet. In der Performance wurde eine Reproduktion in der Größe des Originals beschossen. 

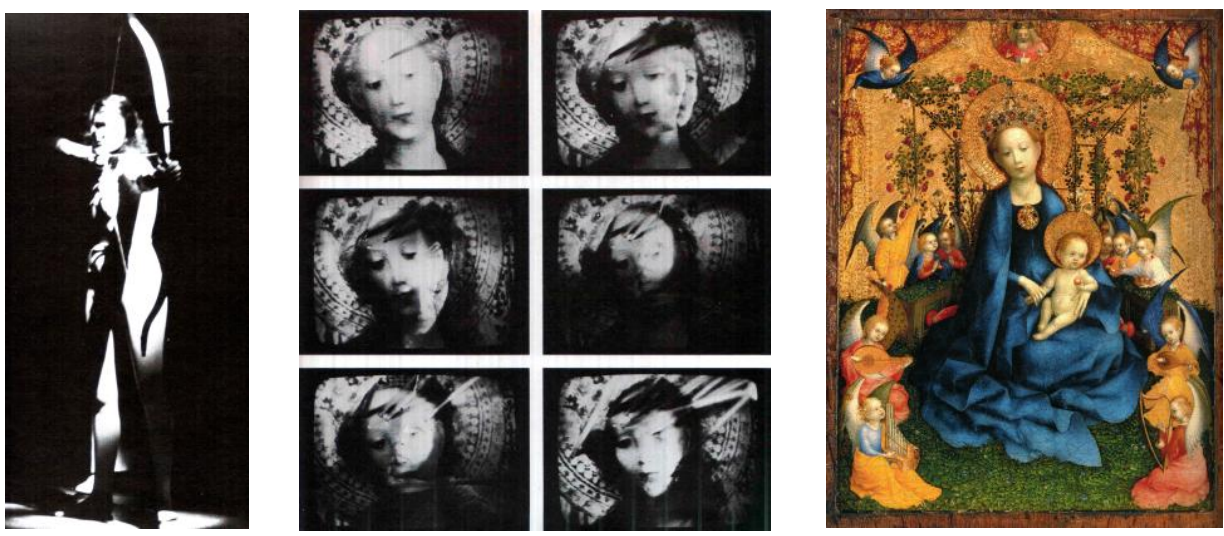

Abb. 39-46: Glauben Sie nicht daß ich eine Amazone bin, 1975, Aktionsfoto, 6 Videostills und Stephan Lochner, Madonna im Rosenhag, um 1450

Währenddessen wird die Aktion aus zwei verschiedenen Perspektiven auf Video aufgezeichnet und auf einem bereitgestellten Monitor werden das Gesicht der Künstlerin und das Antlitz der Madonna live überblendet. Auf diese Weise treffen die Pfeile im elektronischen nicht nur die Reproduktion der Mariendarstellung, sondern auch das hineinprojizierte Abbild der Künstlerin selbst. ${ }^{215}$

In einer kraftvollen Bildsprache nutzte Ulrike Rosenbach die zwei entgegengesetzten Sinnbilder der demütigen Madonna, die als schwach, selbst aufopfernd, mütterlich, zärtlich, sorgend und verständnisvoll charakterisiert ist, und der kämpferischen Amazone, der die Eigenschaften der Aggressivität, der Stärke und des Selbstbewusstseins zugeschrieben werden, um ihre Aussage prägnant zu transportieren. ${ }^{216}$ Die Aktion, bei der die Künstlerin konkret - und in der symbolischen

215 Ulrike Rosenbach wählt aus der Fülle der Madonnendarstellungen eine „Madonna im Rosenhag" für ihre Aktion. In ihrem eigenen Namen, wie auch in dem des historischen Frauenbildes kommt die Rose vor. Zudem ist es ein Werk eines rheinischen Künstlers, auf das sie sich in dieser Aktion bezieht. Mit dieser Wahl scheint wiederum eine Bezogenheit auf die eigene Identiät verknüpft zu sein.

216 „Ulrike Rosenbach hat sich in vielen ihrer Arbeiten damit beschäftigt, wie Frauen darum kämpfen, ein Bild von sich selbst zu entwerfen - mit den Worten von Virginia Woolf gesprochen „ein Zimmer für sich allein“ zu haben; Don't believe I’m an Amazon (1975) halte ich jedoch für ihr in dieser Hinsicht eloquentestes Werk. Darin konfrontierte Rosenbach zwei stereotype Darstellungsformen der Frau: die reine Mutter /Madonna und die kriegerische, maskuline (sprich lesbische) Amazone. Die Künstlerin schoss mit Pfeilen auf eine Zielscheibe, die mit einer Schwarzweißreproduktion von Stephan Lochners berühmten Gemälde Madonna mit Kind bezogen war. Gleichzeitig wurde Rosenbachs Aktion mit einer Videokamera durch ein viereckiges Loch in der Mitte der Zielscheibe gefilmt. In einem späteren Video der Performance „,wird das Bild der Pfeile schießenden Rosenbach über das Bild der Madonna projeziert". (Stiles in: Kat. LA 1998, S. 260) (mehr dazu bei Lupri in: Kat. Toronto 1989, S. 15) Unter einem anderne Tenor interpretiert Karin Thomas das Werk: „Feministische Therapeutik-Übung durch Kunstpraxis, die sich 
Übertragung - auf traditionelle Frauenbilder schoss - hier vertreten durch das Madonnenbild und die Amazone - war Rosenbach nach eigenen Worten ein „wahres Bedürfnis“..217 Zeitzeugen charakterisierten die Eindringlichkeit und das provozierende Potenzial dieser Aktion. Zum Beispiel beschrieb Renate Puvogel die Performance als „schauerliches Ritual“, bei dem Ulrike Rosenbach Lochners „Rosenhagmadonna“" mit Pfeilen treffe, die wie Stigmata schmerzten. ${ }^{218}$

In ihrer Eindringlichkeit und Aggressivität ruft die Aktion deutliche Assoziationen wach zu den „Tir à volonté-Bildern“ der französischen Künstlerin Niki de St. Phalle (*1930). Diese Bilder waren zunächst Reliefs aus Gips, unter deren Oberfläche Farbe verborgen war, die sich nach dem Beschuss mit einem Gewehr durch die Künstlerin frei über das Werk ergoss. Diese inszenierten Angriffe der französischen Künstlerin auf die eigenen Bilder, waren aber nicht nur destruktiv, sondern sie schufen etwas Neues und bildeten für die Künstlerin auch einen therapeutischen Akt der Selbstbefreiung. Niki de St. Phalles Schießbilder sind damit Zeugnisse von Zorn und psychischem Aufruhr, aber auch Bilder vom Überleben der Frau. Am 30. Juni 1961 hatte die Künstlerin in Pierre Restanys Pariser Galerie J. ihre Schießbilder zum ersten Mal der Öffentlichkeit präsentiert und erinnert sich im Rückblick an diese Aktion:
„Ich schoß, weil es mir Spaß machte und mir ein tolles Gefühl gab. Ich schoß, weil mich die Beobachtung faszinierte, wie das Gemälde blutet und stirbt. Ich schoß um dieses ma- gischen Momentes willen. Es war der Moment skorpionischer Wabrbeit. Weiße Rein- heit. Opfer. Schußbereit! Zielen! Feuer! Rot, gelb, blau - das Gemälde weint, das Ge- mälde ist tot. Ich habe das Gemälde getötet. Es ist wiedergeboren. Krieg obne Opfer. "219

\footnotetext{
beispielhaft in der weltweit berühmt gewordenen Installation von Judy Chicago, Dinner Party (1974-79) niederschlug, verband sich im multikulturellen Klima New Yorks mit der sich neu formierenden, den Geschlechterunterschied relativierenden Gender-Theorie, wonach die Mehrzahl der geschlechtlichen Differenzkriterien von Mann und Frau soziokulturelle Produktionen von patriarchalischen Gesellschaftsstrukturen und keineswegs vorgegebene Eigenschaften der Person sind. In ihrem Video Glauben Sie nicht, daß ich eine Amazone bin (1975) verarbeitet Ulrike Rosenbach bereits derartige Erkenntnisse, indem sie die männlich erzeugten Klischeeantagonismen des sanften und aggressiven Weiblichen an der Überblendung zweier Typenbilder, der Madonna und der kampfbereiten Amazone, historisch und psychoanalytisch begründet.“ (Thomas 2002, S. 258f)

217 „Darauf zu schießen, war mir ein wahres Bedürfnis, weil ich mich persönlich von der Erziehung zum Madonnentypus sehr betroffen fühlte.“ (Rosenbach im Gespräch mit Amine Haase in: Rosenbach 1982, S. 132)

218 Puvogel in: Aachener Volkszeitung, 18.10.1975

219 Niki de Saint Phalle in: Schulz-Hoffmann 1987, S. 53
} 


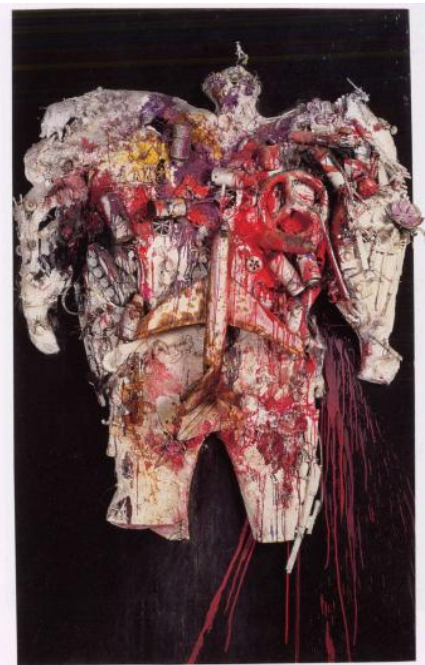

Abb. 47: Niki de Saint Phalle: Der Tod des Patriarchen, 1962

An diese Form eines künstlerischen Befreiungsschlages knüpft Ulrike Rosenbach mit ihrer Amazonenperformance an, doch mit einer anderen Zielsetzung. Die Künstlerin plädiert in ihrer Aktion für ein neues Weiblichkeitsverständnis, das keine Klischeebildung zulasse und in dem das, was traditionell als gegensätzlich angesehen werde, zusammenfließen und in einem Individuum vereinigt werden könne. ${ }^{220}$ Dieser Aspekt des harmonisierenden Verschmelzens von Gegensätzlichem wird in diesem Werk Ulrike Rosenbachs erstmals greifbar, wird sich dann wie ein roter Faden durch die weiteren Werke der Künstlerin ziehen.

\section{III.4.2. Exkurs: Destruktive Tendenzen in der Kunst}

Das Phänomen der Zerstörung ist ein zentrales Thema in der Kunst ab den 1960er Jahren. Gerade die New Yorker Kunstszene war in diesem Jahrzehnt geprägt durch anarchistische Ausdrucksformen aufgeladen mit Gewalt und Sexualität. Aber auch andernorts richteten sich Kunstschaffende in destruktiven Prozessen symbolisch gegen eine Zivilisation, in der Waren und Maschinen Vorrang vor den lebendigen Bedürfnissen des Menschen genossen. So zertrümmerte zum Beispiel der deutsche Künstler Wolf Vostell in schrillen Decollage-Aktionen Fernsehgeräte. Manche der Aktionen von Joseph Beuys oder Vito Acconcis richteten sich in autoaggressiver Handlung gegen deren eigenen Körper. ${ }^{221}$ Und manche Künstler gingen in den 1970ern so weit, dass sie begannen ihre eigenen Körper wirklich zu verletzen. Der kalifornische Künstler Chris Burden (*1946) schoss sich

\footnotetext{
220 Rosenbach 1982, S. 5

221 Zell 2000, S. 43-47
} 
zum Beispiel 1971 selbst in den Arm und erklärte diese Aktion und ihr Ergebnis zum Kunstwerk.

Besonders Frauen haben ihren eigenen Körper in Kunstaktionen verletzt oder verletzen lassen. Hier sind es häufig Frauen, die sich mit kompromissloser Radikalität in ihren Arbeiten konkret Schmerz zufügen, um einem im Inneren verkapselten Leid einen äußeren Ausdruck zu verleihen. Dies Leid ist ein persönliches Leid, doch auch ein gesellschaftliches, resultiert aus den gesellschaftlichen Verhältnissen. Denn wenn ein Geschlecht in einer Gesellschaft unterdrückt wird, führt dies bei diesem zu psychischen Beschädigungen, wie Luise Eichenbaum darlegt:

\begin{abstract}
„Die zweitklassige Stellung der Frau in der patriarchalen Gesellschaft/Kultur spiegelt sich schmerzlich in ihrer Psyche. Frauen fühlen sich nicht ganz. Sie haben kein Selbstvertranen. Sie fühlen sich nicht gleichberechtigt, sie fühlen sich wie Kinder, nicht wie Erwachsene, sie fühlen sich machtlos, übermäßig abbängig, passiv. "222
\end{abstract}

222 Eichenbaum 1984, S. 130-136; Nach Ansicht der Autorinnen gehen aus ihrem in den 1980er Jahren entwickelten Modell der psychischen Entwicklung der Frau zwei Merkmale hervor, die auf die Depression bei Frauen ein Licht werfen. Erstens sei dies der Verlust des Selbst, der in früher Kindheit eintrete, wenn das innere ,kleine Mädchen' abgespalten und versteckt werde. Damit sei die Depression eine Art Trauer um das verlorene Mädchen. Das zweite Merkmal sehen die Autorinnen in der Unfähigkeit, eine Beziehung zu erwarten, in der die Frau das Gefühl habe gesehen, akzeptiert und geliebt zu werden. Die depressive Frau habe das Gefühl in einer düsteren, eindimensionalen Existenz zu überleben. Sie habe einen Teil ihres Selbst verloren, und das Gefühl, die Menschen seien noch weiter weg als vorher und sie fühle sich gelähmt und ohnmächtig, dass sie es nicht ändern könne. (Vgl. Eichenbaum 1984 S. 139-141) Die psychischen Beschädigungen sind demnach vielfältig und können sich ganz unterschiedlich äußern: Frauen könnten sich vom eigenen Körper distanziert fühlen, wie auch unverstanden mit ihren emotionalen Bedürfnissen füjhlen, ein Mangel an psychischer Eigenständigkeit könne sich zeigen, das Fehlen von Grenzen, die ein sicheres Selbstgefühl ausschlössen. Negative Gefühle und der erlittene Mangel könnten in Schuldgefühle und Depression verwandelt werden. Dabei fungiere das Schuldgefühl eine Kette, die einen an den anderen binde, weil Getrenntsein unmöglich sei. All diese Gefühle bliében jedoch unter der Oberfläche verborgen, so dass Frauen in einer Innenwelt gefangen sein könnten, in der das Sehnen nach Zuwendung und Annahme, Liebe und Selbstständigkeit, einsperrt bleibe. (Vgl. Eichenbaum 1984, S. 162f) 

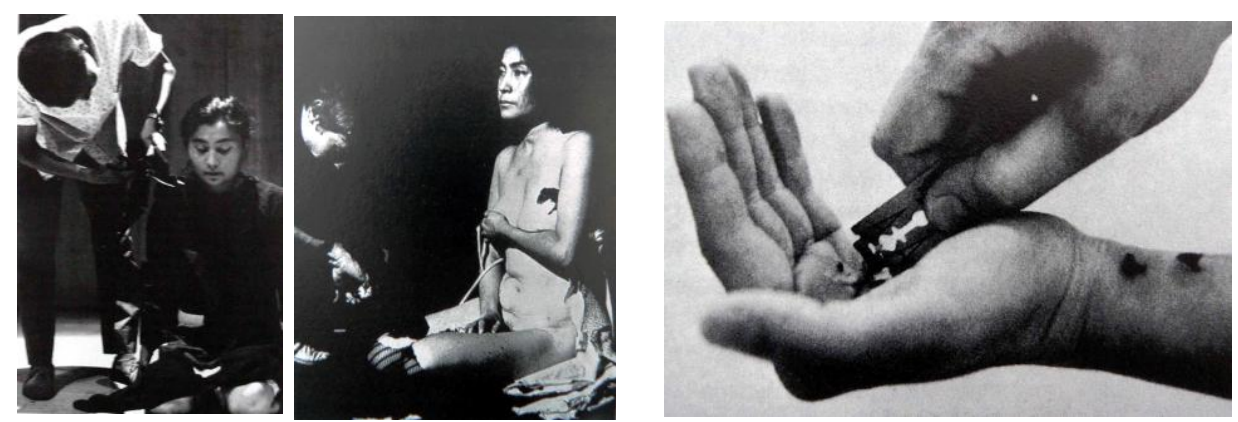

Abb. 48-50: Yoko Ono: Cut Piece, 1964, 2 Aktionsfotos, und Gina Pane, 1973, Autoportrait(s), Aktionsfoto

Wenn die amerikanische Künstlerin Yoko Ono (*1933) sich 1964 in Kioto bei ihrem „Cut Piece“ dem Publikum auslieferte, das nach Belieben Teile von ihrer Kleidung und ihren Haaren abschneiden durfte, ist Destruktion hier ein Mittel zur Thematisierung von Weiblichkeit, Verletzlichkeit und Sexualität.223

Die Künstlerin Gina Pane inszenierte ab Anfang der 1970er Jahre regelrechte Selbstverletzungen. Sie erklomm zum Beispiel 1971 eine mit Nägeln gespickte Leiter, um gegen eine Welt zu protestieren, in der alles betäubt ist. Diese Aktion ist als ein verzweifelter Versuch zu verstehen, etwas zu fühlen, nur nicht das Leiden selbst. Der innere physische und psychischen Schmerz kann dabei so stark sein, dass er ausgeschlossen werden muss, dissoziiert oder aufgeschoben, nur um abgetrennt und dann wieder neu erlebt zu werden. ${ }^{224}$ Und durch diese autoaggressiven Akte wollte sie ein kathartisches Element im Publikum erzeugen ${ }^{225}$, während die jugoslawische Künstlerin Marina Abramovic (*1946), wenn sie sich vor dem Publikum verletzt - wie diese selbst sagte - ein Gefühl der totalen Freiheit erlebe. Im Werk der Jugoslawin findet sich eine Fülle von Performances, in denen diese ihren Körper verletzt oder extrem belastet. Mehrere ihrer Kunstaktionen mussten sogar abgebrochen werden, weil sich die Künstlerin in lebensbedrohlichen Situationen befand. Abramovics Performances zeichnen sich aus durch ein Ausloten, Bestimmen und Überschreiten der physischen Grenzen des Körpers mit dem Ziel eine neue spirituelle Ebene zu erreichen. Häufig wird der Körper bei ihr durch unterschiedliche Rituale an Grenzen gebracht, um diesen geistigen Sprung vollziehen zu können. ${ }^{226}$

Weniger lebensbedrohlich, doch auch mit großer Radikalität, bediente sich die österreichische Künstlerin Valie EXPORT (*1940) ihres Körpers, um Wirklichkeit und Wahrnehmung zu analysieren, das Widersprüchliche und Mehrdeutige erfahr-

\footnotetext{
223 Zell 2000, S. 46

224 Stiles in: Kat. Los Angeles 1998, S. 261-263

225 Zell 2000, S. 48

226 Zell 2000, S. 49f
} 
bar zu machen. ${ }^{227}$ Dabei fungierte in ihren Aktionen, bei denen sie sich zum Teil selber Schnittwunden oder Stiche zufügte, der bei den Messerschnitten oder Stichen zugefügte Schmerz - als etwas nicht Kommunizierbares, das nicht zu leugnen ist aber auch nicht zu beweisen 228 - als Form der Mitteilung. Valie EXPORT machte auf anschauliche Weise in ihren Aktionen der 1970er Jahre den Schmerz sichtbar, der als Folge der Geschlechterdifferenz eintritt. Stiles kommentiert zu all diesen Selbstverletzungen oder Autoaggressionen im Rahmen künstlerischer Aktionen von Frauen:

„Imaginäre und echte Wunden - verbunden (wie in Onos Conversation Piece) oder blutend (wie in den vielen masochistischen Arbeiten Gina Panes) - sind Ausdruck echten Psycho-physischen Schmerzes. Diese Aktionen erzählen vom Leiden, verleiben ibm Gestalt. Sie beschreiben den unsäglichen Zustand, in dem sich das Innenleben einer Frau befinden kann. In dem sie diese psychisch zerstörenden Verletzungen zum Ausdruck bringen, verschaffen sich die Künstlerinnen eine Stimme, durch die sie wieder ein konkretes Gefübl von persönlicher Erfahrung und Selbstintegrität äußern und erleben können. Noch dringlicher ist jedoch das Bedürfnis, anderen ihre innere Realität mitzuteilen - sie zu materialisieren. Schmerz, und Trauma brauchen Zeugen, die an der identitätsspaltenden weiblichen Erfahrung von Vergewaltigung und Zerstörung durch das Patriarchat teilhaben. In solchen Performances liefern die Körper der Frauen dem Betrachter Beweismaterial. Feministische Performance-Künstlerinnen haben körperliche Darstellungen der mannigfaltigen Widersprüche jener Unterdrückung und jenes Leids geschaffen, die es bedeutet, eine Frau im Reich des Patriarchats zu sein, und dabei eine visuelle Sprache entwickelt, die quer durch die politische Bewegung des Feminismus zu sehen und zu bören ist und bis heute fortbesteht." "229

Zusammenfassend lässt sich sagen, dass, weil autoaggressive Verletzung Ausdruck eines bereits erlittenen Leids ist, diese anderen schon erlebten Schmerz visualisiert und sich diese autoaggressive Handlung als eigenständige Form der Mitteilung entziffern lässt. ${ }^{230}$ Oder wie Valie EXPORT formulierte, kann die autoaggressive Handlung die Bedeutung einer „Sprache des Schmerzes“ erlangen. Im Kontext künstlerischer Aktionen bringt die Selbstverletzung dabei in erster Linie das durch (seelische) Verletzungen geprägte Beziehungsgeflecht des Individuums in der Gesellschaft zur Darstellung.

227 Der Name Valie EXPORT ist ein Künstlername, und ist nach Aussagen der Künstlerin als Ausdruck einer soziopolitischen Bewusstheit zu verstehen. Geht es ihr doch darum, mittels ihrer Kunst etwas aus sich herauszuführen.

228 Zell legt dar, dass Schmerz zu haben, das plausibelste Indiz dafür sei, was es heiße „Gewissheit zu haben“. Andererseits sei für andere die Schmerzerfahrung schwer fassbar, so dass von Schmerzen zu hören als Paradebeispiel für Zweifel gelten könne. (Zell 2000, S. 49f)

229 Stiles in: Kat. Los Angeles 1998, S. 271

230 Zell 2000, S. 53-59 
Auch wenn in Rosenbachs Werken der Körper der Künstlerin in der Realität unverletzt bleibt, lediglich im virtuellen, elektronisch erzeugten Bild im Inneren eines Monitores die Pfeile die überblendeten Gesichter treffen, lässt sich ihre Aktionen in diesem Kontext doch auch als Darstellung einer Selbstverletzung lesen, als Schmerz- und Wutausdruck verletzter weiblicher Identitäten lesen.

\section{III.4.3. Begegnungen mit amerikanischen Künstlern}

Edward Lucie-Smith hebt als wichtigste Errungenschaft der Kunst der 1960er Jahre nicht die Pop Art, sondern die grundsätzliche Untersuchung der Eigenschaften und Möglichkeiten im Bereich der Skulptur hervor. ${ }^{231}$ Die mannigfaltigen künstlerischen Experimente sprengten Grenzen: Sie reichten von dem Ineinanderdiffundieren der unterschiedlichen Kunstgattungen, über die Ausweitung des Skulpturalen/ Plastischen zu räumlichen Environments, bis zur Idee der „Sozialen Plastik“ bei Beuys. In Zusammenhang mit dieser sehr produktiven Erweiterung des Kunstbegriffes bildeten sich unterschiedliche neue Kunstformen heraus. So zum Beispiel die konzeptuelle Kunst, „die weniger bildliche Anschauung sein will als vielmehr Vergegenwärtigung methodischer Übung im Anschluß an philosophische, technologische und soziokulturelle Erkenntnisse“"232. Daneben betont die sich ebenfalls in den späten 1960ern entwickelnde so genannte Prozesskunst den Entstehungsprozess stärker als das Endprodukt und thematisiert damit explizit den Verlauf der künstlerischen Gestalterzeugung. ${ }^{233}$ Aspekte der im Jahrzehnt zuvor so wichtigen Richtungen Environment und Aktion vereinigte in den 1970ern die so genannte Body Art. Bei dieser Kunstströmung wurde - wie der Name schon vermuten lässt - der Körper als Medium benutzt. ${ }^{234}$ Die prozesshafte Body Art lässt sich von der Aktionskunst mit ihrem narrativen Charakter abgrenzen. Sie machte den menschlichen Körper, wie zum Beispiel Gesicht, Hautoberfläche, Nägel, zum künstlerischen Werkstoff und reicht somit in den Kontext der PostMinimal Thematik hinein. Da die dabei erfolgten Manipulationen des Körpers bisweilen bis zur Verwundung getrieben wurden, wurde die Body Art häufig als theatralische Gestik missverstanden. Allerdings steht im Mittelpunkt eine Selbsterfahrung durch sinnliche Wahrnehmung des eigenen Körpers. ${ }^{235}$

Wie die ersten Videotapes ist auch die bereits erwähnte Videoarbeit „Sorry, Mister“ aus dem Jahr 1974, die die Künstlerin ebenfalls als Liveperformance 1974 auf dem Kölner Kunstmarkt aufführte, im Kontext der Body Art zu sehen. Durch das wiederholte Schlagen auf den eigenen Oberschenkel, der sich allmählich rötet, setzte die Künstlerin hier den Aspekt einer Selbsterfahrung anschaulich

231 Lucie-Smith 1996, S. 274

232 Thomas 1986, S. 334

233 Thomas 1986, S. 21, auch S. 343

234 Lucie-Smith 1996, S. 314

235 Thomas 2002, S. 243 
ins Bild. Wie auch das Tape „eine Scheibe berühren“ mit dem Element der sinnlichen Wahrnehmung arbeitet: die Stirn der Künstlerin tritt hier über eine an den Enden wattierte Stange in Verbindung mit dem gläsernen Objektiv der Kamera, oder ganz wörtlich aufgefasst, bietet die Akteurin in dem Video der Technik die Stirn.

Die Protagonisten der Body Art agierten zunächst in den USA. Zu den bekanntesten Künstlern dieser Kunstform zählen die Amerikaner Vito Acconci (*1940) und Dennis Oppenheim (*1938). Nach ersten Begegnungen bei Ausstellungen in Deutschland in den Vorjahren mit zeitgenössischen amerikanischen Künstlern, reiste Ulrike Rosenbach im Jahr 1973 noch gemeinsam mit dem Düsseldorfer Filmemacher Gerry Schum in die USA und knüpfte Kontakte zur Konzeptkunst- und experimentellen Performer Szene. Auch Künstler, wie Bruce Nauman, Dan Graham oder Peter Campus $(* 1937)$ gehörten in diesen Jahren zur quirligen Avantgarde in New York, die zudem alle mit der Videotechnik experimentierten.

Nach Abschluss seines Literaturstudiums war der Künstler Vito Acconci ab 1964 in New York zunächst als Schriftsteller aktiv gewesen bevor er dann ab 1968 auch als bildender Künstler agierte. ${ }^{236}$ Während der 1970er Jahre entwickelte er „language pieces“ und körperbezogene Performances, so dass der Künstler heute als Wegbereiter der textgestützten Aktion gilt. ${ }^{237}$ Ausgehend vom Handlungsaspekt des Schreibens interessierten den Künstler in seinen frühen Performances die Kräfte, die situativ aktiviert werden. Bestärkt durch die Lektüre der topologischen Psychologie Kurt Lewins konzipierte Vito Acconci bereits in den 1960er Jahren Arbeiten, die mit Formen grenzüberschreitender Kommunikation spielen. Berühmtestes Beispiel ist wahrscheinlich die Aktion, die Acconci 1972 in der New Yorker Galerie von Ileana Sonnabend aufführte. Der Künstler masturbierte dabei unter einem hölzernen Podest, über das die Besucher gingen. Die Besucher sahen den Akteur nicht, konnten diesen nur hören. Für seine Experimente mit unterschiedlichen Formen der Kommunikation nutzte Acconci auch die Videotechnik. So wird in seinem Tape „Pryings“ aus dem Jahr 1971 der Betrachter zum Voyeur gemacht, der am Bildschirm verfolgt, wie Acconci immer wieder aufs Neue die Augen seiner Partnerin zu öffnen versucht. Auch in der Videoarbeit „Remote Control“" ist der Geschlechterkrieg ins Bild gesetzt. Während auf einem Bildschirm der Künstler seine Partnerin instruiert, sich selbst zu fesseln, zeigt das zweite Gerät deren Antwort darauf. Wenn in diesen Arbeiten dem Betrachter noch die Rolle des unbeteiligten Beobachters zu kommt, wird der Zuschauer in dem Tape „Undertone“, das 1973 entstand, vom Künstler scheinbar direkt ange-

236 Von 1967 an gab Vito Acconci die Literaturzeitschrift „0 through 9“ gemeinsam mit Bernadette Mayer heraus.

237 Seit den 1980er Jahren entwickelt der in New York lebende Künstler unkonventionelle Architekturen. (Zweite 2000, S. 104) 
sprochen und damit zum konkreten Gegenüber Acconcis. Ähnlich ist es auch im „Theme song“, in dem der Zuschauer noch passiver Empfänger einer distanzlosen Interaktion bleibt. In die Rolle eines unfreiwilligen Akteurs rückt Acconci den Betrachter erst in seiner Videoinstallation „Command Performance“ aus dem Jahr 1974. Während der Zuschauer das Tape betrachtet, das Acconci am Boden liegend zeigt, wird dieser selbst aufgenommen. ${ }^{238}$ Den Rahmen dieser interaktiven Videoarbeiten erweitert der Künstler 1976 mit seinem dreiteiligen Videoepos „The Red Tapes“, in dem die bislang psychologisch reflektierte Beziehung von Ich und Umwelt in einen sozialen und kulturellen Kontext rückt:

„Der Ort des Agierenden und dessen Selbstreflexion ist nicht mehr die persönliche Begegnung mit dem anderen sondern die Konfrontation mit Sprache und Geschichte. "239

Diese komplexe Arbeit bereitet die weitere künstlerische Entwicklung des Künstlers bereits vor. In den Möbeln und Architekturen, die Vito Acconci seit den 1980er Jahren fertigt, wird der Betrachter zum Akteur, der im Umgang mit den Objekten seine Handlungsmöglichkeiten erprobt.

Neben Vito Acconci hatte Ulrike Rosenbach in Düsseldorf Willoughby Sharp kennengelernt. Der amerikanische Literat und Künstler gab zusammen mit Liza Bear in den Jahren 1970 bis 1976 das Magazin »Avalanche« heraus. In dieser Mischung aus Zeitschrift, Künstlerbuch und Ausstellungsgelegenheit versammelte Willoughby Sharp Dokumente der zeitgenössischen künstlerischen Praxis und schuf auf diese Weise ein Forum für einen angeregten Dialog unter den Avantgarde-Künstlern. Zumal der rege Kommunikator Kontakte unter den Künstlern vermittelte und pflegte. Sein Künstler-Magazin war auf diese Weise ein vielfältiger „think tank“ für die damalige Kunstszene und auch Ulrike Rosenbachs aktuelle Arbeiten wurden hier rezensiert. Außerdem war Willoughby Sharp in den 1960er Jahren als Kurator aktiv und ist neben Nam June Paik einer der ersten Künstler gewesen, die das Sony-Portapak Video-System mit künstlerischer Zielsetzung genutzt hatten. ${ }^{240}$ So produzierte er unter anderem eine Reihe von „Videoperformances" und auch so genannten „Videoviews“. Letztere waren eine Serie von Interviews mit zeitgenössischen Künstlern, wie zum Beispiel Vito Acconci, Joseph Beuys, Chris Burden, Bruce Nauman, Dennis Oppenheim und Keith Sonnier.

Zu den damals aktiven Künstlern gehörte auch der Amerikaner William Wegman (*1943), der erstmals mit Performances und Fotografien im Jahr 1969 an die Öffentlichkeit getreten war. Während der Konzeptkünstler zunächst im Nordos-

238 Zweite 2000, S. 104

239 Zweite 2000, S. 104

$240 \mathrm{Zu}$ den von Sharp organisierten Ausstellungen zählten unter anderem »Pop Art« (Columbia University, 1964), »Kineticism« (The Official Olympic Games Exhibition, Museum of Art and Science, Mexico City, 1968) und »Earth Art« (White Museum, Cornell University, Ithaca, New York, 1969). 
ten der USA (Madison, Milwaukee, Minneapolis) aktiv war, zog es ihn 1971 in den Westen, nach Kalifornien. Hier entstanden irritierende Schwarzweißfotografien und auch erste Videotapes, die durch ihre Themenvielfalt, die Freiheit der Gestaltung und einen großen Ideenreichtum geprägt sind. Grundlegend ist für das künstlerische Werk Wegmans, das Interesse an der eigenen Biographie, die er in Form von kurzen Geschichten humorvoll aufbereitet. In seinen künstlerischen Aufnahmen beschäftigte sich William Wegman mit Fragen der Wahrnehmung und setzte sich mit Formen des Erzählens von Ereignissen auseinander. Dabei bildeten drei Ideen die Basis für seine Fotos, die er gerne in Paaren gegenüberstellte: der Irrtum, die Umdrehung und die Analogie bestimmten die gezeigten Motive, die er häufig mit Wortspielen betitelte. ${ }^{241}$

Auch der Künstler John Baldessari (*1931) lebte in den 1970er Jahren an der Westküste. In seinem künstlerischen Wirken - der Malerei, Fotografie, Videos, Montagen - beschäftigte er sich bereits in den 1960er Jahren mit Fragen der Wahrnehmung:

„Ich betrachte mich gewissermaßen als einen visuellen Dichter, und zwar in dem Sinne, daß ich Interpretationen schaffe, für die Worte nicht ausreichen. Im Allgemeinen suche ich nach Bildern, die verwirren und die die Unvorbersehbarkeit des Lebens zum Thema haben. Es passieren Dinge, die wir nicht mögen, doch die Welt ist kein Ruheplatz. Und ich neige zu der Annabme, dass die Welt jeden Augenblick zusammenbrechen kann. Das ist bisher nur noch nicht passiert." 242
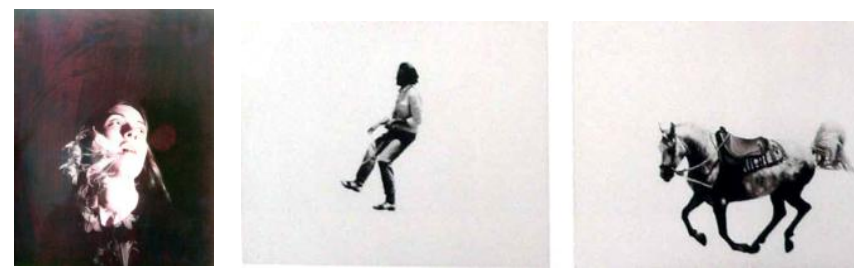

Abb. 51-54: John Baldessari, Strobe Series: Futurist Girl with Flowers Falling from Her Mouth (For Botticelli) \#1, 1975, Farbfoto und Thaumatrope Series: Horse with two Riders (Double Thaumatrope),1975, 3 Schwarzweiffotos

Diese Gedanken des Künstlers manifestieren sich in visueller Form in seinen Fotografien, Videos und auch seiner frühen Malerei, in denen er bereits mit Auslassungen und Irritationen arbeitete. Dabei bildeten konzeptuelle Arbeiten den Ausgangspunkt des künstlerischen Schaffens Baldessaris. Beschäftigte sich der Künstler doch von Anbeginn mit Fragen der Wahrnehmung und Bedeutungsgebung.

241 Auf einer ganzen Anzahl von Fotografien des Konzeptkünstlers und in seinen Tapes findet sich als Protagonist sein Hund abgebildet, dem er den Namen Man Ray gab. (Vgl. Paul in: Kat. Limoges 1993, S. 15-34)

242 Baldessari in: Flyer zur Ausstellung Neues Museum Weserburg Bremen 2005 
Häufig nutzte er dabei das Element der Verdeckung, um etwas Vorhandenes bewusst und damit konkret wahrnehmbar zu machen. Seine vielschichtigen, oft humorvollen Kompositionen, in denen häufig Fotografie und Text kombiniert sind, lassen unterschiedlichste Deutungen zu und zeigen damit, wie relativ Bedeutung sein kann. Der Videokunstexperte John Hanhardt grenzt die Arbeiten Baldessaris von denen seiner amerikanischen Kollegen deutlich ab:

„Das Videowerk Baldessaris wird gern mit dem von Acconci, Nauman und Wegman in Verbindung gebracht. Es läßt sich jedoch aufgrund seiner Konzentration auf Konzept, Prozess, Identität und Narration nicht völlig in die Formel „ein Künstler/ eine Kamera" einordnen. Baldessaris CEuvre entspringt scheinbar mühelos einer lakonischen Diktion und einer zurückhaltenden, ja selbstlosen Präsenz. Ausschlaggebend dafür, dass er in seiner Arbeit vor und hinter der Kamera eine persönliche Sprache fand, war seine Beschäftigung mit der Signifikationskraft des Filmbilds und mit den Repräsentationsstrategien der Performance. Die Bilderzengung ist für ihn eine kritische, reflexive Form der Erzählung. Er entspinnt in seinen Videos einen Dialog mit der Filmgeschichte und den bermeneutischen Deutungspraktiken. "243

Diese vier hier vorgestellten Künstler, denen Ulrike Rosenbach zu Beginn der 1970er Jahre begegnete, nutzten die Medien Fotografie und Video als künstlerische Ausdrucksträger, um mit Formen der Kommunikation zu experimentieren und (wahrnehmungs-)psychologische Fragestellungen zu bearbeiten. Dabei wurde bei diesen das Videotape meist als „sprechender Fotoersatz“ genutzt, und Fotografien sowohl als dokumentarische Zeugnisse von Aktionen als auch als Rohmaterial, das collageartig weiterbearbeitet werden konnte, eingesetzt.

„Das Medium der Fotografie war bestens geeignet, den gegenständlichen und figurativen Inhalt des Darstellungsmittels Aktion zu transportieren. Fotografien materialisierten als Bild die Nähe der Aktion zu ihrem Objekt. Insofern konnte der Körper in Aktionverstärkt durch die Fähigkeit der Kamera den Bruchteil einer Sekunde dieses Momentes des In-der-Welt-Seins einzufangen - für kurze Zeit die Kontingenz. und wechselseitige Abhängigkeit eines menschlichen Subjektes (des Künstlers) von einem anderen, ihm gleichgesetzten menschlichen Subjekt (dem Betrachter) sichtbar machen. Das war es, was Roland Barthes als ,punctum' bezeichnet hat - die Aufgeladenheit eines Fotos. Darüber binaus war Fotografie billig, verfügbar und manipulierbar. Man konnte aus einer Bilderfolge die beste Darstellung auswählen und so auf die Lesart der Aktion Einfluss nehmen. Das Bild konnte beschnitten werden und den Betrachter auf vielerlei Arten täuschen." 244

Während Vito Acconci intensiv mit Sprache arbeitete und auf dieser Ebene unterschiedlichste Kommunikationsformen erprobte, schuf Willoughby Sharp Foren

243 Hanhardt in: Kat. Berlin 2004, S. $42 \mathrm{f}$

244 Stiles in: Kat. Los Angeles 1998, S. 290 
zum Austausch der künstlerischen Inhalte. William Wegman mit seinem humorvollen und konzeptuellen Ansatz bewegten wie auch John Baldessari Fragen der Wahrnehmung, wobei letzterer in seinen künstlerischen Medienreflektionen mit der Wirkung von Verdeckung und Auslassung experimentierte. Besonders Vito Acconci und Wegman mischten in ihrem künstlerischen Wirken Performanceund Videoarbeit und nutzten ihre Soloperformances zum Erforschen der eigenen Identität. „Videonarziss“ lautet das Stichwort unter dem diese intensive Untersuchung der Beziehung zwischen Körperbild, Selbst und Identität mittels der Videotechnik ihren Platz in der Geschichte der Videokunst gefunden hat, und das Thema zieht sich als roter Faden durch die Genealogie der frühen Videokunst. ${ }^{245}$

\section{III.4.4. Die amerikanische Kunstszene an der Westküste}

In den 1960er Jahren entwickelte sich in den USA die Performancekunst parallel zu einer sich dort neu formierenden Frauenbewegung. Amerikanische Frauen begannen sich zu formieren und mit unterschiedlichen Aktionen auf ihre durch Diskriminierung gekennzeichnete gesellschaftliche Situation aufmerksam zu machen. Radikale Feministinnen störten zum Beispiel öffentliche Veranstaltungen und nutzten diese als Bühne für Theateraktionen, in denen sie ihre politischen Ziele vortrugen. ${ }^{246}$

In Selbsterfahrungsgruppen, mittels feministischer Manifeste, poetischen Auseinandersetzungen über Literatur und auch wissenschaftlichen Studien untersuchten die Frauen ihre Situation, werteten im Kollektiv die Grundlagen ihrer Leben und definierten die Modelle neu, auf denen sie ihr Selbstbild gebaut hatten. In der Gemeinschaft konnten die Frauen erkennen, dass es vielen unter ihnen ähnlich erging und damit bekam das Persönliche eine nachhaltige, politische Dimension. Erste Zeichen einer Emanzipationsbewegung auch unter den Künstlerinnen in den USA waren die Proteste gegen den Ausschluss der Werke von Frauen aus öffentlichen Ausstellungen und Sammlungen zeitgenössischer Kunst gewesen.

„In feminist art circles, theatrical means - raw eggs and sanitary napkins littering pristine museum spaces - were used to protest the low percentage of women in the 1970 Whitney Museum's Biennial in New York. "247

Weniger als fünf Prozent der öffentlich ausgestellten Werke waren von Künstlerinnen geschaffen, ein nicht repräsentativer Anteil, gab es doch durch alle Jahrhunderte Frauen, die ernsthaft als Künstlerinnen tätig waren, doch deren Werke kaum dauerhaft an die Öffentlichkeit gelangten. Die Italienierinnen Sofonisba Anguissola (um 1532-1625) und Artemesia Gentileschi (1593-1652/53), die in Frank-

\footnotetext{
245 Zweite 2000, S. 314; zum Begriff „Videonarzis““ vgl. auch Krauss 1976

246 Roth 1983; vgl. auch Stiles in: Kat. Los Angeles 1998, S. 266

247 Roth 1983, S. 16
} 
furt am Main geborene Maria Sibylla Merian (1647-1747), die Schweizerin Angelica Kauffmann (1741-1807), die Französin Elisabeth Vigée-Lebrun (1755-1842), die Amerikanerin Marie Cassatt (1844-1926) oder auch die deutsche Malerin Paula Modersohn-Becker (1876-1907) bis zur Amerikanerin Georgia O'Keefe (18871986), um nur einige Namen bedeutender Künstlerinnen zu nennen, waren als Malerinnen zu ihrer jeweiligen Zeit aktiv und auch angesehen. Doch fanden sich kaum welche ihrer Werke in Museen ausgestellt, so wie sich auch die Situation in Ausstellungen zeitgenössischer Kunst von Werken von Männern dominiert zeigte. Als Reaktion auf diese eingeschränkte Situation wurden Anfang der 1970er Jahre große Ausstellungen zur Kunst von Frauen auf die Beine gestellt, um die Werke der Künstlerinnen vom Schatten ins Licht treten zu lassen, wozu auch die von Lucy Lippard kuratierten Werkschauen zu zählen sind. Mitte des Jahrzehnts formulierten die amerikanischen Feministinnen schließlich das Ziel, den Frauenanteil in Ausstellungen auf 20 Prozent zu erhöhen. Frauen an beiden Küsten - Ost und West - spielten zudem eine dynamische Rolle in der Entwicklung des neuen Mediums der Performance.

„It was this fresh and passionate investigation of self and of identification with other women that created the fervent supportive alliance between the first women performers and their audience. And it was the bounding with this all women audiences, as much as the new personal content in the art, that accounted for the power of the early work. "248

So war die frühe Performancekunst an der Ostküste eng mit den Formen des Happenings, des experimentellen Tanzes, der Musik sowie der Minimal- und Konzeptkunst verknüpft. ${ }^{249}$ Und auch im Westen waren während der 1960er Jahre bereits Gruppen von Performancekünstlerinnen aktiv gewesen, wie zum Beispiel die Tänzerin Ann Halprin in San Francisco oder Racel Rosenthal, die in Los Angeles ihr Improvisationstheater inszenierte. Um 1970 erweiterte sich die Performanceszene hier um Barbara Smith, Bonnie Sherk und verschiedene Mitglieder des Fresno Feminist Art Program, darunter Faith Wilding und Leslie Labowitz. Später kamen Eleanor Antin, Nancy Buchanan, Suzanne Lacy, Linda Montano hinzu. ${ }^{250}$ Gerade an der Westküste, die weniger von der etablierten Kunstwelt dominiert wurde, konnte sich Anfang der 1970er Jahre eine äußerst lebendige und eigenständige feministische Performanceszene entwickeln.

248 Roth 1983, S.16

249 Die Tänzerinnen Yvonne Rainer, Simone Forti, Deborah Hay oder Elaine Summers in 1960er Jahren. Während Alison Knowles und Yoko Ono mit Fluxus Aktivitäten in Erscheinung traten und Charlotte Moorman mit experimenteller Musik. Zu dieser Zeit schufen Carolee Schneeman und Meredith Monk kraftvolle Theaterstücke. Und um 1970 tauchten dann auch Joan Jonas und Mary Beth Edelsonetc neben anderen in der Szene auf. Dabei erhielten die Avantgardekünstler von Anfang an Unterstützung aus der etablierten Kunstwelt. (Hanhardt in: Kat. Berlin 2004, S. 41)

250 Roth 1983, S. 17 
Die Kontakte Rosenbachs in die USA intensivierten sich in dieser Zeit und im Jahr 1974 wurde die Künstlerin von dem Performance- und Videokünstler John Baldessari nach Kalifornien eingeladen. John Baldessari lehrte zu dieser Zeit am „California Institute of Art“ in Valencia bei Los Angeles. Los Angeles bildete neben New York in dieser Zeit das zweite Zentrum der künstlerischen Avantgarde in den Vereinigten Staaten. Die Künstlerin erinnert sich an ihren Wechsel nach Kalifornien:

„1975 bewarb ich mich um eine Stelle am California Art Institut in Los Angeles, um den beiden Initiatorinnen der künstlerischen Frauenbewegung Judy Chicago und Miriam Shapiro zumindest einige Zeit näher zu sein. Ich erhielt mit Hilfe von John Baldessari einen Lehrauftrag für Feministische Kunst und Videokunst und landete in L.A., als die beiden Frauen gerade aus der Schule entlassen worden waren und in ,down town "Los Angeles das „Woman's Building“ gegründet hatten. "251

Ulrike Rosenbach zog zusammen mit ihrem damaligen Lebensgefährten Klaus vom Bruch (*1952) und ihrer Tochter Julia nach Los Angeles. Während Rosenbach sich in der dort sehr aktiven Frauenszene engagierte, studierte Klaus vom Bruch in den Jahren 1975/76 bei John Baldessari am California Institute of the Arts.

III.4.4.1 Judy Chicagos und Miriam Shapiros Feminist Art Programm

Die Situation der Frauen - und speziell Künstlerinnen - sah in den viel stärker multikulturell geprägten USA Anfang der 1970er Jahre bereits anders aus als in Europa, war die Frauenbewegung in Nordamerika doch schon eine Weile aktiv. In Kalifornien fand zudem Anfang der 1970er Jahre eine starke gegenseitige Befruchtung zwischen feministischer Theorie und Kunst statt. Dort bildete sich damals der politische Ansatz heraus, dass das Schaffen eines entsprechenden Kontextes zur Befreiung aus den männlich dominierten Formen der Erziehung und Darstellung auch die Kreativität der Frauen befreien werde. Hatte es doch nach Ansicht der amerikanischen Feministinnen jede Frau in sich kreativ zu sein. ${ }^{252}$

Ulrike Rosenbach zog es nach Los Angeles. Die Millionenstadt war zugleich das Zentrum der kalifornischen Frauenbewegung, deren Protagonistinnen Anfang der 1970er Jahre die beiden Künstlerinnen Judy Chicago (*1939) und Miriam Shapiro (*1923) waren. Nachdem Judy Chicago am Fresno State College 1970 eine

251 Rosenbach in: Jochimsen 1990, S. $141 \mathrm{f}$

252 Pollock 1987; Moira Roth 1983; „Um 1970 hatten einige Feministinnen bereits begriffen, daß sie durch die Betonung der Ähnlichkeiten zwischen den Geschlechtern die Anliegen der Frauen besser vorantreiben konnten, während andere - Anhängerinnen des radikalen oder ,gynozentrischen" Feminismus - immer noch die Unterschiede zwischen den Geschlechtern herausstellten.“ (Stiles in: Kat. Los Angeles 1998, S. 266) 
erste Kunstklasse nur für Frauen ins Leben gerufen hatte, entwickelte sie als Dozentin in den Jahren 1971-74 am California Institute of the Arts zusammen mit ihrer älteren Kollegin Miriam Shapiro das „Feminist Art Programm“. ${ }^{253}$ Bereits bei ihrem Experiment in Fresno hatte man Judy Chicago, die am College als Dozentin im Fachbereich Kunst angestellt war, freie Hand gegeben. 15 Studentinnen mit ganz unterschiedlichem sozialen und künstlerischen Hintergrund hatten an dem Projekt teilgenommen, das für alle Beteiligten - einschließlich der Leiterin - eine völlig neue und intensive Erfahrung darstellen sollte. Grundlegend war in diesem Frauenprogramm für den künstlerischen Prozess die konkrete Auseinandersetzung mit den Gefühlen, Bedürfnissen und Problemen der Teilnehmerinnen. Nach den produktiven und durchweg positiven Erfahrungen dieses ersten Projektes entwickelte Judy Chicago, die Unterstützung der älteren Miriam Shapiro suchend, am California Institute of the Arts das erste Feminist Art Programm, das durch vier Grundideen bestimmt war. An erster Stelle stand die Selbsterfahrung im Rahmen des so genannten „Consciousness-Raising“ - zu übersetzen mit „in das Bewusstsein heben“. Im geschützten Raum der Gruppe konnte jede beteiligte Frau offen über ihre persönlichen Erfahrungen in einer nicht bewertenden Atmosphäre sprechen. Auch oder gerade tabuisierte Themen wie weibliche Sexualität, Vergewaltigung oder Inzest wurden in den Gruppen besprochen und intensiv über sozialisiertes weibliches Rollenverhalten diskutiert. Die persönlichen Erfahrungen bildeten den Ausgangspunkt für die Gruppenarbeit. Die Frauen analysierten die den angesprochenen Problemen zugrunde liegenden Gründe und Mechanismen, doch wurde in der Gruppe keine individuelle Konfliktlösung angestrebt. Vielmehr war das Ziel innerhalb des Gruppenprozesses die Identifikation mit den anderen Frauen herzustellen, gleiche Problematiken zu erkennen, sich patriarchaler Unterdrückungsmechanismen gemeinsam bewusst zu werden und daraus kollektive Energien und letztlich politisches Handeln zu entwickeln. ${ }^{254}$ Aus diesem Consciousness-Raising-Prozess heraus entwickelten die Künstlerinnen ihre kreativen Arbeiten in unterschiedlichen Materialien und Medien. Dabei übernahm die Arbeit mit Verkleidungen eine wichtige Funktion auch im künstlerischen Prozess, mit denen Verhaltensregeln und geschlechtsspezifische Zuschreibungen erkennbar gemacht werden konnten. Zudem wurde die Suche nach dem authentisch Weiblichen hinter tradierten Maskierungen mit dem Identifikationsangebot positiv besetzter Frauenbilder verbunden. ${ }^{255}$ Die Teilnehmerinnen des Programms machten sich zudem in Kunstgeschichte, Mythologie, Geschichte, Literatur und Kulturgeschichte auf die Suche nach positiven weiblichen Rollenmodellen.

253 Engelbach 2001, S. 17

254 Wilding 1977, S. 9-11 und S. $25 \mathrm{f}$

255 Engelbach 2001, S. 17 
„In der Rückbesinnung auf Göttinnen und matriarchale Kulturen suchten Frauen zum einen nach einem Anknüpfungspunkt, um einen alternativen Gesellschaftsentwurf zu entwickeln. Zum anderen versuchten sie, spirituelle Fähigkeiten wiederzubeleben und diese in die Belange der Frauenbewegungn zu integrieren. Feministische Künstlerinnen waren tonangebend in dieser Entwicklung. Sie waren auf der Suche nach Bildern, die starke Frauen zeigten in anderen, als den ibnen traditionell zugebilligten stereotypischen Rollen. Göttinnenbilder und Bilder von Priesterinnen und Kriegerinnen erfüllten diese Funktion und gaben Künstlerinnen auch einen spirituellen Anknüpfungspunkt. Weiterbin wurde die Göttin als verbindendes Symbol betrachtet, das Unterschiedlich-keiten transzendieren und Frauen verschiedener sozialer, kultureller und ethnischer Hintergründe harmonisieren könne. Diese Verbindung, so hofften Frauen, würde auf einer Ebene geschehen, auf der so tief in die Geschichte und kollektive Psyche eingegriffen werden könne, daß Frauentrennende, patriarchalisch geprägte politische und soziale Strukturen überwunden werden könnten. Kurzum, die Göttin wurde von Künstlerinnen als Symbol für die gegenwärtige geistige und psychische Emanzipation der Frau aktiviert. "256

Die Erlaubnis, sie selbst sein zu können und die Ermutigung, Kunst aus ihrer eigenen Erfahrung als Frauen machen zu können, öffnete den Studentinnen des Feminist Art Programs eine ganze Welt neuer Möglichkeiten. Judy Chicago beschreibt in ihrer Biographie „Durch die Blume“, die sie Anfang der 1980er Jahre verfasste, rückblickend die besondere Atmosphäre in der Frauengruppe:

„An diesem Tag geschah das gleiche wie in Fresno und in unserem Theater-Workshop. Die Frauen empfanden sich und die anderen ,als Frauen“, die zusammen etwas tun, was nur Frauen tun, und dieses führte zu einer ungeheuren Erregung. An diesem Nachmittag ,zapften" die Frauen ,sich und ibre Energiequellen an" - ein entscheidender Weg auf dem Weg zur menschlichen und kreativen Entwicklung. Ich habe festgestellt, wenn gebildetete Frauen beginnen, ibre Gefüble als Frauen auszudrücken, verschmelzen Emotionen und Intellekt qu einer größeren Ausdrucksfähigkeit, als es den meisten Männern heutzutage möglich ist. "257

Daneben wurde im Rahmen dieses ersten Feminist Art Programms der Aufbau eines speziell weiblichen Kontextes und einer auf weibliche Wünsche zugeschnittenen Umgebung betrieben: Die Frauen mieteten dafür ein altes Gebäude, das sie für ihre Bedürfnisse herrichteten. Dieser Ort gab der Gruppe die Möglichkeit einen geschützten Platz aufzubauen, den sie selbst kontrollieren und in dem sie sich mit ihren Erfahrungen auseinandersetzen konnten, frei von einer Haltung der Verteidigung oder männlicher Einmischung. Bei der Herrichtung des alten Gebäudes lernten die Frauen zudem zuzupacken und ihre Fertigkeiten zu organisie-

256 Kubitza 2002, S. $165 f$

257 Chicago 1984, S. 132; Judy Chicagos Autobiographie „Durch die Blume“ („Through the Flower. My struggle as a woman artist") erschien Anfang 1975 erstmals. 
ren und erfuhren, dass sie eine starke, festverbundene Gruppe geworden waren, wie Judy Chicago in ihrer Biografie beschreibt. Weil das Programm das erste seiner Art war, schienen die Frauen eine Freiheit von der Geschichte und die besondere Wichtigkeit zu spüren, erinnert sich eine der ehemaligen Teilnehmerinnen Faith Wilding, die zudem beschreibt, dass sich aus dieser Aufbruchsituation eine große Risikobereitschaft und Abenteuerlust entwickelte, die sich in den geschaffenen Kunstwerken niederschlug. Um die Vielfalt ihrer Erfahrungen schließlich einer größeren Öffentlichkeit mitzuteilen, gaben die Frauen zudem eine Sondernummer der feministischen Zeitschrift „Everywoman“ heraus. ${ }^{258}$

Nach einer Vorbereitungsphase konnten die 25 Teilnehmerinnen des ersten Feminist Art Programs im Herbst 1971 mit der Gründung und Einrichtung eines ersten „Womanhouses“ beginnen. Nach zwei Monaten kreativer Arbeit war das Gebäude umgebaut zu einem Ort, an dem „die jahrelange weibliche Aktivität der Haushaltsführung zu fantastischen Verhältnissen geführt wurde. Das Womanhouse wurde zum Verwahrungsort der Tagträume den die Frauen hatten, um ihre Leben weg waschen, backen, kochen, nähen, putzen und plätten zu können“, wie Zeitzeugin Faith Wilding beschreibt. ${ }^{259}$ Jede Frau hatte in dem Haus einen Raum nach ihren Vorstellungen gestaltet oder eine Performance entwickelt. Zum Beispiel war die Küche ganz in fleischfarben rosa gestrichen und nährende SpiegeleiBrüste übersäten die Decke. Mit unkonventionellen Formfindungen in ihren Werken fanden die Künstlerinnen Wege, ihre Identität wieder zu behaupten. Dabei tauchten häufig handelnde Arme und Hände in den Werken auf, die deutliches „Ich bin!““ symbolisierten. ${ }^{260}$ Auch Faith Wildings Performance „Waiting“", die das Warten als elementare Erfahrung des Lebens einer Frau beschreibt, wurde im Womanshouse aufgeführt. ${ }^{261}$ Die Arbeit an dem Gemeinschaftsprojekt bildete eine einschneidende Erfahrung für alle Teilnehmerinnen. So beschrieb Miriam Shapiro das Womanhouse als ihre erste Verbindung mit der anderen Hälfte der Welt - der Welt der Frauen. Und als das „Womanhouse“ am 30. Januar 1972 offiziell eröffnet wurde, hatten die Frauen die erste feministische Kunstausstellung geschaffen, in deren Mittelpunkt die Themen Hausarbeit und parodierte Stereotypen von Frauen standen. ${ }^{262}$ Nie zuvor hatte ein Kunstprojekt das innere und äuBere Leben einer Frau auf diese Weise geschildert.

\footnotetext{
258 Wilding 1977, S. 9-11

259 Wilding 1977, S. $25 \mathrm{f}$

260 Chicago 1984, S. 160

261 Roth 1983, S. 17

262 Wilding 1977, S. 26f; zu den Teilnehmerinnen gehörten neben Judy Chicago und Miriam Shapiro die Studentinnen Judy Huddleston, Ann Mills, Sherry Brody, Kathy Huberland, Sandra Orgel, Christine Rush, Nancy Youdelman, Faith Wilding, Shawnee Wollenman, Beth Bachenheimer, Karen LeCoq, Robin Mitchel, Robin Weltsch, Vicki Hodgetts, Susan Frazier, Paula Longendyke, Mira Schor, Robbin Schiff, Janice Lester, Camille Grey.
} 

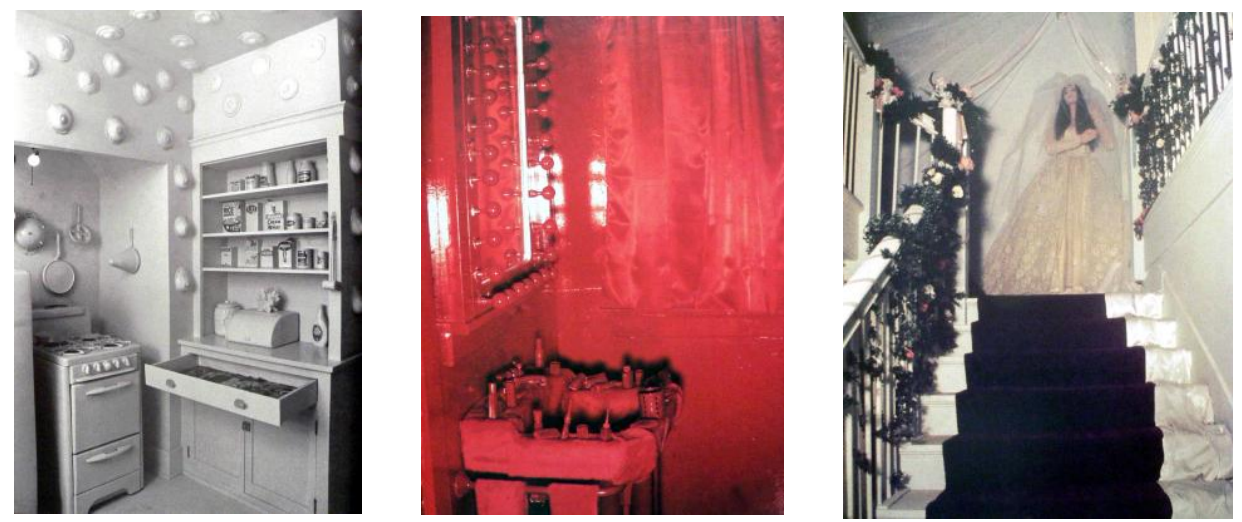

Abb.55-57: Rauminstallationen im Womanhouse, 1972

Die Kunstkritikerin Gislind Nabakowski beschreibt das Womanhouse aus ihrer Sicht:

„Es entstand 1972 (aus einer Gruppe um die Kunsthistorikerin Paula Harper, um Judy Chicago und Miriam Shapiro) in unmittelbarer Nachbarschaft zur Traumfabrik Hollywoods, dessen großbürgerlicher Illusionismus (über Trivialromane, Film und Fernsehen) Einzug in die Ericiehungsstandards des Landes gehalten hat. Im »Womanhouse« suchten die Künstlerinnen kein Asyl. Geschädigte befragten hier ibre Träume von Häuslichkeit und ewigem Glück - und ließen sie zerbröckeln. Die Illusion wurde bin- und bergewendet. Eine Endloskritik an den traditionellen Normen "weiblicher Erziehung" kam dabei heraus. Das Haus gebörte einer alten Dame mit dem biblischen Namen Amanda Psalter. Es stand in einer herunter gekommenen Wohngegend Hollywoods (533 Mariposa Street). An ihm lernten die Studentinnen, was sie in einer traditionellen Kunstschule nicht lernen: Dübeln, Renovieren, Maurer- und Elektroarbeiten, Fenstereinsetzen. Sie formten die Innenräume in ein »Totalkunstwerk《 um, mit jener hausbezogenen, chimärenhaften, verballhornenden Phantasie, die auch Hausfrauen entwickeln können, wenn sie mechanische Arbeit verrichten. Nach einem Monat wurde das alte Herrenhaus für das Publikum geöffnet; angelockt durch die Berichterstattung in den Massenmedien und Mund-zu-Mund-Propaganda kamen 10000 Besucher. Das »Womanhouse« war eine Art Rehabilitationskommune, in dem die Frauen die Zwänge ihrer eigenen Erziehung bedachten. Doch war es weitaus mehr als den Tücken und Widersprüchen der eigenen Sozialisation denjenigen der Mütter gewidmet. Es wurde zum Gesprächsort über die stets fließenden Grenzen der Generationen zwischen Müttern und Töchtern. "263

Das kollektive Environment führte eine Reihe von frauzentrierten Bildern vor, die zu der Zeit in der Kunstästhetik unbekannt waren. Diese Begegnung war für man-

263 Nabakowski 1980, Bd.1, S. 224 
che Besucher in der männerdefinierten Kunstwelt der 1970er Jahre äußerst konfrontierend und die kritischen Stellungnahmen reichten von Erstaunen bis Unverständnis. ${ }^{264}$ Das Womanhouse blieb insgesamt für vier Wochen bis zum 28. Februar 1972 geöffnet. Nach der Schließung folgte als weiteres Projekt der Frauen das „Woman's Building“, ebenfalls in Los Angeles. Dies war ein altes Institutsgebäude an der South Grand View Street, das den Künstlerinnen viel Platz und große Tageslicht durchflutete Studios bot. An diesem Ort richteten die Frauen Ateliers und Galerien ein. Sollte bei diesem zweiten Projekt der Schwerpunkt auf der Kommunikation und Förderung von weiblicher Kunst und Kultur im Mittelpunkt stehen. Bereits am 28. November 1973 konnte das Gebäude unter seiner neuen Bestimmung wieder eröffnet werden. ${ }^{265}$ Und in den kommenden Jahren etablierte sich das Haus als ein Ort feministischer, avantgardistischer Kunst in der Kunstszene von Los Angeles. Auch Ulrike Rosenbach zeigte 1976 hier ihre Performance „Reflexionen über die Geburt der Venus“.266

Die Wege der beiden Initiatorinnen Judy Chicago und Miriam Shapiro trennten sich allerdings wieder, noch bevor Ulrike Rosenbach in Los Angeles eintraf und auf sie treffen konnte. Doch hatte ihr Projekt deutliche Spuren auch am California Institute of the Arts hinterlassen und ihre feministischen Sichtweisen prägten auch das weitere künstlerische Schaffen beider Frauen, die sich allerdings in unterschiedliche Richtungen weiterentwickelten. Doch blieben beide Amerikanerinnen interessiert an den vielfältigen ästhetischen und praktischen Techniken, mit denen Frauen traditionell verbunden werden - wie zum Beispiel das Weben, Quilting oder Nadelarbeiten. Auch waren sie darauf bedacht, diese aus den Kategorien der Volkskunst beziehungsweise des Kunsthandwerks herauszulösen und nachhaltig aufzuwerten.

Bereits vor der Begegnung mit Judy Chicago hatte sich Miriam Shapiro mit ihrer Identität und Rolle als Frau künstlerisch auseinandergesetzt und ihr eigenes Vokabular entwickelt, um ihre beklemmende Situation bildlich auszudrücken. In ihrem weiteren künstlerischen Wirken, in dem sie bis heute fort fuhr ihre Identität zu rekonstruieren und durch ihre Kunst zu definieren, wurden die Formen der Collage und kunsthandwerkliche Techniken zusehends wichtig..267 Judy Chicago

264 Wilding 1977, S. 26f; „Ebenso bedroht eine feministische Kunst, die sich mit körperlichen Prozessen, wie Menstruieren und Transformationen wie Altern und körperlichem Verfall befasst, das bereinigte, fetischisierte Frauenkörperbild, das Kunst und Medien prägt.“" (Kubitza 2002, S. 173) So gestaltete Judy Chicago zum Beispiel einen „Menstruation Bathroom“ im Womanhouse. Wilding 1977, S. 61-63

266 Vgl. Kap. III.4.4.2

267 In ihrer Isolation in einer männlich dominierten Kunstwelt hatte sie vor der Begegnung mit Judy Chicago die Konflikte zwischen der Freiheit zu schaffen und der Falle der Häuslichkeit in einem individuellen Vokabular thematisiert, das ihr erlaubte bis dahin Unausgesprochenes zu benennen. Im Rahmen des Gruppenprojektes betrat die Künstlerin nach eigenen Aussagen eine neue Kultur. Von da an engagierte sie sich als Fürsprecherin künstlerischer Arbeiten von Frau- 
beschreibt in ihrer Biografie ihre künstlerische Suche nach ausdrucksstarken Motiven:

„Diese Motive führten mich zu einer anderen Serie, die den Ort darstellten, an dem ich mich in diesem Augenblick befand - ich bewegte mich über die Grenze der weiblichen Rolle hinaus. Wie Georgia O'Keeffe benutzte ich die Blume als Symbol der Weiblichkeit." 268

Und die Künstlerin ging noch einen Schritt weiter:

„Ich wollte mein Interesse an der Geschichte der Frauen, meine Identifikation mit den Frauen der Vergangenheit, mein Wissen von Frauenkunst und Frauenliteratur mit meiner eigenen Bildsprache verbinden. "269

Die Suche nach einer eigenen, weiblichen Bildsprache führte Chicago - wie andere Künstlerinnen auch - bald zum Arbeiten mit stilisierten Darstellungen der Vagina:

„Die vaginale Ikonologie hat dagegen einen politischen Anspruch, der im Bereich der Tiefenpsychologie ansetz̧t. Künstlerinnen wählten das weibliche Geschlechtsteil, ihr Signum des Anders-Seins, um Konnotationen der Minderwertigkeit mit denen des Stolzes zu ersetzen. "270

Eine Ikonographie, die auch das Werk bestimmte, mit der Judy Chicago dann besonders berühmt geworden ist. „Die Dinner Party“ entstand als Gemeinschaftsprojekt, an dem zahlreiche Frauen mitwirkten, in dem Zeitraum zwischen 1974 und 1979. Das Environment ist in Form eines großen dreieckigen Tisches gestaltet mit 39 symbolischen keramischen Gedecken - elaboriert ausgestaltete Vulven - für drei mal dreizehn weibliche Ehrengäste aus den Bereichen der Historie und der Mythologie. Das kontrovers diskutierte Kunstwerk ist als eine Hommage an die Geschichte der Frauen gedacht und in der Herstellung spielte die Zusammenarbeit, die ein elementares Element in vielen traditionell weiblichen Künsten bildet, eine grundlegende Rolle. ${ }^{271}$

en, setzte sich dafür ein, marginalizierte Bilder von Frauenkultur zu retten und Frauenkunst aus der Unsichtbarkeit zu heben. Sie schuf den Begriff „Femmage“ für künstlerische Arbeiten anonymer Frauen, die von der Hochkunst ausgeschlossen blieben.

268 Chicago 1984, S. 158

269 Chicago 1984, S. 158

270 Kubitza 2002, S. 173; wie Barbara Rose 1974 in einem Artikel über vaginale Ikonologie anmerkte, sei diese Kunst ein Anschlag auf die Freudsche Doktrin des Penisneids und auf die Vorstellung von der Frau als dem unsauberen, mysteriösen, gefährlichen Geschlecht. (Rose 1974, S. 59)

271 Das Werk befindet sich heute im Brooklyn Museum in New York. 


\section{III.4.4.2 Im Licht der Venus}

Die Atmosphäre eines kollektiven Bewusstseins und die daraus resultierenden freigesetzten Energien bei den amerikanischen Frauen hat Ulrike Rosenbach in ihrer 1975 entstandenen Foto- und Videoarbeit „Female Energy Change“ - „Weiblicher Energieaustausch" - anschaulich ins Bild gesetzt. Die dreiteilige Fotoserie entstand während ihres Aufenthaltes in Santa Monica. Sie arbeitete in diesen Fotomontagen mit dem Mittel der Überlagerung. Damit nutzte sie auch in diesem unbewegten Medium eine ähnliche Form wie bei dem Amazonen-Tape, bei dem sie die Videobilder elektronisch überlagerte.
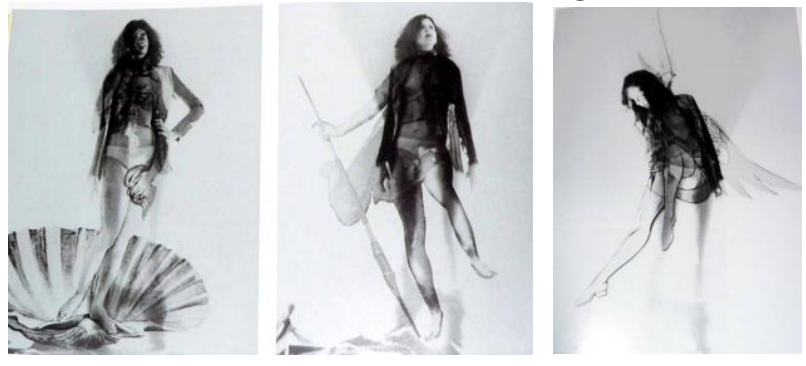

Abb. 58-60: Female Energy Change -Venus, Minerva, Supergirl, 1975, SW-Fotocollagen

Die hochformatigen Schwarzweißfotografien sind Bildmontagen, die jeweils aus zwei unterschiedlichen Aufnahmen montiert sind. Die Ganzkörperporträts der Künstlerin in entsprechender Pose wurden dabei jeweils mit der Darstellung einer weiblichen mythologischen Gestalt überblendet: einer schönen Venus in ihrer Muschel, einer kämpferischen Minerva mit Speer oder einem dynamischen „Supergirl“" mit Flügeln. ${ }^{272}$ Die Fotos zeigen die Künstlerin in unterschiedlichen Posen, bekleidet mit einer geöffneten, langärmeligen Bluse und einem weißen Slip, so dass ihr nackter Körper teilweise zu sehen ist.

Als Beispiel zur genaueren Untersuchung eines Einzelbildes soll hier die Venus-Collage herausgegriffen werden. Für diese Fotomontage findet sich die Venusfigur des italienischen Renaissancemalers Sandro Botticelli (1446-1510) aus dessen Gemälde „Geburt der Venus“ (1485) als kunsthistorisches Vorbild zitiert, das Ernst Gombrich wie folgt beschreibt:

272 Klaus vom Bruch fotografierte die Künstlerin, die die Aufnahmen dann mit den Vorlagen montierte, wie die Künstlerin im Gespräch 2001 erläuterte: „,Female Energy Change` zum Beispiel hat Klaus vom Bruch erstmal fotografiert, bevor es eine Collage wurde, eher Montage. Manche, wie die schwarz-weißen sind collagiert, aber die Farbaufnahmen, wie beim „Female Energy Change", sind montiert, also Negativ auf Negativ. Das war ein anderes System. Und bei den schwarzweißen Fotos habe ich das collagiert und dann erneut abfotografiert, also im Reproverfahren bearbeitet. Die unterschiedlichen technischen Verfahren zu untersuchen, fand ich wahnsinnig spannend.“ (Vgl. Kap. VII.1.) 
„Für diese Gelehrten war die Sage ein Sinnbild für das Mysterium, wie die Schönheit als Abglanz des Göttlichen in die Welt kam. Wir können uns vorstellen, wie ehrfürchtig der Maler daran ging diesen Mythos zu veranschaulichen. Was auf dem Bilde vorgeht ist leicht verständlich. Venus ist auf einer Muschel stehend aus dem Meer aufgestiegen und wird in einem Rosenregen von geflügelten Windgöttern ans Land getrieben. Beim Betreten des Landes wird sie von einer Kore oder Nymphe begrüßt, die ibr einen Purpurmantel umlegt." 273
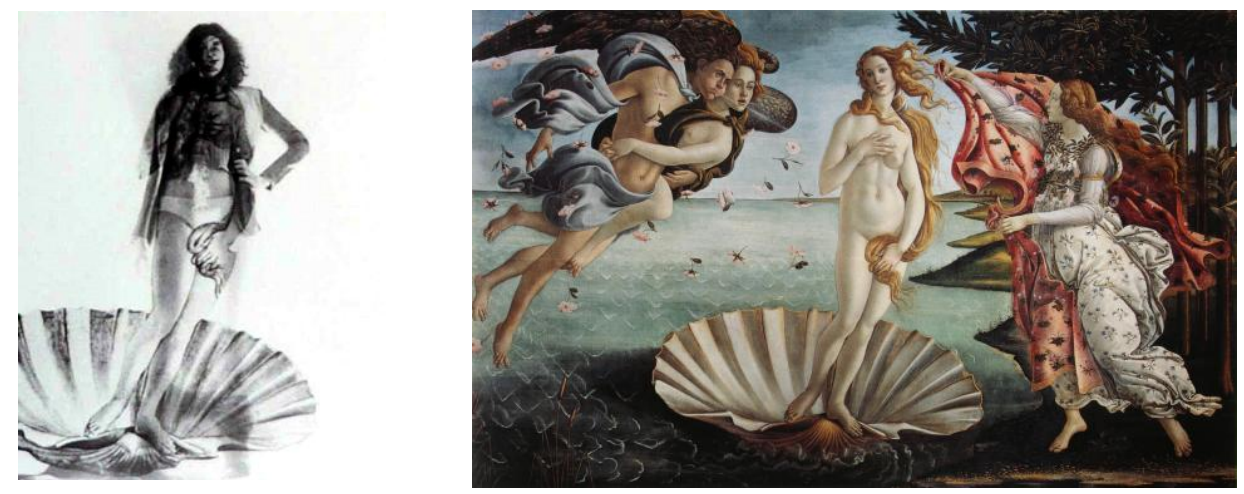

Abb.61-62: Female Energy Change - Venus, 1975, Fotocollage und Sandro Botticelli: Geburt der Venus, um 1485

Rosenbach greift aus der komplexen Komposition Botticellis allein die Figur der Venus für ihre Collage heraus. Die Venus steht in Botticellis Bild im Kontrapost in der Mittelachse des Bildes in einer geöffneten Muschelschale. In diese stehende Figur montiert die Künstlerin ihr Abbild in der entsprechenden Körpergröße. Der Kopf der Künstlerin, der samt den rahmenden Haaren deutlich zu erkennen ist, ist - entsprechend der kunsthistorischen Vorlage - leicht zur Seite geneigt. Die Augen der Künstlerin blicken versonnen. Im Bereich des Oberkörpers ist ihr linker Arm in die Hüfte gestemmt, der rechte hängt locker herunter. Damit weicht die Haltung der abgebildeten Künstlerin deutlich von der der Botticelli-Venus ab, deren Konturen sich ebenfalls deutlich auf dem Foto abzeichnen und die zeigen, dass der linke Arm der Venus ausgestreckt herunter hängt und auf ihrem Oberschenkel ruht.

Die Betrachtung des Fotos zeigt, dass das Porträt der Künstlerin, je weiter man am Körper empor blickt, immer deutlicher vor den Konturen des kunsthistorischen Zitates hervortritt. So tragen die deutlich sichtbaren Beine der BotticelliVenus-Vorlage in der Montage einen Rumpf, in dem beide Frauenabbilder

273 Der italienische Maler hat das Gemälde um 1485 für die Villa des Lorenzo di Pierfrancesco de Medici gemalt und es befindet sich heute in den Uffizien. (Gombrich 1992, S. 209) 
gleichwertig durchscheinen, verschwimmen doch in diesem Bereich die Formen und Konturen der Darstellerin und der Vorlage ineinander, so dass in einigen Bereichen eine genaue Zuordnung kaum mehr möglich scheint. Erst das Gesicht der Künstlerin tritt dann deutlich hervor und ersetzt quasi das historische Bild.

Auf sehr anschauliche Weise ist in der Collage eine symbolische Identifikation der Künstlerin mit der mythischen Venusfigur verbildlicht. In einem übertragenen Sinne könnte man sagen, dass die Mischfigur auf der historischen Basis der mythologischen Frauengestalt ruht und indem die Künstlerin der Figur ihr Gesicht gibt, diese zum Stereotyp gewordene Göttinnnengestalt individualisiert wird. Während die italienische Venus mit ihren Händen schüchtern ihre Scham und eine ihrer Brüste bedeckt, zeigt das durchschimmernde Porträt die Künstlerin als eine Frau, die in selbstbewusster, aktiver Pose ihren rechten Arm in die Hüfte stemmt. In dieser abweichenden Geste zeigt sich auch deutlich ein Bezug auf die im Womanshouse entwickelte weibliche Bildsprache, die, wie dargelegt, durch handelnde Arme und Hände geprägt war. Und mit dieser bildhaften Personifikation und dem Austausch der Energie der Frauen untereinander und durch die Tiefen der Zeit scheint nun die Möglichkeit eines Aufbrechens der überkommenen Haltung gegeben zu sein.

Auffällig ist bei der Fotomontage zudem die große Transparenz, die Durchflutung des Bildes mit Licht. In diesem Zusammenhang kann auf den im Titel der Serie benannten Begriff der Energie verwiesen werden. Die durch das kollektive Bewusstsein freigesetzte Energie ist in der Darstellung durch Helligkeit, die die Darstellung durchflutet zum Ausdruck gebracht. Hinzu kommt, dass die Figur, wie auch die anderen Figuren der Serie, im freien Raum zu schweben scheint. Ist doch in Rosenbachs Kompositionen keinerlei räumlicher Bezug mehr erkennbar.

Etwas später hat Ulrike Rosenbach eine Fotoserie mit Motiven aus dem Tarot gemacht, bei der sie in ähnlicher Weise ihr eigenes Abbild mit der esoterischen Bildwelt zusammenfügt. ${ }^{274}$ „Tarot“, oder auch „Tarock“ genannt, ist ein Orakelsystem, das mit 78 Karten mit unterschiedlichen bildlichen Darstellungen arbeitet. Darunter finden sich 22 Karten der so genannten großen Arkana oder auch Trumpfkarten, die bestimmte Bezeichnungen tragen, wie der Wagen, oder der Turm..$^{275}$ Die Farbfotoserie umfasst insgesamt zehn Bilder zum Tarot und ist aus dem Jahr 1976.276 Dabei zitiert die Künstlerin aber kein bekanntes Tarotdeck für die Collagen, sondern nimmt Gemälde unterschiedlicher Künstler, in die sie ihr Abbild in unterschiedlichen Posen einfügt. Dabei orientieren sich die Haltungen

274 Der Bezug in Kunstwerken zum Tarot findet sich zum Beispiel auch in Arbeiten der Künstlerin Niki de Saint Phalle.

275 Die Wurzeln des Tarot sind nicht klar zu greifen, doch werden sie in den altägyptischen oder indischen Religionen vermutet. (Zerbst/Kafka 2003, S. 390)

276 So heißt es im Katalog 2003, in einem früheren Katalog ist von 9 Bildern die Rede und 1975 wird als Entstehungsjahr der Fotoserie angegeben. 
der Künstlerin an den Haltungen der Figuren des Waite-Tarot. 277 Die Karte mit der Null, die im Deck „The Fool“ oder „der Narr“ heißt zeigt bei Waite eine Figur, die in die Luft schauend auf einen Abgrund zu schreitet. Begleitet wird sie von einem kleinen weißen Hündchen.
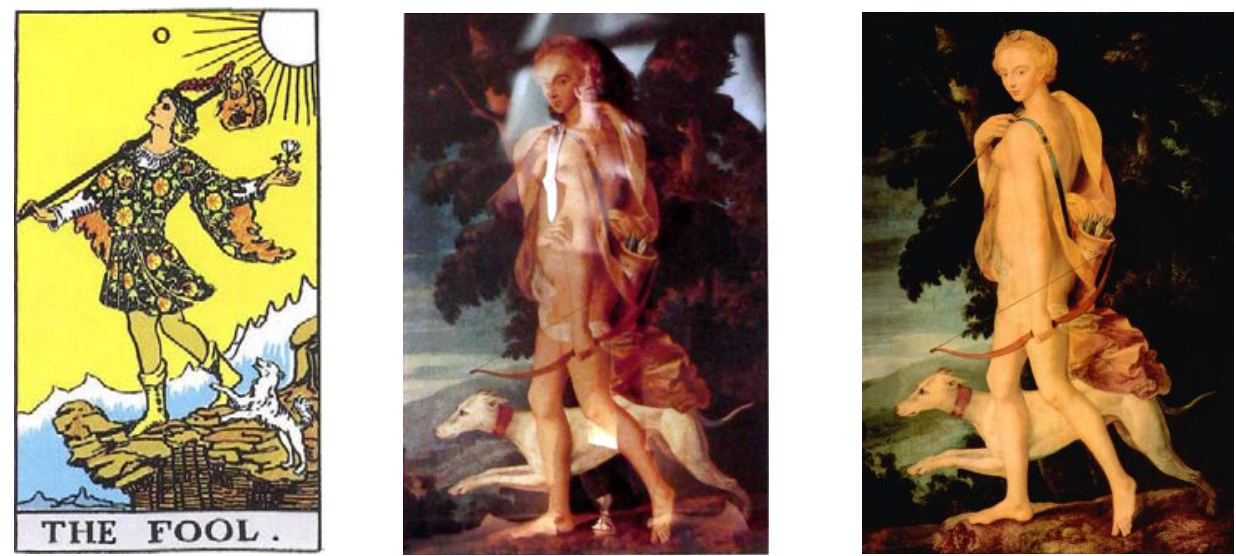

Abb. 63-65: The Fool, Karte Waite-Tarot, Bilder zum Tarot: The Fool 1976 Farbfotocollage und Schule von Fontainebleau: Diana als Jägerin, um 1550

In Rosenbachs Fotoserie gibt es nun gleich zwei Umsetzungen dieses Tarotmotives. Einmal nimmt sie das Gemälde, das Diane de Poitiers als Göttin Diana zeigt, das aus der Schule von Fontainebleau stammt, als Vorlage. ${ }^{278}$ Die Göttin schreitet in dem hochformatigen Akt einen Köcher über der Schulter und einen Bogen in der Hand durch ein Waldstück. Neben ihr läuft im Hintergrund ein weißer Jagdhund. In dieses Bild, montiert sie ihren Oberkörper hinein, der aber anders als im Original dem Betrachter frontal zugewandt ist. Auch die Hände sind abweichend von der Vorlage an die Hüften gelegt.

In der zweiten Vorlage gibt es keinen Hund, der das Erkennen des Motivs erleichtert. Dafür entspricht die Kopfhaltung des Fotos der Künstlerin eher der Tarot-Vorlage. So hat sie ihren Kopf im Halbprofil erhoben und schaut versonnen in die Luft. Als Vorlage zitiert sie hier einen Ausschnitt aus dem Gemälde „The Beguiling of Merlin“ der englischen Malers Edward Burne-Jones (1833-1898).279 Eine weitere Montage aus der Serie ist als „Der Magier“ benannt. Der Magier ist die zweite Karte der großen Arkana im Tarot und trägt die Nummer eins im Waite-Deck. Die Karte zeigt eine Figur, die hinter einem Tisch steht, auf dem sich ein

277 Diese populärsten modernen Tarotkarten stammen aus dem Jahr 1910. Waite veränderte die traditionelle Reihenfolge der Karten, um die astrologische Folge der Zeichen zu verdeutlichen. (Vgl. Wassermann 1995)

278 Die Komposition, die um 1550 entstand, befindet sich im Louvre.

279 Das Gemälde (Öl auf Leinwand, 186 x $111 \mathrm{~cm}$ ) entstand im Jahr 1874 und befindet sich in der Lady Lever Art Gallery in Port Sunlight. 
Kelch befindet. In der rechten Hand hält der Magier einen Stab in die Höhe. Als Vorlage für dieses Motiv wählte Ulrike Rosenbach das Gemälde „Lady of Shalott“ des englischen Präraffaeliten William Holman Hunt. ${ }^{280}$ Das kleine Gemälde, das nach einem gleichnamigen Gedicht des englischen Dichters Tennyson aus dem Jahr 1857 entstand, zeigt eine tanzende Frau, die in einem magischen Kreis gefangen ist und nur durch einen Zauberspiegel, der im Hintergrund zu erkennen ist, sehen kann, wer sich dem Schloss nähert. In diese Komposition hat die Künstlerin ihr eigenes Bild montiert und zwar so, dass der eigene Oberkörper samt Kopf in Frontalansicht aus der Vorlage hervortreten. Dabei hat die Künstlerin entsprechend der Haltung der Figur des Tarotdecks und abweichend von der Haltung der nach vorn gebeugten Tänzerin den rechten Arm erhoben. Anders als bei den drei Schwarzweißarbeiten zum „Female Energy Change“ bleiben in der Tarotserie die Bildorte erhalten, hier ist es die Künstlerin, die im Fotoabbild in diese Bildwelten eindringt und das Bild mit neuen Inhalten füllt.
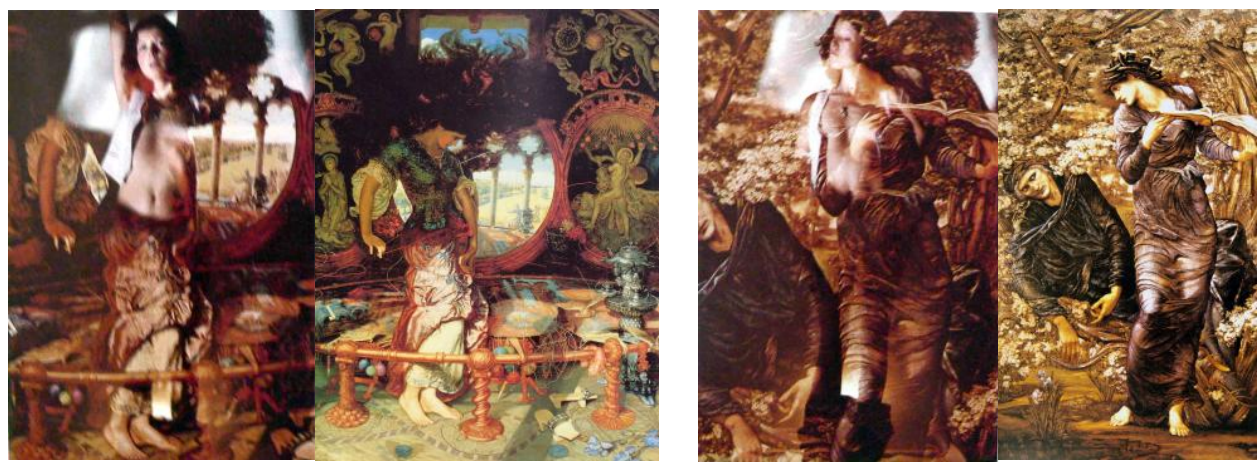

Abb. 66-69: Bilder Zum Tarot - The Fool, Fotocollage, und William Holman Hunt, Die Dame von Shalott, 1896-1905, Bilder zum Tarot - The Magicien, Fotocollage und Edward Burne-Jones, Vivien und Merlin, 1870-4

Der Arbeit mit dem Venusmotiv vorausgegangen war eine intensive Auseinandersetzung der Künstlerin mit Sexismus und weiblichen Schönheitsidealen. Im Jahr 1968 hatten amerikanische Feministinnen erstmals gegen die „Miss America Wahl“" demonstriert und Symbole weiblicher Unterdrückung öffentlich verbrannt. Zahlreiche Frauenorganisationen schossen in den USA aus dem Boden und führten die Kritik an sexistischen Institutionen der Gesellschaft fort. ${ }^{281}$ Auch die Frauen des Feminist Art Programms hatten sich mit dem Thema Anfang der 1970er intensiv beschäftigt. Dieses Mitte der 1970er Jahre auch weiterhin aktuelle

280 Das zwischen 1886 und 1905 entstandene Werk befindet sich in der Manchester City Art Gallery (Öl auf Holz, 44,4 x 34,1 cm). Dieses kleine Gemälde wird uns in Zusammenhang mit dem Orphalia-Werkkomplex in Ulrike Rosenbachs Werk wieder begegnen. (Vgl. Kap. IV.5.3.)

281 Lennox 1982 
Thema bildet im Schaffen von Ulrike Rosenbach einen umfangreichen Werkkomplex. Sowohl das Venus- als auch das Madonnenmotiv erforschte die Künstlerin intensiv im Kontext ihrer Suche nach weiblicher Identität. Sie fand das Venusmotiv häufig in der Produktwerbung wieder - zum Beispiel in der Werbung für Pelzmäntel oder Unterwäsche - als Symbol körperlicher Jugend und Schönheit. Aus der ehemaligen Muttergöttin mit ihren Aspekten der Fruchtbarkeit und Wiedergeburt - der ursprünglichen Bedeutung des Venusmythos - sei ein Klischee für die erotische Anpassung der Frau an die sexuellen Bedürfnisse einer Männerwelt geworden, stellte sie fest. ${ }^{282}$

Ihre Erkenntnisse setzte die Künstlerin in verschiedenen künstlerischen Arbeiten um, wie ihrem „Aphrodite TV“. In dieser Fotoserie mit Porträts prominenter Frauen, ergänzt um Interviews über deren eigenes Selbstverständnis, warf Ulrike Rosenbach 1976 einen entlarvenden Blick auch auf das sexistische und diskriminierende Frauenbild im Fernsehen. Sich auf eine weibliche Bildsprache beziehend, präsentierte sie die Porträts auf einem kleinen Monitor, der - anstelle einer Perle in einer Muschel stand.

Aus der intensiven Auseinandersetzung mit dem ebenfalls in dieser Zeit bearbeiteten Madonnenthema ging nicht nur die bereits vorgestellte Aktion „Glauben sie nicht, dass ich eine Amazone bin“ hervor. Das Thema der „Madonna“ fand Mitte der 1970er Jahre Niederschlag in weiteren Arbeiten, in denen die Reduktion der Frau auf die Aspekte der Schönheit und Mütterlichkeit, wie sie die Künstlerin im Bild der christlichen Madonna konnotiert sah, hinterfragt wurden.

Seinen vorübergehenden Abschluss fand diese künstlerische Auseinandersetzung in dem schwarzweißen, zwölf Minuten langen Videotape „Madonnas of the Flowers“, das im Jahr 1975 entstand und den Untertitel trägt „das Ende einer Identitätsphase“. Angeregt wurde Ulrike Rosenbach zu diesem Werk nach eigenen Aussagen durch die „Pasadena Rose Parade“. Bei diesem kilometerlangen Umzug im kalifornischen Pasadena, den die Künstlerin am Neujahrstag 1975 beobachtet hatte, wurde von Frauen ein Blumenkorso gebildet. Rosenbach selbst beschreibt die Parade als „kalifornisches Spektakel der Werbung für die Schönheitsklischees der Frau“. 283

In dem Videotape sind zwei ähnlich lange Sequenzen als Aufnahmen mit einer festen Bildeinstellung aneinander gereiht, die beide eine ähnliche Aktion zeigen. $\mathrm{Zu}$ sehen sind nacheinander in Großaufnahme die Köpfe der damals siebenjährigen Tochter der Künstlerin und der Künstlerin. Beide Köpfe sind dabei jeweils in durchscheinende Gaze gehüllt. ${ }^{284}$ Hinter ihnen ragt ein transparenter Strahlen-

282 Rosenbach 1982, S. 13

283 Rosenbach 1982, S. 8, zu dieser Parade entstand auch eine Fotoserie Rosenbachs.

284 Hier ist der wichtigste Teil, das Gesicht des Mädchens, der Frau, das auch im Mittelpunkt der thematisierten Schönheitskonkurrenzen steht, verhüllt. Durch diese Verdeckung wird diesem 
kranz mit vierzehn spitzen Zacken heraus, und vor dem Gesicht wird ein durchsichtiger Fächer geschwenkt, der die Darstellung verfremdet, da sich auf ihm zahlreiche Lichtreflexe spiegeln. Generell wird in dem Tape mit Lichteffekten gespielt, so sind die Züge des mit der Gaze überzogenen Gesichtes je nach Ausleuchtung klarer oder verschwommener zu sehen. Zudem wird in dem Schwarzweißband explizit mit Verschattungen gearbeitet, sowie mit dem Wechsel von hell und dunkel zwischen Hintergrund und weiß verschleiertem Kopf gespielt wird. Schließlich löst sich der erste Kopf im Dunkel, der daraus auftauchende zweite Kopf im hellen Licht auf. Während zur ersten Sequenz melodiöse Musik erklingt, die „das En-

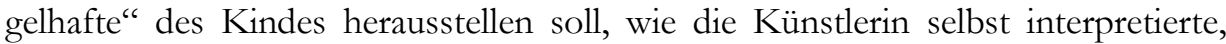
werde die zweite Sequenz mit dem Abbild der erwachsenen Frau, begleitet von säuselnder Hawaiimusik, von der Künstlerin als „lächerliche Kitschigkeit“ beschrieben. ${ }^{285}$

Rosenbach lässt in dieser Arbeit das durch madonnenhafte, heilige Züge charakterisierte Bild der Frau - hier vermittelt durch Schleier und Sternenkrone - sich in Lichtenergie auflösen. Die Krone ist Zeichen der Würde und Macht des Herrschers. Maria trägt in der christlichen Ikonographie als Himmelsgöttin häufig eine Krone aus Sternen. ${ }^{286}$ Die Sternenstrahlen rahmen das verschleierte Gesicht, das damit ganz wörtlich als das eines „Stars“ - Sternes - erscheint. Die Zacken des Strahlenkranzes in Rosenbachs Tape erinnern zudem an die Krone der amerikanischen Freiheitsstatue, so dass bei dem gewählten Bildmotiv auch der Aspekt der Freiheit eine Rolle spielt. Das Tape löst in ganz anschaulicher Weise ein für die Künstlerin als fragwürdig empfundenes Wunschbild auf und stellt die Frage nach dem Wert des jugendlichen Schönheitsideals. ${ }^{287}$

Interessant ist zudem die Motivwahl, denn beide Köpfe sind gekrönt von einem gläsernen Strahlenkranz. Die Krone ist Zeichen der Würde und Macht des Herrschers. Die Jungfrau Maria trägt in der christlichen Ikonographie als Himmelsgöttin häufig eine Krone aus Sternen. ${ }^{288}$ Die zackenförmigen Strahlen des Sternenkranzes in Rosenbachs Tape erinnern zudem an den Sternenkranz der amerikanischen Freiheitsstatue. Die über vierzig Meter hohe Statue, die seit 1885/86 als Geschenk Frankreichs an die USA auf Ellis Island im New Yorker Hafen steht, ist von dem Franzosen Frédéric Auguste Bartholdi geschaffen und im Laufe der Jahrhunderte zum Sinnbild geworden für den Traum von Freiheit im

vom Rezipienten aber eine besondere Aufmerksamkeit zugebracht. Ein stilistisches Mittel, dass sich in ausgeprägter Form im Werk von John Baldessary findet.

Rosenbach 1982, S. 132

286 Zerbst/Kafka 2003, S. 279f

287 Jochimsen kritisierte an diesem Werk Rosenbachs, dass die Arbeit nicht positiv stimulierend wirke. Sie schaffe kein neues Bild, entwerfe kein Bild einer selbstbewussten, starken, mutigen, unabhängigen Frau, die bei allen neuen Qualitäten Frausein bejaht und bewahrt. Jochimsen in: Kat. Bonn 1976, o.S.)

288 Zerbst/Kafka 2003, S. 279f 
„Land der unbegrenzten Möglichkeiten“. Die Personifikation der Freiheit hält in ihrer rechten Hand eine Fackel erhoben, in der linken ein Buch unter dem Arm und ihr Haupt krönt eine Sternenkrone mit sieben Spitzen. ${ }^{289}$ Vor diesem ikonographischen Hintergrund ist bei der Interpretation des Madonnentapes zudem der Aspekt der Freiheit, Befreiung zu berücksichtigen.

Ihre Performance „Reflexionen über die Geburt der Venus“ hat Ulrike Rosenbach erstmals im Jahr $1976 \mathrm{im}$ „Womans Buildung“ aufgeführt. Es ist eine Aktion im Rahmen ihrer Suche nach weiblicher Identität, die das medial geformte und sexistisch belegte Klischee der Göttin der Schönheit hinterfragte. Für die Künstlerin hatte die von ihr für die Aktion ausgewählte schon erwähnte Venusdarstellung von Botticelli eine ganz besondere, positiv Bedeutung:

„Botticelli ist der einzige Maler, den ich kenne, der die Venus tatsächlich im vorpatriarchalischen Sinne interpretiert hat. Sie kommt vom Meer aufs Land und in dem Moment blühen die Blumen auf. Erst später wurde die Venus ein erotisches Symbol. "290

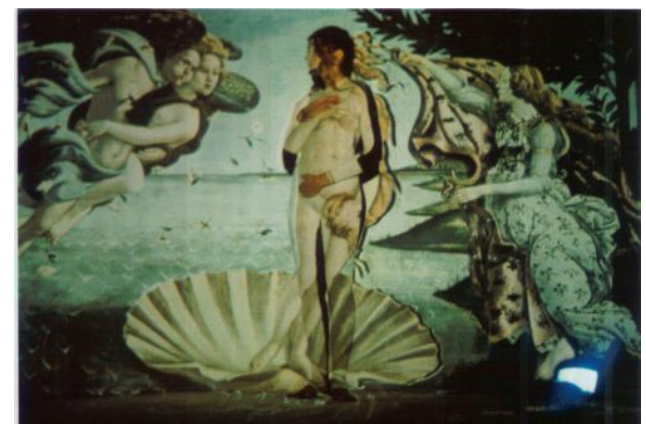

Abb. 70: Reflexionen über die Geburt der Venus, 1976, Aktionsfoto

Das Gemälde von Sandro Botticelli - kultureller Inbegriff der visuellen Darstellung dieser mythologischen Venus - war für die Aktion der Künstlerin lebensgroß an die Wand projiziert. Vor der Bildprojektion war auf den Boden ein großes Dreieck aus Salz gestreut, worauf ein überdimensional großes weißes Muschelobjekt aus Styropor mit einem kleinen Videomonitor stand. Auf dem Bildschirm lief ein Videotape, das die Meeresbrandung zeigte. Für ihre Aktion trat die Künstlerin in die Venusprojektion, so dass das Bild der gemalten Figur genau auf ihrem Körper lag. Die Vorderseite ihres anliegenden Trikotanzuges war weiß, die Rückseite schwarz gefärbt. Sehr langsam begann die Künstlerin nun, sich um sich selbst zu drehen. Fiel das Licht der Projektion auf den schwarzen Rücken, verschwand das Bild, fiel das Dia auf die weiße Vorderseite war die Botticelli-Venus wieder gut

\footnotetext{
289 Vgl. Lurker 1991, S. 214

290 Rosenbach in: EMMA 1978, Nr. 4, S. 16
} 
sichtbar und die historische Malerei Darstellung überzog den Körper der Künstlerin. Die viertelstündige Aktion wurde umrahmt durch eine Tonschleife des Liebesliedes „Sad-eyed Lady of the Lowlands“ des Sängers Bob Dylan. In dem verschlüsselten Text der Ballade aus dem Jahr 1966 geht es um eine schwarze Madonna, dunkle Frau. ${ }^{291}$

Die Künstlerin drehte sich während dieses Songs sehr langsam in der Bildprojektion um ihre eigene Achse. Durch ihre Drehung entzog sie sich immer wieder der Projektion durch das mythische Schönheitsideal der Schaumgeborenen, bevor es erneut auf ihrem Körper sichtbar wurde, um Stück für Stück wieder im Dunkel des Trikots zu verschwinden. Die Kunsthistorikerin Marlis Grüterich stellte in ihrer feministischen Interpretation den Aspekt der Metamorphose in dieser Aktion heraus:

„Die Venus-Aktion und -Installation "Reflektion über die Geburt der Venus" 1976/8, halfen der ewig jungen Dame bei ihrer Wohlstandswiedergeburt aus Pel₹mänteln und Unterwäsche heraus, aus ibrer Schönheitsköniginnen-Pose und Kino-Star-Rolle. Aber wie soll die Schönheit konsumierende Kunstwelt an den Strand von Kythera zurückgelangen, wo die Schaumgeburt der Muttergöttin einst den Frübling beginnen ließ? Auch Botticelli war auf den blühenden Körper der Fran in der Meeresmuschel fixiert. Eine Florentiner Dame, die den Auftraggeber interessierte durfte sich identifizieren. In der lebensgroßen Projektion von Botticellis Früblingsbild drehte sich bei Rosenbach die wohlgeformte Künstlerin/Bildhauerin um sich selbst. Das vorne weiße und hinten schwarze Trikot erlaubte es ihr, mit dem Inbegriff von Jugend und Schönheit eins zu werden und sich wieder davon zu lösen. Der Tod des Bildes und seine Wiedergeburt nahmen menschliche Züge in einem neuen-alten Frauenbild an. In momentaner Selbst-

291 Der Text der ersten Strophe dieses Songs aus dem Jahr 1966, das auf dem Album „Blonde on Blonde" von Bob Dylan erschien, lautet:

„With your mercury mouth in the missionary times,

And your eyes like smoke and your prayers like rhymes,

And your silver cross, and your voice like chimes,

Oh, who among them do they think could bury you?

With your pockets well protected at last,

And your streetcar visions which you place on the grass,

And your flesh like silk, and your face like glass,

Who among them do they think could carry you?

Sad-eyed lady of the lowlands,

Where the sad-eyed prophet says that no man comes,

My warehouse eyes, my Arabian drums,

Should I leave them by your gate,

Or, sad-eyed lady, should I wait?"

Ulrike Rosenbach gibt in ihrem Katalog von 1982, S. 13, die deutsche Übersetzung von Carl

Weissner an (Vgl. Weissner/Hartmann 1985) 
wahrnehmung erneuerte die Frau die mythische Metamorphose oder ihre Symbiose mit der äußeren Natur. "292

Neu ist bei dieser eindringlichen Performance der Künstlerin das formale Element der großformatigen Diaprojektion. Die Ausdrucksweise, die die sie zuvor auf der Bildebene erkundet hat, wird in dieser Performance ins Räumlich-Aktive übertragen und ihr Körper zur Projektionsfläche fremder Bilder. Und Wulf Herzogenrath hob im Interview die monumentale und eindrucksvolle Form dieser Rosenbach'schen Aktion hervor:

„Ich denke, dass diese Botticelli-Venus mit dieser großen Medienprojektion auf ibren Körper, sicher eine ihrer eindrucksvollsten Arbeiten war. (...) Sie hatte da einen unglaublich eingängigen Song verbunden mit dem Medialen - bier nicht dem Closed Circuit dafür aber der Großprojektion der Venus. Und sie selbst drehte sich dort ganz. langsam. Das Bild mit der Botticelli Venus bleib gleich, während man sah, wie sie sich aus der $V$ enus heraus und wieder herein drebte. Heute erleben wir ja ständig, dass diese Großprojektionen eine große Bildkraft haben. Das war damals anders - damals konnte man noch kein Video projizieren, kein Künstler, keine Kunstszene batte das Geld für so etwas, für solche Projektoren - technisch gab es das bestimmt schon, aber das konnten die Künstler sich nicht leisten. Da war das Dia eine ganz interessante Form von Nutzung. Nicht mit dem bewegten Bild zu arbeiten, sondern die Bewegung eben selber zu machen. Also solche sehr einfachen Elemente hat Ulrike genutzt. Sie konnte sehr schön bildlich denken. Deshalb haben ihre Aktionen auch sehr viel mit bildender Kunst, mit Bildern zu tun und es hat eben nichts mit Tanz oder Theater zu tun, wobei sicher auch solche Elemente dazugehören."293

Mit diesem ausdrucksstarken formalen Mittel der großformatigen Bildprojektion hat die Künstlerin auch nach ihrer Rückkehr in Deutschland weiter gearbeitet. Wenngleich diese Methode in den „Reflexionen“ erstmals im Werk Rosenbachs erscheint ist diese Form nicht originär der Künstlerin zuzuschreiben. Andere Künstler vor ihr nutzten Lichtprojektionen auf bewegte Körper in Inszenierungen. Zum Beispiel der Amerikaner Robert Whitman, dem 1965 in seinem Stück „Prime Flat" die Körper der Tänzer als Leinwand dienten. ${ }^{294}$ Auch hatte es bereits im Jahr 1963 die Aktion „Suddenly Last Supper“ des englischen Künstlerpaares Mark Boyle und Joan Hill gegeben. Kristine Stiles weist auf die große formale Ähnlichkeit dieser Aktion zu Rosenbachs Arbeit hin. ${ }^{295}$

Bei dem Event in der Londoner Wohnung des Künstlerpaares wurden die Partygäste zunächst in einen dunklen Raum geführt. Dort projizierte Joan Hill wahllos Filmbilder auf weiß angemalte Mannequins, während Mark Boyle Dias, die er

292 Grüterich 1989, S. 6

293 Interview Herzogenrath 2003, Kap. VII.2.

294 Hanhardt in: Kat. Berlin 2004, S. $240 \mathrm{f}$

295 Stiles in: Kat. Los Angeles 1998, S. 280 
gleichzeitig mit Säure verätzte und anzündete, auf eine als Leinwand dienende weiße Papierfläche projizierte. Zu einem bestimmten Zeitpunkt malte eine Assistentin die Leinwand schwarz an, woraufhin der Künstler das Papier herunter riss. Zum Vorschein kam eine weitere weiße Leinwand, auf die Boyle die Venus von Botticelli als Dia projizierte. Anschließend wurde die Leinwand in Stücke zerschnitten und das Bild auf den nackten Körper einer Frau projiziert, die exakt die gleiche Pose einnahm wie die Botticelli-Venus. Diese Frau war aber erst in dem Moment zu sehen, in dem Boyle das Dia der Venus anzündete. Der Körper der Frau wurde dann schwarz angemalt, während weitere Dias auf eine dritte Leinwand geworfen wurden bis auch diese Leinwand geschwärzt wurde und die Bilder auf einen weiß gekleideten Pantomimen projiziert wurden. Auf die verdutzten Gäste wartete nach Abschluss der aufeinander folgenden schwarzweißen Schöpfungs- und Zerstörungstransformation noch eine weitere Überraschung: Hatte das Künstlerpaar doch während der Aktion die Räume seiner Wohnung leer geräumt und war verschwunden. ${ }^{296}$ Es ist nicht klar, ob Ulrike Rosenbach die ihrer Arbeit vorangegangene Londoner Aktion kannte, doch ist unabhängig davon bei Rosenbach trotz der eindeutigen formalen Ähnlichkeiten eine wesentlich andere inhaltliche Konnotation gegeben.

Zusammenfassend lässt sich an dieser Stelle über den Exkurs von Ulrike Rosenbach in die neue Welt sagen, dass sie in den USA ihre Bildsprache um neue Formen und Zeichen erweiterte. Bereits in Deutschland hatte sie über Erscheinungsformen der beschädigten weiblichen Identität und an der Kritik von Bildern tradierter Weiblichkeit gearbeitet. In den USA traf sie nun auf ein explizit feministisch gefärbtes Umfeld, das sie zu spezifisch weiblichen Symbolen inspirierte, die in ihren Werken nun einen Platz finden. Neben dem Madonnenbild, finden sich Venusadaptionen, zudem taucht die Muschelform - mit ihrer Analogie zum weiblichen Genital - wiederholt auf und das Dreieck als allgemeines Symbol für Frau. Die verschüttete Geschichte der Frau, mit der sie sich in dieser Zeit beschäftigte und die sie so kennenlernte, zieht in ihre Werke ein, beginnt ihr Wirken zu durchdringen. Die Künstlerin stellt in ihren in dieser Zeit stark politisch motivierten Arbeiten die Frage, nach der eigentlichen Substanz des Weiblichen unter den historischen Schichten von kulturell tradierten Bildern. ${ }^{297}$ Ihre Ideen setzte die Künstlerin reflektiert und anschaulich ins (bewegte) Bild um, lässt den Frauenkörper direkt zur Projektionsfläche werden.

Wenn Sigrid Schade für die eine Rolle der Frau in der Kunst zusammenfasst, dass „Weiblichkeit nicht in bestimmten Ideal-Bildern definiert wird, sondern dass ihr Status das Bild-Sein ist. Bild aber des abwesenden Blicks: Projektionsfläche,

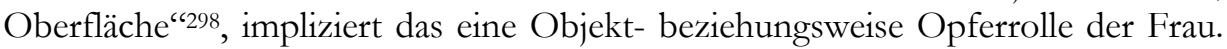

\footnotetext{
296 Stiles in: Kat. Los Angeles 1998, S. 280

297 Zweite 2000, S. 316

298 Schade in: Butin 2002, S. 96
} 
Performerinnen und Körperkünstlerinnen seit den 1970er Jahren haben diese gesellschaftliche zugeschriebene Objektrolle in ihren Arbeiten thematisiert und in der Aktion zu überwinden versucht. ${ }^{299}$ Die Künstlerin - wie auch ihre Kolleginnen - loteten die emanzipatorischen Möglichkeiten der Medien Performance wie auch Video aus. So war das Medium Video von Anfang an ein wesentliches Mittel von Künstlerinnen wie Martha Rosler, Ulrike Rosenbach, Valie EXPORT, Joan Jonas, um die Konstruktionsmechanismen und Zuschreibungen von weiblicher Identität aufzudecken. Und so sagt Lydia Haustein über Rosenbachs Arbeiten:

\section{„Ulrike Rosenbach löste erstmals die durch die Nazizeit geprägten strengen Rollenbilder der Nachkeriegsgeneration auf und überdachte Entstehungsbedingungen von Weiblich- keitklischees, die nach wie vor, von einer patriarchalischen Gesellschaft bestimmt sind. " 300}

Dabei tritt das Gestaltungsmittel der Überlagerung im Werk Rosenbachs zusehends in Erscheinung. Nicht nur im Medium der Fotografie, sondern auch in ihren Videotapes, die in ihrer formalen Gestaltung außer dem elektronischen Stilmittel der weichen Überblendung zu diesem Zeitpunkt noch keine weiteren technischen Tricks aufweisen.

Interessant ist zudem das Motiv des Verhüllens oder auch Einwickelns des Kopfes, das gleich in mehreren der Arbeiten aus der ersten Hälfte der 1970er Jahre auftaucht. Das Motiv zieht sich wie ein roter Faden von den ersten Tapes, wie der „Zeichenhaube“, „Bindenmaske“, „Mon Petit Chou“ bis zu den „Madonnas of the Flowers“, dem Tape, in dem die Gesichter vollständig hinter Gazestoff verhüllt sind. Ein weiteres Motiv das mehrfach wiederkehrt, ist das des Um-dieeigene Achse-Kreisens, wie zum Beispiel in den Reflexionen stehend, im „Frauenkultur - Kontaktversuch“ dann liegend eindringlich vorgeführt. Wie sich diese Formelemente im weiteren Werk entwickeln, soll im Folgenden mit beobachtet werden.

299 Das eine „Projektionsfläche“ eben nicht immer einen Opferstatus implizierte, sondern auch offensiv umgedeutet werden konnte, zeigt vor allem in den 1990er Jahren der Erfolg von Künstlerinnen wie Pipilotti Rist, Sadie Benning oder Tracey Enim, die alle in ihrer Arbeit ohne die Performances von Carolee Schneemann nicht denkbar sind.

300 Haustein 2003, S.78 


\section{III.5. Neuanfang in Deutschland}

Im Jahr 1976 kehrte Ulrike Rosenbach nach Deutschland zurück. Sie lebte und arbeitete die folgenden Jahre in der Kunstmetropole am Rhein. Angeregt durch ihre Erfahrungen mit den amerikanischen Künstlerinnen, beschäftigte sie sich in dieser Zeit weiterhin intensiv mit feministischen Themen. Sie gründet die Arbeitsgruppe „Schule für kreativen Feminismus“, engagierte sich eine Weile bei der von der ebenfalls in Köln ansässigen Alice Schwarzer - neu gegründeten Frauenzeitschrift „Emma“, beteiligte sich an den Anti-Pornographie-Aktionen einer Gruppe Kölner Frauen und gehörte 1979 zu den Mitbegründerinnen des ersten Frauenkulturzentrums in Köln. Sie führte zudem ihre feministisch motivierten Videoperformances an ganz unterschiedlichen Orten in Europa auf, von Amsterdam bis Florenz, war zudem auch an internationalen Schauen beteiligt, wie der documanta 6 beteiligt und der Biennale in Sydney 1979. Dabei hob die Künstlerin im Gespräch die Sonderstellung feministisch ausgerichteter Kunst in Europa Mitte der 1970er Jahre deutlich hervor:

„Zu der Zeit, diesen politischen Mut zu haben, das zu sagen, dazu gebörten wirklich nur sehr wenige. "301

In den USA sei das Klima für feministische Gedanken offener gewesen und die Frauenbewegung dort bereits zur gesellschaftlichen Bewegung gewachsen gewesen. Wieder in Deutschland musste die Künstlerin zunächst Grundlagenarbeit leisten.

\section{III.5.1. Die Schule für kreativen Feminismus}

Gleich nach ihrer Rückkehr aus den USA rief Ulrike Rosenbach in Köln eine Arbeitsgruppe für Frauen mit dem Titel „Schule für kreativen Feminismus“ ins Leben. Fußend auf den erworbenen Erfahrungen, verstand die Künstlerin den gewählten Namen als politische Willenserklärung: Ging es ihr doch darum, mit Hilfe dieser Institution zur Definition eines neuen Kulturbegriffs beizutragen durch den die kreativen Fähigkeiten von Frauen und Männern als gleichwertig anerkannt würden. ${ }^{302} \mathrm{Ihr}$ Vorwort der Dokumentation über die „Schule für kreativen Feminismus“ eröffnete Ulrike Rosenbach 1980 mit den Worten:303

301 Rosenbach im Gespräch 2001, Kap. VII.1.

302 Rosenbach in: Schule für kreativen Feminismus 1980, S. 1

303 In dieser Dokumentation über dieses „Beispiel autonomer Kulturarbeit“, so der Untertitel dieser Dokumentation, wurde das Projekt ausführlich vorgestellt und mehrere der behandelten Themen näher ausgeführt, wie zum Beispiel Mondphasen, Menstruation, Masken, Hexen, die Situation und Position der Künstlerin, Frauen gegen Pornographie. Außerdem wurden Literaturvorschläge gegeben, wie die Klassiker „From the center“ von Lucy Lippard und „Through the 
„Durch die Geschichte unserer Unterdrückung begleitet uns Frauen das Gespenst schöpferischer Unfähigkeit. Die von Männern gescbriebene Kunstgescbichte hat nicht nur die Namen der wenigen Künstlerinnen, die es gab, gerne verschwiegen, sie hat auch eine Definition von Kunst hervorgebracbt, die einem männlichen Schöpfungsbegriff folgt und Frauen eine ausschließlich reproduktive Stelle zuneist." 304

So stellte die Arbeitsgruppe, angelehnt an das Vorbild der amerikanischen Consciousness-Raising-Gruppen (CR-Gruppen), einen Versuch dar, interessierten Frauen einen Raum zu bieten, einerseits die Geschichte der Frau theoretisch aufzuarbeiten, andererseits die eigenen praktischen Erfahrungs- und Ausdrucksmöglichkeiten zu erweitern und zudem sollte die „Schule“ eine Möglichkeit bieten, sich Kunst in all ihrer Vielfalt offener und neugieriger zu nähern.

Im Frübjabr 1977 trafen sich die Teilnehmerinnen zum ersten Mal. Es kam eine heterogene Gruppe zusammen, bestehend aus drei Hausfrauen, drei Sekretärinnen, drei Grafikerinnen, zwei Kunststudentinnen und mehreren Frauen obne Beruf. Die Altersspanne der Teilnehmerinnen lag zwischen 22 und 40 Jahren, so dass die Frauen ganz unterschiedliche Erfahrungen und Bildungshintergründe mitbrachten. ${ }^{305}$ Die Teilnahmegründe, ließen sich laut Rosenbach in zwei Punkten zusammenfassen: Zum einen wollten die Franen etwas für sich tun, zum anderen sucbten sie nach einem neuen Antrieb und ibre Lebensumstände zu ändern. ${ }^{306}$ Die Gruppe traf sich im wöchentlichen Rhythmus und es wurden bei den Treffen abwechselnd drei Arbeitsfelder bearbeitet: theoretische Erforscbung der weiblichen Kulturgeschichte, Selbsterfahrung und praktische künstlerische Arbeit.

Ihre Erfahrungen mit der ersten Gruppe fasste Rosenbach in einem Artikel in der für kurze Zeit erschienenen (Frauenkunst-) Zeitschrift „Kassandra“ zusammen:307 Während die Erarbeitung der Kulturgeschichte der Frau und auch die kreative praktische Arbeit sich sehr fruchtbar entwickelten, sei es zunächst schwierig gewesen, die Frauen zu ebenso großer Anteilnahme an den so genannten Selbsterfahrungsabenden zu bewegen. Diese seien für einige nur schwer zu ertragen gewesen. ${ }^{308}$ Bei diesen Treffen sollten nach dem Vorbild der amerikanischen CRGruppen Gruppengespräche zur Bewusstseinsentwicklung geführt werden. An jedem Abend, der nach bestimmten Regeln gestaltet war, stand jeweils ein bestimm-

Flower" von Judy Chicago, sowie eine ausführliche Anleitung zum Consciousness-Raising. In EMMA wurde diese Buchdokumentation hochgelobt und betont, sie ermögliche Frauen sich auszudrücken und damit auch eine zusätzliche Dimension des Fühlens und Denkens zu erkunden. (EMMA 12/1980, S.56f)

304 EMMA 12/1980, S. 56f

305 EMMA 12/1980, S. 56f; Kassandra 1/1978, S. 58

306 Rosenbach 1980, S. 1

307 Kassandra 1/1978, S. 58

308 Kassandra 1/1978, S. 58 
tes Thema im Mittelpunkt, wie zum Beispiel das persönliche Verhältnis zu Kindheit, Eltern, Freunden oder aber auch Themen wie Ehe, Christentum oder Abhängigkeit. Jedes Gruppenmitglied konnte zunächst fünf Minuten zu dem ausgewählten Thema über seine Erfahrungen sprechen, wobei während dieser Phase des „Zeugnisablegens“ auf Rückfragen aus der Gruppe möglichst verzichtet werden sollte. Wichtig war, dass die Beiträge ehrlich waren, das heißt konkret, mutig und offen über Erfahrenes gesprochen wurde. Die Betroffenheit jeder Einzelnen sei wichtiger gewesen als eine bereits eingetretene Reflexion, hob Rosenbach hervor. Im Anschluss folgte die Phase der analysierenden Gesprächsführung, in der die geschilderten Erfahrungen diskutiert und politisch analysiert wurden, wobei Wertungen vermieden werden sollten. ${ }^{309}$ Ziel der Analyse in der Gruppe sollte die Politisierung des eigenen Bewusstseins sein, woraus sich wiederum ein neuer $\mathrm{Zu}$ gang zum kreativen Potenzial öffnen konnte. Und wenn manche der Frauen mit der Erwartung begonnen hatten, ihre Situation zu verändern, so beobachtete die Künstlerin nach eingier Zeit, dass sich wirklich bei einigen der Frauen im Verlauf des Kurses ihre Lebensumstände positiv verwandelten. ${ }^{310}$ Die Arbeit der Schule für kreativen Feminismus fand im Jahr 1982 ein Ende, als sich Ulrike Rosenbach allgemein von der feministischen Arbeit abwandte.

\section{III.5.2. Fotografische Arbeiten für die Zeitschrift „Emma“}

Am 26. Januar 1977 erschien die erste Ausgabe der Monatszeitschrift „EMMA“, die ein so großer Verkaufserfolg wurde, dass, nachdem die erste Auflage von 200000 Exemplaren ausverkauft war, weitere 100000 nachgedruckt wurden. Alice Schwarzer hatte die Idee für dieses politische Magazin für Frauen entwickelt, das kein Fachblatt für Feministinnen sein sollte, sondern eine Zeitschrift mit hoher Auflage, die sich an alle Frauen richtete. Die Journalistin und Autorin, die im Sommer 1971 mit der Initiierung der Aktion „Ich habe abgetrieben“311 eine breite Kampagne gegen den Paragraphen 218 ausgelöst hatte, lebte damals in Köln, wo auch die Redaktion der Zeitschrift ihren Sitz hatte. ${ }^{312}$

\footnotetext{
309 Rosenbach 1980, S. 50

310 Rosenbach 1980, S. 1

311 Veröffentlicht im Stern am 6.6.1971

312 Dünnebier/Paczensky 1999, S. 115 bis S. 123
} 


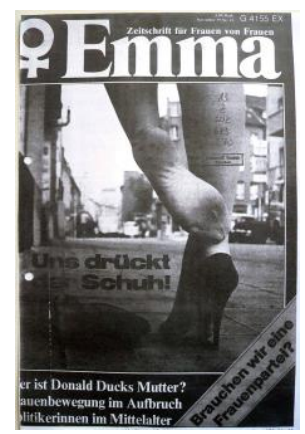

Abb. 71: Titelfoto von Ulrike Rosenbach, Emma November 1979, Nr. 11

„Ich bin Künstlerin, ich bin Feministin. Ich will hier mitarbeiten. “313 Laut der Biographie über Alice Schwarzer hat Ulrike Rosenbach mit diesen Worten die Redaktion am Kolpingplatz im Zentrum Kölns im Jahr 1977 betreten. Bis Ende 1980 fotografierte und collagierte die Künstlerin als freie Mitarbeiterin Titelbilder für verschiedene Ausgaben der „EMMA“. Ihre Fotos fielen „durch Einprägsamkeit und künstlerische Phantasie auf ${ }^{f * 314}$, wie Anna Dünnebier charakterisiert, die zudem beschreibt:

„[Ulrike Rosenbach] arbeitete oft mit geringsten Mitteln: Ein paar Frauenbeine in roten Highbeels, ein Schub ausgezogen, der bloße Fuß verquält verdreht - da tun sich für Frauen sofort alle Widersprüche zwischen Mode und Vernunft, Einsicht und Gefallenwollen auf." 315

\section{III.5.3. Feministische Tapes und Performances}

Seit dem Jahr 1975 bezeichnete Ulrike Rosenbach ihre künstlerische Arbeit explizit als feministisch. ${ }^{316}$ Wenngleich die Künstlerin sich aktiv in der Frauenbewegung engagierte, ist ihre Kunst auch der Kritik von Frauen ausgesetzt gewesen. Als sie zum Beispiel 1977 im Rahmen der Ausstellung „Künstlerinnen international 1877-1977“ im Charlottenburger Schloss in Berlin ihre Performance „10.000 Jahre habe ich geschlafen" zeigte, in der sie in symbolischer Form eine Wiedergeburt der Frau aufführte, reagierte eine Gruppe Frauen unerwartet impulsiv auf dieses als meditativ angelegte Werk.

Für die Aktion war in einem der Säle auf dem Fußboden ein großer Kreis aus weißem Salz ausgebreitet, in dessen Zentrum eine Fläche aus grünem Moos einge-

313 Dünnebier/Paczensky 1999, S. 125

314 Titelfotos von Ulrike Rosenbach zeigen die EMMA-Nummern: 5/1978, 8/1978, 12/1978, 1/1979, 11/1979.

315 Dünnebier/Paczensky 1999, S. $125 f$

316 Rosenbach 1980, S. 1 
fügt war. Eingespannt in einen langen Bambusbogen lag die Künstlerin in dem Moosbett in gekrümmter Haltung, bekleidet mit ihrem weißen Trikot. Um das Ensemble kreiste auf einer schmalen Metallschiene ununterbrochen eine Videokamera mit zum Mittelpunkt gerichtetem Objektiv. Die aufgenommen Videobilder wurden auf Bildschirme außerhalb des Salzkreises übertragen.

Drei volle Stunden sollte der bewegungslose „Schlaf“ der Künstlerin dauern, bevor sie sich schwerfällig aus der kauernden Haltung erheben wollte, um erst den Stromkreis für das Videogerät kurz zuschließen und dann in langsamen Schritten um den weißen Kreis herumzugehen und den Satz „Zehntausend Jahre habe ich geschlafen und nun bin ich erwacht" mit der Hand in das Salz zu schreiben. ${ }^{317}$
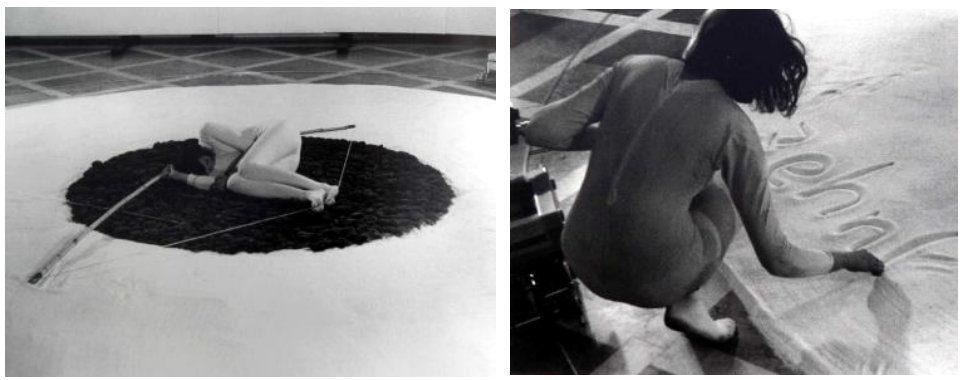

Abb. 72-73: 10000 Jabre habe ich geschlafen, 1977, Aktionsfotos

Diese langatmige Videoperformance provozierte eine Gruppe Hamburger Frauen zu einer spontanen „Aktion gegen Kunst“, die den geplanten Ablauf der Performance veränderte. ${ }^{318}$ Eine der Hamburger Frauen beschrieb das Geschehen:

„Als wir in der Orangerie ankamen, lag Ulrike R. schon in ibrem Bogen, eine Videokamera auf Schienen schnurrte um sie herum und zeigte sie auf dem Fernsehschirm von allen Seiten. Wichtig und geschäftig bedienten 3-4 Typen abwechselnd ein paar Knöpfchen. Andächtige Stille, die gleiche Stille wie in Museen, Konzerten - alle flïsterten, warteten, stierten, warteten, stierten. Allmählich packte uns die Wut: Wir hatten das Gefühl die gleichen inhaltlosen, bedeutungsvoll aufgeblähten, Kunst'inhalte im feministischen Kleid verkauft zu kriegen. Die Szenerie hatte sich kaum gegenüber sonstigen Aktionen des Kunstmarktes geändert: die Männer waren zuständig für Verantwortung, Technike und Ausführung und die Frau war wie immer das passive Medium. Und auch nach einer $3 / 4$ Stunde traute sich kein Mensch laut etwas zu sagen, zu fragen, Überlegungen oder Kritik zu äußern!

Wir überlegten, wie wir eine Verbindung zu der Frau herstellen könnten, uns aus dieser Konsumbaltung befreien, eine Diskussion darüber in Gang bringen könnten. Nach vie-

317 Kat. Berlin 1977, S. 258

318 Die Fotografien, die während der Performance entstanden, zeigen keinerlei Zuschauer. 
lem Hin und Her beschlossen wir, einen Wecker zu kaufen, ibn klingeln ₹u lassen und dann alle - um den Kreis herumgehend - laut zu rufen: „W Wach doch endlich auf!" (...) Als der Wecker dann klingelte - leider viel zu leise - begannen wir dann auch nur ziemlich zaghaft und vereinzelt zu rufen: wach doch endlich auf! Deutlich wurde unsere Aktion erst, als eine Frau den "magischen Kreis" "̈̈berschritt und in das Salz schrieb: „Du bast verschlafen - wir sind schon anfgewacht." Und was passierte?!?! Der stiernackige Hauptmacker kommt auf sie zu, zerrt sie am Arm und sagt: Rauskommen, sonst knall's! (Und wir standen wieder wie gelähmt, statt uns alle auf ihn zu stürzen!) Nur eine Frau reagierte wütend auf uns, wollte alles in Rube betracbten. Die meisten guckten uns nur verständnislos und peinlich berïhrt an.

Endlich fingen wir dann an zu singen: ,Amazone, spann den Bogen an, denn es gibt zu viele Männer bier im Land, laß die Pfeile fliegen.. "Und siehe da Ulrike Rosenbach erhob sich eine Viertelstunde früher als geplant aus ibrem Bogen und schien unsere Aktion gut gefunden zu baben, und entscbuldigte sich für den Typ. Als wir sie später fragten, warum sie nicht schon früher aufgestanden sei und sich mit u $n$ s solidarisiert bätte, meinte sie, daß unsere Aktion noch nicht das entsprechende Niveau zu diesem Zeitpunkt gebabt bätte.(!!!!) [sic] 's19

Diese Beschreibung zeugt zum einen von der emotional sehr aufgeladenen Atmosphäre in dieser Zeit. ${ }^{320}$ Zum anderen kann sie aber auch als Zeugnis gelesen werden für die Eindringlichkeit der Aktion, die in den Frauen ein aktives Handeln provozierte, das wiederum in der Künstlerin einen Impuls auslöste, ihre Aktion vorzeitig zu beenden - beziehungsweise sich ganz konkret wecken und aufrütteln zu lassen und damit eine Form gelungener Kommunikation beschreibt. ${ }^{321}$

Moosbett, Bogen und Salzkreis sowie kreisende Videokamera und ClosedCircuit Videobild sind in der Aktion die tragenden Elemente. Der Bogen beziehungsweise die pfeilschießende Frau begegnetete uns im Werk der Künstlerin bereits und dieses Bildzeichen zieht sich durch feministische Bildentwürfe. Ein mythologisches Vorbild einer Pfeil und Bogen nutzenden Frau findet sich in der römischen Diana, der Göttin des Lichtes, der freien Natur, des Wildes wie auch der Jagd. Diana entspricht zudem der griechischen Artemis, der Göttin der Jagd und Fruchtbarkeit, die ebenfalls mit den Attributen Pfeil und Bogen verbunden ist.

319 Britta in: Frauenzeitung 1977, S. 11-12

320 Diese durch Radikalität geprägte Atmosphäre spiegelt auch ein Zitat von Valie EXPORT: „die frau muß sich also aller Medien als mittel des sozialen kampfes und als mittel für den gesellschaftlichen fortschritt bedienen, um die kultur von den männlichen werten zu befreien. [...] ES IST AN DER ZEIT, daß wir frauen das ausdrucksmittel kunst benützen, um das bewußtsein aller zu beeinflussen, um unsere vorstellungen in die gesellschaftliche konstruktion der wirklichkeit einfließen zu lassen, um eine menschliche wirklichkeit zu schaffen.“ (Export in: Woman's Art 1973, S. 228)

321 Es ist übrigens das einzige gefundene Zeitzeugnis, das über eine solche starke Reaktionen im Publikum bei einer Aktion Rosenbachs berichtet. 
Während bei ihrer Amazonenperformance die Künstlerin aktiv Pfeile auf ein Bild schoss, wird sie in der Berliner-Aktion jetzt selbst zum Pfeil, der in Embryohaltung die im Bogen aufgebaute Spannung über einen langen Zeitraum aushält.

Auch das Element des Salzgrundes ist uns schon im Werk Rosenbachs begegnet, zuvor in Form des Salzdreieckes bei ihren „Reflexionen“. Jetzt zeigt der Salzgrund die Form des Kreises. Diese geometrische Form begegnete uns bereits beim „Projekt Kinem“ als räumliche Markierungslinie des künstlerischen Rituals. Anders als dort, kreist in diesem Werk die Kamera automatisch um das Rund, den Blick auf das Zentrum gerichtet. Damit gibt die Aufnahme auf den außerhalb stehenden Monitoren Bilder der am Boden Liegenden wieder, aufgenommen aus einer Perspektive nah über dem Boden.

Diese elektronische Bildübertragung wird zum Ende der Aktion von der einsetzenden aktiven Handlung der Performerin abgelöst, in dem die Akteurin zunächst den Stromkreis unterbricht und damit der Fokus auf das körperliche Agieren der Künstlerin gelenkt wird. Die Kamerabewegung wird damit durch die Körperbewegung ersetzt. Zudem wird ein weiterer Kommunikationscode hinzugefügt. Mit ihrer Hand schreibt die Künstlerin den Satz „Zehntausend Jahre habe ich geschlafen und nun bin ich erwacht" in das Salz und resümiert und beschließt mit diesen in den weißen Grund eingedrückten Worten die Aktion. ${ }^{322}$

Das Jahr 1977 ist im Werk Ulrike Rosenbachs unglaublich produktiv. Insgesamt sieben unterschiedliche Performances entstehen und werden - zum Teil mehrfach aufgeführt. Auf die „Zehntausend Jahre habe ich geschlafen"-Aktion folgte „Frauenkultur-Kontaktversuch“, der im Anschluss eingehend untersucht werden soll. Und weitere explizit feministische Performances folgten in diesem Jahr, wie die „Venusdepression-Medusaimagination“, „Köln-Florenz 1:1000“ und zwei Videoliveperformances mit der Kölnerin Andrea Siebrasse, die die Künstlerin über die Schule für kreativen Feminismus kennengelernt hatte.

Zunächst soll ein kurzer Blick auf eine andere Aktion aus dem Jahr 1977 geworfen werden. Taucht doch in der Closed-Circuit-Aktion „Maifrau“ erneut das Thema der Diana auf. Bei dieser mit dem Closed-Circuit-Verfahren arbeitenden Aktion, saß die Künstlerin 90 Minuten praktisch unbeweglich auf einem Stuhl, der inmitten einer weißen auf den Boden gezeichneten Spirale stand, vor der Videokamera und wiederholte im Atemrhythmus ununterbrochen das Wort „Frau“.323 Das währenddessen von ihr aufgezeichnete Bild konnte die Künstlerin dabei selbst nicht sehen. Vielmehr wurde dieses in benachbarte Räume übertragen und

322 Der Berliner Katalog druckt als Text zu der Aktion einen Auszug aus dem „ersten manifest zur kulturrevolution der frauen“. (Kat. Berlin 1977, S. 258)

323 Das Motiv der Spirale ist in vielen Kulturen allgegenwärtig, besonders auch spielt es bei den nordamerikanischen Indianern einen wichtige Rolle. Zur Spirale als Sinnbild des Lebens s. a. Zerbst/Waldmann 2003, S. 20f; Die links gedrehte Spirale findet sich auch als Zeichen im keltischen Kult, versinnbildlicht dort das Leben und steht für die Ein- und Ausatmung. (Vgl. Frutiger 2006, S. 144) 
in einem der Räume als Projektion mit einer fotografischen Reproduktion der antiken Skulptur der „Artemis von Ephesus“324 überblendet. 325

In dieser Arbeit wird damit auf eine andere Gestalt der mythologischen DianaFigur Bezug genommen: die der vielbrüstigen, nährenden Göttin, die zudem - als Göttin des Lichtes - im Lichtbild erscheint. ${ }^{326}$ Während die Künstlerin vor der Kamera inmitten der Spirale des Lebens isoliert bleibt, verschmilzt ihr elektronisches Abbild im Nebenraum mit dem der antiken Göttin, Symbol eines autonomen und ganzheitlichen Frauseins. Der elektronische Zirkel ist in dieser Aktion nicht geschlossen, vielmehr wird die Videotechnik für eine Live-Übertragung an einen anderen Ort genutzt, an dem dann die Möglichkeit für eine Überblendung mit dem Kultbild besteht. ${ }^{327}$ Auch andere Künstlerinnen, wie Anne Gauldin und Louise Bourgeois, inspirierte die vielbrüstige Artemesia zu Aktionen und Kostümen.

324 Kapitolinisches Museum, Albani Collection, nach einem griechischen Original des 4. Jh. v. Chr. Marmor 157,5 cm Inv. MC0644; anders als die Artemis von Ephesos ist die Artemis von Versailles im Louvre. Sie zeigt die Göttin im Lauf, einen Pfeil aus dem Köcher nehmend.

325 Vgl. Glüher 2005, S. 29; In der Installation wird das Dia umrahmt von der Form eines Schlüssellochs - zusätzliches Symbol für etwas Geheimnisvolles, Verborgenes.

326 Das Frauenmuseum in Bonn zeigte 2001 die Ausstellung „Artemis, Artemisia, Diana“ und betonte dort die zwei Aspekte der Diana als Gebärerin und Täterin. Karin Thomas interpretierte die „Maifrau“ folgendermaßen: ,, So inszeniert sie das Bild der Diana von Ephesos als ganzheitliche Muttergöttin und Fruchtbarkeitsidol mit phallischen Brüsten, als Transformation des Weiblichen und Männlichen, wie dies bereits vorher, die seinerzeit noch wenig bekannte Louise Bourgeois in einer ihrer Skulpturen der sechziger Jahre gewagt hatte (...).“ (Thomas 2002, S. S. 259)

327 Die Einbeziehung zweier getrennter Räume in die Aktion findet sich zum Beispiel auch bei der „Einsamen Spaziergängerin“ wieder. 

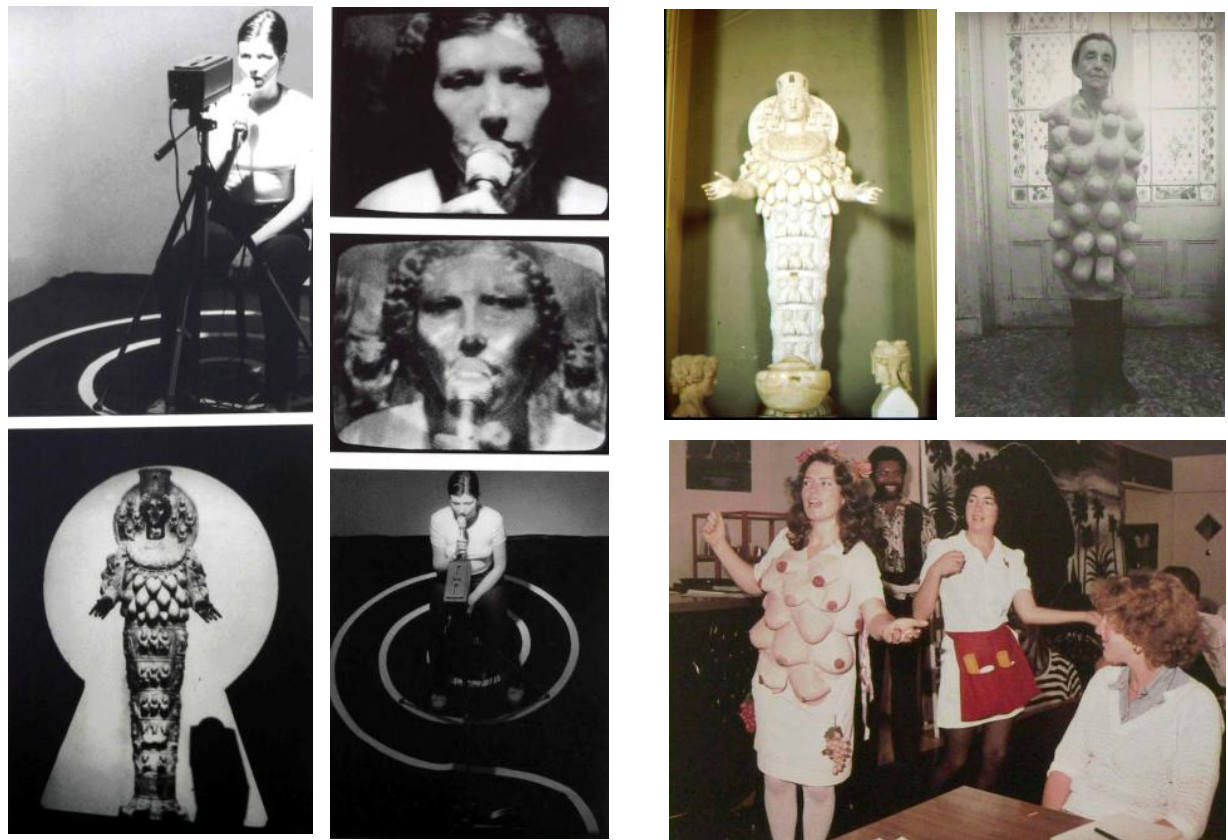

Abb. 74-81: Maifrau, Aktionsfotos und Stills, Artemis von Ephesos, Louis Bourgeois mit selbstgestaltetem Kostüm, 1980, Anne Gauldin und Denise Yarlitr, The waitress godess Diana, 1978

In der Videoperformance „Frauenkultur-Kontaktversuch“, visualisierte die Künstlerin dann ihre vorangegangene physische und psychische Auseinan-dersetzung mit der Kulturgeschichte der Frau. Bei der Performance, die mehrfach aufgeführt wurde - erstmals im Folkwang Museum in Essen - waren 65 Abbildungen mit Frauenporträts aus den verschiedensten Kulturen und Epochen der Menschheitsgeschichte in einer Reihe entlang der Fußleiste an die Wand geheftet. ${ }^{328}$

Die Darstellungsreihe begann mit einer Vertreterin einer frühen Kultur mit einem Grabholz in der Hand und endete mit einem Porträt einer Zeitgenossin. Die Fotoreihe symbolisierte eine quasi evolutionäre Veränderung von einer autonomen Frau in einer frühen Kultur hin zu einer identitätslosen Frau, „dem Abbild

328 In der Neuen Galerie des Folkwang Museums in Essen wurde die einstündige Performance am Sonntag 16. Januar 1977 um 17 Uhr aufgeführt. Außerdem war sie live in Amsterdam und Wien sowie 1979 im Kunstverein in Bonn, Melbourne und Brisbane zu sehen. Künstlerin wies darauf hin, dass während des Aktionsablaufes die Videokamera so eingesetzt wurde, dass das Videobild dem Betrachter neue Dimensionen im angestrebten Kontext und im unmittelbaren Erleben der Aktion vermittelte. (Quelle: Documenta Archiv) Die schwarzweißen Abbildungen, an deren Aufreihung die Künstlerin entlangrollte, hatte sie in ihrer Zeit in den USA aus einer Enzyklopädie, aus dem 19. Jahrhundert über die Geschichte der Frauen, die sich in der Bibliothek des California Institute of the Arts befindet. 
einer Frau, die sich in unseren Tagen lediglich als Zierrat des Patriarchats empfindet", so Rosenbach im Originalton. ${ }^{329}$ Die Künstlerin selbst kommentierte das Grabholz in der Hand der positiv konnotierten Ackerbäuerin als „Zeichen einer autonomen Funktion der Frau als Ackerbäuerin“330 und auffällig ist bei dieser Motivwahl, dass die Bäuerin, im Unterschied zu den anderen Frauenporträts, etwas in der Hand hält, damit handelnde Hände hat im Kontext einer feministischen Ikonographie.

Die Künstlerin legte sich in der Aktion vor die Bildreihe in einem neutralen weißen Trikot auf den Fußboden. Eine kleine Handkamera presste sie vor ihr Gesicht. Dann rollte sie sich um die eigene Achse entlang der Wand und dabei immer fester in das Kabel der Kamera ein. Am Ende der Bildreihe, vor dem Abbild der Frau aus der Gegenwart, war sie ganz eng in das Kabel geschlungen. Dann wechselte die Akteurin die Richtung und rollte sich wieder aus, bis sie sich vor dem ersten Bild der Reihe wieder ganz aus ihrer Gefangenschaft befreit hatte. Während des wiederholten Hin- und Herrollens wurden die dabei aufge-nommenen rotierenden Kamerabilder auf einen Monitor übertragen, untermalt durch ein dumpfes Tam-Tam einer Trommel von einer Tonbandschleife. ${ }^{331}$

Auch diese Aktion ist geprägt durch eine minimalistische, stark komprimierte (Bild-)Sprache. Diese lässt sich zerlegen in die Elemente der räumlich positionierten Bilderreihe, des Entlangrollens und Einwickelns im Videokabel, der Bildaufzeichnung, die die Künstlerin während des Rollens auch in sich aufnimmt und dem Tonaspekt, der aus einem steten Rhythmus besteht.

Die Kamera vollzieht in der Aktion die Bewegung der Künstlerin mit, verlängert deren Wahrnehmung, und die Aufzeichnung mittels dieses elektronischen Auges macht die Eindrücke der Künstlerin auch für die Zuschauer sichtbar. So zeigt der Blick auf das Monitorbild als die Akteurin vollständig in die Kabel eingebunden ist - buchstäblich handlungsunfähig - das Abbild einer Fotografie einer Zeitgenossin, während die Künstlerin auf Höhe des ersten Bildes der Reihe, der autonomen Bäuerin - jeweils aus der Fesselung befreit ist. Bereits in zahlreichen anderen Werken Rosenbachs begegnete die besondere Bedeutung der Hand zum Beispiel in "Sorry, Mister", wo sich die Künstlerin selber mit der Hand schlägt. Die Hand nimmt wie dargelegt in einer feministischen Ikonographie eine besondere Rolle ein. Im Kontext des künstlerischen Werkes von Ulrike Rosenbach wird sich im folgenden der Eindruck weiter verstärken, dass die agierende Hand als ein Symbol der Handlungsfähigkeit gelesen werden kann. Hinzu kommt in dieser Videoaktion, das sich die spezifische Funktion des Videobildes in den Werken Rosenbachs beginnt heraus zu kristallisieren. Ist es hier doch augenfällig, dass sich die Aussagen von Videoaufnahme und dem agierenden Körper im

\footnotetext{
329 Reinke in: Rosenbach 1982, S. 47

330 Rosenbach 1982, S. 47

331 Vgl. Reinke in: Rosenbach 1982, S. 47
} 
Raum, entsprechen. Das Bild, das der Monitor wieder gibt, und das äußere Bild des agierenden Körpers im Raum verstärken sich in dieser Aktion.

\section{III.5.4. Exkurs: Mythos, Symbol, Metapher und Ritual}

Im Rahmen der Beschreibungen der Arbeiten von Ulrike Rosenbach fiel bereits wiederholt der Begriff des Rituals, wie auch die Begriffe des Mythos, des Symboles oder der Metapher, deren Bedeutungen im Folgenden genauer betrachtet werden sollen.

Als Mythos wird eine überlieferte Dichtung, Sage oder Erzählung aus der Vorzeit eines Volkes bezeichnet, die sich besonders mit Göttern, Dämonen, der Entstehung der Welt oder der Erschaffung des Menschen befasst. Der Mythos zeigt eine Grundform des menschlichen Erschließens der Wirklichkeit. Das tragende Prinzip des Mythos ist die allgemeine Beseelung des Weltalls. So ist die mythische Welt lebendig und nichts geschieht in ihr Kraft abstrakter Prinzipien oder unpersönlicher Gesetzmäßigkeiten. Auf diese Weise erlebt der Mensch durch den Mythos die Wirklichkeit unmittelbar und wird mit ihr vertraut und der Mythos fungiert als eine bildliche Sinndeutung der Wirklichkeit. Im mythischen Bewusstsein wird nicht getrennt, vielmehr bilden Bilder und Gedanken, Erlebnisse und Reflexion ein ungeschiedenes Ganzes. Überliefert wird der Mythos durch das Wort und zunächst orale Traditionen, bis dann gegebenenfalls eine schriftliche Überlieferung hinzukommt. ${ }^{332}$

Als Symbol - griechisch „Erkennungszeichen“ - wird allgemein ein Gegenstand oder Vorgang bezeichnet, der stellvertretend für einen anderen - nicht wahrnehmbaren oder geistigen - Sachverhalt steht, wie zum Beispiel das Symbol des Kreuzes für die christliche Kirche stehen kann. ${ }^{333}$ Je mehr ein Symbol ein vielen Menschen gemeinsames Stück unbewusster Psyche ausdrückt, desto größer ist seine Wirkung. So können mythische Symbole eine besonders starke, lebenserzeugende Wirkung besitzen, da sie im Menschen eine kreative, amplifikatorische Vorstellungstätigkeit stimulieren. ${ }^{334}$

Unterschieden vom Symbol bezeichnet die „Metapher“ - griechisch „Übertragung“ - als sprachliches Stilmittel eine bildhafte Übertragung in einen Ausdruck.

332 Vgl. Lurker 1991, S. $511 \mathrm{f}$

333 Vgl. auch Warncke 2005, S. 11-13

334 Der Mitbegründer der Tiefenpsychologie Carl Gustav Jung hat die Unauflösbarkeit der echten Symbole in rationale Begriffe betont. Für ihn ist das Symbol ein heilendes und erlösendes Erzeugnis des Unbewussten. Im Mythos entfaltet der Symbolgehalt seine Fülle. So ist nach Johann Jakob Bachofen der Mythos die „Exegese des Symbols“. Die Sprache, deren sich der Mythos bedienen muss, kann nur erklären und einen Gedanken nach dem anderen ausdrücken. Das Symbol dagegen stellt seinen Inhalt mit einem Blick der Seele zur Verfügung und erweckt Ahnungen vom Unendlichen und Unsagbaren. Für Jung sind die Archetypen das tragende Wesen auch der Mythen. Unter Archetype versteht C.G. Jung dem Menschen arttypisch angeborene, psychische Verhaltensweisen. (Vgl. Lurker 1991, S.719-721) 
Ein Wort oder eine Wortgruppe wird aus seinem eigentümlichen Bedeutungszusammenhang in einen anderen übertragen, ohne dass ein direkter Vergleich die Beziehung zwischen Bezeichnendem und Bezeichnetem verdeutlicht (z.B. das Haupt der Familie). Nicht nur im sprachlichen Bereich auch im Bildlichen kann symbolisch oder metaphorisch kommuniziert werden.

\section{III.5.4.1 Ritual: Funktion und Wirkung}

Der Begriff des Rituals, der allgemein auf das lateinische „Ritus“, das die Bedeutungen heiliger Brauch, Sitte, Gewohnheit trägt, bezogen wird, lässt sich weiter auf das Sanskritwort „r(i)ta“ zurückführen, das Wahrheit und Recht bedeutet. Als Rituale werden allgemein wiederkehrende - nichtalltägliche - Handlungen, auch Worte und Gesten, bezeichnet, die nach einer festgelegten Ordnung vorgenommen werden und einen Inhalt auch durch Symbolik vermitteln. Rituale gehören zu den elementaren Ausdrucksformen der menschlichen Existenz und sind „Werkzeuge der Kommunikation“, wie Smith sie bezeichnete. ${ }^{335}$ Das bewusste Vollziehen der Handlung unterscheidet ein Ritual von einer puren Gewohnheit, wie zum Beispiel dem täglichen Zähneputzen, die in der Alltagssprache gelegentlich auch als Ritual bezeichnet wird. In unserer Gesellschaft treten besonders die so genannten Übergangsrituale - oder rites de passage - die bei einem Wechsel von einer in die nächste Lebensphase gefeiert werden, wie bei Geburt, Heirat oder dem Tod in den Vordergrund. ${ }^{336}$

Im Laufe der Jahrzehnte gab es in den unterschiedlichen wissenschaftlichen Disziplinen zahlreiche Definitionsversuche. ${ }^{337}$ Während die Soziologie ein Ritual allgemein definiert als sozial geregelter, immer wieder gleicher Handlungsablauf, bei dem Situationen symbolisch verarbeitet werden, sieht der Religionswissenschaftler Jürg von Ins im Ritual ,die Brücke, die über die Unendlichkeit zwischen dem Erfahrungsbereich des Politischen und des Religiösen gespannt ist. “338 Aus dieser Warte sind Rituale Handlungen, die dem Menschen den Austritt

335 Smith 1979, S. 51-79; Muecke/Sommer 2003, S. 8; Rituale werden unter anderem nach ihrer Funktion unterschieden, wie zum Beispiel in Begräbnisrituale, Opferrituale, religiöse, säkulare und persönliche Rituale, Monats, Wochen- und Alltagsrituale, Eingangs- und Übergangsrituale, Heilungsrituale, Natur- und Elementerituale.

336 Unter diesem Begriff werden in der Ethnologie oder Soziologie Rituale und Zeremonien zusammengefasst, die den in der Regel krisenhaften Übergang des Menschen von einem Lebensabschnitt in einen anderen - etwa bei Geburt, Heirat und Tod - kennzeichnen.(Hirschberg 1988, S. 494) Diese Rituale haben die Aufgabe, den Menschen beim Verlassen des bisherigen Zustandes vor feindlichen Mächte zu schützen und zu stärken.

337 „Um den schriftlichen, inszenatorischen und körperlichen Dimensionen des Rituals gerecht zu werden, sind nicht nur semiotische Ansätze, die auf syntaktische, semantische und pragmatische Strukturen und Funktionen abheben erforderlich. Sie müssen ergänzt werden durch eine Ikonologie des Rituellen, die den Zusammenhang von Produktions-, Rezeptions- und Werkästhetik rekonstruiert." (Wulf/Zirfas 2004, S. 33)

338 von Ins 1979, S. 117 
aus dem Bereich des Politischen und eine bestimmte religiöse Erfahrung ermöglichen. ${ }^{339}$ Allerdings gab der Psychoanalytiker Sigmund Freud in seiner Schrift „Zwang, Paranoia und Perversion“ zu bedenken, dass den Zwangsakt vom religiösen Ritus nur eine schmale Linie trenne. So sieht Freud in privat gewordenen Ritualen lediglich Zwangshandlungen. Zudem waren gesellschaftliche Rituale in Deutschland im Zuge der 68er Bewegung als reaktionär, rigide Grenzziehungen und damit als Instrumente der herrschenden Klasse verschrien.

Als Minimaldefinition eines Rituals könnte man an dieser Stelle zusammenfassen, dass es sich um ein „regelgeleitetes, symbolisch durchgestaltetes Handlungsgefüge“ handelt. ${ }^{340}$ Außerdem ist eine Ritual ,preeminently a form of communication“, wie die Ethnologin Mary Douglas in einem Satz zusammenfasst. Als lebendige Form der Kommunikation dienen religiöse und säkulare Rituale ein allen Kulturen als kollektives Ausdrucksmittel, dem unter anderem die Funktion zugeschrieben wird, die Identität des Individuums und der Gesellschaft durch kontinuierliche Gedächtnispraktiken zu sichern. ${ }^{341}$ So ist rituelles Wissen ein implizites Routine- und Regelwissen, das auf der Grenze zum Bewusstsein anzusiedeln ist. 342 In Ritualen spielen Gestik und Mimik als nonverbale Ausdrucksformen der Agierenden eine wichtige Rolle. Sie dienen als Mittel der Sinngebung, die soziale Subjekte unterstützen eine Beziehung zueinander aufzubauen und sich verständlich zu machen.

Rituale vermitteln ihre Inhalte über das System des Unbewussten und umgekehrt sind Rituale in der Außenwelt Markierungen für innere Prozesse. Diese Handlungen sind ein machtvolles Instrument der Wandlung, stellen Raum und Mittel zur Verfügung, schwer Vermittelbares oder Unsichtbares durch Symbole zum Ausdruck zu bringen. So könnte man auch sagen, dass Rituale als Werkzeuge der Erkenntnis dienen können. In ihnen wird die Kommunikation als Mittel der Problembewältigung genutzt. ${ }^{343}$

339 von Ins 1979, S. 130

340 Wulf/Zirfas 2004, S. 37

341 Muecke/Sommer 2003, S. 8; Van Gennep benennt in seiner Theorie drei Phasen, die in einem Ritual vollzogen werden. Er versteht ein Ritual als einen symbolischen Übergang und benennt ein Ablaufschema aus Trennung, Umwandlung und Rückkehr. (Wulf/Zirfas 2004, S. 36)

342 Wulf/Zierfas 2004, S. 33

343 Daneben lassen sich weitere Funktionen benennen, durch die Rituale gekennzeichnet sind. Wulf und Zirfas fassen aus soziologischer Sicht sieben zusammen, die in der Forschung genannt werden. Rituale sind demnach: kommunitär, in dem sie Gemeinschaften hervorbringen, restituieren und gestalten und dadurch ihren emotionalen und symbolischen Zusammenhalt gewährleisten. Stabilisatorisch, in dem sie Ordnung, Aufgabenverteilung und Planung gewährleisten, insofern aber auch Einordnung, Anpassung und Unterdrückung möglich machen. Identifikatorischtransformatisch, indem sie die Identität der bisherigen Mitglieder re- oder neudefinieren oder ein neues Mitglied aufnehmen. Gedächtnisstiftend, indem sie den Teilnehmern eine zeitliche Kohärenz sicherstellen und so kontinuitätstiftend und zukunftsorientierend wirken. Kurativphilosophisch, indem sie infolge schmerzhafter Erfahrungen Heilungsprozesse und Krisenbe- 
Ein Ritual ist immer an eine Handlung geknüpft. Agierende Körper dienen der Vermittlung und die Handlungen schreiben sich in diese Körper ein. So sind nach Pierre Bourdieu rituelle Prozesse immer auch körperliche Anerkennungsprozesse. Das körperliche Handeln in rituellen Sequenzen sichert das rituelle Geschehen durch eine körperliche und verkörperte soziale Ordnung. ${ }^{344}$ Der Körper wird dabei zum Gedächtnis des Sozialen. ${ }^{345}$ Auf diese Weise wird in der rituellperformativen Praxis Macht konstituiert. ${ }^{346}$ Und aus einem performativen Blickwinkel werden Rituale beschreibbar als ein Handlungsgefüge, das durch und in seinem Prozess dasjenige hervorbringt, was es vollzieht. ${ }^{347}$ So sind diese als „transformative Performanzen“ nach den Ritualforschern Köpping und Rao „transformative Akte, denen die Macht zugeschrieben wird, jeden Kontext von Handlung und Bedeutung, und auch jeden Rahmen und alle sie konstituierenden Elemente und Personen in jeder möglichen Hinsicht zu transformieren und dadurch Personen und Symbolen einen neuen Zustandsstatus aufzuprägen.“348

Über den Aspekt des Kommunizierens und des bewussten Agierens ergibt sich der Bezug vom Ritual zur künstlerischen Performance. Bei beiden findet eine Kommunikation in zwei unterschiedliche Richtungen statt: Zum einen zwischen dem Agierenden und dem Unbewussten, zum anderen zwischen dem Akteur und den Zuschauenden. Neben den Akteuren und einem zeitlichen und räumlichen Rahmen, entsteht eine Performance erst durch das Beisein von Zuschauern. So kommt den Zuschauern bei dieser Kunstform eine konstitutive Rolle zu.

Denn, um ein Ereignis zu einer künstlerischen Performance zu machen, bedarf es einer entsprechenden Rahmung: Es braucht Akteure, einen zeitlichen und räumlichen Kontext sowie Zuschauer, die für dieses künstlerische Geschehen eine konstitutive Rolle haben. Erst in der Gegenwart von Rezipienten entsteht eine

wältigungsmechanismen in Gang setzen bzw. Fragen im Zusammenhang mit Leben und Tod zu beantworten suchen. Transzendent-magisch, indem sie eine Kommunikation mit dem Anderen, dem Heiligen gewährleisten. Differenz bearbeitend, indem sie zunächst Brüche, Schwellen und Rahmen im Sozialen generieren und markieren, um sie dann gegebenenfalls aufzuheben.(Wulf/Zirfas 2004, S. 18)

344 In diesem Sinne haben auch alltägliche Ritualisierungen eine normative Ordnung, die in und durch formalisierte und repetitive Praktiken ihrer Aufführung gewährleistet wird.

345 Wulf/Zirfas 2004, S. 39

346 Eine rituelle Performance kann aber auch ein Ereignis sein, das die Ordnung des Alltags suspendiert, selbst den Zuschauern eine neue Erfahrung vermittelt, ihnen gelegentlich vielleicht sogar einen Schock versetzt, so zum Beispiel in den Aktionen der Künstlerin Marina Abramovic.

347 Wulf/Zirfas 2004, S. 39

348 Fischer-Lichte in: Fischer-Lichte 2003, S. 27f; In diesem Zusammenhang hebt Pierre Bourdieu unter dem Begriff der „performativen Magie“ die Macht der Sprache hervor, die soziale Welt nicht nur zu beschreiben, sondern aktiv zu gestalten. Die rituelle Kraft der Werte und Handlungen liegt demnach in der Macht der Sprechenden, die einen spezifischen Habitus und eine spezielle Positionierung im sozialen Raum einnehmen. (Vgl. Wulf/Zirfas 2004, S. 40) 
Performance und es lassen sich zwei Wirkungsfelder benennen: das des agierenden Künstlers und das des Zuschauers.

\section{III.5.4.2 Ritualität in der zeitgenössischen Kunst}

Wie weiter oben bereits ausgeführt, entwickelte sich ab den 1950er Jahren die Aktionskunst als neue Gattung der bildenden Kunst. Ganz bewusst den wirkungsvollen kommunikativen Aspekt des Rituellen nutzend, ließen verschiedene europäische Künstler in den 1960er Jahren Opfer- und Heilungsrituale in ihre Arbeiten einfließen und begaben sich so auf einen experimentellen Grenzgang zwischen Ritual und Aktion. Dabei erhoben sie allerdings kaum den Anspruch, mit ihren Aktionen tatsächlich ein Ritual zu vollziehen. Vielmehr bestanden sie darauf, dass es sich um künstlerische Performances handelte, um Aktionen individueller Künstler, ohne jedoch eine klare Grenze zwischen ihren Performances und Ritualen ziehen zu wollen. ${ }^{349}$

„Aktions- und Performancekünstler, wie Hermann Nitsch, Joseph Beuys, Marina Abramovic zum Beispiel, die sich heftig gegen das traditionelle, abbildende „als ob" Theater wandten, verstießen mit ihren auf Opfer-und Heilungsrituale rekurrierenden Aktionen und Performances gegen grundlegende gesellschaftliche Tabus, indem sie in bis dabin gänzlich ungewohnter Weise die Grenzen zwischen phänomenalem und semiotischem Körper, sowie zwischen Akteuren und Zuschauern überschritten. "350

Der genannte Hermann Nitsch (*1938) ist zum Kreis der Wiener Aktionisten zu rechnen, deren extreme Aktionen in den 1960er Jahren sich zum Teil in inszenierte Akte der Selbstverletzung und zu unheimlichen Gewaltszenarien steigerten. Die Happenings der Gruppierung sind als künstlerischer Kampf für die Freiheit zu verstehen, die nach Aussage des österreichischen Künstlers „Realität in ihrer vollen Umfänglichkeit und Geschlechtlichkeit“ darstellt, da der Mensch nur im erlebenden Durchmessen dionysischer Treibdurchbrüche die volle Bewusstwerdung vom Menschsein erlangen könne. Nitsch wollte mit seinem so genannten OrgienMysterien-Theater Einblick geben in die menschliche Psyche bezugnehmend auf die Vorstellung des kollektiven Unterbewusstseins in Anlehnung an die Psychoanalyse von C.G. Jung. ${ }^{351}$

Ähnlich ist es auch in verschiedenen Aktionen der Jugoslawin Marina Abramovic. Diese bereits im Zusammenhang mit dem Thema Selbstverletzung/Gewalt erwähnte Künstlerin vollzog in ihren Ritualarbeiten keine symbolischen Als-ob-Handlungen, sondern Handlungen, mit denen sie ihren eigenen phänomenalen Körper tatsächlich verletzte. In „Lips of Thomas“352 zerbrach sie

349 Fischer-Lichte in: Fischer-Lichte u.a. 2003, S. 26/27

350 Fischer-Lichte in: Fischer-Lichte u.a. 2003, S. 25

351 Thomas 1986, S. 246

352 Die Performance wurde 1975 in der Galerie Krinzinger in Innsbruck aufgeführt. 
zum Beispiel ein Glas in ihrer Hand, ritzte sich mit einem Rasiermesser einen fünfzackigen Stern in die Haut und peitschte sich den Rücken blutig. In einer anderen Aktion mit dem Titel „Rhythm 5“ ging sie noch einen Schritt weiter und gefährdete ihr Leben, in dem sie sich in einen Strohstern legte, der entzündet wurde. Wenn nicht ein Zuschauer eingegriffen hätte und sie noch rechtzeitig herausgezogen hätte, wäre die bereits bewusstlose Künstlerin in dem Feuer erstickt.

Mit diesem aktiven Eingreifen eines eigentlich Unbeteiligten soll der Blick auf eine in dieser und ähnlichen extremen Aktionen krisenbesetzte Rolle des Zuschauers gerichtet werden. Denn das bis dahin scheinbar klar geregelte Verhältnis zwischen Akteuren und Zuschauern wird in solchen radikalen Aktionen grundsätzlich in Frage gestellt. Erika Fischer-Lichte arbeitet den Konflikt, in den der Zuschauer in einer solchen Performance gerät, anschaulich heraus:

„Derartige Aktionen versetzten den Zuschauer in eine Situation, in der viele der bisher geltenden Normen, Regeln und Sicherheiten außer Kraft zu treten schienen. Bisher war er davon ausgegangen, dass seine Rolle im Theater bzw. in einer Galerie im Zuschauen besteht, auch wenn sich auf der Bühne eine Figur anschickt, eine andere umzubringen, wohlwissend, dass der Mord nur gespielt ist. Im Alltagsleben dagegen gilt die Regel, sofort einzugreifen, wenn einer sich oder einen anderen zu verletzen drobt - es sei denn, man setzt sich damit selbst großer Gefahr für Leib und Leben aus.

Welche Regel sollte der Zuschauer in derartigen Performances anwenden?

Ganz offensichtlich verletzte im Fall von Abramovic die Künstlerin sich selbst und war gewillt, ibre Selbstfolterung weiter andauern zu lassen. Täte sie dies irgendwo auf einem öffentlichen Platz würde der Zuschauer vermutlich nicht zögern, sofort einzugreifen. Aber hier? Erforderte es nicht der Respekt vor der Künstlerin sie ausfübren zu lassen, was ihr Plan und ibre künstlerische Absicht zu sein schienen? Würde man nicht das Risiko eingehen, ibr „Werk " zu zerstören? Andererseits, ließ es sich mit den Grenzen der Humanität vereinbaren, ihr rubig dabei zu zuschauen, wie sie sich selbst Schmerzen zufügte, wie sie sich selbst - für wen oder was? - opferte? Oder wollte die Künstlerin den Zuschauer etwa in die Rolle des Voyeurs drängen? Wollte sie ibn gar testen, um herauszufinden, wie weit sie noch gehen musste, ehe Zuschauer sich anschickten, ihrer Qual ein Ende zu bereiten? Was sollte hier gelten?" 353

Und sie folgert:

„Ganz gleich, wie der Zuschauer sich entschied, in jedem Fall musste er eine Grenze übertreten. D.h. mit ihrer Performance schuf die Künstlerin eine Situation, die den Zuschauer in den Zustand einer radikalen Zwischenposition - sozusagen zwischen alle Stüble - versetzte: Bisher gültige Regeln und Normen waren außer Kraft, neue mußten gefunden und erprobt werden. Die Auffübrung stürə̧te den Zuschauer in eine Krise, zu deren Bewältigung er nicht auf allgemein anerkannte Verhaltensstandards zurückgreifen

353 Fischer-Lichte in: Fischer-Lichte 2003, S. 25 
konnte. Die bisherigen Standards wurden nicht mehr akzeptiert, neue waren noch nicht formuliert." "'554

Der durch die Krisensituation für den Künstler und den Zuschauer aufgebaute Zustand einer labilen Zwischenexistenz entspricht dem Zustand der Liminalität oder eines „betwixt and between the positions“, der in der Ritualforschung der 1960er und 1970er Jahre eine wichtige Rolle spielte. Diese künstlich erzeugte Schwellenphase eröffnet allen am Ritual Beteiligten die Möglichkeit zur Schaffung kultureller Spiel- und Freiräume für Experimente und Innovationen, so dass neue Handlungsweisen, neue Kombinationen von Symbolen ausprobiert werden können, um danach endgültig abgelegt oder angenommen zu werden.

Aktions- und Performancekünstler nutzten rituelle Elemente in ihren Aktionen, um die Beteiligten - sich selbst und auch die Zuschauer - in genau diesen Zustand eines radikalen „betwixt and between“ zu versetzen.355 In dieser Weise war es auch ein Anliegen der Kunstaktionen von Joseph Beuys Handlungsspielräume zu eröffnen, bestand doch eine selbst gestellte Aufgabe dieses Künstlers darin, der traumatisierten Gesellschaft - im Kontext der aktuellen politischen Situation der Nachkriegszeit - den Zugang zu einer Art moralischer, sozialer und psychologischer Therapie aufzuzeigen. Der Künstler empfand das nach dem Krieg zwar oberflächlich entnazifizierte und demokratisierte Deutschland als steif, stickig und repressiv. Da es angesichts der Präsenz eines militanten marxistischen Regimes im Ostteil Deutschlands zudem unmöglich schien, die Repression und den Druck zur Konformität mit den üblichen Mitteln linksorientierter politischer Opposition zu bekämpfen, erklärte der Künstler konsequent die Politik als soziale Skulptur zur Kunstform, mittels der er agierte:356

„Ausschlaggebend für die wirkungsvolle Kommunikation seines politischen Standpunktes war die Persönlichkeit von Beuys. Er war sich seines Charismas bewusst und sah sich selbst als modernen Schamanen, als jemanden, der mit Ritualen und magischen Zeremonien zur Gesundung der Gesellschaft beitragen kann. Diese Rituale beinhalteten nicht selten ein gewisses Maß an physischem Leiden oder zumindest Unbequemlichkeit: Liegen oder Stehen in unmöglichen Positionen, über längere Zeit immer wieder die gleichen Handlungen oder Bewegungsabläufe verrichten, teillweise mit erbeblichen körperlichen Einschränkungen, etwa dadurch, dass der gesamte Körper in Filz eingewickelt ist. "357

In Beuys Arbeiten dieser Jahre verbindet sich die Ideenwelt archaischer und christlicher Riten mit prozessualen künstlerischen Handlungen, die eine intensive Wechselwirkung eingehen. Die Transformation - jene im Ritual erfahrene Wandlung, die die Voraussetzung für eine Versöhnung des Gegensatzes von Handeln

354 Fischer-Lichte in: Fischer-Lichte 2003, S. 25

355 Fischer-Lichte in: Fischer-Lichte 2003, S. 26/27

356 Lucie-Smith 1999, S. $315 f$

357 Lucie-Smith 1999, S. $315 f$ 
und Denken schafft und nach der Vorstellung des Künstlers zu einem wesentlichen Wandel der gesellschaftlichen Verhältnisse führen konnte - ist zentrales Thema seiner Kunst. Für die Realisierung seiner Zielprojektion griff Beuys häufig auf die Handlungsformen von Übergangsriten zurück, in denen der Mensch als Periode der Krise und Prüfungen Grenzerfahrungen macht. 358

Bei den drei exemplarisch herausgegriffenen Künstlern zeigen sich unterschiedliche Formen und Zielsetzungen des Rituellen in ihrem künstlerischen Wirken, die aber alle drei das Ziel der Erkenntnis und Wandlung verbindet.

\section{III.5.4.3 Rituale in den Aktionen von Ulrike Rosenbach}

Welche Funktion übernehmen nun Rituale in den Werken von Ulrike Rosenbach? Ohne Frage arbeiten zahlreiche Aktionen der Künstlerin mit rituellen Formen. Wie oben bereits ausgeführt, hatte die junge Künstlerin enge Kontakte zur amerikanischen Frauenbewegung. Künstlerinnen dort beschäftigten sich bereits in den 1960er Jahren intensiv mit spirituellen Ritualen, um darin ihre eigene Identität als Frau wieder zu finden und zu stärken. Durch den rituellen Ansatz in der Kunst Joseph Beuys' könnte die junge Künstlerin zudem für diesen Aspekt sensibilisiert gewesen sein, als sie in den USA neue Formen von Ritualen kennenlernte. Aber anders als ihr Lehrer, der auf einen Fundus archaischer und christlicher Riten Bezug nahm, fand Ulrike Rosenbach in Amerika weibliche Varianten des Rituals, die sie befruchtend in ihre körperorientierten Arbeiten integrierte. Nicht zufällig sondern wohl vielmehr programmatisch - lässt sich unter diesem Gesichtspunkt auch der Titel „Natur-Kreis-Aktion“ ihrer ersten öffentlichen Aktion deuten. Sind doch die wesentlichen Elemente - die prozessuale Handlung wie auch das Zyklische der Natur - darin bereits benannt, die in ihrem weiteren Werk eine elementare Rolle spielen. Im Rückblick sagt die Künstlerin über ihre prägenden Erfahrungen mit der Ritualarbeit:

„Mit den Hexenritualen habe ich in Los Angeles angefangen, doch die Natur-
kreisaktion war auch bereits ein Ritual. Dann habe ich mit den Frauen bier [in
Deutschland] Rituale veranstaltet und meine ganze Performancearbeit weiter auf diesen
Ritualen aufgebaut. Von da aus bin ich auch an dieses Mythologie-Thema gekommen,
wie dann in "Tanz. um einen Baum " umgesetzt. Das ist ja ein Aborigines-Ritual. Per-
formance als Ritual qu veranstalten hat mich von früh an sehr bewegt. Das war ein gro-
Bes Interesse von mir." "359

Unter dem Aspekt des Rituellen kann man die fünf Werke „Naturkreisaktion“, „Isolation is transparent", „Reflexionen über die Geburt der Venus“, „Zehntausend Jahre habe ich geschlafen“ und „Frauenkultur - Kontaktversuch“ als Varia-

\footnotetext{
358 Muecke/Sommer 2003, S. 8f

359 Rosenbach im Gespräch 2001, Kap. VII.1.
} 
tionen eines Befreiungsrituals betrachten. Seinen Höhepunkt erreicht die Form der politisch motivierten, rituellen künstlerischen Aktion dann in ihrer Performance „Venusdepression - Medusaimagination". Dieses Aufbruchsritual setzte die Künstlerin mit fünf anderen Frauen in Szene und es ist damit die einzige Gruppenaktion im Werk Rosenbachs. Die fünf Mitakteurinnen kamen alle aus der ersten Gruppe der Schule für kreativen Feminismus der Künstlerin. ${ }^{360}$
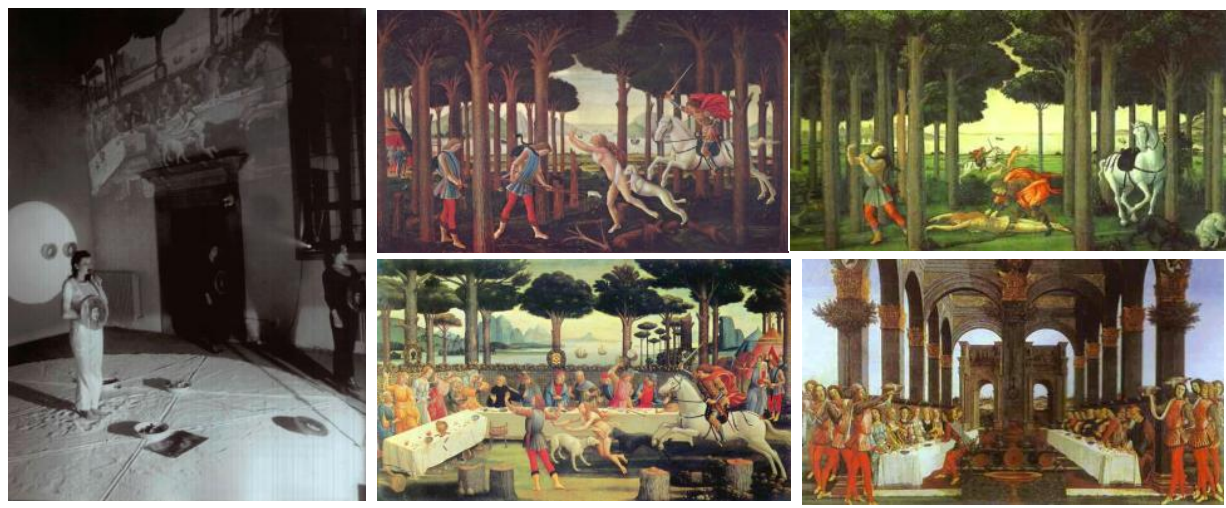

Abb. 82-86: Venusdepression - Medusaimagination, 1977 und Sandro Botticelli: Zyklus, 1482/83: Begegnung mit der Verdammten im Pinienwald, Die infernalische Jagd, Bankett im Pinienwald, Das Hochzeitsbankett

Im Vergleich zu vorangegangenen Arbeiten ist diese Performance, die nur einmal im Dezember 1977 im Palazzo Strozzi in Florenz aufgeführt wurde, durch eine Vielfalt an Einzelelementen geprägt, die sich zu einer komplexen Aussage zusammensetzen. Auf den Boden eines großen Saales in dem Palast war ein großer Kreis aus Salz gestreut, in den ein Pentagramm gezeichnet war. Auf den fünf Schnittpunkten der Linien des Zeichens stand jeweils eine Emailschüssel, die mit glühender Holzkohle befüllt war. Neben jeder Schüssel lag eine Reproduktion einer Venusdarstellung eines italienischen Malers. ${ }^{361}$ An der Wand hinter dem Pentagramm hingen in einer Reihe nebeneinander fünf an der Innenseite versilberte Schilde, die das Gemälde des Medusenhauptes von Caravaggio (1571-1610) auf der Außenseite trugen. ${ }^{362}$ Sie wurden während der gesamten Aktion durch einen hellen Lichtkreis angestrahlt. Zudem wurden drei Diapositive mit Darstellungen aus einem vierteiligen Gemäldezyklus von Sandro Botticelli gleichzeitig an die drei weiteren Wände des Raumes projiziert. In der Mitte des Pentagramms stand zu Beginn der Aktion Ulrike Rosenbach alleine mit einem Medusenschild in ihrer rechten Hand. Die Künstlerin führte im Mittelpunkt des Pentagramms fünf verschiedene Kör-

\footnotetext{
360 Allerdings endete die Zusammenarbeit der Gruppe genau an diesem Punkt.

361 So fanden sich Reproduktionen einer Venus von Tintoretto und auch von Tizian.

362 Das Original der Medusa von Caravaggio findet sich in den Uffizien in Florenz.
} 
perstellungen aus: zunächst kauerte sie sich auf der Erde zusammen, den Kopf durch den Schild geschützt. Dann saß sie dort zusammen gekauert mit dem Schild vor dem Bauch; schließlich wechselte sie ins Stehen, den Schild vor ihren Leib und an die Seite haltend. Dann hob sie den Schild mit der silbernen Innenseite hinter den Kopf, bevor sie den Schild am ausgestreckten Arm hoch hielt, ihre freie Hand zur Faust ballte, und dann die silberne Innenseite des Schildes nach außen wendete. ${ }^{363}$ Nach der ersten Bewegungsabfolge, die symbolisch den Weg aus der Unterdrückung bis zur Befreiung vollzog, ging die Akteurin zur ersten Emailleschüssel und verbrannte darin eine Venusreproduktion. Darauf trat eine zweite Frau hervor, nahm einen Schild von der Wand und stellte sich an die Sternspitze, um die Abfolge der fünf Körperstellungen mitzuvollziehen, und im Anschluss die zweite Reproduktion verbrannt wurde bevor die dritte Frau an Stelle der zweiten in die Aktion eintrat. Dieses Befreiungsritual wiederholte sich insgesamt fünf Mal, während die Künstlerin ununterbrochen die Worte „Frau-Frau“ flüsterte. ${ }^{364}$

Die intensiv mit den Elementen der Wiederholung arbeitende Performance wandelte mit symbolischen Zeichen agierend die Haltung der Unterwerfung in ein Bild des weiblichen Aufbruchs und der Solidarität um. Die Frau behält hier keine Opferrolle mehr, sondern handelt und gestaltet aktiv inmitten einer deutlich gekennzeichneten Schutzzone. So findet sich in dieser Aktion auch keine Videotechnik - als Vermittler des Inneren - integriert. Vielmehr wird das innere Aufbegehren konkret im rituell wirkenden, durch eine starke Symbolik gekennzeichneten Handeln zum Ausdruck gebracht und bedarf keines weiteren Mediums der Vermittlung.

Während im Mittelpunkt des Raumes innerhalb des schützenden Pentagramms auf dem weißen Salzgrund die Frauen handeln, zeigen an die Wände projizierte Lichtbilder eine Geschichte, die der Maler Sandro Botticelli nach einer Erzählung im „Decamerone“ des italienischen Schriftstellers Giovanni Boccaccio (1313-75) malte. ${ }^{365}$ Es ist die Geschichte des Festmahls des Nastagio degli Onesti, das hier zu sehen ist. Im Jahr 1483 hatte Lorenzo di Medici den Maler mit der Dekoration von vier Aussteuertruhen anlässlich der Hochzeit des Gianozza Pucci mit Lucrezia di Piero di Giovanni Bini beauftragt. ${ }^{366}$ Ausgesucht wurde aus diesem Anlass eine der Geschichten, die Boccaccio am vierten Tag seines „Decamerone“ erzählt.

363 Die Reihenfolge der Positionen, die die Künstlerin nacheinander einnahm, war die folgende: (Vgl. Halbertsma in: Rosenbach 1982, S.31)

364 Halbertsma in: Rosenbach 1982, S. 31

365 Das Decamerone hat seinen Namen vom griechischen „deka“ - zehn - und „hemara“ - Tag -, also Zehntagebuch - und Boccaccio verfasste es zwischen 1348-53.

366 Der von Sandro Botticelli 1482/83 mit Tempera auf Holz gemalte Zyklus umfasst folgende vier Gemälde: Die Begegnung mit der Verdammten im Pinienwald, die infernalische Jagd und das Bankett im Pinienwald (alle drei im Prado in Madrid), sowie die vierte Tafel: das Hochzeitsbankett, das sich in italienischem Privatbesitz befindet. 
Es ist der Tag, an dem vom Liebesleid gesprochen wird. Botticellis bildliche Darstellung verschränkt die zwei Handlungsabläufe der Geschichte und schwankt dabei zwischen Fiktion und Wirklichkeit, Märchenton und Albtraum. Erzählt wird wie Nastagio von seiner Angebeteten, einer jungen Dame aus Ravenna, verschmäht wird und sich zur Bewältigung seines Schmerzes in einen Wald zurück zieht. Hier wird dieser Zeuge der Hetzjagd eines Ritters auf eine nackte junge Frau. Die Jagd endet grausam mit dem Tod der Verfolgten und der Ritter weidet den Körper des Opfers anschließend aus und wirft Herz und Leber seinen Hunden zum Fraß vor. Nastagio erfährt, dass sich diese tödliche Jagd an jedem Freitag wiederholt. Diesem grausamen Schauspiel liegt, in genauer Spiegelung des rahmenden Geschehens, eine Liebes- und Eheverweigerung zugrunde, die mit der mörderischen Jagd bestraft wird. Der liebeskranke Nastagio lädt daraufhin die Familie seiner vergeblich Geliebten zum Abschiedsmahl an eben einem Freitag in den Wald, so das die Tafelgesellschaft Zeuge der blutrünstigen Verfolgungsjagd wird und erschreckt von dem schaurigen Schauspiel willigt die junge Dame aus Ravenna schließlich in die Ehe mit Nastagio ein.

In der Geschichte des Nastagio degli Onesti, die die Künstlerin hier in der Auswahl des Botticelli-Zyklus zitiert, wird von Männern Gewalt gegen Frauen ausgeübt. Während die eine Frau grausam ermordet wird, wird eine andere in die Heirat gezwungen. Diese Darstellungen bilden die Umgebung der BefreiungsAktion. Als äußere Dekoration hölzerner Truhenwände entworfen, werden diese Renaissancedarstellungen in der Aktion auf die steinernen Wände des umgebenden Raumes geworfen, so dass sie für die in dem Raum Weilenden sichtbar sind. Dem kunsthistorischen Zitat, das die Jahrhunderte überdauerte, steht das aktive Handeln. Dieses geschieht im Schein des Mondes - symbolisiert durch den runden Lichtfleck an der Wand, der die silbernen Schilde anstrahlt - und unter dem Schutz des Schildes - Zeichen für Unverletzlichkeit und Sicherheit, zusätzlich mit Medusen- oder Gorgonenhauptes ${ }^{367}$ versehen, das ebenfalls zur Abwehr böser Mächte dient, und des Pentagramms, Sinnbild für die Harmonie des Kosmos, siegbringendes Feldzeichen und Zauberzeichen mit apotropäischer Funktion. Innerhalb dieses Schutzraumes fasst die Künstlerin ihr Begehren der Selbstbehauptung in einem Wort - flüsternd - zusammen: „Frau.“ Ununterbrochen wiederholt sie dieses Wort, das der Befreiungsaktion einen tragenden Rhythmus gibt.

In dieser Aktion sind alle Elemente eines Rituales vertreten. Dabei wird sich einer mit Symbolen arbeitenden Bildsprache bedient und die zweidimensionalen Reproduktionen der gemalten Venusdarstellungen werden Stück für Stück durch lebendige Individuen ersetzt. Anschaulich setzt die Aktion eine Vision in kämpferische Bilder. Außerdem zeigt sich bei dieser Aktion erneut ein konkreter Bezug

367 Das zitierte Gemälde „Das Haupt der Medusa“ (1595/96) von Carravaggio befindet sich in den Uffizien in Florenz. 
zum Aufführungsort. Sind die zitierten Bilder doch in Florenz entstanden, gehören sozusagen an den Ort der Aufführung.

Greift man an dieser Stelle zurück auf das, was weiter oben über Rituale gesagt wurde, dass nämlich Rituale ihre Inhalte über das System des Unbewussten vermitteln und umgekehrt in der Außenwelt Markierungen für innere Prozesse sind, dann zeigt sich, das genau diese Mechanismen auch in dieser Aktion greifen. Mit ihrer hohen Symbolträchtigkeit wirkt die Aktion auf des Unbewusste und zudem wird in der Aktion ein innerer Befreiungsprozess zum Ausdruck gebracht. Auf diese Weise übernimmt das Ritual in dieser Aktion die Funktion das in vorangegangenen Arbeiten die Videotechnik übernahm, nämlich einen Raum zu bieten, Inneres direkt auszudrücken.

\section{III.5.5. Die documenta 6 im Jahr 1977 in Kassel}

Die stete Wiederholung des Wortes „Frau“ begleitete noch eine weitere Arbeit der Künstlerin: Die Videoinstallation „Herakles - Herkules - Kingkong“, die den Untertitel „Die Vorbilder der Mannsbilder“ trug, wurde im Sommer 1977 in Kassel auf der „documenta 6“ gezeigt, deren künstlerischer Leiter Manfred Schneckenburger war. Erstmals gab es auf dieser documenta eine eigene umfangreiche Videoabteilung, die von Wulf Herzogenrath betreut wurde. ${ }^{368}$ Im Ausstellungskatalog wird die Bedeutung des Medialen in der zeitgenössischen Kunst besonders herausgestellt:

\section{„Der Medienaspekt bleibt ein archimedischer Punkt, auf den sich das breite Panorama der Gegenwartskunst beziehen läßt, vom Videodschungel des elektronisch enthusiasmier- ten Nam June Paik bis zum vertikalen Erdkilometer Walter De Marias, dessen a- visuelle Konzeptualität eine fast schon therapeutische Gegenposition zum visuellen Totali- tarismus unserer Dekade bedeutet" "369}

Auch wird die These formuliert, das Grundmuster der Kunst der 1970er Jahre lasse sich auf das Medienthema beziehen. Zudem werden mehrere Tendenzen benannt: So zeige sich zum einen eine Tendenz zur Grundlagenforschung und Selbstreflexion der künstlerischen Medien als Realitätssicherung des Künstlers. Zum anderen gebe es einen Hang zur analytischen Transparenz des Machens als Gegengewicht zur Vortäuschung dokumentarischer Wirklichkeit durch mediale Herstellungsverfahren. Drittens zeige sich unter den Werken eine Neigung zu körperlicher Primärerfahrung in der Plastik als Alternative zu einer sekundär vermittelten Welt. Schließlich wird auf die Tendenz zum Purismus monochromer Bilder als Antwort auf eine Bilderinflation rundum gewiesen. Diese Fokussierung

368 Bereits auf der d5 hatten Harald Szeemann und Gerry Schum eine kleine Videoabteilung eingerichtet gehabt.

369 Kat. Kassel 1977, Bd. 1, S. 17 
auf die mediale Innovation aufnehmend, wurde die Eröffnungsaktion der d6, die von den drei Künstlern Joseph Beuys, Nam June Paik und Douglas Davis zusammen gestaltet wurde, weltweit per Satellit übertragen.

Neben den zahlreichen Videowerken - überwiegend Closed-Circuit-Arbeiten und Videoobjekten - die bei dieser documenta ausgestellt waren, war auch eine umfangreiche Videothek eingerichtet worden mit aktuellen Tapes von internationalen Künstlern. ${ }^{370}$ Dort waren auch zwei Tapes von Ulrike Rosenbach vertreten: „Glauben sie nicht, dass ich eine Amazone bin“ und „Tanz für eine Frau“. ${ }^{371} \mathrm{Zu}$ dem trug die Künstlerin zur wichtigsten Schau zeitgenössischer Kunst die Videoinstallation „Herakles - Herkules - Kingkong“ bei. ${ }^{372}$ An einer Wand des mit schrägen Wänden ausgestatteten Dachraumes war an die Giebelseite ein Großfoto installiert, das ein Detail des „Herkules-Farnese“ zeigte, der auf der Kasseler Wil-

370 Hier konnten zum Beispiel Videotapes angeschaut werden von Vito Acconci, Chris Burden, Peter Campus, Douglas Davis, Ed Emschwiller, Valie EXPORT, Nan Hoover, Joan Jonas, Allan Kaprow, Bruce Nauman, Dennis Oppenheim, Nam June Paik, Richard Serra, Keith Sonnier, William Wegman oder Peter Weibel.

371 „Tanz für eine Frau“ D, 1974, 8', s/w, mono, Mitwirkende: Ulrike Rosenbach; Kamera: Ulrike Rosenbach, Klaus vom Bruch; Schnitt: Ulrike Rosenbach; Musik von Annunzio Paolo Mantovani: „Ich tanze mit dir in den Himmel hinein“ (aus dem Film „Die sieben Ohrfeigen“); Produktion: Alternativ Television; Produktionsformat: $1 / 2$ Zoll CV Sony; Produktionsgeschichte: Die Kamera war auf einen runden an der Decke befestigten aber leicht schwingenden Spiegel gerichtet. Technisch handelt es sich um eine Froschperspektive, visuell jedoch um eine Vogelperspektive, denn im Spiegelbild ist Ulrike Rosenbach von oben zu sehen. (Vgl. Frieling/Herzogenrath 2006, S. 147) Frieling weist weiter darauf hin, dass Tape ab Mitte der 1970er Jahre vorrangig in Begriffen einer feministischen Kunstpraxis rezipiert wurde. Und er ordnet das Band an den Übergang zwischen autobiographischer Phase mit der intensiven Videobandproduktion im Studio, unter randerem bei Ingrid Oppenheim, und der folgenden, eher intermedialen Phase von Aktionen, Performances, sowie installativen und raumbezogenen Arbeiten. Dabei sei „Tanz für eine Frau“ offensichtlich eine Arbeit zum Thema Selbstreflexion. Spiegelung, Narzissmus, mit denen nicht nur das Medium Video in seinen Anfängen häufig indentifiziert wurde, sondern auch die spezifisch weibliche Ästhetik ikonographisch verbunden gewesen sei. Dabei breche Rosenbach aber den Narzissmus und deute ihn um als Form des kreativen Feminismus. Solch eine Verschiebung des Blickes zeigt in diesem Video aus der Vogelperspektive die sich um sich selbst drehende Frau im schulterfreien Ballkeid. „Hier sind es genau acht Minuten, die diese illusionistische Balance gelingt, bevor die Fliehkräfte und die eigene Erschöpfung dazu führen, dass sie am Ende zu Boden fällt, während das Mantovanische Motiv der Melodie immer nocheinmal eine Runde eröffnet. Die Mechanik der Plattenaufnahme kontrastiert plötzlich in aller Schärfe mit dem am Boden liegenden weiblichen Körper." Frieling greift in seiner Betrachtung weiter auf kunsthistorische Vorbilder - wie Actionpaintings von Alfons Schilling oder die Rotoreliefs Duchamps - zurück (Frieling/Herzogenrath 2006, S. 149f). „Insofern gelingt „Tanz für eine Frau“ eine doppelte Bewegung: die Fortführung einer langen künstlerisch-konzeptionellen, aber auch einer mythologischen Tradition und zugleich die Frage nach dem Blick, der das Geschlecht kadriert.“ (Frieling 2006, S.150) Neben dem Rückgriff auf vielfältige kunsthistorische Vorbilder scheint mir die Bildgebung aber viel konkreter motiviert. Erinnert die drehende weiße Scheibe, auf der sie tanzt, doch direkt an einen Plattenteller, auf dem die aus dem Off ertönende Melodie abgespielt wird.

372 Heute befindet sich die Installation im Museum Wiesbaden. 
helmshöhe als monumentale Bronzeplastik steht und hier nun als fotografische Reproduktion in die Installation eingebunden wurde. Im umschließenden Griff des linken Armes der Herkulesplastik klemmte ein kleiner Monitor, auf dem das Gesicht der Künstlerin zu sehen war, die ununterbrochen das Wort „Frau“ wiederholte. Eine zweite Wand in dem Raum zeigte ein weiteres Fototableau mit eingebautem Monitor. Die hier präsentierten Fotoreihen, Ausschnitte aus Texten und Büchern und ein Zusammenschnitt von Dokumentarvideos und Filmausschnitten untersuchten Parallelen zwischen „männlichen“ Prototypen wie unter anderem Herakles oder auch King Kong. ${ }^{373}$

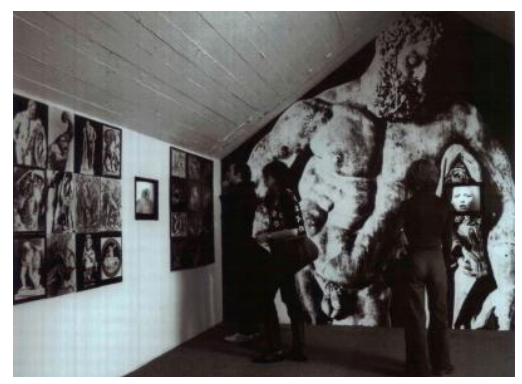

Abb.87: Hercules - Herakles - King Kong, 1978

Mit ihrer Installation stellte sie den Aspekt männlicher Körperstärke, personifiziert in der mythologischen Figur des römischen Gottes Herkules, der dem griechischen Heros Herakles entspricht, der den Riesen Cacus tötete und als eine Personifikation für Kraft steht, in den Mittelpunkt ihrer Arbeit. Dabei sah die Künstlerin männliche Körperstärke gepaart mit Macht, bereits angelegt in der mythologischen Figur des Herkules, in den damals aktuellen Neuverfilmungen der KingKong-Filmen auf die Spitze getrieben. Auch Margarethe Jochimsen stellt in ihrer zeitgenössischen Interpretation der Installation heraus, dass männliche Körperstärke gepaart mit Macht in Filmen wie „King Kong und die weiße Frau“ pervertiert werde. ${ }^{374}$ Zudem zeigt sich in der Wahl des Herkulesbildes, das das Zentrum der Installation bildete - wie schon bei der Florentiner Aktion - ein direkter Bezug zum Ausstellungsort.

Wieder ganz wörtlich wird in der Installation die Frau, genauer der Kopf einer Frau, von einem Herkules-Mann im Würgegriff gehalten und ist in dieser Gefangenschaft nur noch knapp in der Lage, Luft holen zu können beziehungsweise sich zu artikulieren. So ist die Installation ein sprechendes Bild, das zeigt, wie

373 Die amerikanische Verfilmung von 1932/33 war in der BRD erst im Jahr 1952 in den Kinos gelaufen. Das Remake dieser Verfilmung unter der Regie von John Guillermin hatte in den USA dann 1976 Premiere, in der Bundesrepublik im Folgejahr, so dass der Film zum Zeitpunkt des Entstehens der Installation Rosenbachs zum aktuellen Kinoprogramm gehörte.

374 Jochimsen in: Neusüß 1979, S. 252-255 
Frauen der Macht des Mannes ausgeliefert sein können und es zeigt zudem den Versuch der Selbstbehauptung in dieser Unterdrückung. Das „Frau-Frau“ aus dem kleinen Monitor veranschaulicht somit die Anstrengung einer Frau - hier vertreten durch das sprechende Abbild der Künstlerin - in einer Welt mit dominierendem Männlichkeitsideal ihre Persönlichkeit zu finden und $\mathrm{zu}$ entwickeln, oder wie Margarete Jochimsen in den 1980ern interpretierte:

„Die Installation ist eine ironische Abhandlung über die Verhältnisse, wie sie sich in unserer Gesellschaft widerspiegeln $\square^{375}$

Nachdem die Künstlerin aus der Performance „Reflektionen über die Geburt der Venus" bereits im Anschluss eine von der Aufführung autonome Installation gefertigt hatte, ist hier nun eine weitere Videoinstallation (ohne zugehörige Aktion) entstanden, die eine Gesellschaftsanalyse in für sich allein sprechende Bilder umsetzt. Die Form der autonomen Videoinstallation ist im Werk Ulrike Rosenbachs zu diesem Zeitpunkt neu. Diese Darstellungsform begleitet von nun an aber ihr weiteres künstlerisches Wirken, bis es in den Installationen der 1990er Jahre perfektioniert wird.

Die documenta 6 hatte 355000 Besucher. Zudem rief der Hessische Rundfunk in Kooperation mit dem Westdeutschen Rundfunk während der Ausstellungswochen eine neunteilige Serie mit künstlerischen Tapes aus der Videothek der d6 ins Leben, die im Regionalprogramm gesendet wurde. Jeweils 45 Minuten dauerte ein solches Videokunst-Spezial und am 3. August 1977 lief im Hessischen Rundfunk eine Sendung im Spätprogramm, in der zusammen die Arbeiten von drei Videokünstlerinnen gezeigt wurden. Darunter waren die „Körperteile“ von Friederike Petzold, ein 15-minütiges Videoband der Berliner Künstlerin Rebecca Horn (*1944) sowie das Tape „Glauben Sie nicht, dass ich eine Amazone bin“ von Ulrike Rosenbach. Mit diesen Sendungen im öffentlich-rechtlichen Fernsehen trat die Videokunst im Rahmen der d6 über den Kunstkontext hinaus und erreichte vielleicht auch den einen oder anderen Zuschauer, der nicht die Kunstausstellung besucht hatte. ${ }^{376}$

\section{III.5.6. Politische Statements}

Am 19. Februar 1978 führte Ulrike Rosenbach im Rahmen des „Forum Bremer Dom“ ihre Videoperformance „Meine Verwandlung ist meine Befreiung“ in der Krypta des Sankt Petri Domes in Bremen auf. Wie bereits in ihrem kurzen Videotape von $1973^{377}$ bezieht sich die Künstlerin in dieser Aktion erneut auf die Aus-

375 Jochimsen in: Neusüß 1979, S. 252-255

376 Im Rahmen der documenta wurden noch weitere regionale und überregionale Beiträge im Fernsehen ausgestrahlt. Außerdem zeigte der WDR am 14.06.1978 im Rahmen der Sendereihe „Frauen in der Kunst“ Rosenbachs „Amazonen-Signale“

377 Vgl. Kap. III.1. 
sage des Apostels Paulus „Der Mann sei das Haupt der Frau“. Der Satz findet sich im Neuen Testament der Bibel bei Paulus sowohl im Brief an die Korinther ${ }^{378}$ als auch im Brief an die Epheser ${ }^{379}$, in dem der Apostel eine patriarchal anmutende christliche Familienordnung umreißt. Während Ulrike Rosenbach in ihrem vorangegangenen Tape den Geschlechteraspekt in den Mittelpunkt gestellt hatte, kreist sie in dieser Aktion die Thematik ein und kritisiert die Frauenfeindlichkeit und Unterdrückung der Frauen in der christlichen Kirche. ${ }^{380}$

Für die 45-minütige Aktion waren an einer Seite der Krypta des Bremer Domes 13 Monitore pyramidenförmig aufeinander gestapelt worden. Während der oberste Monitor zu Beginn der Aktion allein das Flackern der Bildröhre zeigte, war auf den zwölf Bildschirmen darunter in Großaufnahme der Kopf des Apostels Paulus im Profil nach links zu sehen. Die Darstellung ist aus einem der beiden bekannten „Vier Apostel“-Gemälde des Malers Albrecht Dürers (1471-1528) gewählt. ${ }^{381}$

378 NT 1 Kor 11, 3: „Ihr sollt aber wissen, daß Christus das Haupt des Mannes ist, der Mann das Haupt der Frau und Gott das Haupt Christi.“

379 NT 5 Eph. 21-26: „Einer ordne sich dem anderen unter in der gemeinsamen Ehrfurcht vor vor Christus. Ihr Frauen ordnet euch euren Männern unter wie dem Herrn (Christus); denn der Mann ist das Haupt der Frau, wie auch Christus das Haupt der Kirche ist; er hat sie gerettet, denn sie ist sein Leib. Wie aber die Kirche sich Christus unterordnet, sollen sich die Frauen in allem den Männern unterordnen. Ihr Männer liebt eure Frauen, wie Christus die Kirche geliebt und sich für sie hingegeben hat.“"

380 Ross Saunders interpretiert die Aussage des Paulus im historischen Zusammenhang, wodurch sie einen neuen Sinn bekommt. Gehe es Paul doch in seinem Brief darum, die Stellung und Achtung der Frauen aufzuwerten. Waren die Frauen in der Korinther Gesellschaft, die für ihre sexuellen Ausschweifungen bekannt war, doch eher als Spielzeuge und Lustobjekte betrachtet worden. So fordere Paulus die Frauen auf sich in angemessener Weise als Ehefrauen, Töchter und Mütter zu verhalten. Auch sei der Begriff „Haupt“ nicht in der Bedeutung von „Befehlshaber“ benutzt worden, vielmehr im eigentlichen Sinne als „Ursprung, Ausgangspunkt“ oder „Koordinator“. So sollte die Ehefrau eine verantwortliche und entgegenkommende Rolle in der Ehe spielen. (Vgl. Saunders 1999, S. 130)

381 Jeder der zwölf Monitore zeigte denselben Ausschnitt des Gesichtes des Apostels Paulus aus dem Gemälde „Die Apostel Paulus und Marcus“ (die rechte Tafel der „Vier Apostel“ 1526, Holz, 212,8 x 76,2 cm, Alte Pinakothek München (Inv.-Nr. 545, 540)) von Albrecht Dürer; dargestellt sind auf den zwei Tafeln die vier Apostel Johannes, Petrus, Markus und Paulus als knapp überlebensgroße Gestalten. Zu ihren Füßen befindet sich eine schmale Inschriftenleiste, die Bestandteil des Bildes ist. Sie enthält die Aufforderung an die „weltlichen Regenten“, das reine Bibelwort zu achten und sich vor religiösen Verführern, „falschen Propheten“ zu hüten. Diese „Warnung“ wird mit Zitaten aus den biblischen Schriften der Dargestellten untermauert, die nur im Zusammenhang mit der 1525 eingeführten Reformation in Nürnberg verständlich sind. Adressat der Mahnung ist der Rat der Reichsstadt Nürnberg, dem Dürers die Tafeln schenkte. Zudem sind in den vier Aposteln die vier Temperamente dargestellt. Paulus versinnbildlicht hier das melancholische Temperament. 

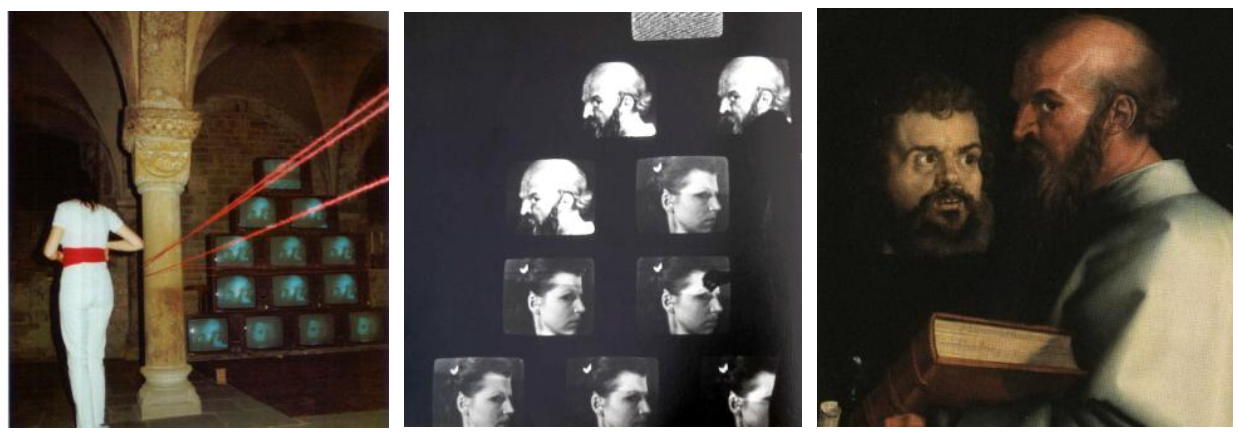

Abb. 88-90: Meine Verwandlung ist meine Befreiung, 1978, 2 Aktionsfotos und Albrecht Dürer: Die vier Apostel (Detail), 1526

Die Künstlerin wandelte in der Aktion die Bilder der Monitorpyramide, in dem sie die Paulusporträts eines nach dem anderen durch ein Porträt ihres Gesichtes ersetzte. Dazu vollzog sie eine sich insgesamt 13 Mal wiederholende Handlung. Sie trat vor die Zuschauer, die ihren Platz innerhalb des Säulenganges der Krypta gefunden hatten, eingeschnürt in ein rotes Band, das sie sich zuvor um den Oberkörper gewickelt hatte. Langsam begann sie sich dann um ihre eigene Achse drehend um die Säulengruppe zu bewegen, in deren Mitte die Zuschauer auf Bänken saßen, und sie entwickelte und sich so während ihres Rundganges aus ihrer fesselnden Umschnürung. Nach jeder vollendeten Runde wurde in der Monitorpyramide von unten nach oben eines der Paulusbilder durch eine Abbildung des Gesichtes der Künstlerin ersetzt. Dabei war auf dem dann erscheinenden vorgefertigten Tape zu sehen, wie die Künstlerin versuchte, ihr Gesicht, das zunächst frontal in die Kamera blickte, zur Seite zu wenden und damit in die gleiche Profilpose des Pauluskopfes zu bringen.

Runde um Runde wiederholte sich diese buchstäblich in Aktion übersetzte Entwicklung. Begleitet wurde die gesamte Aktion dabei von einem gleichmäßigen Herzschlag, der in verstärkter Form in der Krypta erklang. Ihren Abschluss fand die stete Wiederholung, nachdem die dreizehnte Runde um die Säulen vollzogen war und auch der letzte, oberste - bis dahin weiß flimmernde Bildschirm mit dem Abbild der Künstlerin ausgefüllt war. Zudem war der rote Faden, der die Akteurin eingeschnürt hatte, nun vollständig abgewickelt und die Künstlerin stand befreit vor den Zuschauern, die sich nun allerdings hinter einer Einzäunung dieses roten Bandes befanden.

Die Bedeutung der Schriften des Kirchenmannes Paulus, die die Künstlerin im zitierten Bildnis des Apostels symbolisch einbringt, ist für die Entwicklung des Christentums fundamental: 


\begin{abstract}
„Die Briefe des Paulus sind die ältesten zusammenhängenden Schriften des Christentums, die uns erhalten sind, und sie bilden innerhalb der frühchristlichen Literatur das größte geschlossene Corpus. Sie haben im weiteren Verlauf der Kirchengeschichte mit ihrer angreifend-ernsten und tiefsinnigen Interpretation des Christus-Ereignisses überaus weit- und tiefgreifende Wirkung ausgeübt und die Kirche immer wieder aus Irrwegen und Krisen zu ibrer Sache selbst qurückgeführt. "382
\end{abstract}

Während das Wirken des Paulus somit als eine Basis des Christentums zu verstehen ist - wie es auch in der Pyramide ins Bild gesetzt ist - wird in dem Monitorstapel - zwölf Bildschirme entsprechend der zwölf Apostel, die das Paulusbild stellvertretend vertritt - von unten Bild für Bild und Schicht für Schicht das Porträt des Paulus durch ein Porträt der Künstlerin abgelöst, während diese sich in der parallel verlaufenden Aktion durch stetes Drehen um die eigene Achse aus ihrer beengenden Fesselung durch einen an eine Nabelschnur erinnernden dicken roten Faden befreit. Anstelle ihres eigenen Körpers hat dieses rote Band am Ende der Aktion die Säulen der Krypta - metaphorisch auch die Säulen der Kirche und die darin versammelten Menschen - umschnürt. Und auch der oberste dreizehnte Bildschirm war schließlich mit einem elektronischen Bild gefüllt, das ebenfalls das Gesicht der Künstlerin zeigte.

Mittels einer sehr minimalistischen und chiffrierten Bildsprache, verbildlichte die Künstlerin in dieser Performance, die selbst in einer Kirche aufgeführt wurde, das patriarchale System des Christentums, um sich gleichzeitig - symbolisch - von diesem zu lösen. Dabei sind die Monitore, die allmählich mit dem Porträt der Künstlerin gefüllt werden, in Dreiecksform angeordnet. Dies ist ein formales Element, das im Werk der Künstlerin bereits im Salzdreieck bei den „Reflexionen" begegnete. Genauso ist das formale Element des Ein- beziehungsweise Auswickelns nicht neu, begegnete es doch bereits inhaltlich sehr ähnlich konnotiert in der „Frauenkultur-Performance“, nur dass dort nicht mit rotem Band, sondern mit dem Videokabel gearbeitet wurde.

Die komprimierte Aktion im Dom traf allerdings auf wenig Verständnis, zumindest wenn man die Reaktionen in der örtlichen Tagespresse auf diese Kunstaktion betrachtet. Äußerten sich die Kritiker dort doch abwertend bis regelrecht feindselig. Die Künstlerin wurde nicht nur als Feministin angefeindet, sondern ihrer Sichtweise zudem Einseitigkeit und Unfähigkeit vorgeworfen, sich den tatsächlichen Problemen der Frau in der damaligen Gesellschaft zuzuwenden. ${ }^{383}$ Als „enttäuschend und dürftig"384 bezeichnete zum Beipiel Hartmut Lück in seiner Rezension in den Bremer Nachrichten die 45-minütige Aktion und bei dem Kulturredakteur Simon Neubauer des Weser-Kuriers erzeugte die Aufführung „Fra-

\footnotetext{
382 Moeller 1992, S. 31

383 Lück in: Bremer Nachrichten 21.2.1978

384 Lück in: Bremer Nachrichten 21.2.1978
} 
gezeichen und löste Kopfschütteln aus.“385 Die Kritik der beiden Männer zielte zudem darauf, dass sich die Aktion für den Betrachter nur schwer aus sich selbst heraus erschließen lasse, seien die gesellschaftskritischen Aussagen doch ohne Hinweise der Akteurin nicht zu ergründen. ${ }^{386}$ Auf dieses Unverständnis des Kritikers angesprochen, erläuterte Wulf Herzogenrath:

„Bleibt die Frage, wer ging damals zu solchen Veranstaltungen, um darüber zu berichten. Wenn der Theatermann dorthin ging, war dieser natürlich frustrierter als der bildende Kunstmann es gewesen wäre. Das wäre dann ein Beleg dafür, dass das NichtNarrative, sehr Konzentrierte auf eine Situation etwas war, das Theaterleute schwierig fanden. Natürlich gab es das damals schon bei Beckett etcetera, aber auch dort musste es interessant gestaltet werden. Während die Performances von Ulrike Rosenbach eher mit Minimalmusik zu vergleichen wären. Wie zum Beispiel bei La Monte Young oder Steve Reich, bei denen kleine Variationen des scheinbar immer Gleichen als selbstverständlich und akzeptiert galten.

Diese Aussage könnte man noch folgendermaßen bestärken. In der Ausstellung „Projekt 1974", in der Ulrike ja auch dabei war, war zum ersten Mal für Europa auch der Musiker Philipp Glass im Kunstkontext vertreten. Dies war also nicht Musik, sondern wir sahen diese Art von Minimalismus in der Kunst. Doch auch in der Musik, im Performancebereich oder Experimentalfilm. Es war etwas Verwandtes, das mit der künstlerischen Haltung der Reduktion, der Vereinfachung in der bildenden Kunst zu tun hatte. Das gab es so nicht in den Klassischeren Bereichen des Theaters. Und Leute aus diesem Bereich hatten damit ibre Probleme."

In Ulrike RosenbachsVideoaktion im Bremer Dom dominiert das Nicht-Narrative und komprimierte ähnlich stark wie bei der „Venusdepression“-Aktion. Hinzu kommt in diesem Werk der von Herzogenrath betonte deutliche Bezug zur modernen Musik durch den Minimalismus.

Dass diese Nähe in den 1970ern von anderen erkannt wurde, zeigt sich darin, dass die Künstlerin nicht nur mit verschiedenen Musikern zusammenarbeitete, sondern auch im selben Jahr zu einem Festival moderner Musik eingeladen wurde, und zwar noch einmal an die Weser. Im Rahmen des „Festival Pro Musica Nova“387 in Bremen führte sie im dortigen Theater im Packhaus am 6. Mai ihre Per-

385 Neubauer in: Weser Kurier 21.2.1978

386 Neubauer in: Weser Kurier 21.2.1978; Diese Kritik, die auf den Abstraktionsgrad der Arbeit Rosenbachs zielt, lässt sich nachvollziehen, ist der Gedanke, das Los der Frau in der Kirche darzustellen, doch sehr abstrahiert, intellektuell komprimiert umgesetzt. Kennt man allerdings die Codes der Künstlerin erschließen sich die Aussagen jedoch klar und augenfällig.

Dieses Festival der modernen Musik wurde 1978 zum zehnten Mal von Radio Bremen unter der Leitung von Hans Otte veranstaltet. Auch andere Performancekünstlerinnen wie Charlotte Moormann und Rebecca Horn waren in diesem Jahr nach Bremen eingeladen, wie in dem Programmheft zur Veranstaltung ausgewiesen. 
formance „Salto Mortale“ auf, die erneut am 9. Juni im Bonnefantenmuseum in Maastricht gezeigt wurde.

Das Environment dieser Aktion bestand aus einer Fotowand mit Porträts, die Frauen aus allen Teilen der Welt und unterschiedlichen Zeiten zeigte. Ein Teil der hier verwendeten Darstellungen begegnete bereits im „Kontaktversuch“. Ergänzt wurde die Auswahl in dieser Aktion um die Extreme einer Madonna wie zudem einer palästinensischen Freiheitskämpferin, „die ihr Gewehr auf gleiche Weise hält, wie die Madonna ihr Kind“", wie Marlita Halbertsma kommentierte. ${ }^{388}$ Auf diese großformatige Bildfläche aus Frauenporträts wurde ein rautenförmiger, heller Lichtfleck gestrahlt. Auf den Boden vor dieser Wand war ein Salzkreis gestreut, dessen Mitte von einem Streifen spiegelnder Silberfolie durchzogen war. Eine Fotografie von der Aktion in Maastricht zeigt zudem, wie die Tochter der Künstlerin mit gekreuzten Beinen vor der Fotowand auf der Silberfolie sitzt. Über dem Spiegelstreifen schwang die Künstlerin auf einer Trapezschaukel im schwarzen langen Rock, dessen Saum mit Glöckchen besetzt war. Die Akteurin auf der Schaukel hielt eine Videokamera in der Hand, deren Aufnahmen gleichzeitig an vier Monitore übertragen wurden. Dabei unterstützten die im Schwingen leicht klingenden Glöckchen am Rocksaum den Eindruck von Bewegung auf der aktustischen Ebene. Nach einiger Zeit des Schaukelns, ließ sich die Performerin dann unerwartet nach hinten fallen. Während sie in den Kniekehlen an der Schaukel hing, fiel ihr Rock über ihren überkopfhängenden Oberkörper. Während für das Publikum der Oberkörper der Künstlerin nun durch den Rock verdeckt war, nahm die Kamera in den Händen der Akteurin nun den Kopf der Künstlerin in der Reflektion der Silberfolie auf, während diese ununterbrochen die Worte „Frau...sein...Frau...sein“ sprach.
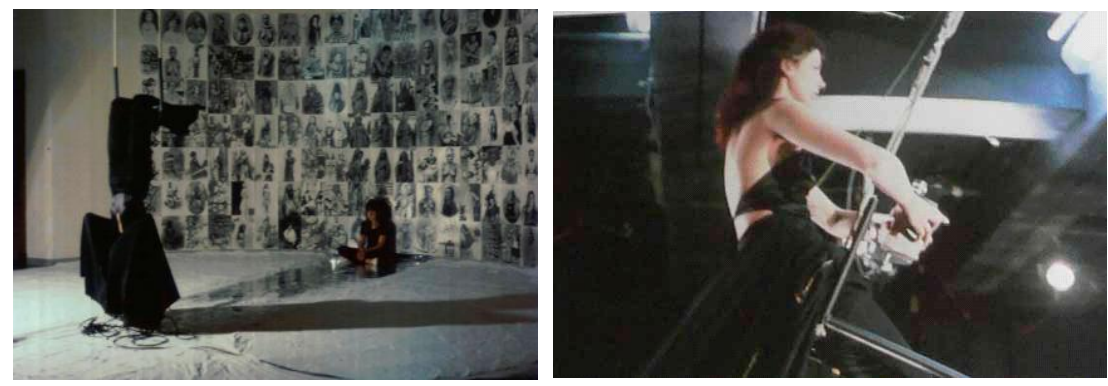

Abb. 91-92: Salto Mortale, 1978

Das inzwischen schon vertraute formale Element der steten Wiederholung steckt hier nun in dem Schwingen auf der Schaukel, das die Aktion begleitet. Zudem ist das Schaukeln eine Hin- und Zurückbewegung, die zu nichts führt. Beim Schaukeln wird immer wieder an den Ausgangspunkt zurückgekehrt. Dieses formale

Halbertsma in: Rosenbach 1982, S. 58 
Element des Hin- und Herschwingens begegnete im Werk Rosenbachs zuvor im „Projekt Kinem“, wo die Künstlerin die Kreisform abwechselnd in die beiden unterschiedlichen Richtungen beschritt. In dieser Performance ist das Schwingen nun in luftige Höhen gehoben und das Motiv des Schaukelns, Schwingens wird in späteren Werken Rosenbachs wieder begegnen.

Das Motiv des Schaukelns gilt zudem als ein weibliches Klischee, das für das unbewusste Mädchen stehen kann, eine Bedeutung wie sie zum Beispiel in dem Rokoko-Gemälde „Die Schaukel“ des französischen Malers Jean-Honoré Fragonard (1732-1806) zu finden ist. ${ }^{389}$ In dieser Komposition sitzt eine Frau im roten Kleid auf einer Schaukel, die von einem Mann geschwungen wird. Andererseits bieten sich bei der akrobatisch anmutenden Einlage Ulrike Rosenbachs - eine Dimension, auf die ja auch der Titel „Salto mortale“ verweist - ebenso Assoziationen an eine Trapezkünstlerin, der es in der schwindelnden Höhe der Zirkuskuppel gelingt, den Raum zu beherrschen. ${ }^{390}$

Die Künstlerin selbst verwies auf die schaukelnde Hanna Schygulla in der Effi Briest-Verfilmung von Fassbinder, die sie sehr beeindruckt habe. ${ }^{391}$ Der Film, nach dem Roman des Schriftstellers Theodor Fontane, wird nach einer Beschreibung der Örtlichkeiten eröffnet mit einer Szene, in der die Protagonistin Effi Briest als junge Frau in einem rüschenbesetzten hellen Kleid mit großer Schleife auf dem Rücken im Garten ihrer Eltern auf einer Schaukel sitzt und im Vordergrund der Einstellung durch das Bild schwingt. Im Hintergrund steht ihre Mutter und beobachtet die junge Frau in ihrem temperamentvollen Treiben. Während die Schaukel beim Schwingen quietscht, sagt Frau Briest zu ihrer Tochter: „Effi, eigentlich hättest du doch wohl Kunstreiterin werden müssen, immer am Trapez, immer Tochter der Luft. Ich glaube beinahe, dass du sowas möchtest.“ Und Effi antwortet von der Schaukel: „Vielleicht Mama. Aber wenn es so wäre, wer hat denn dann Schuld, von wem hab' ich es denn? Doch nur von dir! Oder meinst du vielleicht von Papa, da musst du wohl selber lachen. Und dann, warum, machst du denn keine Dame aus mir?““ „Möchtest du das“, fragt die Mutter zurück, woraufhin Effi von ihrer Schaukel springt, zu ihrer Mutter läuft und diese umarmt mit den Worten: „Nein, nein!“ Während sich die beiden Frauen umschlungen über die

389 Jean-Honoré Fragonard, „Die Schaukel“, 1767, Öl auf Leinwand, 81 x 65 cm, Wallace Collection, London

390 Halbertsma in: Rosenbach 1982, S. 58

391 Halbertsma in: Rosenbach 1982, S. 58; Der insgesamt 140 Minuten dauernde Fassbinder-Film lief ab 1974 in den Kinos (Uraufführung am 28.6.74). Es war der erste gemeinsame Kinoerfolg von Reiner Werner Fassbinder und Hanna Schygulla. Theodor Fontanes Gesellschaftsroman, auf dem die Literaturverfilmung beruht, erschien 1894/95 zunächst in der Frankfurter Rundschau als Zeitungsroman. Die Erstausgabe in Buchform trägt die Jahreszahl 1896. In dem Roman erzählt der Autor von Effi Briest, einer jungen Frau mit kindlichem Wesen, die an den gesellschaftlichen Konventionen in Preußen des 19. Jahrhunderts zerbricht. 
Wiese drehen, entgegnet die Mutter: „Nicht so wild, nicht so leidenschaftlich! Ich beunruhige mich immer, wenn ich dich so sehe. “392
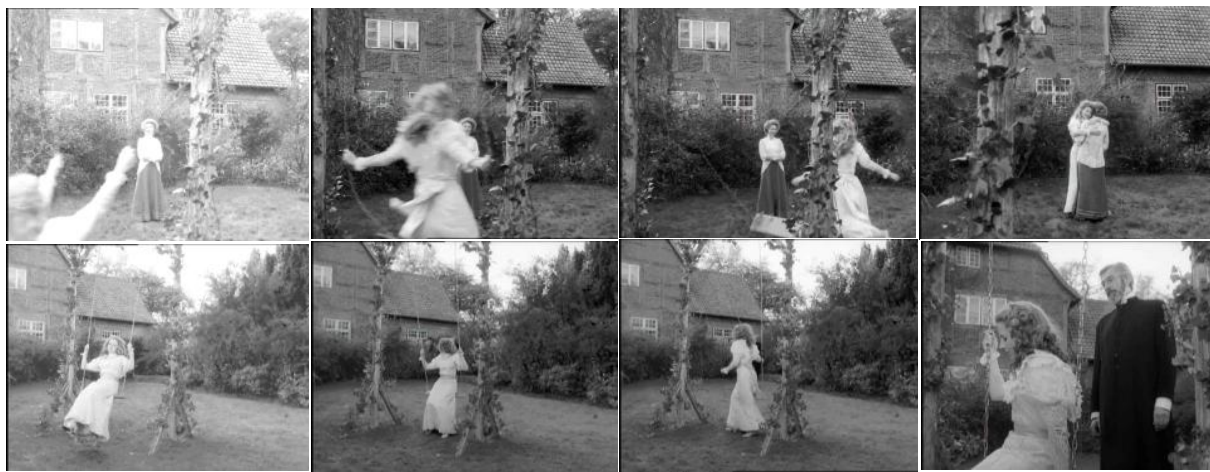

Abb. 93-100: Standbilder aus „Effi Briest" von Rainer Werner Fassbinder, 1974. Obere Reibe Szene in der Mitte des Films, untere Reibe Szene am Ende des Films

In dem Film findet sich später noch eine Szene, in der die Protagonistin im Garten schaukelt, doch scheint diese erste Sequenz besonders interessant, in der das leidenschaftliche, ungestüme Lebensgefühl der jungen Frau dargestellt wird, die später an den sie einschnürenden gesellschaftlichen Konventionen zerbrechen wird. In dieser Szene ist explizit das Thema der Trapezkünstlerin benannt. Marlite Halbertsma analysierte Rosenbachs „Salto Mortale“ Ende der 1970er Jahre:

„Die Performance stellt mit feierlichen, tragischen Mitteln eine traurige Realität dar: die schwierige Position der feministischen Künstlerin und den schier aussichtslosen Kampf der Frauenbewegung. Das Bewußtsein, daß kurz gesagt ,die Befreiung" lange auf sich warten läßt, ist das der 70er Jahre. Im heutigen West-Deutschland zeigt der Kampf für eine gerechte Welt veraweifelte Züge und ist das Sprechen in Symbolen wohl die einzige Sprache, die die Realität unverblümt an den Pranger stellen kann. In dieser Hinsicht folgt Ulrike Rosenbach, obne es zu wollen und es zu beabsichtigen, einer deutschen romantischen Tradition. Durch ibre Fähigkeit, das größtenteils patriarchalische Erbgut der westlichen und auch nicht-westlichen Kulturen neu zu betrachten, nimmt ibre Arbeit einen besonderen und fesselnden Platz ein, sowohl innerhalb des Bereiches von Video und Performance als auch innerhalb feministischer Kunst." 393

392 Die kleine Szene mit Hanna Schygulla und Lilo Pempeit in der Rolle der Frau Briest mit dem Dialog der beiden Frauen liegt in der Fassbinder-Verfilmung circa zwischen der 2:23 und 3:00 Filmminute.

393 Halbertsma in: Rosenbach 1982, S. 59 


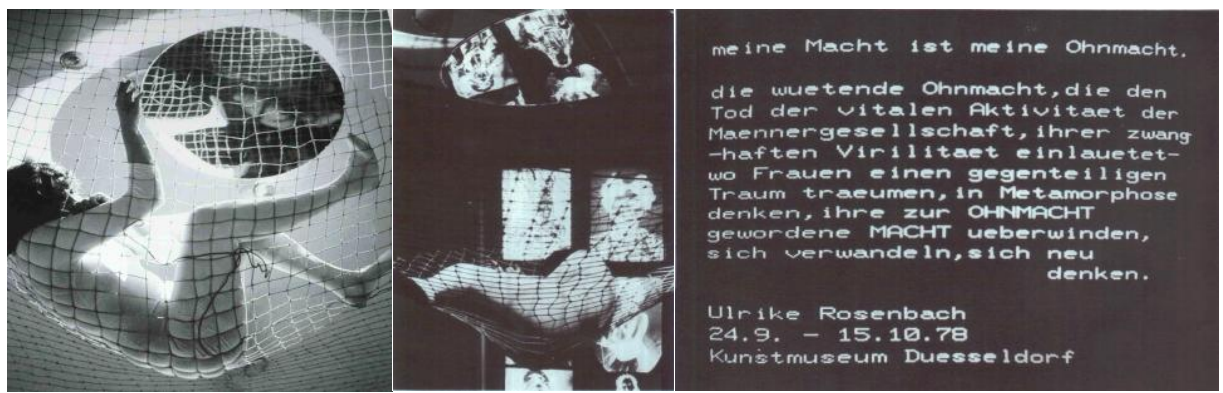

Abb. 101-103: Meine Macht ist meine Ohnmacht, 1978, 2 Aktionsfotos und Videostill

An diese Performance schloss sich zum Abschluss dieser inhaltlich eng verbundenen Trilogie aus „Frauenkultur-Kontaktversuch“ und „Salto Mortale“ als drittes die Videoaktion „Meine Macht ist meine Ohnmacht“ an. Hier hat sich die Künstlerin in einem durch den Raum gespannten großen Netz verfangen. Videomonitore, die ins Hochformat gedreht sind, und deren Format sich damit dem der gezeigten bereits bekannten hochformatigen Frauenporträts anpasst. Allerdings erscheinen die Porträts in dieser Aktion als Negativbilder. Die resignativen Elemente, die bereits im „Salto Mortale“ deutlich wurden, treten in dieser Aktion noch einmal verstärkt hervor und es zeigt sich ein resignatives Gefälle innerhalb dieses Dreierzyklus, auf das bereits Amine Haase hinwies. ${ }^{394}$ So spiegelt sich in den drei Arbeiten Schritt für Schritt die Lösung von der ursprünglichen feministischen Idee, dass es möglich sei für eine Veränderung der gesellschaftlichen Verhältnisse, sich auf positive weibliche Beispiele alter Kulturen oder der Naturvölker zu berufen. ${ }^{395}$ Das utopische Modell des radikalen Feminismus beginnt Ende der 1970er Jahre zu wackeln.

Diese Arbeiten Rosenbachs fallen in eine Zeit, in der die damit einhergehende Desillusionierung nicht nur in der Frauenbewegung begann spürbar zu werden, auch die Innenpolitik in der Bundesrepublik stand unter großen Belastungen. Nachdem Westdeutschland einen enormen Aufschwung in einem politisch stabilen Umfeld erlebt hatte ${ }^{396}$, nagte die Existenz der kommunistisch beherrschten DDR am nationalen Selbstbewusstsein. Zudem hatte die terroristische „BaaderMeinhof-Gruppe“ oder auch „Rote Armee Fraktion“ (RAF) im geteilten Deutschland eine emblematische Bedeutung, die weit über das Maß tatsächlich verursachter Störung hinausging. ${ }^{397}$ Die bewaffnete Terrororganisation war aus der Radikalisierung des aktionistischen Flügels der APO entstanden und unternahm ab Mitte der 1970er Jahre mehrere gewaltsame Versuche zur Befreiung inhaftierter Mitglieder. Nachdem die inhaftierte Terroristin Ulrike Meinhof (1934-1976) am 9. Mai

\footnotetext{
394 Haase in: Rosenbach 1982, S. 131

395 Rosenbach 1982, S. 131

396 Abgesehen von den Auswirkungen der Wirtschaftskrise in den 1970er Jahren.

397 Lucie-Smith 1999, S. $315 f$
} 
1976 in ihrer Gefängniszelle Tod aufgefunden worden war, spitzte sich daraufhin die Situation weiter zu. Am 7. April 1977 kam der damalige Generalbundesanwalt Michael Buback bei einem Attentat der RAF ums Leben, am 30. Juli desselben Jahres ermordeten Mitglieder der Terrororganisation den Bankier Jürgen Ponto. Im September folgte die Entführung des damaligen Arbeitgeberpräsidenten HansMartin Schleyer. Die daraufhin im Oktober innerhalb einer Woche eskalierenden politischen Ereignisse fasst folgendes Zitat zusammen:

„Palästinensische Terroristen entfïhren die Lufthansa Mascbine „Landshut" und for-
dern die Freilassung der in Stuttgart-Stammbeim inhaftierten RAF-Mitglieder (13.10.)
Die Geiseln werden am 18.10. in Mogadischu/Somalia durch die GSG 9, eine Son-
dereinheit des Bundesgrenzschutzes, befreit. Nach Bekanntwerden der mißgglïckten Frei-
pressung begehen die inhaftierten Terroristen Gudrun Ensslin, Andreas Baader und
Jan-Carl Raspe Selbstmord. Der am 5.9. entfübrte Hanns-Martin Schleyer wird am
19.10. ermordet aufgefunden. "398

Die politischen Ereignisse, die das demokratische Selbstverständnis der Bundesrepublik zu zerreißen drohten, fanden auch in den Medien großen Widerhall. So wurde erstmals in der Geschichte des bundesdeutschen Fernsehens das laufende Fernsehprogramm unterbrochen, um über Neuigkeiten des Verlaufs der Flugzeugentführung zu berichten.

Der mit Ulrike Rosenbach befreundete Kölner Künstler Klaus vom Bruch verarbeitete die Ereignisse direkt in seinen „Schleyer-Bändern“, zwei Videodokumentationen, die noch 1977/78 entstanden. ${ }^{399}$ Die Tapes wurde bei „Alternativ Television“ (ATV) produziert, dem bereits erwähnten Medienprojekt um Ulrike Rosenbach, an dem auch der Kölner Künstler Marcel Odenbach (*1953) beteiligt war. Die beiden Bänder Klaus vom Bruchs, der zuvor erst ein anderes Videoband gedreht hatte, bestehen ausschließlich aus Fernsehmitschnitten, die zwischen September 1977 und Juni 1978 gesendet wurden. Sabine Maria Schmidt kommentiert die Entstehung des „Schleyer-Bandes“ aus heutiger Sicht:

„Klaus vom Bruch batte zu diesem Zeitpunkt wobl kaum daran gedacht aus dem Material ein Künstlervideo zu scbneiden. Die nur sparsamen Eingriffe in das rein dokumentarische Material bezengen vielmehr die Sprachlosigkeit der Kunst angesichts der Ereig-

398 Börnreuter/Schuster 1999, „1977“

399 Erst 1976 hatte Sony ein Videosystem entwickelt, dass im Amateurbereich die Aufzeichnung von Fernsehprogrammen auf Videoband ermöglichte und so war es seitdem möglich mit Found footage - also vorgefundenen Bildern - zu arbeiten. Ulrike Rosenbach, Marcel Odenbach und Klaus vom Bruch hatten 1975 in Köln das private Videostudio „Alternativ Televison“ gegründet. In diesem Studio fand sich eine solche Schneideanlage. Zudem hatte der Künstler die Möglichkeit durch die Installation einer Dachantenne am Studio den belgischen Armeesender für stationierte Soldaten empfangen und über U-matic mitschneiden. So finden sich in dem Schleyerband auch Aufnahmen ausländischer Fernsehsender eingearbeitet. (Vgl. Schmidt in: Frieling/Herzogenrath 2006, S. 163f) 
nisse, zugleich aber auch das Bedürnis, den gelenk.ten Informationen und Berichten eine eigene Sichtweise gegenüberstellen zu können. Und sie belegen die emotionale und intellektuelle Involviertheit des Künstlers. "

Karin Thomas charakterisiert das Band ähnlich:

„Künstler, die sich der Videoaufzeichnung bedienen, vergegenwärtigen die Spuren der Geschichte durch ein Recycling von vorgefundenen Bildern. So unternimmt Klaus vom Bruch den Blick zurück aus der eigenen Gegenwart in die Vergangenheit, als ihm die fortschreitende Videotechnologie die Möglichkeit offeriert, in selektiven Mitschnitten Teile dokumentarischer Fenrsehsendungen selbst zu speichern und nach seinen Vorstellungen zu kombinieren. Konkreter Anlaß wird für ihn 1976/77 die eigene Auseinandersetzung mit dem eskalierenden Terrorismus der Rote Armee Fraktion. Die kontaminierende Schnitttechnik, die vom Bruch beispielsweise im SCHLEYERBAND anwendet, zielt darauf ab, die Härte der seinerzeit aufeinanderprallenden gesellschaftlichen Gegensätze in ihrer Militanz zu akezentuieren. Aus der technischen Perfektion der Schnittmontagen und der Spannung der daraus resultierenden Bildinhalte geht eine spezifische Dramaturgie der Bildsequenzen hervor, in der sich die Befindlichkeit des Künstlers in seiner engagierten Zeitzengenschaft widerspiegelt. " 400

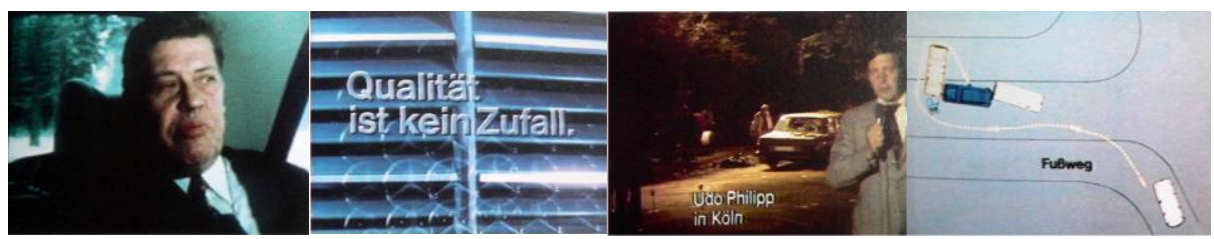

Abb. 104-107: Klaus vom Bruch: Das Schleyer Band, 1978, 4 Videostills

Ähnlich wie Klaus vom Bruch beschäftigte auch den Künstler Marcel Odenbach Politik und Zeitgeschichte. Ebenfalls ab Mitte der 1970er Jahre fertigte Odenbach Videobänder und -installationen, deren zentrales Thema die assoziative Überlagerung der Gegenwart durch historisch signifikante Momente ist. Es sind verfremdete Darstellungen schockierender Ereignisse, wie dem Holocaust, dem Vietnamkrieg oder Hungerkatastrophen, die er mit dem Verhalten des Zuschauers konfrontiert, der Berichte darüber konsumierend im Fernsehen betrachtet. ${ }^{401}$ Karin Thomas weist auf den zentralen Aspekt des Erinnerns im Werk dieses Künstlers:

„Odenbachs Installation, die dem Ungleichzeitigen eine bildhafte Gleichzeitigkeit in der Kunst ermöglicht, macht deutlich, daß das nacheräählende Bild immer ein erinnertes ist, das die Gedächtnisschleusen des Subjektes durchlaufen hat. Und dieses Bild ist keineswegs identisch mit den historisch gewordenen Bildern einer vergangenen Realität, aber es

400 Thomas 2002, S. 395

401 Brockhaus 2003, S. 267 
hat die Verarbeitung der subjektiven Psyche passiert, es ist das angeeignete Bild, in dem sich individuelle Identitätssuche spiegelt. "402

Während die beiden jüngeren Künstlerkollegen in ihren Werken explizit und mit politischem Blick Bezug nehmen auf die deutsche Zeitgeschichte, hatte Ulrike Rosenbach ihren politischen Fokus auf einen anderen Schwerpunkt gelegt: ihre Werke zeigen eine individuelle künstlerische Auseinandersetzung mit der Ideologie des radikalen Feminismus.

Wenn ihre beiden männlichen Kollegen konkret (bundes-)deutsche Geschichte in ihren Arbeiten thematisieren, gesellen sich deren Themen damit zu denen des älteren Künstlers Anselm Kiefer (*1945), der bereits 1969 den Mut hatte, die verdrängte Geschichte des Dritten Reiches und dessen emotionsträchtige Symbolik mit ihrer affektiven Stimulationskraft für seine künstlerische Strategie auszuwerten, die sich überspitzt als „Selbstheilung durch Exorzismus“ charakterisieren lässt. 403

Wulf Herzogenrath umriss die enge Verbundenheit der Werke der drei aus unterschiedlichen Generationen stammenden Künstler Rosenbach, Odenbach und vom Bruch und deren künstlerische Bindung an die deutsche Geschichte:

„Die Szene in Deutschland ist dadurch, dass sie die Kunstvereine hat, sehr reich und wichtig und viele der ausländischen Avantgarde-Künstler - besonders die AvantgardeKünstler aus Amerika - haben fast davon gelebt haben, dass sie in Deutschland gut unterkamen. Zum Beispiel waren Vito Acconci oder Dennis Oppenheim ja fast mehr in Deutschland als in Amerika. Unsere Medienk.ünstler aber waren gegenüber Malern und dem was „normale verkaufbare Kunst“ war, hier natürlich sehr im Nachteil, während diese Kunstform wiederum selbstverständlich in Kanada und Amerika war.

Alle drei - Marcel Odenbach, Klaus vom Bruch und Ulrike Rosenbach - haben sehr viel von der Grundhaltung, dass Sprache und erst recht deutsche Sprache ganz selten vorkommt. Es geht um Klänge und Klang, was natürlich international viel eher vermittelbar ist. Auch wenn Bilder sehr individuell sein können, sind diese immer transportierbar. Diese Problematik des Individuellen ist bei Ulrike vielleicht nicht ganz so scharf, weil es bei ihr oft in dieses Franenthema geht, das natürlich international gleicher ist, aber bei Klaus vom Bruch oder Marcel Odenbach ist die deutsche Geschichte und das deutsche Thema sehr wichtig. Das ist aber bildlich transportierbar und zudem, wenn man so will, transponierbar für einen intellektuellen Amerikaner und Kanadier. Wenn das Ganze zudem mit deutschen Erzählungen und Texten wäre, wäre die Rezeption sehr viel mühsamer. Ich glaube auch, dass bei den dreien der Gedanke an eine internationalen Verwertbarkeit nicht unterschätzt werden darf.

402 Thomas 2002, S. 397; Die Beschreibung bezieht sich auf das Werk „Wenn die Wand an den Tisch rückt" aus dem Jahr 1990.

403 Thomas 2002, S. 264 
So wie dann ja eben parallel ein Kiefer und die deutsche Malerei, die ja viel mehr im Ausland, wie in Holland und Amerika akzeptiert wurde als in Deutschland. Hier wurde gesagt, dieses ist ja schrecklich. Das ist vergleichbar mit Themen bei Klaus vom Bruch und Marcel Odenbach. Oder aber auch das feministische Thema, das fand man in Deutschland ja auch nicht toll. Während das etwas war, das sich in Amerika visuell sofort umsetzte. " 404

Anselm Kiefer ließ sich zum Beispiel in kavallerieähnlicher Reitkleidung mit dem ausgestreckten rechten Arm des Nazigrußes an geschichtsträchtigen Orten in der Schweiz, Frankreich und Italien fotografieren. Durch diese Aktionen der symbolischen Besetzungen ging der Künstler ein kleines Stück den Weg des Faschismus mit, um durch Projektionsbildung in seiner privaten Historiografie die faschistische Versuchung „am eigenen Leibe“ zu erfahren. In seiner Malerei der 1970er Jahre schafft der Künstler dann bühnenhafte holzgerahmte Räume, in die er andere Wirklichkeitsebenen hinein projiziert:

„Diese Projektionen, die sich zumeist auf einer merkwürdig flachen Ebene vor dem eigentlichen Bildraum aufhalten, entstammen vorwiegend der deutschen Nationalgeschichte, der germanisch-nordischen Mythologie und religiös-biblischen Stoffen. Ihre Beschwörung erfolgt unter Verwendung von symbolisch benutzten Bildemblemen. In den $W$ egen der Weltweisheit - Hermannschlacht (1876-78) ordnen sich die Repräsentanten deutschen Geisteslebens - Dichter, Denker und Generäle - wie eine stammbaumbafte Genealogie der deutschen Seele um ein imaginierendes Zentrum. ${ }^{405}$

\footnotetext{
404 Vgl. Interview Herzogenrath 2003, Kap. VII.2.
}

405 Thomas 2002, S. 266 


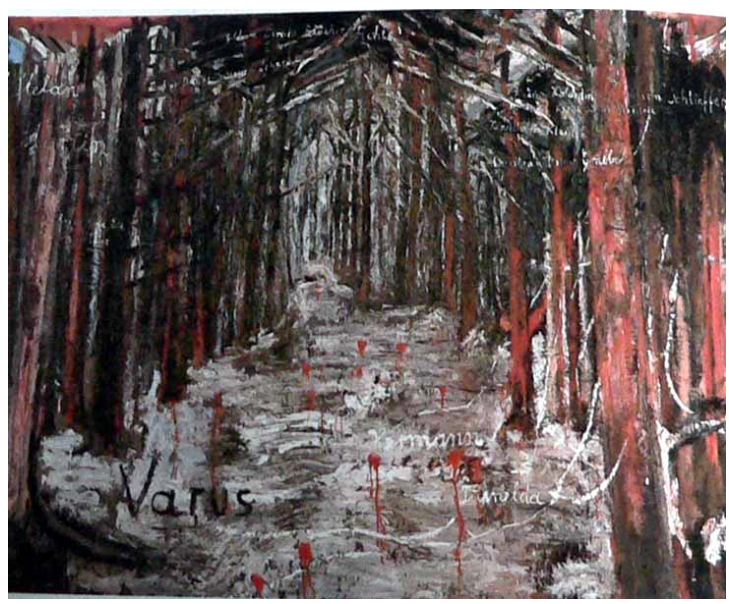

Abb. 108: Anselm Kiefer: Varus, 1976

In seiner Bilderserie zum „Unbekannten Maler“, die den Künstler ab Mitte der 1970er Jahre für ein ganzes Jahrzehnt beschäftigte, verbindet Kiefer das selbstkritische Reflektieren über sein eigenes Künstlerdasein und dessen mögliche Anfälligkeit für Ideologien mit der spezifisch deutschen Kunstgeschichte und dessen Topos des unbekannten Soldaten:

„Zu ibren unzähligen Opfern der anonymen, befehlsgesteuerten Soldatenmasse des ersten Weltkriegs gehörten auch viele expressionstische (sic) Maler und Dichter, die noch vor 1914 im Rückgriff auf die Romantik den Subjektivismus der sich für die deutsche Nation verantwortlich fühlenden Künstlerpersönlichkeit bymnisch gefeiert hatten und als Freiwillige in den Krieg gezogen waren. Durch Transformation des Topos vom Unbekannten Soldaten auf den ,unbekannten Maler' exemplifiziert Kiefer die Entmündigungstaktik des Faschismus gegenüber dem Individuum in der Apotheose des Führers und in der Idee des Völkischen." 406

Anselm Kiefers Frühwerk war in der Bundesrepublik zum Teil auf heftige Ablehnung gestoßen, fand dagegen in den USA große Resonanz. Erst als sich der Künstler in den frühen achtziger Jahren mit seinen Bildern den Opfern des Holocaust zu wandte, begann man sein Malen auch in der Bundesrepublik ,als existentiellen Gang durch die Geschichte zu begreifen“. ${ }^{407}$

Die Geschehnisse im Herbst 1977 hinterließen ebenso Spuren in der Kunst vieler anderer deutscher Künstler. So verarbeitete zum Beispiel der Maler Gerhard

406 Thomas 2002, S. 270
407 Thomas 2002, S. 270 
Richter (*1932) die Ereignisse erst elf Jahre später im Jahr 1988 in einem 15teiligen Gemäldezyklus „18. Oktober 1977“. Aus der Erinnerung elf Jahre war die ästhetische Reflexion des Künstlers für Gerhard Richter zugleich ein Abschied laut einer Tagebuchnotiz:

„Die Bilder sind auch ein Abschied und dies in vielerlei Richtungen. Der Sache nach: diese bestimmten Personen sind tot; dann ganz allgemein: Tod ist Abschied schlechthin. Dann im ideologischen Sinn: Abschied von einer bestimmten Heilslebre [...] sie beendet meine in den 60er Jahren begonnene Arbeit (Bilder nach Schwarz-weiß-Photos) in der Form einer komprimierten Zusammenfassung, die kein weitergehen mehr zuläßt. Und damit ist das ein Abschied von meinem Denken und Fühlen in sehr grundsätzlicher Form." 408

Von all diesem aufwühlenden politischen Zeitgeschehen taucht in den Arbeiten dieser Zeit einzig in Rosenbachs „Salto Mortale“ und ihrer Ohnmacht ein direktes Bild einer palästinensischen Freiheitskämpferin auf. Doch war Ulrike Rosenbach mit den beiden Künstlern Marcel Odenbach und Klaus vom Bruch befreundet, so dass deren Arbeiten und Diskussionen sicher nicht spurlos an ihr vorbeigegangen sein können. Und so manifestiert sich auch zum Ende des Jahrzehntes das die Werke der Künstlerkollegen bestimmende Grundthema „Gewalt“ in einer ihrer Aktionen.

\section{III.5.7. Erste Grenzgänge}

In ihrer Aktion „Konzert im Gewaltakt“409 reflektierte die Künstlerin das Thema Pornografie. Bei dieser Videoperformance projizierte sie nacheinander 140 DiaAufnahmen mit Szenen aus italienischen gewaltverherrlichenden pornographischen Heften an die Decke. In einem verdunkelten Raum stand die Künstlerin während der Aktion auf einem Fernsehgerät. Auf dem Bildschirm lief ein Tape, das in Großaufnahme einen Kopf zeigte, monoton hin- und herschleuderte. Durch die große Geschwindigkeit verschwammen die Videoaufnahmen zum Teil, doch war das Gesicht der Künstlerin erkennbar. Zu der Videobildschleife sirrte der hohe Ton zweier Frauenstimmen durch den Raum. Außerdem ließ die Künstlerin von ihrem erhöhten Standpunkt aus ein Schwirrholz über ihrem Kopf kreisen, das zusätzlich einen dunklen, bedrohlichen Klang erzeugte. Das Schwirrholz wird von den australischen Aborigines für rituelle Zwecke zur Abwehr von Feinden eingesetzt.

\footnotetext{
408 Notiz des Künstlers vom 1.10.1989 in: Börnreuter/Schuster 1999, o.S. „1977“

409 Aufgeführt wurde die Aktion erstmals im Hamburger Kunstverein 1979.
} 
„Ich will damit zeigen, was mit uns Frauen geschieht, meine Beklommenheit darüber ausdrücken, aber deutlich machen, daß ich nicht Opfer sein, daß ich mich wehren will. ${ }^{4} 410$

Mit diesen Worten kommentierte die Künstlerin selbst zum Entstehungszeitpunkt ihr Werk. Grundlage für diese Aktion war zum einen ihr Aufenthalt während eines Stipendiums in Florenz gewesen. In Italien hatte die Künstlerin beobachtet, dass, während in Deutschland gewaltverherrlichende pornographische Darstellungen wegen Verbots nur unter dem Ladentisch gehandelt würden, diese in Italien an jedem Kiosk „gleich neben den Micky-Mouse-Heften“ auslagen. ${ }^{411}$ Eine Auswahl dieser italienischen Druckerzeugnisse verarbeitete die Künstlerin dann in ihrer Aktion. Zudem hatte sich in Köln 1979 eine Gruppe von Frauen zusammen gefunden, die eine Anti-Pornografie-Kampagne ins Leben riefen, an der auch Ulrike Rosenbach beteiligt war. Die Frauen hatten das Angebot in Kölner Sexshops unter die Lupe genommen und vor Ort intensiv recherchiert. ${ }^{412}$ Auch erschien in diesem Jahr das Buch „Pornography: Men Posessing Women“ der amerikanischen Feministin Andrea Dworkin. Alice Schwarzer schrieb in ihrem Vorwort zur deutschen Ausgabe:

„Erniedrigung ist Voraussetzung zur enthemmten Ausbeutung, Benutzung und Zerstörung von Menschen durch Menschen. Das funktioniert beim Sexismus nicht anders als beim Rassismus oder Antisemitismus. Pornographie ist die moderne Propaganda von der Minderwertigkeit der weiblichen Menschen. Pornographie ist „das kalte Herz" (Mac Kinnon) des Frauenhasses. Direkt dafür benutzt werden bisher „nur" einige (allerdings zunehmend mehr) Frauen, betroffen sind viele, gemeint sind alle. Gemeint sind wir. " $" 13$

Aus den auf diese Weise gewonnenen Erkenntnissen destillierte die Künstlerin ihre Aktion.Während die Künstlerin aufrecht stehend abwehrend das schützende Schwirrholz zwischen sich und den Bildprojektionen an der Decke über sich kreisen lässt, steht sie erhöht auf einem Monitor, der nur ihren hin- und hergeworfenen Kopf zeigt. Als Jactatio ${ }^{414}$ oder auch Jaktation bezeichnet die Medizin solch eine krankhafte Ruhelosigkeit, das Sichherumwälzen oder Hin- und Herwerfen des Kopfes.

\footnotetext{
410 Emma 1979, Nr. 11, S. 57

411 Emma 1979, Nr. 11, S. 57

412 Das Buch erschien 1987 in deutscher Übersetzung unter dem Titel „Pornography: Männer beherrschen Frauen“ mit einem Vorwort von Alice Schwarzer.

413 Schwarzer in: Dworkin 1987, S. 9 f

414 Iactatio (lat.): das Hin- und Herwerfen, das Schütteln, Erschütterung
} 

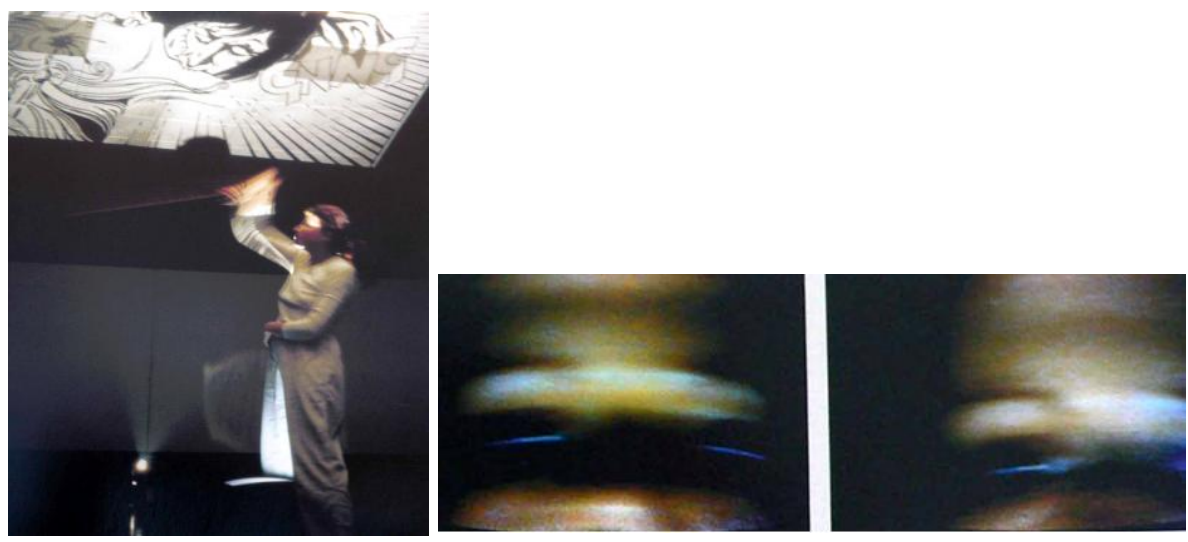

Abb. 109-111: Konzert im Gewaltakt, 1979, Aktionsfoto und 2 Videostills aus Jactatio

Die stereotype motorische Belastungsstörung tritt häufig bei Kindern mit Hospitalismus oder auch authistischen Störungen auf, kann aber auch durch Verwahrlosung oder Vernachlässigung ausgelöst werden sowie als posttraumatische Belastungsstörung auftreten. ${ }^{415}$ Die Künstlerin selbst erläutert die Jaktation als durch eine autoritäre Erziehung verursachte Störung.

Diese Belastungsstörung setzt das in die Aktion integrierte Video in symbolischer Form ins Bild. Unabhängig von der medizinischen Deutung, vermittelt sich in der zwanghaften Bewegungswiederholung auf dem Tapes ein starker Eindruck des Gefangenseins oder auch einer elementaren Erschütterung. Unterstützt wird dieser Eindruck noch durch die bedrohliche Geräuschkulisse. In der Aktion steht die Künstlerin nun auf diesem Bild. Damit bildet diese Bewegung wortwörtlich und figurativ den Grund dar, auf dem die Künstlerin steht und agiert. Andererseits hat sie sich aber auch über dieses Bild erhoben, der Erniedrigung symbolisch eine Erhöhung gegenübergestellt. Außerdem hat sie ihre Hände zur Abwehr der unter der Decke in überdimensionaler Größe prangenden Bilder in die Höhe gehoben und vollzieht ein individuelles Abwehrritual mit einem Utensil, dass in seiner Herkunftskultur ebenfalls mit apotropäischer Funktion besetzt ist.

Die Aktion arbeitet in der bereits bekannten charakteristischen Weise. In einer stark komprimierten Form und unter Einsatz von Symbolen sind die Elemente Diaprojektion, Video und körperliches Handeln mit einer raumfüllenden Klangkulisse verbunden. Erneut begegnet hier zudem das Element der monotonen Wiederholung, sowohl im körperlichen Agieren, als auch auf dem Bild des Monitors.

415 Durch das monotone Schaukeln, Wackeln, Wiegen oder Wippen beruhigen und stimulieren sich die Betroffenen. Die ständige Jaktation stumpft den Betroffenen ab und versetzt ihn in eine Art von Trance. Bei heftiger Jaktation, insbesondere beim Anschlagen mit dem Kopf an die Wand oder bei autoaggresiven Jaktationen besteht zudem Verletzungsgefahr. 


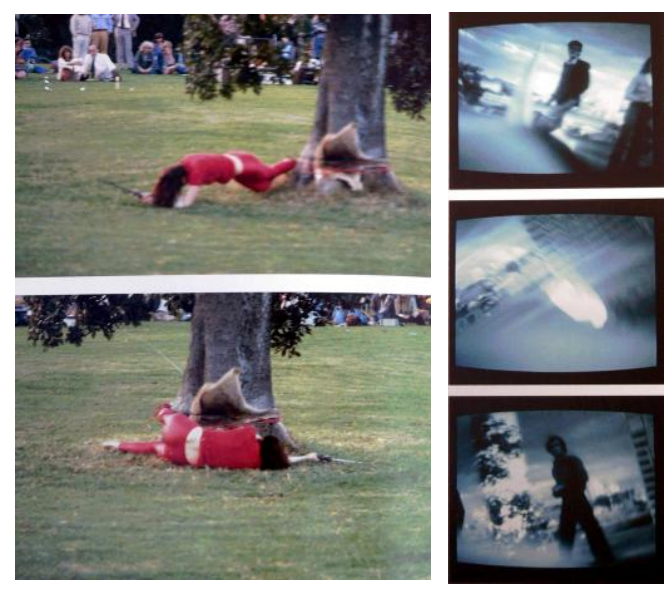

Abb. 112-116: Tanz um einen Baum, 1979, 2 Aktionsfotos und 3 Videostills

Das Schwirrholz, das in der oben beschriebenen Aktion eine wichtige Rolle spielt, hat die Künstlerin von einer Reise nach Australien mitgebracht. Und im Rahmen dieses Aufenthaltes auf dem fünften Kontinent nimmt die Künstlerin an der Biennale in Sydney teil. Dort führte Ulrike Rosenbach ihre Performance „Tanz um einen Baum" auf. Um einen Baum, der auf einer Wiese stand, waren spiralförmig in einigen Metern Entfernung vom Mittelpunkt Spiegelstücke in den Rasen gesteckt. Während die Dunkelheit herein brach, rollte sich die Künstlerin an einem Videokabel hängend, um den im Mittelpunkt stehenden Baum über den Rasen. Während des Rollens versuchte sie die Spiegelstücke mit einem Schwert zu zerschlagen. Auch diese Aktion erinnert an ein Ritual. Diesmal an einen energetisch aufgeladenen Derwischtanz, bei dem die Künstlerin im Zerschlagen der Spiegelspirale ihre eigenen reflektierenden Abbilder zertrümmerte. ${ }^{416}$ Damit ist auch diese Aktion wiederum durch die Elemente des Kreisens und Zerschlagens bestimmt ist.

Bereits im „Projekt Kinem“ war das Baumsymbol zugegen gewesen. Hier hatte die Künstlerin die Mitte des Mandalas, das bei den Sioux ein Baum bildet, durch die Videotechnologie ersetzt, genauer einen ihren Bewegungen folgenden Monitor. Hier nun begibt sie sich nach zahlreichen Aktionen, die in Räumen stattfanden wieder in die Natur und sucht sich einen realen Baum, der den Mittelpunkt ihres Aktionskreises bildet.

Der Baum hat vielfältige Symbolbezüge: In zahlreichen Religionen ist er eine heilige Stätte und dem naturverbundenen Menschen wurde er zum Erscheinungsort des Numinosen, Wohnort von Göttern und Geistern. In verschiedenen My-

416 Kat. Arolsen 1997a, S. 11 
then wird beschrieben, wie man vermeinte, in Bäumen die Stimme Gottes zu vernehmen und Buddha fand unter einem Baum zur Erleuchtung. Der Baum wird gedacht als kosmischer Baum, als Lebensbaum, als Baum der Weisheit oder auch als Alter Ego. In der Alchemie ist der Baum dem Mercurius vergleichbar und Vorstufe zum großen Mysterium. Ähnlich erkennt die Tiefenpsychologie den Baum in einem Bezug zur Mutter und zur seelisch-geistigen Entfaltung. ${ }^{417}$ Dieses mythische Symbol des Lebens fand sich gerade in der Malerei der Romantik häufig ins Bild gesetzt. Im weiteren Werk Rosenbachs wird der Baum oder auch Teile des Baumes in zeichenhafter Weise weiter begegnen.
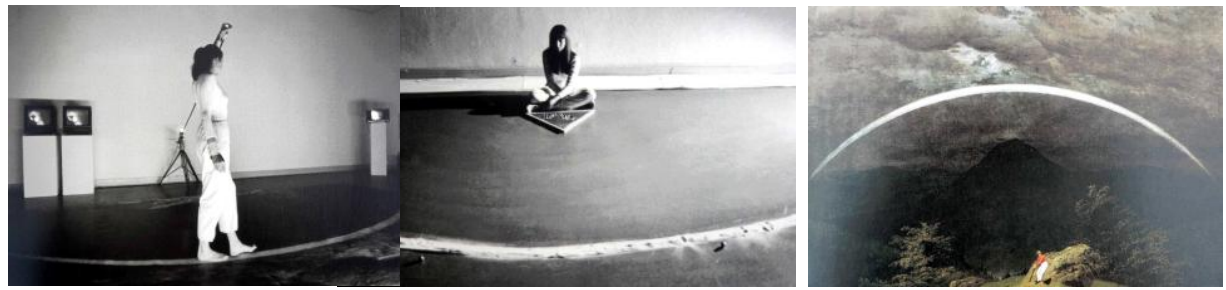

Abb. 117-119: Die einsame Spaziergängerin, 1979, 2 Aktionsfotos und Caspar David Friedrich: Gebirgslandschaft mit Regenbogen, 1809/10

Ebenfalls die Eindrücke der australischen Kultur aufnehmend, verarbeitete die Künstlerin in ihrer Videoaktion „Die einsame Spaziergängerin“ den Ursprungsmythos der Aborigines. Im Mythos der Regenbogenschlange wird ein bisexuelles Schöpferwesen beschrieben, das in der Vereinigung aller Aspekte des Lebens die Einheit der Gegensätze symbolisiert und das Prinzip göttlicher Fruchtbarkeit verkörpert. Die Künstlerin verwebt in ihrer komplexen Performance Symbole aus dem australischen Mythos mit einem bildlichen Zitat aus der europäischen Kunstgeschichte, genauer der Phase der Romantik. Bildet doch eine am Boden liegende, stark vergrößerte Schwarzweiß-Reproduktion des Gemäldes „Gebirgslandschaft mit Regenbogen“ (1809/10) des Malers Caspar David Friedrich (1774-1840) ein tragendes gestalterisches Element der Aktion. ${ }^{418}$ Der Sichelform des das Gemälde durchziehenden Regenbogens folgt die stete Bewegung der Schreitenden, die die Künstlerin barfuß vollzog. Dabei hielt sie einen Stab in ihrer Hand, der mit der im Zentrum eines gedachten Halbkreises stehenden Kamera verbunden war, so dass das Objektiv der Kamera auch während des Schreitens immer auf die Hand der Künstlerin gerichtet blieb. Das Detail der Daumen und Zeigefinger zu einem geschlossenen Kreis zusammendrückenden Hand, das die Kamera aufzeichnete, erschien als Closed-Circuit-Schwarzweiß-Bild auf zwei Monitoren, die an der Wand links von dem Bodenbild standen. Zudem wurde der Schatten der Fingergeste

\footnotetext{
417 Vgl. Lurker 1991, S. 80f

418 Im Original misst das Gemälde 70 x $103 \mathrm{~cm}$.
} 
durch den Schein einer am Handgelenk der Künstlerin befestigten Taschenlampe während des Ganges an die Wände des Raumes projiziert.

In der gegenüberliegenden Ecke des Raumes lief auf einem Farbmonitor ein Tape, das den sich schnell hin und her bewegenden Kopf Rosenbachs zeigte, bei dem die Augen über die ganze Fläche des Bildschirms zu einem farbigen Kreisbogen verschwammen, die gleiche bereits erwähnte Jactatio-Bildsequenz. Dazu stieBen zwei Frauenstimmen hohe und tiefe Schreie aus. Zudem projizierte ein Videobeamer in einer anderen Ecke des Raumes in Farbe und mit authentischem Ton einen Lavaausbruch an die Wand. In der Nähe des Einganges des Aufführungsraumes stand ein weiterer Monitor. Auf dessen Bildschirm stand ein Text des Ethnologen Hans-Peter Duerr, aus dessen Buch „Traumzeit“ über die Hagazussa. Die auch als Zaunbesetzerin bezeichnete mythologische Figur bewegt sich auf der Grenze zwischen Innen- und Außenwelt. ${ }^{419}$ In der von dem Ethnologen beschriebenen "Traumzeit", sei das Außen und das Innen der Menschen noch nicht hermetisch voneinander getrennt gewesen. Auf diesen komplexen Begriff „Traumzeit" nimmt die Künstlerin in ihrem eingeblendeten Duerr-Zitat Bezug, setzt ihn explizit ins Bild.

Im angrenzenden Raum saß während der gesamten Aktion die Tochter der Künstlerin. Ganz in Weiß gekleidet hockte sie auf dem Boden vor einem Kreisbogen aus Salz, der die Form des Regenbogens im Nebenraum wiederholte. Vor ihr lag ein gleichseitiges hölzernes Dreieck. Während der Stunde, die die Performance andauerte, nahm das Mädchen in regelmäßigen Abständen Stahlkugeln aus einem Regal, insgesamt 120 Stück, die sie willkürlich über den Boden rollen ließ.

Ein tieferer Sinn der Aktion erschließt sich, wenn man die Bild- und Tonelemente auf den australischen Mythos bezieht, wie es Marlite Halbertsma in ihrer schlüssigen Interpretation der Performance tat. So entspricht die Handhaltung der Künstlerin dem Symbol der Aborigines für die Schlange. In dieser Haltung wandert die Künstlerin nun über einen gemalten Regenbogen, wodurch sich in visueller Umsetzung der Begriff der „Regenbogenschlange“ zusammenfügt, der Figur, die im australischen Mythos die Totalität des Lebens als solches verkörpert. Und um dieses Thema des Kreislaufs der Natur und der Einheit von Mensch und Natur kreist diese Videoperformance:

„Diese drei Bilder von Leben und Frucbtbarkeit begegnen uns auch in der Performance: die junge Göttin, die im Himmel mit den Sternen (den Silberkugeln) spielt, die erwachsene Göttin, die über die Erde geht und die Regenbogenschlange, die das Ende und den

419 Duerr 1978, Der Ethnologe zeichnet in seinem Werk den Prozess nach, in dem die Zivilisation die Hexe, die einst auf dem Zaun zwischen Kultur und Wildnis hockte, nach ,draußen' vertrieben hat und aber wie diese in verzerrter Gestalt und als drohende Gefahr über die Kellertreppe wiederkehrt. 
Neuanfang des Lebenszyklus symbolisiert. Zusammen bilden sie die Triade der drei Aspekte des Lebens: Geburt, Leben und Tod. " 20

Unter dieser Bedeutungsschicht liege aber noch eine zweite, wie Halbertsma aufzeigt. Spielten doch die Aspekte der Zeit und der Energie eine grundlegende Rolle in dieser Aktion. Während die Akteurin in ihrem Raum auf die historische Zeit Bezug nehme, verkörpere die junge Frau im Nebenraum den Aspekt der kosmischen Zeit, bei den australischen Ureinwohnern auch „Traumzeit“ genannt, auf die das Duerr-Zitat verweist.

Den Aspekt der Energie visualisieren zum einen die an die Wand projizierten Lavaströme. Zum anderen bestehen die Monitorbilder selbst aus Energie, erzeugt durch einen Quarz im Inneren der Bildröhre, der den elektrischen Strom in strahlendes Licht umwandelt. Halbertsma fasste zusammen:

„Die Performance entwickelt sich wie ein Kristall in der Zeit, in einer Stunde zeigt sie die verschiedenen Facetten der Energieauswechslung und -eržengung. In dieser VideoLive-Aktion werden die Naturkräfte und -elemente gefiltert. "421

Bei dieser Performance wird der Zuschauer mit einer Vielfalt an formalen Elementen konfrontiert, die inhaltlich miteinander verknüpft sind und deren vorangegangener Interpretation noch einige Aspekte hinzugefügt werden sollen. Wie bei der „Maifrau“ werden auch in dieser Aktion zwei voneinander getrennte Räume bespielt. Beim Vergleich dieser beiden Aktionen Rosenbachs zeigt sich, dass bei beiden der aktuellen, individuellen Situation - von der Künstlerin in dem einen Raum verkörpert - ein weiterer Raum mit einer Aussage überzeitlicher Gültigkeit gegenübergestellt ist. In der „Maifrau“ ist es der Raum mit dem Artemis-Dia, in der „Spaziergängerin“ ist es das Kind, das die eine Göttin verkörpert.

Die Tochter der Künstlerin, zum Zeitpunkt der Aufführung dreizehn Jahre alt, ist in dieser Aktion aktiv eingebunden und nimmt entsprechend der feministischen Interpretation die Rolle einer ,jungen Göttin“ ein. In ihrem kosmischen Raum ist der Regenbogen als Salzsichel plastisch, ins Dreidimensinale gehöht, nachgeformt. Auf diesem geschwungenen Lichtbogen, der auch als eine Grenze zwischen den Welten - auch entsprechend der christlichen Ikonographie, die den Regenbogen als Bund Gottes mit den Menschen deutet - verstanden werden kann, wandelt die Künstlerin im Nebenraum stetig hin und her. ${ }^{422}$ Dieses Zeichen stammt aus einem Gemälde aus der Zeit der Romantik und wird von der Künstlerin - wie durch eine Lupe betrachtet - in stark vergrößerter Form zitiert.

In der Romantik begannen Künstler zu Beginn des 19. Jahrhunderts die Inhalte eines inneren Erlebens zu gestalten, den geistig-seelischen Ereignisbereich ans

\footnotetext{
420 Halbertsma in: Rosenbach 1982, S. 78

421 Halbertsma in: Rosenbach 1982, S. 82

422 Zur Ikonographie des Regenbogens vgl. Lurker 1991, S. $608 f$
} 
Tageslicht zu heben, das Zuständliche bildlich zu erfassen. Mit besonderer Stärke tritt diese gefühlsaufgeladene Haltung in der Landschaftsmalerei hervor, in der Menschen und Natur zueinander in innige Beziehung gesetzt, landschaftliche Stimmungen erfasst und das beziehungsreiche Ineinanderweben der Erscheinungen darstellenswert werden. Zu diesem Zeitpunkt erschlossen in Deutschland Gelehrte und Dichter vergessene Sagen und machten einen verloren gegangenen Märchenschatz wieder zugänglich. Da sich die romantische Malerei eng an die Dichtkunst anschloss, gewann diese ganz entschieden an nationaler Eigenart und die Malerei wurde in Deutschland wieder zu einer nationalen Kunst. Die Gemälde Casper David Friedrichs erfüllen dabei den Begriff der Malerei der Romantik am Reinsten. Das romantische Bewusstsein ist hier deutlich sichtbar und durchdringt das klassische Formengut. So auch in der nächtlichen „Gebirgslandschaft mit Regenbogen“, die eine zauberhafte, fast unwirkliche Stimmung verbreitet. Ein Werk das zu den Meisterwerken im Essener Folkwang Museum gezählt wird.

„Die Widersprüche von Mondlicht und Regenbogen, von Beleuchtung und Lichtquelle
lassen sich nur mit einem subjektiven Naturerlebnis erklären. Die Kleinheit des Men-
schen ist der mächtigen Natur gegenübergestellt. Die tiefe Dunkelheit, der Blick des
Wanderers in den Abgrund, dessen Tiefe er nicht ermessen kann, und der flackernde
Wolkenhimmel haben etwas Bedrohliches. Der Mensch ist der Natur ausgesetzt. Ein
uraltes Symbol für die Versöhnung des Menschen mit Gott ist der Regenbogen. Wenn
auch die Integration des Menschen in die Natur beabsichtigt wird, so ist der Mensch ihr
doch entfremdet. Die pointierte Heraushebung des Wanderers durch Lichteffekte, seine
Funktion im Bild als Betrachter stellen ihn aus der Natur heraus. " ${ }^{23}$

Dieses sehnsuchtsvolle, melancholische Bild, mit seiner romantischen Botschaft und perfekt harmonischen Komposition, bildet den Grund, auf dem die Künstlerin in dieser Performance agiert. Ähnlich wie in dem „Konzert im Gewaltakt“, bei dem ein Monitor - mit dem steten Schwingen des Kopfes - die Basis des Agierens bildete, wählte die Künstlerin hier ein statisches Bild als Grund, auf dessen gemaltem Schwung sie sich bewegt. Die Absichtlichkeit der Ähnlichkeit beider Schwungformen wird noch bestärkt durch das konkrete Zitat des Jactatio-Tapes innerhalb der Aktion, das einen inneren Bezug vermittelt.

Das Hin- und Herschreiten während einer Aktion auf einem Kreissegment ist bereits im „Projekt Kinem“ begegnet. Während jedoch dort die Kamera senkrecht nach oben gerichtet war, verfolgt hier der Blick der Kamera die Ganzheitlichkeitsgeste der Hände der Schreitenden, die als stark vergrößerter Schatten während des Ganges über die Wände des umgebenden Raumes wanderte.

Die Künstlerin begegnet uns in dieser Aktion erstmals als Grenzgängerin und setzt sich zudem zum ersten Mal explizit mit dem Thema der Einheit von Innen-

423 Froning in: Kat. Essen 1983, S. 22 
und Außenwelt auseinander. Diese neue Thematik wird in späteren Werken weiter vertieft wird. Hier scheint eine innere Einheit gefunden zu sein. Mit dieser versöhnlichen Aktion schließt Ulrike Rosenbach nach zum Teil äußerst kämpferischen Werken ihr erstes Schaffensjahrzehnt als freie Künstlerin und bereitet inhaltlich die kommende Phase vor, in der die Werke formal komplexer werden und sich die Themen wandeln. Doch bevor die Werke die im kommenden Jahrzehnt entstehen, untersucht werden, soll eine Zusammenfassung die bis hierher gewonnenen Erkenntnisse umreißen.

III.6. Kleine nicht-narrative Schleifen:

Die Ikonographie der Werke der 1970er Jahre

Mit der Performance „Die einsame Spaziergängerin“ schließt dieses erste Jahrzehnt intensiven künstlerischen Schaffens, in dem sich eine inhaltliche und formale Entwicklung innerhalb der Arbeiten erkennen lässt. Gleich nach Abschluss ihres Studiums der Bildhauerei fand die Künstlerin in einer Mischung aus Performance- und Videoarbeit zu der künstlerischen Ausdrucksform, die für ihr Schaffen in den 1970er Jahren prägend ist. Für die Künstlerin war der kreative Prozess der wichtigste Aspekt eines Kunstwerkes, und so lag es nahe, dass sie von der Bildhauerei kommend und durch die dokumentierende Fotografie geprägt, das bewegte Bild für sich entdeckte. Dabei steht die Künstlerin selbst, ihr Körperabbild, ihr Handeln im Mittelpunkt der Werke, sei es in den Performancetapes, die im Studio entstanden, als auch in den vor Publikum aufgeführten Aktionen.

Neben dem Sichtbarmachen des Prozesses nehmen die Werke in der ersten Zeit eine autobiographische Selbstbespiegelung und Befragungen der Rolle der Frau als weitere Inhalte in den Fokus, die sich ab dem zweiten Drittel des Jahrzehntes um konkret feministische Impulse erweitern. Formal sind die frühen Bänder durch zeichenhafte Strukturen geprägt und arbeiten mit einem stark didaktischen Ansatz.

Der Körper bildet bei all diesen Untersuchungen das Medium, über das sich die Künstlerin mitteilt. Sie setzt ihren Körper ein ,aber nicht aus dem Bauch heraus, sondern aus dem Kopf “424, wie Ulrike Rosenbach selbst zum Ausdruck brachte. Bereits ihre raumgreifenden Haubenobjekte können als Ergänzungen oder Fortführungen der Körperglieder verstanden werden, skulpturale Bewegungsnachbildungen im Raum. In den ersten Tapes modelliert die Künstlerin dann ihren oder auch die Körper mit verschiedenen Materialien. Bei der „Einwicklung“ ist es Mullbinde, beim „Petit Chou“ sind es Kohlblätter.

Der Körper wird in manchen Aktionen enthüllt, wie in der Naturkreisaktion, der ersten Fassung des Projektes Kinem oder dem Female Energy Change, in anderen wiederum teilweise verhüllt, wie im weit schwingendenn Ballkleid beim „Tanz für

424 Rosenbach in: Du 1/1981, S. 42 
eine Frau“, des Gazeschleiers in der „Madonna of the Flowers“ oder dem verhüllenden Rock im „Salto Mortale“. Allerdings zeichnet sich in den Aktionen relativ schnell eine Art „Uniform“ ab, die die Künstlerin trägt. Es ist ein eng anliegendes weißes Trikot, in das die Künstlerin ab Mitte der 1970er Jahre gekleidet ist. Und der so gewandete Körper dient in der Reflexionen-Aktion auch konkret als Projektionsfläche. Und bei den Videoaktionen „Glauben sie nicht, dass ich eine Amazone bin“ wie der „Maifrau“ werden Kopf oder Körper im elektronischen Bild überblendet. Außerdem findet sich in den Arbeiten der ersten Hälfte des Jahrzehntes wiederholt ein Einhüllen des Kopfes in den entstandenen Tapes verbildlicht. Beginnend mit der Zeichenhaube, folgen mehrere Bänder, wo die Künstlerin konkret ihren Kopf vor der Kamera verhüllt, wie im Kohltape, dem Bindentape und außerdem in den „Madonnas of the Flowers“.

Wie einerseits der Kopf in den Tapes bearbeitet und im Videobild hervorgehoben wird, spielt zudem die Hand eine wichtige Rolle in den Arbeiten Rosenbachs. Zeichen der Hand hinterlassen nicht nur Spuren auf der Haut, wie in „Sorry Mister", sondern sie werfen auch Schatten auf die umgebenden Wände, wie bei der „Spaziergängerin“. Zudem erscheinen spätestens seit ihrem Aufenthalt in den USA handelnde Hände in ihren Werken, ein wichtiges Motiv, das durch Arbeit mit den amerikanischen Feministinnen inspiriert sein könnte. Auch die Begegnung mit John Baldessari scheint ihre Spuren in Rosenbachs Kunst hinterlassen zu haben, zeigt sich doch gerade in ihrem Hauptwerk in den USA, den „Reflexionen“, das Mittel der Verdeckung als wichtiges Ausdrucksmittel.

In ihren Aktionen schreitet die Künstlerin im Kreis oder auf Kreissegmenten, schwingt hin und her, steht konzentriert auf einer Stelle, liegt unbeweglich am Boden oder rollt beziehungsweise dreht sich um ihre eigene Achse. Bei all diesen Handlungen, deren Bewegungsrepertoire auf bestimmte elementare Elemente begrenzt erscheint, bildet die Wiederholung ein charakteristisches Element, das auch die Tonebene kennzeichnet.

Der Ton - bestehend aus Geräuschen des Atems, des Herzschlags, gleichmäBigen Schlägen, auch artikulierten Wortwiederholungen oder Musik - gibt jeder Aktion und jedem Tape ihren eigenen Rhythmus und trägt die Handlung. Besonders die ein- oder zweisilbigen Tonschleifen aus dem Wort „Frau“ oder den Worten „Frau sein“, die die Künstlerin während mehrerer Aktionen, der Maifrau, der Venusdepression wie auch der Herkulesinstallation - live oder aufgenommen spricht, schaffen eine starke Intensität, werden zu einem eindringlichen Rhythmus, der die Aktion beziehungsweise Installation trägt.

In ihrer einprägsamen reduzierten Form sind die Aktionen Rosenbachs wenig narrativ. Vielmehr erinnern sie in ihrer Eindringlichkeit und Zeichenhaftigkeit an elementare Rituale. Wie dargelegt, sind Rituale Markierungen für innere Prozesse, bei denen sich vieles über das symbolhaft Unbewusste kommuniziert, so dass sich das Anliegen der Künstlerin Inneres zum Ausdruck zu bringen auch in der für die 
Vermittlung gewählten Form spiegelt. Im Kontext ritueller Kommunikation kann man die Arbeiten aus der Trilogie „Frauenkultur - Kontaktversuch“, „Salto Mortale“ und „Meine Macht ist meine Ohnmacht" als Variationen eines individuellen Befreiungsrituals lesen, ein Versuch der allerdings scheitert. Auch die beiden Arbeiten, die am Ende dieses Jahrzehntes entstanden - „Tanz um einen Baum“ und „Die einsame Spaziergängerin“ - sind entsprechend obiger Definition regelgeleitete, symbolisch durchgestaltete Handlungsgefüge, die den Zuschauer mitnehmen auf eine nach außen transformierte Reise ins Innere. Während die genannten Werke ihre Inhalte mit einer gewissen emotionalen Zurückhaltung transportieren, wirken die drei Aktionen „Glauben Sie nicht, dass ich eine Amazone bin“, „Venusdepression - Medusaimagination“ und „Konzert im Gewaltakt" aggressiver und deutlicher politisch motiviert. Hier manifestiert sich in der Form ritueller Inszenierung Wut, die aber kanalisiert und kontrolliert bleibt und immer konstruktiv - nicht selbstzerstörerisch - genutzt wird. Sie wird - eingebunden in die ritualhafte Form - vielmehr ästhetisiert.

Die Künstlerin arbeitet in diesen Aktionen mit bestimmten formalen Elementen. Die Abläufe sind vorbereitet, Gestik und Mimik einstudiert. Die Wiederholungen betonen häufig die künstlerischen Inhalte, wie auch gesprochene Texte und musikalisch-rhythmische Umrahmungen die Aussagen intensivieren. Auch nimmt die Künstlerin körperliche Unbequemlichkeiten - wie zum Beispiel stundenlanges, bewegungsloses Liegen - und Anstrengungen auf sich, um ihre Inhalte zu kommunizieren.

Ihre vielschichtigen Aussagen setzt Ulrike Rosenbach in ganz spezifischer Form mittels der elektronischen Technik um. Sie arbeitet mit der Videokamera, die als Stand- oder Handkamera oder auch an den Körper gebunden zum Einsatz kommt. Im Raum angeordnete Monitore - die Tapes oder Closed-CircuitAufnahmen zeigen - verdoppeln die Bildebenen in den Aktionen, erzeugen zusätzliche Bilder im Bild. Großformatige Diaprojektionen fügen den Aktionsräumen weiteres visuelles Material hinzu.

Die Analyse hat gezeigt, dass diese einzelnen Elemente - gleich eines Codes ganz konkrete Konnotationen tragen. So übernimmt das elektronische Auge der Videokamera im Werk die Aufgabe, innere Eindrücke der Künstlerin während des Agierens aufzuzeichnen. Am Körper fixiert oder außerhalb stehend positioniert erfasst sie die Bewegungseindrücke aus den unterschiedlichen ihr zugewiesenen Perspektiven, die über einen Monitor an das Publikum - manchmal auch die Künstlerin selbst - weitergegeben werden. In dieser Form wird in die Aktionen eine zweite Bildebene eingefügt. Das Bild auf dem Monitor zeigt einen Ausschnitt der Aktion, ein Detail des Körpers aus einer spezifischen Perspektive. Auf diese Weise visualisiert das Videobild auf dem Monitor ein inneres Bild, vergrößert dieses und macht es auch für den Zuschauer sichtbar. 
In ähnlicher Form sind auch die Videotapes lesbar, die innere Realitäten visualisieren und keine Abbildung äußerer Gegebenheiten sind - wenngleich aufgrund der Gegenständlichkeit des Abgebildeten ein solcher Eindruck naheliegen könnte. Interessant ist auch, dass bei mehreren der frühen Tapes mit eine Bildverdoppelung gearbeitet wird. Mit einfachen Mitteln ohne elektronische Tricks wird in der „Zeichenhaube“ oder dem „Haupt der Frau“ eine zweite Bildebene mittels fotografischer Reproduktionen eingefügt. Auch sonst sind die Tapes in diesem Jahrzehnt sehr einfach gestaltet. Bis auf das Tape „Mutterliebe“ aus dem Jahr 1977 sind in den 1970er Jahren alle Tapes von Ulrike Rosenbach in schwarzweiß gedreht. ${ }^{425}$ Meist mit nur einer Standkamera aufgenommen, bilden sie in einer festen Einstellung das Geschehen ab. Ohne Schnitt dokumentieren sie aus der spezifischen Kameraperspektive die Aktion. Einzig das Gestaltungsmittel der elektronischen Überblendung wird eingesetzt, um zwei unterschiedliche Einstellungen miteinander zu verknüpfen. Mit diesen reduzierten filmischen Ausdrucksmitteln setzen sich die Videos Ulrike Rosenbachs deutlich von der in den 1970er Jahren geläufigen Film- oder Fernsehästhetik ab, die durch harte Schnitte gekennzeichnet war. Ihr Schaffen fügt sich vielmehr in die medienreflexiven Ansätze der Videokunst dieses Jahrzehntes und bezieht sich auf die Charakterisitik des Fließens der Videotechnologie, wie auch auf eine aus heutiger Sicht für die frühe Videokunst charakteristische „Ästhetik der Langeweile“.

Auffällig ist in Bezug auf die Videotechnik ein Widerspruch in den Aussagen der Künstlerin. Während sie zunächst die Videotechnik als „das tolle, unvorbelastete Ding“426 zur Aufzeichnung und Vermittlung auffasste, beschreibt sie kurz darauf das Medium als feindlich, assoziiert mit diesem ein Gefühl der Gefangenschaft, Begrenzung, Abhängigkeit.

Diese aus der zweiten Aussage sprechende „Enttäuschung“ könnte mit den Grundlagen der Videotechnik - die als Kontrolltechnologie entwickelt wurde und

425 Im Gespräch erläuterte die Künstlerin die Entstehungsweise, dieses frühen Farbtapes, das mit Fernsehkameras aufgenommen wurde: „Es war so früh farbig, weil es in einem Symposion entstanden ist. Das hätte ich nie selber drehen können. Das Fernsehen hat es aufgenommen. Wir haben es vor Publikum präsentiert. Man sprach uns an und dann hieß es: „So, jetzt machen wir eine Pause für das Publikum, und in dieser Pause zeigen wir ihnen, wie die Künstlerin“ - das war nur ich - ,ein Livetape mit ihrer Tochter herstellt und das wird hier im Raum übertragen“. Ich habe das also mit meiner Tochter live vor Publikum hergestellt. (...) Und dann wurde der Videoshot, den man auch auf den Tapes sieht, dem Publikum gleichzeitig übertragen. Das war also eine reine Closed-Circuit-Performance, nur man konnte uns nicht sehen." Zudem finden sich auch noch Dokumentationen von Aktionen aus diesem Jahrzehnt, die in Farbe aufgenommen wurden.

426 Diese Unvorbelastetheit bezieht sich allein auf die Nutzung des Mediums für Künstlerinnen. Über den politischen Kontext der Videotechnik als Kontroll- und Überwachungstechnologie, sowie des Filmes und des Fernsehens als Medien der selektiven Realitätswiedergabe, ist sich Ulrike Rosenbach im Klaren, doch versucht sie die der Technik innewohnenden Möglichkeiten in ihren Arbeiten für sich zu nutzen und mit neuen Inhalten zu belegen. 
zudem an apparative Gegebenheiten gebunden ist (Kamera, Stromquelle, Kabel, Monitor etc.) - zusammenhängen. Gibt die Elektronik doch klare Formen und Regeln vor. Und gerade in den 1970er Jahren waren die Möglichkeiten der analogen Bildgestaltung im Amateurbereich noch äußerst begrenzt.

Anders verhält es sich mit den Diaprojektionen, die in Rosenbachs Aktionen durchweg mit positiven Inhalten konnotiert sind und für die sich bei der Analyse als gemeinsam herausstellt, dass diese - wortwörtlich „Licht-Bilder“ die man auch als Energie-Bilder beschrieben kann - Identifikationsfiguren in die Aktionen einfügen, die mittels entsprechender Vergrößerung an die jeweiligen Gegebenenheiten angepasst werden. Besonders deutlich wird diese Identifikationsfunktion der Diaprojektion bei den „Reflexionen“. Hier wird die Venusfigur von Botticelli nicht nur auf die Wand, sondern direkt auf den Körper der Künstlerin projiziert. Hingegen wird bei der „Maifrau“ das elektronische Abbild der Künstlerin mit dem Dia überblendet. In der Regel sind es positiv besetzte, im allgemeinen kulturellen Kanon verankerte Vor-Bilder, die zitiert werden, wie zum Beispiel die Venus von Botticelli, die als ursprüngliche Fruchtbarkeitsgöttin aufgefasst wird oder die Göttin Artemis, aber es finden sich auch negative, wie im „Konzert im Gewaltakt“. In der Aktion verkörpern die an die Decke projizierten Comicbilder, die durch männliche Gewalt gedemütigten Frauen, sind auch Identifikationsfiguren, aber keine positiven. Als weiteres Element tauchen Fotografien als Ausdrucksmittel im künstlerischen Schaffen auf, über die die Künstlerin selber im Gespräch allgemein reflektierte:

\section{„Wir wollten Leben festhalten. Und zwar nicht nur als Reportage, sondern die Substanz. von Leben in der Fotografie erfassen. " 427}

So kommt auch diesem Medium eine spezifische Funktion im Werk Rosenbachs zu. Zunächst nutzte Ulrike Rosenbach, in deren Umfeld sich verschiedene Fotografinnen und Fotografen fanden, Fotografien zur Dokumentation: Sie ließ ihre Haubenobjekte in diesem Medium dauerhaft In-Szene-Setzen. Diese Funktion beibehaltend steht bei den in die Installationen und Aktionen eingebrachten Fotografien der Dokumentationsaspekt im Mittelpunkt. Die Schwarzweißfotografien sind Abbilder vergangener, gegenwärtiger oder auch (potenzieller) zukünftiger Wirklichkeiten. Dabei bildet in diesem Medium die Montage eine wichtige Rolle. Mit dem für das elektronische Medium des Videotapes charakteristischen Mittel der Überblendung arbeitet die Künstlerin auch in ihren fotografischen Arbeiten, und verknüpft mittels dieses Gestaltungsmittels zwei in der Wirklichkeit getrennte Bildmotive miteinander - Überbrachtes und Neues - beziehungsweise montiert ganz konkret - ihr Abbild in die kulturellen Vorlagen.

427 Rosenbach im Gespräch 2001, Kap. VII.1. 
Neben diesen körperlich-technischen Elementen wiederholt sich ein Repertoire an Materialien und Formen in den Werken, das sich im Laufe der Zeit weiterentwickelt und auf der Zeichenebene allmählich als ein - für Ergänzungen offener - Kanon persönlicher Chiffren herauskristallisiert. So bildet ein Feld aus weißem Salz den Grund der beiden Aktionen „Venusdepression“ und „10000 Jahre“. Auf diesem Salzgrund - hier zunächst in Kreisform - wird agiert und in ihn werden Spuren und Zeichen mit dem Körper eingeschrieben. ${ }^{428}$ Häufig verfängt sich der Körper der Künstlerin in den Aktionen auch in Fäden, Kabeln, Seilen: Sei es im bewussten Akt des Verbindens in der „Einwicklung“ oder dem - sich oder einen Baum - Einschnüren in die roten Videokabel während des Um-die-eigeneAchse-Drehens. Als eine Variation des einzelnen Fadens kann das Netz betrachtet werden, das sich in Mantelform in der „Naturkreisaktion" findet oder als Zeichnung in der Zeichenhaube. Dann in „Isolation is transparent" werden viele Fäden zu einem Netzwerk verknüpft und schließlich hängt sie Künstlerin in einem Netz in der „Macht der Ohnmacht-Aktion“. Mit der Faden/Netz-Symbolik scheint dabei in allen erwähnten Kontexten im Werk Ulrike Rosenbachs eine Bedeutung von Gefangenschaft verbunden zu sein.

Videokamera und -monitor wurden von bildenden Künstlern in diesem Jahrzehnt - wie erwähnt - zur Selbstbefragung und in diesem Sinne in einer Spiegelfunktion benutzt. Zusätzlich zur Videoselbstbespiegelung fügt die Künstlerin in verschiedenen ihrer Werke konkret Spiegelflächen ein: als Schilde oder Folie, in runder Form oder als spiralförmig angeordnete Kette tauchen Spiegelflächen in den Werken auf. Auch spielt das Licht eine wichtige Rolle. Schon das Monitorbild ist ein Lichtbild und die Dias werden mit Licht an die Wände der bespielten Räume projiziert, erhellen - wie auch weitere künstliche Lichtquellen - auf diese Weise den Grund. Auch wird eine Lichtquelle eingesetzt, um Schatten zu werfen und Kerzen flackern in der Dunkelheit und weisen den Weg durch das Labyrinth.

Auf drei weitere Elemente soll noch hingewiesen werden: Zum einen die Muschel - mit ihrer Ähnlichkeit der weiblichen Vulva - die im Rahmen der Venusmotivuntersuchungen das Formenrepertoire Ulrike Rosenbachs bereichert. Zum anderen findet sich der Bogen gleich in zwei Aktionen eingesetzt. Während die Waffe in der „Amazone“ aktiv zum Einsatz kommt, und die Künstlerin Pfeile mit ihm abschießt, dient der Bogen in „10000 Jahre habe ich geschlafen“ als „Bett“ oder Rahmen, für eine in Embryohaltung zusammengerollte Akteurin.

In mehrfacher Weise findet sich zudem das Schaukeln oder Schwingen in den Werken Rosenbachs wieder: konkret als Bewegung in der Luft auf einer Schaukel im „Salto Mortale“, aber auch im Hin- und Hergehen auf Kreissegmenten und auch das Schwingen des Kopfes im Tape „Jactatio“ entspricht dieser Bewegungs-

428 Salz taucht auch in der „Einsamen Spaziergängerin“ auf. Es bildet hier den Regenbogen der Gemäldereproduktion nach, auf dem die Künstlerin im Nebenzimmer schreitet. Und zuvor kam es auch schon bei den Reflexionen zum Einsatz. 
form. Als geometrische Figuren begegnen in den Werken zudem wiederholt die Spirale, wie in der Maifrau, der Aktion Florenz-Köln oder dem Tanz um einen Baum, Symbol des zyklischen, sich entfaltenden Lebens. Der Kreis bildet eine häufig begegnende Grundform in Rosenbachs Aktionen. Wir finden ihn als Salzkreis, drehende Scheibe, im geschlossenen Kreis der Finger oder im Wandeln auf einem Kreissegment. Doch auch das Rechteck, wie in der Säulenumkleidung in der „Verwandlungsaktion“ oder der Casper David Friedrich oder Botticelli Reproduktion und das Dreieck, in Gestalt der Monitorpyramide wie auch aus Salz tauchen auf. Auch wird in den Werken deutlich Bezug genommen auf traditionelle Symbole oder mystische Zeichen, wie das Pentagramm, die fünfzackige Krone oder andere archaische Zeichen.

Ein Blick auf die gewählten Räume bei den Aktionen Rosenbachs zeigt, dass diese sich in zwei Gruppen unterteilen lassen: Solche, die in der Natur aufgeführt werden, hier wären unter anderem die Naturkreisaktion, Florenz-Köln und wieder der Tanz um einen Baum zu nennen, und solche, die in Räumen gezeigt werden. Letztere lassen sich noch einmal unterteilen in Aufführungen mit Publikum und solche ohne. Dazu sind die frühen Tapes zu zählen, die als Studioarbeiten entstanden und durch eine in bestimmter Perspektive gewählte (Nah-)Einstellung mit einer Standkamera charakterisiert sind.

Bei vielen Werken zeigt sich eine direkte Bezugnahme zum Aufführungsort. So zum Beispiel bei der „Venusdepression“ in Florenz in den Zitaten italienischer Künstler oder bei der documenta-Installation mit der Einbeziehung des Herkulesmotives, so dass sich hier die aktuelle Umgebung im Inhalt der Aktion spiegelt. In den Performances, die in Räumen spielen, wurden zudem der Boden, zum Teil die Wände und einmal auch die Decke mit einbezogen. So wird das Environment zur Raumcollage, die Aussage regelrecht in den Aktionsraum eingeschrieben. Dabei wird zum Teil auch mit zwei getrennten Räumen gearbeitet, die entweder künstlich getrennt werden, wie in der „Isolation-Aktion“ oder wie in der „Maifrau“ oder der „Spaziergängerin“, bei denen zwei vorhandene Räume bespielt werden, die zudem mit unterschiedlichen Bedeutungen besetzt sind: das Aktuelle wird in dieser Weise etwas Dauerndem, oder auch ein äußeres Bild einem inneren gegenübergestellt. In dieser Form der Nutzung des Raumes spiegelt sich ein Grundthema des Bildhauerischen: Die Darstellung von Innen und Außen.

Mittels dieses umrissenen kompakten oder minimalistischen Formenrepertoires gelingt es der Künstlerin auf sinnfällige Weise komplexe Sachverhalte zu vermitteln, oder wie es Wulf Herzogenrath knapp und treffend charakterisiert:

„Sie hat ein großes Vermögen Abläufe, Aussagen in sprechende Bilder umzusetzen. “429

429 Herzogenrath im Interview 2003, vgl. Kap. VII.2. 
Diese sprechenden Bilder zeigen sich auch bei der Auswahl der Motive. Findet sich doch wiederholt ein Bezug bei zitierten Arbeiten zum eigenen Namen der Künstlerin. So taucht die Rose mehrfach auf, sei es in der Madonna im Rosenhag, sei es in der Bezugnahme auf die Pasadena Rose Parade. Dies ist sicher kein $\mathrm{Zu}$ fall, da die Künstlerin selbst immer wieder auf den autobiographischen Ansatz in ihrem Wirken verwies. Von diesem autobiographischen Ansatz ausgehend, bei dem sie Themen wie Beziehung und Kommunikation thematisierte, rückte die Künstlerin während der Dekade zusehends so genannte Frauenthemen in den Fokus ihres Wirkens und die Suche nach weiblicher Identität.

„Ich arbeite mit identifikatorischen Prozessen, d.h. dass die Themen aus meiner Autobi-
ografie, aus meinem Leben sind, wenn sich das auch nicht immer im Titel der Arbeit er-
kennen läßt... es sind Untersuchungen meiner selbst und meiner gesellschaftlichen oder ge-
schichtlichen Umgebung. Dazu gehören auch die Arbeiten über Frauenklischees... Diese
gesellschaftlichen Prozesse sind die Strukturen, in die ich hineingeboren werde, und um
über sie binausgehen ₹u können, habe ich sie erst einmal untersucht und ibre Form in
mir, was davon in mir wiederzufinden ist, in den Arbeiten wiedergegeben. "430

Geprägt durch die Erfahrungen mit den amerikanischen Feministinnen untersucht sie unter Einbeziehung historischer und ethnologischer Bezüge die Rolle und Klischees der Frau in der Gesellschaft. Ihre politisch motivierten Werke spiegeln so nicht nur ihre eigene, sondern auch die gesellschaftliche Situation, heben ihre Aussagen ins Allgemeingültige.

Wenn die Künstlerin sagt, dass ihre autobiographische Phase 1973 vorbei gewesen sei ${ }^{431}$, so soll diese Selbsteinschätzung an dieser Stelle mit einem Fragezeichen versehen werden. Zeigen doch die Arbeiten der späteren 1970er Jahre weiter autobiographische Bezüge. Und dieser Aspekt soll auch in der Untersuchung des Wirkens im kommenden Jahrzehnt im Auge behalten werden.

Mit dem in dem Zitat der Künstlerin angedeuteten Überbrücken der Schere aus Individuellem und Allgemeingültigem steht die Künstlerin unter anderem auch dem Wirken der Tänzerin Pina Bausch sehr nahe. Beide Künstlerinnen beschäftigen sich zur gleichen Zeit mit dem, was Menschen bewegt und beide nutzen den menschlichen Körper, um Inneres, Bewegendes zum Ausdruck zu bringen. Die Arbeiten beider Frauen kreisen in den 1970er Jahren um Themen wie Frau, Beziehung, Schmerz, Trauer und auch besonders das Geschlechterverhältnis. Diese künstlerischen Selbsterkundungen werden jedoch mit unterschiedlichen Mitteln ins Bild gesetzt. So arbeitet Pina Bausch in ihren Theaterinszenierungen, in denen sie versucht Bekanntes erkennbar zu machen, mit Gruppen. Zum Teil wird von den Tänzerinnen und Tänzern in den Inszenierungen das Publikum auch direkt angesprochen und in das Stück einbezogen. Ulrike Rosenbach agiert im Großteil

430 Rosenbach in einem Tonbandinterview mit Kiki Martins, Berlin 1981

431 Rosenbach 1982, S. 131 
ihrer Aktionen alleine, nur gelegentlich wird sie von ihrer Tochter oder weiteren Frauen begleitet. Das Publikum, das sich während der Performances um ihre abgegrenzte Aktionsfläche gruppiert, bleibt in jedem Fall ausgegrenzt.

Doch in den Werken beider Frauen spielen Wiederholungen eine wichtige Rolle, die allerdings mit unterschiedlichen Zielsetzungen eingesetzt werden. Die Tänzerin Pina Bausch zeigt in ihren vielfigurigen Inszenierungen eine Vielfalt von Handlungsalternativen auf und entblößt durch Wiederholungen das Begrenzte, Zwanghafte der dargestellten Handlungen. Das Gestaltungsmittel der Wiederholung erfüllt im Werk der Ulrike Rosenbach hingegen einen anderen Zweck. Es dient zum einen der Bekräftigung, wie zum Beispiel in der „Venusdepression“, wenn mehrere Frauen nacheinander die gleichen symbolgeladenen Gesten vollziehen. Aber auch innerhalb einer Aktion wird von der Akteurin häufig eine Bewegung stetig wiederholt, wie das Ein- und Ausschnüren beim Über-den-BodenRollen oder das Hin- und Herschreiten. Die wiederkehrenden Bewegungsschleifen geben aber auch den Eindruck von Verfangensein, Gefangenschaft. Die Werke entblößen die Situation in eindringlicher Weise, doch bieten sie keine Lösung an, schlagen keine Alternativen vor.

Trotz dieses Verfangenbleibens sind Ulrike Rosenbachs Arbeiten der 1970er Jahre, die im Kontext des radikalen Feminismus zu lesen sind, geprägt von der Suche nach Vorbildern. Im Rahmen ihrer künstlerischen Suche nach der eigenen Identität hält sie Ausschau nach starken Frau und positiven weiblichen Rollenmodellen, die sie zum Beispiel in Göttinnen archaischer oder antiker Mythologien entdeckt. Bei ihrer künstlerischen Untersuchung dreier klischeebelegter Frauentypen - der Venus, der Madonna und der Amazone - in der Mitte dieser Dekade hebt sie aus den Tiefen der Geschichte die Venus in ihrer usprünglichen Funktion der Fruchtbarkeitsgöttin ins Licht. Die christliche Madonna hingegen assoziiert mit einer demütigen, fürsorglichen Mutterrolle bleibt - im Rahmen patriarchaler Machtmechanismen - gefangen und auch die Freiheitskämpferin, inszeniert als Diana-Amazone, greift ihr eigenes Lichtbild an und verletzt sich damit letztlich selbst.

Die Künstlerin formuliert in ihren Werken dieses Jahrzehntes - eingebunden in die zeittypischen Kunstströmungen der Body Art, Performance Kunst und experimenteller Videoarbeiten und deutlich inspiriert durch Impulse aus dem radikalen Feminismus - Emanzipationsansätze und Befreiungsrituale in audiovisueller, symbolgeladener Form. Den Schwerpunkt ihres facettenreichen thematischen Spektrums bildet dabei innerhalb Rosenbachs künstlerischem Schaffen das Sichtbarmachen innerer Prozesse.

Wie im Verlauf der Darstellung aufgezeigt, ist es charakteristisch für das Wirken Ulrike Rosenbachs die gewonnen Erkenntnisse gleich mehrfach und dabei in unterschiedlichen Medien zu bearbeiten, wie zum Beispiel fotografisch, als LivePerformance und zudem im Videotape. Dieses wesentliche Charakteristikum der 
Arbeitsweise Künstlerin soll im Rahmen der Betrachtung des künstlerischen Schaffens des kommenden Jahrzehntes weiter untersucht werden. 


\section{Alleingänge - in den 1980er Jahren}

IV.1. Die Dekade der 1980er Jahre im Kontext der Politik und Kultur „Wir erinnern uns, wie Anfang der 80er Jabre das Umweltbewusstsein sich des Landes bemächtigte - mit einer neuen Partei und einer Serie von Weltuntergangsszenarien. Besonders furcbterregend war die Entdeckung des Waldsterbens. ${ }^{\text {"432 }}$

Mit diesem Satz leitete der Journalist Giovanni di Lorenzo jüngst leicht lakonisch einen Artikel in der Wochenzeitung „Die Zeit“ ein und belegte die Brisanz des Themas ökologische Bedrohung vor einem Vierteljahrhundert mit dem Hinweis auf einen Spiegeltitel im November 1981, der plakativ lautete: „Saurer Regen über Deutschland - Der Wald stirbt" ${ }^{\text {"433 }}$. Aus den Nachwehen der Studentenbewegung wuchs zu Beginn der neuen Dekade europaweit eine ökologische Bewegung, die sich nicht nur in Bürgerinitiativen, sondern auch in der neuen Partei der Grünen ein politisches Sprachrohr schuf. Neben der als beunruhigend eingeschätzten ökologischen Situation - der Reaktorunfall von Tschernobyl am 26. April 1986 mit nuklearem Fallout bildete ein weiteres Glied in einer Kette eines wachsenden apokalyptischen Szenarios - blieb der schwelende Ostwestkonflikt und das atomare Wettrüsten beider Machtblöcke als latente Bedrohung während dieses Jahrzehntes bestehen.

Auf diese aufgeladene, bedrohliche Atmosphäre wurde unterschiedlich reagiert. Die einen beteiligten sich an Großdemonstrationen, andere wirkten mit kleinen Handlungen im Alltag. Geduldige politische Kämpfer begaben sich auf den langen Weg durch die Institutionen, doch mancher bis dahin politisch Aktive zog sich resigniert ins Private zurück. Die so genannte New-Age-Bewegung blühte in diesem Jahrzehnt auf und manche Glaubensgemeinschaft oder Sekte fand breiten Zuspruch bei verunsicherten Menschen, die in einer zusehends unüberschaubaren und bedrohlich wirkenden Welt nach Sinn und Spiritualität suchten. Daneben belebten die farbenfroh frisierten Punks mit ihren „No Future“-Parolen auf nietenbesetzten schwarzen Lederjacken das Straßenbild schon ab Ende der 1970er Jahre.

Die relativ stabile ökonomische Situation in dieser Dekade gab Gelegenheit verbunden mit einer finanziellen Basis für kulturelle Aktivitäten. Neue mit elektronischen Effekten arbeitende Musikrichtungen entstanden. Darunter zum Beispiel der avantgardistische Elektropop der Gruppe „Kraftwerk“, die als erste deut-

432 di Lorenzo in: Die Zeit, Nr. 50, 8. Dezember 2005, S. 1

433 Der Spiegel Nr. 48, 1981 
sche Band 1981 mit ihrem Song „The Model“ auf Platz eins der usamerikanischen wie auch der britischen Charts landete. Die Songs der so genannten „Neuen deutschen Welle“ mit einem minimalistischen Konzept, elektronischen Melodien und hohem Spaßfaktor erklangen im Radio, und zogen zum Teil auch in Europa und Übersee in die Hitparaden ein. Im Jahr 1981 ging zudem in London ein neuer Fernsehsender mit einem innovativen Konzept auf Sendung. „Musictelevision“ (MTV) hatte als Zielgruppe die unter Dreißigjährigen und strahlte rund um die Uhr aktuelle Musik aus. Um dieses mediale Novum herum, entstand rasch eine neue Form der Jugendkultur. Zudem fanden im für diese Form der Fernsehunterhaltung kreierten „Videoclip“ die zahllosen Popbands ein neues Werbemedium. Im Videoclip wurde intensiv mit innovativen filmischen Gestaltungsformen experimentiert. Bildende Künstler zog dieses neue Medium an. Besonders Videokünstler entdeckten die kommerzielle Musikbranche für sich, deren vorhandene Technik auf dem modernsten Stand den audiovisuell Kreativen Gelegenheit zum Experiment bot. Rasch entwickelte sich eine bis dahin unbekannte so genannte Videoästhetik, fußend auf sehr schnellen Schnittfolgen und integrierten Trickeffekten. Diese komplexe Bildsprache, die durch die Videotechnik erst möglich wurde, wandelt sich bis heute stetig, gebunden an die jeweiligen technischen Innovationen.

Doch auch unabhängig von der Musikindustrie loteten bildende Künstler unter Überschreitung der Grenzen ihrer Disziplinen die Ausdrucksmöglichkeiten von Video und Performance weiter aus. Gerade bei der künstlerischen Arbeit mit Video eröffneten sich neue bahnbrechende Möglichkeiten dadurch, dass die analoge Technik allmählich mit digitalen Technologien verknüpft wurde. Zudem hatte die Firma Sony 1978 das U-matic-System vorgestellt, ein Kassettensystem, das auch den Mitschnitt von Fernsehsendungen ermöglichte, das für den Konsumentenmarkt entwickelt worden war. Das U-matic-System fand dann aber auch im Profibereich breite Verwendung, bis es 1981 durch das professionnelle Aufzeichnungssystem Betacam ergänzt wurde. In den 1980ern entwickelte sich zudem eine breite Technikindustrie, um das Medium Video im Amateurbereich breit anzusiedeln und der Videorekorder - und gelegentlich auch eine eigene Videokamera zog in viele westliche Haushalte ein.

Für Künstlervideos bestand eine besondere Situation in Deutschland, während in den USA und Kanada sich über die Jahre ein Markt für dieses künstlerische Medium etabliert hatte, blieb es in Deutschland begrenzt und schwierig zu vermarkten. Doch wurde zum Beispiel im Jahr 1982 in Köln die „235 Media“ gegründet, der erste kommerzielle Verbund zum Vertrieb von Videokunst in der Bundesrepublik.

In den USA oder auch Großbritannien fanden sich verschiedene Künstler und zudem Gruppen zusammen, um mit der aufwändigen Technik, die von einer Person kaum alleine zu finanzieren und auch zu betätigen war, formal komplex ge- 
staltete Werke entstehen zu lassen. Ulrike Rosenbach ist - nach dem kurzen Exkurs mit einer Gruppenarbeit mit Frauen aus der Frauenbewegung und einem vorübergehenden Versuch des Aufbaus eines Alternativen TV mit Klaus vom Bruch und Marcel Odenbach noch in den 1970ern sowie einem zweiten Anlauf mit der temporären Künstlergruppe der „Videorebellen“ Anfang der 80er, zu der auch Rune Mields gehörte - ihren künstlerischen Weg in den 1980er Jahren jedoch konsequent alleine weiter gegangen. ${ }^{434}$ Kontinuierliche Begleiterin in ihren Kunstwerken war bis zu diesem Zeitpunkt ihre Tochter Julia gewesen, die in mehreren Aktionen der Künstlerin aktiv mitwirkte. Diese Zusammenarbeit wird Anfang des neuen Jahrzehntes mit einer kurzen Reihe an gemeinsamen Aktionen einen Abschluss finden.

Die Kunst Ulrike Rosenbachs war in den 1970er Jahren, wie im vorhergehenden Kapitel dargelegt, von einer Art Suche geprägt, die sich in unterschiedlicher Weise manifestierte. Die Künstlerin forschte in ihren Arbeiten nach einem Bild der starken Frau, allgemeiner formuliert nach positiven weiblichen Vorbildern. Auch experimentierte sie in ihren Tapes und Performances mit den Möglichkeiten der Kontaktaufnahme und Kommunikation, nach einem Weg zur Lösung aus den Verstrickungen der eigenen Geschichte. Viele ihrer Aktionen waren in den 1970er Jahren politisch motiviert gewesen und standen im engen Zusammenhang mit dem aktiven Engagement der Künstlerin in der Frauenbewegung.

In den 1980er Jahren bleibt der Aspekt der Suche weiterhin der Antrieb für ihr künstlerisches Wirken, doch scheint sich die Motivation ihres künstlerischen Wirkens zu ändern. Löste sie sich doch aus dem politischen Kontext - der sich auch allgemein wieder im Ausklang befindlichen - Frauenbewegung. Stattdessen rückte die Künstlerin psychologische, spirituelle und metaphysische Ansätze in den Mittelpunkt ihrer künstlerischen Auseinandersetzung. Klang diese spirituelle Seite in früheren Arbeiten im Begriff der schon im Werk ihres Lehrers Beuys wichtigen „Alchemie“ bereits an, so verstärkt dieser Aspekt sich in den kommenden Arbeiten zunehmend. Insgesamt über 40 umfangreiche Werke schuf Ulrike Rosenbach während der 1980er Jahre, die im folgenden inhaltlich vier unterschiedlichen Themenkreisen zugeordnet werden und mit denen sich die folgenden Kapitel intensiv auseinandersetzen:

- Mutter-Tochter-Beziehungen (Kap. IV.2.)

- Erinnerungsarbeiten (Kap. IV.3.)

- Östliche Spiritualität (Kap. IV.4.) und

434 Nachdem die Künstlerin ab Mitte der 1970er versucht hatte mit anderen Kölner Künstlern wie Klaus vom Bruch und Marcel Odenbach - ein „Alternatives Fernsehen“ aufzubauen, unter dessen Namen auch verschiedene Tapes der Künstlerin produziert wurden, gab es Anfang der 1980er Jahre für kurze Zeit das weitere Gemeinschaftsprojekt der „Videorebellen“, an dem neben Ulrike Rosenbach Klaus vom Bruch, Marcel Odenbach und Rune Mields mitwirkten. (Vgl. Herzogenrath 1994, S. 284) 
- Androgynität (Kap. IV.5.).

IV.2. Werkkomplex: Mutter-Tochter-Beziehungen

Die „Spiegelaktion mit Julia“ beschloss im Jahr 1981 eine lange Reihe von gemeinsamen Arbeiten, die die Künstlerin zusammen mit ihrer Tochter Julia seit dem

Jahr 1972 aufgeführt hatte. Begonnen hatte dieser Mutter-Tochter-Zyklus bereits mit dem allerersten künstlerischen Videotape der Künstlerin „Einwicklung mit Julia“, das die Künstlerin mit ihrer damals fünfjährigen Tochter in Szene setzte. Das darauf folgende „Brennesseltape“, die späteren Bänder „Mutterliebe“ oder auch „Kleine Stücke von Julia“ gehören ebenso in die Reihe dieser gemeinsamen autobiographisch geprägten Tapes.

In den darauf folgenden Live-Performances „Salto mortale“, „Die einsame Spaziergängerin“, „Narzissen Scheiden Weg“ oder auch der im Folgenden vorgestellten „Wechselfrau-Aktion“ agierte die Tochter dann zusammen mit ihrer Mutter live vor Publikum. So führten die beiden die Aktion, die den Titel trägt „Wechselfrau im Spiegelbild“ im Jahr 1981 im historischen Ambiente eines Saales des Schlossmuseums in Morsbroich vor einem riesigen Barockspiegel auf, umkreist vom Publikum. Im Katalogtext heißt es zu der Performance:

„Es gebt um das Wachsen und das Wechseln in eine andere Lebenszeit. Das junge Mädchen steht an der Schwelle zum Frausein, die Mutter an der Schwelle zur reifen Frau. Die Künstlerin markiert die Transformation, indem sie die riesige Spiegelfläche mit undurchsichtiger Fettmasse verschmiert und bezeichnet. Die Tochter sitzt auf dem Boden davor und schreibt mit dem gleichen Fett ein Zitat über das Wachsen aus ,Alice im Wunderland" auf einen am Boden liegenden großen, runden Spiegel. Kratzgeräusche, die Ambivalenz. von Spiegel und Eis assoziieren, begleiten die Aktion." "435

Das Spiegelthema war jedoch im Werk Rosenbachs bereits in der „Einwicklung“ angelegt, in der der Videomonitor das Reflexionsmedium bildete. Und auch in anderen Aktionen schwang des Spiegelthema bereits motivisch mit, wie zum Beispiel bei der „Salto-Mortale-Aktion“ der Künstlerin, in der deren agierendes Abbild in der Silberfolie reflektierte.

435 Kat. Schwerin 1999, S. 22. Das Tape „Spiegeleis“ wird bei Glüher 2005 auf 1979 datiert. Es tauchte in voran gegangenen Katalogen nicht auf. Die beschriebene Beziehung zwischen den Motiven Spiegel und Eis ist auch in dem Tape „Spiegeleis“ geknüpft, das dann in den 1990er Jahren in eine Videoinstallation im Schloss in Bad Arolsen eingebunden wurde. 


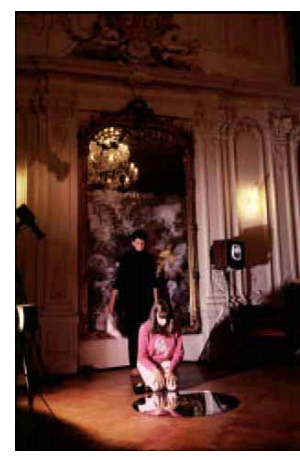

Abb. 120: Wechselfran im Spiegelbild, 1980, Aktionsfoto

Selbst im „Tanz für eine Frau“ aus dem Jahr 1974 ist ein Spiegel eingebunden, da die aus der Vogelperspektive aufgezeichnete Aktion doch mittels eines reflektierenden Spiegel aufgenommen worden ist.

Das Wort Spiegel ist vom Lateinischen ,speculum' entlehnt, das wiederum von „specere“, mit der Bedeutung „spähen“, abgeleitet ist. Der Spiegel kann als vieldeutiges Symbol für die innere oder diskursive Erkenntnis, die Schönheit, die Tugend der Klugheit oder das Laster der Eitelkeit stehen:436

„Der Spiegel als Symbol enthält stets eine Doppelbedeutung. Moralisch gesehen wird er in der Regel negativ eingesetzt, beispielsweise im Mythos von Narziss oder in den Allegorien der Sünden Unkeuschbeit, Eitelkeit und Stolz. Eine positive Akzeptanz erfährt er bingegen als Symbol für innere Erkenntnis (büßende Magdalena) oder das Geheimwissen (magischer Spiegel) und die Tugend der Klugheit. Die Etymologie reflektiert diesen zweifachen Deutungsgehalt: Das lateinische speculum betont die Bedeutung der Erkenntnis und "Spekulation" über das Abbild der Wirklichkeit; das französische mirroir beschränkt sich auf die kontemplative Funktion des „Widerspiegelns" und bezieht auch die selbstgefällige Eigenbetrachtung mit ein. " 437

Die Bedeutung dieses Gegenstandes kreist allgemein um das Thema „Erkenntnis“: In der reflektierenden Oberfläche spiegelt sich das Sein. Im Orakel oder im Märchen bringen Spiegel die Wahrheit ans Licht, wie auch in der Mystik der Spiegel zum Symbol für die Offenbarung einer höheren, verborgenen Wirklichkeit steht oder in philosophischen Schilderungen dem geduldigen und gläubigen Betrachter mehr als die äußere Erscheinung offenbart: Der Spiegel zeigt dem Betrachter sein inneres Wesen. ${ }^{438}$

\footnotetext{
436 Vgl. Battistini 2003, S. 138

437 Battistini 2003, S. 138

438 Vgl. Lurker 1991, S. 693
} 
Das Symbol des Spiegels findet auch in der Psychoanalyse im Rahmen der Psychogenese des Menschen seinen Niederschlag. Der französische Psychoanalytiker Jacques Lacan (1901-1981) erklärt die von ihm als „Spiegelstadium“ benannte Entwicklungsphase im Alter von sechs bis achtzehn Monaten zu einem zentralen Moment menschlicher Identitätsbildung. Nach der ersten Phase, in der der Säugling in symbiotischer Beziehung zur Mutter und zur Außenwelt stand, erkenne das Kind nun beim Blick in den Spiegel ein integriertes Bild seiner Selbst. Erstmals nehme es seinen Körper nicht fragmentarisch, sondern als Ganzes wahr, so wie er auch von den anderen Menschen wahrgenommen werde. Nach Lacan erfährt das Kind in dieser frühen vorsprachlichen Entwicklungsphase sein physisches Ungenügen, seine motorische und physiologische Unvollkommenheit als ein Defizit, dem es den Entwurf eines Selbst-Bildes entgegensetze. Indem es sich in anderen Menschen, vor allem aber beim Blick in den Spiegel in seinem eigenen Bild wiedererkenne, entwerfe es zugleich ein Idealbild seiner selbst, das fortan sein umgrenztes, einheitliches, geformtes Ich ausmachen werde:

„Diese Entwicklung wird erlebt als eine zeitliche Dialektik, welche die Bildung des Individuums entscheidend als Geschichte projiziert: das Spiegelstadium ist ein Drama, dessen innere Spannung von der Unzulänglichkeit auf die Antizipation überspringt und für das an der lockenden Täuschung der räumlichen Identifikation festgehaltene Subjekt die Phantasmen ausheckt, die [...] in einer Form enden, die wir in ihrer Ganzheit eine orthopädische nennen könnten, und in einem Panzer, der aufgenommen wird von einer wabnhaften Identität, deren starre Strukturen die ganze mentale Entwicklung des Subjektes bestimmen werden. ${ }^{4} 439$

Nach Lacan leitet der Blick, das visuelle Erkennen eine neue Lebensphase ein, die den Eintritt des Menschen in die symbolische Ordnung oder das Soziale mit sich bringt. Erst mit dem Eintritt in die Sprache vollziehe sich später die Aufspaltung des Ichs. Damit entstehe das Unbewusste, denn dieser „Eintritt [in die Sprache] bedeutet zugleich den Ausgang aus dem Paradies der Symbiose (vom ich und dem anderen) und damit jene Urverdrängung, die das Subjekt spaltet." ${ }^{\text {"440 }}$

Während in den frühen Tapes Ulrike Rosenbachs der Videomonitor als reflektierendes Gegenüber diente ${ }^{441}$, ist in dieser Aktion ein realer - im Falle der Künstlerin historischer eckiger, in Bezug auf die Tochter zeitgenössischer runder - Spiegel eingesetzt. Diese Wahrheit und Ganzheit enthüllende Spiegelfläche beschmiert die Künstlerin in der Aktion allerdings mit Fett. Durch diese Schicht verschwimmt ihr Abbild und verschwindet schließlich ganz, so dass die Künstlerin ihr gespiegeltes Gegenüber nicht mehr erkennen kann.

\footnotetext{
439 Lacan in: Haas 1986, S. 67

440 Hiebel in: Bogdal 1990, S. 59

441 Zum Begriff „Videonarziss“ vgl. Krauss 1976 oder auch Friedel in: Herzogenrath 1982, S. 1-9
} 
Der Einsatz von Fett als Material in einer Aktion ist zu diesem Zeitpunkt neu im Werk von Ulrike Rosenbach und wird auch nur noch einmal in der Installation „Spiegeleis“ auftauchen.442 Der schmierige, ästhetisch wenig anziehende Werkstoff ist jedoch zum Beispiel im Werk von Joseph Beuys und dessen individueller Mythologie sehr positiv konnotiert. Steht Fett bei Beuys doch symbolisch für das Heilen, Nähren, Reifen oder auch die Transformation. Bedeutungen, die auch zur Aktion Rosenbachs passen. Denn genau diesen Aspekt des „Wachsens“ thematisiert das literarische Zitat, das die Tochter mit Fett spiralförmig auf ihren Spiegel schreibt. Es stammt aus dem Roman „Alice im Spiegelland““43 des Engländers Lewis Carroll, in dem die weibliche Heldin durch einen Spiegel in eine ihr unbekannte Welt tritt, in der die in ihrer herkömmlichen Umgebung geltenden Regeln außer Kraft gesetzt sind. Dieser Gedanke des örtlich Unbekannten und Neuen ist in der Aktion Ulrike Rosenbachs auf die zeitliche Ebene übertragen und wird genutzt, um damit den Übergang von einer Lebensphase in die nächste zu beschreiben. Da ein Blick in die Zukunft dem Menschen jedoch nicht möglich ist, bleibt diese Aussicht durch den Spiegel an der Wand in der Aktion verstellt. Anders ist es bei dem Kind, es blickt in den am Boden liegenden Spiegel, und damit im übertragenen Sinne in den Grund.

Mit dieser Gemeinschaftsaktion, die nach der Narzissen-Aktion erneut den Trennungsaspekt in zeichenhafter Weise visualisiert, endet das Zusammenwirken von Mutter und Tochter auf künstlerischer Ebene. Während der vorangegangenen neun Jahre hatte die heranwachsende Tochter in insgesamt sieben Werken mitgewirkt. Während sie in einer ersten Phase in den Videotapes auftauchte, übernahm sie in verschiedenen der späteren Aktionen einen wichtigen Live-Part. Die Betrachtung der Funktion des Kindes in diesen Aktionen zeigt, dass sie durchweg sich selbst darstellte, also in ihrer aktuellen Rolle als Tochter in das künstlerische Werk integriert wurde.

Ein solches Zusammenwirken von Mutter und Tochter - oder allgemeiner Künstler oder Künstlerin und dem eigenen Kind - über zudem einen langen Zeitraum, ist außergewöhnlich und kontrovers zu diskutieren, stellt sich doch die Frage nach der Fremdbestimmtheit oder Institutionalisierung des Kindes innerhalb der künstlerischen Aktionen. ${ }^{444}$ Meine Recherchen konnten zudem keinen ande-

442 Vgl. Kap. V.3.6.

443 „Alice im Spiegelland“ (im Original „Through the Looking-Glass, and what Alice found there“ aus dem Jahr 1872) ist die Fortsetzung von „Alice im Wunderland“ des Engländers Lewis Caroll, einem Mathematiker, der mit bürgerlichem Namen Charles Lutwidge Dodgson hieß. Die fantastische Geschichte berichtet von den Erlebnissen des Mädchens Alice im Land jenseits des Spiegels, durch den diese gesprungen ist.

444 Interessant wäre es, zu diesem Punkt der „Grenzüberschreitung“ und „Institutionalisierung“ die Tochter zu befragen, zu der sich aber leider kein Kontakt herstellen ließ. In aktuellen Katalogen dankt die Künstlerin ihrer Tochter immer wieder für deren Engagement und betont zum Bei- 
ren Fall in der bildenden Kunst ausfindig machen, in der Künstler in gleicher oder ähnlicher Weise ihre Kinder in ihr künstlerisches Wirken eingebunden haben. ${ }^{445}$ Verschiedene Künstlerinnen haben in einzelnen Werke auf die Entwicklung ihrer Kinder Bezug genommen. Dies geschah häufig im Kontext einer feministischen, autobiographisch ausgerichteten Kunst. Ein Beispiel dafür ist zum Beispiel die feministische Künstlerin Mary Kelly (*1941) mit ihrem „Post-PartumDocument". 446

Die Installation bildet eine langfristige feministische Analyse einer MutterKind-Beziehung von der Geburt an. Körperabdrücke des Kindes auf Papier, Windeln und andere Materialien, aber auch das von der Mutter während der Jahre geführte Tagebuch, das Zeugnis ablegt über deren Gefühle, bilden eine facettenreiche Collage, die gleichzeitig Zeitdokument wie auch Gesellschafts-analyse ist. Die Kritikerin Lucy Lippard schrieb zu Kellys Post-Partum-Document:

\section{„,Post-Partum Document" ist die Geschichte eines kulturellen Kidnappings und des Wi- derstands einer Frau dagegen, der durch die visuelle und verbale Analyse aktiviert wird. " 447}

In dieser Arbeit werden aktuelle Lebensverhältnisse dokumentiert und zudem analysiert, sowie unterschiedliche Relikte aus dem Leben des Kindes eingefügt, die Person des Jungen jedoch nicht selbst mit einbezogen. Anders ist das bei einer Fotoarbeit „Primapara, Bathing Series“, aus dem Jahr 1974. ${ }^{448}$ Hier ist ein Baby in ausschnitthaften Nahaufnahmen auf sehr intime Weise fotografiert.

Eigene Kinder werden zudem häufiger in Künstlerfotografien porträtiert, wie zum Beispiel bei Linda McCartney, wodurch wiederum eine große Nähe zwischen Kunst und Autobiographie erzeugt wird.

spiel in ihrer Danksagung bei Glüher 2005 deutlich, dass die Tochter immer mit Freude mitgemacht habe.

445 Anders ist dies in den darstellenden Künsten, wo Kinder von Schauspielern oder Sängern oder als Schauspieler und Sänger häufiger in Erscheinung treten.

446 „Post-Partum-Document, 1978-1979, Installation in 18 Einheiten, Mischtechnik, 35,5 x 27,9 cm. Postmasters Gallery New York. „Diese feministische Analyse eines Mutter-Kind Verhältnisses seit der Geburt hat viele Facetten, wovon die wichtigsten sicherlich Körperabdrücke des Kindes auf Papier, Windeln und anderen Materialien, aber auch das von der Mutter geführte Tagebuch über ihre Gefühle bezüglich der eigenen Herkunft sind. Kommentare zu den Aktivitäten wurden sowohl zum Lesen wie auch für die visuelle Wahrnehmung ausgestellt." (LucieSmith 1996, S. 325)

447 Lippard in: Kat. New York 1983, S. x

448 Vgl. Kat. Kassel 2007, S. $94 \mathrm{f}$ 


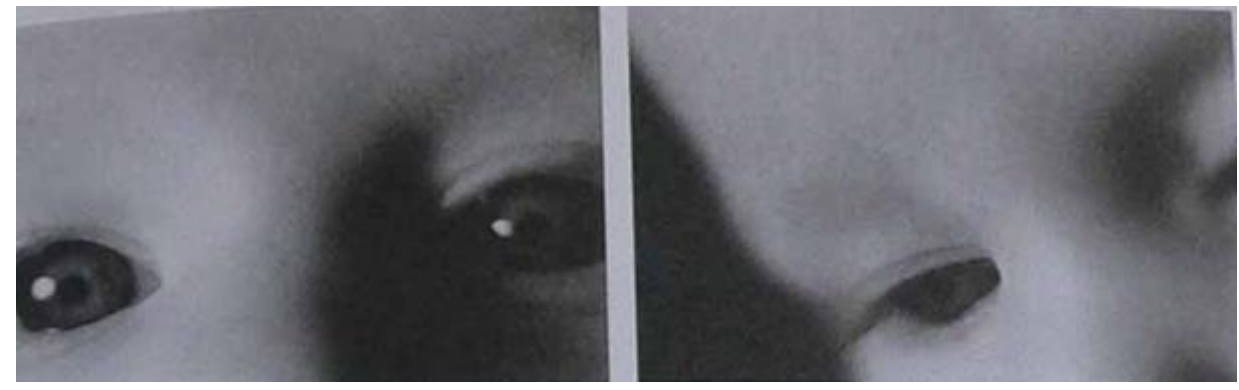

Abb. 121-122: Mary Kelly - Primapara, Bathing Series, Fotoserie, 1974

An diese fotografischen Porträts schließen sich thematisch Kinderporträts von Malern an, die sich durch die Kunstgeschichte ziehen. So malte zum Beispiel Otto Dix seine Tochter Nelly im Jahr 1924 auf einer Blumenwiese. ${ }^{449}$ Doch nur Ulrike Rosenbach scheint ihre Tochter - wortwörtlich - so dicht in ihre Arbeit eingebunden und Kunst und Leben so eng verknüpft zu haben.

Die folgenden Werke der Künstlerin zeigen weiterhin klare autobiographische Bezüge. Die schmerzhafte Erfahrung des Todes ihrer Mutter Anfang der 1980er Jahre verarbeitet die Künstlerin gleich in mehreren Arbeiten, die in den ersten Jahren dieser Dekade entstehen, auf unterschiedliche Weise. In der Rauminstallation „Denkmal für eine verzweifelte Frau“, die 1981 in der Galerie Magers in Bonn gezeigt wurde, liegt im Mittelpunkt ein lebensgroßes Foto einer ernst blickenden, mittelalten Frau, die in einem Lehnstuhl auf einer Wiese sitzt. Es ist eine Porträtaufnahme der Mutter der Künstlerin. Umrahmt ist die am Boden liegende Fotografie von einer Reihe von Leinwänden, die an die Wände gestellt sind und Darstellungen von Rosenkränzen zeigen. In einer Ecke des Raumes steht ein Videomonitor, auf dem ein Videotape läuft, das ein Gespräch der Künstlerin mit deren Großmutter wiedergibt. ${ }^{450}$ In der Aufzeichnung der alten Frau, die die Künstlerin im Altersheim besuchte, spricht diese anscheinend von der Verstorbenen, weiteren Familienmitgliedern und ihrem gegenwärtigen Alltag. Ihre nüchternen Erzählungen geben dem inszenierten, statischen Denkmal - das als Gedächtnishilfe oder auch als visuellem Erinnerungszeichen verstanden werden kann - biografische Hintergrundinformationen, zum anderen stellen sie Bezug zum Alltag, zum gegenwärtigen Leben her.

449 Otto Dix, Nelly in Blumen, 1924, 80 x 55,5 cm, ÖL/LW, Folkwang Museum Essen. Auch die amerikanische Malerin Marie Cassatt malte eine ganze Reihe von Gemälden, die das Motiv Mutter und Tochter zeigen. (Vgl. Pollock 1989)

450 Die Großmutter der Künstlerin starb ein halbes Jahr nach der Mutter im Jahr 1981 im Alter von 93 Jahren. (Vgl. zu der Installation und dem Gespräch mit der Großmutter auch Rosenbach 1982, S. 169-174) 


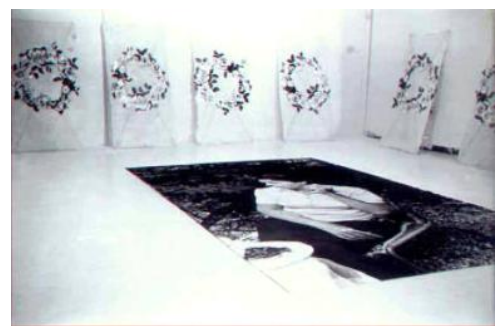

Abb. 123: Denkmal für eine verzweifelte Frau, 1981, Installation

In dem zugehörigen, sachlichen Katalogtext, greift die Künstlerin das Thema des Selbstmordes heraus. ${ }^{451}$ Konkret beschäftigt sie sich hier mit dem Erhängen. Diese Art der Selbstentleibung deutet der Text als „Selbst-Enthauptung“. Sie versteht das Erhängen als symbolischen Versuch den Körper vom Leib zu trennen, der die Konsequenz einer gescheiterten oder nicht vorhandenen weiblichen Selbstbehauptung darstellen könne. Diese zusätzliche Information gibt der Installation eine zusätzliche politische Dimension. Hinterfragt die Künstlerin damit doch auf einer allgemeineren Ebene auch die Stellung der Frau in der Gesellschaft. So wird auch in diesem Werk - unausgesprochen - die Frage gestellt nach den tiefen Verletzungen der weiblichen Identität, die das Gefühl von Ausweglosigkeit und Verzweiflung entstehen lassen können. ${ }^{452}$

Die künstlerischen Arbeiten, die in dieser Werkphase entstehen, setzen sich einerseits - wie das gerade besprochene „Denkmal“ - auf abstrahierter Ebene mit dem Leben der verstorbenen Mutter, andererseits allgemeiner mit der MutterTochter-Thematik auseinander. Die Künstlerin bemerkte rückblickend in einem Interview, dass nach dem Tod ihrer Mutter das Thema der Mutter-TochterBeziehung für sie neu aufgelebt sei. ${ }^{453}$ Die Auseinandersetzung über die erste prägende Beziehung, die das Sein des Menschen in elementarer Weise mitbestimmt, scheint mit dem „Denkmal“ und dem zuvor aufgeführten „Requiem“ ihren Abschluss zu finden.

Während die Künstlerin in ihren früheren Arbeiten die Rolle der Mutter verkörpert hatte und die Tochter Julia dabei in der künstlerischen Inszenierung - die Wirklichkeit spiegelnd - die Rolle der Tochter ausfüllte, betrachtet die Künstlerin

451 Rosenbach 1982, S. 169

452 Der Maler Marc Chagall zeigt in seinem Gemälde „Russland, den Eseln und den anderen“ aus dem Jahr 1911 (Paris, Musee d'Art Moderne) wie auch in „Ich und das Dorf“ (ebenfalls 1911, New York, Museum of Modern Art) phantastische, schwebende Gestalten, die in ihrer Losgelöstheit vom Bildgrund die perspektivische Räumlichkeit aufheben und eine völlige Trennung von Bildgrund und Figur vollziehen. Der vom Leib getrennte Kopf einer Frau in der „RusslandKomposition“ zeigt einen starken seelischen Eindruck, Zustand einer gewissen Entrückung, einer leibfreien Seelenverfassung.

453 Vgl. Kap. VII.1. 
die Generationenthematik in der Performance „Requiem für Mütter“ aus der entgegengesetzten Richtung: Sie blickt nun aus ihrer eigenen Perspektive in der Rolle der erwachsenen Tochter auf ihre Bindungen an die Mutter und auch die Großmutter. ${ }^{454}$

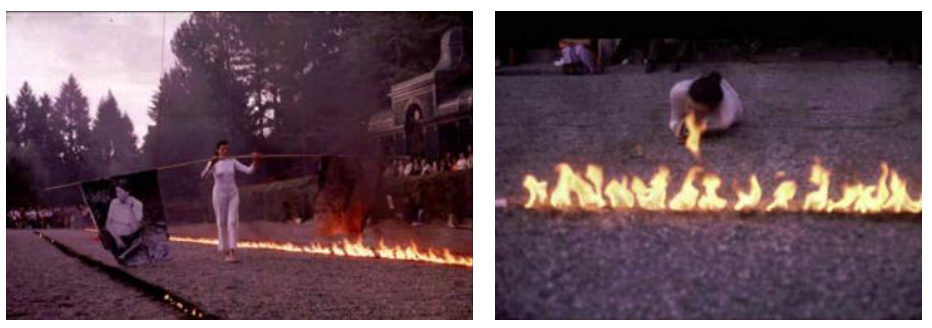

Abb. 124-125 Requiem für Mütter, 1980, 2 Aktionsfotos

Der Begriff „Requiem“ kommt aus dem Lateinischen und bedeutet Rast, Ruhe oder auch Erholung. Das Wort benennt zudem die katholische Seelenmesse, sowie eine musikalische Komposition, die die Totenmesse zum Leitthema hat. Ulrike Rosenbach zelebrierte ihre Messe für ihre Vorfahren als einen eindrucksvollen "rite de passage" ${ }^{455}$, der ihre Lösung aus den prägenden Bindungen ins Bild setzte. Während der rund 50-minütigen Aktion schritt die Künstlerin, bekleidet mit einem weißen Trikot und beladen mit zwei durch ein Band miteinander verknüpften Bambusstangen, an der rechts und links je ein großformatiges Porträt ihrer Mutter - übrigens das gleiche Bild wie im „Denkmal“ - und ihrer Großmutter hing, einen rund 50 Meter langen geraden Parcours entlang. Seitlich war der Weg durch drei Furchen begrenzt, in denen zu Beginn der Aktion Feuer entzündet wurde. Zwischen zweien der parallel verlaufenden Furchen bewegte sich die Künstlerin entlang. Zunächst trug sie die Bambusstäbe auf Taillenhöhe und schritt mit ihnen aufrecht gehend, konzentriert und langsam voran. Dabei schliffen die Fotografien der Frauen hinter ihr über den Boden. Symbolisch schleppte die Künstlerin in der Aktion somit ihre Mutterbilder "mit sich" oder "hinter sich her". Die fotografischen Abbilder waren dabei zunächst nach rückwärts gewandt, dem Publikum an der Startseite zugekehrt, während die Zuschauer, auf die die Künstlerin zuschritt, allein zwei weiße Flächen zu sehen bekamen. Die papiernen Fotografien der Mütter wurden während des Weges von dem Feuer am Boden angegriffen und zum Teil angesengt. Sie erstickten im Schleifen aber auch selbst einige Flammen. Dabei war das Papier teilweise mit Feuerschutzmittel imprägniert worden, so dass die Fotos nicht völlig ausgelöscht werden konnten. Denn, wie es im Katalog zu der Aktion interpretierend heißt:

454 Die Performance „Requiem für Mütter“ wurde am 30. August 1980 im Wenkenpark in BaselRiehen uraufgeführt.

455 Vgl. Kap. III.5.4. 


\section{„Unsere Mütterbilder lassen sich nicht verbrennen, dafür sind die Bindungen, liebevolle und hassvolle, zu stark." 456}

In der Mitte des Platzes war ein Knäuel aus neun dicken, roten Gummiseilen, die in die umliegenden Bäume abgespannt waren, installiert. Der Knoten war auf eine Reflektorenscheibe in einem naheliegenden Gartenpavillon gerichtet, deren erzeugte Sonnenenergie zum Auslösen eines Alarmtones genutzt wurde, der stetig die Aktion begleitend erklang. In diesem Pavillon stand auch ein Monitor, auf dem Videobilder zu sehen waren, die die Künstlerin vor der Aktion von den zündelnden Flammen aufgenommen hatte.

Dazu hatte sie sich an der Feuerspur entlang, die Kamera in der schon bekannten Weise nah vor ihrem Auge, über das Gras gerollt, wobei sie sich zunehmend in das Kabel der Kamera eingewickelt hatte. Als die Akteurin dann während der Aktion das verknotete Zentrum auf dem Parcours erreichte, drehte sie ihre symbolische Fracht parallel zum Verlauf der Furchen. Sie stieg - ihre Last nun über ihrem Kopf balancierend - über die komplexe Verknotung hinweg. Dabei drehte die Künstlerin die Mutterbilder jenen Zuschauern zu, auf die sie beständig weiter zuschritt. Im Weitergehen nahm sie dabei rechts und links von sich zwei der Gummiseile unter die Bambusstangen. Da die Seile leicht gegen die Bäume anstiegen und die Künstlerin die Stricke mit ihrer Last der Mutterbilder herabdrückte, erhöhte sich die Spannung, nicht nur in den Gummibändern, sondern auch im Körper der Künstlerin selbst, so dass dieser die körperliche Anstrengung ins Gesicht geschrieben stand. Am jenseitigen Ende des Furchenparcours angekommen, löste die Künstlerin die kleinen roten Bänder, die die beiden Bambusstangen zusammenhielten. Daraufhin schleuderten die auf Spannung stehenden Gummiseile die Mutterbilder-Fahnen zunächst in die Höhe, bevor die papiernen Fotografien zu Boden fielen. Währenddessen verharrte die Künstlerin eine Weile auf der Stelle, die Arme steil hoch gestreckt in Priesterinnenhaltung. Dann machte sie sich ohne ihre Last und befreit von der Spannung auf den Weg zurück zu dem großen Seilknäuel, dessen Knoten sie nun durch sanftes Lösen zu entwirren suchte, was ihr auch gelang. Nach dieser Auflösung ergriff die Künstlerin eines der roten Bänder und verließ damit den Schauplatz in Richtung zweier sich kreuzender Gartenrechen, die den Ausgang zwischen der umgebenden Hecke versperrten. Dort angekommen hing sie die rote Schnur in dem Grün fest und verließ den Aufführungsort. Auf dem beschrittenen Parcour zurück blieben allein drei lange, gradlinige Aschespuren. ${ }^{457}$

Die Aktion wurde auch auf Video aufgenommen. Zur Aufzeichnung war eine Perspektive außerhalb des Parcours gewählt und der Kameramann mit einer fahrbaren Kamera begleitete die Schreitende auf ihrem Weg und setzte die Künstlerin

456 Thomas-Jankowski in: Rosenbach 1982, S. 161

457 Thomas-Jankowski in: Rosenbach 1982, S. 161 
damit als dritte im Bunde der Mütter ins Bild, formal entsprechend der drei Feuerspuren.

Die Aktion zeigt die Performerin auf ihrem gradlinigen Weg durch ein Knäuel an Verstrickungen sowie die Lösung aus diesen. Untermalt ist die Aktion durch einen sonnenenergetisch erzeugten Ton, der Lichtenergie in Klang verwandelt. Das Motiv der „Verstrickung, Verknotung“, das durch den Einsatz der verknoteten Seile wortwörtlich ins Bild gesetzt wird, ist ja bereits in früheren Arbeiten Ulrike Rosenbachs aufgetaucht, zum Beispiel in der in ihren formalen Elementen sehr ähnlichen Videoperformance „Isolation is Transparent", bei der die Künstlerin mit ihrem Körper in der Verknotung feststeckte. Zudem fällt eine formale Nähe der Erscheinung dieses Knotengebildes zum Beispiel mit den Spinnenobjekten der Künstlerin Louise Bourgeois auf. Seit Mitte der 1940er Jahre beschäftigt die Französin dieses Motiv der Spinne, das sie in raumgreifende schaurigfaszinierende Objekte verwandelt. 458
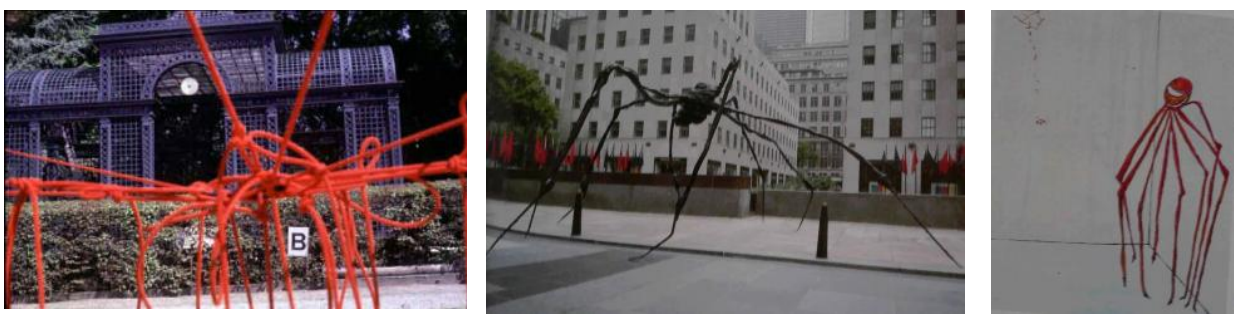

Abb. 126-128: Requiem für Mütter, 1980, Aktionsfoto und Louise Bourgeois, Spiders, Objekt 1994 und Zeichnung, 1944

In Rosenbachs Werk ist nun das Knotenknäuel ein Hindernis, das zunächst am Weitergehen hindert. Der Künstlerin gelingt es jedoch im Verlauf der Aktion dieses aktiv zu überschreiten und - nachdem sie sich von ihrer Last befreit hat - die Bindungen aufzulösen. Die symbolische Handlung begegnet so weniger als ein Requiem für die Ahninnen, als das sie als ein ins Künstlerische übertragener "rite de passage" für die Akteurin verstanden werden kann. Nach der Theorie des Ethnologen Arnold van Gennep zeichnen sich die auch als Übergangsriten bezeichneten sozialen Phänomene, die in den verschiedensten Gesellschaften in großer Vielfalt zu finden sind, durch eine immer wiederkehrende gleiche Struktur aus: Nach einer ersten Phase der Trennung setzt das Übergangsstadium ein, bei dem das Individuum besonders gefährdet erscheint, bevor dann mit der dritten Phase der Inkorporation oder Einfügung, das Individuum in den neuen Stand versetzt wird. ${ }^{459}$

Diese drei Phasen können auch auf diese Aktion Rosenbachs übertragen werden. Zunächst sind die inneren, prägenden Bilder, die die Künstlerin als Fotos auBerhalb mit sich trägt, für das, was kommt unsichtbar. Mit dem Überschreiten des

458 Vgl. Kat. Berlin 2003, auch Rinder 1996, S. 178 f

459 Hirschberg 1988, S. 494 
Knotens setzt der Übergangsritus ein, bei dem die Bilder gedreht und gehoben werden. Die historischen Fotografien werden dadurch für das Zukünftige sichtbar und treten ins Bewusstsein. Doch entsteht durch dieses, in der Aktion ins Physische übertragene, Heben auch eine große Spannung, da die Last weiter gegenwärtig bleibt und nach unten drückt. Dieser Druck kann sich erst auflösen, als die Bilder voneinander und gleichfalls von der Trägerin getrennt werden, als die Künstlerin sie handelnd loslässt. Erst an dieser Stelle der Performance, dem symbolischen Abwerfen der prägenden Bilder, liegt das Moment der Trennung.

In ihrer neuen Rolle, befreit von der zuvor drückenden Last, hat die Künstlerin nun die Hände frei, um die alten Bindungen lösen zu können. In der Aktion ist es ein praktisches Aufknoten, im übertragenen Sinn zu deuten als ein Auflösen der inneren Verstrickungen. Nach dieser Handlung sucht die Akteurin sich eines der neun roten Seile aus und wählt es als eine sie noch an die Vergangenheit bindende Nabelschnur. Doch reicht diese Verbindung nur bis an die den Parcours umschließende Hecke. An dieser Grenze verlässt die Künstlerin den Ahninnenparcours allein und frei jeglicher Bindung. 460

Diese künstlerische Aktion abstrahiert im rituellen Gewand in symbolischer Sprache Beziehungserfahrungen und das Überschreiten sowie Lösen der damit verbundenen inneren Verstrickungen. Sie bildet einen inneren Prozess im Außen ab. Auch in diese Aktion ist ein Videomonitor eingebunden, er zeigt Aufnahmen von Feuer. Wenn wir davon ausgehen, dass die frühere Praxis beibehalten wurde und das Videobild auch hier wieder für ein inneres Erleben steht, wird dieser in der Aktion aufgezeigte Lösungs- oder Reinigungsprozess mit diesen Bildern bestärkt und vollendet. ${ }^{461}$

Durch den Einsatz der Fotografien ihrer Angehörigen ist diese künstlerische Arbeit erneut sehr persönlich geprägt und wendet den historisch Frauenbilder betrachtenden Ansatz, der bereits im „Frauenkultur - Kontaktversuch“ begegnete, ins Biografische. Dabei fällt in dieser Aktion die negative Konnotation der definierten Beziehungen auf, die als hemmend, leidvoll und schwer mitgeteilt werden.

Die Künstlerin selbst sieht in dieser Aktion die Repräsentation des Lebensweges der erwachsenen Frau. Das „Requiem für Mütter“ sei eine rituelle Performance über das Mutterbild als Identifikationsmodell für die erwachsene Frau, beschreibt die Künstlerin selbst ihre mit der Aktion verbundene Intention. Damit bilde die Arbeit den abschließenden Teil einer Trilogie, der die beiden Aktionen

460 Das Thema der Grenze begegnete ja bereits in der „Einsamen Spaziergängerin“. Interessanterweise findet sich auf dem Einband der Ausgabe von 1978 des Buches von Hans Peter Duerr das Gemälde „Der Mann von der Straße“ von Paul Delvaux (Musée des Beaux- Arts et de L'Art Wallon, Lüttich). Die surrealistische Komposition zeigt im Vordergrund eine nackte Frau, hinter der eine Efeuranke wächst. Die Efeublätter bedecken ihren Kopf und wickeln sich um ihre leicht angehobene linke Hand.

461 Das Element des Feuers begegnet uns später wieder im Rahmen des Themas Alchemie (Kap. IV.5.) 
„Narzissen scheiden weg“ und „Konzert im Gewaltakt“ vorangegangen sind. Diese drei Werke seien aus der Auseinandersetzung mit den Fresken in der "Villa dei misteri” entstanden. ${ }^{462}$ Die so genannte „Mysterienvilla“ liegt in der Nähe der durch einen Vulkanausbruch im Jahr 89 n.Chr. Gänzlich verschütteten antiken Stadt Pompeji. Ulrike Rosenbach lernte das antike wieder unter der Vulkanasche freigelegte Gebäude während ihres Stipendienaufenthaltes 1977 in Florenz kennen. Die antike Villa erhielt ihren Namen von einem ihrer Räume mit Wandgemälden, auf denen antike Mysterien dargestellt sind. Was hier allerdings genau abgebildet ist, darüber ist sich die Forschung nicht einig. Kleinster gemeinsamer Konsens der vielfältigen Hypothesen scheint die Annahme zu sein, dass hier Initiationsriten des Dionysoskultes zu sehen sind. In dem griechischen Gott Dionysos, der dem römischen Bacchus entspricht, und der in den griechischen Mysterien eine wichtige Rolle spielte, gewinnen die zeugenden Kräfte der Natur Gestalt. Der Religionswissenschaftler Mircea Eliade beschreibt den Gott wie folgt:

„Dionysos ist ein ungewöhnlicher Gott. Obwohl er der Sohn des Zeus und der thebanischen Prinzessin Semele ist, soll er aus den geheimnisumwitterten Regionen Thrakiens oder Phrygiens stammen. Selbst wenn er autochton ist, so stellt er doch den Fremden in uns selbst dar, eben die furchtbaren gesellschaftsfeindlichen Kräfte, welche durch jene göttliche Raserei entfesselt werden. Trunkenheit durch Wein, sexuelle Exzesse, Masken und Theater sind nur die äußeren Anzeichen dieses göttlichen Rausches. Ganze Scharen seiner Mänaden, besessener Frauen, streifen im Zustand der Hypnose durch die Berge und zerstückeln mit eigenen Händen die wilden Tiere, um sich an ibrem rohen Fleisch zu laben. Und auf solche Weise widerspricht die Lehre des Dionysos ganz und gar den sozialen Normen." 463

Im modernen Bildungsbewusstsein gilt Dionysos im Gegensatz zum Verstandes geprägten Apoll als Gott der Ekstase, verkörpert das Rauschhafte, Irrationale im Welterlebnis wie im Künstlerischen.

Bezogen auf die an den Wänden des Gebäudes dargestellte Geschichte geht die Forschung derzeit davon aus, dass es sich um die Initiation einer jungen Braut handeln könnte. Die gemalte Szenenfolge beginnt mit der Darstellung eines Knaben - der einzigen männlichen Gestalt - die einen Text vorliest. Auf der folgenden Wand sieht man eine geflügelte Gestalt, die auf das zu initiierende Mädchen, das auf der weiter rechts angrenzenden Wand dargestellt ist, einschlägt. ${ }^{464}$

462 Rosenbach 1982, S. 167

463 Eliade in: Eliade/Culianu 1995, S. 97

464 Das Motiv dieser geflügelten Frau mit Peitsche aus der Villa dei Misteri wird uns in späteren Arbeiten der Künstlerin noch wieder begegnen und nimmt in den kommenden Werken Ulrike Rosenbachs eine zusehends bedeutende Rolle ein. 

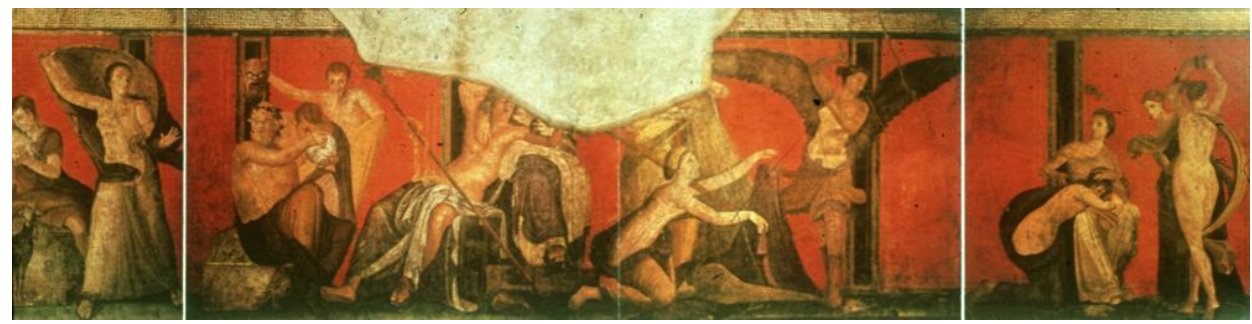

Abb. 129: Villa dei Misteri, Mysteriensaal, Pompeji, Fresken, 70-50 v.Chr.

Das Mädchen, dessen Rücken für die Peitschenschläge entblößt ist, verbirgt seinen Kopf im Schoß einer weiteren Frau. Links neben der geflügelten Figur auf der zweiten Wand befindet sich ein verhüllter Gegenstand, vermutlich ein riesiger Phallus für rituelle Zwecke. Die letzte Wand zeigt zwei Figuren, von der die eine ein Tuch von einer Art runder Schale oder auch Spiegel hebt. Dabei könnte es sich um eine Orakelszene handeln. Daneben nehmen an dieser vierten Wand nicht menschliche Wesen an der Handlung teil. ${ }^{465}$

Ulrike Rosenbach sieht in diesen pompejanischen Malereien den Lebensweg der Frau in drei Teilen beschrieben:466 Zunächst erkennt sie in den Darstellungen das Leben des Mädchens mit der Mutter in der häuslichen Umgebung, darauf folgend die rituelle Hochzeit des Mädchens mit Bacchus, als sexuelle Einweihung interpretiert, an die sich das Leben als erwachsene Frau anschließt. Diese drei Lebensphasen lassen sich auch auf die Thematiken ihrer Werktrilogie „Narzissen Scheiden Weg“, „Konzert im Gewaltakt“ und „Requiem für Mütter“ übertragen: Während in der „Narzissen-Aktion“ die Abnabelung von Mutter und Tochter thematisiert wurde, geht es im „Konzert im Gewaltakt“ um das Thema Sexualität, in Rosenbachs Umsetzung geprägt durch Darstellungen von Gewalt und Unterdrückung. Im „Requiem“ findet dann eine Befreiung ihren Ausdruck, als Voraussetzung für den unabhängigen Weg der erwachsenen Frau.

Beim Vergleich dieser Werke auf formaler Ebene zeigt sich, dass die Künstlerin im „Requiem“ mit ähnlichen Darstellungsmitteln wie in der „NarzissenAktion" gearbeitet hat: Das Schreiten auf einem begrenzten Parcours steht jeweils im Mittelpunkt, und in beide Aktionen ist wieder ein Videomonitor eingefügt, der eine andere Raum-Zeitebene hinzufügt. Während im Verlauf des „Requiems“ die zuvor aufgezeichnete Feuerspur zu sehen ist, ist es bei den „Narzissen“ ein Zitat aus dem Werk der Künstlerin, von dem sich die beiden schreitenden Akteurinnen immer weiter entfernen: Die „Einwicklung mit Julia“ ist hier am Ende des Parcours im Monitorbild zu sehen, ein Bild der inneren Verbundenheit. Kennzeichnend ist für alle drei Werke auf der inhaltlichen Ebene, dass die tiefen, existentiel-

465 Vanags 1983, S. 63; Nach Vanags kann es sich bei den Dargestellten um den Walddämon Silenus und mehrere Satyrn handeln.

466 Rosenbach 1982, S. 167 
len Gefühle, die diese Entwicklungsprozesse begleiten, in der bereits bekannten Form auf eine sehr abstrahierte und wortwörtliche Weise künstlerisch vermittelt werden.
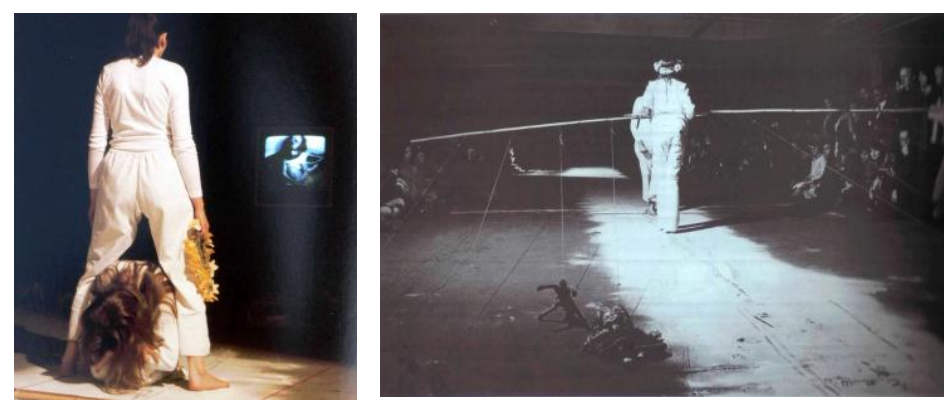

Abb.130-131: Narzissen scheiden weg, 1980, Aktionsfotos

Nach diesem Exkurs in die antike Ideenwelt, schließt sich in dem nun folgenden Werk eine weitere Geschichte aus der griechischen Mythologie an.

\section{IV.3. Werkkomplex: Erinnerungsarbeiten}

Eine Reihe von Werken, die hier unter dem Begriff „Erinnerungsarbeiten“ zusammengefasst werden, entstehen parallel zur künstlerischen Auseinandersetzung mit dem Mutter-Tochter-Thema. Dazu zählt die Videoperformance „Psyche aber, sie irrte gänzlich umher", die erstmals im Jahr 1980 im Rahmen der Kulturwochen in Hamburg aufgeführt wurde. In dieser Performance nimmt die Künstlerin Bezug auf den antiken Mythos über den Göttersohn Amor und die schöne Königstochter Psyche. ${ }^{467}$ Von der Liebe der beiden erzählen die Metamorphosen des römischen Dichters Lucius Apuleius. ${ }^{468}$ Dort ist zu lesen, dass Psyche, die Tochter eines unbekannten Königs, so schön war, dass die Menschen aufhörten, die Göttin der Schönheit und der Liebe zu verehren. Die eifersüchtige Venus rief ihren Sohn Amor zu Hilfe und sandte ihn aus, dafür zu sorgen, dass Psyche sich in jemand Niederes verliebe. Doch statt den Auftrag zu erfüllen, verliebte sich der Göttersohn in das schöne Mädchen. Als Psyche von ihrem Vater einem bösen Dämon geopfert werden sollte, rettete Amor Psyche und ließ diese in sein Schloss entführen. Hier suchte er sie Nacht für Nacht in Gestalt einer Schlange auf und teilte mit ihr das Lager. Doch tagsüber verschwand er, ohne dass sie ihn je zu Gesicht bekam. Als die Schwestern, die die Vermisste schließlich fanden, Psyche be-

467 Die Psyche - der Begriff wird auch als Synonym für die menschliche Seele benutzt - bezeichnet in der modernen Wissenschaft die Instanz des Menschen, die für sein Verhalten verantwortlich ist, worunter sowohl bewusst rationale als auch emotionale Handlungen gefasst werden. 
suchten, gewährte der Gatte deren Besuch, warnte Psyche aber, sie dürfe sich von ihnen nicht verleiten lassen herauszufinden, wer er sei. Die Schwestern waren schnell vom Neid verzehrt. Es gelang ihnen, das naive Mädchen davon zu überzeugen, dass sie eine Schlange geheiratet hätte, welche sie auffressen würde, wenn ihre Schwangerschaft weiter fortgeschritten sei. Aus Angst um sich und ihr ungeborenes Kind, befolgte sie den Rat ihrer Schwestern und wartete in der kommenden Nacht mit einer Lampe und einem Messer auf ihren Gatten. Als sie ihren schlafenden Geliebten aber beleuchtete, erblickte sie kein Ungeheuer, sondern den schönen Körper des geflügelten Amor. Psyche - von Liebe zu ihrem göttlichen Gatten überwältigt - merkte nicht, wie ein Tropfen des heißen Öls auf dessen Schulter fiel. Amor jedoch erwachte, wusste sich erkannt und fühlte sich betrogen. Er flog davon und ließ Psyche untröstlich zurück. Die auf ihren ihre Befehle missachtenden Sohn wütende Venus, machte sich auf die Suche nach der Schwangeren und lud ihr kaum lösbare Aufgaben auf. ${ }^{469}$ Mit wundersamer Hilfe gelang es ihr die Aufgaben erfolgreich zu erfüllen. Doch die unversöhnliche Venus forderte weiter. Diesmal galt es ein Kästchen voll Schönheitssalbe der Proserpina aus dem Hades zu holen. Psyche war bewusst, dass sie damit nun direkt in den Tod geschickt wurde. So stieg sie - ihr Schicksal annehmend - auf einen Turm, um von dessen Spitze herab in den Hades zu springen. Doch der Turm begann plötzlich zu sprechen und gab ihr hilfreiche Anweisungen, wie sie die scheinbar todbringende Aufgabe lebend lösen könne. Diesen Rat befolgend konnte Psyche das Kästchen unbeschadet aus der Unterwelt holen. Doch wieder in der Oberwelt wurde sie von ihrer Neugierde und dem Wunsch überwältigt, die Zaubertinktur auszuprobieren. Allerdings hatte die für Venus bestimmte Salbe bei ihr eine giftige Wirkung, so dass Psyche in einen todesähnlichen Schlaf fiel. Amor, der von seiner Verbrennung genesen war und Psyche weiterhin liebte, eilte zu ihrer Rettung. Er scheuchte mit seinen Flügeln deren Schlaf fort. Während die Schwangere das Kästchen bei Venus ablieferte, flog Amor zu Jupiter und erlangte die Erlaubnis, die Geliebte zu heiraten. Der oberste Gott vermählte die beiden und verlieh Psyche Unsterblichkeit. ${ }^{470}$

„In der römischen Fabel wurde die Union von Liebe (Amor) und Seele (Psyche) als heiteres, wie besinnliches Thema behandelt. Auch im christlichen Sinne lässt sich das Mär-

469 So musste Psyche zunächst bis Tagesanbruch einen Raum voll gemischten Getreides sortieren. Hierbei standen der Unglücklichen jedoch zahlreiche fleißige Ameisen bei, so dass es ihr gelang, die Aufgabe rechtzeitig zu bewältigen. Venus zürnte jedoch weiter und forderte Psyche die nächste Aufgabe ab: ein Knäuel Wolle von einer Herde menschenfressender Schafe. Auch hier stand dem Mädchen, das sich mit dem bevorstehenden Tod bereits arrangiert hatte, sprechendes Schilfgras mit hilfreichem Rat bei, so dass sie die Wolle ohne Schaden zu nehmen bekam. Bei dem dritten, vermeintlich tödlichen Auftrag, einen Krug Wasser aus dem Fluss Styx zu füllen, half ihr der Adler des Jupiter.

470 Psyche gebar eine Tochter, die den Namen Voluptas (Vergnügen) bekam. (Vgl. Neumann 1979, S. 11-60) 
chen auslegen als Läuterung der Seele durch qualvolle Prüfungen, die durch die göttliche Liebe unsterblich und in himmlische Sphären erhoben wird. "471

Das Thema ist seit der Renaissance beliebt und findet sich seitdem häufig malerisch und bildhauerisch umgesetzt. Während kunsthistorische Vorbilder die Liebe von Amor und Psyche ästhetisch ins Bild setzen, oder auch die Aufnahme Psyches unter die Unsterblichen bildnerisch umsetzen, bezieht sich die Videoperformance der Ulrike Rosenbach auf einen anderen Ausschnitt des antiken Mythos. ${ }^{472}$ Während das Märchen im Original ein positives Ende hat, die Liebe nach einschneidenden Komplikationen ein glückliches Ende findet, interpretiert die Künstlerin die antike Geschichte neu. Sie verarbeitet in ihrem Werk eine Textpassage, die sich auf die vierte Aufgabe der Psyche bezieht, dem Punkt der äußersten Verzweiflung und Ausweglosigkeit in dem Mythos. Geflüstert gesprochen ertönte während der Performance aus den Lautsprechern:

„Da merk.t Psyche nun allermeist, dass ibr letətes Schicksal gekommen ist, und erfährt handgreiflich, dass jede Hülle jetzt fallen gelassen ist und sie geradewegs in das Verderben getrieben wird. Wie auch nicht? Da sie gezwungen wurde, freiwillig und auf eigenen Füßen zum Tartarus und den Geistern der Toten zu wandeln. Ohne zu zaudern macht sie sich zu einem sebr hohen Turm auf, um sich von dort köpflings herunter zu stürzen; denn so dachte sie, gerade und aufs Schönste zu den Unteren hinab steigen zu können. Aber der Turm bricht in eine plötzliche Stimme aus, und: „Warum", so sprach er, „du Arme, suchst du dich kopfüber zu vertilgen? Und warum erliegst du schon wieder dieser neuesten Gefahr und Arbeit? Wenn der Geist sich nämlich einmal von deinem Körper getrennt hat, so wirst du zwar tatsächlich zum untersten Tartarus gehen, aber von dort auf keine Weise zurückekehren können. Höre auf mich!‘ ${ }^{473}$

471 Poeschel 2005, S. 284

$472 \mathrm{Zu}$ nennen sind hier zum Beispiel Raffaels (1483-1520) Deckengemälde in der Villa Farnesia (1519) oder das Gemälde von 1622 von Peter Paul Rubens (1577-1640). Auch Guiseppe Maria Crespi (1665-1747) malte das Thema um 1700 sowie Francois Gérard das Paar im Jahr 1798 klassizistisch darstellte, wie auch der italienische Bildhauer Antonio Canova (1757-1822) das Thema in Marmor gestaltete (1810).

473 Übersetzung von Schaeffer in: Neumann 1979, S. 54-55. 

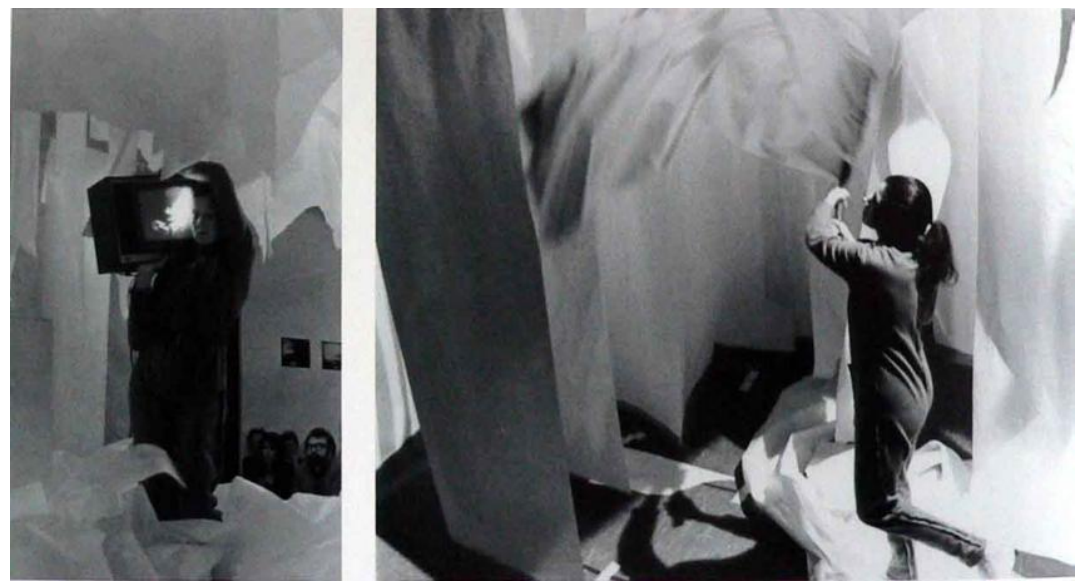

Abb.132-133: Psyche, aber sie irrte gänzlich umber, 1980, Aktionsfotos und Videostill

Eine Warnung, die die Akteurin während der Aktion, deren Aufbau im Folgenden zunächst beschrieben wird, nicht zu hören scheint: Auf einer quadratischen Fläche unter der Decke war für die Aktion ein Gitter aus roten Fäden gespannt. Über diese waren weiße Papierbahnen gelegt, die bis zum Boden reichten. In der Mitte des Karrees stand ein Videomonitor. Das Bild auf diesem zeigte das Gesicht der Künstlerin, als ob diese schwebe. Während ihrer Performance trug die Künstlerin diesmal einen grauen Arbeitsoverall, dessen Innenseite nach außen gekehrt ist. ${ }^{474}$ In der Mitte stehend begann sie zunächst mit einem Knüppel aus Haselnussholz die sie umgebenden Papierbahnen zu zerschlagen. Als dies vollbracht war, nahm sie den Videomonitor auf ihre Schultern und bewegte sich - einer spiralförmigen Bahn folgend - nach außen. Doch verfingen sich ihre Beine mehr und mehr in den abgeschlagenen, am Boden liegenden Papierschichten und dem Monitorkabel, bis die Akteurin schließlich nicht mehr weiter gehen konnte und sich unter der Last des Bildschirms erschöpft zu Boden fallen ließ.

Neben der antiken Fassung hat der Autor C.S. Lewis ${ }^{475}$ den Mythos in seinem Buch „Till We Have Faces“, das im Jahr 1956 erschien, neu erzählt. Geschildert aus der Perspektive einer der eifersüchtigen Schwestern wird in dem literarischen Werk der Kampf zwischen heiliger und profaner Liebe aufgezeigt, und das Buch kreist um die Kernfrage, ob der Mensch im Leben das Göttliche treffen könne. ${ }^{476}$

474 Die Farbe Grau entsteht durch die Mischung von Schwarz und Weiß, formale Elemente, die ja bereits begegneten. Die Kleidung verkehrt herum zu tragen, ist nach alter Tradition zudem ein Schutzgestus.

475 Der Literaturwissenschaftler und Autor Clive Staples Lewis lebte von 1898 bis 1963.

476 „Ah, Psyche,“ I said. „Have I made you so little happy as that?“ „No, no, no,“ she said. „You don't understand... It was when I was the happiest that I longed most... Somewhere else there 
Dabei verkörpert die an ihren Glauben gebundene Psyche die Seite der reinen, himmlischen Liebe. Den Part der irdischen, als besitzergreifende und selbstsüchtig charakterisierten Liebe übernimmt deren Schwester Orual. Der Roman „Till we have faces“ kann als ein Märchen verstanden werden, in dem „Mutter und Frau und Kind und Freund gemeinsame Sache machen, um eine Seele davon abzuhalten mit der göttlichen Natur vereint zu werden“" 477 Ähnlich ist der Tenor in der Perfomance von Ulrike Rosenbach, und Teile dieser sehr freien Interpretation des Mythos von C.S. Lewis scheinen in die Aktion der Künstlerin Eingang gefunden zu haben.

Ulrike Rosenbach hat mit dem von ihr für die Aktion ausgewählten Text eine Passage aus dem antiken Mythos herausgegriffen, in der Psyche zum Äußersten entschlossen ist, dem Tod nahe erscheint. Jedoch geschieht in diesem ausweglos scheinenden Moment ein Wunder: Der Turm beginnt zu sprechen, gibt die Unumkehrbarkeit solchen Handelns zu bedenken und ruft damit die Todesbereite ins Leben zurück. Mit diesem Aufruf endet die in der Performance zitierte Passage. Die lebensbejahende Entscheidung, die Psyche in dem Mythos trifft, wird in der Aktion nicht benannt, vielmehr durch das selbständige Handeln der Künstlerin abgelöst: Sie wandert schwerbeladen mit ihrem Fernsehgerät auf der Spirale nach außen. Ein Lebenssymbol, das schon häufiger im Werk Rosenbachs begegnete. Mit ihrem beschwerten Gang greift die Akteurin verändernd in den Verlauf der antiken Geschichte ein: Der Videomonitor - dessen Videosequenz auch hier wiederum die innere Verfassung spiegeln könnte - im Zentrum des spiralförmigen Aktionsraumes, zeigt das Gesicht der Künstlerin in einer schwebenden Position, Zeichen für den innerlich bereits vollzogenen Sprung in die Tiefe. In der Aktion bürdet sich die Künstlerin diesen Monitor auf und beginnt die schwere Last, um den Mittelpunkt der Bühne kreisend, abzutransportieren, wobei sie sich jedoch mit den Beinen in den Papierbahnen, die sich am Boden aufgehäuft haben, wie auch dem energiespendenden Kabel verfängt, das sich wie eine lange Schlange um den Mittelpunkt windet. Die Hemmung um die Füße und das Gewicht der Last werden so mächtig, dass sie schließlich innerhalb der Spirale erschöpft zu Boden sinkt, und auf diese Weise ganz bildlich in ihrem Handeln scheitert.

Interessant ist das Material des Seidenpapiers, das in dieser Aktion erstmals eingesetzt wird. Zuvor ist Papier in Rosenbachs Werken als Untergrund für die fotografischen Reproduktionen - zum Beispiel bei den Frauen- oder Mutterbildern - benutzt worden. Hier nun bleibt es erstmals weiß. Und die aufgehängten Papierbahnen rauben der Akteurin zunächst die Sicht, im Fortschreiten hindern sie sie an ihrem Gang. Die Künstlerin kämpft in ihrer Aktion ratlos und in gewisser

must be more of it. Everything seemed to be saying, Psyche, come! But I couldn't (not yet) come and I didn't know where I was to come to... I felt like a bird in a cage when the other birds of its kind are flying home." (Lewis 1978, S. 82)

477 Vgl. Lewis 1978, S. 315 
Weise auch orientierungslos mit der ihr aufgebürdeten Aufgabe, bis diese sie schließlich überwältigt. In Folge ihrer vehementen Befreiungsschläge sind es genau die durch diese Tat herunter gefallenen Papierbahnen und die Last des Videomonitors, die die Künstlerin bezwingen und eine konstruktive Lösung in der Performance verhindern. Auf eindrucksvolle Weise findet sich in diesem Werk erneut - wie bereits im „Denkmal“ - das Thema der Ausweglosigkeit und Verzweiflung künstlerisch ins Bild gesetzt. Diesmal wirft die Künstlerin aber aus einer anderen Perspektive einen Blick auf diese Gefühl. Ist sie es doch selbst, die in die Rolle der verzweifelt Kämpfenden schlüpft.

In Ulrike Rosenbachs moderner Interpretation agiert Psyche, personifiziert durch die Künstlerin, allein und hat ihr Innerstes - symbolisiert durch den umgedrehten Overall - nach außen gekehrt. Doch sie verheddert sich auf ihrem Weg hinaus in den am Boden liegenden Papierschichten, von denen sie sich eigentlich befreien wollte und schafft damit eine vielschichtige Metapher des Scheiterns. ${ }^{478}$ Damit greift „Psyche aber, sie irrte gänzlich umher“ den antiken Mythos auf, doch erzählt ihn neu, in individualisierter Form und aus einer spezifisch weiblichen Sicht. Die hier erzählte Geschichte handelt vom Versuch der Eigenständigkeit, von Orientierungslosigkeit und vom Scheitern. Im Kontext des CEuvres der Künstlerin scheint es eine Fortsetzung der Geschichte der „Einsamen Spaziergängerin“ zu sein, der Grenzgängerin auf der Suche nach dem Numinosen, die nun den innerlichen Sprung gewagt hat, sich aber diesmal auf ihrem Spiralweg im Blätterwald verirrt.

In einer vorangegangenen Videoaktion „Keine Madame Pompadour“, die im Jahr 1980 im Centre Pompidou in Paris aufgeführt wurde - arbeitete die Künstlerin nach einer längeren Pause erneut mit dem Closed-Circuit-Verfahren. Sie agierte in einem der Kinoräume des Museums für moderne Kunst, vor dessen metallbelegten Wänden schwarze Vorhänge hingen. Diese vorgefundene räumliche Situation nutzte sie für ihre Videoperformance. Während sich die Künstlerin - einen Schlagring in der rechten Hand und die Kamera in der linken - zwischen Vorhang und Wand durch den Raum bewegte und die Wand Meter für Meter mit dem Schlagring abklopfte, wurde die Videoaufzeichnung des Schlagens auf den Monitor, der im Inneren des Raumes aufgestellt war, übertragen. So konnten die Zuschauer die Handlungen der Künstlerin hinter dem Vorhang nur hören, sichtbar war für sie ausschließlich das durch die Kamera vermittelte, verschwommene Videobild, das die Künstlerin selbst wie folgt beschrieb:

478 Die Videoarbeit „Psyche und Eros“ arbeitet nicht mit Dokumentarmaterial der Aktion. Auch greift sie einen anderen Aspekt aus dem Mythos heraus. In dem Tape steht der Moment des Erkennens des Gattens im Mittelpunkt. 
„Es hat den Anschein als würde ich von innen gegen die graue, gläserne Bildröhre klopfen. Warnend, aggressiv, dann wieder zögernd. Einlass begehrend. " ${ }^{479}$

Schon die Beschreibung des Szenariums wirkt bedrohlich. Unterstützt wird dieser Eindruck noch durch einen erläuternden Katalogtext der Künstlerin, in der sie ihre Wut über sexistisches Denken zum Ausdruck bringt und bereits ein Gespräch als Kampf charakterisiert. Ihre Ausführungen schließen resigniert:

"Sie werden mich ignorieren, denn ich bin sozusagen nicht vorbanden. "480

Vermittelt durch die Darstellung körperlicher Abwesenheit geht es in dieser Aktion um das Thema, sich Gehör zu verschaffen und vollständig wahrgenommen zu werden. Die Künstlerin nutzt in der Aktion das aggressive Schlagen mit dem Ring als nonverbale Ausdrucksform. Ihr Körper bleibt den als voyeurhaft konnotierten Blicken der Zuschauer verborgen. Das mit der Kamera erfasste und auf dem Monitor übermittelte Bild zeigt allein ihre schlagende Faust.

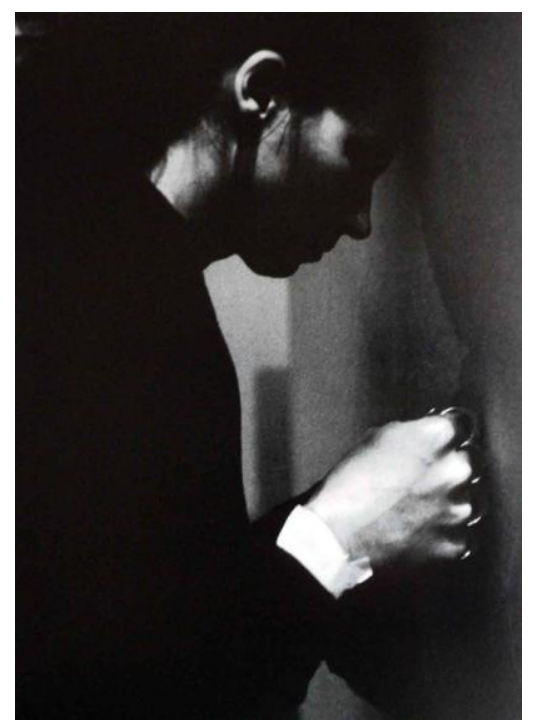

Abb.134: Keine Madame Pompadour, 1980, Aktionsfotografie

Anders als die historische Person der Marquise de Pompadour (1721-1764) - mit bürgerlichem Namen Jeane-Antoinette Poisson - , die sich als Geliebte des französischen Königs am Hof Ludwig XV. ab Mitte des 18. Jahrhunderts Einfluss verschaffte, negiert die Künstlerin in dieser Aktion alles Körperliche, verhüllt ihren Körper vor den Blicken der Zuschauer durch den im Raum vorhandenen

\footnotetext{
479 Rosenbach 1982, S. 137

480 Rosenbach 1982, S. 137
} 
Vorhang, und fordert stattdessen Gehör. ${ }^{481}$ Dabei manifestiert sie ihre innere Wut im Klang des schlagenden Ringes, wie auch im Monitorbild mit der bewegten Faust.

Mit dem Titel ihrer Aktion nimmt sie als Wortspiel sowohl Bezug auf den Namen des Aufführungsortes, das Centre Pompidou, als auch gibt sie mit dem Bezug auf die historische Persönlichkeit der Madame de Pompadour, einen Hinweis auf die Deutbarkeit dieser Videoperformance.

„Judofrauen haben als Hilfe Boten“ lautet der rätselhaft anmutende Titel einer weiteren Performance Ulrike Rosenbachs, die am 10. November 1981 in der Moltkerei Werkstatt in Köln aufgeführt wurde und die wiederum um das Thema der Mann-Frau Beziehung kreist. Die Hände, der bei dieser Aktion ganz in schwarz gekleideten Künstlerin, berühren zunächst einen großen Videomonitor, der in Großaufnahme den Kopf eines Mannes im Profil zeigt. Dann begann die Künstlerin mit geschlossenen Augen langsam zu sprechen:

\section{„Miteinander leben - miteinander sterben. Miteinander schlafen - miteinander wa- chen..."}

Die Hände streichen im Rhythmus der Worte über den Monitor mit dem Männerkopf. Mit geöffneten Augen beginnt sie die Beschwörungsformel von neuem zu sprechen. Die Hände tasten derweil über den Bildschirm, streicheln das elektronische Abbild, versuchen es zu fassen. Der Körper der Akteurin beugt sich über den Monitor, erstarrt, dann sagt sie:

\section{„Miteinander lachen - miteinander weinen. Miteinander spielen ... auseinandergehen."}

Hier richtet die Künstlerin sich auf und wendet sich ab von dem Bild des Mannes. Sie macht große Schritte, die sie laut zählt, auf eine Wand zu. Vor dieser bleibt sie eine Weile regungslos stehen, dann krallen sich ihre Finger in die Papierbahnen und ihr Körper sackt in sich zusammen. Das Papier reißt sie im Fallen ein, wobei sie sagt: „Und du bist weg!“

Die am Boden Liegende rafft sich wieder auf, geht zählend zur gegenüber liegenden Wand, wo sich der Zusammenbruch wiederholte. Diesen Akt vollzieht sie mehrfach, bis ihr Gang leichter wird. „Eine alte Frau kocht Rüben, eine alte Frau kocht Speck“, führt sie nun den kindlichen Abzählreim der mit dem Zählen von eins bis sieben begann, weiter, doch nach den nächsten sieben Schritten heißt es wieder, wie betäubt: „Und du bist weg.““

Inzwischen ist auf dem Monitor das Gesicht der Künstlerin ebenfalls in Großaufnahme erschienen.

481 Ein Porträt von Francois-Hubert Drouais (1727-1775) zeigt die Marquise de Pompadour im Jahr 1763/4 [Öl/Leinwand, 217 x 157 cm, London, National Gallerie (NG 6440)] 


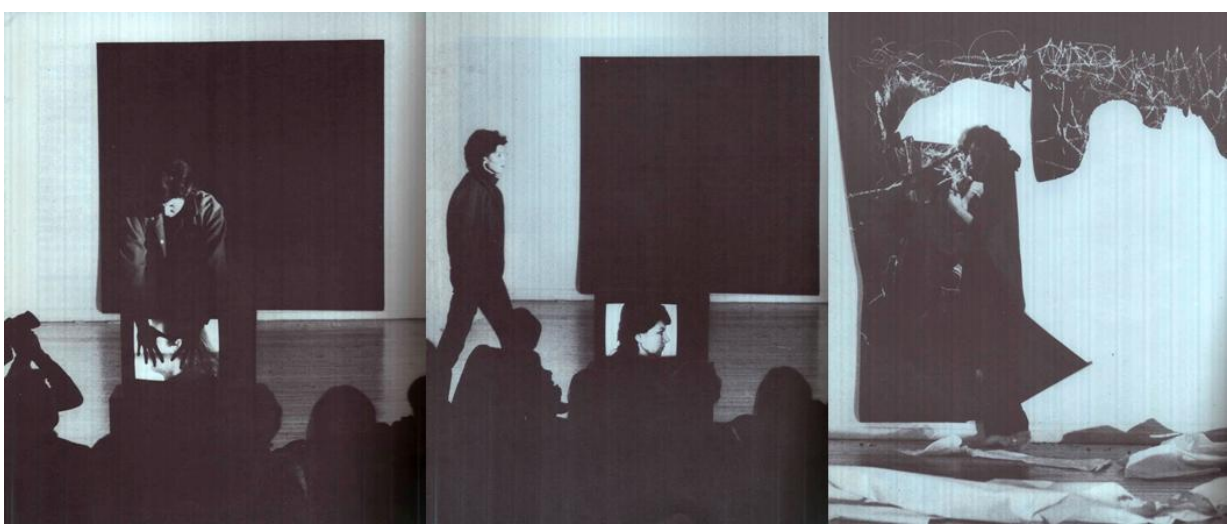

Abb. 135-137: Judofrauen haben als Hilfe Boten, Aktionsfotos

Doch ihr Profil blickt in die genau entgegengesetzte Richtung, bis es langsam verbrennt. Das Motiv des Feuers begegnete ja bereits unter anderem in der ReqiemAktion, dort verbunden mit einer reinigenden Konnotation. Und so gibt es schließlich kein Abbild mehr auf dem Monitor, nur noch die schwarze Farbe des Bildschirmes bleibt sichtbar. ${ }^{482}$ Stattdessen wird ein fremder, eindringlicher Ton hörbar. Es seien Schreie von Inuitfrauen, „rhythmisch gesteigerte Emotion“, wie Amine Haase diese beschreibt.

Die Künstlerin kommt derweil wieder an der Querwand an, die ebenfalls mit schwarzem Papier bespannt ist. Davor stehend zieht sie ihre Stiefel aus und stellt sich barfuß hin. Mit einem Stück weißer Kreide beginnt sie zögernd, auf die Töne hörend, unleserliche Schriftzeichen auf die schwarze Papiertafel zu schreiben. Erst langsam und verkrampft, dann flüssiger beschreibt sie schließlich mit beiden Händen den schwarzen Grund. Ihr ganzer Körper wirkt am Schreiben mit und ihr schwarzer Anzug färbt sich als sie sich an der Wand entlang dreht, allmählich durch die anhaftenden Kreidespuren weiß. Die schwarze Papierbahn reißt schließlich und wickelte sich um die Akteurin, während diese sich weiter und immer schneller dreht. Auch die weißen Papierbahnen geraten in den Strudel des um die eigene Achse kreisenden Körpers, so dass ein schwarz-weißes Bündel entsteht: Die Künstlerin, eingewickelt in die weißen Fetzen und den schwarzen Grund mit der Kreideschrift, steckt nun in den Fesseln aus Papier. Erst durch das Ändern der Drehrichtung kann sie sich schließlich lächelnd aus den sie zuvor umfangenden Bahnen befreien. 483

482 Als Ausdruck der Trauer? Die Farbe entspricht der schwarzen Kleidung der Künstlerin, wie dem schwarzen Papiergrund, der mit weißer Kreide beschrieben wird.

483 Haase in: Rosenbach 1982, S. 183f; Kreide taucht immer wieder als Schreibmaterial in den Arbeiten Rosenbachs auf. Dieses Material, dessen Spuren sich leicht verwischen lassen, wird zum Beispiel auch im Schulunterricht benutzt zur Vermittlung der Inhalte. Interessant ist aber auch eine Assoziation zu der Formulierung ,,in der Kreide stehen“. 
Die Performance mit dem verschlüsselten Titel hat eine klare Aussage: Nach der Trennung vom Partner werden die tiefen Gefühle erinnert, ausgedrückt und die Trauer verarbeitet, um dann in einem willentlichen Akt der Befreiung hinter sich gelassen zu werden. Für diesen Erkenntnisprozess haben, wie der Titel beschreibt „Judofrauen“, also Kämpferinnen, ,als Hilfe“ also zur Unterstützung, „Boten“ also Vermittler, die Botschaften überbringen. ${ }^{484}$

In ihrer charakteristischen bildhaften Darstellungsweise arbeitet die - als Ausdruck der Trauer - in schwarz gekleidete Künstlerin diesmal mit Gegensatzpaaren: Leben - Sterben, Schlafen - Wachen, Liebe - Trennung entsprechen auf der Ebene der farblichen Gestaltung die Polaritäten Schwarz und Weiß. Der im Rahmen der Performance verarbeitete Verlust des Partners lässt die Künstlerin zunächst konkret bildhaft „zu Boden gehen“. Sie steht jedoch wieder auf.

In der Performance verstärkt das Element der mehrmaligen Wiederholung zum einen die Aussage, zum anderen könnte es auf die Beschwerlichkeit hindeuten, eine Lösung zu finden. Die Akteurin bewegt sich eine Weile in einer Handlungsschleife, braucht eine Weile, um zu ihrer Erinnerung zu finden. Mit dem Erinnern ist dann ein Einlassen auf die erlebten Gefühle - Trauer und Schmerz verbunden. Diese tiefe emotionale Ebene wird in der Aktion durch den Einsatz von Klang direkt angesprochen. Während zuvor im Verlauf nur der gesprochene Text und die Aktionsgeräusche zu hören waren, ist an dieser Stelle eine Klangkulisse eingefügt, die das Erleben intensiviert. Die Künstlerin beginnt dabei die schwarze Fläche mit weißer Kreide zu beschreiben und erhellt damit den schwarzen Grund konkret physikalisch - und damit vielleicht auch die psychische Ursache. Dabei wird der ganze Körper in den schriftlichen Ausdruck einbezogen. Als die Künstlerin dann aber wie im Rausch beginnt, sich um sich selbst zu drehen, verfängt sie sich - wie bereits in der Psyche-Aktion - in den Papierbahnen, die hier symbolisch als Schichten der Erinnerungen gelesen werden können. Eine Befreiung aus dieser schließlich die Handlungsfähigkeit hemmenden Fesselung wird erst möglich mit dem einem Richtungswechsel.

Die Aussage der Aktion ist einerseits sehr persönlich durch den Einsatz konkreter Porträts, die einen autobiographischen Bezug erzeugen. Arbeitet die Künstlerin doch in der Aktion mit ihrem eigenen Porträt wie dem ihres langjährigen Lebensgefährten Klaus vom Bruch. Andererseits zeigt sich eine allgemeingültige Übertragbarkeit: Man müsse sich erinnern, aber dann gelte es aufzupassen, nicht unter der Lawine der Erinnerungen begraben zu werden, interpretierte die Kunsthistorikerin Amine Haase als Zeitgenossin die Aussage dieser Videoperformance:

484 Wer diese Boten sind, bleibt an dieser Stelle aber noch offen. Dies wird aus dieser Performance nicht direkt ersichtlich. Dies wird sich erst später im Rückblick erschließen lassen (Vgl. Kap.V.4.) 
„Es bedarf einer großen Willensanstrengung seinem Leben einen neuen Dreh zu geben." 485

Nur das ermögliche aber die Befreiung, und sie fasst zusammen:

„Emanzipation als Handlung, die das Geschehen als Erinnerung nachbuchstabiert, abzählt, emotional rekapitulierend durchsteht und schließlich in Ablösung voran kommt." "486

Diese Aktion schließt dieser Lesart nach an die feministischen Arbeiten Ulrike Rosenbachs aus den 1970er Jahren an. Den formal bekannten Ausdrucksformen, wie der ritualhaften Wiederholung, fügt die Künstlerin hier neue Darstellungselemente hinzu. So kommt auch in dieser Aktion wieder Papier zum Einsatz. Die großen Bahnen hängen diesmal vor den Wänden: Das Papier hängt hier in Schichten, erzählt Geschichten, scheint letztlich für Geschichte zu stehen. Die Aktion der Künstlerin hinterlässt auf zwei Arten Spuren in diesem tastbaren Material: Sie überzieht die Papierbahnen zum einen mit Kreidestrichen, zum anderen zerreißt sie das Papier erst mit ihren Fingern, dann wird es durch ihren Tanz mitgerissen. Beide Ausdruckselemente - Kreideschrift wie Tanz - sind neu, ergänzen die persönliche Chiffre, die das Papier im Werk einnimmt und werden in den folgenden Aktionen wieder begegnen.

Ähnliche formale Elemente wie in den Judofrauen tauchen auch in dem Werkkomplex „Wer hat Angst vor der schwarzen Frau“ auf. Die dazugehörige Performance ist erstmals im Jahr 1982 aufgeführt worden und in einem Videotape dokumentiert worden. Später wurde unter dem Titel zudem die folgende Videoinstallation geschaffen: Auf einem dreieckigen Salzfeld liegen fünf Schalen aus der Aktion „Venusdepression - Medusaimagination“, gefüllt mit der Asche der verbrannten Abbildungen der italienischen Venus-Renaissancegemälde. ${ }^{487}$ Auf den Schalen liegen die ebenfalls aus dieser Aktion bekannten Schilde, mit der Darstellung des Medusenhauptes nach dem Gemälde Caravaggios.

Das schon bekannte Abbild der Medusa steht auch in dieser Installation wieder für das Ungeheure, das Unbändige, Dunkle der Frau, die archaische Frauenfigur. In jeder Ecke des Salzdreieckes ist ein Monitor aufgestellt. Während auf dem mittleren Bildschirm das schon bekannte Tape „Jactatio“488 läuft, ist auf den beiden anderen synchron das Dokumentationstape der Aktion „Wer hat Angst vor der schwarzen Frau“ zu sehen. In diesem Videotape, das die Künstlerin während der gleichnamigen Performance in einem roten Kleid tanzend und auch wieder mit Kreide auf einen schwarzen Papieruntergrund schreibend zeigt, findet sich ein Part, in dem ihr Gesicht langsam hinter einer dunklen, runden Scheibe verschwindet, gleich dem Mond bei einer Mondfinsternis. Auch sind in diese Aktion orange-

485 Haase in: Rosenbach 1982, S. 183

486 Haase in: Rosenbach 1982, S. $183 f$

487 Vgl. Kap. III.5.6.

488 Vgl. Kap. III.5.7. 
farbene Blüten der so genannten Flamingoblume eingebunden. ${ }^{489}$ In diesem Element der Blüte zeigt sich erneut eine motivische Nähe zur Ikonographie aus der amerikanischen Frauenbewegung beziehungsweise noch konkreter einer Vertreterin aus der prefeministischen Phase. Liegen hier doch sofort Assoziationen zu den üppigen Blumenbildern von Georgia O'Keefe (1887-1986) nahe, wie der „Yellow Calla“ aus dem Jahr $1926 .{ }^{490}$

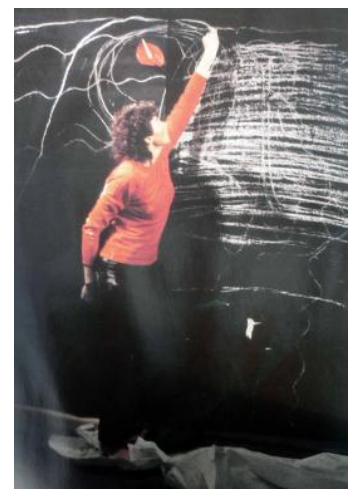

Abb. 138: Wer hat Angst vor der schwarzen Frau, 1982

Auf der Tonebene wird permanent der Titel der Aktion wiederholt, ein formales Mittel der Wortschleife, das schon häufiger genutzt und als „ein echohaftes Pausenzeichen aus dem Äther“491, charakterisiert wurde, das sich hier zudem mit dem bedrohlichen Schwirren aus dem Jactatio-Band mischt.

In dieser Videoinstallation versammelt die Künstlerin eine Ansammlung von Angst besetzten Bildern der Frau. Es geht um die vermeintlich dunkle, schwarze Seite des Weiblichen, die sich in der Hexe, der Zauberin, der Mächtigen, der Selbständigen, der Kreativen, der Künstlerin, die aus sich selbst gebärt, offenbaren kann. Es ist das Angst Machende, das als bedrohlich Empfundene des Weiblichen, das hier zeichenhaft zusammengestellt ist. Diese Verdichtung greift erneut das bekannte Thema aus den 1970er Jahren - die Suche nach der starken Frau - auf. Diesmal mit dem Fokus auf das Dunkle, die gefürchteten Seiten, die die Künstle-

489 „Dieser farbenprächtige Vertreter der Aronstabgewächse stammt aus Mittelamerika. (...) Ihre roten, rosafarbenen oder weißen lilienartigen „Blüten“ bestehen aus einem blattartigen Spartha und einem geringelten Kolben. Die Hybriden von Anthurium andreanum werden größer; ihre Blätter sind herzförmig. Die Sparthe ist leuchtend rot oder orange. Sie wird von einem gelben Kolben gekrönt.“ (Wickham 1978, S.154) Damit verbindet diese Blüte „weibliche“ wie auch „männliche“ Formen.

490 Georgie O'Keefe, Yellow Calla, 1926, Öl auf Hartfaserplatte, $93 / 8$ x 12 3/4 Inch. National Collection of Fine Arts, Smithsonian Institution, Washington D.C.

491 EMMA Nr. 11, 1979, S. $56 \mathrm{f}$ 
rin auf dem bekannten dreieckigen Salzgrund - ebenfalls Symbol für das Weibliche - präsentiert.

Die in diesem Kapitel beschriebenenen Arbeiten der Künstlerin erinnern an Vergangenes - Tradiertes oder individuell Erlebtes - und holen Verschüttetes in die Gegenwart des Bewusstseins zurück. In der „Psyche-Aktion“ geschieht dies in der Bezugnahme auf den antiken Mythos. In der „Madame-PompadourPerformance" bezieht sich die Künstlerin sehr abstrahiert auf eine historische Figur. In den „Judofrauen“ wird konkret wieder mit autobiographischem Material gearbeitet und mit der „schwarzen Frau“ an die klischeehaft dunklen Seiten des Weiblichen erinnert.

Dieses repetierende Erinnern, das in den Judofrauen anschaulich ins Bild gesetzt ist, hat Ähnlichkeit mit dem Prinzip der Psychoanalyse, die sich im Prozess zwischen Analytiker und Analysant auf die Spur nach den verdrängten psychischen Inhalten macht. In ihren Aktionen agiert die Künstlerin allerdings ohne konkretes Gegenüber, auch das Publikum bleibt weitestgehend ausgegrenzt. Die Akteurin bereitet die reflektierenden Aktionen allein vor, führt ihre abstrahiert aufgearbeiteten Inhalte auf, Erlebtes für sich nachempfindend, woran sie das Publikum in der Rolle eines passiven Beobachters teilnehmen lässt.

In der Judofrauen-Aktion finden sich verschiedene Phasen der psychischen Verarbeitung eines Trauerprozesses benannt: Während zu Beginn das konkrete erinnerte Bild auf dem Bildschirm sichtbar ist, wird dieses zunächst durch ein anderes ersetzt, bevor beide ausgelöscht und durch aktives Handeln abgelöst werden. Wenn die Formel „Was ich nicht verstehe, kann ich nicht vergessen“ den Grundmechanismus eines Traumas beschreibt, zeigt diese Aktion den umgekehrten Prozess, das aktive Verarbeiten. ${ }^{492}$ Erst wenn erfahrene Verletzungen verstanden werden, können sie verarbeitet werden und schließlich ihren Platz in der Erinnerung erhalten oder auch gänzlich verblassen. Damit tragen diese künstlerischen Erinnerungsarbeiten erstmals im Werk Rosenbach einen deutlichen therapeutischen Aspekt in sich, beschreiben sie doch nicht mehr nur einen bestehenden $\mathrm{Zu}$ stand, sondern suchen aktiv nach Lösungen für innere Konflikte.

Das Gegenüber und Synchrone von Innen und Außen, das bereits in den Arbeiten aus den 1970er Jahren begegnete, zieht sich auch weiter durch diese Werke und nimmt in dem Videotape „Alle lieben Carmen“ aus dem Jahr 1984 eine neue Ausdrucksform an: Es ist die Verschachtelung zweier Bilder auf dem Monitor mittels eines äußeren Rahmenbildes und eines inneren Rechtecks, ein Trickeffekt, der durch den Einsatz elektronischer Blenden erzeugt werden kann, die Bilder mit jeweils unterschiedlichem Inhalt zusammenfügen.

492 Vgl. Kap. IV.6.1. 


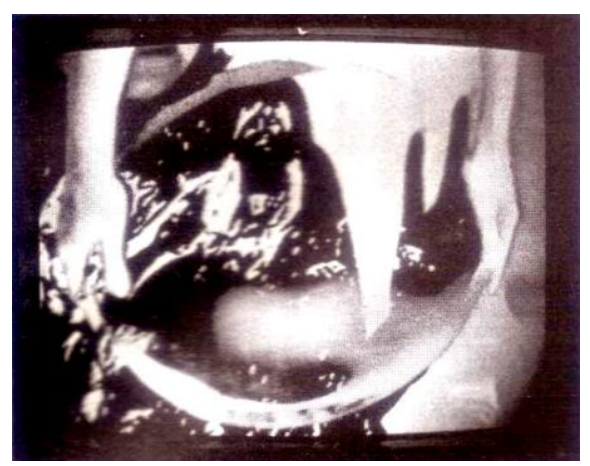

Abb. 139: Das Feenband, 1983, Videostill

Die Reihe der hier unter dem Titel „Erinnerungsarbeiten“ zusammen gefassten Werke soll beschlossen werden mit einem Blick auf ein Videotape, das ohne Bezug zu einer Aktion entstanden ist, jedoch zu diesem Thema einen passenden Abschluss bildet. Das „Feenband“, aus dem Jahr 1983, zeigt auf einer bewegten Wasseroberfläche gespiegelte Aufnahmen aus der Welt der Erinnerungen, wie Landschaften, Fotografien aus dem Familienalbum, dazwischen taucht das Gesicht der Künstlerin auf. Allerdings sind die Aufnahmen nicht deutlich sichtbar, vielmehr sind die Motive durch die Spiegelungen nur verzerrt und verschwommen zu erkennen, bis sich diese „seltsam träumerische Feenwelt“ ganz auflöst zum Klang von Zimbeln und Gongs.

\section{IV.4. Werkkomplex: Östliche Spiritualität}

Mit dem Titel „Lotus-Knospen-Töne“ ist das Farbvideotape aus dem Jahr 1979 benannt, das im Werk von Ulrike Rosenbach die künstlerische Auseinandersetzung mit einem neuen Themenkreis eröffnet: dem der östlichen Spiritualität. Das 17-minütige Farbtape zeigt in einer einzigen festen Einstellung das Gesicht der Künstlerin frontal in Großaufnahme, während diese zunächst zwei Klanghölzer mit ihren Händen senkrecht vor ihrem Gesicht hält, diese wiederholt voneinander löst und gegeneinander schlägt, so dass dabei jeweils ein kurzer heller Klang entsteht.

Das Tape beginnt mit einem weißen Bildschirm, in den zunächst in schwarzen Buchstaben „Ulrike Rosenbach“ eingeblendet wird. Nach einer Weile wechselt der Schriftzug in „LOTUS-KNOSPEN-TÖNE“. Zu diesem bildlichen Vorspann auf weißem Grund hört man insgesamt 13 Mal die Klanghölzer aus dem Off schlagen. Außerdem erscheinen gelbliche Schatten zwischendurch auf dem weißen Grund. Nach knapp zwei Minuten Vorspann gibt es einen harten Schnitt und die Großaufnahme des Gesichtes der Künstlerin erscheint, ihr Blick ist gerade auf den Betrachtenden gerichtet. Als Ton ist zunächst nichts zu hören, dann ertönen aus 
dem Off - wie durch ein geöffnetes Fenster aus der Ferne - leise Straßengeräusche. Nach knapp einer Minute Großaufnahme, in der die Künstlerin völlig unbewegt erscheint, bis auf das gelegentliche Blinzeln der Augen, nimmt sie die beiden Klanghölzer in der Bildmitte einen Spalt auseinander, um sie daraufhin schnell zusammen zuschlagen, wodurch ein leiser Ton entsteht. Nach einer Weile des regungslosen Verharrens wiederholt sie diesen Vorgang. Dies geschieht in der Folge in einem Takt von ungefähr zehn Sekunden. Nach einigen Wiederholungen erhöht sich diese Frequenz, so dass die Hölzer schneller zusammengebracht und auch mit mehr Schwung geschlagen werden. Dadurch entsteht zudem ein stärkerer Klang. Allmählich werden die Klanghölzer von Mal zu Mal vor dem Zusammenschlagen weiter auseinander geführt und gleichzeitig die zeitliche Spanne zwischen den Schlägen verlängert. So liegen nach einer Weile bis zu einer Minute zwischen den einzelnen Schlägen. Die Hölzer werden inzwischen soweit auseinander genommen, dass in der entstandenen Lücke zwischen ihnen, das Gesicht der Künstlerin, das sonst durch die Hölzer zum Teil verdeckt war, zwischendurch ganz zu sehen ist.
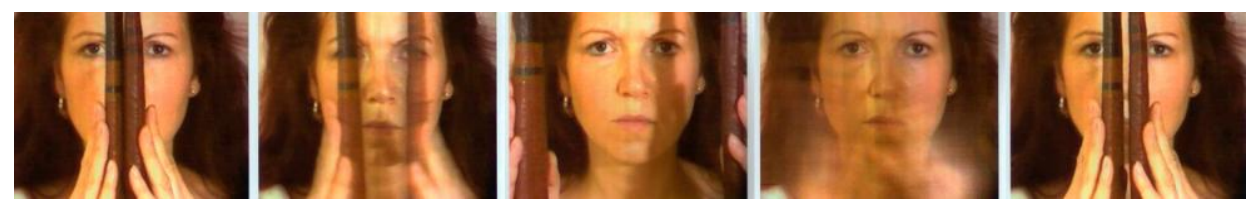

Abb. 140-144: Lotus-Knospen-Töne, 1979, Videostills

Insgesamt schlägt die Künstlerin die Hölzer während der rund siebzehn Minuten, die das Tape dauert, $41 \mathrm{Mal}$ zusammen. Nach dem letzten Schlag verharrt sie noch einen Moment mit den Hölzern in der Ausgangshaltung vor ihrem Gesicht. Dann steht sie, sich zunächst nach vorne beugend, unvermittelt auf und geht aus dem Bild. Der leere weiße Hintergrund bleibt zunächst in der Aufnahme zu sehen, bevor auf dem weißen Grund mit schwarzer Schrift ein fünfzackiger Stern in einem Kreis erscheint. Darunter steht „Alternativ Television“ und etwas tiefer unten rechts die Jahreszahl „1979“. Zu diesem Abspann ertönt noch zweimal der Klang der Hölzer aus dem Off.

In dem Tape ist der Versuch unternommen, die Atmosphäre einer Meditation über das Medium des Videotapes zu vermitteln. Das Anliegen einer Meditation ist es, den Geist zu leeren, um so zu einer Erfahrung des innersten Selbst zu kommen. Es gibt ganz unterschiedliche Formen, wie diese geistig-religiöse Übung im Hinduismus wie Buddhismus aber auch Christentum praktiziert wird. So kann diese Übung in vollkommener körperlicher Ruhe geschehen oder auch in ritualisierte Bewegungsabläufe eingebunden sein.

Das Videotape legt den Schwerpunkt auf die Langsamkeit der abgebildeten Handlung, die im Verlauf mit leichten Veränderungen stetig wiederholt wird. Die 
Kamera fokussiert dabei mit einer Nahaufnahme das Gesicht der Künstlerin und der Blick aus der Monitorröhre bleibt ununterbrochen auf den Betrachtenden vor dem Bildschirm gerichtet. Die stete Wiederholung einer Handlung ist ein charakteristisches formales Element im Werk der Künstlerin. Bei diesem Tape bleibt die Kameraeinstellung unverändert und in der 15-minütigen Sequenz ist kein Schnitt erkennbar, so dass die Aktion in einem Stück aufgenommen zu sein scheint. Dieses Fehlen so genannter harter Schnitte ist charakteristisch für das bisherige videographische Werk der Künstlerin.

Aus heutiger Sicht, die an die die schnelle, verschachtelte Bildästhetik der Videoclips gewohnt ist, erscheint diese Darstellungsweise ungewöhnlich und langweilig. Aber auch schon in der Entstehungszeit wich diese Gestaltungsweise von der konventionellen Bildsprache ab, und die Sehgewohnheiten des Betrachtenden, der in der populären Film- und Fernsehästetik an eine durch Schnitte geprägte Bildsprache gewöhnt war, stießen an Grenzen.

Diese spezielle Darstellungsweise, die in künstlerischen Videotapes der 1970er Jahre bewusst von den Künstlern als Kritik an den manipulierenden und konsumfreundlichen Ausdrucksformen der Massenmedien genutzt wurde, fordert anders als die allägliche Fernsehkost ein Sich-Einlassen auf die Situation, ein Sich-ZeitNehmen und Innehalten. Dann lässt sich der vorgeführten Langsamkeit nachspüren, die damit wahrnehmbar wird.

Das Erklingen des Holzes strukturiert die Aktion auf der akustischen Ebene, gibt ihr einen tragenden Rhythmus. Auf den wichtigen Aspekt des Akustischen weist auch der Titel des Tapes. „Lotusknospentöne“ bedeutet, dass der knospende Lotus - das wichtigste und vieldeutigste Pflanzensymbol des Buddhismus - erklingt. Er ist nicht zu sehen, doch hörbar. In diesem Tape übersetzt Ulrike Rosenbach ein geistig-mentales Erleben in ein sinnlich fassbares. Während zuvor Gefühle in den Werken der Künstlerin ihren audiovisuellen Ausdruck fanden, ist es jetzt ein spirituelles Erleben, das in dem Tape versucht wird, zu vermitteln.

Unterschiedliche Formen von Meditation fließen ab diesem Zeitpunkt auch als Elemente in weitere Aktionen der Künstlerin ein. So tauchen in der Performance und dem gleichnamigen kurzen Tape „Aufwärts zum Mount Everest“ aus dem Jahr 1983 - das zu der gleichnamigen Aktion entstanden ist, auf die im Folgenden eingegangen wird ${ }^{493}$ - im Werk der Künstlerin erstmals Sequenzen auf, die aus der so genannten Kundalini-Meditation ${ }^{494}$ übernommen sind. ${ }^{495}$ Diese Meditationsart

\footnotetext{
493 Vgl. Kap. IV.4.6.

494 Im Namen steckt der Begriff „Kundalini“, der auch aus dem Yoga bekannt ist. Kundalini ist die Lebensenergie, die als eingerollte Schlange am unteren Ende der Wirbelsäule vorgestellt wird und durch yogische Übungen geweckt werden kann, um durch die sechs Chakren zum Scheitelpunkt aufzusteigen. Das Kundalini Yoga legt den Schwerpunkt auf die Erweckung und Lenkung der Kundalini-Energie und ist darauf ausgerichtet, den Körper zu heilen, die Urteilsfähigkeit zu erhöhen und die Intuition zu entwickeln.
} 
ist eine körperlich aktive Form der Meditation, bestehend aus mehreren Phasen: dem aktiven Schütteln des Körpers, dem tanzenden Ausdruck, dem sitzenden Beobachten und dem Liegen in der Stille zum Ausklang, die der Inder Chandra Mohan Rajneesh (1931-1990) - der sich zunächst Bhagwan und später Osho nennen ließ - aus traditionellen Meditationsformen entwickelte. ${ }^{496}$ Die „Lehre“ oder auch „Nichtlehre“ des umstrittenen Gurus scheint elementar für das Verständnis, der in dieser Dekade entstandenen Werke der Künstlerin zu sein, so dass im folgenden Abschnitt Grundanschauungen Bhagwans, sowie Bezüge zum Werk dargelegt werden. Im „Lexikon der Sekten, Sondergruppen und Weltanschauungen“ heißt es:
„Osho gilt als einer der kreativsten Synkretisten unserer Zeit, der sich nie zu einem be- stimmten Glauben bekannte. Der indische Tantrismus steht ibm wabrscheinlich näher als jede andere religiöse Tradition. Er verbindet alle ibm bekannten religiösen und philo- sophischen Traditionen und verweist mit den Worten fast aller mystischer Meister der Vergangenheit auf eigenes Erleben. Jesus wird zum Osho des frühen Christentums und Buddha zum Rajneesh der frühen Buddhisten. Der Lebemensch und der Asket, Zorba und Buddha, verbinden sich in einer Gestalt. ${ }^{497}$

Bhagwan provozierte mit seinen Anschauungen und griff zudem die gängigen Moralvorstellungen an. Er lehrte einen spirituellen Weg, der Elemente aus dem Hinduismus, dem Jainismus, dem Sufismus, dem Zen-Buddhismus, dem Taoismus, dem Christentum, der alten griechischen Philosophie und humanistischer Psychologie mit neuen Formen von Therapie und Meditation verband. Allerdings sah der Denker seine Anschauung nicht als Religion, auch nicht als Lehre, sondern seine Botschaft galt der Destruktion jeglicher Glaubenssysteme. Auf diesem Weg wollte Bhagwan den Menschen - nach eigener Aussage - letztlich zu absoluter Freiheit führen. ${ }^{498}$

Mit seinem Charisma und seiner synkretistischen, umfassenden Nicht-Lehre, zog der umstrittene Guru, der zunächst Philosophie studiert und gelehrt hatte, ab Mitte der 1970er Jahre zahllose spirituell Suchende, vornehmlich aus den westlichen Industrieländern, in seinen Ashram in der südindischen Stadt Poona, heute

495 Der Werkkomplex, bestehend aus Tape, Performance und Videoskulptur, kreist inhaltlich - wie der Titel schon verweist - auf die Besteigung des Mount Everest, dem so genannten „Dach der Welt“. Marlis Grüterich bezeichnet die Performance, bei der das Environment im Laufe der Aktion völlig verändert/zerstört wird, als „,sinnlose Wanderung“. Auch das Tape lässt den Ausgang der symbolischen Besteigung des höchsten Bergs der Welt, dessen Name „Gourichankar“ der ewig Seiende bedeutet, noch offen. (Vgl. Kat. Saarbrücken 1990, o.S.)

496 Während sich die Künstlerin in den 80er Jahren offen zu ihrer Bhagwansympathie bekannt hatte, was ihr Angriffe und Ausgrenzungen in der Kunstszene einbrachte, wird dieser Bezug in jüngeren Publikationen über ihr Werk, an denen sie beteiligt war, nicht hergestellt.

497 Gasper 1990, S. 841-844

498 Karow 1990, S. 1 
Pune. 1980 wurde die Zahl der Sannyassins, wie sich die Anhänger bis heute nennen, weltweit auf eine Million geschätzt. ${ }^{499}$ Bhagwan flüchtete 1981 vor Gegnern und der indischen Steuerbehörde in die USA nach Oregon, wo seine Anhänger die Big Muddy Ranch kauften, um dort die größte spirituelle Kommune der Welt zu errichten. Dieses Projekt scheiterte allerdings und nach seiner Ausweisung aus den USA im Jahr 1986 kehrte Osho, wie er von da an genannt wurde, nach Poona zurück, wo die Einrichtung seit seinem Tod im Kollektiv weitergeführt wird.

„Die dortige Osho Commune International gilt als das meist frequentierte Therapiezentrum der Welt, in das jährlich zehntausende von Menschen, vor allem aus Westeuropa, den USA und Japan strömen. Die faschistoiden Verhältnisse, die die Kommune in den 80ern kennzeichneten - während ihres Aufenthaltes in Oregon/USA war sie zu einer totalitär strukturierten kriminellen Vereinigung (einschließlich bewaffneter „PeaceForce"-Truppen) mutiert - haben dem massenhaften Zulauf nach ibrer Rückkehr nach Poona keinerlei Abbruch getan. "500

Heute sei der Post-Bhagwan-Ashram ein gepflegtes Luxusressort mit Clubcharakter, und Colin Goldner schreibt weiter: „Die aufgeheizte Atmosphäre von einst ist teuer bezahlter Selbstbetrachtung gewichen. "501 Seine Eindrücke beim Besuch der Gemeinschaft im Jahr 2001 schildert er so:

„Hier drinnen ist man in einer anderen Welt, einer komplett künstlichen. Indien ist woanders. Ein breit angelegter Weg führt vom strengbewachten Haupteingang ins Innere. Die ehemalige britische Kolonialvilla, die immer schon zentrale Verwaltung der Rajneesh-Kommune war, dient auch heute noch als solche. Nur dass sie inzwischen pechschwarz angestrichen ist, von oben bis unten. Auch die anderen Gebäude sind schwary, alles ist schwary, Bänke, Stühle... „Osho hat es so gewünscht“. Ein paar Schritte weiter der abgetrennte und eigens bewachte Eingang zu des Meisters Wohnhaus, heute Aufbewabrungsort seiner Asche. Mehrfach am Tag finden hier schweigende Sitzmeditationen statt. Ansonsten ist der Bereich nicht zugänglich. Daneben ein überdachter Freiplatz mit Infotafeln über das aktuelle Kursangebot des Ashram - „Multiversity“. Das übliche

499 Zu dieser Zeit hatte die Bewegung ihren Höhepunkt. Wenn Ende der 80er Jahre in Westdeutschland noch 41000 Anhänger der „Rajneesh Foundation/Osho“, wie die Gruppierung inzwischen genannt wird, gezählt wurden (nach Clarke 1987, S. 10-14) war die Anhängerschaft in Deutschland nach offiziellen Daten bis Ende der 1990er Jahre (1997) auf 5000 gesunken. (Religionswissenschaftlicher Medien- und Informationsdienst (REMID) Marburg; Webseite: „Informationen und Standpunkte“ (gesehen 2. Aug. 1999). Tafel: „Religious communities in Germany: Numbers of members" [Daten veröffentlicht im Juli 1999]; aufgelistet als „OshoBewegung“, Quelle: REMID.

500 Goldner 2000, S. 47

501 Goldner in: die tageszeitung Nr. 6627 vom 15.12.2001, S. 20 
Sammelsurium der Psychoszene: Atem-, Körper-, Primärtherapie, dazu Reiki, Tantra, oder auch ,schamanistische Energiearbeit". "502

Zur Unterstützung der persönlichen Entwicklung auf dem Weg zu einem neuen Bewusstsein, einem befreiten Leben, warten die unterschiedlichsten Angebote auf den Sannyassin: von der Gruppentherapie, über Yoga ${ }^{503}$ und Körperarbeit bis zu eigens von Osho entwickelten unterschiedlichen Meditationsformen. ${ }^{504}$

\section{IV.4.1. Grundzüge der Lehre Oshos}

In den - in ihren Inhalten zum Teil widersprüchlichen - Aussagen Oshos gibt es keine Trennung zwischen Objekt und Subjekt. Der Mensch ist hier Teil eines großen Ganzen und bildet letztlich eine Einheit mit allem, was mit einer Auflösung im Nichts gleichzusetzen ist. Bedingung eines solchen Lebens in Einheit mit dem Ganzen ist das Zerstören des Egos. Ganzheit ist somit gleichzeitig als „Nichts-

502 Goldner in: die tageszeitung Nr. 6627 vom 15.12.2001, S. 20; diese Vielfalt an Therapieangeboten wird auch in den zahlreichen Osho-Zentren angeboten, die in der westlichen Welt aufgebaut worden sind. In Deutschland wurde in Köln Ende der 1980er Jahre eine große Zentrale eingerichtet.

503 In den klassischen indischen Schriften werden vier Yogawege beschrieben: Raja Yoga nennen sich die meditativ orientierten Stufen des Achtgliedrigen Yoga nach Patanjali (auch Ashtanga Yoga genannt: ,Asta ${ }^{6}=$ acht,, Anga ${ }^{\circ}=$ Teile), Jnana Yoga (Yoga der Erkenntnis, intellektuelle Richtung), Karma Yoga (Yoga der Tat, des selbstlosen Handelns) sowie Bhakti Yoga (Yoga der Verehrung/Hingabe). Ursprünglich war Yoga vermutlich ein rein spiritueller Weg, und es ging vor allem um Erleuchtung durch Meditation. Die vielen Asanas entstanden erst im Laufe der Zeit, und ihr vorrangiges Ziel war zunächst, den Körper so zu kräftigen und zu mobilisieren, dass er möglichst beschwerdefrei über einen längeren Zeitraum im Meditationssitz - also in der Regel im vollen Lotossitz - verweilen konnte. Mit der Zeit wurde die positive Wirkung der körperlichen Übungen auf das gesamte Wohlbefinden des Menschen erkannt. Die Asanas wurden weiter entwickelt, und die körperliche Betätigung im Yoga bekam einen immer höheren Stellenwert. Einen ersten Niederschlag findet diese Entwicklung in der Entstehung des Hatha Yoga. In der „Hatha Yoga Pradipika“, einem Text aus dem 15. Jahrhundert, werden die Grundlagen dieser körperbetonenden Yoga-Schule dargelegt. Raja Yoga ist eine auf dem Hatha Yoga fußende Yogalehre, in der spirituelle Ziele betont werden.

504 Dazu zu zählen ist auch der Bezug auf den Tantrismus, der seit dem 7. Jahrhundert nach Christus in Indien fest verwurzelt ist und der dort vom 9. bis 14. Jahrhundert eine Blütezeit erlebte. Eliade definiert: „Auch wenn es einen Vishnu-Tantrismus gibt, so sind Shiva und seine Shakti (die weibliche Energie) oder einfach eine Shakti die Hauptgötter des Tantrismus. Die verschiedenen Lehren der heiligen tantrischen Schriften, die sogenannten agamas, tantras oder samhitas sind nicht ursprünglich. Sie entlehnen viele Elemente dem Sankhya Yoga. Die tantrischen Bräuche sind in hohem Maße verfeinert worden und fußen auf einer subtilen Physiologie, die mehr oder weniger eng der des Yoga angeglichen ist, sich jedoch stets einer „doppelsinnigen Sprache“ mit sexuellen Anspielungen bedient. Die Betonung liegt dabei vor allem auf der Meditation anhand von mantras, die dem Schüler bei seiner Initiation (diksha) übermittelt werden, auf Körperhaltungen (mudras) und auf symbolischen Bildern (mandatas, unter denen der yantra eines der einfachsten und verbreitetsten ist), auf vielfältigen Zeremonien (pujas) und schließlich auf sexuellen Techniken, die übrigens nicht immer die rituelle Paarung und auch nicht die Samenverhaltung voraussetzen." (Eliade/Culianu 1995, S. 300f) 
heit" gedacht. Dieses Aufgehen im Ganzen, einem egolosen Leben im Einklang, wird als Erleuchtung verstanden, die eintrete durch die Enthüllung des wirklichen Wesens des Menschen. ${ }^{505}$

Auf dem Weg zum Erlebnis dieser völligen Freiheit, bildet die Selbstakzeptanz eine grundsätzliche Voraussetzung: „Nimm dich an, so wie du bist und zwar vollkommen - bedingungslos“, zeichnet die Lehre den Weg. Ein Leben im Einklang mit dem Ganzen ist im Sinne Oshos aber auch eine Loslösung von allem Begrenzten - wozu auch Beziehungen zählen. Es ist ein absichts- und bindungsloses Leben, in dem es keine Zielvorstellungen und Pläne zu verfolgen gibt. Es ist geprägt von einem inneren Sich-Abwenden von der äußeren, als Scheinwelt aufgefassten Mayawelt, um in der unmittelbaren Erfahrung zu leben und „ganz und heil“" zu werden. Statt der ständigen Anspannung zwischen Misserfolg und Erfolg ausgesetzt zu sein, die zu immer neuen Leistungen drängt, findet der Sanyasin in einer gleichgültigen Gelassenheit, die auf der Auflösung seines Ichs beruht, einen Frieden, der ihn von allen Anforderungen befreit. ${ }^{506}$ Bhagwan schrieb:

„Getrennt sein, als ein Ego, ist die Basis allen Unglücks. Einszusein, dabinzufließen mit allem, was das Leben uns bringt, so völlig darin versunken zu sein, daß man nicht mehr ist, daß man sich völlig vergißt, ist Seligkeit. "507

Die Egolosigkeit gibt dem Sanyasin die Möglichkeit neu zu beginnen und die Ketten, an die als leidvoll empfundene Vergangenheit zu durchschneiden. So ist ein wichtiger Schritt für den Sanyasin das Ritual des „Sanyas Nehmen“. Damit ist verbunden, alles, woran man bis dahin noch festhielt, fallenzulassen. Mit diesem symbolischen Akt bekommt auch jeder Initiand einen neuen Namen. Durch den damit symbolisierten inneren Ausstieg aus der äußeren Welt erfährt der Sanyasin Entlastung von allen Problemen. Bhagwan erklärte:

„Man muss nur seine Sichtweise ändern und das ganze Leben wird zu einem sagenhaften Schauspiel. 508

Veränderung im Leben hängt dieser Aussage nach also nicht von einem aktiven Handeln in der Welt ab, sondern geschieht allein durch die Modifizierung der inneren Einstellung. Der neue Mensch - „rein, ursprünglich, unschuldig“ - werde geboren, wenn er alles Vergangene abgelegt habe und ein Leben im radikalen Hier und Jetzt führe. In dieser inneren Veränderung des Menschen, die auch als „Revolution des Herzens" charakterisiert wird, liegt demnach auch die Rettung der Welt

\footnotetext{
505 Karow 1990, S. $17 \mathrm{f}$

506 Karow 1990, S. $19 \mathrm{f}$

507 Karow 1990, S. 9

508 Karow 1990, S. 16
} 
begründet. ${ }^{509}$ Somit ist der Mensch auch von seinem Anspruch, seine Umwelt in Ordnung zu bringen, befreit:

„Ihr müßt [die Dinge] nicht in Ordnung bringen; ibr bringt euch nur selbst in Ordnung

(...) Wenn sich die innere Harmonie eingestellt hat, gibt es keine Dissonanz in der ganzen Welt." 510

Das Bewusstsein, das zur inneren Harmonie und Erleuchtung führe, könne der Einzelne nur durch völlige Entspannung und Offenheit erlangen, da jegliche Anstrengung etwas erreichen zu wollen, Spannung und Differenz erzeuge, die der Einheit entgegenstehe. So sollen die Erfahrungen in den therapeutischen Gruppen wie auch die unterschiedlichen Meditationen die blockierten Energien lockern, aufgestaute Aggressionen und Sexualität freisetzen und dadurch Selbsterfahrung und Bewusstheit ermöglichen.

Bei der von Bhagwan entwickelten „dynamischen Meditation“ wird zum Beispiel der Körper zunächst durch chaotisches Atmen und Bewegung erschöpft, bevor dann der Blick nach innen gerichtet wird, um sich und seine Gedanken zu betrachten, zum Zeugen des eigenen Inneren zu werden und Ruhe zu finden. Dieses „Zeuge sein“, das auch als „,bewusstes Beobachten“ bezeichnet wird, bildet nach Osho einen Schlüssel zur eigenen Befreiung:

„Du kannst dich von all dem Wahnsinn befreien, den die Vergangenheit in dir angerichtet hat. Du musst nur zum Zeugen deiner Gedankenprozesse werden. Beobachte nur die Gedanken, störe sie nicht und vor allem bewerte sie nicht." "511

So beschrieb Bhagwan die Methode in einem Fernsehinterview. Diesen Spalt zwischen dem Zeuge-Sein und dem Geist gelte es stetig zu vertiefen, bis man nur noch Beobachter sei, nicht mehr Geist, beschrieb Osho das Ziel dieses Weges. In diesem meditativen Beobachten sah er die wahre Alchemie, in seinen Worten die „echte“ Religion.

\section{IV.4.2. Einflüsse auf das künstlerische Werk Ulrike Rosenbachs}

Teile dieser spirituellen Ideenwelt haben in das künstlerische Werk Ulrike Rosenbachs Eingang gefunden, wie sich in der Betrachtung der folgenden Werke deutlich zeigen wird. Schon die „Lotus-Knospen-Töne“ lassen sich vor diesem Hintergrund als eine audiovisuelle Übersetzung der Meditationserfahrung und des Zeuge-Seins lesen. Nimmt man die bildliche Umsetzung buchstäblich, dann wird in dem Tape der Spalt, durch den das Gesicht der Künstlerin zwischen den beiden

5091979 erschien das Buch „Intelligenz des Herzens“ von Bhagwan Shree Rajneesh.

510 Karow 1990, S. $15 f$

511 Osho in: „Osho, genannt Bhagwan“, ein Film von Marieke Schroeder, der am 20.10.2003 um 21.45 Uhr in der ARD gezeigt wurde. 
Hölzern sichtbar wird, entsprechend dem Spalt zwischen dem oben beschriebenen Zeuge-Sein und dem Geist, den es stetig zu erweitern gilt, visualisiert. ${ }^{512}$

Deutliche Bezüge zu Bhagwans spiritueller Ideenwelt finden sich zudem in der Performance mit dem dramatisch anmutenden Titel „Eleven - es wurde eine Frage auf Leben und Tod"“ aus dem Jahr 1985. Die Werkgenese, die im Katalog von der Künstlerin beschrieben wird, zeigt den Entstehungsprozess der Arbeit auf. Es ist dort zu erfahren, dass sich das Museum Ludwig in Köln eine Aktion, die etwas mit der Stadt oder der Sammlung des Museums zu tun haben sollte, gewünscht hatte. Zunächst habe sie für diese Auftragsarbeit daran gedacht, die Geschichte der Heiligen Ursula und deren elf mal elf Brautjungfern, die bei der Belagerung Kölns durch die Hunnen ums Leben kamen, zu bearbeiten, erläutert Ulrike Rosenbach. ${ }^{513}$ Die christliche Legende wird in unterschiedlichen Versionen erzählt. ${ }^{514}$

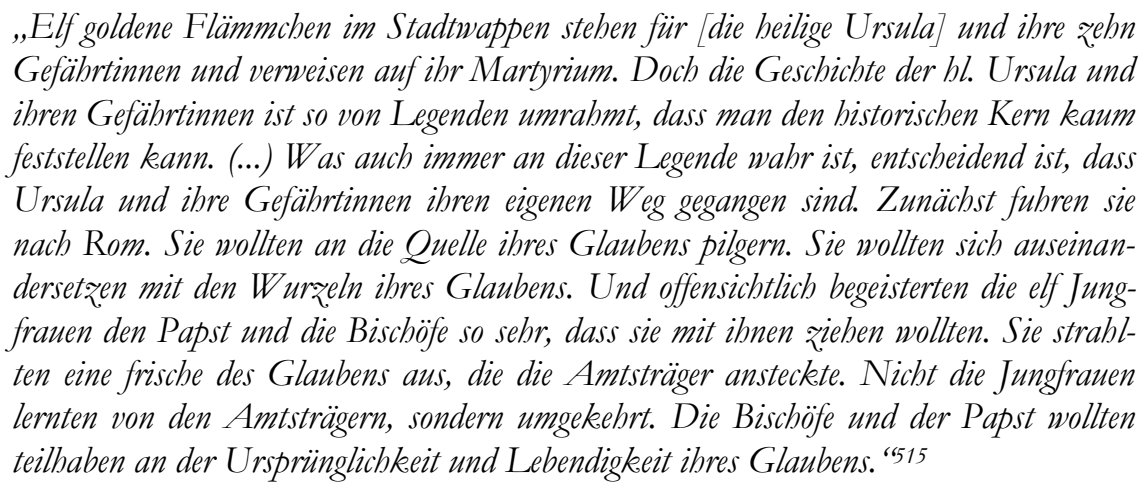

Auf diese Weise interpretiert der Benediktinerabt Anselm Grün die Legende über eine eigenwillige Frau, die den Quellen nach wohl im Jahr 452 von den Hunnen getötet wurde. Doch im Verlauf der Recherche habe sie sich immer weiter von der regionalen Historie entfernt, hin zur Beschäftigung mit der Bedeutung der für die Legende bedeutsamen Zahl Elf, erläutert Ulrike Rosenbach. Auf dieser Symbolebene erschlossen sich der Künstlerin, die Zahlen Eins und Zehn als Zahlen des Anfangs und des Endes. Die Elf ist demnach die Zahl von Tod und Wiedergeburt. In der chinesischen Religion entspricht diese Zahl dem Tao, ein Begriff der sich mit Weg, Urgrund, Logos, Naturgesetz, Sinn oder auch höchstem Wesen übersetzen lässt. 516

\footnotetext{
512 Zudem wird das Motiv des Herzens in späteren Arbeiten immer wieder begegnen.

513 Vgl. Kat. Saarbrücken 1990, o.S.

514 Besonders über die Anzahl der sie begleitenden Gefährtinnen herrschen unterschiedliche Auffassungen.

515 Grün 2002, S. $168 \mathrm{f}$

516 Dammann 1988, S. 60
} 
Diese Mischung aus dem Kerngedanken der christlichen Legende und symbolischer Umdeutung bildet den Hintergrund der Performance, für die sich die Künstlerin die Treppe im Foyer des Museums als Aufführungsort auswählte. Die 111 Stufen wurden symbolisch abstrahiert für die elf mal elf Jungfrauen, die die Heilige in der Legende begleiteten. ${ }^{517}$

Dabei bieten kunsthistorische Vorbilder einen Bezug zum Treppenmotiv in der Heiligenlegende. So befindet sich im Kölner Wallraf-Richartz Museum der 19teilige Zyklus der in Köln verehrten Heiligen vom Meister der Ursula Legende, der zwischen 1485 und 1510 in Köln tätig war. ${ }^{518}$ Innerhalb dieses Zyklus zeigt die mittelalterliche Tafel, in dem die Heilige Ursula am Hof ihres Vaters die Pilgerfahrt ankündigt, eine ganze Reihe von Stufen. ${ }^{519}$ Zudem befindet sich in der Nationalgalerie in London ein Gemälde des französischen Malers Claude Lorrain (1600-1682) mit dem Motiv der Einschiffung der Heiligen, eine Komposition, die ebenfalls eine lange Treppe zeigt. ${ }^{520}$

Für ihre Performance hatte die Künstlerin auf 111 großformatigen weißen Seidenpapierbögen zuvor mit breitem Pinselstrich das Taozeichen gemalt - einen fast geschlossenen Kreis in Blau. Diese Bögen hatte sie aufeinander gelegt und schritt in der Performance den Stapel auf dem Kopf balancierend zunächst die Treppe hinunter. Beim anschließenden Hinaufsteigen zog die Künstlerin auf jeder Stufe eines der Blätter von dem Stapel auf ihrem Kopf und ließ dieses zu Boden gleiten. Auf diese Weise verteilte sie die Schichten, die auf ihrem Kopf lagerten, Bogen für Bogen auf der Treppe, bis sie schließlich ohne Last und mit freiem Blick wieder die oberste Stufe, den Ausgangspunkt der Performance, erreichte.
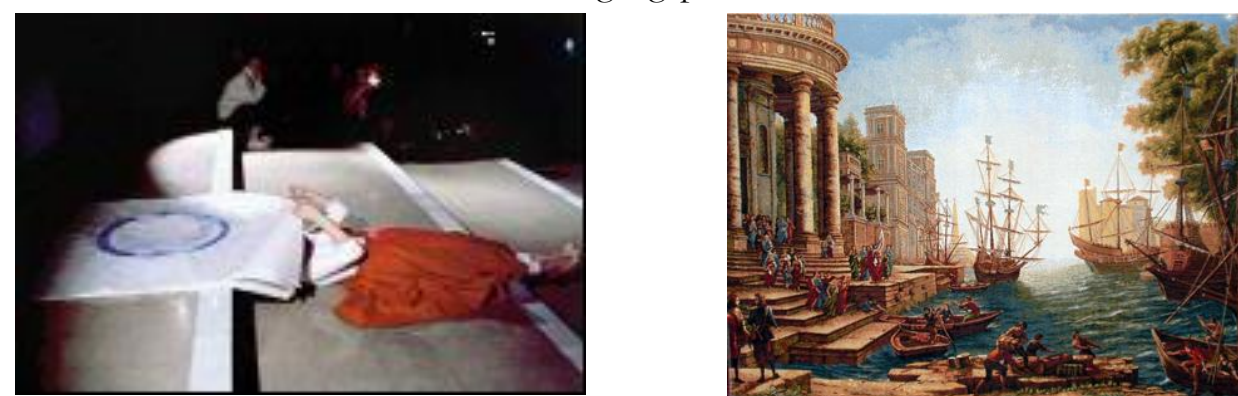

Abb. 145-146: Eleven - es wurde eine Frage auf Leben und Tod, 1985, Aktionsfotos und und Claude Lorrain: Einschiffung der Hl. Ursula, 1641

517 Hier findet sich ein Rechenfehler: $11 \mathrm{x} 11=121$ und nicht 111. Doch ist das Ergebnis aus $11 \mathrm{x}$ 11 gemeint, wie der Katalogtext belegt. (Vgl. Kat. Saarbrücken 1990, o. S.)

518 Meister der Ursula Legende, Legende der Heiligen Ursula, Erscheinung des Engels, Öl auf Leinwand $123 \times 114 \mathrm{~cm}$, WRM 197

519 Zudem findet sich auf einer anderen Tafel, die die Erscheinung des Engels ins Bild setzt, einen Engel, der der Figur in der Villa dei Misteri ähnelt.

520 Claude Lorrain, Einschiffung der Hl. Ursula, 1641, Öl auf Leinwand, $113 \times 149 \mathrm{~cm}$ National Gallery, London 
$\mathrm{Zu}$ sehen ist in der Performance, wie ein Mensch beim Fortschreiten, genauer Emporsteigen, unter den ihn umgebenden Schichten freigelegt wird. Damit hat die Künstlerin eine Parabel auf die Selbstfindung geschaffen, in der Elemente aus östlicher Philosophie und westlicher Mystik vermischt werden.

Jedes der Blätter trägt das Zeichen des Tao, Symbol des Naturgesetzes. Und Stufe für Stufe der Treppe wird mit dem Beschreiten zum Teil des Weges. Umgekehrt wird mit jeder beschrittenen Stufe eine weitere Schicht der Kopflast freigelegt. Bis, oben angekommen, der Kopf - wie der gesamte Körper - freigelegt und die Last vollständig abgelegt ist. Damit findet sich hier in variierter Form ein Element wieder, dass zuvor mit dem Einschnüren und Herauswinden aus den Videokabeln mehrfach begegnete: Anstelle der Schnüre sind es nun Papierschichten, die die Künstlerin zunächst einhüllen und von deren Last sie sich Bogen um Bogen befreit.

Als steter Ton und rhythmusgebendes Element erklang zu der Aktion aus einem Lautsprecher die endlose Wortschleife „Eleven“, ein Element, das uns bereits mehrfach begegnete, und zu dem die Künstlerin wortspielerisch assoziiert:

\section{„Wie eine Mantra können die Zuschauer im Wort eigene Variationen erkennen: Elf, Schüler, Eleven, I love him, - beloved... "521}

„Eleven“ steht im Englischen für die Zahl „elf“. Bei den weiteren Assoziationen, die die Künstlerin im erklärenden Text benennt, ist allerdings fraglich, ob diese das Publikum auch in diesen Variationen wahrgenommen hat.

Doch wenn der bereits erwähnte Theologe Anselm Grün als tiefenpsychologisches Fazit über die Legende der heiligen Ursula zieht: „Werde du selbst, und geh deinen Weg" dann ist es genau dieser Weg, den die Künstlerin mit dieser Aktion in ihrer prägnant symbolisch-abstrahierten Ausdrucksweise ins Bild gesetzt hat.

Der Bezug zur Lehre Oshos, der in den vorgegebenen Interpretation des Wortes „Eleven“ im Zitat der Künstlerin anklingt, tritt in dem im Anschluss an die Performance entstandenen Videotape deutlich zu Tage. Allerdings - ähnlich wie in dem Tape zur Psyche-Aktion, bildet dieses Band mit dem Titel „Eleven - verstehen ist wie Hitze“ nicht den Verlauf der Performance ab, vielmehr ist hier allein der Sound aus der Performance übernommen. Die Bildebene zeigt Vulkaneruptionen und fließendes Wasser, überblendet mit elektronisch verfremdeten Handund Kopfbewegungen. Der gewählte Titel für das Videotape zitiert einen Vers aus einer Textsammlung von Bhagwan und lautet: ${ }^{522}$

521 Rosenbach in: Kat. Saarbrücken 1990

522 Der Text ist aus „Mein Weg: Der Weg der weißen Wolke“. (Bhagwan 1988, S. 184f) Dort heißt es im Zusammenhang:

„Unbewußte Kräfte wirken in euch, ohne euer Wissen.

Sie müssen bewußt gemacht werden. 
„Versteben ist wie Hitze/erbitzen. Wenn die Hitze einen bestimmten Punkt erreicht hat, verschwindet das Wasser. "523

Der gesamte spirituelle Text arbeitet mit sehr plastischen Bildern und fasst die wesentlichen Inhalte der Lehre Oshos zusammen: Den Weg zum Auflösen des Ego. Und das Videotape nimmt das in dem vorangegangenen Textausschnitt enthaltene Zitat konkret zum Ausgangspunkt und im Katalog heißt es zu dem Tape:

„Das Prinzip „Eleven“ wird jetzt angewandt auf die Erneuerung der Natur, auf den Kreislauf von Wachsen und Vergehen. "524

Ihr müßt alle Wurzeln des Egos aus der Erde heben, so daß ihr es sehen könnt.

Wenn ihr unbeschäftigt ausharren könnt, wenn ihr zufrieden bleibt, auch wenn ihr nicht gebraucht werdet, kann das Ego sofort in diesem Moment verschwinden.

Aber das ist ein großes Wenn.

Meditation macht euch reif für das große Wenn.

Das eigentliche Geschehnis

passiert in einem einzigen Moment,

aber das Verständnis braucht Zeit.

Es ist, wie wenn man Wasser zum Kochen bringt.

Es wird heißer und heißer und heißer

und dann bei hundert Grad verdampft es.

Das Verdampfen geschieht in einem einzigen Moment.

Es geht nicht schrittweise vor sich, es geschieht plötzlich.

Vom Wasser zum Dampf ist es ein Sprung.

Auf einmal verschwindet das Wasser.

Aber die Zeit spielt eine Rolle,

weil das Wasser erst zum Kochen gebracht werden muß.

Die Verdampfung geschieht plötzlich,

nur das Erhitzen braucht Zeit.

Verstehen ist wie erhitzen.

Es braucht seine Zeit.

Das Verschwinden des Egos ist wie verdampfen.

Es geschieht plötzlich.

Also versucht nicht, das Ego fallen zu lassen.

Versucht, euer Verständnis zu vertiefen.

Versucht nicht, Wasser in Dampf zu verwandeln.

Macht es heiß.

Der zweite Schritt folgt automatisch.

Es geschieht von selbst.“

523 So zu finden in: Kat. Saarbrücken 1990, o.S.

524 Kat. Saarbrücken 1990, o.S. 
Mit dem hier benannten „Prinzip Eleven“ ist der Kreislauf von Tod und Wiedergeburt, von Wachsen und Vergehen, allgemein das Tao gemeint, das auch in den Videobildern visualisiert wird.
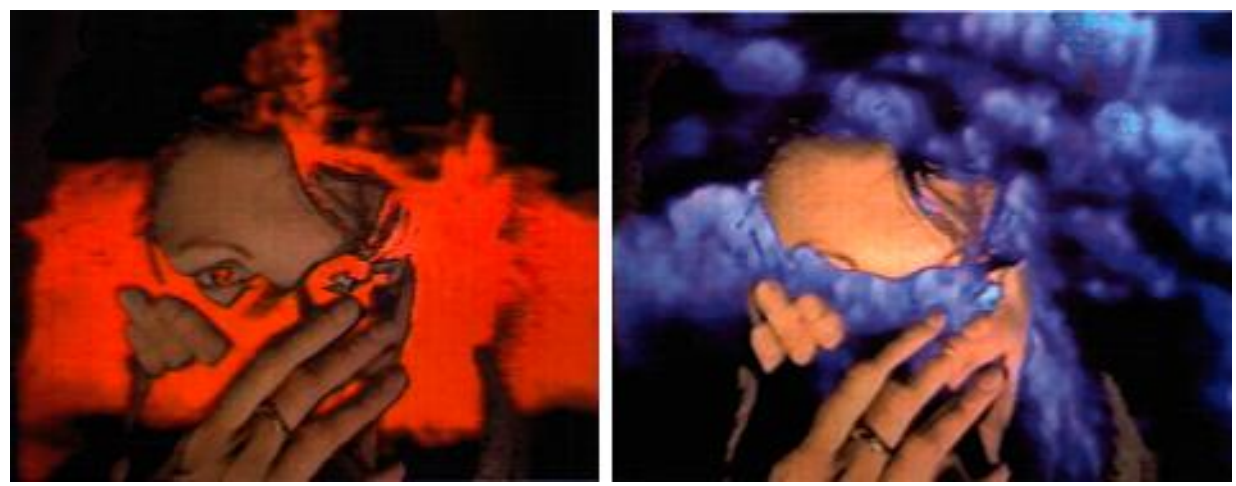

Abb.147-148: Eleven - verstehen ist wie Hitre, 1985, 2 Videostills

Die mysteriösen Hand- und Kopfzeichen, die in dem Tape erscheinen sind dabei so genannte Mudras, magisch-symbolische Finger- und Handstellungen, die in buddhistischen und hinduistischen Kulten benutzt werden. Das Wort „Mudra“ bedeutet ursprünglich Siegel oder Mysterium. In Indien haben Mudras eine lange religiöse Tradition, in spirituellen Tänzen - wie zum Beispiel dem indischen Tempeltanz - erzählen die Hände der Tänzerinnen in Verbindung mit der Körperund Augenbewegung überlieferte Geschichten vom Wirken der Götter. Eine bestimmte Handgeste symbolisiert hierbei einen bestimmten Bewusstseinszustand. Auf dieser Symbolebene können Mudras seelische Beweggründe und Gefühle ausdrücken. ${ }^{525}$ Umgekehrt wird Mudras auch eine heilende Wirkung zugesprochen. Da in der östlichen Medizin eine Krankheit als eine Disharmonie der Energieflüsse verstanden wird, geht es dort im Heilungsprozess darum, das verlorene Gleichgewicht wieder herzustellen. Durch das Verbinden, Beugen und Strecken

525 Moshé Feldenkrais, der Begründer der Feldenkrais-Methode, schreibt zum Zusammenhang von Augen, Muskeln und Gefühlen: „Sie bemerken: die Augen leisten Wesentliches, um die Muskulatur des ganzen Körpers zu koordinieren. Ihre Rolle ist noch größer und wichtiger, als die der Nackenmuskeln. Die meisten Körperteile haben eine zweifache Funktion: der Mund dient sowohl zum Essen als auch zum Sprechen, die Nase zum Riechen und zum Atmen, usw. Manche dieser Doppelfunktionen sind nicht auf den ersten Blick zu erkennen. So dient das innere Ohr nicht nur zum Hören: mittels seiner bewahrt der Körper in langsamen wie auch in schnellen Bewegungen sein Gleichgewicht. Analog dazu bestimmen die Augenmuskeln auf eine entscheidende Weise die Art, wie sich die Nackenmuskeln zusammenziehen, und umgekehrt die Halsmuskeln die der Augenmuskeln. Augen und Halsmuskeln wirken auf die Muskulatur des ganzen Körpers.“ (Feldenkrais 1978, S. 205f) 
bestimmter Finger kann der Energiefluss in den Händen und dem gesamten Körper verändert werden. Durch das regelmäßige Ausüben der entsprechenden Mudras lassen sich der Lehre nach Bewusstseinszustände hervorrufen, die den Menschen ganzheitlich harmonisieren und Heilungsprozesse in Gang setzen sollen. ${ }^{526}$ Diese Mudras, die jedes eine eigene, spezifische Bedeutung haben, kehren in einer ganzen Reihe weiterer Arbeiten Ulrike Rosenbachs wieder und fügen ihren auf Symbolkraft setzenden künstlerischen Werken eine zusätzliche Inhalte signalisierende Zeichenebene hinzu. ${ }^{527}$

Mit seiner fließenden, mit Überblendungen arbeitenden Bildsprache lässt sich das Videotape in die Reihe der bereits kurz angesprochenen Meditationstapes zählen und erinnert in seiner formalen Umsetzung an das Band „Inner Landscape Insight Image“ aus dem Jahr 1984. ${ }^{528}$ Dieses auch als „Videogedicht“"529 charakterisierte Tape erforscht in vier Sequenzen den menschlichen Körper: Bauch-, Herzgegend, Hals- und Augenpartie werden hier mit Naturaufnahmen überblendet. Diese werden auch durch Streifenblenden eingefügt, die sich vom Zentrum des Bildes nach außen öffnen. Zum Beispiel wird die Aufnahme eines Wasserfalls - in der Totalen aufgenommen - auf diese Weise mit der Nahaufnahme eines menschlichen Bauches zusammengefügt, oder auch eine Großaufnahme einer Blume mit einer Nahaufnahme der menschlichen Brust in der Gegend des Herzens. Zu hören sind dazu Motive aus einem Violinkonzert von Beethoven gemischt mit sirrenden Synthesizertönen. Der menschliche Körper wird auf diese poetische Weise in eine Landschaft für die Seele umgestaltet.
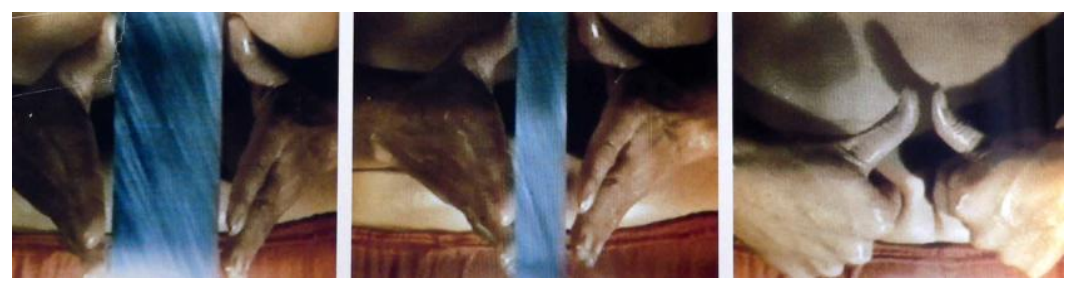

Abb. 149-151: Inner Landscape - Insight Image, 1984, Videostill

In diesem so genannten Meditationstape spiegeln sich die Anfang der 1980er Jahre fortgeschrittenen Gestaltungsmöglichkeiten in der Videobearbeitung wieder. Dabei konzentrieren sich die gewählten Ausdrucksmittel darauf, die inhaltliche Aussage zu stärken.

526 Christiansen 2003, S. 5-9

527 Auch in der mittelalterlichen christlichen Kunst spielen Handhaltungen eine signifikante Rolle.

528 Farbe, U-matic, $3 / 4$ Zoll, NTSC/PAL, Sound, 20 min.

529 Kat. Saarbrücken 1990, o.S. 
Ähnlich ist das 10-minütige Band „Aufwärts zum Mount Everest“ ${ }^{\star 530}$ aus dem Jahr 1983 gestaltet, das zu der gleichnamigen - aber wesentlich längeren - Performance entstand. Hier folgen sukzessive Ausschnitte aus den Aufnahmen der Performance und Studioproduktionen in langsamen Schnittsequenzen aufeinander. Doch es tanzen auch nackte Füße in Großaufnahme auf einer astrologischen Zeichnung, vermischt mit Bildsequenzen aus der Kundalini-Meditation. Ein gesprochener Text erklingt und verbindet die Bilder zusätzlich auf der Tonebene: Es sind Tagebuchnotizen einer Bergsteigerin, die 1965 den Mount Everest bestieg. Die dort erzählte Geschichte klingt aus mit den Worten: „Um uns ist Schnee.“

Die Aktion, erstmals 1983 in anderer Form aufgeführt, im Jahr 1986 dann durch einen zweiten Teil ergänzt, dauerte hingegen sehr viel länger als das eben beschriebene Videotape. ${ }^{531}$ An eine Wand des sonst dunklen Raumes wurde dafür ein Dia projiziert, das den schneebedeckten Gipfel des Mount Everest zeigte. Davor war ein Teppich aus Speisesalz gestreut, auf dem einige Metallplatten eine Art Gehweg bildeten. Ein Videomonitor stand auf dem Boden. Auf diesem war die Großaufnahme des Gesichtes der Künstlerin zu sehen, während sie ihre Hände davor verschränkte, von aufsteigendem Wasserdampf teilweise verdeckt.

Neben diesem Monitor stand ein Paar Turnschuhe mit Spikes bereit. Diese zog sich die Akteurin an, und stapfte krachend über die Metallplatten. Sie drehte und wendete sich zu dem von ihr herausfordernd wiederholten „Sat - Nam“, was „Himmel - Erde“ oder auch „oben - unten“ bedeutet, vor der Diaprojektion, so dass diese ihr weißes Trikot überzog und die Akteurin in dieses Bild aufgenommen wurde. Während der Aktion wandt sie sich in roten Wollfäden, trat auf und gegen den Videomonitor, schleifte diesen hinter sich her. Sie begann mit schwarzer Kreide die Bergprojektion zu um- und übermalen. Verdeckt wurden auch die Wände des Monitors mittels der Metallplatten. Dann wurde das Salz darüber zusammen geschaufelt und am Ende der Aktion wirkte der Monitor selbst wie ein Berg. Marlis Grüterich beschrieb das sich am Ende der Performance bietende Szenario:

„Die sinnlose Wanderung ist beendet. In schöner rot-weiß-schwarzer Farbigkeit bleiben die Relikte zurück." "532

530 Farbe, PAL, Ton: Kundalini Meditation, Osho Rajnesh, Hari Ch. Deuter, (7 min.) $10 \mathrm{~min}$.

531 Teil I der Performance wurde 1983 im Musée Communal des Beaux-Arts in Charleroi aufgeführt, der Teil II 1986 gleich zweimal: Zunächst in der Fachhochschule in Köln und danach in München.

532 Grüterich in: Kat. Saarbrücken 1990, o.S. 

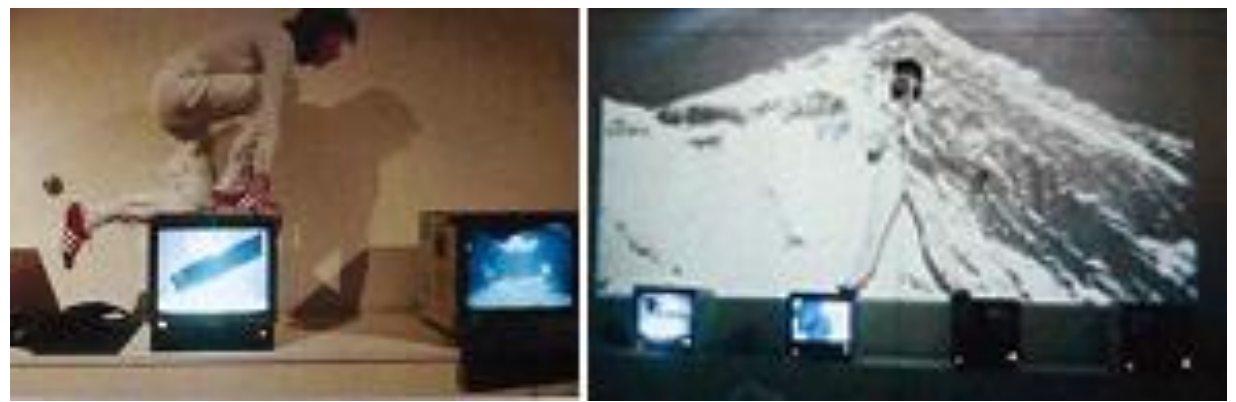

Abb. 152-153: Aufwärts zum Mount Everest, 1983, Aktionsfotos

Der Salzgrund, die Diaprojektion wie auch das Gehen sind bereits bekannte Zeichen im Bildrepertoire der Künstlerin. Auch das Element des Bemalens der Wand ist im vorangegangenen Werk bereits begegnet. Neu ist hier allerdings das unter Einsatz schwarzer Kreide die auf den weißen Grund projizierte Bildprojektion ausgelöscht wird. Ein formales Element, das sich entfernt mit der Drehung des einseitig schwarzen Trikots aus den „Reflexionen“ vergleichen lässt, bei dem der schwarze Stoff das Lichtbild verdeckte.

Auch der Faden ist ein Element, das in den bisherigen Aktionen meist in Form des Kabels begegnete. Hier findet sich nun erstmals in einer Performance rote Wolle eingesetzt, ein Material, das in späteren Aktionen wiederkehren wird. Allerdings begegnete das Motiv roter Wolle bereits kurz in einer der Fotomontagen der Künstlerin in der Mitte der 1970er Jahre. Die Montage aus der Serie „Bilder zum Tarot“, die das Gemälde der „Lady of Shalott“ zeigte. In dieser Komposition des Präraffaeliten William Holman Hunt tanzt die dargestellte Frauenfigur innerhalb eines hölzernen Webrahmens, während um sie herum ein leuchtend roter Faden wirbelt. $^{533}$

Der Bezug auf den Schnee, die massiven Eisenplatten und die spikebesetzten Schuhe bilden weitere neue formale Elemente in dieser Aktion, sowie auch erstmals der Monitorkasten mit dem Bild der Künstlerin ummantelt und zum abstrahierten skulpturalen Abbild eines Berges wird. Damit wird das zunächst an die Wand projizierte Lichtbild quasi materialisiert, in dreidimensionaler Form in den Raum übertragen.

Die Künstlerin hat eine Installation aus ähnlichen Elementen mit dem Titel „Beuys zu Ehren“ im Jahr 1985 im Lehnbachhaus ausgestellt. Auch Joseph Beuys hat in seinen künstlerischen Werken wiederholt Eisen als Material eingesetzt. Zudem war die erste Arbeit Ulrike Rosenbachs bei ihrem neuen Lehrer an der Düsseldorfer Akademie eine Arbeit aus Metall gewesen. Im multimedialen Wirken der Künstlerin taucht dieses Material dann in diesem Werk erstmals wieder auf. ${ }^{534}$ So

533 Vgl. Kap. IV.5.3.3.

534 Allerdings hatte sie früher schon Metalldrähte zur Konstruktion der Haubenobjekte eingesetzt. 
soll zunächst eine konkrete Konnotation an dieser Stelle noch offenbleiben. Doch bleibt festzuhalten, dass die Eisenplatten der Künstlerin im Verlauf der Aktion zunächst Wege durch das Salzfeld bieten. Schließlich verlässt sie diese aber und die Platten werden von ihr angehoben, um damit den Videomonitor, der das Porträt der Künstlerin im Nebel zeigt, zu verpacken.

In gewandelten Materialien findet sich in dieser Aktion das charakteristische Element des Umhüllens oder Umschnürens wieder, nur dass es diesmal nicht der Körper der Künstlerin ist, der eingepackt wird, sondern der Monitor mit dem elektronischen (Ab-)Bild. Zudem begleitet auch hier wieder eine stete, live gesprochene Wortschleife das Agieren.

Interessant ist die unterschiedliche Verarbeitung des Themas in den zwei Ausdrucksformen Tape und Performance. Während im Videotape keine Handlung, vielmehr Assoziationsmomente eines inneren Erlebens zusammengefügt sind, wird in der Aktion eine dramatische Handlung ins Bild gesetzt. Eine Bergwanderung und die damit verbundenen Unwegsamkeiten und Beschwernisse werden von der Künstlerin in zeichenhafter - und zum Teil auch konkreter Form - verbildlicht. Ihren Abschluss finden die Bemühungen im Verhüllen des bildtragenden Monitors - der uns in den Werken zuvor als Träger des Ausdrucks einer inneren Verfasstheit begegnete - nachdem in der Aktion zuvor bereits versucht wurde, die identifikatorische Diaprojektion zu verdunkeln. Zunächst die äußere Lichtprojektion und auch das innere Bild werden hier im Verlauf der Aktion verdeckt und letzteres in einer undurchsichtigen, plastischen Hülle verpackt, Bewegung und Energie werden darin abgeschottet.

Im Werk des Videokünstlers Bill Viola findet sich das Motiv des Berges oder auch Felsens, als „Zeitmonument“, als Symbol einer vom menschlichen Maßstab enthobenen Zeit:

„Was Viola letztlich daran interessiert ist der Berg 'as a conceptual image in the mind.'

Als Projektionsfläche verweist er auf die Beschränktheit des menschlichen Geistes, der vergeblich versucht das Unfassbare zu erfassen. "535

Im Jahr 1983 entstand auch das Werk „Room for St. John of the Cross“ des amerikanischen Künstlers. Diese Installation weist eine gewisse formale Ähnlichkeit auf mit dem Performanceenvironment bei Ulrike Rosenbachs Mount-EverestAktion. So ist auch bei Viola ein Dia mit schneebedeckten Berggipfeln an eine Wand projiziert. In einigem Abstand davor findet sich eine große Box, deren von der Wand abgewandte Seite eine eckige Öffnung trägt. Darin befindet sich eine Fläche mit verschiedenen Gegenständen. Unter anderem steht darauf ein kleiner Farbmonitor, der wiederum im Film Berglandschaften zeigt, die sich aus Wiesen

535 Torcelli 1996, S. 238 
und Wäldern emporheben. ${ }^{536}$ Viola spielt in der Rauminstallation mit dem Spannungsfeld zwischen einem Innen und Außen.

Die Performance „Ana l'haq, der Wind meiner Träume“ wurde im Jahr 1986 von Ulrike Rosenbach im Rahmen einer Ausstellungsreihe zum Thema „Bilder des Heiligen in der Kunst" in der Sammlung Ludwig in der Neuen Galerie in Aachen aufgeführt. Sie war ähnlich wie „Aufwärts zum Mount Everest“ ein komplexes Arrangement aus Performance, Environment, Videoprojektion und Sound, das inhaltlich um das Thema „Ganzheit“ kreiste.

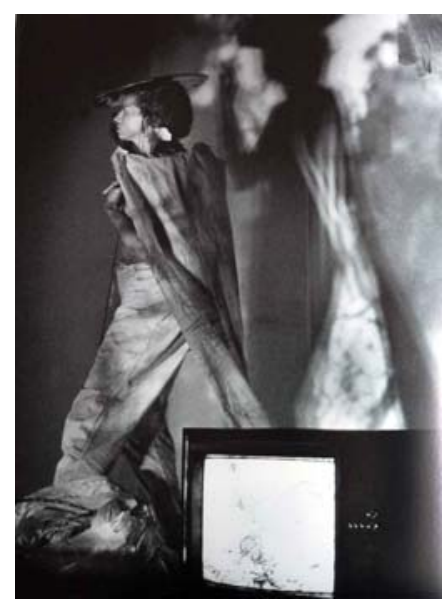

Abb. 154: Ana l'haq, der Wind meiner Träume, 1986, Aktionsfoto

Der arabische, aus dem islamischen Sufismus stammende, Begriff „Ana l'haq“ bedeutet übersetzt „Ich bin die Wahrheit“ und beschreibt einen heilen, vollständigen Zustand. ${ }^{537}$ Im symbolischen Sinn kann der Wind, der als Wort in dem Titel der Aktion auftaucht, der Atem der Erde sein, das immateriell Geistige. ${ }^{538}$ Die mehrere Meter lange Projektionswand war für diese 40-minütige Aktion mit Seidenpapier verhängt worden. Davor fand sich wieder ein weißes Salzfeld, auf dem Boden lagen ein runder Hohlspiegel, dicke rote Wollfäden und Zweige verteilt. Der Monitor auf dem Salzgrund vor der Projektionswand zeigte zunächst ein kreisendes rotes Herz und über den Videoprojektor strahlte auf das helle Seidenpapier an der Wand - stark vergrößert - das gleiche Herz, das sich dort aber durch Baumkronen bewegte. Die Videobilder, die Naturaufnahmen mit Bildanimation verbanden, wurden unterbrochen von Sequenzen aus Kriegsszenen. Aus dem Found footage Material fügte die Künstlerine eine Collage zusammen aus Dokumentationen von Kampfflugzeugen im Einsatz, der Landung der Alliierten in Dünkirchen, sowie

\footnotetext{
536 Vgl. Townsend 2004, S. 124-141

537 Zum Thema Sufismus vgl. Kap. IV.4.3

538 Vgl. Lurker 1991, S. 834
} 
Schlachtenszene aus Spielfilmen. In diesem Multimedialen-Environment begann die Künstlerin ihr Spiel. Getragen wurde dies auf der Tonebene von einem narrativen Textauszug aus dem „Cad Gaddeau“.539 Dies ist eine keltische Ballade über die so genannte „Schlacht der Bäume“. Bei dieser „glücklichen Schlacht“, wie der Titel auch übersetzt wird, verwandelten sich die Bäume zum Kämpfen in Krieger.

Entsprechend der Beschreibung in dem keltischen Mythos, dass die Bäume zu Kriegern werden, sind in dem Aktionstape die Bilder der Baumkronen mit den medialen Kampfszenen überblendet. Diese Bilder zeichneten sich wiederum während der Aktion auf dem Körper der agierenden Künstlerin ab. ${ }^{540}$

In dem eigenständigen Videotape innerhalb dieses Werkzyklus mit dem verlängerten Titel „Der Wind meiner Träume ... hat mich erreicht“, das im Folgejahr entstand, lässt sich der Ablauf der vorangegangenen Aktion nicht rekonstruieren. Ein Tape, dessen in der bekannten Weise verbundene Bildsequenzen mit laotischer Volksmusik unterlegt sind, die zudem eine meditative Atmosphäre entstehen lässt, das Friedemann Malsch wie folgt beschreibt: ${ }^{541}$

„Vielmehr ist der Betrachter mit der Bricolage aus zwei Bildquellen und einer Tonquelle konfrontiert, die in sich keine dynamische, d.h. narrative Entwicklung zeigen. Den Aufnabmen, die Rosenbach während der Aktion zeigen (sitzend, einen Pfeil auf den Kopf gebunden und mit einem groben Wollknäuel und Zweigen hantierend, später tanzend und einen runden Spiegel auf dem Kopf haltend), die erst in der zweiten Hälfte des Bandes erscheinen, geht eine intensive Vernetzung von Ausschnitten aus Spielfilmen mit Kampfszenen („Ben Hur", „Theseus", „Angriff der Riesenspinnen“) mit dem Videotape, das Rosenbach für die Aktion produziert hatte: Aufnabmen einer kereisenden (tanzenden) Kamera mit Blick in die Wipfel der Bäume einer Waldlichtung. In der Bildmitte ist per Bildcomputer ein kreisendes Herz montiert. "542

Der Kunsthistoriker charakterisiert dieses Videotape wiederum als eines der so genannten „Meditationsbänder“, die er wie folgt beschreibt:

539 Diese Legende wird in Arbeiten der Künstlerin in den 1990er Jahren wieder begegnen. (Vgl. Kap. V.3.3., hier auch mehr zur Baumsymbolik.)

540 Der Baum kann dabei symbolisch als für das Zyklische der Natur stehen, wie auch als Symbol für Wechsel und Transformation gelesen werden. Vgl. Lurker 1991, S. 80)

541 1987, Farbe, PAL/U-matic-Lowband, 8 min., Zusammengestellt aus Video-Dokumentar- und Außenaufnahmen; Spielfilmsequenzen; Bildcomputer; basierend aus der Performance „Ana’l haq" in der Neuen Galerie in Aachen 1986, Kamera Martin Käteloen, Musik: Gesänge aus Laos, Videotechnik: Elmar Ferber

542 Aus dem Off wird zudem in Abständen folgender Text gesprochen: „Ich war in vielen Gestalten bevor ich die passende Form fand./ Ich war das Binsenkraut/ ich war die schwarze Wand/ der dunkle Rauch war ich/ich kreuzte durch die Sterne/ ich floh den Berg hinab ins Moor/ ich saß auf einem Baum/ ich lief dem weißen Nebel nach/ ich war der weiße Nebel." (Malsch in: Kat. Köln 1991, o.S.) 
„Diese Bänder gehen nicht direkt auf eine Aktion zurück, zeigen mithin auch keinen dramatischen Handlungsverlauf. Vielmehr präsentieren sie ein reduziertes Bildvokabular, das in einem offenen Collageraster angeboten wird. Der Betrachter sollte diesen Bändern gegenüber eine erwartungslose Haltung einnehmen, ähnlich wie gegenüber den gebräuchlicheren und verbreiteten „Meditationsbildern".

Die Videobänder der vergangenen fünf Jahre zeigen deutlich ein sich stabilisierendes Interesse Rosenbachs an grundlegenden kulturellen Fragen der westlichen Gesellschaft. In diesem Zusammenhang ist interessant, daß sich die formale Durchbildung des Materials stark gewandelt hat. Nach den semiologischen Strukturen der frühen Bänder mit stark. didaktischem Interesse zeigen die neueren Arbeiten deutlich malerische Ansätze. "543

\section{IV.4.3. Tanzend die Mitte finden}

Ein weiteres körperlich-emotionales Ausdrucksmittel tritt Mitte der 1980er Jahre verstärkt in den Mittelpunkt im künstlerischen Wirken Ulrike Rosenbachs: Während das Tanzen in den Arbeiten der 1970er Jahre an bestimmte Formen gebunden war - wie an die traditionelle Weise des Walzers in „Tanz für eine Frau“ oder an das um die eigene Achse Kreisen in den „Judofrauen“ - steht in verschiedenen der neuen Werke der freie Tanz, die Bewegungsimprovisation im Mittelpunkt, wie sich schon in den nackten, tanzenden Füßen in dem „Mount Everest Tape“ andeutete.

Die Performance „Im Garten der Göttin“ aus dem Jahr 1986 verbindet die frühere Ritualarbeit mit Formen der östlichen Tanzmeditation. Gekleidet in ein leuchtend rotes Kleid mit weitem Glockenrock tanzte die Künstlerin in einem Raum des Kasseler Fridericianums zu eindringlichen, spannungsgeladenen, instrumentalen Klängen. Sie wirkte bei ihrer Aktion im Rahmen der documenta 8 wie in Trance, während sie im Tanz mit der bunten Kreide in ihren Händen Spuren auf den sie umgebenden schwarzen Wänden des Raumes hinterließ. Die improvisierten Körperbewegungen wurden bei der Aktion über das Medium des Kreidestriches auf den dunklen Untergrund übertragen, zeichneten sich dort in unterschiedlichen Farben ab, und bleiben als aufgezeichnete Körperbewegungsspuren über die Performance hinaus erhalten. Wie schon in den ,Judofrauen“ oder in der „Schwarzen Frau“ arbeitete die Künstlerin hier mit dem Element der Kreidespur. Die Körpererinnerung - in den Körper eingeschriebene Erfahrungen oder Spannungen - werden auf diese abstrahierte, doch sehr direkte Weise sichtbar gemacht, nach außen getragen und dort zudem aufgezeichnet.

543 Malsch in: Kat. Köln 1991, o.S. 

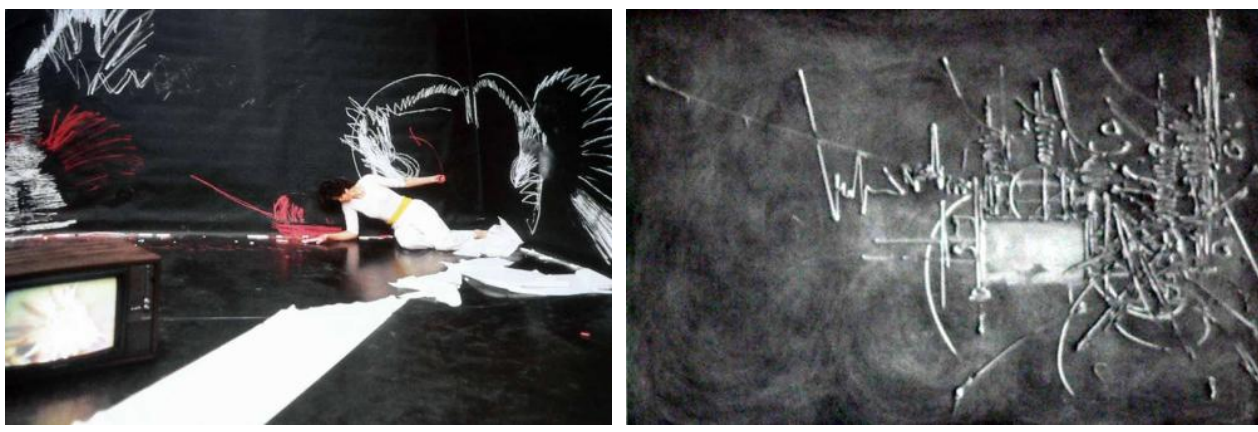

Abb.155-156: Im Garten der Göttin, Aktionsfoto, 1986 und Georges Mathieu: Dâna, 1958

Assoziationen zum Beispiel zu den wilden Malaktionen des französischen Künstlers George Mathieu (*1921), die dieser in den 1950er Jahren in Szene setzte, liegen hier nahe. Der Künstler presste oder schleuderte die Farbe während seiner Malaktionen mit Körpereinsatz und schwungvoller Geste auf die aufgestellte Leinwand, getragen von dem Gedanken, dass Schnelligkeit und Zufall Garanten emotionaler Direktheit seien. Diese wilden, fast gewalttätigen Kunstaktionen hinterließen damit spontane Gefühlsspuren auf seinen Leinwänden. ${ }^{544}$ Ulrike Rosenbach bleibt bei ihrer Aktion allerdings über die Kreide im direkten Körperkontakt mit dem Untergrund, den sie beschreibt.

In der Tanzperformance „Dance for a madhouse“"545 aus dem Jahr 1988 steht dann ein wilder, befreiender Tanz der Künstlerin im Mittelpunkt. Im roten Kleid mit weit schwingendem Glockenrock kreiste sie hier um ihre eigene Achse: Ein Bild der Verrücktheit von außen betrachtet. Als innere Erfahrung verändert dieses Kreisen die sinnliche Wahrnehmung. Es versetzt in einen anderen Bewusstseinszustand und lässt schließlich im Inneren völlige Stille spüren. Dieses wilde Sich-um-die-eigene-Achse-Drehen erinnert deutlich an ein rituelles Vorbild: Gemeint ist der Wirbeltanz der Derwische ${ }^{546}$ im islamischen Sufismus. ${ }^{547}$ Diese Religionsform ist durch Hingabe und Ergriffenheit charakterisiert und die islamischen Mystiker suchen durch asketische und meditative Übungen, ihre Seele mit Gott zu vereinigen. 548 Der religiöse Dienst, der meist in Bruderschaften lebenden Mystiker,

544 Stiles in: Kat. Los Angeles 1998, S. 288

545 Auch mit dem Titel ,The image of madness“ benannt.

546 Der Name Derwish stammt aus dem Persischen („darwish“ = arm) und wird als „Pfortensucher" übersetzt. (Hirschberg 1988, S. 97)

547 Der Begriff Sufismus wird abgeleitet vom arabischen „suf“ für „Wolle“, weil die ersten dieser Mystiker ein Gewand aus grober Wolle trugen.

548 Dabei finden sich auch Ähnlichkeiten zu buddhistischen Mönchsorden, was Überlegungen stärkt, ob sich diese religiöse Bewegung aus buddhistischen Quellen speiste, da zudem der indopakistanische Subkontinent als eigentliche Heimat dieser wandernden Mystiker und Asketen gilt. (Frembgen 1993, S. 13) Außerdem ist anzumerken, dass es auch Sufi-Frauen gibt, also weibliche Derwische. 
äußert sich in unterschiedlichen, gefühlsmäßig belegten Virtuosenleistungen, von denen der Wirbeltanz des im 13. Jahrhundert gegründeten Mevlevi-Ordens, der in Europa bekannteste ist. ${ }^{549}$ Während des rund 700 Jahre alten Tanzrituals, das auch Sema oder Mukabele genannt wird, drehen sich die Tänzer entgegen des Uhrzeigersinnes - also von rechts nach links dem Herzen zu - um die eigene Achse. Das Sema, das übersetzt „nach innen hören“ heißt, oder so viel bedeutet wie „mit der Erde verwurzelt sein und den Himmel berühren", fand seinen Ursprung in einer Inspiration des islamischen Mystikers Mevlana Celaleddin Rumi (1207-1273).550 Dabei ist es nicht das Ziel des Semazen, wie der Drehende genannt wird, in eine Ekstase zu verfallen. Vielmehr dreht er in Harmonie mit der Natur - mit den kleinsten Zellen wie den Sternen am Himmelsgewölbe - um dabei zum Zeugen für die Majestät und Existenz des Schöpfers zu werden.

Mit diesem Ritual sollen die drei - nach der islamischen Mystik - fundamentalen Elemente der menschlichen Natur zusammengeführt werden: Das Element des Verstandes (das Wissen und die Gedanken), das Element des Herzens (entsprechend dem Gefühlsausdruck, der Poesie und Musik) und das Element des Körpers. Dabei wird das Drehen als Anspornen des Lebens verstanden und die gesamte mehrere Phasen umfassende Zeremonie des Sema bildet einen spirituellen Weg des Menschen: Der Wirbeltanz verkörpert das geistige Wachsen bis zur Vollkommenheit. ${ }^{51}$ Zurückgekehrt von dieser spirituellen Wanderung sei der Wirbeltänzer fähig zu lieben und der Schöpfung mit allen Geschöpfen zu dienen. Dieser Wirbeltanz als mystisches Element und spirituelle Erfahrung lehrt demnach Lebensbalance und Harmonie, ist körperlicher Ausdruck eines spirituellen Erwachens.

Die transzendierende Macht dieser Übung beschrieb bereits der rumänische Künstler Paul Neagu (1938-2004), der sich in seinen Aktionen mit dem sprechenden Titel „Going Tornado“ Mitte der 1970er Jahre in einen wild tanzenden Derwisch, der sich wie ein Kreisel um sich selbst drehte, verwandelte. An seinem herum wirbelnden Körper befestigte der Künstler während der Aktion kulturelles Gepäck, das als Ballast diente und ihm zudem ermöglichte, sich noch schneller zu drehen. Der Künstler beschrieb seine Erfahrung während dieses Kreiselns:

„Der quasi-ekstatische Charakter eines „Tornados" als Höhepunkt eines Zyklus ist ein reinigender und absorbierender Strom, er ist die außergewöhnliche und verschwenderische Entwirrung, die alles transzendiert, was in seinen Strudel gerät. "'552

549 Hirschberg 1988, S. 97; „Zum westlichen Mythos von Orient gehört das Bild der „tanzenden“ und „heulenden“ Derwische, die seit dem 17. Jahrhundert besonders den Malern ein beliebtes Sujet boten.“ (Frembgen 1993, S. 11)

550 Der Name wird auch geschrieben als: Djelal ad Din Rumi.

551 Im Drehen bewege sich der Mensch der Wahrheit entgegen, wachse durch Liebe, transzendiere das Ego, treffe die Wahrheit und erlange schließlich Vollkommenheit.

552 Stiles in: Kat. Los Angeles 1998, S. 327 
In ähnlicher Weise scheint der therapeutische Wirbelsturm-Tanz auch im Werk Rosenbachs als Symbol der Reinigung, Heilung und Pforte zu innerer Harmonie zu stehen. ${ }^{553}$ Das in dieser Aktion mit der Bezugnahme auf das Sufiritual deutlich thematisierte künstlerische Motiv der Suche nach einer Einheit mit Gott begegnete bereits in der „Psyche Aktion“ Anfang des Jahrzehntes. Ein Thema, das nun im Werk Rosenbachs eine neue, dynamische künstlerische Ausdrucksform gefunden hat und das in den folgenden Aktionen und Installationen weiter begegnen wird. Es mündet schließlich zum Ende der Dekade der Rauminstallation „Herzpendel Energetisches Phänomen“.554

\section{IV.4.4. In Bild und Raum gelöst}

Von den in den vorangegangenen Kapitel vorgestellten Arbeiten zu den Themen Mutter-Tochter-Beziehung, Erinnerungsarbeiten und östliche Spiritualität, sind verschiedene als Werkkomplexe, variiert in den unterschiedlichen Ausdrucksmitteln Videoperformance, -tape oder Medieninstallation, künstlerisch bearbeitet worden. Dabei zeigte sich bereits, dass in der Aktion und dem gleichnamigen Tape auch unterschiedliche Aspekte zum bearbeiteten Thema herausgestellt werden können. Jetzt sollen drei einzelne Videoskulpturen beziehungsweise Videoinstallationen aus den späten 1980ern vorgestellt werden, die sich aber an dieser Stelle inhaltlich gut in den Themenkreis der künstlerischen Auseinandersetzung Ulrike Rosenbachs mit der östlichen Spiritualität einordnen lassen: Es sind dies die Medieninstallation „Ama-Zonas - Seelenzone“ aus dem Jahr 1987, die Videoskulptur „Zenkocher - Energetisches Phänomen“ im Jahr 1988 entstanden und das Werk „Ein Moment im Leben des chinesischen Malers Hu em ay“ aus dem Jahr 1989.

In der Medieninstallation „Ama-Zonas - Seelenzone“ aus dem Jahr 1987555 fügte die Künstlerin - wie es uns in vorangegangenen Arbeiten bereits begegnet ${ }^{556}$ - Zitate aus eigenen Werken mit neuen Inhalten zusammen. Die Rauminstallation ist aus einem Monitor und mehreren rechteckigen Spiegeln komponiert, die auf einer weißen Salzfläche verteilt sind. Die gezeigten Videobilder geben die Flusslandschaft des Amazonas in Totalen und Großaufnahmen wieder - und zwar als Spiegelung in der Wasseroberfläche des Flusses. Das Element der Spiegelung im

553 Auch das fünfminütige Farbtape aus dem Jahr 1985 „Center of Cyclon“ zeigt diesen Wirbeltanz. (Musik: David Kerr) Das Videotape sei die videogerechte Weiterverarbeitung einer Körperbewegung die Rosenbach seit der Videoperformance „Tanz für eine Frau“ immer wieder einsetzte, schrieb Gerhard Glüher über diese Arbeit: „Das Drehen um die eigene Körperachse, dem sufistischen Derwischtanz ähnlich, ist hier gepaart mit dem Klang schneller Trommelschläge, die der Bewegung den Rhythmus geben.“ (Glüher 2005, S. 226)

554 Vgl. Kap. V.3.1.

555 Es gibt unterschiedliche Fassungen dieser Installation. So wurde eine 1988 im Prinz Max Palais in Karlsruhe gezeigt, eine Variation 1990 im Museum für Moderne Kunst in Brüssel.

556 Zum Beispiel „Narzissen scheiden weg“, „,Wer hat Angst vor der schwarzen Frau“ und anderen. 
Wasser begegnete bereits in dem Videotape „Feenband“ und wird in einem weiteren Werk erneut auftauchen.

Der brasilianische Fluss Amazonas ist der wasserreichste Strom der Welt. Er bildet damit den Superlativ unter den Flüssen, so wie der Mount Everest, der uns bereits in einem voran gegangenen Werk begegnete, der Superlativ unter den Bergen ist. Für die Etymologie des Flussnamens gibt es unterschiedliche Vorschläge. Neben verschiedenen Ableitungen indianischer Wörter ${ }^{557}$, findet sich auch eine Erklärung, die den Namen darauf zurückführt, dass die portugiesischen „Entdecker" dort kämpfende Eingeborenenfrauen gesehen hätten und den Fluss daraufhin nach den kämpferischen mythologischen Amazonen benannten, die uns ja bereits im Werk der Künstlerin über den Weg liefen. Nach dieser Deutung wäre der Amazonas der Fluss der kriegerischen Frauen. Doch zeigt sich ein weiteres Wortspiel im Titel. Der Flussname als zusammengesetzter Begriff lässt sich aufspalten in die Teile „Ama“ und „Zonas“. Auf Latein heißt Seele „Anima“. Das Sanskritwort atma(n) steht für das Selbst. Die Lesarten dieser ähnlich klingenden Worte scheinen - betont durch die von der Künstlerin im Titel vorgegebenen Trennung - in den Titel einzufließen und den Begriff mit zusätzlichen Bedeutungen zu füllen. Der Fluss der kämpferischen Amazonen wird im Wortspiel zum Seelenstrom - oder wie sie selbst vorgibt - zur Seelenzone uminterpretiert. Eine Lesart, die sich auch in den Bildern des in die Installation eingefügten Videotapes wiederfinden lässt. Begleitet in den elektronisch collagierten Bildsequenzen des Videotapes die Künstlerin die Spiegellandschaft doch mit Großaufnahmen ihrer Hände. Deren Finger sind zu Mudras geformt. Mit der Gebärde des sich Einfügens, wird ein Rhythmus auf Holz geschlagen.

Wie im Video die gespiegelten Naturaufnahmen mit Ritualhandlungen verwoben sind, und damit die zwei Ebenen im Blick von außen und von innen visuell zusammengeführt werden, sieht sich bei der Installation der Betrachtende in den aufgestellten Spiegeln innerhalb der Installation gespiegelt und damit in das Werk einbezogen. Aus ganz unterschiedlichen Perspektiven reflektieren die Selbstbilder den Betrachtenden auf den gläsernen Flächen. Als „,naturstimmige Visualisierung einer Meditation in kosmische Sphären“ interpretiert Sigmar Gassert diese Arbeit, in der Natur- und Kulturbilder zusammenfließen, und er fügte bezugnehmend auf den Aspekt eines weiblichen Blickwinkels, der im Werk Rosenbachs elementar ist, an:

557 So sollen die Tupi-Indianer den Fluss als „Amassunú“ bezeichnet haben. Weitere Möglichkeiten sind die indianischen Wörter „amazonassa, amacunu“ für „Wasserlärm“, wie ihn die am Oberlauf lebende Indianer nannten oder auch „Amassonas“ für „Schiffsverstörer“, wie den Strom die am Rio Negro beheimateten Indianer nannten. 
„Die Amazone, diese geschichtsträchtige Franenfigur ist hier in der Einheit von Mensch und Natur ein Wesen höherer Selbstbestimmung. " 558

Auch „Zenkocher - Energetisches Phänomen“ und das nachfolgende „Ein Moment im Leben des chinesischen Malers Hu em ay" gehen auf dem künstlerischen Pfad, der versucht, geistige Erfahrungen in sinnliches Erleben umzusetzen. Doch gehen sie noch einen Schritt weiter.

Die Videoskulptur „Zenkocher - Energetisches Phänomen“ besteht aus sechs nebeneinander gestellten Monitoren. ${ }^{559}$ Jeder einzelne Bildschirm ist auf eine andere Grundfarbe eingestellt. Auf den in rot, blau und grün leuchtenden Mattscheiben haften durch die elektromagnetische Anziehung Seidenpapierstücke. In unterschiedliche Größen und Formen gerissen überlagern diese weißen Papierfetzen teilweise die farbigen Bildschirme und verdunkeln das ausstrahlende Licht. Auf den Monitorbildern dahinter sind Dampfwolken zu sehen, die - von einem Zischen begleitet - in regelmäßigen Abständen ausgestoßen werden.

Der Medienwissenschaftler Dieter Daniels hebt in seiner Interpretation der Installation hervor, dass es der Künstlerin in dieser Arbeit gelingt, dem Videobild eine taktile Sensibilität zu geben, eine Eigenschaft, die dem genormten Glasschirm sonst fehle:

„Das Leuchten des Bildes durch das dünne Papier gibt dem Videobild seine Materialität wieder, und der amorphe, unscharfe, künstlich eingefärbte Blick in den Dampf wird immer wieder zur Oberfläche der Mattscheibe zurückgeführt. An dieser Oberfläche findet der Übergang vom Elektronischen zum Optischen statt. Durch das V akuum der Röhre, hier scheinbar mit Dampf gefüllt, treffen die Elektronen auf den Leuchtschirm, um dort ihre für das Auge sichtbare Spur zu hinterlassen. Ihre überschüssige Energie führt zur elektrostatischen Aufladung der Röhre, die das Seidenpapier auf der Oberfläche haften lässt. Die Entstehung des elektronischen Bildes und sein Übergang in die materielle Welt werden in ein sinnvolles Wechselspiel gestellt." 560

\footnotetext{
558 Gassert in: Kat. Saarbrücken 1990

559 In einer Variation der Installation aus dem Jahr 1991 stehen die Bildschirme in einer Reihe.

560 Daniels in: Kat. Saarbrücken 1990, o.S.
} 


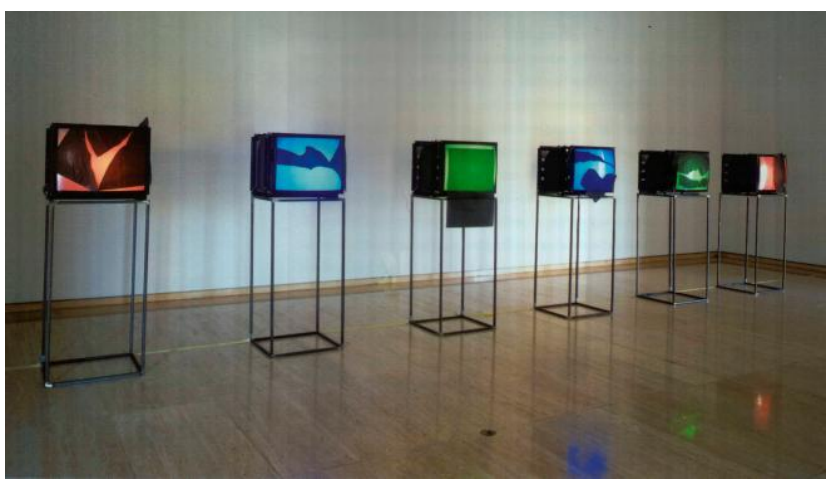

Abb. 157: Zenkocher - Energetisches Phänomen, 1988, Installation

Eine weitere inhaltliche Ebene lässt sich dieser auf den technisch-energetischen Aspekt des Werkes bezugnehmenden Interpretation hinzufügen. Zeigt das Videobild doch Wasserdampf, der plötzlich hervortritt und immer wieder den auf dem Monitor gezeigten Raum ausfüllt. Ein Bild, das Assoziationen an das in Zusammenhang mit dem „Eleven-Tape“ aufgeführte Zitat hervorruft:

„Verstehen ist wie erbitzen.

Es braucht seine Zeit.

Das Verschwinden des Egos ist wie verdampfen.

Es geschieht plötzlich."

Dieses Verdampfen - als Metapher für ein Verschwinden des Ich - scheint in diesem Werk quasi wörtlich ins Bild gesetzt. Der neue Aggregatzustand des Wassers entspricht in diesem Sinn einem neuen Seinszustand, der alles Personale sich auflösen lässt. So ist auch kein Gesicht oder keine Handgebärde, wie zuvor in vielen der Videos, mehr zu sehen, nur noch Farbe und Dampf füllen in dieser Skulptur die Bildschirme.

Diese Installation zeigt in plastischer Form eine existentielle Meditiationserfahrung auf. Und dieses nicht nur einfach, sondern sechsfach in unterschiedlichen Farbräumen variiert und in jedem zudem in steter Wiederholung. Die im Inneren des Monitors bei der Bilderzeugung in der Kathodenstrahlröhre entstehende Energie bindet dabei Papier am gläsernen Übergang zwischen Bild und Umwelt und wird damit im Außen materialisiert, taktil zu fassen, erfahrbar. Allerdings hindern diese durch die elektromagnetische Aufladung am Bildschirm klebenden Papierstücke den Betrachter am vollständigen Erkennen des Vorganges im Inneren des Monitors. Nur in Ausschnitten kann er den Prozess im Inneren erahnen.

Die bildlichen Elemente sind in dieser Arbeit erstmalig auf ein Minimum reduziert. Allerdings bedient sich die Künstlerin auch auf dieser stark abstrahierten Ebene ihrer charakteristischen Bildsprache, vermittelt ihre philosophischen Inhal- 
te buchstäblich ins bewegte Bild. Auch der Ton ist in dieser Arbeit auf das kontinuierliche Zischen der Dampfwolken reduziert, das dem Werk einen meditativen Rhythmus gibt.

Ganz ohne Ton kommt die zweite raumgreifende Medieninstallation aus dem Jahr 1989 mit dem Titel „Ein Moment im Leben des chinesischen Malers HU EM AY“ aus. Das englische „Who am I?" - „Wer bin ich?" eine der grundlegenden Fragen des menschlichen Seins - verbirgt sich hinter dem lautmalerischen Wortspiel des Titels. Zwei Monitore stehen sich in dieser Rauminstallation auf erhöhten weißen Podesten gegenüber. Der eine Bildschirm bildet in Großaufnahme das Gesicht der Künstlerin ab. Die Bildsequenz ist dabei auf den Kopf gestellt. Weitestgehend unbewegt sind die Züge der Porträtierten in dem Tape, nur ab und zu zeigt ein Zwinkern der Augen Lebendigkeit an. Über den anderen in einigen Metern auf gleicher Höhe gegenüberstehenden Bildschirm läuft langsam eine Folge von Naturbildern von oben nach unten ab. ${ }^{561}$ Beide Monitore sind verbunden über eine weiße Seidenpapierbahn, die durch die elektromagnetische Aufladung auf den Bildschirmen klebt und durch die die Videobilder hindurch scheinen. Die Papierbahn hängt zwischen den beiden Podesten parabelförmig durch. Unter dem Tiefpunkt der weißen Papierbahn ist ein kleiner heller Sandhaufen auf dem Boden aufgeschichtet. ${ }^{562}$ Auf ihm steht eine Lackschale, die mit schwarzer Tusche gefüllt ist. In diese taucht das helle Seidenpapier ein, das die dunkle Farbe an dieser Stelle auch zum Teil aufsaugt.

In dieser Installation „blickt“ das Videoabbild der Künstlerin - reduziert auf deren Gesicht - auf dem Kopf stehend auf ein Kaleidoskop aus bunten Naturbildern. Anstelle eines Spiegels hat sich die Künstlerin hier ein elektronisches Gegenüber geschaffen. Zudem steht das elektronische Abbild der Künstlerin aus Sicht des Betrachtenden auf dem Kopf, aus der Perspektive des Abbildes allerdings die umgebende Welt. Das Bildzeichen des Auf-dem-Kopf-Stehens, erläuterte die Künstlerin selbst:

561 Beide Tapes (U-matic, Lowband, PAL), die jeweils als Schleife gezeigt werden, haben eine Dauer von rund $10 \mathrm{~min}$.

562 In dieser Form gezeigt in der Galerie Buchholz in Köln 1989. Eine andere Fassung zeigt nur eine große schwarze Metallschale, die auf ihren drei metallenen Füßen auf dem Boden steht. 


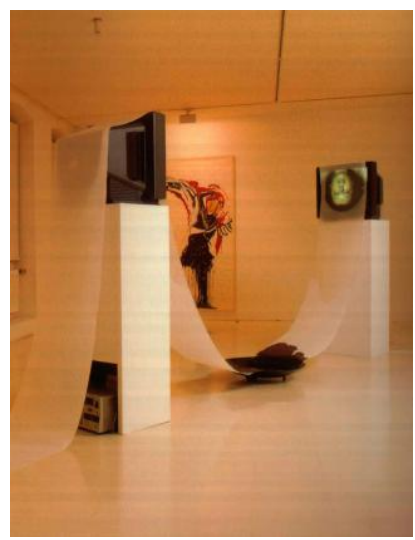

Abb. 158: Ein Moment im Leben des chinesischen Malers HU EM AY, 1989, Installation

„Wer oder was ist denn der Künstler? Und die sich auf den Kopf stellen, um etwas zu machen, das ist einmal das Symbol der Anstrengung. Das kennen wir ja auch als saying, als Sprichwort. Und dann gibt es das auch im Schamanismus. Und im Tarot ist es zum Beispiel „, the hanged man", also derjenige, der über Kopf hängt. Das kommt aus dem sibirischen Schamanismus, dieses Bild, desjenigen, der sich verändern will, stellt sich auf den Kopf oder hängt sich an den Füßen auf. Und wir sagen ja auch „,du kannst dich auf den Kopf stellen, da passiert nichts". Das heißt, du musst dich erst auf den Kopf stellen, also du musst erst unbeimlich viel unternebmen und dich quasi völlig ändern bis tatsächlich die Veränderung eintritt. ""563

Das auf dem Kopfstehen wäre demnach als Symbol der Anstrengung etwas zu verändern zu verstehen, aber auch der Rolle des Künstlers. Die Künstlerin verweist in ihrer Aussage auch auf das Tarot. Im Handbuch zum Crowley Tarot heißt es zum „Gehängten“, der zwölften Karte der großen Arkana im Tarotdeck:

Der Gehängte ist kopfüber festgenagelt. Eine Position, in der jede Form des Eigenwillens ganz und gar gebrochen ist. Die Situation ist festgefahren; es gibt keinerlei Bewegungsund Spielraum mehr. Ausflüchte sind unmöglich geworden. (...) Doch in dieser Ausweglosigkeit kann das Wunder geschehen! Es ist der Punkt erreicht, in der man der Realität in ibrer nackten Wirklichkeit nicht länger ausweichen kann. Es bleibt nichts anderes übrig, als sich zu stellen - und loszulassen. Diese Art des Kapitulierens, des Aufgebens des starren Eigenwillens und der festgefabrenen Ideologien trägt eine tiefgreifende $W$ andlung in sich: Das Durchbrechen rigider Verhaltensmuster, die Entrümpelung von altem Unrat; vollständige Hingabe an sein höheres Selbst, befreit von Engstirnigkeit und

563 Rosenbach im Gespräch 2001, Kap. VII.1. 
Rechthaberei. Ein freiwilliges Unterordnen gegenüber den kosmischen Gesetzmäßigkeiten ermöglicht das Einswerden mit dem Strom des Tao. "564

Loslassen, Veränderung, Einnehmen einer neuen Perspektive sprechen aus diesem Zitat. So könnte die Installation auch als Ausdruck einer ungewohnten Sehweise vermittelt durch eine andere Weltanschauung verstanden werden. Erinnert dieser Installationsaufbau doch erneut - wie schon in den Lotusknospentönen - an die Aufforderung Oshos, während der Meditation zum Zeugen der eigenen Gedanken zu werden. Auch dieser Gedanke scheint hier bildlich umgesetzt. ${ }^{565}$ Der entstandene Spalt - in diesem Fall ein weiter Raum zwischen den beiden erhöht stehenden Monitoren mit den Abbildern - ist gefüllt mit einer leeren Papierbahn, die auf beiden Seiten an der mit elekromagnetischer Energie aufgeladenen Bildschirmoberflächen klebt.

Als Material ist Papier ein möglicher Grund für jegliche Form von Malerei, Zeichnung oder Schrift - künstlerische Ausdrucksformen - in denen sich das Geistige in materieller Form manifestieren kann. Dabei ist gerade das Medium der Zeichnung verbunden mit einer Schulung des Sehens, der Koordination von Auge und Hand. Doch auf dieser Papierbahn ist nichts gezeichnet, so wie auch in dem Videoabbild Hände - als Zeichen für den Tastsinn oder ein Handeln - fehlen. Auf der weißen Papierbahn ist nichts Äußeres eingefangen oder Inneres ausgedrückt, sondern sie ist einfach Gelassen, wie sie vorgefunden wurde. Allerdings steht dunkle Tinte bereit, und die Bahn taucht an ihrer tiefsten Stelle in diese Flüssigkeit, die das weiße Papier schwärzt.

Die Installation thematisiert auf diese Weise auch ganz konkret das Sehen. Dieses wird hier neu interpretiert: Nicht als einfangen oder begreifen, sondern meditativ als loslassen, geschehen lassen. In dieser Weise wurde dieses Werk auch als „eine kinetische Buddhastatue“ beschrieben.56 Die im Titel gestellte Frage bleibt dabei unbeantwortet, oder aber beantwortet sich in jedem Augenblick neu. Gerhard Glüher fasste zu diesem Werk zusammen:

„Wieder einmal sind in dieser Arbeit der Prozess und der Vorgang selbst das Ziel. Wenn der chinesische Maler erkannt hat, dass seine Suche nach dem Selbst bereits in seinem Namen beantwortet ist, wird er am Ziel angekommen sein. Die Frage zu stellen „Wer bin ich?" bedeutet, die fundamentale Frage nach dem Sein zu stellen. Das heißt mit anderen Worten, dass der imaginäre Maler zur Vollendung seines Werkes nichts beitragen kann, denn es ist bereits alles getan. Dies ist in nuce die Grundannabme der chinesisch-buddhistischen Philosophie, womit der ironische Titel letztlich doch eine geistige Ergänzung findet." "567

\footnotetext{
564 Ziegler 1988, S. 45

565 Vgl. Kap. IV.4.2.

566 Prem Nirvano in: Kat. Saarbrücken 1990

567 Glüher 2005, S. 161
} 


\section{IV.5. Die Alchemie des Hermaphrodit}

Parallel zu den drei vorab umrissenen Themenkomplexen taucht im Werk der Künstlerin Ulrike Rosenbach ab Anfang der 1980er Jahre ein viertes Grundmotiv auf: Die Beschäftigung mit dem Hermaphrodit beziehungsweise dem Thema der Androgynität. Die körperlich-seelische Mischung beider Geschlechter in einer Person ist ein künstlerischer Inhalt, der in der Avantgardekunst der sechziger Jahre verstärkt bearbeitet wurde. Doch nicht nur in der modernen Kunst, sondern bereits in der mittelalterlichen Alchemie findet diese Vorstellung ihre Wurzeln, eine Ideenwelt, die übrigens auch für das künstlerische Wirken Joseph Beuys' eine wichtige Rolle spielte. ${ }^{568}$

Die Alchemie ist die „Chemie des Mittelalters“, die jedoch wesentlich mehr umfasste, als nur das stoffliche Experiment. Vielmehr bildete die Alchemie eine ganzheitliche Methode der Naturerkenntnis, die eingebunden war in eine Geisteswelt am Kreuzungspunkt zwischen Religion, Kunst und Wissenschaft. Ulrike Rosenbach schöpft für ihre zukünftigen Arbeiten aus dieser Ideenwelt, nimmt Bezug auf alchemistische Zeichen und Symbole, worauf in den nun folgenden Kapiteln genauer eingegangen wird. Dabei soll mit der Untersuchung einer konkreten Arbeit in diese komplexe Thematik eingestiegen werden.

Im Werk Ulrike Rosenbachs tritt das Motiv des alchemistischen Androgyn erstmals deutlich in der im Jahr 1982 uraufgeführten Videoperformance „Begegnung mit Ewa und Adam“ zu Tage. Dies ist eine Performance, die das Thema der Beziehungsarbeiten, während der Lösung der Künstlerin aus den Zusammenhängen der Frauenbewegung, auf einer anderen Ebene weiterzuführen scheint. Intensiviert wurde diese künstlerische Auseinandersetzung mit der Alchemie und der Androgynität in dem variantenreichen Werkkomplex um „Die Eulenspieglerin“, der 1984 seinen Ausgang nahm und in den folgenden Jahren weiterbearbeitet wurde. ${ }^{569}$ Der, um die auf der documenta 8 im Jahr 1987 gezeigte Videoinstallation entstandene Or-Phelia-Werkkomplex verknüpft schließlich das Motiv des Hermaphrodits mit der Gedankenwelt der fernöstlichen Spiritualität. An diese Arbeit schließen sich weitere im letzten Drittel der 1980er Jahre entstandene Werke der Künstlerin an, die im Kontext der Alchemie wie auch der östlichen Spiritualität zu lesen sind.

568 In der Ausstellung „Zeichen und Mythen - Orte der Entfaltung“, die Ende des Jahres 1980 im Bonner Kunstverein gezeigt wurde, begegneten sich, neben anderen, die Werke von Ulrike Rosenbach und Joseph Beuys.

569 Der dann in Kapitel IV.5.2. ausführlich untersucht wird. 


\section{IV.5.1. Werkuntersuchung: Begegnung mit Ewa und Adam}

Im Jahr 1982 wurde im Landesmuseum Münster eine Performance uraufgeführt, die den Titel trägt „Begegnung mit Ewa und Adam“. Es ist die erste Aktion im künstlerischen Wirken von Ulrike Rosenbach, in der sie innerhalb eines Environments improvisierte. Bis dahin war in ihren Auftritten ihr Agieren weitestgehend vorbereitet gewesen. Jetzt galt es in einem umrissenen Raum dem Grundthema folgend spontanen Impulsen zu folgen. Damit stellte sich die Performerin nach eigenen Aussagen einer neuen Herausforderung, wie sie in einem Text zu ihrer Arbeit beschrieb. ${ }^{570}$ Galt es doch die Aufmerksamkeit des Publikums durch eine starke Präsenz auch während der Improvisation zu binden, was mit einer großen psychischen Anstrengung verbunden gewesen sei. Im Gespräch führte die Künstlerin zudem zu der veränderten Rolle des Publikums bei den Improvisationen aus:

„In der Improvisation versuche ich das psychologische Feedback, daß vom Publikum zu mir herïber kommt, umzusetzen. Ich versuche, die Atmosphäre, die im Raum ist, aufzufangen und umzusetzen in meinen Bewregungen, und dazu auch meine eigenen Gefüble zu formulieren, also Gefüble von Angst, Gefüble von Freude, Gefüble von Bedürfnissen aller Art. Das ist eine Herausforderung, es war eine wabnsinnige Herausforderung an mich selber. Aber das war notwendig, weil ich anfing, mich mit der vorherigen Form von Performance zu langweilen Ende der 70er Jahre. Ich musste mich also auf irgendeine Art und Weise herausfordern, um nicht in eine Routine zu geraten, denn das wollte ich auf keinen Fall. Und deswegen habe ich eine neue Form von Kunst angefangen, die den Männern nicht mehr so geheuer war, weil sie außerordentlich weiblich ist in ibrer Umsetzung sind. Sie abstrabiert nicht so stark. Sie ist aus sebr subjektiven Gefüblen und seelischen Zuständen her geschaffen und bringt sehr viel Unbewußtes nach vorne. Das heißt, sie hat eine relativ psychologische Struktur diese Form der Performance. Und das ist auch angemessen und anlegbar an die Ausbildung, die ich damals gemacht habe. Nicht nur über Tantra, sondern auch über die ganzen Formen der Körper-Seele-Verbindung, die es in der Ganzheitstherapie, die sich auf C.G. Jungs Philosophien basieren läßt, aufbaut. Aber es war schon für die Leute eine sebr weibliche Form. "571

Der Titel der Arbeit „Begegnung mit Ewa und Adam“ legt das Thema oberflächlich offen: Wörtlich genommen geht es um eine Begegnung mit dem - nach christlicher Tradition - Urmenschen und der Urmutter des Menschengeschlechtes, wie es in der Genesis des Alten Testamentes der Bibel überliefert ist. ${ }^{572}$

\footnotetext{
570 Rosenbach im Gespräch 2001 Kap. VII.1.

571 Rosenbach im Gespräch 2001 Kap. VII.2.

572 AT, Gen. 2 und 3
} 

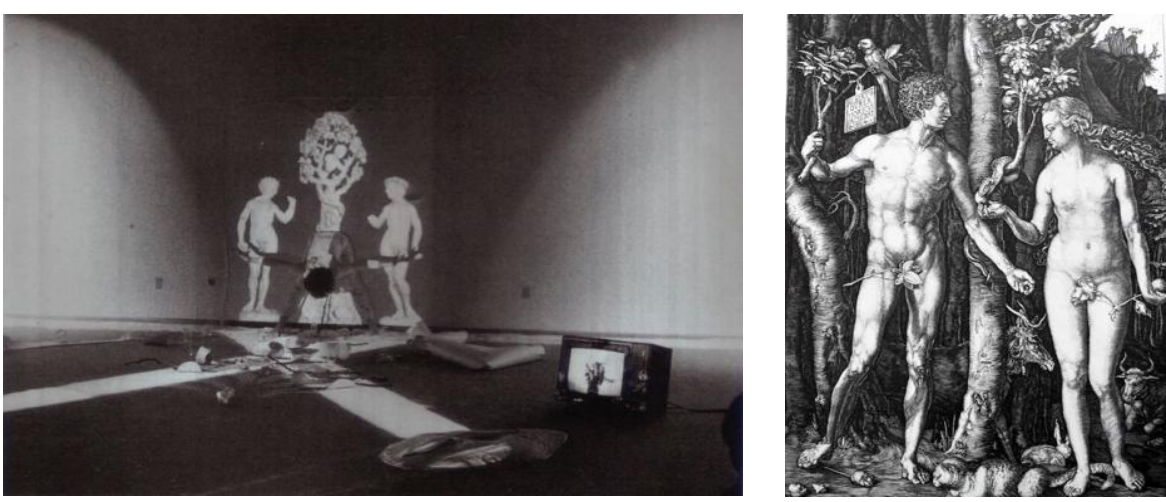

Abb. 159-160: Begegnung mit Ewa und Adam, 1982, Aktionsfoto und Albrecht Dürer, Adam und Eva, Kupferstich 1504

Dabei spielen in dem Wort „Begegnung“ zwei Bedeutungsschichten eine Rolle. Zum einen im Sinne von Treffen oder Zusammenkunft, zum anderen kann dieses Wort aber auch als Synonym für Kampf, Spiel, Wettkampf stehen. Auffallend ist, dass der Name Ewa mit einem w - anstelle eines geläufigeren v - in einer vom allgemeinen Kanon abweichenden Fassung geschrieben. ${ }^{573}$ Zwei Ideen liegen hier nahe: Das eine ist die Übernahme des w aus dem hebräischen Wort, was indirekt auf den Aspekt des Lebensspendenden der Frau verweisen würde, oder aber es könnte ebenfalls ein anderes Wortspiel damit verbunden sein. Steckt der Name Ewa doch auch in dem Wort „G-ewa-lt“, was auf den Aspekt des Kämpferischen in dieser Figur weisen könnte.

Zudem ist in dem Titel des Werkes der Name der Frau dem des Mannes vorangestellt. Dies ist eine weitere Abweichung von der Konvention, in der die Formulierung „Adam und Eva“ ein feststehender Begriff ist. Dieser Platztausch im Titel wird sich auch in der bildlichen Umsetzung zeigen, steht in Ulrike Rosenbachs Environment doch die Figur der Ewa links, Adam rechts vom Baum der Erkenntnis. Denn aus den verschiedenen Szenen, die in der abendländischen Kunstgeschichte um die biblischen Figuren Adam und Eva ins Bild gesetzt wurden, greift die Künstlerin für ihre Performance ein Zitat heraus, das den Moment des Sündenfalls zeigt. Der überwiegende Teil der kunsthistorischen Vorbilder des Sündenfalls zeigt Adam links und Eva rechts stehend in der Sündenfallszene. Wie zum Beispiel bei Albrecht Dürers Kupferstich aus dem Jahr 1504 oder den Altarflügeln bei Lucas Cranach. ${ }^{574}$ Ulrike Rosenbach bezieht sich in ihrer Performance jedoch auf eine künstlerische Darstellung aus der Region. So fügt sie eine Diapro-

573 Die hebräische Benennung „Chawwa“ bedeutet „Leben“ oder „Lebensspendende“.

574 Ein Gegenbeispiel wäre der Holzschnitt von Hans Baldung Grien, hier steht wie bei Rosenbach Eva links neben Adam. Allerdings ist dies auch eine Druckgraphik, die im Abdruck seitenverkehrt entsprechend der Gestaltung erscheint. 
jektion einer Sandsteinskulptur von Johann Brabender (1498/99-1562) aus dem Besitz des Landesmuseums Münster als Teil des Bühnenbildes ein. ${ }^{575}$ Wie bereits vorangegangene Werke konkret Bezug auf den Aufführungsort nahmen, griff die Künstlerin auch hier auf ein Sammlungsstück des Museums zurück, an dem sie diese Performance erstmals zeigte. 576 Während im Original von Brabender Adam links und Eva rechts vom Baum angeordnet sind ${ }^{577}$, erscheinen die beiden Figuren in der Projektion der Performance seitenverkehrt, so dass die Figur der Eva für den Betrachter links und Adam rechts vom in der Mitte stehenden Baum der Erkenntnis hell aus dem dunklen Grund leuchten. Auf dem vor der Wand liegenden Boden des Raumes war ein großes Kreuz aus Salz gestreut worden, dessen zwei Enden auf die abgebildeten Sockel der Skulpturen zuliefen. Auf dem Salzweg lagen Papier und Astwerk, daneben standen mit Wasser gefüllte Gläser.

Für diesen Platzwechsel der beiden Protagonisten gibt es ein gemaltes Vorbild, das zudem von einer Künstlerin stammt: Die französische Malerin Suzanne Valadon (1865-1938) malte ihre beiden Fassungen von „Adam und Eve“ im Jahr 1909. ${ }^{578}$ Sie hängen im Centre Pompidou, in dem Ulrike Rosenbach zwei Jahre zuvor ihre Madame-Pompadour-Aktion aufführte und das der Künstlerin so bekannt gewesen sein wird.

Das in der Aktion Rosenbachs an die Wand projizierte Renaissancekunstwerk zeigt die beiden biblischen Stammeltern in dem Moment des Sündenfalls. Dazu heißt es in der Genesis des Alten Testamentes:

„Die Schlange war schlauer als alle Tiere des Feldes, die Gott der Herr gemacht hatte. Sie sagte zu der Frau: Hat Gott wirklich gesagt: Ihr dürtt von keinem Baum des Gartens essen? Die Frau entgegnete der Schlange: Von den Früchten der Bäume im Garten dürfen wir essen; nur von den Früchten des Baumes, der in der Mitte des Gartens steht, hat Gott gesagt: Davon dürft ibr nicht essen, und daran dürft ibr nicht rübren, sonst werdet ibr sterben. Darauf sagte die Schlange zur Frau: Nein, ibr werdet nicht sterben. Gott weiß vielmehr: Sobald ibr davon eßt, gehen euch die Augen auf; ibr werdet wie Gott und erkennt Gut und

575 Johann Brabender, Sandstein: Adam 107 cm, Eva $106 \mathrm{~cm}$ und der Baum 155 cm, Landesmuseum Münster. (vgl. Jászai 1983)

576 Die Aktion wurde in der Folge in variierter Form an verschiedenen Orten aufgeführt. Das ausgewählte Bildmotiv, das auf die erste Aufführung in Münster Bezug nimmt, wurde dabei bei den späteren Aufführungsorten beibehalten. Ursprünglich befand sich die zitierte Sündenfallskulptur am Paradiesportal im südwestlichen Querschiffgiebel des Domes zu Münster.

577 In vielen Darstellungen des Sündenfalls findet sich Adam links und Eva rechts angeordnet: wie in Dürers berühmtem Kupferstich oder auch bei Cranach, Rembrand, Raffael.

578 Öl auf Leinwand, $162 \times 131 \mathrm{~cm}$. Musée National d'Art Moderne, Paris. Renate berger schreibt zu dem Doppelbildnis: „Obgleich das Gemälde aus einem exponiert biografischen, sexuell definierten Zusammenhang entsteht, wählt Suzanne Valadon einen verfremdenden Schlüssel. Als andere Künstler (Egon Schiele z.B.) vergleichbare Beziehungen unumwunden ins Bild setzen, greift sie ein biblisches Thema auf und gibt so dem Doppelakt eine traditionelle Fassung. Eva hat nur vage Ähnlichkeit mit der Malerin, während Adam die Züge Utters trägt.“ (Berger 1982, S. 130f) 
Böse. Da sah die Frau, daß es köstlich wäre, von dem Baum zu essen, daß der Baum eine Augenweide war und dazu verlockte, klug zu werden. Sie nahm von seinen Früchten und aß; sie gab auch ibrem Mann, der bei ibr war, und auch er aß. ${ }^{579}$

Der mit dem Sündenfall verbundene Erkenntnisgewinn, der als Strafe für den Übertritt des Verbotes die Vertreibung aus dem Paradies nach sich zog, gab den beiden ersten Menschen erst ihr Selbst-Bewusstsein. Indem auch in Ulrike Rosenbachs „Begegnung“ die Frucht der Versuchung zum Apfel des Selbstbewusstseins wird, ergibt sich erneut ein emanzipatorisches Motiv in dieser Performance. Doch geht die Künstlerin noch einen Schritt weiter und lässt in ihrer Aktion die beiden projizierten Figuren über den biblischen Kontext hinaus, zu Sinnbildern des Männlichen und Weiblichen werden. Konkret ist es der Gedanke der androgynen Natur des menschlichen Seins, der in dieser Aktion ins Bild gesetzt wird.

Das Prinzip des Androgyn findet sich in vielen Kulturen als eine frühe Stufe mythischen Denkens. Am Ursprung der Dinge gab es in dieser Denkweise keine Trennung der Geschlechter bis der bisexuelle Urkosmos in den unterschiedlichen Mythologien in die beiden Ureltern zerfiel. Auch dem biblischen Schöpfungsmythos nach schuf Gott zunächst nur einen Menschen, aus dessen Seite dann die Frau - Eva - geschaffen wurde. ${ }^{580}$

Diese männliche und weibliche Seite hob die Künstlerin mit der Kunstaktion ins Bewusstsein: Dem Salzweg folgend trat sie in die - die Frau und den Mann auf Lebensgröße vergrößernde - Projektion. Vor der Wand agierend gab sie ihren Impulsen Ausdruck, bewegte sich in dem Lichtbild von rechts nach links, zurück vom Abbild der Eva zu Adam, auch vom Boden in den Stand.

$\mathrm{Zu}$ der Performance erklang ein von der Akteurin verfasster Text, der wie folgt begann:

„Ich hatte schon viel zusammengesammelt.

Das erste war diese seltsame Erkenntnis,

daß meine linke Seite weiblich

und meine recbte männlich sei.

579 AT, Genesis 3,1-3,6 (Einheitsübersetzung)

580 Auch im biblischen Mythos bildeten das Männliche und Weibliche zunächst eine Einheit, bevor aus der Seite (oder Rippe) Adams seine Frau geschaffen wurde. Zusammen bilden Adam und Eva nach dem christlichen Mythos die Ureltern, auf denen das Menschengeschlecht gründet. „Nach 1 Mos 1,26ff ist A[dam] eine männlich-weibliche Zweieinheit (nicht androgyn; erschuf er sie) und in dieser Zweieinheit Bild Gottes. Die Einheit in der Zweiheit kommt zum Ausdruck in dem einen Namen A[dam]. Erst nach dem Sündenfall wird A[dam] Eigenname des Mannes, das Weib erhält den Namen Eva." (Lurker 1991, S. 5) Hiernach erscheint die Frau, die sich von der Schlange zum Gesetzesbruch verleiten ließ und auch den Mann verführte es ihr gleich zu tun, als die Schuldige für den Sündenfall des Menschen. Es finden sich jedoch auch andere Auslegungen, in denen sich der Mann und die Frau die Verantwortung für den Gesetztesbruch gemeinsam teilen. 
Ich bestehe sozusagen aus zwei Hälften, und beide sind sebr verschieden."

Im Weiteren wird die linke, weibliche Seite als gebrochen, mit einem Gefühl der Schwäche und Passivität besetzt beschrieben. Die rechte, männliche heißt es, sei auch zerstört. Obwohl kräftig und muskulös, verkrampfe diese sich vor Aktivität, sei fast unfähig zur Entspannung. Als Folgerung wird festgestellt, dass das eigene Frausein als schwach empfunden werde.

„Bei der Recherche an diesen Abbildungsformen über „Ewa und Adam", sind mir zwei Sachen aufgefallen: einmal die Bedeutung des Baumes der Erkenntnis im Paradies, und dann die Bedeutung des Engels, der zu Füßen des Baumes sitžt." "581

Dieser Engel, den Ulrike Rosenbach in den kunsthistorischen Vorbildern sieht, taucht in ihrem Werk ebenfalls auf. Denn der Aktionsaufbau war noch um ein weiteres Element erweitert. Am Rande des Environments stand ein Monitor, auf dem ein Videotape lief, das eine fliegende Engelsfigur zeigte. Der zweite Teil des Textes zur Aktion nahm Bezug auf dieses Engelsthema, beschrieb er doch den Traum, in dem ein Engel erscheint:

„Im Traumbildschirm setzt der Barbarella-Seraphim immer wieder zur Landung an. Umsonst. Er hat zwar wunderbare Flügel, aber keine Arme, wiederbolt die Franenstimme aus dem Off. Er hat weder rechts noch links. Er kann nicht zu ibr kommen. "582

Auf diese Weise beschreibt Marlis Grüterich das Tape zur Aktion, dessen Ton nach jeder vollen Schleife - alle paar Minuten aussetzte. Das Motiv des Videos weckt Assoziationen an den Videoflug der Psyche ${ }^{583}$, der ja in der Interpretation Ulrike Rosenbachs mit dem Aspekt des Scheiterns verknüpft wurde. Und auch in der Ewa-und-Adam-Aktion kann der Widerspruch nicht gelöst werden. Denn Video und Text zeigen, dass der Traumengel den Grund nicht erfassen kann, da ihm zwei Dinge fehlen: zum einen die beiden - den Androgyn bildenden - Hälften, die eine menschlich-körperliche Gestalt erst vervollständigen, zum anderen fehlen ihm die Arme, Symbol der Handlungsfähigkeit im Werk Rosenbachs, wie es bereits mehrfach - besonders anschaulich im „weiblichen Energieaustausch“ - begegnete.

Wenn bisher die in den vorangegangenen Aktionen auf den integrierten Videomonitoren gezeigten Bilder als Ausdruck im weitesten Sinne innerer Verfasstheiten gedeutet werden konnten, so ergibt diese Lesart auch in dieser Aktion Sinn und eine solche Deutung wird noch durch den Hinweis auf die Traumebene - die Tür zum Unbewussten - im Text betont.

581 Rosenbach im Gespräch 2001 Kap. VII.1.

582 Grüterich, 1989, S. 11

583 Vgl. Kap. IV.3. 
Das Videotape fügt damit der Performance eine weitere Ebene hinzu, die dem Aktionsgeschehen konträr zu sein scheint. Im Gegensatz zu der fliegenden, federnen Engelsfigur über den Wolken in dem Videotape-Traum steht die Künstlerin in ihrer Aktion fest auf dem Grund und kann sich mit ihren Bewegungen zwischen den beiden projizierten Figuren rechts und links bewegen. Diese zeichenhafte Vermittlung wird begleitet vom Agieren mit Wasser und Ästen. „Man spürt, wie die Frau links und rechts gleichzeitig spüren möchte", fasst Marlis Grüterich ihren Eindruck der improvisierten Performance in Worte und fügt über das Agieren der Künstlerin an:

„Im Schlangenbaum treibt sie mit Adam und Eva Bild-Alcbimie. In beiden Händen bält sie Wassergläser und gießt das Merkur Element um und um."584

Das Wasser ist das Merkurelement und auf Merkur oder „Mercurius“ - in der Alchemie das Element des Verstandes - wird in der Aktion explizit Bezug genommen. So endet der Text zur Aktion mit den Worten:

„Der Weg des Merkur (des Planeten der Bewegung) ist der des mittleren Planeten, darum sein Tag der Mittwoch ist. " 585

Die Künstlerin selbst erläuterte die Aktion im Rückblick wie folgt:

„Mercurius als der Gott der Veränderung und der Kommunikation [hat] als Symbole Wasser und Glas. Das sind die transparenten Symbole. Und das ist auch in der Alchemie schon im 12. Jahrbundert so gewesen. Das heißt also, daß die Transparenz oder Transformation bereits gan₹ früh ausgedrückt wurde durch fließende oder transparente Materialien."

Die Künstlerin stellt hier explizit den Aspekt der Transparenz und Transformation heraus. Und die angestrebte Allianz zwischen Weiblichem und Männlichem, spiegelt sich zudem im Aufbau des Environments. Das weiße Salzkreuz am Boden greift in abstrakter Form das Thema des Zusammenschlusses der Gegensätze wieder auf. Wird das Kreuz doch als Symbol für die Vereinigung von Himmel und Erde gedacht mit dem Kreuzmittelpunkt als kosmischem Zentrum, denn so sagt das Wörterbuch der Symbole über das Kreuz:

„Spekulatives Denken will in ihm auch die coniunctio des geistig-männlichen (Vertikale) mit dem materiell-weiblichen Prinzip (Horizontale) erkennen. "586

Die Künstlerin hat in ihrem Environment das Kreuz in einer Weise gedreht, dass die sich kreuzenden Linien nicht nur jeweils mit ihrem einen Ende auf die Figuren von Mann und Frau zulaufen, sondern zudem den Verlauf der sich kreuzenden Lichtstrahlen der Bildprojektion materiell nachbilden.

\footnotetext{
584 Grüterich 1989, S. 6

585 Kat. Saarbrücken 1990, o.S.

586 Lurker 1991, S. 406
} 
Zusammenfassend lässt sich festhalten, dass „Begegnung mit Ewa und Adam“ eine komplexe Performance ist, die mit inzwischen aus dem Kontext des Werkes bekannten Elementen - Rückgriff auf einen Mythos, Salzgrund, den Dia- und Videobildern - in einer für die Künstlerin charakteristischen bildhaften Sprache arbeitet. Dabei begegnet auf der Tonebene ein poetischer Text, der die Aktionshandlung in narrativer Weise ergänzt. In dieser sehr dichten Darstellungsweise wurde die „Begegnung mit Ewa und Adam“ zu einer Begegnung der Künstlerin mit sich selbst, die in dieser Performance den weiblichen und männlichen Anteilen in ihrer eigenen Person Ausdruck gab. Die Ideenwelt der Alchemie, die in dieser Aktion in den verwendeten Chiffren in Erscheinung tritt, soll im Folgenden kurz umrissen werden.

\section{IV.5.1.1 Die Ideenwelt der Alchemie}

\section{„Wer ein verborgen’ Ding hervorbringen kann, der ist ein Meister der Kunst. "“887}

So heißt es im Splendor Solis, einem alchemistischen Traktat, das den alchemistischen Transformationsprozess beschreibt. Die frühesten handschriftlichen Fassungen werden in das 16. Jahrhundert datiert. In diesen Handschriften finden sich auch 22 farbige Illustrationen, die in vereinfachter Form als Holzschnitte in den „Aureum Vellus“ übernommen wurden, der 1598 erstmals erschien.

587 Aus dem Tractator III Splendor Solis erschienen im Aureum Vellus. Der Splendor Solis ist das schönste erhaltene alchemistische Manuskript. Die früheste Version, die sich im Kupferstichkabinett der staatlichen Museen zu Berlin befindet, ist datiert auf die Jahre 1531-32 und ist eine kostbar illustrierte mittelalterliche Handschrift. Spätere Kopien der alchemistischen Handschrift befinden sich in London, Kassel, Paris oder auch Nürnberg. Das Buch enthält 22 kunstvoll ausgeführte Illustrationen, die in ornamentale Rahmen gesetzt sind. Der ins Bild gesetzte symbolische Prozess zeigt den klassischen alchemistischen Tod und die Wiedergeburt des Königs, und beinhaltet eine Serie von sieben gläsernen Kolben, von denen jeder mit einem anderen Planeten verbunden wird. In diesen gläsernen Gefäßen wird die Transformation von Vogel- und Tiersymbolen in den König und die Königin, die weiße und rote Tinktur. Das alchemistische Traktat wird dem legendären Salomon Trismosin zugeschrieben, dem angeblichen Lehrer von Paracelsus. Die Trismonischen Schriften wurden 1598 zusammen mit Holzschnittillustrationen veröffentlicht im „Aureum Vellus, oder Guldin Schatz und Kunst-kammer“, spätere Ausgaben folgten nach. 

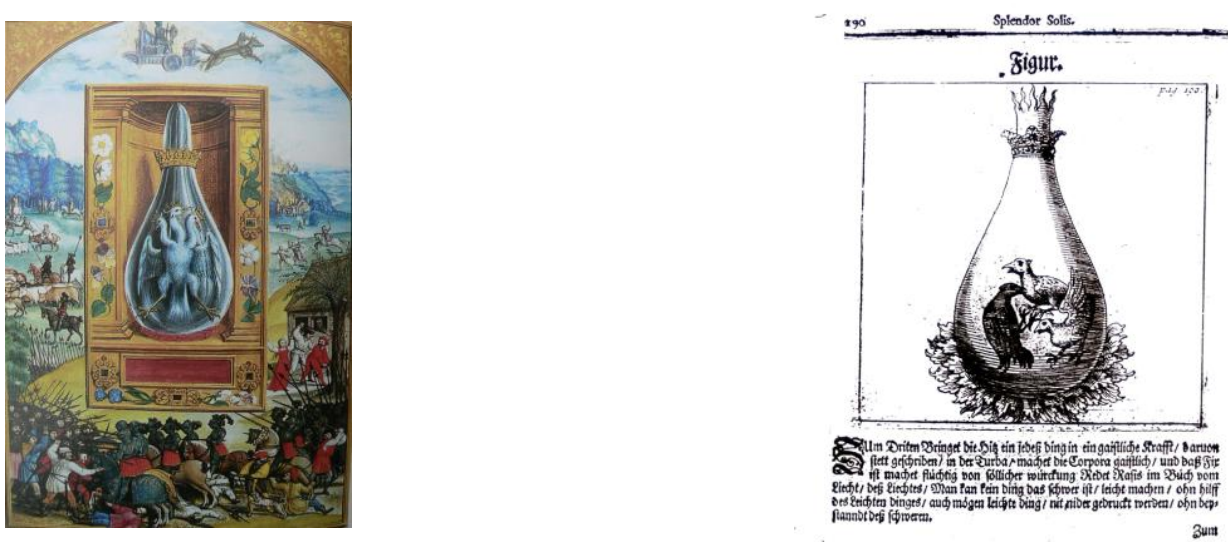

Abb. 161-162: Splendor Solis 1582 und Aureum Velus 1708

Das praktische metallurgische Wirken des Alchemisten war eingebunden in das naturphilosophische System der so genannten „hermetischen Philosophie“, einer in der gnostischen Tradition stehenden Geisteshaltung.

Die Alchemisten suchten in Schmelzprozessen im Laboratorium - ihren „opus“ - den so genannten „Stein der Weisen“ herzustellen. Mit dem auf diese Weise gewonnenen „lapis philosophorum“ sollte es möglich sein, unedle Metalle in Gold zu verwandeln. Eine der alchemistische Grundannahmen ist, dass es einen Urstoff gibt, die so genannte Materia Prima. Dieser hypothetische Ausgangsstoff, der auch zur Herstellung des Steins der Weisen dient, ist zwar in allen Substanzen enthalten, muss aber erst erzeugt werden. ${ }^{588}$ Gebelein erläutert zu diesem Urstoff:

\section{„Die Vorstellung, dass alles in den Urstoff zurückgeführt werden kann und wieder neue Körper durch Formgebung gebildet werden können, bedeutet, dass der Stoff erhalten bleibt, nichts davon verloren geht. Es gibt nur einen ständigen Wandel. "589}

Dieses grundlegende Prinzip des ewigen Wachsens und Vergehens, der Verwandlung, das in der Alchemie in Bezug auf die Bearbeitung der Metalle „Transmutation" genannt wird, entspricht auch den Vorgängen im Kreislauf der Natur. ${ }^{590}$ So steckt in der Methode der Alchemie die Kunst mit der Natur zu arbeiten, diese in Harmonie zu verbessern und der Versuch, diese durch Partizipation zu beeinflussen. So sieht die Geisteshaltung der Alchemie auch die Aufgabe des Menschen da-

588 Gebelein 1991, S. 64

589 Gebelein 1991, S. 65

590 Das alchemistische Symbol der sich stetig wandelnden Materie ist das Bild der sich in den Schwanz beißenden Schlange, der Uroboros. Diese Symbolik bringt die Koinzidenz der Gegensätze zu einem Ringschluss von Anfang und Ende. 
rin, die Natur zu vervollständigen, Himmlisches und Irdisches zu verbinden und aus einer prägenden dualistischen Auffassung eine vollkommene Einheit zu schaffen. ${ }^{591} \mathrm{Zu}$ dieser dualistischen Struktur gehören die beiden Grundprinzipien der Alchemie: Sulfur (Seele) und Merkur (Geist), die mit dem Weiblichen und dem Männlichen gleichgesetzt werden. Auf ein Gleichgewicht bedacht gilt es auch Sulfur und Merkur im Opus wieder zu vereinen. Als Resultat dieser Vereinigung wird auf der symbolischen Ebene der Hermaphrodit imaginiert, der beide Prinzipien in sich trägt und der daher als das Symbol der wiedergewonnenen Einheit der Materie gesehen wird, als „göttliches Kind“. Der erwähnte Urstoff enthält jedoch noch ein weiteres, drittes Prinzip, das als Vermittler zwischen den beiden zu verstehen ist und als Grundlage aller Formgebung angesehen wird: Sal. Dabei ist mit diesem alchemistischen Begriff „Sal“ nicht einfach Salz gemeint, sondern das unterste stoffliche Lebensprinzip, das Körperliche ganz allgemein. ${ }^{592}$ In dieser Tradition lehrte schon der deutsche Mystiker Jakob Böhme:

\section{„Das Salz ist der Vater der Natur. Von ibm wird erzenget der Sulfur (Seele) und Merkur (Geist)".593}

So geht die Alchemie letztlich von einer Dreiteilung in die Prinzipien Sal entsprechend dem Körper, Mercurius dem Geist und Sulphur der Seele aus, die es durch das Opus in neue Beziehungen zu bringen gilt. ${ }^{594}$ Denn für den echten Adepten der Alchemie sei die „Goldmacherkunst" immer nur ein Nebenwerk seines Strebens gewesen, während die eigene Läuterung im Vordergrund gestanden habe, wie Gebelein darlegt. ${ }^{595}$ Und auch von Ins fasst die mit dem alchemistischen Prozess verbundene Veränderung des Bewusstseins wie folgt zusammen:

„Es ist die Initiation des Menschen ins Sein, die die Alchemisten in den Laboratorien vollyogen. "596

591 von Ins 1979, S. 144

592 von Ins 1979, S. 135; In der modernen Chemie bezeichnet der Begriff „Salz“ einen Stoff von bestimmtem Aufbau und bestimmten Eigenschaften, gekennzeichnet durch Ionenverbindung, unabhängig von seiner chemischen Zusammensetzung oder Herstellungsweise. Dabei sind Ionengitter durch starke Bindungskräfte gekennzeichnet.

593 „Es ist unklar, warum in vielen Texten, durch die Jahrhunderte gerade das dritte Prinzip nicht erwähnt wird. Es muss allerdings darauf hingewiesen werden, dass auch Merkur häufig als Vermittler angesehen wird. Der Götterbote Hermes bzw. Merkur ist unter anderem ja auch Vermittler zwischen dem Olymp der Götter und der Unterwelt." (Gebelein 1991, S. 68)

594 Gebelein 1991, S. 13; Als Quellen dieser alchemistischen Trias Körper, Geist und Seele, sind die ägyptische Mysterientradition (alchemistisch wird daraus Sulfur = Seele), die griechischen Philosophie $($ Merkur $=$ Geist) und die technisch-metallurgischen Kenntnisse (Sal = Körper) der Handwerker und Schmiede zu nennen. Allein aus letzteren erwuchs die moderne Chemie, die sich im 18. Jahrhundert abspaltete.

595 Gebelein 1991, S. 79

596 von Ins 1979, S. 143 
So habe der Mensch, der von Erleuchtung begabt sei und das Prinzip erkenne, die Aufgabe, die in der geschaffenen Materiewelt gefangenen „Lichtatome“ freizumachen und sie in das uranfängliche Geistesreich zurückzuführen. ${ }^{597}$

Überträgt man das hier Ausgeführte auf die Ewa-und-Adam-Aktion zeigt sich eine nochmal neue Leseweise der Performance. Sind doch die Begriffe des alchemistischen Hermaphrodit, das göttliche Kind, Mercurius und Sal in der Performance verbildlicht und schließlich sogar Lichtatome in der Projektion des Diabildes freigesetzt, die Bilder aus einem Ursprungsmythos zeigen.

\section{IV.5.1.2 Die Deutung der Alchemie im Werk C.G. Jungs}

Der Denker, der in der Neuzeit als erster auf den Zusammenhang zwischen den metallurgisch-stofflichen Schmelzprozessen der Alchemie und Abbildern psychischer Abläufe stieß, war der Schweizer Psychiater und Psychoanalytiker Carl Gustav Jung (1875-1961). Bevor im Anschluss auf die Deutung der Alchemie im Werk von C.G. Jung eingegangen wird, sollen zunächst kurz die Grundlagen der Lehre des Schweizer Psychoanalytikers umrissen werden. Der Schüler Sigmund Freuds (1856-1939) deckte das kollektive Unbewusste auf, entdeckte die so genannten Komplexe ${ }^{598}$ und erforschte die Archetypen der menschlichen Psyche - worunter nach Jung dem Menschen arttypisch angeborene, psychische Verhaltensweisen zu verstehen sind. ${ }^{599}$

In Abgrenzung zu Freud umfasst bei C.G. Jung das Unbewusste als Ort der verdrängten Triebtendenzen das unbekannt Psychische zusammen mit dem so genannten psychoiden System, das als seelenähnliches Feld umrissen wird. ${ }^{600}$ Aus

597 Biedermann in: Kat. Berlin 1986, S. 58

598 Unter Komplexen sind emotionsgeladene Vorstellungsbündel zu verstehen.

599 „Während die Instinkthandlungen der Tiere nur von außen beobachtbar sind, erschließt sich der Archetyp durch Introspektion. Er ist unanschaulich; seine Existenz ist eine vom Beobachter erschlossene. Beobachtbar sind nur eine Auswirkungen, nämlich die Tatsache, daß Menschen aller Zeiten und Völker strukturähnliche, mythische, (archetypische) Ritualgesten, sprachliche Bildvorstellungen und Gedanken erzeugen, die emotionsgeladen und faszinierend wirken. ... So sind die Manifestationen des Archetypus in erster Linie Geste und sprachliches Bild. ... Die Archetypen erzeugen das Rohmaterial aller Religionen, welche eine kollektiv und teilweise bewusst weiter ausgeformte Version desselben darstellen. Weil die Archetypen funktionell wichtige organe der Seele sind, bedeutet es eine soziale Katastrophe, wenn ihr Sinngehalt nicht mehr verstanden wird. ...Vom richtigen Umgang mit den Archetypen hängt unsere seelische Gesundheit ab.“ (Lurker 1991, S. 49f) Lurker definiert weiter: „Der Archetypus stellt wesentlich einen unbewussten Inhalt dar, welcher durch seine Bewusstwerdung und das Wahrgenommensein verändert wird, und zwar im Sinne des jeweiligen individuellen Bewusstseins, in welchem er auftaucht."

600 Jung umschreibt dies selbst als: „Alles, was ich weiß, an das ich aber momentan nicht denke; alles, was mir einmal bewusst war, jetzt aber vergessen ist; alles, was von meinen Sinnen wahrgenommen, aber von meinem Bewusstsein nicht beachtet wird; alles, was ich absichts- und aufmerksamkeitslos, das heißt unbewusst fühle, denke, erinnere, will und tue; alles Zukünftige, das sich in mir vorberietet und später erst zum Bewusstsein kommen wird; all das ist Inhalt des Unbewussten." (Wehr 1997, S. 36) 
dieser Flut des individuellen und kollektiven Unbewussten ragt das „Ich“ heraus, das als Teil der Psyche Zentrum und Subjekt des Bewusstseinsfeldes ist. Von diesem „Ich“ deutlich unterschieden wird das „Selbst", dessen größerer Radius die gesamte Psyche vereint - Bewusstes und Unbewusstes. Das Selbst drückt damit die Einheit der Gesamtpersönlichkeit aus, die sich allerdings erst im Laufe des Lebens zu einer Ganzheit entwickelt. Diese seelische Entwicklung - den Prozess der so genannten Selbstwerdung - benannte Jung als Individuation:601

„Individuation bedeutet: zum Einzelwesen werden, und, insofern wir unter Individualität unsere innerste, letzte und unvergleichbare Einzigartigkeit verstehen, zum eigenen Selbst werden. Man könnte „Individuation“ darum auch als „Verselbstung“ oder als „Selbstverwirklichung " ̈̈bersetzen. "802

Dieser Vorgang, der in der Regel in der zweiten Lebenshälfte beschritten werde, könne als schwieriger und gefahrvoller Weg empfunden werden, denn das Archetypische flute dann aus sonst unbewusst bleibenden Seelentiefen hervor, gab C.G. Jung zu bedenken. ${ }^{603}$

Um die Dynamik der Psyche auszudrücken, hatte bereits Freud die Bezeichnung der Libido - als psychische Repräsentanz des Sexualtriebes - gewählt. C.G. Jung übernahm diesen Terminus, definierte ihn jedoch nicht allein als Ausdruck für sexuelle Energien, sondern versteht ihn als „psychische Energie“ im Allgemeinen. Indem er sich diese energetische Anschauung zu eigen machte, lehnte er eine einseitig mechanistische, kausal zu begreifende Auffassung des psychischen Geschehens ab. ${ }^{604}$ Das Leben als energetischer Prozess - wie es Jung versteht - bedarf der Gegensätze. So ist ein wichtiges Element seiner Lehre die Aufdeckung dieser zugrunde liegenden Gegensatzproblematik. Dabei ist dem Analytiker gelegen an der Integration der aufgedeckten Gegensätze im Rahmen einer größeren Ganzheit. So zeugt C.G. Jungs Wirken von einem Bedürfnis einer ganzheitlichen Schau der Welt und des Menschen, und der Blick des Forschers galt der Gesamtheit seelischer Phänomene. ${ }^{605}$ Schon diese Auffassungen spiegeln eine erstaunliche Ähnlichkeit zu den aufgezeigten Prämissen der Alchemie. Das ist kein Zufall, be-

601 Individuation ist allgemein der Vorgang der Bildung und Besonderung von Einzelwesen, speziell die Entwicklung des psychologischen Individuums als eines vom Allgemeinen, von der Kollektivpsychologie unterschiedenen Wesens. Die Individuation ist daher ein Differenzierungsprozess, der die Entwicklung der individuellen Persönlichkeit zum Ziel hat. Die Notwendigkeit der Individuation ist insofern eine natürliche, als eine Verhinderung der Individuation durch überwiegende oder gar ausschließliche Normierung an Kaollektivmaßstäben eine Beeinträchtigung der individuellen Lebenstätigkeit bedeutet.“ (Jung 1989, Bd. 6, S. 477)

602 Jung 1989, Bd. 7, S. 191

603 So bedürfe dieses zur Selbstbegegnung fähig machende Schwellenerlebnis der Vorbereitung, der Begleitung und des Beistandes. Der Psychologe entwickelte zur Orientierung in diesem Prozess eine komplexe Amplifikationsmethode.

604 Wehr 1997, S. 36f

605 Wehr 1997. S. 49 
schränkte sich der Schweizer Seelenarzt bei seinen Forschungen doch nicht allein auf seine unmittelbare Praxis mit seinen Patienten, sondern prüfte zudem kritisch die Zeugnisse spirituell-religiöser Erfahrung: die Weisheitsüberlieferungen und Praktiken Asiens ebenso wie die Schriften der frühchristlichen Gnosis und der spätmittelalterlichen Alchemie. ${ }^{606}$ Mit dem reichhaltigen Material an Gleichnissen, Symbolen, Rezepten und Erlebnisschilderungen der Alchemisten beschäftigte sich Jung ab Mitte der zwanziger Jahre intensiv. Seine Forschungsergebnisse veröffentlichte er im Jahr 1944 in dem Werk „Psychologie und Alchemie“. Hier beschrieb er als ein Pionier in seiner Zeit die Alchemie nicht allein als eine Geisteshaltung, die der vorwissenschaftlich betriebenen Chemie zugrunde lag, sondern erkannte in ihr auch einen geistigen Erkenntnisweg, auf dem es sowohl um die Stoffumwandlung (Transmutation), wie auch um die Verwandlung des eigenen Wesens - um Selbst- wie auch Welterkenntnis - gehe. ${ }^{607}$ Hier schreibt Jung, dass

„,der alchemistische Laborant während der Ausfübrung des chemischen Experiments gewisse psychische Erlebnisse hatte, welche ihm aber als ein besonderes Verhalten des chemischen Prozesses erschienen. Da es sich um Projektionen handelte, war es ihm natürlich unbewusst, daß das Erlebnis mit dem Stoff an sich (d.h. wie wir denselben beute kennen) nichts zu tun hatte. Er erlebte seine Projektion als Eigenschaft des Stoffes. Was er in Wirklichkeit erlebte, war sein Unbewusstes".608

Das alchemistische Wirken wird hier als Individuationsprozess verstanden, als ein Finden des Selbst. ${ }^{609}$ Der Hintergrund der Alchemie ist für Jung die Einweihung des Alchemisten in eine über die Jahrtausende reichende Mysterienschulung, wie auch ein innerer Transformationsprozess. ${ }^{610}$

Eine weitere wichtige Entdeckung C.G. Jungs liegt zudem in der Beobachtung, dass das menschliche Unbewusste Prozesse durchlaufe, die den Resultaten der Alchemisten ihrem Bildgehalt nach in verblüffender Weise ähneln. So sieht der Psychoanalytiker zum Beispiel in der alchemistischen „coniunctio“ eine archetypische Metapher für den Prozess der Bewegung vom Gegensatz hin zur großen Einheit und Ganzheit, die Verbindung von Gegensätzlichem in der Begegnung, die zur Geburt eines Dritten führt und die dem jungianischen Konstrukt der „transzen-

\footnotetext{
606 Wehr 1997, S. 8

607 Wehr 1997, S. 70; Kritisiert wurde allerdings die Einseitigkeit dieses Ansatzes. So widmete sich Jung in seinen Forschungen allein dem spirituellen Aspekt der Alchemie. Ihm wurde vorgeworfen, die laborantische Alchemie zu unterschätzen, zeigten die Vorgänge im Reagenzglas eine konkrete Utopie, die Möglichkeit der Veränderung.

608 Jung 1978, S. 339

609 So sei nach Jung zum Beispiel der erste Schritt im alchemistischen Opus - wie auch in der psychoanalytischen Therapie - das Unbewusste, das Dunkle, den Schatten zu akzeptieren und in die Person zu integrieren, die vorher nur das Helle, das Sozialakzeptierte kannte. Der zweite Schritt umfasse dann die Schwärzung, in der Alchemie als Nigredo bezeichnet, was bedeute das Unbewusste gleichermaßen wie das Bewusste anzunehmen. (Wehr 1997, S. 105f)

610 Wehr 1997, S. 72
} 
denten Funktion“, dem versöhnenden Dritten entspricht. ${ }^{611}$ Vor diesem Hintergrund erscheint auch das Engelbild im Video aus der Ewa-und-Adam-Aktion in einem tieferen Zusammenhang. Lässt es sich doch als göttliches Kind oder auch versöhnendes Drittes lesen, dass allerdings mangels Handlungsfähigkeit in seiner transzendenten Funktion an dieser Stelle noch scheitert. ${ }^{612}$

Zusammenfassend lässt sich sagen, dass Jung die Symbole der Alchemie als im kollektiven Unbewussten angesiedelt erkannte und damit den archetypischen Bildern zuordnete. Der Psychologe erblickte in den Berichten der Alchemisten Projektionen des Archetypischen und in der Alchemie ein Ordnungssystem psychischer Fakten. So sieht Jung den großen Wert alchemistischer Bilder darin, dass sie eine objektive Basis geben, mit der man sich Träumen und unbewusstem Material nähern kann. ${ }^{613}$ Mit diesen Erkenntnissen fand er neue Zugänge zur Traumforschung.

\section{IV.5.1.3 Dem Traum Bilder geben}

Die symbolträchtige und surreale Welt der Träume spielte in verschiedenen Strömungen der Kunst eine elementare Rolle, wie zum Beispiel im zur Zeit bis zur Wende des 20. Jahrhundert verbreiteten Symbolismus, aber auch im späteren Surrealismus.614 Der Surrealismus, der sich als Kunstströmung zu Anfang der 1920er Jahre entwickelt hatte, bündelte unterschiedliche Tendenzen in einer neuen - zunächst auf die Sprache zielenden - Aktion, die etwas völlig Neues hervorbrachte, das von Ins auch als „Alchemie des Wortes“ 615 beschreibt. So hatten zum einen Sigmund Freuds Untersuchungen über die Bedeutung von Träumen und des Unbewussten großen Einfluss auf die Überlegungen der Surrealisten. Eine andere wichtige Wirkung auf die Surrealisten hatte „Dada“, die anarchische Kunstströmung des zweiten Jahrzehntes des 20. Jahrhunderts, mit ihren die bürgerlichen Konventionen sprengenden Aktionen. Gemeinsam ist den Ansätzen bei den Dadaisten wie auch im Surrealismus die Ablehnung der Logik sowie gesellschaftlicher

611 Auf die uralte religiöse Vorstellungen vom weiblichen Element in der Gottheit Bezug nehmend verkündete Papst Pius XII am 1. November 1950 das Dogma der leibhaftigen Himmelfahrt Mariens. Dieses steht für Jung in Zusammenhang mit dem Bedürfnis der menschlichen Psyche nach Ganzwerdung. (Wehr 1997, S. 122f)

612 Vgl. zur Symbolik des Engels allgemein und im Werk Ulrike Rosenbachs Kap. V.4.

613 „Sehr bald hatte ich gesehen, dass die Analytische Psychologie mit der Alchemie merkwürdig übereinstimmt. Die Erfahrungen der Alchemisten waren meine eigenen Erfahrungen, und ihre Welt war in gewissem Sinne meine Welt. Das war für mich natürlich eine ideale Entdeckung, denn damit hatte ich das historische Gegenstück zu meiner Psychologie des Unbewussten gefunden.“ (Jung in: Wehr 1997, S. 83) Die Naturphilosophie der Alchemie schlug damit für C.G. Jung eine Brücke von der Gegenwart in die Vergangenheit des Gnostizismus, als auch in die Zukunft der modernen Psychologie des Unbewussten.

614 Der Symbolismus fand dabei gerade auch in England zahlreiche Anhänger.

615 von Ins 1979, S. 146 
Konventionen auf der Suche nach dem wahrhaften menschlichen Verstand. Auf dieser Suche bildete ebenfalls die Untersuchung der Bedeutung der Sprache eine wichtige Säule. Zudem beeinflussten die vom Okkulten geprägten Bildwelten der Symbolisten die surrealistische Malerei. ${ }^{616}$

Die Surrealisten waren allerdings zunächst eine Gruppe französischer Dichter um den Literaten André Breton gewesen, der in seiner Programmschrift „Manifeste du Surréalisme“ (1924) Bedeutung hinter den zufälligen Erscheinungsweisen der Welt postuliert. So heißt es dort:

„Der Surrealismus berubt auf dem Glauben an die böhere Wirklichkeit gewisser, bis dabin vernacblässigter Assoziationsformen, an die Allmacht des Traumes, an das zweckfreie Spiel des Denkens. "\$17

Später, als Richtung der modernen Malerei, die durch die literarischen Ansätze inspiriert wurde, ging es den Surrealisten um die Darstellung des Überwirklichen, der Traumwelten. Die Künstler suchten die Gedankengänge psychoanalytischer Forschungen folgend das Unbewusste, Traumhafte in ihren Bildern anschaulich zu machen, wobei in der Darstellung keine Rücksicht auf die naturgesetzliche, kausale Ordnung der Sinnendinge genommen wurde, hingegen das Irrationale zu uneingeschränkter Geltung gebracht wurde. ${ }^{618}$ So war ein gundlegendes Prinzip des Surrealismus die Kombinatorik: Das assoziative Vermengen an sich wesensfremder Bildelemente zu irritierenden und befremdenden Seherfahrungen.

Die engste Verbundenheit zum literarischen Surrealismus hatte unter den bildenden Künstlern der in Deutschland geborene Max Ernst (1891-1976). Der Maler, Graphiker und Bildhauer, der im Jahr 1922 nach Paris, dem Zentrum der Surrealisten, ging, wird zu den Hauptvertretern dieser Kunstströmung gezählt:

„In seinen anfangs unter dem Einfluss der pittura metafisica entstandenen technisch meist hervorragenden Bildern stellt er Phantastisches und Absurdes, Träume und Halluzinationen dar, eisige Mondlandschaften und tropische Vegetationen, wuchernde Formen, die sich in Tier und Mensch verwandeln und Porträts aus geometrischen Körpern."619

616 Lucie-Smith 1996, S. 135-137

617 Breton 2001

618 Jahn 1983, S. 773 f

${ }_{619}$ Jahn 1983, S. $207 \mathrm{f}$ 


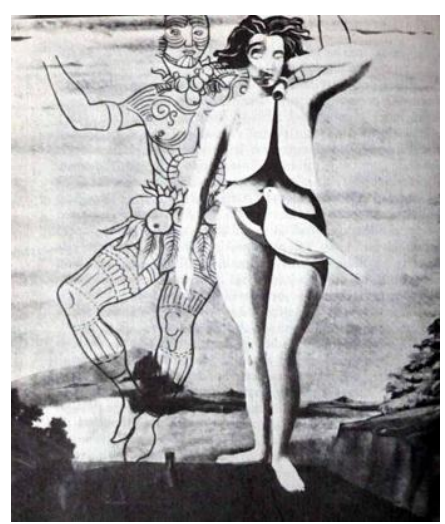

Abb. 163: Max Ernst - La belle Jardinière, 1923

Dabei bilden die Titel, die der Künstler seinen Bildern gab, häufig Wortspiele oder Rätsel. ${ }^{620}$ Die Symbolwelten der Psychoanalyse - wie auch der Alchemie - sprechen in vielen Varianten aus Max Ernsts bildlichen Kompositionen. Auch findet sich die Idee des Androgyn im künstlerischen Schaffen des Malers ins Bild gesetzt, ein Thema, das allgemein im Schaffen der Surrealisten eine wichtige Bedeutung einnahm:

„Als selbsternannte Erben mystischer Philosophie übernabmen die Surrealisten auch den Androgyn und all das, was er verkörperte, indem er das Mysterium mit Erotik verband." 621

Denn wie Peter Short zusammenfasst, sei der Androgyn in der surrealistischen Ikonographie ein dynamischer Ausdruck des Begehrens:

„Er steht nicht für einen entsexualisierten, befriedeten Zustand des Seins, sondern für ein unerreichbares, vitales Ziel zu dem Leidenschaft führt. Er ist ein „signe ascendant" (aufsteigendes Zeichen). Er bedeutet auch eine Fragestellung der unermüdlichen Vorstöße des Surrealismus in die Tiefen und das Herz des menschlichen Seins. Als solche ist die entschiedenste Verkörperung die Collage "Ödipus und die Sphinx" von Max Ernst, 1935: Diese zusammengesetzte androgyne Figur verschmilat mit wunderbarer Ausgewogenheit nicht nur die beiden Geschlechter miteinander, sondern, indem sie Ödipus und seine Gegenspielerin in einer einzigen Gestalt vereint, offenbart sie, daß unsere Erlösung nur um den Preis der Energie und durchdringenden Kraft der Selbsterforschung zu erlangen ist." 222

620 Lucie-Smith 1996, S. 135-137, auch Short in: Kat. Berlin 1986, S. 149

621 Short in: Kat. Berlin 1986, S. 149

622 Short in: Kat. Berlin 1986, S. 158 
Diesen Weg der Selbsterforschung beschreitet auch Ulrike Rosenbach in ihren folgenden künstlerischen Werken weiter.

\section{IV.5.1.4 Schmelzprozesse im Werk von Ulrike Rosenbach}

Wie dargestellt bildet der Schmelzprozess eine elementare Rolle in der Alchemie. „Schmelzprozesse“ war auch der Titel einer Rauminstallation, die die Künstlerin 1982 in der Vleeshall im niederländischen Middlebourg zeigte. Von den Kreuzungen des Netzgewölbes der hohen Halle waren gelbe Seidenbänder abgehängt, die mit trockenen Zweigen und Fäden im Gewölbe befestigt waren. In der Mitte der großen Halle stand auf einem gelben Sockel, der umgeben war von Zweigen und Reisig ein Videomonitor. So ragte der Monitor gleich einer Flamme aus den aufgetürmten Holzscheiten heraus. Das Tape auf dem Bildschirm zeigte in Großaufnahme, wie sehr langsam zwei dunkle Hände über eine hellbeleuchtete, runde Metallscheibe aufeinander zu glitten. Als beide zueinander fanden, formten die Daumen und Zeigefinger der beiden Hände kurz ein Herz, bevor sie sich wieder voneinander entfernten. An den weißen Wänden der Halle war siebenmal der gleiche fast lebensgroße Scherenschnitte aus schwarzem Papier gehängt.
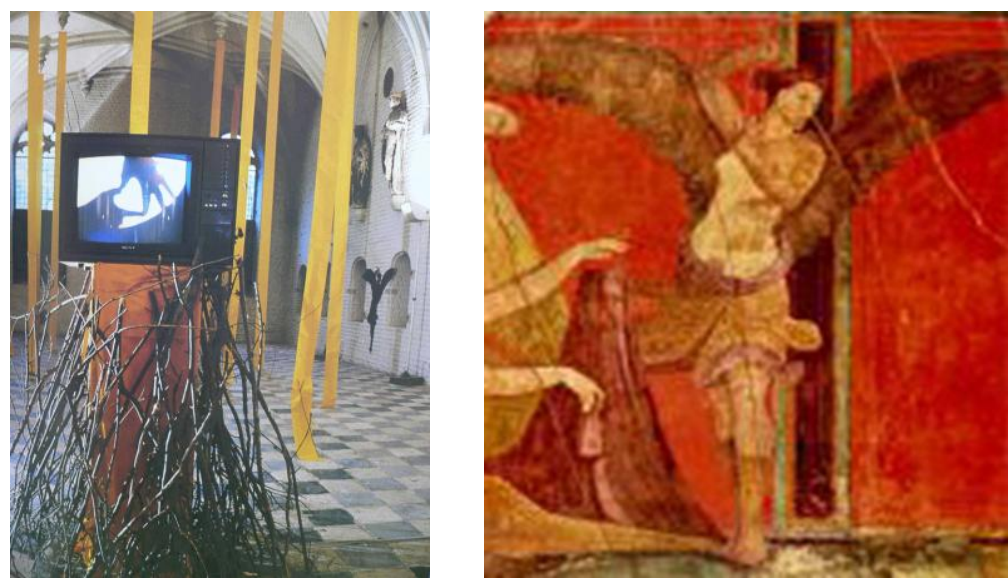

Abb. 164-165: Schmelipprozesse, 1982, Foto der Installation und geflügelte Figur, Fresko aus der Villa die Misteri 
Die hier gezeigte geflügelte Frauenfigur hat ihr Vorbild in einer der Figuren aus dem Fresko der pompejanischen Mysterienvilla. ${ }^{623}$ Es ist die geflügelte Gestalt, die eine Geißel in ihrer erhoben linken Hand hält. Die Handlung der Selbstgeißelung wird in religiösen Riten genutzt, um spirituelle Grenzerfahrungen hervorzurufen, die dazu dienen über sich hinaus zu treten. In Rosenbachs Werk wird diese in ein ritual eingebundene Figur - hier zum ersten Mal, doch in der Folge noch häufiger - als schwarze Silhouette zitiert. Anstelle der gemalten Geißel in dem antiken Fresko ist den Schattenfiguren in dieser Rauminstallation allerdings jeweils ein echter Zweig in die erhobene Hand gegeben worden. ${ }^{624}$ Die Zweige können als Symbol für die lebenspendende und transformierende Kraft gelesen werden und finden sich gleich mehrfach in die Installation integriert. So werden Äste in der Installation zudem als Verbindungsmittel zwischen Oben und Unten eingesetzt: Sie fixieren die gelben Seidenbänder einerseits an der Decke, andererseits am Boden. Auch speisen Zweige das alchemistische Bildschirmopus.

Ebenso ist die Zahl Sieben - die geflügelten Figuren erscheinen siebenfach symbolisch aufgeladen. Die Sieben ist eine heilige Zahl, Ausdruck der Vollkommenheit und Totalität. Sie ist zudem Summe aus der himmlischen Drei und irdischen Vier, verschmilzt so zusätzlich auf der symbolischen Ebene diese beiden Sphären miteinander.

Die Idee des „Schmelzprozesses“ ist - wie dargelegt - Grundlage alchemistischen Denkens. Auf dem - entsprechend einer Flamme aus dem Zweig- und Reisighaufen ragenden - Videomonitor verschmelzen die Schatten einer rechten und einer linken Hand vor helleuchtendem metallenem Grund zu einer Herzform. ${ }^{625}$ $\mathrm{Zu}$ sehen ist in vertrauter ganz buchstäblicher Bildlichkeit im Energiebild eine oben beschriebene alchemistische „conjunctio“. Aber noch weitere Gegensätze werden im Raum verschmolzen: Die gelben Bänder hängen von der Decke des Raumes herunter bis zum Boden, oben und unten sind auf diese Weise miteinander verbunden und das zudem durch die Farbe Gelb, die man auch als Gold interpretieren kann. Steht doch Gold in der symbolischen Bedeutung für die gelungene Transformation und so auch für Weisheit. ${ }^{626}$ Zudem sind auf die weißen Wände des Raumes sieben geflügelte schwarze Frauensilhouetten gesetzt, von der Künstlerin selbst übrigens als „aufstrebende Engelsfigur“ benannt. Die an sich statische Wand wird auf diese Weise mit dynamischen Schattenfiguren versehen. Diese visualisierten Verbindungen oder auch Verschmelzungen von Gegensätzli-

623 Bezuggenommen wurde im Werk Rosenbachs auf dieses Fresko bereits in der Trilogie Narzissen-Requiem-Konzert im Gewaltakt Ende der 1970er Jahre. (Vgl. Kap. IV.2.)

624 Der segensbringende Zweig ist nicht nur als pars pro toto für die lebensspendende und transformierende Symbolik des Baumes zu verstehen, sondern gilt zum Beispiel auch als ein altmesapotamisches Götterzeichen. (Vgl. Lurker 1991, S. 84)

625 Erstmals taucht hier das Herz als Motiv im Werk Rosenbachs auf, das später dann unter anderem in der Wind-meiner-Träume-Aktion wiederkehren wird.

626 Diese Farbsymbolik wird uns wieder begegnen in „Über den Tod“. (Vgl. Kap. V.3.8.) 
chem, die in Rosenbachs „Schmelzprozessen“ visualisiert werden, bringen schließlich etwas zuvor nicht Sichtbares hervor: Ein Herz, einen kosmischen - gelben Raum und ein Schattenreich. Und damit gelingt der Künstlerin das, was im alchemistischen Traktat mit den Worten „Wer ein verborgen' Ding hervorbringen kann, der ist ein Meister der Kunst"627 beschrieben wird.

Ähnlich wie in den „Schmelzprozessen“ sind im Aufbau des Environments der Performance „Begegnung mit Ewa und Adam“ Prämissen der Alchemie fast wortgetreu ins Bild gesetzt. Liest man die projizierte Figur der Ewa als das weibliche Element, das damit dem alchemistischen Sulphur entspricht, und Adam als männliches Merkur-Element, gründen beide im weißen Salzweg, dem alchemistischen Körperelement Sal. Beide Prinzipien werden zusätzlich durch das körperliche Agieren der Künstlerin miteinander verbunden. Damit hat diese in ihrer Performance eine Art alchemistischen Schmelzprozess zwischen Mann und Frau, oben und unten, Mensch und Natur in Szene gesetzt. Vor diesem Hintergrund zeigt ein Blick auf das vorangegangene Werk der Künstlerin bereits Spuren alchemistischer Bildwelten. So lässt sich zum Beispiel auch dem Salz, das in zahlreichen Arbeiten als materielle Basis genutzt wurde, eine zusätzliche inhaltliche Bedeutung geben: Das Salz als Ausdruck des Körperlichen.

Auf ihrer Suche nach immer neuen Kommunikationsformen für inneres Erleben hat die Künstlerin bis zu diesem Zeitpunkt bereits ein umfangreiches Ausdrucksrepertoire zusammengetragen: Sie griff zurück auf Märchen, Mythen, Kunstwerke, Rituale, feministische und psychoanalytische Ideen, sowie Tanz und Meditation. Dabei ist ein Charakteristikum in allen bisher vorgestellten Werken eine plastische Wortwörtlichkeit in der bildlichen Umsetzung. Diese findet sich nun auch beim Verarbeiten der Motive der Alchemie. Die mittelalterliche Läuterungslehre, die der analytischen Psychologie eines Carl Gustav Jung und der Ideenwelt der Surrealisten nahe steht, bildet damit einen weiteren befruchtenden Hintergrund im Werk Ulrike Rosenbachs, auf deren künstlerischem Weg der Selbsterforschung. Auf diesem Weg wird das Motiv des Androgyn noch mehrfach bearbeitet. Die Begegnung mit „Ewa und Adam“ war die erste Aktion, in der sich Ulrike Rosenbach explizit mit der Idee des Hermaphrodit auseinandersetzte. ${ }^{628} \mathrm{Al}$ lerdings zeigt ein Rückblick auf vorangegangene Werke, dass die Idee des Androgyn bereits in den Haubenobjekten mit schwang, in denen weibliche und männliche Formen verbunden sind. In dem folgenden Werkkomplex mit dem Obertitel „Die Eulenspieglerin“ verdichtet die Künstlerin ihre Aussagen zum Thema Androgyn und verändert ihre Perspektive.

627 Aus dem Splendor Solis, vgl. Kap. IV.5.1.1.

628 In der Installation zu der Aktion in der Ausstellung „Androgyn“ in der Akademie der Künste in Berlin 1986 wurde die Figur der Eva durch eine schwarze Silhouette ersetzt. 


\section{IV.5.2. Werkuntersuchung: Die Eulenspieglerin}

In dem mehrteiligen Zyklus „Die Eulenspieglerin“, dessen erster Teil am 15. Juni 1984 im Kunstverein in Hamburg uraufgeführt wurde ${ }^{629}$, kulminiert die künstlerische Auseinandersetzung mit der Androgynität sowie die Hinterfragung des Themas der Frau als Künstlerin. Zudem fügt sich in diesem Werk, das als eines der Hauptwerke der Künstlerin zu betrachten ist, eine Fülle ihrer spezifischen Zeichenwelt zusammen. In Variation und unter dem Namen „...das Mädchen wächst weiter“ wird das Werk im gleichen Jahr erneut beim Musikfestival in Köln gezeigt, und im darauf folgenden Jahr werden die insgesamt drei variierende Teile in Kopenhagen, Bremen, Gent und Lissabon in Szene gesetzt. Außerdem entstehen mehrere Videoinstallationen zu dieser Aktion, wie auch ein 20-minütiges Videotape aus dem Jahr 1985 Aufnahmen aus den unterschiedlichen Aufführungen zu einem eigenständigen Tape verbindet. ${ }^{630}$ So findet sich im Rahmen dieses umfangreichen Werkkomplexes das schon bekannte Bearbeiten der Inhalte in den verschiedenen künstlerischen Ausdrucksmitteln wieder. ${ }^{631}$

Bereits der Titel dieser Arbeit verweist auf die sagenhafte Figur des Till Eulenspiegel, dem wandernden Narren, der mit Sarkasmus und Radikalität die Scheinheiligkeit und Absurdität der gesellschaftlichen Formen und Normen attackierte und übrigens aus Kneitlingen im Lande Braunschweig stammt. ${ }^{632}$

„Eulenspiegel übt als Außenseiter der Gesellschaft Kritik an Zeitverhältnissen, Ständen und Verhaltensweisen. Obwohl der Schalk selbst die von ihm anfgezeigten und kritisierten Phänomene verkörpert, ist er kaum an gesellschaftliche Zwänge ausgeliefert. Selbst als Eulenspiegel in offenbar existentieller Notlage im Kloster Mariental renevoll um Aufnahme ersucht, gibt er bereits mit seinem für viele seiner auf Sprachwitz basierenden Streiche programmgemäßem Anerbieten, alles zu tun, was man ibn heiße, zu verstehen, daß er seinen Prinzipien treu bleiben wird. Auch unter dem Galgen noch erwirbt Eulen-

629 Diese Aufführung stand im Rahmen der Ausstellung „Kunstlandschaft BRD“; die Aktion wurde noch mehrfach aufgeführt und 1985 entstand das Tape zur Aktion.

630 Rosenbach im Gespräch 2001: „Das Videotape „Die Eulenspieglerin“ setzt sich zusammen aus „Demeter“ und „Das Mädchen wächst weiter“. Das waren in Gent und in Köln die zwei Performances, die zusammen mit der dritten in Hamburg das Videotape 'Die Eulenspieglerin' bilden."

631 Da diese Arbeit in der Literatur, explizit bei Schröder intensiv untersucht wurde, werden hier die Ergebnisse zusammengefasst und stattdessen ein anderes, ebenso komplexes Werk genauer untersucht: die „Or-Phelia“.

632 Till Eulenspiegel ist zu den so genannten „Trickster“ zu rechnen. So werden in der Mythologie schillernde Gestalten bezeichnet, im Deutschen am ehesten mit „Schelm“ oder „Schalk“ aber auch als Betrüger oder Tölpel zu bezeichnen. Trickster bringen in ihren ganz unterschiedlichen Erscheinungen die Menschen zum Lachen, doch verbirgt sich hinter ihren Handlungen und Aussprüchen meist bitterer Ernst. (Vgl. Hirschberg 1988, S. 490) 
spiegel durch einen Streich die Freiheit, was ibm einen übermenschlichen Charakter verleiht." "r33

Neben dem Außenseitertum und dem Sprachwitz kennzeichnet zudem eine symbolische Handlungsweise die Eulenspiegelfigur:
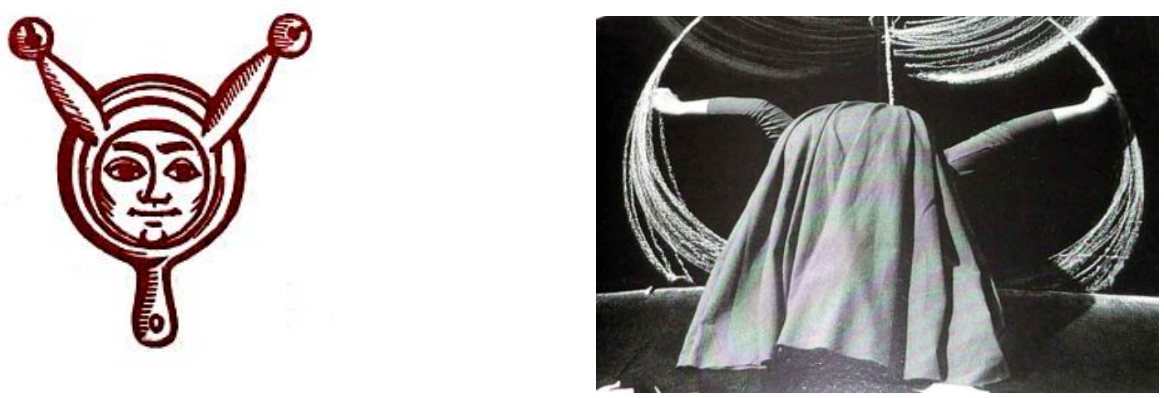

Abb. 166-167: Eulenspiegel Darstellung und Die Eulenspieglerin, 1985, Aktionsfoto

„Der symbolische Gestus der Handlungsweisen Eulenspiegels wird von einer Figur getragen, die selbst, umgeben von einer symbolischen Aura, von gesellschaftlichen Zwängen weitgehend unabhängig ist." "334

Der Name dieses provozierenden Schalks setzt sich aus dem Wort „Eule“, dem Symbol der Weisheit, und „Spiegel“, dem Symbol der Reflexion zusammen. 635 Doch haben diese beiden Begriffe eine tiefere - aus dem Niederdeutschen abzuleitende - Bedeutungsschicht, die der Künstlerin bekannt war. ${ }^{636}$ „Ulenspegel“ wird als Satzname „Feg (mir) den Spiegel“ gedeutet, wobei Spiegel scherzhaft für „Hinterteil“" steht.

633 Aichmayr 1991, S. 29

634 Aichmayr 1991, S. 29

635 Aichmayr weist zudem auf die jeweiligen mehrdeutigen Symbolgehalt, die in diesen Begriffen mitschwingen. (Vgl. Aichmayr 1991, S. 35-37) Die Eule sei seit der Antike „Symbol der die Dunkelheit des Nichtwissens durchdringenden Weisheit“. Seit dem Mittelalter erfolgte allerdings eine Dämonisierung dieses Tieres und in Ägypten und Indien galt die Eule als Totenvogel und in diesem Sinne sieht der Volksglauben bis heute im Ruf der Eule eine Vorankündigung von Unglück oder Tod. Ähnlich vereine die Symbolik des Begriffs „Spiegel“ Konträres: Einerseits Symbol der Eitelkeit und Wollust, andererseits der Klugheit und Wahrheit. Der Begriff verweist im Mittelalter auch auf einen Kodex von Gesetzen. Aychmayr fasst zusammen, dass auf die Eulenspiegelfigur die Bedeutungen „Weisheit und Schalktreiben“ zutreffen: „In diesem Sinne möchte er dem Häßlichen in der Welt einen Spiegel vorhalten." (Aichmayr 1991, S. 37)

636 Vgl. Kat. Toronto 1989 
Und genau dieses wandte die Künstlerin im Verlauf der Aktion dem Publikum zu. So zeigt ein Foto der Aktion die Künstlerin vor der - bis entsprechend der Körpergröße der Künstlerin mit schwarzem Papier überzogenen - Wand unter einer der schwarzen Engelsfiguren nach vorne gebeugt mit den ausgestreckten Armen mit weißer Kreide Kreise auf den schwarzen Untergrund zeichnend.

Für die Aktion waren an der Stirnwand des rechteckigen Ausstellungsraumes insgesamt vier Scherenschnitte aus schwarzem Papier mit der Figur aus der Villa dei Misteri aufgehängt, die bereits bei den Schmelzprozessen begegnete.637 Oberhalb der schwarzen Papierbahn waren diese aus dieser immer höher hervorragend, aufsteigend angeordnet. In der Hand hielt jede auch hier einen Zweig. An der linken Seitenwand waren fünf großformatige farbige Zeichnungen mit alchemistischen Darstellungen übereinander gehängt. An der gegenüberliegenden Wand hing ein Paar blanke, silberne Hörner aus massivem Metallguss. ${ }^{638}$ In der Mitte des Raumes lagen ausgerissene, tellergroße Seidenpapierbögen auf dem Boden, die auf einer dreieckigen Fläche ausgebreitet waren. In der Mitte dieses Dreiecks stand ein Monitor am Boden. Sein Bild zeigte ein Tape mit der Großaufnahme des Gesichtes der Künstlerin, wie dieses sich durch die Reflexion einer Spiegeloberfläche der Kamera darbot. Durch die physische Anstrengung des Haltens des Spiegels begann das Spiegelbild immer wieder zu vibrieren, wodurch die Gesichtszüge verzerrt und verwischt wurden, so wie dadurch auch ein schwaches Geräusch erzeugt wurde. ${ }^{639}$ Die Künstlerin agierte zwischen den Zeichnungen auf der einen, und den metallenen Hörnern auf der anderen Seite. Ihr Agieren fand in einem kreisenden Tanz ihren Höhepunkt und Abschluss. Während der Aktion wurde zweimal nacheinander der gleiche Text gesprochen, der um das Thema des Weges, der Grenze und der Zeit kreiste. ${ }^{640}$ Claudia Lupri analysierte die Aktion wie folgt:

637 Schröder benennt die Figur als Siegesgöttin Nike, die geflügelte Göttin oder griechische Götterbotin und Personifikation des Sieges, die meist schwebend dargestellt wird oder geflügelt mit Palmzweig und Lorbeerkranz. Ich sehe in ihr aber die Gestalt der geflügelten Figur aus der Villa Mysterie in Pompeji, die uns bereits begegnete und im weiteren Werk immer wieder eingesetzt ist. Aber natürlich kann die positive Konnotation auf die Symbolik der Aktion übertragen werden.

638 Das Horn wird auch im sakralen Zusammenhang genutzt und tritt auch als Füllhorn in Erscheinung. Dieses war ursprünglich das Horn der großen Mutter in ihrer Kuh- oder Ziegengestalt. Alle guten Dinge strömten aus dem Horn hervor. Dies war ein symbolisches Gebet zur Göttin, die Fruchtbarkeit der Erde und den Überfluss an Feldfrüchten andauern zu lassen. (Walker 1997, S. 132) Die Kegelform, die bereits bei den Hauben auftauchte, kehrt hier in der Form der Hörner wieder.

639 Im Monitor erscheint das Spiegelbild des Gesichtes der Künstlerin mit Verzerrungen. Der Spiegel ermöglicht den Blick hinter die Oberfläche ins Innere. Dieses Motiv begegnete bereits im Feentape und außerdem findet sich dieses Motiv einer Frau, die in eine Schüssel blickt, auch in dem antiken Fresko.

640 Der genaue Text ist in Kap. IV.5.2.3e) zu finden. 
„Rosenbachs weibliche Version der Legende beinhaltet nichts von der Robeit, aber alles von der Vielfältigkeit von Bedeutung und Weisheit. Die Eulenspieglerin ist eine Figur von Stärke und Mut, sie wagt das Unbekannte obne Angst. Sie zieht es vor sich nicht vorzustellen, was kommt; sie weiß, dass sie alle Hindernisse bewältigen kann, die ibr in den Weg gelegt werden. "641

Und die Kunsthistorikerin fügte an:

„Das Unvermeidliche der menschlichen Schwachheit so verrückt, wie es in der zynischen Till Eulenspiegel Sage porträtiert wird, wandelt Rosenbachs poetisches Werk in ein Potential von menschlicher Stärke, Mut und Hoffnung. Die Lektion wurde gelernt. "642

In seiner eingehenden Untersuchung und Deutung der Aktion verweist Johannes Lothar Schröder auf die Gleichzeitigkeit von Fiktion und Realität entsprechend der „Traumzeit“ und der „Jetztzeit“. ${ }^{643}$ Durch das Verbinden beider Ebenen in einem synchronen Erleben werde versucht, den Zuschauer zum Zeugen des inneren Geschehens zu machen, und ihm den Einstieg in die Tranceebene zu ermöglichen. ${ }^{644}$ Weiter analysiert der Kunsthistoriker:

„Der abschließende Tanz verdichtete die Inhalte auf das Wesentliche: Der Androgyn der Alchemisten wurde inszenatorisch verkörpert. Durch die Drehung wurden seine körperlichen Spezifike and die Gegensätze von vorne und hinten verwischt. Mit den rotierenden Händen wurden oberhalb des Kopfes und in der Höhe des Rumpfes zwei imaginäre Kreise, Ellipsen oder Spiralen beschrieben, die den Körper umfaßten und in eine Aura büllten. Der Kreis als das den Körper strukturierende Schema der Renaissance, wie es durch die Kreidezeichnung am Fuße der Nikefigur angedeutet worden war, wird durch ein neues, auf Bewegung fußendes rituelles Konzept abgelöst. Das im Dualismus von männlich und weiblich gründende System der vier Elemente, wie es im Androgyn verkörpert ist, wurde durch Bewegung verzeitlicht. "645

Er fasst interpretierend zusammen:

„Die vierte Dimension in einer Performance wie „Die Eulen-Spieglerin“ wird zu einem Modell der Seele, zur Ausdrucksform ihrer Zustände und Bewegung, die durch den agie-

641 „Rosenbach's female version of the folk legend contains none of the crudity, but all of the multiplicity of meaning and of wisdom. The „Eulenspieglerin“ is a figure of strength and courage, she ventures into the unknown without fear. She prefers not to imagine that which is to come; she knows that she can handle whatever obstacles are laid in her way." (Lupri in: Kat. Toronto 1989, S. 22)

642 „The inevitability of human weakness as folly as portrayed in the cynical Till Eulenspiegel saga, is transformed in Rosenbachs poetic work into potentiality of human strenght and courage and hope. The lessons have been learned.“ (Lupri in: Kat. Ontario 1989, S. 23f)

643 Dieser Begriff der für innerliche Prozesse stehenden „Traumzeit“ begegnete bereits bei der „Einsamen Spaziergängerin“.

644 Schröder 1990, S. 161-179

645 Schröder 1990, S. 178 
renden Körper repräsentiert wird. Körper und Installation in einer Performance werden zu einer ,symbolischen Form" der Zeit. "\$46

\section{IV.5.2.1 Das Videotape „Die Eulenspieglerin“}

Für das 1985 entstandene Tape mit dem Titel „Die Eulenspieglerin“647 wurden nun Videoaufnahmen, die während der Aufführungen im Kunstverein Hamburg, beim Musikfestival in Köln sowie im Museum Van Hadendaagse Kunst, Antwerpen gemacht wurden mit videospezifischen Gestaltungsmitteln zusammengefügt. ${ }^{648}$ Aus den Dokumentarsequenzen entstand ein eigenständiges Tape, das den vorangegangenen Performanceablauf nicht mehr nachvollziehen lässt. Dabei weichen die Dauer der Performance und die des Tapes stark voneinander ab. Das verbindende Glied in der bildlichen Umsetzung der inhaltlichen Aussage bleibt aber in beiden Kunstformen der identische poetische Text, der die Performances wie auch das Tape begleitet. Dieses Tape soll nun in der im Kapitel Methodik vorgestellten Weise untersucht werden.

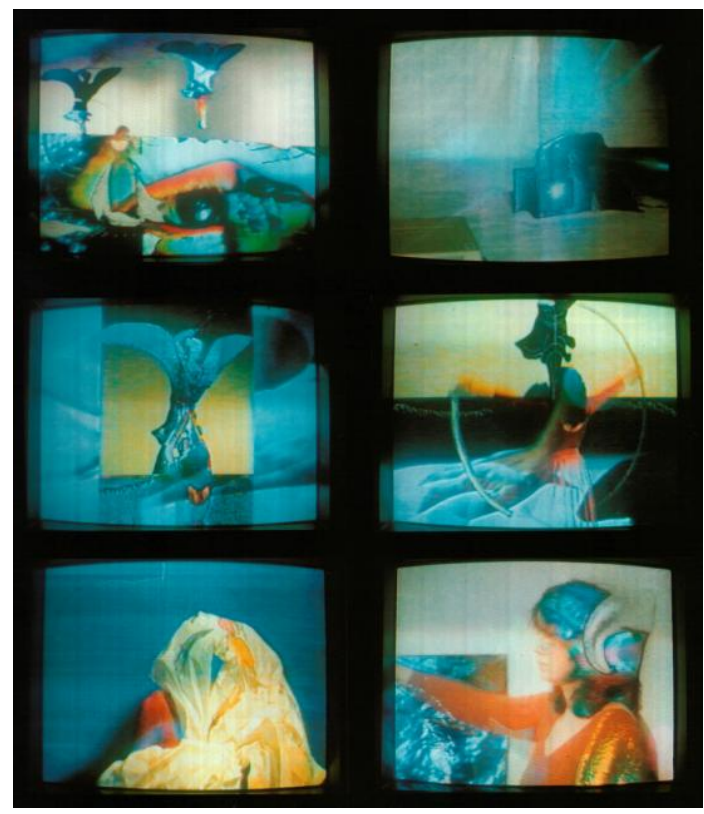

Abb. 168-173: Die Eulenspieglerin, 1985, Videostills

646 Schröder 1990, S. 179

647 Die 18-minütige Videoarbeit ist auf der beiliegenden DVD gespeichert. Das Protokoll zu diesem Tape findet sich im Anhang in Kap. VIII.1.

648 Die Kameras führten dabei unter anderem Ursula Braun und Dirk Pauvels. 


\section{IV.5.2.2 Beschreibung des Tapes}

Auf dem schwarzen Grund steht oben links in hellblauer Blockschrift: „1985“, am unteren Rand in der Mitte „DIE EULENSPIEGLERIN“. In der Bildmitte öffnet sich nach sechs Sekunden eine Kreisblende, die soweit wächst, bis sie am unteren Rand die Schrift berührt. Der Kreisinsert zeigt die Künstlerin in Großaufnahme, während sie sich gekleidet in ein rotes Kleid mit ausgestreckten Armen um ihre eigene Achse dreht - gegen den Uhrzeigersinn. Bei ihren Drehungen hält sie einen weißen Schal in den Händen. Der Hintergrund zeigt ein rotes Schriftzeichen auf einem weißen Foliengrund. Nach rund 20 Sekunden wechselt die Schrift auf dem schwarzen Rand, oben links steht jetzt in weiß: „von“ und unten in der Mitte ebenfalls in weiß und in Großbuchstaben: „ULRIKE ROSENBACH“. Dann wird die Kreisblende wieder kleiner und auch die weiße Schrift wird ausgeblendet und der Bildschirm ist für mehrere Sekunden vollkommen schwarz.

Die neue Aufnahme in amerikanischer Einstellung zeigt im unteren rechten Teil den Oberkörper der Künstlerin im Dreiviertelprofil von links in dem roten Kleid. Das untere Drittel der Aufnahme, im Performanceenvironment ursprünglich die schwarze Papierwand, ist durchwoben mit einem elektronisch eingefügten Motiv, aus zunächst unklaren Formen in den Farben blau, schwarz und weiß. Die oberen Zweidrittel der Aufnahme zeigen die gelbe Wand des Raumes.

Die Kamera zoomt an die Frau vor der Wand heran, so dass der untere Streifen mit der zweiten Aufnahme breiter wird. Der in Großaufnahme zu sehende Oberkörper der Frau, läuft dabei von rechts nach links durch das Bild, wobei die Kamera der Bewegung folgt. Die Aufnahme mit den schwarzen Schwüngen auf dem weißen Grund - es ist der Ausschnitt einer Spirale - wird stärker, hebt sich aus dem Hintergrund und verschluckt zusehends die Frau, die immer weiter Richtung rechten Rand wandert, während ihr Kopf über die Hintergrundwand herausragt. Die Überblendung beider Bildsequenzen setzt sich so lange fort, bis schließlich das Gesicht und der Körper der Frau vollständig von den schwarzen Schwüngen der Spirale auf weißem Grund überzogen sind. Der Kopf im Profil in der Großaufnahme wandert herauf und herunter im Bild, während die Künstlerin mehr und mehr ihren Hinterkopf der Kamera zuwendet.

Ein Zoom zur Halbnahen setzt ein und zeigt die Frau, wie sie in der Mitte des Bildes - den Rücken der Kamera zugewandt - vor dieser Wand steht. Während der Zoom immer weiter zurückweicht, hebt die Akteurin ihren ausgestreckten rechten Arm von unten nach oben. Die Künstlerin steht dann in der Halbtotalen aufrecht in der Mitte der Aufnahme vor einer großformatigen Zeichnung, in der ein in ein Rad eingeschriebener Körper zu sehen ist. ${ }^{649}$ Dann wird die rote Kleidung der Frau mit einer zweiten Aufnahme durchwoben, während diese ihre

649 Es ist ein der bereits erwähnten alchemistischen Zeichnungen, die Darstellung zeigt den hinduistischen Gott Shiva, vgl. Kap. IV.5.2.3d) 
Hand nach unten führt. Dabei wird kurz ein Auge in Detailaufnahme im Rücken der Agierenden sichtbar. In flüsterndem, hallendem, die Worte zum Teil wiederholenden Ton erklingt die Stimme der Künstlerin nun aus dem Off, die sagt: „Es gab keine Hindernisse, die nicht zu überwinden gewesen wären..." Dazu schiebt sich vom unteren Rand ein neues Motiv in blauen Farben nach oben. Allmählich erscheint der blaue Rand auch von oben und von beiden Seiten, so dass die zuvor bildschirmfüllende, jetzt innere Aufnahme in Rechteckform immer weiter in sich zusammen schrumpft. Der zugleich wachsende blaue Rahmen zeigt schließlich bildschirmfüllend das Gesicht der Künstlerin in Bewegung als Frontalansicht in Nahaufnahme. Der Blick der Agierenden ist dabei durchdringend auf den Betrachtenden gerichtet.

Das kleine Rechteck verharrt in der Mitte des Bildschirms, während das rahmende Porträt der Künstlerin mehr Farbigkeit zeigt, während in dem Rechteckinsert Bewegung zu beobachten ist. Die Künstlerin zeigt in der dort zu sehenden Halbnahen der Kamera den Rücken und geht nach rechts. Während sich ihr Gesicht in der Nahaufnahme hin und her bewegt, beginnt das Mittelrechteck wieder zu wachsen, bis es den Bildschirm erneut ganz ausfüllt und eine Halbnahe der Künstlerin im roten Kleid zeigt, die mit dem Rücken zur Kamera und vor einer großformatigen Zeichnung auf gelbem Grund steht.

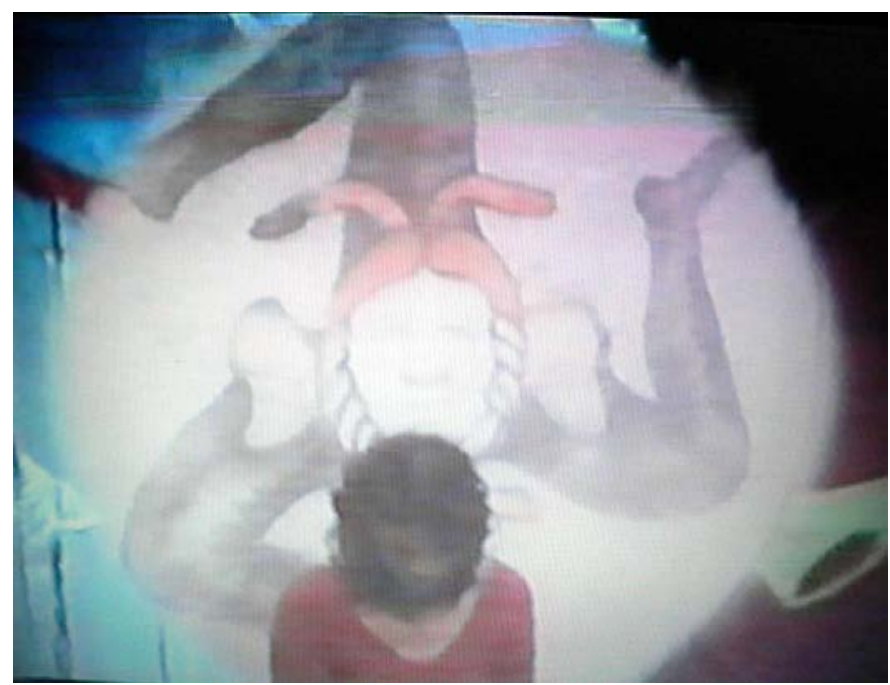

Abb. 174: Alchemistische Zeichnung mit Eulenspiegelmotiv, Videostill aus die Eulenspieglerin, 1985

Auf der Zeichnung ist eine Figur zu sehen, die in der Mitte einen Kopf hat, der an den des Till Eulenspiegel erinnert, ergänzt um sehr große Augen. Von diesem Kopf greifen drei Beine in den Raum. ${ }^{650}$ Die Künstlerin tritt zurück und hebt die

650 Es handelt sich hier um eine weitere der erwähnten alchemistischen Zeichnungen. 
Zeichnung von der Wand. Dabei dunkelt die Aufnahme ein. Als sie die Zeichnung über den Kopf hebt, wird die Aufnahme wieder heller. Dann reißt sie das Blatt von der Wand, und während die Kamera in Amerikanischer um die Akteurin herum fährt, tritt die Frau rückwärts an den rechten Bildrand. Die linke Bildschirmseite bleibt durch die gelbe Papierbahn gefüllt. Im Hintergrund findet sich derweil wieder der Blueboxeffekt in der zuvor schwarzen Wandfläche: Sie zeigt leuchtend blau-weiße Farben mit noch unklaren Formen.

Dann ist der Blick frei auf die Rückwand, während die Künstlerin angeschnitten im Profil am rechten Bildrand zu sehen ist. Ein Blueboxbild füllt im Hintergrund die schwarze Papierbahn und die Figurensilhouetten, die oben herausragen. Die elektronische Einblendung zeigt rechts eine weiße Fläche, dann einen gelbrot-blauen Lichtbogen und eine graue Fläche, die sich rechts anschließt. Die Stimme aus dem Off setzt nun fort: „Was hatte sie schon zu verlieren. Und (und, und) sie hatte nie so etwas wie Angst gehabt." Die Agierende in roter Kleidung hebt währenddessen wieder die gelbe Papierbahn mit der Zeichnung. Der Hintergrund zeigt dazu die Künstlerin im weißen Trikot vor einer weißen Wand, ihr Kopf samt Blick ist nach rechts gewendet. Auf dem hellen Trikot zeichnen sich farbige Lichtstreifen ab. Dann zeigt die Halbnahe die Frau im roten Kleid in die gelbliche Papierbahn gehüllt. Sie steht in der rechten Bildhälfte mit dem Rücken zur Kamera bis der Hintergrund mit der Nahaufnahme der Künstlerin im weißen Trikot wieder sichtbar wird. Von der Agierenden ist dabei nur der Oberkörper zu sehen. Ihr Kopf ist vom oberen Bildrand abgeschnitten. Dann schrumpft die Rechteckblende schnell zusammen, und die Aufnahme, die zuvor auf der schwarzen Fläche eingeblendet war, füllt nun das ganze Bild und wandert auf diese Weise vom Hintergrund vollständig in den Vordergrund. Diese Bildsequenz zeigt zunächst in Amerikanischer die Frau, die erst am Boden sitzt, dann aufsteht, wobei die Kamera in Großaufnahme auf deren Brust und Hände fokussiert. Dann öffnet sich die Rechteckblende schnell. Sie ist nun unterlegt mit einem zweiten, zunächst schwer zu erkennenden Motiv. Die Großaufnahme im Vordergrund zeigt währenddessen die Künstlerin in Frontalansicht, wie diese in die Hocke geht. Sie hockt schließlich von der Mitte aus etwas nach rechts versetzt im Bild. Dann verweben sich die beiden Aufnahmen mittels Trickblende und Blueboxeffekt, wodurch das Vordergrundmotiv in den Hintergrund wandert. Die Stimme begleitet diese Bilder mit den Worten: „Sie war verwöhnt von ihrem Mut.“

Nach einem Schnitt zeigt die folgende Nahaufnahme im Standbild eine linke Hand, die von unten in die Bildmitte hineinragt und ein silbernes Horn hält, dessen Spitze nach rechts gebogen ist. Im Hintergrund ist eine weiße Fläche zu sehen, auf der ein schwarzer Schwung gezeichnet ist, der von der linken Seitenmitte nach oben rechts ansteigt. Rote und gelbe Dreiecke erscheinen in der Bildecke, als Rahmen einer Kreisblende. Die Stimme spricht dazu aus dem Off: „An fünf verschiedenen Tagen zog sie zwei Hörner auf.“ Wieder folgt ein harter Schnitt. Das 
Gesicht der Künstlerin ist danach frontal in Großaufnahme mit buntem Licht überzogen, ein pinker Lichtstrahl verläuft über ihr rechtes Auge und die Stirn. Das silberne Horn wird nun von rechts ins Bild bewegt. Es wandert weiter nach rechts durch die Aufnahme und links erscheint ein zweites Horn, bevor beide Hörner zurück wandern. Die Augen blinzeln und die Kamera fokussiert auf die zwei Hörner in Großaufnahme. Diese werden nun auf den beiden Handrücken befestigt und vor der Brust der Künstlerin in Nahaufnahme präsentiert. Dabei wandert der Kopf nach oben aus der Aufnahme heraus. Es folgt ein leichter Zoom auf eine Amerikanische, so dass auch der Kopf zusammen mit dem Oberkörper der Frau im weißen Trikot allmählich das Bild füllen. Die Akteurin hebt ihren linken Arm über den rechten Bildrand aus der Aufnahme. Der weiße Arm ist dabei überzogen mit farbigen Lichtstreifen in rot, gelb und blau. Die auf einen Schnitt folgende amerikanische Einstellung zeigt die Künstlerin, die im Profil mit dem Rücken vor der Wand am rechten Bildrand steht. Vor ihren Haaren im oberen linken Bildviertel ragt jetzt eines der Hörner aus der Wand heraus. Im Hintergrund füllt ein schwarzes Quadrat die untere, rechte Ecke.

Nach einem weiteren harten Schnitt liegt die Performerin im weißen Trikot im Zentrum des Bildes auf dem Rücken am Boden. Sie blickt in der Halbnahen, die leicht von oben aufgenommen ist, in die Kamera. Durch diese Aufnahme sieht man eine zweite schimmern. Sie zeigt in Amerikanischer wie der Oberkörper der Frau im roten Kleid von rechts oben nach links unten über den Boden durch das Bild robbt, während die Kamera mit der Bewegung mit wandert. Dabei zeigt der untere Rand der Aufnahme weiße Papierfetzen und die Stimme spricht kontinuierlich: „... und machte sich auf den Weg. Es war leicht sich zu verlieren....“ Beide sich überlagernden Motive sind auch weiter zu sehen. Nun aus einer etwas anderen Perspektive. Sieht man doch jetzt in einer Halbtotalen, wie sich in der linken Bildhälfte die Frau im weißen Trikot versucht aufzurichten, während in der anderen Einstellung, einer Großaufnahme, die Frau im roten Kleid weiterhin nach links über den Boden robbt und es so wirkt, als würde der Kopf der rot gekleideten Frau den Körper der weißen Frau durchdringen, beziehungsweise von ihr verschluckt werden. Dann wird die Figur im weißen Trikot zunächst blasser, richtet sich in der Bildmitte auf, und wird wieder stärker sichtbar. Als sie erneut blasser wird, robbt die rote Figur immer näher an die Kamera heran, wobei diese der Bewegung im Schwenk folgt. Schließlich schiebt sich eine Kreisblende von den Ecken her in dieses Bild. Aus dem Off spricht die Stimme dazu: „Es gab keine Hindernisse, die nicht zu überwinden gewesen wären und sie hatte nie so etwas wie Angst gekannt. Was hatte sie schon zu verlieren..."

Die folgende Nahaufnahme nach einem Schnitt geht noch näher an das Gesicht und die Hände der Künstlerin heran, während diese sich weiter schüttelt, wodurch eine Unschärfe in der Aufnahme entsteht. Dann taucht die Kreisblende erneut auf und fügt in ihrem Rand ein neues Motiv ein, wodurch die obere linke 
Ecke blau und die untere rechte Ecke rosa erscheint. Die Stimme setzt dazu fort: ,...Sie war verwöhnt von ihrem Mut.“

Die durch Schnitt angefügte Nahaufnahme zeigt den linken Arm der Künstlerin, dessen Oberarm parallel zur unteren Bildkante verläuft, während der Unterarm nach oben angewinkelt ist. Dann hebt sich der rot beärmelte Arm. Die rotbekleidete Akteurin tritt von rechts in die Aufnahme, zeigt der Kamera den Rücken. Dabei schimmert das Gesicht der Knieenden durch das rote Kleid und die Hände. Eine Rückenansicht in Nahaufnahme ist angefügt und die Hände der Knieenden schwimmen hier durch den Rücken. Dann wandert die Akteurin nach links aus der Aufnahme, kommt wieder zurück und dreht sich ins Profil von links. Eine an dieser Stelle eingefügte Kreisblende fokussiert auf die Knieende und die folgende Halbnahe zeigt, wie die rote Frau erst im verlorenen Profil, dann in Rückenansicht in der Mitte vor der schwarzen Wand steht. Stille setzt an dieser Stelle ein bis zum Schluss dieser Einstellung, während sich in dem zweiten sichtbaren Motiv die Künstlerin kontinuierlich weiter über den Boden schiebt - von rechts nach links. Dann wird der Hintergrund ausgeblendet und nur die Kreisblende wird mit der Detailaufnahme der im Profil Knieenden gezeigt.

Zu sehen ist in dem nun durch Schnitt angefügten Standbild in Großaufnahme eine linke Hand, die von unten in die Bildmitte hineinragt und ein silbernes Horn hält, dessen Spitze nach rechts gebogen ist. Im Hintergrund ist eine weiße Fläche zu sehen, auf der ein schwarzer Schwung gezeichnet ist, der von der linken Seitenmitte nach oben rechts ansteigend verläuft. Die Stimme aus dem Off setzt wieder ein: „An...“ Eine Großaufnahme des Gesichtes der Künstlerin folgt. Zwei Hörner ragen von rechts und links unten in die folgende Aufnahme. Ihr Gesicht ist überzogen von einer gelben und rosafarbenen Diagonale aus Licht. Die Kamera zoomt auf eine Amerikanische und die Stimme setzt fort: „,... fünf verschiedenen Tagen zog sie zwei Hörner an..." Der Oberkörper und Kopf der Frau im roten Kleid sind im Profil von links am rechten Rand zu sehen. In der Halbnahen beginnt sie sich an der dahinterliegenden schwarzen Wand entlang zu bewegen nach links, die Kamera folgt der Bewegung. Die Akteurin reißt, während sie an ihr entlang schreitet, an verschiedenen Stellen den oberen Rand der Papierbahn ein. Die Papierfläche wird dabei im Blueboxeffekt durchwoben mit einem Motiv, das einen schneebedeckten Berg zeigt. Das Bild, das die Schreitende zeigt, zoomt auf eine Halbtotale. Und eine kleine Kreisblende öffnet sich in der oberen Hälfte. In dem Insert ist kurzzeitig ein Auge in Großaufnahme zu sehen. Dann verschwindet die Blende wieder und ein riesiges Auge in Detailaufnahme wandert von links nach rechts durch die, die untere Bildfläche füllende, Papierbahn. Synchron mit einem Augenaufschlag erfolgt der Schnitt. Und die Stimme begleitet diese Bildsequenz: „...und machte sich auf den Weg. Es war leicht sich in der Dunkelheit zu orientieren." Die Detailaufnahme des Auges füllt als Blueboxbild in der schwarzen Papierbahn die unteren Zweidrittel des Bildschirms und auch die Figuren, die oben 
aus der schwarzen Fläche herausragen, sind mit der Großaufnahme des Gesichtes gefüllt. Dazu ist zu hören: „, Sie zog es vor, keine Vorstellung zu haben, von dem, was kommt..." In der Aufnahme ist weiter im oberen Teil die Bergspritze zu sehen. Das große Auge blinzelt wieder, beide Motive durchweben sich, und die Stimme setzt fort: ,...und keine Antwort zu wissen auf das, was gefragt ist und...“ Ein runder Kreisinsert in der oberen Mitte des Bildes zeigt nun eine schneebedeckte Bergspitze, sowie eine menschliche Figur im Profil in überdimensionaler Größe links daneben stehend. Während die linke obere Fläche neben dem Kreis Blau eingefärbt ist, füllt die restliche Bildfläche eine Detailaufnahme des Gesichtes der Künstlerin, wobei ihr rechtes Auge, das manchmal blinzelt, direkt unter der Kreisblende erscheint. Die Blende wandert dann langsam auf der Waagerechten zum rechten Bildrand, während eine große Fläche des Bildschirms inzwischen Blau gefärbt ist und die gesamte Szene von dem Bergmotiv überspannt wird. Die Stimme spricht: ,... sich aus nichts, nichts zu machen.“

Die Halbnahe nach einem Schnitt zeigt die Künstlerin, die im weißen Trikot auf der rechten Bildhälfte am Boden frontal zur Kamera hockt. Ein gelber, roter und blauer Lichtstreifen verlaufen nebeneinander senkrecht über ihre linke Brusthälfte. Hinter der Hockenden erscheint ihr Umriss in vergrößerter Form in den Farben gelb, rot und blau, bevor die Lichtstreifen von links nach rechts durch das Bild pendeln. Die Stimme aus dem Off lässt dazu verlauten: „Alles erschien ihr...“ Währenddessen fokussiert die Amerikanische das Profil von Kopf, Armen, Rumpf und Oberschenkeln der Künstlerin, die das weiße Trikot trägt. Sie macht auf dem Boden eine Brücke. Dazu hat sie die Hände und Füße aufgestellt, ihr Gesäß in die Luft gehoben, den Kopf in den Nacken gelegt. Während sie in dieser Haltung zu sehen ist, wird ihr Unterleib mit den farbigen Lichtstreifen angestrahlt, während die Stimme den Satz vollendet: ,,... ein wenig abgehoben.“ Die Künstlerin senkt ihr Gesäß nach unten und setzt sich auf den Boden. Und die Stimme spricht weiter: „Sie war aufgeregt, doch nach außen blieb sie cool.“ Ein Zoom zur Halbnahen setzt ein und zeigt hinter der Agierenden einen bunten Schatten an der weißen Wand, an der auch ein schwarzes Zeichen steht, das an ein „T“ erinnert. ${ }^{651}$ Sie beugt sich sitzend vor und streckt die Arme nach vorne. Die anschließende Halbnahe zeigt die Akteurin am Boden sitzend auf der rechten Bildschirmseite. Und nach einem Schnitt zeigt die Halbnahe die Frau im weißen Trikot, die in der rechten Bildhälfte steht. Sie hat nun den Oberkörper nach vorne gebeugt und ihre Arme hängen nach unten. In dieser Haltung wendet sie ihr Gesäß der Kamera zu. Dann schlägt sie einen Purzelbaum rückwärts und steht auf. Durchwebt ist diese Performanceaufnahme von einer zweiten Einstellung. Diese zeigt in Halbnaher die Akteurin, die in Schwarz gekleidet einen großen Fernsehapparat von rechts nach links über einen mit weißem Salz überzogenen Boden durch das Bild schiebt.

651 Es handelt sich um griechischen Großbuchstaben „Tau“ 
Dabei folgt die Kamera der Bewegung, so dass die agierende Figur während der gesamten Sequenz in der Halbtotalen in der rechten Bildhälfte verbleibt. Die Stimme kommentiert: „Es gab keine Hindernisse, die nicht zu überwinden gewesen wären..." Nach einem Schnitt ist dieselbe Aktion aus zwei veränderten Aufnahmeperspektiven zu sehen. Der Monitor wird nun durch diesen Salzgrund auf die Kamera - und damit den Betrachter - zugeschoben. In der unterlegten Aufnahme - einer Halbnahen - liegt die Frau im weißen Trikot auf dem Rücken im Salz, die Arme und Beine sind in die Luft gestreckt. Zu hören ist dazu: „Und sie hatte nie so etwas ...." Nach einem Schnitt zeigt die Nahaufnahme die erhobene linke Hand in der Bildmitte. An der Fläche im Hintergrund sind schwarze Spiralschwünge und farbige Lichtstreifen zu sehen. Der Arm bewegt sich während eines leichten Zooms zum rechten Bildrand. Die angefügten Aufnahmen nach dem Schnitt zeigen wie der Monitor nun durch das Salz auf die Kamera - beziehungsweise den Betrachtenden - zugeschoben wird. In der unterlegten Aufnahme in Halbnahe liegt die Frau im weißen Trikot mit dem Rücken im Salz, die Arme und Beine sind in die Luft gestreckt. Auch nach dem folgenden Schnitt sind zwei Motive miteinander verwoben. Die eine Aufnahme in Halbnaher zeigt die Spirale an der Wand mit der Frau, die am Boden davor liegt. Zunächst liegt sie auf der Seite, das Gesicht der Kamera zugewendet. Dann dreht sie sich im Salz auf den Bauch und stützt das Gesicht auf die Hände. Die Stimme spricht kontinuierlich weiter:,,... wie Angst gekannt.“ Das Gesicht in der folgenden Großaufnahme wird durchwirkt von einem gleichbleibenden zweiten Motiv, das als Blueboxbild ins Schwarze eingefügt wird. Dabei wird es zunächst kurz aus- dann wieder eingeblendet. Die Künstlerin im weißen Trikot agiert darin zum einen im Vordergrund, während sie im Hintergrund in Schwarz gekleidet das Fernsehgerät von rechts nach links durch den Raum schiebt. Diese Handlung setzt sie fort bis schließlich die Weißgekleidete nach unten abtaucht und die Schwarzgekleidete über den Monitor gebeugt in Nahaufnahme zu sehen ist. Aus dem Off ertönt dazu: „Was hatte sie schon zu verlieren? Sie war verwöhnt von ihrem Mut.“

Nach einem Schnitt zeigt die Halbtotale die Künstlerin im dunklen Gewand, wie sie den Monitor durch den Raum schiebt. Alles Schwarze in der Aufnahme der Aktion ist nun allerdings durch ein blauweißes Licht ersetzt, dass eine fließende Bewegung zeigt. Die Bildsequenz erinnert an eine sehr schnellen Fahrt durch einen Tunnel oder auch Teilchenbeschleuniger. ${ }^{652}$ Begleitet wird diese Sequenz von einer Geräuschcollage, die an Windböen oder ein Strahlen erinnert, untermalt von leichten sphärischen Klängen. Zwischendurch verschwindet auf der Bildebene kurzfristig dieses zweite fließende Motiv und die Aufnahme bildet wieder die schiebende Frau in der Halbtotalen ab, bevor das Fließen wieder auftaucht. Auch während die Kamera dann an sie heranzoomt bis zur Nahaufnahme, bleibt das

652 Dies Motiv kehrt in dem Tape „An die Kinder“ wieder. (Vgl. Kap.V.5.) 
Fließen im Bild. Die Einstellung zoomt schließlich zurück zur Halbnahen und nach diesem Zoom ist der Monitor am linken Bildrand stehend zu sehen.
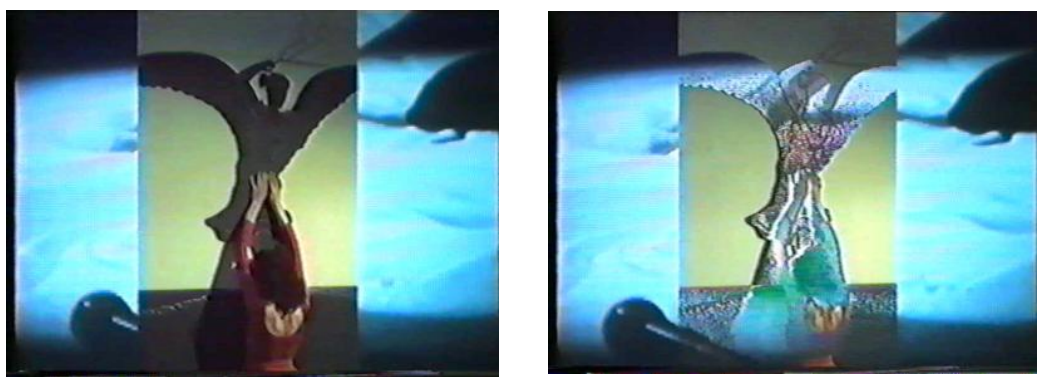

Abb. 175-176: 2 Videostills aus die Eulenspieglerin, 1985

Die folgende mit einem Schnitt angefügte Halbnahe zeigt in der Bildmitte stehend die Künstlerin im roten Kleid. Ihre beiden Arme hat sie vor der schwarzen Wand unter der oben herausragenden Figur über ihren Kopf erhoben. In der anschlieBenden Sequenz wird der Bildschirm senkrecht gedrittelt. In dem mittleren Feld bleibt die vorangegangene Einstellung zunächst unverändert sichtbar. Die beiden Streifen links und rechts bilden ein gemeinsames Motiv, dessen Mittelfeld überdeckt ist. Sie zeigen als Halbnahe eine kniende Frau im weißen Trikot. Ihre Hände streichen durch das weiße Salz und bald setzt ein Zoom ein zur Nahaufnahme der Hände. Auch im mittleren Streifen wird nun die schwarze Farbe der Wand und der Figurensilhouette im Hintergrund durch das Motiv der Hände, die durch das weiße Salz streichen, durchwoben. Und der folgende Zoom zur Nahaufnahme in den beiden rahmenden Feldern zeigt, wie sich die Künstlerin im weißen Trikot auf den Salzgrund legt. Während in dem Mittelfeld die Aufnahme der Rotgekleideten vor der Wand wegzoomt, füllt sich ein immer breiterer unterer Streifen mit dem Motiv der Seiten, der am Boden im Salz liegenden Frau. Bis schließlich dieser Mittelstreifen über die rechte Seite sukzessive aus dem Bild heraus wandert. Die verbleibende Aufnahme zeigt die Künstlerin in der Halbtotalen am Salzboden liegend. Sie rollt vom Bauch über die rechte Seite auf den Rücken und zurück, greift schließlich ein Mikrofon und hockt sich ins Salz. Als sie dann langsam aufsteht wird ihr Kopf vom oberen Bildrand abgeschnitten. Die Stimme aus dem Off begleitet: „Alles erschien ihr ein wenig abgehoben aber wie immer blieb sie cool. Sie zog es deshalb vor, keine Vorstellung zu haben, von dem, was kommt. Keine Antwort zu wissen, auf das, was gefragt ist..."

Der angeschlossene harte Schnitt fügt eine Amerikanische an. Diese zeigt die Künstlerin im roten Kleid, die in Rückenansicht vor der unten schwarz, oben gelb gefärbten Wand steht. Sie schlägt mit den ausgestreckten Armen neben ihrem Körper und malt dabei weiße Kreidekreise auf das Papier, die sich auf dem schwarzen Grund abzeichnen. Das zweite Motiv, das währenddessen in die schwarzen Partien der Aufnahme eingeblendet wird, zeigt wieder die Hände der 
Künstlerin auf dem Salzboden in Großaufnahme. Die Stimme spricht dazu: „,... und sich aus nichts, nichts zu machen."

Die Großaufnahme, die mit einem Schnitt angefügt ist, zeigt die Agierende nun mit einer grauen Jacke bekleidet. Sie hockt am Boden vor einem schwarzen Hintergrund und schwenkt den Oberkörper von links nach rechts hin und her. Dabei hält sie ein rotes Band in den Händen und ihre Stimme kommentiert: „,Der Weg wandt sich und verschwand ständig vor ihren Augen. Die Gegend veränderte bei jeder Wegbiegung ihre Sicht..." Eine Großaufnahme zeigt das Gesicht der Künstlerin, die erst am Boden sitzt, dann aufsteht. Die Stimme sagt dazu:,,...doch es gab..." Und eine Kreisblende zeigt dann in Amerikanischer die Künstlerin im roten Trikot vor einer großformatigen Zeichnung auf gelbem Grund. Es handelt sich erneut um eine alchemistische Zeichnung. Es ist dasselbe Motiv der Figur im Rad mit mehreren armen, das bereits begegnete. Die Akteurin hat davor stehend den rechten Arm erhoben, ihr Rücken zeigt zur Kamera. Um den Kreisinsert ist der Bildschirm zunächst schwarz, doch wird allmählich wird auch in diesen Flächen ein Motiv erkennbar. Es ist eine Nahaufnahme der Künstlerin, die im Salzgrund sitzt und deren Hände durch das weiße Mineral fegen. Langsam wird die Kreisblende größer und in ihr setzt ein Zoom ein zur Großaufnahme auf die Agierende. Zudem beginnt das äußere Randmotiv das Kreismotiv im Inneren zu durchdringen, während aus dem Off zu hören ist: „...keine Hindernisse, die nicht zu überwinden gewesen wären.“

Die Kreisblende zeigt nun die Künstlerin im roten Trikot, die in gelbe Papierbahnen gehüllt auf dem Fußboden sitzt. Vorne rechts im Bild steht ein Monitor am Boden. Dann beginnt die Performerin mit der weißen Kreide an die schwarze Wand im Hintergrund zu zeichnen. Durch dieses Motiv in dem Kreisinsert schimmert zudem die Gehende in Halbnaher. Die Stimme aus dem Off spricht dazu wieder: „Und sie hatte nie so etwas wie Angst gekannt. Was hatte sie schon zu verlieren. Sie war verwöhnt von ihrem Mut." Die Aufnahme in der Kreisblende zeigt weiter die in das Papier eingehüllte Künstlerin, die währenddessen mit der Kreide auf den schwarzen Hintergrund zeichnet. Durchwoben wird diese Halbnahe vom Motiv der Frau, die im Salz rollt. Aus dem Off ist zu hören: „Der Weg blieb, was er war."

Die Nahaufnahme zeigt die Frau mit der gelben Zeichnung über dem Kopf, dahinter findet sich die Tafel mit den Kreidezeichnungen. Die Kamera schwenkt nach unten, zoomt zunächst weg auf Halbnah und dann wieder heran auf eine Großaufnahme. Mittels Blueboxeffekt sind in dieser Einstellung die schwarzen Flächen mit der Aufnahme der stehenden Künstlerin im weißen Trikot gefüllt, bis dann diese Aufnahme ausgeblendet wird. Dann zoomt die Einstellungsgröße wieder weg auf eine Amerikanische, die zeigt, wie die am Boden vor der Wand sitzende Künstlerin aufsteht. Die Akteurin geht in die gelben Zeichnungen eingehülllt mit dem Rücken an der Wand entlang, wobei die Kamera ihrer Bewegung 
folgt. Die Stimme, die kontinuierlich diese Sequenz begleitet, hat an dieser Stelle einen leicht bitteren Klang: „Er war unveränderbar. Sie zog es deshalb vor, keine Vorstellung zu haben von dem, (...?) keine Antwort zu wissen auf das, was gefragt ist, und sich aus nichts nichts zu machen." Stille schließt sich an, während sich die Akteurin schließlich auf den Boden hockt, was als Halbtotale erscheint. Die folgende Trickeinstellung zeigt, wie sich der gelbe Papierhaufen vor der schwarzen Wand mit den Kreidezeichnungen bewegt. Das Papierknäuel, in dem die Künstlerin steckt, robbt, ohne dass die Akteurin sichtbar wäre, von rechts nach links durch das Bild und rollt auch über den Boden. Diese Halbnahe wird durchwoben von einer Großaufnahme der stehenden Künstlerin im weißen Trikot. Sie trägt hier die Hörner auf ihren Händen. Die Farben dieser Aufnahme sind unnatürlich eingefärbt: Blau-, Gelb- und Schwarztöne dominieren. Eine leicht glucksende Stimme beginnt dazu zu sprechen: „Die Zeit schien unendlich lang zu sein. Sie hatte das Gefühl, sich zu verirren und es gab keine Hindernisse, die nicht zu überwinden gewesen wären. Und sie hatte nie so etwas wie Angst gekannt.“

Die folgende Halbtotale zeigt die Frau im roten Trikot am Boden liegend in das gelbe Papier gehüllt vor der schwarzen Kreidewand. Daran schließt sich eine Einstellung mit einem Kreisinsert im blauen Rand an. In dieser Amerikanischen rollt die Künstlerin auf dem Boden hin und her, bis sie schließlich aufsteht und man erkennt, dass ihre Augen mit einem roten Schal verbunden sind. Die blau umrandete Kreisblende schließt sich nun schnell, so dass nach kurzer Zeit fast der gesamte Bildschirm blau ist, bis auf einen kleinen schwarzen Fleck. Aus diesem entwickelt sich ein schwarzes Zeichen, das schon mal in dem Tape begegnete, und als „Tau-Zeichen“ bezeichnet werden soll. Dieses steht - wie der einsetzende Zoom sichtbar macht - auf einer weißen Wand. Die Stimme aus dem Off spricht dazu: „Was hatte sie schon zu verlieren? Sie war verwöhnt von ihrem Mut.“

Die folgende Halbnahe zeigt die Künstlerin im weißen Trikot, während diese in der Mitte der Aufnahme auf dem Rücken am Boden liegt. Die Beine streckt sie in die Luft vor einer Wand mit nun grünem „Tau-Zeichen“ und einer schwarzen Spirale. Dabei überlagern die Schatten der in die Höhe gestreckten Beine die beiden übereinander liegenden Zeichen. Die Künstlerin spreizt die Beine auseinander. Das Motiv einer schwarzen Spirale wird nun auf einer anderen Bildebene in der Bildmitte mit einem Pinsel hinzugefügt. Es wird von innen nach außen und gegen den Uhrzeigersinn gezeichnet. Dann ist der Bildschirm kurz ganz Schwarz bevor ein grünes „Tau-Zeichen“ über die zuvor gemalte schwarze Spirale geblendet wird und dieses grüne Zeichen dann allein vor einem farbigen Hintergrund zu sehen ist. Die weiße Hand schwingt von rechts ins Bild und zurück und aus dem Off erklingt mit ruhiger Stimme: „Nach langer Zeit doch hatte sie die Orientierung im Griff..." Eine Großaufnahme zeigt die Künstlerin im Vordergrund, deren Körper hin und her schwingt. Hinter ihr liegt die schwarze Spirale im grünen 
Licht. Sie beugt sich in das Spiralzeichen, während ein blauer Grund - mit dunklem Bogen von unten rechts zur Mitte links - ins Bild hineinragt.

Als die Aufnahme zurück zoomt, zeigt sich das Tauzeichen im unteren linken Viertel des Bildschirms ganz. Und die Stimme setzt fort: „...Sie wußte genau, wann und wo sie ankam..." Die Kreisblende zeigt nun die Künstlerin im roten Kleid, die sich vor der schwarzen Kreidewand entgegen dem Uhrzeigersinn um ihre eigene Achse dreht. Den Rand des Bildschirms um den Kreisinsert füllt die Aufnahme der Künstlerin im roten Kleid vor der weißen Wand mit den Zeichen. Auch hier dreht sie sich - synchron zur inneren Bildsequenz - um die eigene Achse. Die Kreisblende wird größer und die Aufnahme in ihr zoomt auf eine Nahaufnahme, während die unsichtbare Stimme begleitet: „,..sie zog es deshalb vor, keine Vorstellung zu haben, von dem was kommt. Keine Antwort zu wissen, auf das, was gefragt ist..." Die angeschlossene Großaufnahme zeigt die Künstlerin im roten Kleid vor der weißen Wand mit roten Zeichen. Ihr Kopf ist hier vom Bildschirmrand abgeschnitten. Sie dreht sich kontinuierlich in der rechten Bildhälfte um ihre Achse, während sich im Zentrum der Aufnahme eine Kreisblende öffnet. Diese wächst schnell und zeigt in Großaufnahme die Künstlerin, die ihren Kopf mit dem Papier der Zeichnung verhüllt hat. Es ist zu erkennen, dass die Akteurin die Zeichnung schließlich fort wirft und ihren Kopf auf die Brust sinken lässt. Und aus dem Off heißt es weiter: „....und sich aus nichts, nichts zu machen. Es wurde eine Frage auf Leben und Tod. Sie hatte drei Hörner und zwei Wünsche.“

Die nach einem Schnitt angeschlossene Nahaufnahme zeigt die Künstlerin am rechten Bildrand. Sie trägt das weiße Trikot und streicht sich mit den Händen, an denen die Hörner befestigt sind, nun durch die Haare und dreht sich vor dem grünen Hintergrund. Die Stimme spricht: „Aber es war schwer, sie zu benutzen.“ Weiße Kreidestriche, die auf eine Tafel oder den Scwarzen Papiergrund gemalt wurden, sind währenddessen als Nahaufnahme sichtbar. Hinter diesem Motiv auf einer vorderen Bildebene hockt die Künstlerin im weißen Trikot am Boden mit einem roten Faden in den Händen, den sie aufsammelt. „Es gab keine Hindernisse, die nicht zu überwinden gewesen wären und sie hatte nie so etwas wie Angst gekannt...", hört man die Stimme sprechen. Die Nahaufnahme zeigt den roten Faden auf den Oberschenkeln der am Boden hockenden Künstlerin, während ihre Hände den Faden einsammeln. Um diese Einstellung fügt sich dann eine Kreisblende, in der die Kamera auf eine Halbnahe zoomt, und die Aufnahme zeigt, wie die Künstlerin vom Boden aufsteht. Die Stimme aus dem Off begleitet diese Aktion mit den Worten: „... was hatte sie schon zu verlieren? Sie war verwöhnt von ihrem Mut."

Diese Kreisblende, die zunächst noch von der alchemistischen Zeichnung umrahmt ist, zeigt im Anschluss in einer Nahaufnahme die Künstlerin im roten Kleid mit einem Stock über dem Kopf vor der schwarzen Kreidewand. Während sie von rechts nach links wandert, folgt die Kamera der Bewegung im Raum. Dann fällt 
die Kreisblende weg. Die Aufnahme zeigt nun, wie die Künstlerin zunächst vor einer weiteren alchemistischen Zeichnung steht und dann hinter die Zeichnungswand tritt. ${ }^{653}$

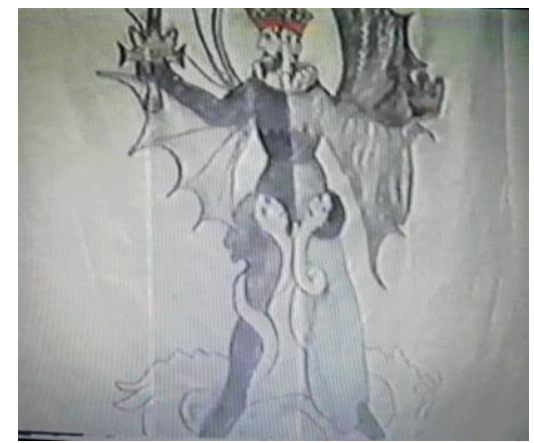

Abb. 177: Alchemistische Zeichnung mit Motiv des Hermaphrodit, Videostill aus die Eulenspieglerin, 1985

Die Aufnahme zoomt währenddessen auf eine Halbnahe und die Stimme spricht: „Es wurde eine Frage auf Leben und Tod.“ Das folgende Standbild zeigt dann nur diese alchemistische Zeichnung mit der zweigeteilten androgynen Figur, deren Kopf allerdings durch den oberen Bildrand abgeschnitten ist. Die mit hartem Schnitt angefügte Nahaufnahme zeigt die Künstlerin im Profil mit roten Haaren. Die Silhouette ihrer Haare ist durchwoben von dem androgynen alchemistischen Motiv. Die Aufnahme zeigt die Künstlerin vor der Wand mit dem herausragenden Horn. Dazu sagt die Stimme: „Sie hatte zwei Hörner und drei Wünsche und es würde ihr freistehen, sie zu benutzen..." Die Nahaufnahme zeigt dann die Künstlerin im weißen Trikot mit von der alchemistischen androgynen Darstellung durchwirkten Haaren, und sie dreht sich auf der rechten Bildschirmseite mit den Hörnern langsam um die eigene Achse. Während der Drehung taucht das Gesicht kurz auf und verschwindet wieder. Zudem ist in dieser zwei Motive verwebenden Bildsequenz zu sehen, wie die Künstlerin die Zeichnung des Hermaphroditen hebt und über ihrem Kopf zerknüllt.

Die andere Akteurin im weißen Trikot dreht sich derweil weiter, wobei sie ein rotes und ein weißes Tuch in den Händen hält, und die Motive beginnen sich zu durchwirken. Aus dem Off ist dazu weiter zu hören: „,... sie zog es deshalb vor, keine Vorstellung zu haben, von dem, was kommt. Keine Antwort zu wissen...“ Die Großaufnahme zeigt die sich um die eigene Achse drehende Künstlerin in der rechten Bildhälfte. Ihre Haare sind mit der Aufnahme der Zeichung durchwirkt, die nun grünlich schimmern und die Performerin ist diesmal in rote und weiße

653 Dies ist nun das dritte Motiv bei den alchemistischen Zeichnungen: der Hermaphrodit. 
Kleidung gewandet. Dann steht die Frau in rot gekleidet in Großaufnahme vor der alchemistischen Zeichnung. Aus dieser Einstellung wächst aus der Mitte eine Kreisblende. Diese zeigt erst sehr verschwommen, dann allmählich deutlicher die Großaufnahme des Kopfes der Künstlerin, deren Augen mit einem roten Schal verbunden sind und die um die eigene Achse kreist. Die Einstellungsgröße in der Blende zoomt zur Nahaufnahme, bis der Insert nur noch den drehenden Kopf abbildet. Die Stimme setzt fort: „,...auf das, was gefragt ist.“

Die folgende Bildsequenz zeigt zunächst nur den blauen Grund, bevor ein Schwenk einsetzt, verbunden mit einem Zoom auf das geöffnete Kreiszeichen, das auf die Hintergrundwand geblendet wird und sich dann nach unten rechts aus dem Bild schiebt, während die Stimme den begleitenden Text abschließt: „Und sich aus nichts nichts zu machen." Dann folgt Stille und ein schwarzer Bildschirm, an den sich der Abspann anschließt: Hier stehen zunächst rosafarbene Buchstaben auf dem schwarzen Grund: „Die Eulenspieglerin“ / Text: Ulrike Rosenbach / copyright: Köln 1985“. Danach ist der Bildschirm für zwei Sekunden wieder ganz schwarz, bis dann in hellbauen Buchstaben erscheint: „Idee \& Videoscnitt [sic]: / ULRIKE ROSENBACH / Kamera: / Ursula Braun / Dirk Pauvels / TVs Endemann". Dann ist der Schirm wieder kurz schwarz, bevor der dritte Teil folgt, nun ist in weißen Buchstaben zu lesen: „Entstanden mit der Unterstützung von/ in cooperation with: / Dr. Uwe Schneede, Kunstverein Hamburg / Victoria von Flemming, NDR3 / Sabine Huth, TVS Endemann / Thomas Schmitt, „Tag und Traum“ / Koeln, „235“ Koeln / Jan Hout, Museum van Haden- / daagse Kunst, Gent ----_-_. Das Tape endet nach 18 Minuten wie es begann: mit einem schwarzen Bildschirm.

\section{IV.5.2.3 Formale und inhaltliche Analyse des Tapes}

Auf die Beschreibung dieses audiovisuellen Kunstwerkes, das mit Vor- und Abspann genau 18 Minuten dauert, folgt nun zunächst die formale, dann die inhaltliche Untersuchung. Dafür werden nacheinander die elektronischen Gestaltungsmittel des Videotapes, die Farben, die Funktion des Körpers, die eingesetzten Attribute, die auditive Ebene, wie auch der Zusammenhang zwischen Bild und Ton, sowie die zeitliche Dimension in den Blick genommen.

Blickt man auf die äußere formale Struktur, zeigt sich, dass das Videotape aus insgesamt 56 Einstellungen zusammengefügt ist, die mittels harter Schnitte verknüpft sind. Allerdings sind in dem Tape wesentlich mehr unterschiedliche Bildsequenzen mittels elektronischer Effekte miteinander verwoben, da häufig zwei oder mehrere Bildsequenzen durch Blenden synchron miteinander verknüpft sind. Die dokumentarischen Aufnahmen, aus denen das gesamte Tape komponiert ist, sind während unterschiedlicher Aufführungen der Performance entstanden. Das umfangreiche Bildmaterial aus diesen Performances wurde im zeitlichen 
Fluss zu einer dichten Bildkomposition zusammengesetzt und der aus dem Off gesprochene Ton hinzugefügt.
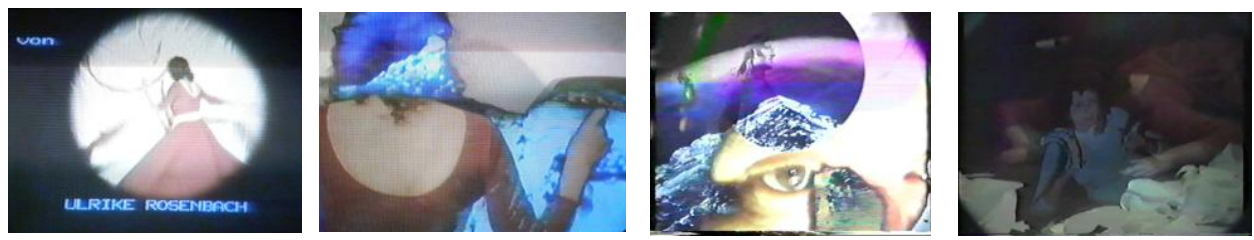

Abb. 178-181: Die Eulenspieglerin, Videostills, Beispiele für elektronische Effekte

a) Elektronische Gestaltungsmittel

Neben dem filmischen Kompositionsmittel des harten Schnittes finden sich unterschiedliche Trickblenden und Effekte in dem Tape eingesetzt. So begegnet wiederholt die Kreisblende, die sich entweder aus dem Zentrum des Bildes öffnet oder sich von den Ecken her um die jeweilige Aufnahme im Zentrum schließt. ${ }^{654}$ Zudem kommt der so genannte Blueboxeffekt zum Einsatz, mittels dem eine zweite Aufnahme in die durch eine bestimmte Farbe gefüllten Flächen einer Einstellung eingefügt wird. Dadurch werden - wie schon bei der Verwendung der Trickblenden - zwei unterschiedliche Bildinhalte synchron miteinander verbunden. Häufig findet sich beim Blueboxeffekt in „Die Eulenspieglerin“ die Farbe Schwarz - als konkretes Objekt die schwarze Papierfläche, auf der in der Performance mit weißer Kreide gezeichnet wird - mit anderen Motiven, farbigen und auch bewegten Aufnahmen gefüllt. Zudem sind rote Bildanteile in bestimmten Sequenzen durch andere Bildinhalte gefüllt. Außerdem findet sich das Übereinanderblenden zweier Bildsequenzen als Kompositionsmittel in dem Band eingesetzt. Dieser elektronische Effekt erinnert in der in dem Tape umgesetzten Weise an eine Spiegelung, bei der durch optische Täuschung zwei räumlich voneinander getrennte Gegebenheiten miteinander verbunden werden. Und dieses bildimmanente Motiv der Spiegelung findet sich bereits im den Begriff „Spiegel“ beinhaltenden Titel der Arbeit angedeutet. ${ }^{655}$ Zusammenfassend lässt sich an dieser Stelle über die formale Gestaltung des Tapes zunächst festhalten, dass durch Blenden und andere elektronische Verfahren Bildsequenzen, die voneinander getrennt aufgenommen wurden, miteinander verbunden sind.

In welcher Beziehung steht nun die formale Darstellungsweise zur inhaltlichen Ebene? Die verschiedenen Blenden und Effekte verbinden Bildsequenzen im zeitlichen Fluss und synchronisieren zudem unterschiedliche Bildinhalte. Dabei geht es besonders bei der Synchronisation unterschiedlicher Bildsequenzen, um die

654 Dieses „Schlüsselloch-Motiv“ begegnete in ähnlicher Form bereits bei der „Maifrau“.

655 Und in der Performance selbst findet sich das Motiv auf dem Monitor, das die Künstlerin zeigt, die die Wasserschale hält. Auf der zitternden Wasseroberfläche zeichnet sich ihr Gesicht verzerrt ab, ergibt keine deutliche Spiegelung dadurch verzerrt. 
bildliche Umsetzung eines Innen und Außen. Dies wird besonders anschaulich beim Einsatz von Kreis- oder Rechtecktrickblende. Hier findet sich jeweils eine innere Bildsequenz, die von einer äußeren gerahmt wird. Ein Beispiel dafür ist die Sequenz mit der Rechteckblende, die zu Beginn der zweiten Minute eingefügt ist, in der das innere Bild der im roten Kleid agierenden Performerin von der Blau eingefärbten Großaufnahme ihres Gesichtes umrahmt ist. Die künstlerische Aktion, die im Außen stattfand, wird damit visuell in das Innere, den Kopf der Künstlerin, übertragen. Und dieses Rahmenbild ist durch die zusätzliche Verfremdung in Blautönen noch farbsymbolisch aufgeladen. 656

In ganz ähnlicher Form werden Ausdrucksweisen für innere Prozesse und äuBere Abläufe auch in anderen Bildsequenzen zusammengefügt, wie zum Beispiel beim Blueboxeffekt. Nehmen wir hierfür zum Beispiel das Motiv des Auges, das am Ende der zweiten Einstellung anstelle des roten Stoffes des Kleides der Künstlerin zu sehen ist und mittels dieses Effektes eingefügt wurde. Das geöffnete Auge blickt hier aus dem Bildgrund - der Rückenansicht der Agierenden - heraus. Es blickt damit nicht nur den Betrachtenden an, sondern durchdringt in entgegengesetzter Richtung auch das Gewand der Künstlerin, blickt rückwärts. Es ist also ein die Oberfläche durchdringender Blick, der hier ganz anschaulich visualisiert wird. Und es ist keine fremde Sicht, sondern die Sicht der Künstlerin auf sich selbst, die hier ins Bild gesetzt ist. Diese, übrigens der zuvor analysierten Sequenz vorangehende, Einstellung scheint zudem in konkreter syntaktischer Verknüpfung mit der nachfolgenden zu stehen. So wird der folgende nach innen gerichtete Blick hier an der gesamten Figur vorbereitet, bevor dann - ganz wörtlich visualisiert - ein Fenster mit neuen Bildinhalten im Zentrum des Bildschirms geöffnet wird, wodurch sich zusätzlich das performative Außen als innerer Prozess erschließt.

Neben der Trickblende und dem Blue-Box-Effekt findet sich als drittes Gestaltungsmittel die Überlagerung zweier Bildsequenzen in dem Tape eingesetzt. Wie oben bereits angeschnitten, erzeugt dieser elektronische Effekt ein Bild, das den Eindruck hervorruft, der sich ergibt, wenn man durch eine transparente Glasscheibe blickt, in der sich gleichzeitig Reflexe eines hinter dem Betrachtenden liegenden Raumes finden. Auf diese Weise verbinden sich in der reflektierenden Glas(ober)fläche zwei Räume miteinander: der Raum des Davor und der Raum des Dahinter, des Innen und Außen. In den Bildsequenzen des Tapes kommt zu der örtlichen Dimension noch eine zeitliche Ebene hinzu: Zukünftiges und Vergangenes fügen sich in der Spiegelung im Jetzt zusammen.

${ }_{656} \mathrm{Zu}$ den Farben mehr im folgenden Abschnitt. 
b) Die Farben

Im Verlauf der Betrachtung und Beschreibung des Tapes fällt auf, dass bestimmte Farben - beziehungsweise Farbkombinationen - wiederkehren. Dazu gehören die drei Farben Rot, Schwarz und Weiß. So agiert die Performerin im Verlauf des Tapes gekleidet in unterschiedliche Kleidungsstücke in genau diesen drei Farben: entweder im roten Kleid, im weißen Trikot oder im grauschwarzen Mantel. Erst in den letzten Bildsequenzen trägt sie ein Kleid aus rotem wie weißem Stoff. Da die Künstlerin während des gesamten Tapes in (fast) allen Bildsequenzen gegenwärtig ist, ist damit auch (fast durchgängig) mindestens eine dieser drei Farben jeweils auf dem Bildschirm zugegen.

Doch nicht nur die Kleidung, auch andere wiederkehrende Objekte sind in der Aktion und damit auch in dem Tape mit diesen drei Farben verknüpft. So begegnet die Farbe Rot zudem in dem dicken (Woll-)Faden und in dem langen Schal, mit dem sich die Tänzerin zum Schluss ihre Augen verbindet. In schwarzer Farbe erscheint die (Papier-)Wand mit den herausragenden Silhouetten. Aber auch der Bildschirmgrund während des Vor- und Abspanns ist schwarz, aus dem sich die farbigen Bilder und Buchstaben erhellen. Weiß ist dagegen die Kreide, mit der die Künstlerin Spuren auf dem schwarzen Grund hinterlässt. Zudem ist das Salz weiß, auf dem sie agiert. Dieser Farbdreiklang aus Schwarz, Rot und Weiß begegnete bereits in anderen Werken der Künstlerin aus dieser Zeit, wie zum Beispiel „Aufwärts zum Mount Everest"657 oder auch „Wer hat Angst vor der schwarzen Frau?“"658, so dass sich erneut die Frage nach der Bedeutung gerade dieser Farben stellt. Diese Farben werden im feministisch-spirituellen Kontext der „Großen Mutter“ zu geordnet. Sie stehen symbolisch für die Trinität der Frau:

„Die Farben weiß-rot-schwarz sind die heiligen Farben des Matriarchats. Sie und der dreifaltige Mond versinnbildlichen die Lebensphasen der Frau und damit der Natur im Kreislauf des Jahres:

- Die weiße Sichel ist das Symbol der Göttin in ihrer Mädchengestalt, der Göttin des zunehmenden Jahres (des Früblings), der jugendlichen Jägerin mit dem silbernen Bogen.

- Die purpurne Doppelsichel, deren Spitzen einander zugewandt sind, so daß sie eine Rundung ergeben, ist das Zeichen des Vollmonds, wenn er glühend am Horizont stebt. So ist er das Symbol der Göttin in ibrer Gestalt als erwachsener Frau, der Göttin der Liebe und Fruchtbarkeit, die im Höhepunkt des Jahres (im Sommer) regiert. Sie ist die Schöpferin der Welt, denn der rote Vollmond bedeutet das Welt-Ei, das sie in Gestalt einer Taube legte: Als es zerbrach fiel die ganze Schöpfung heraus. Darum ist auch dieses Zeichen gespalten.

- Die schwarze Sichel ist das Symbol der Göttin in ibrer Greisengestalt, der Schnitterin mit der Todessichel (sie) ist die Herrin der tiefsten Region, der Unterwelt. Dort wohnt sie als

657 Vgl. Kap. IV.4.2.

658 Vgl. Kap. IV.3. 
winterliche Todesgöttin, die alles Leben mit sich in die Tiefe nimmt, um es nach seiner Metamorphose im neuen Jahr wieder zum Licht aufsteigen zu lassen. Und damit beginnt der Kreislauf des mythischen Jahres der Göttin von vorn.

Doch wie der Mond in allen drei Phasen eine Einheit ist, so ist die Göttin in allen drei Gesichtern nur eine Gottheit. Die Triade der heiligen Farben Weiß-Rot-Schwarz ist bereits ein Symbol für sie selbst; deshalb trägt manche mythische Gestalt diesen Dreiklang. "659

Auch wenn sich die Künstlerin zum Entstehungszeitpunkt des Eulenspiegelerinnen-Komplexes bereits aus den Kontext der Frauenbewegung gelöst hatte, scheint dieser spirituelle Gedankenhintergrund von Bedeutung. Immerhin erscheint die Künstlerin in dem Tape, sowohl weißen Trikot ${ }^{660}$, im roten Kleid wie auch im schwarzgrauen Mantel. In diesen gekleidet ist sie unter anderem damit beschäftigt einen roten Faden aufzusammeln. So scheint die Künstlerin in alle drei Frauenrollen zu schlüpfen in der „Eulenspieglerin“: Mädchen, erwachsene Frau und Greisin. Alle diese Gestalten tauchen in dem Tape auf, jedoch abwechselnd und mehrfach.

Dieser, die Trinität der Frau spiegelnde, Farbkanon wird in dem Tape ergänzt. Hinzu kommt ein begrenztes Zeichen- beziehungsweise Symbolrepertoire. Hierbei wechseln zum Teil die Farben der gleichen Objekte im Verlauf des Tapes. Eine zunächst schwarze Spirale wird zum Beispiel im letzten Viertel der Eulenspieglerin in grünes Licht getaucht. In ähnlicher Form wechselt auch der griechische Buchstabe „Tau“ im Verlauf des Tapes seine Farbe. Wenn er zunächst mehrfach in schwarzer Farbe auf dem jeweiligen Hintergrund geschrieben steht, taucht er schließlich erst im Hintergrund in grüner Farbe auf, bevor er dann weiter in Grün gefärbt in den Vordergrund gehoben wird. Schließlich ist er in leuchtend roter Farbe auf die weiße Wand im Hintergrund gezeichnet.

So zeigt sich, dass neben dem Farbtrio weitere Töne den Kanon des Farbspiels des Bandes bereichern: Das eben erwähnte Grün, wie auch Blau und Gelb spielen in dem Band eine weitere Rolle.

Die ursprünglich dokumentarischen Aufnahmen sind in „Die Eulenspieglerin“ nicht durchgängig in den Originalfarben wiedergegeben. So finden sich zum Beispiel Sequenzen mit dem Körper oder Gesicht der Künstlerin zum Teil farblich

659 Aus: http://www.philognosie.net/index.php/article/articleview/426/3/ (1.2.2008); Andererseits gibt es noch einen anderen Bezugspunkt. Ist die Dreiheit der Farben schwarz-weiß-rot doch ebenso im politischen Kontext der deutschen Geschichte zu lesen. Entsprechen diese Farben doch unter anderem den Farben der Nationalflagge des Deutschen Reiches in den Jahren 1871-1918. Auch in dem in der „Einsamen Spaziergängerin“ zitierten Gemälde Caspar David Friedrichs spielen diese Farben eine Rolle, und weisen auf die nationale Haltung. So ist der dort ins Bild gesetzte Spaziergänger in genau diesen Farben gekleidet. Aber auch die Hakenkreuzfahne der Nationalsozialisten trug diese Farben: Eine schwarze Swastika auf einem weißen Kreis, der in einem roten Grund lag.

660 Hier zwar nicht, doch in der Amazonen-Aktion, wie der 10000-Jahre-Aktion tauchte als Attribut zudem der Bogen der Jägerin auf. 
verfremdet: Diese erscheinen in Schwarzweiß oder mit vielen Blauanteilen unterlegt. So wie auch ursprünglich rote Farbanteile der Aufnahmen im hinteren Teil des Tapes durch Grün ersetzt sind. Dort sind zum Beispiel in einer Bildsequenz die ursprünglich rot schimmernden Haarpartien in der Komplementärfarbe eingefärbt. Neben dem in Blau gefärbten Gesicht der Künstlerin, erscheint der Grund des Bildschirms in dem Tape mehrfach in Blau. Außerdem sind manche der Buchstaben im Vor- und Abspann Blau. Gelb ist in diesem Tape die Farbe der großformatig bemalten Papierbahnen mit den alchemistischen Zeichnungen, in die sich die Künstlerin auch mehrfach einhüllt. Auffällig ist, dass die verschiedenen Farben überwiegend an bestimmte Objekte gebunden sind. Neben dieser direkten Verknüpfung zwischen Farbe und Objekt, kann eine Farbe zudem gleich mehrere Objekte besetzen. Jedoch auch das umgekehrte Prinzip taucht auf, wie bei dem Tau-Zeichen, das in unterschiedlichen Farben in Erscheinung tritt. Genau dieser Wechsel bestärkt den Eindruck, dass den in dem Tape auftauchenden Farben eine explizit eingesetzte symbolische Konnotation innewohnt.

Blau weist zum Beispiel als Farbe des Himmels wie auch des Meeres auf die Unendlichkeit, auf lichte Höhe und dunkle Tiefe und die Farbe ist Hinweis auf das Geistige, Göttliche oder Transzendente. Andererseits ist es auch die Farbe der Trauer und Melancholie. ${ }^{661} \mathrm{Im}$ Werk der Künstlerin kommt der Farbe eine besondere Bedeutung zu, ist doch nicht nur ihre Homepage im Internet in Blau gestaltet, sondern auch in weiteren Tapes finden sich wiederholt farblich überarbeitete Bildsequenzen, die mit Blauanteilen versehen sind. ${ }^{662}$ In der Eulenspieglerin taucht die Farbe Blau explizit in zweifacher Weise auf: Zum einen als Bildgrund und zum anderen in Zusammenhang mit der Wiedergabe des Gesichtes beziehungsweise Körpers der Künstlerin. Ersteres nimmt Bezug auf ein Charakteristikum der Elektronik. Wenn der Monitor kein Bildsignal erhält, erscheint der Bildschirm in intensivem Blau, und zwar genau dem Blauton, den auch die großflächig blauen Bildsequenzen und Buchstaben in diesem Tape zeigen. Dieses lichte Blau, in dem sich unter anderem die Buchstaben aus der Dunkelheit der schwarzen Fläche abheben, steht damit in der Elektronik für den neutralen, inhaltsleeren Grund. ${ }^{663}$ Aus einem blauen Bildgrund öffnet sich zudem in einer Bildsequenz oberhalb einer Berglandschaft ein runder Kreisinsert mit dem Auge der Künstlerin, Ausdruck eines allumfassenden Blickes.

661 Bei ägyptischen Göttern findet sich ein blauer Bart, der indische Krishna trägt eine blaue Hautfarbe, und nicht nur Wodan trägt in der Edda einen blauen Mantel auch Gottvater in der christlichen Kunst. Mit dem zum Weiß tendierenden Blau verbindet sich die Vorstellung der Reinheit, es ist häufig die Gewandfarbe der Jungfrau und Gottesmutter Maria. Allerdings nicht nur positiv besetzt, auch Farbe der Trauer, des Unheils und der Lüge. (Vgl. Lurker 1991, S.100f) So zum Beispiel auch im späteren Hildegard Walk

663 Der Name der Künstlerin, der zu Beginn in blauen Buchstaben geschrieben steht, ist im Abspann übrigens rosa eingefärbt. 
Hingegen scheint mit der Blauverfärbung der Aufnahmen des Kopfes oder Körpers der Künstlerin in verschiedenen Sequenzen des Tapes ein anderes Ziel verbunden zu sein. Scheint hier doch durch die Verfremdung der natürlichen Farben in den Aufnahmen auf eine andere Ebene hingewiesen zu werden: Die Blaufärbung kann hier als Hinweis auf geistige, transzendente Prozesse gelesen werden. Bei beiden Beispielen wird die inhaltliche Aussage der jeweiligen Sequenz durch eine explizite Farbsymbolik verstärkt.

In ähnlicher Weise wie beim Blau verhält es sich mit dem Einsatz der Farbe Grün in dem Tape. „Grün ist Symbol der Erwartung, der Hoffnung des Auf-demWeg-Seins" "664, beschreibt Manfred Lurker in seinem Wörterbuch der Symbolik. Auch diese Bedeutung fügt sich passend zu den entsprechenden inhaltlichen Passagen des Tapes. Taucht doch das zunächst schwarze Tau-Zeichen ${ }^{665}$ in einer Tapesequenz in Grün im Bild auf. Auch werden die braunroten Haare der Künstlerin in einer Sequenz grün eingefärbt. Das Haar gilt auf der symbolischen Ebene aufgrund seines Wachstums als Träger von Lebenskraft, bei den Griechen auch als Sitz des Lebens, wird in der Traumdeutung auch als emotionales Outfit verstanden. ${ }^{666}$ Das Symbol der Lebenskraft, des Gefühlslebens ist so in dieser Passage in Grün eingefärbt, und damit wird ein Zeichen der Hoffnung, des Auf-dem-WegSeins oder auch des Wachstums gesetzt.

Wenn nun die alchemistischen Zeichnungen auf gelblichem Papier gezeichnet sind, wird auch damit eine symbolische Bedeutung verknüpft sein. Die Farbe Gelb ist die der Sonne und auch des Goldes und so sind beide in ihrer symbolischen Bedeutung verwandt. Gold ist der Stoff, auf dessen Gewinnung die materiellen Anstrengungen der Alchemie gerichtet sind. So sind die drei alchemistischen Motive, auf einen hellgelben Grund gezeichnet, die Farbe der Alchemie bildet deren Grund.

Zusammenfassend lässt sich über die Dimension der Farben in dem Videotape sagen, dass in den betrachteten Sequenzen der Eulenspieglerin unterschiedliche Bedeutungsebenen angesprochen werden. Dabei übernehmen die Farben eine wichtige symbolische Funktion - werden explizit ausgewählt oder auch hinzugefügt. Sie transportieren zusätzliche Inhalte und verstärken oder präzisieren die inhaltliche Aussage der jeweiligen Passage.

664 Lurker 1991, S.268; In der Edda findet sich Topos des grünen Weges, in der Alchemie entspricht der grüne Stein einem Übergangsstadium auf dem Weg zum Gold, im Volkslied deutet grün auf die Liebe, die grüne Seite ist die Herzseite, mit der man fühlt und liebt. Aber auch hier wieder negative Bedeutung, Grün gleich Gift und Tod. (Vgl. Lurker 1991, S.268)

665 Zur Bedeutung dieses Zeichens siehe dann Kap. IV.5.2.3 g)

666 Vgl. Lurker 1991, S. 272 


\section{c) Der Körper}

Legen wir nun den Fokus auf die Darstellung des Körpers in dem Tape, der in (fast) allen Sequenzen der „Eulenspieglerin“ gegenwärtig ist. Die Akteurin unternimmt im Verlauf des Tapes unterschiedliche Handlungen, die zum Teil auch rituelle Züge aufweisen: Sie schreitet im Raum, zeichnet mit weißer Kreide auf die schwarze Wand, hantiert mit den metallenen Hörnern, agiert auf dem Salzgrund, wickelt sich in die Zeichnungen ein, schiebt den Monitor durch den Raum, macht in farbiges Licht getaucht eine Brücke, dreht sich um ihre eigene Achse oder sammelt einen dicken roten Faden ein. Bei der Wiedergabe dieser Vorgänge findet sich das gesamte Spektrum an Einstellungsgrößen in dem Band verwendet: von der die Szenerie der Aktion im Überblick einfangenden Halbtotalen bis zur Detailaufnahme, die zum Beipiel nur das Auge oder die Hände der Künstlerin abbildet. Dabei lässt sich quantitativ feststellen, dass neben der Halbnahen und Amerikanischen auch die Großaufnahme besonders häufig bei der Wiedergabe des Geschehens genutzt wird. Zudem findet sich gelegentlich der Zoom eingesetzt, um fließend von einer Einstellungsgröße in eine andere überzuwechseln. Dieser Effekt des optischen Näherns an eine Situation mittels eines Zooms wird gelegentlich ergänzt, beziehungsweise verstärkt, durch den Einsatz einer Trickblende - in Form eines Kreises oder eines Rechteckes - die sich parallel dazu sukzessive öffnet.

Auffällig ist bei der Abbildung der Akteurin in dem Tape, dass sich wiederholt Aufnahmen finden, die den Körper fragmentiert wiedergeben. So wird zum einen wiederholt auf einzelne Körperpartien fokussiert: Der Kopf, die Hände oder auch der Bauch sind häufiger isoliert in Großaufnahmen zu sehen. Zum anderen ist umgekehrt gleich in mehreren Einstellungen die Kopfpartie vom Bildschirmrand abgeschnitten und der Körper erscheint damit als Torso ohne das Haupt auf dem Monitor.

Zudem sind im Verlauf des Tapes in die unterschiedlichen Körperteile- oder Kleidungstücke andere Bildinhalte eingefügt, wie zum Beispiel in die Partie der Haare, des Armes, sowie in das rote Kleid oder den schwarzen Mantel. Die dreidimensionale Körperform wird auf diese Weise zu einer flächigen Silhouette, die als Rahmen für andere Bildinhalte genutzt wird. In ähnlicher Form wird auch der schwarze Papiergrund mit den am oberen Rand hervorragenden Figurensilhouetten als Fläche genutzt, in die zusätzliche Bildsequenzen eingefügt werden. Diese Nutzung des Körpers beziehungsweise Raumes als Projektionsfläche für andere Bildinhalte fand sich auch in der Performance selber eingesetzt. Hier wurde allerdings nicht - wie in vorangegangenen Aktionen - mit Bildprojektionen gearbeitet, sondern hier ist es farbiges Licht, das auf die Agierende projiziert wird. Die bunten Lichtstreifen, die den weiß gekleideten Körper der Künstlerin überziehen, sind in dem Tape in mehreren Bildsequenzen zwischen der zweiten und siebten Minute 
des Tapes wiedergegeben. Der Dreiklang der Farben Gelb, Rot und Blau bestrahlt dabei zum einen die Brust, zum anderen den Unterleib der Künstlerin.

Die Farbkombination der drei Grundfarben der additiven Farbmischung setzt Assoziationen an den Regenbogen frei, das christliche Symbol des Bundes Gottes mit den Menschen ${ }^{667}$, lässt aber im Kontext des Werkes der Künstlerin auch an die Regenbogenschlange ${ }^{668}$ der australischen Mythologie denken, die Weibliches und Männliches in sich vereinigt, und damit ein Zeichen für Ganzheit darstellt.

Daneben ist der Körper der Agierenden in manchen Passagen durch elektronische Trickeffekte auch doppelt sichtbar. So findet sich eine längere Bildsequenz ab der zweiten Minute, in der sich Aufnahmen der Agierenden im roten Kleid mit Bildern der in weiß gekleideten Performerin durchwirken. Zwei ursprünglich zeitlich und örtlich unabhängige Ereignisse sind hier auf eine Weise zusammengefügt, in der der Kopf der roten Frau zusehends den Körper der weißen Frau durchdringt, bis schließlich - nach vorübergehend hervorgehobener Sichtbarkeit der weißen Frau - diese gänzlich verblasst und die rot gekleidete Frau allein zurückbleibt. Hier findet sich zum einen - gebunden an eine figürliche Darstellungsweise, die für das künstlerische Wirken Ulrike Rosenbachs charakteristisch ist - eine Verbindung oder auch Vereinigung der beiden Farben Rot und Weiß visualisiert, die in der Farbsymbolik der Alchemie, wie bereits dargelegt, für das weibliche und das männliche Prinzip stehen. So durchdringt in der Bildsequenz ganz wörtlich umgesetzt, das weibliche, rote Prinzip das weiße, männliche. Aber die Farben vermischen sich hier nicht zu einem neuen Farbton, sondern sie sind in ähnlicher Intensität übereinander gelegt, bis der rote Anteil schließlich überwiegt und die weiße Farbe aus dem Bild verdrängt.

In diesem elektronischen Austausch der Protagonistinnen zeigt sich übrigens eine weitere Parallele zur Chronologie im Werk der Performerin. Trat die Künstlerin doch in den 1970er Jahren zunächst in dem weißen Trikot auf, das sie auch in manchen der Aufführungen der „Eulenspieglerin“ trug. Doch ab Beginn der 1980er Jahre wechselte sie ihr Performance-Outfit und das weiße Trikot wurde in den Aufführungen immer häufiger durch ein rotes Kleid mit weit schwingendem Glockenrock abgelöst. ${ }^{669}$ Vor diesem Hintergrund lässt sich diese Sequenz einerseits als visuelle Verbindung der beiden symbolisch aufgeladenen Farben Rot und Weiß lesen, andererseits als Visualisierung der Vereinigung und Ablösung verschiedener künstlerischer Identitäten.

6671 Mose 9, 12-16; aber auch in anderen Religionen und Mythlogien symbolische Bedeutung, Symbol der Verbindung zwischen Himmel und Erde, auch Assoziation an bisexuelle Regenbogenschlange. (Vgl. Lurker 1991, S. 608f)

668 Vgl. Kap. III.5.7.

669 Dabei zeigt sich der geschlechtspezifisch konnotierte Aspekt der Kleidung nicht nur in den gewählten Farben, sondern auch in den Formen. Zum Trikot gehört eine weiße Hose, dagegen ist es später ein rotes Kleid mit weit schwingendem Rock. 
Neben dem Einfügen einer zweiten Bildebene, die ebenfalls Aufnahmen der Performerin zeigt, sind an anderer Stelle weitere Inhalte visuell in die Körpersilhouette der Agierenden eingefügt, wie zum Beispiel das bläulich eingefärbte Strahlen in dem sphärisch anmutenden Mittelteil des Tapes, hier symbolischer Ausdruck eines inneren Transformationsprozesses.

In Bezug auf die Darstellung der Agierenden fällt in dem Tape zudem auf, dass diese sich häufig in Bewegung befindet. Dabei sind zwei Bewegungsformen grundsätzlich voneinander zu unterscheiden. Zum einen bewegt sich die Agierende auf einer Geraden - sie schreitet an der Wand entlang, robbt durch den Raum, schiebt den Monitor vorwärts über den Bogen - zum anderen dreht sie sich um ihre eigene Achse - stehend beim Derwischtanz oder auch im Salz auf dem Boden hin- und her rollend. Bei den Bewegungen ist zu beobachten, dass die Richtung dabei grundsätzlich von rechts nach links vollführt wird. Das ist genau entgegen der konventionellen Leserichtung im westlichen Kulturkontext. Diese räumliche Konvention prägt im Westen auch die bildliche Umsetzung zeitlicher Prozesse, bei denen chronologische Abläufe von links - das Vergangene - nach rechts - das Gegenwärtige und auch das Zukünftige - aufgeführt sind. Also schreitet die Künstlerin nach westlicher Lesart zurück im Raum und damit verknüpft auch in der Zeit.

Umgekehrt wie im Westen ist jedoch die Leserichtung im östlichen Kulturkreis. Hier wird von rechts nach links geschrieben - und auch gelesen. Ein Bezug auf islamische Motive zeigt sich in diesem Tape in dem an den Derwischtanz der islamischen Sufis erinnernden Sich-um-die-eigene-Achse-Drehens. ${ }^{670}$ Dieses erfolgt wiederum entgegen des Uhrzeigersinns - also links herum - und damit dem Herzen entgegen. Bei dieser Tanzform, die die Derwische nutzen, um in Trance zu fallen, steht allerdings kein Zurückschreiten in der Zeit im Mittelpunkt, vielmehr ist die damit verbundene mentale Erfahrung ein Auflösen der zeitlichen, wie auch der örtlichen Wahrnehmung.

An dieser Stelle ist es wichtig herauszustellen, dass sich Bezüge zu einer westlichen, wie auch östlichen Lesart in dem Tape finden lassen. Diese beiden Bedeutungsebenen aufgreifend ergibt sich zunächst eine widersprüchlich erscheinende Doppeldeutigkeit, die zudem an eine spezifische Eigenart der Eulenspiegelgeschichten erinnert. Diese Doppeldeutigkeit in Rosenbachs „Eulenspieglerin“ lässt sich jedoch auflösen in dem Gedanken: Das Verfolgen der fortschreitenden „Leserichtung“ - oder auch Philosophie - der östlichen Welt, ermöglicht ein Zurückschreiten in der Zeit oder auch den Erfahrungen.

670 Zuvor begegnete dieses dynamische Drehen bereits in den „Judofrauen“, als wirbelnder Befreiungstanz um die eigene Mitte. (Vgl. Kap. IV.4.3.) Und als Bewegungselement findet sich dieses Um-die-Achse-Drehen seit Anbeginn im Werk der Künstlerin, begonnen mit der „Einwicklung“. 
$\mathrm{Zu}$ diesem Schreiten oder allgemein: der Bewegung in eine Richtung, kommt die bereits aufgegriffenen Drehbewegungen auf der Stelle: der Wirbeltanz wie auch das Hin- und Herrollen auf dem Boden. Hier finden wir eine in sich geschlossene Bewegung, die keinen Anfang und kein Ende hat. Sie beginnt immer wieder von vorne, und entspricht damit dem „Tao-Zeichen“, dem an einer Stelle leicht geöffneten Kreissymbol. Wenn die Künstlerin in dem Tape in einer Passage auf einer Stelle stehend um ihre eigene Achse wirbelt, rollt sie sich an anderer Stelle hin- und her durch den Salzgrund. Dieses Über-den-Boden-Rollen ist in früheren Werken Rosenbachs bereits begegnet, zum Beispiel im „Kulturaustausch“ oder im „Requiem“. Die Assoziationen einer Gefangenschaft wie auch von Befreiungsversuchen, die hier hervorgerufen wurden, ruft auch in der „Eulenspieglerin“ das Bild der sich im Salzgrund hin- und herwälzenden Performerin hervor.

Zusammenfassend lässt sich über die Darstellung des Körpers in dem Tape „Die Eulenspieglerin“ sagen, dass der Körper sowohl mittels seines konkreten Agierens inhaltliche Aussagen formuliert, als auch, dass in diesen durch technische Effekte weitere Inhalte hinein projiziert werden. Dabei wird in den unterschiedlichen Einstellungen, die in dem Tape zusammengefügt sind, vorübergehend auf bestimmte Körperteile fokussiert, dann wieder der Körper als Ganzes in den Blick genommen. Dabei zeigen sich figurative Bedeutungen, wie zum Beispiel das Erscheinen eines großen Auges im Rücken der Künstlerin, das als bildliche Metapher für „Rückblick“ gelesen werden kann. In ähnlicher Weise scheint auch in diesem Werk das Bild der Hand - wie schon mehrfach begegnet - eine Metapher für „Handlung“ oder „Handeln“ zu sein. Daneben zeigt sich, dass die jeweilige Wahl des Bildausschnittes und der Einstellungsgröße die inhaltliche Bedeutung verstärkt. Diese symbolisch-metaphorische Aufladung der figurativen Inhalte zeigt sich zusätzlich beim Verweben unterschiedlicher Bildsequenzen wie auch bei der Darstellung von Bewegung.

\section{d) Attributive Objekte}

Die Künstlerin agiert mit unterschiedlichen Objekten in dem Tape. Neben den Kleidungsstücken Trikot, Kleid und Mantel finden sich weitere Attribute: ein Schal, mit dem in einer Passage die Augen der Künstlerin verbunden sind, ein roter Faden, ein Fernsehmonitor, der auf seinem Bildschirm eine Spiegelung oder auch eine Sternenexplosion zeigt, drei unterschiedliche, großformatige Zeichnungen, auf die gleich noch ausführlicher eingegangen wird, sowie ein Paar silberner Hörner. Diese silbernen Hörner, die auch im begleitenden Text eine wichtige Rolle spielen, werden wiederholt in Großaufnahme in dem Tape gezeigt, an denen man sieht, dass sie an den gebogenen Spitzen kleine Glöckchen tragen. Damit erinnern sie an die Narrenkappe des Till Eulenspiegel, an deren Spitzen sich auch Glöckchen befinden. 


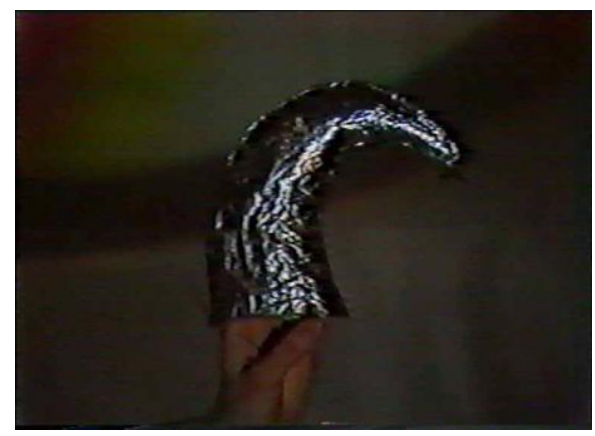

Abb. 182: Die Eulenspieglerin, Videostill, 1985

Außerdem findet sich die schwarze Wand, auf der die Künstlerin im Agieren ihre Spuren hinterlässt und aus der die Silhouettenfigur oben herausragt. Dieses antike Zitat tauchte bereits in den Schmelzprozessen im Werk der Künstlerin auf. Es ist wieder die geflügelte weibliche Figur aus der pompejanischen Wandmalerei, die hier als schwarze Silhouette erscheint. Diese Gestalt ist in der Aktion in gleichmäBigen Abständen mehrfach am oberen Rand der schwarzen Papierfläche angeordnet. Dabei ragt sie jeweils unterschiedlich weit aus der schwarzen Fläche heraus. Direkt unter der am weitesten herausragenden Figuren positioniert sich die Künstlerin für ihre Malaktion, bei der sie hinter ihrem Rücken mit den Armen Halbkreise schlägt, die sich in weiß auf dem schwarzen Grund abzeichnen.

Als wichtige Motive, die in dem Tape auftauchen, sind zudem das bereits erwähnte Auge sowie der Berg zu nennen. Das Bergmotiv ist im Mittelteil des Tapes auf dem blauen Grund eingefügt und füllt auch zwischendurch als Blueboxbild den papiernen Wandstreifen. Es handelt sich bei der hier gezeigten Schwarzweißfotografie übrigens um dasselbe Motiv, das auch in der Performance „Aufwärts zum Mount Everest" gezeigt wird.

Was sind das nun für Zeichnungen, die die Künstlerin in ihre Performance integriert hat? Sie selbst benennt sie allgemein als „alchemistische Zeichnungen“. Das erste Motiv, das großfomatig und farbig in dem Tape zu sehen ist, zeigt den hinduistischen Gott Shiva. Shiva repräsentiert im Hinduismus die schöpferischen wie auch zerstörerischen Kräfte des Alls. Ulrike Rosenbach hat eine bekannte Darstellung des Gottes gewählt, die Shiva tanzend zeigt. Es ist der so genannte Shiva-Nataraj. Diese Darstellung des tanzenden Gottes, auch Shiva-Nataraj genannt, ist in der hinduistischen Ikonographie kanonisiert und weit verbreitet: 
„Auf vielen Darstellungen findet sich der tanzende Shiva. Der Tanz ist aber nicht eine Art Unterhaltung, sondern ein Handeln, das der Erhaltung des Kosmos dient. "ש71
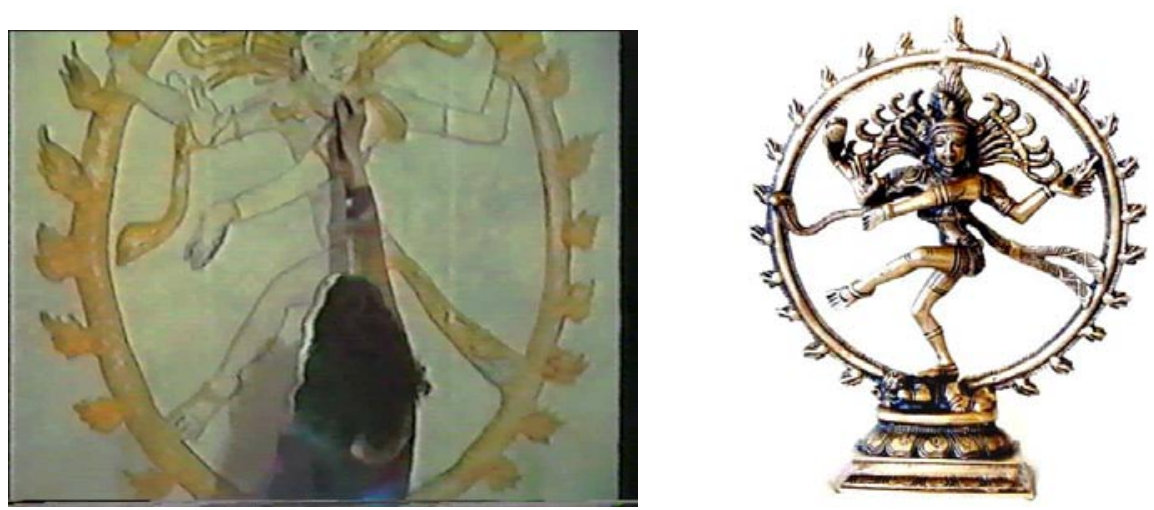

Abb. 183-184: Die Eulenspieglerin, alchemistische Zeichnung mit Darstellung Shivas, Videostill und traditionelle Darstellung Shiva Nataraja.

Zudem ist Shiva, insbesondere in seiner Form als Nataraj, der Inbegriff und die Repräsentation des zyklischen Zeitverständnisses gläubiger Hindus. Es ist also kein alchemistisches Motiv, sondern eines aus der Ikonographie des Hinduismus, das hier integriert ist.
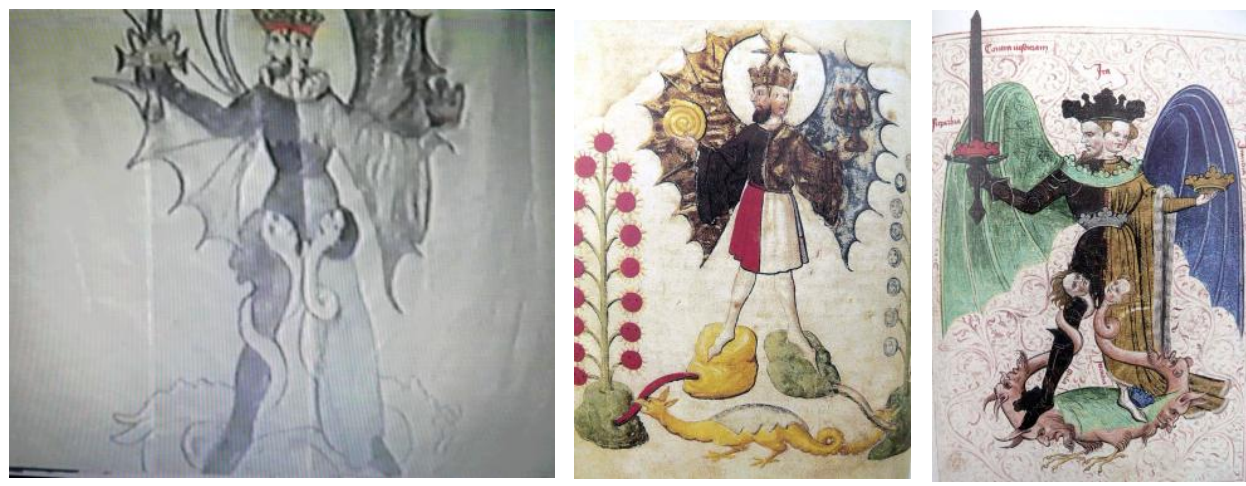

Abb. 185-187: Die Eulenspieglerin, alchemistische Zeichnung mit Hermaphrodit, 1985, Videostill und ]ZHD arstellungen eines Hermaphroditen aus dem Buch der Heiligen Dreifaltigkeit, 15. Jh.

${ }^{671}$ Dammann 1988, S. 31 
Desweiteren ist eine Zeichnung zu sehen, die das Motiv eines Hermaphroditen zeigt. Dies ist nun eine explizit alchemistische Zeichnung. Die Vorbilder stammen aus einem mittelalterlichen Manuskript, dem Buch der Heiligen Dreifaltigkeit aus dem 15. Jahrhundert. Die Künstlerin komponiert aus beiden Vorbildern eine farblich vereinfachte und stark vergrößerte Darstellung einer weiblich-männlichen Gestalt, die in der rechten Hand - männlichen Seite - ein Schwert erhebt, in der linken - weiblichen - Hand einen Kelch hält. ${ }^{672}$

Zudem taucht ein weiteres rätselhaftes Motiv auf. Es ist ein Kopffüßler. Von einem Gesicht, das mit seiner Narrenkappe an das der Figur des Till Eulenspiegel erinnert, greifen drei einander nachlaufende Menschenbeine kreisförmig nach auBen. Dabei ist auffallend, dass das Eulenspiegel-Gesicht, anders als in Eulenspiegeldarstellungen üblich, in denen der Kopf außer dem Bereich des Gesichtes vollständig durch die Narrenkappe verdeckt ist, sehr große Ohren trägt.
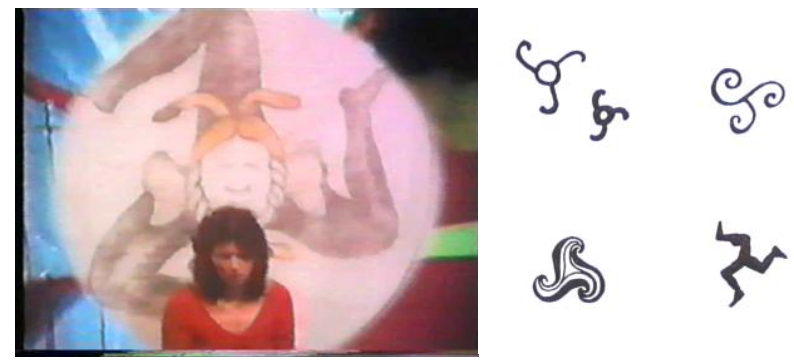

Abb 188-189: Die Eulenspieglerin, Videostill mit alchemistischer Zeichnung, 1985 und Triskelen

Diese Betonung der Ohren, dem Organ des Hörens, kann als Hinweis auf seine große Aufnahme- und Kommunikationsfähigkeit gelesen werden. Als Synthese findet diese großformatige Zeichnung der Künstlerin keine klassische oder alchemistische Vorlage. Vielmehr ist sie zusammengefügt aus dem Motiv des Kopffüßlers, dem Dreibein und der Eulenspiegelfigur. Dabei ist der Kopffüßler ein Sinnbild der Kreativität. ${ }^{673}$ Wie übrigens auch die Eulenspiegelfigur, die diesem Kopffüßler das Gesicht gibt, als äußerst kreativ verstanden werden kann. Das Dreibein, auch Triskeles genannt, ist ein altes Symbol, das sich zum Beispiel auf Münzen ${ }^{674}$ findet und eine Abwandlung der dreischwüngigen Spirale ist und damit zu den starken Lebens- und Sonnensymbolen zählt. ${ }^{675}$ Kopffüßler, Dreibein und das Ge-

672 Vgl. Kap. IV.5.1.1

673 Kopffüßler finden sich zum Beispiel in den Bildern bei Hieronymus Bosch und Pieter Breughel d. Ä.

674 Nicht nur auf historischen Münzen, auch auf einer Münze der Isle of Man, ist doch das Triskeles das Symbol dieser Insel.

675 Dieses verdreifachte Spiralsymbol - ebenfalls Triskele genannt - tauchte übrigens schon im „Tanz um einen Baum“ auf. „Triskele“ ist das griechische Wort für Dreifuß, Dreibein oder Dreischuh und ist ein Wahrzeichen von Sizilien, der Bretagne und der Isle of Man. Sie ist auf 
sicht des Till Eulenspiegel bilden in dieser Zeichung eine Einheit, die von der verwandelnden Kraft der Kreativität spricht.
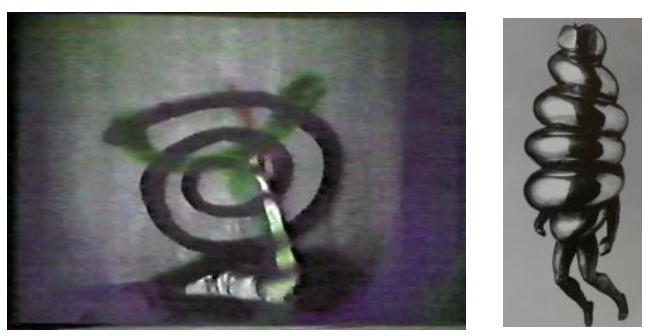

Abb. 190-191: Die Eulenspieglerin, Videostill mit Spirale und Tau-Zeichen und Louise Bourgeoise, Spiral woman, 2003

Außerdem finden sich noch drei Zeichen in dem Tape, die zum Teil auch wiederholt im Hintergrund eingeblendet werden. Es sind dies zum einen die Spirale, das schon ausführlich erläuterte Tau-Zeichen und ein weiteres Zeichen, das aus drei Schwüngen zusammengefügt ist. Zu dem Tau-Zeichen lässt sich an dieser Stelle noch hinzufügen, dass dem Tau in der Alchemie eine lebensspendende Bedeutung zukommt. Doch soll an dieser Stelle ein vertiefender Blick auf die Bedeutung der Spirale geworfen werden, ein Symbol das ja bereits mehrfach im Werk Rosenbachs begegnete und das auch in den Werken zahlreicher anderer zeitgenössischer Künstlerinnen wie auch Künstler zu finden ist. ${ }^{676}$ Das alte, in unterschiedlichsten Kulturen zu findende Symbol der Spirale, trägt eine Vielfalt an Bedeutungen in sich:

„Oft stellt es vermutlich sykklische Bewegungen von Himmelskörpern (Mond, Sonne) dar. In früben Mittelmeerkulturen sind Spiralen in der Genitalgegend weiblicher Statuetten abgebildet wabrscheinlich als Symbole des sich entfaltenden, werdenden Lebens. Im weiteren Sinne kann die Spirale auch ein Symbol für den Lebens- und Entwicklungsweg des Menschen, für Werden und Vergehen sein - wobei die von innen nach außen gerichtete Spiralbewegung als Symbol für die Entwicklung des Kindes zum Erwachsenen, die von außen nach innen sich einrollende Spirale hingegen als Sinnbild für Alter, Vergänglichkeit, Tod gedeutet werden kann. "'77

Münzen (Sizilien), antiken Schalen (Mykene) und Felszeichnungen (Irland) zu finden, stammt vermutlich aus verschiedenen Kulturkreisen und symbolisiert die Sonne. Wahrscheinlich stellt das Motiv das keltische Sonnenrad darstellen. Deutungen kreisen auch um Begriffe wie Dreieinigkeit von „Körper-Geist-Seele“, „Geburt-Leben-Tod“ oder „Werden-Sein-Vergehen“. Sie gilt als Schutzamulett gegen alle möglichen negativen Kräfte und soll „Selbstvertrauen und Kreativität“ oder „Optimismus und Fortschritt“" vermitteln. Im Grunde jedoch bedeutet der dreifache Wirbel dieses Symbols die Einheit von Vergangenheit, Gegenwart und Zukunft, entsprechend den Schicksalsfrauen der Vergangenheit, Gegenwart und Zukunft, welche die Griechen als Moiren, Römer als Parzen und Germanen als Nornen bekannt war.

676 Auf das „T(au)-Zeichen“ wird in Kap. IV.5.2.3g) eingegangen.

677 Zerbst/Waldmann 2003, S.20 
In Rosenbachs Tape taucht mehrfach die linksdrehende Spirale auf, die zudem in einer Bildsequenz von innen nach außen gemalt wird, zu lesen allgemein als Lebensweg - im konkreteren Zusammenhang des Tapes, Entwicklungsweg vom Kind zum Erwachsenen.

Zusammenfassend lässt sich festhalten, dass sich auch bei den in diesem Tape zu findenden visuellen Attributen eine starke symbolische Bedeutungsebene zeigt, die diese Trägerobjekte erst in den größeren inhaltlichen Kontext einfügt.

e) Die auditive Ebene des Tapes

Das Band beginnt ohne jegliche Geräuschkulisse. Der Vorspann und die eröffnenden Bildsequenzen sind von Stille umfangen. Auch in der weiteren Folge gibt es keinen Originalton in den Aufnahmen zu hören. Stattdessen setzt nach ungefähr 45 Sekunden aus dem Off eine Stimme ein. Es ist die Stimme der Künstlerin, die durch ein Flüstern und leichte Halleffekte verändert ist. Auch werden manche der Worte - ähnlich einem Echo - wiederholt gesprochen. Zu hören ist nun, verteilt auf rund 16 Minuten, folgender Text: ${ }^{678}$

„Es gab keine Hindernisse, die nicht zu überwinden gewesen wären. Und sie hatte nie so etwas wie Angst gekannt.

Was hatte sie schon zu verlieren?

Sie war verwöhnt von ihrem $M u$.

An fünf verschiedenen Tagen zog sie zwei Hörner auf und machte sich auf den Weg. Es war leicht sich zu verlieren.

Es gab keine Hindernisse, die nicht zu überwinden gewesen wären und sie hatte nie so etwas wie Angst gekannt.

Was hatte sie schon zu verlieren? [Geflüstert:] Sie war verwöhnt von ibrem Mut.

[Längere Pause]

An fünf verschiedenen Tagen zog sie zwei Hörner an und machte sich auf den Weg. Es war leicht sich in der Dunkelheit zu orientieren. Sie zog es deshalb vor, keine Vorstellung zu haben von dem, was kommt, keine Antwort zu wissen auf das, was gefragt ist und sich aus nichts nichts zu machen.

Alles erschien ibr ein wenig abgehoben. Sie war aufgeregt, aber nach außen wirkte sie cool. Es gab keine Hindernisse, die nicht zu überwinden gewesen wären. Und sie hatte nie so etwas wie Angst gekannt. Was hatte sie schon zu verlieren? Sie war verwöhnt von ihrem Mut."

[Längere Pause: Geräusch wie Wind, Strablen untermalt mit sphärischen Klängen begleitet die folgende Einstellung obne Text.]

Alles erschien ihr ein wenig abgehoben, aber wie immer blieb sie cool.

678 Der Text war zwar bereits in die Beschreibung eingefügt, aber zum besseren Überblick wird er hier nun noch einmal in seiner Gesamtheit zusammengefasst. 
Sie zog es deshalb vor keine Vorstellung zu haben, von dem, was kommt. Keine Antwort zu wissen, auf das, was gefragt ist und sich aus nichts nichts zu machen.

[Pause]

Der Weg wand sich und verschwand ständig vor ibren Augen. Die Gegend veränderte bei jeder Wegbiegung ibr Gesicht. Doch es gab keine Hindernisse, die nicht zu überwinden gewesen wären. Und sie hatte nie so etwas wie Angst gekannt. Was hatte sie schon zu verlieren? Sie war verwöhnt von ibrem Mut.

[Längere Pause]

Der Weg blieb, was er war. [Mit leichter Bitterkeit in der Stimme:] Die Gegend war unveränderbar.

Sie zog es deshalb vor, keine Vorstellung zu haben von dem, was kommt, keine Antwort zu wissen auf das, was gefragt ist, und sich aus nichts nichts zu machen.

[Pause: Dann spricht die Stimme leicht glucksend weiter:]

Die Zeit schien unendlich lang zu sein. Sie hatte das Gefühl, sich zu verirren. Doch es gab keine Hindernisse, die nicht zu überwinden gewesen wären. Und sie hatte nie so etwas wie Angst gekannt. Was hatte sie schon zu verlieren? Sie war verwöhnt von ihrem Mut.

[Pause]

Nach langer Zeit noch hatte sie die Orientierung im Griff. Sie wußte genau wann und wo sie ankam. Sie zog es deshalb vor, keine Vorstellung zu haben, von dem was kommt. Keine Antwort zu wissen, auf das, was gefragt ist und sich aus nichts nichts zu machen.

[Pause]

Es wurde eine Frage auf Leben und Tod. Sie hatte drei Hörner und zwei Wünsche. Aber es war schwer, sie zu besitzen.

[Pause]

Es gab keine Hindernisse, die nicht zu überwinden gewesen wären, und sie hatte nie so etwas wie Angst gekannt. W as hatte sie schon zu verlieren? Sie war verwöhnt von ihrem Mut.

[Pause]

Es wurde eine Frage auf Leben und Tod.

Sie hatte zwei Hörner und drei Wünsche und es würde ihr freistehen, sie zu benutzen.

Sie zog es deshalb vor, keine Vorstellung zu haben, von dem, was kommt, keine Antwort zu wissen auf das, was gefragt ist und sich aus nichts, nichts zu machen."

Diese Worte begleiten das Tape mit kleinen Pausen, die als Absätze beziehungsweise als „,Pause]“ eingefügt sind. Untergliedert wird das Tape auf der Tonebene durch drei längere Pausen. Im Verlauf des Tapes wird der Ton zweimal durch eine Passage der Stille abgelöst. In der längeren Textpause dazwischen wird die Bildsequenz von einer Geräuschkulisse begleitet, die wie Wind und ein sphärisches Strahlen klingt.

Ein Blick auf den formalen Aufbau dieses Textes zeigt, dass er durch die Tonpausen in vier Abschnitte unterteilt ist. Zudem werden im Verlauf des gesamten Textes bestimmte Sätze, wie auch einzelne Wort wiederholt. Gleich fünf Mal stellt die Stimme die rhetorische Frage, die dann im Folgesatz gleich beantwortet wird: 
„Was hatte sie schon zu verlieren? Sie war verwöhnt von ihrem Mut.“ Viermal heißt es mit kleinen Variationen: „Sie zog es deshalb vor, keine Vorstellung zu haben, von dem, was kommt, keine Antwort zu wissen auf das, was gefragt ist und sich aus nichts, nichts zu machen.“ Dreimal wiederholt sie: „Doch es gab keine Hindernisse, die nicht zu überwinden gewesen wären. Und sie hatte nie so etwas wie Angst gekannt.“ Und zweimal sagt die Stimme: „An fünf verschiedenen Tagen zog sie zwei Hörner auf und machte sich auf den Weg."

Neben dem rhetorischen Mittel der Wiederholung arbeitet der Text mit einer deutlich erkennbaren Schleifenstruktur. So wird in der jeweils nachfolgenden Passage in der Wiederholung, bei dem die gesagten Worte auch leichte Variationen aufweisen können, eines oder mehrerer Sätze ein vorangegangener Gedanke wieder aufgenommen und mit einer neuen, gewandelten Aussage verknüpft. Auf diese verschachtelte Weise wird jedoch keine fortlaufende Geschichte erzählt. Vielmehr scheint es sich um eine Kette von Gedanken zu handeln.

In poetischer Form gibt dieser Text die Assoziationen einer Frau wieder, die über ihren Lebensweg reflektiert und Lehren aus ihren Erfahrungen zieht. Dabei werden die Worte aus dem Off durch die Künstlerin selbst wiedergegeben. Doch spricht diese in der dritten - nicht in der ersten - Person über die Dinge. Auf diese Weise übernimmt die Stimme aus dem Off die Rolle eines distanzierten Beobachters, Erzählers wie auch Kommentators.

In der ersten Passage bildet die Kernaussage der Satz: „Es gab keine Hindernisse, die nicht zu überwinden gewesen wären.“

Im zweiten Abschnitt, der von der langen Geräuschpause unterbrochen wird, geht es um die Suche nach dem Weg und nach Orientierung. Als „Lösung“ wird hier schließlich folgende inhaltliche Aussage gefunden: „Sie zog es vor, keine Vorstellung zu haben von dem, was kommt und keine Antwort zu wissen auf das, was gefragt ist und sich aus nichts, nichts zu machen."

Im abschließenden Abschnitt wird dann betont, dass die Person die Orientierung im Griff habe. Allerdings wird dabei das Existentielle dieses Ringens deutlich benannt, ein Motiv, das bereits bei den beiden „Eleven-Arbeiten“ begegnete: „Es wurde eine Frage auf Leben und Tod“".679

Zudem tauchen in dem Text bestimmte Zahlen auf. Es sind die Zwei, die Drei und die Fünf, die wiederholt benannt werden. So ist von fünf Tagen, drei Hörnern und zwei Wünschen - sowie die Ziffern vertauschend - von zwei Hörnern und drei Wünschen die Rede. Manfred Lurker schreibt im „Wörterbuch der Symbolik“":

679 Ein Thema, das bereits bei „Eleven“ begegnete. 
„Zablen sind der ideale Maßstab für Raum und Zeit und wurden schon in alter Zeit als Mittel zur Erkenntnis der Welt angesehen; in ihnen glaubte man das Spiegelbild kosmischer und menschlicher Ordnungen. "680

Auf der symbolischen Ebene heißt es zur Zahl Zwei:

„Es ist die erste Zabl, welche die Spaltung, der in der Eins repräsentierten Einheit bezeichnet. Die Zweiheit ist Ausdruck der Unvollkommenheit, da jedes ibrer beiden Teile vom anderen abhängig ist; die polare Zweiheit gebört zur Grundstruktur des geschöpflichen Seins (...) Während die Eins die Zabl des Göttlichen, Unerschaffenen, Ewigen ist, weist die Zwei auf alles geschlechtlich Geborene, das dem Gesetz, von Leben und Tod unterliegt. "681

Dagegen findet sich für die Drei eine andere Symbolik:

„Drei bedeutet die Überwindung der Ent_oveiung und drückt in ibrem umfassenden Wesen die Vollkommenheit aus, daher Grundlage verschiedener Systembildungen. "682

Aber Lurker schreibt auch:

„Die Drei (und ibre Vielfachen 9 und 27) ist, Ausdruck des Zeitgefübls der lunaren Kultur" (nach Leo Frobenius). "683

Die Fünf ist die Summe aus der Zwei und der Drei und diese mathematische Grundlage fließt auch in die symbolische Deutung. So heißt es über die Fünf:

„Fïnf gilt als numinose Zabl bei den Manicbäern (...), im Hinduismus (...) und im Jainismus. Auch im chinesischen Denken spielt die Fünf eine wichtige Rolle. (...) In der pythagoreischen Zablenspekulation galt die Fünf als Vereinigung der männlichen Drei mit der weiblichen Zwei und damit als Symbol der Hochzeit. "684

Die Rede ist zunächst von zwei Hörnern - den zwei Polaritäten - doch drei Wünschen - in denen das Motiv der Überwindung der Zweiheit, Trennung steckt. Dieser Prozess erstreckt sich über fünf Tage - Summe aus der Zwei und der Drei und zudem Symbol der Hochzeit, die dann zudem in Form des Hermaphroditen ins Bild gesetzt wird.

Vor diesem symbolischen Deutungshintergrund geben die Zahlen zusätzliche Informationen zu den bildlichen Aussagen. Interessant ist auch ein Blick auf die tieferen Bedeutungen der weiteren gewählten Begrifflichkeiten in dem Text. So taucht zum Beispiel der Ausdruck „cool“ auf. Nach eigenen Aussagen der Künstlerin war dies ein Modeausdruck ab den 1980er Jahren, der zudem eine allgemein

\footnotetext{
680 Lurker 1991, S.845

681 Lurker 1991, S.857

682 Lurker 1991, S.151

683 Lurker 1991, S.845

684 Lurker 1991, S.225f
} 
sehr kühle emotionale Lage widerspiegelte. 685 Zum anderen steckt darin auch das Eismotiv, das englische Wort „,cool“ bedeutet übersetzt „kalt“ oder auch „unnahbar“. Im Tape erscheint dazu im Bild der mit Schnee bedeckte Berg, mit dem Foto einer Bergsteigerin, der bereits in der Mount-Everest-Aktion begegnete. Auch ist die Wahl der Formulierungen zu beachten, so heißt es: „Sie hatte nie so etwas wie Angst ,gekannt،“" Das bedeutet etwas anderes als: „Sie hatte nie so etwas wie Angst ,gehabt'“" Die Künstlerin betont mit der gewählten Formulierung den Aspekt des Erkennens, nicht des Seins.

Zusammenfassend lässt sich in Bezug auf die auditive Ebene der „Eulenspieglerin“ an dieser Stelle sagen, dass der Text einen in sich geschlossenen inhaltlichen Rahmen anbietet, in dem die assoziativ wirkenden Informationen in poetischer wie symbolischer Weise verdichtet werden. Dabei werden mittels der formalen Schleifen- oder auch Spiralstruktur Variationen im inhaltlichen Verständnis und Lösungsmöglichkeiten erkundet und vermittelt.

f) Verbindung von Bild und Ton

Es zeigte sich, dass in dem Tape „Die Eulenspieglerin“ die Bildebene die Inhalte in einerseits zeichenhafter-metaphorischer, andererseits sehr buchstäblicher Weise wiedergibt. Dabei unterstützt die formale Präsentation der collagierten Bildsequenzen die inhaltlichen Aussagen in signifikanter Weise. Bei der Untersuchung der Tonebene des Tapes zeigte sich, dass es hier keinen Originalton gibt, vielmehr sind Text- und Geräuschkulissen hinzugefügt. Dabei arbeitet der poetische und komponierte Text mit Assoziationsketten, Wiederholungen und Metaphern.

Blickt man auf die Verknüpfung von Bild- und Tonebene zeigt sich deutlich, dass sich die textlichen Aussagen auf der auditiven Ebene in den synchron sichtbaren Bildsequenzen spiegeln. Zu erkennen ist eine große inhaltliche Nähe zwischen visueller und auditiver Aussage. In manchen Passagen erschließt sich die nicht immer leicht zu entschlüsselnde bildliche Aussage durch die zusätzlichen Informationen der Tonebene. Ist zum Beispiel die Rede im Text vom „Weg“, sieht man in dem Tape die Künstlerin an der schwarzen Wand entlang schreiten. Als sie später von „drei Hörnern“ spricht, wird diese textliche Aussage auf der Bildebene von der Zeichnung des Triskelen begleitet, dem Kopffüßler mit den drei angewinkelten Beinen, ein Motiv, das auch Assoziationen an Hörner erlaubt. Neben diesen beiden Beispielen, die zeigen sollen, wie konkret der Bezug zwischen Bildund Textebene in dem Tape ist, verstärkt auch in der Bildsequenz in der Tapemitte, mit der Künstlerin, die den Monitor durch den Raum schiebt, auf dem eine Art Sternenexplosion zu sehen ist, die sphärische Geräuschkulisse, die transzendente Atmosphäre der elektronisch bearbeiteten Aufnahmen. Diese drei Beispiele sollen

685 Gespräch mit Rosenbach 2001, Kap. VII.1. 
reichen, die direkte Bezogenheit von visueller und auditiver Ebene zu verdeutlichen.

Zusammenfassend lässt sich damit ebenfalls für die synästhetische Wirkung von Bild und Ton zusammenfassen, dass das Tape „Die Eulenspieglerin“ auch hier durch eine große Direktheit und Anschaulichkeit geprägt ist.

\section{g) Die zeitliche Ebene}

Das Tape dauert fast genau 18 Minuten. ${ }^{686}$ Während dieser Zeitspanne sind die Bildsequenzen sowohl auf der auditiven, wie auch auf der visuellen Ebene in kleinere Einheiten untergliedert. Dabei sind sowohl die Text- wie auch die Bildebene durch keine klare narrative Struktur gekennzeichnet. Sie spiegeln auf den ersten Blick keine fortlaufende Handlung. Vielmehr erinnern sie an eine Assoziationskette, in der unterschiedlichste Bildmotive ineinander verwoben sind. In dieser Bildcollage, wie auch dem Text, kehren allerdings Motive wieder, ein Hinweis aus zyklische Abläufe, die sich auch in dem wiederholt eingeblendeten Bild der linkskreisenden Spirale zeichenhaft manifestieren. Wie bereits für die Textebene herausgearbeitet, zeigt sich diese Spiral- oder Schleifenstruktur auf der visuellen Ebene besonders deutlich, in dem das Tape beginnt und auch seinen Ausklang findet, mit einer sehr ähnlichen Bildsequenz. Die Akteurin dreht sich zu Beginn des Tapes im schwarz umrandeten Kreisinsert um ihre eigene Achse. Dabei ist in Großaufnahme auf den Oberkörper und den Kopf der Drehenden fokussiert. Zu sehen ist die Künstlerin im roten Kleid, über dem sie um die Taille ein weißes Kleidungsstück geschlungen trägt. ${ }^{687}$ In der Wiederholungssequenz zum Ende des Tapes sind dann auffallende Variationen $z u$ finden. Wieder findet sich zwar der Kreisinsert, der die Um-die-eigene-Achse-Kreisende zeigt. Doch diesmal trägt sie Kleidung in rot-weißer Farbe, sowie rote und weiße Tücher in den Händen. Ihre Augen sind nun mit einem roten Schal verbunden und die Kamera ist von ihr abgerückt, so dass der gesamte Körper in Großaufnahme sichtbar ist, sowie zudem der weiße Hintergrund mit dem roten Drei-Mond-Zeichen.

Dieser Kreisinsert im Zentrum des Bildes ist nun von einer weiteren Darstellung der Drehenden umgeben. Die Figuren in den beiden verschachtelten Bildsequenzen drehen sich synchronisiert im Kreis. Inneres und äußeres Bild finden sich an dieser Stelle der „Eulenspieglerin“ in ganz anschaulicher Weise im Einklang und Gleichmaß. Das Tape endet allerdings nicht mit dieser Einheit, sondern wird mit einer weiteren Szene fortgesetzt, bevor den Abschlusspunkt das Zeigen des Tao-Zeichens auf türkisem Grund bildet: ein schwarzer Kreis, der an einer Stelle geöffnet ist, und schließlich nach rechts unten aus dem Bild heraus wandert. Mit

686 Auch wenn in den Katalogen in der Regel 20 Minuten genannt werden.

687 Es scheint sich um ein Oberteil zu handeln, vielleicht ein Body. Außerdem scheint ein Loch vorne vor dem Schritt in dem Stoff des Rockes der Künstlerin zu sein. 
dieser Fortführung wird im zeitlichen Fortschreiten sozusagen der nächste Spiralkreis im Kreislauf des Lebens eröffnet, der dann im Abschlussbild nochmal sinnfällig als Tao-Kreis ins Bild gesetzt wird.

Interessant ist, dass während der Hintergrund in dem Kreisinsert zu Beginn des Tapes fast unsichtbar blieb, in der Wiederaufnahme der griechische Buchstabe "Tau" in leuchtendem Rot auf die weiße Wand gemalt sichtbar wird. Tau ist der 19. Buchstabe des griechischen Alphabetes und in der Physik die Bezeichnung für die so genannte „Zeitkonstante“ ${ }^{688}$ Wichtiger als der physikalische Hintergrund ist für das Verständnis dieses Zeichens und seine Deutung der Begriff „Zeitkonstante“. Da das aus dem Lateinischen abgeleitete Wort „konstant" so viel bedeutet wie „unveränderlich, ständig gleichbleibend" ist die Zeitkonstante in einer wörtlichen Auslegung also „Zeit, die gleichbleibt“. Und genau dafür steht auch die abgebildete, Trance hervorrufende Drehung. ${ }^{689}$ Denn, wie bereits beschrieben, tritt bei einer solchen steten Drehbewegung bei dem Kreisenden mit dem einsetzenden Verlust des Raumgefühls auch ein Eindruck eines sich auflösenden Zeitgefühls ein. Genau an dieser Stelle des Tapes heißt es stimmig im begleitenden Text: „Die Zeit schien unendlich lang zu sein."

Neben dieser das Zyklische in den Mittelpunkt stellenden Interpretation des Tapes, soll noch ein weiterer Aspekt betrachtet werden. Denn der Name des Buchstabens „Tau“ erinnert stark an das chinesische „Tao“, das im Zusammenhang mit den Eleven-Arbeiten begegnete, so dass hier die physikalischelektronische und die religiöse-spirituelle Dimension, durch ein Wortspiel - ein Mittel, das im Werk Rosenbachs bereits begegnete - assoziativ verknüpft sind. ${ }^{690}$ Das Tao ist der „Weg“ und Grundgedanke der chinesischen Philosophie. Vom „Weg“ ist in dem begleitenden Text gleich mehrfach die Rede: Die Akteurin macht sich mit zwei Hörnern auf den Weg, der sich wand und ständig vor ihren Augen verschwand. Zudem wird erläutert, dass die Gegend bei jeder Wegbiegung ihr Gesicht änderte. Später im Text, in dem das Wort „Weg“ nicht mehr auftaucht, heißt es dann: "Nach langer Zeit hatte sie die Orientierung im Griff, sie wusste genau, wo sie ankam.“ Passend zu dieser Wandlung verändert auch das Tau-Zeichen im Verlauf des Tapes mehrfach seine Farbe: von Schwarz über Grün zu leuchtendem Rot. Zusätzlich bereichert auch die Spirale, ein weiteres Symbol des Lebensweges in unterschiedlichen Farben das Tape, bis schließlich auch das Tao-Zeichen Eingang findet-.

Entgegen der zyklischen Struktur, die in dem Tape auf unterschiedlichen Ebenen inszeniert wird, ist es dem Medium des Videotapes immanent, dass es sich

688 Der Begriff stammt aus der Elektronik und ist von bedeutung bei der Entzerrung von Tonbändern, Sendern oder auch Schallplatten. Die Zeitkonstante, die in der Physik das Produkt aus Widerstand $(\mathrm{R})$ und Kondensator $(\mathrm{C})$ darstellt (also R x C = T), hat die Einheit Sekunde.

689 Vgl. Kap. IV.4.3.

690 Vgl. Kap. IV.4.2. 
chronologisch im Zeitablauf entwickelt. Die Eulenspieglerin ist fast genau 18 Minuten lang. Stellt sich die Frage - bei all der bisher erschlossenen Symbolhaftigkeit der Zeichen - ob nicht vielleicht auch die gewählte Länge der audiovisuellen Komposition mit Symbolik gefüllt sein könnte? Wie oben dargelegt sind Zahlen der ideale Maßstab für Raum und Zeit und wurden bereits in alten Zeiten als Mittel zur Welterkenntnis angesehen. ${ }^{691}$

Die Zahl 18 setzt im westlichen Kulturkreis Assoziationen an Volljährigkeit und Reife frei. Markiert doch der achtzehnte Geburtstag den offiziellen Übergang von der Jugend zum Erwachsensein, zur vollen Mündigkeit vor dem Gesetz. Und das Tape „Die Eulenspieglerin“ kreist genau um diesen Prozess des Reifens, Wachsens, Erwachsenwerdens, in dem es die Lebensstufen der Frau thematisiert. Und mit dem Einfügen des „Tau“, des 19. Buchstabens des griechischen Alphabetes, wird eine neue Schleife im Lebenszyklus eröffnet, angedeutet, dass der Wachstums- und Reifeprozess sich im Leben stetig fortsetzt.

Die Untersuchung der Zeitebene in dem Tape zeigt einen sehr reflektierten Umgang mit dem schwer fassbaren Phänomen der Zeit, in dem zyklische und chronologische Abläufe miteinander verwoben werden. Die Zeitebene ist dabei auch in der Zeichenebene präsent. So zeigt sich in der 18-minütigen Komposition ein sehr dichtes, verschachteltes Symbolsystem.

\section{IV.5.2.4 Analyseergebnisse}

In der vorangegangenen Analyse wurde das Tape „Die Eulenspieglerin“ mit dem Fokus auf unterschiedliche Gestaltungsmittel und deren Zusammenwirken untersucht. Neben den Verknüpfungen der Bildsequenzen wurden die Farben, die Darstellung des Körpers, die Einbeziehung anderer Objekte, die auditive Ebene, die Beziehung zwischen Bild und Ton sowie die zeitliche Ebene betrachtet. Dabei zeigte sich, dass in dieser komponierten Bild-Ton-Collage Bildmotive visuell durchlässig werden für andere Handlungsebenen. Hier geben neben dem Einsatz von Blenden, durch die unterschiedliche Bildinhalte verknüpft werden, besonders auch die Formen und Farben Raum für das Einfügen zusätzlicher visueller Informationen, werden sie doch mit anderen Bildsequenzen gefüllt, was auch einen Eindruck des „Durchdringens“ oder „Durchschauens“ hervorruft. Dabei übernehmen die Farben in dem Tape eine wichtige Symbolfunktion, werden zum Teil explizit eingefügt. Sie transportieren zusätzliche Inhalte und verstärken oder präzisieren die Aussagen der jeweiligen Passage.

Der Körper wird in dem Tape zum einen als agierender Träger der Handlung, aber auch als Projektionsfläche genutzt, und er wird in den Aufnahmen gestaltet, in dem er einerseits fragmentiert oder auch auf bestimmte seiner Teile fokussiert wird. Dabei zeigen sich figurative Motive, wie zum Beispiel das Erscheinen eines

691 Vgl. Lurker 1991, S.845 
großen Auges im Rücken der Künstlerin, das zum Beispiel als bildliche Metapher für „Rückblick“ gelesen werden kann. In ähnlicher Weise scheint auch das Bild der Hand eine Metapher für „Handlung“ oder „Handeln“ zu sein. Daneben zeigt sich, dass die jeweilige Größe des Bildausschnittes die inhaltliche Bedeutung verstärkt. Diese symbolisch-metaphorische Aufladung der figurativen Inhalte findet sich zusätzlich beim Verweben unterschiedlicher Bildsequenzen wie auch bei der Darstellung von Bewegung.

Neben dem Einsatz des Mediums des Körpers arbeitet die Künstlerin in diesem Tape mit einem begrenzten Formenrepertoire. Sie nutzt verschiedene Objekte und Elemente. Davon begegneten einige bereits in vorangehenden Werken wie die geflügelte Frauengestalt - andere kommen neu hinzu, wie die Hörner oder die Zeichnungen mit den drei vorgestellten Motiven. Aus diesem begrenzten Objektschatz schöpft sie und kombiniert diese im Verlauf des Tapes mehrfach neu. So verfährt sie formal auf der visuellen Ebene ähnlich wie auf der auditiven.

In dem begleitenden Text werden die Worte und Inhalte verdichtenden Sätze ebenfalls in Variationen wiederholt und durch neue Kombinationen zu gewandelten Inhalten verknüpft. Dabei wird auf die große Bedeutung des Hörens durch die überdimensionalen Ohren an dem Eulenspiegelkopf hingewiesen. Der poetische Text ist somit Träger der bildlichen Assoziationskette, und es findet sich in dem Tape zum Teil ein sehr direkter, quasi buchstäblicher, Bezug zwischen Bild und Ton. Diese Buchstäblichkeit ist eine Eigenschaft, die genau der Till Eulenspiegelfigur eigen ist, beruht Eulenspiegels Witz doch darauf, dass er durch das Wortwörtlich-Nehmen dessen, was ihm aufgetragen wurde, die Absurdität des Gesagten vorführte und mit Wortbedeutungen spielt. Dabei findet sich in diesem Tape neben einer starken Buchstäblichkeit in der bildlichen Umsetzung eine Bearbeitung des namengebenden Spiegelthemas - dem Symbol der Reflektion und Erkenntnis - gleich auf mehreren Ebenen. Dieses zeigt sich nicht nur in der Nutzung des Monitorbildes als Spiegelfläche für innere Prozesse, auch reflektiert das gesamte Tape verschiedene Erkenntniswege in abstrahierter Form und erlaubt im Durchschauen einen Blick unter die Oberfläche der Dinge.

Die Untersuchung der Zeitebene in dem Tape zeigte zudem einen reflektierten Umgang mit dem Phänomen der Zeit, indem zyklische und chronologische Abläufe miteinander verwoben werden. Die Zeitebene ist dabei auch in der Zeichenebene des Tapes stetig präsent.

Unabhängig von den Performances, die die bildgebende Basis für diese elektronische Komposition darstellten, schafft das Tape etwas grundsätzlich Neues. Die Komposition verdichtet in sich überlagernden Bedeutungsschichten die mehrdeutigen Aussagen der Aktion zu Aspekten des Lebens, Wachsens wie auch der Identität im zeitlichen Fluss, verbindet zyklische Struktur mit zeitlicher Abfolge und bildet letztlich ein verschachteltes, wohlkomponiertes Symbolsystem. 
In der Analyse offenbart sich, dass neben einer starken Zeichenhaftigkeit auf der Bild- und Tonebene, das Tape auf der Basis einer zweiten Zeichenebene komplex durchkomponiert ist. So schwingt neben dem, was man konkret sieht, eine zweite, symbolische Bedeutungsebene durchweg mit, bildet einen begleitenden Subtext und führt die semiotischen Ansätze der Tapes der 1970er Jahre in differenzierter und komplexer Form weiter.

\section{IV.5.3. Werkuntersuchung: „Or-Phelia - Ein Transformationsstück“}

Mit dem Namen „Or-Phelia“ ist eine weitere Gruppe von Werken betitelt, die im folgenden in den Blick genommen wird. Der Werkkomplex besteht hier aus zwei Videoperformances, einer Installation und einem Performancetape, in dem das künstlerische Schaffen Ulrike Rosenbachs in den bisher umrissenen zwei Jahrzehnten kulminiert. So ordnet die Kunstwissenschaftlerin Lydia Haustein die Installation als Abschlusspunkt einer Phase in das Werk Ulrike Rosenbachs ein, wenn sie schreibt:

„Mit der Installation, Or-Phelia' (1987) fasste sie die Grundprinzipien ibrer ersten Phase mittels einer ausgeprägten biografischen Radikalität und kanalisierte diese in Richtung Geschlecbterdifferen₹:" "992

Während die Installation mit dem Titel „Or-Phelia“ im Jahr 1987 im Rahmen der documenta 8 in Kassel gezeigt wurde, entstand das Videotape im Jahr 1988. es wurde aus dem bei einer vorangegangenen Performance aufgenommenen Bildmaterial produziert, die in Karlsruhe stattfand. ${ }^{693}$ Dieses Tape, das den Titel trägt „Or-Phelia - Ein Transformationsstück“" wird im Folgenden analysiert.

${ }^{692}$ Haustein 2003, S.78

693 Das zweite Mal führte die Künstlerin die Performance unter dem Titel „Or-phelia II, Osterstück“ 1989 in der Kölner Kirche Sankt Peter auf. 


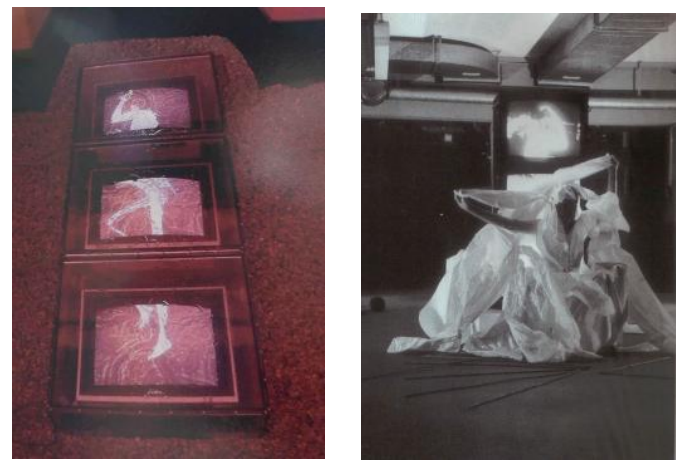

Abb. 192-193: Or-Phelia, 1987, Installation und Or-phelia, 1988, Aktionsfoto

Doch zuvor soll ein kurzer Blick auf die Videoinstallation „Or-Phelia“ geworfen werden, die im Jahr 1987 auf der documenta 8 in Kassel zu sehen war. Die Installation zeigte in einem eckigen Plexiglasobjekt in Kreuzform, das mit Lavakies gefüllt war, drei nebeneinander liegende Monitore, deren Bildschirme nach oben zeigten. Die darauf zu sehenden Videoaufnahmen waren miteinander gekoppelt gesplittet - so dass sich auf den drei Bildschirmen der Körper einer weiß gekleideten menschlichen Gestalt zusammenfügte - vielleicht eine Großaufnahme der Künstlerin in einem eng anliegenden weißen Trikot. Die weiße Figur drehte sich langsam um die eigene Achse und bewegte während dieser Drehung zudem im Laufe der Zeit Kopf, Arme und Hände. Diese elektronisch generierte Bildsequenz, die auf die drei Bildschirme verteilt war, war durchwoben und umspült von sich gemächlich bewegenden Aufnahmen einer menschlichen Blutbahn in starker Vergrößerung. Zusätzlich erschienen helle farbige „Wellen“, die waagerecht auf dem Bildschirm, der den Oberkörper der Figur zeigte, zunächst den Kopf umspülten, dann mit ihm verschmolzen und ihn schließlich vorübergehend ersetzten. Als Ton erklang zu der Installation meditative, mit Wassergeräuschen durchsetzte Flötenmusik. ${ }^{694}$

Die weiße Figur wird von der Künstlerin selbst als „Or-Pheliafigur“ bezeichnet. Der Begriff „Or-Phelia“ ist aus zwei Namen zusammengesetzt. In ihm ist der männliche Name „Orpheus“ mit dem weiblichen „Ophelia“ verbunden. Diese Verknüpfung von weiblich und männlich ruft deutliche Assoziationen an das Thema des Androgyn wach. Neben dem Aspekt des Androgyn sind es zudem Elemente der östlichen und westlichen Spiritualität, der Alchemie, wie auch des Rituellen, die sich in diesem Werk zu einer sehr persönlichen wie auch politischen Aussage verweben, die Marlies Grüterich für die Performance beschreibt:

\footnotetext{
694 Vgl. Rosenbach in: Kat. Saarbrücken 1990, o. S.
} 
„Die Or-Phelia Akteurin ist in ihrem Natur-Kultur-Element. Sie hat eine Blumengeburt. So wird die Welt konstruktiv abgebildet, und auch ibre Konstruktionsgeheimnisse werden sichtbar und hörbar in ibrem Ebenbild, Mensch: Unser Planet braucht den Energie-Austausch mit uns. Wir müssen begreifen, daß er mehr umgreift als uns rational in den Kopf geht. Ulrike Rosenbachs Bilder sehen das. "695

\section{IV.5.3.1 Beschreibung des Tapes}

Zunächst soll nun als Grundlage für die folgende Analyse das Tape beschrieben werden. ${ }^{696}$ Das Farbtape ist im in den 1980er Jahren gängigen Videoformat im Seitenverhältnis drei zu vier aufgezeichnet. Es beginnt mit einer Einblendung des Titels in rosafarbenen Buchstaben auf schwarzem Grund, bevor das Performanceenvironment in der Halbtotalen erscheint: Hinter einem in weiße Papierbahnen gehüllten Turm, bestehend aus drei aufeinandergestapelten Videomonitoren, wie sich später zeigen wird, steht die Künstlerin in einem weißen Kleid mit langem Glockenrock, während aus dem Off das rhythmische Tropfen von Wasser zu hören ist, das das gesamte Tape stetig begleiten wird. Dann setzen musikalische Klänge ein und die Performerin tritt in der Halbtotalen des Tapes in den Vordergrund der Einstellung. Man sieht sie gegen den Uhrzeigersinn um den Turm herumschreiten, wobei sie Schicht für Schicht, die diesen umschließenden Papierbahnen raschelnd entblättert. Die Geräusche sind dabei im Originalton zu hören. So werden schließlich die drei gestapelten Monitore sichtbar, die gemeinsam das Bild einer weißen, menschlichen Figur zeigen, die in ein blaurotes Fließen und Pulsieren eingebettet ist.

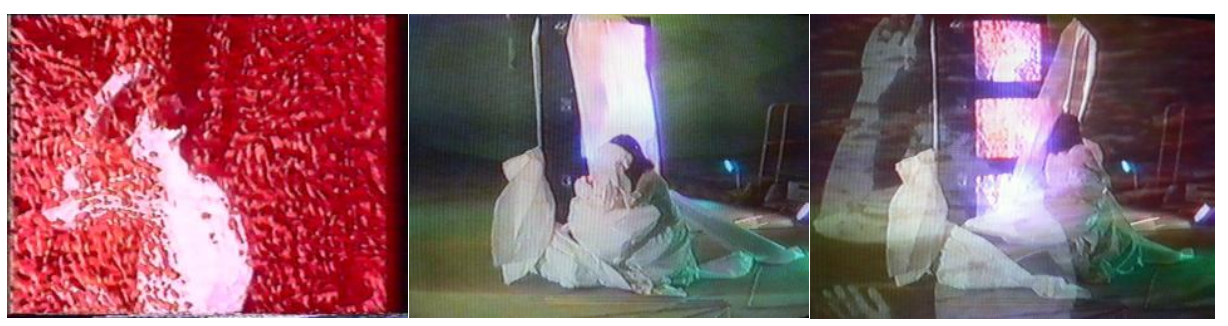

Abb. 194-196: Or-Phelia, 1987, 3 Videostills

Eine weiche Überblendung schließt dann das bewegte Bild des obersten Monitors an. Es zeigt in Großaufnahme den Oberkörper und Kopf der weißen Figur im Profil von links. Die Figur hat den rechten Arm erhoben und wird umspült von roten, orangenen und blauen Strukturen, die an eine pulsierende, stark vergrößerte Blutbahn erinnern. Aus dem Off setzt zu dieser Bildsequenz die Stimme der

695 Grüterich in: Kat. Saarbrücken 1990, o.S.
696 Das Protokoll findet sich im Anhang, Kap. VIII.2. 
Künstlerin ein, die allerdings durch einen Halleffekt schwer zu verstehen ist. Sie sagt: „Ich öffne meine Hände und sehe nichts.“ Nach kurzer Pause schließt sich aus dem Off an: „Ich öffne meine Füße und sehe nichts.“ Dazu ist nach einer Überblendung zu sehen, wie sich die Künstlerin in der angeschlossenen Halbnahen auf den Boden vor die Monitore hockt.

„Ich öffne meine Brüste und sehe nichts“, heißt es weiter. Die Halbnahe zeigt dazu, wie die Künstlerin auf dem Boden sitzt und sich das Papier vor das Gesicht hält. „Ich öffne meinen Bauch und sehe nichts.“ Hier zieht die Akteurin vor den Monitoren die letzte Papierbahn weg. Daraufhin wird diese Einstellung mit dem schon bekannten Monitorbild der Or-pheliafigur halb überblendet, so dass von nun an beide Bildsequenzen durcheinander scheinen. Die Stimme kommentiert: „Ich öffne meine Augen und sehe nichts.“ Die Künstlerin hat sich inzwischen in das Papier eingehüllt, wie die Halbnahe zeigt. Daraufhin wechselt die Einstellung mittels eines harten Schnittes und das Monitorbild mit der Or-Phelia-Figur ist zu sehen, das nun die weiße Figur in Nahaufnahme von rotem Fließen umgeben zeigt.

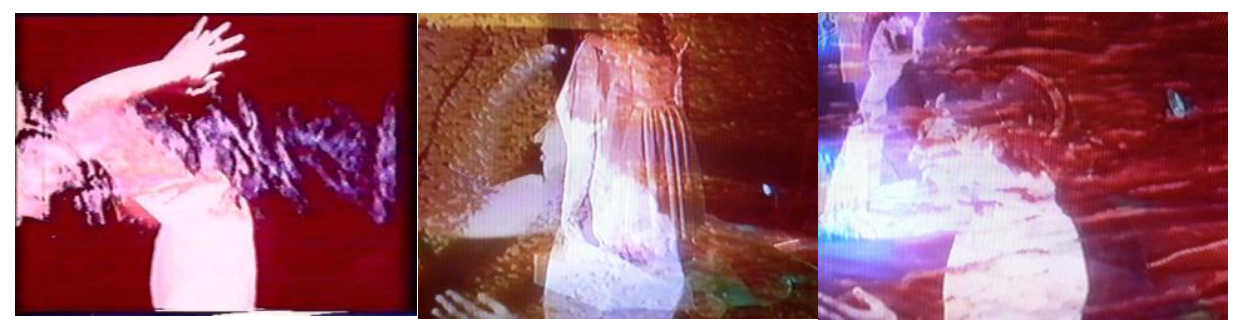

Abb. 197-199: Or-Phelia, 1987, 3 Videostills

„Ich öffne meinen Hals und sehe nichts.“ Nach einem Schnitt zeigt die Aufnahme die Agierende im Performanceenvironment. Von der Halbnahen wird auf Großaufnahme gezoomt und die folgende Bildsequenz zeigt die Agierende, die in den Papierhaufen eingehüllt bleibt, im Zentrum sitzend. Dann heißt es: „Ich öffne meine Seele und sehe nichts. " Vollständig überblendet werden die beiden Bildebenen - Aktionsszene und Monitorbild - als es schließlich heißt: „Ich öffne mir mein Herz und sehe mich an. " Hierbei hält die Künstlerin in ihrer Bewegung inne, so dass sie eine Weile unbewegt im Profil am Boden hockend zu sehen ist. Dazu ist nur das gleichmäßige, etwas treibende Tropfen aus dem Off deutlich zu hören. 

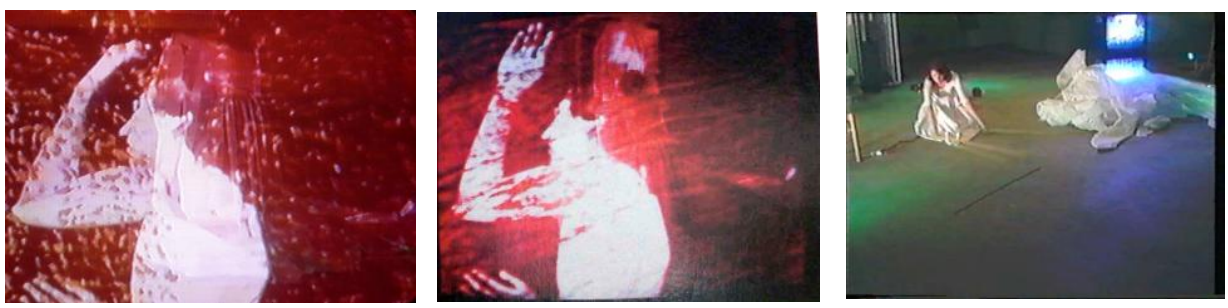

Abb. 200-202: Or-Phelia, 1987, 3 Videostills

Es wird dann auf den oberen Teil des dreiteiligen Monitorbildes überblendet, das jetzt den weißen Oberkörper der Figur im Profil zeigt, beide Arme sind erhoben. Die pulsierende farbige Flüssigkeit umfließt weiter die weiße menschliche Silhouette. In diese Bildsequenz wird für einen Augenblick eine Nahaufnahme des Gesichtes der Künstlerin eingeblendet. Dann wird sofort wieder weich auf die Aktionsansicht überblendet. Hier sieht man nun zunächst in Großaufnahme, dann wird auf Halbtotale gezoomt, wie die Künstlerin am Boden hockt und unter dem Papier lange dünne Stäbe an ihren Händen befestigt, fächerförmig - drei auf jeder Seite. Währenddessen stimmt ein Frauenchor aus dem Off ein melodisches „Hallo, Hey, Hallo...“ an. Die in der Halbnahen im Bildzentrum auf dem Boden hockende Performerin beginnt zunächst - vorsichtig tastend - mit den Stäben von links nach rechts in einem großen Bogen vor ihrem Körper über den Boden zu streichen. Der Rhythmus für die ausladende Fegebewegung wird immer schneller, während die Künstlerin auf den Knien durch den Raum krabbelt. Zu hören ist währenddessen - neben dem Chorgesang und dem steten Tropfen - das Schleifen der Stäbe über den Grund. Als das Schwingen noch schneller wird, fasst die Künstlerin die Stäbe schließlich zu einem Bündel zusammen. Hierbei verklingt der Gesang und es bleiben nur das Tropf- und Schleifgeräusch. Dann folgt eine weiche Überblendung zunächst zum Monitorbild und dann wieder zurück zur Halbnahen, die die Szene mit der Akteurin zeigt, die jetzt mit einem Knäuel roter Wolle am Boden hockt. Aus dem Off beginnt die Stimme erneut die Sätze zu sprechen. Währenddessen steht die Künstlerin vom Boden auf und beginnt - sich um ihre eigene Achse drehend - durch den Raum zu tanzen, so dass sich der rote Wollfaden allmählich um ihre Taille wickelt. Die Kamera folgt den Bewegungen der Agierenden, bildet die Szene als Halbtotale ab. Dann wird wieder schwach auf das Monitorbild der Or-Pheliafigur überblendet, so dass zunächst die beiden Bildebenen aus der weißen Figur und der tanzenden Performerin ineinander verschwimmen. Dann ist wieder nur das Monitorbild mit der weißen Figur zu sehen bis bei dem Satz „Ich öffne mein Herz“ erneut beide Ebenen miteinander verschwimmen. Während das Bild der Or-pheliafigur bis auf weiteres die Aufnahme der Aktion überlagert, ist auch weiter zu erkennen, dass die Performerin sich im- 
mer noch im Kreis dreht, wobei sich der rote Faden nun auch um deren Füße wickelt.
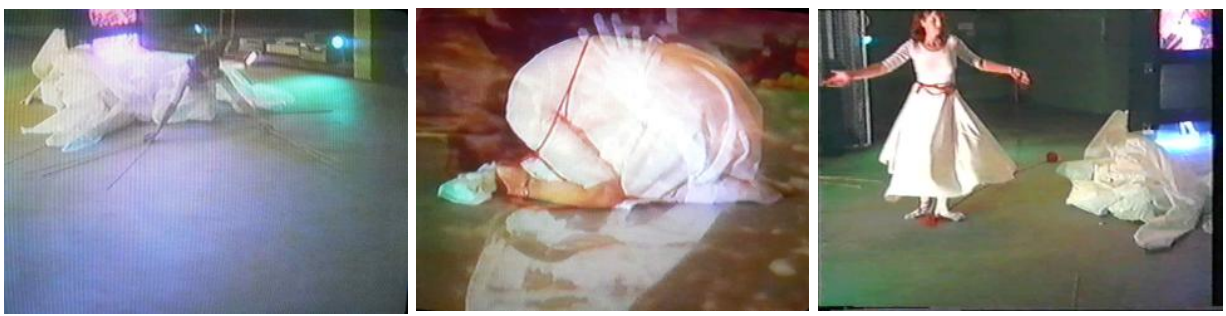

Abb. 203-205: Or-Phelia, 1987, 3 Videostills

Schließlich ist zunächst in einer Halbtotalen zu sehen, wie sie sich auf einen hölzernen Stuhl setzt, der bereit steht und an dem der lange rote Faden zu einem dicken Strang gebündelt über der Lehne hängt. Ein Zoom geht dann bis zur Nahaufnahme an diese Szene heran und zeigt wie die Künstlerin ihre Füße sitzende aus der Umwicklung befreit, wobei sie ihre Arme und Füße synchron fließend bewegt, bis diese schließlich ohne Fesselung sind. Während einer weiteren Überblendung mit dem Fließen auf dem Monitorschirm, sieht man die Agierende kurzfristig durch den Raum laufen, bis das Pulsieren des Videomonitorbildes schließlich vollständig in den Vordergrund tritt.

Nach einer weiteren Überblendung sieht man die Künstlerin, die den roten Faden weiter um ihre Taille geknüpft trägt und nun beginnt die Papierbahnen auf dem Boden zu ordnen. Dazu ist aus dem Off neben dem Rascheln des Papiers und einsetzender spannungerzeugender Klänge ein tiefes Aus- und Einatmen zu hören ist. Das Hin- und Herblenden zwischen den beiden Bildebenen - Aktion und Or-Pheliafigur - setzt sich in dieser Sequenz eine ganze Weile fort bis aus dem Off die Stimme der Künstlerin erklingt:

„Zwischen den Türen von Leben und Tod gibt es noch eine andere Tür, völlig unerwartet. Die, die geboren werden an der Schwelle des Todes sind dem Ewigen geweibt."
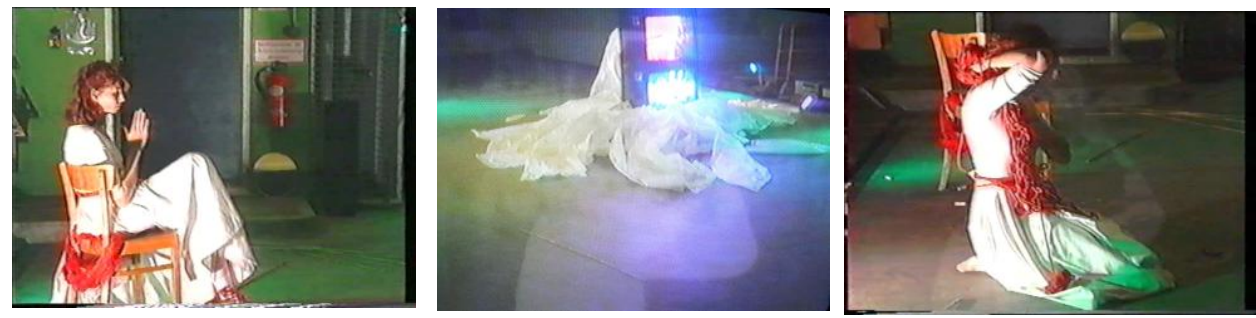

Abb. 206-208: Or-Phelia, 1987, 3 Videostills 
Das Tape zeigt nun in der Halbnahen, wie die Künstlerin über den Boden rollt, bevor sie sich hinhockt und den Wollstrang in locker gewickelter Lage aufnimmt und ihn sich - die Seiten abwechselnd - über die Schultern schmiegt und sich, wie die Großaufnahme zeigt, in die rote Wolle kuschelt. Zu diesen schmeichelnden Bewegungen beginnen fernöstliche, meditative Klänge in den Vordergrund zu dringen, während die Akteurin langsam aufsteht. Hier setzt nun wieder eine Überblendung zur Or-Pheliafigur auf dem oberen Monitor ein. Die weiße Silhouette hat jetzt ihre Arme hinter dem Kopf verschränkt. Nach der nächsten Überblendung sieht man die Künstlerin in Großaufnahme frontal am Boden hocken, wo sie mit weißer Kreide einen Halbkreis zeichnet. Von diesem weißen Bogen gehen eine Reihe nach außen weisender Pfeile aus. Dazu setzt wieder aus dem Off Gesang ein - diesmal ein forderndes „MIA, MIA“ - während die Künstlerin auf dem Grund sitzend eine Geburtshaltung einnimmt, um schließlich unter dem hochgehobenen Rock zwischen ihren gespreizten Beinen einen Strauß gelber und roter Rosen zum Vorschein zu bringen, den sie aufhebt und vor ihr Gesicht hält. Die Kamera zoomt dabei von der Großaufnahme des Schoßes der Künstlerin auf eine Halbnahe und auf der Tonebene verwandelt sich der Chorgesang beim Auftauchen der Rosen in ein fröhliches „Lalala“. Bis dann wieder zum Monitorbild überblendet wird und der mehrstimmige Gesang deutlich in den Vordergrund tritt, sich das „Mia, Mia“ Spannung erzeugend steigert. Die weiße Or-pheliafigur erscheint dabei nun in Frontalansicht, so wie auch die Künstlerin mit den Rosen, die ihren Kopf verdecken, frontal zu sehen ist. Dabei zoomt die Kamera zwischen Großaufnahme und Halbnaher auf die Künstlerin hin und her. Die Künstlerin schwingt dabei zunächst leicht mit den Schultern bis dann der ganze Körper hin und her schaukelt. Aus dem Off ertönen schließlich nur verschwommen zu verstehende Worte:

„... binter goldenen Masken tragen sie dicke Schminke - fernab von der Welt - verbüllt in arabische Mäntel - unter denen sie Kostüme von Dior tragen... ich habe sie neulich bei einer Zwischenlandung in Oman gesehen und sie waren mir ein Rätsel und sie werden mir immer ein Rätsel bleiben - verborgen sind sie wabrscheinlich nicht und doch sind sie zum Anfassen nah und sind verführerisch wie die in Sonne getauchte Erde an einem Frühlingstag. Vermutlich durch grünende Bäume strömt ihre Energie aus dem Herzen im Schutz der Fantasie - alles was lebt." 

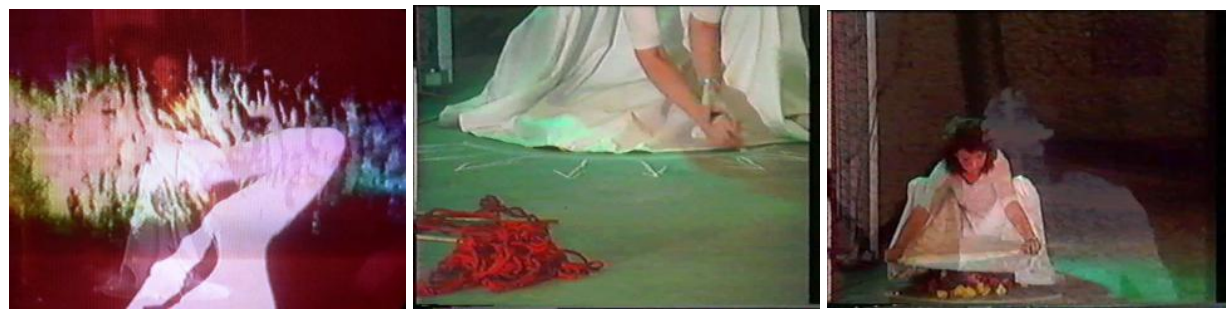

Abb. 209-211: Or-Phelia, 1987, 3 Videostills

Auch zu diesem Text wird weiterhin auf der Bildebene hin und her geblendet zwischen der Or-pheliafigur und der Aktionsaufnahme. Die Or-pheliafigur hat sich dabei wieder weiter gedreht und ist im Profil von rechts zu sehen. In einem Zoom auf das Gesicht der Künstlerin, ist dann zu sehen, wie diese die Rosen weiterhin vor ihr Gesicht hält, während ihr Körper in der Großaufnahme hin und her schwingt. Die angefügte Halbtotale zeigt wie die Künstlerin die Blumen in ihrem linken Arm birgt. Mit der freien rechten Hand streckt sie zunächst den erhobenen Daumen dem Publikum entgegen, bevor sie nacheinander, vom Zeige- bis zum kleinen Finger, ihre Finger aufrichtet, wie beim Zählen. Dies wiederholt sie gleich im Anschluss ein zweites Mal. Danach streckt sie die geöffnete Handfläche dem Publikum als Abwehrgeste entgegen. Damit endet das Tape, dem ein kurzer Abspann angefügt ist.
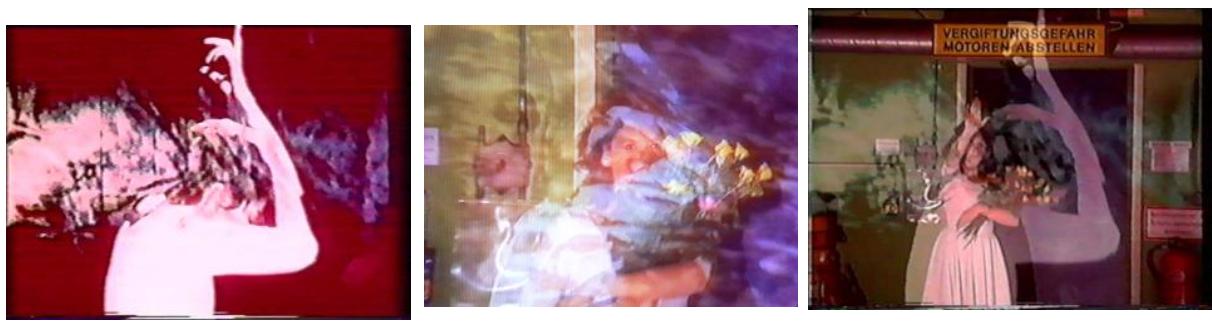

Abb. 212-214: Or-Phelia, 1987, 3 Videostills

Vor einer Einstellung, die die Künstlerin in Halbnaher auf dem Stuhl sitzend zeigt, erscheint in blauen Buchstaben der Text. Dabei hält sie zunächst die Bambusstäbe waagerecht, an die eine rosafarbene Rose gebunden ist. Als Schrift erscheint dazu: „Or-phelia-Video und Text: Ulrike Rosenbach“. Dann dreht sie die Stäbe langsam in die Senkrechte, und in blauer Schrift steht vor diesem Bildgrund: „Kamera, Performance Dokumentation: Michael Jahn/ Musik: Shantiprem H. Grab/ BildKlang-Studio. Dann zoomt die Aufnahme auf eine Nahaufnahme des Schoßes der Künstlerin, vor dem die an den Bambusstäben hängende Rose steht. Schließlich erscheint der Text: „Eine Produktion der städtischen Galerie Prinz Max Palais, Karlsruhe/ Copyright Ulrike Rosenbach“. 

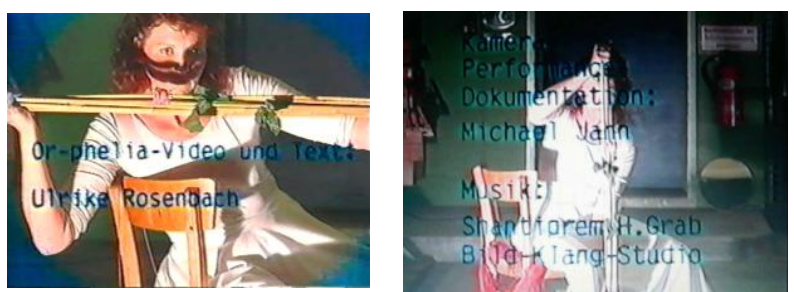

Abb. 215-216: Or-Phelia, 1987, 2 Videostills

\section{IV.5.3.2 Ein steter Bildfluss - formale Aspekte}

Das oben beschriebene Tape ist eine Produktion der Städtischen Galerie in Karlsruhe, die dieses im Jahr 1988 zusammen mit der Künstlerin produzierte. Es mischt dokumentarische Videoaufnahmen, die während der gleichnamigen Performance der Künstlerin in der Tiefgarage der Städtischen Galerie im Prinz-Max-Palais gemacht wurden697, mit elektronisch generierten Bildern aus der gleichnamigen Videoinstallation der Künstlerin zu einer 33-minütigen Ton-Bildcollage.

Dabei wurden die drei Monitore mit der „Or-pheliafrau“ auch in das Environment der Performance eingefügt. Hier waren die drei Bildschirme allerdings als Turm übereinander gestellt. Die auf diesem Monitorturm zu sehenden elektronisch generierten Bilder sind in dem Videotape mit den Performanceaufnahmen verwoben. Während der Aktion wurde nur mit einer Videokamera gefilmt, wodurch die Beobachtungsperspektive in der audiovisuellen Dokumentation auf eine Sichtweise reduziert ist. Bei diesen Performanceaufnahmen ist meist mit der so genannten Halbtotalen gearbeitet worden, die um einzelne Zooms, Schwenks und Nahaufnahmen ergänzt sind. ${ }^{698}$ Das geläufigste Gestaltungsmittel bei der Verbindung der einzelnen Einstellungen in diesem Tape ist die weiche Überblendung. Die collagierten Bildsequenzen werden begleitet von den Originalgeräuschen der Aufnahmen und einer Toncollage aus tropfendem Wasser, gesprochenen Textpassagen, Chorgesang und meditativen Melodien. ${ }^{699}$

Die Struktur der Performance, die in vier Teile untergliedert ist, ist auch in dem Videotape nachvollziehbar. Wenn die Performance mit drei, sich durch wiederholende Abläufe gekennzeichnete Phasen arbeitet, an die sich eine vierte, stärker narrative anschließt, gibt das Tape diese entsprechend wieder. Die vier - auch

697 Die Dokumentation filmte Michael Jahn.

698 Dabei konnte zu dem Entstehungszeitpunkt des Tapes Ende der 1980er Jahre mit dem entsprechenden Equipment das Bildmaterial bereits vielfältig elektronisch nachbearbeitet werden, so dass zum Beispiel nachträglich Zoome oder andere Aufnahmegrößen hätten eingefügt werden können. Ob dies hier gemacht wurde, ist ungeklärt.

699 So waren an dem Videotape mehrere Mitwirkende beteiligt, wobei die Produktion des Tapes unter der Regie der Künstlerin entstand. Und während der gesprochene Text von der Künstlerin selbst verfasst und gesprochen ist, ist die Musik von Shantiprem H. Grab komponiert worden. 
akustisch - unterschiedlich gestalteten Passagen, bauen voneinander abweichende Atmosphären auf. Die dokumentarischen Aufnahmen bilden dabei die Grundlage des Tapes, in die die Sequenzen mit der Nahaufnahme des Oberkörpers der OrPheliafigur punktuell eingefügt wurden. Dabei sind die Aufnahmen der Aktion mit den elektronisch generierten Bildern neben dem Hintereinanderfügen im zeitlichen Ablauf, zum Teil durch eine Überlagerung in direkten Bezug gesetzt, so dass sich zwei Aufnahmen vorübergehend durchdringen, bis sie sich wieder voneinander lösen. Diese Überblendung und Überlagerung unterschiedlicher Bildsequenzen war ein Gestaltungsmittel, dass im vorangegangenen Werk der Künstlerin bereits begegnete. Nur ganz selten sind in diesem Band harte Schnitte eingesetzt und das weiche Überblenden erzeugt den Eindruck eines steten Bilderflusses. Dieses elektronisch-filmische Fließen wird auf der Tonebene unterstützt, durch das rhythmische, treibende Tropfen, das das gesamte Tape begleitet. ${ }^{700}$ Damit sind die wichtigsten formalen Kennzeichen dieses Tapes benannt und es soll sich nun den inhaltlichen Aspekten zugewandt werden.

IV.5.3.3 Eine Geburt an der Schwelle des Todes - inhaltliche Aspekte

Bereits der Titel des Werkes „Or-phelia“ weckt Assoziationen. ${ }^{701}$ Setzt sich das Wort doch zusammen aus den beiden Namen „Orpheus“ und „Ophelia“, dem Sänger aus der griechischen Mythologie und der literarischen Figur aus Shakespeares Tragödie „Hamlet“. Ophelia zerbricht an der unerfüllten Liebe zu dem Königssohn Hamlet und der Trauer um den Tod ihres Vaters, so dass sie sich, dem Wahnsinn verfallen, in Shakespeares Tragödie im Fluss ertränkt. Orpheus steht in der griechischen Mythologie als Personifikation der den Tod überwindenden Liebe, doch bleibt auch seine Sehnsucht unerfüllt. Zwar steigt der Heros nach dem Ableben seiner Gattin Eurydike zu ihr in die Unterwelt hinab und überzeugt den Hades mit seinem bezaubernden Gesang die Verstorbene frei zu geben. Geführt vom Klang seiner Leier folgt Eurydike dem Orpheus durch die Gänge der Unterwelt, doch bevor beide in die Oberwelt gelangen, dreht sich Orpheus voll Sehnsucht nach seiner Gemahlin um, was ihm verboten war, und verliert diese so für immer. ${ }^{702}$

Den tragischen Schicksalen dieser beiden Charaktere - die die Künstlerin in dem Titel ihrer Arbeit vereint - ist gemeinsam, dass ihre Liebe unerfüllt bleibt. Auch bringt die Erfahrung der Liebe die beiden literarischen Figuren dem Tod nahe. Erleben doch beide das Stadium des Überganges zwischen dem Diesseits

700 In dem auch häufig der Originalton der Performance wiedergegeben zu sein scheint, so ist zum Beispiel an einer Stelle ein Husten aus dem Publikum deutlich zu hören.

701 Es gibt zudem den Roman „Orlando“ der Schriftstellerin Virginia Woolf. In diesem feministischen Roman hebt die Autorin die Geschlechterdifferenz auf.

702 Später stirbt Orpheus einen qualvollen Martertod bei den dionysisch-rasenden Mänaden. 
und dem Jenseits: Orpheus bei seinem Besuch bei lebendigem Leib im Hades, Ophelia im Zustand des Wahnsinns, bevor sie in den Fluten umkommt.

Die Künstlerin fasst diese beiden unglücklich liebenden Charaktere in ihrem symbolträchtigen Werk zu einer androgynen Kunstfigur zusammen, der es aber anders als den fiktiven Vorbildern - gelingt, dem Tod zu entgehen und in neuer Form wiedergeboren $\mathrm{zu}$ werden. Die Künstlerin lässt ihre androgyne OrPheliafigur in einem blauroten elektronischen Pulsieren um die eigene Achse kreisen. Und diese Figur scheint zu leben, bewegt sie sich doch im Inneren der Monitore.
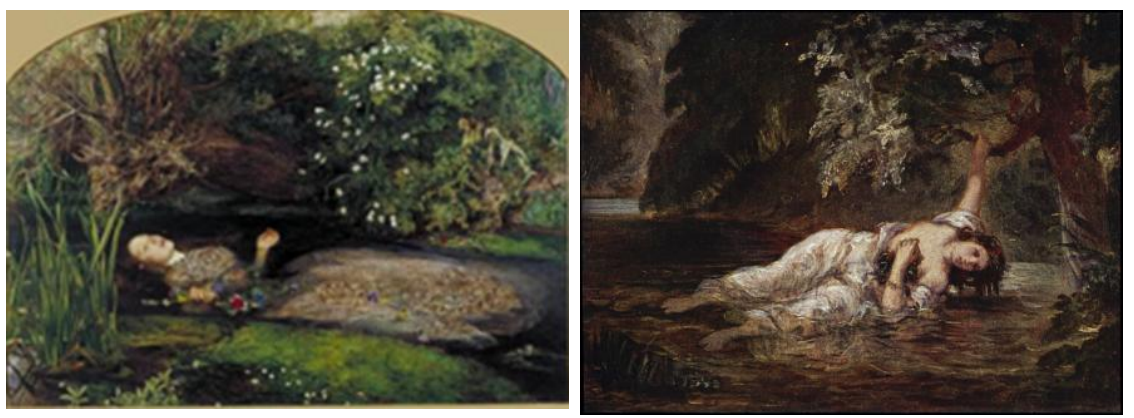

Abb. 217-218: John Everett Millais: Ophelia, 1852 und Eugene Delacroix: Tod der Ophelia, 1844

Für die Darstellung der liebeskranken Ophelia gibt es berühmte kunsthistorische Vorbilder. Das bekannteste ist wohl die Darstellung des englischen Malers John Everett Millais (1829-1896), der zur Gruppe der Präraffaeliten zu zählen ist, und der die dem Wahnsinn verfallene Selbstmörderin im Jahr 1852 voller Anmut ins Bild setzte. ${ }^{703}$ In dem Gemälde schwimmt der Körper der Toten auf dem Rücken, in ein helles Kleid gewandet, zwischen bunten Blüten im dunklen Wasser. Die Augen und der Mund sind in dem bleichen Gesicht leicht geöffnet. Der englische Künstler folgt in seiner Darstellung einer romantisierenden, auf Seelentiefe zielenden Interpretation der Tragödie, indem er zeigt, dass sich Ophelia im Sterben mit der Natur vereint hat. Shakespeares Tragödie wurde zur Zeit Millais allerdings ganz unterschiedlich gedeutet. So erlebte Frankreich im beginnenden 19. Jahrhundert in Folge der Französischen Revolution einen regelrechten Ophelia-Boom, der mit einer Wiederentdeckung der tragischen Helden des englischen Dichters Shakespeare einherging. Der „terreur“ der französischen Revolution sowie die napoleonischen Kriege hatte die Gesellschaft der „grande nation“ umfassend traumatisiert, ein Grund weshalb in diese Zeit auch die Eröffnung der ersten Irrenanstalten in Frankreich fiel. Französische Theater spielten besonders gerne Shakespeare, da sich die vom Schrecken der blutigen Revolution müde gewordenen Be-

703 Ophelia, 1851-52, Öl auf Leinwand, 76,2 x 111,8 cm, Tate Gallery, London 
sucherinnen und Besucher erst jetzt mit den tragischen Heldinnen und Helden identifizieren konnten, obgleich der französische Philosoph Voltaire Shakespeare bereits im 17. Jahrhundert ins Französische übersetzt hatte. Die Figur der Ophelia ließ Raum für Empathie, und als eine „femme fragile“ eignete sie sich weit besser als zum Beispiel Elektra und Medea als Spiegel eigener Gefühle und Sensibilitäten. ${ }^{704}$ Der Franzose Eugène Delacroix (1798-1863) setzte die sterbende Ophelia so auch wesentlich dramatischer als sein englischer Kollege in Szene. Im weißen Kleid, Blumen vor der Brust, hält sich die Unglückliche mit der rechten Hand noch an einem Ast fest, der über das Wasser ragt. ${ }^{75}$ Delacroix zeigt Ophelia damit genau an der Schnittstelle zwischen Leben und Tod.

Eine zeitgenössische Bearbeitung des Themas findet sich bei der englischen Künstlerin Hannah O'Shea. Ihr „A Visual Time Span (A Visual Diary)“, das zwischen 1964-76 entstand, wurde 1980 in der Ausstellung „About Time“ im Institute of Contemporary Arts in London gezeigt. Hier scheint Millais mit seiner romantisierenden Auffassung der Tragödie Vorbild gewesen zu sein, wie auch bei Rosenbach Millais Komposition Pate gestanden hat. Das Motiv der schwimmenden Figur wird von der Künstlerin in ihrer Or-Pheliafigur, die auf den drei Monitoren zu sehen ist, aufgenommen. Auch ist bei Rosenbach, wie in dem kunsthistorischen Vorbild, der Körper hell bekleidet. Allerdings nicht in einem weiten Kleid, sondern in einem weißen, eng anliegenden Trikot, das die Körperformen nachzeichnet und an die frühere Performancekleidung der Künstlerin erinnert. ${ }^{706}$ Die Or-Pheliafigur ist in den elektronischen Bildern eingebettet in einen pulsierenden Blutfluss und der Körper ist keineswegs tot, vielmehr bewegt er sich - einem Fötus gleich - in dem Pulsieren und vermittelt mit sprechenden Händen Botschaften von Lebendigkeit und Erkenntnis. Denn die vermeintlich stumme Gestalt kommuniziert. Die Figur bewegt Kopf, Arme und Hände in langsamer Veränderung. Diese Gesten, die Kopf und Hände bilden, sind so genannte buddhistischhinduistische Mudras, die uns bereits unter anderem in dem Werk „Eleven“ begegneten. In Ulrike Rosenbachs „Or-phelia“ taucht in den Monitorbildern das Pran-Mudra (Lebensmudra) und das Gyan-Mudra (Geste des Bewusstseins) wiederholt auf. Beim Pran-Mudra werden die Spitzen von Daumen, Ringfinger und kleinem Finger zusammengelegt und leicht gedrückt. Das Gyan-Mudra entsteht durch das Berühren der Spitzen von Daumen und Zeigefinger. Die drei übrigen Finger sind locker gestreckt. ${ }^{707}$ Die androgyne Figur auf den Monitoren kommuni-

\footnotetext{
704 Vgl. Kindler 2004

705 Eugène Delacroix, Tod der Ophelia, 1844, 23 x 31 cm, Öl auf Leinwand, Musée du Louvre, Paris.

706 Ein weißes Kleid trägt hingegen die Akteurin selbst während der Aktion.

707 Eine Variation dieses Zeichens ist das Chin-Mudra (Geste des Wissens) bei dem die Handflächen nach unten zeigen und der Daumen den Zeigefinger in der Grube des ersten Fingergliedes berührt. (Vgl. Christiansen 2003, S. 24)
} 
ziert damit auf dieser Zeichenebene Leben und Bewusstsein, eingebettet in ein lebensspendendes Pulsieren.

In dem „Or-phelia“-Tape sieht man zunächst, wie die Künstlerin - einer Priesterin bei einer kultischen Handlung gleich - gegen den Uhrzeigersinn um den Monitorturm schreitet und die umhüllenden Papierbahnen Schicht um Schicht löst, so dass sie zu Boden fallen. Ein Ablauf, der an das Öffnen einer Blüte erinnert.

Wie die Or-Pheliafigur auf den Bildschirmen ist die Künstlerin in der Aktion ebenfalls in weiß gekleidet, allerdings - ähnlich wie Millets „Ophelia“ - trägt sie in der Performance einen langen Rock und ihr Handeln steht in dem Tape in direktem Bezug zu dem begleitend Gesagten. So zeigen die Videobilder sie hockend geben den Blick auf die Füße frei - als die Stimme davon spricht, ihre Füße zu öffnen. Als von der Öffnung des Bauches die Rede ist, ist zu sehen, wie die Performerin sich gerade eine Papierbahn vor ihren Bauch hält. Als die Augen thematisiert werden, hat sie sich Papierschichten um den Kopf gewickelt. Bei mehreren der Sätze wird die aktuelle Performanceszene kurz mit der Or-Pheliafigur überblendet, wie bei den Themen Bauch und Seele sowie schließlich nach dem Satz: „Ich öffne mir mein Herz und sehe mich an." Hier füllt die Or-Pheliafigur schließlich vollständig den Bildschirm, dann ist kurz ein Detail der Blutbahn zu sehen, bevor wieder die Or-Pheliafigur erscheint, die die Hände bewegt, während sich deren weißer Kopf allmählich in dem Fließen der Umgebung auflöst.
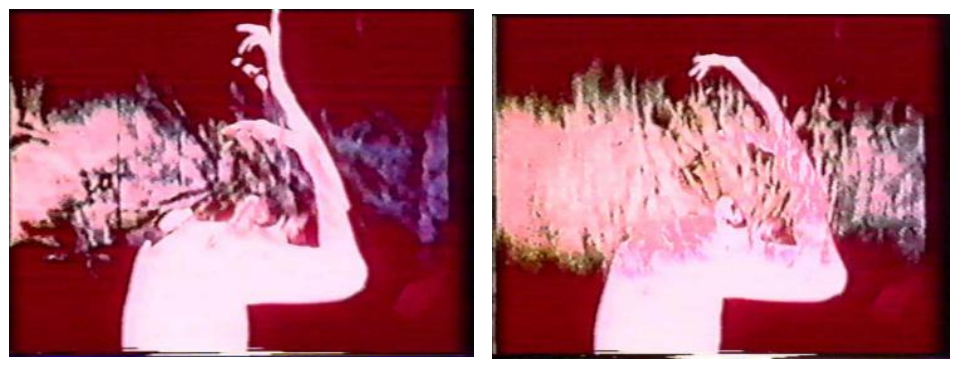

Abb. 219-220: Or-Phelia, 1987, 2 Videostills

Die Textaussage wird an dieser Stelle besonders anschaulich umgesetzt. Die in dem Text benannte Öffnung des Herzens ermöglicht den Blick, das vollständige Hervortreten der inneren Or-Pheliafigur, die in dieser Phase zudem transformiert, in dem sich deren Kopf im umgebenden „Lebensstrom“ vorübergehend auflöst, wie es vielleicht einer Meditationserfahrung entspricht.

Ulrike Rosenbach ist nicht die einzige zeitgenössische Künstlerin, die mit diesen, aus einem religiösen Kontext stammenden, Handzeichen arbeitet. Sie bereichern auch Werke anderer zeitgenössischer Künstler. So drückte die amerikanische Künstlerin Laurie Anderson (*1947) zum Beispiel in den 1970er Jahren diese 
rituellen Fingerhaltungen in Pappmaché. Auf diese Weise fertigte sie Tastobjekte, die Schablonen für die körperlichen Energiezeichen bieten. Es sind spielerische Arbeiten, die die Auseinandersetzung der amerikanischen Künstlerin mit dem Zen-Buddhismus spiegeln. ${ }^{708}$

Nach dieser ersten Phase des Entblätterns, die in dem Tape abgebildet ist, bewegt sich die Künstlerin in der zweiten Phase der Aktion auf den Knien krabbelnd durch den Raum, wobei sie mit den weit ausgreifenden Stöcken, die ihre Finger verlängern, in rhythmischen Schwüngen über den Boden fegt. Dieses Motiv des Verlängerns der Körperteile durch unterschiedliche Werkzeuge ist bereits mehrfach begegnet im Werk der Künstlerin. Es findet sich aber auch bei anderen zeitgenössischen Künstlern oder Künstlerinnen. So gibt es eine Performance der Künstlerin Rebecca Horn mit dem Titel „Einhorn“, bei der die Künstlerin auf dem Kopf eine hohe, kegelförmig zulaufende Bedeckung trägt.

Und speziell das Motiv des Fegens findet sich auch im Werk der Künstlerin Lili Fischer (*1947), die in ihren Performances die Spurensuche weiblichen Lebens mit dem Animationsimpetus des happeningartigen Aktionismus verbindet. Lili Fischer zeigte zum Beispiel 1986 ihren „Besentanz“, den Karin Thomas wie folgt beschreibt:

„Lili Fischers Darbietungsform ihrer Animationen lässt sich als eine Synthese aus rituellem Tanz und Sprechgesang beschreiben, so erinnert sie an Volksbräuche, Schamanismus und Bänkelgesang. Witzige und zugleich kritisch-hintersinnige Reimsprüche versetzen mit ibren Pointen das Publikum in einen Wirbel, der Kopf und Körper zu aktiven Teilnabme ermuntert. Künstlerische Arbeitsweisen wie die von Lili Fischer entwickeln sich vor dem Hintergrund eines wachsenden ökologischen Bewusstseins in der Gesellschaft. "709

708 „Bei der Meditation gibt es eine Reihe von Handpositionen zur Steigerung der Konzentration. 1972 gestaltete ich eine Serie von „Mudra“ aus Zeitungspapier - „negative“ Formen, die durch bestimmte Positionen der hand entstehen. Mudra haben weniger mit Worten zu tun als mit Konzepten - Ideen, die die Konzentration des Geistes fördern. Die Reihe besteht aus „Boot“, „Weg“, „Schrift“, „Natur“ und „Gefängnis“. Dies schreibt die Amerikanerin selbst über ihre Mudra-Skulpturen aus Zeitungspapier. (Kat. Düsseldorf 2003 , S. 62)

709 Thomas 2002, S. 256. Interessant ist zudem in diesem Zusammenhang, dass im Chinesischen die Hausfrau „Besenfrau“ heißt. 
Fegen ist ein Akt der äußeren Reinigung, aber nicht nur das, mit ihm verbunden sein kann auch eine innere Reinigung und Transformation, das Grundthema der Or-Phelia. Das gleiche Thema der inneren Reinigung greift ein Videtape aus dem Jahr 1998 der jugoslawischen Künstlerin Vesna Vesic (*1975) auf. Ihre Arbeit „Wash me and I will be whiter than snow“ ist ein Videodokument eines emotionalen Zustandes: ein Selbstporträt voll Trauer. ${ }^{710}$ Während das Gesicht, das zu Beginn und zum Ende der Aufnahme mit Haaren bedeckt ist, in einer Nahaufnahme zu sehen ist, liest die Künstlerin den biblischen Psalm. Über ihr Gesicht laufen dabei Tränen.711 Einen ähnlichen Erfahrungsraum zum Eintauchen wie dieses Tape der Jugoslawin bieten auch Performance und Tape Ulrike Rosenbachs, die die innere Reinigung in der symbolischen Form des Fegens zum Ausdruck bringt.
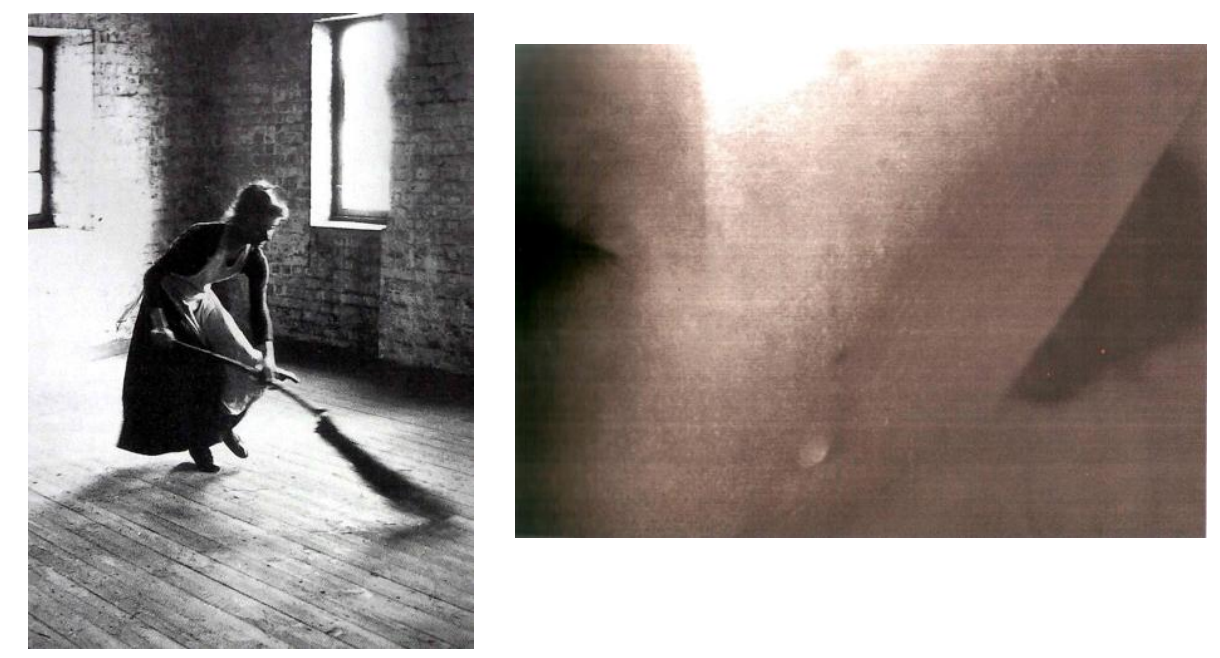

Abb. 221-222: Lili Fischer: Besentanz, 1986, Aktionsfoto und Vesna Vesic, Wash me and I will be whiter than snow, 1998, Videostill

Fegen ist ein Akt der äußeren Reinigung, aber nicht nur das, mit ihm verbunden sein kann auch eine innere Reinigung und Transformation, das Grundthema der Or-Phelia. Das gleiche Thema der inneren Reinigung greift ein Videtape aus dem Jahr 1998 der jugoslawischen Künstlerin Vesna Vesic (*1975) auf. Ihre Arbeit „Wash me and I will be whiter than snow“ ist ein Videodokument eines emotio-

\footnotetext{
710 Vesna Vesic, Wash Me and I Will Be Whiter than Snow, 1998, VHS video production, 7', Vladimir Zaric e CybeREX, Belgrad.

711 Kat. Venedig 1999, S. 342
} 
nalen Zustandes: ein Selbstporträt voll Trauer. ${ }^{712}$ Während das Gesicht, das zu Beginn und zum Ende der Aufnahme mit Haaren bedeckt ist, in einer Nahaufnahme zu sehen ist, liest die Künstlerin den biblischen Psalm. Über ihr Gesicht laufen dabei Tränen. ${ }^{713}$ Einen ähnlichen Erfahrungsraum zum Eintauchen wie dieses Tape der Jugoslawin bieten auch Performance und Tape Ulrike Rosenbachs, die die innere Reinigung in der symbolischen Form des Fegens zum Ausdruck bringt.

In plastischer Form begegnete bei Ulrike Rosenbach das Verlängern der Körperteile in den raumgreifenden Haubenobjekten, aber auch mittels der elektronischen Geräte während der Videoperformances. Welchen Zweck haben die Finger verlängernden Bambusstöcke in der Or-Pheliaperformance? Mit den verlängerten Fingern ist ganz real der Tast- und auch Wirkungsradius vergrößert, im übertragenen Sinne könnte man auch sagen: die Handlungsfähigkeit wird erweitert. Diese Vergrößerung des Wirkungsradius wird noch unterstützt in den zusehends weiter ausgreifenden und schneller werdenden Schwüngen, mit denen der Grund frei gefegt wird. Diese Aktionsphase hat durch die stete Wiederholung derselben Bewegung, in die die Handelnde völlig versunken scheint, etwas stark Ritualhaftes. Die sich intensivierende Handlung des raumgreifenden Freifegens des Grundes wird auf der Tonebene ermuntert von den weiblichen Stimmen mit ihrem begrüßenden „hey, hallo“. Mit diesem Chor aus Frauenstimmen greift die Künstlerin auf ein klassisches Element der griechischen Tragödie zurück, in der der Gesang des Chores die Handlung trägt. Die beiden Motive der erweiterten Handlungsfähigkeit und des Chores legen aber neben der allgemeinen Deutbarkeit auch Assoziationen an die Biographie der Künstlerin nahe, namentlich deren Phase der intensiven Auseinandersetzung mit der Frauenbewegung. Die damit verbundenen individuellen Befreiungsversuche scheinen in dieser Bewegungsschleife abstrahiert in Szene gesetzt zu sein, wie in der vorangegangenen Phase die Entdeckung - im Sinne der Aufdeckung - der künstlerischen Ausdrucksform des Videos von der Künstlerin in abstrahiert anschaulicher Weise in Szene gesetzt wurde.

Im dritten Abschnitt der Performance erlebt der Zuschauer wie die Akteurin einen doppelten Ent-Fesselungsritus vollzieht. Aufrecht stehend beginnt sie einen Wirbeltanz entgegen dem Uhrzeigersinn um ihre eigene Achse. Dabei wickelt sich ein roter Wollfaden von einem dicken, am Boden liegenden Knäuel um ihre Taille. Als der Faden aufgebraucht ist, ändert die Tänzerin ihre Drehrichtung, um sich buchstäblich zu „entwickeln“. Nachdem sie sich aus der Fesselung um ihre Taille befreit hat, wechselt sie erneut die Drehrichtung. Jetzt schlingt sich die rote Wolle lose um ihre Füße und fesselt diese. Aus dieser Umschlingung kann sie sich nicht stehend im Tanz, sondern erst im Sitzen wieder befreien.

712 Vesna Vesic, Wash Me and I Will Be Whiter than Snow, 1998, VHS video production, 7', Vladimir Zaric e CybeREX, Belgrad.

713 Kat. Venedig 1999, S. 342 
Das Motiv des Fadens - wie auch schon konkret roten Fadens - begegnete uns im Werk der Künstlerin bereits mehrfach: als weiße Mullbinde, rotes Videokabel, weißes Seil, rotes Gummiseil oder auch roter Wollfaden. Sowohl in der westlichen als auch in der östlichen Tradition gilt der Faden als Symbol der Bindung beziehungsweise Verbindung. Im griechischen Mythos teilen die drei Moiren den Menschen ihren Anteil am Lebensfaden zu. Diese drei Schicksalsgöttinnen sind Klotho als die Spinnerin, die den Lebensfaden erzeugt, Lachesis erhält und misst den Faden bis Atropos, die Unabwendbare, ihn schließlich durchschneidet. An anderer Stelle findet in der griechischen Mythologie der Heros Theseus mit Hilfe eines ihm von Ariadne gegebenen Garnknäuels den Weg durch das Labyrinth. In dieser Lesart ist der Faden auch Weg oder Wegweiser. ${ }^{714}$

Ein roter Wollfaden spielt auch eine wichtige Rolle in einem Gemälde des englischen Präraffaeliten William Holman Hunt (1827-1910). Die „Lady of Shalott ${ }^{\text {“715 }}$ begegnete bereits kurz in Zusammenhang mit den Bildern zum Tarot. ${ }^{716}$

Ein Thema, das übrigens im 19. Jahrhundert in England sehr beliebt war. Bei der Lady of Shalott handelt es sich wohl um die Fee Elaine of Astolat, die durch einen Zauber in einem Turm auf einer Insel inmitten eines Flusses, der nach Camelot fließt, gefangen ist. Sie webt in ihrem Gefängnis an einem endlosen Teppich. Eines Tages erblickt sie durch ihren Spiegel - dank ihrer seherischen Fähigkeiten - den stolzen Ritter Lanzelot, in den sie sich verliebt. Ihrer Gefangenschaft überdrüssig, möchte sie zu Lanzelot gelangen und besteigt ein Boot, um damit nach Camelot zu fahren. Doch der Fluch, der sie gefangen hält, lässt sich nicht bannen und so verliert sie mit jedem Ruderschlag, der sie weiter von der Insel entfernt, mehr und mehr von ihrer Lebenskraft. Als sie schließlich Camelot erreicht, ist sie tot. Die Bewohner, die sie sehen, sind geschockt, aber auch verblüfft über ihre große Schönheit, für die Lanzelot bewundernde Worte findet.

Ein insgesamt 19 Strophen umfassendes Gedicht von Lord Alfred Tennyson (1809-1892) beschreibt das Schicksal der Lady of Shalott. In der dreizehnten Strophe beschreibt Tennysons Gedicht den Moment, als die Gefangene Lanzelot in ihrem Spiegel erblickt hat. Die Strophe lautet im englischen Original aus dem Jahr $1842: 717$

„She left the web, she left the loom, / She made three paces through the room, / She saw the water-lily bloom, / She saw the helmet and the plume, / She look'd down to Camelot./ Out

714 Lurker 1991, S. 192

715 „The Lady of Shalott“ (ca. 1886-1905), Öl auf Leinwand, 44,4 x 34,1 cm, Manchester City Art Gallery.

716 Vgl. Kap. III.4.4.2

717 Eine ältere Fassung ist von 1833. 


\section{flew the web and floated wide;/ The mirror crack'd from side to side;/ „The curse is come upon me", cried/ The Lady of Shalott." "718}

Der englische Maler den dramatischen Moment der Erkenntnis der Gefangenen auf seine eigene Weise. Die Weberin, die barfuß im Vordergrund der Komposition in dem am Boden liegenden Webrahmen steht, der sie wie ein magischer Kreis umfängt, ist dabei selbst von einem leuchtend roten Wollfaden umfangen, der ihren Körper - ein wenig an einen Kokon erinnernd - einwickelt und der zudem noch wild verschlungen durch den Raum wirbelt. Im Hintergrund des Gemäldes ist der riesige runde Spiegel zu sehen, in dem sich schemenhaft und klein die Silhouette des Ritters abzeichnet. Der Spiegel ist in diesem Bild die Trennwand zwischen zwei Erkenntnisebenen: der Welt der Gedanken und ihrem matt verschwommenen Abbild der Welt der Empfindungen. ${ }^{719}$ Doch die Lady of Shalott blickt in der romantischen Komposition nicht auf das Abbild des Davonreitenden. Vielmehr hat sie den Blick gesenkt, wirkt nach innen gekehrt und in ihre tanzende Drehung versunken. ${ }^{720}$ Es zeigt sich eine verblüffende ikonographische Nähe dieser Darstellung und der Ent-Fesselungspassage in dem „Or-pheliaTape“, die das Element des Wirbeltanzes mit dem Motiv, der sich im aufbrechenden Wahnsinn in der Wolle verfangenden verliebten „Lady of Shalott“ verbin$\operatorname{det}^{721}$

718 In deutscher Übersetzung: „Vergessen waren Tuch und Mühn,/ Man sah sie hin zum Fenster gehn,/ Sie sah die Wasserlilien blühn,/ Seine Feder im Sonnenlicht glühn,/ Sie schaute hinab nach Camelot./ Das Tuch flog weit aus dem Gemach,/ Ihr gelber Spiegel klirrend brach,/ Der Fluch, er ist gekommen, sprach/ Die Lady von Shalott.“

719 Battistini 2003, S. 143; „In mehreren von Tennysons frühen Gedichten, nicht zuletzt in The Lady of Shalott (Die Dame von Shalott), ein ebenso wie Keats Lamia bei den Malern des späten 19. Jahrhunderts beliebtes Motiv, finden sich Anklänge an den Symbolismus avant la lettre. Das Hauptmotiv der Lady of Shalott, der Spiegel, in dem eine verbotene Welt zu sehen ist, barg ein beträchtliches symbolistisches Potential, und die Artussage stellte für viele Künstler einen reichen Fundus an Motiven dar." (Wilton in: Wilton/Upstone 1998, S. 21) Auch in Rosenbachs Performanceenvironment ist ein Spiegel zu erkennen: Der Sockel, auf dem die drei Monitore stehen, trägt eine abgerundete Spiegelfläche, in der sich die Füße der Agierenden spiegeln.

720 Diese sehr freie und eigenwillige Interpretation des Textes brachte dem Maler William Holman Hunt Kritik ein von Seiten seiner Zeitgenossen, die fanden, dass sich eine Gedichtillustration genau an die literarische Vorlage halten müsse. Trotzdem wurde seine Komposition, umgesetzt als Holzschnitt, als Buchillustration veröffentlicht und fand damit weite Verbreitung.

721 Ulrike Rosenbach wies im Gespräch darauf hin, die umfangreiche Sammlung mit Werken präraphaelitischer Maler im Museum in Manchester eingehend studiert zu haben. (Vgl. Kap. VII.1.) 


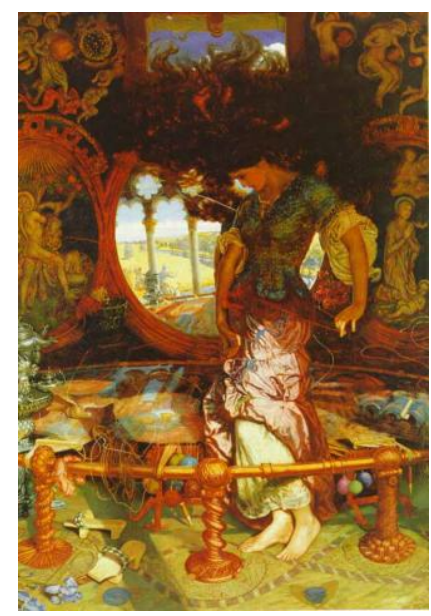

Abb. 223: Holman Hunt: Lady of Shalott, 1886-1905

In der „Or-Phelia“ der Künstlerin ist der Faden ebenfalls leuchtend rot. In diesem Lebensfaden verfängt sich die Künstlerin im dritten Werkteil des Tapes, während sie sich ununterbrochen um ihre eigene Achse dreht. ${ }^{722}$ Doch löst dieses in vorangegangenen Aktionen als befreiend interpretierte Kreisen in dieser Performance die Fesselung nicht vollständig auf. Während die Körpermitte der Künstlerin zwar befreit wird, verfangen sich im Tanz die Füße in der roten Wolle.

An der Stelle, an der es aus dem Off heißt: „Ich öffne mein Herz und sehe mich an“ zeigt das Tape ein Verschwimmen der Bildsequenz, die die Künstlerin in Aktion zeigt, mit der Or-Pheliafigur. Die tanzende Künstlerin wird an dieser Stelle im elektronischen Bild eins mit dem Oberkörper dieser Figur. Friedemann Malsch deutet dieses Gestaltungsmittel in dem Tape:

„Durch Zwischenschnitte wird die Aktion dem Bild der Installation eng verbunden, das überpersönlich Schicksalhafte den individuellen Befreiungsversuchen nebengeordnet. "723

Es ist aber auch die bildliche Übersetzung des Gedankens einer Identifikation, zumal die Darstellung der Or-Pheliafigur auch hier erneut ein fast vollständiges Auflösen in dem sie umgebenden Fließen zeigt, symbolischer Ausdruck eines Aufgehens im Lebensstrom. Die Bildebene setzt die textliche Aussage prägnant ins Bild.

Geht man mit der Interpretation noch einen Schritt weiter, kann auch in diesem Or-Phelia-Werkkomplex das in die Performance eingefügte Monitorbild der

722 Es ist eine Tanzform, die uns bereits im Werk der Künstlerin begegnete und dort mit den spirituellen Wirbeltänzen der Derwische in Bezug gesetzt wurde. (Vgl. Kap. IV.4.4.)

723 Malsch in: Kat. Köln 1991, o.S. 
Figur als Ausdruck für inneres Sein gelesen werden. Nehmen wir diese Bedeutungsschicht für die Deutung des Performancetapes noch hinzu, zeigt sich nicht nur anschaulich eine Identifikation der Künstlerin mit ihrer elektronisch-erzeugten Kunstfigur, sondern auch eine vorübergehende Kongruenz zwischen energetischer Innen- und materieller Außenwelt in den Videosequenzen visualisiert.

In der anschließenden Sequenz des Tapes ist dann zu sehen, wie sich die Künstlerin in loser Umschlingung gefesselt auf einen bereit stehenden hölzernen Stuhl setzt. Erhöht sitzend - Assoziationen an einen Thron liegen nahe - kann die Gefesselte beide Füße gleichzeitig vom Boden heben und durch synchron fließende Bewegungen von Armen und Beinen die Füße aus den Umschlingungen befreien. Ohne Fesselung steht sie schließlich auf. Allerdings bleibt der rote Faden wie eine Nabelschnur - weiter um ihre Taille geknüpft. So beginnt sie die Papierschichten, die durcheinander am Boden liegen, zu ordnen.

Auch in diesem Werk können die Papierbahnen als Sinnbilder der eigenen Geschichte verstanden werden. Hier ummanteln die weißen Bahnen zunächst die drei Monitore - die Träger des elektronischen Bildes. Dieses, von den Papierbahnen ummantelte innere Bild, wird von der Künstlerin in der Aktion freigelegt. ${ }^{724}$ In dieser Phase der Aktion - nach dem Freifegen des Grundes, befreit von den fesselnden Fängen und verbunden mit ihrer Nabelschnur ${ }^{725}$ - können diese weiBen Schichten nun geordnet werden. Dazu ertönt ein tiefes, stetes Atemgeräusch aus dem Off. Im Yoga bildet der Atem die Basis für jegliches Agieren. Der flieBende Atem wird zunächst mit den Körperbewegungen bei den verschiedenen Asanas - wie die Haltungen im Yoga heißen - verbunden. ${ }^{726}$ Zudem wandert man im Yoga mit der Konzentration von außen durch die Körperteile immer weiter ins Innere des Körpers. In dem Or-Pheliatape nimmt die Bildebene diesen Atemrhythmus auf durch ein regelmäßiges Hin- und Herblenden zwischen dem Bild der Or-Pheliafigur und der Aktion - dem Innen und Außen. ${ }^{727}$

Während zwischendurch das mittlere Bild der drei Bildschirme in der Monitorstele, das sonst den Unterleib der Figur zeigte, ausgeschaltet war und man im Hintergrund den Bildern des Tapes nur Oberkörper und Beine kreisen sah, leuchtet jetzt wieder die ganze Videoinstallation und die Or-Pheliafigur ist vollständig in der Halbnahen des Tapes sichtbar.

Nach den drei ersten Phasen des Tapes, die durch Handlungen, die mit Wiederholungen arbeiteten, setzt die die vierte Phase des „Transformationsstückes“

724 Dieses Freilegen erinnert formal an die Eleven-Aktion, nur das hier im Kreis gegangen wird.

725 Ein Motiv, das bereits in der Requiem-Aktion begegnete. (Vgl. Kap. IV.3.)

726 Später wird erlernt den Atem zu kontrollieren, denn die Kontrolle des Atems ist die Vorstufe der Kontrolle des Geistes in der Meditation.

727 Der Atemrhythmus als Gestaltungsmittel begegnete übrigens schon in dem allerersten Tape der Künstlerin, der „Einwicklung“. 
nun eine Wiedergeburt symbolisch ins Bild. Diese wird eingeleitet durch die aus dem Off gesprochenen Worte:

„Zwischen den Türen von Leben und Tod gibt es noch eine andere Tür, völlig unerwartet. Die, die geboren werden an der Schwelle des Todes, sind dem Ewigen geweiht."

Bei diesem Satz kommt einem Delacroix ${ }^{6}$ Ophelia in den Sinn, die sich - noch lebend - über den sie bald verschlingenden Fluten an einen Ast klammert. Die Künstlerin rollt sich, wie in dem Tape in der Halbnahen zu sehen ist, zu diesen Worten zunächst über den Boden, bevor sie sich hin hockt und den in lockerer Lage gewickelten Wollstrang aufnimmt. Diesen schmiegt sie abwechselnd über die rechte und linke Schulter, um sich schließlich genuss- und vertrauensvoll in die rote Wolle - Sinnbild des Lebens - zu kuscheln. Auch an dieser Stelle sind im Tape wieder langsame Überblendungen mit der Or-pheliafigur eingefügt, deren weißer Kopf hier erneut fast vollständig durch ein farbiges Fließen ersetzt wird. Das Bildmotiv verbildlicht hier wieder eine Bewusstseinserfahrung. Ein geistiges oder spirituelles Erlebnis - eine geistige Transformation - das als Fließen, Strömen oder auch Auflösung empfunden werden kann, wird hier visualisiert. Diese innere Transformation geht der bevorstehenden Geburt im Außen voraus. Zu diesem Akt, in dem etwas Inneres nach außen drängt, setzen ruhige, fernöstliche Melodien als neues Tonelement aus dem Off ein. Der meditative Klang erzeugt eine entspannte Atmosphäre und die Bilder in Großaufnahme zeigen, wie sich die Künstlerin auf den Boden setzt. Mit Kreide malt sie in einer intensiven, sich wiederholenden Bewegung einen Kreisbogen nach, von dem verschiedene Pfeile nach außen gehen. Mit dieser Kreidezeichnung scheint der folgende Geburtsvorgang eingeleitet zu werden. Sich mit Händen und Füßen am Boden abstützend ,gebiert“ die Künstlerin, die weiter in Großaufnahme zu sehen ist, unter ihrem weiten Rock einen Strauß roter und gelber Rosen. Lurker schreibt zur Symbolik der Rose:

„Rose, auf Grund ihres Duftes, ihrer Schönheit und ibrer Vergänglichkeit Symbolbezüge zu Liebe, Tod und Paradies. (...) In der Alchemie galt die R[ose] als flos sapentium, als Blume der Weisheit und der Weisen, bei den Rosenkreuzern deutet sie auf Natur und Schöpfung und als freimaurerisches Symbol auf ein höheres Leben. "728

Guckt man auf die Millais Ophelia-Darstellung sind es die Blumen, die die Tote schmückten, Symbol der Vereinigung im Tode mit der Natur. Doch in Rosenbachs Aktion ist es das Leben, das Blumen gebiert, sich mit der Natur vereint. Begleitet wird diese Blumengeburt, die in dem Tape in Halbnaher abgebildet wird, durch ein sehnsuchtsvolles Rufen der Worte „Mia, mia“ aus dem Off. Dieses Worte legen Assoziationen zu dem Namen „Meera“ nahe, der als „Mira“ gespro-

728 Lurker 1991, S. 630 
chen wird. Es ist der Name, der indischen Mystikerin und Dichterin Mirabai (um 1498-1546), deren persönlich gehaltene ekstatische Liebes-, Preis- und Klagelieder durch die Jahrhunderte lebendig geblieben sind. ${ }^{729}$

Nachdem sie aufgestanden ist, wiegt die Akteurin ihren Rosenstrauß wie ein Baby im Arm. Nach einer Weile hebt sie die Rosen vor ihr Gesicht. Der in sich widersprüchliche und schwer verständliche Text, der verzerrt aus dem Off zu hören ist, weist darauf hin, dass nach der geistigen Wiedergeburt ein Erkennen der Masken der Menschen möglich sei, trotzdem blieben die Menschen - nach dieser Aussage - ein Rätsel. Trotz einer großen Anziehung, die die Menschen hätten, wie es im Text heißt, wendet sich die Aussage zu diesen Distanz haltend der Natur zu und mündet in ein Poetisches:

„Vermutlich durch grünende Bäume strömt ibre Energie aus dem Herzen - im Schutz. der Fantasie - alles was lebt."

$\mathrm{Zu}$ diesen Metaphern nimmt die Künstlerin in der Halbnahen eine Siegerpose ein, bevor sie sich - isoliert bleibend - mit einer Abwehrgeste vom Publikum abwendet. Allein das stete Tropfen aus dem Off setzt sich weiter fort, das das gesamte Tape begleitete. Dieser rhythmische Klang bildete einerseits ein kontinuitätstiftendes, die verschiedenen Phasen der Handlung verbindendes Element, andererseits symbolisiert das Tropfen auch eine stete Veränderung, die nun auch nach der geistigen Transformation noch weiter zu wirken scheint.

Die Beschreibung zeigte, dass sich die Transformationsgeschichte, die in einer Blumengeburt mündet, die im Tape abstrahiert und als kontinuierlicher Bildfluss erzählt wird, in vier Phasen unterteilen lässt, die sich wiederum in zwei inhaltliche Abschnitte gliedern lassen: Die ersten drei Phasen umfassen erstens das Entblättern, zweitens das Freifegen und drittens das Entfesseln des eigenen Körpers. Diese drei, durch Wiederholungshandlungen gekennzeichneten Abschnitte, sollen hier unter dem Aspekt „Methoden der Selbsterkenntnis“ zusammengefasst werden. Der letzte Abschnitt setzt schließlich die erlösende „Transformation“ in Szene, die von einer fernöstlichen Atmosphäre getragen und durch eine klare Rückzugsgeste abgeschlossen wird.

Interessant ist das mehrfache Auftauchen der Zahl Drei in dem Tape: Es gibt drei Monitore, drei Stöcke an jeder Hand, drei durch Wiederholung gekennzeichnete Phasen (der eine vierte narrativere folgt). Auch von drei Zuständen ist die Rede: dem Leben, dem Tod, und der Schwelle dazwischen. Symbolisch drückt die Zahl Drei die Überwindung der Entzweiung und damit die Vollkommenheit aus und sie ist damit auch die Zahl der himmlischen Ordnung. Diesen drei Phasen folgt im Verlauf der Performance eine vierte. Die Vier steht symbolisch für das Irdische, ein Aspekt, der in dieser aktiven Transformationsphase der Performance

729 Vgl. Mirabai 2006 
zum Tragen kommt, wird doch eine körperliche Geburt inszeniert. Diese Beispiele zeigen, wie sich auch in diesem Werk in sehr abstrahierter Weise in der formalen Struktur Inhaltliches spiegelt.

Auf den Punkt gebracht wird diese dichte Symbolsprache im Abspann des Tapes, der folgende Einstellung zeigt. Die Künstlerin sitzt in Großaufnahme auf dem Stuhl und hält das Bündel aus Bambusstäben in der Hand, an das eine rosafarbene Rose gebunden ist. Zunächst hält sie den Stab waagerecht vor sich. Die Waagerechte entspricht dem Weiblichen und so erscheint dazu auch der Name der Künstlerin in blauer Schrift auf dem Bildschirm. Dann dreht die Akteurin das Bündel in die Senkrechte und zu lesen sind dazu zwei Männernamen.

\section{5.3.4 Transformation zur Erkenntnis}

In verdichteter, symbolisch aufgeladener Form umkreist das Tape „Or-Phelia ein Transformationsstück“ das Thema der Selbsterkenntnis auf der Suche nach jenem mythisch-mystischen Bereich jenseits von Leben und Tod, der Erlösung bedeutet und geistige Wiedergeburt. Es ist eine inhaltlich komplexe Arbeit, in der sich Elemente fernöstlicher Spiritualität und westlicher, in archaischen Urbildern wurzelnde Vorstellungen zur Transzendenz durchdringen. Diese Elemente werden im Agieren der Künstlerin zu einer höheren Einheit gebracht. ${ }^{730}$

Neben der Deutung als archetypische Stationen eines Erkenntnisweges können die einzelnen Phasen der Performance aber auch biografisch gedeutet werden. Einer ersten Phase - des Findens des künstlerischen Ausdrucks im Medium Video - folgte ein Klärungsprozess im Kreis der Frauen, bis sich die Künstlerin neuen spirituellen Erfahrung zuwandte. Nach dem In-Szene-Setzen des Sich-Öffnens, des Um-den-Kern-Kreisens, dem Ordnung-Schaffen, den Irrungen und Wirrungen auf dem Lebensweg, wird abschließend eine befreiende Lösung dargestellt, die das Abgeschnittensein vom inneren Selbst ganz anschaulich überwindet: Das sich Niederlassen an einem Ort, auf einer Art Thron - womit ein vertrauenvolles Loslassen der Kontrolle einerseits und andererseits ein Sich-Tragen-Lassen vom Grund und vollständiges Angenommensein verbunden ist - ermöglicht schließlich eine geistige Wiedergeburt und ebnet damit den Weg, die im Inneren verschlossene Liebe auszudrücken. Dies geschieht in der Aktion in symbolischer Form, ein Rosenstrauß taucht aus dem Schoß der Künstlerin auf.

Für die der westlichen Denktradition entstammenden Figuren Orpheus und Ophelia blieb die Sehnsucht nach sich erfüllender Liebe unerfüllt. Orpheus konnte seine geliebte Eurydike und Ophelia konnte ihr Selbst nicht retten. Letztere konnte sich erst sterbend mit der Natur vereinen. Für die von der Künstlerin imaginierte androgyne Sucherin Or-phelia, in der sich Weibliches und Männliches zum ganzheitlichen Sein verbunden haben, und die in einer Atmosphäre östlicher

730 Rödiger-Diruf in: Kat. Saarbrücken 1990, o. S. 
Spiritualität die Lösung der Fesseln erfuhr, bietet die Suche ein Ziel, die innere Transformation ermöglicht ihr selbst wieder Liebe zu gebären. Doch bleibt die Akteurin auch nach der erlösenden Transformation für sich allein - wie es heißt: „im Schutz der Fantasie“.

Die Grundaussage des Transitorischen des menschlichen Seins findet auch in der formalen Gestaltung des Tapes seinen Niederschlag. Wie umrissen, gehen die einzelnen Einstellungen in ihrer zeitlichen Abfolge langsam ineinander über, sei es durch Zoom oder Schwenk oder - wie meist - durch Überblendung, so dass das Tape die sich verändernden Handlungen in der Performance kontinuierlich wiedergibt. Hinzu kommt das Element der Verknüpfung der dokumentarischen Aufnahmen der Aktion mit den künstlich erzeugten Bildern der Kunstfigur. Auch hier wird mit dem Mittel der Überblendung gearbeitet. Diese Form der Darstellung setzt die Nähe der beiden Figuren Künstlerin und Or-Pheliafigur - oder auch abstrahierter: äußeres Agieren und inneres Sein - ganz anschaulich ins Bild. Sie verschwimmen ineinander, werden eins, bis sie dann wieder elektronisch voneinander getrennt werden. Auch dabei zeigt sich jeweils ein sehr enger Bezug zur entsprechenden inhaltlichen Aussage. Das Überblenden verbildlicht eine Symbiose und Metamorphose - oder wie die Künstlerin es selbst betitelte: eine Transformation. Die Inhalte der Performance sind im Übertragen in das Medium des Videotapes noch verstärkt und intensiviert worden. Dabei wird in dem Tape mit einer sehr direkten Bildsprache gearbeitet. Es werden visuelle Metaphern eingesetzt, die persönliche Wirklichkeit spiegeln und gleichzeitig elementare menschliche Erfahrungen visualisieren.

Das Thema Tod, das bereits in mehreren vorangegangenen Werken Rosenbachs, wie dem „Requiem“, begegnete, spielt auch in diesem Werk wieder eine elementare Rolle. Dies wird besonders deutlich in der Präsentation der ursprünglichen Installation in einer Art Sarkophag. Doch zeigt sich hier eine neue Sicht: Der Tod bildet keinen Endpunkt, sondern wird durch innere Transformation überwunden und etwas Neues wird geboren, der Kreislauf des Lebens fortgesetzt. 


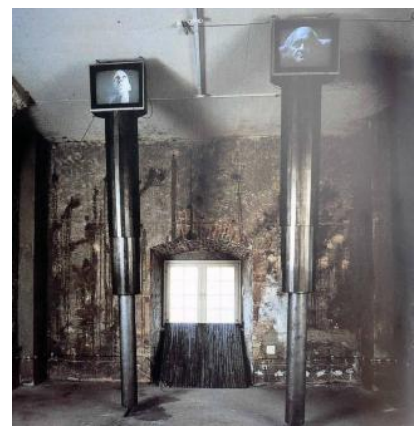

Abb. 224: Klaus vom Bruch: War Requiem, 1987

Ein audiovisuelles „Requiem“ inszenierte auch Klaus vom Bruch 1987, das ebenfalls - parallel zu Rosenbachs Or-Phelia-Installation - auf der documenta 8 präsent war. Das „Coventry - War Requiem“ ist eine sehr persönlich ausgerichtete Videoskulptur dieses Künstlers, deren zwei Monitore von zwei gigantischen Teleskopröhren aus Metall getragen werden. Auf den fast unter die Decke des Raumes gedrückten Bildschirmen sind als statische Bilder der Künstler und sein Vater in Porträtansicht zu sehen. Zwischen den beiden Monitoren gibt es keine innere Verbindung, keinerlei Sender-Empfänger-Kommunikation. Stattdessen wird der Raum rund um die hoch gesockelten Monitore von der Musik Benjamin Brittens erfüllt. Im Gedenken an die Opfer der deutschen Luftangriffe auf die südenglische Stadt Coventry im Zweiten Weltkrieg komponierte Britten 1961 das „War Requiem“, das im Jahr 1962 in der wiederaufgebauten Kathedrale von Coventry anläßlich deren Einweihung zur Uraufführung gebracht worden war. Karin Thomas merkt zu Klaus von Bruchs Videoskulptur an:

„Nach eigenem Bekunden, ließ sich Klaus vom Bruch nicht nur von der Musik Benjamin Brittens, sondern auch von dem Dichter Wilfred Owen zu seiner Videoskulptur für die documenta 8 inspirieren. Owen, der wie auch viele deutsche Dichter aus dem Umfeld des Expressionismus mit dem Enthusiasmus des Freiwilligen in den Ersten Weltkrieg gezogen und kurz vor Kriegsende 1918 gefallen war, hatte in seinen Gedichten aus dem Felde das Elend der modernen Kriegsmaschinerie und die eigenen Erfahrungen als mitleidgebietende Tragödie in lautmalerischer Diktion beschrieben. Mit der audiovisuellen Suggestivität einer Videoskulptur nimmt Klaus vom Bruch Bezug auf diese Katharsis Dimension der Owenschen Lyrik und verbindet im Mut zum biografischen Bekenntnis den scharfen Blick des nachgeborenen Sohnes auf die verdrängte Kriegsschuld der Vätergeneration mit der Melancholie des gemeinsamen Leidens an dieser noch immer unüberbrückbaren Kluft. "731

731 Thomas 2002, S. 395 
Vom Bruch visualisiert in seiner Rauminstallation die Sprachlosigkeit und die Beziehungslosigleit zwischen Vater und Sohn angesichts der Last der Vergangenheit, hebt damit eine persönliche Erfahrung in eine konkrete historische Dimension. Die Skulptur ist Beschreibung, Analyse und Bekenntnis in einem, zeigt jedoch keinen Lösungsansatz.

Anders Ulrike Rosenbach, deren künstlerisches Werk auch mit den Erfahrungen von Leid und Sprachlosigkeit ringt. Hier wird die politische Thematik allerdings auf einer ahistorisch-mythischen Ebene bearbeitet, jedoch nicht weniger persönlich. In der Or-Phelia-Performance und dem Tape treten zusehends therapeutische Aspekte in den Vordergrund, die Lösungsmöglichkeiten anbieten. Die Künstlerin zeigt in dieser Arbeit einen - individuellen - Weg der Heilung auf. Sie vermittelt eingebettet in die Gedanken der ökologischen Bewegung, die Mitte der 1980er Jahre wuchs, eine spirituelle Transformation, die die Möglichkeit des SichWieder-Einfügens in den Kreislauf der Natur mit sich bringt. Und in destillierter Form spricht aus der Bildschirmstele mit der kreisenden Or-Pheliafigur eine ganzheitliche Botschaft: Das Leben beginnt immer wieder neu.

\section{IV .5.4. Werkuntersuchung: Wie ein Pbönix aus der Asche}

Um den steten Kreislauf der Natur aus Werden und Vergehen kreist auch die Performance „Wie ein Phönix aus der Asche“, die die Künstlerin erstmals 1989 in der Art Galerie of Ontario im kanadischen Toronto aufführte. ${ }^{732}$ Phönix, das ist der sich im Feuer verjüngende göttliche Vogel der mythischen Sagenwelt. Im altägyptischen Mythos heißt er „Benu“ und ist bei der Entstehung der Welt auf dem Urhügel erschienen. Als Phönix taucht die Figur dann in verschiedenen Fassungen der Mythologie der Antike auf. Nach der Version des Physiologus fliegt der Phönix alle 500 Jahre zu den Zedern des Libanon, füllt die Flügel mit Wohlgerüchen, erscheint einem Priester in Heliopolis und verbrennt sich dort auf einem Altar. Tags darauf findet sich in der Asche ein Wurm oder ein Vogeljunges, der - beziehungsweise das - am dritten Tag wieder zu einem Phönix ausgewachsen ist und in seine Heimat zurückkehrt. ${ }^{733}$ Der Vogel Phönix gilt in diesem antiken mythologischen Zusammenhang als Sinnbild der ewigen Erneuerung. Aber auch vom Christentum wurde die Figur übernommen, hier als Sinnbild des durch den Tod erneuerten Lebens. So zeigt ihn die ältere christliche Kunst als Paradiesvogel mit Strahlennimbus auf einer Palme oder mit einem Palmzweig. Später wurde der Phönix

732 In den 1990er Jahren wurde die Performance dann noch mehrfach aufgeführt.

733 Lexikon der christlichen Ikonographie, Bd. 3, S. 430; So auch seit dem ersten Jahrhundert nach Christus im römischen Mythos. In dieser Fassung verbrennt er sich auch hier selbst in gewissen Abständen - erwähnt wird hier ein Zeitraum von 500 oder auch 1461 Jahren. Nach dem Verbrennen ersteht er nach einiger Zeit wieder neu und verjüngt aus der Asche. 
auch hier als ein sich aus den Flammen heraus erneuernder Vogel dargestellt und theologisch in Beziehung zu Christi Opfertod und Auferstehung gesetzt. ${ }^{734}$

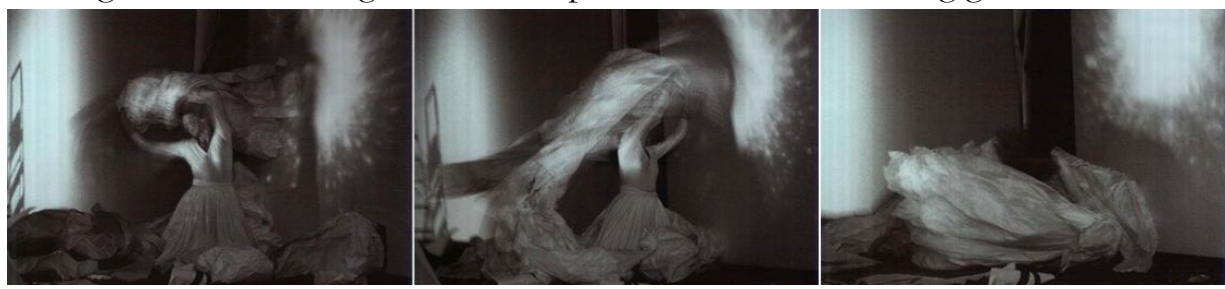

Abb.225-227: Wie ein Phönix aus der Asche, 1989 Aktionsfoto

Auch als alchemistisches Symbol findet sich der Phönix. Hier verkörpert er im Sinne eines Symbols der Erneuerung die in der Hitze des Ofens sterbende und auf höherer Ebene neu belebte Materie. So heißt es im alchemistischen Traktat „Splendor Solis“ zu diesem reinigenden Schmelzproezess wie folgt: ${ }^{735}$

„Zum Vierten reiniget die hitze/ und scheidet ab/ das unrein/ dann es nimpt ab die Mineralischen zusebl/ und allen bösen gestanck/ und ernewert das Elixir davon spricht Hermes/ du soltst absondern da dick ist/ von dem Subtillen/ die Erde von dem Feur/ darvon redet Alphidius also/ die Erde laßt sich schmelzen/ und wird Feur heraus entspringen/ spricht Rafis/ etliche weichmachung der Kunst/ welche müssen vorgen/ vor der vollkommnen bereitung die da genant wirt Mudificatio dann allererst ist das werck vollbracht/ wann die unreinen theil binweck sind. "736

Die Druckgraphik über dieser Textpassage zeigt einen dreiköpfigen Vogel in einer gläsernen Fiole, unter der kleine Flammen züngeln. Diesen alchemistischen Reinigungsprozess und die damit verbundene geistige Transformation strebt die Künstlerin in ihrer Aktion an, ins Bild zu setzen. Dazu improvisierte sie vor einer groBen Videoprojektion, die eine Collage aus Flammen, Vulkanausbrüchen und Sternenexplosionen zeigte. Die unterschiedlichen Motive zum Thema Feuer, die auf den Wänden im projizierten Lichtbild erscheinen, sind Symbol des Wandels, der Reinigung. Dieser visualisierte Kreislauf der Metamorphose materialisiert sich im auf dem Boden des Raumes verteilten Lavakies: handelt es sich doch um erkaltetes, ehemals erhitztes Gestein aus dem Inneren der Erde. ${ }^{737}$

\footnotetext{
734 Lurker 1991, S. 608

735 Splendor Solis in: Aureum Vellus 1708, S. 191

736 Kat. Saarbrücken 1990, o.S.

737 Mit solchem Lavakies füllte die Künstlerin bereits den „Sarkophag“ der Or-Phelia-Skulptur, damit nimmt sie die Wandlungssymbolik des Lavakies bereits an dieser Stelle vorweg. Man könnte auch sagen, die Phönix-Performance setzt das Or-Phelia Thema noch einmal variiert in Bewegung um.
} 
An den Wänden hing zudem mit roten und schwarzen Runen beschriebenes weißes Papier. Manche der Papierbögen waren auch auf dem mit Lavakies ausgelegten Boden verteilt. Und auch die mit Runen beschriebenen Papierstücke teilen verschlüsselte Botschaften mit. Der Ausdruck „Rune“ bedeutet „Geheimnis, Mysterium“ und findet im altirischen „run“ eine lautverwandte wie bedeutungsgemäße Entsprechung.

„Die Runen waren - besonders in der älteren Zeit - ein esoterisches Mittel mystisch orientierter Kommunikation, wobei die Idee des Schreibens durchaus nicht im Sinn der Übermittlung profaner Information verstanden wurde. Das Lesen von Runen war wobl nicht im modernen Sinn des Ausdrucks als Assoziation von Lautzeichen und Bedeutungsinhalten zu verstehen, sondern es ging um eine echtes „Entriffern", um ein Ausdeuten und vielschichtiges Interpretieren von Texten. "'38

Leider sind die in der Performance benutzten Runen auf den Fotografien der Performance nicht genau zu erkennen. Allein Striche, Spiralen, Kreuze sind zu sehen. Doch scheint wichtiger als die konkrete Rune, deren Bedeutung sich für den einzelnen Zuschauer auch nicht erschließen lässt, die Aura des Geheimnisvollen dieser Schriftzeichen zu sein. ${ }^{739}$

Als Tonkulisse war eine Geräuschmischung aus Feuerknistern, Sphärenmusik und Kinderweinen zu hören. In diesem Environment tanzte die Künstlerin, wobei sich anstelle von Flügeln wirbelnde Stoffbahnen in die Luft hoben:

„Wie ein Phoenix aus der Asche - machtvolle Wiederholung eines alten Vorgangs. Vorzeigen des Willens zur Veränderung - Metapher für ein Lebensprinzip. Wo nichts Neues wächst, da wächst kein Gras mehr - eine winzige Warnung mit ernstem Ausgang - Transformation nach vorne oder nach binten - Geburt und/ oder Tod. "740

Der als Schmelzprozess imaginierte Wandel wird von der Künstlerin als ein elementares Lebensprinzip in Szene gesetzt und die Performance kann als eine Metapher für einen Prozess der steten - inneren - Veränderung verstanden werden. Eine Erneuerung, die die Künstlerin in der Performance direkt initiiert. Zudem scheint sie dies als eine Art Initiationsritual selbst zu durchleben, und gleichzeitig versucht die Künstlerin dies Erlebte dem Publikum zu vermitteln. Damit scheint die Aktion auch einen Appell zu umfassen. ${ }^{741}$

738 Haarmann 1990, S.462; Zudem weist der Autor auch noch auf die Mathematizität der Runen hin.

739 Dabei sind Runen von den Nationalsozialisten genutzt worden. Nicht nur das Hakenkreuz stammt aus diesem nordischen Symbolzusammenhang, auch die SS nutzte das Runen-S als Erkennungszeichen. Zudem findet sich auch in dieser Performance die Farbkombination schwarzweiß-rot.

740 Rosenbach in: Kat. Bonn 1999, S. 18

741 „Es ist Zeit zu sagen, Kunst oder jedenfalls diese Performance ist ein Vorwand - ein Vorwand, um die Leute und mich an etwas zu erinnern, was seit einigen Jahrhunderten als verboten gilt. 
Um ihre Botschaft zu vermitteln bedient sich die Künstlerin auch in dieser Aktion wieder unterschiedlicher Zeichenebenen, neben dem körperlichen Agieren, den Bildprojektionen und der Toncollage bilden rote und schwarze Runen, eine weitere Kommunikationsform, ergänzt um den Katalogtext.

\section{IV.6. Tanzende Körperzeichen im Raum -}

Charakteristisches der Arbeiten der 1980er

In den frühen 1980ern ist Ulrike Rosenbach in ihrem künstlerischen Wirken nicht länger darauf ausgerichtet, das Bild der Frau in Geschichte und Kunst zu berichtigen, so dass sich ihr Fokus für neue Fragestellungen öffnet. Sie gibt auch ihre aktive Beteiligung in der Frauenbewegung auf. Stattdessen sucht sie in ihrem Werk ein Verstehen von Menschlichkeit in der Dualität des Menschen und im zyklischen evolutionären Charakter der Natur. In diesem Prozess wird aus dem Zorn in der vorangegangenen Dekade ein Verstehen und Akzeptieren der Verwandlung.

Der Blick auf die vier in diesem Jahrzehnt entstandenen Werkkomplexe, die unter den Aspekten Mutter-Tochter-Beziehungen, Erinnerungsarbeiten, östliche Spiritualität und Androgynität zusammengefasst wurden, hat gezeigt, dass in diese Werke weitere Inhalte und vielfältige Motive hineinspielen. Um diese komplexen Inhalte zum Ausdruck zu bringen, schöpft die Künstlerin aus unterschiedlichen Quellen, durchstreift die Erkenntnisphilosophie der Kulturen. Neben der Mythologie und Kunstgeschichte gewinnen die Alchemie, religiöse Fragestellun-gen und Kontexte an Bedeutung. Auch literarische Vorlagen werden als Quellen heran gezogen sowie auch die eigene Autobiografie weiter als Quelle präsent bleibt.

Aus all diesen Elementen formt die Künstlerin ihre spezifische audiovisuelle Sprache. Bei der Untersuchung ihrer Ausdrucksformen hat sich gezeigt, dass die mediale Umsetzung der Inhalte in den betrachteten Werken durch eine große Buchstäblichkeit gekennzeichnet ist. Menschliche Erfahrungen, Gefühle oder auch sprachliche Metaphern werden wortwörtlich visualisiert, in Worte, Bilder oder Handlungen übertragen. Dabei kommt ein Repertoire an Materialien zum Einsatz, das einen festen, wiederkehrenden Kern hat und sukzessive um neue Bedeutungsobjekte erweitert wird. So begegnen dem Rezipienten zum Beispiel Elemente wie der rote Faden, das Schwingen oder das Um-die-eigene-Achse-Drehen des Körpers, der Salzgrund sowie der Einsatz des Videobildes innerhalb der Aktionen bereits seit den 1970er Jahren und auch im anschließenden Jahrzehnt weiter. Neu tritt in den Aktionen der 1980er Jahren das Element des Papieres hinzu. Dieses Material, das allgemein der Vermittlung und Speicherung von Informationen, aber auch dem Verhüllen dient, wird in Rosenbachs Werk eingesetzt als Hintergrund

An das Recht sich zu verändern ... ich meine unter der Oberfläche, kein neues Kleid, sondern ein „,neues“ Herz, eine erneuerte Seele, einen gecleanten Geist, neuerdings Worte, die als pathetisch gelten, weil sie die materiellen Werte nicht erfassen - WERT, ein ganzes Wort auf der Tastatur meiner Schreibmaschine." (Kat. Saarbrücken 1990, o.S.) 
für Bildprojektionen. Es wird bemalt, zerrissen, geschichtet, umhüllt den Körper oder den Videomonitor und wird mit geheimnisvollen Schriftzeichen beschrieben.

Den materiellen Elementen, der zu den Aktionen aufgebauten Environments, lassen sich spezifische symbolische Bedeutungen zuordnen, wobei die Künstlerin auf im kulturellen wie auch im universellen Kontext verwurzelte Symbole zurückgreift, diese aber in einen neuen individuellen Zusammenhang einfügt und damit zu persönlichen Chiffren umgestaltet. Mit dem Entschlüsseln dieses werkspezifischen Bedeutungscodes erschließt sich durch das Benennen des Gesehenen die jeweilige Aussage.

Dabei arbeitet die Künstlerin in ihrer spezifischen Sprache mit einem Zusammenwirken der Bild- und Tonebene. Anders als im ersten Jahrzehnt, in dem die Tonebene der Arbeiten meist durch Wortschleifen gekennzeichnet war, wird dieses Muster nun aufgebrochen und durch poetische Texte, die zusätzliche Informationen zum Geschehen geben oder die Handlungen in einen größeren Kontext einfügen, abgelöst und es zeigt sich allgemein in ihrem Werk eine Zuwendung zum Narrativen. Dabei spricht die Künstlerin ihre Texte auf deutsch, wobei es für die Eulenspieglerin auch eine englische Fassung gibt. ${ }^{72}$ Wenn in den 1970ern der Einsatz von Sprache stark reduziert war, ein Konzept, dass sich auch bei Marcel Odenbach und Klaus vom Bruch findet ${ }^{743}$, wird im Werk Rosenbachs dieser Dekade die Sprache nun zu einem wesentlichen bedeutungstransportierenden Element. Auch die stimmungsbildende Wirkung von Musik und Geräuschkulissen kommt in den audiovisuellen Arbeiten der Künstlerin in diesem Jahrzehnt verstärkt zum Einsatz.

Der spezifischen Funktion des Videobildes in den Aktionen Ulrike Rosenbachs Rechnung tragend, soll an dieser Stelle der Blick zunächst auf die Bedeutung des Videobildes - der so genannten Aktionsvideos - in den Performances und auch Installationen dieses Jahrzehntes geworfen werden. Es hat sich gezeigt, dass mindestens ein Monitor im Mittelpunkt oder am Rand des Environments steht. Er wird während der Aktionen häufig bewegt - getragen oder zur Seite geschoben - manchmal stellt die Künstlerin sich auch auf den kastenförmigen Bildschirm, umhüllt ihn oder entpackt ihn aus einer Ummantelung.

Außerdem werden die auf ihm gezeigten vorproduzierten Aktionsvideos - das Closed-Circuit-Verfahren findet sich in den 1980ern bei Ulrike Rosenbach nicht eingesetzt - nun auch vermehrt großformatig auf die Wände projiziert. Die collagierte Videoprojektion löst damit in ihrer Funktion die Diaprojektionen der 1970er Jahre ab. Das bewegte Lichtbild ersetzt nun das statische. Eine Veränderung, die durch das Voranschreiten der Technik motiviert scheint, ist der Videobeamer doch in den 1980ern salonfähig geworden. Die in dieser Werkphase durchweg farbigen eigenen Aufnahmen ergänzt um Found footage werden in den

742 Vgl. Kat. Toronto 1989

743 Erleichtert doch eine nicht auf Sprache basierte Aussage die internationale Rezipierbarkeit. 
Tapes zu fließenden Bildcollagen verwoben. Dabei zeigt sich deutlich eine Veränderung der stilistischen Formulierungen, die in diesem Jahrzehnt vor dem Hintergrund der erweiterten technischen Möglichkeiten komplexer gestaltet werden. Die Künstlerin stieg bereits Ende der 1970er Jahre auf das damals neu eingeführte Umatic-Lowband-System um, und zur Bildbearbeitung und -generierung wurde in dieser zweiten Dekade bereits zum Teil mit einem Bildcomputer und unterschiedlichen elektronischen Effekten gearbeitet.

Die Videobilder fügen in die Aktionen eine weitere Wirklichkeitsebene ein. Sie bringen eine Innenwelt zum Ausdruck, die in der stofflichen Welt unsichtbar ist, dem Bereich des Geistigen, der Fantasie zugeordnet bleibt. Dabei orientieren sich die Bildschöpfungen entsprechend der sich ändernden technischen Voraussetzungen in diesem Jahrzehnt, trotz ihrer Collagehaftigkeit, am stofflichen oder figürlichen Naturvorbild. Damit bleibt die künstlerische Darstellungsweise mit der Abbildhaftigkeit des gewählten Mediums Video verbunden. Die in die Performances integrierten Videobilder stellen der äußeren, materiellen Aktion damit eine geistigspirituelle Dimension gegenüber, erlauben einen Blick unter die Oberfläche und integrieren diese zusätzliche Information in den im Raum angeordneten künstlerischen Gesamtausdruck.

Dieses Prinzip der Verknüpfung zweier paralleler Wirklichkeitsebenen spiegelt auch die mediale Gestaltung der weiteren Videoarbeiten wieder, die in diesem Jahrzehnt entstehen. Diese sollen in drei Kategorien unterschieden werden. Neben erstens den reinen Dokumentationen der Aktionen, die meist mit einer Kamera aufgenommen wurden, kann die zweite Gruppe Tapes, die durch ihre explizit künstlerische Gestaltung gekennzeichnet ist, in zwei Untergruppen unterschieden werden: Zum einen die so genannten Meditationstapes, die unabhängig von einer Aktion entstanden sind, sich aber meist in einen thematisch übergeordneten Werkkomplex einfügen lassen. Zum anderen, die explizit auf einer Performance fußenden Videotapes, die Dokumentarmaterial und Aktionstapes auf spezifische Weise verbinden. Bei beiden werden im Verlauf der Tapes - wie dargelegt - punktuell unterschiedliche Ebenen miteinander verknüpft, die unter anderem ein Verschmelzen von Innen und Außen visualisieren und bei denen die formale Gestaltung die inhaltliche Aussage unterstützt.

Neben dem elektronischen Videobild steht der Körper der Künstlerin im Mittelpunkt der Aktionen und Tapes. Er ist weiterhin der elementare Handlungsträger. In diesem Medium beginnt sie jetzt in einer neuen Dimension Geschichten zu erzählen. Denn die Künstlerin fängt an in ihren Aktionen zu improvisieren, Formen des freien Tanzes aufzuführen, wenn man den Begriff des Tanzes - im Sinne Pina Bauschs - allgemein auf ein körperliches Agieren erweitert. Eine wesentliche Voraussetzung für dieses freie Agieren hätten Meditations- und Körperübungen 
gebildet, die zum Trainingsprogramm der Künstlerin seit diesem Jahrzehnt gehörten, wie sie selbst anmerkte. ${ }^{74}$

Innerhalb dieses erweiterten Verständnisses der Körperarbeit bilden bestimmte Bewegungen - zum Beispiel das Schwingen, Schreiten oder Um-die-eigeneAchse-Wirbeln - elementare Ausdrucksformen, mit denen sich die Künstlerin den Raum wie auch die Dimension der Zeit erschließt. Dabei scheint das Ritualhafte dieser Aufführungen die Akteurin selbst in den Bereich mystischer Erfahrung zu versetzen, so dass sie von der „Einsamen Spaziergängerin“ an, die symbolisch auf der Grenze zwischen Zivilisation und Wildnis wandelte, zu einer Grenzgängerin zwischen den Welten - dem Bewussten und dem Unbewussten oder auch dem Profanen und Sakralen sowie dem Innen und Außen - wird. Damit stellt sich die Frage nach der Symbolik in ihrem Werk neu. Wenn die Performerin Marina Abramovics für ihr künstlerisches Wirken darauf hinwies, dass sie nicht mit einer symbolischen Sprache arbeite, weil die gezeigten Erfahrungen real seien, dann nähert sich auch Ulrike Rosenbach in diesem Jahrzehnt dieser Haltung in ihren künstlerischen Aktionen auf gewisse Weise an, wenngleich bei ihr die Abstraktion der Handlung auf einer Zeichenebene bestehen bleibt. ${ }^{745}$

Bei allem körperlichen Agieren ist auffällig, dass die Künstlerin ihren Körper neutralisiert. Die Künstlerin agiert in einem räumlichen Environment, hinterlässt im Salzgrund ihre Abdrücke, auf dem Papier an den Wänden ihre Mal- und Rissspuren. So bleiben Spuren des Tanzes zurück: materialisierte Körpererinnerungen, abstrakt und spannungsreich. Ganz konkret schreibt die Künstlerin ihre Erfahrungen in diese Aktionsräume ein.

Hinzu tritt in den Performances und Aktionstapes ein beredtes Repertoire an körperlichen Gebärden als weitere Kommunikationsebene. An dieser Stelle soll besonders auf die Handzeichen hingewiesen werden. Gesten der Hände fanden sich schon in den Arbeiten der 1970er Jahre als Bedeutungsträger. Zum Beispiel gab es die schlagende Hand in „Sorry Mister“, die zur Faust geballte, erhobene Hand in der „Medusaimagination“ oder schließlich in der „Einsamen Spaziergängerin“, die Fingergeste des Kreissymbols. Zu diesem Zeitpunkt werden dieser sehr bildlichen Gebärdensprache mit den in den östlichen Religionen beheimateten Mudras subtilere Chiffren hinzugefügt. Diese Fingerhaltungen werden in asiatischen Traditionen genutzt um seelische Beweggründe und Gefühle auszudrücken, und es heißt von ihnen, dass sie Energieflüsse stimulieren können. Diese Mudras aus einem anderen kulturellen Kontext sind allerdings für Uneingeweihte schwer zu entschlüsseln, vielleicht gar nicht zu erkennen.

Wenn der Körper von Ulrike Rosenbach in vielen Arbeiten direktes Sprachrohr ist, bestimmt zudem sein elektronisches Abbild wesentlich die Videobilder, die in die Performances oder Installationen eingefügt sind. Auf dieser Ebene des

\footnotetext{
744 Vgl. Kap. V.1.2

745 Fischer-Lichte 2003, S. 27
} 
Objektes der Abbildung fällt eine Zerteilung des Körpers auf. So erscheinen entweder nur einzelne Körperteile auf dem Bildschirm oder aber der Gesamtkörper ist auf mehrere Bildschirme verteilt, wird virtuell fragmentiert. Zudem sind zum Ende des Jahrzehntes die entstehenden künstlerischen Arbeiten durch einen wachsenden Reduktionismus gekennzeichnet. Außerdem tritt der menschliche Körper als Protagonist zurück. So werden die Themen und Motive zum Beispiel im „Zenkocher" oder im „Augenblick“ auf eine bildliche Essenz reduziert und die Fragestellungen zudem in skulpturaler Form gelöst.

Blickt man inhaltlich auf das Gemeinsame der vier oben benannten Themenkomplexe dieses Jahrzehntes, lässt sich in allen das Moment der Transition oder der Metamorphose finden. Scheinen die Werke doch allesamt künstlerische „Rites de Passage“ zu den unterschiedlichen Lebensphasen des Menschen zu sein. Sie zeigen in Variationen die Lösung von Mutter und Kind, den Übergang vom Mädchen zur reifen Frau, das Verschmelzen von Frau und Mann oder die Transformation vom Teil zum Ganzen. Konfliktträchtige und schmerzhafte Übergangserfahrungen des menschlichen Lebens werden aus einer explizit weiblichen Sicht aufgeführt, in symbolhafter Weise kommuniziert und in der künstlerischen Aktion wird nun auch eine Lösung mitgeliefert.

Bei der Betrachtung des künstlerischen Werkes ist auffallend, dass die Tochter der Künstlerin während ihrer Kindheit und Jugend - insgesamt über einen Zeitraum von zehn Jahren - in verschiedenen der Werke nicht nur auftauchte, sondern ihren aktiven Part in diesen Arbeiten übernahm. Bereits im allerersten Videotape war das damals noch junge Mädchen gegenwärtig. Das Ende der gemeinsamen Performancetapes und Aufführungen leitete dann neun Jahre später die Aktion „Narzissen scheiden weg“ ein, die genau dieses Thema der Trennung von Mutter und Kind verarbeitet. Die letzte gemeinsame Arbeit von Mutter und Kind war dann die „Wechselfrau“, die ebenfalls das Thema Trennung thematisierte. Das wiederholte künstlerische Zusammenwirken einer Mutter mit ihrer Tochter, oder allgemeiner eines Künstlers mit seinem Kind, ist etwas Ungewöhnliches in der modernen Kunst, in der Kunst allgemein. Bei der Recherche konnten keine anderen Beispiele gefunden werden für Künstler oder Künstlerinnen, die ihre Kinder so konkret ins Werk einbezogen haben. Zwar finden sich immer wieder Bezüge auf eigene Kinder, wie Bildnisse oder Fotografien, aber keine konkrete Einbindung ins künstlerische Werk. ${ }^{746}$

Betrachtet man die Aktionen, die Ulrike Rosenbach mit ihrer Tochter aufführte, scheinen diese sich entlang der Autobiographien beider zu bewegen. Es werden in den Aktionen exemplarisch Entwicklungsstufen herausgegriffen. In der „Einwicklung“ ist es die Bindung zwischen Mutter und Kind. In der „Mutterliebe“

746 Otto Dix zum Beispiel malte seine kleine Tochter Nelly auf sehr eindrucksvolle Weise auf einer Blumenwiese stehend. Das Kinderporträt entstand 1924. Weitere Beispiele für Kinderbildnisse durchziehen die Kunstgeschichte. 
geht es um eine Vereinnahmung des Kindes durch die Mutter. Bei den „Narzissen“ und der „Wechselfrau“ steht die Lösung beider voneinander und der Übergang in eine nachfolgende Lebensphase im Mittelpunkt.

Nachdem das Thema der Mutter-Tochter Beziehung in den Arbeiten zu Beginn der 1980er Jahre aus unterschiedlichen Blickwinkeln reflektiert wurde, wird das Beziehungsmotiv fortgeführt in der künstlerischen Bearbeitung der partnerschaftlichen Beziehung. So steht zum Beispiel in den ,Judofrauen“ die Trauerarbeit einer Trennung aus einer Liebesbeziehung im Mittelpunkt. Aus diesem künstlerisch aufgearbeiteten Lösungsprozess erwächst schließlich das versöhnliche Motiv des Androgyn, in dem die Dualität aus Weiblichem und Männlichem integriert wird.

Wenn während der 1970er Jahre in den Werken Rosenbachs auf Vorbilder aus der westlichen Kunst- und Kulturgeschichte zurückgegriffen wurde, aber auch Bezüge zu Mythologien anderer Kulturen zu finden sind, wie der nordamerikanischen Indianer oder australischen Aborigines, und das Werk zudem geprägt ist durch feministische Denkweisen, fließen durch die Begegnung mit der östlichen Spiritualität wie der Geisteswelt der Alchemie in den 1980er Jahren neue Formen, unbekannte Bilder und erweiterte Ansätze des Denkens in die Werke Rosenbachs ein, und das Motiv des Lösens, der Ganzheit, der Versöhnung nimmt sich Raum im künstlerischen Wirken. Nach der gelungenen Allianz von Männlichem und Weiblichem in den Werken, die um das Thema „Androgyn“ kreisen, scheint es in den folgenden Aktionen vermehrt um das Thema der Heilung zu gehen: Abgespaltene Teile werden sichtbar und integriert, innere und äußere Welten ergänzt. Auch Bilder von Natur und Mensch werden in den künstlerischen Collagen wieder zusammengefügt, und so wieder - ganz wörtlich - der Mensch in die Natur eingefügt. In dieser Motivik spiegelt sich ein grundsätzlich ökologisches Denken der Künstlerin, die sich nun in der ökologischen Bewegung verwurzelt sieht, die wiederum für die Dekade der 1980er Jahre als zum prägenden Zeitgeist gehörig gezählt werden kann.

\section{IV.6.1. Exkurs: Trauma und Kunst}

„Die Kunst als Therapie, ja manchmal wurde die Therapie sogar selbst das Motiv ${ }^{* 747}$, sagt die französische Künstlerin Sophie Calle $(* 1953)$ über den therapeutischen Aspekt ihres künstlerischen Wirkens. Und auch Joseph Beuys hob heraus: „Kunst ist ja Therapie!" 748 Im Wirken Ulrike Rosenbachs wird der therapeutische Aspekt, einerseits für die Akteurin andererseits aber auch als Angebot für den Rezipienten, in den Arbeiten der 1980er Jahre immer greifbarer.

\footnotetext{
747 Sophie Calle im Interview mit Fabian Stech, in: Kunstforum international Nr. 162, Nov/Dez. 2002, S. 220

748 Kraus 1996, S. 10
} 
Zudem taucht mit dem Ausscheiden der Tochter bei der Mitwirkung an den Aktionen eine neue Figur im Werk der Künstlerin auf: Es ist der schwarze Schattenriss in Form einer geflügelten Frauenfigur. Dieser zitiert eine Wandmalerei aus der Antike, die die Künstlerin bereits im Jahr 1977 für sich entdeckt hatte. Nachdem sie die darin gefundene Thematik - den Weg der erwachsenen Frau - zunächst in Aktionen bearbeitet hatte, taucht 1982 dieser Schatten auf. Eine schwarze Frauengestalt, die mit ihrer Flügelsilhouette an einen Engel oder auch eine Siegesgöttin erinnert. Da diese Figur in unterschiedlichen Größen stetig im weiteren Werk präsent bleibt, stellt sich die Frage, wofür steht dieser Schattenriss, welche Bedeutung könnte diese schwarze Figur haben?

Der aus dem Griechischen entlehnte Begriff „Trauma“ bedeutet Verletzung oder auch Wunde. Von einem Trauma spricht die Psychologie, wenn die Linie der Kontinuität im Dasein eines Individuums unterbrochen wird. Dieser Abbruch kann durch die unterschiedlichsten Faktoren ausgelöst werden, wie Gewalt- oder Verlusterfahrungen oder andere schmerzhafte Erlebnisse. Dabei lässt sich das Grundprinzip des Traumas wie folgt benennen: Es manifestiert sich im Leben in der steten Gegenwart des vermeintlich Abwesenden, es ist nicht deutlich zu erkennen, und doch gegenwärtig, ein wenig wie Rosenbachs schwarze Engelsfigur. Beim Trauma bedeutet dessen stete Gegenwart, dass sich über die Ebene des Unbewussten das nicht verarbeitete Ereignis in ganz unterschiedlichen Gestalten immer wieder mitteilt. ${ }^{749}$

Der Zweite Weltkrieg mit seinen Erfahrungen, die der Totalitarismus in den unterschiedlichen Ländern wie auch die Kriegserlebnisse in die Zeitzeugen eingeschrieben haben, ist sicherlich ein solches universelles Traumata, das ganz unterschiedliche Gesichter trägt. ${ }^{750}$ Dabei kommt Deutschland eine spezifische Rolle in der Geschichte zu, zum einen als die Nation, die den Krieg begonnen hat und zum anderen als Land, das die Schuld am Holocaust trägt. Eine Schuld, die die Aufarbeitung des eigenen erlittenen Leids lange Zeit verhinderte. Vielmehr haben viele Deutsche, die Nationalsozialismus wie auch den Krieg erlebten, Teile von

749 In der Therapie mit traumatisierten Menschen nehmen Malerei, Bildnerei oder Zeichnung als Ausdrucksmittel eine wichtige Funktion ein. Können in Bildwerken doch unaussprechliche Störungen und Traumata zum Ausdruck gebracht werden, die sich durch das Bewusstwerden zudem lösen und Heilungsprozesse einleiten können. So ist es ein Ziel der Kunsttherapie mittels des produktiven Ausdrucks den Prozess der Selbsterfahrung zu intensivieren, um auf diese Weise tiefere psychische Schichten freizulegen. In der Therapie kommen den künstlerischen Werken dabei zwei Funktionen zu: Zum einen geht es um die innere Erfahrung während des kreativen Prozesses. Zum anderen kann der Patient am ästhetischen Objekt den gewinnbringenden Umgang mit den eigenen Potenzialen erlernen. Ähnliches gilt im übrigen auch für die Tanz- oder körperorientierte Therapie.

750 Der französische Schriftsteller Albert Camus bezeichnete das 20. Jahrhundert treffend auch als "Jahrhundert der Angst“. Dabei äußern sich die global prägenden Erfahrungen des Ersten und Zweiten Weltkriegs mit den Spuren der unterdrückerischen Totalirismen und menschenverachtender Ideologien in den verschiedenen Ländern ganz unterschiedlich. 
sich einfach abgespalten. Doch Traumata, die nicht aufgearbeitet werden, werden unbewusst an die nachfolgenden Generationen weitergegeben. ${ }^{751}$

In der Kunst von Joseph Beuys, der selbst als Sturzkampfflieger auf der Krim nach einem Angriff auf eine russische Flakstellung beim Abfangmanöver getroffen worden war und abstürzte und der nur schwer verletzt überlebte dank der Fürsorge russischer Tartaren, die den Bewusstlosen fanden, finden sich therapeutische Angebote diese traumatischen Erfahrungen durch die das Seelenleben im Nachkriegsdeutschland geprägt war, zu verarbeiten. ${ }^{752}$ Der Künstler weist hier Denkwege in die Demokratie. In der Kunst nach dem Zweiten Weltkrieg finden sich zahllose Beispiele für Künstler und Künstlerinnen, die in ihren Werken persönliche, länderspezifische, kulturelle oder universelle Traumata bearbeiten und deren Kunst neben einer einen kritischen Geist schärfenden Auseinandersetzung mit dem Selbst, in der Welt auch als soziales oder kulturelles Erinnerungsorgan wirkt.

751 Dieses Phänomen wurde zunächst in Familien von Holocaustüberlebenden beobachtet. Psychologische Untersuchungen bei Überlebenden des Holocaust haben gezeigt, dass die Traumata, wie auch tiefe Schuldgefühle, sind sie nicht aufgearbeitet worden, unbewusst von einer Generation an die nächste weitergegeben werden. Gleiche psychologische Mechanismen greifen bei den Tätern und deren Folgegenerationen. (Vgl. Soerensen-Cassier in: psychosozial 2003, S. 61-66)

752 Der Beuys Biograph Heiner Stachelhaus schreibt zu dem Erlebnis mit nachhaltiger Wirkung: „Daß Beuys überlebt, ist ein Wunder - und er verdankt dies einer Gruppe nomadisierender Tataren, die auf ihren Wanderzügen über die Krim das Wrack des Stukas und den schwerverletzten ohnmächtigen Flieger im hohen Schnee entdecken. Sie bringen ihn in eines ihrer Zelte, pflegen den meist Bewußtlosen acht Tage lang aufopfernd mit ihren Hausmitteln, salben seine schweren Wunden mit tierischem Fett, wickeln ihn in Filz ein, damit er warm wird und Wärme speichern kann. Und sie flößen ihm Nahrung in Form von Milch, Quark, Käse ein. Beuys hat einen doppelten Schädelbasisbruch erlitten, er hat Splitter im Körper, von denen später nur ein Teil entfernt werden kann. Rippen, Beine, Arme sind gebrochen. Die Haare sind bis in die Wurzeln hinein versengt, das Nasenbein zertrümmert. Ohne die Fürsorge der Tartaren wäre Beuys seinen Verletzungen erlegen. All dies hat ihn tief angerührt." (Stachelhaus 2001, S. 26) Demgegenüber korrigiert Frank Gieseke diese romantisierende Sichtweise und erläutert die historischen Fakten des Geschehens wie folgt: „Laut Auskunft der Deutschen Dienststelle vom 20. Februar 1995 datiert der besagte Absturz auf den 16. März 1944. Die deutsche Wehrmacht war auf dem Rückzug, die Krim zum größten Teil von der Roten Armee zurückerobert. Der Unfallort liegt bei Freifeld im nördlichen Teil der Krim. Die Verletzungen von Beuys werden mit Gehirnerschütterung und Platzwunde über den Augen angegeben. Der Flugzeugführer Hans Laurinck starb noch am Unfallort (...) Die abgestürzte Maschine war eine JU 87. Den Eintragungen im Soldbuch und dem Eintrag im Krankenbuchlager Berlin ist zu entnehmen, daß Beuys vom 17. März bis 7. April 1944 im mobilen Feldlazarett 179, Kruman-Kemektschi gepflegt wurde. Der acht- bis zwölftägige Aufenthalt bei den Tartaren, wie ihn Stachelhaus und anderen überliefern kann, kann also höchstens 24 Stunden gedauert haben.“ (Gieseke 1996, S. 76) 
Diese schöpferische Auseinandersetzung mit Traumata unterschiedlichster Art, von individuellen ${ }^{753}$ bis zu kulturellen, bildet ganz unterschiedliche Formen aus. Neben konstruktiven Formen finden sich auch stark destruktive Tendenzen, wie im vorangegangenen Kapitel über die Kunst der 1970er Jahre ausgeführt wurde. ${ }^{754}$ Als eine besonders heftige Form war in diesem Zusammenhang die im künstlerischen Rahmen erfolgten Selbstverletzung oder auch Autoaggression genannt worden. Gerade hier sind es häufig Frauen, die sich mit kompromissloser Radikalität in ihren Arbeiten konkret Schmerz zufügen, um einem im Inneren verkapselten Leid einen äußeren Ausdruck zu verleihen.

Ulrike Rosenbach ist geprägt von der Frauenbewegung und auch in ihrem künstlerischen Wirken geht es um den Ausdruck von Leid, doch beschreitet sie in ihrem künstlerischen Wirken einen eigenen Weg der kulturellen Erinnerungsarbeit verbunden mit der künstlerischen Katharsis. So entfernt sie sich während der 1980er Jahre deutlich vom radikalen Feminismus, arbeitet immer stärker mit privaten Chiffren und entwickelt individuelle Mythologien. Sie nimmt Bezug auf archetypische Bilder. Ihr Rückgriff auf vielfältige Vorbilder ist dabei gekennzeichnet durch Neudeutungen und das Freilegen überlagerter Bedeutungsschichten. Dabei arbeitet sie auf der Ebene des Individuellen, des Geschlechtsspezifischen wie auch des Allgemeinmenschlichen. Eine konkrete historische Dimension ist in ihrem Werk ersetzt oder übertragen in eine mythologische, quasi archetypische Dimension. Ihr künstlerisches Wirken erscheint damit weitestgehend ahistorisch.

Damit setzt sie sich deutlich von anderen deutschen Künstlern ihrer Generation ab. Anselm Kiefer - Jahrgang 1945 - ging einen radikal historischen Weg, indem er verdrängte deutsche Geschichte thematisierte. Auch die folgende in der BRD aktive Künstlergeneration - mit Protagonisten wie Marcel Odenbach und Klaus vom Bruch - arbeitete mit einem konkret historischen Ansatz. Die Künstlerin sucht in ihrem künstlerischen Schaffen hingegen nach Wegen der individuellen Befreiung und der seelischen Heilung der Verletzungen, sucht nach ganzheitlichen Seinsweisen und tiefwirkenden Kommunikationsmöglichkeiten. Sie verarbeitet in ihrem Werk, gebunden an die eigene Person, letztlich allgemeine psychische Erfahrungen einer durch Krieg, Gewaltherrschaft und Schuld gezeichneten Gesellschaft auf. Und in dieser Weise manifestiert sich in ihrem Werk, auf der Suche nach einer Überwindung des Leids, eine Ikonographie der Seele. Damit nimmt ihr Werk im kunsthistorischen Kontext eine originäre Position ein. Zudem schlüpft die Künstlerin in ihrem eigenen Werk immer mehr in eine bestimmte Rolle. Wird sie doch in diesem Jahrzehnt zur Grenzgängerin zwischen den Welten - Außen und Innenwelt.

753 Auf der hier als individuelle bezeichneten Ebene durch konkrete persönliche Erfahrungen auf dem Lebensweg oder auch familiäre Prägungen. Auf dieser Ebene sind die wodurch auch immer verursachten Verletzungen und Traumata vielleicht noch am ehesten fassbar.

754 Vgl. Kap. III.4.2. 
So wie der schwarze Schattenriss aus der Verarbeitung der Generationenproblematik als materielle Manifestation zum Anfang der 1980er Jahre erwuchs, manifestiert sich ein weiteres Symbol im Verlauf dieses Jahrzehntes in ihrem Werk. Es erscheint ein Herz - erstmals auf dem Bildschirm in den Schmelzprozessen, dann auch als Projektion in der „Wind meiner Träume- Aktion“ und schließlich materiell und greifbar: Aus goldschimmernder Bronze tritt es in dreidimensionaler Form in den Raum. Das Herz als Symbol der Liebe, aber auch Sinnbild einer gefundenen inneren Versöhnung und Harmonie, das in den Arbeiten des kommenden Jahrzehntes weiter begegnen wird. 


\section{Grenzgänge - Die 1990er Jahre}

Das Jahr 1989 brachte eine einschneidende Veränderung für Europa. Die „Mau$\mathrm{er}^{\text {" }}$ fiel, die in den vorangegangenen Jahrzehnten die beiden deutschen Staaten getrennt hatte. Unabhängig von den politischen und sozialen Ereignissen rund um das wiedervereinigte Deutschland wurde auch in der Entwicklung im Bereich der digitalen Technologie zu Beginn der 1990er Jahre ein neues Kapitel aufgeschlagen. Die digitale Revolution setzte sich mit immer größerer Geschwindigkeit fort und die Möglichkeiten der digitalen Bildbearbeitung und -effekte wuchsen rasant an. Nachdem zuvor diese Technologie sehr teuer gewesen war, wurde sie im Verlauf des Jahrzehntes für immer mehr Menschen zugänglich und allgemein wurde vielfältige neue Hardware entwickelt, wie zum Beispiel äußerst lichtstarke Videobeamer, mit denen großformatige Bildprojektionen möglich wurden.

\section{V.1. Verschiebung der Schwerpunkte}

Auch in der Biografie von Ulrike Rosenbach bildet das Jahr 1989 eine Zäsur. Wurde sie doch nach zwei Jahrzehnten mit Lehraufträgen in vielen Ländern der Welt zu diesem Zeitpunkt als Professorin an die Hochschule für Künste in Saarbrücken im Saarland berufen. Die Kunsterzieherin und Bildhauerin trat dort die Nachfolge des Gründungsrektors Jo Enzweiler an, der zu diesem Zeitpunkt von 230 Studenten besuchten Hochschule, und sie bekleidete diese Leitungsposition während der kommenden vier Jahre. Damit sei eine international anerkannte Künstlerin und darüber hinaus erstmals eine Frau, die zugleich in der künstlerischen Lehre tätig sei, zur Rektorin einer bundesdeutschen Hochschule berufen worden, teilte das saarländische Kultusministerium mit.

Mit diesem Posten als Professorin, den die Künstlerin dort bis heute inne hat ${ }^{755}$, war neben der öffentlichen Anerkennung ihres künstlerischen Schaffens eine verlässliche ökonomische Basis für die bis dahin freischaffend tätige Künstlerin gegeben. Ulrike Rosenbach lebte und arbeitete in den folgenden Jahren zunächst auf dem Land in der Nähe der französischen Grenze, bis sie Mitte der Dekade wieder in die Nähe von Köln zog.

\section{V.1.1. Dozentin und Kuratorin}

„In den 80er Jahren war bereits die Tendenz da, sebr in die Vermittlung zu gehen. Durch die Professur ist der Gedanke noch einmal verstärkt worden, das Lehrprogramm als ein Pro-

\footnotetext{
755 Seit 2008 ist Ulriche Rosenbach emiritiert.
} 
gramm zu sehen, das zur Kunst gehört. Das ist das, was zum Beispiel auch Forsythe gemacht hat oder auch Forty. Im Tanz oder in der Musik ist es sehr gebräuchlich, dass das Lehrprogramm wirklich ein Teil deines Lebens ist, eines künstlerischen Lebens und auch ein Teil deines Werkes, dass das Lehrprogramm einen Teil deiner künstlerischen Vermittlung bildet. Das ist nicht gerade ein deutsches Konzept. Ich habe mich da sehr engagiert. Deshalb ist das Buch - die "Medienkunstprojekte" - für mich sebr wichtig gewesen, als ein Abschluss der vergangenen zehn Jahre von 1989 bis 2000 mit Lehrtätigkeit und Vermittlung, die komplett ein eigenes System gezeigt haben: Mit dem Performancetraining, mit der Art und Weise, wie ich Fotografie und Video sehe, und wie ich das vermittle. Das ist integrativ in meine Arbeit eingeflossen. Damit ist dieses Buch in gewisser Weise mein Buch. Es sind zwar die Arbeiten der Studenten, doch es bildet einen Teil meines Lebenswerkes. "756

„10 Jahre Medienkunst“ ist der Titel dieses Kataloges, der 1999 von der HBK Saar herausgegeben wurde und in dem Ulrike Rosenbach gemeinsam mit 13 ihrer Studentinnen und Studenten das künstlerische Schaffen präsentiert. ${ }^{757}$ An der Hochschule für Künste in Saarbrücken leitet die Künstlerin seit ihrer Berufung die Klasse für Neue künstlerische Medien. Ulrike Rosenbach hat hier mit ihren Studentinnen und Studenten zahlreiche Projekte und Ausstellungen auf die Beine gestellt, wie der Katalog dokumentiert. Die Internetzeitung „TightRope“ ist nur ein Beispiel für ihr Engagement mit den Studierenden an intermedialen Projekten zu arbeiten. ${ }^{758}$ Als Kuratorin betreute Ulrike Rosenbach zudem während der vergangenen Jahre zahlreiche Ausstellungen, wie unter anderem das Projekt „Mediasplit“ im Jahr 2000, das das Foyer der Deutschen Bank in Saarbrücken als Forum nutzen konnte, oder die Schau „Gegen den Strich“ mit multimedialen Arbeiten ihrer Studentinnen, die im Jahr $2001 \mathrm{im}$ Frauenmuseum in Bonn gezeigt wurde. ${ }^{759}$ In ihrer Lehrtätigkeit knüpft die Künstlerin bewusst an die ganzheitliche Grundlage des Bauhauses in Weimar in den 1920er Jahren an. Ihr experimenteller Ansatz umfasst so nicht nur die Arbeit mit den neuen technischen Medien, sondern zudem ein Kreativ- und Performancetraining mit ihren StudentInnen, welches sich aus der Beschäftigung mit dem Zen-Buddhismus speist. ${ }^{760}$

756 Gespräch 2001, vgl. Kap. VII.1.; die Rede ist von den beiden amerikanischen Tänzern John Forsythe und Simon Forty.

757 Die Studentinnen und Studenten sind: Christian H. Cordes, Jens Geelhaar, Robert Hutter, Leslie Huppert, Christiane Hommelsheim, Walli Höfinger, Gertrud Riethmüller, Klaudia Stoll, Dietlinde Stroh, Annette Weber, Christa Werner-Geiselhofer, Caroline Wilms, Susanne Wilms.

758 http://www.hbks.uni-sb.de/tightrope/ (TightRope - the digital journal (since 1993)) (Zugriff 5.5.2008); http://www.geelhaar.de/TR/intro.html (Zugriff 3.8.2011)

759 Vgl. Kat. Saarbrücken 2000

760 Petzinger 2000 in http//:www.ulrike-rosenbach.de/text/tod/gedal.html (Zugriff 5.5.2008); verschiedene Künstler des Bauhauses, wie Johannes Itten setzten sich intensiv mit der Lehre des Zen auseinander, aber auch viele zeitgenössische Künstler - von Laurie Anderson bis John Cage - praktizieren Formen des Zen. 


\section{V.1.2. Das Körpertraining als Bestandteil der künstlerischen Ausbildung}

„Performance zu machen, heißt total konzentriert im Augenblick da zu sein und die gegenwärtige Stimmung des Augenblicks mit in die Entwicklung der körperlichen Prozesse einzubequiehen." "761

Konzentration und Gegenwärtigkeit hebt Ulrike Rosenbach für ihr Performanceschaffen hervor. Im Rahmen ihrer eigenen Performancetätigkeit hat die Künstlerin durch die Jahrzehnte Ausbildungen im Integrativtraining und in Meditationstechniken erfahren. Aus der Fülle an Erfahrungen hat sie selbst erprobte Techniken und eine Vielzahl an Übungen zusammengetragen. Aus diesem Repertoire entwickelte sie ein „Performance- und Kreativtraining“, das sie über zehn Jahre lang an der Hochschule für Künste wöchentlich anbot und das die Künstlerin wie folgt beschreibt:

„Das komplette Angebot „Performancetraining“ nimmt einen Tag wöchentlich in Anspruch. Es beginnt mit einer morgendlichen Stunde von leichten Yoga-und Stretchingübungen, die auf den Ablauf des Tages Bezug nehmen. Um 14 Uhr beginnt das eigentliche Training für 2 Stunden. Der Tag schließt mit einer Meditationsübung, die sich aus dem Tagesprogramm entwickelt. Alle körperlichen Übungen sind auf das Potential von Anfängern berogen. Das Programm verfolgt nicht das Ziel einer körperlich-geistigen Turnstunde. Für die sonst eher körperfeindliche Arbeit an Videomaschinen und Computern, aber auch zum Beispiel vor der Staffelei, bietet das Training in dem wunderschönen Dachatelier der Hochschule eine willkommene Abwechslung. Einige Generationen von StudentInnen sind inzwischen durch meine Hände gegangen. Nicht alle kommen aus der Medienklasse, sondern auch aus der Malerei, der Plastik oder sogar aus dem Fachbereich Design der Hochschule. Es ist keine Auflage, die Seminare mit einer Performancearbeit oder Aktion abzuschließen. Für einige TeilnehmerInnen ist das wöchentliche Training einfach wichtig zur Entspannung oder um eigene Prozesse kennenzulernen, die dann in den eigenen Atelierarbeiten, auf Bildern oder Zeichnungen weiter reflektiert werden. Die drei Übungsabschnitte - Yoga-Stretching, Performancetraining und Meditation - sind im besten Sinne ein leichtes, aber effektives Integrationstraining. " $" 62$

Die Performerin erläutert die Ziele dieses ganzheitlichen Körpertrainings ausführlicher:

„Integration von Körper, Seele und Geist hilft, kreative Prozesse zu erkennen und zu akzeptieren. Das Erkennen der eigenen Körper-Geist-Verfassung ist der erste Schritt für AnfängerInnen in den Seminaren. Eigene, individuelle Körper-Geist-Befindlichkeiten als die ,eigene Welt" zu akzeptieren ist der zweite wichtige Schritt des Trainings. Zwischen beiden Pha-

\footnotetext{
761 Beckers 1998, S. 34

762 Rosenbach in: Kat. Osnabrück 1997 (http://www.wallihoefinger.com/html/presse.html\#97f (Zugriff 3.5.2008))
} 
sen liegt eine Folge wichtiger Hindernisse und Blockaden. Ängste und fehlendes Vertrauen verbindern den Schritt zum Akzeptieren oft noch viele Übungsfolgen. Über Körperimprovisationen wird das Vertrauen zum eigenen Körper-Geist-Niveau aufgebaut und verstärkt und das Überwinden von Ängsten ermöglicht den TeilnehmerInnen, sich freier zu bewegen, authentische Materialien und Medien zu finden, mit denen sie ibre künstlerischen Prozesse realisieren können. Die Akzeptanz der individuellen Verfasstheit wächst und ermöglicht den StudentInnen, mit ibrer Arbeit authentischer und deshalb lebendiger zu werden. Die „eigenen Themen" sind nun primär der Gegenstand der Entwicklung und nicht nur technische Prozesse in imitierten Formen. Die Entwicklung zur Authentizität in den künstlerischen Prozessen, die Entscheidung zu eigenen Themen wird durch die Arbeit in den PerformanceSeminaren zwar schnell greifbar, aber sie ist für die StudentInnen auch recht intensiv. Das Tempo und die Intensität, mit der die Erkenntnis individueller, authentischer Prozesse sichtbar wird, fübrt zuweilen zu neuen Hindernissen auf dem Weg. Widerstand gegen die neuen Erkenntnisse kann sich aufbauen und muss in eigener Initiative wieder bearbeitet werden. So entwickelt die Performancearbeit in diesem Training eine Art spiralförmiger Bewegung, in der die Thematik von „Angst und Misstrauen" zuweilen großen Raum einnimmt. Dieses Thema als eigenes zu erkennen ist einer der wichtigsten Schritte im Laufe der Zeit. So ist Schritt drei Überwindung, die Öffnung und der Wille, die eigene Kraft zu sehen und zu nutzen - und künstlerisch umzusetzen, sei es nun in der Performance oder in anderen Techniken. " "63

Eine Suche nach Authentizität und Akzeptanz der individuellen Verfasstheit spricht aus dieser Beschreibung. Zwei Charakteristika, die auch im Werk der Künstlerin als grundlegend begegneten.

Doch bevor weiter auf das künstlerische Wirken Ulrike Rosenbachs geblickt wird, soll an dieser Stelle ein Seitenblick den vielfältigen kreativen Ansätzen einiger ihrer ehemaligen Studenten und Studentinnen gelten, um daran auch die Einflüsse der Lehrerin aufzuzeigen. Als bekannteste Studentin Ulrike Rosenbachs ist derzeit wohl Ingrid Mwangi (*1975) zu nennen, deren künstlerische Arbeiten in den vergangenen Jahren mit zahlreichen Preisen ausgezeichnet worden sind.

Die gebürtige Kenianerin setzt sich in ihren Arbeiten mit ihrer Identität als Afrikanerin auseinander. Dabei zeigen ihre körperorientierten Arbeiten ein enges Zusammenspiel von Gesang, Körperarbeit und Video. ${ }^{764}$ Walli Höfinger (*1966) arbeitet in ihren zum Teil akrobatischen Performances - die zum Teil an Tanztheater erinnern - ganz konkret mit ihrem Körper, den sie in unterschiedlichen Techniken schult. Sie sagt über ihre Kunst: „Was zählt ist der Ausdruck des Körpers in einem bestimmten Moment. "765

763 Rosenbach in: Kat. Osnabrück 1997 (http://www.wallihoefinger.com/html/presse.html\#97f (Zugriff 3.5.2008))

$764 \mathrm{http} / /$ :www.ingridmwangi.de (Zugriff 5.5.2008)

$765 \mathrm{http} / /$ :www.wallihoefinger.com (Zugriff 3.5.2008) 


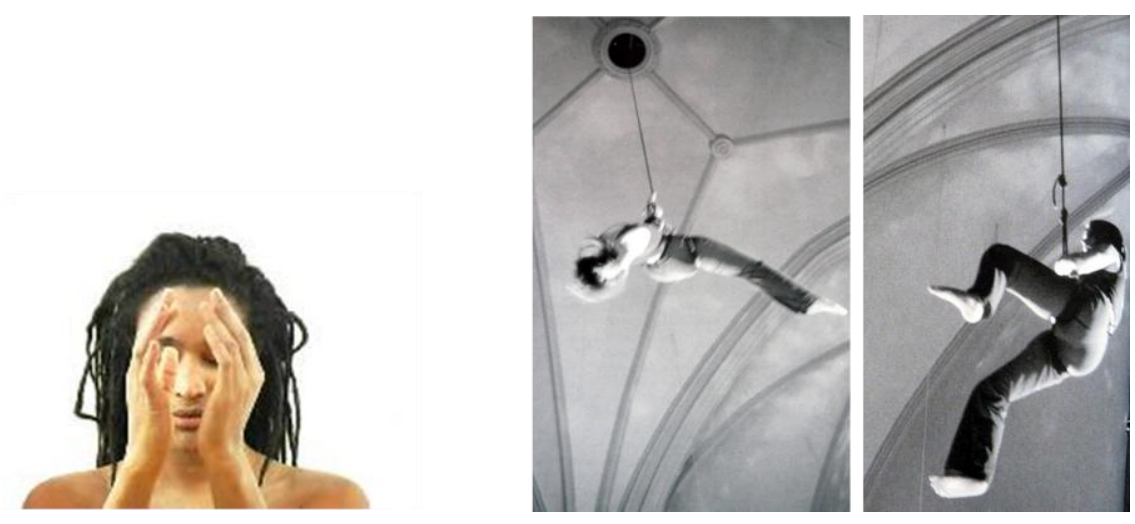

Abb. 228-230: Ingrid Mwangi: Coloured und Walli Höfinger: Hängen, Aktionsfotos

Anders verhält es sich bei Dietlinde Stroh (*1966), die die Arbeit mit der Videokamera in den Mittelpunkt ihres Schaffens stellt. Unter ihren Videowerken finden sich verschiedene Aufträge für Bühneninstallationen, wie zum Beispiel für die Bremer Kresnik-Inszenierung „Intolleranza“ (2000). In ähnlicher Weise hat auch Robert Hutter (*1964) als Medium die digitalen Technologien für sich entdeckt und die philosophische Reflektion über Medien als künstlerischen Schwerpunkt gewählt. Grundlegend bleibt aber bei allen vier hier vorgestellten Künstlern und Künstlerinnen das Körperliche, auch wenn elektronische Medien zum konkreten Ausdrucksträger werden.

Die Kombination aus Authentizität und Dichte, die aus den Werken spricht und die aus einer gewonnen Einheit von Körper, Geist und Seele gespeist wird, formuliert sich auch in Ulrike Rosenbachs Werken der 1990er Jahre noch einmal neu. In diesem Jahrzehnt konzentriert sich der künstlerische Ausdruck in Rosenbachs Werk auf die technisch-mediale Vermittlung, während ihr live agierender menschlicher Körper zurück tritt - bis er völlig verschwindet. Dabei wird allerdings Ulrike Rosenbachs Bildsprache figürlich bleiben. Zudem entstehen mehrere Ulrike-Rosenbach-Projekte. Das sind Gruppenarbeiten mit anderen Künstlerinnen und Künstler, die ebenfalls die Struktur von Rosenbachs Medien- oder Performancearbeit tragen, und auf die im Folgenden kurz eingegangen wird. ${ }^{766}$ Doch zuvor ein intensiver Blick auf ein Videotape der Künstlerin.

766 Vgl. Kap. V.3. 


\section{V.2. Werkuntersuchung des Videotapes „Osho-Samadhi“}

Das Tape „Osho-Samadhi“ eröffnet 1990 das videographische CEuvre des folgenden Jahrzehntes. ${ }^{767}$ Die in dem knapp zwölfminütigen Tape in Großaufnahme gezeigten Details eines Meditationsraumes sind in dem durch seinen Bildfluss charakterisierten Band gegengeschnitten und überblendet mit Aufnahmen aus dem umgebenden Zen-Garten, die fließendes Wasser, Lichtspiele und Pflanzen zeigen. Es ist damit zu den „Meditationstapes“ zu zählen, von denen bereits einige begegneten. Friedemann Malsch beschreibt die Eigenarten dieses Tapes weiter:

\section{„Untermalt werden die rubigen, in ibrer formalen Qualität bestechenden und für Rosenbachs} Videoarbeiten ungewöhnlich malerischen Bilder, von einer sebr dramatischen Musik auf einer traditionellen Zen-Flöte. "768

Er weist zudem daraufhin, dass der Titel des Videotapes „Osho - Samadhi“ auf die traditionelle japanische Bezeichnung für den in den Bildern gezeigten erleuchteten Ort, der Samadhi heißt, beziehungsweise seinen Initiator, den Meister, der Osho genannt wird, verweist. ${ }^{769}$ Dieses Tape wird im Folgenden genauer untersucht.

\section{V.2.1. Beschreibung des Tapes}

In weißer Blockschrift steht auf schwarzem Grund im Zentrum des Bildschirms „Ulrike Rosenbach“. Die Schrift wird dann in den schwarzen Hintergrund ausgeblendetm bevor aus dem Schwarz eine Nahaufnahme eingeblendet wird, die in Schrägperspektive von vorne einen rechteckigen weißen Marmorstein im Bildzentrum zeigt, der durch die perspektivische Verkürzung als Trapez erscheint. Mit der Bildsequenz setzt gleichzeitig meditative Musik ein, die das gesamte Band begleitet, eine Melodie aus Flötenspiel und Saitenklängen. Den Marmorstein umfängt ein Wasserbassin und wiederum einen Rand aus weißem Marmor hat, der die restliche Bildfläche mit seinen weißen mit schwarzen Adern durchsetzten Strukturen füllt. Auf der Wasserfläche finden sich Spiegelungen. Unter anderem reflektieren in der oberen rechten Ecke des Bassins, das in der rechten oberen

767 Das Tape gehört seit 2005 aus copyrightrechtlichen Gründen nicht mehr zum Werk der Künstlerin (Mitteilung per E-mail am 22.8.2011 von Ulrike Rosenbach. Deshalb können hier leider auch keine Videostills aus der Arbeit gezeigt werden.

768 Malsch in: Kat. Köln 1991, o.S.

769 Vgl. Kap. V.2.2. 
Ecke des Bildschirms zu sehen ist, kleine Lichter. In weißer Schreibschrift wird „Osho / Samadhi“ - in zwei Zeilen untereinander geschrieben - über dieser Nahaufnahme eingeblendet, genau im Zentrum des Bildes, direkt über dem zentralen Marmortrapez. Dann zerfällt der Schriftzug und gibt den Blick frei auf die darunter liegende eingemeißelte schwarze Inschrift auf dem weißen Marmorstein: „Osho / Never Born / Never Died / only visited this / Planet Earth between / Dec. 11.1931 - Jan. 19.1990“ ist dort zu lesen, während die Kamera an die Schrift zoomt.

Nach einem harten Schnitt füllt eine Nahaufnahme mit einer grauen, unebenen Felswand die Bildfläche, auf der sich Schatten in unterschiedlichen Grauschattierungen abzeichnen. Die Wand scheint ein wenig aus der Unterperspektive aufgenommen. Am rechten Bildrand sind Pflanzenteile zu sehen, dunkelgrüne Blätter ragen in die Aufnahme. Dann setzt ein Zoom ein, der immer mehr die räumliche Situation zeigt. Er endet in einer Totalen, die den Blick frei gibt aus dem Inneren eines Raumes: Zu sehen sind nun Säulen und schmale, hohe Marmorflächen mit dazwischen liegenden Fensterflächen, hinter denen ein Garten liegt, in dem sich die zuvor in Nahaufnahme gezeigte Felsformation findet. Rechts und links gliedern zwei geriffelte Säulen die Bildfläche der Totalen in symmetrischer Form.

Nach einer weichen Überblendung sind in einer Halbnahen am rechten Rand und rechts oben graue, raue Felsformationen aus aufgestapelten Steinen zu sehen. Am linken Rand stehen Pflanzen. Die untere Hälfte der Aufnahme ist gefüllt mit einer Fläche aus quadratischen blau, grauen Steinplatten, die gleichmäßig mit Abständen auf dem Boden verteilt sind. Aufgenommen aus einer schrägen Perspektive, erscheinen sie als Rauten. Auf sie fallen sich verändernde weiße Lichtreflexe. Eine langsame Überblendung von diesem Standbild zu einem unscharfen, grünen Motiv setzt ein, das durchsetzt ist mit hellen Flecken in blau und gelb. Es wird schärfer und lässt eine Nahaufnahme leuchtend grüner Bambusblätter erkennen, die zum Teil im Wind wehen und Lücken, durch die das Licht fällt.

Nach einer weiteren Überblendung erscheint eine in der Mitte senkrecht zweigeteilte Bildfläche. Während die linke Seite der halbnahen Aufnahme dunkle, unklare Strukturen zeigt - vielleicht Felsen oder Säulen - erhellt in dem rechten Motiv orangenes Licht, das als Quelle durchschimmerndes Glas in Pyramidenform hat, den umgebenden Raum. Die Lichtquelle ist am rechten Bildrand zu sehen, steht auf einer geschwungenen Bank aus Marmor und taucht die Marmorwände rechts neben und unter sich in gelbes Licht. Auch fallen weiße Lichtreflexe auf die Steine. Im Hintergrund dieses rechts angeordneten Motivs ist auf der linken Seite im Hintergrund eine hoch rechteckige rotbraune Fläche, die oben mit einem Halbkreis abgerundet ist - vielleicht eine Tür. Sie ist von einer hellen Marmorfassung umfasst.

Nach der nächsten Überblendung zeigen sich verzweigende dicke Äste und Blätter, die von unten rechts nach oben links durch die Nahaufnahme ragen. In 
der Bildmitte ist ein senkrechter Streifen dunkler eingefärbt, der die Hälfte der Fläche bedeckt. Auf dem rechten hellen Feld hebt sich allmählich ein gelb schimmernder waagerechter Streifen immer deutlicher ab. Dann nach einer weiteren weichen Überblendung erscheinen zwei Aufnahmen, die übereinander-gelegt sind: Das zu erkennende Motiv in den unteren Zweidritteln der Bildfläche ist wieder die Steinplattenfläche in schräger Perspektive, am linken Bildrand sind Pflanzen, am rechten Rand sind Felsen zu erkennen. Von dieser Standaufnahme wird überblendet zu einer Nahaufnahme. Sie zeigt auf der rechten Seite einen breiteren Streifen einer weißen Marmorwand. Rechts daneben liegt ein dunkler senkrechter Streifen. Die Fläche links neben der Marmorfläche zeigt eine Fensterfläche. Auf ihr spiegeln sich im oberen Drittel zwei parallele gebogene Segmente des Lichterkranzes und auch im unteren Feld findet sich ein länglicher Lichtreflex. Es ist eine Spiegelung auf einer Glasfläche, die aus dem Inneren des Raumes strahlt.

Die folgende Überblendung lässt ein weiteres Doppelmotiv erscheinen, das Ausschnitte der beiden Lichtkreise zeigt, die von oben links nach unten rechts durch das Bild verlaufen. Im Hintergrund ist Astwerk zu erkennen. In dieser Bildsequenz wird nun mehrfach die Schärfe verändert: von scharf zu unscharf zu scharf, bis schließlich in ein neues Motiv überblendet wird. Zusehen ist nun eine Spiegelung im Wasser, die in drei Felder geteilt ist: Ein auf der rechten Seite spitz auslaufendes waagerecht verlaufendes ovales Feld, das eine leicht bewegte Wasserfläche zeigt, in der sich Bäume und Himmel spiegeln. Eingefasst wird diese Wasserfläche am oberen und unteren rechten Rand durch zwei gebogene Dreiecksflächen, die Segmente der Lichtkränze zeigen.

Es folgt eine weitere Überblendung zu einer Nahaufnahme, die Aufnahme einer Spiegelung in der Fensterscheibe. Sie zeigt einen senkrecht durch Bild laufenden, mitteldicken, astlosen Baumstamm in der Mitte. Neben diesem ist rechts und links in der Halbnahen grünes Blattwerk zu sehen. Quer schimmert ein breites Lichterband durch das Bild. Die Aufnahme zoomt dann weg und gibt schließlich wieder den Blick in den Raum frei. Die beiden kannellierten runden Pfeiler und die Marmorflächen sind wieder symmetrisch links und rechts angeordnet.

Es folgt eine Überblendung zu einer Halbtotalen, die eine Aufnahme zeigt, die ein dreigeteiltes Motiv zeigt: Es zeigt in der Mitte eine helle Fläche, links dunkle Blätter, rechts ist es mittelhell, vielleicht eine Fläche, die auch Marmorstrukturen zeigt. Eine in Rot gekleidete Frau tritt dann von links ins Bild. Die Amerikanische zeigt den Oberkörper und Kopf der Frau Profil, die sich rückwärts durch das Bild bewegt. Sie macht mit ihren Armen ausladende Bewegungen in die linke Bildseite, hält in den Händen einen Besenstiel, so dass es scheint, dass sie damit den Boden wischt oder fegt. Nachdem sie rechts aus der Aufnahme getreten ist, tritt sie noch einmall kurz hinein, macht erneut die Wischbewegungen, bevor sie wieder über den rechten Bildrand hinaus tritt. 
Nun wird in eine zunächst völlig schwarze Fläche überblendet. Sie zeigt dann im oberen Drittel in ähnlichem Abstand zueinander drei waagerechte blaue Schlitze, etwas tiefer liegend vier weitere blaue Streifen. Gleichmäßig wird es heller, weil Licht angedimmt wird und schließlich ist in einer Totalen der Raum mit den drei Marmorpfeilern und den Lichtkränzen unter der Decke, die sich in den verdunkelten Scheiben spiegeln. ${ }^{770}$ Der Innenraum spiegelt sich mehrfach in den verdunkelten Scheiben. Dann beginnen sich die dunklen Rollos vor den vier Fensterflächen zwischen den Marmorpfeilern langsam und synchron von unten zu öffnen und durch die Scheiben einen zunehmend größer werdenden Blick in den Garten freizugeben. Die feste Einstellung zeigt das Öffnen bis zur Hälfte der Fensterhöhe, was auch der Hälfte der Bildhöhe entspricht. An dieser Stelle wird überblendet zu einem neuen Motiv: Die folgende Nahaufnahme zeigt eine dreigeteilte Fläche, von der durch das einsetzende Wegzoomen zu erkennen ist, dass es das orangene Licht war, das im Raum auf der Marmorbank steht. Das Licht bleibt während des Zooms in der Mitte der Aufnahme. Es reflektiert Orange in der Scheibe dahinter und auf dem Boden. Es schließt sich eine Überblendung in eine Nahaufnahme aus blaugrauen Formen an. Oben links ist eine trapezförmige Marmorfläche, darunter schließt sich eine dreieckige blaue Fläche an. Zur Mitte hin findet sich ein Bogensegment aus Marmor. In der oberen rechten Ecke findet sich ein blaugrünes Kreissegment - das einen Viertelkreis zeigt. Darunter schließt sich eine tiefblaue Fläche an, die links von dem - sich im Wasser spiegelnden - Marmorbogen und rechts von der - sich im Wasser spiegelnden - Marmorwand begrenzt wird. Der einsetzende Zoom zur Halbtotalen zeigt, dass es sich um die untere rechte Ecke von Oshos marmornem Grabstein handelt, und den verschiedenen Spiegelungen in dem umgebenden Wasserbassin.

Eine weiche Überblendung führt ein neues, durch eine verschobene Bilddiagonale zweigeteiltes Motiv vor Augen: In der oberen linken Hälfte ist eine grauweiße Marmorfläche zu sehen, in dem unteren rechten Teil spiegelt sich in der Wasseroberfläche Licht und auch Wald. Auch hier zeigt der nun einsetzende Zoom, dass es eine Ecke des Bassins ist. Blaues Licht fällt von der linken Seite herein und das Licht wirft Reflexe und Schatten auf die Marmorfläche.

Es folgt die Überblendung auf ein neues Motiv. Es zeigt die spitzen Ecken der quadratischen Steine in Schrägperspektive und das Spiel des Lichtes und Schattens auf den Stufen. Zwischen den Steinen scheint etwas wie weißes Papier zu liegen. Dann wird auf ein zweigeteiltes Motiv überblendet: Zweidrittel der Aufnahme nimmt ein braunes Ellipsensegment ein, das von oben und links ins Bild ragt. Umfangen wird es am rechten und unteren Rand von dem gelben Lichterkranz. Die Nahaufnahme zeigt einen Blick unter die Decke des Saales.

770 Die blauen ,Schlitze ${ }^{6}$ erschließen sich nun als Lichter an den Säulen. 
Von hier wird wieder überblendet, diesmal zu einem Wasserfall vor Felsen und auch bei der nächsten Überblendung setzt sich das Motiv des fließenden Wassers fort. Bei dem diffusen Motiv sind links eine Art Pfeiler, vorne unten Steine, und oben rechts eine dunklere Fläche zu sehen. In der Mitte fließt, in der zweiten unterlegten Aufnahme, Wasser herunter. Und auch bei der nächsten Überblendung bleibt das Wassermotiv, es zeigt in der Halbtotalen einen kleinen Wasserfall über Stufen und Felsblöcke. Dann nach der nächsten Überblendung sind im oberen Bildteil Pflanzen zu sehen. Darunter stehen auf dem Steinboden drei schwarze Kissen aufrecht. Von den quadratischen Steinplatte im Vordergrund ist eine ganz zu sehen. Die beiden äußeren sind nur angeschnitten. Das zweite Motiv, das unterlegt ist, zeigt Wasser, das über Steinstufen fließt.

Es folgte eine Überblendung zu einem doppelten Motiv: Links sind Pflanzen, rechts ist eine Felsenformation zu erkennen, von der Wasser fließt. Die Mitte zeigt eine weiße Fläche, darunter schimmern drei blaue, helle Flecken. Darüber ist eine Aufnahme gelegt, die fließendes Wasser zeigt. Das folgende Motiv, in das dann weich überblendet, wird zeigt links eine dunkle Säule, rechts grüne Pflanzen, unten findet sich ein breiter grauer Streifen, darüber liegt im Zentrum der Aufnahme ein weißer quadratischer Stein. Davon zoomt die Aufnahme weg und zeigt in einer Halbtotalen ein Steinplattenfeld im Vordergrund, unterlegt mit der Aufnahme eines Wasserfalles, der von einem von rechts hereinragenden Stein herunterfällt. Das fließende Wasser schimmert weißblau.

Von hier wird weich überblendet in weiteres Wassermotiv. Die linke Seite der Aufnahme zeigt eine schmale senkrechte graue Fläche, der rechte Teil ist ein Drittel in diffuses Grau getaucht. Die verbleibende Fläche in der Mitte ist mit grünen Pflanzen gefüllt. Das Wasser fließt auf der rechten Seite herunter. Und auch die folgende - mit weicher Blende angeschlossene - Aufnahme zeigt eine Felsgrotte, bei der Wasser im Vordergrund über die Steine am rechten und linken Rand fließt. Die grauen Felsen schimmern dabei teilweise blau.

Nach der nächsten Überblendung erscheint eine Nahaufnahme einer Palmenpflanze im Zentrum mit weiß-schimmernde Palmenblätter und hellen Lichtpunkten. Die Nahaufnahme zoomt weg bis zur Totalen und fließt über in eine Waldansicht, die sich im Wasser spiegelt. Oben bleibt der Lichterkranz im Bild zu sehen, der sich als Ausschnitt von der oberen Mitte zur rechten Bildmitte zieht.

Dann wird wieder auf den Grabstein mit Bassin und Säulen, diesmal schräg angeschnitten und auch leicht von oben aufgenommen, überblendet. Die Aufnahme zoomt näher auf die hintere, rechte obere Ecke der Marmoreinfassung des Bassins. Die zunächst links sichtbare Fotografie Oshos auf der Spiegelfläche wandert während dieses Zooms allmählich nach oben links aus dem Bild heraus. Als Detail treten bei diesem Zoom blaue und grüne Lichtreflexe auf dem Marmor ins Bild, bevor von hier auf die rechte Ecke aus Marmor und Spiegelstücken überblendet wird. Dieser Nahaufnahme folgt die Überblendung auf ein anderes Motiv 
aus der Grabarchitektur, die eine andere Ecke in den Blick nimmt. Zu sehen sind nun vier Farbfelder: Oben links ein helles Dreieck, darunter ein breiter blauer gebogener Streifen, außerdem die graue Fläche des Marmorbogens und die noch helle Ecke unten rechts. Von dieser Standaufnahme setzt ein Zoom ein, so dass der Grabstein schließlich in Schrägperspektive - schräg von linken Seite und von oben - im Bildzentrum der Halbtotalen zu sehen ist. Als dieser Zoom verebbt, beginnt die Aufnahme immer blasser zu werden und sich im hellen Licht aufzulösen, bis schließlich nur eine helle weißblaue Fläche sichtbar bleibt. Mit dem Ausblenden der Aufnahme verklingt auch die Musik ganz sanft. Nach einer Weile wechselt die Farbe der Fläche in Gelbweiß, bevor auf diesem Hintergrund der Abspann in schwarzer Schrift erscheint: „dyan smita Ulrike Rosenbach copyright / Saarbrücken 1991“ Diese Worte bleiben einige Momente stehen. Dann lösen sie sich auf und es erscheint: „technische Bearbeitung Hansy Berwanger“. Auch diese Worte bleiben kurz stehen bevor sie durch: „Musik Yoko Rajneesh Foundation / Poona / India“ ersetzt werden. Schließlich erscheint ein Schwarz auf Weißes: „Dank an / thanks to: Basha Tüngler / Ma Anando, Osho Ashram Poona, India/ Hochschule für bildende Künste Saar". Als dieser Dank verblasst bleibt eine weiBe Fläche zurück.

\section{V.2.2. Analyse des Videotapes}

Das mit Vor- und Abspann 11 Minuten und 45 Sekunden lange Tape ist als steter Bildfluss gestaltet, in dem - wie bereits in den beiden vorangegangenen analysierten Tapes - die Gestaltungsmittel der Überblendung und des Zooms charakteristisch sind. Das Band ist aus dokumentarisch-künstlerischen Aufnahmen zusammengefügt, die im Rajneesh-Meditationszentrum im indischen Poona entstanden sind, wie der Betrachter im Abspann erfährt. ${ }^{771}$ Im Mittelpunkt der Aufnahmen steht das dort befindliche Grab oder Denkmal für den im Jahr 1990 verstorbenen Osho - ehemals Bhagwan Shree Rajneesh.

Es findet sich nur ein einziger harter Schnitt in dem Tape. Dieser verbindet nach den ersten 35 Sekunden Spielzeit die in Frontalperspektive gefilmte Nahaufnahme der weißen Grabplatte mit der Nahaufnahme eines weißen Felsens in Frontalperspektive. In dem Tape werden diese beiden Motive direkt aneinander gehängt, und damit im zeitlichen Ablauf gegenübergestellt. Davor und danach sind in dem Band alle Bildsequenzen mit zum Teil länger andauernden oder aber auch schneller ablaufenden Überblendungen weich aneinander gefügt und ineinander verwoben. Dabei ist die Dauer der einzelnen Einstellungen ganz unterschiedlich lange gewählt, variiert zwischen 10 und 40 Sekunden. Die einzelne Ein-

771 In der Literatur (vgl. Glüher 2005 oder Malsch in: Kölnischer Kunstverein 1991) ist die allgemeine Rede von einem indischen Meditationszentrum und der konkrete Ort, der auch im Abspann mit „Osho Ashram Poona, India“ benannt wird, bleibt unerwähnt. 
stellung hat im Durchschnitt eine Länge von um die 20 Sekunden, so dass dem Betrachter Zeit bleibt, das jeweilige Standbild, das gegebenenfalls durch einen Zoom in Bewegung gesetzt wird, zu betrachten. Diese Kontinuität und Langsamkeit im Bildfluss spiegelt sich auch in der fortlaufenden meditativen Musik wieder, die die Bildsequenzen von Beginn bis Ende begleitet. Nahaufnahmen bilden den Großteil der Einstellungen des Tapes. Häufiger finden sich als Stilmittel auch zwei übereinandergelegte Aufnahmen, deren Motive sich durchwirken. Die mit Zooms und Überblendungen zu einem Bildfluss komponierten Detail- und Nahaufnahmen, sowie Halbtotalen und Totalen zeigen Innen- und Außenaufnahmen. Dabei spielen die Aufnahmen mit diesen Raumeindrücken. Das Innen und das Außen unterschiedlicher Räume - wie der Marmorhalle, dem Garten - wird in den verschiedenen Bildsequenzen zum Teil auch durch reale Spiegelungen wie auch Überblendungen miteinander verbunden. So wird durch spiegelnde Scheiben hindurch von innen nach außen gefilmt oder auch spiegelnde Wasseroberflächen, die Reflektionen von Natur oder Architektur auf sich tragen, ins Bild gesetzt.

Während im ersten Teil des Tapes auf diese anschauliche und für Rosenbachs Bildsprache charakteristische Weise das Thema der Spiegelung visualisiert wird, fokussiert die Motivik nach rund vier Minuten ein weiteres Thema. Zunächst tritt während dieser vierten Minute in einer Nahaufnahme eine fegende Frau in roter Kleidung ins Bild, übrigens der einzige aktiv handelnde Mensch, der in dem Tape sichtbar ist. ${ }^{772} \mathrm{Zu}$ sehen sind dabei nur der Oberkörper, die agierenden Arme wie auch der Kopf der Frau, die sich rückwärts durch die Aufnahme bewegt und einen Besen hinter sich her bewegt. Nach dieser Fege-Aktion in Halbnahaufnahme füllt zunächst Dunkelheit den Bildschirm. Der gefilmte Ort ist in der angeschlossenen Totalen zu erkennen, nachdem das Deckenlicht des gefilmten Raumes allmählich aufleuchtet, und die in der festen Einstellung symmetrisch erfasste Architektur sichtbar wird. Je eine Säule ist links und rechts am Bildrand zu sehen, dazwischen liegen drei schmale Marmorwände, die von den Fensterflächen durchbrochen werden. In den von außen verdunkelten Fenstern spiegelt sich die kranzförmige Beleuchtung unter der Decke des Raumes. Interessant ist auch hier ein Blick auf den zeitlichen Ablauf. Denn nach genau fünf Minuten Dauer des Tapes findet sich eine Art Zäsur. Dies ist der Augenblick, an dem Bewegung durch die Aufnahme geht, indem sich die dunklen Rolläden vor den bis dahin das Innere des Raumes spiegelnden Fenstern beginnen zu öffnen und den Blick in den dahinter liegenden Garten freigeben.

In der weiteren Folge taucht, nachdem im ersten Abschnitt das Motiv der Spiegelung dominierte, wiederholt das Motiv des fließenden Wassers auf. So zeigen viele der Bildsequenzen des zweiten Teils des Tapes Aufnahmen mit kleinen Wasserfällen. Zudem ist für diesen Teil besonders charakteristisch, dass zwei un-

772 Als weiteres Abbild einer Person ist nur noch am Ende des Tapes eine Fotografie Oshos zu sehen, ein Porträt seines Kopfes. 
terschiedliche Aufnahmen übereinander gelegt erscheinen und ihre Motive sich so elektronisch durchwirken.

Der Blick auf die Farbigkeit der Aufnahmen zeigt zum einen eine begrenzte Farbpalette in den Aufnahmen, zum anderen die Verbindung von einzelnen Farben und farbigen Lichtreflexen mit Gegenständen. So findet sich Blau für die Wasser- und Grün bei den Pflanzenmotiven. Allerdings findet sich im Verlauf des Tapes eine Veränderung der Farbigkeit bei einzelnen Motive. Damit ist gemeint, dass zum Beispiel das häufig in dem Tape erscheinende Motiv des Felsens zunächst in seiner natürlichen Farbe weiß, grau oder auch braun erscheint. In späteren Einstellungen werden die Steinblöcke dann vom Blau - der Farbe des fließenden Wassers - überzogen. Umgekehrt ist es bei den Pflanzenmotiven, die lange Zeit in dem Band in ihrer natürlichen grünen Farbigkeit abgebildet sind. Doch schließlich kurz vor einem Überblick gebenden Zoom auf einen Wald und der Überblendung in die finale Ansicht der Grabanlage erscheint eine Palme mit hellen weißen Lichtreflexen auf den Blättern. Hier ist es das Licht, dass die grünen Blätter der Pflanze in Weiß taucht.

Neben den Farben Orange, das für Vitalität steht, Blau - die Farbe des Geistes und der Kommunikation - und Grün, die Farbe des Lebens und der Natur, die neben dem nur singulär erscheinenden Rot in der Kleidung der Frau in dem Tape eine Rolle spielen, sind gerade auch hier wieder die Farben Schwarz und Weiß in der Gestaltung dieses Tapes von großer Bedeutung. So finden sich in verschiedenen der Bildsequenzen Motive, die von hellem Licht und dunklen Schatten geprägt sind. Auffällig ist in diesem Zusammenhang auch die Wandlung der Schriftgestaltung im Vorspann mit weißen Buchstaben auf schwarzem Grund zu einem weißen Grund mit schwarzer Schrift im Abspann.

Zudem fällt in der Analyse eine unterschiedliche Konnotation von rechter und linker Bildhälfte auf, die in den Aufnahmen sichtbar ist. Auf der linken Seite sind in vielen der Einstellungen Pflanzen, rechts häufig Felsformationen und Steine zu sehen. Besonders anschaulich wird diese Teilung oder auch unterschiedliche Gewichtung bei der zweigeteilten Einstellung, die nach knapp zwei Minuten zu sehen ist. Hier zeigt die linke Seite etwas Dunkles, Unkonkretes, während die rechte Bildhälfte der Einstellung durch eine Architekturaufnahme geprägt ist, die helle, klare, geordnete Formen zeigt. Vergleicht man diese unterschiedlichen Gestaltungen der beiden Bildhälften innerhalb verschiedener Bildsequenzen des Tapes mit dem Prinzip des Yin und Yang in der chinesischen Philosophie mit der männlichen rechten Seite und dem weiblichen Links, so scheint dieses hier zeichenhaft in die Gestaltung der verschiedenen Bildsequenzen eingeflossen zu sein.

Interessant ist auch die Wahl der Perspektiven in dem bis ins Kleinste komponierten Tape. Während zu Beginn die Einstellungen in Frontalperspektive aufgenommen sind, tauchen zunehmend - besonders in Verbindung mit dem steinernen Fußboden - Schrägansichten auf. Auch die zunächst in Frontalperspektive ins 
Bild gesetzte Grabanlage erscheint schließlich in einer neuen Ansicht in dem Tape: Sie ist in leichter Obersicht von schräg links aufgenommen. Ohne dass es einen sichtbaren Schwenk in den Aufnahmen gegeben hätte, hat sich die Sicht durch Zooms und Überblendungen im Verlauf der elf Minuten von einer starren Frontalsicht zu einer spielerischeren Schrägansicht gewandelt. Und weiter noch wandert die Kameraaufnahme schließlich nach rechts unten aus dem Bild. Dies ist die Richtung, in die Gegenwart', denn das Geschaute, wandert in Leserichtung auf den Betrachtenden zu.

Blickt man schließlich auf die Verbindung von Form und Inhalt in dem Tape fällt Folgendes ins Auge. Das Wort „Samadhi“, das im Titel des Tapes auftaucht, bedeutet „erleuchtet“. Ganz wortwörtlich umgesetzt, löst sich die Aufnahme des Grabes des als erleuchtet angesehenen Verstorbenen schließlich in weißem Licht auf, wird damit bildhaft „erleuchtet“. Und diese Erleuchtung erfolgt bei genau elfminütiger Dauer des Tapes. Wenn man davon ausgeht, das in der Zahlenmystik die Elf eine so genannte Meisterzahl ist und zudem diese Zahl im Werk Ulrike Rosenbachs ja bereits ganz konkret in der „Eleven-Aktion“"773 im Zusammenhang mit der Lehre Oshos begegnete, erscheint dies kein Zufall mehr zu sein, sondern vielmehr in symbolischer Weise den vermittelten Inhalt zu verdichten. Verbunden ist mit dem langsamen Verblassen des Bildes auch ein sanftes Ausklingen der begleitenden Musik.

Die aufgeführten Beispiele zeigen, dass die einzelnen Elemente in dem Tape mit Symbolbedeutungen aufgeladen sind. Begegnen doch hier Motive wieder, die aus den vorangegangenen Werken der Künstlerin bekannt sind: Bäume, Pflanzen, Steine, Spiegel, Wasser oder auch eine rot gekleidete Frau. Auch hier sind in abstrahierter Form Motive aus dem Werk Rosenbachs eingefügt. Spannend ist dabei, dass eine Zuordnung von bestimmten Elementen zu bestimmten Bildseiten im ersten Teil des Tapes zu erkennen ist. Zudem scheinen die einzelnen Motive mit Symbolik aufgeladen. Der Spiegel oder auch die Spiegelung ist mit dem Thema der Reflektion verknüpft, das Fließen des Wassers mit Kommunikation und Verwandlung, ${ }^{, 74}$ die Pflanzen und der Baum sind mit Erkenntnis und Weisheit verknüpft, das Licht schließlich ganz konkret mit Erleuchtung. Hinzu kommt, dass diese verdichtete, symbolische Bildsprache in diesem Tape auch die Zeitebene einzuschließen scheint. Betrachtet man den zeitlichen Ablauf, zeigt sich, dass die erste Minute durch das Bild des ,einen“ Meisters geprägt ist, in der zweiten Minute, mit der Zwei als Symbol der Entzweiung, taucht die in zwei konträre Bildmotive aufgeteilte Einstellung auf. In der dritten Minute des Tapes, die Drei steht für das weibliche Prinzip, wie auch die Vollkommenheit, finden sich häufig die Lichtkreise als Motiv. Bis diese Lichtkreise dann in der vierten Minute von der rot

773 Vgl. Kap. IV.4.2.

774 Hier liegt eine Assoziation nahe zu dem Zitat „Das einzig Bleibende ist die Veränderung“, das sich als Motto auch auf der Homepage der Künstlerin findet. 
gekleideten, fegenden Frau abgelöst werden. Die Vier gilt auch als Zahl der Ganzheit, wie auch des Irdischen. Genau bei fünf Minuten Dauer des Tapes öffnet sich der Horizont und gibt den Blick von der Spiegelung nach Innen ins Außen frei. Die Fünf ist auch die Zahl der Vereinigung, der Hochzeit. Und mit exakt elf Minuten - die Elf gilt als Meisterzahl und steht für Vollendung - enden die Aufnahmen und es bleibt nur der weiße Grund auf dem Bildschirm.

So erzählt dieses auf den ersten Blick willkürliche Motive durch Blenden und auch Zooms zu einem Bildfluss verbindende Band in abstrahierter Form eine die vorgefundenen Gegebenheiten nutzende symbolträchtige Geschichte über Innenund Außenansichten, Wege der Erkenntnis und Erleuchtung. Das Tape verdichtet Teile der Lehre Oshos in poetischen Bildern und bildet ein würdigendes Andenken.

\section{V.3. Performances und Medieninstallationen}

Wie schon angedeutet, verlagert sich der Schwerpunkt des künstlerischen Wirkens von Ulrike Rosenbach in diesem Jahrzehnt auf die Medieninstallation. Doch bleiben auch weiterhin einige Live-Performances integraler Bestandteil ihres Schaffens. Neben einigen Wiederaufnahmen bereits aufgeführter Aktionen - so zeigte die Künstlerin die Phönix-Performance erneut in Toronto wie auch in Barcelona entwickelt die Künstlerin alte Themenkomplexe weiter sowie neue hinzu. Zu einem neuen Themenkreis zählen die „Sonnenspiele“, die sich Anfang des Jahrzehntes inhaltlich mit verschiedenen Sonnenkulten auseinandersetzen. ${ }^{775}$

Als zentral ist für dieses Jahrzehnt der dreiteilige Performance-Zyklus „Über die Engel“" anzusehen, der zwischen 1995 und 1997 nacheinander und in Variationen an drei unterschiedlichen Orten aufgeführt wurde: Zunächst im Bollwerk in Fribourg in der Schweiz, dann in der Kreuzkirche in Hannover und schließlich in der Nienburger Martinskirche. Dieser Werkkomplex, zu dem außerdem die Rauminstallation „Last Call für Engel“ ebenfalls zu zählen ist, wird in einem eigenen Kapitel genauer untersucht werden. ${ }^{776}$

Demgegenüber greift der „Tower of Babylon“, eine Medienperformance, die im Rahmen des Babylon-Festivals im Jahr 1993 in Helsinki gezeigt wurde, das alte Thema der Ambivalenz der Frau im neuen Gewand wieder auf. ${ }^{777}$ Das Thema

775 Auch die Installation „Erdenfahrt“ aus dem Jahr 1991 ist in diesen Themenkreis einzuordnen.

776 Kap. V.4.

777 Die Performance fand im Rahmen des Videofestivals in Helsinki statt. (Heute: Media Art Festival des Museums für zeitgenössische Kunst Kiasma) und diese Aktion wird auch mit „Ishtar von Babylon" benannt. Ishtar ist die sumerisch-babylonische Göttin der Liebe und Fruchtbarkeit: ,akkad. Venussterngöttin, Göttin des Abend- und Morgensterns, dem sie mit dem Doppelcharakter ihres lichten und dunklen Antlitzes entspricht: als Himmels- und Unterweltsgöttin, als Mutter- und Liebesgöttin, als Göttin der Fruchtbarkeit und der Wollust. (...) in Babylon stand das ihr zu Ehren errichtete Ishtartor. Dargestellt wird sie oft als Kriegsgöttin mit Hörnermütze, Köchern auf dem Rücken und Pfeil und Bogen in den Händen. (...) Der Stern ist ihr Emblem, 
Frau stand auch nochmal im Zentrum in der Medienperformance „Das Demeterprojekt", in dem das performative künstlerische Wirken Ulrike Rosenbachs seinen vorläufigen Abschluss fand. Die Künstlerin zeigte diese Medienperformance zusammen mit zweien ihrer Studentinnen am 24. September 2000 im Deutschen Pavillion auf der Expo 2000 in Hannover. ${ }^{778}$ Die weitere Performance in diesem Rahmen mit dem Titel „Clan communication“ gehört in die Reihe der UlrikeRosenbach-Projekte und war ein Gruppenprojekt von Studierenden der Künstlerin, bei dem Robert Hutter, Walli Höfinger, Ingrid Mwangi, Klaudia Stoll sowie Jaqueline Wachall mitwirkten und als Special Guest auch Ulrike Rosenbach selbst auftrat. In diesem Gemeinschaftswerk wurde der Aspekt der Kommunikation auf unterschiedlichsten Ebenen in den Mittelpunkt gesetzt.
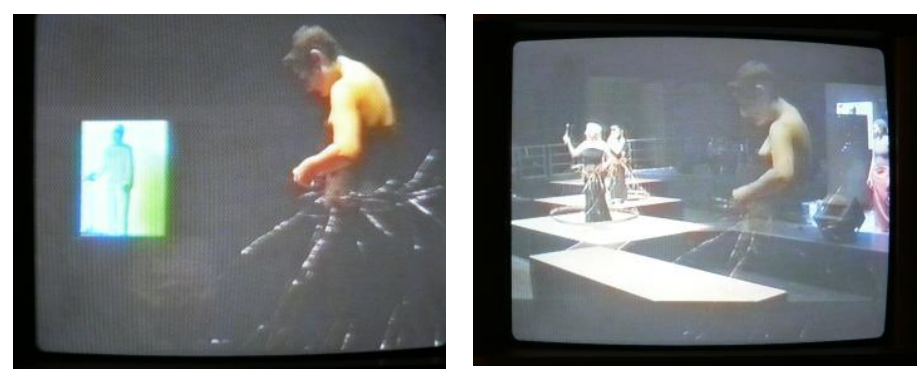

Abb. 231-232: Clan Communication, 2000, 2 Videostills

Bei den während der 1990er Jahren entstandenen Installationen Ulrike Rosenbachs, die sich alle mit Grundfragen des menschlichen Seins beschäftigen, lassen sich ebenfalls verschiedene inhaltliche Gruppen bilden: Die Natur, Wachstum, auch nochmal das Bild der Frau, aber auch der Tod, Engel oder auch die Rolle der

und ihre hl. Zahl ist fünfzehn.“ (Bellinger 1989, S. 220) Damit verkörpert Ischtar auch wieder beide Seiten in sich, das Lebensspende wie auch das Dunkle. Das so genannte Ishtar-Tor, eines der ehemaligen Stadttore von Babylon, das von Nebukadnezar II errichtet wurde (605-562 v.Chr.), steht heute im Vorderasiatischen Museum, das sich im Pergamonmuseum in Berlin befindet.

778 Auch für dieses Werk tauchen wieder unterschiedliche Titel auf. Es gab zwei Medienperformances bei der Expo 2000, an denen die Künstlerin mitwirkte. Eine unter dem Titel „Milleniumsfrauen“. In dieser wurde eine gleichnamige Videobildcollage (Farbe, 20 min.) aus Porträts bekannter und unbekannter weiblicher Persönlichkeiten verschiedener Jahrhunderte, verbunden mit Ausschnitten aus vorangegangen Werken der Künstlerin auf Großleinwand projiziert. Vor diesem Hintergrund führte Ulrike Rosenbach zusammen mit Ingrid Mwangi und Walli Höfinger dann die Performance auf. Die weitere Performance „Clan communication“ gehört zu den Ulrike-Rosenbach-Projekten und war ein Gruppenprojekt von Studierenden der Künstlerin, bei dem Robert Hutter, Walli Höfinger, Ingrid Mwangi, Klaudia Stoll, Jaqueline Wachall mitwirkten und als Special Guest auch Ulrike Rosenbach. Hier wurde der Aspekt der Kommunikation in den Mittelpunkt gesetzt, und die Akteure brachten ihre Körper mit großer Dynamik zum Sprechen. 
Kinder werden hier in den Blick genommen. Diese installativen Werke der ersten Hälfte des Jahrzehntes werden zudem durch drei - sich abwechselnde oder auch in den einzelnen Installationen gemeinsam erscheinende - Motive gekennzeichnet: Das Herz, der Baum und das Licht.

In der im Jahr 1990 entstandenen Rauminstallation „Herzpendel“ tritt das Herz erstmals in Objektform auf. Die bronzenen Herzobjekte bestimmen dann auch die Installation der „Schlacht der Bäume“. In einer weiteren Gruppe steht das Bild des Baumes im Mittelpunkt, wie in „Isabel im Wald“, dem „Requiem für eine Eiche“ oder der „Schlacht der Bäume“. .779 Das dritte Motiv ist das Licht, das auch in den performativen „Sonnenspielen“ aus dem Jahr 1990 im Mittelpunkt steht, zeigt und in weiteren installativen Arbeiten, wie den „Erdenlichtern - Dimlights“, dem „Australischen Altar“ wie auch dem „Requiem für eine Eiche“, weitere Bearbeitung findet.

In der riesigen Videowand „Das Bild der Frau in der Nachkriegszeit“, die 1994 als Auftragsarbeit für das Haus der Geschichte in Bonn entstand, wendet sich die Künstlerin einem Ausschnitt der deutschen Geschichte zu, collagiert dokumentarische Aufnahmen mit eigenen Werken. Zu der großformatigen Videoinstallation entstand noch eine kleinere Fassung mit gleichem Titel. In dieser kleineren Arbeit, die zudem den Untertitel trägt „Die Illusion der Wirklichkeit“ transzendiert die Künstlerin sehr deutlich die historische Dimension, wie noch genauer ausgeführt wird. ${ }^{780}$ In ähnlich Form greift auch die im Jahr 1995 entstandene Videoinstallation „Das Eiserne Zeitalter“ das „Konzert im Gewaltakt“ aus dem Jahr 1979 wieder auf, das durch den neuen Titel in eine ahistorische, mythologische Dimension gehoben wird. 781

Die weiteren Arbeiten ab der Mitte dieses Jahrzehntes stehen im Zeichen der Spiritualität. Sei es im „Hildegard Walk“, der Bezug nimmt auf die Äbtissin Hildegard von Bingen, oder dem Performancezyklus „Über die Engel“, in den die Medieninstallation „Last Call für Engel“ inhaltlich und formal eingebettet ist. ${ }^{782}$ Eine neue verdichtete - quasi existenzielle - Dimension nimmt die Auseinandersetzung mit dem menschlichen Sein in der im Jahr 1995 präsentierten Videoinstallation „Über den Tod““ an ${ }^{783}$, bevor schließlich mit der im Jahr 1997 gezeigten Raumin-

779 Die Videoinstallationen „Isabel im Wald“ entstand 1990, das „Requiem für eine Eiche“ wurde 1990 sowie 1993 gezeigt. Hinzu kommt der Werkkomplex um die „Schlacht der Bäume“, der zwischen 1991 und 1996 entstanden ist.

780 Kap. V.3.5.

781 Kap. V.3.7.

782 Zu dem „Engelzyklus“ sind neben den drei zwischen 1995 und 1997 aufgeführten Performances noch folgende Werke zu rechnen: Die Videoinstallation „Last Call für Engel“ aus dem Jahr 1996, die Computeranimation „Erzengel“ von 1998, sowie das Videotape „Über die Engel")

783 Die gleichnamige Videoinstallation ist aus dem Jahr 1995 und das Videotape von 1996. 
stallation „Im Palast der Neugeborenen“ der Kreislauf des Lebens symbolisch von Neuem beginnen kann. ${ }^{784}$

Nach diesem kurzen Überblick der Arbeiten der 1990er Jahre sollen nun die einzelnen Werke beziehungsweise Werkkomplexe in chronologischer Reihenfolge kaleidoskopartig aus unterschiedlichen Perspektiven näher betrachtet und außerdem im zeitgenössischen kunsthistorischen Kontext wie auch im Werk der Künstlerin verortet werden.

\section{V.3.1. Werkuntersuchung: Herapendel - Energetisches Phänomen}

Das Herz ist das zentrale Organ, bildet die symbolische Mitte des Menschen. Es gilt im menschlichen Körper als der Sitz des Gefühls wie auch der Seele, des Mutes, des Bewusstseins und der Vernunft. ${ }^{75}$ Und der Romantiker Casper David Friedrich formulierte: „Die einzig wahre Quelle der Kunst ist unser Herz.“786

An roten Wollfäden, ummantelt von weißen Seidenpapierbahnen hingen in Ulrike Rosenbachs Raum-Klang-Installation „Herzpendel - Energetisches Phänomen“ (1990) jeweils von den Mitten der neun Gewölbesegmente der Erdgeschosshalle des historischen Pellerhauses in Nürnberg kleine herzförmige Bronzen als Lot über weißen, aufgehäuften Kreidekegeln. ${ }^{787}$ Insgesamt neun dieser Herzobjekte, in die eine kreisrunde Vertiefung eingedrückt ist, deren Mitte poliert ist und hell schimmert, füllen den geometrisch gegliederten Raum der Renaissancearchitektur. Die Künstlerin beschrieb die Atmosphäre der Installation selbst:

„Ein schwebender Ton schwingt durch die Halle, sich drehend, von Windtönen begleitet, simuliert der Ton Bewegung, Pendeln zu den Herapendeln, die still über den weißen Kreisen bängen. " 788

784 Im Jahr 1997 kam noch das Videotape „Über die Kinder“ hinzu.

785 Vgl. Lurker 1991, S. 298

786 http://www.onlinekunst.de/zitate/kunstzitate.html (Zugriff 3.8.2011)

787 Das Pellerhaus wurde 1602/07 erbaut, im Zweiten Weltkrieg teilweise zerstört, doch die Erdgeschosshalle, in der die Installation aufgebaut war, war nicht zerstört gewesen.

788 Rosenbach in: Kat. Saarbrücken 1990, o.S. 

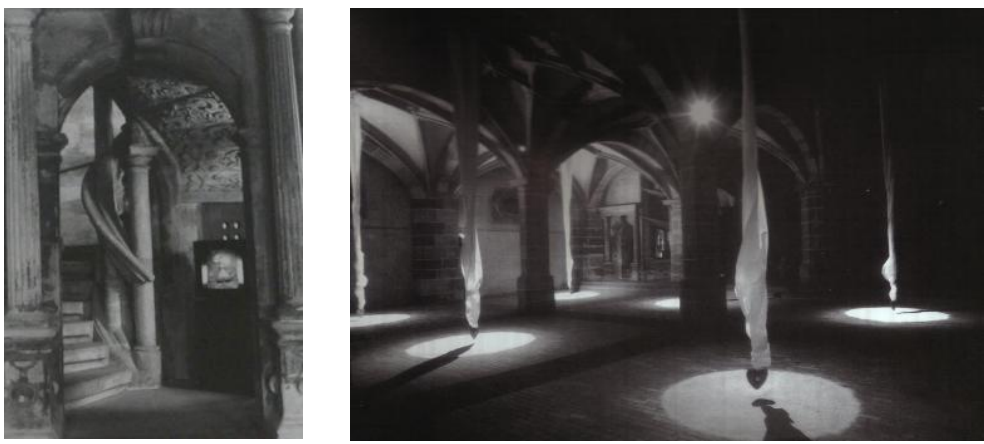

Abb. 233-234: Herppendel. 1989, Installation

Die Künstlerin weist damit auf den Spannungsaspekt, der sich in dieser Raumklanginstallation zwischen der Bild- und Tonebene ergibt. Während die neun bronzenen Herzen unbewegt im Raum schweben, suggeriert der Ton, der die Halle mit seinem Klang erfüllt, Energiefluss und damit Bewegung und erläutert selbstredend den Titel dieser meditativen Arbeit: „Herzpendel - Energetisches Phänomen“.

In einer Treppennische war die Rauminstallation um einen Videomonitor ergänzt. Die elektronischen Bilder zeigten neben der Spindeltreppe, die in das nächste Stockwerk des Gebäudes führte, eine sich ununterbrochen im Derwischtanz um die eigene Achse drehende Tänzerin, durchwoben von sphärischen Bildern kosmischer Nebel. Begleitet wurden die Bilder von einem Funksignal, das mit den Klängen im Raum harmonisch kommunizierte. Wenn sich bisher im Werk Rosenbachs zeigte, dass die audiovisuellen Videosequenzen, der in die Environments integrierten Monitore innere Prozesse zum Ausdruck bringen, so bestätigt sich diese Funktion auch in dieser Installation. Die innere Balance und Harmonie, die in vorangegangenen performativen Arbeiten der Künstlerin im körperlichen Tanz um die eigene Achse erspürt wurde, ein Tanz, der in diesem Werk auch im Videobild zu sehen ist, ist in dieser Rauminstallation nun zusätzlich in eine räumlich-plastische Ausdrucksweise übersetzt worden. ${ }^{789}$ Die innere Erfahrung manifestiert sich im plastischen Objekt des bronzenen Herzens, das am roten Faden hängend, unbewegt in die Tiefe lotet, doch den steinernen, mit Kreide bedeckten Boden nicht berührt.

Wenn das Motiv des Herzens im Werk der Künstlerin bisher in Form seiner elektronischen Abbildung begegnete - transparent und rot gefärbt erschien es in „Anal'haq“ oder als Handzeichen in den Schmelzprozessen, zudem begleiteten pochende Herztöne weitere Performances - ist das Motiv jetzt greifbar im Raum.

789 Vgl. Kap. IV.4.3. 
Verstärkt wird der Eindruck von Balance und Ausgeglichenheit durch eine Prägung auf jedem einzelnen Herz: In jedes Bronzeobjekt findet sich von einer Seite ein an einer Stelle geöffneter Kreis graviert. Diese Gravur erinnert zum einen an ein Schloss, in das ein Schlüssel gesteckt werden kann, zum anderen lässt sich die Prägung auch als Taozeichen lesen, dessen Mitte - im Unterschied zur restlichen stumpfen Oberfläche des Herzobjektes - poliert ist und damit im Licht verlockend schimmert. Blickt man zudem auf die unterschiedlichen Symbole der Alchemisten für die Metalle, so zeigt sich, dass eines der Zeichen für Gold eine groBe Ähnlichkeit aufweist. In dem alchemistischen Zeichen umfängt anstelle eines Herzens ein geschlossener Kreis den geöffneten Kreis im Zentrum. ${ }^{790}$

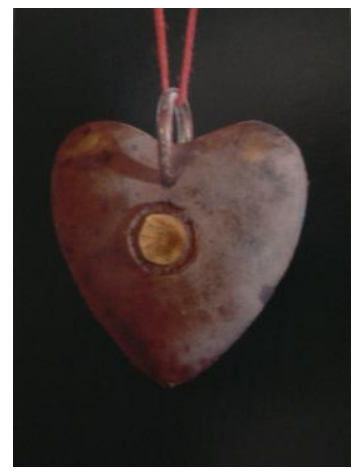

Abb. 235: Herapendel, 1989

Das Herz manifestiert sich in dieser Rauminstallation als dreidimensionales Objekt, das in sich noch eine weitere Symbolik trägt, indem es das Taozeichen mit dem Hinweis auf das Gold der Alchemisten verbindet. An diesem Objekt zeigt sich damit ein weiteres Mal eine Nähe zur Gedankenwelt der Alchemie wie auch des Taoismus, und zugleich eine Synthese unterschiedlicher Elemente innerhalb der Formensprache, in ähnlicher Weise, wie es bei dem Kopffüßler in dem Eulenspiegeltape der Fall war. ${ }^{791}$ Auch wenn das Herzobjekt selbst nicht aus Gold ist, verweist doch das Symbol auf dieses Metall, das in der Alchemie dem Element Sonne zugeordnet ist. Zudem ist in der Alchemie das menschliche Herz mit dem Element des Feuers verbunden. Auch hier zeigt sich wieder eine Entsprechung von Form und Inhalt. Musste doch die Bronze zum Guss der Herzobjekte zunächst im Feuer erhitzt werden. So zeigt sich in diesem einzelnen Objekt ganz konkret eine weitere Verdichtung der Formensprache, in genau der Art und Wei-

790 Außerdem ist das Metall des Goldes in der Alchemie mit der Sonne verbunden, im Sinne der Lehre, dass die Metalle auf Erden das Gegenbild der makrokosmischen Planeten seien. So wird Silber mit dem Mond, Eisen mit dem Mars und Quecksilber mit dem Merkur in Verbindung gebracht. (Vgl. Schwarz-Winklhofer 1994, S. 144)

791 Vgl. Kap. IV.5.2.3 d) 
se, die für die Künstlerin bisher charakteristisch war. Ulrike Rosenbach findet so ihre eigene Herzchiffre. Es ist ein bronzenes Herz, zu dem als Schlüssel das TaoZeichen passt. In Rosenbachs Werk wird dieses Herz, das an einem roten Faden in die Tiefe lotet, zum Ausdruck der gefundenen inneren Balance und Harmonie.

\section{V.3.2. Werkuntersuchung: Requiem für eine Eiche}

In der Videoinstallation „Requiem für eine Eiche“ fließen zwei Themenkomplexe zusammen: das der Seelenmesse, das bereits zehn Jahre zuvor im Werk Rosenbachs Thema war und das des Baumes, das mehrfach begegnete. ${ }^{792}$ Hier nun ist der Baum konkret als Eiche benannt. Renate Petzinger beschrieb und interpretierte diese Installation wie folgt:

„Auf drei aus Stahl geschweißten Gerüsten sind etwas über Augenhöhe drei Monitore angebracht. Auf den Videobändern dieser Monitore sehen wir flackernde Fackeln im Dunkel eines nicht näher zu definierenden Hintergrundes. Unter den Monitoren wächst Wurzelwerk der Eiche. Monitor und Wurzelwerk werden betrachtet durch große Seidenpapierbahnen hindurch, die Ulrike Rosenbach mit Öl getränkt und damit auf den Mattscheiben zur Haftung gebracht hat. Durch das so erzeugte Schattenspiel erscheinen die Wurzeln optisch vergrößert, als geheimnisvolles Gewirr, das sich mal zu einem Türbogen, mal zu einer chinesischen Tuschezeichnung zu formen scheint. Die Eiche, der diese Wurzeln entstammen, ist wie kein anderer Baum Symbol für Kraft, Mut, Schutz, Beständigkeit, aber auch für den Menschen selber. In der chinesischen Tradition ist sie die männliche Stärke, auch die schwache Seite der Kraft, die sich widersetzt und im Sturme bricht, im Gegensatz zur Kraft der Schwäche in der Weide, die sich im Sturme biegt und am Leben bleibt. Die Fackel, mit der Ulrike Rosenbach das Requiem für diese Eiche zelebriert, erhellt die Dunkelheit, wie bei einer nächtlichen Wanderung durch den Wald, ihre Flamme lodert heftig auf und scheint dann aus dem Monitor auf das Seidenpapier überzuspringen, ja sogar aus dem Monitor selbst herauszuschlagen. Die von ihr verströmte Kraft und Energie ist lebendig, es gibt Phasen auf dem Video, da wirkt sie wie der riesige schwingende Rock der Tänzerin, dann wieder brennt sie ruhig vor sich hin, bis der Wind sich ihrer erneut bemächtigt. “793

\footnotetext{
792 Vgl. Kap. III.5.7. und IV.5.1.4

793 Petzinger in: Kat. Dortmund 1995, o.S.; auch in: Kat. Arolsen 1997, S. 7
} 


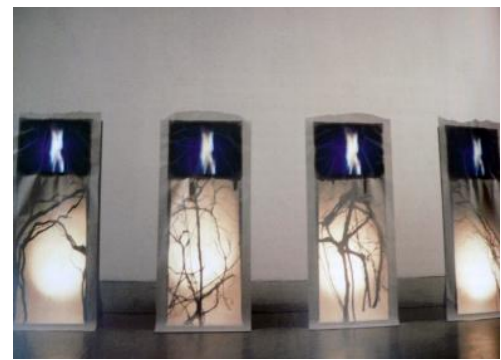

Abb. 236: Requiem für eine Eiche, 1990, Installation

Abweichend von der Beschreibung finden sich Variationen dieses Werkes bestehend aus entweder vier Monitoren oder auch gebildet aus sechs Geräteeinheiten.794 Während Renate Petzinger von Wurzelwerk spricht, heißt es in einer anderen Beschreibung des Werkes, dass es Äste seien. Die gebogenen Formen legen nahe, dass in dieser Arbeit Wurzelwerk verwendet wurde, doch lässt sich das aus den Abbildungen nicht mit Sicherheit klären. In jedem Fall sind es wohl Teile einer Eiche, die im ursprünglichen Kontext des Baumes entweder in den Boden oder in den Himmel ragten.

In verschiedenen Kulturen zeigt sich zudem eine Umkehrung der Wurzel-Ast Symbolik. So sind zum Beispiel in den indischen Veden die Wurzeln des Weltenbaumes als im Himmel verankert beschrieben. Auch im Islam weisen die Wurzeln des Baumes des Glückes nach oben. Dante Aligheri vergleicht in seiner „Divina Comedia“ die Gesamtheit der himmlischen Sphäre mit der Krone eines Baumes, dessen Wurzeln nach oben gerichtet sind. ${ }^{795}$ Lurker schreibt weiter:

„,Verwurzelt sein', ,Wurzeln schlagen; das bedeutet, mit den Quellgründen des Lebens in Verbindung steben."796

In all diesen Vorstellungen ist der tragende Grund nicht irdischer sondern in himmlischer Art aufgefasst. Dieser Auffassung scheint sich auch die Künstlerin in ihrem Werk anzuschließen. Wird doch das Wurzel- (oder Ast-)werk in ihrer Installation von weißem Licht umgeben. ${ }^{797}$ Durch diese Lichtumflutung zeichnen sich die organischen Formen als wechselhaftes Schattenspiel hinter den ölgetränkten Papierbahn ab und fordern die Fantasie des Betrachtenden heraus. Das Motiv des Schattens begegnete bereits bei dem Umriss der geflügelten Frau, der schwarzen

\footnotetext{
794 Die einzelnen Einheiten der Installation bestehen aus 62 × $190 \times 50 \mathrm{~cm}$ großen Stahlgestellen, in deren oberem Bereich jeweils ein Monitor steht. Die Installation wurde am 20.11.1999 in der Sendung Kulturspiegel auf SWR3-Saarland in einem Beitrag vorgestellt.

795 Lurker 1991, S. 840

796 Lurker 1991, S. $840 f$

797 Auf der Zeichenebene liegen hier Assoziationen nahe, etwa wie „durch Weisheit genährt“.
} 
Silhouette auf der Wand. In dieser Installation nun sind durch Licht gezeichnete Schatten zu sehen, die durch das helle Papier sichtbar werden.

Wie schon im Zenkocher sind auch in dieser Videoinstallation mehrere Monitore nebeneinander gestellt. Während die jeweils unteren Teile mit dem Schattenspiel Variationen aufweisen, ist auf den drei beziehungsweise vier Bildschirmen synchron die selbe Videosequenz zu sehen. Die Darstellung ist mit der Wiederholung nicht nur vervielfacht und intensiviert, sondern es bietet sich auch an, einen Blick auf die Zahlensymbolik zu werfen: Während die Zahl drei als Überwindung der Entzweiung als Ausdruck der Vollkommenheit zu deuten ist, gilt die Zahl vier als Symbol der Ganzheit und Körperlichkeit. ${ }^{798}$ Das elektronische Bild bildet eine brennende Fackel umgeben von Dunkelheit ab. Die Fackel, die symbolisch als reinigend und Dämonen abwehrend gilt, steht zudem für geistige Erleuchtung, Erkenntnis wie auch Freiheit. ${ }^{799}$ Anders als im „Requiem für Mütter“, der Aktion, bei der real Feuer entzündet wurde ${ }^{800}$, ist bei dieser stillen Seelenmesse das energetisch übertragene Abbild gewählt, das sich zudem gefangen im eisernen Gerüst präsentiert:

„Die symbolische Darstellung der Elemente Luft (Farbe Blau), Feuer (Flamme) und Erde (Baum - innerhalb der deutschen Geistestradition die Eiche) präsentiert sich in dieser Arbeit als nahezu meditativ anmutende Reflexion des Werdens und Vergehens: Der „Blitz des Geistes" erhellt die Erde und macht somit Leben, aber auch Erkenntnis möglich. Doch dieses harmonische Bild mag trügen, schließlich heißt die Arbeit REQUIEM für eine Eiche und Kann somit auch andersherum gelesen werden: Die Herrschaft des Geistes über die Natur hat zur Destruktion derselben geführt. Doch, um bei der kathartischen Kraft des Feuers zu bleiben und in Anlehnung an Ulrike Rosenbachs Aussage, dass ihre Kunst immer auch der Heilung dienen solle, zielt diese Arbeit letztendlich auf die Versöhnung des Menschen mit der Natur." 801

Dieser philosophischen Interpretation soll ein weiterer Gedanken hinzugefügt werden, der den Fokus auf die Bedeutung des Baumes der Eiche wirft. Die Eiche wurde wegen der Härte ihres Holzes und ihrem stattlichen Wuchs bereits in der Antike zum Symbol der Stärke und Männlichkeit. Vor diesem Hintergrund ist auch das Verleihen von Eichenlaub an den Sieger von Turnierwettkämpfen zu verstehen.

Zudem hat die Eiche in deutschen Geistestradition eine besondere Stellung. In Deutschland wurde die Eiche im 18. Jahrhundert zum Symbol für Heldentum -

\footnotetext{
798 Vgl. Lurker 1991, S. $151 \mathrm{f}$ und S. 795

799 Lurker 1991, S.192

800 Vgl. Kap. IV.3.

801 http//:www.235media.com (Zugriff 3.5.2008); die 235 MEDIA GmbH (Gesellschaft für Medientechnologie und Kunst $\mathrm{mbH}$ ) bietet eine Sammlung von Künstlervideos und anderen Sparten an.
} 
und der Begriff „deutsche Eiche“ geprägt. Zudem wurden Eichenbäume zum Gedächtnis der in den Kriegen Gefallenen gepflanzt. ${ }^{802}$ Damit ergibt sich eine spezielle Konnotation im Kontext eines Werkes einer Künstlerin, die in Deutschland lebt und wirkt. ${ }^{803}$ So findet sich in dieser Arbeit nicht nur, wie oben zitiert, eine ins Spirituelle gehöhte Versöhnung des Menschen mit der Natur, sondern viel konkreter und in der charakteristischen buchstäblichen Sprache der Künstlerin - ist ein Beleuchten der Wurzeln der eigenen Identität ins Bild gesetzt. Das „Requiem für eine Eiche“ ist ein Erinnerungsbild auf ein leidbringendes Heldentum - für Rosenbachs individuelle Chiffren stimmig im eisernen also männlichen - Korsett präsentiert. 804

Dieser - einerseits buchstäblich und gleichzeitig symbolisch-chiffrierte - Inhalt wird jedoch in der Arbeit transzendiert. Der Grund - auch im figurativen Sinne wird in der Installation erhellt und zeichnet sich als assoziatives Schattenspiel ab. Doch die Fackel der Erkenntnis bringt im Videobild versöhnlich Licht ins Dunkel, so dass sich die läuternde Kraft des Feuers, mit der ebenfalls kathartischen Kraft des Baumes verbindet, denn der Baum wird in Rosenbachs Werk mehr und mehr zum Sinnbild des Lebens und übernimmt eine Schutzfunktion.

\section{V.3.3. Werkuntersuchung: Die Scblacht der Bäume}

In einem weiteren Werk finden sich das Motiv des Baumes und das Motiv des Herzens verbunden. Für die Raum-Klang-Installation „Die Schlacht der Bäume“ diente im Mai 1996 ein ehemaliger Bunker auf dem Gelände der amerikanischen Militäranlage Ober-Olmer Wald bei Mainz, die sich zu diesem Zeitpunkt im Prozess der Umwandlung in ein zivil genutztes Gelände befand, als Ausstellungsort. Die schon bekannten bronzenen Herzpendel hingen hier an roten Bändern von der Decke des Betonkubus, der ehemals zur Lagerung von Munition und militärischen Gütern gedient hatte. Wie schon bei der Installation „Herzpendel“ hingen auch hier die Herzobjekte wieder bis kurz über den Boden herab, und es lagen kegelförmige Haufen darunter, hier allerdings aus Salz aufgeschüttet. Die Herzpendel bildeten einen Gang zur großformatigen Videoprojektion an der Stirnwand des Bunkerraumes. Das hier zu sehende Video zeigte eine Collage aus Aufnahmen von Bäumen und Blattwerk. Zwischen den Ästen der verlangsamt wiedergegebe-

802 Lurker 1991, S. 163

803 Bezugnehmend auf den historischen Kontext können auch beim Bild brennender Fackeln zusätzliche Aspekte mitschwingen und zum Beispiel beim Rezipienten Assoziationen an die Fackelzüge der Nationalsozialisten hervorrufen.

804 So mag es auch kein Zufall sein, dass die Stahlgestelle eine Höhe von 1,90 Meter haben, was ungefähr der Körpergröße eines (großen) Mannes entspricht. Es zeichnete sich bereits eine Bedeutung der Materialien an. So scheint es auch bei den Metallen zu sein. Eisen taucht im Werk mit männlichen Konnotationen auf, vgl. dazu genauer dann Kap. V.3.7. 
nen Bildsequenzen schwebte ein rotierendes rotes Herz und der eindringliche Rhythmus eines klopfenden Herzens füllte den Raum.
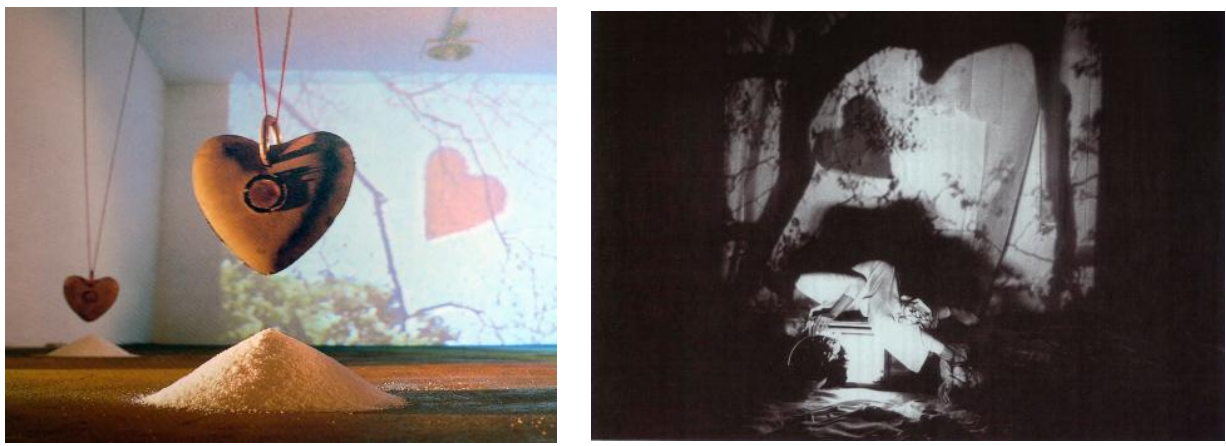

Abb. 237-238: Die Schlacht der Bäume, 1991, Installation und Der Wind meiner Träume, 1986, Aktionsfoto

Die Videobilder der Bildprojektion erinnern an Teile der Bildsequenzen, die in der „Der Wind meiner Träume-Aktion“ zu sehen waren. ${ }^{805}$ Und auch der Text aus der keltischen Ballade „Cad Gaddeau“ - der Schlacht der Bäume, die diesem Werk Rosenbachs zudem den Namen gab - taucht wieder auf. So nimmt die Künstlerin in dieser Installation die bereits Mitte der 1980er Jahre angerissene Thematik knapp ein Jahrzehnt später konkret wieder auf und entwickelt sie weiter.

Die keltische Ballade „Le Cad Gaddeau“ wird dem Barden Taliesin, der im 6. Jahrhundert gelebt haben soll, zugeschrieben und handelt von einem Freiheitskampf. Dieser wird ausgelöst durch einen Diebstahl. Dabei bedeutet die Übersetzung des Titels auch ,die glückliche Schlacht“. In dieser Schlacht, so erzählt der keltische Mythos weiter, verzauberte Amatheons Bruder Gwydion Bäume in Krieger, damit diese kämpften:

„Hervorgegangen aus einer in Gärung befindlichen Welt, ruft diese Dichtung die Vision der Genese der Bewegung im Schmelztigel der „Menschwerdung" vor Augen. Mensch, Bäume, mit Bewußtsein ausgestattete Objekte nebmen mit gleichen Chancen an einem Ringen um Freiheit teil, das zugleich, und mit größerem Recht, ein seit Urzeiten geführter, nicht endender Kampf eines sich in Bewegung befindenden Universums ist. "806

Zudem weist der Interpret Lengyel auf die hohe Musikalität und das kunstvolle poetische System dieser Dichtung, dessen Ziel es sei, die Interdependenz aller Dinge ins Bewusstsein zu rufen:

\footnotetext{
805 Vgl. Kap. IV.4.2.

806 Lengyel 1976, S. 205
} 
„Die vollendete Metrik sollte dem Inhalt der Dichtung entsprechen und etwas von der unausweichlichen Schicksalsgemeinschaft aller Erscheinungen übermitteln. Die Eigenart der keltischen Verse ist aus dem inneren Drang geboren, schon allein in der Form den allem Bestehenden innewohnenden Impetus zum Ausdruck zu bringen. Diese Tatsache muß besonders betont werden: Unabhängig davon, ob man den Text versteht, vermitteln schon allein Klang und Rhythmus den sakralen Inhalt der keltischen Dichtung, der lautet: Rhythmus ist zengende schöpferische Kraft. Soll diese Übereinstimmung von Inhalt und Form erreicht werden, müssen die Worte die unaufhörliche Genese schildern, während dem Rhythmus deren Mechanik innewohnt, die das Geheimnis des Weltalls ist. Damit haben wir den Schlüssel zum Gewölbe des keltischen Geistes, der schon damals die organische Einheit aller Erscheinungen erkannt hatte. Feblerlos und in der Bildwabl absolut sicher entstebt ein Gewebe, das die mannigfaltigen Geschöpfe durch die Mannigfaltigkeit ibrer Wechselbeziehungen miteinander verbindet: Ein und dieselbe Substanz. zeigt sich in einer endlosen Zabl von Facetten. Materie und Geist sind nicht exakt gegeneinander abgegrenzt. (...) Weder Metaphern noch poetische Technik sind Leistungen des fabrenden Sängers; TALIESIN war an diesem Proze $\beta$ nicht beteiligt. Sie sind Leistungen einer Religion voller subtiler Symbole, bei der jede Aussage ein Argument zugunsten der Seelenwanderung ist, - der W anderung einer Seele, die auf allen ihr zugänglichen Wegen dem endgültigen Tod zu entgehen trachtet. Sie ist eine Folge von Zuständen, jenseits der sich, ewig unvollendet, Dauer ohne Anfang und Ende erstreck.t." 807

In der Ballade „Cad Gaddeau“ stehen in der deutschen Übersetzung die Worte, die auch Rosenbach in ihrer Arbeit zitiert:
„Die Wipfel der Buche
Haben jüngst erst geknospt,
Sind verändert und verjüngt
Aus Ibrem welken Zustand.
Wenn die Buche gedeibt
Trotz Bannfluch und Litaneien,
Die Eichenwipfel sich verflechten,
Dann ist Hoffnung für die Bäume... "ros

Ranke-Graves kommentiert, dass diese Zeilen, die inmitten des Cad Gaddeau stehen, offenbar eine Einleitung sind zu dem eigentlichen Bericht der Schlacht. ${ }^{809}$ In einem gleichnamigen Tape hat die Künstlerin den Text dieser Ballade - einer Lithurgie gleich - unter die Videobilder gelegt. Dabei hat sie jedoch die Aufnahmen von Blättern, Bäumen und Kronen hier - wie schon in der Anal'haq-Aktion in

\footnotetext{
807 Lengyel 1976, S. $205 \mathrm{f}$

808 Ranke-Graves 1981, S. 41

809 Ranke-Graves 1981, S. 41
} 
schnellen Schnittfolgen mit Kampf- und Kriegsszenen überblendet und damit eine andere Interpretation der Schlacht der Bäume ins Videobild gesetzt.

Anders wird der keltische Mythos in der Installation verarbeitet. Hier - an einem Ort, der zuvor Kriegsmaterial beherbergte - wird eine Atmosphäre von Harmonie und Ruhe geschaffen. Die bekannten Herzobjekte - die eine harmonisierte Balance des Menschen ins Bild setzen - schweben frei im mit pochendem Klang gefüllten Raum, sowie das rote Herz im Videobild auf der Bunkerwand frei zwischen dem in den Himmel greifenden Astwerk schwebt.

Die Videobilder von Bäumen in der Projektion auf der Bunkerwand zeigen verlangsamt wiedergegeben - Äste, die in den Himmel greifen. Dazwischen rotiert ein rotes Herz. Das lichtdurchlässige, bewegte Herz im Videobild korrespondiert mit den lotenden Herzobjekten im Raum. Die Bilder der Prinzipien der Natur und damit des menschlichen Seins werden auf der Tonebene mit rhythmischem Herzschlag unterlegt, dem Rhythmus, der die zeugende schöpferische Kraft bildet.

„Konversion heißt die langsame Umwandlung als Prozess. Die Umnutzung eines Konversionsgeländes ist nicht nur eine landschaftliche und städtebauliche Veränderung. Sie geht einher mit der Veränderung im Kopf: Der Prozess des Umdenkens und Umwandelns lange zementierter Gesinnung, die Hoffnung auf eine veränderte Geisteshaltung. Auch im ökologischen Sinn. Wie steht es mit der ursprünglich vorhandenen und dann auseinander gefallenen Einheit von Mensch und Natur? Kann der Versuch Konversion mit Kunst und Ökologie in Einklang zu bringen ein Schritt in diese Richtung sein?

Die verlangsamten Aufnahmen von Bäumen, das flirrende rote Herz. und die eindringlichen Herafrequenztöne der Arbeit von Ulrike Rosenbach stellen die Frage der Korrespondenz. zwischen Mensch und Natur. Es scheint, als ob die Zeichen für Leben und Reinheit im Raum den Bunker entwaffnen. Video - ursprünglich eine Erfindung zur Kontrolle für Rüstung, Raketen und für die Weltraumfahrt - kommt als Antipode auf ein Militärgelände zurück. " 810

Auch die Künstlerin beschrieb diese Installation als Reflexion der Beziehung des Menschen zu seiner Natur und hob hervor:

„Die Synonymität von Mensch und Baum ist der Schlüssel zur Erkenntnis der wirklichen Bedeutung von der Verbindung des Menschen und seiner natürlichen Umgebung. "

Der Baum als Alter Ego des Menschen wird hier direkt benannt. Eine Parallele, die sich auf philosophischer Ebene nachvollziehen lässt. Der Baum hat Wurzeln in der Erde, die ihn tränken und nähren. Doch ein Baum zieht seine Nahrung auch über seine Blätter aus der Luft im chemischen Prozess der Fotosynthese. Diese doppelte Grundlage des Wachstums lässt sich abstrahiert auch auf den Menschen übertragen. Hat der Mensch doch biologische, wie auch historische Wurzeln. Aber er hat auch einen neugierigen Geist, der mit seinen Gedanken in

810 Bertram in: Kat. Mainz 1996, o.S.

811 Rosenbach in: Kat. Mainz 1996, o.S. 
den Himmel greifen kann und sich mit geistiger Nahrung versorgt. In ähnlicher Weise erläuterte die Künstlerin ihre Baumsymbolik, die sich in ihrem künstlerischen Werk erstmals bereits in Arbeiten der späten 1970er Jahre manifestierte:

„Das habe ich auch schon in den "Judofrauen" gemacht. Diesen Riesenbaum, den ich da zeichne und der gleichreitig wie zwei Flügel aussiebt. Das ist eine ganz alchemistische Auffassung diese Symmetrie, die der Baum hat. Der Stamm ist der menschliche Körper. Sehr bäufig sogar mit Wirbelsäule, Nervensträngen wie in der Abbildung, die ich auch in „Ewa und Adam" benutzt habe. Und die beiden Seiten des Baumes, die Kronen, sind wie zwei Flïgel. Dies kommt ganz, bäufig in alchemistischen Darstellungen vor. Es entspricht auch der anthroposophischen Darstellung des Baumes als Grundsituation für den Menschen, der von den Wurzeln bis zur Krone wächst. Und die Obren, also die Aufnahmefäbigkeit oder auch Kommunikationsfäbigkeit ist die Krone. Hier bindet sich im Alchemistischen eine sehr lange Untersuchung von Zeichen und Bedeutungen dran, ähnlich wie man es bei Lévi-Strauß untersuchen könnte, oder in der ganzen Ethnologie. Das habe ich als Vorïbung absolviert. Man darf nicht glauben, dass diese Sachen unbewußt entstanden sind. Vor ibnen liegt eine lange und bewußte Recherche über diese Formen, die ich da zeichne. Ich zeichne sie dann jedoch nicht intellektuell, sondern aus diesen Ausfübrungen versuche ich umzusetzen und zu erforschen, ob dies auch wirklich stimmt. "'812

Im Werk Ulrike Rosenbachs sind Bäume durchweg mit positiver Bedeutung besetzt, entsprechend einer Baumsymbolik, die Bäume als heilig, als Erscheinungsort des Numinosen oder auch als Lebensbaum auffasst. Wenn der Zisterziensermönch Bernhard von Clairvaux (1091-1153) vor rund 900 Jahren sagte „Die Bäume werden euch Dinge lehren, die dir kein Mensch sagen wird“ dann scheint Ulrike Rosenbach diese Lehre erkannt zu haben und in ihrem Werk weiter zu vermitteln. So tritt der Baum als grundlegendes Lebensprinzip in dieser Arbeit in Erscheinung und setzt in der Verschmelzung mit dem Herzen gebundene Energie frei.

\section{V.3.4. Werkuntersuchung: Isabel im Wald}

Dagegen zeigt die Videoinstallation „Isabel im Wald“ aus dem Jahr 1990, die ebenfalls auf die Baumsymbolik Bezug nahm, noch eine andere Konnotation. Dabei finden sich zwei unterschiedliche Fassungen dieser kleinen Installation. In der einen steht ein Monitor im Mittelpunkt eines Kreises, der aus braunen Rindenstücken angeordnet ist. In der anderen steht der Monitor in einem Kreis aus Salz, umsäumt von einem dünnen Streifen aus kleinen braunen Rindenstücken.

Das Video, das auf dem Bildschirm zu sehen ist, ist in beiden Varianten das gleiche. Es zeigt verschiedene generierte Bildsequenzen, die zudem ineinander überblendet sind. Zum einen erscheint in schwarzweiß die Nahaufnahme eines

812 Rosenbach im Interview 2001, Kap. VII.1. 
Mädchengesichtes im Profil. Gesichtszüge und Augenpartie wirken abstrahiert und das graue Gesicht zerfließt in einer dunkelgrauen Spur, die sich vertikal durch die Augenpartie zieht. Eine weitere Tapesequenz zeigt anstelle des hellen Gesichtes einen runden, weißen Fleck. Hinter diesem schwingt ein Mädchen auf einer Schaukel hin und her. Das Schaukelmotiv begegnete ja schon im Werk der Künstlerin, wie zum Beispiel in der "Salto-Mortale-Aktion“ .813 Dort war die Bedeutung ambivalent, einerseits war das Schaukeln beruhigendes Sinnbild des Lebenslaufes, andererseits schwangen in diesem Bildmotiv des Schwingens auch in früheren Arbeiten Gefangenschaft, wie auch sexuelle Konnotationen mit.
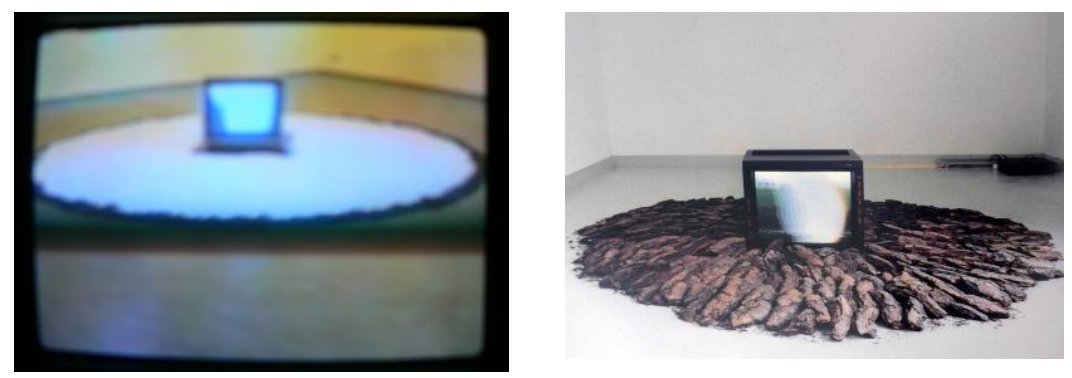

Abb. 239-240: Isabell im Wald, 1990, Installationen

Zudem sind in dem Tape der „Isabel-im-Wald-Installation“ in einer Totalen Bäume und der Saum eines Waldstückes im Hintergrund zu erkennen. Das stete Klingen eines Gonges begleitet die schwarzweißen Bilder des Bandes, die mit vielen Graunuancen durchsetzt sind. Der Name „Isabel“, der im Titel auftaucht, ist eine Mischung aus gleich drei Sprachursprüngen: hebräisch, italienisch und spanisch. Übersetzt bedeutet er „die Unberührte“.

Ein schaukelndes Mädchen, ein Wald, ein weißer Fleck auf dem Bildschirm, ein anscheinend weinendes, schemenhaftes Gesicht fügen sich in dem Tape zu einem fließenden Eindruck zusammen und der Monitor, der diese Sequenzen zeigt, steht in einer der beiden Varianten inmitten eines weißen Salzkreises. Bei der zweiten Variante umrahmen Rindenstücke den bildtragenden Monitor.

Liest man den weißen Salzkreis als sprichwörtlichen „weißen Fleck“ - der sich ja auch in dem Tape verbildlicht findet - dann steht er für eine Leerstelle, einen Verlust, oder auch eine Erinnerungs- oder Wissenslücke, die in dieser Installation mit dem bildtragenden Monitor gefüllt ist. ${ }^{814}$ Auch die Monitorbilder zeigen diese Spur eines Traumas. Hinter dieser bildlichen Fehlstelle schwingt in der Bildsequenz in einer Halbtotalen vor dem Hintergrund eines Waldrandes ein Mädchen auf einer Schaukel hin und her. Doch es bleibt unberührt, geschützt vom Wald.

\footnotetext{
813 Vgl. Kap. III.5.6.

814 In der Installationsvariante mit den rahmenden Rindenstücken wird der Monitor selbst zum Baumstamm.
} 
Dies findet sich auch in der zweiten Variante, der Installation mit den rahmenden Rindenstücken, die den Monitor zeichenhaft in einen Baumstamm verwandeln. So zeigt sich in dieser Arbeit eine Wandlung von der Bedrohung zur Versöhnung.

\section{V.3.5.Das Bild der Fran in der Nachkriegszeit}

Das Motiv einer Frau auf einer Schaukel durchzieht ebenfalls die Videoinstallation, die die Künstlerin für das Haus der Geschichte der Bundesrepublik Deutschland in Bonn inszenierte. Insgesamt 96 Monitore - sechs Geräte senkrecht mal 16 Monitore waagerecht - fügen sich in der Halle des Museums zu einer großformatigen Videowand zusammen. Für diese monumentale Monitorfläche entwickelte die Künstlerin zur Eröffnung des Hauses im Jahr 1994 als Auftragsarbeit eine Videocollage unter dem Titel „Das Bild der Frau in der Nachkriegszeit“. Ausschnitte aus Wochenschauen und Ufa-Spielfilmen sowie Illustrationen aus Zeitschriften aus den 1940er und 1950er Jahren werden hier mit frühen Videoarbeiten der Künstlerin kontrastiert und öffnen den Blick auf die Vermittlung des Zeitgeschehens nach dem Krieg in medialen Bildern. Ulrike Rosenbach selbst hat ihre Arbeit wie folgt charakterisiert:

„Dokumentaraufnahmen aus der direkten Nachkriegszeit mit Frauen, die am Wiederaufbau beteiligt sind: auf dem Bau, in der Fabrik, in der Forschung. Im Wechsel dazu ist das Bild der Frau aus der deutschen Traumfabrik UFA zu sehen: im Abendkleid, als jugendliche Ballettratte oder Schönheitskönigin. Eine weibliche Person mit gelbem Schal schwingt auf einer Schaukel in regelmäßigem Rhythmus durch das Bild des zerstörten Nachkriegsdeutschland.“"815

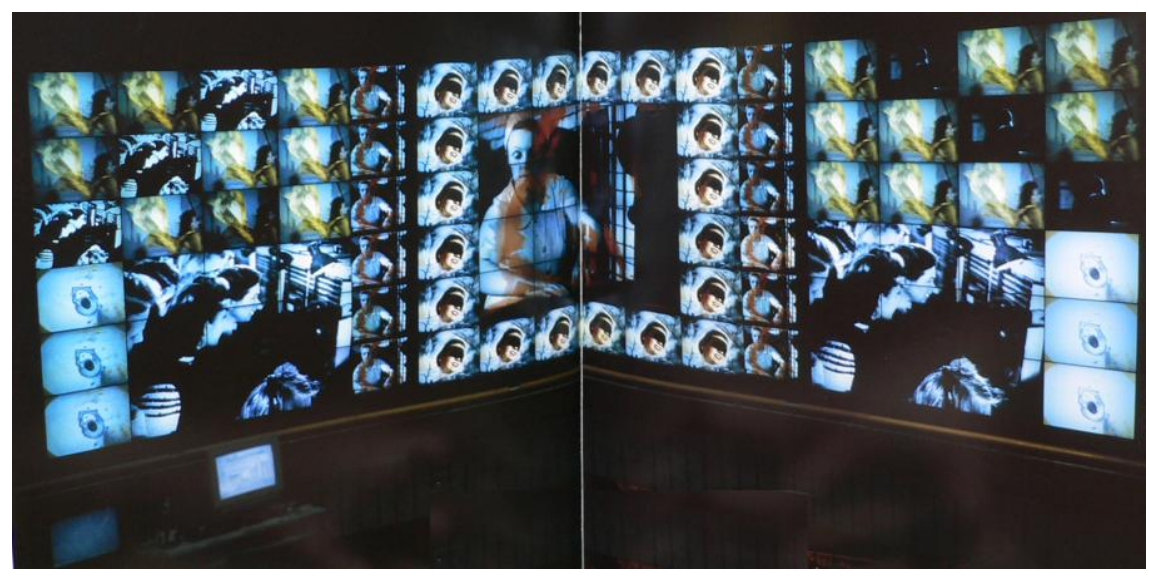

Abb. 241: Das Bild der Frau in der Nachkeriegszeit, 1994, Installation

815 Rosenbach in: http//:www.235media.com (Zugriff 3.5.2008) 
Dokumentaraufnahmen, Fernsehbilder und eigene künstlerische Videotapes sind in der Komposition zu einem Kaleidoskop aus medial vermittelten Frauenbildern zusammengefügt. Das in der Arbeit verwendete Found footage ist digital überarbeitet worden. Farben sind in den historischen Dokumentaraufzeichnungen verändert oder auch neu hinzugefügt worden. Zum Teil sind unterschiedliche Aufnahmen elektronisch zu mehrschichtigen Bildern zusammengefügt worden und das gesamte Material wurde zu einer bewegten, vielmotivigen Bilderflut komponiert.

Die monumentale Videofläche ist in unterschiedliche Felder zergliedert, die ihre Gestalt variieren und im Ablauf des Loops meist symmetrisch angeordnet sind. Innerhalb der einzelnen Themenfelder, die jeweils aus mehreren Monitoren gebildet werden, wiederholt entweder jeder der Bildschirme die gleiche Sequenz, oder aber das jeweilige Motiv ist auf mehrere Monitore aufgesplittet gezeigt. Die vielmotivische Komposition befindet sich in steter Veränderung. Begleitet wird die visuelle Collage durch ein Potpourri aus populären Melodien der 1940er und 1950er Jahre. „Ich weiß, es wird einmal ein Wunder geschehen“ erklingt zum Beispiel zwischendurch Zarah Leanders Stimme aus den Lautsprechern. ${ }^{816}$

Die gezeigten Bildsequenzen auf der Monitorwand wechseln sich ab und tauschen untereinander die Plätze. Zwischendurch werden an unterschiedlichen Stellen auch Wochenschautitel eingeblendet: „Frauen im Beruf“ oder „Frauen helfen Bauern" prangt dann Weiß auf Schwarz auf den Bildschirmen.

Wenn Lydia Haustein herausgestellt hatte, dass Ulrike Rosenbach in ihrem künstlerischen Schaffen der 1970er Jahre erstmals die durch die Nazizeit geprägten strengen Rollenbilder der Nachkriegsgeneration in Deutschland auflöste und die Entstehungsbedingungen von Weiblichkeitsklischees überdachte, ${ }^{817}$ dann zeigt sich dieser reflektierende Ansatz aus der zeitlichen Distanz in dieser Videoinstallation verdichtet in der Gegenüberstellung eigener Werke der Künstlerin mit Frauenbildern, die in den 1940er und 1950er Jahren medial, durch Kino oder später das Fernsehen, vermittelt wurden.

Eine mehrfach publizierte Fotografie greift eine konkrete Komposition aus der Bilderflut aus Rosenbachs „Bild der Frau in der Nachkriegszeit“ heraus: Die Mitte aus vier mal vier Monitoren bildet eine Schwarzweißaufnahme - durchzogen mit orangener Färbung. Die Darstellung zeigt eine Wäscherin in weißer Tracht. Gerahmt wird dieses monumentale Porträt einer Frau bei der Arbeit, durch das strahlende Gesicht einer Schauspielerin in Nahaufnahme, das sich auf den dieses Bildmotiv umgebenden 20 Monitoren jeweils wiederholt. Die Augen der hier in 20facher Wiederholung lächelnden Schönheit sind verschattet und ihr rosiges, makelloses Gesicht ist vor einen schwarzweißen Hintergrund montiert, in dem ein Baum ohne Blätter und eine Trümmerlandschaft erkennbar werden. Flankiert

816 Dieser Schlager des Jahres 1942 stammt aus dem UFA-Film „Die große Liebe“.

817 Haustein 2003, S.78 
wird diese das Zentrum der Videowand ausfüllende Bildkombination rechts und links durch eine senkrechte Reihe von Bildschirmen, die das Mittelmotiv der Wäscherin nun auf jedem einzelnen Monitor in klein wieder aufnimmt. Die beiden rechts und links angrenzenden Flächen aus vier mal sechs Monitoren sind wiederum in drei unterschiedlich bebilderte Felder aufgeteilt. Während die obere Hälfte der Bildschirme das Motiv einer Frau mit gelbem Schal, die auf einer Schaukel inmitten der kriegszerstörten Trümmerlandschaft schwingt, wiederholt, das zudem durch drei - eine Treppe bildende - Monitorbilder einer Arbeitssituation durchbrochen wird, unterteilt sich die untere Hälfte in zwei unterschiedlich große Felder: Drei mal drei Monitore bilden jeweils gemeinsam die Schwarzweißaufnahme einer tatkräftigen Frauengruppe. Nach außen wird diese Darstellung flankiert von der dreimal untereinander wiederholten Sequenz aus einem der frühen Werke der Künstlerin: dem „Tanz für eine Frau“. Frieling kommentierte weiter:

„Wie sehr diese Wunschdimension nach Lust und Glamour auch Teil der besonderen bundesdeutschen Nachkriegswirklichkeit war, führt Ulrike Rosenbach eindringlich in ihrer deutlich späteren Außeninstallation im Bonner Haus der Geschichte vor, der permanenten Panoramawand ,Das Bild der Frau in der Nachkriegszeit' (1994). Inmitten einer Fülle von Archivmaterial, vorallem zu den Trümmerfrauen und ihrer tragenden Rolle in der Bundesrepublik, tauchen wieder die Bilder der sich drehenden Ballerina aus Tanz für eine Frau auf. Das Drehmoment ist eben auch eine positive Antriebskraft, nicht notwendig nur ein Klischee von Weiblichkeit." "818

„Das Bild der Frau in der Nachkriegszeit“ ist in Rosenbachs künstlerischer Auslegung zersplittert und vielfach überlagert. Das großformatige Bild der fürsorglichen und zupackenden Frau in der herausgegriffenen Momentaufnahme digital nachgefärbt mit Orangetönen - der Farbe der Wandlung - wird zum Beispiel umrahmt vom in zahlreicher Wiederholung erscheinenden Bild der Diva, dass die Trümmer im Nachkriegsdeutschland ganz buchstäblich überstrahlt und lebendig färbt. Der Bruch zwischen rauher Wirklichkeit im Alltag der Nachkriegsjahre und schönem Schein im zeitgenössischen Film wird am Rand der Komposition aus anderem Blickwinkel wieder aufgenommen: Hier ist wiederum eine großformatige, auf mehrere Monitore verteilte Dokumentaraufnahme einer fröhlichen und engagierten Frauengruppe aus den späten 1940er und frühen 1950er Jahren neben die dreifach wiederholte Bildsequenz des „Tanzes für eine Frau“ aus den 1970er Jahren gestellt, die eine Frau zeigt,die alleine tanzt, bis sie schließlich erschöpft zusammenbricht. ${ }^{819}$ Versteht man, wie zuvor herausgearbeitet, die Videobilder in den Werken der Künstlerin als Ausdrucksweisen innerer Verfasstheiten, dann wird in diesem Ausschnitt aus der Videowand die äußere Fröhlichkeit einer im Wieder- 
aufbau engagierten Frauengruppe mit der inneren Einsamkeit einer Frau kontrastiert.
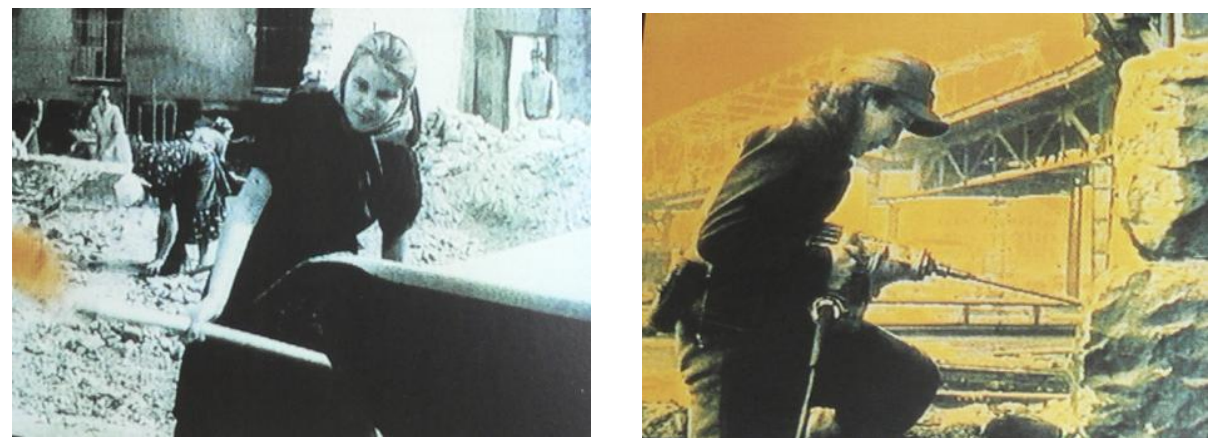

Abb. 242-243: Das Bild der Fran in der Nachkeriegszeit, 1994, 2 Videostills

Zu der aus der Distanz erfolgten historischen Darstellung, die diese Arbeit prägt und die je nach Perspektive als eine Darstellung des Wiederaufbaus, des Wirtschaftswunders oder auch der neuerlichen Verfestigung tradierter Gesellschaftsbilder gelesen werden kann, kommt noch ein weiterer verfremdender Aspekt hinzu, den die Künstlerin soitwohl durch die digitale Überarbeitung des historische Found footage als auch der Integration ihrer eigenen Arbeiten in das Werk erzeugt. Denn alle gezeigten Dokumentarbilder sind digital überarbeitet, wodurch das bereits in der Vergangenheit medial Vermittelte in neuer Form erscheint, die einen Bezug zur heutigen visuellen Ästhetik herstellt. Die überkommene historische Aufnahme bildet die Grundlage, die digital verfremdet, verwandelt und damit ästhetisiert wird.

Der Begriff „Nachkriegszeit“, mit dem dies Werk betitelt ist, wurde in Deutschland zur umgangssprachlichen Zeitbestimmung für die Jahre nach dem Ende des Zweiten Weltkriegs, wobei die Dauer dieses Abschnittes als unterschiedlich lang bestimmt wird. ${ }^{820}$ So wird dazu die so genannte „Schlechte Zeit“ mit Hunger, Kälte und Trümmerlandschaft gerechnet, die bis zur Währungsreform ím Jahr 1948 dauerte. Aber auch die dann beginnende Phase des Wiederaufbaus und des damit verknüpften Wirtschaftswunders in den 1950er Jahren werden noch unter diesem Begriff summiert. ${ }^{821}$ Die Künstlerin bezieht sich in ihrem Werk im Kern auf die direkte Nachkriegszeit, in dem sie überwiegend mit dokumentarischem Material aus der Zeit nach dem Ende des Zweiten Weltkriegs arbeitet.

820 Allgemein wird die Zeit nach einem Krieg als Nachkriegszeit bezeichnet. Obwohl es in der deutschen Geschichte mehrere markante Nachkriegszeiten gab, hat sich das Wort „Nachkrieg“ eigens nur nach 1945 eingebürgert.

821 Einige Historiker datieren das Ende der Nachkriegszeit in Europa auch erst mit dem Zusammenbruch der kommunistischen Staaten Osteuropas 1989 und der damit verbundenen Auflösung des Warschauer Paktes. 
Doch stellt sie diesen relativ kurzen Zeitraum in einen größeren historischen Zusammenhang, in dem sie exemplarisch Beispiele ihrer eigenen Kunstwerke aus den 1970er Jahren einfügt, die weibliche Klischees in Frage stellen.

Zusammenfassend lässt sich feststellen, dass sich das Ins-Bild-Setzen der Kontinuität und Brüche auf der formalen Ebene auch im Inhaltlichen widerspiegelt. Es wird ein zersplittertes, flutendes Bild gezeigt, das sich der vollständigen Erfassung entzieht. Dabei steht die großformatige Videoinstallation „Bild der Frau in der Nachkriegszeit" singulär im Werk der Künstlerin, nicht nur wegen der räumlichen Größe, sondern auch wegen des konkreten Blicks auf die deutsche Geschichte, der dieses Werk charakterisiert. In dieser Videocollage wird das Historische in etwas Gegenwärtiges verwandelt, das einnehmend und in dominanter Form gegenwärtig ist. Die Komposition visualisiert ein mediales Kaleidoskop mit seinen Brüchen und setzt den Dokumenten vermeintlich heiler - durch Tatkraft gekennzeichneter - äußerer Welten ein verstummtes inneres Bild entgegen.

Damit formuliert die Künstlerin in ihrer opulenten Komposition Mitte der 1990er bereits das, was inzwischen bei den noch lebenden Zeitzeugen des Zweiten Weltkriegs wieder an die Oberfläche kommt und benennbar wird: die Brüche, traumata, inneren Abspaltungen. So hat Ulrike Rosenbach weniger ein historisches als vielmehr psychisches Bild der Frau - allgemeiner auch der Gesellschaft - von heute entworfen und damit implizit die Nachkriegszeit als bis heute anhaltend bezeichnet.

Eine kleinere Fassung dieser monumentalen Installation macht „das Bild der Frau“ überschaubarer, die Klaus Honnef wie folgt interpretiert ${ }^{822}$ :

„,Die Illusion der Wirklichkeit' lautet der signifikante Untertitel der Arbeit, die vertraute Rollenbilder der Frau mit anderen mischt, anthropologisch gestütəte und soziologisch definierte, das Bild der Mutter, der Arbeiterin, der Wäscherin und der Trümmerfrau, der Diva und der Mauerin. Vielfältig überlagerte Bilder unterschiedlicher Schichten des Wirklichen, der Empirie und des Traums. Kraft der Digitalisierung der filmischen Bilder, ergibt sich eine ungeheuer imaginative Weltsicht, mit bisweilen halluzinatorischen Qualitäten, vor allem durch die sorgfältigen Bearbeitungsfolgen hervorgerufen, die den für die Kunst notwendigen, ästhetischen Überschuß produzieren, der sich nicht in bloßer Kommunikation erschöpft. Bilder dieser großen Medien-Künstlerin verhalten sich querläufig zu den konsumtiven der Massenmedien. Sie verstören, sie fixieren die Brüche und Widersprüche, öffnen den geschlossenen Kreis der selbst-referentiellen Medienwelt, da sie die Maßstäbe der gewöhnlichen Wabrnehmung verrücken. ${ }^{\text {g823 }}$

822 „Das Bild der Frau in der Nachkriegszeit - Die Illusion der Wirklichkeit“ ebenfalls 1994. Diese Videoinstallation mit fünf Monitoren in unterschiedlicher Größe, auf Stahlgestellen in unterschiedlichen Höhen aufgebaut, stellt die unterschiedlichen historischen Sequenzen gegenüber. 


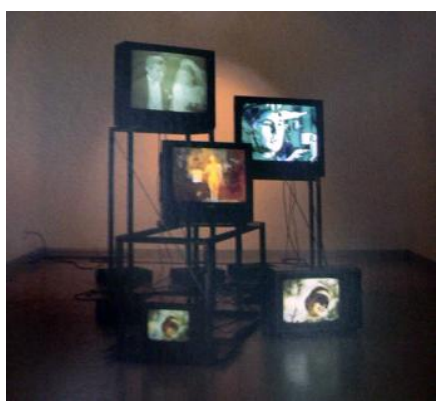

Abb. 244: Das Bild der Frau in der Nachkriegszeit, 1994, kleinere Fassung

Dabei fällt ins Auge, dass die Künstlerin bei der Auswahl der Bilder in diesen beiden Installationen auf bestimmte Motive zurückgreift, die in ihrem Werk bereits begegnet sind. Dazu ist das Schwingen auf der Schaukel zu zählen, das seit dem „Salto mortale“ zum Bestandteil ihrer persönlichen Ikonographie zu zählen ist. Auch bleiben Überblendungen von Bildern ein weiterhin genutztes charakteristisches Mittel, um ein Überlagern von unterschiedlichen Wirklichkeitsebenen zu visualisieren. Gerade durch den Einsatz von Überlagerungen und elektronischem Verweben transzendiert die Künstlerin ihre Aussage auf eine spirituelle Ebene entsprechend eines buddhistischen Verständnisses, das die äußere Dingwelt als Scheinwelt - die so genannte Mayawelt - versteht. 824

„Die Lebenserscheinungen kann man vergleichen mit einem Traum, einem Phantom, einer $W$ asserblase, einem Schatten, dem glitzernden Tau oder dem Blitz - und so sollten sie auch betrachtet werden. "'825

Das vermeintliche Abbild der Wirklichkeit wird zur Illusion, wird abgelöst von anderen Visionen und löst sich selbst wieder auf im steten Bilderfluss. Die Wirklichkeit selbst wird so zur flüchtigen Illusion, die „Illusion der Wirklichkeit“ ins Bild gesetzt und die konkrete Historie überwunden. Bei dieser transformierenden Form der Auffassung der Historie, die in diesem Auftragswerk greifbar wird, liegt der Umkehrschluss nahe, dass auch in den vorangegangenen - bisher überwiegend in einer spirituellen Perspektive aufgefassten - Arbeiten der Künstlerin der historische Kern implizit vorhanden ist.

824 Nach buddhistischem Verständnis ist das Universum durch und durch belebt. In ihm gibt es weder inerten Stoff noch bloße Mechanismen. Der Buddhist ist sich seiner unendlichen Vielzahl von Existenzmöglichkeiten bewusst und einer ebenso unbegrenzten Anzahl von Wirklichkeitsaspekten. (Zum Aspekt „Illusion der Wirklichkeit“ vgl. Jung in: Tibetanisches Totenbuch 1987, S. 41-56)

825 Aus dem Prajnaparamita-Sutra in: Tibetanisches Totenbuch 1987, S. 76 


\section{V.3.6. Werkuntersuchung: Hildegard Walk}

Die überlebensgroße Videoprojektion „Hildegard Walk“ bildet - ins Hochformat gedreht - eine Waldlandschaft in der Halbtotalen ab. Zwischen den säumenden Bäumen schreitet aus dem Zentrum der in Zentralperspektive aufgenommenen Einstellung auf einem Weg eine in schwarzweiße Schwesterntracht gekleidete Nonne hervor. Diese hat in sich ruhend, die Handflächen gegeneinander gelegt. Die Schreitende nähert sich der Kamera - und damit anscheinend dem Betrachtenden - bis auf wenige Meter. Dann verharrt sie kurzzeitig, bevor der Loop wieder von vorne beginnt und die Frau erneut aus der Tiefe des Bildes hervortritt. Die mit einer Standkamera und fester Einstellungsgröße aufgezeichnete Videoaufnahme ist digital überarbeitet worden. Dabei sind Teile der Darstellung in ein tiefes Blau getaucht worden: zum Beispiel der intensiv leuchtende Hintergrund, aus dem die Nonne hervortritt, wie auch die weißen Manschetten ihrer Tracht, die an einigen Stellen in Blau schimmern.
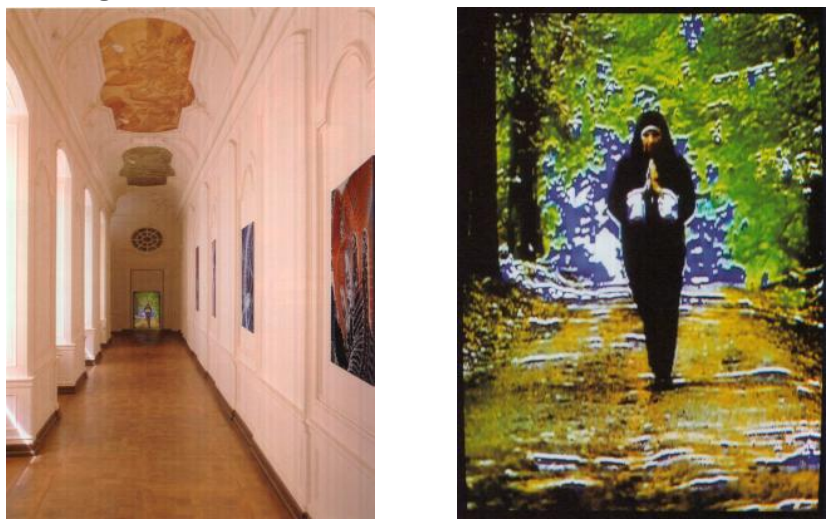

Abb. 245-246: Hildegard Walk, 1994, Installation

Der Titel der Arbeit verweist auf eine historische Persönlichkeit. Die Benedektineräbtissin Hildegard von Bingen (1098-1179) lebte im 12. Jahrhundert.

„Es ist Hildegard von Bingen, eine Frau, die ibre wenigen berübmten männlichen Zeitgenossen im Gedächtnis der Menschen weit überfluigelt, mag die Prophetin samt ibrem Werk als Konsequenz. ibrer Popularisierung auch von Legenden und Klischees verzerrt sein. ${ }^{\circ} 826$

In dieser Weise würdigt Barbara Beuys in ihrer Biographie die rege Ordensfrau, die sich zu ihrer Zeit für eine Reform des kirchlichen Lebens einsetzte. Und die Biografin fasst weiter über die Mystikerin zusammen:

826 Beuys 2001, S. 12 
„Sie verkörpert den Aufbruch in eine neue Zeit. Von Zeitgenossen als „göttliches Orakel" verehrt und von Königen und Fürsten um Rat und Trost gebeten, vertritt Hildegard von Bingen eine optimistische Theologie, in der Mann und Fran die gleiche Würde zukommt. Mit ibren Worten und Taten betritt sie Neuland, ehrgeizig und risikobereit, aber auch klug und pragmatisch, wenn es gilt eigene Auffassungen und Interessen durchzusetzen. "827

Bereits im Kindesalter hatte die spätere Mystikerin ihre ersten Visionen. Im Jahr 1141 begann sie unter dem Eindruck visionärer Erlebnisse ihre Schau von der Schöpfung und Erlösung der Welt unter dem Titel „Scivias“ - übersetzt „Wisse die Wege" - niederzuschreiben. Bereits in dieser Erstschrift ihrer mystischen Glaubenslehre begegnet nicht nur das symbolisch vertiefte Welt- und Menschenbild, sondern auch ein politisches Dokument, in welchem die Ordensfrau ihre Zeitkritik vorträgt. Ergänzt wird dieses Werk unter anderem um eine visionäre Trilogie. Diese umfasst die „Liber scivias“, die zwischen 1141 und 1151 entstand. Dies ist eine Glaubenslehre, die Kosmologie und Anthropologie auf das Engste mit der Theologie verknüpft. Zudem gehört zu Hildegard von Bingens Werk die „Liber vitae meritorum“, zwischen 1158 und 1163 verfasst. Dies sind Wechselgespräche der Tugenden und Laster. In der die Trilogie abschließenden „Liber divinorum operum“ - dem „Buch der Gotteswerke“ - geschrieben zwischen 1163 bis 1173 , entfaltet die Seherin in zehn Visionen eine kosmologisch unterbaute Heilsgeschichte von der Genesis bis zur Apokalypse, wobei die Deutung des Johannesprologs die verbindliche Sicht auf den Menschen als die leibhaftige Mitte des Kosmos zeigt. Die Einheit der darin umrissenen Schöpfungsordnung umfaßt die Welt der Engel ebenso wie die Pflanzen und Tiere. Sie verknüpft das Sinnenleben mit dem Gnadenwirken und stellt den Menschen mit Leib und Seele, Welt und Kirche, Natur und Gnade in die Verantwortung seiner 'operatio'. 828

Die Verknüpfung von Spiritualität und weltlicher Verantwortlichkeit spricht aus dem Werk der mittelalterlichen Prophetin, eine Haltung, die auch im Wirken der Ulrike Rosenbach zu finden ist. So ist eine gleichberechtigte Stellung von Mann und Frau, so wie die Nähe von Mensch und Natur im ganzheitlich ausgerichteten Denken beider Frauen zentral. In Hildegard von Bingen fand die Künstlerin eine weitere historische Identifikationsfigur, in deren Rolle Ulrike Rosenbach als Botschafterin eines ganzheitlichen Verständnisses der göttlichen Schöpfung für diese Videoinstallation vorübergehend schlüpfte.

Dabei komprimierte die Künstlerin die komplexe Botschaft auf die zentrierte Formel: „Wisse die Wege.“ Damit nimmt die Künstlerin in dieser Arbeit auch das Thema des Grenzganges wieder auf, das bereits in der „Einsamen Spaziergängerin" begegnete. ${ }^{829}$ Denn auch die Mystikerin Hildegard von Bingen wandelte mit

\footnotetext{
827 Beuys 2001

828 Lurker 1991 S. 304

829 Vgl. Kap. III.5.7.
} 
ihrem Zugang zu göttlichen Visionen zwischen den Welten, blieb dabei aber auf ihrem spirituellen Weg mit beiden Beinen im irdischen Leben verwurzelt. In der schlichten Inszenierung in Rosenbachs Videoinstallation tritt die Figur der Nonne auf einem Weg aus einem Wald hervor. Bäume und Wald können im Kontext des Werkes der Künstlerin - wie bereits dargelegt - als Symbol für eine lebendige, positiv besetzte Natur gelesen werden. Diese positive Konnotation wird noch unterstützt durch das leuchtende Grün, in dem Partien der Bäume dem Betrachtenden entgegenleuchten. Das Blau, in das der Hintergrund eingefärbt ist, weist als Farbe des Himmels wie des Wassers auf die Unendlichkeit und weist in seiner Symbolik auch auf die Bereiche Kommunikation, das Geistige oder auch Göttliche, aus dem die Nonnengestalt in der Projektion hervortritt. Dieses göttliche, mystische Blau umfängt auch die Ränder der Ärmel des Gewandes. ${ }^{830}$ Die als christliche Nonne dargestellte Mystikerin tritt in sich selbst ruhend aus der Tiefe des Bildes hervor, und tritt damit dem die Projektion Betrachtenden Schritt für Schritt mit vor der Brust zusammengelegten Handflächen gegenüber. Eine Handgeste die ambivalent zu deuten ist. Entspricht diese doch zum einen einer innigen Gebetshaltung. Der Vergleich liegt hier zum Bespiel nahe zu Albrecht Dürers Zeichnung der „Betenden Händen“"831. Doch die aneinander gelegten Hände sind zum Beispiel in Asien auch eine Geste des freundlichen Grußes, und damit könnten sie genauso ein wohlwollendes, würdigendes Gegenübertreten kennzeichnen. ${ }^{832}$

Gezeigt wurde der „Hildegard Walk“ im Jahr 1994 in der Ausstellung „Made for Arolsen" am Ende eines langen Flures des Schlosses. Die Betrachtenden schritten durch den Gang auf die Projektion zu bis es zur distanzierten Begegnung zwischen virtueller Gestalt und Betrachtendem kam. ${ }^{833}$ Der Präsentationsraum unterstützte dabei in optimaler Weise die Aussage des Werkes.

In ihrer formalen Umsetzung zeigen die Aufnahmen einen realen Vorgang, der farblich verfremdet wurde. Die Originalfarben wurden intensiviert beziehungsweise angepasst, wodurch auf eine symbolische Bedeutung zu schließen ist. Intensives Blau, frisches Grün und leuchtendes Weiß sind die dominierenden Farben der Projektion. Auf der Ebene der Farbsymbolik verweist auch in diesem Werk äußerlich Dargestelltes auf inneres Sein.

Diese Rauminstallation, deren Videoloop jeweils nur wenige Minuten umfasst, ist in ihren Ausdrucksmitteln sehr reduziert. Doch zeigt die Analyse in dieser for-

830 Auf die besondere Bedeutung der Farbe Blau im Werk Rosenbachs wurde bereits hingewiesen. (Vgl. IV.5.2.3.c).

831 Albrecht Dürer (1471-1528), „Studie zu den Händen eines Apostels“ (Die betenden Hände). Pinselzeichnung auf blau grundiertem Papier, weiß gehöht, 290 x $197 \mathrm{~cm}$. Wien, Graphische Sammlung Albertina, Vorstudie für den Heller-Altar, 1508, Pinselzeichnung (W.461)

832 Buschmann untersuchte Gebetshaltungen in Werbeanzeigen. (Buschmann 2002, http://www.theophil-online.de/praxis/mfpraxi6.htm (Zugriff 3.5.2008))

833 Der Weg der Betrachtenden führte dort entlang an einer Reihe von Bildkompositionen, die zum Werkkomplex „Über den Tod“ gehörten, der in Kapitel V.3.8. besprochen wird. 
malen Einfachheit eine Symbolik und Tiefe der ins Bild gesetzten Aussage mit nachhaltiger Wirkung. Zudem hat Ulrike Rosenbach dieser meditativen Videoarbeit ihrem im Laufe der Jahre gewachsenen Bilderreigen starker Frauen eine weitere gewichtige Protagonistin hinzugefügt.
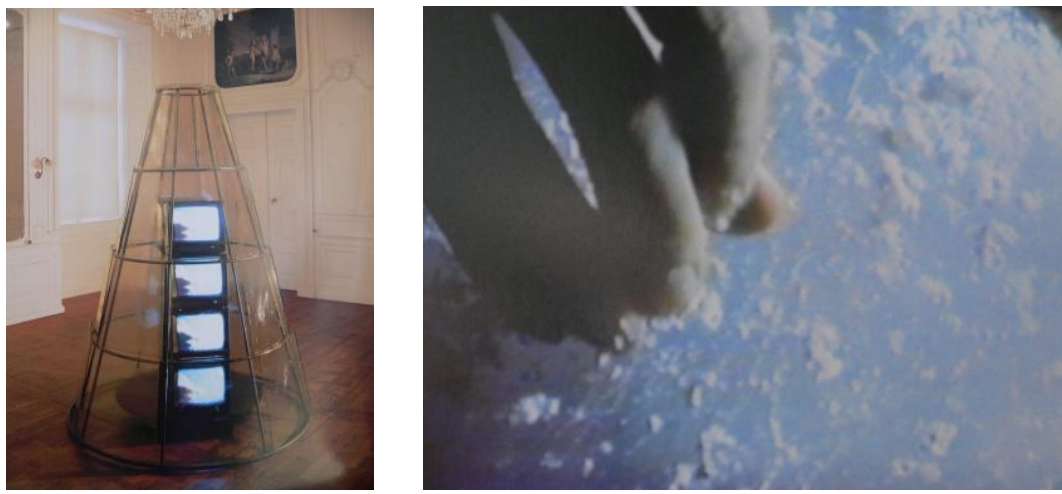

Abb. 247-248: Spiegeleis, 1994, Installation und Videostill

Für die Ausstellung in Arolsen, einem Ort, an dem sich übrigens ein umfassendes Archiv zum NS-Terror befindet, zeigte die Künstlerin noch ein anderes Werk. ${ }^{834}$ Diese Videoskulptur bestand aus einem Turm aus acht Videomonitoren. Jeweils vier von ihnen waren übereinander gestapelt und mit den Rücken zueinander gedreht. Der Turm befand sich unter einem Kegel aus einem Metallgestell und Glasscheiben, dessen Scheiben teilweise mit Vaseline benetzt waren. Die acht Bildschirme zeigten synchron das Tape „Spiegeleis“, das in Nahaufnahme eine Hand zeigt, die zum Teil mit Hilfe einer Nadel an einem Eisblock kratzt. Das Motiv des Spiegels begegnete schon mehrfach im Werk. Hier scheint das Videobild für die reflektierende Spiegelfläche zu stehen. Zudem, das Videobild wieder als Ausdruck innerer Prozesse gelesen, zeigt das Tape einen mühsamen und letztlich erfolglosen Akt das Eis zu durchbrechen. Zumal die Tapes auf den Monitoren noch abgeschirmt bleiben durch den zusätzlich ummantelnden Kegel aus Glas und Metall.

Das Farbvideo ist eine Arbeit aus dem Jahr 1979, das die Künstlerin hier erstmals im skulpturalen Zusammenhang zeigt. ${ }^{835}$ So nimmt sie in diesem Werk altes

834 Das Archiv war jahrelang öffentlich nicht zugänglich, ist seit Mai 2007 aber für die Allgemeinheit geöffnet worden.

835 In alten Katalogen taucht dieses Tape nicht auf, doch fällt die Entstehung nach Glüher in die Zeit der „Konzert im Gewaltakt-Aktion“. Interessant ist zudem im Zusammenhang mit dem Motiv des Eises, dass der Eiskunstlauf in den 1970er Jahren eine große mediale Popularität erfuhr. Das Motiv des Eises ist aber auch bei vielen anderen zeitgenössischen Künstlern in dieser Zeit präsent. Als Beispiel soll hier die Performance der amerikanischen Künstlerin Laurie Anderson erwähnt werden „Duets on ice“, die diese im Juni 1975 im Zentrum von Genua zeigte. 
künstlerisches Material wieder auf, das sie in eine neue Form einbindet. Eine Methode, die auch in einer weiteren Arbeit praktiziert wurde, die zu diesem Zeitpunkt entsteht: Das „Eiserne Zeitalter“ aus dem Jahr 1995 präsentiert alte Inhalte in neuem Kontext und deutet diese um. 836

\section{V.3.7. Werkuntersuchung: Das Eiserne Zeitalter}

Die Videoinstallation „Das Eiserne Zeitalter“ zitiert das Video „Jactatio“ und die pornographischen Comics, die bereits in der Aktion „Konzert im Gewaltakt“ im Jahr 1979 gezeigt wurden. ${ }^{837}$ Die Installation besteht aus fünf Monitoren und drei Rekordern verbunden mittels roter Kabel, die in einem schwarzen Stahlgestell verteilt auf drei übereinander liegenden Regalböden angeordnet sind. Während auf dem obersten und untersten Regal jeweils am linken und rechten äußersten Rand ein kleiner Monitor steht, der das Video „Jactatio“ zeigt, bildet das Zentrum der Installation ein größerer Bildschirm, der auf dem mittleren Regal in der Mitte steht und auf dem in steter Folge die Comiczeichnungen aus dem „Konzert im Gewaltakt" auftauchen. Dabei öffnet sich das jeweils sichtbare Comicbild nach einiger Zeit in der Mitte, teilt das Motiv in zwei Hälften und die Blende lässt - während das vorherige Motiv zu den beiden Seiten hinaus läuft - das Folgebild auftauchen. Von den vier rahmenden Monitoren in der Installation, die alle den stetig hin und her schleudernden Frauenkopf zeigen, sind jeweils zwei synchronisiert, so dass die Köpfe sich jeweils aufeinander zu - beziehungsweise voneinander weg - bewegen. $\mathrm{Zu}$ hören ist zu diesem monoton sich wiederholenden Szenario der schrille, beunruhigende Ton aus dem Jactatio-Video, das als Endlosschleife läuft.

Während in der früheren Aktion das Band „Jactatio“ ebenfalls als Video auf einem Monitor gezeigt wurde, sind die in der Aktion als Dias analog projizierten Bilder in dieser Arbeit ebenfalls auf einem Monitor zu sehen, zumal die in das elektronische Medium des Videos übertragenen Bilder als auseinander hervorgehender Bildfluss erscheinen.

Dabei spielte die Musikerin Geige, während sie auf Schlittschuhen in zwei Eisblöcken stand, die in der Wärme langsam dahin schmolzen. (Vgl. Broude/Garrard 1994, S. 159)

837 Vgl. Kap. III.5.6. 


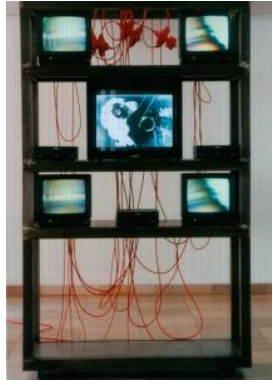

Abb. 249: Das eiserne Zeitalter, 1995, Installation

Diese Installation greift in neuer Form die Thematik des „Konzertes im Gewaltakt" ganz konkret im Zitieren der aus der alten Arbeit bereits bekannten Bilder wieder auf. Doch werden die wiederaufgenommenen Elemente aus der künstlerischen Vergangenheit, die männliche Gewaltfantasien, Machtmecha-nismen und innere Verletzungen zeigen, neu interpretiert und die alten Inhalte damit aktualisiert. Durch den Titel, der auf die mythologische Ära des so genannten „Eisernen Zeitalters" verweist - auch als ehernes Zeitalter bezeichnet - wird die ehemals politische Aussage auf eine allgemeinere Ebene gehoben und inhaltlich um einen pessimistischen Ausblick ergänzt. ${ }^{838}$ Ist doch das so genannte „Eiserne Zeitalter“ das letzte der vier mit Namen von Metallen bezeichneten Weltalter: dem harmonischen Goldenen Zeitalter folgen absteigend das Silberne und Bronzene Zeitalter, bis schließlich im Eisernen Zeitalter die Verschlechterung der politischen, wirtschaftlichen und sozialen Verhältnisse zum völligen Verfall führt.

Das paradiesisch anmutende Goldene Zeitalter, das Ovid in seinen Metarmophosen beschreibt ${ }^{839}$ und auch das Silberne Zeitalter finden sich im Verlauf der Kunstgeschichte vielfach ins Bild gesetzt, wie zum Beispiel in Gemälden von Lucas Cranach (1472-1553) oder Jacopo Zucci (1541-1596). ${ }^{840}$ Der Bildhauer Auguste Rodin zeigte - begeistert von den von ihm entdeckten Möglichkeiten der Suggestion von Bewegung im Medium der Plastik - das „Eherne Zeitalter“641 im

838 Dabei findet sich auch hier in zeitlicher Nähe zu der Spiegeleisarbeit in Bad Arolsen ein Bezug zum Thema Eis. Steckt doch im Begriff „Eisern“ auch das Wort „Eis“.

839 Ovid, Metamorphosen 1, 89-110

840 Lucas Cranach d.Ä., Das Goldene Zeitalter, um 1530, $50 \times 36$ cm, Öl auf Holz, National Gallery, London. Der Künstler schuf auch: Die Wirkung der Eifersucht (auch als Das Silberne Zeitalter bezeichnet). Es befindet sich es heute im Museum zu Allerheiligen, Schaffhausen. Jacopo Zucchi „Das Goldene Zeitalter“, 38 x 50 cm, Öl auf Holz, Galleria degli Uffizi, Florenz. Dort ebenfalls von Jacopo Zucchi „Das Silberne Zeitalter“ (um 1570), 38 x $50 \mathrm{~cm}$.

841 Ein Abguß von der lebensgroßen Bronzeskulptur findet sich unter anderem in der Kunsthalle Bremen: „Das eherne Zeitalter“, 1875/76, Bronze, braun, grün und schwarz patiniert, $180 \times 66$ x $60 \mathrm{~cm}$, davon Standplatte: 10 x 54 x 52 cm, Bez. auf der Standplatte r.: Rodin (Inv. Nr. 138- 
Jahr 1875/76 als einen sich in die Höhe reckenden Jüngling, der unterschiedliche Bewegungsstadien des Vorwärtsgehens in seiner Körperhaltung vereinte. Der Künstler stellte damit den Aspekt des Erwachsens und Aufbrechens, der sich ebenfalls im Motiv des Ehernen Zeitalters findet, in den Mittelpunkt.

Ulrike Rosenbachs Videoarbeit mit dem gleichen Titelthema stellt Zeichnungen, die den Ausdruck eines Frauen verachtenden Sexismus bilden ins Zentrum ihrer Installation. Die Auswirkungen dieser entgegengebrachten Haltung zeigen die vier kleineren, den mittleren Monitor rahmenden Bildschirme im Motiv des beunruhigenden Hin- und Herwerfens des Kopfes einer Frau. Durch die schnelle Bewegung erscheint das elektronische Abbild verzerrt, verschwommen, wie auch der dieses Kopfpendeln begleitende Ton verzerrt erklingt. ${ }^{842}$

Rote Kabel sind ein gestalterisches Element, das sich in Variationen des Fadens oder Bandes durch Rosenbachs künstlerisches Werk zieht. Diese verbinden hier deutlich sichtbar die Rekorder mit den Monitoren. Vier rote Steckverbindungen zwischen den Kabelstücken, so dass die Energie durch die Kabel in die Monitore fließen kann, sind deutlich sichtbar zwischen den oberen beiden Monitoren positioniert. So wird hier, auf der technologisch-formalen Ebene Verbindung visualisiert. Dieses Motiv der Ver-Bindung ist vielleicht auch zu verstehen als Abhängigkeit, denn ohne das Zuführen von Strom durch diese zusammengesteckten roten Kabel kann kein elektronisches Bild entstehen. Interessant ist zudem ein Blick auf das Material, aus dem die Installation gefertigt ist. Stehen die fünf Monitore doch in einem schwarzen Stahl- oder auch Eisengestell. Der Einsatz des Materials Metall begegnete bisher im Werk Rosenbachs in Zusammenhang mit männlichen Bezügen. Stahlplatten ebneten zum Beispiel der Künstlerin ihren Weg in der Mount-Everest-Aktion, umstellten später den bildtragenden Monitor. Die regalähnlichen Stahlgestelle begegneten dann bereits im „Requiem für eine Eiche“ bevor ein Gerüst aus Eisen nun im pessimistisch anmutenden „Eisernen Zeitalter", in dem sich - quasi ins Mythologische gehoben - Ausweglosigkeit manifestiert, tragende Funktion für die Monitore übernimmt.

\section{V.3.8. Werkuntersuchung: Über den Tod}

„Wenn man intensiv lebt, setzt man sich mehr Veränderungen aus, und wenn man sich Veränderungen mehr aussetžt, ist der Tod auch präsenter. Man könnte in diesem Sinne auch sagen, die Arbeit „Über den Tod" ist eine Arbeit über das Leben. "843

1905/24 der Kunsthalle Bremen, Geschenk der Vereinigung von Freunden der Kunsthalle 1905, erworben vom Künstler.)

842 Vgl. Kap. III.5.6.

843 Ulrike Rosenbach im Gespräch mit Renate Petzinger am 17. September 1995 in: Kat. Dortmund 1995, o.S. 
In dieser Weise beschrieb Ulrike Rosenbach im Gespräch mit Renate Petzinger ihre Videoinstallation „Über den Tod“, die in der Zeit zwischen dem 29. Oktober bis zum 26. November 1995 im Eingangsbereich des Mittelschiffs der St. PetriKirche in Dortmund aufgebaut war. Die evangelische Kirche gibt Künstlern regelmäßig Raum zur Präsentation ihrer im spirituellen Kontext stehenden Werke. ${ }^{844}$
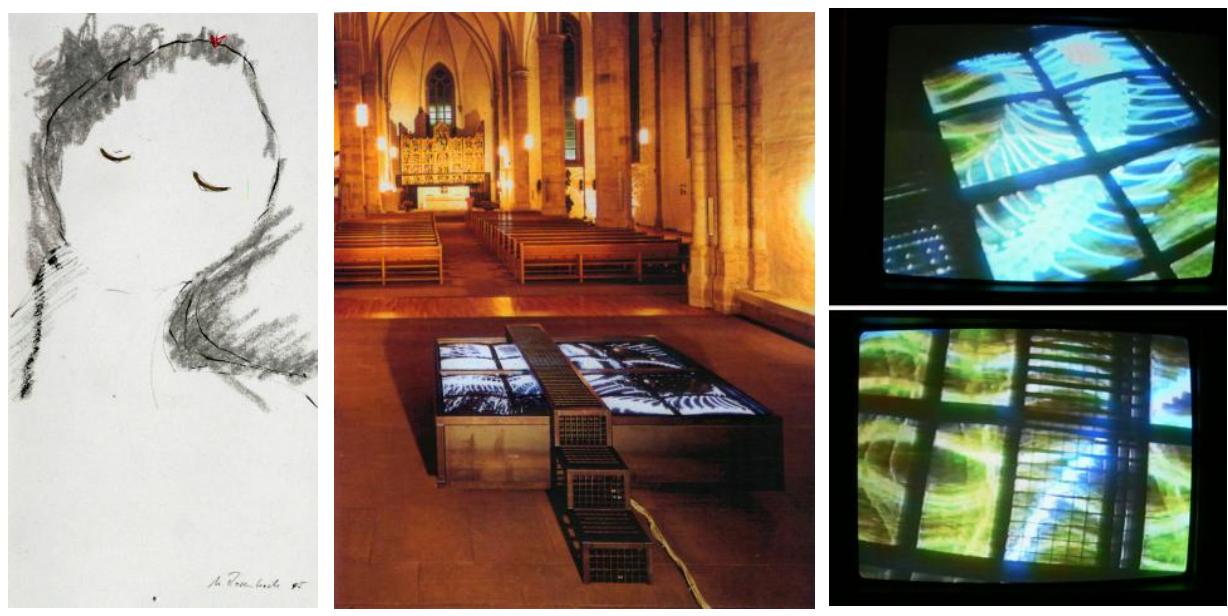

Abb. 250-253: Über den Tod, 1995, Einladungskarte und Installationsansichten

Die hochformatige Einladungskarte zur Eröffnung der Schau trägt eine Reproduktion einer Zeichnung der Künstlerin. Das Motiv zeigt ein mit wenigen Strichen skizziertes Gesicht. Die zarten Umrisse der Figur sind in schwarz gezeichnet. Breite, graue Striche deuten die Haare der Figur an. Die Augen sind in Form von zwei goldenen Schwüngen als geschlossen charakterisiert und zeigen damit den Schlaf an, vielleicht auch den Tod. Diese Konnotation liegt zumindest nahe im Kontext der Installation, zumal auch die transformatiorische Symbolik des Goldes auf den Augenlidern auf diese Lesart weist:

„Gold, wegen seiner Seltenheit, Rostfreibeit und seines Glanzes Symbol des himmlischen Lichtes und der Unvergänglichkeit. "845

Ein kleines rotes Strichgewirr im Haar am Scheitel bildet einen zarten Farbtupfer - das kleine verbleibende Knäuel des Tantrafadens. Die blasse Gestalt hat keine

844 http//:www.st-petri-dortmund.de (Zugriff 3.5.2008)

845 Lurker 1991, S. 253; und er erläutert weiter, dass während das edle Metall in der christlichen Ikonographie in Zusammenhang stehe mit ewiger Glückseligkeit, göttliches Königtum, Verklärung und die Herrlichkeit Gottes, habe das Gold im Buddhismus ontologischen Sinn und kultische Funktion. Die Goldsuche der Alchemisten sei wiederum letztendlich das Streben nach Befreiung des Geistes/der Seele von den Schlacken der Materie. (Vgl. Lurker 1991, S. 253) 
Nase und keinen Mund und wirkt in ihrem farblichen Aufgehen im hellen Untergrund seltsam entrückt.

Während die Zeichnung auf der Einladungskarte sich dem Thema von außen nähert, fasst die aus 16 Monitoren bestehende raumgreifende Videoinstallation den Tod anders ins Bild, nämlich, stringent zur Bildsprache Rosenbachs, visualisieren die bewegten Bildsequenzen auf den Monitoren eine Innenwelt. Sie sind zu einem Rechteck von vier mal vier Geräten angeordnet und liegen mit den Bildschirmen nach oben in einer metallenen Umkleidung auf dem Boden. ${ }^{846}$ Die skulpturale Form des stählernen Kastens lässt im Kontext von Kirche und Tod an einen Sarkophag denken. Über das Monitorfeld in dem metallenen Sarkophag führt ein schmaler Steg. Etwas seitlich aus der Mitte versetzt ist diese Brücke aus Gitterrosten über drei Stufen zu betreten. Sie gibt dem Betrachtenden von oben den Blick frei auf die flimmernde Monitorfläche. Dabei zeigen die sechzehn gläsernen Schirme ein zusammen gehöriges, auf die Monitore aufgesplittetes Bild, dessen gesamte Fläche von der Brücke aus allerdings nicht auf einen Blick zu erfassen ist. Die Augen des Betrachtenden sehen von der mehrere Quadratmeter umfassenden Komposition immer nur einen Teil. Dabei wird die Bilderflut durch die besondere Perspektive des Darüberstehens als sehr direkt und unmittelbar erlebt, wie Renate Petzinger beschrieb. Zudem ist durch digitale Schnitt- und Mischeffekte der Eindruck der Dreidimensionalität der computergenerierten Darstellung erzeugt, die eine suggestive Komposition aus gegenständlichen Symbolen der Vergänglichkeit visualisiert.

So findet sich zum Beispiel ein Strudel aus weißem Salz auf dunklem Grund in der vielmotivischen Bildsequenz, der den Blick des Betrachtenden in die Tiefe zieht. Ein illuminierter Stahlstab dreht an anderer Stelle einem Uhrzeiger gleich seine Kreise durch das elektronische Fließen. Weiße Knochen bilden zudem organische Skelettformen und die weißen Rippen, wie auch das gebogene Rückgrat des Skelettes eines an eine Schlange erinnernden Tieres, schwimmen durch das Bild, bis der knöcherne Kopf die Schwanzspitze erreicht und sich damit der Knochenkreis schließt. Ein mit kleinen Schädeln gekrönter Totenkopf wandert durch die Bildsequenz, die sich stetig in Bewegung und Fließen befindet. Interessant ist zudem, dass die schützende Glasscheibe, die die Skulptur überzieht, die Betrachtenden spiegelt und auf diese Weise dessen Abbild in die Komposition eingewebt wird. Der Rezipient kann in dieser Rauminstallation buchstäblich „Über den Tod“ schreiten, der visuell formuliert ist als ein Zeichenfluss der Vergänglichkeit.

Die Bedeutung des Aspektes der Suggestion von Tiefe in diesem Werk hob die Künstlerin selbst hervor, solle doch das Gefühl für den Betrachtenden entstehen, in den Monitoren zu versinken, einer Tunnelerfahrung gleich, wie man sie von

846 Auch hier findet sich damit wieder Metall als Rahmen eingesetzt. 
Nah-Tod-Erfahrungen kenne oder aus dem Bild eines Stundenglases, das das Salz nach unten ziehe. ${ }^{847}$

Diese Videoskulptur beschäftigt sich als ein modernes „Memento Mori““ mit einer der Grundfragen des menschlichen Lebens „Was bedeutet der Tod?“ Ein Tabuthema in einer auf Jugendlichkeit und Körperlichkeit ausgerichteten Gesellschaft. Der Tod findet im modernen Leben nicht mehr statt, ist weitestgehend aus der Wahrnehmung ausgegrenzt. Alte Menschen werden in Heime am Rande der Gesellschaft abgeschoben und die Verwaltung des Todes übernehmen Bestattungsinstitute, diskret und sachlich. Dabei ist der auf der einen Seite aus der Wahrnehmung ausgegrenzte Tod in den Medien allgegenwärtig - ein Blick in die Tageszeitung oder die TV-Nachrichten genügt, um täglich mit Bildern von Todesopfern aus Kriegsgebieten konfrontiert zu werden. ${ }^{848}$ Zudem bleibt das Leben - bei allem Vermögen der Medizin - endlich und der Tod ist der „existentielle Ernstfall“, an dem sich auch das Verhältnis zur Religion entscheidet, worauf Silke Konieczny und Michael Küstermann im Katalogtext zur Ausstellung hinwiesen. ${ }^{849}$

Im christlichen Kontext ist eine Kirche traditionell der Ort, an dem sich die Frage nach Leben und Tod deutlich stellt und so passt diese Videoskulptur optimal in einen Kirchenraum. Dabei formuliert Ulrike Rosenbach in ihrer künstlerischen Auseinandersetzung allerdings weniger christliche Auffassungen, vielmehr entwirft die Künstlerin eine individuelle Collage, die auf Mythen aus fremden Kulturen und Kulte vergangener Zeiten Bezug nimmt. Damit rührt sie an Archetypisches und aktiviert mit ihren persönlichen Chiffren ein inhärentes kollektives Gedächtnis, das sich aus unterschiedlichen Quellen speist.

„,... meine gesamte Anstrengung geht dabin, euch die Angst zu nehmen, denn nur durch das Herz. kommt ibr zur Neugeburt. Aber bevor ibr nengeboren werdet, müßt ibr sterben. Keiner kann neu geboren werden, bevor er nicht gestorben ist. ... die Kunst zu sterben ist das eigentliche Fundament. Ich lebre euch bier eigentlich nur das: die Kunst zu sterben. "

Diese Anschauung der Kunst des Sterbens als Anleitung zum Leben hat verschiedene Quellen. Sie findet sich sowohl in den Büchern der östlichen als auch in der westlichen Spiritualität, wie zum Beispiel in den Mysterien des Altertums oder dem „Tibetanischen Totenbuch“. In der geistigen Schulung des tibetischen „Bardo Thödol ${ }^{\text {‘851 }}$ müssen die Eingeweihten zum Beispiel durch das Erlebnis des To-

847 Rosenbach im Gespräch mit Renate Petzinger am 17. September 1995 in: Kat. Dortmund 1995, o.S.

848 Das Videotape „Cleaning the Mirror“ aus dem Jahr 1995 der jugoslawischen Künstlerin Marina Abramovic arbeitet ebenfalls mit dem Motiv des Skelettes. Die Künstlerin liegt dabei unter den Knochen - unter dem Tod - und das Augenmerk wird im Bild auf das Atmen der Künstlerin gerichtet.

849 Kat. Dortmund 1995, o.S.

850 Osho in: Kat. Dortmund 1995, o.S.

851 So lautet der tibetische Name. 
des gehen, um zur inneren Befreiung zu gelangen. Sie müssen ihrer Vergangenheit und ihrem inneren Ich sterben, bevor sie in die geistige Gemeinschaft und in das höhere Leben eintreten und Söhne des Buddha werden können. ${ }^{852}$ Der tibetische Name des zeitlosen Weisheitsbuches bedeutet übersetzt „Befreiung durch Hören im Zwischenzustand“. Dieser Zwischenzustand liegt nach buddhistischer Anschauung zwischen dem körperlichen Tod und der Wiedergeburt. Es ist ein Zustand, in dem der Geist des Toten dem wahren Sein in Gestalt gleißenden Lichtes begegnet.

Laut Totenbuch erlebt der Geist eine dreiteilige Schau, die mit dem Urlicht beginnt, dem Symbol der allem zugrunde liegenden Geist-Natur. Ihm folgt die Pentade der Buddhas, die in eine wilde Verfolgungsjagd durch düstere, Furcht einflöBende Geister mündet. Vor ihnen sucht der verfolgte Geist des Toten Unterschlupf und findet ihn schließlich im Mutterschoß, womit die Wiedergeburt einsetzt. Erst das Eingehen ins Nirwana - die Befreiung aus der „samsarischen Sklaverei“ oder der ,an Erscheinungen gebundenen Existenz" - bedeutet nach der buddhistischen Lehre der Unbeständigkeit ein Ausbrechen aus diesem Kreislauf der Wiedergeburten. Genau dazu weist der Text des tibetanischen Totenbuches den Weg. Das Buch wird dem Sterbenden beziehungsweise Verstorbenen vorgelesen, um ihn die Illusion des Sterbens durchschauen zu helfen und ihn damit von der Furcht und damit letztlich dem Kreislauf der Wiedergeburten zu befreien. Um diesen Grad von Bewusstheit nach dem Tode zu erreichen, bedarf es allerdings der intensiven Vorbereitung im Leben, eine Schulung, die zudem hilft das Leben besser zu verstehen und die Natur zu durchschauen. C.G. Jung sagt, dass der Bardo Thödol als Wissen vom Tode verkleidet das Geheimnis des Lebens enthalte. Darin liege sein geistiger Wert und seine universelle Bedeutung:
„Wenn der Jünger schließlich gelernt hat sich mit dem Ewigen, dem Dharma, dem Unver- gänglichen Licht der Buddhaschaft in seinem Inneren zu identifizieren, dann wird seine To- desfurcht wie eine Wolke vor der aufgehenden Sonne verschwinden. Keine geistig geschaffene Illusion kann mehr Macht über ihn gewinnen, wenn er ibren Ursprung kennt und im Stan- de ist, ibre Natur zu durchschauen. Somit ist das tibetanische Totenbuch als Brevier für die Lebenden zu verstehen, das den Weg weist aus der Gefangenschaft der Wiedergeburten aus- zubrechen. " 853

Die Symbole und Bilder des Textes des Tibetanischen Totenbuches werden aus psychologischer Sicht auch als Zeichen mentaler Vorgänge gedeutet. So verstand zum Beispiel C.G. Jung das Buch auch als menschlich begreifbare Philosophie, die eine tiefere Einsicht in seelische Geheimnisse offenbare und in der dreiteiligen Schau einen umgekehrten Initiationsweg beschreibe. Die Symbolformen dieser Schauungen seien dabei nicht willkürliche Schöpfungen, sondern die leuchtenden

852 Tibetanisches Totenbuch 1981, S. 33

853 Jung in: Tibetanisches Totenbuch 1987, S. 45 
Spuren, die Jahrtausende geistiger Erfahrung und Vervollkommnung in der menschlichen Psyche zurückgelassen hätten, oder wie es der Lama Amariga Govinda beschreibt:

„Sie sind der Strablungskörper aller Erleucbteten, die je über unsere Erde gescbritten sind. " 8554

Die illusorischen Bardo-Visionen wechselten dabei je nach der religiösen oder kulturellen Tradition, in der der Wahrnehmende aufgewachsen sei, doch die ihnen zugrunde liegenden Motive und seelischen Triebkräfte seien dieselben in allen menschlichen Wesen. ${ }^{855}$ Demnach geht es in der Lehre des Bardo Thödol letztlich um die Schulung, die Schichten des Unbewussten ins Bewusstsein zu heben. Die erste Stufe der Jüngerschaft umfasst das Lernen, mit dem Herzen zu hören. Auf der zweiten Stufe wird das intuitive Gefühl gedanklich verarbeitet und von der prüfenden Vernunft bestätigt. Auf der dritten, höchsten Stufe wird das gefühlsmäßig Geahnte und intellektuell Erkannte durch unmittelbares Erleben zur Wirklichkeit. An diesem Punkt wird aus dem verstandesmäßigen Wissen Gewissheit, indem der Wissende eins wird mit dem Gewussten. Dies ist die Stufe des Bardo Thödol, die den Jünger über den Bereich des Todes hinaushebt und ihn befähigt, die Illusion des Sterbens zu durchschauen und sich damit auch von der Furcht vor diesem zu befreien. ${ }^{856}$

Blickt man mit diesem Wissen auf die Skulptur Rosenbachs, lassen sich deutliche Bezüge zur Lehre des Bardo Thodöl erkennen. So führen drei Stufen auf die Brücke, die die Videoinstallation überspannt. Auf der ersten Stufe ist der Blick noch nicht frei, doch kann der Betrachtende die pulsierenden Geräusche der Installation deutlich hören, entsprechend des mit dem Herzen Hörens. Auf der zweiten Stufe kann das Auge bereits das Bild erkennen, sogar vollständiger als auf der dritten, da ihm noch eine gewisse räumliche Distanz bleibt, die die Erkenntnis erst ermöglicht. Die dritte Stufe bildet gleichzeitig die Brücke über den Bildstrudel. Aus dieser Perspektive wird der Blick in die Tiefe gezogen, das Erkannte in Erfahrung verwandelt. Doch bleibt dieser Eindruck ein Schein, denn der Betrachter kann unbeschadet über die Visionen hinweg schreiten und sich aus der virtuellen Todeserfahrung wieder lösen. Damit wird diese Skulptur zu einer Allegorie des körperlichen Todes und seiner geistigen Überwindung und ihre Begehung ist für den Rezipienten als eine Art Initiationserlebnis aufgebaut. ${ }^{857}$ Dabei greift die Künstlerin nach eigener Erläuterung in den von ihr gewählten Bildsymbolen über die Aussagen des tibetanischen Totenbuches hinaus:

854 Tibetanisches Totenbuch 1987, S. 25

855 Tibetanisches Totenbuch 1987, S. 37

856 Tibetanisches Totenbuch 1987, S. 36

857 Das Tape wurde am 7.11.1996 in der Reihe „Die 50 Besten“ im Programm des Südwestfunks (SWF) gezeigt. 
„Für mich hat die mittelalterliche Darstellung des Todes als Skelettmensch, an dem es übrigens nichts geschlechtliches mehr gibt, nach diesen Studien etwas sehr Reines und Klares bekommen. Der Knochen, dessen Fleisch längst verwest ist, hat etwas von Unsterblichkeit, weil er so lange hält. Das Skelett ist also auch ein Symbol der Tröstung und des Überlebens, weil es jabrhundertelang oder sogar jahrtausendelang bewahrt werden kann. Als Reliquie wurde das Skelett im Mittelalter auch so behandelt. Insofern sehe ich die Würde in dieser Darstellung des Skeletts im Mittelalter konserviert. Wir haben das in der jüngeren Geschichte auch in der Kultur von Tibet. Die Bardos im tibetanischen Totenbuch enthüllen eine Kultgeschichte vom Sterben und vom Tod, in der ₹.B. das Verbältnis zum Knochen des Toten sehr weit getrieben ist. Man bläst auf dem Knochen für die Toten Musik und der Totenkopf selber ist ein ganz starkes Symbol in den Ritualen für die Toten. Dazu kommt noch die Geschichte der Daquinis [sic], das ist die Geschichte einer Franenkultur, die sich ausschließlich mit dem Tod beschäftigt. Die Darquini [sic] ist eine weise Frau, die auf Friedhöfen lebt und mit den Toten und ibren energetischen Umgebungen verbunden ist. Überhaupt sind Totenkulte immer auch Kulte von Frauen gewesen, wie z.B. auch der Kult der Klageweiber oder der Kult des Totentanzes. "858

Eine so genannte Dakini ist ein tantrisches Geistwesen, welches nach der indischen Mythologie die Seelen der Toten in den Himmel bringt. ${ }^{859}$ Auch existiere diese weiter als Figuren im tibetischen Buddhismus:

"Just as St. George cuts the head of the dragon in icons throughout Christendom, so the Dakini severs the heads of beings who are none other than her own demons. To see the Dakini as a being who revels in anger or violence for its own sake is to misunderstand the imagery. Hers is not a glorification of anger and violence but a transformation of it. "'860

858 Rosenbach in: Kat. Dortmund 1995, o.S.

859 Das Wort Dakini stammt aus dem Sankrit. Es bedeutet Himmelstänzerin. Eine Dakini ist demnach ein weibliches erleuchtetes Geistwesen, das sich in der Gesellschaft von Buddhas aufhält. Sie gilt als Vermittlerin zwischen den Erleuchteten und den Menschen. Dakini heißt im Tibetischen Khadroma. Kha bedeutet Himmel, in seiner Unendlichkeit ein Symbol für die Leerheit (im Sanskrit: Shunyata), „dro“ bedeutet, sich fortzubewegen, und „ma“ weist auf das weibliche Geschlecht hin. (Vgl. http://www.bilderdermitte.de/buddhistisches_glossar.php (Zugriff am 22.5.2008))

860 http://www.moonlitmysticsm.com/angelsdakinis.htm (Zugriff am 22.5.2008) 


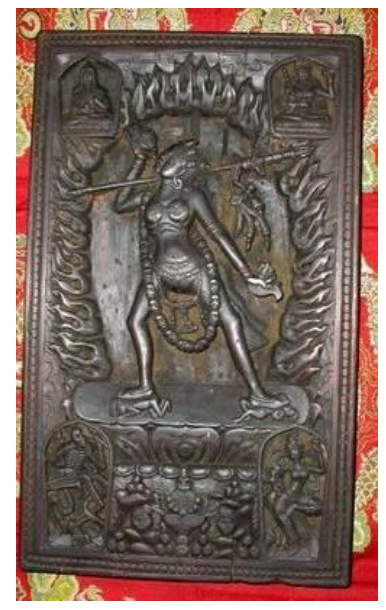

Abb. 254: Tanzende Dakini

Diese Dakini-Schädel tauchen auch in den Bildsequenzen der Videoskulptur auf. Die Bilder der weißen Knochen und Skelette, die uns in der Videoinstallation begegnen, erinnern an die so genannten „Beinhäuser“ in südlichen Ländern, in denen die Gebeine Verstorbener aufbewahrt werden. Zudem lässt die weiße Farbe der Knochen Reinheit assoziieren, die sich mit der Darstellung von Bewegung zu einem Bild des Weiterlebens nach dem Tod - in gewandelter Gestalt - verbindet.

Die Schlange, die in den Bildsequenzen begegnet, ist als konkretes Motiv neu im Werk Rosenbachs, legt aber in ihrer Darstellung als geschlossener Kreis die Assoziation an den alchemistischen Ouroboros nahe.

Ulrike Rosenbach entwirft in der Installation aus Elementen unterschiedlichen Ursprungs ihre eigene Ikonographie des Todes. Dazu visualisiert sie das Unvorstellbare in bewegten Bildern und lässt die diesmal computergenerierten Simulationen zu visuellen Schablonen innerer Vorstellungswelten werden. Eine Auffassung, die sich auch in der Interpretation der Arbeit durch die Kunstpädagogin Ruth Hampe findet:

„So wird das Lebendige wie in der Installation von Ulrike Rosenbach mit dem Allegorischen des Vergänglichen in Gestalt des Todes konfrontiert. Eine sprechende Folge von Bildmetaphern läßt sich über eine Treppe überschreiten und gibt den Blick frei in die Tiefenvision von sechzehn vibrierenden Monitoren in quadratischer Anordnung, die Bildschablonen in Gestalt von Schädel und Skelett unter einem vorbeiziehen lassen und in dieser gläsernen Verstellung der Bildfolge den unmittelbaren Fall ins V ergängliche, dem V erwesten gleich, vorwegnehmen. Es ist die Konfrontation mit dem Irrealen in den verzerten Bildüberblendungen der generierten Videobilder, die wie Ulrike Rosenbach selbst ausführt, in der Spannung und Dichte der Bildbewegungen ,eine schnelle Fahrt der Seele ins Universum zu beschreiben scheinen oder die hochgradige und totale Auflösung und Loslösung von Körper und Seele" (...) Dies sind 
Musterbilder, die in ibrer elektronischen Rasterung vibrierende Wabrnebmungsformen entstehen lassen und damit die Unwirklichkeit des ganzen unterstreichen. Einzelne Fragmente werden im Betrachten der sich durchziehenden Formgestalten zu einer neuen Einheit verwoben, unterliegen nur scheinbaren Grenzen im Aneinanderfügen der Monitore. Die Direktheit der Bildinhalte löst sich auf im Medium der Präsentation, folgt der Logik des technisch Macbbaren in der Transzendierung von Raum- und Zeitbezügen. In der Ausstellung der Installation im sakralen Raum des Kirchenschiffes wird diese einem Opfertisch gleich, zu einer begebbaren Transformationsbrücke - wie zwischen Tod und Auferstehung - im Gegenüber zum Altar. Unabhängig von der technischen Modernität der Gestaltung erlangt sie eine sakrale Dimension, in der Stimulation bildlicher Eindrücke, die innere Bilder des Todes verstärken und Gefüble zu mobilisieren vermögen, sich dem Allegorischen in der Wiedererlangung einer gewandelten Lebensperspektive neu zu stellen. "861

Das Thema des Todes begegnete bereits mehrfach im Werk der Künstlerin. Zum ersten Mal tauchte es konkret und personalisiert in der Rauminstallation „Denkmal für eine verzweifelte Frau" auf, die sich mit dem Tod der Mutter auseinander setzte, also auf eine autobiographische Erfahrung Bezug nahm. ${ }^{862}$ Kurz darauf trat das Thema Tod erneut in Erscheinung. Diesmal verpackt in das „Requiem für Mütter“. Von diesem Zeitpunkt an bleibt dieses Motiv latent gegenwärtig im Werk der Künstlerin. Kreist ihr Schaffen doch ab Anfang der 1980er Jahre um den Kreislauf des Lebens - das Werden und Vergehen der Natur und damit auch des Menschen. Nicht zufällig scheint die „Or-Phelia-Skulptur“ in einen den Körper konservierenden Sarkophag gebettet - oder wie Ruth Hampe interpretierte auf einem Opfertisch - entgegengetreten zu sein. Eine allgegenwärtige Todesnähe spricht bereits aus diesen vorangegangenen Arbeiten. In der Arbeit „Über den Tod" kristallisiert sich das Thema dann - eingebettet in die sich wandelnde Ausdrucksformen der Künstlerin in den 1990er Jahren - in überpersönlicher Weise und formt sich zu einer Einladung zur Reflexion über den Kreislauf des Lebens ließe sich der Titel doch ergänzen zu „Über den Tod hinaus“, womit der Gedanke der Transformation konkret verbunden wäre.

Diese Wandlung der Auffassung findet sich auch inhaltlich wieder. Wenn im Denkmal für eine verzweifelte Frau der Tod in Zusammenhang mit einer Reflektion über eine demütigende Enthauptung vorgeführt wurde, so treibt nun in dieser Skulptur durch den düsteren Strudel der Todesvisionen ein weißer Totenkopf, der eine Schädelkrone trägt: Ein gekröntes Haupt tritt in Erscheinung. Die Bedeutung eines Motives wird hier elementar gewandelt, mit neuem Inhalt gefüllt und in eine positive Aussage transformiert. Auch hier findet sich also - wie im Symbol des die Gegensätze versöhnenden Ouroboros - Heilung, und damit ein grundsätzlich therapeutischer Ansatz verbildlicht.

861 Hampe 1999, S. 253 f (Hervorhebung aus dem Original übernommen.)

862 Vgl. Kap. IV.III. 
Damit liegt hinter dieser Arbeit eine grundlegend andere Motivation als zum Beispiel hinter den Arbeiten zum gleichen Thema anderer Künstler, die ebenfalls in den 1990er Jahren entstanden. Als ein Vergleich soll hier die Arbeit des Briten Damien Hirst herausgegriffen werden. Dessen Werk „Die physische Unmöglichkeit des Todes in den Gedanken eines Lebenden" reflektierte Anfang der 1990er Jahre über den Tod mittels eines Objektes, das einen toten Tigerhai zeigt, der präpariert in einer Formaldehydlösung in einem Aquarium schwimmt. ${ }^{863}$ Das Objekt befremdet im Kontext seiner Präsentation in einem Kunstmuseum, scheint es doch eher einem Naturkundemuseum zu entstammen. Erst der weit-schweifige Titel weist das vermeintliche Naturkundeobjekt als Kunstwerk aus und stellt Fragen an den Betrachtenden, die damit zum einen die Museumskultur und zum anderen die Sterblichkeit alles Lebenden reflektieren. Der britische Künstler betrachtet das Phänomen des Todes von außen. Er führt ein Tier vor Augen, das zu Forschungszwecken präpariert wurde, auf den ersten Blick vielleicht noch lebendig wirkten könnte, doch konfrontiert er den Betrachtenden mit der leblosen Materie.
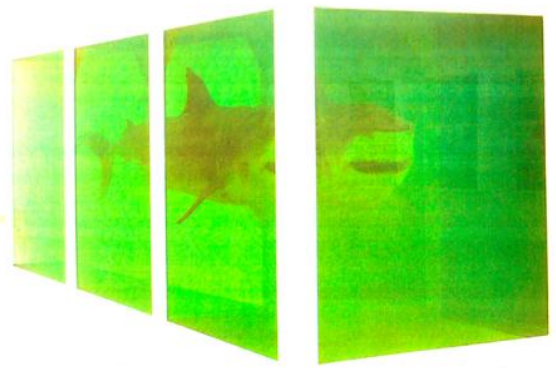

Abb. 255: Damien Hirst: Die physische Unmöglichkeit des Todes in den Gedanken eines Lebenden, 1991, Installation

Auch Bill Viola blickt in seinen Werken „Nantes Trytych“ oder „Beten ohne Unterlaß" auch von außen auf das Phänomen der Endlichkeit des menschlichen respektive körperlichen Lebens. ${ }^{864} \mathrm{Er}$ thematisiert in den beiden Videoarbeiten Aspekte des Lebenslaufes, von der Geburt bis zum körperlichen Verfall. Ulrike Rosenbach geht einen Schritt weiter. Sie löst sich in ihren Bildern aus der körperlichen Wirklichkeit und führt den Tod als vorübergehenden Abschluss eines körperlichen Lebens nicht vor Augen, sondern lässt den Betrachtenden in eine virtuelle Nach-Tod-Vision eintauchen. Bei diesem Blick in eine andere Lebensdimen-

863 Lucie-Smith 1996, S. 377

864 Die Video- und Klanginstallation „Beten ohne Unterlaß“ von Bill Viola aus dem Jahr 1992 zeigt als zwölfstündiges Video den Lebenszyklus eines Menschen von der Geburt bis zum Tod. 
sion überlagern sich zudem die Wirklichkeitsebenen der visionären Videobilder mit den Spiegelbildern der Betrachtenden.

\section{V.3.9. Wiedergeboren: Im Palast der neugeborenen Kinder}

„Der Palast der neugeborenen Kinder“ ist der Titel einer Rauminstallation, die im Jahr 1997 zunächst im MedienKunstRaum der Kunst- und Ausstellungshalle in Bonn und im Anschluss im Museum für zeitgenössische Kunst, dem Hamburger Bahnhof in Berlin gezeigt wurde. Wenn der Besucher durch einen engen Eingang diese Rauminstallation betritt, kommt er in einen verdunkelten, lang gezogenenn achteckigen Raum, dessen Seiten von Videoleinwänden gebildet werden.

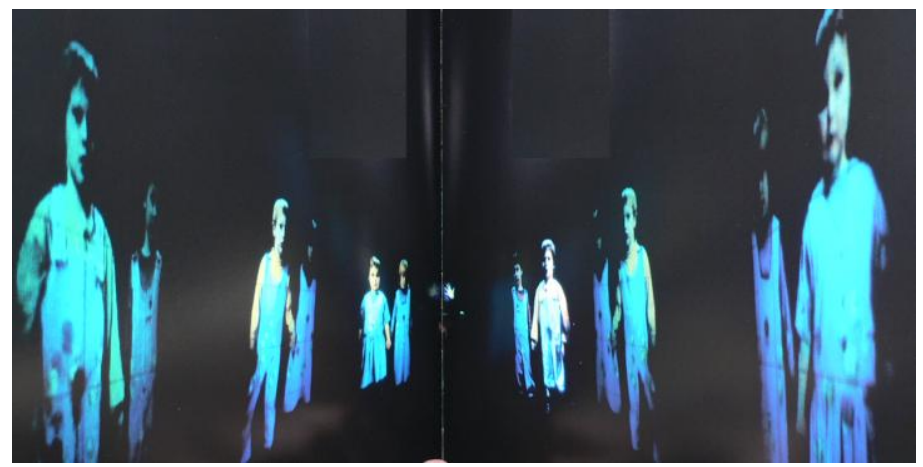

Abb. 256: Im Palast der neugeborenen Kinder, 1997, Installation

Von den Projektionsflächen blicken zwölf überlebensgroße Bilder von Mädchen und Jungen. $\mathrm{Zu}$ einer Tonkomposition aus einem monotonen, tiefen Herztonrhythmus und elektronisch verzerrten Kinderstimmen bilden jeweils zwei der Kinder - sich an der Hand haltend - ein Paar und wiegen sich monoton und langsam hin und her. Die überdimensionalen Kindergestalten blicken ernst, in sich gekehrt. Dabei tragen sie farbenfrohe Kleidung: hellblaue Latzhosen oder - wie zwei der Mädchen - hellblaue Kleider, dazu rote oder gelbe Pullover. Die Füße der Figuren sind nicht zu erkennen. Sie lösen sich auf im dunklen Hintergrund, in dem die Gestalten zu schweben scheinen. Perlende farbige Luftblasen umhüllen zudem die monoton schwingenden Paare. An der schmalen Stirnseite des achteckigen Projektionsraumes steht ein Computermonitor mit einer Tastatur. Auf dem Monitorschirm ist vor einem dunkelblauen Grund die helle Handfläche eines Kindes zu sehen, die zögerlich von innen gegen das Glas des Bildschirms zu drücken scheint. $\mathrm{Zu}$ dieser Handlung erscheinen nacheinander in hellblauen Großbuchstaben verschiedene Worte auf dem Monitor: „Lifechecker“ - Lebensprüfer, „Lifesaver“ Lebensretter, „Lifecaretaker“ - Lebensbehüter oder auch „Liferunner“ - Lebensläufer. 
Aufgrund der Abgeschlossenheit und Verdunkelung gewinnt das räumliche Ensemble sakrale Züge, das Assoziationen an eine Kapelle wachruft. Obgleich die Mädchen und Jungen in ihren blauen Kleidern und Latzhosen zunächst unschuldig und fröhlich wirken, befremdet ihr Verhalten, ihr monotones Sich-Hin-undHer Wiegen, das weit entfernt von kindlicher Ausgelassenheit und Freude zu liegen scheint. Zudem deuten die perlenden Luftblasen, die die frei in einem undefinierten dunklen Raum schwebenden Kinderpaare umgeben, auf einen fremdartigen, rätselhaften Ort jenseits alltäglicher Erfahrbarkeit. Zudem sind klagendverzerrte Kinderstimmen zu hören, die den zunächst harmlos-sympathischen visuellen Eindruck der Kleinen rasch einem bedrängenden Gefühl weichen lassen. Hinzu kommt noch die Monumentalität und beängstigende Präsenz der riesigen Kinderbilder, die mit ihrem fremdartigen Reigen den Besucher umschließen und ihn unentrinnbar mit ihrer Gegenwart konfrontieren. 865

Während die Kinder abgeschlossen in ihrer Leinwandwelt hin und her schwingen, scheint es einen Versuch einer Kontaktaufnahme zum Betrachtenden über den Bildschirm des Computers zu geben. Die tastende Kinderhand, die aus dem dunkelblauen Grund greift, scheint die bildgebende Glasscheibe, die Schnittstelle zwischen Innen und Außen, von innen zu berühren. Diese Darstellung - die zudem an das frühe Werk Rosenbachs „Eine Scheibe berühren“ erinnert ${ }^{866}$ - legt die Assoziation nahe, dass ein Kind in dem Computer gefangen ist, das versucht nach außen zu gelangen. Die an die Oberfläche greifende Handfläche kann so als eine visuelle Metapher gelesen werden. Sind in der postmodernen Wirklichkeit in den digitalen Speichern der Computer, die inzwischen in Folge der digitalen Revolution in fast alle Lebensbereiche Einzug gezogen haben, doch riesige Datenmengen gespeichert. In den Computern in Form von „Lifecheckern“ stecken zahllose Informationen über die Menschen, gläsern und greifbar. Die digitale Erfassung des Menschen beginnt bereits mit der Geburt. In den digitalen Datensammlungen stecken chiffriert die Identitäten der Menschen. Die Künstlerin findet für diese Gegebenheit eine klare Metapher: eine Kinderhand, die aus der Tiefe an die Oberfläche greift, nach Kontaktaufnahme sucht, versucht die Grenze zu überwinden.

Dieser sehr nüchterne Umgang mit Menschen, ihre Reduktion auf Zahlen und Daten, scheint der Künstlerin symptomatisch zu sein für die technische Moderne des ausgehenden 20. Jahrhunderts, wie Gerhard Graulich kommentierte.867 Kindheit, Technik und gesellschaftliche Ideologie stünden sich in dieser Installation in kritischer Weise gegenüber, greife doch die Technik als Ausdruck politischen und gesellschaftlichen Willens in viele Bereiche des Lebens ein:

„Obwohl - oder vielleicht gerade weil - Ulrike Rosenbach Medienkünstlerin ist, betrachtet sie die medialen Entwicklungen nicht unbedingt als alleiniges Heil

\footnotetext{
865 Schaumberger in: Kat. Schwerin 1999, S. 16

866 Vgl. Kap. III.1.

867 Vgl. Kat. Schwerin 1999, S. $9 f$
} 
der künftigen Gesellschaft. Medien sieht sie dort skeptisch, wo sie statt zur Befreiung des Menschen zu seiner Unfreiheit beitragen. " ${ }^{668}$

Mit diesem Gedanken schließt sich der Kreis zum Titel der Arbeit. In Polen heißt das Einwohnermeldeamt, der Ort der nüchternen Registrierung von Personendaten „Palast der Neugeborenen“, wie die Künstlerin auf einer Reise erfuhr. ${ }^{869}$ Der irritierende Titel der Installation ist so auch ironisch zu verstehen. Meint das Wort „Palast“ in diesem Zusammenhang doch weniger ein schlossartiges Gebäude. Vielmehr beschreibt es einen Ort, an dem ehemals Menschen im Sinne der sozialistischen Ideologie statistisch erfasst und verwaltet wurden. ${ }^{870}$

Die Künstlerin selbst benennt als Thema ihrer düsteren Kindheitsvision ein so genanntes „Endzeitphänomen“ einer zusehends artifiziellen Welt, die einen psychologischen Druck auf die Generation des neuen Jahrtausends ausübe. ${ }^{871}$

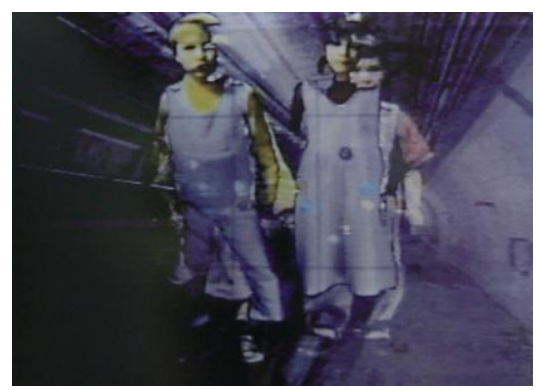

Abb. 257: Über die Kinder, 1997, Videostill

In dem Videotape mit dem Titel „Über die Kinder“, das die Bilder aus der Installation wieder aufnimmt und variiert formuliert die Künstlerin ihre Auffassung einer Kindheit zwischen Ängsten und Hoffnungen noch einmal neu. Das Grundmotiv des pendelnden Kinderpaares ist hier wieder aufgenommen, doch ändert sich hier von Zeit zu Zeit der dunkle Hintergrund hinter den schwingenden Paaren. Überblendet wird die Aufnahme des Kinderpaares mit einer Bildsequenz, die an einen Blick in einem Teilchenbeschleuniger oder auch eine rasante Fahrt durch einen U-Bahntunnel erinnert. Damit werden die monoton pendelnden Gestalten in dem Videotape buchstäblich in einen durch Technik hervorgerufenen Sog gestellt. Andererseits erinnert dieser Sog durch den Kanal auch an das Bild des den Blick in die Tiefe ziehenden Salzstrudels in der Installation „Über den Tod“. Und so überrascht es nicht, dass dieses Tape eingeleitet wird mit den Worten „Back to Earth“. Diese werden übrigens begleitet durch ein Geräusch, das eine Landung as-

868 Kat. Schwerin 1999, S. $9 f$

869 Kat. Schwerin 1999, S. 10

870 Graulich in: Kat. Schwerin 1999, S. 10

871 Kat. Schwerin 1999, S. 10 
soziieren lässt. Mit diesem Kommentar verortet sich das Tape explizit im Gesamtwerk der Künstlerin. Schließt es doch an die beiden Werkkomplexe, die sich mit Grundfragen des menschlichen Seins beschäftigten - dem Tod und der engelhaften Zwischenwelt - eine dritte Stufe an: Die Wiedergeburt. Nach der buddhistischen Anschauung folgt, wie bereits dargelegt, nach dem physischen Tod des Körpers und der Reise des Geistes des Toten durch den so genannten Zwischenzustand, die körperliche Wiedergeburt in einem Neugeborenen, mit dem das irdische Leben für die reinkarnierte Seele auf der Erde von vorne beginnt: back to earth. Es ist allerdings keine einladende Welt, die die Wiedergeborenen hier erwartet, sondern eine düstere, mahnende Vision der Kindheit, die die Künstlerin in ihrem „Palast der neugeborenen Kinder“ entwirft.

Aber nicht nur auf dieser philosophischen Ebene schließt sich mit der Arbeit ein Kreis. Auch im Kontext des CEuvres Ulrike Rosenbachs stellt der Werkkomplex „Über die Kinder“ eine Wiederaufnahme eines Themas dar, das das gesamte Werk der Künstlerin durchzieht. So durchzog das Sujet Kind und Kindheit das künstlerische Werk Ulrike Rosenbachs seit deren künstlerischen Anfängen. Thr eigenes Muttersein thematisierte die Künstlerin in ihrem Schaffen, und ihr allererstes Tape zeigte die junge Künstlerin mit ihrer kleinen Tochter auf dem Schoß. In den kommenden Jahren folgten eine Reihe Tapes und Performances mit der heranwachsenden Tochter, deren Entwicklung sich in den Arbeiten der Mutter spiegelt. Parallel zu und auch nach Abschluss dieser Mutter-Tochter-Phase beschäftigte sich die Künstlerin dann aus einer anderen Perspektive mit dem MutterTochter-Thema. Nun nahm sie ihr eigenes Tochtersein in den künstlerischen Fokus und setzt sich aus Tochtersicht mit ihren Ahninnen auseinander. Die künstlerische Auseinandersetzung diffundiert in spirituelle Sphären, wobei auch hier das Generationenthema weiter bearbeitet wurde, bis das Thema Kind beziehungsweise Kindheit entpersonalisiert, abstrahiert und verallgemeinert Ende der 1990er noch einmal in den Mittelpunkt des künstlerischen Schaffens tritt. Gleich ein Dutzend Mädchen und Jungen bevölkern die Rauminstallation, in deren Inneres gleich einer Gebärmutterhöhle - der Betrachtende aufgefordert wird, sich zu begeben. Doch ist es kein Geborgenheit und Lebendigkeit vermittelnder Raum, sondern diese Arbeit vermittelt ein Eintauchen in eine fremdartige, befangene Welt. Dabei schrumpft der Betrachtende durch die Monumentalität der Kinderabbilder, wird selbst in eine Kinderperspektive gedrängt.

In ihrer charakteristischen Ausdrucksweise kombiniert die Künstlerin in diesem Werk eine kritische Sichtweise auf eine durch elektronische Medien kontrollierte Welt, eingebunden in eine durch buddhistische Philosophie geprägte Weltsicht. Bei einer solch pessimistischen, ausweglosen Sicht auf die Zukunft, die aus diesem Werk spricht, bleibt dann vielleicht nur noch ein Ausweg dieser irdischen Gefangenschaft zu entkommen: das Erreichen des Nirwana, das entsprechend der buddhistischen Lehre den Kreislauf der irdischen Wiedergeburten beendet. 


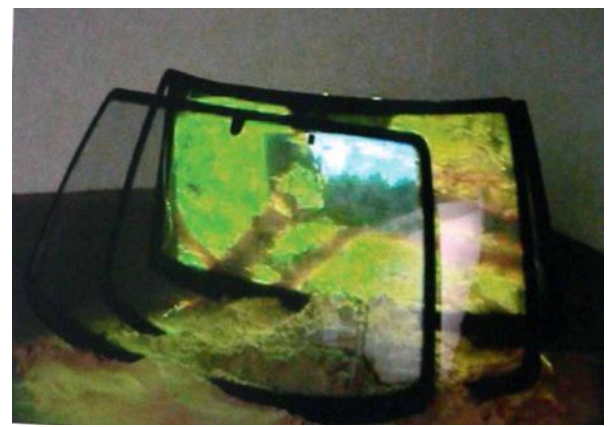

Abb. 258: Nirwana, 2002, Installation

Und tatsächlich formulierte die Künstlerin Anfang des neuen Jahrhunderts (2002) eine Arbeit, der sie den Titel „Nirwana“ gab, und die als Schlusspunkt ihres medialen künstlerischen Schaffens verstanden werden kann. Es handelt sich dabei um eine kleine Video-Klang-Installation, bestehend aus drei aneinander gestellten Windschutzscheiben, in denen eine Videoprojektion erscheint, die mit einem gesprochenen Text kommentiert wird. Die Videobilder zeigen die Künstlerin in Nahaufnahme gemeinsam mit einer anderen Frau während einer Autofahrt durch eine grüne Landschaft. Gerahmt werden diese Videoaufnahmen im Blendverfahren von pulsierenden Blutbahnen, ähnlich denen, in denen die OrPheliafrau schwebte ${ }^{872}$, und auch der gesprochene Text, der im Raum zu hören ist, handelt von der Lebendigkeit des Blutkreislaufes. Das Motiv des Blutes beziehungsweise des Blutkreislaufes begegnete im Werk der Künstlerin seit Mitte der 1980er Jahre, erstmals mit der Or-Pheliafigur, dann aber auch in einer Engelperformance. Zuvor war es aber bereits durch die roten Fäden und Kabel präsent, die als Nabelschnur wie auch Energie spendende Adern gelesen werden können.

Damit hat die Künstlerin mit ihrer Installation „Nirwana“, die eine Begegnung mit einem zweiten Menschen wie auch der Natur ins Bild setzt, eine lebendige, pulsierende Alternative zur Rauminstallation „Über die Kinder“ geschaffen, die von gelungener Kommunikation spricht.

\section{V.4. Ein letzter Aufruf für Engel}

Zwischen der „Nur-Geistwelt“ der Toten und der lebendigen Körperwelt der Menschen vermitteln nach Auffassung der Künstlerin Engel. ${ }^{873}$ Diesen Engeln, ein Motiv, das ja bereits seit den 1980er Jahren in der geflügelten Frauenfigur im Werk Rosenbachs angelegt war, widmete Ulrike Rosenbach ab Mitte der 1990er Jahre einen vierteiligen Werkzyklus. Interessant ist bei diesen vier Arbeiten, dass

\footnotetext{
872 Vgl. Kap. IV.5.3.

873 Auch die bereits erwähnten Dakinis können zu dieser Welt der Engel gezählt werden.
} 
die Künstlerin dabei vorübergehend zur Vermittlungsform der Medienperformance zurückkehrt, bei der das körperliche Agieren medial vermittelten Wirklichkeitsebenen gegenübergestellt wird. Allerdings gibt es innerhalb des Zyklus auch eine großformatige Rauminstallation mit dem Titel „Last Call für Engel“, die 1996 präsentiert wurde, und die zunächst genauer in den Blick genommen werden soll.

Auf dem hellen Parkettfußboden der großen Halle des Kunstmuseums Heidenheim, einem ehemaligen Schwimmbad, lag ein mehrere Meter langer schwarzer Scherenschnitt. Er zeigte die geflügelte Frauenfigur, die seit den Schmelzprozessen die Werke Rosenbachs durchzieht. ${ }^{874}$ Hier war die Binnenzeichnung mit weißen Kreidestrichen hervorgehoben. Rote Kabel überzogen sich netzförmig kreuzend die schwarze Gestalt. Sie verbanden die sieben Monitore, die um die Figur angeordnet waren, miteinander sowie mit den Steckdosen in der Stirnwand der Halle und versorgten so die Bildschirme mit Strom. Die bewegten Videobilder auf den sieben Monitoren zeigten unterschiedliche Szenen: Unter anderem sind dort zu sehen das Schlagen eines metallenen Gonges mittels vier roter Schlegel, federne Flügelschläge, der blaue Himmel, ein runder Planet und der volle Mond wie auch der schwarze Schatten einer Hand vor einem hellen Hintergrund. ${ }^{875}$ An den weiBen Wänden der ehemaligen Schwimmbadhalle hingen zudem mehrere Zeichnungen der Künstlerin. Darunter war auch eine großformatige Darstellung, die eine geflügelte, menschliche Figur zeigt - deren Gestalt ebenfalls an die Frauenfigur aus Pompeji erinnert, hier aber als Erot bezeichnet wird. Die Zeichnung, in der die Farben schwarz, rot und weiß dominieren, 876 ist umgeben von einem handschriftlichen Text, der durch Teile der Darstellung übermalt und dadurch teilweise unleserlich ist. ${ }^{877}$

874 Auf das pompejanische Fresko bezog sich bereits die Werktrilogie „Requiem“, „Narzissen“ und "Jactatio" in den 1970er Jahren. Die Silhouette dieses geflügelten, weiblichen Eroten taucht dann seit Anfang der 1980er Jahre immer wieder im Werk auf: In den „Schmelzprozessen“ war die Figur gleich siebenfach zugegen, wie auch in der „Eulenspieglerin“ vierfach eingefügt. Hier wurde sie in der Interpretation von Lothar Schröder als „Siegesgöttin Nike“ beschrieben. Auch in vielen Zeichnungen Rosenbachs ist die geflügelte Gestalt präsent, dann farbig angelegt und differenzierter gemalt.

875 Die Installation wurde 1999 erneut in Bonn gezeigt, wobei der schwarze Engel hier auf Salz gebettet war.

876 Eine wichtige Farbkombination im Werk Rosenbachs, die ja schon mehrfach begegnete (vgl. Kap. IV.4).

877 Erotenzeichnung, 1984 (datiert mit 1985) Papier, 150 x $170 \mathrm{~cm}$; die Transkription des Textes auf der Erotenzeichnung lautet: „Ich bin wertlos verschrumpelt und unvollkommen, meine Haut ist zu dünn, mein Kopf ist zu voll, ich bin (...) meine Liebe ist (...)heit, meine Weichheit wird als Schwäche angesehen. Frausein ist ein unverbesserlicher Nachteil. Die Ähnli (...) ist fein andere Wolle (...) mir wird davon. Dies alles sind Glaubensätze, die ich fallen ließ. Ein gut geerdeter Engel braucht keine Flügel. Habe vergessen bedeutet nicht jetzt kann ich (...) was es nehmen und hier zu sein nichts beschrieb / lange Erden ziehn langsam den Himmel herauf und wachsen uns über den Kopf. Informationen dieser Art lassen sich nicht verhindern. Ulrike Ro- 


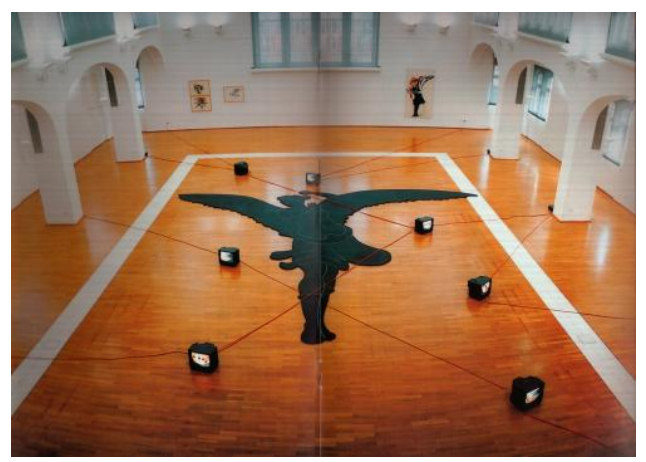

Abb. 259: Last Call für Engel, 1996, Installation

Während die zititerte Flügelgestalt in den Fresken in der Villa dei Misteri in eine vielfigurige Szene eingebunden ist, erscheint diese im Werk Ulrike Rosenbachs isoliert und wurde innerhalb ihrer Installationen und Performances bisher in Form eines Schattenrisses zitiert, und zudem auf die Form des Umrisses reduziert. Die magische Kraft, die von dem Fresko in Pompeji ausgeht, wird auch von anderen Besuchern der antiken Ausgrabungen beschrieben. Agnes Hidveghby nimmt zum Beispiel eine eigene spirituelle Deutung dieses Mysterienzyklus vor und beschreibt diesen als den Ab- und Aufstieg auf dem inneren Weg der Frau. ${ }^{878}$ Doch bleibt die genaue Bedeutung der von Ulrike Rosenbach ausgewählten Figur aus einer antiken Kultdarstellung, auch bei ihr ungeklärt und lässt damit Raum für individuelle Interpretationen. Ulrike Rosenbach sagte selbst, dass sie in dieser Darstellung für sich ein Bild einer aufschwebenden Engelsfrau gefunden habe, an der sie fasziniere, „dass sie die Rute oder Gerte über ihrer rechten Schulter schwingt, als wollte sie sich geiseln. ${ }^{\text {"879 }}$ Durch diese Haltung verweise die Figur für die Künstlerin sowohl auf die im mittelalterlichen Mystizismus als auch im Zen-Buddhismus verbreitete Praxis der Selbstgeißelung, durch die der Meditierende das „Paradies gewinne, ohne dabei seinen Körper zu verlieren“, erläuterte René Hirner in seiner Interpretation des „Last Call für Engel“ 880

Anders als in den voran gegangenen Werken, in denen die Engelsfrau in der Originalgröße zitiert wurde, erscheint die schwarze Gestalt in dieser Installation überdimensional groß. Zudem trägt sie hier keinen Zweig in der erhobenen Hand, der sonst, anstelle der Geißel im Original, meist von der Künstlerin hinzugefügt

senbach (...) Dhram Sanita 1985 / Alte Mauern brechen zusammen und geben den Blick frei auf eine neue Landschaft. Etliches erscheint angenehm und silbern.“

878 http//:www.arssacra.org/villa_dei_misteri_deutsch.html (Zugriff 22.5.2008)

879 Hirner in: Kat. Heidenheim 1996. In dem antiken Fresko sieht es allerdings eher so aus, als ob die Figur nicht sich selbst sondern eine andere auspeitscht.

880 Kat. Heidenheim 1996, o.S. 
wurde. Vielmehr führt eines der roten Videokabel direkt über die zum Schlag ausholende Hand und löst die Rute ab.

Auch der Titel der Installation verweist auf eine besondere Situation. Mit dem Aufruf „Last Call für ..." werden die noch säumigen Passagiere am Flughafen über Lautsprecher als letzte Gelegenheit an Bord ihres Fliegers gerufen. So ist es sicher kein Zufall, dass der gleichnamige Katalog als Schrifttype die Form der Buchstaben auf Anzeigetafeln einsetzt. Auch wird der Name der Künstlerin als vergrößerter grauer Schatten auf dem Cover wiederholt - in der Farbe der Engelssphäre. 881

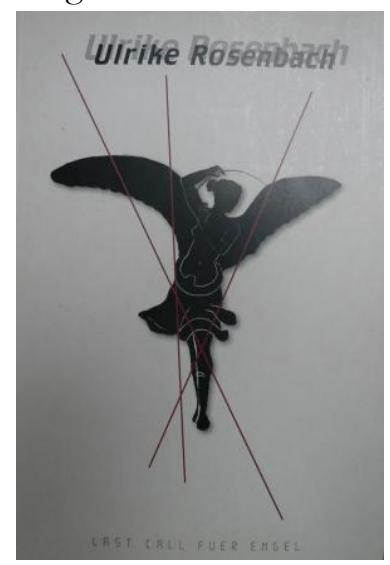

Abb. 260: Last call für Engel, Katalogcover

Wenn die Installation auch einen letzten Aufruf für Engel bekundet, bleibt doch die riesige Engelsfrau in der Installation unbewegt und durch die Energie durchströmten roten Kabel am Boden gefesselt. Allein die elektronischen Bilder auf den sieben im Raum verteilten Monitoren zeigen Bewegung an, sind auch hier wieder eingesetzt als bildliche Ausdrucksträger innerer Prozesse.882 Der Kunsthistoriker René Hirner interpretierte die Rauminstallation:

„Die Heidenheimer Videoskulptur, in der Ulrike Rosenbach auf die Darstellung der Rute verzichtet hat, evoziert den Eindruck der irdischen Gebundenheit mittels roter Kabel, die den Engel am Boden festzuhalten scheinen. Der rote Faden, der in der deutschen Sprache als Bildmetapher für den Fortgang einer Argumentation steht, erscheint hier als ein Netv, welches den Flug des Engels zu unterbinden scheint. "'883

881 Kat. Bonn 1999

882 Es liegt die Vermutung nahe, dass sich die Sequenzen der Monitorbilder inhaltlich auf das jeweilige Körperteil beziehen, in dessen Nähe sie stehen. So ist zum Beispiel interessant, dass die Sequenz mit der Schattenhand in unmittelbarer Nähe des erhobenen Armes angeordnet ist.

883 Hirner in: Kat. Heidenheim 1996 
Und er kommt zu dem Schluss:

„Die Erhebung in die dritte Dimension, d.h. bimmlische Dimension und in die Freiheit, die wir mit der Vorstellung vom Fliegen verbinden, wird somit als Schein begreifbar (....) Die feblende Erhebung des Engels aus der Fläche in den Raum, von der zweiten in die dritte Dimension - das macht diese Installation deutlich - kann nicht im Bild erfolgen. Sie ist nicht kü̈nstlerisch darstellbar, sondern offenkundig ein Akt der Aktivität des Betrachters selbst. Einer Aktivität, die hier nicht im körperlichen Sinne zu verstehen ist, sondern im geistigen - oder wie es Ulrike Rosenbach ausdrücken würde: im spirituellen - Sinne. "884

\section{V.4.1.Exkurs: Engel - Mittler zwischen den Seinsebenen}

Im Zentrum dieser Rauminstallation liegt eine Engelsfrau als schwarzer Schattenriss am Boden. Das deutsche Wort „Engel“ ist vom griechischen ,angeloi“ abgeleitet, das „Bote“ bedeutet. In der Funktion des Götterbotens oder Geistwesens der Umgebung Gottes oder der Götter finden sich Engel in den unterschiedlichen Religionen, vom Awesta bis zum Koran. Im Werk Rosenbachs tauchte der Begriff des Botens erstmals mit der Aktion ,Judofrauen haben als Hilfe Boten"auf. 885 Und auch in den Interpretationen zu der Videoskulptur „Über den Tod“ tauchten die Dakinis auf, bei denen es sich auch um „Himmelswandlerinnen“ handelt. 886

Im Alten Testament werden die Engel auch als Wächter bezeichnet. In der christlichen Ikonographie bildet zunächst die Leiter - und noch nicht Flügel - das Symbol der Mittlerschaft zwischen Himmel und Erde. Deshalb wurden Engel auch noch in den ersten christlichen Jahrhunderten als ungeflügelte, zudem männliche Gestalten dargestellt. Erst seit dem vierten Jahrhundert erscheinen sie in der christlichen Ikonographie als geschlechtslose oder auch androgyne Wesen mit Flügeln, die im Neuen Testament die himmlische Welt repräsentieren oder auch Protagonisten der Heilsgeschichte sind. 887

Während diese Quelle den männlichen Ursprung der vermittelnden Götterboten hervorhebt, betont Barbara Walker in ihrem „Lexikon der weiblichen Spiritualität" den weiblichen Ursprung der Engelsgestalten und weist auf die nicht nur spirituelle, sondern auch sexuelle Konnotation dieser Himmelswesen hin:

\footnotetext{
884 Hirner in: Kat. Heidenheim 1996

885 Vgl. Kap. IV.3.

886 Vgl. Kap. V.3.8

887 Der Hermaphrodit findet sich auch in der christlichen Ikonographie, hier in Form der androgyn dargestellten Engelfiguren. (Short in: Kat. Berlin 1986, S. 158) In der abendländischen Malerei und Bildnerei finden sich durch die Jahrhunderte zahllose Beispiele für Darstellungen von Engeln, darunter häufig auch Kinder als Engelsgestalten, wie bei Raffaels (1483-1520) Sixtinischer Madonna (1512/13), 265 x 196 cm, Öl auf Leinwand, Staatliche Kunstsammlung Dresden.
} 
„Engel (...) entsprangen der männlichen Vorstellung der vollkommenen Belohnung im Himmel: Sie galten als „Spenderinnen der Seligkeit", als ,immer lockende Mätressen all jener gesegneten Seelen, die in Indras bimmlischer Welt wiedergeboren wurden. '888

Erst innerhalb der patriarchalen Tradition mit deren asketischer Ablehnung der Frauen wie der Sexualität seien die Engel vermännlicht worden. Zudem verweist Walker im Kontext der Engel auf die Bedeutung der Zahl Sieben, die der Anzahl der Monitore in Rosenbachs Installation entspricht. So sei nicht nur die ägyptische Gottheit Cherub oftmals auch als die siebenfache Gottheit angerufen worden, auch habe die Siebenheit in Gestalt der sieben Planetengeister Eingang in die gnostische Tradition gefunden, sowie das Zend Avesta von sieben Hauptengeln spreche. In der christlichen Kirche seien diese sieben Geister schließlich als Erzengel übernommen worden, die unter der Leitung des heiligen Michael die himmlischen Heerscharen anführen und als die sieben Engel der göttlichen Gegenwart stehen. ${ }^{889}$ Zur Bedeutung der Zahl Sieben schreibt Lurker:

„Sieben, hl. Zabl: 7-tägige Mondphasen; 7 Planeten (einschließlich Sonne und Mond) in späterem spekulativen Denken Summe der bimmlischen 3 und der irdischen 4. In Babylonien Zeichen für Ganzhbit, Fülle (kissatu), ähnlich bei Augustinus für universitas, totus, perfectio; so ist die 7 eine Rundzabl, die einfach für ,groß', viel' oder, alles' eingesetzt wird. Das Kreisen der Planeten ist Ausdruck. kosmischer Ordnung, die sich auch in den 7 Tönen, den 7 Farben und in den mit Planetennamen versehenen Wochentagen widerspiegelt."

$\mathrm{Ob}$ die Figur des Engels nun weiblichen oder männlichen Ursprungs ist, muss an dieser Stelle ungeklärt bleiben. Wichtig scheint vielmehr die symbolische Verbundenheit dieser Himmelswesen mit der heiligen Zahl Sieben und ihre Mittlerfunktion zwischen zwei Seinsebenen - dem im weitesten Sinne Göttlichen oder auch Spirituellen zum einen und zum anderen dem Menschlichen. ${ }^{891}$

Doch mit der Gestalt des Engels ist noch eine weitere Bedeutung verbunden. So gilt er auch als Symbol der Wandlung oder Transformation, wie Cathrin Pichler im Vorwort des Katalogs zur Ausstellung „:Engel :Engel Legenden der Gegenwart" herausstellte:

888 Walker 1997, S. 229

889 Walker 1997, S. 230-232

890 „Sieben, hl. Zahl: 7-tägige Mondphasen; 7 Planeten (einschließlich Sonne und Mond) in späterem spekulativen Denken Summe der himmlischen 3 und der irdischen 4. In Babylonien Zeichen für Ganzheit, Fülle (kissatu), ähnlich bei Augustinus für universitas, totus, perfectio; so ist die 7 eine Rundzahl, die einfach für ,groß‘, ,viel' oder ,alles' eingesetzt wird. Das Kreisen der Planeten ist Ausdruck kosmischer ordnung, die sich auch in den 7 Tönen, den 7 Farben und in den mit Planetennamen versehenen Wochentagen widerspiegelt." Lurker 1991, S. 679

891 In einem solchen Sinne sind zum Beispiel die Engel im Werk des Malers Marc Chagalls als Hinweis auf den Einbruch des Überwirklichen zu verstehen. 
„Es ist das „Andere" in Ort und Zeit in den Phantasien, den Ideen und Sehnsücbten des Menschen, das der Engel repräsentiert, es ist dies seine Immanenz in der Welt. "'892

Diese weitere Auffassung findet sich in den Werken verschiedener Künstler ausgedrückt. So sah zum Beispiel der Dichter Rainer Maria Rilke im Engel seiner Elegien ein „Geschöpf, in dem die Verwandlung des Sichtbaren in Unsichtbares, die wir leisten, schon vollzogen erscheint.“ Dieser wesentliche Aspekt der Transformation spielt auch in einer Engel-Arbeit des amerikanischen Videokünstlers Bill Viola (*1951) eine zentrale Rolle. ${ }^{893}$ Das 2000/2001 entstandene Werk „Five Angels for the Millennium“ besteht aus fünf unterschiedlichen jeweils zwischen fünf und neun Minuten dauernden, in sich abgeschlossenen Videosequenzen mit jeweils eigenem Sound, die gleichzeitig auf fünf großformatige, rechteckige Leinwände an den Wänden des über 110 Meter hohen Innenraumes des Gasometers in Oberhausen projiziert wurden. ${ }^{894}$ Die Videos wurden simultan als Endlosschleifen abgespielt. Die präzise aufeinander abgestimmten und zyklisch sich wiederholenden Filmsequenzen konnten von den Besuchern durch einen punktuell verstärkten Ton gleichzeitig gehört werden:

\begin{abstract}
„Die Videosequenzen zeigen einen bekleideten Mann, der in ein Wasserbecken gezogen wird. Mit einer plätzlichen Explosion von Licht und Klang durchbricht er die Oberfläche, so dass die friedliche, wasserartige Landschaft zerstört wird. Reglos, schwerelos, betritt die menschliche Figur die Tiefen einer mysteriösen Unterwasserwelt. Eine leuchtende Leere unbekannter Dimensionen in denen physikalische Gesetze aufgehoben scheinen und die Grenzen zwischen unbegrenจtem Kosmos und begren₹tem menschlichen Körper eins werden. Leuchtende Blasen schweben wie Sterne in den Nacbthimmel, wenn die menscbliche Form den Spalt zwischen Himmel und Erde überquert. Aufgehoben zwischen Licht und Dunkelheit, Zeit und Ewigkeit, Leben und Tod. Die Materien heißen: Departing Angel (Engel des Abschieds und Neubeginn), Birth Angel (Geburtsengel), Fire Angel (Feuerengel), Ascending Angel (Aufsteigender Engel), Creation Angel (Engel der Schöpfung). "1895
\end{abstract}

892 Kat. Wien 1997, S. 12

893 Bei einem Vergleich zeigt die Entwicklung des künstlerischen Schaffens von Rosenbach und Viola gewisse Parallelen. Nachdem sich der Amerikaner anfangs auf medienkritische didaktischorientierte Fernseharbeiten konzentriert hatte, fokussierte er zusehends komplexe, philosophisch-existentielle Dimensionen in seinen multimedialen Werken. Seine Arbeit wurde zudem geprägt durch das Studium der traditionellen japanischen Kultur und spirituelle Erfahrungen in tibetanisch-buddhistischen Klöstern im Himalaja. Bei der Umsetzung seiner künstlerischen Ideen in Form von Videoinstallationen nutzt Viola computerunterstützte Montagetechniken, mit denen er Töne, gesprochene Texte und Bildsequenzen verbindet und seine Arbeiten thematisieren häufig die Beziehung des Menschen zu dessen Körper.

894 Die gigantische Raum-Klang-Installation „Five Angels for the Millenium“ war zwischen dem 17. Mai und dem 19. Oktober $2003 \mathrm{im}$ Gasometer in Oberhausen aufgebaut.

$895 \mathrm{http} / /$ :www.bill-viola.com (Zugriff 21.5.2008) 
Der Künstler versucht in seinen am Computer bearbeiteten Bildern die spirituellen Übergänge oder rites de passage im Leben eines Menschen - wie Geburt und Tod - atmosphärisch zu erfassen. In seiner künstlerischen Auseinandersetzung mit diesen Phänomenen richtet er sein Augenmerk vornehmlich auf meditative Schwebezustände, nutzt die scheinbare Schwerelosigkeit unter Wasser oder aber Bewegungsabläufe in Super-Zeitlupe wie auch Rückwärtsprojektion aus, um ein Schweben, den Übergang und die damit verbundene Verwandlung zu visualisieren. Das Element Wasser assoziiert zusätzlich zum Schweben auch eine starke Schöpfungssymbolik. So haben Violas Menschen-Engel keine Flügel, doch auch ohne dieses Symbol der Schwerelosigkeit wird der ins Wasser tauchende Mensch zur bildlichen Metapher der Transzendenz.

Nur die Welt der Engel erlaube Gott sich auszudrücken und dennoch unsagbar zu bleiben, erläutert Andrei Plesu im Rahmen seiner Theorie der Nähe, in der der Philosoph den Engel als in der Atmosphäre Gottes schwimmend charakterisiert. Engel relativierten als Gefährten die Einsamkeit des Menschen, wie auch die Einsamkeit Gottes, indem sie den Abgrund zwischen Gott und den Menschen in einen Raum des Verständnisses verwandelten, stellt Plesu zudem heraus. Damit stehe der Engel für das Dazwischen, das Grau, die Brücke auch die menschliche Seele sei ein latenter Engel. ${ }^{896}$ Und Ulrike Rosenbachs Engelsfrau trägt Flügel als Zeichen für die Möglichkeit, sich in die Schwerelosigkeit zu erheben. Zudem sind Flügel auch ein Symbol des Schutzes. So heißt es zum Beispiel in einem biblischen Psalm: „In deiner Schwingen Schatten berge ich mich. “897

Auf diese für sie den Engeln innewohnende Schutzfunktion wies auch Ulrike Rosenbach hin, in deren Zeichnungen Engelsfiguren häufig gemeinsam mit dem Motiv des lebenspendenden Baumes auftauchen. ${ }^{898}$ Die Künstlerin hob zudem im Gespräch mit Renate Petzinger bezüglich ihrer während des gleichen Zeitraums entstandenen Videoinstallation „Über den Tod“ explizit hervor, dass in ihrem Denken Engel zwischen den Lebenden und Toten vermitteln. Damit sind auch die beiden Seinsebenen benannt, zwischen denen die Wesen mit den Schwingen im Denken Ulrike Rosenbachs wandeln: Es sind Diesseits und Jenseits. Diese vielschichtigen Hintergründe in seine Interpretation des „Last Call für Engel“ einbeziehend, kommt René Hirner für die Engel-Installation Rosenbachs zu folgendem Schluss:

„Die Engel als Wesen, die sich zwischen Oben und Unten, zwischen Himmel und Erde bewegen können, sind letztlich wir selbst. Ob man die Fähigkeit zu dieser Form der Bewegung

896 Kat. Wien 1997, S. 18-23

897 Psalm 57, 2; Allerdings sind auch die Mächte des Dämonischen und der Unterwelt geflügelt. So erscheinen auch Chronos, Fortuna, der Tod und wie der Teufel in geflügelter Gestalt. (Vgl. Lurker 1991, S. 211)

898 Vgl. Kap. VII.1.; für die Künstlerin ist im eigenen Rückblick die Engelsfrau bereits seit den 1980er Jahren zentral, auch wenn sie zunächst nur vereinzelt im Werk auftaucht. 
nun in einem seelischen, geistigen, transzendentalen oder religiösen Sinne deuten mag, sei dem Betrachter überlassen. Dass der weibliche Engel aber für die Möglichkeiten eines Denkens, Handelns und Empfindens steht, das über den alläglichen Lebensvolling binaus weist, dies ist nicht zuletat auch eindeutig, weil Ulrike Rosenbach die Engelsgestalt selbst nur in ihren Konturen wiedergibt. Als Schattenriss ist die Gestalt jedoch ausschließlich (geformte) Fläche und damit Projektionsfläche für Gedanken und Vorstellungsbilder, die auf jene dritte Dimension, den Raum verweisen, die der Gestalt selbst fehlt. "'899

\section{V.4.2. Der Performancezyklus „Über die Engel“}

Ein Raum des Verständnisses entsteht in Rosenbachs Engel-Installation. Ihren dreiteiligen Performancezyklus „Über die Engel“ eröffnete Ulrike Rosenbach bereits ein Jahr vor der Rauminstallation im Bollwerk in Fribourg (Schweiz), führte ihn im gleichen Jahr in der Kreuzkirche in Hannover fort, bevor sie ihn zwei Jahre später in der St. Martinskirche in Nienburg an der Weser abschloss. Die drei Aufführungen unterschieden sich in ihrer Dramaturgie wie auch in der Choreographie grundsätzlich voneinander.

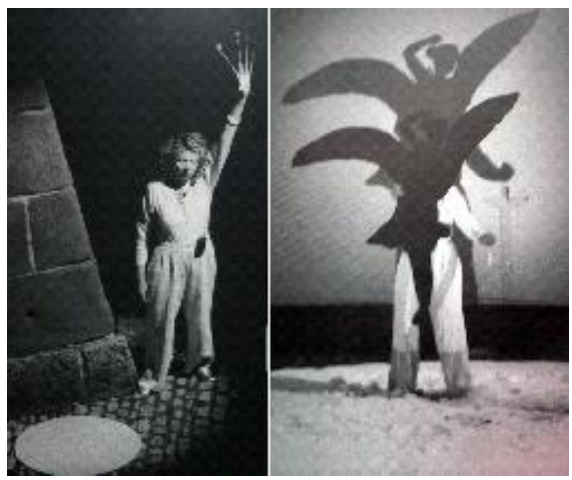

Abb. 261-262: Über die Engel, Fribourg, 1995, Aktionsfotos

Die wenigen Fotografien in Katalogen der Fribourger Performance aus dem Jahr 1995 zeigen unterschiedliche Momentaufnahmen, die den Raum und die räumliche Situation, den Aufbau des Environments und die benutzten Requisiten erkennen lassen. Ein weißer Salzkreis mit circa vier Meter Durchmesser bedeckte den Steinfußboden. Ein kleines, weißes Tambourin lag am Rand, zwischen Salzkreis und angrenzender Wand, an der eine rechteckige Leinwand hing, auf die Licht und Videos projiziert wurden. Die Künstlerin - ganz in weiß gekleidet - agierte mit der geflügelten schwarzen Silhouette und einem großen transparenten Schwert, während die Schatten der Aktion auf die Leinwand fielen. In der Per-

899 Hirner in: Kat. Heidenheim 1996 
formance hob die Künstlerin die schwarze Figur vor sich in die Höhe, während sie sich mit der linken Hand auf das Schwert stützte. Im Schatten verschmolz der Schatten ihres Körpers mit dem der Figur zu einer geflügelten Form. Außerdem zeichnete sich auch der Schatten des transparenten Schwertes - als graue Fläche zart auf der Leinwand ab. Ein anderes Foto zeigt die Künstlerin mit erhobenem Schattenriss und Schwert. Eine weitere Aufnahme bildet die Künstlerin am Boden hockend $\mathrm{ab}$, den Schattenriss aufrecht in die Luft haltend, während im Video im Hintergrund das Video mit dem Schlagen des Tambourins mit vier roten Schlegeln abgebildet wurde. Auch in diese Projektion ragt der schwarze Schatten einer Ecke des linken Flügels der Silhouette, so dass auf der Projektionsfläche das farbige Videobild mit dem Schattenwurf verschmilzt. Eine weitere Aufnahme zeigt die Künstlerin mit einem nach oben gestreckten linken Arm, über dessen Hand ein Schlegelhandschuh gezogen ist. So wiederholt sich das Motiv der trommelnden Schlegel aus der Videoprojektion mit dem die Finger verlängernden Schlegelhandschuh auf der körperlichen Ebene. Die Künstlerin steht währenddessen in sich gekehrt außerhalb des Salzkreises auf dem Steinboden. Neben ihr liegt ein gesprenkelter Kreis. ${ }^{900}$

Der Klang des Gonges oder das im Rhythmus geschlagene Tambourin gelten im Buddhismus als Türen zwischen den Welten. ${ }^{901}$ Auf diese Mittlerfunktion des Instrumentes bezugnehmend könnte man die vier irdischen Schlegelfinger, die den Rhythmus auf dem Tambourin erzeugen, als Schlüssel zu einer anderen Sphäre deuten. Zudem ist es interessant, dass das aus Foto- wie auch Videowerken bekannte Mittel der Überblendung in dieser Performance in mehrfacher Weise genutzt wird. Zum einen bildet helles Licht den Schatten der Agierenden ab. Das führt dazu, dass zwei in der „Realität“ voneinander getrennte Gestalten - die Künstlerin und die schwarze Silhouette - im Schattenbild zu einem Umriss zusammen gefügt erscheinen. Zum anderen werden in dieser Aktion unterschiedliche Schattenqualitäten entworfen. Steht doch neben dem opaken Schatten der Silhouette der hellere, graue des ,gläsernen“ Schwertes. Grau begegnete in diesem Zyklus bereits als Farbe der Zwischenwelt. Hinzu kommt ein Verschmelzen dieser Schatten mit der Videoprojektion. Zwei weitere Realitätsebenen - diesmal Schatten und elektronische Bildprojektion - fügen sich auf der Fläche der Leinwand zu einem einzigen visuellen Eindruck zusammen, bei dem der schwarze Schatten die Videoprojektion überlagert, sich aber harmonisch in die Komposition einfügt.

900 Es könnte auch der Boden sein, der durch einen hellen Lichtspot angestrahlt wird.

901 So wird ein Gong zu Beginn und auch zum Ende einer Meditation geschlagen, um den Meditierenden zunächst einzustimmen und dann wieder aus der Meditation herauszuholen. 


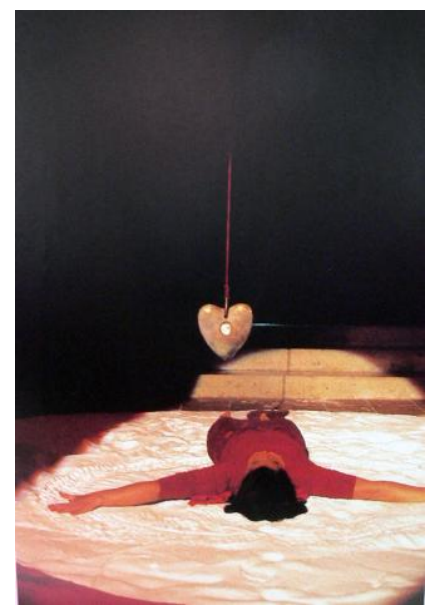

Abb. 263: Über die Engel, Hannover, 1995, Aktionsfoto

In der hannoveraner Performance standen andere Elemente im Mittelpunkt der Aufführung. Zudem agierte die Künstlerin hier mit einer zweiten Frau zusammen. Über die Performance, die am Sonntag, 13. August 1995 in der Kreuzkirche Hannover - im Rahmen der Gemeinschaftsausstellung „Andere Orte - Überall“ - zu sehen war, schrieb Alexandra Glanz:

„Der Himmel über Hannover war voller Engel. Zumindest waren ibre schlagenden Flügel für die unüberbörbar, die sich am Sonntagabend in der Krenzkirche kurzentschlossen auf den Steinfußboden hockten: Müde vom vielen Gehen und Sehen der Ausstellung „Andere Orte Überall" lauschten sie gebannt, was die frühere Beuys-Schülerin Ulrike Rosenbach zum Abschluß des Eröffnungstages „Über die Engel“ erzählte. Rosenbachs Geschichte über die Engel ist ein sichtbar gewordener Traum: Das Flügelrauschen dringt aus verhangenen Monitoren und Papier. Schwingfrequenzen aus Lautsprechern verheißen das Herannahen der androgynen Wesen, Videos bannen die Flügelschläge des Überirdischen, hinter dem transparenten Papier raunen die Wälder. Vielleicht ist es auch nur ein bißchen Gestrüpp, das dramatisch beleuchtet ist. Eine Frau in Rot liegt auf einem roten Feld, vom Kreurrippengewölbe des gotischen Pfarrkirchleins baumelt ein graues Herz, direkt darunter das Herz. der Frau in Rot. Eine Frau in Weiß (die Künstlerin) wird im Verlauf der einstündigen Performance einen weiten Kreis schneiden. Der rote Kreis wird eine Wolke werden, die sich pirouettenhaft dreht. Eine Stimme wird sich aus dieser Wolke lösen, die trancehaft die Schwingungen des Blutes beschwört... eine Stunde mit bewegenden Bildern. Am Anfang und am Ende war das Bild und das Bedauern, daß Rosenbach ibr Wissen „Über die Engel“ nur dieses eine Mal weitergibt." 02

902 Hannoversche Allgemeine Zeitung vom 15.8.1995 
Die eindringliche Beschreibung macht die große Intensität der Performance nachträglich spürbar, die als sinnliches Erleben spirituelle Einsichten mitteilte, oder, wie es die Rezensentin formulierte „einen Traum sichtbar werden ließ“. In dieser Inszenierung tauchte das schon bekannte bronzene Herzobjekt wieder auf, das wie ein Pendel von der Decke hing und dessen Mitte golden glänzte. Unter ihm lag eine rot gekleidete Frau im weißen Salzgrund. Während der Performance wurde ein roter Kreis aus Pappe ausgeschnitten und durch Drehung um die Mittelachse in eine wirbelnde Wolke verwandelt. Eingebunden war auch in diese Aktion eine großformatige Videoprojektion und eine Rezitation der Künstlerin. Außerdem beschreibt die Rezensentin beleuchtetes Astwerk, das sich in Form von Schatten an den Wänden abzeichnete.

Rot bildet - neben Weiß und Schwarz, der Farbkanon, der viele Werke Rosenbachs seit den 1980er Jahren prägt - in dieser Aktion eine der dominierenden Farben. Rot ist die Farbe der Liebe aber auch die Farbe des Blutes und damit des Lebens. Beide Konnotationen fanden sich im Werk bereits. Das Bild einer roten Wolke wird in der Performance durch das Wirbeln eines Kreises um die eigene Achse gebildet. Sowohl das Motiv der Wolke trafen wir in voran gegangenen Videosequenzen, wie zum Beispiel als elektronisches Abbild einer weißen Dampfwolke im „Zenkocher“. ${ }^{903}$ Dort war die Wolke Symbol für Meditation, das Finden des Kontaktes zu einer anderen Wahrnehmungsebene. Hier nun entsteht die wirbelnde Wolke als dreidimensionaler Eindruck im Raum durch das schnelle Drehen einer Pappscheibe und ist rot eingefärbt. Auch das Element des Um-dieeigene-Achse-Kreisens gehört zum Formenrepertoire der Künstlerin. Doch ist es hier nicht sie, die um ihre Achse wirbelt, sondern sie lässt eine Scheibe im Raum rotieren, die zudem noch rot gefärbt ist. Das bronzene Herz lotet von der Decke der Kirche herab. ${ }^{904}$ Dieses hängt dabei direkt über dem Herzen der zweiten am Boden liegenden Akteurin und deutet auf Harmonie und gefundene innere Balance.

Auch das Schatten werfende Astwerk begegnete bereits im Werk, zum Beispiel im „Requiem für eine Eiche“"905 aber das Motiv des Astwerkes begegnete auch im Zyklus der „Schlacht der Bäume“.906 So zeigt sich in dieser Performance eine Symbiose bekannter Elemente.

\footnotetext{
903 Vgl. Kap. IV.4.4.

904 Vgl. Kap. V.3.1.

905 Vgl. Kap. V.3.2.

906 Vgl. Kap. V.3.3.
} 

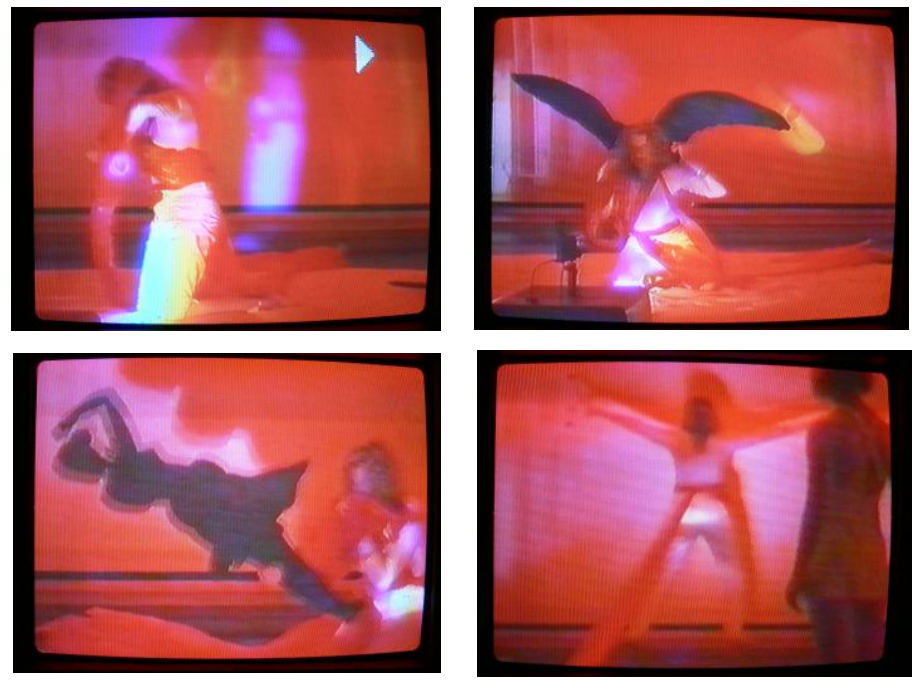

Abb. 264-267: Über die Engel, Nienburg, 1997, 4 Videostills

Die dritte Performance fand rund zwei Jahre später am Dienstag, 10. Juni 1997 in der St. Martinskirche in Nienburg statt. 907 Auch hier ähnelte der Aufbau den beiden vorangegangenen Werken und die Künstlerin agiert auch hier wieder mit einer zweiten Akteurin. Der Boden der Kirche war für die Aktion mit einem runden Kreis aus Salz bedeckt. Ein Videobeamer stand daneben auf dem Boden. Darauf stand eine Kamera, die die Aktion der Performerin auf dem Salzgrund aufzeichnete. Die Videoaufzeichung wurde als Closed-Circuit-Übertragung gleichzeitig an die hinter der Agierenden liegende Wand projiziert. Neben der Künstlerin, die auch in dieser Aktion eine weiße Hose und ein weißes Oberteil trug, agierte auch in dieser Performance eine weitere Frau. Diese erschien engelsgleich mit blonden Haaren im weißen Minikleid und begleitete die Performance mit ihrem intensiven Gesang. ${ }^{908}$ Die Kamera behielt aber allein Ulrike Rosenbach im Fokus. ${ }^{909}$

In der Halbtotalen zu Beginn des Tapes steht die Künstlerin unter zwei sich kreuzenden roten Tüllbahnen, aus denen sie sich allmählich befreit. Dazu erklingen sphärische Töne und warmes rosa, gelb, rot getränktes Licht füllt den Raum. Die Künstlerin knotet sich die beiden Stoffschals um die Hüfte. In das Tape wird jetzt kurz eine Nahaufnahme einer aus Federn geschaffenen Schwinge eingeblendet, bevor der Fortgang der Aktion zu sehen ist. Nun sitzt die Künstlerin auf dem Boden und zieht ihre Schuhe aus. Die zweite Frau steht im Hintergrund, zwischen

907 Von dieser im Original rund einstündigen Performance gibt es einen rund 15 minütigen Videozusammenschnitt.

908 Beate Kercher agierte hier zusammen mit Ulrike Rosenbach.

909 Es filmte Dietlinde Stroh. 
der Künstlerin im Salzkreis und der Projektionsfläche, und stimmt einen wortlosen, intensiven Gesang an. Die Künstlerin hockt sich auf den Boden, verbindet sich die Augen mit einem freien Ende des roten Schals und hebt mit ihren Händen Salz in die Höhe, das sie dann durch ihre Finger rinnen lässt. Das von der Standkamera aufgezeichnete Bild wird dazu synchron auf die weiße Wand projiziert. Wieder wird in dem Tape die federne Schwinge eingeblendet. Die Künstlerin hockt danach weiter am Boden, lautes Atmen ist zu hören und die Akteurin streckt sich mit kreisenden Armen in den Kniestand bevor sie sich wieder auf die Unterschenkel setzt. Diese fließende, als Schleife in steter Wiederholung praktizierte Bewegung vermittelt etwas sehr Öffnendes, Befreiendes. Darauf folgt wieder ein Flügelschlag im Tape. Anschließend liegt die Akteurin im Salz, hält die Schlegel in der Hand, steht langsam auf und zeigt diese der zweiten Frau. Dann tritt sie vor die Wand, stellt sich breitbeinig mit dem Gesicht davor und beginnt mit den Schlegeln in der Hand ihren Körper nach rechts und links zu schwingen. Dabei hängt das rote Tuch hinter ihr im Salz. Anschließend folgt in dem Tape eine weiche Überblendung, nach der zu sehen ist, wie die Künstlerin eine schwarze Silhouette herein trägt. Doch ist es nicht - wie noch in Fribourg - der Scherenschnitt mit Flügeln. Dieser Silhouette fehlen die Schwingen. Es ist allein die Form der Frauenfigur mit dem erhobenen Arm. Die Künstlerin hockt sich mit der Figur in den Salzkreis und beginnt die Schattengestalt, indem sie diese an den Beinen umfasst, von der Waagerechten in die Senkrechte zu heben und wieder zu senken. Dieses In-die-Luft-Heben und Auf-den-Salzgrund-Senken wiederholt die Akteurin mehrfach, während ein Geräusch von Wind oder Raunen erklingt. Die bewegten Schatten von der agierenden Künstlerin und der Silhouette fallen dabei auf die Leinwand, während die zweite Frau am Rand des Kreises hockt. Nach einer weiteren Nahaufnahme des Flügelschlags sieht man die Künstlerin in einer Halbtotalen im Salzkreis stehen, während sie selbst das schwarze - bei der zuvor gesehenen Silhouette fehlende - Flügelpaar trägt. Sie schwingt es vor ihrem Körper hin und her. Dann hält sie die schwarzen Schwingen vor ihren Kopf, so dass dieser durch den Schattenriss ersetzt wird. Dazu ertönt ein heller Klang. Nach dem nächsten Flügelschlag liegt die Künstlerin auf dem Rücken am Boden, hat die Beine gespreizt in die Luft erhoben. Die Flügel liegen über Kopf im Salz und überbrücken den Oberkörper der Liegenden. Nach dem nächsten Flügelschlag in Nahaufnahme folgt ein Zoom auf die erhobenen Beine der Akteurin, die leicht zittern. Nach einem weiteren Flügelschlag hockt die Künstlerin wieder im Salz, hält die schwarzen Flügel in ihrer rechten Hand und schwingt sie auf und ab. Dann beugt sie ihr Haupt und führt das Flügelpaar senkrecht über ihren Kopf, bevor sie ihren Kopf wieder aufrichtet und das Flügelpaar aus ihrem Rücken herauszutreten scheint. In dieser Pose friert das Bild schließlich ein und die Aufzeichnung endet mit einem kurzen Abspann. 
Die unterschiedlichen dokumentarischen Aufnahmen der Performanceszenen sind verbunden durch die Flügelschwinge. Dabei zeigen die einzelnen Bildsequenzen eine narrative Struktur. Unterteilt sich die Handlung der Akteurin doch in unterschiedliche Stationen: Nach der Befreiung aus dem roten Schleierschal, den sie schließlich - ähnlich einer Nabelschnur - um ihre Taille bindet, bewegt sie sich vom Stehen über ein Hinknien bis zu einem befreienden Aufbäumen. ${ }^{910}$ Erst im Anschluss daran nimmt die Künstlerin die - in dieser Aktion flügellose - Silhouette der schwarzen Figur hinzu. Nachdem die Künstlerin die schwarze Gestalt eine Weile zwischen Salzgrund und freiem Raum unter vollem Körpereinsatz hin und her geschwenkt hat, legt die Akteurin diese Figur wieder beiseite und greift stattdessen deren abgetrenntes Flügelpaar. Abschließend bleibt sie mit fragendem Blick mit den aufwärts gerichteten schwarzen Schwingen im weißen Salz geerdet knien.

Entsprechend des Weges des Yoga, dessen Ziel es ist, sich in eine bestimmte Haltung - ein so genanntes Asana - zu begeben, könnte diese Performance als eine dynamische Form des Yoga aufgefasst werden, die sich in unterschiedlichen Schritten auf die zum Abschluss konzentriert eingenommene Haltung vorbereitet. Dabei scheint der Atem in der Performance eine wichtige Rolle zu spielen, der in den Aufnahmen immer wieder deutlich zu hören ist. Die Bedeutung des Atems ist im Yoga elementar, gilt es doch, die Atmung mit den Bewegungen zu koordinieren, um schließlich Bewusstheit und Kontrolle über die Atmung zu erlangen. Zudem ist auch in diesem Werk eine Videoprojektion eingesetzt, hier in Form des Closed-Circuit, das die Handlung im Salzkreis direkt auf die Leinwand überträgt. Dadurch findet eine Verdoppelung der Aktion statt, die so gleichzeitig - neben der stofflich-körperlichen - in eine andere Wirklichkeitsebene - eine energetischgeistige - übertragen wird. Doch bildet die körperliche Erdung auch hier das wesentliche Abschlusselement. ${ }^{911}$ Das Videotape, das aus den dokumentarischen Aufnahmen geschnitten wurde, verdichtet in der charakteristischen Darstellungsweise Rosenbachs, die inhaltliche Aussage: Einen Traum vom Fliegen. Doch wie in der Installation bleibt die Künstlerin mit beiden Beinen auf der Erde.

910 Diese Bewegungsfolge entspricht der des so genannten „Sonnengrußes“ im Hatha Yoga.

911 Dabei ähnelt die hockende Haltung der Künstlerin am Ende der Performance stark der Haltung der Figur des Johannes in der Felsgrottenmadonna Leonardo da Vincis.Es finden sich zwei Fassungen der Felsgrottenmadonna des Malers Leonardo da Vinci (1452 - 1519). Eine befindet sich im Louvre (Madonna in der Felsengrotte (erste Fassung), 1482, Öl auf Holz, 122 x 199 cm), die zweite aus der Werkstatt des Künstlers in der National Gallery in London (um 1495-1508, Öl auf Holz, 189,5 x 120 cm, London, National Gallery). 


\section{V.4.3. Geerdete Flugversuche}

Im Werk der Künstlerin tritt das Motiv des Engels im Verlauf der 1980er und 1990er Jahre immer deutlicher in den Vordergrund, das sich in Form des geflügelten schwarzen Schattenrisses schließlich materialisiert. ${ }^{912}$ War doch bereits bei den „Judofrauen“ Anfang der 1980er von „Boten“ die Rede gewesen. Hier, noch nicht visualisiert, wies doch der Titel bereits auf diese vermittelnden Wesen hin. In den 1982 folgenden „Schmelzprozessen“ tauchte erstmals der schwarze Schattenriss in Form der geflügelten Frau aus der antiken Malerei auf, dessen Bedeutung sich innerhalb des Werkes der Künstlerin über mehrere Stufen von der „schwarzen Frau" in eine Engelsfrau wandeln sollte. Transformierte doch der in Zusammenhang mit dem Ewa-und-Adam-Zyklus intensiv erforschte ganzheitliche Hermaphrodit in die schließlich deutlich als weiblich ausgewiesene Botengestalt. Dieser gab die Künstlerin zunächst anstelle der Geißel beim antiken Vorbild einen Zweig in die erhobene Hand, bis dieser Zweig im „Last Call“ durch ein rotes Stromkabel abgelöst wurde. Innerhalb der Engel-Aktionen blieb die Hand des Schattenrisses leer. Stattdessen wurden die Finger der Hand der Akteurin mittels vier Schlegeln verlängert, die als „Schlüssel“ zu neuen Seinsebenen fungieren. Sowie der Ast als pars pro toto - Symbol der Ganzheitlichkeit der Natur - zeichenhaft die Aussage unterstützt, lädt die Künstlerin die mysteriöse antike Figur mit ihren eigenen Inhalten auf. Diese zum Schattenriss reduzierte Gestalt verkörpert für die Künstlerin schließlich eine positiv besetzte Engelsgestalt, mit der die Akteurin in ihren Performances im Abbild symbolisch zu einer Einheit verschmilzt. Diese Verbindung findet in den verschiedenen Aktionen auf unterschiedlichen Ebenen statt. Sind es in der ersten Aktion die Schatten, die zu einer Einheit verschmelzen, wird in der dritten Aktion ganz konkret eine Identifikation mit dieser Gestalt visualisiert. Wie schon in der Arbeit „Über den Tod“ zeigt sich auch in diesem Zyklus ein Bedeutungswandel der aus dem Werk der Künstlerin bekannten Zeichen und Chiffren. Die ehemals negativ konnotierte schwarze Frau wird zur Schablone für positive Assoziationen: zum Engel mit der Funktion der Vermittlung und des Verständnisses.

Was in der Installation „Last Call für Engel“ auf der Ebene des Raumes in statischer Form zum Ausdruck gebracht wurde, erscheint in den drei Performances in aktiver Weise umgesetzt. Dabei bilden die drei Performances Varianten zu ei-

912 Am 30.11.1996 wurde im SW3-Saarland aus Anlass der Verleihung des saarländischen Kunstpreises an Ulrike Rosenbach in dem Jahr auch das aktuelle Schaffen der Künstlerin vorgestellt, unter dem Titel „Ulrike Rosenbach und die Engel“. Blickt man auf die Biographie der Künstlerin, zeigt sich, dass die schwarze Engelsfigur kurz nach dem Tod der Mutter und Großmutter im Werk der Künstlerin auftaucht. Vielleicht versucht der Engel, diese durch den Tod eingetretene Trennung zu überwinden. Damit würde sich auch die Verknüpfung erklären zwischen den beiden Werkkomplexen „Über den Tod“ und die „Engel“. 
nem Thema. Alle drei sind Improvisationen mit vorbereiteten Elementen, jedoch deren genauer Ablauf aus der Situation und Atmosphäre der Performance entstand. Interessant ist dabei die zu beobachtenden inhaltlichen Verlagerungen innerhalb des Zyklus. Bei der ersten Performance „Über die Engel“ tauchte ein Schwert auf und es wurde mit dem Mittel der Überlagerung von Licht und Schatten gearbeitet. Im Tarot ist die kleine Arkana der Karten in die vier Gruppen Stäbe, Kelche, Schwerter und Scheiben unterteilt. Dabei sind die Schwerter dem Element Luft zugeordnet und beschreiben mentale, gedankliche Zustände und Prozesse:

\section{„Sie spiegeln geistige Haltungen, die als Schlüsselerfahrung von Meditation gelten kön- nen. "' 13}

In dieser Performance stand eine Siegesgeste am Ende - ähnlich wie in der viel früheren „Medusaimagination“ “.914 In der zweiten Variation spielten das bronzene Herz und die Farbe Rot eine zentrale Rolle. ${ }^{115}$ Sowie auch die traumhaften Flügel hier in Form der Videoprojektion erschienen, die Engelsfigur selbst nicht in Erscheinung trat. Diese taucht erst wieder in der dritten Aktion auf. Die Akteurin hebt sich und auch den zweidimensionalen Schattenriss hier nun in die dritte Dimension empor. Dabei tritt die schwarze Gestalt mit dem Körper der Künstlerin in direkte Verbindung. Dies geht soweit, dass beide im Schatten vollständig miteinander verschmelzen. Letztlich sind dann die Flügel von dem Schattenriss abgelöst und werden selbst von der Akteurin geschultert, die jedoch nach verschiedenen Flugversuchen, die sie in den einzelnen Performanceszenen zeigt, im Salzgrund geerdet am Boden hocken bleibt. Auf sehr anschauliche Weise verbinden sich in dieser Performance durch das eingesetzte Closed-Circuit-Verfahren, unterschiedliche Realitätsebenen in einem Raum: Neben der Handlung der Künstlerin erscheint ihr projiziertes Videoabbild. Liest man die Bildprojektion wie herausgearbeitet als Identifikationsbilder, so ist die Künstlerin nun selbst zu ihrer eigenen Projektionsfigur geworden, die in die Rolle der Engelsfrau schlüpft. So wird der Aufführungsort hier selbst zum Transformationsraum. ${ }^{916}$

913 Ziegler 1986, S. 12. Das graue Schwert wäre somit ein Zeichen dafür, dass der geist „fliegen“ kann.

914 Vgl. Kap. II.5.3.

915 Die Bronze steht für den Bauchbereich, zum Beispiel für Individualismus und Entscheidungen „aus dem Bauche heraus“, verkörpert das emotionale Denken.

916 Dieser künstlerisch inszenierte „Zwischen-Raum“ erinnert wiederum an die „Or-PheliaAktion“, bei der auch von einer „dritten Tür“ gesprochen wurde, die sich zwischen Leben und Tod auftat. Im Werk von Ulrike Rosenbach spielt das Schweben - ähnlich wie bei Bill Viola eine wichtige Rolle. Sie arbeitet aber mit der Luft als Umgebungselement - dem Atem als elementarem Lebenselement - , betont damit eher die geistige als die materiell-körperliche Dimension bei der Transformation. 

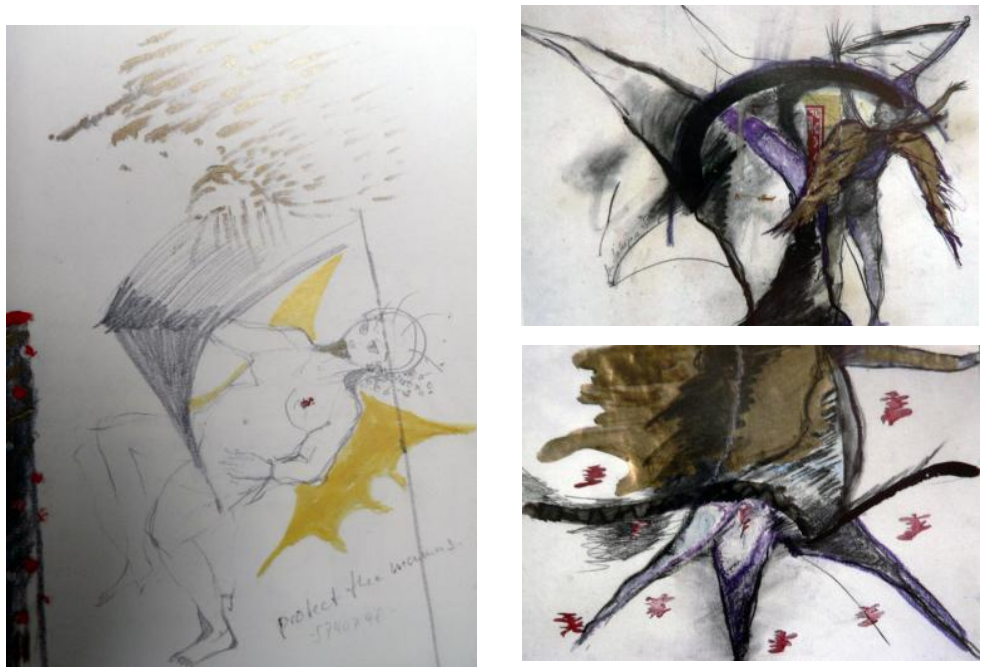

Abb. 268-270: Protect the Mamas, 1990 und Baumengel (zweiteilig), 1985, Zeichnungen

Während in den Installationen und Performances die geflügelte Frau nur als schwarzer Schattenriss auftaucht und der dunkle Grund damit Schablone bleibt für die eigene Imagination der Betrachtenden, taucht das Motiv des Engels in freierer Form in den zahlreichen Zeichnungen der Künstlerin immer wieder auf. ${ }^{917}$

\section{V.5. Skulpturales aus Licht und Energie - Die Ikonographie der 1990er}

In den 1990er Jahren definiert die Künstlerin ihre Lehre an der Hochschule für Künste in Saarbrücken als einen wichtigen Teil ihres künstlerischen Schaffens. Daneben arbeitet sie weiter mit den Medien des Videotapes, der Videoinstallation und der Performance. Dabei zeigt ihr zu Beginn dieses Jahrzehntes entstandenes Videotape „Osho Samadhi“ wieder ihre klare, buchstäbliche Bildsprache mit einer großer Bezogenheit von Form und Inhalt. Zudem trat gerade bei diesem Werk eine starke Zahlensymbolik in den Blick.

Die analytischen Streiflichter betrachteten die in diesem Jahrzehnt entstandenen Videoinstallationen und -skulpturen aus unterschiedlichen Perspektiven. Für das Werk „Herzpendel“ zeigte sich der Aspekt der materialisierten Energie als elementar. Im „Requiem für eine Eiche“ wie auch im „Eisernen Zeitalter“ begegneten Metallgestelle als Träger der bildgebenden Monitore und es zeigte sich eine

917 Im „Baumengel“ löst sich eine geflügelte Gestalt zum Beispiel aus einem Stamm, die Zeichung aus dem Jahr 1985 ist zweiteilig mit jeweils den Maßen 50 x $60 \mathrm{~cm}$. In „Protect the Mamas“ (Zeichnung 1990, 21 x $30 \mathrm{~cm}$ ) liegt eine Frau auf dem Rücken, hinter dem zwei gelbe Flügel hervorragen. Ein weiteres Blatt mit dem Titel „Hitlerengel“ (Zeichnung 2002, 21 x $30 \mathrm{~cm}$ ) zeigt ebenfalls eine geflügelte Figur. 
große Nähe dieses Materials zu den inhaltlichen Aussagen. Der Baum wird zu einem wesentlichen Lebenssymbol im Wirken Rosenbachs in diesem Jahrzehnt und begegnet in Details in unterschiedlichen Arbeiten, ganz augenscheinlich dann in der Rauminstallation „Schlacht der Bäume“, die einen ehemaligen Militärbunker in einen Raum des wieder erwachenden Lebens verwandelte. Auch im „Bild der Frau in der Nachkriegszeit" klingt das Thema Krieg an, dessen Folgen die Künstlerin analysiert und gleichzeitig transzendiert. Denn zunehmend dringt das Spirituelle in die Werke Rosenbachs, das im „Hildegard Walk“ in Form einer virtuellen Begegnung mit der Mystikerin Hildegard von Bingen in Erscheinung tritt. Wenn der Rezipient im „Hildegard Walk“ analog zu einem Spiegelbild auf die Protagonistin in der Bildprojektion zu geht, kann er in der Videoskulptur ganz konkret „Über den Tod“ schreiten, bevor er dann im „Im Palast der neugeborenen Kinder" selbst wieder in eine Kindperspektive schlüpft. Zu den Rauminstallationen Rosenbachs in diesem Jahrzehnt gesellt sich zudem der „Last Call für Engel“. Das Thema der Engel und Transzendenz, das in verschiedenen Installationen schon anklang, wird dann in drei Aktionen bearbeitet und mittels Licht, Projektionen und Schatten mit Leben gefüllt.

Der Blick auf die Arbeiten der 1990er Jahre zeigt einen Wandel von der in den 1980er Jahren im Werk der Künstlerin vorherrschenden Ausdrucksform der Performance hin zum skulpturalen Medium der Videoinstallation. Diese Wandlung im Oeuvre Ulrike Rosenbachs geht konform mit einem allgemein zu erkennenden Trend innerhalb der internationalen Video- respektive Medienkunst. Diese wendet sich in den 1990er Jahren - auch aufgrund der perfektionierten technischen Möglichkeiten - raumgreifenden, installativen Lösungen zu. Die Ausweitung der technischen Möglichkeiten zum Ausklang des 20. Jahrhunderts, durch zum Beispiel digitale Bildbearbeitungsmethoden und die Entwicklung sehr lichtstarker Videobeamer, spiegelt sich auch in den Werken Ulrike Rosenbachs wider. Werden in ihren Tapes aus dieser Zeit nun eigene elektronische Aufnahmen oder filmisches Found footage digital überarbeitet und mit 3D- oder auch Farbeffekten versehen. Mit der Rückbesinnung auf installative Werke wird zudem auf der formalen Ebene im Schaffen der Künstlerin ein Kreis geschlossen. Kehrt sie doch zu ihren künstlerischen Wurzeln - der Bildhauerei - zurück, die hier mittels elektronischer Bildverfahren um die Dimension des Temporären erweitert wird. Dabei nimmt Ulrike Rosenbach in ihren künstlerischen Untersuchungen in diesem Jahrzehnt grundlegende Fragen des menschlichen Seins in den Blick, die die Künstlerin aus einer bestimmten Perspektive betrachtet. Anders als in den Jahrzehnten zuvor, tritt nun ihre eigene Person in den nun entstehenden Videoarbeiten in den Hintergrund. In der medialen künstlerischen Auseinandersetzung zeigt sich aber weiter ein im Gegenständlichen verankertes Wandeln zwischen unterschiedlichen Ebenen, wie der Innen- und der Außenwelt. Während die Künstlerin in dem zentralen Performancezyklus „Über die Engel“ explizit in die Rolle eines zwischen den 
Seinsebenen wandelnden Engels schlüpft und auf künstlerische Weise dem Zuschauer ein Angebot macht, an ihren spirituellen Erfahrungen teilzuhaben, ließ sie den neugierigen Betrachter in ihrer Bodenskulptur „Über den Tod“ aktiv eigene Erfahrungen machen, in dem sie diesen einlud ganz buchstäblich über den Tod zu schreiten, visualisiert durch eine einnehmende Vision innerer Bilder. In einer ihrer jüngsten Rauminstallationen lässt die Künstlerin den Besucher eintauchen in eine überdimensionale Gebärmutterhöhle, um den Rezipienten aus einer Kindperspektive etwas über ihre düstere Vision von Kindheit erfahren zu lassen.

Die Künstlerin bricht in diesen dichten Arbeiten, die in der zweiten Hälfte der 1990 er Jahre entstehen die gewohnten Sichtweisen auf und vermittelt durch ungewohnte Perspektiven neue Einblicke in parallele Seinsebenen. Diese imaginierten Wirklichkeitsebenen werden mittels elektronischer Bildverfahren vor Augen geführt und in einen atmosphärisch aufgeladenen Klangraum eingebettet.

„Gerade die Simulationen generierter Computerbilder vermögen visuelle Schablonen innerer Bilder zu erzengen, die auf ganz. andere Weise den inneren Dialog wiedergeben. In der Überschreitung des Statischen, der Überlagerung von Wirklichkeitsebenen, der Verschmelzung von akustischen und visuellen Bezügen $u$. ̈̈. wird eine Transformation von Erlebnisschablonen geschaffen, die eine Transzendenz des Realen eröffnet. Es ist die Einbeziehung der vierten Dimension in der Überschreitung von Raum und Zeit, die in der Verknüpfung von Bildvisionen, dem Netzwerk der Computeranimation und multimedialer Kommunikation zustande kommt.

Die geträumten Bilder in ihren Wunsch- und Angstvisionen wie auch im Vorausdenken einer anderen Wirklichkeitsdimension scheinen damit die nachgestellten Bilder des Filmes zu überschreiten und in der Generierung des Bildmaterials eine geronnene Spur einer zuvor nicht gestaltbaren Wahrnehmungsvision festzuhalten. Damit wird das Phantastische als nur geträumte und gedachte Vision zur festen Bildschablone, die dem Betrachter seine individuelle Wahrnehmung voraus nimmt. Das Bild wird zum sprechenden Organ, das sich im Sichtbaren verkleidet, das in den beweglichen Montagen täuschend echt die Realität einzufangen vermag. Zugleich wird der Entwurf einer kollektiven Gedächtnisschablone über das kulturelle Netzwerk vorgegeben, und zwar im Speichermedium einer intermedialen Kommunikationsstruktur." "18

Die Künstlerin beschreibt in ihren Werken der 1990er Jahre immer wieder Grenzgänge zwischen dem Diesseits und einer imaginierten anderen Welt. Die Videotechnik mit ihren weit entwickelten Möglichkeiten der digitalen Bildgeneration und -animation ist seit spätestens Mitte der 1990er Jahre - neben der Malerei prädestiniert um solchen Imaginationen Ausdruck zu geben. Können hier doch

918 Hampe 1999, S. $253 \mathrm{f}$ 
realistisch wirkende bewegte Bildwelten entwickelt werden, die wie Abbilder von Realitäten wirken, doch künstlich generiert sind.919

In dieser eigene Bildwelten gestaltenden Nutzung der Videotechnik bei Ulrike Rosenbach zeigen sich Berührungspunkte mit den Werken anderer zeitgenössischer Künstler. An dieser Stelle soll exemplarisch das Werk der finnischen Künstlerin Eija-Liisa Ahtila (*1959) angeführt werden, deren Film- und Videoarbeiten ebenfalls von Erfahrungen des Übergangs sprechen. Die Finnin relativiert dabei in ihren sowohl als Mehrfachprojektionen als auch als Einkanalarbeiten funktionierenden Arbeiten bestehende Konzepte von Normalität und Abweichung und beschreibt einfühlsam die „Wahrheit“" vergangener Gefühle:

„Fern der Ironie formalistischer Medienreflexivität untersucht sie die Möglichkeiten, Wahrnebmung und Abbildbarkeit von Wirklichkeit erzäblerisch zu durchdringen. Abtilas Geschichten handeln vielfach von Grenzsituationen. Immer ein wenig rätselhaft, mit Witz und sensibel beobachtet, werden Erlebnisse und Erfahrungen des Übergangs geschildert: Mädchen auf der Schwelle zum Erwachsenwerden, die ihre körperliche Selbstwahrnehmung beschreiben (If 6 was 9, 1995), ein junges Paar im Prozess seiner Trennung (Consolation Service, 1999), Wissenschaftlerinnen, die die Ausmaße einer nuklearen Katastrophe zu begreifen versuchen (Gray, 1993). "'20

Auf der documenta 11 war Ahtilas Arbeit „The House“ ${ }^{(621}$ als Raumprojektion zu sehen. In dem verdunkelten Saal wurde das filmische Geschehen gleichzeitig auf drei der Wände projiziert, so dass den Anwesenden der Eindruck vermittelt wurde, sich inmitten eines imaginären Wohnzimmers zu befinden:

„The House (2002) ist die Geschichte einer Frau, die Stimmen zu bören beginnt, welche immer stärker ihre Wahrnehmung beeinträchtigen und die Zeit und den Raum um sie herum durchdringen. Um den Stimmen näher zu kommen, begibt sich die Protagonistin in einen Zustand der Isolation." "'22

919 Bei all diesen künstlerischen Grenzgängen ist es wichtig, dass die Künstlerin Grenze real nicht überschreitet, damit sozusagen auf dem Boden bleibt, wie in den Engelperformances. So auch in der Installation in Schleswig 2001 „Nur nicht Überstür-ZEN“, die ironisch die Verzweiflung des Psyche Themas wieder aufnimmt, nun aber mit Humor wandelt.

920 Metzel in: Kat. Kassel 2002, S. 12

921 The House, 2002, DVD-Projektion auf drei Leinwänden, Farbe, Ton, 14 Min; The House basiert auf Gesprächen mit Frauen, die eine Psychose überwunden haben. Berichte vom Verlust kohärenter Raum- und Zeiterfahrung bis zum Zusammenbruch der Logik der Wahrnehmung finden in Ahtilas diskontinuierlichem Erzählmodus ihre formale Entsprechung. (Vgl. Metzel in: Kat. Kassel 2002, S. 12)

922 Metzel in: Kat. Kassel 2002, S. 12 


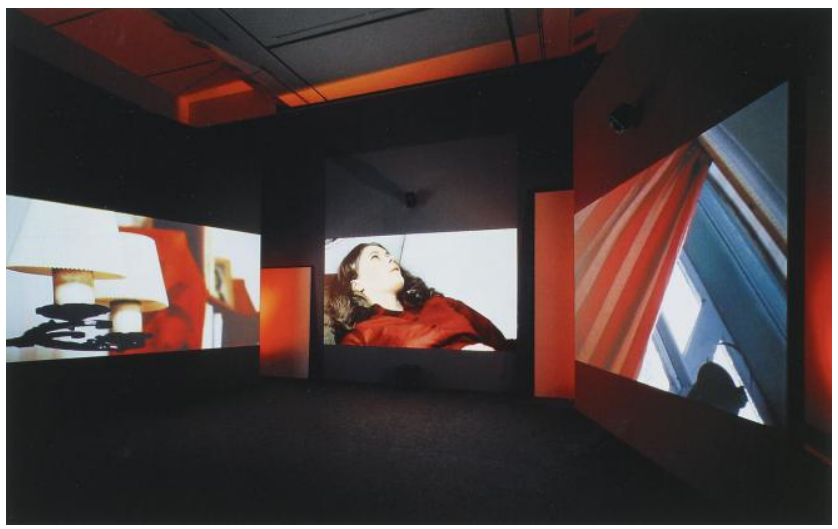

Abb. 271: Eija-Liisa Abtila: The House, 2002, Installation

In dem Film beginnt zum Beispiel ein an der Wand hängendes Bild sich ohne ersichtlichen Grund zu bewegen oder auch eine schwarzweiße Kuh spaziert plötzlich lautlos durch den Wohnraum. Wenn zunächst noch unklar ist, ob diese Ereignisse „real“ sind, wird im Verlauf der rund 15-minütigen Geschichte deutlich, dass es sich um Wahnvorstellungen handelt, die anschaulich ins Bild gesetzt sind. Die Künstlerin ermöglicht den Zuschauern mit ihrer Inszenierung ein direktes Erleben einer Ausnahmesituation.

Ganz ähnlich werden auch die Videowelten von Ulrike Rosenbach zu Erfahrungsräumen anderer Wirklichkeiten. Die Künstlerin formuliert dabei eine ganzheitliche Botschaft, die sie in ihrer sehr buchstäblichen Bildsprache vermittelt. ${ }^{923}$ Es zeigt sich, dass ein zunächst oberflächlicher Zugang zu den Arbeiten an tiefere Symbolschichten rührt und die audiovisuellen Chiffren der Werke Ulrike Rosenbachs bilden dabei ein in sich schlüssiges System, eine eigene, bildhafte Sprache. Das Formenrepertoire wiederholt sich dabei, sowie die Bildsprache im Gegenständlichen verhaftet bleibt: Das Herz, der Baum, das geschlagene Tambourin, die Wolke oder auch die Fackel werden in diesem Jahrzehnt zu Symbolen, die von einer anderen Seinsebene und spirituellen Grenzerfahrungen Zeugnis ablegen.

Außerdem findet sich bei der Betrachtung der Formen, Zeichen und Requisiten in den Arbeiten Rosenbachs ein weiteres interessantes Phänomen. Wie bereits dargelegt, zeigte sich im bisherigen Werk die Belegung von verschiedenen Materialien mit bestimmten figurativen Bedeutungen, die damit zu visuellen Metaphern

923 Dabei entfernen sich die Arbeiten immer mehr von einer westlichen Lesart und werden von buddhistischen Anschauungen durchdrungen. Dies wird vielleicht am sinnfälligsten bei der Installation „Über den Tod“. Die vor Augen geführten Bilder der Skelette und Knochen berühren einerseits westliche Todesassoziationen, wie die des knöchernen „Sensemanns“ oder des „Totentanzes“. Die tiefere Symbolbedeutung dieser bildlichen Chiffren wird aber erst im Kontext buddhistischer Weltanschauung und der individuellen Chiffren der Künstlerin verständlich. 
werden, zu materiellen Ausdrucksträgern immaterieller Erfahrungs-schichten. Jetzt wandelt sich sukzessive die Beschaffenheit dieser unter-schiedlichen Ausdrucksträger. So wird zum Beispiel das Papier, das nun mit Öl getränkt wird, lichtdurchlässig und erlaubt den schemenhaften Blick auf das Dahinterliegende, wie im „Requiem für eine Eiche“ auf die Wurzeln. Diese Wandlung der Funktion lässt sich auch am Beispiel des Motives der Hand durch die Jahrzehnte im künstlerischen Wirken Rosenbachs verfolgen. So tauchte die Hand bereits früh in unterschiedlichen Gesten im Werk der Künstlerin auf. Während sie bei „Sorry Mister“ als schlagende Hand zum Einsatz kam, unterstützte ihre kämpferische Geste in der aus den späten 1970ern stammenden „Medusaimagination“ feministische Aussagen. In den 1980ern werden die Handzeichen dann zunächst subtiler eingesetzt. So bildeten in den „Schmelzprozessen“ die Schatten der Finger zweier Hände ein Herz oder die Hand der „Einsamen Spaziergängerin“ formte das Zeichen der Ganzheit. Die Or-Phelia-Frau kommunizierte schließlich aus dem Inneren ihrer Monitorwelt mit den Handgesten der Mudras. Außerdem verlängerte die Künstlerin in den 1980ern ihre Finger durch Bambusrohre, mit denen sie den Boden frei fegte. Diese Bambusfinger verwandeln sich in den Arbeiten der 1990er Jahre weiter zu roten Trommelschlegeln, die an einem Handschuh befestigt sind. In dem Engelszyklus sind einerseits trommelnde Schlegel zu sehen, andererseits verschattete Hände. Schließlich tastet im „Palast der Neugeborenen“ eine helle Handfläche aus den Tiefen des Monitors an die Bildschirmoberfläche, während sich die Kinderpaare an den Händen halten. Die Hand ist im Werk Rosenbach seit den Anfängen ein bedeutsames Motiv. Spätestens seit dem Aufenthalt der Künstlerin in den USA und der Auseinandersetzung mit der feministischen Ikonographie ist die Hand im Werk Rosenbachs Zeichen der Handlungsfähigkeit, und ihre Arbeiten sind zunehmend gekennzeichnet durch aktive Hände. Ab den 1980er Jahren tritt dann eine neue Kommunikationsform hinzu, die Hände beginnen Zeichen zu geben, in symbolisch-ritueller Form zu kommunizieren. Allerdings arbeitet die Künstlerin mit Zeichen aus anderen Kulturen und Religionen, seien es Symbole der Aborigines oder auch rituelle Handhaltungen dem Buddhismus, was einerseits für den Rezipienten einen Zugang zu dieser Informationsebene erschwert, andererseits die Aussagen transzendiert.

Das künstlerische Euvre Rosenbachs durchzieht ebenso das Motiv des körperlichen Schwingens, das ja in Zusammenhang mit der Salto-Mortale-Aktion untersucht wurde. ${ }^{924}$ In den 1990er Jahren erscheint es mehrfach im Videobild in Form einer schaukelnden Frau. Doch findet es sich auch in der Nienburger Engelsperformance wieder. Hier schwingt die Akteurin über einen längeren Zeitraum auf dem Boden stehend von ihrer rechten zur linken Seite und zurück - Sinnbild für ein meditatives Flugerlebnis.

924 Vgl. Kap. III.5.6. 
Auch der schwarze Scherenschnitt, der zusehends präsenter wird im künstlerischen Werk, kann gedeutet werden als eine materialisierte Form der dunklen, schattenhaften Seite der Frau oder auch ,schwarzen Frau“. 925 Gleichzeitig wird in den Arbeiten dieses Jahrzehntes auch ganz konkret das Element des Schattens als Leerstelle in die Installationen, wie auch Performances eingefügt.

Auch das Herz - als Symbol des Lebens und der wieder gefundenen Mitte findet sich schließlich plastisch und begreifbar in Rosenbachs Werk als Bronzeobjekt manifestiert. Und schließlich wird aus dem Bild der Enthauptung im „Denkmal" ${ }^{\prime \prime 26}$ in der das Thema Tod transzendierenden Arbeit „Über den Tod" ein gekröntes Haupt. Auch bleibt das Thema des Androgyn seit seinem Erscheinen im Werk Rosenbachs zu Beginn der 1980er Jahre bis zum Ende präsent. Tauchen doch im „Palast der Neugeborenen“ die Kinder jeweils als Paare auf. Jeweils ein Mädchen und ein Junge halten sich hier in ihrer artifiziellen Welt an der Hand.

Wenn der stete Bedeutungswandel wie aufgezeigt für viele Formen und Zeichen im Werk der Künstlerin signifikant ist, so trifft dies für ein Material offenbar nicht zu: Es ist das Salz. In vielen Performances und auch Installationen beziehungsweise Environments bildete das kristalline Material wortwörtlich den Grund, auf denen diese sich entfalten und die Künstlerin agiert. Dieser Salzgrund wird in unterschiedlichen Formen eingebunden: Er erscheint in Form des Streifens, des Kreuzes, des Dreiecks und am häufigsten als Kreis, hier auch in der Variante des angehäuften Kegels unter den Herzpendeln.

Dieser weiße Kreisgrund lässt sich in Beziehung setzen mit der Biographie der Künstlerin. Ist sie doch aus Bad Salzdetfurth gebürtig, einer kleinen Stadt am Rand des Harzes unter der sich Salinen finden. So wurde die Künstlerin quasi ,auf Salz geboren", und assoziiert mit diesem Material zunächst einmal ihre Herkunft, ihren Grund. ${ }^{927}$ Daneben steckt natürlich noch weitere Symbolkraft in diesem Mineral, das auch in der Alchemie elementar ist. Steht dort das „Sal“ doch für das Körperliche schlechthin. ${ }^{928}$ Außerdem gilt Salz in rituellen Zusammenhängen als reinigend. Doch wird in den 1990ern ein weiterer ikonographischer Aspekt dieses Materials im Werk Rosenbachs greifbar. Hat die Künstlerin doch zuvor in verschiedenen ihrer Werke, wie unter anderem der Eulenspieglerin, Kreise ausgeschnitten und dadurch weiße Flecken auf dem Grund entstehen lassen. Ein solcher weißer Fleck manifestiert sich in der Installation „Isabel im Wald“ ebenfalls auf dem Bildschirm, während der bildtragende Monitor inmitten eines weißen Salzkreises steht und damit einen „weißen Fleck“ inmitten eines „weißen Fleckes“ verbildlicht. ${ }^{929}$

\footnotetext{
925 Wie eine Arbeit zu Anfang der 1980er Dekade titelte.

926 Vgl. Kap. IV.3.

927 Interview in: DU, 1982, S. 41

928 Vgl. Kap. IV.5.1.1

929 Vgl. Kap. IV.6.1.
} 
Sowie dieser weiße Fleck einerseits für eine Lücke - respektive traumatische Erinnerungslücke - stehen kann, kann eine helle Leerstelle ebenso die Aufmerksamkeit auf diese Lücke lenken und zu einer Projektionsfläche für Fantasien oder auch Wünsche werden. Auch der Künstler John Baldessari arbeitet in vielen seiner Werke mit den Motiven Schatten wie auch Leerstelle. So fasste die Ausstellung „While something is happening here, something else is happening there“, die im Jahr 2000 in Hannover gezeigt wurde ${ }^{930}$, eine Reihe Fotografien zum Thema Schatten zusammen, die das Düstere und vielleicht auch Dämonische dieses Motives verbildlichten.

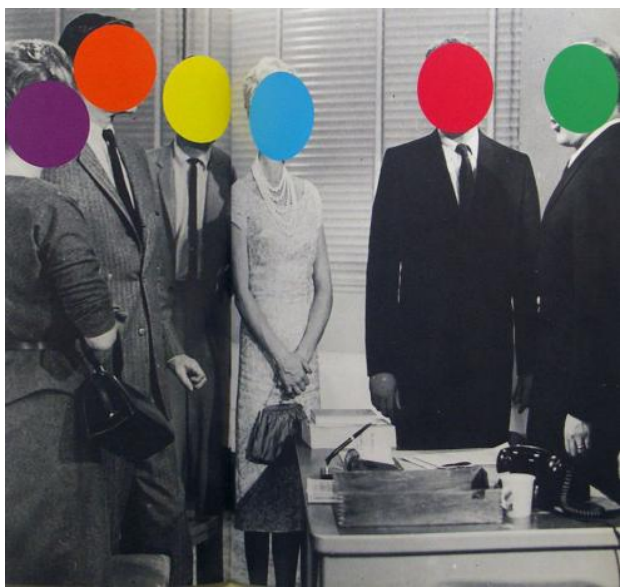

Abb. 272: John Baldessari: The Telephonebook (With Pearls), 1988, Fotografie

In jüngeren Collagearbeiten des amerikanischen Künstlers sind Bereiche der großformatigen fotografischen Abbilder ausgespart und durch knallige Farbpartien ersetzt worden. Bei Baldessari werden die vermeintlichen Leerstellen bunt eingefärbt, so dass diese irritierend ins Auge springen, die Darstellungen dominieren und die Fotografien nachhaltig verfremden. ${ }^{931}$

In den Arbeiten Ulrike Rosenbachs der 1990er werden die eingesetzten Symbole weiter komprimiert und der Farbe kommt eine zunehmende Symbolkraft zu. Außerdem ist eine sich verstärkende Entkörperlichung und Vergeistigung auf der Zeichenebene zu beobachten. Zudem kommt in diesem Jahrzehnt ein weiteres Phänomen hinzu. Die künstlerischen Aussagen werden auf eine spirituelle Ebene bezogen. Altes Material, das im Zitat wieder aufgenommen wird - wie zum Beispiel aus dem „Konzert im Gewaltakt“ - wird jetzt transzendiert. Auch konkret historische Themen - wie die Nachkriegszeit - werden in dieser Form sich über-

930 „Baldessari. While something is happening here, something else is happening there. Works 1988-1999“ im Sprengel Museum Hannover vom 26. September 1999 bis 2. Januar 2000.

931 Kat. Hannover 2000 und Kat. Berlin 2004 
lagernder Visionen künstlerisch verarbeitet, die Botschaften abstrahiert und auf eine zeitlose, zyklische Ebene gehoben. Auf diese spezifische Weise entwickeln sich die persönlichen Chiffren durch die Jahrzehnte im Werk der Künstlerin stetig in einem fließenden Übergang weiter. In diesem steten Überarbeiten der wiederkehrenden Motive und Themen aus einer zunehmenden Distanz scheint eine allmähliche Versöhnung ablesbar. Manches wird während dieses Heilungsprozesses konkreter, anderes verschwimmt und löst sich schließlich auf, wie der weiße Salzstrudel, der in „Über den Tod“ in den Tiefen der elektronischen Vision verschwindet. 



\section{Ausgänge - Metamorphosen in inneren Räumen}

Im Verlauf der Untersuchung wurden Aktionen, Videotapes, Installationen wie auch Fotografien der Künstlerin Ulrike Rosenbach analysiert. Es zeigte sich, dass ihre künstlerischen Werke aus den unterschiedlichen Schaffensjahrzehnten geprägt sind durch die jeweiligen zeittypischen Strömungen, wie Minimal- und Bodyart oder auch die Personal-Performance. Zudem sind die Werke der Künstlerin durch politische Aussagen geprägt. Wenn zunächst feministische Forderungen in Rosenbachs Arbeiten ihren künstlerischen Ausdruck finden, sind die Werke ab den 1980er Jahren eingebettet in die Ideenwelt der zu diesem Zeitpunkt auflebenden ökologischen Bewegung. Vor diesem Hintergrund bestätigte sich im Werk Rosenbachs das, was der österreichische Künstler und Mitbegründer des Zentrums für Kunst und Medientechnologie (ZKM) in Karlsruhe Peter Weibel in einem Vortrag herausstellte:

„Künstler sind ernsthafte Menschen, die sich mit den Phänomenen, die sie beschäftigen, intensiv auseinandersetzen." "932

Und die Künstlerin Ulrike Rosenbach sagt selbst:

„Ich denke wirklich, es ist wichtig zu begreifen, daß Kunst viel Arbeit ist. Theoretische und praktische Arbeit. Das ist ja bei Musik genau so. "933

Im Rahmen der Auseinandersetzung mit den künstlerischen Werken Ulrike Rosenbachs entwickelte sich ein Schwerpunkt in der Untersuchung ikonographischer und symbolischer Formen. Hier kristallisierte sich heraus, dass die Künstlerin eine individuelle Zeichensprache entwickelt hat, die getragen wird von alchemistischen und spirituellen Gedankenwelten, Symbolen und Metaphern.

Gespeist aus den Lehren verschiedener Religionen, der Alchemie, überlieferten Weisheiten und Philosophien und den damit verbundenen Erkenntnissen lotet Ulrike Rosenbach in ihren Werken in die Tiefen des menschlichen Seins, sucht und findet starke Bilder für die Leben prägenden Gefühle und Abläufe. Neben den inhaltlichen Schwerpunkten, die um Selbstfindung, Transformation und Heilung kreisen, sind auf der Ebene der formalen und stilistischen Gestaltung ihre künstlerischen Arbeiten durch ganz bestimmte, wiederkehrende Charakteristika geprägt.

Die zusammengetragenen Erkenntnisse sollen nun zunächst unter den drei Schwerpunkten Bildsprache, Körperzeichen und Tonvermittlung zusammen-

\footnotetext{
932 Peter Weibel bei einem Vortrag im Edith-Russ-Haus am 9.2.2007
}

933 Rosenbach im Gespräch 2001, vgl. Kap. VII.1. 
gefasst werden, bevor ein abschließender Blick auf das künstlerische Wirken der Künstlerin und ihre spezifische Form der Kommunikation auf tieferer Ebene geworfen wird.

VI.1. Eine klare Sprache der Bilder

„Ich bin Künstlerin. Ich denke in Bildern“9934, bemerkte Ulrike Rosenbach in einem Interview treffend, haben die vorangegangenen Untersuchungen doch in die spezifische Zeichenwelt und das klare Bilderdenken im Werk der Künstlerin eingeführt. Ihre Wahl der Motive und Ausdrucksträger ist geprägt durch symbolische wie auch psychologische Bezüge, und es stellte sich heraus, dass viele ihrer künstlerischen Aussagen quasi wortwörtlich visualisiert werden. Ein Vorgehen, das wie ein Blick zurück an die künstlerischen Anfänge der Künstlerin zeigt - das gesamte künstlerische Werk Ulrike Rosenbachs begleitet. Mit dieser visuellen Buchstäblichkeit in der Umsetzung kommt auch den häufig durch Wortspiele geprägten Titeln der Arbeiten eine nicht zu unterschätzende Bedeutung zu. Sie drücken die Grundaussage des jeweiligen Werkes in einer sonst eher für den englischen Sprachraum charakteristischen verschlüsselten und wortspielerischen Weise aus.

In den künstlerischen Arbeiten Rosenbachs zeigt sich zudem, dass jede der unterschiedlichen künstlerischen Ausdrucksformen - Fotografie, Videobild oder auch das Environment - mit einer spezifischen Funktion verknüpft ist. Diese Verbindung von Ausdrucksform und Funktion addiert sich in den Aktionen und Videotapes. Im Folgenden sollen nun diese Funktionen, die den einzelnen Elementen in Ulrike Rosenbachs Werk zukommen, umrissen werden.

\section{VI.1.1. Die Ausdrucksform als Funktionsträger}

Die Fotografie steht im Werk Ulrike Rosenbachs zunächst im Kontext der Dokumentation. Die in den Aktionen zu sehenden Schwarzweißfotografien zeigen äußere Abbilder von Personen - meist Frauen - oder auch Dingen. Fotomontagen hingegen verbinden unterschiedliche Bildmotive miteinander - meist eine Aufnahme der Künstlerin mit einem anderen Motiv - und generieren damit virtuelle Bildwelten, dokumentieren ein inneres Sein oder visualisieren ein Wunschoder Traumbild.

In die Aktionen eingeblendete Fotografien, die zunächst Zitate kunsthistorischer Vorbilder zeigen, übernehmen in Form großformatiger Bildprojektionen die Funktion von Idealbildern oder auch Identifikationsfiguren. Wenn zunächst aus technischen Gründen nur Diapositive projiziert werden konnten, finden sich ab Mitte der 1980er Jahre während der Aktionen auch Videobilder großformatig an die Raumwände projiziert. Dabei übernimmt diese Präsentationsform die gleiche Funktion des Idenfikatorischen wie die fotografischen Lichtbilder.

934 Kat. Dortmund 1995, o.S. 
Im Gegensatz dazu übernehmen die auf Monitoren vermittelten Videobilder eine ganz andere Aufgabe. Die aus dem „elektronischen Kasten“ flimmernden Bilder visualisieren innere Prozesse oder auch seelische Befindlichkeiten. Sie geben dem Betrachtenden Zeugnis eines energetischen Innenlebens. Ulrike Rosenbach merkte selbst an, dass ihre an ihre Körperbewegungen gebundenen Videoaufnahmen keine Dokumentationen äußerer Realitäten seien, sondern „Dokumente des Innenlebens “935. Die für die Closed-Circuit-Aktionstapes entdeckte Lesbarkeit lässt sich auch auf die anderen beiden Gruppen von Videoarbeiten im Werk Rosenbachs übertragen, seien es die frühen Studioproduktionen, wie auch spätere komplexer gestaltete Performancetapes: Diese Bilder vermitteln einen Zugang zu inneren Welten - Träume, psychische Prozesse oder Emotionen - die audiovisuell umgesetzt und innerhalb des künstlerischen Environments kommuniziert werden.

In den Aktionen aus den 1970er Jahren wurde auf der Bildebene des Videomonitors häufig eine Closed-Circuit-Schleife eingefügt und das Performancegeschehen dadurch um eine zusätzliche Bildebene erweitert. Diese gibt die Aktion meist aus einer spezifischen Perspektive wieder. Auch der gewählten Perspektive kommt dabei eine symbolisch-inhaltliche Bedeutung zu. ${ }^{936}$ Zeigt sich doch, dass für die Aufnahmen ein begrenztes Repertoire an unterschiedlichen Blickwinkeln gewählt wird. Am häufigsten zu finden sind hier folgende Aufnahmen:

- Aufnahmen, die an die Bewegung des Körpers gebunden sind: Das elektronische Auge erforscht in Nahaufnahme die widerständigen Beine beim „Projekt Kinem“ oder aber die Bilder auf dem Monitor drehen sich um sich selbst während des „Frauenkultur-Kontaktversuchs“.

- Aufnahmen, die vom Zentrum des Aktionsraumes nach außen oder entgegengesetzt von außen ins Innere gefilmt wurden: Der Kamerablick aus der Mitte in der „Einsamen Spaziergängerin“ fokussiert nach außen, gibt ein Detail der Handlung im Monitorbild wieder. Der Blick in die Mitte umkreist die im Bogen liegende Künstlerin in der „10000 Jahre-Aktion“, fokussiert damit auf die Schlafende, die im Monitor zu sehen ist.

- Aufnahmen, die aus einer Frosch- oder Vogelperspektive aufgenommen sind: Wenn die Froschperspektive das Aufgenommene erhöht, wie zum Beispiel in dem Flug der Psyche, findet sich die Vogelperspektive häufig eingesetzt, wenn es um eine Beobachtungssituation geht, wie zum Beispiel beim „Tanz für eine Frau“ oder auch bei „Isolation is transparent“.

- Nahaufnahmen von Gesichtern - frontal oder im Profil.

935 Rosenbach in: Rosenbach 1982, S.115; Dies stellt auch Barbara Engelbach heraus: „Weil sie die Videoaufnahme an ihre Körperbewegungen binde, seien ihre Aufzeichnungen keine Dokumentationen, sondern „Dokumente des [ihres] Innenlebens“. (Engelbach 2001, S. 59)

936 Vgl. auch Panofsky 1978 zur symbolischen Bedeutung der Perspektive. 
Dabei wird während der Aufnahmen - wie auch bei der Wiedergabe - sehr häufig mit dem Einsatz von Spiegeln gearbeitet, so dass der Betrachtende schließlich ohne dass es unbedingt deutlich erkennbar sein muss - ein Spiegelbild sieht und der direkten Aussage damit eine weitere symbolische - nicht sofort ersichtliche hinzugefügt wird: Das Videobild ist rein technisch Spiegelbild, das in der künstlerischen Umsetzung den Blick unter die Oberfläche der Dinge ermöglicht, den Blick ins Innere öffnet.

Innerhalb der unterschiedlichen Videotapes der Künstlerin zeigen sich weitere spezifische Stilmittel, die im Verlauf des Gesamtwerkes wiederkehren. Die ersten Tapes der Künstlerin zeigen schwarzweiße Sequenzen, die in einer festen Einstellung aufgenommen wurden. Bereits bei diesen Arbeiten findet sich gelegentlich ein Zusammenfügen zweier Bildinhalte, hier auf der materiellen Ebene gelöst durch das Hinzufügen einer Abbildung oder eines Fotos zur vor der Kamera agierenden Künstlerin. ${ }^{937}$ In einem zweiten Schritt wurden dann auf elektronischem Weg zwei Bildebenen zusammengefügt. Hierbei wird dann vielfach mit der Bildüberlagerung gearbeitet - einem Gestaltungsmittel, das man als videotypisch bezeichnen könnte. Das Überblenden zweier oder auch mehrerer Bildsequenzen durch die elektronische Bildbearbeitung ist leicht möglich und unterstreicht zudem die fließende Struktur der elektronischen Aufnahme. Unterschiedliche Bildebenen und Inhalte - häufig aus den beiden Bereichen Natur und Mensch - werden mit dieser Technik ganz sinnfällig miteinander verbunden.

Ab Anfang der 1980er Jahre finden sich dann durchgängig farbige Videoarbeiten im Werk der Künstlerin und ein weiteres elektronisches Gestaltungsmittel tritt hinzu: die Streifen- beziehungsweise Rahmenblende. Zum einen können auf diese Weise neue Bildinhalte vorhandene fließend ablösen, sei es, dass das neue Bild vom Zentrum nach außen wächst, oder sich vom Rand allmählich ins Bild schiebt. Zum anderen kann mit der Rahmenblende, die häufig bei den so genannten „Meditationstapes" zu finden ist, die innere Bildsequenz von einem äußeren Rahmenbild umgeben werden. Auf diese Weise werden auch bei dieser formalen Gestaltung der Aufteilung der Bildschirmfläche in mehrere Motive unterschiedliche Bildinhalte miteinander verbunden und ein inhaltlicher Bezug zwischen Innen und Außen visuell umgesetzt. Als drittes Gestaltungsmittel tritt zu diesem Zeitpunkt auch das so genannte Blue-Box-Verfahren hinzu. Bei diesem elektronischen Effekt werden bestimmte farbige Partien einer Bildsequenz durch Aufnahmen einer anderen Videosequenz ersetzt. ${ }^{938}$ So steht auch hier das Verbinden zweier Inhalte in einem Bild im Mittelpunkt. Ulrike Rosenbach nutzt dieses Gestaltungsmittel besonders intensiv in ihrem Eulenspieglerin-Tape, in dem Dokumentaraufnahmen von anderen Bildsequenzen durchdrungen werden und entsprechend ein Durch-

937 Anders als zum Beispiel Valie Export in „Raum sehen - Raum hören“ (1974), die mit der Teilung der Bildfläche arbeitet und zwei Sequenzen synchron und nebeneinander zusammenfügt.

938 Zum Beispiel bei „Eleven“, vgl. Kapitel IV.4.2. 
schauen der oberflächlichen Erscheinungsweisen der Dinge visualisiert wird. Allgemein lässt sich zusammenfassen, dass die drei genannten elektronischen Gestaltungsmittel in den Videoarbeiten Ulrike Rosenbachs genutzt werden, um neue Bildwelten zu generieren, die unterschiedliche Raum- und auch Zeitebenen miteinander in Beziehung setzen.

Die mit zeichenhaften Aussagen aufgeladenen Monitorbilder werden wiederum in die Aktionen, Rauminstallationen oder Medienskulpturen eingefügt. Diese drei Kunstformen sind im Werk Ulrike Rosenbachs charakterisiert durch ihre räumlich-materielle Dimension. So kommt auch dem Raum eine konkrete Funktion zu: Er übernimmt die Aufgabe des Handlungsraumes für die Künstlerin beziehungsweise des Erfahrungsraumes für sich selbst wie das Publikum. Zwei räumliche Situationen lassen sich dabei in den Arbeiten Rosenbachs grundsätzlich unterscheiden: zum einen Aufführungen in Innenräumen und zum anderen solche in der Natur. Einige der frühen Aktionen der Künstlerin - bis zum Beginn des zweiten Schaffensjahrzehntes - wurden im Freien aufgeführt. Später dann zeigte sie die Performances, wie auch alle ihre Installationen durchweg in Innenräumen. ${ }^{939}$ Die Aktionen im Freien waren eingebunden in die gegebene Umgebung. Es wurde ein umgrenzter Parcour aufgebaut und gestaltet, wobei die natürlichen Gegebenheiten in die Aktionen eingewoben werden. So findet sich mehrfach im Werk, dass Bäume in die Handlung eingeflochten sind, und die Künstlerin - zum Beispiel mittels eines Seiles - mit ihnen in Verbindung tritt.940

Spielen die künstlerischen Aktionen in Innenräumen, wird ebenfalls auf die vorgefundene räumliche Situation Bezug genommen. In jedem Fall ist in den Innenraum-Aktionen der Fußboden einbezogen, meist auch noch mehrere Wände und gelegentlich ebenfalls die Decke. Der Boden wird in den Aktionen und Installationen häufig mit einer Salzdecke überzogen, doch auch Kies, Bildreproduktionen oder Spiegelfolie finden sich dort angeordnet, auf denen agiert wird. So wie auch schließlich - in einer der späten Rauminstallationen - die überdimensionale, schwarze Schattenfigur auf dem Boden ausgebreitet liegt.

In einer Vielzahl der Aktionen werden auf eine oder mehrere Wände des bespielten Raumes Lichtbilder oder Schatten projiziert. Auch werden an die Wände Gegenstände gehängt oder sie werden mit Papier überzogen - einfarbig in schwarz oder weiß oder auch mehrfarbig bunt bemalt -, auf das dann zum Teil gemalt wird oder das manchmal auch zerrissen wird. Und auch an den Raumwänden taucht die für die späteren Arbeiten Rosenbachs charakteristische geflügelte Gestalt aus dunklem Papier auf, deren Vorbild eine antike Wandmalerei ist. In wenigen Aktionen wird auch die Decke des Aktionsraumes mit einbezogen. Sei es,

939 Wobei die „Or-Phelia-Skulptur“ für die documenta zunächst für einen Standort in den Karlsauen konzipiert war, was sich aber aufgrund der technischen Gegebenheiten nicht umsetzen ließ, so dass die Installation doch im Innenraum gezeigt wurde, wie Wulf Herzogenrath anmerkte.

940 Zum Beispiel beim „Requiem“ oder im „Tanz um einen Baum“. 
dass etwas von ihr abgehängt wird - wie zum Beispiel eine Trapezschaukel oder Papierbahnen - oder auch an diesen Raumteil werden Bilder projiziert.

Auffallend ist, dass die Räume in der Regel nicht geformt werden, sondern sich auf die gegebene Situation bezogen wird. Diese Bezugnahme auf den örtlichen Gegebenheiten spiegelt sich noch in zwei weiteren Aspekten wider. So bezieht sich die Künstlerin häufig explizit - auch inhaltlich - auf den Aufführungsort: Sei es mit dem monumentalen Kasseler Herkules, dessen großformatiges Abbild sie unter die Dachschräge des Fridericianums „quetschte“, sei es in der Münsteraner Brabender-Skulptur in der dort aufgeführten „Ewa-und-Adam-Aktion“ oder dem zweiten Teil der „Or-Phelia-Aktion“, das sich im christlich-sakralen Raum in ein „Osterstück“ verwandelt. Die Künstlerin arbeitet mit den konkreten örtlichen Gegebenheiten und nutzt diese für ihre eigenen Aussagen.

Auch wird - wenn es den Galeriegegebenheiten entspricht - in den Werken Rosenbachs mit unterschiedlichen Räumen gearbeitet. So zum Beispiel in der „Maifrau“ oder der „Spaziergängerin“. Das Bespielen mehrerer Zimmer ist gekennzeichnet durch die klare räumliche Trennung der Aufführungsorte. Dabei verbleibt die Künstlerin jeweils allein - mit ihrem Publikum - in einem bestimmten Raum. Die anderen Räume werden mit Licht(-ab-)bildern gefüllt oder aber ihre Tochter als Partnerin nimmt dort während der künstlerischen Aktion Platz. Dabei scheinen an diese unterschiedlichen Aktionsräume auch verschiedene Zeitebenen geknüpft zu sein. Gegenwärtiges in dem einen Raum wird auf diese Weise mit einer Vorstellung von Immerwährendem, Kosmischem - allgemein einem Ideal kontrastiert - der gegenwärtige Erfahrungsraum um die Dimensionen der Vergangenheit oder auch Zukunft erweitert.

Während die Environments, die belebt und bespielt werden, in den frühen Aktionen kaum verändert wurden - hier vielmehr der Körper im Mittelpunkt der Bearbeitung und Modellierung stand - zeigt sich zum Ende des ersten Jahrzehntes eine deutliche Wandlung im künstlerischen Schaffen: Die Ordnung der Räume wird verändert während des künstlerischen Agierens. Die künstlerische Handlung wird auf diese Weise regelrecht in die Umgebung eingeschrieben und die zuvor angelegten Environments werden umgestaltet und durch die Aktionen in spurtragende Räume verwandelt. Diese - meist eine Weile nach der Performance noch als materielle Spur zugänglichen - räumlichen Handlungsträger bleiben jedoch in der Regel eine temporäre Erscheinung und werden mit Ausstellungsschluss wieder abgebaut. ${ }^{941}$

Ein Blick auf die Rolle des Publikums bei den Performances von Ulrike Rosenbach zeigt, dass dieses durchweg außerhalb der umgrenzten Aktionsfläche bleibt oder in einem abgesperrten Bereich innerhalb des Handlungsradius. ${ }^{942}$ Der

941 Anders ist es bei dauerhaften Rauminstallationen, die längerfristig aufgebaut bleiben, die dann jedoch unabhängig von einer Aktion entstanden sind.

942 Wie zum Beispiel bei der „Paulus-Aktion“ in Bremen. 
künstlerische Erfahrungsraum bleibt damit deutlich abgegrenzt vom Außen des Publikums. Dabei weist die Künstlerin jedoch auf den kommunikativen Aspekt, der sie während der Aktionen mit dem Publikum verbindet. Etwas, das sie selbst als „psychologisches feedback“ "benennt. ${ }^{943}$ Mit dieser Rückkoppelung agiert sie auf unterschiedliche Weise und findet dafür innerhalb ihrer Improvisationen spontan bildhafte Ausdrucksformen.

Der wesentliche Ausdrucksträger ist dabei der Körper der Künstlerin. Er ist in den Aktionen das aktive Medium, womit auch seine Funktion als wesentlicher Handlungsträger umrissen ist. Wenn es in der Kunstform der Performance nahe liegt, den Körper zum Handlungsträger zu machen, ist auch bei den Videotapes Rosenbachs auffällig, dass die Videobilder überwiegend durch figürlichkörperliche Darstellungen - meist Abbilder der Künstlerin - geprägt sind. Abstraktes findet sich in den Tapes hingegen kaum verbildlicht. Die eingesetzten Bilder sind vielmehr an Natur- beziehungsweise Kulturformen gebunden, wenngleich sich auch abstrahierte Darstellungen finden.

Die räumlichen Environments, in denen die Künstlerin agiert, werden auf spezifische Weise gestaltet und auch in den Tapes wird mit unterschiedlichen Materialien und Gegenständen gearbeitet, die aber wiederkehren und somit ein begrenztes Repertoire bilden. Diese Gegenstände fungieren ebenfalls als Ausdrucksträger und dieses auf symbolischer Ebene ,sprechende“ Repertoire wird im Folgenden umrissen.

\section{V1.1.2. Eine Systematik der Zeichen}

Neben den zentralen Medien des Körpers und des Videobildes im Werk Rosenbachs finden sich die Environments durch verschiedene Objekte oder Materialien gestaltet, mit denen im Verlauf der Handlung gearbeitet wird.

„Rosenbach setżt nie gewöhnliche Gegenstände ein, die sie zufällig findet, sondern sie wäblt solche aus, die bereits mit kulturgeschichtlichen oder symbolisch-rituellen Vorbedeutungen besetzt sind. Hierbei muss man betonen, dass die Künstlerin ibre Materialien danach aussucht, wie sie in sperifischen Eigenschaften übereinstimmen, obne dass sich diese Qualität auf den ersten Blick offenbart. Dies bedeutet zum Beispiel, dass die Plastikfolie, die Vaseline und die Bildröbre (um einige beliebige Dinge auszuwählen) auf den ersten Blick sicher keine gemeinsamen Gebrauchseigenschaften baben, doch sie besitzen auf den zweiten Blick mindestens eine gemeinsame Eigenschaft, die einer teilweisen Transparen₹, obne eigentlich durchsichtig zu sein. "944

So erläutert Gerhard Glüher Rosenbachs Vorgehen. Dabei stellte der Kunsthistoriker des weiteren heraus, dass drei Materialien in den Werken der Künstlerin ste-

\footnotetext{
943 Rosenbach im Gespräch 2001, vgl. Kap. VII.1.

944 Glüher 2005, S. 141-143
} 
tig wiederkehren: Salz, rote Videokabel beziehungsweise Wolle und Seidenpapier. Deren konkrete symbolische Bedeutung umriss er wie folgt. ${ }^{945}$ Für die anderen in Variationen eingesetzten Materialien wies er auf semantische Ketten, deren Bedeutung aber jeweils erst im spezifischen installativen Kontext geklärt werden könnte. ${ }^{946}$

Für das Salz, das im Werk Rosenbachs in der Form des Kegels aufgehäuft oder auch als Fläche ausgebreitet auftaucht, stellte er bezüglich der Symbolik im Kontext des Werkes heraus, dass das Mineral ein Kulturgut sei. So stehe Salz in Mythen zum Beispiel für etwas Göttliches:
„(...) mit Salz wurde Unheil vertrieben, und die Menschen besiegelten Freundschaften mit ihm. Die Bedeutung des Salzes als Kulturgut, das in Kunst, Literatur und Religio- nen über Jabrbunderte binweg geehrt wurde, ist heute verloren gegangen. Salz ist außer- dem ein Heilmittel. Im westeuropä̈schen Kulturbereich findet es in der Kur-und Bade- kultur Anwendung. Doch im Mittelalter wurde vor allem im keltischen Raum um Hall eine Art von Loge oder Geheimbund geführt, der die traditionelle, so genannte ,Haller Medizin' jabrbundertelang überlieferte und die Grundlagen für die Salimystik und Salzbeilkunde schuf. In der Salzmystike sind drei Eigenschaften von großer Bedeutung: Die Fäbigkeit zu scbütžen, zu reinigen und zu beilen." "947

Zudem hinterlasse das Agieren Rosenbachs Spuren in dem weichen Material und außerdem reflektiere das weiße Salz das Licht sehr gut. Die Künstlerin selbst erläuterte im Gespräch zu ihrer Nutzung von Salz:

„Ich habe häufig Salz, als Untergrund genommen, um die Böden zu neutralisieren, einfach um mir einen guten, neutralen Untergrund zu schaffen. Es ist sebr anstrengend, auf Salz Performance zu machen. Außerdem ist Salz auch bereits in der Alchemie transformatorisches Material. ' 948

Für die roten Videokabel bemerkte Glüher die Funktion des Verbindens, der Energieleitung an und benannte für die rote Wolle zudem die Assoziation der Nabelschnur. Bezüglich des Seidenpapiers wird von seiner Seite auf die Eigenschaft verwiesen, dass es durch seine Glätte eine gute Reflektions- und Projektionsfläche für die Video- und Diaprojektionen biete. Zudem wird die membranartige, durchscheinende Qualität hervorgehoben, die im künstlerischen Werk auch in der Funktion des Verhüllens eingesetzt werde. Seidenpapier umhülle in verschiedenen Arbeiten den Körper der Künstlerin, die Monitore oder die Wände des Raumes, beziehungsweise diene als Raumteiler und segmentiere die Aktionszonen. ${ }^{949} \mathrm{Au}$ -

\footnotetext{
945 Glüher 2005, S. 141-143

946 Glüher 2005, S. 143

947 Glüher 2005, S. 143

948 Rosenbach im Gespräch 2001

949 Glüher 2005, S. 144
} 
Berdem diene Seidenpapier als Zeichengrund. Ulrike Rosenbach merkte zur Verwendung dieses Materials in ihren Werken ergänzend an:

„Seidenpapiere habe ich wegen des Sounds gewählt. In der Zeit habe ich angefangen, mit Sprache zu arbeiten, Live-Sprache oder Live-Sound und um den Sound zu verstärken oder mir den Sound weiterzugeben mit Seidenpapier. Das knistert laut. Und was bei Seidenpapier für mich höchst wichtig war, ist die Durchsichtigkeit, also die Transparen₹. des Materials. Das hat auch etwas mit dem Thema Transformation zu tun. Dazu wird bei anderen Künstlern auch bäufig das Symbol des Wassers benutzt. " "950

Und an anderer Stelle erläuterte sie weiter, warum sie Papier und nicht textile Stoffe eingesetzt hat:

„Es hätten auch sehr viele Bahnen dünnen Stoffes sein können. Aber das war mir als Material zu kunstgewerblich. Es erinnerte mich zu sehr an den Kontext Frau, weil Stoff und Frau wird in der männlichen Kunstlesung sofort zusammen geschaltet. Frauenkunst ist mit Stoff verbunden. Deswegen habe ich das Seidenpapier genommen, und vor allen Dingen wegen des Raschelns. "'951

Auf die besondere Bedeutung des Sounds im Werk der Künstlerin wird weiter unten ausführlich eingegangen. Hier sollen nun zunächst noch die weiteren Materialien, die in den Werken Rosenbachs auftauchen, in den Blick genommen werden. Die Bedeutungen dieser anderen Objekte würden wechseln und während der jeweiligen Aktion mit neuen Bedeutungen aufgeladen, legte Glüher dar:

„Halten wir noch einmal fest, dass das ausgewählte Objekt je nach Intention des Ganzen der Aktion oder Installation handlungstragender und formgebender Bestandteil der Plastik wird. Der ursprüngliche ideelle oder materielle Wert, den die Dinge einmal gehabt haben, spielt keine Rolle mehr. Ganz im Gegenteil, die magisch-symbolische Aufladung vollizieht sich während des künstlerischen Prozesses. Mit diesem gezielten und bewußten Auswablakt und dem dann folgenden symbolischen Verwandlungsakt - sowobl in der Aktion als auch in der Installation - setzt sich Rosenbach ganz entschieden ab, sowohl von den Readymades als auch von den dadaistischen und surrealistischen Objekten der 20er-Jahre des 20. Jahrhunderts. "'52

Während der Gedanke der semantischen Ketten, die sich mit den Materialien verbinden, für das Werk zuzutreffen scheint, soll Gerhard Glühers Aussage, dass sich eine die alte Bedeutung bereinigende magisch-symbolische Aufladung erst während des künstlerischen Prozesses vollziehe, hier hinterfragt werden. Deutlich zeigt sich, dass die Auswahl der Materialien - wie von Glüher dargelegt - bewusst erfolgt und zwar nach deren kulturgeschichtlicher oder symbolisch-ritueller Vor-

950 Rosenbach im Gespräch 2001

951 Rosenbach im Gespräch 2001

952 Glüher 2005, S. 147 
bedeutung. Auf diese Weise versammelt die Künstlerin im Laufe der Zeit ein spezifisches und überschaubares Zeichenrepertoire, das sukzessive Ergänzung findet. Dieses benutzte künstlerische Vokabular lässt sich - inklusive der in den Aktionen Agierenden und den Gestaltungsmitteln der Videosequenzen - in folgende Element gliedern:

a) Auf der Bildebene:

Akteure: - allein

- mit Kind

- mit anderen - Frau

- Mann

Körper:

- Bekleidung

- unbekleidet

$$
\begin{array}{ll}
\text { - Trikot } & \text { - weiß } \\
\text { - Hosenanzug } & \text { - weiß } \\
\text { - Kleid } & \text { - rot } \\
& \text { - schwa } \\
\text { - sonstiges } & \text { - Body }
\end{array}
$$

- als Projektionsfläche

- in Details in Tapes - Kopf

- Bauch

- Brust

- Hand

- Füße

- in Bewegung: - Tanzen

- Liegen

- Hocken

- Sitzen

- Rollen

- Kreisen

- Schreiten

- Schlagen

- Schwingen - Arme

- ganzer Körper

Videotechnik:

- Monitorbild: - Closed-Circuit-Bild (Livebild)

(s/w, Farbe) - Bild vom Tape - eigenes Material

- Found footage 
- Projektion: - Closed-Circuit-Bild (Livebild)

(Farbe) - Bild vom Tape - eigenes Material

- Found footage

- auch Diapositive, die Bilder zitieren

- Kamera:

- Standkamera

- Persp. von oben

- Persp. von gegenüber

- bewegte Kamera

- Persp. von unten

- am Körper

- automatisch

- Kabel:- rot

Weitere Materialien:

- Salz

- Papier

- weiß

- schwarz

- Wolle

- rot

- Seile

- weiß

- rot (aus Gummi)

- Netz

- weiß

- Mullverband - weiß

- Holz

- Baum

- Blätter

- Zweige

- Rinde

- Wurzeln

- Klangholz

- Keule

- Sand

- Stoff - gelb

- durchscheinend

- Tusche

- schwarz

- Kreide - schwarz

- weiß

- bunt

- Glas

- Spiegel - eckig

- rund

- Splitter

- Metall 
- Feuer - ,echt“"

- im Videobild

- Eis

- Wasser

Formen:

- Quadrat

- Rechteck/Streifen

- Kreuz

- Dreieck

- Pfeil

- Kreis

- Spirale

Farben:

- Schwarz

- Weiß

- Rot

- Orange

- Gelb

- Blau

- Grün

- Gold

Objekte:

- Baum - Wurzel

- Zweig

- Blume - Margerite - weiß

- Rose - rot

- Flamingoblume

- Berg

- Bogen - Waffe

- Engel

- Regenbogen

- Flügel

- Fluss

- Frosch

- Fotografien -Schwarzweiß

- Farbe

- Gestell - aus Eisen 
- Glas

- Haube

- Herz - aus rotem Licht

- aus Bronze

- Kragen

- Kranz

- Madonna

- Messer

- Pfeil

- Pflanzen - Brennessel

- Kohl

- Sarkophag

- Schale

- Schatten - schwarz

$\begin{array}{ll} & - \text { grau } \\ \text { - Schal } & - \text { rot }\end{array}$

- Schleier

- Schrift- Runen

- Taozeichen

- Stab

- Stuhl - aus Holz

- Venus

- Vogel

b) Auf der Tonebene:

Sprechen:

- Stimme der Künstlerin - eigene poetische Texte

- zitierte Texte - Mythologie

- andere Stimme - Texte

- Märchen

Musik:

- instrumental

- klassisch

- elektronisch

- meditativ

- Gesang

- Rhythmus 


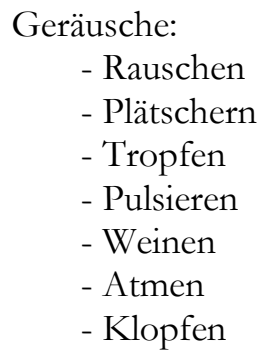

Effekte:

- Echo

- Wiederholungen

- Flüstern

Dieser begrenzte Materialkanon ist im Werk Rosenbachs bestimmt durch seine buchstäbliche Lesbarkeit entsprechend der diesen Dingen auf symbolischkulturhistorischer Ebene innewohnenden spezifischen Eigenschaften, denn prägend für die künstlerische Ausdrucksweise Rosenbachs ist die Symbolhaftigkeit ihres plastischen Denkens. In dem überschaubaren Repertoire an Formen sind bestimmte Motive von Anfang an dabei. Zum Beispiel auf der Bildebene der Kreis oder auf der Tonebene der Rhythmus. Auch das Motiv der Haube durchzieht das Werk in Variationen. Parallel zu ihr taucht - besonders im Frühwerk - der verschleierte Kopf mehrfach auf, der letztlich auch Symbol wird für - zu diesem Zeitpunkt noch- verborgenes Wissen.

Andere Motive kommen im Verlauf der Jahre sukzessive hinzu, wie der Baum oder der Engel. Allerdings werden die benutzten Objekte während der Aktionen nicht magisch aufgeladen, wie Glüher darlegte. Vielmehr werden die diesen Elementen innewohnenden symbolischen Bedeutungen an die Oberfläche geholt. So hat zum Beispiel das Salz in vielen Aktionen ganz konkret die Funktion des Grundes, auf dem die Akteurin agiert. Fäden, Seile, Schals, Kabel - wie auch das Netz - sind im Zusammenhang mit Verbundenheit zu lesen - in positiver wie auch negativer Bedeutung: Sie stehen meist gleichzeitig für Bindung und auch Hemmung.

Papier ist im Schaffen Rosenbachs ganz wörtlich im Sinne der Schicht lesbar, entsprechend der „Ge-schichte“. Allerdings begegnet es im Werk meist als weißes Blatt, das leer bleibt. Nur manchmal wird es mit Zeichen - Symbolen, Runen oder Buchstaben aus anderen Schriften - besetzt. Schwarzes Papier wird mit weißer oder farbiger Kreide beschrieben, eingefärbt, mit Körperzeichen versehen. Die transparente Eigenschaft des weißen Papieres nutzend, wird dieses auch eingesetzt 
als Schattenträger, wie im „Requiem für eine Eiche“, bei dem das Licht, die im Untergrund liegenden Dinge auf der Oberfläche sichtbar werden lässt.

Das Motiv des Baumes ist neben dem des Engels zentral im Werk der Künstlerin. Der Baum wird schon früh in das künstlerische Vokabular aufgenommen und taucht in ganz unterschiedlichen Formen auf. Im „Projekt Kinem“ wurde der zentrale Mandala-Baum zunächst durch einen Monitor ersetzt. Später bindet sich die Künstlerin in der ritualhaften Aktion „Tanz um einen Baum“ an einen im Grund verwurzelten Baum und zeigt damit buchstäblich ihre Verbundenheit mit diesem. Als Baum der Erkenntnis taucht das Motiv in der „Ewa-und-AdamAktion" auf, dort auch als pars pro toto in Form des Zweiges. Baumkronen und als in Licht getauchte Wurzeln sind häufige Motive in weiteren Werken der 1980er und 1990er Jahre. In dem Motiv des rhythmusgebenden Klang-Holzes in den „Lotusknospentönen“ manifestiert sich ebenfalls das Baum-Motiv, hier auch auf der Tonebene. Hölzerne Dinge sind damit im Werk Rosenbachs gekennzeichnet als - gelegentlich schlagkräftige - Wegweiser auf dem Pfad der Erkenntnis, zumal sich das wiederkehrende Zeichen des Baumes als „Alter Ego“ der Künstlerin beziehungsweise Grundsymbol des Lebens im Werkkontext herauskristallisiert.

Hingegen steht zum Beispiel Eisen - allgemeiner Metall - im Werk Rosenbachs im Kontext des Aggressiven und Männlichen. Dieser Lesart folgend ist das Feuer im Werk Rosenbachs als reinigend konnotiert, entsprechend des Neues erzeugenden Schmelzprozesses der Alchemie. In diesem - in die Tiefen der Symbolik - lotenden Sinne ist auch der Wind als geistige, das Wasser demgegenüber als emotionale Kraft zu verstehen. Wolle wiederum ist im Werk Rosenbachs nährend und weiblich konnotiert.

Die eingesetzten Gegenstände werden in den Aktionen im Raum verortet, dabei meist auf dem weißen Salzgrund verteilt. Im Rahmen der Installationen werden die Monitore hingegen häufig auch in Metallregalen präsentiert. ${ }^{953}$

Auffällig ist im Cuvre Rosenbachs zudem die Arbeit mit Gegensatzpaaren, zwischen deren Dualität versucht wird, zu vermitteln. Im Motiv des steten Schwingens von rechts nach links, aber auch in der rhythmischen Umrahmung auf der akustischen Ebene, wie zudem in der Figur des Schattenengels, der zwischen Dies- und Jenseits vermittelt, steckt das Thema des Verbindens von Polaritäten. Auch dem Spiegel, einem ebenfalls im Rosenbach'schen Werk sehr präsenten Motiv, kommt die Konnotation des Übergangs, der Transformation wie zudem der Reflexion zu. Es manifestiert sich in diesem Gegenstand eine anhaltende Suche nach einer hinter der Oberfläche der Dinge liegenden Wahrheit. Die Licht reflektierende Spiegelfläche wird so ganz wortwörtlich in den Arbeiten der Künstlerin als Reflektionsfläche genutzt.

953 Es ist interessant, dass diese Verortung in den Zeichnungen nicht existiert. Dort schweben Figuren und Gegenstände frei im Raum. 
Zudem findet sich das Motiv des Kreisens um die eigene Mitte durchgängig im künstlerischen Werk Rosenbachs. Die stete Drehbewegung und die damit verbundene Erfahrung einer inneren Harmonie und Balance wird schließlich in abstrahierter Form materialisiert und in das Objekt des Herzens übertragen. Ähnlich verhält es sich bei anderen Objekten im Werk Rosenbachs, die in materialisierter Form Erfahrungen wiedergeben. Zu diesen gehört unter anderem der geflügelte Schatten, der eine innerliche Aufwärtsbewegung ins Visuelle überträgt.

Die den Dingen innewohnende Symbolik kumuliert sich zudem. Zur Bedeutung des Materials addiert sich die jeweilige Form oder auch der Farbe. So blickt das Kind in den kleinen runden, die Gegenwart symbolisierenden Spiegel, während die Mutter vor dem historischen, eckigen Pendant steht. Bei ihr ist der klare Blick in die Vergangenheit verstellt, nachdem die Oberfläche mit Fett beschmiert ist. Wenn Kreis und Rechteck unterschiedliche symbolische Bedeutungen zukommen, so symbolisiert die Dreiecksform im Werk Rosenbachs entsprechend alter Überlieferung und anknüpfend an die Ikonographie des Feminismus das Weibliche, so wie die Spirale als Symbol des Lebens steht.

Die Bedeutung der Farben nimmt im Werk der Künstlerin im Verlauf der Jahrzehnte zu. Während in den Anfängen, bedingt durch die auf Schwarzweißwiedergabe reduzierte Videotechnik, Farben zunächst kaum eine Rolle spielten, arbeitet die Künstlerin besonders in ihren Tapes ab den 1980er Jahren explizit mit einer die Aussagen vertiefenden Farbsymbolik. Dies kündigt sich bereits in den "Judofrauen" mit der starken Schwarzweißsymbolik an und zeigt sich im späteren Werk besonders deutlich beim minimalistischen „Hildegard Walk“. Hier sind Blau als die Farbe des Geistigen, Weiß als Farbe des Lichtes und der Reinheit und Grün als Symbol der Hoffnung, wie auch des Wachstums und Lebens die drei maßgeblichen Farben. Häufig findet sich im Werk Rosenbachs zudem die Zusammenstellung der Farben Rot, Weiß und Schwarz. Dieser Farbkanon, der besonders in den Werken der 1980er Jahre begegnet, symbolisiert die Farben der Großen Mutter und stellt damit das künstlerische Wirken Rosenbachs in ein größeres Bedeutungsgeflecht im Zeichen feministischer Ikonographie. ${ }^{954}$

Das benannte künstlerische Vokabular fügt sich auf der symbolischen Ebene zu den komplexen Aussagen zusammen, wie Karin Thomas charakterisierte:

„Die Performances sind dabei so weit offen, daß jede einzelne Aktion zu neuen Bildund Begriffsüberlagerungen fübren kann. "'955

Auf diese Weise dringt Ulrike Rosenbach auf ihrem künstlerischen Weg immer tiefer in symbolische Bedeutungsebenen vor. Die Beispiele zeigen, wie diese Materialien mit spezifischen Eigenschaften verknüpft sind, die auf einer Zeichen- oder Symbolebene zu deuten sind. Im Sinne Mircea Eliades ist das Symbol eine „eigen-

954 Vgl. Kap. IV.5.2.

955 Thomas 1986, S. 353 
gesetzliche Form der Erkenntnis“9956, zu der der Religonswissenschaftler weiter ausführt:

„Das Symboldenken ist kein ausscbließlicher Besitz, des Kindes, des Dichters oder des Gestörten: Es gehört wesentlich zum Menschen: Es ist der Vorläufer der Sprache und des diskursiven Denkens! Das Symbol entbüllt ganz bestimmte Aspekte der Wirklichkeit - jene, die sich allein anderen Hilfsmitteln des Erkennens widersetzen. Die Bilder, die Symbole, die Mythen sind keineswegs »nicht verantwortete« Schöpfungen der Psyche; sie entsprechen einer Notwendigkeit und erfüllen eine Funktion: nämlich die geleisteten Formen des Seins bloßzulegen. Deren Studium gestattet uns deshalb den Menschen besser kennenzulernen, den Menschen schlechthin, den noch nicht in die Bedingtheiten der Geschichte verstrickten Menschen. Jedes geschichtliche Sein ist zugleich Bebälter und Träger eines großen Teils "vorgeschichtlicher" Menscbheit. "'557

Und genau diesem „Kennenlernen des Menschen schlechthin” ist Ulrike Rosenbach in ihren Werken auf der Spur und dringt auf ihrem Weg Werk um Werk zu neuen Erkenntnissen vor. 


\section{VI.2. Der Körper als elementarer Ausdrucksträger}

Dabei begegnet im CEuvre Rosenbachs durch die Jahrzehnte der Körper als elementarer und gestalteter Ausdrucksträger. Damit fügt sich das Wirken in den Kontext der körperorientierten Kunstströmungen der 1960er und 1970er Jahre, wie der Body Art und der Performance Kunst. In ihren frühen Aktionen modellierte Ulrike Rosenbach - gleich einem plastischen Material - ihren Körper, „umhüllte“ ihn mit unterschiedlichen Materialien, auch mit Licht. Bald begann sie im Raum zu agieren, gebunden an vorgegebene Formen und Wege.

Während die Künstlerin in den Anfängen in unterschiedlichen, durchaus erotisch konnotierten Bekleidungen auftrat, fand sie Mitte der 1970er Jahre zu dem weißen, eng anliegenden Trikot. Eine Bekleidung, durch die der weibliche Körper neutralisiert wurde, wenngleich die Künstlerin selbst anmerkte, dass ein gewisser Voyeurismus des männlichen Publikums zu spüren blieb. ${ }^{958}$ So wählte sie auch später verhüllendere Kleidung für ihre Auftritte, bis zum völligen Verschwinden des Körpers hinter einem verbergenden Vorhang. Für die Arbeiten der 1980er Jahre war schließlich das rote Kleid mit weitem Glockenrock charakteristisch.

Der weiß gekleidete Körper wurde durch die Jahrzehnte auch als Projektionsfläche für Dia- oder Videoaufnahmen genutzt, wodurch die Akteurin aktiv in das Lichtbild eingefügt wurde und die Abbildung auf der Wand um die lebendige Bewegung im Raum erweitert wurde. In anderen Aktionen warf der Körper der Künstlerin seinen Schatten auf die dahinter liegende Wand oder er wurde mittels der Videotechnik im projizierten Abbild verdoppelt. Diesem Motiv des figürlichen Schattens, mit dem Ulrike Rosenbach in metaphorischer Weise spielt, kommt in ihrem künstlerischen CEuvre eine ganz besondere Bedeutung zu, auf die weiter unten erneut eingegangen wird.

In ihren Aktionen steht, sitzt, schreitet, rollt, dreht, tanzt, gestikuliert oder spricht die Künstlerin. Barbara Engelbach wies in diesem Zusammenhang auf einen gewissen Automatismus der Körperbewegungen der Akteurin in deren Arbeiten der 1970er Jahre hin. Die Kunsthistorikerin interpretierte, dass ein kontinuierliches Drehen, Schlagen, Pendeln in der Kunst häufig auf Automaten anspiele, und fügte an, dass, wenn Rosenbach Körperlichkeit als letzte, nicht hinterfragbare Instanz bewerte, die als Garant authentischer Weiblichkeit gelten könne, das automatenhafte Agieren zum Sinnbild der entfremdeten Frau werde, die so auf einen „Dingcharakter“ reduziert sei. ${ }^{959}$ Diese Körperauffassung ist in den Arbeiten der ersten Schaffensdekade Rosenbachs wahrzunehmen und weist erneut auf die enge Verknüpfung von Form und Inhalt in ihren Werken. Diese wandelt sich dann

958 Gespräch mit Ulrike Rosenbach 2001

959 Engelbach 2001, S. 59 
aber in den Werken der 1980er Jahre. Denn während die Künstlerin im ersten Jahrzehnt die in dieser Zeit auf ein Minimum reduzierten, sich immer wiederholenden Bewegungsfolgen quasi choreographierte, nahmen sich ab dem Beginn der nächsten Dekade Formen der Improvisation Raum in ihren Aktionen. Dabei blieben aber auch in dieser Improvisationsphase weiter Bewegungsmuster vorgegeben, die nun aber narrativen Freiraum ließen für aus dem Agieren entstehende, spontane Impulse und befreiende Bewegungen innerhalb tänzerischer Improvisationen.

Eine besonders wichtige Zeichenfunktion nehmen in den durchweg aus figürlichen Darstellungen geprägten Werke das Gesicht und Gesten der Hände ein. Die Körperdetails des Kopfes, des Gesichtes wie auch der Augen durchziehen als wiederkehrende Bildmotive das Euvre bereits seit den Anfängen und scheinen von der elementaren Bedeutung dieser Körperteile zu zeugen. Sowie auch die Hand immer wieder ins Blickfeld der Videokamera genommen wird. Inhaltlich aufgeladen durch die Bedeutung der „Handlung “960, wandeln sich diese abgebildeten Handzeichen, wie aufgezeigt, von groben, klaren Bewegungen - wie dem Schlagen in „Sorry Mister“ - sukzessive hin zu unscheinbaren, fließenden Gesten in „OrPhelia“, die aber weiterhin an energetische Inhalte geknüpft bleiben.

Bei aller körperlichen Bezogenheit bleibt Sexualität in den Arbeiten der Künstlerin negativ konnotiert, an Aspekte männlicher Gewalt und Unterdrückung gebunden. ${ }^{961}$ Damit geht die Künstlerin völlig anders mit dem weiblichen Körper um, als zum Beispiel Niki de Saint Phalle. Wenngleich beide Frauen ein ähnlicher künstlerischer Weg und auch entsprechende Motive vom Ausdruck der Wut in den Anfängen zum Ausdruck der liebenden Freiheit verbindet, findet sich der elementare Unterschied, dass die Französin in ihrem durch ihre „Nanas“ geprägten Werk den weiblichen Körper und sexuelle Konnotationen bereits seit den 1960er Jahren spielerisch unterstrich, das Körperliche im künstlerischen Wirken Rosenbachs zusehends negiert wurde. So fügt sich das völlige Zurücktreten des Körpers im Werk Rosenbachs, das Ende der 1980er einsetzte, als schlüssige Weiterentwicklung in ihr CEuvre. Parallel zu diesem elementaren Wandel fand die Künstlerin vermehrt skulpturale Lösungen für ihre Themen, wobei auch hier das Materiell-Figürliche Bildgegenstand blieb. Im Rahmen dieses Zurücktretens der Gegenwart der eigenen Person zeigte sich zudem ein Überführen von (Bewegungs-)Erfahrung in objekthafte Gegenstände - wie am Beispiel „Herzpendel“ gut nachvollziehbar, in denen sich die im Inneren lotende Erfahrung des Derwischtanzes in materialisierter Form manifestiert. Umgekehrt verhält es sich mit dem Engelschatten. In dem abschließenden Performancezyklus der 1990er Jahre, in dem die Künstlerin ihr über drei Jahrzehnte zusammengetragenes und bis zu diesem Zeitpunkt kondensiertes Bildvokabular noch einmal zusammenfasste, verbin-

960 Vgl. Kapitel III.4.4.1

961 Ausnahme sind die beiden Arbeiten „Frauenlachen“ und „Frauenzärtlichkeit“. 
det die Engelsfigur sinnfällig die Welten des Diesseits und des Jenseits. Der Engelsschatten erscheint damit letztlich als eine Fortführung des Motivs des Androgyn, der die gelungene Allianz zwischen Männlichem und Weiblichem ausdrückte, nun erweitert um die Dimension des Zeitlichen.

In ihrem Performancezyklus „Über die Engel“ belebt die Künstlerin das Schattenmotiv, indem sie - ganz in weiß gekleidet - sich schließlich selbst die schwarzen Flügel anlegt und damit - auch farbsymbolisch - elementare Gegensätze vereinigt. Diese metaphorische Besetzung des Körpers - wie auch der Technik - durchzieht das künstlerische Wirken genauso, wie das Thema der Auflösung der Dualismen in einem verbindenden Dritten. Dies zeigt sich ebenfalls auf der Tonebene, deren spezifische Funktion im Werk der Künstlerin jetzt zusammenfassend analysiert werden soll.

\section{VI.3. Die vermittelnde Rolle des Tones}

Die Ebene des Tones spielt in den prozessualen Werken Ulrike Rosenbachs eine nicht zu unterschätzende Rolle. Die die Aktionen begleitenden Geräusche, Klänge oder auch Worte übernehmen seit den ersten Tapes eine die Aktion tragende Funktion, vermitteln explizit Inhalte haben eine suggestive Wirkung. So wies die Künstlerin in einem weiter oben eingefügten Zitat explizit auf die Bedeutung des Seidenpapierraschelns in ihren Aktionen.

Mit dieser reflektierten Integration der Tonebene zollt die Künstlerin den audiovisuellen Eigenschaften der Videotechnik Rechnung, denn in allen ihren Videotapes - wie auch Performances - wird neben dem Sehen auch das Hören des Rezipienten gleichermaßen angesprochen. Dabei sind diese beiden Sinne des Menschen durch unterschiedliche Eigenschaften charakterisiert. Ist doch das Sehen durch Aktivität gekennzeichnet und damit kann man sagen, dass das Auge den Menschen in die Welt führt, während das Ohr bei der Wahrnehmung den passiven Part übernimmt, wodurch die Welt in den Menschen geführt wird. Diese unterschiedlichen Eigenschaften berücksichtigend leitet Ulrike Rosenbach in ihren Werken dem Rezipienten über die auditive Ebene elementare Informationen zu. In ihren Videos - wie auch den Aktionen - verstärkt der Ton die Inhalte in atmosphärischer Weise, sei es im Weinen der Inuitfrauen als Trauer ausdrückende Klangkulisse bei den „Judofrauen“, wie auch in den wechselnden melodischen Begleitungen im Or-Phelia-Tape, die einen spannungsgeladenen Bogen spannen vom öffnenden Papierrascheln über dynamische Klänge, die die Befreiungsversuche begleiten bis zu meditativen Melodien, die den Ausklang begleiten. Zudem ist bei einem Blick auf das Gesamtwerk festzustellen, dass sich künstlerische Inhalte und Beweggründe auf der Tonebene frühzeitiger als auf der Bildebene mitteilen. Dies wird besonders deutlich greifbar in dem Tape „Lotusknospentöne“, das bereits im Titel den Tonaspekt hervorhebt und in der Spannung zwischen Stille und Erklingen der Hölzer ein Grundthema der folgenden Dekade ankündigt: die Aus- 
einandersetzung mit der östlichen Spiritualität. In den meisten Aktionen und Tapes, die bis zu diesem Zeitpunkt entstanden waren, ist die Tonebene durch eine gleichmäßige, einprägsame Rhythmik geprägt gewesen. Sei es durch das wiederkehrende Geräusch des Ein- und Ausatmens, des pochenden Herzschlags, des fortdauernden Schlagens oder der stetig wiederholten Wort- oder auch Liedschleifen. Das Wort „Rhythmus“, das griechisch-lateinischen Ursprung hat, bedeutet in seiner wörtlichen Übersetzung „Fließen“, und genau dieses Charakteristikum ist es, das die Tonebene dieser Werke kennzeichnet. Der fließende Rhythmus trägt den bildlichen Ablauf und vermittelt Kontinuität.

Besonders die Art des Einsatzes des Gesprochenen in den künstlerischen Aktionen und Tapes der ersten Dekade erinnert dabei stark an Mantras, also Sprüche oder Formeln, die ursprünglich in einem religiösen Kontext stetig wiederholt werden und deren inhaltliche Bedeutung sich in der Wiederholung zusehends in Rhythmus und Melodie auflöst, zum energetischen Schwingen wird. Neben dieser Verwandlung des Wörtlichen in Energetisches, die mit der steten Wiederholung verbunden ist, erleichterte zudem die Reduzierung der Tonebene auf wenige Worte die Rezipierbarkeit der Werke auch im internationalen Kontext. Diese Tendenz zeigte sich nicht nur in den Arbeiten Rosenbachs dieser Zeit, sondern eine ganze Gruppe von Künstlern im Umkreis Rosenbachs - wie die Künstler Klaus vom Bruch oder auch Marcel Odenbach - arbeiteten in ihren audiovisuellen Werken mit dieser Minimalisierung beziehungsweise dem Rückgriff auf die in jedem Fall international verständliche Sprache der Musik.

Zudem zeigt gerade das Motiv der Wiederholung im Werk Rosenbachs eine große Nähe zu musikalischen Ausdrucksformen. Findet sich doch in musikalischen Kompositionen das Motiv der Wiederholung in ausgeprägter Form. Vor diesem Hintergrund ist es gut nachvollziehbar, dass die frühen - durch Reduktion und Rhythmus geprägten - Arbeiten von Ulrike Rosenbach auch viel Beachtung fanden in musikalischen Kontexten. Umgekehrt hat die Künstlerin mit verschiedenen Vertretern elektronischer Musik zusammengearbeitet, so dass Klangelemente unterschiedlichster Stilrichtungen - vom Schlager bis zu experimentellen Melodien - ihre Werke bereichern.

Auffällig ist, dass sich in dem Moment, als ein religiös inspirierter Kontext inhaltlich im Werk der Künstlerin greifbar wird, die bis dahin schon praktizierte „Mantra-Form“, die religiösen Ursprungs ist, abgelöst wird durch poetische Formulierungen. ${ }^{962}$ Auf diese Weise zieht Anfang der 1980er-Dekade das Narrative auf der auditiven, wie auch der visuellen Ebene in das künstlerische Werk Ulrike Rosenbachs ein. Die von nun an integrierten umfangreichen Textpassagen stammen dabei entweder von der Künstlerin selbst oder sind Zitate literarischer Vorlagen. Parallel werden mit dem Umschwenken auf Sprache und das Einfügen länge-

962 Auch hier nahm eine bestimmte Form den Inhalt vorweg, der in einer späteren Phase explizit formuliert wurde. 
rer Texte literarische Vorlagen für die Arbeiten Rosenbachs wichtig. Diese Dominanz des Erzählerischen in dieser Dekade veränderte sich Ende der 1980er Jahre wieder. Seitdem werden die häufig installativen Arbeiten verstärkt in collagierte, instrumentale Klangkulissen eingebettet, die einen meditativ-atmosphärischen Raum um das Werk schaffen.

Zusammenfassend lässt sich festhalten, dass im künstlerischen Werk Ulrike Rosenbachs dem Ton eine, die auf der Bildebene vermittelten Aussagen verstärkende Rolle zukommt. Das Eindringliche und das emotional Berührende des Tones nutzend bilden Geräusche und Musik im Werk Rosenbachs atmosphärisch dichte Klangräume, die die visuellen Inhalte tragen.

\section{VI.4. Die Form spiegelt den Inhalt - Fazit und Ausblick}

Die vorangegangene Untersuchung hat gezeigt, dass sich das künstlerische Wirken Ulrike Rosenbachs in die Entwicklung der zeitgenössischen Kunst einfügt. Spiegeln sich in ihrem Werk doch zunächst deutlich Strömungen künstlerischer Avantgarden. So experimentierte sie, inspiriert durch die Videowerke amerikanischer Künstler, in den 1970er Jahren mit der damals ganz jungen Videotechnik. In diesem Medium, das sie in ihre Kunstaktionen integrierte, fand sie sehr schnell zu ihrem ganz spezifischen Ausdruck der Videoperformance. In ihren Videoaktionen nutzte sie Kamera- und Monitorbild, um den Betrachtenden zusätzliche Einblicke in das Geschehen zu vermitteln. Diese spezifische Ausdrucksform entwickelte sie - die technischen Fortschritte einbeziehend - stetig für sich weiter, wobei sie weiterhin thematisch an Themen des Zeitgeistes anknüpfte. Nach einer feministischen Phase - dem Schwerpunkt der Arbeiten der 1970er Jahre - wandte sie sich in der folgenden Dekade ganzheitlichen Themen zu, wie der Ökologie oder auch der Spiritualität. Wenn die internationale Aktionskunst während der 1980er Jahre durch die sprachgestützte Performance geprägt war, dann spiegelt sich diese Tendenz auch im Wirken Rosenbachs wider, die während dieser Dekade zunehmend poetischen Texten in ihren Werken Raum gab. In den 1990er Jahren fand sie schließlich - back to the roots - zu skulpturalen Lösungen, einer neuen Werkphase, die zudem einer allgemeinen Entwicklung in der internationalen Medienkunst während dieser Dekade entspricht.

Kennzeichnend für das gesamte künstlerische Wirken Ulrike Rosenbachs ist eine Ausdrucksweise, bei der die Form den Inhalt spiegelt. Ihre streng reduzierte Formensprache wurzelt dabei in der Minimal-Art der 1960er Jahre und der Auseinandersetzung mit der Semiotik. Die unterschiedlichen Medien werden in Rosenbachs Werk zu spezifischen Funktionsträgern, und die audiovisuell präsentierten Inhalte werden gleichzeitig auf der formalen Ebene abstrahiert und in verdichtete Chiffren umgesetzt. Das audiovisuelle Gestalten der Künstlerin mündet dabei in eine buchstäbliche Lesbarkeit, entsprechend ihrer aus allgemeiner Symbolik abgeleiteten persönlichen Chiffren. 
Die Themen ihrer Kunst, die auch nach der Öffnung zu allgemein menschlichen Motiven, grundsätzlich autobiographisch geprägt bleiben, untersucht die Künstlerin in Werkkomplexen, in denen sie das jeweilige Thema nicht nur mittels unterschiedlicher Medien, sondern auch aus verschiedenen Perspektiven in den Blick nimmt. Diese Werkkomplexe werden parallel zu anderen Themen über längere Zeiträume bearbeitet, so wie es umgekehrt auch unterschiedliche Fassungen einzelner Performances gibt, in denen die Künstlerin ihre Aussagen variiert und weiterentwickelt.

Inhaltlich scheint die Künstlerin in ihren künstlerischen Grenzgängen - in denen sie eine konkrete historische Perspektive entweder völlig ausklammert oder die geschichtlichen Komponenten ins Zyklische transzendiert - einer spezifischen Spur zu folgen, die sich in der Ikonographie im Verlauf des Wandels der Motivik in ihrem Werk immer deutlicher manifestiert: Es sind „Metamorphosen in inneren Räumen“, an denen die Künstlerin den Betrachtenden teilnehmen lässt. Schließlich steht der Ausdruck emotionalen Innenlebens im Mittelpunkt ihrer Werke. Zum Sichtbarmachen dieser - von außen unsichtbaren - Innenwelt nutzt die Künstlerin besonders die Videotechnik mit ihren verschiedenen elektronischen Gestaltungsmitteln, mit deren Unterstützung sie ihre zum Teil komplex gestalteten Dokumente des Innenlebens entstehen lässt. Dabei erinnern diese vielschichtigen Bildcollagen oftmals an Traumbilder und haben im Werk auch ähnliche Funktion wie die Träume im menschlichen Leben, die als realwirkende audiovisuelle Filme während des Schlafes das Unbewusste an die Oberfläche bringen.

Wenn die Traumforscherin Ortrud Grön auf den Grundlagen der Traumforschung von C.G. Jung während der vergangenen drei Jahrzehnte die gleichnishafte Sprache der Träume herausgearbeitet hat, lässt sich diese Gleichnishaftigkeit auch auf die Bildwelten Ulrike Rosenbach übertragen. ${ }^{963}$

Dabei wandeln sich die im Werk auftauchenden Motive sukzessive. Diese Motivmetamorphose findet im „Engelszyklus“ ihre abschließende Form. Das Motiv des Engels, das die christliche Kunst durchzieht, zeigt sich im Werk Rosenbachs allerdings in Form einer geflügelten Gestalt aus den antiken Mysterien verbildlicht. Die gewählte Engelsfrau antiken Ursprungs - zentrales Motiv im Spätwerk der Künstlerin - trägt Flügel, Symbol des Fliegens, doch bleibt diese Figur letztlich mit beiden Füßen auf der Erde, das Sich-Erheben findet allein innerlich statt. 

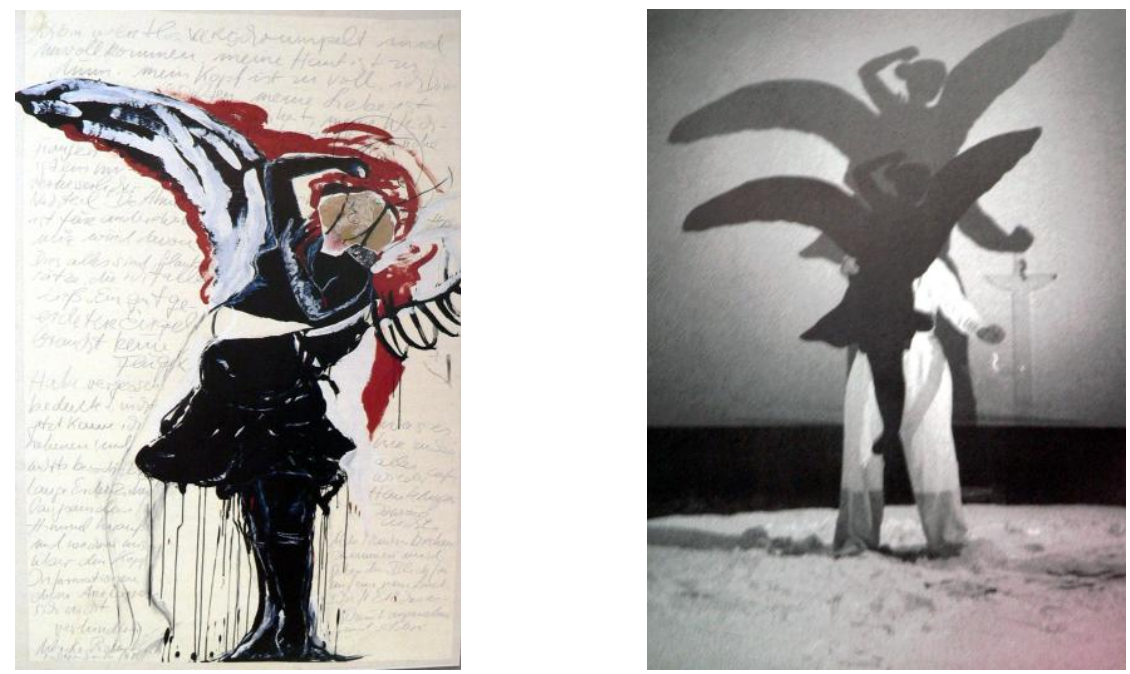

Abb.273-274: Ein geerdeter Engel braucht keine Flügel, 1985, Zeichnung und Über die Engel, Fribourg, 1995, Aktionsfoto

In ähnlicher Form mischt die Künstlerin in ihren Werken Motive aus unterschiedlichen Bedeutungszusammenhängen - wie Mythologie und Religion sowie Zitaten aus der Kunstgeschichte - zu persönlich gefärbten Aussagen, die Allgemeingültigkeit anstreben und die sie sinnbildhaft auch im eigenen Werk wieder zitiert. Im Vordergrund ihres künstlerischen Schaffens stehen dabei ihre Botschaften von Emanzipation und Ganzheit. Im Verlauf ihres künstlerischen Wirkens tritt zusehends der Weg der Heilung in den Mittelpunkt, getragen von einem spirituellökologischen Kontext.

Mit ihrem grundlegenden Bedürfnis nach Ausdruck von Gefühltem und Innerlichkeit fügt sich Rosenbachs Werk in die Nachfolge einer romantischen Kunst, auf deren Vertreter sie sich auch direkt in ihren Arbeiten durch das Einbringen von Zitaten bezieht. Dabei gelingt es der Künstlerin ihre Aussagen unabhängig von Zeitgeschichte und Zeitgeist auf eine allgemeingültige Ebene zu heben, womit auch eine zeitlose Gültigkeit der Werke - sofern die Technik mitspielt und die Videos überliefert bleiben - verbunden ist, die vielleicht getragen ist durch das, was der Religionswissenschaftler Mircea Eliade wie folgt beschreibt:

„Die Träume, die Tagträume, die Bilder, die seine Heimwehgefühle begleiten, seine Sehnsüchte, seine Begeisterung, all das sind Gewalten, die den in seine geschichtlichen Bedingtheiten gesperrten Menschen in eine geistige Welt entführen, die unendlich reicher an Geist ist als die geschlossene Welt seines "geschichtlichen Moments«. "964 


\title{
VII. Interviews
}

\author{
VII.1. Auszüge aus einem Gespräch mit Ulrike Rosenbach
}

Interview zwischen Ulrike Rosenbach (UR) und Meike Rotermund (MR) im August 2001

MR: Wie gestaltete sich die Verbindung nach Amerika zum Beispiel zu Lucy Lippert?

UR: Lucy Lippert hatte diese Adressliste. Dieses Board war eigentlich ein riesiges Adressteil, und aus dieser Arbeit mit diesen Adressen von internationalen jungen Künstlerinnen ging dann eine Ausstellung hervor. Das ist diese Ausstellung „C. 7500“, die in Amerika herumging. Da war ich mit Christiane Möbus die einzige deutsche Künstlerin. Und diese Verbindung mit Lucy Lippard ist sehr lange nicht abgerissen. Sie hat sehr viel von meinen Arbeiten in ihren Büchern erwähnt und diese ganze Verbindung zu Amerika und der „Feminist Art“ war in diesen Jahren sehr intensiv durch eine Kommilitonin. Gleichzeitig haben wir 1971 eine Ausstellung gemacht, mit Studenten der Beuys-Klasse und dem Goethe-Institut in London. Der Vorläufer zu dieser Ausstellung war ein „between“. Zwischen zwei Ausstellungen gab es immer junge Ausstellungen in der Kunsthalle in Düsseldorf. Und bei diesem „,between“ da habe ich gesagt, da mache ich mit. Aber ich möchte mit meiner Frauengruppe mitmachen, darunter Maria Fisahn und Leslie Labowitz. Dann haben wir als allererstes Performances gemacht, vor allem Leslie. Sie kam von Judy Chicago und hatte schon diese Womens-Building-Sachen gemacht. Sie hat sich in den Eingang gestellt und ihr Haar aufgerollt, und wir haben das mit Video aufgezeichnet und hatten auch vorher schon ein Video fertig gestellt wo wir mit Tampons gearbeitet haben. Wir haben Menstruationstapes gemacht. Das „,between“ ging über zwei Jahre. Es wurde später in London im Gallery House gezeigt, da war es auch größer. ${ }^{965}$ Es waren mehr Leute da, es war ein richtiger Event. Und dann habe ich zusätzlich noch meine erste Performance gemacht: „Naturkreisaktion“. Die habe bei dieser Ausstellung öffentlich gezeigt. Das war aber keine Videoperformance. Die Videosachen hatten wir mit der Gruppe noch irgendwie extra gemacht. Das waren diese frühen Sachen. Dann ging das weiter, dass ich 1973 auf dem Kölner Kunstmarkt gearbeitet habe mit Konrad Schnitzler. Das war eine Improvisation, weil wir kannten uns gar nicht. Wir haben ganz adhoc beschlossen, etwas zusammen zu machen. Er war ein Musiker von „Tangerine“ Dream und wir haben dieses improvisierte Konzert gemacht. Der Organisator war René Block. Und von da aus hab ich dann in 112 Greenstreet gearbeitet, da schließt sich dieser Kreis. Dieses Konzert in Köln, das hatte Willoughby Sharp gesehen, der war beim Kunstmarkt und der hatte noch nie Video-Live-Performance gesehen und sofort begriffen, dass es etwas ganz Extraordinäres ist. Und dann haben wir diese Video-Live-Performance-Event in 112 Greenstreet gemacht mit den anderen amerikanischen Künstlern. Das ging nur über

965 Die „between 7 - Yes Sir, That's my Baby“ fand vom 2.- 6.5.1973 in Düsseldorf statt und hatte fast 90 Teilnehmer, darunter u.a. Ulrike Rosenbach, Katharina Sieverding, Michael Buthe. Die Ausstellung wurde im Gallery House in London unter dem Titel „Some 260 miles from here: Art from the Rhein-Ruhr Germany 1973“ vom 14.5. bis 20.6.1973 gezeigt. (Buschmann 2002, S. 290) 
diese Live-Geschichten, also den Close-Circuit-Aspekt. Man kann dann Vito Acconci nennen, mit dem Aufbau 1973/74 und dann aus diesem Bekanntheitsgrad in Amerika über Lucie Lippard und Willoughby Sharp hinaus wurde ich von John Baldessari eingeladen ans California Institute of Art in Los Angeles für Practical Video Art und Feminist Art.a ist heutzutage jeder erstaunt, daß es das damals schon gegeben hat.

MR: Unterrichtete zu der Zeit an dem California Institute of Art nicht auch Judy Chicago?

UR: Das war interessant, weil an diesem Institut war eigentlich Judy Chicago gewesen, doch als ich den Lehrauftrag bekam, wusste John Baldessary schon, dass sie gehen musste, weil diese Feminist Art dem Board, also den Professoren und dem Dean, nicht passte. Es waren die 70er Jahre, das war ja nicht so ohne. Und dann war da noch Miriam Shapiro, und die war sehr tough. Und ich denke mir, daß Miriam Shapiro eigentlich diejenige war, die das Ganze ,in Arsch geritten hat“. Sie war politisch so tough, weil sie auch Jüdin war. Sie war so extrem auch mit ihren Ansichten, die hat den Leuten Angst gemacht. Die fand ich selbst auch extrem. Sie war so aggressiv, aber sehr nett. Aber ich wollte ihr auch nicht so nahe kommen, das war mir ein bisschen viel. Die beiden Frauen mussten dann gehen. Und dann gab es natürlich noch diese vielen Studentinnen, die bei denen studiert hatten. Diese Frauen, die eigentlich gar nicht darauf verzichten wollten, bei diesen zwei Frauen zu studieren, und deswegen hat das Institute dann das Feminist Art Board geschaffen, ähnlich wie Judy Chicago das in New York hatte, und in dem konnten sich die Studentinnen Lehrbeauftragte suchen, die in diese Richtung gingen. Also es war etwas, worüber man die Kontrolle hatte. Die man raussetzen konnte, wie mich. Ich wusste das alles nicht, als ich da anfing. Ich hab also da angefangen und auch sehr gut gearbeitet. Gleichzeitig mit mir war Vito Acconci da und Vito hat eine Männergruppe gemacht, während ich eine Frauengruppe gemacht habe.

MR: War der Lehrauftrag dort befristet oder unbefristet?

UR: Er war befristet auf zwei Turns. Und aufgrund meiner Haltung wurde er auch nicht verlängert.

MR: Wie ging es dann weiter?

UR: Cal-Arts war eine sehr große Schule mit tollen Departments für Tanz, Schauspiel und Musik. Ich hatte Diplomandinnen, die Feministinnen waren und aus der Choreographie kamen und ihre eigene Choreographie machen wollten so in dem Muster von Simon Fourty, Tricia Brown, Cunningham-Ballett in New York. Das war ja alles auf der anderen Seite, wir hatten das im Westen ja nicht. Die hab ich durch das Diplom geführt damals aber das war sehr unbeliebt, weil das so übergriff von einem Department, da waren nicht nur Judy Chicago und Miriam Shapiro für Malerei, sondern durch meine Arbeit mit Performance griff da so über. Und dann hab ich noch ganz zum Schlusss, das war der größte Fehler, eine Konferenz der Frauen einberufen, a womens conference. Alle Frauen waren ganz begeistert und fanden das ganz toll, und ich hab vorgeschlagen, eben diese einzelnen Departments der Frauen und der Männer mit Programmen zu verflechten, wo die Tänzerinnen eben auch diese weibliche Form mit entwickeln können in ihren eigenen Choreographien. Das fanden alle ganz toll, nur eben nicht die Leute aus dem ArtDepartment, die mich dahin geholt hatten und dann musste ich also nach den zwei Semestern gehen. Das war sehr schade, denn ich hab mich dort sehr wohl gefühlt. Ja, ich hatte keine Ahnung von Politik damals. Das war das Ende dieser ersten Phase. Und dann bin ich nach Köln gegangen mit Klaus vom Bruch und meinem Kind. Klaus vom Bruchs erstes Tape war „Die Entführung eines Kunsthändlers ist keine Utopie mehr“. Und das 
entstand eigentlich erst, als wir wieder in Köln waren. Das war also 1975/76. Und dort trafen wir auf Ingrid Oppenheim, die Galerie Oppenheim. Mit Ingrid Oppenheim zusammen haben wir dann weiter gearbeitet. Da ging das richtig los bei mir, auch mit Biennale und documenta. Bis dahin hatte ich eigentlich in Amerika vor allen Dingen mit dem Venus-Madonnen-Thema gearbeitet und der Abschluss meiner Zeit in Amerika 1975 „Reflektionen über die Geburt der Venus“. Diesen ganzen Arbeitszyklus mit allen Fotos oder dem „Aphrodite-TV“ hatte ich in Los Angeles entwickelt.

MR: Ihre künstlerische Entwicklung mit dem Schwerpunkt auf Performance und Video verlief unerwartet, denn studiert hatten sie ja zunächst Bildhauerei an der Düsseldorfer Akademie.

UR: Ja, ich habe dort Bildhauerei studiert. Und ich habe alles gelernt. Erst einmal figürliche Tonbildhauerei und Aktbildhauerei bei Karl Bobek, dann Raumplastik bei Norbert Kricke, und dann bei Beuys anschließend Objektbildhauerei. Die Raumplastik, aber die hat ja mit Objekten nichts zu tun. Das bei Beuys war ja nicht klassische Bildhauerei, das war Plastik. Wie er selbst sagte: „Ich bin Plastiker“. Mit Video hatte ich da noch nichts zu tun. Damit habe eigentlich erst nach der Natur-Kreis-Aktion angefangen.

MR: Und die Videotechnik war ja auch erst Anfang der 70er Jahre für Amateure zugänglich, zumindest in Europa, in den USA ja schon etwas früher.

UR: Das gab's hier gar nicht. Man konnte es gar nicht kaufen. Ja, und wenn, dann war es so teuer, daß man es nicht bezahlen konnte. Zumindest ich nicht, auch Gerry Schum hat ja nicht vor 1973 mit Video gearbeitet. Also Anfang der 70er Jahre konnte man überhaupt erst mit Video arbeiten. Und dieses Philips-Deck, das ich hatte, mit der Kontrollkamera, das war eins der ersten, das auf dem Markt war. Für 999 Mark, und das hatte ja auch keinen Gucker oder keinen Sucher, man musste es an den Fernseher anschließen und dann sah man erst das Bild.

MR: Also es war eine reine Kontrollkamera, die nur mit Monitor lief?

UR: Ja, auf dem Fernseher. Das heißt, ich hatte das Closed-Circuit-System sowieso schon drin, das war so, wie das heute mit Kontrollkameras immer noch ist. Die werden auf das Haus gesetzt und im Fernseher oder im Monitor sieht man dann das Bild.

MR: Okay, aber nochmal zurück zu ihrer künstlerischen Ausbildung. Warum hatten sie sich ursprünglich für die Bildhauerei entschieden?

UR: Also ich wollte ursprünglich eigentlich Bühnenbildnerin werden. Aber das ging nicht in Düsseldorf ohne Malerei. Aber ich wollte Plastik, das Bühnenbild war für mich eine plastische Angelegenheit, ich war immer plastisch interessiert. Und deswegen bin ich in die Plastik gegangen. Weil es vom Bühnenbild her nicht funktionierte und dann hätte ich auch noch eine Lehre machen müssen als Schreiner, ich hatte gerade mein Abitur gemacht, und keine Lust auf eine handwerkliche Lehre. Mit dem Abitur, da hätte ich natürlich auch Bühnenbild studieren können, aber ich wollte wirklich nicht malen. Ich wollte Plastik machen. Zeichnen war für mich dann im Studium auch erstmal ein Riesenproblem. Wir mussten soviel zeichnen, dass mir die Ohren weg geflogen sind. Jeden Tag Aktzeichnen. So habe ich Zeichnen gelernt. Wir wurden so getriezt zum Zeichnen, das kann man sich nicht vorstellen. 
MR: Aber das Zeichnen ist ja auch eine sehr gute Sehschule, oder?

UR: Auf jeden Fall, ich stehe da völlig hinter heute und ich finde es äußerst schade, dass die Medienstudenten nicht zeichnen, und daß an den Kunsthochschulen nicht mehr Zeichnen gelehrt wird. Ich habe in der Kunsthochschule in Saarbrücken immer wieder Zeichnen angeboten und da sagten die Studierenden immer: „O, bei dir muss man immer so genau sein und so, beim Gruber kann man immer so losmalen“. Ich sage, Zeichnen nützt dir nur vorm Aktmodell als Sehschule und zur Präzision. Das ist der Sinn von Zeichnen. Es geht dabei nicht um große Kunst oder so. Das ist eine Übung wie Klavier spielen üben. Aber da haben die keine Lust mehr zu, auch vielleicht keine Zeit.

MR: Ja, die Studienbedingungen haben sich in den Jahrzehnten gewandelt.

UR: Ja klar, man muss sehen, dass die meisten Studenten heute sehr viel arbeiten müssen. Ich meine, das mussten wir auch damals. Das Irre ist, dass sie im Saarland 12 Mark Stundenlohn bekommen. Das habe ich schon in Düsseldorf 1966 verdient. Das ist völlig absurd bei der Inflationsrate. Das heißt, man kann nicht einfach mehr in den Semesterferien jobben gehen und dann hat man für das Semester genug Geld, das gibt es nicht mehr. Und es macht mich auch schon sehr traurig, daß viele so gespalten sind, auch in sich so wahnsinnig überfordert und überlastet sind durch diese Doppelgeschichte mit Studium und Arbeitengehen. Das ist wirklich furchtbar. Ich meine, auch das BAFÖG hat sich nie entwickelt, das ist eher zurück gestaffelt worden. Ich meine, damals als ich studierte, da gab es überhaupt kein BAFÖG. Ich war wirklich arm im Studium, ich war unglaublich arm. Ich habe kein Geld von Zuhause gekriegt und wirklich nur in den Semesterferien arbeiten können. Im Semester zu arbeiten war völlig undenkbar bei dem Programm, das wir absolvieren mussten. Ich habe ja gleichzeitig künstlerisches Lehramt studiert, das heißt, ich hatte ein doppeltes Programm.

MR: Wie war der Unterricht bei Joseph Beuys?

UR: Beuys hat hohe Ansprüche gestellt. Er war immer da in dieser Zeit, und er war bereits morgens um $8 \mathrm{Uhr}$ da. Jeden Tag wurde gezeichnet. Einmal in der Woche war dann Korrektur und du hattest deine Sachen vorzuzeigen. Also mindestens einmal in der Woche. Also, es war einfach auch ein Anspruch da an deine Präsenz. Und der ist heute irgendwie bei Kunststudenten selten. Ich kann die ja nicht zwingen. Und die machen es sich halt unheimlich einfach. Ein Projekt im Semester ist das, was man verlangen kann, das ist alles. Ja, und sonst ist es, wenn ich sage Anwesenheit bei drei Mal in der Woche, wenn ich da bin, alle 14 Tage, das ist schon viel. Also es ist in der freien Kunst heute etwas ganz anderes als das, was ich gemacht habe. Ich hatte Philosophie, Kunstgeschichte, Pädagogik, ich musste die ganzen Sachen nebenbei bedienen.

MR: Philosophie und Kunstgeschichte?

UR: Ja, für Kunstgeschichte haben wir einen Lehrbeauftragten in Saarbrücken, da schick ich die Studierenden auch hin, aber das ist einmal in der Woche. Ich hatte ein Seminar in der Woche, eine Vorlesung, dann hatte ich Philosophie, das war sehr anstrengend, ein Seminar, eine Vorlesung. Ich habe auch wahnsinnig viel gearbeitet, ich denke wirklich, es ist wichtig zu begreifen, daß Kunst viel Arbeit ist. Theoretische und praktische Arbeit. Das ist ja bei Musik genau so.

MR: Ja, man braucht, denke ich, das Handwerkszeug erst einmal. 
UR: Ja, das macht ja keiner mehr. Ich meine, die kleine Schule bei uns hat das auch nicht parat. Wir haben keinen, der Schnitzen kann aber wir haben einen Metaller, der schweißt, das gibt es schon, aber das ist natürlich auch nicht meine Medienkunstklasse. Und darauf bin ich in gewisser Weise auch festgelegt. Ich kann froh sein, dass der Performance-Teil ein bisschen angenommen wurde jetzt. Den gibt es bald nicht mehr.

MR: Warum?

UR: Ich hab jetzt ein Forschungssemester und dann werde ich den Performanceteil auflösen.

MR: Aber können sie vielleicht ihr Performancetraining kurz umreißen? In der Literatur finden sich Symposien aus Osnabrück und Darmstadt. Wie ist das Vorgehen und wie entwickelt sich die Performancearbeit. Letztlich läuft es ja darauf hinaus, zu lernen, seine Kraft für sich einzusetzen. Das finde ich einen ganz wichtigen Aspekt, das auch weiter zu geben.

UR: Ja, das wird im Moment aber nicht mehr sehr angenommen. Also es gibt nicht mehr viele Studenten, die das machen wollen. Aber das ist auch nicht schlimm, weil das Performance-Training geht wirklich stark über den Körper. Und das heißt, daß man schon fit sein muss. Und wenn man dazu keine Lust hat, sich generell überhaupt fit zu machen, dann hat man mit Performance-Training von mir auch nicht viel zu tun. Dann muss man Performance irgendwie anders machen, das geht ja auch. Performancekunst heißt ja nicht, fit mit dem Körper zu sein. Das ist ja jetzt ein bestimmtes Body-Programm gewesen, und ich denke, was ich mache, ich mache Performance-Projekte, die aber einfach PerformanceProjekte sind und nicht mit diesem Fitness-Training zu tun haben, was ich dann gemacht habe wie Body-Flow und Meditation.

MR: Aber woher kam das?

UR: Die Venus- oder auch die Amazonen-Performance habe ich ja noch nicht gemacht mit einem besonderen Body-Training. Generell kam es daher, daß ich in meinem Leben sehr viel Sport getrieben habe. Das war vielleicht erst einmal schon überhaupt die Konzentration auf den Körper. Aber das Training selber, das habe ich eigentlich entwickelt in der Schule für kreativen Feminismus und gelernt im Womens Building in Los Angeles aus diesem Conciousness-Raising-Training, aber das Conciousness-Training war ja eigentlich kein Body-Training, sondern es war ein Bewusstseins-Training. Das war das alte klassische Esalan -Training, das die Frauenbewegung in Amerika übernommen hat für Frauen. Also wo du in einer Runde sitzt, es gibt ein Thema und jeder spuckt was aus und keine darf es kritisieren oder dir einen guten Rat geben. Also keiner darf den Therapeuten spielen. Es geht nur um Erzählen und als Result daraus bekommt man so eine Art von „Ah, den anderen geht's genau so wie mir, die hatten also auch einen Vater, der sie verhauen hat oder einen Vater, der sie zu viel umarmt hat". Also es ging um diese Problematik der Kindheitskomplexe in den meisten Fällen oder auch später. Beziehungs-, Kindheits- und Beziehungstraumas. Und das hab ich mit der Schule der Kreativität hier weitergemacht, das und die Hexensache, also Rituale. Mit den Hexenritualen habe ich in Los Angeles angefangen und die Naturkreisaktion war ja auch schon Ritual, das kam mir also sehr entgegen, Rituale zu veranstalten. Dann habe ich mit den Frauen hier Rituale veranstaltet und meine ganze Performancearbeit weiter auf diesen Ritualen eigentlich aufgebaut. Und von da aus bin ich auch an dieses Mythologie-Thema gekommen wie „Tanz um einen Baum“, das ist ja ein Aborigine-Ritual, und Performance als Ritual zu veranstalten hat mich von ganz früh an sehr bewegt. Das war ein großes Interesse von mir. 
MR: Welche ihrer Aktionen zählen würden sie in den Ritualkomplex einbeziehen?

UR: Es gibt ganz viele Aktionen, die wirklich Rituale sind. Zum Beispiel „Tanz um einen Baum" fällt mir immer als erstes ein, weil das so ein starkes Aborigines-Ritual ist, das ich falsch angewendet habe.

MR: Wieso?

UR: Weil das ein Sonnenaufgangsritual ist aber ich hab es an den Sonnenuntergang angelehnt. Und das fand ich ziemlich hart hinterher, weil es funktioniert hat. Ich hab es natürlich ausgebaut auf meine künstlerische Art und Weise. Und dann gibt es noch eines, das heißt „Projekt Kinem“, das ist auch aus den 70ern. Das ist aufgebaut auf einem alten Sioux-Ritual. Die die Sioux-Mandala ist Dreiviertelkreis groß und es steht auch, glaube ich, im Buch, in der Mitte ist ein Baum und auf dieser Mandalaform war das Ritual aufgebaut. Und so gibt es einige, also besonders die Kreis-Performances sind in den meisten Fällen Ritual-Performances gewesen.

MR: Und die Ritualarbeit hat sich dann mit der Körperarbeit verknüpft?

UR: Diese Body-Geschichte kam erst in den 80er Jahren richtig durch. Weil zum Beispiel in „Meine Macht ist meine Ohnmacht“ oder „Meine Verwandlung ist meine Befreiung“im Dom von Bremen, diese Sachen, das waren ja eigentlich keine Sachen, zu denen ich jetzt 'n Body-Flow brauche. Das begann erst mit Anfang der 80er Jahre. Das kam dadurch, dass ich dann die Tantra-Ausbildung gemacht habe. Tantra und Atem. Und in dieser Ausbildung lernte man das. Und das habe ich dann für mich weiter entwickelt. Das, was ich da gelernt habe an Atemtherapie und Bewegungstherapie habe ich umgesetzt in Performancetraining. Und dann hatte ich auch schon, das ist die vielleicht etwas frühere Variante, Ende der 70er, 77/78, Tanzworkshops bei Simon Forty gemacht. Und Simon Forty arbeitete auch mit diesen Sachen und auch andere Tänzer, die sich mit Improvisation beschäftigt haben. Improvisation und Body-Flow. Das ist eine amerikanische Erfindung von Leuten wie Merce Cunningham. Das ist Bestandteil der modernen Tanztechnik. Modern Dance. Und Forty und andere hatten es entwickelt, die kamen zum Teil alle aus Esalen, dort wurden diese ganzen Techniken zu aller erst entwickelt. Auch für die Schauspieler in Hollywood, da war Esalen quasi ein Therapiezentrum, das Therapiezentrum der New-Age-Bewegung in der Hippie-Zeit. In den 60er Jahren kamen schon ganz viele Hollywood-Schauspieler dahin, und Hollywood-Leute, die überarbeitet waren, um neu aufzutanken. Selbsterfahrung war ein wichtiger Bestandteil dieser Therapie. Und auch ganz viel Body-Bewegung, also heiße Quellen, Massage, richtiges Essen. Diese Ganzheitstherapie, das war eigentlich schon Esalen. ${ }^{966}$ Und dann folgte darauf Arika. Das ist ein ähnliches Konzept, ein südamerikanisches Konzept, die Bücher habe ich auch alle gelesen. Ich habe ganz viel aus Büchern. Was also auch noch in den 70er Jahren wirklich wichtig war, wenn man auf Bücher kommt, war das Interesse für Ethnologie. Da kam ja auch gerade dieses Fach auf und auch in dem Sinn wie es schon Margaret Mead bereits in der 30er Jahren gemacht hat. Also mit der Untersuchung von Stammesritualen und kulturen, das waren alles Bücher, die ich gelesen habe. Daraus habe ich ganz viel für meine Ideen rekrutiert. Ich war sehr interessiert an ethnologischen Zusammenhängen. Und neben Marcuse und Adorno auch Eco zu lesen war wirklich eine Erleuchtung. Also Umberto Eco war ein wesentlicher Autor neben Roland Barthes. Das sind ja alles Juden

966 Esalen Institute, 55000 Highway 1, Big Sur, CA 93920, http:/ /www.esalen.org 
meiner Zeit, das sind alles die Leute, die die 60er und 70er Jahre, die unseren Geist geprägt haben. Wie in den 80er Jahren Popper? Ja und so kam ich also auf diese Body-FlowSachen, die eigentlich erst Anfang der 80er Jahre richtig ausgewachsen waren. Und die erste Performance, die ich damit gemacht habe, die wirklich im Body-Flow war, die also keine Videoperformance mehr war, sondern die eine Kombination war aus Improvisation und aufgebautem Performance-Installationsbild im Raum, das war „Begegnung mit Ewa und Adam“. Und die „Eulenspieglerin“ hinterher.

MR: Und damit kommen dann auch inhaltlich neue Aspekte in die Werke?

UR: Nicht nur. Die „Eulenspieglerin“ greift ja zurück auf die vorangegangene „Begegnung mit Ewa und Adam“. Und „Begegnung mit Ewa und Adam“ habe ich zwar für das Landesmuseum Münster entwickelt, weil die Plastik ja in der Sammlung ist, und das war in diesen Jahren wiederholt eine Anfrage „Machen sie uns doch eine Performance mit irgendetwas, das wir in unserer Sammlung haben“. Das erste Museum, das eine solche Anfrage gestellt hatte, war das Folkwang-Museum. Da habe ich die „Spaziergängerin“ entwickelt, die ja keine Improvisation hat. Sie ist noch eine klassische Video-LivePerformance mit diesem Caspar-David-Friedrich-Bild, das in der Kollektion war. Und dann kam „Ewa und Adam“ und dieses Androgynthema, zu dem man natürlich sagen muß, daß Androgynität ein aktuelles Thema aus den 60er Jahre war und ich sehr befreundet bin mit Peter Gorsen und Silvia Bovenschen und das immer diskutiert wurde und ich auch von den beiden immer in diese Urs-Lüthi-Klicke eingeladen wurde. Also ein Bein war die Androgynen-Konzeption, die Urs Lüthi mit vertreten hat. Wir kennen uns auch gut aus diesen Jahren. Das andere Bein war in den Jahren schon die FluxusBewegung, wo ich immer zu Live-Performances eingeladen wurde.

MR: Ich hatte jetzt gedacht, daß es eine Entwicklung war, also nicht parallel verlief, sondern, daß sich das androgyne Thema, oder das Thema der Androgynität ableitet aus dem was vorher war.

UR: Das ist immer, was die Historiker machen. (lacht) Bei einem selber entwickelt sich so etwas leise und dann ist es da. Aber es gibt Vorläufer zu diesen Arbeiten. Ja, zum Beispiel auch diese ganzen Engelsgeschichten. „Female energy change“ und die Fotoserien, gehören da rein. Urs Lüthi, Katharina Sieverding, die war in diesen androgynen Shows gewesen. Also alles, was mit Erotik dealte. Ich habe mich da nie so wiederfinden können. Fand ich immer ein bisschen komisch, weil ich damit eigentlich nichts zu tun hatte.

MR: Stichpunkt Fotografie, wie sind Sie denn zur Fotografie gekommen?

UR: Das habe ich natürlich nicht gelernt, das gab es damals an den Kunstakademien noch nicht. Das kam erst viel später, Bernd und Hilla Becher waren die ersten für Fotografie in Düsseldorf. Foto war eigentlich so ein Privathobby von mir. Ich fand Fotos immer faszinierend und zu der Zeit, als ich die „Natur-Kreis-Aktion“ gemacht habe, hatte ich immer Freunde, die Fotografen waren. Und bei denen habe ich gelernt. Nic Tenwiggenhorn ist einer meiner Lehrer. Zum Beispiel „Art is a criminal action“, dieses Foto mit dem Warhol-Elvis von 1969. Dafür hat mich Nic Tenwiggenhorn fotografiert. Das ist ja eine Studioaufnahme von mir, die habe ich hinterher zusammen collagiert. Und dann war Klaus vom Bruch Fotograf und hat sehr viel aufgenommen. „Female energy change" zum Beispiel hat Klaus vom Bruch erstmal fotografiert, bevor das dann so eine Collage wurde, eher Montage. Manche, wie die schwarz-weißen sind collagiert, und die Farbaufnahmen, wie beim ,female energy change“, die sind montiert, also Negativ auf Negativ. Das war ein anderes System. Und bei den schwarz-weißen habe ich das collagiert 
und dann wieder abfotografiert, also im Reproverfahren, das sind andere technische Verfahren. Aber das zu untersuchen, fand ich wahnsinnig spannend. Ich hab also 73 und 74 unheimlich viel fotografiert wie Sigmar Polke auch, der auch seine ersten Fotoserien um die Zeit gemacht hat, und mich sehr angeregt hat, Fotografie zu machen. Ich war damals mit Polke befreundet, und die ganze Clique um Polke herum hat viel mit Fotografie gearbeitet. Wir haben alle viel fotografiert. Ich habe viele Versuche in der Dunkelkammer gemacht, extrem viel in Dunkelkammern gearbeitet, mit Klaus vom Bruch zum Beispiel riesige Großformate gemacht. Also wir haben viel experimentiert mit Fotografie. Aber es gibt keine Ausstellungen davon. Das liegt alles in meinem Archiv. Also, die erste Serie, die ich überhaupt verkauft habe und das auch nur dank Klaus Honnef, weil er sich eben sehr früh auf Fotografie spezialisiert hat, und deswegen war Klaus Honnef auch wichtig für Polke, Bute und die ganzen Leute. Weil der war eigentlich der erste, der Fotografie in der Kunst so akzeptiert hat, wie wir das gemacht haben. Sowie Wolfgang Becker in Aachen, als Museumsdirektor damals sehr wichtig war, weil er einer der ersten jungen Museumsdirektoren war, der diese Kunst ausgestellt hat. Als ich 75 oder 77 die erste große Ausstellung bei Becker gemacht habe, da konnte ich diese Fotos alle zeigen, da habe ich die zum ersten Mal gezeigt. Außer bei Ernst 72. Da hatte ich auch schon so ein, zwei Aufnahmen von den Hauptfotos gezeigt, die eine Freundin von mir gemacht hat, die Fotografin ist. Das heißt, ich war immer auf Leute angewiesen, das ist bei Fotografie ja leider so. Bei Video war das einfacher, da konnte ich das selbst machen.

\section{MR: Wer war diese Fotografin?}

UR: Sabine Quitter hieß sie, die später nach London gegangen ist. Also Fotografie war für mich immer so ein Ding. Weil das immer andere fotografiert haben, habe ich die Sachen eigentlich nicht heraus gegeben. Meine Fotoserien habe ich dann total reduziert auf das, was ich auch wirklich aufnehmen konnte und das waren die Videostandfotos. Und Klaus hat das dann später mit seinen Videos auch gemacht und hat neulich gesagt, daß es für ihn nicht gestimmt hätte, weil der Charme der Videos irgendwie verloren ging. Für ihn war Fotografie so nicht möglich. Während ich die Serie „Lotusknospentöne“ auch extrem viel verkauft habe. Ich fand die Abläufe, die ich dort fabriziere, unglaublich wichtig, um zu erkennen, was ist eigentlich ein Bewegungsablauf.

MR: Das war ja in der Ausstellung „Gegen den Strich“ jetzt im Frauenmuseum Bonn, auch bei mindestens zwei Arbeiten so, dass mit der Gegenüberstellung von Foto und Video gearbeitet wurde.

UR: Ja, das ist meine Art, das übernehmen meine Studenten natürlich. Wir haben ein Projekt, das wahnsinnig eingeschlagen hat, ohne dass ich das überhaupt geahnt hätte. Es hieß „Das stille und das bewegte Bild“. Da gibt es bei Zweit- oder Drittsemestern so einen richtigen Aha-Effekt. Weil die sehen das immer, aber die untersuchen das nicht. Also da kommt dieses Reportagefoto rein, wie sich so eine Bildsequenz ergibt und die Bewegungen. Deswegen sind dann auch solche Sachen, wie Klaus vom Bruch sie manchmal macht oder wie man sie auch bei Sigmar Polke finden kann, für die Studenten schon sehr aufschlussreich. Und das ist ja alles meine Generation. So wurde da fotografiert und diese ganze Nummer mit Thomas Ruff, das ist ja erst eine Generation später. Solche Apparate hatten wir gar nicht und solche Finanzen hatten wir auch nicht. Ganz unmöglich, das war in den Händen von irgendwelchen Superprofis, aber wir waren keine Superprofis. Wir wollten auch etwas anderes. Wir wollten Leben festhalten. Und zwar nicht nur als Reportage, sondern auch irgendwo die Substanz von Leben in der Fotografie erfassen. 
MR: Der Schwerpunkt ihres künstlerischen Wirkens lag also Mitte der 70er Jahre in den USA?

UR: Ja, ich war zwischen 1972/3 und 1976 extrem viel in Amerika und habe von den Entwicklungen in Europa nicht so viel mitbekommen. 1975 gab es eine wichtige Ausstellung, die „Magna-Feminismus“ hieß, mit Valie Export. Und da war also auch eine Arbeit von mir dabei. Das sollte etwas Äquivalentes sein zu dem, was Lucy Lippart Jahre früher in Amerika gemacht hat, dieses „C. 7500“. Valie Export hatte viel mit Helge Sander zu tun. Und Performance hat sie ausschließlich in Österreich gemacht, und meistens mit Peter Weibel zusammen, und diese Art von Performance war für mich völlig nichts sagend. Da konnte ich nichts mit anfangen, weil ich schon ganz früh aus dieser BodyGeschichte kam. Ich habe immer mit dem Körper gearbeitet und die nicht. Die haben mit dem Konzept gearbeitet.

\section{MR: So sehen sie die Arbeit von Valie Export im Kontext der Konzeptkunst verankert?}

UR: Ja, Konzeptkunst. Und mich hat man zwar auch immer mit meiner Arbeit unter Konzeptkunst eingeordnet, aber ehrlich gesagt, hab ich das nie richtig verstanden warum. Schon damals nicht. Aber ich hing immer zwischen den Seilen. Einerseits waren Konzepte da und andererseits war diese starke Verbindung zum Tanz da oder zur Bewegung, könnte man eher sagen, zur Körperbewegung. Aber bei den Tänzern war ich überhaupt nicht drin, denn die Art und Weise, wie ich das gemacht habe, war für die völlig unprofessionell. Also da war ich so auf beiden Seiten. Ich war ja bei Performances eine Einzelgängerin. Die einzigen, mit denen ich viel zusammen gemacht habe in diesen Performance-Festivals, die haben ähnlich gearbeitet wie ich. Ähnliche Konzepte. Marina Abramovic und Ulay waren die engsten Freunde auf der Ebene.

MR: Die Arbeiten von Marina Abramovic und Ulay wirken sehr intensiv.

UR: Es ist meditativ, es ist ruhig, es kommt vom Konzept her und geht über den Körper. Das ist ein ähnlich ganzheitliches System und es ist ja auch das, was Marina Abramovic in Braunschweig immer probiert. Und Ulay war wie Klaus Fotograf. Nur Ulay war ein ganz professioneller Fotograf. Er hatte sein Handwerk gelernt, das er heute in Karlsruhe weiter ausbilden kann. Also Großbildfotografien und so etwas. Klaus war viel jünger als wir, Klaus war 21, als wir ihn kennengelernt haben.

MR: Okay, aber neben der Fotografie nehmen ja die Arbeiten im Raum eine große Rolle ein in ihrem Werk, wie fing das an?

UR: Nach meinem Abschluss wurde ich zur Meisterschülerin ernannt, so wie das heute noch ist. Also war ich Meisterschülerin bei Joseph Beuys. Und davor hatte ich mein erstes Staatsexamen gemacht und da gehörte bei den Kunsterziehern auch eine künstlerische Arbeit dazu, die wurde von Beuys betreut. Und da ich zu der Zeit sehr viel mit unterschiedlichen Materialien experimentiert habe, mit Zwei-Komponenten-Kunststoffen wie Polyester, habe ich also Plastiken aus Polyester gemacht. Das war so ähnlich wie bei Niki de Saint-Phalle. Das war gerade die Zeit, wo wir damit anfingen, und Niki hat sich dann ja dann auch richtig gut eine Vergiftung zugezogen, weil keiner hatte Angst, keiner hatte eine Ahnung, wie giftig das Zeug ist. Wir hatten auch überhaupt keine Werkstatt dafür, wir haben es im Steinatelier gemacht. Das Steinatelier war sehr hoch und und riesig groß, und da zog das ab. Und dann hatte ich zu Hause einen alten Schuppen als Atelier.

MR: Zum Glück ist alles gut gegangen. 
UR: Das Arbeiten in der Polyesterzeit war schon heftig. Und dann hatte ich also Objekte gemacht aus Polyester und das waren Knie, die im Raum - das war schon bereits eine Rauminstallation - die die Wand mit dem Fußboden verbinden sollten. Das waren so witzige Sachen zwischen organisch und räumlich, das waren ziemlich anspruchsvolle Arbeiten.

MR: Gibt es dazu irgendwelche Dokumentationen?

UR: Da gibt es vielleicht ein schlechtes Foto, was Katharina Sieverding gemacht hat, aber ich glaub, das ist auch wirklich alles.

MR: Und die weiteren Arbeiten Ende der 60er Jahre setzten sich auch mit Körperformen oder figuralen Themen auseinander?

UR: Also woran ich mich noch erinnere, waren zum Beispiel Themen, die mit Körper schon eine Menge zu tun hatten. Zum Beispiel war ein Thema „Fallen“ und dann Spielzeuge für ein Kind, aber ohne dies möglichst gebrauchen zu können. Also ich hatte immer sehr so surrealistische Interessen. Ich habe auch über Max Ernst noch in meinem zweiten Staatsexamen geschrieben. Ich hab Max Ernst mit Beuys verglichen und mit Duchamp. Und es heißt also Surrealismus beziehungsweise besonders die Arbeiten von Max Ernst waren für mich so wichtig wie Picabia für Sigmar Polke. Zum Beispiel dieses Ölgemälde von Ernst über diese eingemauerte Frau. Das war schon ein bisschen das, was auch die Objekte waren, die Knie. Diese Höhlen. Und dann war ich natürlich auch Mutter und hatte diese Spielzeuge gemacht, die ein Kind nicht gebrauchen kann oder wo alles zu schwer ist wie für Monster oder Riesen, ja, zu schwer oder zu groß. Aus Blei, kleine Bleiobjekte, ich habe sehr viel mit Blei und Wachs gearbeitet, Die Wachsobjekte gibt es nicht mehr, aber die Bleiobjekte, die gibt es noch. Und die habe ich lange gemacht, die habe ich gern gemacht. Also, das heißt, ich habe in Ton modelliert und die Formen dann in Blei abgegossen. Objekte für den Körper waren das schon, denn die waren bereits mit dem Körper zusammen gedacht.

MR: Wie kamen Sie auf das Madonnenthema?

UR: Ich komme aus einer hochprotestantischen Familie. Vielleicht war es gerade die Faszination, dass die Madonna, die ja im katholischen Kontext eine große Rolle spielt, in meiner Vergangenheit überhaupt keine spielte, die mich daran so fasziniert hat. Das kann gut sein. Eigentlich ging es darum, dieses schöne Gesicht, also diese Schönheit der Madonna zu reflektieren in dieser Arbeit.

Also Dokumentationen sind ganz was anderes als das Closed-Circuit-System. Das war von der Technik her der Anfang. Meine Amazonenarbeit kommt schon stark aus der feministischen Bewegung heraus. Weil, mich hat ja immer der Kulturkontext, das hab ich auch oft genug gesagt, der Kulturkontext in der Untersuchung der Frauenwissenschaften interessiert, nicht der soziologische oder anderes. Und aus diesem Interesse heraus ist die Amazonenarbeit entstanden, ist Frauenkultur entstanden, ist die Venus entstanden. Frauenkultur ist ja eigentlich direkt nach der Venus entstanden. Ist aber nicht aufgeführt worden, bevor ich die Amazone gemacht habe. Aber recherchiert habe ich die Frauenkulturarbeit noch in Kalifornien, dort in den Bibliotheken. Da gab es diese Enzyklopädie, aus der ich alle Fotos habe. Die gibt es inzwischen hier auch. Das ist eine tolle Enzyklopädie des 19. Jahrhundert bereits, eine Enzyklopädie der ersten Frauenbewegung. Das ist ein reines Ethnobild der Frauenkultur, also was für Ketten und was für Stoffe und was weiß ich tragen Frauen in den Kulturstämmen. Das ist ein tolles 
Teil. Also ich habe dieses mehrbändige Lexikon durchgearbeitet, da war alles drin, von Polynesien bis China.

MR: Die eben angesprochenen Arbeiten gehören ja noch in den vorhin umrissenen Ritualkontext, doch zum Übergang der 80er gibt es dann ja einen Wechsel in der Umsetzungsart ihrer Performances.

UR: Ja irgendwann hab ich dann aufgehört mit dieser Video-Live-PerformanceGeschichte. Und die erste Performance, bei der ich nicht mehr damit gearbeitet habe, hieß „Judofrauen haben als Hilfe Boten“. Ich hatte einfach das Bedürfnis, mich mehr zu bewegen. Ich habe damals das Gefühl gehabt, dass ich die Art und Weise, wie man VideoLive-Performance mit dem Close-Circuit-System machen kann, ausgeschöpft zu haben. Und außerdem wurden meine Themen vielfältiger. Also die Themen, die wir im Consciousness-Raising-Training hatten, die Themen der Selbsterfahrung, die wurden irgendwie vielfältiger, so dass ich die mit solchen einfach strukturierten Performances nicht mehr richtig darstellen konnte. Also in "Judofrauen haben als Hilfe Boten“ da geht es ja um Beziehung. Und dann geht es auch um die Anonymität in der Beziehung.

MR: Als ich die Beschreibung von Amine Haase las zu den Judofrauen, fiel mir das Prinzip der Psychoanalyse ein, das dahinter steckt.

UR: Möglich. Aber das war ganz intuitiv. Obwohl ich sehr viel C.G. Jung zu der Zeit schon gelesen hatte. Also sehr viel eingestiegen war in die Ganzheitsphilosophie von C.G. Jung, aber ich hatte nie etwas mit Psychoanalyse zu tun. Ich komme zwar auch aus einer Arztfamilie, in der ich aufgewachsen bin mütterlicherseits, aber bei uns zuhause gab es den Begriff Psychoanalyse überhaupt nicht. Mein Großvater hat den gestrichen. Es gab kein einziges Buch in seiner Bibliothek über Psychoanalyse. In diesem strengen bürgerlichen Familien des 19. Jahrhunderts, aus der diese Familie noch kam, gab es diese Thematik nicht. Über Gefühle wurde nicht gesprochen, über Geld wurde nicht gesprochen (lacht). O.k. Erst als ich geheiratet habe, bin ich in eine Familie hinein gekommen, in der man über Geld sprach. Das kannte ich überhaupt nicht. Wir hatten zwar keines mehr nach dem Krieg, aber man sprach nicht über Geld. Auch wenn man sich die Sachen im Garten anbauen musste, weil ja das Geld weg war nach dem Krieg. Es wurde nicht über Geld gesprochen. Das Konzept wurde beibehalten. Das war unglaublich, das war der reinste Untergang. In der ganzen bürgerlichen Kultur, im bürgerlichen Akademikertum. Und zu diesem Kontext habe ich dann auch eine Performance gemacht.

Die hieß „Requiem“. Die war nicht sehr glücklich vom Titel. Und darin waren diese Bilder dieser Familien und ihre autoritären Strukturen. Das war die einzige Performance, von der ich sagen kann, sie hat mit meiner eigenen Kindheit zu tun, oder mit meiner eigenen Erziehung. Und die beste Aufführung, die ich dazu gemacht habe, die war hier auf der Bühne in der Kölner Uni. Ich habe zwei Sachen hier gemacht und eine davon war in der Kölner Uni auf der großen Bühne und das war diese Demeter-Improvisation. Und die ist hinterher eingewachsen mit der Videotechnik in die „Eulenspieglerin“. Das heißt, das Videotape „Die Eulenspieglerin“ setzt sich zusammen aus „Requiem“ und „Das Mädchen wächst weiter". Das waren in Gent und in Köln die zwei Performances, die beiden und die dritte in Hamburg bilden das Videotape „Die Eulenspieglerin“.

MR: Wie ist das, eine einmal aufgeführte Performance zu wiederholen?

UR: Also es gibt verschiedene Formen. In den 70er Jahren gab es ein paar Formen wie zum Beispiel die „Frauenkultur“. Mit denen konnte man relativ gut reisen. Das war ja auch eine finanzielle Sache. Es gab überall irgendeinen Raum mit einer langen Wand, an der 
man diese Fotos anbringen konnte. Die Perofrmance hab ich, glaube ich, $10 \mathrm{Mal}$ aufgeführt. Mit der bin ich wirklich um die Welt gereist, mit der „Frauenkultur“. Aber dann gibt es natürlich andere wie zum Beispiel die aus dem Dom in Bremen. Die ist so angewiesen auf die Architektur, die kann man nirgendwo anders machen. Auch die „Spaziergängerin“ hab ich dann nochmal woanders gemacht, im Stedeliik-Museum zum Beispiel in Amsterdam. Aber da ist die ist ganz anders ausgegangen. Manche habe ich zweimal oder auch dreimal aufgeführt, aber immer seltener. Eigentlich habe ich sie dann fast immer nur noch einmal aufgeführt und gemerkt, dass das nicht so toll ist. Nur dann, wenn die andere Architektur dazu auch passte oder wenn ich ein Konzept mit dieser Idee entwickeln konnte für die andere Architektur. Also zum Beispiel, auch bei der „Venus“ war das relativ einfach in den 70er Jahren. Die „Venus“ habe ich in Amerika auch zigmal, drei-, vier-, fünfmal aufgeführt. Da brauchte man eine Wand, einen Diaprojektor, fertig. Die "Judofrauen" habe ich hier in der Moltkerei aufgeführt und im Stalleschen Herbst* zweimal. Und aus dem Stalleschen Herbst ist die Videodokumentation. Das ist eigentlich die einzige richtige Filmdokumentation. Die einzige wirkliche Performancedokumentation, die ich besitze aus diesen Jahren von einer Performance. Sie ist von vorne bis hinten vom ORF gedreht worden, die konnten so was, und das war die Judofrauengeschichte. Und dann kam als nächstes Tape „Begegnung mit Ewa und Adam“. Und „Ewa und Adam“, wie gesagt, habe ich für Münster entwickelt, für den Kunstverein und dort auch gemacht. Thomas Deecke vom Kunstmuseum Münster hat das damals gemacht. Und dann war ich sechs Wochen in Banff in Kanada an einer Schule engagiert, um Performancetraining zu geben. Und also habe ich das gemacht, was ich in Los Angeles gemacht habe. Gruppen von Studentinnen, die mit Consciousness-Raising gearbeitet haben und Video, und die aus diesen beiden Komponenten dann Performance mit Medien entwickelt haben. Das war Anfang der 80er Jahre. Da hatte ich das schon gemacht, sieh mal an.

Ja, ich meine, ich habe das auch mit den Studenten in Cal Arts schon gemacht. Aber das war eben dieses klassische Consciousness-Raising-Training aus der Frauenbewegung, das die ja auch angenommen haben, die kannten das ja. Und dann haben wir mit Medien dazu etwas gearbeitet. Das war nicht immer das Tollste. Also in Banff waren es eigentlich schöne Arbeiten, da kann ich mich gut daran erinnern. Die Studenten haben sehr schöne Arbeiten gemacht. Aber die haben auch sehr viel mit Natur gearbeitet. Banff liegt in den Rocky Mountains, ist so etwas wie das Davos in den Rocky Mountains, das ist National Park. Es ist also eine wahnsinnige Umgebung. Natürlich haben wir mit der Natur gearbeitet, sind mit dem Video heraus gegangen und haben Performance in der Natur gemacht. Und das lag mir ja, das hatte ich in den Natur-Kreis-Aktionen ja auch schon gemacht. Und deswegen war „Begegnung mit Eva und Adam“ in Banff für mich eigentlich eine völlig neue Performance. Also den ganzen Text über das Verhältnis des Mercurius zur Natur, der ist mir in Banff eigentlich erst richtig aufgegangen. Und dann habe ich da auch sehr stark mit den sterbenden Bäumen gearbeitet, das war in den 80er Jahren. Und das hab ich da integriert in die Performance „Ewa und Adam“. Da hatten wir natürlich auch exzessiv viel Videotechnik. Daraus ist das Tape entstanden, in dem, glaube ich, nur eine Sequenz aus der „Ewa und Adam“-Performance hier in der Mensa in Köln mit dabei ist. Aus den zwei Aufführungen ist das Tape entstanden. Das Tape ist leider zu dunkel. Ich hatte solche Schwierigkeiten, das Video hinterher zu schneiden, weil es so dunkel war. Das ist so schlecht in der Qualität. Aber wir hatten ja auch gar nicht diese Kameras damals. Wir hatten Röhrenkameras.

MR: Das ist dann natürlich schwierig.

UR: Wir konnten froh sein, daß wir Farbkameras hatten. Aber wir mußten ja mit einem Dia arbeiten, dass heißt dafür mußten wir wenig Licht haben. Und deswegen sind diese 
ganzen Performancedokumentationen ja so wahnsinnig schwierig überhaupt zu machen. Bei den Judofrauen dagegen konnte man viel Licht haben. Aber die „Reflektion über die Geburt der Venus“, die mit Dias war, die haben wir ja hinterher bei Bosch nachgestellt. Das war ja dann sozusagen eine Förderung der Bosch, und da habe ich die ganze Performance im Videostudio mit MAZ-Anlage noch einmal gemacht. Das ist das Tape. Aber das ging ja auch, weil sich das nicht verändert hat, das war kein Problem.

MR: Aber sonst ist es schon so, wenn man die Performance nochmal aufführt, ist das jedes Mal etwas Neues, oder?

UR: Auf jeden Fall. Also jetzt bei der Venus, will ich mal sagen, ist es nur deswegen etwas Neues, weil ich ja nie bemesse, wie bewege ich mich. Das ist aber beim Schauspieler auf der Bühne ja auch bei jeder Vorstellung immer eine neue in dem Sinn, ja? Also ich würd' mal sagen, bis zu den Judofrauen, wo wirklich Improvisation rein kommt, sind die Performances zwar an einem anderen Ort, aber die Bewegung von mir bleibt basicly die gleiche, nur der Ort ist völlig anders. Und die Installation um den Performer, um die Performance herum, die kann sich völlig anders aufbauen. Und das beste Beispiel dafür ist „Begegnung mit Adam und Ewa“, die ich also hier im Landesmuseum in Münster gemacht hab, dann in Banff ganz anders mit Natur und den Zweigen und so weiter, und dann noch mal in Boston später. Und in Boston war die wieder völlig anders, weil die Räume so anders waren. Da hab eich angefangen, ganz viel zu zeichnen, ganz viel auf dem Boden zu machen, da gibt es sehr schöne Fotos von. Da hatte ich eine tolle Fotografin, die hat ganz superschöne Schwarz-Weiß-Fotos gemacht. Und auch Farbfotos. Die hätte ich einkaufen und mitnehmen können, die Frau, das war, die hat es genau erfasst.

MR: Ja, man muss das können.

UR: Man muss eigentlich Theaterfotograf sein, um so etwas machen zu können. Man muss mit wenig Licht fotografieren können und man muss die Situation erfassen können, ganz schnell. Also ich meine, meine Performance, und symposium

das sagte eine Künstlerin der jüngeren Generation bei einem Symposium einmal: „Eigentlich sind deine Performances ja Theaterperformances“. Aber das stimmte für die damaligen Verhältnisse natürlich überhaupt nicht. Weil Theaterperformance und Improvisation waren ganz anders aufgebaut als meine Performances. Da war nicht so viel Improvisation. Aber solche Sachen wie „Warten auf Godot“ oder so, das waren natürlich schon unglaublich einflussreiche Theaterstücke für mich. Also dies Verhältnis von Gegenstand und Mensch auf der Bühne. Das war ein absoluter Insult. Das Verhältnis von Gegenstand und Mensch und der Gegenstand, mit dem auf der Bühne agiert wird, das sind schon sehr wesentliche Geschichten. Und auch Forsythe natürlich in den 90er Jahren hatte so seine Stücke. Also heute sehe ich das nicht mehr so. Aber es gab Stücke von Forsythe, von denen ich sagen könnte, das sie mehr Performance als Tanztheater waren. Aber der hat natürlich dann auch sehr viel eingebaut aus den 70er Jahren. Unheimlich viel. Auch Laurie Anderson hat sehr viel gemacht, unheimlich viel. Sachen, die hier in Deutschland nicht so bekannt sind, die keiner kennt. Klassische Laurie-AndersonPerformance kennt man hier überhaupt nicht. Man kennt nur diese großen Konzerte. Dabei war Laurie Anderson, als sie noch Studentin war, also da hat sie schon angefangen mit der Performance „Meine Mutter“, wo sie mit der Geige vor dem Video oder Dia steht. Das ist in Cal Arts entstanden. Das ist ein typisches Performanceteil, das sie da zeigt. Aber das ist ja schon eine Generation später. Wir waren quasi die Lehrerinnen dieser Generation von Laurie Anderson. Und auch Vito Acconci kann man ja nehmen, der gleichzeitig mit mir in Cal Arts war, das waren also die 70er. 
MR: Die 80er waren dann schwerpunktmäig von Performance geprägt?

UR: Performance ist da Schwerpunkt mit einer anderen Prämisse. Und dann war da ja auch die documenta 8. Die ist ja auch in den 80er Jahren. Und dann eben die Form von Performance, wie in "Judofrauen“ beschrieben und in „Begegnung mit Ewa und Adam“. Und als dritte sehr wichtige Arbeit der 80er Jahre die „Eulenspieglerin“.

MR: Diese Arbeiten liegen alle am Anfang des Jahrzehntes. Was kam dann?

UR: Also es gab dann diese eine wichtige Performance im Schwarzen Kloster in Freiburg, „Wer hat Angst vor der schwarzen Frau?" Und in den 80ern war ja dieses ganzee Thema Natur aktuell und los ging es eigentlich 1982 mit der Aktion „Ewa und Adam“ in Banff. Die „Begegnung mit Eva und Adam“ ist eine der wichtigsten Auslöser gewesen für das, was ich in den 80er Jahren angefangen habe. Und zwar sind mir bei der Recherche zu dieser Arbeit an diesen Abbildungsformen über „Ewa und Adam“, zwei Sachen aufgefallen: einmal die Bedeutung des Baumes, im Paradies des Baumes der Erkenntnis, und dann die Bedeutung des Engels, der zu Füßen des Baumes sitzt. Und ich habe mich immer gefragt in den 80er Jahren, womit ich jetzt am liebsten arbeite, wenn ich aufhöre mit diesem androgynen Kontext. Mit dem Baum oder mit dem Engel? Das war zum Beispiel ein Thema, das da durch ging. Die „Eulenspieglerin“ ist sozusagen so ein ExtraStatement über die Künstlerin. Das ist eine sehr exzeptionelle Arbeit im Kunstverein Hamburg gewesen, bei der vor allem die Hinterfragung der Frau als Künstlerin im Mittelpunkt steht. Also die wirkliche Auslöserfunktion für die Arbeiten der 80er Jahre und im Weiteren hatte „Begegnung mit Ewa und Adam“, obwohl die Videoarbeit dazu nicht so toll ist. Und dann gab es da die Schmelzprozesse 1982 und da habe ich angefangen, mit dem Engel zu arbeiten. Also da kamen auch wieder die Zweige aus „Ewa und Adam“. Sie hören das ja hier auf Video, aber eben auch die Begegnung mit dem Engel, und das ist diese Engelsfigurr aus dem Villa dei Misteri in Pompeji.

MR: Der dann in der Videoinstallation „Last call für Engel“ riesengroß erscheint?

UR: Also was wichtig ist in „Schmelzprozesse“ und „Ewa und Adam“ ist die Auseinandersetzung mit der Alchemie, mit den alchemistischen Philosophien. Im „Splendor solis“ taucht das auf, was wir dann in den „Schmelzprozessen“ haben, auch die Funktion des Herzens. Und die Funktion des Herzens war schon sehr wichtig für mich. Ich habe diese untersucht. Es war sehr schwierig, mit dem Herz zu arbeiten. Ich wollte tatsächlich jetzt auch mit ontologischen Prinzipien arbeiten, also über das Sein des Menschen. Und das Herz ist eigentlich so ein Symbol im Mythos für das Sein des Menschen. Aber es ist sehr schwer in der bildenden Kunst damit zu arbeiten, weil das so belebt ist. Die einzige Kultur, die heute noch authentisch mit dem Herzen arbeitet, ist die arabische Kultur. Und da habe ich dann auch die Ernsthaftigkeit der Funktion dieser Symbolik wiedergefunden. Also bei den Arabesken zum Beispiel, diese Herzform. Und was das für die Bedeutung der Liebe im geistigen Sinne bedeutet in der arabischen Philosophie. Das ist bei den Sufis zum Beispiel sehr ausgeprägt. Das waren dann meine Gänge in die Erkenntnisphilosophie der Kulturen. Also viel abstrakter als in den 70er Jahren. Das war die Thematik mit dem Engel. Und dann hab ich auch an diesem Kontext des Baumes weitergearbeitet oder allgemeiner der Natur, den es auch schon in „Ewa und Adam“ und natürlich bereits in der „Naturkreisaktion“ gab. Das ist zum Beispiel „Im Garten der Göttin" sehr wichtig, weil wie Garten schon sagt, ist es eine Auseinandersetzung mit dem Prinzip der göttlichen Natur und der Göttinnen, und das entspricht auch den tantrischen Erfahrungen, die ich in meiner Ausbildung gemacht habe. Und das kam auch in den sehr energetischen Bewegungen in dieser Performance zum 
Ausdruck, die eigentlich ganz schön von Nic Tenwiggenhorn dokumentiert wurde. Hinzu kommt da auch die erste Installation „Amazonas“, 1986, die niemals eine Performance, sondern immer eine Installation war und eine Fotoarbeit. Sowie auch die Performance „Aufwärts zum Mount Everest“. Wobei der Mount Everest natürlich für die Buddhisten auch eben ein Übertragungssymbol ist in Bezug auf die Ewigkeitsbedeutung des Seins. Und das ist eigentlich von Marlies [Grüterich, Anm. M.R.] in dem Heftchen zum Kunstlexikon ganz schön ausgeführt gewesen.

MR: Was passierte noch in den 80er Jahren?

UR: Die 80er Jahre sind sehr geprägt von Reisen, ja, mit Performances, Ausstellungen und Installationen. Ich habe sehr viel ausgestellt in den 80er Jahren. Aber auch sehr viel in Festivals und Gruppenausstellungen, so daß es keinen einzigen Einzelkatalog gibt. Erst Ende der 80er Jahre, als ich 89 diese Ausstellung in Saarbrücken machte, hatte ich eine große Einzelausstellung mit einem Katalog. Es gab vom Stedelijk Museum Ende der 70er Jahre diesen kleinen Katalog mit Valie Export zusammen, aber wir haben uns da quasi nicht berührt. Das waren zwei Einzelausstellungen, aber eben ein Katalog. Und ansonsten waren das immer Arbeiten in dem Kontext von Gruppenausstellungen in den 80er Jahren. Und zum Beispiel wenn man jetzt den „Wind meiner Träume“ nimmt, oder diese Bunkerinstallation in den 90ern.

Und den „Wind meiner Träume“ hatte ich als Performance auf der documenta gemacht. Und an ganz vielen anderen Stätten. Und dann ist daraus irgendwo mal die Videoarbeit entstanden. Aber die ist nur 8 Minuten lang und hat mit der Performance überhaupt nichts zu tun. Und das Gleiche gibt es eigentlich mit „Eleven“. „Eleven - es wurde eine Frage auf Leben und Tod", war "ne Performance im Wallraf-Richartz-Museum und dann auch eine in Barcelona. Und das Tape daraus ist etwas völlig anderes. Das hat mit der Performance gar nichts zu tun. Das ist eine eigene Arbeit. Das war so die Kombination.

MR: Sehen Sie in den 80ern auch wieder eine Entwicklung sich abzeichnen?

UR: Ich sehe da einmal die Beschäftigung mit der Natur, immer an „Ewa und Adam“ aufgehängt, und dann die mit den Engeln. Und die Arbeit mit der Natur, da habe ich sehr viele Zeichnungen gemacht in den 80er Jahren, auch sehr große Zeichnungen. Davon sind einige in dem Göttinger Katalog. Und dann geht es eigentlich ständig um diesen Versuch der Erneuerung, Aber in „Wechselfrau“, in „Wechselkranz“, diesen Geschichten, oder „Hu em ay - Wer bin ich?“, diese Selbsthinterfragung, „Zen-Kocher“ und „Or-Phelia“ und so weiter, das sind ja alles die gleichen Geschichten. „Der Wind meiner Träume“ ist zum Beispiel auch so eine Performance- und Installationsarbeit, in der ich mich sehr stark mit der Natur auseinander gesetzt habe. Denn die Grundlage zu dieser Arbeit ist „die Schlacht der Bäume“. Das ist dieser Epos aus dem Keltischen, von Ranke-Graves übersetzt: „Ich war in vielen Gestalten, bevor ich die passende Form fand. Ich lachte...“.

MR: Den Text kenne ich.

UR: Also das ist ein starker Selbstfindungskontext, würde ich sagen. Und die auslösende Performance war „Ewa und Adam“. Aber das hat jetzt nichts mit diesem androgynen Kontext zu tun, sondern eher mit der Frage, wie ist der Mensch in der Welt, in der Natur.

Was dann anfängt, ist, daß die Performances zu einem Zyklus werden. Also Performance kombiniert mit Installation und Videoarbeit. Und die Videoarbeit der Performance, die dann in der Performance mit gebraucht wird, braucht durchaus nicht die Videoarbeit zu sein, die hinterher die Videoarbeit mit dem gleichen Namen ist. So wie in „Ewa und Adam“, „Eulenspieglerin“, „Der Wind meiner Träume“ etc. „Or-Phelia“ gehört da hinein. 
Das war dann 1987 die documenta 8, die Selbsthinterfragung. Das ist eine reine Installation. Und dann kommen die Zen-Sachen schon. Das ist der „Zen-Kocher“ und „Hu em ay“ und dann wieder eine Herz-Installation. Das Herz ist ja auch ein Zyklus, dazu gehört auch „Der Wind meiner Träume - Ana'l hak" und dann kommt als Abschluss dieser Geschichte noch „Herzpendel - Energetisches Phänomen“ in Nürnberg. Und was wir jetzt noch gar nicht berührt haben, ist dieser ganze Psyche-Kontext, bei „Psyche und Eros" wie auch das „Feenband“. Das sind Arbeiten der 80er Jahre. Und auch Performances der 80er Jahre.

MR: Aber das Thema ist das gleiche dabei, die Selbstfindung.

UR: Ja, dasselbe. Es ist quasi eigentlich sogar dasselbe wie „Or-Phelia“. Weil in dem Orpheus-Zyklus ist ja auch der männliche Teil, der seinen weiblichen, also seine Anima, in der Unterwelt suchen geht und die Psyche ist auch jemand, der in die Unterwelt nach sich selbst suchen geht. Aber das ist der Übergang von der alten Kultur zur neuen Kultur, die Psyche als matriarchale Göttin oder als eine androgyne Göttin. Und geprägt wurde das eben einfach von der Innensuche. Das kommt biographisch vielleicht daher, weil meine Mutter 82 gestorben ist. Und danach habe ich also diesen Mutter-Tochter-Komplex eröffnet. Die ganzen Mutter-Tochter-Arbeiten, bis auf „Einwicklung mit Julia“ sind in den 80er Jahren entstanden. „Requiem für Mütter“ war 82, und dann kommt Morsbroich. Und „Mutterliebe“ war in den 70er Jahren.

MR: Ja, das war früher. Wobei das ist ein Farbtape, also kann es nicht ganz so früh sein.

UR: Doch, es war so früh, weil das ist entstanden in einem Symposion. Das hätte ich nie selber drehen können, das Fernsehen hat es aufgenommen. Dadurch daß das Fernsehen mit seinem Team die aufgenommen hat, war das vor Publikum, wo wir das präsentiert haben. Es war während eines Symposions. Man sprach uns an, und dann sagten die „So, jetzt machen wir 'ne Pause für das Publikum, und in dieser Pause zeigen wir ihnen, wie die Künstlerin“, das war nur ich, „ein Livetape mit ihrer Tochter herstellt und das wird hier im Raum übertragen“. Und ich habe das nicht mit meiner Tochter live vor Publikum hergestellt. Die war noch zu jung, die war sechs oder 5. So wurde der Videoshot, den man auch auf den Tapes sieht, der wurde dem Publikum gleichzeitig übertragen. Das war also eine reine Closed-Circuit-Performance, nur man konnte uns nicht sehen.

\section{MR: Eine Live-Performance?}

UR: Ja. Und dieses Tape, das ich erst für diese Ausstellung in Schwerin neu ausgegraben habe. Ich mag das total gerne. Weil es sich mit Farbe beschäftigt. Und ich meine, es gab nie irgendwie ein Feedback auf dieses Tape. Ich habe es auch nicht so ernst genommen. Die Idee war es dem Publikum zu zeigen, aber dennoch ist das eigentlich ein sehr schönes, vor allem auch vom Stillfoto her, find ich das sehr schön. Also Standfotos geben mir viel. Dieses Kind, was mit diesen Lippenstiftabdrücken überlegt ist. Es hat schon sehr grundsätzlichen Charakter.

MR: Das finde ich auch sehr einprägsam.

UR: Bei der „Mutterliebe“ geben die Standfotos etwas her. Da spielen sie eine ähnlich große Rolle wie bei den „Lotus-Knospen-Tönen“. Das Tape „Lotus-Knospen“ war nie so erfolgreich wie die Standfotos. Die Fotoserie, die wird heute noch angefragt. Alle fragen: „Können wir die haben?“ 
MR: Es hat einen klaren formaler Ablauf.

UR: Ja, es ist dieser rein formale Ablauf, wie er hier aussieht auf diesem Vulva-Symbol. Das hat etwas, das für alle allgemein verständlich ist.

MR: Da gibt es doch auch noch die Standfotoserie aus der „Eulenspieglerin“ in Gent?

UR: Ja, da kommt auch im Video durch diese Haarbewegung soviel Feuer herüber. Diese enorm tantrische Bewegung, das ist ja eine lange Zeit, in der ich mich ständig hin und her werfe, und es ist eine ganz tantrische Bewegung, auch vom Atmen her. Wenn sie dabei nicht atmen, können sie das nie ausführen. Und Tantra hat ja in seiner Körperbezogenheit einfach nur etwas mit Atem zu tun. Es geht ja nicht um den sexuellen Akt im Tantra, sondern es geht um die Energie, um die sexuelle Energie und die wird durch Atem sozusagen entfacht wie ein Blasebalg das Feuer entfacht. Und hier kommt das so rüber mit den roten Haaren. Weil das wie so eine Flamme hin und her weht. Das find ich sehr schön. Das liebe ich sehr. Hier ist es nochmal, das ist auch so eine Sequenz zu der Performance, aus der ebenfalls das Videostill ist. Das hat hier jemand während der Performance aufgenommen. Und das geht tatsächlich nur um Transformation. In den 80er Jahren geht es um das Thema Transformation, den Übergang von einem Zustand in den anderen. Und das bekommt seine Eskalation in der Performance „Wie ein Phönix aus der Asche“, die ich 89 in Toronto und auch in Barcelona aufführte. Und da geht es eben nochmal um diesen alchemistischen Kontext, den ich 82 mit „Ewa und Adam“ begonnen habe, und um die Untersuchung der Transformation im alchemistischen Kontext.

MR: Ende der 80er Jahre entstehen dann mehrere Installationen.

UR: In der Installation „Ein Moment aus dem Leben des chinesischen Malers „Hu em ay“ habe ich sehr bewußt keine weibliche Form gewählt. Weil es mir tatsächlich um den allgemeinen Kontext ging. „Who am I“, das betrifft jeden. Und außerdem ist der Titel wirklich aus dem Englischen übersetzt. Ich konnte da nicht sagen „der chinesischen Malerin $\mathrm{Hu}$ em ay“, weil die bekannten chinesischen Maler sind eigentlich alles Männer. Ich kenne zumindest keine Frau, aber das hätte ja ein Titel sein können, um das mal in Frage zu stellen. Habe ich aber nicht gemacht. Ich war nicht an diesem Thema interessiert. An dem Thema, an dem ich interessiert war, war das der Transformation vom Objekt zum Subjekt. Was stellt man eigentlich dar? Wie in der „Eulenspieglerin“, die Untersuchung des Künstlers. Selbstuntersuchung, wer oder was ist denn der Künstler? Und die sich auf den Kopf stellen, um etwas zu machen, das ist einmal das Symbol der Anstrengung. Das kennen wir ja auch als saying, als Sprichwort. Und dann gibt es das auch im Schamanismus. Und im Tarot ist es zum Beispiel „the hanged man“, also das ist derjenige, der über Kopf hängt, und das kommt aus dem sibirischen Schamanismus, dieses Bild, desjenigen, der sich verändern will. Er stellt sich auf den Kopf oder hängt sich an den Füßen auf. Und wir sagen ja auch „du kannst dich auf den Kopf stellen, da passiert nichts". Ja, das heißt, du musst dich erst auf den Kopf stellen. Also du musst erst unheimlich viel unternehmen und dich quasi völlig ändern bis tatsächlich die Veränderung eintritt. Ein anderes Symbol dafür ist der Derwischtanz, den ich in den 80er Jahren immer wieder aufgreife. Derwischtanz als Symbol der Wiederholung, die Wiederholung bedeutet aber auch, dass sich dadurch etwas verändert. Wie beim Atmen. Durch einen langen Prozess des gleichen Tuns verändert sich etwas. Der ganze Recherchekomplex über dieses Thema mit dem Kreis und dem Drehen, das ich ja bereits in der „Eulenspieglerin“ exzessiv betrieben habe, der kommt nicht nur aus dem Sufi-Dance über das Herz, das hängt einfach so komplex zusammen. Denn es hängt auch damit zusammen, dass ich Untersuchungen über die Bedeutung der Spirale und des Labyrinths gemacht habe. Und 
das habe ich bereits in den 70er Jahren mit der Arbeit „Maifrau“ angefangen. Und dann geht es darum, dass Atmen und Zentrum was miteinander zu tun haben. Auch bei den Derwischtänzen muss man ganz frei atmen können, sonst kann man das auf gar keinen Fall durchhalten. Und hier in Nürnberg, das war so total schön, weil das Tape vom Derwischtanz neben die Wendeltreppe gestellt, das ist eine Spirale. Es war ein wunderschönes Haus, das hatte sich ein Nürnberger Kaufmann für seine italienische Frau gebaut und es ist venezianisch und pompejanisch. Er hat sich ganz viele Elemente, auch fertige Elemente, aus Italien kommen lassen. Und das Prunkstück dieses alten Gebäudes war diese Halle, die relativ deutsch geraten ist, finde ich. Aber dieser Aufgang hier, der ist einfach zauberhaft. Und das war diese Wendeltreppe. Und das war wirklich hoch, das waren 10 Meter mindestens. Dann wurden diese Papiere wie eine Spirale gewunden, wurden einfach nur gedreht, wie ein Pendel, und dann wie so ein Lot an diesen Bronzeherzen aufgehängt. Ich liebe diese Installation sehr.

MR: Worin würden Sie die Arbeiten der 70er Jahre und der 80er Jahre unterscheiden?

UR: Während der ganze Kontext mit den 70ern biographisch aufgefasst ist, ist das in den $80 \mathrm{ern}$ nicht so. Ich habe extrem viel gearbeitet in den 80er Jahren. Ich war sehr viel auf Reisen, habe unglaublich viele Lectures gemacht, wahnsinnig viele Workshopstourneen, bei denen ich Workshops für Performance und Video gegeben habe weltweit, durch Kanada, durch Australien. Also wirklich viele Sachen, die gar nicht in meiner Biographie erscheinen, weil es keine Ausstellungen sind. Aber ich habe sehr viel schon in diesem Vermittlungskontext gestanden, der dann darin gipfelt, daß ich diese Professur in Saarbrücken bekam.

MR: Das Anliegen der Vermittlung zieht sich als roter Faden durch ihre Biografie.

UR: Ja gut, also Vermittlung ist gleich Kommunikation. Und ich finde, was man in Performance sowieso macht, ist eben Vermittlung. Das heißt, man vermittelt eigentlich einen bestimmten Kontext und in den 80er Jahren habe ich Gastprofessuren gehabt, Lehraufträge, Workshops veranstaltet, die „Schule für kreativen Feminismus“ weiterentwickelt. Das war ein sehr fleißiges Jahrzehnt, wo ich sehr viel nach außen gearbeitet habe. Und die Beziehung zum Publikum habe ich auch anders aufgebaut. Also das Publikum habe ich in den 70er Jahren ja klar definiert, dieses psychological feedback. Und in den 80er Jahren ist es eher so, daß ich eine Improvisation in einer vorher komponierten Installation mache. Und während dieser Improvisation verändert sich die Installation. Das ist es auch, was ich mit komprimiert meine. Die Installation ist am Anfang geordnet und dann am Ende ziehe ich diese ganzen Papers raus und zerreiße die und bringe die in einen anderen Kontext oder ich male wie in der „Göttin“. Also die Installation hier ist erst so, und dann zum Schluss ist es etwas ganz Chaotisches. Alles ist kaputt.

MR: Und was ist anders an der Rolle des Publikums?

UR: Ja, an der Rolle des Publikums ist anders, daß ich in der Improvisation das psychologische Feedback, so wie ich das in den 70er Jahren genannt habe, umzusetzen versuche, daß vom Publikum zu mir rüber kommt. Also ich versuche, die Atmosphäre, die im Raum ist, aufzufangen und umzusetzen in meinen Bewegungen. Und dazu auch meine eigenen Gefühle zu formulieren. Also Gefühle von Angst, Gefühle von Freude, Gefühle von Bedürfnissen aller Art. Das ist die, ja, das ist eine Herausforderung. Also es war wirklich ein riesen Challenge. Das war eine wahnsinnige Herausforderung an mich selber. Aber das war notwendig, weil ich anfing, mich mit diesen Performancesachen zu 
langweilen Ende der 70er Jahre. Ich musste mich also auf irgendeine Art und Weise herausfordern, um überhaupt nicht in so eine Routine zu geraten. Das wollte ich auf keinen Fall. Und deswegen habe ich eine neue Form von Kunst angefangen, die den Männern nicht mehr so geheuer war, weil sie außerordentlich weiblich ist in ihrer Umsetzung. Sie abstrahiert nicht so stark. Sie ist aus sehr subjektiven Gefühlen und seelischen Zuständen her geschaffen und bringt sehr viel Unbewusstes nach vorne. Das heißt, sie hat eine relativ psychologische Struktur, diese Form der Performance. Und das ist auch angemessen und anlegbar an die Ausbildung, die ich damals gemacht habe. Nicht nur über Tantra, sondern auch über die ganzen Formen der Körper-Seele-Verbindung, die es in der Ganzheitstherapie, die sich auf C.G. Jung, Philosophien basieren lässt, aufbaut. Aber es war schon für die Leute eine sehr weibliche Form. Das war nicht mehr so klar konzeptioniert. Sondern es war viel chaotischer. Es ging viel mehr zurück an den wirklichen Darstellungsbereich der großen Göttin als Kali, als derjenigen, die zerstört, bevor sie schafft.

Das hier ist nicht einfach ein fliegender Engel, sondern die Figur ist eben auch untergebracht im Stirnfresko der Villa de Misteri und bedeutet eigentlich das Transformationsmoment im Tantra. Also dort wo sich die Luft hebt, wo sich der Atem hebt, wo die Energie aufsteigt. Weil es ist eigentlich ein schwebender Engel. Das ist kein Engel, der auf der Erde steht oder fliegt. Sondern im Fresko selbst ist er genau so dargestellt, nämlich einen halben Meter über der Erde. Etwas, das sich gerade aufrichtet.

\section{MR: Sie haben die Figur in Pompeji entdeckt?}

UR: Ja, ich hatte ein Ferienstipendium in Florenz. Ich hatte aber nie das ganze am Stück, so bin bin ich immer nur sechs Wochen gefahren und das dann ein paar Mal. Bei einem Aufenthalt hatte ich dann versucht, diesen Pompeji-Zyklus einfach erst einmal fotografisch nachzustellen und dachte, da käme nun eine Fotoserie bei heraus. Aber das war viel zu wenig abstrakt. Also das waren schöne Szenen, ich mag die Fotos. Aber es hat erstmal nicht das gebracht, was ich gesucht hatte. Aber wie oft bei diesen Untersuchungen mit anderen Kulturen oder Mythosgeschichten kam dann letztendlich dieser Engel dabei raus. Wahrscheinlich erst im Zusammenhang mit der Untersuchung oder der Suche nach Bildern in der Kunst für den Zustand der Transformation. Und „Schmelzprozesse“, das sagt schon der Name, ist natürlich eins von diesen Teilen. Schade ist, daß hier nur Schwarz-Weiß-Abbildungen drin sind. Gerade für diese Arbeit, weil das sind ja Goldseidenbänder. Und der ganze Raum, das ist ja wirklich das Phänomen, das ist ein sehr weißer Raum gewesen, war dadurch in Gold getaucht. Das Licht hat sich total verändert, weil das Licht durch die sehr hohen Fenster da durch fiel. Also von der Rauminstallation war das unglaublich gelungen. Das war ein sehr großer Raum, und dann hatte der hier hinten im Durchbruch diese seltsamen Teile oben. Die sehen so aus wie die Hand, diese Hand auf dem Goldteller in dem Tape. Dieses Zackige, seltsam, was hier in der Hand ist, das ist hier auch in den Fenstern. Das war eine sehr ausgeklügelte Angelegenheit, dieses Teil. Dies Fototableau ist im Wallraf-Richartz-Museum in der Sammlung Ludwig hergestellt, die ja Altarbilder und mittelalterliche Malerei gesammelt haben. Und da gibt es natürlich sehr viele Engelabbildungen, und die sind zum Teil sehr klar. Sie sind hier im Detail vergrößert auf 50 mal 60 in Farbe. Und an diesen Abbildungen habe ich gemerkt, daß das durchaus nicht immer freundliche Sachen sind. Sondern daß es ganz häufig Transformation vom Leben zum Tod bedeutet. Dies hier sind Verkündigungsengel, aber dies hier sind eigentlich kleine Leichen. Das sind oft Gestalten wie fliegende Geister der Lebenden ins Totenreich. Es ist ziemlich erschreckend, wenn man diese Engel in mittelalterlichen Bildern untersucht. Das sind nicht die freundlichen Barockengelchen. Und deswegen hat mich das hier interessiert, weil das auch einen Transformationscharakter hat, diese Darstellung der Engel. Und in dieser Installation, die es hinterher war, 
das blieb als Installation für die Dauer der Ausstellung stehen, wurde ja sehr viel gezeichnet, auch in bunt.

MR: In ihren Zeichnungen tauchen als Motiv häufig Bäume und auch Engelsfiguren auf.

UR: Das habe ich sehr gut gelernt diese Baumsymbolik, die Natur mit der Engelszeichnung zu verbinden. Das habe ich auch schon in den "Judofrauen“ gemacht. Diesen Riesenbaum, den ich da zeichne und der gleichzeitig wie zwei Flügel aussieht. Und das ist ein ganz alchemistisches Auffassungsteil. Diese Symmetrie, die der Baum hat. Und der Stamm ist der menschliche Körper, sehr häufig auch sogar mit Wirbelsäulen, Nervensträngen wie in dieser Abbildung, die ich auch in „Eva und Adam“ benutzt habe. Und die beiden Seiten des Baumes, die Kronen, sind wie zwei Flügel. Das kommt ganz häufig auch vor in alchemistischen Darstellungen. Das entspricht auch der anthroposophischen Darstellung des Baumes als Grundsituation für den Menschen, der von den Wurzeln bis zur Krone wächst. Und die Ohren oder die Aufnahmefähigkeit, die Kommunikationsfähigkeit ist die Krone. Und da bindet sich auch im Alchemistischen eine ganz lange Untersuchung von Zeichen und Bedeutungen von Zeichen dran. So wie man das auch bei Lévi-Strauss untersuchen könnte, oder in der ganzen Ethnologie eigentlich. Das habe ich alles absolviert als Vorübung. Man musss nicht glauben, daß diese Sachenunbewusstt entstanden sind. Davor liegt eine ganz lange und bewusste Recherche über diese Formen, die ich da zeichne. Die ich dann aber nicht intellektuell zeichne, sondern die ich aus dieser Lehre, die ich da empfangen habe, aus diesen Ausführungen, versuche umzusetzen und zu erforschen, ob das auch wirklich stimmt.

Da ich nicht mehr so viel mit Video während der Performance arbeite, ist mein bildhauerische oder mein plastisches Interesse wieder in den Vordergrund getreten, Material mit einzubeziehen. Und das waren eben vor allen Dingen Farben, Formen, Raum und Material. Also die Installationselemente waren von höchstem Interesse. Das heißt meine plastische Arbeit wurde also sehr weitgehend wieder entwickelt. Deswegen waren die Performances vielleicht hinterher auch alles Installationen, wie diese hier ja auch eine Installation ist. Und ich habe damals halt wirklich viel immer mit Untergründen gearbeitet, weil diese vielen Reiseperformances, die ich da gemacht habe die hatten ja immer mit Böden zu tun, die wirklich nicht brauchbar waren. Und deswegen habe ich häufig Salz als Untergrund genommen, um diese Böden zu neutralisieren. Einfach um mir einen guten, neutralen Untergrund zu schaffen. Es ist sehr anstrengend, auf Salz Performance zu machen. Außerdem ist Salz auch bereits in der Alchemie transformatorisches Material. Dazu kommen Seidenpapiere. Seidenpapiere habe ich deswegen gewählt, eigentlich wegen des Sounds. Weil ich habe in der Zeit angefangen, mit Sprache zu arbeiten, Live-Sprache oder Live-Sound und um den Sound zu verstärken oder mir den Sound weiterzugeben mit Seidenpapier. Das knistert laut, so wie in den „Milleniums-Frauen“. Und was bei Seidenpapier für mich höchst wichtig war, ist die Durchsichtigkeit von Seidenpapier, also die Transparenz des Materials. Und das hat auch etwas mit mit dem Thema Transformation zu tun, und das das oft an Transparenz von einem Zustand in den anderen gebunden ist. Dazu wird viel das Symbol des Wassers benutzt. Oder auch Glasscheiben. Es lässt sich alles auf „Eva und Adam“ zurückverfolgen, weil Mercurius als der Gott der Veränderung und der Kommunikation als Symbole Wasser und Glas hat. Und das sind eben die transparenten Symbole, und das ist auch in der Alchemie so, schon im 12. Jahrhundert. Das heißt also, daß die Transparenz oder Transformation schon ganz früh ausgedrückt wurde durch fließende oder transparente Materialien. Das fließende Wasser kann man mit Seidenpapier so schön machen, das Fließen des Papieres darstellen, ohne daß man jetzt hier mit Wasser herumschleppt. Weil, wie Barbara London so gut sagte: „Ich kann keine Videos mit Wasser mehr sehen. Jedes Jahr kommen 20 Videokünstler und zeigen mir Wassertapes.“ Das ist auch etwas, das mir immer zu einfach 
war. Also Wasser und Video gehen immer zusammen. Ich habe etwas gegen diese Kombination. Vielleicht auch aus dem Grund, weil das zu einfach ist. Für mich habe ich das Papier als Material gewählt. Es hätten auch sehr viele Bahnen dünnen Stoffes sein können. Aber das war mir als Material zu kunstgewerblich. Es erinnerte mich zu sehr an den Kontext Frau, weil Stoff und Frau wird in der männlichen Kunstlesung das wird sofort zusammen geschaltet. Frauenkunst ist mit Stoff verbunden. Deswegen habe ich das Seidenpapier genommen, und dann vor allen Dingen wegen dem Rascheln. Also dieses Rascheln kann ich bei Stoffen nur bei sehr teuren Stoffen erreichen und ich habe eben kein Geld gehabt in den 80er Jahren. Ich habe gelebt von Performance und Workshops, und das war nie viel Geld, und ich habe auch kaum Sachen verkauft in den 80er Jahren. Das heißt also, ich hatte ein Material zu nehmen, der auch in diesen Low-Budget-Etat von Performance unterzubringen war.

MR: Ja aber es gibt ja auch sehr große Videoarbeiten von ihnen, wie „Das Bild der Frau in der Nachkriegszeit"“.

UR: Wenn ich 200.000 Mark bekomme, klar mache ich dann ein tolles Ding. Und wenn mir Wulf Herzogenrath sagt in der documenta, du kannst aber nur zwei Monitore haben und den Rest bekommen Bill Viola und Joan Jonas, weil sie amerikanische Künstler sind, du kannst froh sein, daß du als deutsche Künstlerin überhaupt dabei bist, dann mache ich eben etwas mit zwei Monitoren, so wie „Herakles, Herkules, King Kong“. So absurd ist das. Bei Medienkunst ist das so. Es gibt ein sehr schönes Buch, das leider sehr unbekannt ist, es heißt „Artemisia“.

\section{MR: Ein Roman?}

UR: Ja. Und es ist eine vorzügliche Recherche zu dem Thema. Die Autorin hat sehr gut recherchiert. Wie sich bereits in der Renaissance und im Barock die einzelnen Künstler das katholische Geld gegenseitig weggezogen haben und wie das verteilt wurde. Das Buch ist genial. Aber es ist mal wieder bezeichnend für die deutsche Szene, auch in der Literatur, daß so etwas komplett runtergespielt wird, weil wir keine Kulturszene haben unter den Frauen.

MR: Die ist versandet.

UR: Die hat es nie gegeben. Neulich sagte eine Frau während eines Diskussionsgesprächs zu mir, ja Sie werden geführt als feministische Künstlerin und Videokünstlerin in absolut allen Lexika, die uns zur Verfügung stehen. Aber Feminismus kann doch wohl nicht sein. Ich sage: „Doch, aber feministische Kunst.“ Und feminist art ist eigentlich eher ein englischer Begriff gewesen. Das gab es hier gar nicht. Es gab eine Filmbewegung, aber keiner von den Frauenkünstlerinnen, auch nicht von den Malerinnen in Berlin, würde sich feministische Künstlerin nennen. Feministische Kunst als Begriff gibt es hier nicht. Sarah Schumann hat sich nie feministische Künstlerin genannt. Rebecca Horn auch nicht. Keine von den Künstlerinnen war daran interessiert. Den Begriff gab es nicht. Ich habe den für meine Arbeit geprägt. Und irgendwelche Kritiker haben dann versucht, den für eine ganze Bewegung zu übernehmen und die Künstlerinnen waren total sauer auf mich. Ich habe nichts dazu getan. Ich habe den für meine Arbeit geprägt. Ich habe gesagt, dies ist ein Stück feministischer Kunst, das war meine Arbeit, ich war Künstlerin. Und dann wurde gesagt ,in der feministischen Kunst“. Leute wie Silvia Bovenschen haben dann angefangen, darüber zu sprechen und haben „feministische Kunst" gesagt und da wurde dann auch Sarah Schumann eingeladen. Historisch sieht das immer ganz anders aus, als das wirklich war. Das ist wirklich interessant. 
MR: Ja natürlich, der historische Rückblick verändert.

UR: Das verändert sich total. Das ist so. Valie Export ist jemand, die sich bewusst in diesen historischen Strategien verhält. Sie geht damit ganz bewusst mit den historischen Strategien um und verändert bewusst diese Strategien vom heutigen Gesichtspunkt her. Das ist interessant, wie sie das macht. Dieses „Ich war feministische Künstlerin“. Sie war die einzige neben mir, die sich übrigens so genannt hat. Valie Export war in den 60er und 70er Jahren die einzige, die gesagt hat ,ich bin feministische Künstlerin“, die ich kannte. In Europa dann vielleicht noch Gina Pane.

MR: In Frankreich.

UR: Ja, oder Yoko Ono, das war dann in den USA, der Rest war in Amerika. Aber wenn man Gislind Nabakowsky fragt, wer sich hier feministische Künstlerin genannt hat, wird sie bestätigen, das es unheimlich wenige Leute waren. Also die Historie, die verschleißt das, weil die Bücher das verschlissen haben. Man musss eben Silvia Bovenschen lesen, und dann hat man diesen Begriff, und dann nimmt man diese ganzen Künstlerinnen und ordnet die dort ein. Aber zu der Zeit, diesen politischen Mut zu haben, das zu sagen, das waren wirklich sehr wenige, das muss ich jetzt mal ganz klar ausdrücken. In Amerika lief das völlig anders. Das war eine völlig andere Nummer. Da gab es ja 75 bereits feminist art am California-Arts-Institute. Das hatte auch einen ganz anderen Kontext, das war auch politisch ganz anders gemeint. Das hätte man so nicht übertragen können. Bei uns gab es das nur im Film, bei Helge Sander, das war der Feminismus in der deutschen Frauenbewegung, das war der Frauenfilm. Margarethe von Trotta. Das war die Frauenbewegung. Aber in der bildenden Kunst ist das eine völlig andere Geschichte.

MR: Den Unterschied zwischen Frauenkunst und feministischer Kunst sehen Sie also im politischen Kontext?

UR: Ja, Frauenkunst hat ja keinen politischen Kontext. Es führt keine Veränderungen herbei. Ich meine, vielleicht bin ich es auch, die das nicht akzeptieren kann. Für Sarahs Arbeiten kann ich feministische Kunst nicht akzeptieren, weil sie keine Veränderungen im Konzept vornimmt. Sie stellt nur dar. Und dann ist Artemisia Genteleschi auch Feministin. Und so wird sie ja auch immer eingestuft, weil sie sich als Salome darstellt. Sicher, war sie auch. Sie war die erste Feministin in der Kunst, die wir vielleicht kennen. Sie hat dafür gekämpft, daß die Vergewaltigung, die sie erfahren hatte von ihrem Freund, als solche angepackt wurde gerichtlich. Obwohl es nach heutigen Recherchen wirklich fragwürdig ist, daß es eine war. Also es war schon eine sehr, im Englischen würde man sagen: spicy women. Eine, die Haare auf den Zähnen hatte, eine sehr kämpferische Frau. Aber Salome war ein ständig wiederholtes Sujet. Man musste ja an den Themen lang gehen, die es gab. Man konnte sich ja nicht einfach irgendwelche Themen ausdenken. Und was es halt gab in der Renaissance waren Malerinnen, die sich benannten, weil man ja zum ersten Mal überhaupt etwas benennen konnte. Im Mittelalter konnte man nichts benennen. Das Mittelalter kannte Werkstätten und die liefen unter irgendwelchen Namen.

MR: Das ist ja heutzutage zum Teil noch schwierig die Namen der Künstler zuzuordnen.

UR: Weil es das in der Renaissance einfach noch nicht gegeben hat. Und da kam dann halt die erste und sagte: „Hier bin ich. Ich male die hauptsächlichen Sachen in der Werkstatt meines Vaters. Mein Name ist Ursula Meier." Das war eben die Renaissance als solche. Aber seitdem hat sich dann für viele Jahrhunderte eigentlich auch nicht sonderlich etwas verändert. Eigentlich hat sich erst im 19. Jahrhundert etwas verändert. In den 80er Jahren 
war das aber für mich überhaupt kein Thema mehr, weil das ja auch kein gesellschaftliches Thema mehr war. Ich würde mal sagen, was halt das Problem war, daß man unglaublich bekämpft wurde in Deutschland als Frau hier, die an diesem Kontext entlang arbeitet. Aber symptomatisch ist sicherlich eine Entwicklung, die mir Wulf Herzogenrath damals gesagt hat: ,Jetzt wollten wir eigentlich gerade das Phänomen des Feminismus akzeptieren und jetzt fängst du an, was anderes zu arbeiten." Und dann kam eben die nächste Generation und hat das adaptiert, wie Rosemarie Trockel, die ja in Amerika sagt, daß sie feministische Kunst macht. Das kann man in jedem amerikanischen Katalog von Rosemarie Trockel lesen, aber nicht in jedem deutschen. In Deutschland wird das überhaupt nicht gesagt. Langsam fühlt sie sich so sicher auf ihrem Terrain, und da hat sie ja auch allen Grund zu, daß sie, neulich hat sie einmal irgendetwas in Deutschland zum Thema Feminismus gesagt, zum ersten Mal, ich glaub das war dieses Jahr, öffentlich. Einfach weil es uns so geschadet hat, und das beste Beispiel bin ich. Es hat uns im Kunsthandel so geschadet, in der Kunstszene derartig geschadet und das sagte Monika Sprut* auch vor einigen Jahren bei einer Diskussion, daß keiner das gewagt hat außer Valie und mir. Sarah Schumann hat vielleicht ihre Bilder verkauft, aber sie war nie eine Größe in der Kölner Kunstszene. Das war ganz konventionelle Malerei. Für mich ist Sarahs Arbeit sehr schön, ich mag sie sehr, aber sie ist sehr konventionell. Ich glaube meine Chance war, daß ich das halt nicht war. Ich war halt immer eine AvantgardeKünstlerin. Das war die Chance, die mich nach vorn geschossen hat. Trotz dieses brenzligen Themas. Und in den 80er Jahren wurde das schon ziemlich runter gestapelt, auch bei der documenta. Da war es dann also wirklich wichtig, aggressiv zu bleiben. Und ich habe das nicht gemacht. Da war dann Marie Joe Lafontaine als Künstlerin, die in den 80er Jahren auftauchte. Das ist ja auch schön, was Marie Joe Lafontaine auf der documenta 8 gebracht hat, diesen androgynen, aber sehr aggressiven Kontext, vom Bildmaterial her, also dieses erotisch-pornographische Element sado-masochistischer Grausamkeit, das war ja dann auch gesellschaftliches Thema der 80er Jahre. Und dem ist sie gefolgt, und deswegen war sie folgerichtig der Newcomer der Szene. So wie das in 70er Jahren halt die Frauenbewegung war. Und meine eher reflektiven Themen über Transformation des Menschen, Seinsfragen und so weiter waren eigentlich völlig out. Das waren eigentlich keine gesellschaftlichen Fragen des normalen Bürgertums. Das waren alternative Kontexte wieder mal, aber meine Arbeiten und Performances, wenn einer von den Leuten die sah, die aus New-Age-Bewegung kamen, die es ja in den 80er Jahren sehr stark gab. Das ist genial, was die gemacht haben. Und die sahen das nicht nur vom Tanztheater oder von der bildenden Kunst, sondern vom Kontext her. Und meine Arbeit ist eben Arbeit mit Kontext. Und die Arbeit mit Kontext wurde eben wegen der postmodernen Entwicklung immer uninteressanter. Die postmoderne Entwicklung war oder ist am Material interessiert und an einer sehr kühlen, emotionalen Lage. „Cool“ wurde das Modewort die nächsten Jahrzehnte. Und deswegen war eine Arbeit mit Kontext, in der Emotionen transformiert werden sollten, nicht gefragt. Sie wurde an den Rand gedrängt.

MR: Ja, diese Intensität der Emotionen wird besonders in der Or-phelia greifbar und dort scheinen auch vielfältige ikonographische Bezüge gegeben.

UR: Ja, zum Beispiel diese rote Wolle. Die kommt wirklich aus der Ophelia-Geschichte. Ich hab dann einmal auf einer dieser Tourneen durch England in Manchester im Museum geguckt und die ganzen Originale gesehen. Das war schön. Da hat ein Fabrikant des späten 19. Jahrhunderts diese Romantiker gesammelt. Ich habe die alle im Original gesehen. Und die sind ja manchmal so klein, unglaublich. William Holman Hunt war da sehr viel. Von dem ist ein Bild, das heißt „Die Lady von Shalott“. Das ist ein Bild, in dem ich ganz viel gefunden habe von dem, was ich benutze. Die Recherche dazu, die die 
Feministinnen in England gemacht haben, war, daß sich das am Hof von König Artus abgespielt hat und daß diese Frau verliebt war in Lancelot. Und daß, dies hier zeigt Lancelot und die Ritter, wie sie wegreiten, um den Gral zu suchen. Und sie wurde in den Turm gesperrt. Das hier hat auch noch eine ganz wesentliche Bedeutung hier. Dies hier ist auch der „Baum der Erkenntnis“ und das hier ist auch etwas ganz Androgynes. Das ist sowohl eine Frau als auch ein Mann. Und hat eine ganz muskuläre Struktur. Das ist wohl wirklich alchemistisch gemeint. Und hier die Frau, die sich nur anlehnt, die Mondgöttin mit dem Mond dahinter. Also es ist noch eine richtige Alchemie-Struktur. Und das zeigt die Symbole der Verwirrung. Dieses Gewebe wird zerstört. Das ist hier oft, das ist auch die ganze Maja-Geschichte, die Maja, die am Webstuhl sitzt und den Lebensbaum webt.

Aber dies Bild ist so klein, hat sehr dunkle Farben. Das ist wieder in der Abbildung besser. Und diese habe ich zum Teil aufgenommen als Vorlagen für „Female energy change“. Das sind zum Teil Sachen, die auf diesen Tarot-Karten wieder auffindbar sind, die ich gemacht hatte. Und da ist auch die Ophelia. Dieses Teil hier hat mich durch viele Dinge geleitet. Die Ophelia, auf die ich mich in der Abbildung gründe und bei der ich meine Anregung habe, ist aus der englischen Malerei.

\section{MR: Hat sich durch die Professur verändert?}

UR: In den 80er Jahren war ja schon diese Tendenz da, sehr viel in die Vermittlung zu gehen. Und durch die Professur ist es natürlich noch einmal verstärkt worden, das Lehrprogramm als ein Programm zu sehen, das zur Kunst gehört. Das ist das, was zum Beispiel auch Forsythe gemacht hat oder auch Forty. Im Tanz oder in der Musik ist das wirklich sehr gebräuchlich, daß das Lehrprogramm wirklich ein Teil deines Lebens ist, eines künstlerischen Lebens und auch ein Teil deines Werkes. Daß das Lehrprogramm ein Teil deiner künstlerischen Vermittlung ist. Das ist wiederum auch nicht gerade ein deutsches Konzept. Der deutsche Künstler kommt eher selten an seine Kunsthochschule und tut nichts, weil es nicht integrierbar ist in sein eigenes künstlerisches Werk. Und das ist bei mir völlig anders gewesen bisher. Ich habe mich da sehr engagiert. Und deswegen ist dieses Buch, das ich im letzten Jahr gemacht habe, die „Medienkunstprojekte“, für mich sehr wichtig gewesen als ein Abschluss dieser vergangenen 10 Jahre, also von 1989 bis 2000, mit Lehrtätigkeit und Vermittlung, die komplett ein eigenes System gezeigt hat. Also mit dem Performancetraining, mit der Art und Weise, wie ich Fotografie und Video sehe, und wie ich das vermittle. Das ist integrativ in meine Arbeit eingeflossen. Und dieses Buch ist in gewisser Weise mein Buch. Es sind zwar die Arbeiten der Studenten, aber es hat damit zu tun, daß es ein Teil meines Lebenswerkes ist.

MR: In den vergangenen Jahren sind dann ja auch noch andere Projekte entstanden.

UR: Und in diesem System sind diese neuen Projekte zu sehen: Ulrike-RosenbachProjekte. Das sind eben Arbeiten, die die Struktur dieser Arbeit zeigen, dieser Medienarbeit, Performancearbeit oder wie man das auch nennen will, dieser künstlerischen Arbeit, und die sich auf ein Team überträgt. Die von dem Team mitgetragen wird auch. Positiv selber mitgetragen wird. Leute, die sich in diesem Kontext sehen, bis sie sich abnabeln. Und dann gehen sie ihre eigenen Wege. Also ich würde mal sagen, nach 35 ist es damit zu Ende. Ab 35 willst du deine eigene Arbeit machen. Es gibt gerade wieder ein Medienkunstprojekt „Web“ im Saarland, wird sehr gesponsert vom Saarland, das ist worldwide, also eben ein Web-Projekt, und das sind alles alte Studenten von mir, über 35, und die gehen ihren eigenen Weg, das sind Medienkünstlerinnen und -künstler des Saarlandes.

MR: Ist das bereits im Internet? 
UR: Ja, und es ist ein reines Kommunikationsprojekt. Zusammenfassend würde ich sagen, dass die Arbeit in den 90er Jahren eigentlich wie in den 80er Jahren geblieben ist. Man kann ja diese Bögen ziehen mit Natur und mit Transformation. Da findet man dann zum Beispiel „Zen-Kocher“. In dieser Installation wird dieses Seidenpapier sehr schön eingesetzt mit der Transparenz, und Kochen eben wie in der Alchemie, wo eigentlich das Wasser in einen anderen Zustand gebracht wird. Das ist ein reines alchemistisches Stück. Und das ist hervorgegangen aus „Aufwärts zum Mount Everest“. „Aufwärts zum Mount Everest" und „Zen-Kocher" sind verknüpfbare Arbeiten. Und die Videoinstallation „Requiem für eine Eiche“ ist ja auch mit dem Seidenpapier und Licht, und gehört wieder in den Kontext „Zen-Kocher“. Dann kommen die letzten Arbeiten der 90er Jahre, diese großen über den Tod, über die Kinder, über den Engel. Diese drei Arbeiten fassen die Kontexte der 80er und auch in gewisser Weise der 70er Jahre zusammen. „Über den Tod“ wäre also das Thema Transformation von einem Zustand in den anderen. „Über die Kinder" und im „Palast der Neugeborenen“ beschließt den ganzen Kindheitsarbeitszyklus.

MR: Und als drittes „Über die Engel.“

UR: Ja. Da gibt es auch einen eigenen Katalog zu. Die einzige Arbeit, die nirgends so richtig rein passt, ist „Das Bild der Frau in der Nachkriegszeit“.

MR: Die Auftragsarbeit für das Haus der Geschichte in Bonn?

UR: Ja, das ist ein völlig anderes Arbeiten. Ich hätte die natürlich nicht schaffen können ohne die Arbeit der 70er Jahre. Die Arbeit am Frauenkontext, ohne dieses Bewusstsein hätte ich das nicht geschaffen. Also es sind diese vier großen Komplexe, besonders die drei ersten. Denn danach, ich meine in gewisser Weise würde ich heute sagen, ist mein Lebenswerk abgeschlossen. Und auch diese Arbeit „Psyche und Eros“ in dieser Ausstellung „Nichts überstürZen“ derzeit in Eutin, greift auf andere Arbeiten zurück. Und das werde ich wohl auch weiter machen, daß ich auf ältere Arbeiten zurückgreife und diese neu formuliere. Aber ich glaube nicht, daß es zu meinem Kontext noch etwas Neues dazu geben kann. Das kann ich mir nicht vorstellen. Ich habe eine ganze Lebenslinie ausgearbeitet: die junge Frau, die nach dem Bild der Schönheit fragt, die Mutter, die nach dem Bild der Mutter fragt, dann das Nach-Innen-Gehen, die reife Frau, die nach dem Bild der Seele fragt, so wie das im Pompeji-Fresko auch dargestellt wird. Und die ältere Frau, die zurückblickt auf diesen ganzen Zyklus der Arbeiten und diese miteinander verquickt. Und der Schluss „Über den Tod“. Übrigens genau diese Abfolge ist im Fresko von Pompeji dargestellt. Und das Fresko heißt in der Archäologie „Mystische Hochzeit“. Die Archäologen betrachten das nur aus der Funktion des Mittelgemäldes heraus, diese Bacchus-Hochzeit. Selbstverständlich spielt der Bacchus die wesentliche Rolle, aber im Rest dieses Riesenfreskos, das immerhin über vier Wände geht und auf dem Bacchus nur einmal wirklich abgebildet wird, ist ansonsten wirklich ein Fresko über den Lebensweg der Frau. Bei diesen historischen Sachen wird feministische Wissenschaft gebraucht, und so habe ich mich auch immer verstanden. Und diese Forschung habe ich eigentlich in den 80er Jahren am Kontext der Transformation weiterentwickelt. Vielleicht auch ein Punkt, warum ich immer wieder zu Kirchenausstellungen eingeladen werde.

MR: Stimmt, das ist auffällig.

UR: Das kommt aus diesem Kontext über die Transformation. Das ist einfach ein religiöses Thema. Und das Letzte, was ich in dieser Ausstellung in Blumenthal hatte, das ist jetzt auch auf meiner neuen Website. Das war eben auch eine Zusammenfassung zu 
diesem Thema eben in diesem wirklich transformatorischen Visualisierungskomplex. Das dritte war das Androgyne, die ganze Zusammenstellung über androgyne Kontexte. Und da kommt natürlich besonders die Alchemie heraus. Also da hab ich Bücher drüber, aber das sind alles englische Bücher. Die hab ich alle in London gefunden. Kein einziges deutsches Buch ist dabei. Der ganze Kontext, alles englisch.

MR: Warum sind Sie nicht in Amerika geblieben?

UR: Warum ich nicht in Amerika lebe? Ich war ja sehr viel in Amerika, und ich weiß, daß es sehr schwierig ist, auch finanziell, dort durch zu kommen. Wenn ich nicht diese Professur bekommen hätte, ist es fraglich, ob ich nicht weg gegangen wäre. Aber eine lebenslange Professur, darum beneidet uns jeder amerikanische Künstler. Weil das gibt es in Amerika nur ganz selten. Die einzigen, die ich kenne, die das hatten, sind Alan Kaprow, John Baldessari und Hans Haake, die drei haben lebenslange Professuren gehabt als Künstler. Alle anderen sind nur drei Jahre lang und dann musst du wieder gehen. Es ist zwar ein Netzsystem, du wirst dann weitergereicht von einem College zum anderen. Aber es ist ein ständiges moving. Zum Beispiel Joan Jonas, mit der ich auch sehr befreundet bin rein mental und die ich total gerne mag, war unheimlich froh über ihre Professur hier in Stuttgart, weil sie gerade in der Zeit Geld hatte, wo sie sehr krank war, es war wie ein Himmelsgeschenk. Und das ist für die amerikanischen Künstler, auch für Paik war das immer ein Versorgungssystem hier. Der sagte immer nur „Ich mache das nur wegen der Pension“. Was zählt, ist die Länge der Zeit, daß man über eine lange Zeit versorgt ist.

\section{VII.2. Gespräch mit Wulf Herzogenrath}

Gespräch mit Wulf Herzogenrath (WH) am 4.3.2003 in der Kunsthalle Bremen

MR: Das Charakteristische der Kunstform der Performance ist, dass sie ein einmaliges Ereignis ist und damit nicht wiederholbar. Wie haben die Performances von Ulrike Rosenbach auf Sie als Zuschauer gewirkt?

WH: Ersteinmal hat Ulrike Rosenbach als Persönlichkeit eine große Ausstrahlung. Daneben hat sie in ihren Performances mit der Faszination das Closed Circuit in der Live-Situation sehr schön gearbeitet, also mit der Faszination, dass das was man sah sich auch gleichzeitig in verkleinerter Form auf einem Monitor abbildete.

Ein dritter Aspekt ist die Faszination des Einsatzes von Klang, von Ton, der Einsatz von oftmals kleinen Schleifen, Tonschleifen, die sofort eine ganz bestimmte Atmosphäre geschaffen haben. Auch hatte man immer gleich so eine bestimmte visuelle Haltung. Sie war ja in so einem ganz weißen Dress gekleidet. Relativ sparsam gestaltet war das, was man Umfeld nennen könnte, immer sehr wenige Elemente, die dann aber sehr präzise waren. Genauso war das im Ton. Es gab eine ganz kleine Klangspur, die solche Stimmungen auch schuf. Oftmals poetisch träumerisch oder auch kämpferisch in der Wiederholung, intensiv, je nach dem Stück.

Ihre Aktionen waren ungewöhnlich, das kann man sagen. Sie war ja in Deutschland die erste die im Performancebereich überhaupt auftrat. Und sie war sicher auch die erste, die mit Video diese Performances machte und damit auch relativ schnell erfolgreich war.

Wenn sie die Anzahl der Auftritte sehen ist es doch erstaunlich und erfreulich, welche Breite gleich Anfang der 70er Jahre erreicht wurde. Bereits Mitte der 70er Jahre war sie eine der erfolgreichsten Künstlerinnen.

Allerdings gibt es dann einen Knick in der Karriere von Ulrike Rosenbach ab Mitte 
der 80er Jahre.

Das hat sicher mit ihrer Bhagwan-Anhängerschaft und all dem zu tun. Damit wurde auch das Umfeld ihrer Person etwas anders und die Thematik änderte sich radikal. Dadurch hatten die meisten - ich gebe gern zu ich auch - doch sehr viel mehr Schwierigkeiten mit den Arbeiten.

Außerdem war einer der frühen Partner und Gegenpartner im Guten und im Kraftvollen ja Klaus vom Bruch gewesen. Als sich das nun trennte kam irgendwann, irgendwie dieser Bhagwan dazwischen und das war sicherlich nicht ein so anregender (Gegenpart). Es ist ja manchmal gut, wenn Dinge zusammengehen und sich aber auch aneinander reiben. Doch an Bhagwan konnte man sich nicht so sehr reiben. So wurde ihre künstlerische Arbeit meiner Meinung nach auch etwas eindimensionaler.

Und diese Zeit hat Ulrike dann auch in den 90er Jahren, als das alles wieder vorbei war, dann noch nach gehangen, wie es dann oftmals so ist. Man kann ja Künstlerkarrieren nicht abstrakt betrachten. Der Zeitgeist gehört immer als Parallele dazu. Da gibt es Zufälle, Schichtungen, Personenkonstellationen, die etwas beflügeln und an einem bestimmten Punkt dann auch abbrechen lassen, was nur bedingt mit dem Werk zu tun hat, aber dann wiederum auch Auswirkungen auf das Werk hat. Und warum etwas In ist oder nicht In ist, das ist dann wieder ein noch ganz anderer Punkt. Da sind vielleicht auch manche Zufälle wichtig.

MR: Beim Stichwort „Tanz“ fällt mir der Name Pina Bausch mit ihrem Wuppertaler Tanztheater ein, die ja auch in den siebziger Jahren den Tanz revolutionierte, in dem sich in ihren Inszenierungen der Tanz in Bewegung auflöste.

WH: Ja, aber nicht nur Bewegung, sicher auch in starke Bilder. Aber bei Ulrike Rosenbach ist es eben doch noch konzentrierter auf kürzere Dinge. Ein weiterer Unterschied ist sicher auch, dass eine Pina Bausch oder auch ein anderes modernes Tanztheater, mit einem gewissen Ablauf über eine längere Zeit arbeitet, während es sich bei Ulrike auf eine bestimmte Situation konzentriert, die dann zwar verlängert wird, aber nicht eine Dreiviertelstunde sein muss, es können auch mal nur eine halbe Stunde oder zwanzig Minuten sein. D.h. das Zeitmaß darf bei der bildenden Kunst anders, gegenüber einem Theaterabend kürzer, sein und es muss nicht diese Narration haben, die man in den 70er Jahren von Theater und auch vom Tanztheater noch erwartete. Es war in diesem Bereich damals noch ganz neu, dass der Stillstand an sich eine Qualität sein konnte. Ein Stillstand, der natürlich dann gestaltet werden muss.

MR: Das Werk von Ulrike Rosenbach ist ja sehr vielfältig. Von Videoperformances über Videotapes, Videoskulpturen und Installationen hat sie vieles erkundet. Gibt es noch andere Arbeiten, die sie hier nennen möchten?

WH: Sicherlich gehören diese kleinen räumlichen Situationen, die sie geschaffen hat, zu den eindrucksvollen Arbeiten. Oder aber auch, dass sie ja auch zeichnete während der Performances. Das war dann etwas später, wo sie diese großen schwarzen Wände hat, auf denen sie zeichnet oder ihre Engel, die sie dann ausreisst oder ausschneidet, die dann die Zeichen dahinter sind. Also es geht schon immer um bildliche Formen.

MR: Die Bildsprache Ulrike Rosenbachs erscheint mir sehr wörtlich, d.h. aus ihren Bildern kann man Formulierungen ableiten, die die Inhalte erschließen. Hat man diesen Zugang gefunden, sind die Arbeiten gut zu verstehen, was auch in der kunsthistorischen Literatur vertreten wird. Erstaunt haben mich deshalb Kritiken in der Tagespresse zu Aufführungen der Künstlerin in Bremen 1978, aus denen ein deutliches Unverständnis und doch sehr harsche Ablehnung der Arbeiten spricht. 
WH: Das ist ja erfreulich, dass es das überhaupt gibt, dass sich jemand getraut hat, da mal etwas anderes zu schreiben. Aber vielleicht liegt es genau an diesem Grund. Da ist die Frage, wer war der Schreiber, kam der vielleicht vom Theater? Denn das ist ja immer die berühmte Frage, wer kritisiert? Und das ist es ja auch bei Video - jetzt heutzutage natürlich nicht mehr - aber in den 70er Jahren und frühen 80ern auch noch hatten die Kunstkritiker die Haltung, das ist ja Video, da habe ich nichts mit zu tun.

Bleibt die Frage, wer ging damals zu solchen Veranstaltungen, um darüber zu schreiben. Wenn der Theatermann dorthin ging war dieser natürlich frustrierter als der bildende Kunstmann es gewesen wäre.

Das wäre dann ein Beleg dafür, dass das Nicht-Narrative, sehr Konzentrierte auf eine Situation etwas war, das Theaterleute schwierig fanden. Natürlich gab es das damals schon bei Beckett etc. aber auch dort wieder musste es interessant gestaltet werden. Während die Performances von Ulrike Rosenbach eher mit Minimalmusik zu vergleichen wären - wie z.B. bei La Monte Young oder Steve Reich - wo kleine Variationen des scheinbar immer Gleichen als selbstverständlich und als akzeptiert galten.

Diese Aussage könnte man noch einmal folgendermaßen bestärken. In der Ausstellung „Projekt 1974“, in der Ulrike ja auch dabei war, da war zum ersten mal für Europa auch Phil Glass vertreten im Kunstkontext. Es war also nicht Musik, sondern wir sahen diese Art von Minimalismus in der Kunst aber auch in der Musik oder auch im Performancebereich oder Experimentalfilm eben als etwas Verwandtes, was mit der künstlerischen Haltung der Reduktion, der Vereinfachung in der bildenden Kunst zu tun hatte. Das gab es eben so nicht im Theater, in den klassischeren Bereichen. Und die hatten dann damit auch ihre Probleme.

MR: In den vergangenen dreißig Jahren hat sich vieles in der Videotechnik und Bildästhetik verändert. Heute ist vieles selbstverständlich, was in den Anfängen noch nicht einmal vorstellbar war. Wie war es damals Anfang der 70er Jahre?

WH: Für Sie muss ja das, was da in den alten Videotapes von Ulrike abläuft als unglaublich langweilig erscheinen, denn damals galt schon ein Paik als wahnsinnig schnelle Schnitte. Heute können Sie kaum noch ein Band von Paik in der alten Schnittfolge sehen, weil er sie im Nachhinein dann noch wieder verschnellert hat. Denn das war ja die Idee. Zum Beispiel beim originalen „Global Groove“ dachte man damals, man ist das schnell geschnitten,doch da konnte ich immer noch die einzelnen Teile gut sehen. Dagegen waren natürlich diese Dinge (langatmig) wie Ulrike oder wie Jochen Geerz sie gemacht haben. Zum Beispiel „Rufen bis zur Erschöpfung“ dauerte 29 Minuten, weil es auch nur ein 30 Minuten Band gab. Längere Bänder existierten nicht, also war die Erschöpfung vorprogrammiert. Das heißt, dieses Zeitdehnen hat bestimmte physische Längen, die wir heute gar nicht mehr ertragen, es sei denn, wir setzen uns dem ganz bewusst aus, weil bei uns schon etwas, das sich sieben Minuten nicht verändert, unglaublich lang ist. Das war damals noch anders. Da brauchte es noch zwanzig bzw. 29 Minuten. Auf der anderen Seite war es aber eben auch nie länger als dreißig Minuten, weil die technischen Voraussetzungen fehlten.

Die beiden Grenzen liegen zwischen einer bestimmten Zeitgeistschnelligkeit, die da ist, und einer technischen Möglichkeit. Dies ist sehr schwer so im Nachhinein, so abstrakt von Ihnen als jüngere Generation nachzuvollziehen. (...)

Im Film ist es einem klar, das es diese Entwicklung gab. Aber in den neuen elektronischen Medien macht man sich nicht klar, dass 1974 schnell etwas ganz anderes hieß als heute. Das Wort schnell muss dann belegt werden. Was genau heißt schnell? Man sagt so, das ist „,schnell geschnitten“, doch schnell geschnitten 2003 ist etwas ganz 
Anderes als schnell geschnitten 73 .

Auch ist das heute Gezeigte nicht mehr unbedingt das Originale. Wie schon erwähnt, Paik macht das z.B. ganz bewusst, weil Paik zurecht sagt, zeigte ich das Alte, würde man das heute für völlig antiquiert halten und das will ich ja gar nicht. Ich will ja schon, dass die Zuschauer eine gewisse Haltung dort sehen. Als Kunsthistoriker fragen wir uns natürlich, ob das richtig ist, doch der Künstler hat natürlich das Recht, sein Werk zu überarbeiten.

MR: Zeigte sich in den 70er Jahren ein unterschiedlicher künstlerischer Umgang mit Video in den USA und in Europa bzw. Deutschland? bei Künstlern und Fernsehanstalten?

WH: Bei der Documenta 77 gab es ja erstmals diese Satellitenübertragung, erstmals Kunst über Satellit. Die Aktion von Douglas Davis, Joseph Beuys und Nam June Paik. Jeder von ihnen konnte neun Minuten gestalten und Paik wollte dafür eben einen Synthesizer haben, den er vor sieben Jahren selber gebaut hatte und der in Amerika inzwischen überall rum stand. Doch im gesamten deutschen Fernsehbereich hatte nur der Hessische Rundfunk so ein ganz harmloses Gerät, das sich dort einer selbst "gebastelt" hatte. Weil der deutsche Fernsehmann, der wollte ja nicht so einen Quatsch. Der wollte das Rot und das Blau, genauso wie es vor der Kamera erschien, so sollte es übertragen werden. Das jemand das nun noch verändern oder sogar künstlich herstellen will, auf die Idee war der deutsche Fernsehmensch nicht gekommen. Deshalb wollten die auch überhaupt keine Synthesizer haben.

Die Haltung beim Fernsehen war da eine ganz andere als beim Radio. Die Rundfunkleute hatten sehr schnell verstanden, dass sie ein eigenständiges Medium sind, wo ein Synthesizer zum Erzeugen künstlicher Klänge, künstliche Geräuschformen einfach hoch interessant sind. Der Fernsehmann glaubte eben daran, dass das, was er dann vor der Linse hatte möglichst farbgenau rüber kommt, als ob das das höchte und einzige Wahrheitsziel sei. Er hat nie begriffen, dass er alles ja eh künstlich herstellt. Und deshalb gab es im riesigen WDR, der größten Anstalt Europas vielleicht, dort gab es keinen Synthesizer. Und Paik war völlig von den Socken und dann kam eben so ein ganz harmloser Synthesizer vom Hessischen Rundfunk. Und Paik war schon genervt, weil er gerne richtig loslegen wollte, hier jedoch die technischen Möglichkeiten nicht gegeben waren. Da war dann natürlich schon alles zu spät und zu teuer um die Sachen aus Amerika noch zu holen. Aber das war für Paik nicht vorstellbar gewesen. Das als Beispiel wie damals auch gerade bei den Fernsehanstalten - was heute natürlich anders ist - eine konservative Grundhaltung herrschte, die schwer vorstellbar ist. Wobei sie heute vielleicht sogar wieder vorstellbar ist, weil hier experimentelles Fernsehen nun ja auch wieder nicht mehr statt findet.

(Damals gab es immerhin verschiedene Ansätze Videokunst im Fernsehen auszustrahlen.) Ich habe ja dann so neun Abende gemacht während der Documenta, die dann vom hessischen Rundfunk aufgezeichnet und vom HR und WDR gezeigt wurden. Und bei einer waren dann die drei Frauen zusammen dabei: Rebecca Horn, Friederike Petzold und Ulrike Rosenbach. Das war natürlich die größte Ausstrahlung überhaupt. Mehrere hunderttausend Leute konnten sich das an einem Abend vor ihrem Fernseher anschauen.

MR: Sie waren einer der ersten Kunsthistoriker in Deutschland, der sich bereits in den 70er jahren mit der damals noch ganz jungen Videokunst beschäftigte. Wie ist ihr Interesse an diesem Medium geweckt worden?

WH: Das ist biografisch bei mir ziemlich einfach. Ich fing eben 1971/72 im Folkwang 
Museum Essen an, das damals von Herrn Vogt geleitet wurde. Der hatte auch zwei oder drei Semester Physik studiert gehabt, oder war auf jeden Fall immer sehr interessiert an Technik und hatte etwas wie ein Videostudio an Land gezogen, mit der Idee, etwas was wir damals „Kulturfilme“ nannten, zu machen, also pädagogische Einführungen. Diese Aufgabe wurde mir als jüngstem Mitarbeiter des Museums übertragen. Wir versuchten dann mit den Pädagogen und einem Techniker einen Film über ein Kunstwerk zu machen. Das Projekt wurde dann aber doch in professionelle Hände abgegeben.

Parallel dazu hatte $71 / 72$ Gerry Schum in Düsseldorf seine Fernsehgalerie gemacht, war im Fernsehen aber gescheitert, aus den bekannten Gründen. Die Leute, die ihn zunächst unterstützt hatten, wurden von der Mehrheit überstimmt, die sagte, so einen „Quatsch“ könne man nicht pur zeigen, die Arbeiten müssten kommentiert werden. Der Konflikt ging soweit, dass man ihm sagte, er könne noch einen dritten Film machen, doch müsse er dann Musik drunterlegen oder es müsse immer einer die Tapes srklären. Denn wenn da drei Minuten auf dem Fernseher nichts passiere und nur die Wellen kommen, so was könnte nicht gezeigt werden. Wenn dann müsse er eben dramatische Musik oder Ähnliches drunterlegen. Natürlich hat dann Gerry Schum gesagt, das das nicht gehe, und damit war er da am Ende.

Doch so kamen die ersten Gespräche, ob nicht Gerry Schum dieses Studio im Museum übernehmen könnte, also hab ich mich da auch so ein bisschen dran gehängt. Allerdings war er sagen wir mal auch ein sehr komplexer, komplizierter Typ psychologisch - und dann kamen auch noch Schwierigkeiten in der Verhandlung dazu. Wie geht so etwas überhaupt einzubauen in eine Museumsbürokratie? Auf der anderen Seite hatte er auch sehr viele Probleme und dann kam leider sein Selbstmord, der dieses Thema dann auch beendete. Wohin gegen ich so ein bisschen Blut geleckt hatte: Aha, da ist ja doch was Interessantes, was irgendwie mit bildender Kunst zu tun hat. Wo gehört das hin? Es gehört nicht ins Theater und es gehört nicht in die Musik, obwohl es ein Zeitmedium ist, sondern es hat sehr stark mit Bildern und Bildersprache zu tun.

Und dann war ich ja eben ab Januar 1973 im Kölnischen Kunstverein Direktor und dann kam eben dieses berühmte „Projekt 74“, diese Ausstellung „Kunst bleibt Kunst“ zum angeblich 150 jährigen Jubiläum des Wallraf Richartz Museums, das ja eigentlich gar nicht so alt ist, aber das war der Grund und es stand eine Menge Geld zur Verfügung für eine richtig große, aktuelle Ausstellung. Die war auch als Kampfausstellung zwischen den beiden Documenten 72 und 77 gedacht. Köln wollte zeigen, sie seien viel besser, das war als eine Art Documenta gemeint, und da hab ich gesagt okay, find ich spannend und als Kunstverein war ich ja sowieso mit dabei, dann mache ich da die große Videoabteilung. Das war zum ersten Mal überhaupt in dieser Ausstellung. Mit ein Paar Installationen, mit einer großen Videobandabteilung. Und dann gab es dort ein Arbeitsfeld, einen richtigen Workshop, da hatte ich das Lijnbaanzentrum eingeladen aus Rotterdam. Die kamen mit drei Mann mit ihrer ganzen Technik, die sie damals schon besaßen für zweieinhalb Monate nach Köln, um dort mit Künstlern Neues zu realisieren. Da waren dann auch Vito Acconci ober Hans Brelow, der noch nie was mit Video gemacht hatte und danach auch kaum wieder. Die haben einfach mal was gemacht mit denen und dann erschienen auch ein paar Bänder, und da war eben auch Ulrike mit dabei, die natürlich schon ein bisschen vorher mit Konrad Schnitzler diese Auftritte mit Video gemacht hatte. So war sie dort auch zum ersten Mal auf so einer internationalen Plattform als Kölnerin, was sicher auch nicht ganz unwichtig war. Da gibt es so etwas wie den ersten Videokatalog, über das was da produziert wurde, der jetzt im ZKM archiviert ist, auf dem auch ein kleines Stück von Ulrike drauf sein müsste.

Das war, wie gesagt das Projekt 74 und damit war ich dann irgendwie der Video- 
onkel. Ich war dann auch im MOMA zum ersten großen Symposium in New York, wo ich dann auch Paik kennengelernt habe. Es war ja gerade die Paik-Ausstellung in Syracuse, wo wir hingefahren sind. Ich sage immer, ich war der einzige damals in der Museums- und Kunstszene, der Video nicht ausschloss. Ich habe die anderen Themen deshalb ja auch weiterverfolgt. Nur ich sah, dass das ein neues Feld war, das meine Kollegen vielleicht aus technischer Angst umgingen. Ich konnte auch nie ein Gerät bedienen, darum ging es mir auch gar nicht, sondern mich interesssierte das Medium als Teil der bildenden Kunst einzubeziehen, und es nicht als Teil der Tanzwelt oder der Theaterwelt zu sehen.

Es ist wahrscheinlich für die jüngere Generationen kaum mehr vorstellbar, doch hatte man in der bürgerlichen Gesellschaft auch 1975 noch nicht den Fernseher akzeptiert, die hatten ihn auch alle zuhause, doch wurde er nur ab und zu benutzt und wenn man nachfragte, wurde natürlich gesagt nie. Mir ging es also darum, Video als Teil der Kunstszene mit einzubeziehen. In diesem Zusammenhang ist John Cage für mich die wichtigste Figur, obwohl er mit Video nun gar nichts zu tun hat, aber eben wesentlich mit diesem anderen Begriff von bildender Kunst als einem viereckigen Bild, was dann ein Künstler statisch mal mit schönen Farben und Linien gefüllt hat. Also dass Bilder und Bildwelten - jetzt reden wir ja auch über 21. Jahrhundert - etwas mit Bewegung, mit Klängen, mit gesamtheitlichem Erleben zu tun haben. Und je mehr das ist, um so eindringlicher können diese Bilder sein. In den 70er Jahren lebten wir im Normalfall immer noch vom statischen Bild, wenn wir aus der Kunstgeschichte kamen, was aber schon gar nicht mehr der Generation, die da aufwuchs, entsprach. Die Generation der 60er Jahre und erst recht die Generationen der 70er Jahre sind natürlich mit dem Fernseher aufgewachsen, ob die Eltern das wollten oder nicht, und dass da ganz andere Bildprägungen und ganz andere Vorstellungen da sind, ist klar. Und da denke ich, dass Ulrike eine ganz wichtige Rolle gespielt hat, weil es eben etwas ganz anderes war als Fernsehen. Bei ihren Sachen kam gar keiner auf die Idee, das ist ja wie Fernsehen, sondern es waren ganz andere Bilder, sehr intensive Bilder, sehr intensive Erlebnisse. Denen konnten sich dann auch die „Kunstszenen Konservativen“ schwerer entziehen.

\section{MR: Was war das Charakteristische an der deutschen Videokunstszene?}

WH: Die Szene in Deutschland ist dadurch, dass sie diese ganzen Kunstvereine hat, sehr reich und wichtig und viele der ausländischen Avantgarde-Künstler und besonders die Avantgarde-Künstler aus Amerika haben fast davon gelebt haben, dass sie in Deutschland gut unterkamen. Z.B. Vito Acconci oder Dennis Oppenheim, die waren ja fast mehr hier als in Amerika. Unsere Medienkünstler aber wiederum waren gegenüber Malern und dem was „normale verkaufbare Kunst“ war, natürlich doch sehr im Nachteil, während das wiederum selbstverständlich in Kanada und Amerika war.

Alle drei - Marcel Odenbach, Klaus vom Bruch und Ulrike Rosenbach - haben sehr viel von der Grundhaltung, dass Sprache und erst recht deutsche Sprache eben ganz selten vor kommt, sondern es immer um Klänge und Klang geht und das das natürlich international viel eher vermittelbar ist. Während Bilder sehr individuell sein können, die sind immer transportierbar. Das ist jetzt bei Ulrike vielleicht nicht ganz so scharf im Individuellen, weil es bei ihr oftmals ja eher in dieses feministische - sagen wir mal Frauenthema - geht, das natürlich international gleicher ist, aber bei Klaus vom Bruch oder Marcel Odenbach ist die deutsche Geschichte und das deutsche Thema sehr wichtig. Das ist aber bildlich transportierbar und zudem, wenn man so will, transponierbar für einen intellektuellen Amerikaner und Kanadier. Wenn das Ganze jetzt mit deutschen Erzählungen und Texten wäre, wäre es alles wieder sehr viel mühsamer gewesen. Ich glaube auch, dass die drei damals sehr stark - ich will nicht 
sagen, dass sie dahin gedacht haben, das die Arbeiten so gleich international verwertbar sind - aber das dieser Gedanke sicher auch nicht unterschätzt werden darf. So wie dann ja eben parallel ein Kiefer und diese deutsche Malerei, die ja gerade viel mehr im Ausland, also gerade in Holland und dann Amerika akzeptiert wurde als in Deutschland selber. Hier wurde gesagt, dieses ist ja schrecklich. Das ist dann vergleichbar mit Themen bei Klaus vom Bruch und Marcel Odenbach. Oder aber auch das feministische Thema, das fand man in Deutschland ja auch nicht toll. Während das ja doch etwas war, das sich in Amerika visuell sofort umsetzte.

MR: Bleibt noch die Frage, dass erstaunlich viele Frauen mit Video arbeiteten. Wie sehen sie das?

WH: Ulrikes These, dass das nun ein unbesetztes Feld war, in dem die Männer noch nicht ihre Pflugspuren hinterlassen hatten, finde ich ein bisschen kess, aber im Prinzip sicherlich nicht ganz falsch, weil es einfach neuer war und dieses „Warum wir Männer die Technik so lieben“ in Frage stellte. 


\section{Protokolle der analysierten Videoarbeiten}

VIII.1. Einwicklung mit Julia, 1972

\begin{tabular}{|c|c|c|c|}
\hline Nr. & Zeit & Einstellung & Bildinhalt \\
\hline & $0-0.14$ & & $\begin{array}{l}\text { Vorspann: Auf hellem Grund steht dort in schwarzen Buchstaben, die mit einer Schreibmaschine getippt sind: } \\
\text {,Ulrike Rosenbach / Einwicklung mit / Julia / } 6^{\prime} \quad 1972^{*}\end{array}$ \\
\hline & $0.15=$ & Nahaufnahme & 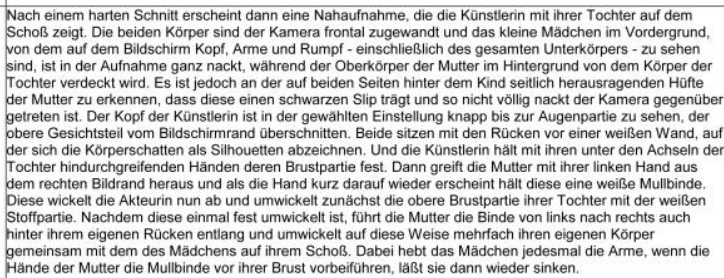 \\
\hline & & & 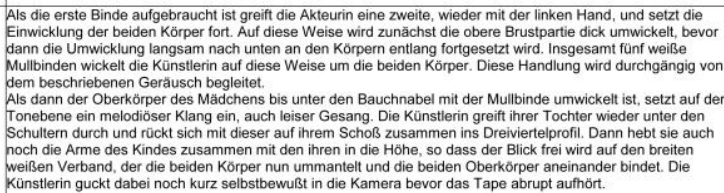 \\
\hline & $5.50 \ldots$ & & \\
\hline
\end{tabular}


VIII.2. Lotus-Knospen-Töne, 1979

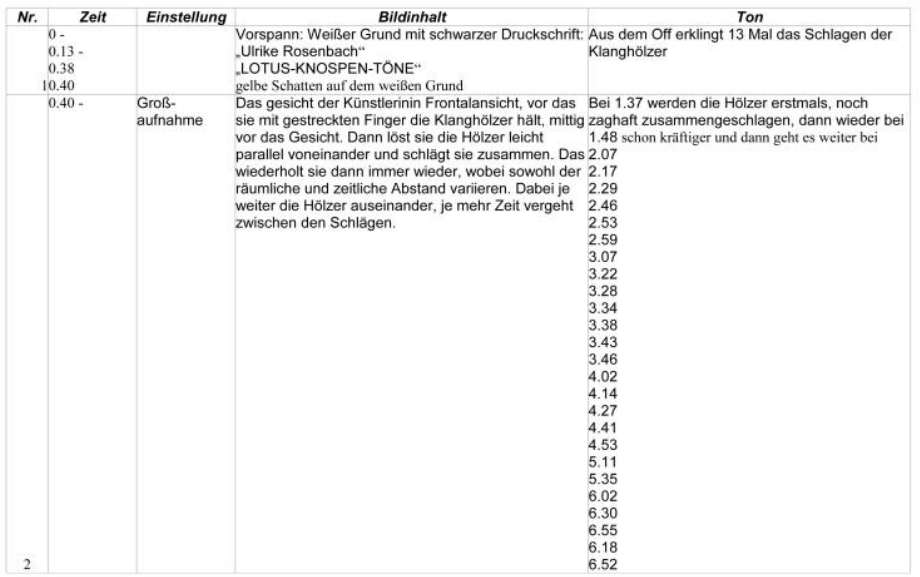

\begin{tabular}{|c|c|c|c|c|}
\hline Nr. & Zeit & Einstellung & Bildinhalt & $\begin{array}{ll} & \text { Ton } \\
7.44 & \\
7.52 & 8.11 \\
8.20 & \\
8.26 & \\
8.32 & \\
8.56 & \end{array}$ \\
\hline & Bei 16.49 & & Sie steht auf und geht aus dem Bild & $\begin{array}{l}9.28 \\
10.21 \\
11.40 \\
13.18 \\
14.44 \text { bis sie sie bei } \\
16.30 \text { zum letzen Mal zusammen schlägt. }\end{array}$ \\
\hline 3 & $\begin{array}{l}\text { Bei } 16.54 \\
\text { bei } 17.25\end{array}$ & & $\begin{array}{l}\text { Abspann: Auf dem weißen Grund erscheint mit } \\
\text { schwarzer Schrift ein fünfzackiger Stern in einem } \\
\text { Kreis und darunter steht „Alternativ Television" und } \\
\text { etwas tiefer unten rechts "1979". } \\
\text { Dann ausgeblendet. }\end{array}$ & $\begin{array}{l}\text { Dazu ertönt noch zweimal der Klang der Hölzer } \\
\text { aus dem Off. }\end{array}$ \\
\hline
\end{tabular}


VIII.3. Die Eulenspieglerin, 1985

\begin{tabular}{|c|c|c|c|c|c|}
\hline Nr. & Zeit & Einstellung & Bildaufbau & Anmerkungen & Ton \\
\hline & $\begin{array}{l}0.00-0.01 \\
0.01-0.06 \\
\text { ab } 0.06\end{array}$ & Schrift & 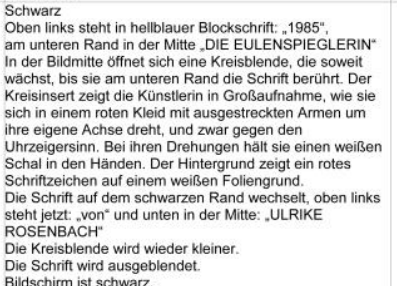 & & \\
\hline & $\mathrm{Ab} 0.45$ & $\begin{array}{l}\text { Schnitt } \\
\text { Amerikanisch } \\
\text { Bluebox, } \\
\text { schwarze } \\
\text { Farbe ist } \\
\text { durchwoben } \\
\text { von 2. Motiv } \\
\text { Zoom }\end{array}$ & $\begin{array}{l}\text { Die Aufnahme in Amerikanischer Einstellung zeigt im } \\
\text { unteren rechten Teil den Oberkörper im Dreiviertelprofil } \\
\text { von links der Künstlerin in einem roten Kleid. Das untere } \\
\text { Drittel der Aufnahme, ursprünglich die schwarze } \\
\text { Papierwand, ist durchwoben mit einem elektronisch } \\
\text { eingefügten Motiv, aus zunächst unklaren Formen in den } \\
\text { Farben blau, schwarz und weiß̉. Die oberen Zweidrittel der } \\
\text { Aufnahme zeigen die gelbe Wand des Raumes. } \\
\text { Die Kamera zoomt an das erste Motiv heran, so dass der } \\
\text { untere Streifen mit der zweiten Aufnahme breiter wird. Die } \\
\text { Frau lauft dabei von rechts nach links durch das Bild, } \\
\text { wobei ihr die Kamera folgt. Due Aufnahme mit den } \\
\text { schwarzen Schwüngen (Ausschnitt einer Spirale) wird } \\
\text { stärker, hebt sich aus dem Hintergrund und verschluckt } \\
\text { auch zusehends die Frau, die immer wieter an den rechten }\end{array}$ & & $\begin{array}{l}\text { Mit flüsternder, } \\
\text { hallender, die Worte } \\
\text { zum Teil } \\
\text { wiederholenden } \\
\text { Stimme spricht die } \\
\text { Künstlerin aus dem } \\
\text { Off: } \\
\text { Es gab keine } \\
\text { Hindernisse, die nicht } \\
\text { zu überwinden } \\
\text { gewesen wären... }\end{array}$ \\
\hline
\end{tabular}

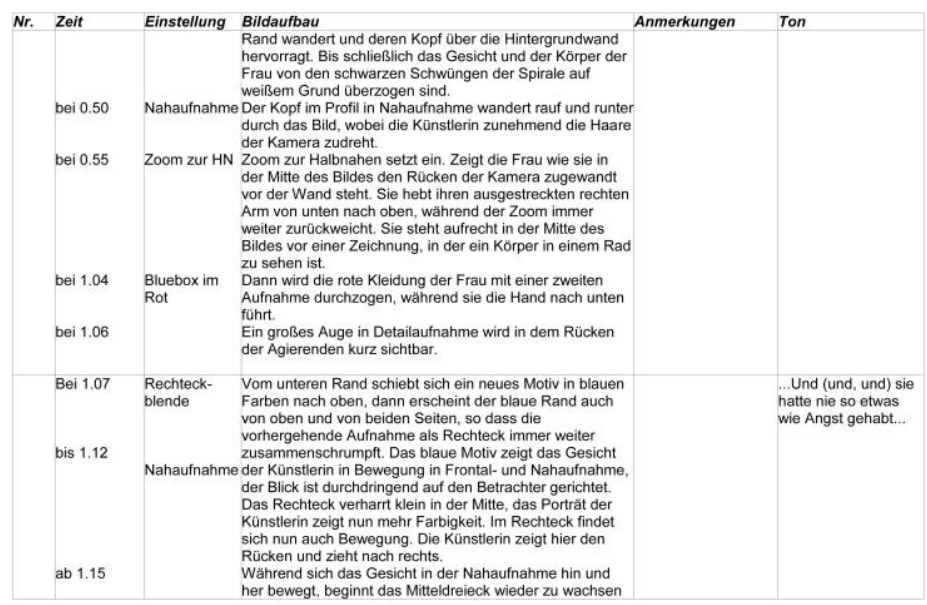




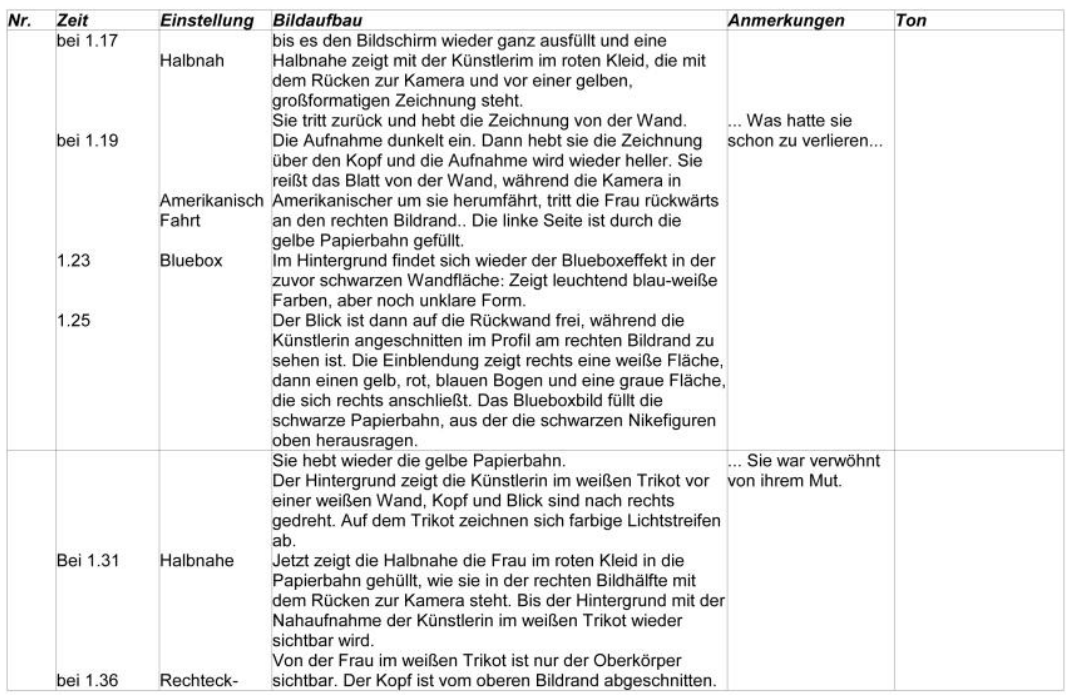

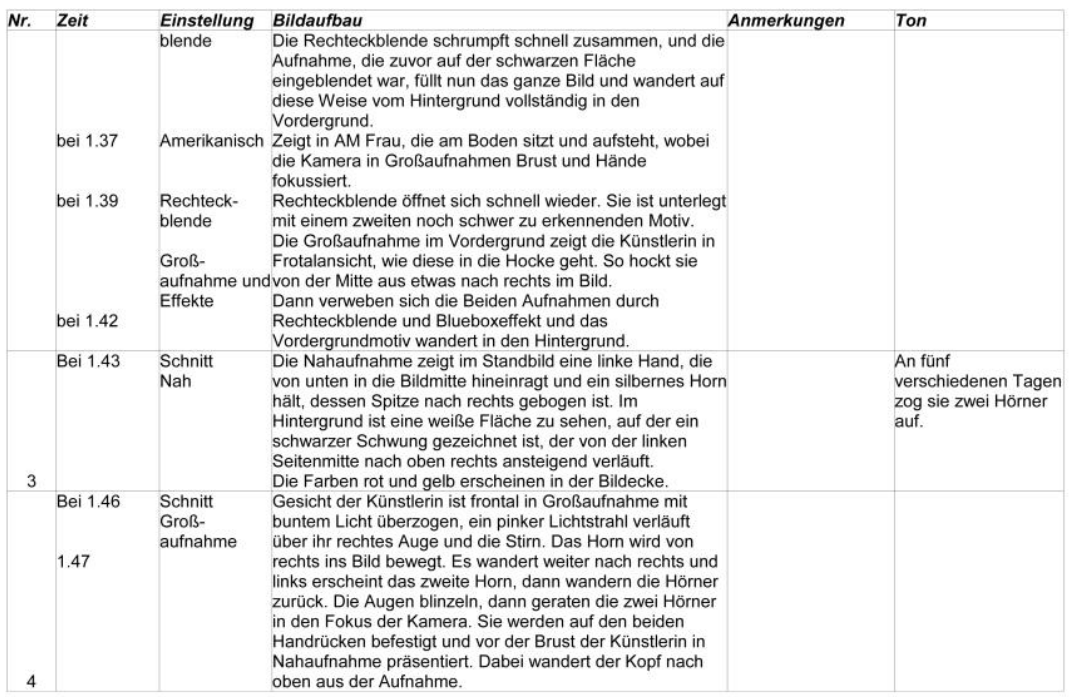




\begin{tabular}{|c|c|c|c|c|c|}
\hline \multirow[t]{2}{*}{$\mathrm{Nr}$. } & Zeit & Einstellung & Bildaufbau & Anmerkungen & Ton \\
\hline & & Zoom & $\begin{array}{l}\text { Dann folgt ein leichter Zoom zurück. Kopf und Oberkörper } \\
\text { der Frau im weißen Trikot füllen das Bild. Sie hebt den } \\
\text { linken Arm aus der Aufnahme, der überzogen ist mit } \\
\text { farbigen Lichtstreifen in rot, gelb und blau. }\end{array}$ & & \\
\hline \multirow[t]{2}{*}{5} & Bei 1.58 & $\begin{array}{l}\text { Schnitt } \\
\text { Amerikanisch }\end{array}$ & $\begin{array}{l}\text { AM: Frau steht im Profil mit Rücken an der Wand am } \\
\text { rechten Bildrand. Vor ihren Haaren ragt ein Horn aus der } \\
\text { Wand heraus. Im Hintergrund fült ein schwarzes Quadrat } \\
\text { die untere, rechte Ecke. }\end{array}$ & & \\
\hline & Bei 1.58 & $\begin{array}{l}\text { Schnitt } \\
\text { Doppelaufnah } \\
\text { me aus } \\
\text { Halbnah und } \\
\text { Amerikanisch }\end{array}$ & $\begin{array}{l}\text { Die Frau im weißen Trikot liegt im Zentrum des Bildes auf } \\
\text { dem Rücken am Boden in der Halbtotalen. Sie blickt in der } \\
\text { Halbnahen, die leicht von oben aufgenommen ist, in die } \\
\text { Kamera. } \\
\text { Durch diese Aufnahme sieht man eine zweite. Sie zeigt in } \\
\text { AM wie der Oberkörper der Frau im roten Kleid von rechts } \\
\text { oben nach links unten über den Boden durch das Bild } \\
\text { robbt. Die Kamera wandert mit der Bewegung mit. Der } \\
\text { untere Rand der Aufnahme zeigt weiße Papierfetzen. }\end{array}$ & & $\begin{array}{l}\text {... und machte sich } \\
\text { auf den Weg. } \\
\text { Es war leicht sich zu } \\
\text { verlieren.... }\end{array}$ \\
\hline 7 & $\begin{array}{l}\text { bei } 2.16 \\
\text { bei } 2.22\end{array}$ & $\begin{array}{l}\text { Schnitt } \\
\text { Doppelaufnah } \\
\text { me }\end{array}$ & $\begin{array}{l}\text { Weiter beide Motive, nun aus etwas anderen Perspektiven. } \\
\text { Nun sieht man in einer Halbtotalen wie sich in der linken } \\
\text { Bildhălfte die Frau im weißen Trikot versucht aufzurichten, } \\
\text { während in der anderen Einstellung, eine Großaufnahme, } \\
\text { die Frau im roten Kleid weiterhin nach links über den } \\
\text { Boden robbt und es so wirkt, als würde der Kopf der roten } \\
\text { Frau den Körper der weißen Frau durchdringen } \\
\text { beziehungsweise verschluckt werden. Dann wird die weiße } \\
\text { Figur blasser, richtet sich in der Bildmitte auf und wird } \\
\text { wieder stärker sichtbar. } \\
\text { Dann wird sie wieder blasser und die rote Figur robbt } \\
\text { immer näher an die Kamera, wobei die Kamera der } \\
\text { Bewegung schwenkend folgt. } \\
\text { Eine Kreisblende schiebt sich von den Ecken ins Bild. }\end{array}$ & & $\begin{array}{l}\text {...es gab keine } \\
\text { Hindernisse, die nicht } \\
\text { zu überwinden } \\
\text { gewesen wären und } \\
\text { sie hatte nie so etwas } \\
\text { wie Angst gekannt. } \\
\text { Was hatte sie schon } \\
\text { zu verlieren.... }\end{array}$ \\
\hline 8 & Bei 2.45 & Schnitt & $\begin{array}{l}\text { Nahaufnahme geht noch näher an das Gesicht und Hände } \\
\text { der Künstlerin heran, die sich weiter schüttelt, wodurch }\end{array}$ & & $\begin{array}{l}\text {...sie war verwöhnt } \\
\text { von... }\end{array}$ \\
\hline
\end{tabular}

\begin{tabular}{|c|c|c|c|c|c|}
\hline \multirow[t]{3}{*}{ Nr. } & Zeit & Einstellung & Bildaufbau & Anmerkungen & Ton \\
\hline & & Kreisblende & $\begin{array}{l}\text { eine Unschärfe in der Aufnahme entsteht. } \\
\text { Kreisblende taucht auf, wodurch die obere linker Ecke blau } \\
\text { und untere rechte Ecke rosa erscheint. }\end{array}$ & & \\
\hline & & Überblendung & & & \\
\hline 9 & $\begin{array}{l}\text { bei } 3.37 \\
\text { bis } 3.57\end{array}$ & $\begin{array}{l}\text { Kreisblende } \\
\text { Halbnah }\end{array}$ & $\begin{array}{l}\text { Die Nahaufnahme zeigt den linken Arm der Künstlerin, } \\
\text { dessen Oberarm parallel zur unteren Bildkante und der } \\
\text { Unterarm nach oben angewinkelt. Der rotbeärmelte Arm } \\
\text { hebt sich. Die rotbekleidete Frau tritt von rechts in die } \\
\text { Aufnahme, zeigt der Kamera den Rücken. Das Gesicht der } \\
\text { Knieenden scheint durch rotes Kleid und die Hände. } \\
\text { Rückenansicht in Nahaufnahme. Die Hände der } \\
\text { Knieenden schwimmen durch den Rücken. Die Frau } \\
\text { wandert nach links aus der Aufnahme. Kommt wieder } \\
\text { zurück und dreht sich ins Profil (von links). } \\
\text { Kreisblende mit Knieender. } \\
\text { Halbnahe zeigt, wie die rote Frau erst im verlorenen Profil, } \\
\text { dann in Rückenansicht in der Mitte vor der schwarzen } \\
\text { Wand steht. } \\
\text { In dem anderen Motiv schiebt sich die Künstlerin } \\
\text { kontinuierlich weiter über den Boden von rechts nach links. } \\
\text { Hintergrund wird ausgeblendet. Und die Kreisblende bleibt } \\
\text { mit Detail der Knieenden im Profil. }\end{array}$ & & $\begin{array}{l}\text {...ihrem Mut. } \\
\text { Stille schließt sich } \\
\text { hier an bis zum } \\
\text { Schluss der } \\
\text { Einstellung. }\end{array}$ \\
\hline 10 & Bei 3.57 & Schnitt & $\begin{array}{l}\text { Nahaufnahme zeigt Arm mit Horn wie in Nr. } 3 \\
\text { Zu sehen ist in dem Standbild eine linke Hand, die von } \\
\text { unten in die Bildmitte hineinragt und ein silbernes Horn } \\
\text { hält, dessen Spitze nach rechts gebogen ist. Im } \\
\text { Hintergrund ist eine weiße Fläche zu sehen, auf der ein } \\
\text { schwarzer Schwung gezeichnet ist, der von der linken } \\
\text { Seitenmitte nach oben rechts ansteigend verläuft. }\end{array}$ & & An... \\
\hline 11 & $A b 4.00$ & Schnitt & $\begin{array}{l}\text { Großaufnahme des Gesichtes der Künstlerin. Zwei Hörner } \\
\text { ragen von rechts und links unten in die Aufnahme. Ihr } \\
\text { Gesicht ist überzogen von einer gelben und rosafarbenen }\end{array}$ & & $\begin{array}{l}\text {...fünf verschiedenen } \\
\text { Tagen zog sie zwei } \\
\text { Hörner an... }\end{array}$ \\
\hline
\end{tabular}




\begin{tabular}{|c|c|c|c|c|c|}
\hline Nr. & Zeit & Einstellung & Bildaufbau & Anmerkungen & Ton \\
\hline & ab 4.09 & Zoom & $\begin{array}{l}\text { Diagonale aus Licht. } \\
\text { Zoom auf Amerikanische }\end{array}$ & & \\
\hline 12 & Bei 4.12 & $\begin{array}{l}\text { Schnitt } \\
\text { Fahrt/ } \\
\text { Schwenk } \\
\text { Bluebox } \\
\\
\text { Zoom auf } \\
\text { Halbtotale } \\
\text { Bluebox } \\
\text { Detail }\end{array}$ & $\begin{array}{l}\text { Oberkörper und Kopf der Frau im roten Kleid im Profil von } \\
\text { links am rechten Rand. Sie beginnt sich an der } \\
\text { dahinterliegenden schwarzen Wand entlang zu bewegen } \\
\text { nach links, die Kamera folgt der Bewegung. Sie reißt an } \\
\text { verschiedenen Stellen den oberen Rand der (schwarzen) } \\
\text { Papierbahn ein. Die Fläche wird im Blueboxeffekt } \\
\text { durchwoben mit einem Motiv, das einen schneebedeckten } \\
\text { Berg zeigt. } \\
\text { Zoom auf Halbtotale. Eine kleine Kreisblende öffnet sich in } \\
\text { der oberen Hälfte in der kurzzeitig ein Auge zu sehen ist. } \\
\text { Dann veschwindet die Blende wieder und ein riesiges } \\
\text { Auge in Detailaufnahme wandert von links nach rechts } \\
\text { durch die, die untere Bildfläche füllende Papierbahn. } \\
\text { Synchron mit dem Augenaufschlag erfogt der Schnitt. }\end{array}$ & & $\begin{array}{l}\text {...und machte sich } \\
\text { auf den Weg. Es war } \\
\text { leicht sich in der } \\
\text { Dunkelheit zu } \\
\text { orientieren. Sie zog } \\
\text { es vor keine } \\
\text { Vorstellung zu } \\
\text { haben.. }\end{array}$ \\
\hline 13 & Bei 5.03 & $\begin{array}{l}\text { Schnitt } \\
\text { Detail } \\
\text { Bluebox }\end{array}$ & $\begin{array}{l}\text { Die Detailaufnahme des Auges füllt Zweidrittel des } \\
\text { Bildschirms (als Bluebox im Schwarz) und auch die } \\
\text { Nikefiguren, die oben aus der schwarzen Flăche } \\
\text { herausragen sind mit Gesichtsaufnahme gefullt. }\end{array}$ & & $\begin{array}{l}\text {...von dem, was } \\
\text { kommt und keine } \\
\text { Antwort zu wissen auf } \\
\text { das, ... }\end{array}$ \\
\hline 14 & Bei 5.03 & $\begin{array}{l}\text { Schnitt } \\
\text { Doppelmotiv }\end{array}$ & $\begin{array}{l}\text { Oben guckt Bergspritze heraus, Auge blinzelt wieder, } \\
\text { beide Motive durchweben sich. }\end{array}$ & & $\begin{array}{l}\text {...was gefragt ist } \\
\text { und... }\end{array}$ \\
\hline 15 & $\begin{array}{l}\text { (bei } 5.08 \text { und } \\
5.10)\end{array}$ & Kreisblende & $\begin{array}{l}\text { Ein runder Kreis in der oberen Mitte des Bildes zeigt eine } \\
\text { schneebedeckte Bergspitze, sowie eine menschliche Figur } \\
\text { im Profil in überdimensionaler Größe links daneben } \\
\text { stehend. Während linke obere Hälfte neben dem Kreis } \\
\text { Blau eingefärbt ist, füllt die restliche Bildfläche eine } \\
\text { Detailaufnahme des Gesichtes der Künstlerin, wobei ihr } \\
\text { rechtes Auge, das manchmal blinzelt, direkt unter der } \\
\text { Kreisblende erscheint. Die Kreisblende wandert dann auf } \\
\text { der Waagerechten zum rechten Bildrand. } \\
\text { Eine große Fläche des Bildschirms ist inzwischen Blau } \\
\text { gefärbt, während die gesamte Szene von dem Bergmotiv }\end{array}$ & & ... sich aus Nichts... \\
\hline
\end{tabular}

\begin{tabular}{|c|c|c|c|c|c|}
\hline Nr. & Zeit & Einstellung & Bildaufbau & Anmerkungen & Ton \\
\hline & & & überspannt wird. & & ...Nichts zu machen. \\
\hline 16 & Bei 5.21 & $\begin{array}{l}\text { Schnitt } \\
\text { Halbnah }\end{array}$ & $\begin{array}{l}\text { Halbnahe zeigt die Künstlerin, die im weißen Trikot auf der } \\
\text { rechten Bildhălfte am Boden frontal zur Kamera hockt. Ein } \\
\text { rosafarbener und ein gelber Lichtstreifen verlaufen über } \\
\text { inre linke Brustseite. Hinter ihr erscheint ihr Umriss in } \\
\text { vergrößerter Form in den Farben gelb, rot und blau. Die } \\
\text { Lichtstreifen pendeln von links nach rechts nach links } \\
\text { durch das Bild. }\end{array}$ & & Alles erschien ihr... \\
\hline 17 & $\begin{array}{l}\text { bei } 5.37 \text { - } \\
5.39\end{array}$ & $\begin{array}{l}\text { Schnitt } \\
\text { Amerikanisch }\end{array}$ & $\begin{array}{l}\text { Amerikanische zeigt Profil von Kopf, Armen, Rumpf und } \\
\text { Oberschenkeln der Künstlerin im weißen Trikot, die eine } \\
\text { Brücke macht (Hände und Füße aufgestellt, Gesăß in die } \\
\text { Luft gehoben, Kopf in den Nacken gelegt.) Der Unterleib } \\
\text { ist wieder mit bunten Lichtstreifen angestrahlt. Das Gesäß } \\
\text { senkt sich nach unten und sie setzt sich auf den Boden. } \\
\text { Zoom zur Halbnahen setzt ein und zeigt hinter ihr bunten } \\
\text { Schatten an der weißen Wand, an der auch ein schwarzes } \\
\text { T-Zeichen steht. Sie beugt sich und streckt die Arme nach } \\
\text { vorne. }\end{array}$ & & $\begin{array}{l}\text {... ein wenig } \\
\text { abgehoben. } \\
\text { Sie war aufgeregt, } \\
\text { doch nach außen } \\
\text { blieb sie cool. }\end{array}$ \\
\hline 18 & Bei 5.47 & Schnitt, HN & Halbnahe zeigt Frau am Boden sitzend auf rechter Seite. & & \\
\hline 19 & Bei 5.47 & $\begin{array}{l}\text { Schnitt } \\
\text { Halbnahe } \\
\text { Doppelaufnah } \\
\text { me }\end{array}$ & $\begin{array}{l}\text { Halbnahe zeigt die Frau im weißen Trikot, die in der } \\
\text { rechten Bildhälfte steht, sie zeigt ihr Gesäß der Kamera, } \\
\text { hat den Oberkörper nach vorne gebeugt und die Arme } \\
\text { hăngen nach unten. Dann schlägt sie einen Purzelbaum } \\
\text { und steht auf. } \\
\text { Durchwebt ist die Aufnahme mit einer zweiten Einstellung. } \\
\text { Sie zeigt in Halbnaher die Frau, die in schwarz gekleidet } \\
\text { einen Fernseher von rechts nach links über einen mit Salz } \\
\text { überzogenen Boden durch das Bild schiebt. Dabei folgt die } \\
\text { Kamera der Bewegung, so dass die Figur immer in der } \\
\text { rechten Seite bleibt. }\end{array}$ & & $\begin{array}{l}\text { Es gab keine } \\
\text { Hindernisse, die nicht } \\
\text { zu überwinden } \\
\text { gewesen wären... }\end{array}$ \\
\hline 20 & Bei 6.06 & $\begin{array}{l}\text { Schnitt } \\
\text { Doppel- } \\
\text { aufnahme }\end{array}$ & $\begin{array}{l}\text { Doppelszene aus veränderter Perspektive. Der Monitor } \\
\text { wird nun durch das Salz auf die Kamera/den Betrachter } \\
\text { zugeschoben. }\end{array}$ & & $\begin{array}{l}\text { Und sie hatte nie so } \\
\text { etwas.... }\end{array}$ \\
\hline
\end{tabular}




\begin{tabular}{|c|c|c|c|c|c|}
\hline $\mathrm{Nr}$. & Zeit & Einstellung & Bildaufbau & Anmerkungen & Ton \\
\hline & & Halbnah & $\begin{array}{l}\text { In der anderen unterlegten Aufnahme (HN) liegt die Frau } \\
\text { im weißen Trikot mit dem Rücken im Salz, die Arme und } \\
\text { Beine sind in die Luft gestreckt. }\end{array}$ & & \\
\hline 2 & Bei 6.10 & $\begin{array}{l}\text { Schnitt } \\
\text { Nahaufnahme }\end{array}$ & $\begin{array}{l}\text { Nahaufnahme zeigt die erhobene linke Hand in der } \\
\text { Bildmitte. An der Fläche im Hintergrund sind schwarze } \\
\text { Spiralenschwünge und farbige Lichtstreifen zu sehen. Der } \\
\text { Arm bewegt sich verbunden mit einem leichten Zoom zum } \\
\text { rechten Bildrand }\end{array}$ & & ... \\
\hline 21 & Bei 6.12 & $\begin{array}{l}\text { Schnitt } \\
\text { Doppelmotiv } \\
\text { Halbnah }\end{array}$ & $\begin{array}{l}\text { Doppelszene wie ab 6.06. Der Monitor wird nun durch das } \\
\text { Salz auf die Kamera/ den Betrachter zugeschoben. } \\
\text { In der anderen unterlegten Aufnahme (HN) liegt die Frau } \\
\text { im weißen Trikot mit dem Rücken im Salz, die Arme und } \\
\text { Beine sind in die Luft gestreckt. }\end{array}$ & & \\
\hline 22 & Bei 6.12 & $\begin{array}{l}\text { Schnitt } \\
\text { Doppelaufnah } \\
\text { me }\end{array}$ & $\begin{array}{l}\text { Zwei Motive verwoben. Spirale an der Wand mit der Frau } \\
\text { die in Halbnah am Boden liegt. Zunächst liegt sie auf der } \\
\text { Seite, das Gesicht der Kamera zugewendet. Dann dreht } \\
\text { sie sich im Salz auf den Bauch und stützt das Gesicht auf } \\
\text { die Hände. }\end{array}$ & & $\begin{array}{l}\text {.... Wie Angst } \\
\text { gekannt. }\end{array}$ \\
\hline 23 & Bei 6.17 & $\begin{array}{l}\text { Schnitt } \\
\text { Groß } \\
\text { Bluebox } \\
\text { Doppelmotiv }\end{array}$ & $\begin{array}{l}\text { Gesicht in Großaufnahme durchwirkt von } \\
\text { gleichbleibendem zweiten Motiv, das aber bei } 6.19 \text { erst } \\
\text { aus, dann bei } 6.20 \text { wieder eingeblendet wird als Bluebox } \\
\text { ins Schwarze. } \\
\text { Frau im weißen Trikot agiert vorne und im Hintergrund } \\
\text { schiebt die Frau in schwarz das Fernsehgerät von rechts } \\
\text { nach links durch den Raumes. } \\
\text { Die Weißgekleidete taucht nach unten ab und die } \\
\text { Schwarzgekleidete ist über den Monitor gebeugt in } \\
\text { Nahaufnahme zu sehen. }\end{array}$ & & $\begin{array}{l}\text { Was hatte sie schon } \\
\text { zu verlieren?... }\end{array}$ \\
\hline 24 & Bei 6.30 & $\begin{array}{l}\text { Schnitt } \\
\text { Doppelmotiv/ } \\
\text { Bluebox }\end{array}$ & $\begin{array}{l}\text { Halbtotale zeigt die Künstlerin im schwarzen Gewand, die } \\
\text { den Monitor durch den Raum schiebt. Alles Schwarze ist } \\
\text { durch ein blauweißes Licht ersetzt, dass eine fließende } \\
\text { Bewegung zeigt, etwas wie eine sehr schnelle Fahrt durch } \\
\text { einen Tunnel oder Teilchenbeschleuniger. }\end{array}$ & & $\begin{array}{l}\text { Geräusch wie Wind, } \\
\text { Strahlen untermalt } \\
\text { mit sphärischen } \\
\text { Klängen begleitet } \\
\text { diese lange }\end{array}$ \\
\hline
\end{tabular}

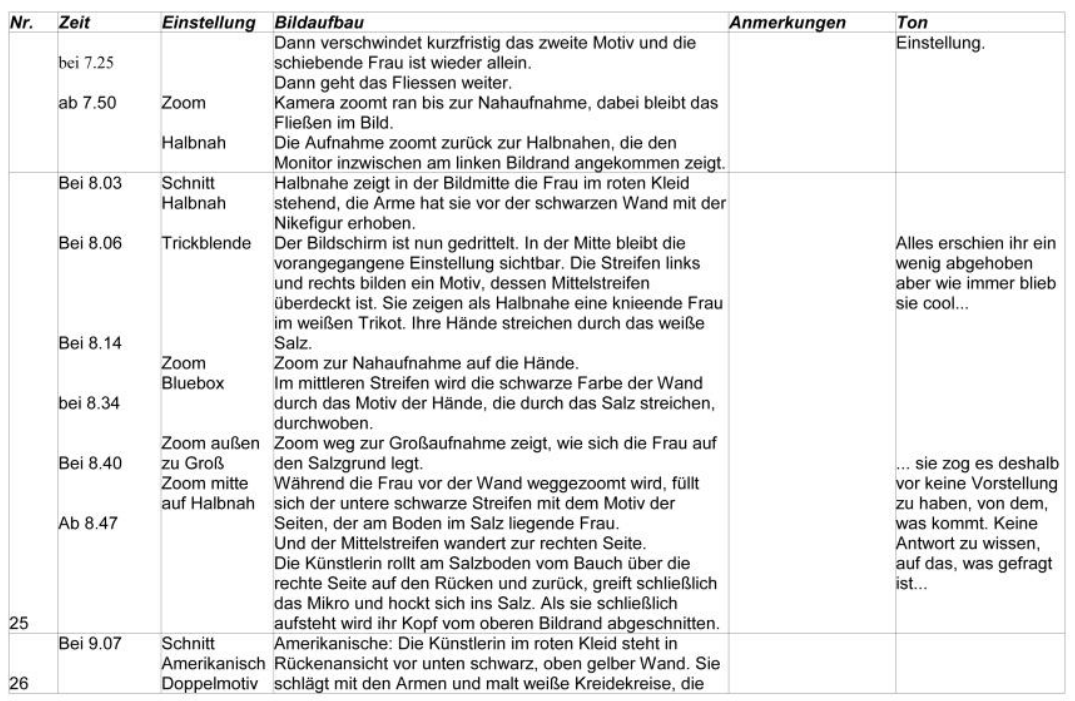




\begin{tabular}{|c|c|c|c|c|c|}
\hline Nr. & Zeit & Einstellung & Bildaufbau & Anmerkungen & Ton \\
\hline & bei 9.15 & $\begin{array}{l}\text { Großaufnahm } \\
\mathrm{e}\end{array}$ & $\begin{array}{l}\text { sich auf dem schwarzen Grund abzeichnen. } \\
\text { Das zweite Motiv eingeblendet in die schwarzen Partien } \\
\text { der anderen Aufnahme zeigt wieder die Hände der } \\
\text { Künstlerin auf dem Salzboden in Großaufnahme. }\end{array}$ & & $\begin{array}{l}\ldots \text { und sich aus } \\
\text { Nichts Nichts zu } \\
\text { machen. }\end{array}$ \\
\hline 27 & Bei 9.35 & $\begin{array}{l}\text { Schnitt } \\
\text { Groß } \\
\text { Standbild }\end{array}$ & $\begin{array}{l}\text { Die Großaufnahme zeigt die Künstlerin mit einer grauen } \\
\text { Jacke bekleidet. Sie hockt am Boden vor einem schwarzen } \\
\text { Hintergrund und schwenkt den Oberkörper von links nach } \\
\text { rechts, dabei hält sie ein rotes Band in den Händen. }\end{array}$ & & $\begin{array}{l}\text { Der Weg wand sich } \\
\text { und verschwand } \\
\text { städnig vor ihren } \\
\text { Augen. Die Gegend } \\
\text { veränderte bei jeder } \\
\text { Wegbiegung ihre } \\
\text { Sicht... }\end{array}$ \\
\hline 28 & Bei 10.08 & Schnitt & $\begin{array}{l}\text { Die Großaufnahme zeigt das Gesicht der Künstlerin, die } \\
\text { erst am Boden sitzt, dann aufsteht. }\end{array}$ & & ... doch es gab... \\
\hline 29 & Bei 10.15 & $\begin{array}{l}\text { Nah } \\
\text { Zoom } \\
\text { Groß } \\
\text { Überblendung }\end{array}$ & $\begin{array}{l}\text { Eine Kreisblende zeigt in Amerikanischer die Künstlerin im } \\
\text { roten Trikot vor einem gelben Bild. Sie hat den rechten } \\
\text { Arm erhoben und steht mit dem Rücken zur Kamera. } \\
\text { Um den Kreis ist es schwarz, doch wird ein Motiv } \\
\text { erkennbar, es ist eine Nahaufnahme der Künstlerin, die im } \\
\text { Salz sitzt und deren Hände durch das Salz fegen. } \\
\text { Die Kreisblende wird größer und zoomt zur Großaufnahme } \\
\text { auf die Agierende. Zudem beginnt das Randmotiv das } \\
\text { Kreismotiv zu durchdringen. }\end{array}$ & & $\begin{array}{l}\text {...keine Hindernisse, } \\
\text { die nicht zu } \\
\text { überwinden gewesen } \\
\text { wären. }\end{array}$ \\
\hline 30 & Ab 10.29 & $\begin{array}{l}\text { Schnitt } \\
\text { Kreisblende }\end{array}$ & $\begin{array}{l}\text { Die Kreisblende zeigt Künstlerin im roten Trikot, die in } \\
\text { gelbe Papierbahnen gehültt am Boden sitzt. Vorne rechts } \\
\text { steht ein Monitor am Boden. Sie beginnt Kreide an die } \\
\text { Wand zu zeichnen. } \\
\text { Die Gehende in Halbnahe schimmert durch das Motiv in } \\
\text { der Kreisblende. }\end{array}$ & & $\begin{array}{l}\text { Und sie hatte nie so } \\
\text { etwas wie Angst } \\
\text { gekannt. Was hatte } \\
\text { sie schon zu verlie- } \\
\text { ren. Sie war verwöhnt } \\
\text { von ihrem Mut. }\end{array}$ \\
\hline 31 & Ab 11.16 & $\begin{array}{l}\text { Schnitt } \\
\text { Kreisblende } \\
\text { Doppelmotiv }\end{array}$ & $\begin{array}{l}\text { Die Kreisblende zeigt die Künstlerin in das Papier } \\
\text { eingehüllt, die mit der Kreide zeichnet. } \\
\text { Durchwoben wird diese Halbnahe vom Motiv der Frau, die } \\
\text { im Salz rollt. }\end{array}$ & & $\begin{array}{l}\text { Der Weg blieb, } \\
\text { was er war. }\end{array}$ \\
\hline 32 & Bei 11.24 & Schnitt & Die Nahaufnahme zeigt die Frau mit der gelben Zeichnung & & ) Er war unveränder- \\
\hline
\end{tabular}

\begin{tabular}{|c|c|c|c|c|c|}
\hline$N r$. & Zeit & Einstellung & Bildaufbau & Anmerkungen & Ton \\
\hline & $\begin{array}{l}\text { bei } 11.56 \\
\text { ab } 12.00 \\
12.09\end{array}$ & $\begin{array}{l}\text { Nah } \\
\text { Schwenk } \\
\text { Zoom } \\
\text { Bluebox }\end{array}$ & $\begin{array}{l}\text { über dem Kopf, dahinter findet sich die Tafel mit den } \\
\text { Kreidezeichnungen. Die Kamera schwenkt nach unten. } \\
\text { Zoomt weg auf Halbnah und dann wieder ran auf } \\
\text { Großaufnahme. Mittels Bluebox sind die schwarzen } \\
\text { Flächen mit der Aufnahme der stehenden Künstlerin im } \\
\text { weißen Trikot gefültt. } \\
\text { Die zweite Aufnahme wird ausgeblendet. } \\
\text { Zoomt wieder weg auf Amerikanische, die zeigt, wie die } \\
\text { Künstlerin vom Boden vor der Wand aufsteht. Dann geht } \\
\text { sie in die Zeichnungen eingehülllt mit dem Rücken an der } \\
\text { Wand entlang, wobei ihr die Kamera folgt. Schlielich hockt } \\
\text { sie sich auf den Boden. }\end{array}$ & & $\begin{array}{l}\text { bar. Sie zog es des- } \\
\text { halb vor, keine Vor- } \\
\text { stellung zu haben } \\
\text { von dem, keine Ant- } \\
\text { wort zu wissen auf } \\
\text { das, was gefragt ist, } \\
\text { und sich aus Nichts } \\
\text { Nichts zu machen. } \\
\text { >Stille }\end{array}$ \\
\hline 33 & Bei 12.27 & $\begin{array}{l}\text { Schnitt } \\
\text { Doppelmotiv } \\
\text { Bluebox } \\
\text { Halbnah/ } \\
\text { Groß }\end{array}$ & $\begin{array}{l}\text { Der gelbe Papierhaufen bewegt sich vor der schwarzen } \\
\text { Wand mit den Kreidezeichnungen. Das Papier robbt von } \\
\text { rechts nach links durch das Bild und rollt auch über den } \\
\text { Boden. } \\
\text { Diese Halbnahe wird durchwoben von einer } \\
\text { Großaufnahme der Künstlerin im weißen Trikot, die steht } \\
\text { und sich bewegt. Sie hält die Hörner, trägt diese auf ihren } \\
\text { Händen. Die Farben sind hier blau, gelb und schwarz. }\end{array}$ & $>$ glucksend & $\begin{array}{l}\text { Die Zeit schien unendlich } \\
\text { lang zu sein. } \\
\text { Sie hatte das Gefühl, sich } \\
\text { zu veriren und es gab } \\
\text { keine Hindernisse, die } \\
\text { nicht zu überwinden } \\
\text { gewesen wären. Und sie } \\
\text { hatte nie so etwas wie } \\
\text { Angst gekannt. }\end{array}$ \\
\hline 34 & $\begin{array}{l}\text { Bei } 13.15 \\
\text { bei } 13.18\end{array}$ & $\begin{array}{l}\text { Schnitt } \\
\text { Halbtotale } \\
\text { Kreisblende }\end{array}$ & $\begin{array}{l}\text { Halbtotale zeigt die Frau im roten Trikot am Boden liegend } \\
\text { in das Papier gehüllt vor der schwarzen Kreidewand. } \\
\text { Kreisblende mit blauem Rand. Die Künstlerin rollt auf dem } \\
\text { Boden hin und her. Dann steht sie schließlich auf, und } \\
\text { man sieht, dass sie verbundene Augen hat. } \\
\text { Die blau umrandete Kreisblende schließt sich schnell, so } \\
\text { dass schließlich fast der gesamte Bildschirm blau ist, bis } \\
\text { auf einen schwarzen Fleck. } \\
\text { Ein schwarzes „T" steht an der weißen Wand. }\end{array}$ & & $\begin{array}{l}\text { Was hatte sie schon } \\
\text { zu verlieren? } \\
\text { Sie war verwöhnt von } \\
\text { ihrem Mut. }\end{array}$ \\
\hline 35 & Bei 13.27 & $\begin{array}{l}\text { Schnitt } \\
\text { Halbnah }\end{array}$ & $\begin{array}{l}\text { Die Halbnahe zeigt die Künstlerin im weißen Trikot, die } \\
\text { der Mitte der Aufnahme auf dem Rücken am Boden liegt. } \\
\text { Die Beine streckt sie in die Luft vor einer Wand mit grünem } \\
\text { „T“ und schwarzer Spirale. Die Schatten der Beine }\end{array}$ & & \\
\hline
\end{tabular}




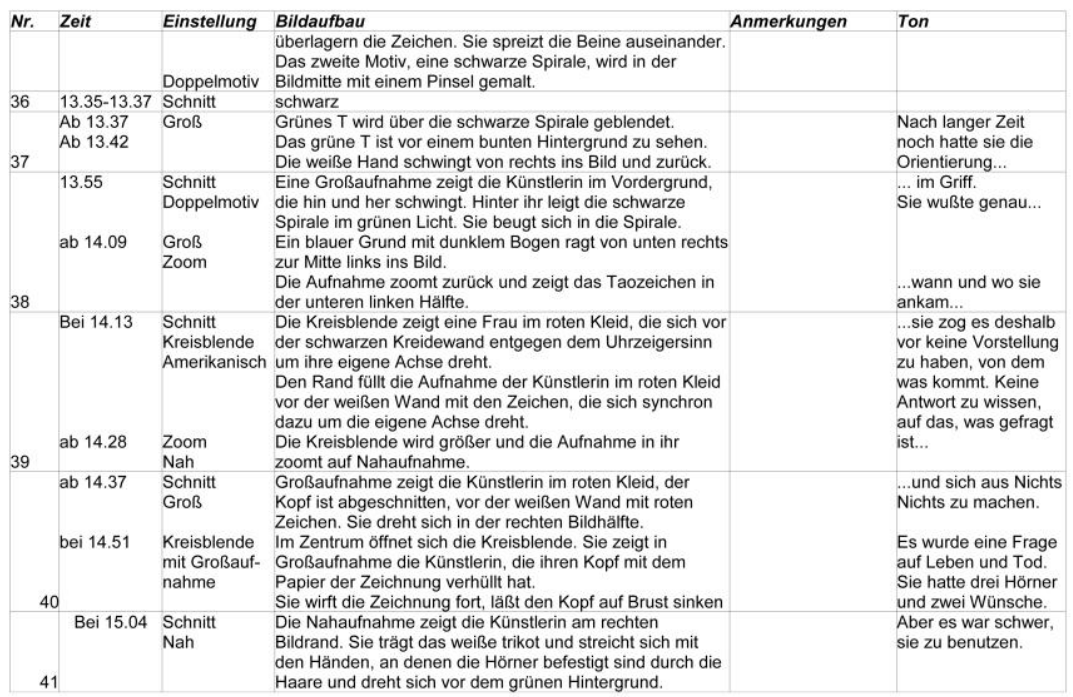

\begin{tabular}{|c|c|c|c|c|c|}
\hline Nr. & Zeit & Einstellung & Bildaufbau & Anmerkungen & Ton \\
\hline 4 & Bei 15.21 & $\begin{array}{l}\text { Schnitt } \\
\text { Nah }\end{array}$ & $\begin{array}{l}\text { Weiße Kreidestriche, die auf Tafel gemalt wurden sind als } \\
\text { Nahaufnahme sichtbar. Hinter diesem Motiv hockt die } \\
\text { Künstlerin im weißen Trikot am Boden mit einem roten } \\
\text { Faden in den Hănden, den sie aufsammelt. }\end{array}$ & & $\begin{array}{l}\text { Es gab keine Hindernisse, } \\
\text { die nicht zu überwinden } \\
\text { gewesen wären und sie } \\
\text { hatte nie so etwas wie } \\
\text { Angst gekannt... }\end{array}$ \\
\hline 4 & Bei 15.35 & $\begin{array}{l}\text { Schnitt, Nah } \\
\text { Kreisblende } \\
\text { Zoom } \\
\text { Halbnahe }\end{array}$ & $\begin{array}{l}\text { Nahaufnahme zeigt den roten Faden auf den } \\
\text { Oberschenkeln und die Hände, die den Faden } \\
\text { einsammeln. Darum fügt sich dann eine Kreisblende, in } \\
\text { der der Zoom auf Halbnah zeigt, wie die Künstlerin } \\
\text { aufsteht. }\end{array}$ & & $\begin{array}{l}\text {... Was hatte sie } \\
\text { schon zu verlieren... } \\
\text {... } \\
\text { verwöhnt von ihrem } \\
\text { Mut. }\end{array}$ \\
\hline 4 & Bei 16.00 & $\begin{array}{l}\text { Schnitt } \\
\text { Kreisblende } \\
\text { Fahrt } \\
\text { Zoom auf } \\
\text { Halbnahe }\end{array}$ & $\begin{array}{l}\text { Die Kreisblende zeigt in einer Nahaufnahme die Künstlerin } \\
\text { im roten Kleid mit einem Stock über dem Kopf vor der } \\
\text { schwarzen Kreidewand. Sie wandert von rechts nach links, } \\
\text { die Kamera folgt der Bewegung. } \\
\text { Die Blende fällt weg. Die Künstlerin steht vor der } \\
\text { Zeichnung und tritt dann hinter die Zeichnungswand. Die } \\
\text { Aufnahme zoomt auf eine Halbnahe. }\end{array}$ & & $\begin{array}{l}\text { Es wurde eine } \\
\text { Frage... }\end{array}$ \\
\hline & Bei 16.12 & $\begin{array}{l}\text { Schnitt } \\
\text { Standbild }\end{array}$ & $\begin{array}{l}\text { Aufnahme zeigt die alchemistische zeichung mit der } \\
\text { zweigeteilten androgynen Figur, deren Kopf allerdings } \\
\text { durch den oberen Bildrand abgeschnitten ist. }\end{array}$ & & ...auf Leben und Tod. \\
\hline 4 & Bei 16.24 & $\begin{array}{l}\text { Schnitt } \\
\text { Nah } \\
\text { Bluebox }\end{array}$ & $\begin{array}{l}\text { Die Nahaufnahme zeigt die Künstlerin in Nahaufnahme im } \\
\text { Profil mit roten Haaren. Die Haare sind durchwoben von } \\
\text { einem zweiten Motiv. }\end{array}$ & $\begin{array}{l}\text { Dies Motiv ist schon } \\
\text { zwei Mal begegnet, nur } \\
\text { diesmal näher dran. }\end{array}$ & $\begin{array}{l}\text { Sie hatte zwei Hörner und } \\
\text { rdrei Wünsche und es } \\
\text { würde ihr freistehen, sie } \\
\text { zu benutzen... }\end{array}$ \\
\hline 4 & Bei 16.30 & $\begin{array}{l}\text { Schnitt } \\
\text { Nah } \\
\text { Bluebox } \\
\text { Doppelmotiv }\end{array}$ & $\begin{array}{l}\text { Die Nahaufnahme zeigt die Künstlerin im weißen Trikot. } \\
\text { Die Haare sind durchwirkt von der alchemistischen } \\
\text { androgynen Darstellung. Die Künstlerin dreht sich mit den } \\
\text { Hörnern auf der rechten Aufnahmeseite langsam um die } \\
\text { eigene Achse. Dabei taucht das Gesicht auf und } \\
\text { verschwindet. } \\
\text { Nun findet sich die zerknautschte Zeichnung anstelle des } \\
\text { Bildes vorher. Sie dreht sich weiter. Die Motive von der } \\
\text { weißen und roten Frau durchwirken sich. }\end{array}$ & & $\begin{array}{l}\text {... sie zog es deshalb } \\
\text { vor, keine Vorstellung } \\
\text { zu haben, von dem, } \\
\text { was kommt... } \\
\text { wi.keine Antwort zu } \\
\text { wissen... }\end{array}$ \\
\hline & Bei 17.08 & $\begin{array}{l}\text { Schnitt } \\
\text { Groß }\end{array}$ & $\begin{array}{l}\text { Großaufnahme zeigt die sich um die eigene Achse } \\
\text { drehende Künstlerin in der rechten Bildhälfte. Die Haare }\end{array}$ & & \\
\hline
\end{tabular}




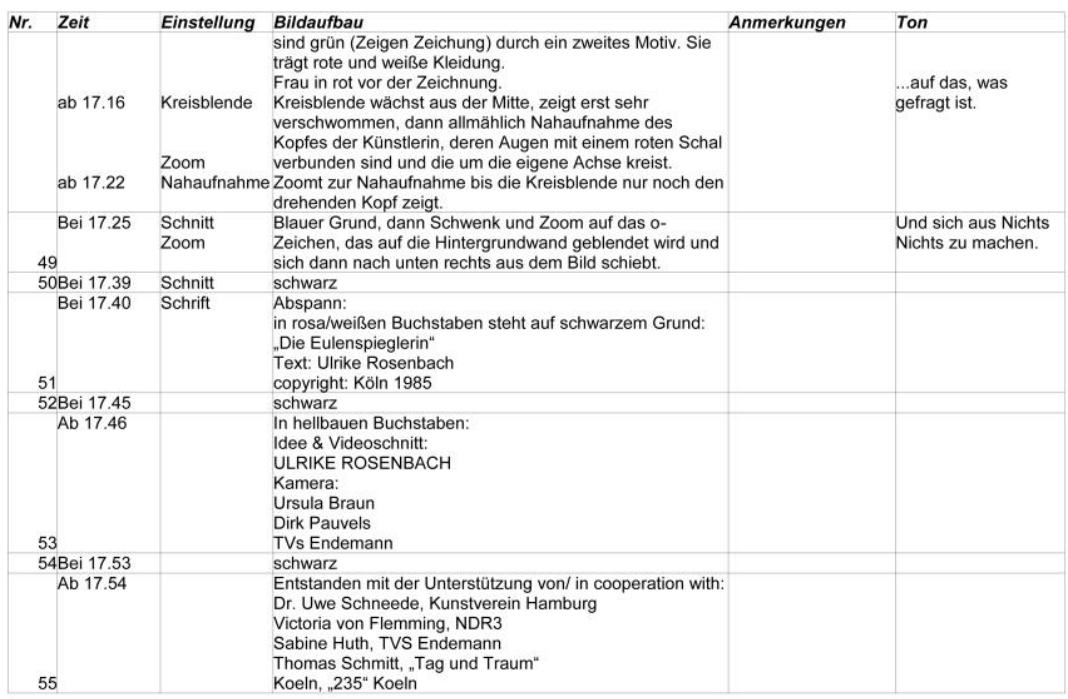

\begin{tabular}{|c|c|c|c|c|c|}
\hline Nr. & Zeit & Einstellung & Bildaufbau & Anmerkungen & Ton \\
\hline & & & $\begin{array}{l}\text { Jan Hout, Museum van Haden- } \\
\text { daagse Kunst, Gent }\end{array}$ & & \\
\hline & $6 \mathrm{Ab} 18.00$ & & schwarz & & \\
\hline
\end{tabular}




\section{VIII.4. Or-phelia, 1988}

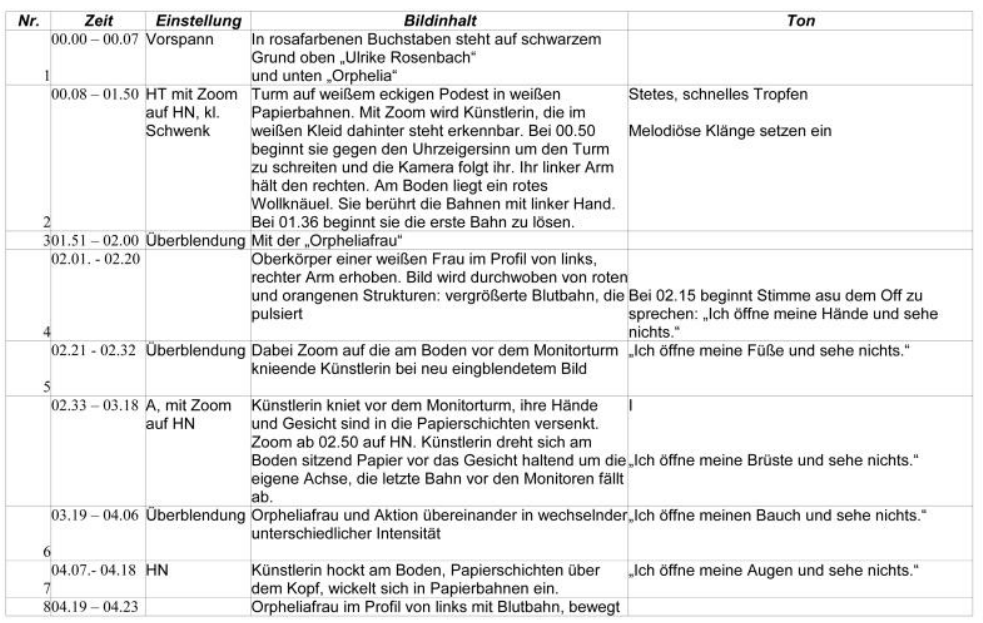

\begin{tabular}{|c|c|c|c|c|}
\hline Nr. & Zeit & Einstellung & Bildinhalt & Ton \\
\hline & & & sich aus Starre & \\
\hline & $04.24-05.27$ & $\begin{array}{l}\text { HN mit Zoom } \\
\text { auf } \mathrm{N}\end{array}$ & Künstlerin am Boden von Papierbahnen eingehüllt & Ich öffne meinen Hals und sehe nichts." \\
\hline & $05.28-06.27$ & Überblendung & $\begin{array}{l}\text { Orpheliafrau im Profil von rechts und agierende } \\
\text { Künstlerin auf die gezoomt wird im Wechsel } \\
\text { unterscheidlich intensiv }\end{array}$ & "Ich öffne meine Seele und sehe nichts." \\
\hline 10 & & & & $\begin{array}{l}\text { Ich offne mir mein Herz und sehe mich an." Hier } \\
\text { hält die Künstlerin in ihrer Bewegung inne. }\end{array}$ \\
\hline & $06.28-07.11$ & $\begin{array}{l}\text { HN dann } \\
\text { zoom zur HT }\end{array}$ & Kûnstlerin hockt vor den Papiernbahnen & (nur Tropfen) \\
\hline & $07.12 \ldots \ldots \ldots \ldots \ldots$ & & Orpheliafrau & \\
\hline & $07.13 \ldots$ & & Blutbe & \\
\hline & $07.14-07.41$ & & $\begin{array}{l}\text { Orpheliafrau, die die Hănde bew } \\
\text { langsam durch ein Fließen aufge }\end{array}$ & \\
\hline & $07.42 \ldots \ldots . . . .$. & & Künstlerin am Boden hockend & \\
\hline & $07.43-07.48$ & & Orphel & \\
\hline 17 & $07.49-11.30$ & $\begin{array}{l}\text { G mit Zoom } \\
\text { auf HN, } \\
\text { zwischen- } \\
\text { durch Zoom } \\
\text { auf G, dann } \\
\text { wieder } \mathrm{HN}\end{array}$ & $\begin{array}{l}\text { Papierbahn, darunter liegen sechs lange, dünne } \\
\text { Stöcke, die die Künstlerin ergreift - in jeder Hand } \\
\text { drei, sie beginnt damit über den Boden zu fegen, erst } \\
\text { langsam, dann immer schwungvoller }\end{array}$ & $\begin{array}{l}\text { Leises "Hallo, hallo, hallo" von Frauenstimmen } \\
\text { aus dem Off. } \\
\text { t } \\
\text { Stimmen werden lauter: „Hallo, hey, hey, hey“ } \\
\text { außerdem Ton, der Spannung erzeugt. } \\
\text { Als Stimmen und Ton verstummen bleibt Fegen } \\
\text { zu hören }\end{array}$ \\
\hline & $11.31-11.52$ & Ūberblendung & $\begin{array}{l}\text { Orpheliafrau / Künstlerin in Großaufnahme dann auf } \\
\text { HT gezoomt }\end{array}$ & \\
\hline & $11.53-12.00$ & & f rotes Fließen & \\
\hline 20 & $12.01 .-12.25$ & Überblendung & Zu Künstlerin, die am Boden hockt & $\begin{array}{l}\text { Bei } 12.15 \text { erklingt Stimme aus dem Off: Ich (ich, } \\
\text { ich, wie Echo) "Ich öfne meine Hände und sehe } \\
\text { nichts." }\end{array}$ \\
\hline 21 & $12.26-13.07$ & $\begin{array}{l}\text { Zoom von } \mathrm{N} \\
\text { auf HT, } \\
\text { Schwenk }\end{array}$ & $\begin{array}{l}\text { Künstlerin steht auf, über ihrem Rücken liegt ein roter } \\
\text { Faden, der zu einem Knäuel, das am Boden liegt, } \\
\text { gehört. Sie breitet stehend die Arme aus. Sie beginnt } \\
\text { sich gegen den Uhrzeigersinn um ihre eigene Achse }\end{array}$ & $\begin{array}{l}\text { r.lch öffne meine Füße und sehe nichts." } \\
\text { "Ich öfne meine Brüste und sehe nichts." } \\
\text { "Ich öffne meine Bauch und sehe nichts." }\end{array}$ \\
\hline
\end{tabular}




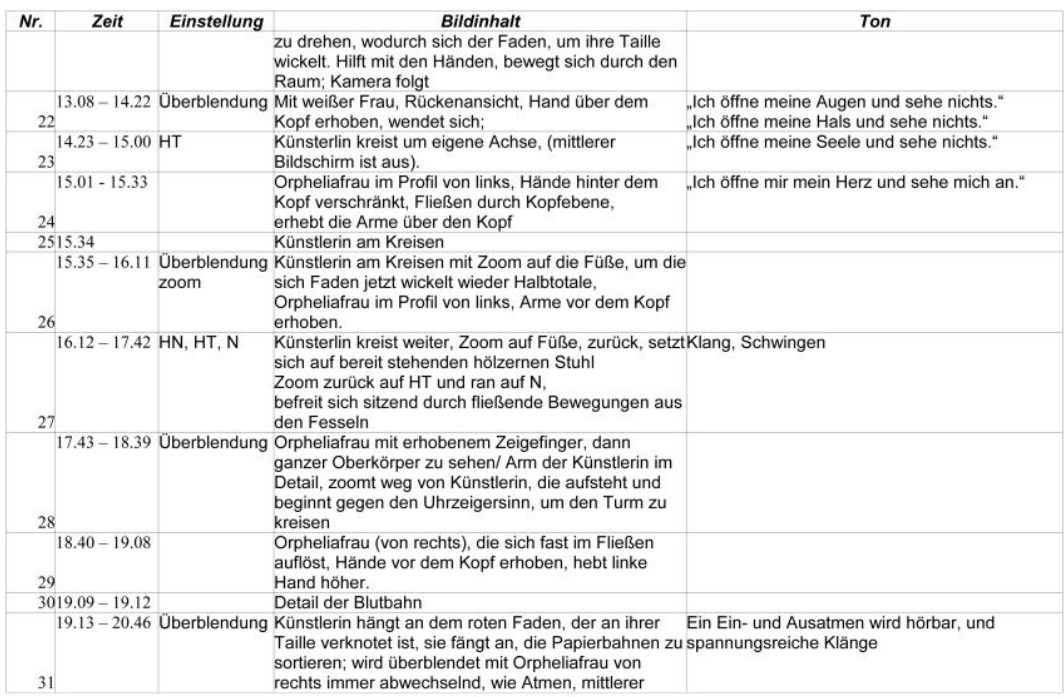

\begin{tabular}{|c|c|c|c|c|}
\hline Nr. & Zeit & Einstellung & Bildinhalt & Ton \\
\hline & & & Monitor ist wieder an & \\
\hline & $20.47-20.48$ & & Detail Blutbahn, hinter der Orpheliafrau erscheint & \\
\hline 33 & $20.49-21.29$ & Überblendung & $\begin{array}{l}\text { Orpheliafrau von rechts mit schützenden Armen über } \\
\text { dem nach vorn gebeugten Kopf, Finger bewegen } \\
\text { sich; Überblendet mit Künsterin, die sich } \\
\text { ausgestreckt über den Boden rollt. }\end{array}$ & $\begin{array}{l}\text { Ab } 21.05, \ldots \text { zwischen den Türen von Leben und } \\
\text { Tod gibt es noch eine andere Tür, ... }\end{array}$ \\
\hline & $+21.30-21.37$ & & Orpheliafrau von rechts & Völlig unerwartet... \\
\hline 35 & $21.38-22.05$ & $\begin{array}{l}\text { HN, Kamera } \\
\text { rollt um } \\
\text { bewegung zu } \\
\text { folgen }\end{array}$ & $\begin{array}{l}\text { Künstlerin rollt mit dem Strang roter Wolle über den } \\
\text { Boden }\end{array}$ & $\begin{array}{l}\text { Die, die geboren werden an der Schwelle des } \\
\text { Todes sind dem Ewigen geweiht", ist aus dem } \\
\text { Off zu hören. }\end{array}$ \\
\hline 36 & 22.06.-23.35 & Uberblendung & $\begin{array}{l}\text { Orpheliafrau von rechts und Künsterin, die am Boden } \\
\text { rollt und dann versucht aufzustehen und sich } \\
\text { hinhockt, um Wolle lose aufzuwickeln, Künstlerin mit } \\
\text { dem Wollstrang am Boden hockend, beginnt sich die } \\
\text { Wolle abwechselnd rechts und links über die Schulter } \\
\text { zu legen }\end{array}$ & $\begin{array}{l}\text { Ab } 22.40 \text { meditative Klänge / wie } \\
\text { Glocke/Zimbeln setzen ein } \\
\text { und werden immer lauter }\end{array}$ \\
\hline & $723.36-23.50$ & G & Künstlerin, die sich in die Wolle kuschelt & \\
\hline 38 & $23.51-27.28$ & Überblendung & $\begin{array}{l}\text { Mit Orpheliafrau von rechts, die die Hände vor das } \\
\text { gesicht erhoben hat, Zoom auf Künsterin und wieder } \\
\text { weg, Aufnahmeperspektive wechselt auf frontal, } \\
\text { schwingt mit Musik, läßt roten Faden schließlich los, } \\
\text { die Überblendung ist unterschiedlich intensiv, ordnet } \\
\text { den Saum des Rockes ihres Kleides zum Halbkreis, } \\
\text { malt von da ausgehend Pfeile mit weißer Kreide auf } \\
\text { den Boden }\end{array}$ & $\begin{array}{l}\text { Meditative Klănge und Summen einer } \\
\text { Frauenstimmen }\end{array}$ \\
\hline 39 & $27.29-28.14$ & $\begin{array}{l}\mathrm{G} \text { mit zoom } \\
\text { auf } \mathrm{HN}\end{array}$ & $\begin{array}{l}\text { Künstlerin steht in der Hocke am Boden und malt mit } \\
\text { schwingenden Bewegungen den Kreisbogen nach. } \\
\text { Bewegt sich rückwărts, hălt den Saum am Boden } \\
\text { und hockt sich mit gespreizten Beinen hin. }\end{array}$ & Bei 28.05 setzt „Mia, mia“- Rufen ein. \\
\hline 40 & $28.15-28.45$ & Überblendung & $\begin{array}{l}\text { Auf Orpheliafrau frontal, die sich rekelt, außerdem } \\
\text { zieht die Künstlerin unter ihrem Rock einen Strauß } \\
\text { gelber, rosaner und orangener Rosen hervor, }\end{array}$ & Als Rosen auftauchen setzt dazu fröhliches \\
\hline
\end{tabular}




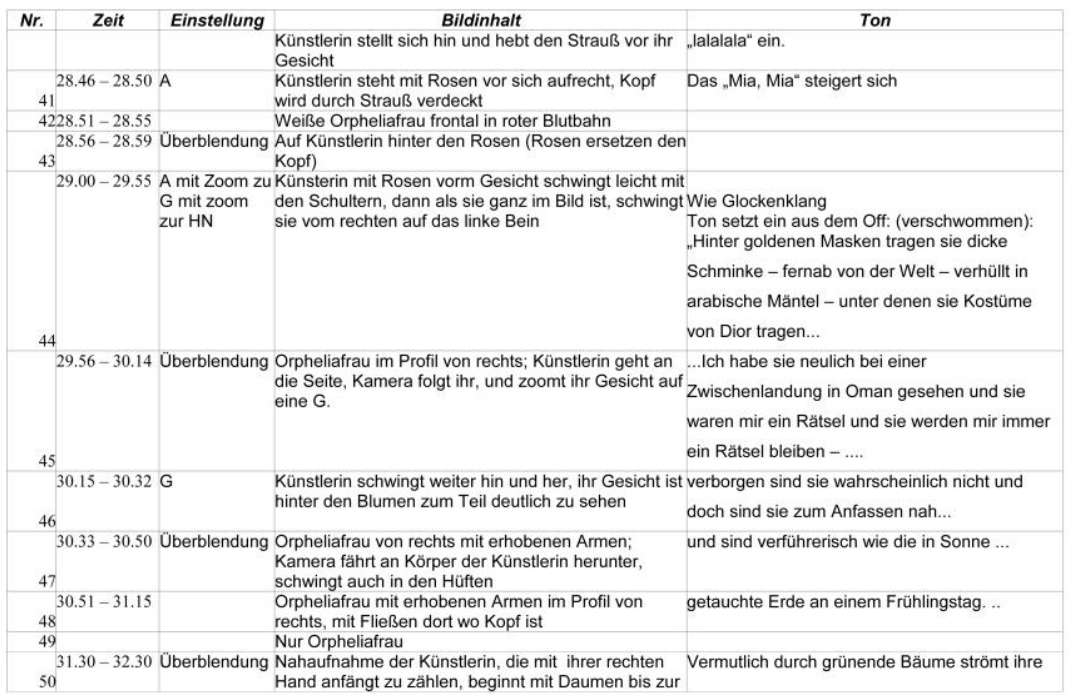

\begin{tabular}{|c|c|c|c|c|}
\hline \multirow[t]{2}{*}{ Nr. } & Zeit & Einstellung & Bildinhalt & Ton \\
\hline & & & $\begin{array}{l}\text { ganzen Hand, beim zweiten Mal dreht sie Handfläche } \\
\text { zu sich, bei fünf dann Handfläche Richtung Publikum } \\
\text { gestreckt, hält Rosen wie Kind im linken Arm, Finger } \\
\text { der Orpheliafrau bilden Ring und öffnen sich dann }\end{array}$ & $\begin{array}{l}\text { Energie aus dem Herzen - im Schutz der } \\
\text { Fantasie - ... }\end{array}$ \\
\hline \multirow{2}{*}{\multicolumn{2}{|c|}{$\begin{array}{l}5132.31-32.42 \\
5232.43\end{array}$}} & & Orpheliafrau von rechts mit Fließen & Alles, was lebt!" \\
\hline & & & schwarz & \\
\hline 53 & & Abspann & $\begin{array}{l}\text { Or-phelia-Video und Text: Ulrike Rosenbach in Blau } \\
\text { vor Aufnahme mit der Künstlerin, die auf dem Stuhl } \\
\text { sitzt und die Stäbe mit Rose quer hält, dreht inn dann } \\
\text { langsam in die Senkrechte. } \\
\text { Blaue Schrift: Kamera, Performance Dokumentation: } \\
\text { Michael Jahn } \\
\text { Musik: Shantiprem H. Grab } \\
\text { Bild-Klang- Studio } \\
\text { Eine Produktion der städischen Galerie, Prinz Max } \\
\text { Palais, Karlsruhe. } \\
\text { Copyright Ulrike Rosenbach }\end{array}$ & Tropfen endet erst hier \\
\hline
\end{tabular}


VIII.5. Osho Samadhi, 1990

\begin{tabular}{|c|c|c|c|c|c|}
\hline \multirow[t]{2}{*}{$\mathrm{Nr}$. } & Zeit & Einstellung & Bildaufbau & Anmerkungen & Ton \\
\hline & $0.00-0.10$ & Schrift & $\begin{array}{l}\text { In weißer Blockschrift steht auf schwarzem Grund „Ulrike } \\
\text { Rosenbach" im Zentrum des Bildes }\end{array}$ & & \\
\hline \multirow{2}{*}{1} & & Überblendung & & & \\
\hline & $0.10-0.12$ & Schwarz & $\begin{array}{l}\text { In den schwarzen Untergrund ausgeblendet, dann wird } \\
\text { aus dem Schwarz eine Aufnahme eingeblendet }\end{array}$ & & \\
\hline \multirow{2}{*}{2} & & Überblendung & & & \\
\hline & $0.12-0.18$ & $\begin{array}{l}\text { Nah/ Zoom } \\
\text { Zum Detail }\end{array}$ & $\begin{array}{l}\text { Aufnahme zeigt in Schrägperspektive von vorne einen } \\
\text { rechteckigen weißen Marmorstein im Bildzentrum, der } \\
\text { durch die perspektive als Trapez erscheint. } \\
\text { Um ihn herum ist ein Wasserbassin, das als umgekehrtes } \\
\text { Trapez den Marmorblock umfängt und wiederum einen } \\
\text { Rand aus weißem Marmor hat, der die restliche Bildfläche } \\
\text { mit seinen weiß, schwarzen Strukturen füllt. Auf der } \\
\text { Wasserfläche finden sich Spiegelungen, unter anderem } \\
\text { reflektieren in der oberen rechten Ecke des Bassins kleine } \\
\text { Lichter. } \\
\text { In weißer Schreibschrift wird "Osho / Samadhi" in zwei } \\
\text { Zeilen geschrieben über der Aufnahme eingeblendet, } \\
\text { genau im Zentrum des Bildes, direkt über dem zentralen } \\
\text { Marmortrapez. Dann zerfällt der Schriftzug und gibt Blick } \\
\text { frei auf die darunterliegende eingemeißelte schwarze } \\
\text { Inschrift in dem weißen Marmorstein: „Osho / Never Born / } \\
\text { Never Died / only visited this / Planet Earth between / Dec. } \\
11.1931 \text { - Jan. 19.1990" Kamera zoomt an die Schrift } \\
\text { heran. }\end{array}$ & $\begin{array}{l}\text { Es ist die Grabplatte } \\
\text { des Gründers der } \\
\text { Bhagwan- oder } \\
\text { Osho-Bewegung } \\
\text { Shree Rajneesh } \\
\text { Bhagwan, die hier in } \\
\text { der Aufnahme } \\
\text { gezeigt wird. Sie } \\
\text { befindet sich im } \\
\text { indischen Poona im } \\
\text { ehemaligen Ashram } \\
\text { Oshos. } \\
\text { (spannend Aufbau: } \\
\text { Wasserfläche und } \\
\text { Spiegelung um } \\
\text { Grabplatte) }\end{array}$ & $\begin{array}{l}\text { Musik setzt ein } \\
\text { Meditationsmusik aus } \\
\text { Flöten und ... }\end{array}$ \\
\hline 3 & $0.35-0.48$ & Schnitt/ Nah & $\begin{array}{l}\text { Eine graue, unebene Felswand füllt die Bildfläche, auf der } \\
\text { sich Schatten in unterschiedlichen Grauschattierungen } \\
\text { abzeichnen. Es scheint ein wenig aus der } \\
\text { Unterperspektive aufgenommen, am rechten Rand sind } \\
\text { Pflanzenteile zu sehen, dunkelgrüne Blătter. }\end{array}$ & & \\
\hline
\end{tabular}

\begin{tabular}{|c|c|c|c|c|c|}
\hline$N r$. & Zeit & Einstellung & Bildaufbau & Anmerkungen & Ton \\
\hline & ab 0.48 & Zoom weg & $\begin{array}{l}\text { Zoom setzt ein, der immer mehr von der räumlichen } \\
\text { Situation frei gibt. Endet mit Blick aus dem Inneren eines } \\
\text { Raumes auf Säulen und schmale, hohe Marmorflächen mit } \\
\text { dazwischen liegenden Fensterflächen, durch die ein } \\
\text { Garten, in dem sich auch die zuvor in Nahaufnahme } \\
\text { gezeigte Felsformation findet, zu sehen ist. Rechts und } \\
\text { links gliedern zwei geriffelte Säulen die Bildfläche } \\
\text { symmetrisch. }\end{array}$ & & \\
\hline & & Überblendung & & & \\
\hline 5 & $1.12-1.34$ & $\begin{array}{l}\text { Standbild/ } \\
\text { Halbtotale } \\
\text { (zwei Motive } \\
\text { übereinander } \\
\text { gelegt }\end{array}$ & $\begin{array}{l}\text { Zu sehen sind am rechten Rand und rechts oben graue, } \\
\text { raue Felsformationen. Am linken Rand stehen Pflanzen. } \\
\text { Die untere Hălfte der Fläche ist gefüllt mit einer Aufnahme } \\
\text { von quadratischen blau, grauen Steinplatten, die } \\
\text { gleichmäßig mit Abständen auf dem Boden verteilt sind, } \\
\text { aufgenommen sin sie aus einer schrägen Perspektive, so } \\
\text { dass sie als Rauten erscheinen. Auf sie fallen im Verlauf } \\
\text { unterschiedliche weiße Lichtreflexe. }\end{array}$ & $\begin{array}{l}\text { Die Farben, } \\
\text { Intensităt verändert } \\
\text { sich, als ob der } \\
\text { Sonneneinfall } \\
\text { schwankt. }\end{array}$ & \\
\hline & & Überblendung & & & \\
\hline 6 & $1.35-1.53$ & $\begin{array}{l}\text { Nah/ } \\
\text { Unscharf/ } \\
\text { Zoom }\end{array}$ & $\begin{array}{l}\text { Langsame Überblendung zu einem unscharfen grünen } \\
\text { Motiv, das durchsetzt ist mit hellen Flecken in blau und } \\
\text { gelb. Es wird schärfer und läßt leuchtend grüne } \\
\text { Bambusblătter erkennen, die zum Teil im Wind wehen und } \\
\text { Lücken, durch die das Licht făllt. }\end{array}$ & & \\
\hline & & Überblendung & & & \\
\hline 7 & 1.53 & $\begin{array}{l}\text { Bild halbiert } \\
\text { (vertikal), } \\
\text { (zwei Motive } \\
\text { neben- } \\
\text { einander) }\end{array}$ & $\begin{array}{l}\text { Nach der Überblendung erscheint eine zweigeteilte } \\
\text { Bildflăche. Wăhrend die linke Seite dunkle, graue, unklare } \\
\text { Strukturen zeigt, vielleicht Felsen, Săulen, erhellt in dem } \\
\text { rechten Motiv orangenes Licht, das als Quelle eine } \\
\text { Pyramidenform aus durchschimmerndem Glas hat den } \\
\text { umgebenden Raum. Es steht am rechten Bildrand auf } \\
\text { einer geschwungenen Bank aus Marmor und taucht die } \\
\text { Marmorwănde rechts und unter sich in gelbes Licht. Auch } \\
\text { fallen weiße Lichtreflexe auf die Steine. Im Hintergrund }\end{array}$ & & \\
\hline
\end{tabular}




\begin{tabular}{|c|c|c|c|c|c|}
\hline Nr. & Zeit & Einstellung & $\begin{array}{l}\text { Bildaufbau } \\
\text { dieses rechten Motivs ist auf der linken Seite im } \\
\text { Hintergrund eine hochrechteckige rot-braune Fläche, die } \\
\text { oben mit einem Halbkreis abgerundet ist. Und von einer } \\
\text { hellen, mittelbreiten Marmorfassung umfasst ist. }\end{array}$ & Anmerkungen & Ton \\
\hline & & Überblendung & & & \\
\hline \multirow[t]{3}{*}{8} & $A b 2.12$ & $\begin{array}{l}\text { Mittelstreifen } \\
\text { der Aufnahme } \\
\text { ist dunkel } \\
2 \text { Bilder sind } \\
\text { ubereinander } \\
\text { gelegt }\end{array}$ & $\begin{array}{l}\text { Nach der Überblendung zeigen sich verzweigende dicke } \\
\text { Äste und Blătter, die von unten rechts nach oben links } \\
\text { durch das Bild ragen. In der Bildmitte ist ein senkrechter } \\
\text { Streifen dunkler eingefärbt, der so breit ist, wie die Hälfte } \\
\text { des Bildes. } \\
\text { Allmählich hebt sich ein gelbschimmernder waagerechter } \\
\text { Streifen auf dem rechten hellen Feld hervor. }\end{array}$ & & \\
\hline & & Überblendung & & & \\
\hline & $2.24-3.02$ & $\begin{array}{l}\text { Bilder } \\
\text { übereinander } \\
\text { gelegt }\end{array}$ & $\begin{array}{l}\text { Überblendung zu neuem Motiv, bei dem wieder zwei } \\
\text { Bildebenen übereinandergelegt erscheinen: Die unteren } \\
\text { Zweidrittel zeigen wieder die Steinplattenfläche in schräger } \\
\text { Perspektive, am linken Bildrand sind Pflanzen zu sehen, } \\
\text { am rechten Rand sind Felsen zu erkennen }\end{array}$ & & \\
\hline & & Überblendung & & & \\
\hline 10 & $\mathrm{Ab} 3.02$ & & $\begin{array}{l}\text { Überblendet zu neuem Motiv: Es zeigt auf der rechten } \\
\text { Seite einen breiteren Streifen einer weißen Marmorwand. } \\
\text { Rechts daneben liegt ein dunkler senkrechter Streifen. Die } \\
\text { Flăche links neben der Marmorfläche zeigt eine } \\
\text { Fensterfläche. Auf ihr spiegeln sich im oberen Drittel zwei } \\
\text { parallele gebogene Segmente des Lichterkranzes und } \\
\text { auch im unteren Feld findet sich ein lănglicher } \\
\text { Lichterreflex. }\end{array}$ & $\begin{array}{l}\text { Spiegelungen auf der } \\
\text { Glasfläche geben } \\
\text { das Innere des } \\
\text { Raumes wieder }\end{array}$ & \\
\hline & & Überblendung & & & \\
\hline 11 & $\mathrm{Ab} 3.14$ & Nah & $\begin{array}{l}\text { Uberblendung zu weiterem Doppelmotiv, das Ausschnitte } \\
\text { der beiden Lichtkreise zeigt, die von oben links nach unten } \\
\text { rechts durch das Bild verlaufen. Im Hintergrund ist Astwerk } \\
\text { zu erkennen. }\end{array}$ & & \\
\hline
\end{tabular}

\begin{tabular}{|c|c|c|c|c|c|}
\hline Nr. & Zeit & Einstellung & Bildaufbau & Anmerkungen & Tor \\
\hline & $3.24-3.26$ & Schärfe & Schärfe wird verändert: scharf - unscharf - scharf & & \\
\hline & & Überblendung & & & \\
\hline \multirow[t]{3}{*}{12} & ab 3.32 & Nah & $\begin{array}{l}\text { Überblendung in neues Motiv. Es ist in drei Felder geteilt: } \\
\text { Ein auf der rechten Seite spitzauslaufendes waagerecht } \\
\text { verlaufendes ovales Feld, eine leicht bewegte } \\
\text { Wasserfläche, in der sich Bäume und Himmel spiegeln. } \\
\text { Eingefasst wird es am oberen und unteren rechten Rand } \\
\text { durch zwei gebogenen Dreiecksflächen, die Segmente der } \\
\text { Lichtkränze zeigen. }\end{array}$ & $\begin{array}{l}\text { Die Aufnahme zeigt } \\
\text { eine Spiegelung im } \\
\text { Wasser }\end{array}$ & \\
\hline & & Überblendung & & & \\
\hline & $\mathrm{Ab} 3.46$ & $\begin{array}{l}\text { Zoom vonNah } \\
\text { auf Totale }\end{array}$ & $\begin{array}{l}\text { Überblendung zu neuem Motiv: Es zeigt einen } \\
\text { senkrechten mitteldicken astlosen Baumstamm in der } \\
\text { Mitte, daneben rechts und links ist grünes Blattwerk zu } \\
\text { sehen. Quer schimmert ein breites Lichterband hindurch. } \\
\text { Die Aufnahme zoomt weg und gibt schließlich Blick in den } \\
\text { Raum frei. Die beiden kannellierten runden Pfeiler und die } \\
\text { Marmorflächen sind symmetrisch links und rechts } \\
\text { angeordnet. }\end{array}$ & $\begin{array}{l}\text { Blick durch Fenster, } \\
\text { Spiegelung } \\
\text { läßt Detail oben } \\
\text { erkennen }\end{array}$ & \\
\hline \multirow{2}{*}{13} & & Überblendung & & & \\
\hline & $\begin{array}{l}\text { Ab } 4.05 \\
\text { ab } 4.09 \\
\text { bis } 4.19 \\
\text { Einstellung } \\
\text { bleibt dann } \\
\text { noch bis } \\
4.27\end{array}$ & Halbtotale & $\begin{array}{l}\text { Überblendung zu einem dreigeteilten Motiv: in der Mitte } \\
\text { helle Fläche, links dunkle Blätter, rechts mittelhell, auch } \\
\text { Marmorstrukturen zu sehen. } \\
\text { Der Oberkörper und Kopf einer in rot gekleideten Frau tritt } \\
\text { im Profil sich rückwärtsbewegend von links ins Bild. Sie } \\
\text { macht mit ihren Armen ausladende Bewegungen nach } \\
\text { links, hält einen Stiel, scheint zu wischen oder fegen. } \\
\text { Nachdem sie rechts aus dem Bild verschwunden ist, tritt } \\
\text { sie nocheinmal hinein, macht die Wischbewegungen und } \\
\text { verschwindet wieder rechts aus dem Bild. }\end{array}$ & & \\
\hline 14 & & Überblendung & & & \\
\hline 15 & Bei 4.28 & Totale & $\begin{array}{l}\text { Uberblendung in ein schwarzes Bild. Es zeigt im oberen } \\
\text { waagerechten Drittel in ähnlichem Abstand zueinander } \\
\text { drei blaue Schlitze, etwas tiefer liegend noch weitere vier }\end{array}$ & & \\
\hline
\end{tabular}




\begin{tabular}{|c|c|c|c|c|c|}
\hline Nr. & Zeit & Einstellung & Bildaufbau & Anmerkungen & Ton \\
\hline & ab 4.32 & & $\begin{array}{l}\text { blaue Flecken. } \\
\text { Gleichmäßig wird es heller und zeigt wieder den Raum mit } \\
\text { den drei Marmor Pfeilern und den Lichtkränzen, die sich in } \\
\text { den verdunkelten Scheiben dazwischen spiegeln. (Die } \\
\text { blauen Schlitze waren Lichter an den Säulen) } \\
\text { Jetzt beginnen sich dunklen Rollos vor den } 4 \\
\text { Fensterflächen zwischen den Pfeilern langsam von unten } \\
\text { zu öffnen und durch die Scheiben einen Blick in den } \\
\text { Garten freizugeben. Feste Einstellung zeigt das Öffnen bis } \\
\text { zur Hälfte der Fensterhöhe/des Bildes. }\end{array}$ & $\begin{array}{l}\text { Der Raum spiegelt } \\
\text { sich mehrfach in den } \\
\text { in den verdunkelten } \\
\text { Scheiben }\end{array}$ & \\
\hline & & \multicolumn{2}{|l|}{ Überblendung } & & \\
\hline \multirow[t]{2}{*}{16} & ab 5.09 & $\begin{array}{l}\text { Nah } \\
\text { Zoom auf } \\
\text { Halbtotale }\end{array}$ & $\begin{array}{l}\text { Dann wird überblendet zu einem neuen Motiv: Die } \\
\text { Nahaufnahme zeigt eine dreigeteilte Fläche. } \\
\text { Beginnt dann wegzuzoomen, wodurch zu erkennen ist, } \\
\text { dass es das orangene Licht ist, dass im Raum auf } \\
\text { Marmorbank steht. Das Licht bleibt in der Mitte der } \\
\text { Aufnahme. Es reflektiert orange in der Scheibe dahinter } \\
\text { und dem Boden. }\end{array}$ & & \\
\hline & & \multicolumn{2}{|c|}{ Überblendung } & & \\
\hline 17 & Ab 5.22 & & $\begin{array}{l}\text { Überblendung in blau, graue Formen. Oben links ist eine } \\
\text { trapezförmige Marmorfläche, darunter schließt sich eine } \\
\text { dreieckige blaue Fläche an. Zur Mitte hin findet sich ein } \\
\text { Bogensegment aus Marmor. In der oberen rechten Ecke } \\
\text { findet sich ein blaugrünes Kreissegment (Viertelkreis). } \\
\text { Drunter schließt sich eine tiefblaue Fläche an, die links von } \\
\text { dem (sich spiegelnden) Marmorbogen und rechts von der } \\
\text { (sich spiegelnden) Marmorwand begrenzt wird. } \\
\text { Der einsetzende Zoom, zeigt, dass es sich um die Ecke } \\
\text { von Oshos Grabstein handelt, und den verschiedenen } \\
\text { Spiegelungen in dem umgebenden Wasserbassin. }\end{array}$ & & \\
\hline & & & Überblendung & & \\
\hline 18 & Ab 5.34 & Detail & $\begin{array}{l}\text { Uberblendung ein neues durch eine verschobene } \\
\text { Bilddiagonale zweigeteiltes Motiv: in der oberen linken }\end{array}$ & & \\
\hline
\end{tabular}

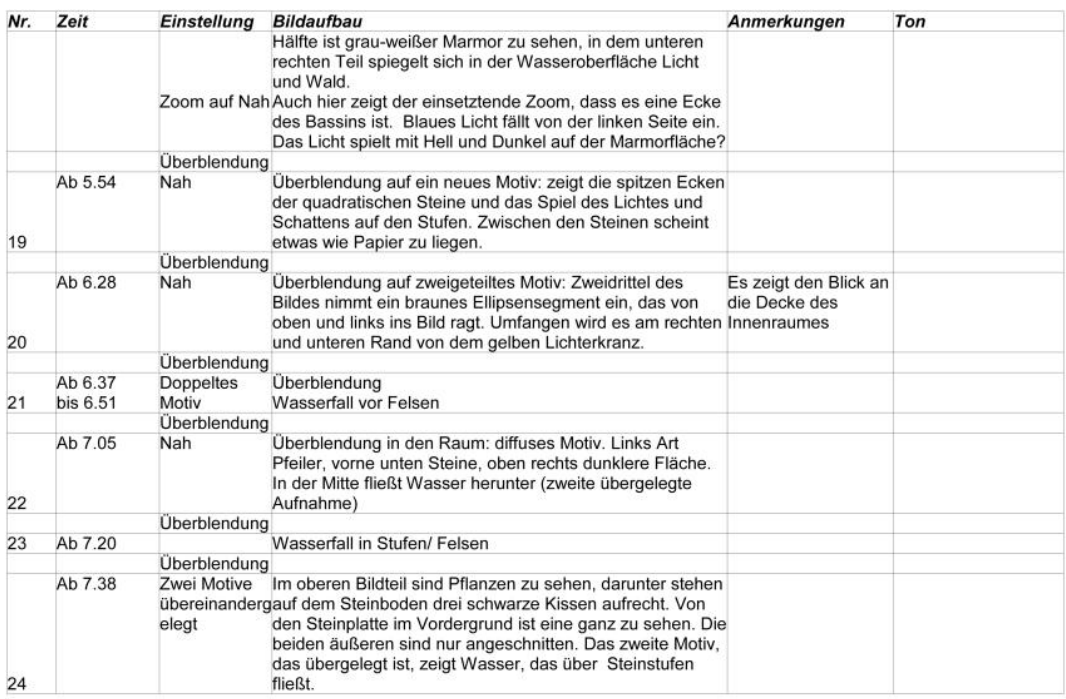




\begin{tabular}{|c|c|c|c|c|c|}
\hline Nr. & Zeit & Einstellung & Bildaufbau & Anmerkungen & Ton \\
\hline \multirow[t]{2}{*}{30} & Ab 9.48 & $\begin{array}{l}\text { Halbtotale } \\
\text { Schräg- } \\
\text { perspektive } \\
\text { Zoom heran } \\
\text { bis Detail }\end{array}$ & $\begin{array}{l}\text { Überblendung auf Grabstein mit Bassin und Säulen, } \\
\text { schräg angeschnitten, auch schräg von oben } \\
\text { aufgenommen. } \\
\text { Zoomt näher auf die hintere (rechte) obere Ecke der } \\
\text { Marmoreinfassung des Bassins. Das Bild Oshos auf der } \\
\text { Spiegelfläche wandert während des Zooms oben links aus } \\
\text { dem Bild heraus. Als Detail kommen blaue und grüne } \\
\text { Lichtreflexe auf dem Marmor ins Bild. }\end{array}$ & $\begin{array}{l}\text { Auch Blick vor } \\
\text { Spiegelfläche mit } \\
\text { weißem Marmorrand. }\end{array}$ & \\
\hline & & Überblendung & & & \\
\hline \multirow[t]{2}{*}{31} & Ab 10.02 & $\begin{array}{l}\text { Standbild } \\
\text { Nah }\end{array}$ & $\begin{array}{l}\text { Überblendung auf Ecke aus Marmor und Spiegelstücken } \\
\text { (rechte Ecke) }\end{array}$ & & \\
\hline & & Überblendung & & & \\
\hline & Ab 10.13 & Detail & $\begin{array}{l}\text { Überblendung auf anderes Motiv aus der Grabarchitektur } \\
\text { (andere Ecke), bestehend aus vier Feldern: oben links } \\
\text { helles Dreieck, darunter breiter blauer gebogener Strefen, } \\
\text { dann graue Flắche des Marmorbogens und dann noch } \\
\text { helle Ecke unten rechts. }\end{array}$ & & \\
\hline & ab 10.20 & Zoom zur & Zoom weg setzt ein & & \\
\hline & bis 10.54 & Halbtotalen & $\begin{array}{l}\text { Perspektive schräg von Seite und von oben. Grabstein nun } \\
\text { schräg im Zentrum }\end{array}$ & $\begin{array}{l}\text { nie Einstellung } \\
\text { âhnelt starkt Nr. } 17\end{array}$ & \\
\hline & $10.54-10.57$ & & $\begin{array}{l}\text { Motiv beginnt sich aufzulösen im hellen Licht, bis } \\
\text { schließlich ganz aufgelöst in weiß-blauer Fläche. }\end{array}$ & & $\begin{array}{l}\text { Musik verklingt mit } \\
\text { der Bildausblendung. }\end{array}$ \\
\hline & bis 11.00 & & Die weiß-blaue Fläche bleibt & & \\
\hline & ab 11.00 & & Farbe wechselt in gelb-weiß & & \\
\hline & $11.01-11.12$ & & $\begin{array}{l}\text { Abspann: schwarze Schrift auf weißem Grund: dyan smita } \\
\text { Ulrike Rosenbach copyright / Saarbrücken } 1991\end{array}$ & & \\
\hline & $11.12-11.17$ & & technische Bearbeitung Hansy Berwanger & & \\
\hline & $11.17-11.18$ & & Musik Yoko Rajneesh Foundation / Poona / India & & \\
\hline & $11.18-11.24$ & & $\begin{array}{l}\text { Dank an / thanks to: Basha Tüngler / } \\
\text { Ma Anando, Osho Ashram Poona, India/ } \\
\text { Hochschule für bildende Künste Saar }\end{array}$ & & \\
\hline 32 & $11.24-11.45$ & & e fur Dildente Kunste Satar & & \\
\hline
\end{tabular}





\section{Werkverzeichnis}

Kursive Angaben weisen darauf hin, dass sich die Angaben bei Glüher 2005 mit voran gegangenen Katalogen nicht decken

a) Videoarbeiten

Zeichenerklärung:
a Videoproduktion im Studio
b Video Live Aktion, entstanden bei einer Aktion
c entstanden für eine Aktion/Performance
d Dokumentation einer Videoaktion oder Performance

\begin{tabular}{|c|c|c|c|c|}
\hline 1972 & Bindenmaske & $\mathrm{s} / \mathrm{w}$ & 12 ' & $\mathrm{a}$ \\
\hline 1972 & Einwicklung mit Julia & $\mathrm{s} / \mathrm{w}$ & $6^{\prime}$ & $/ \mathrm{c}$ \\
\hline 1972 & Eine Scheibe berühren... & $\mathrm{s} / \mathrm{w}$ & 5 , & $\mathrm{a}$ \\
\hline $1972 / 73$ & Naturkreisaktion & $\mathrm{s} / \mathrm{w}$ & 5 ' & $\mathrm{b}$ \\
\hline 1972 & Brennesseltape & $\mathrm{s} / \mathrm{w}$ & $35^{\prime}$ & $\mathrm{a}$ \\
\hline 1972 & Eine Frau ist eine Frau & $\mathrm{s} / \mathrm{w}$ & 4 ' & $\mathrm{a}$ \\
\hline 1972 & Der Muff und das Mädchen & $\mathrm{s} / \mathrm{w}$ & $12^{\prime}$ & $\mathrm{a}$ \\
\hline 1973 & Zeichenhaube & $\mathrm{s} / \mathrm{w}$ & 5 , & $\mathrm{a}$ \\
\hline 1973 & Mon Petit Chou & $\mathrm{s} / \mathrm{w}$ & 8 & $\mathrm{a}$ \\
\hline 1973 & Brustkorbtape & $\mathrm{s} / \mathrm{w}$ & $10^{\prime}$ & \\
\hline 1973 & Der Mann sei das Haupt der Frau & $\mathrm{s} / \mathrm{w}$ & 6 & $\mathrm{a}$ \\
\hline 1973 & Videokonzert Improvisation mit K. Schnitzler & $\mathrm{s} / \mathrm{w}$ & $30^{\prime}$ & $\mathrm{b}$ \\
\hline $1973 / 74$ & Isolation ist transparent & $\mathrm{s} / \mathrm{w}$ & $40^{\prime}$ & $\mathrm{b}$ \\
\hline 1974 & Five Point Star & NTSC/PAL & 8 & $\mathrm{a}$ \\
\hline 1974 & Die Perlen dort, sie waren seine Augen & $\mathrm{s} / \mathrm{w}$ & $10^{\prime}$ & $\mathrm{a}$ \\
\hline 1974 & Sorry, Mister & Farbe & $10^{\prime}$ & $\mathrm{a}$ \\
\hline 1974 & Der innere Widerstand sind meine Füße & $\mathrm{s} / \mathrm{w}$ & $40^{\prime}$ & $\mathrm{b}$ \\
\hline 1975 & Port of Paradise & $\mathrm{s} / \mathrm{w}$ & $15^{\prime}$ & $\mathrm{a}$ \\
\hline 1975 & Madonnas of the flowers & $\mathrm{s} / \mathrm{w}$ & $12^{\prime}$ & $\mathrm{a}$ \\
\hline 1975 & Tanz für eine Frau & $\mathrm{s} / \mathrm{w}$ & 8 ' & $\mathrm{a}$ \\
\hline 1975 & Glauben Sie nicht, dass ich eine Amazone bin & $\mathrm{s} / \mathrm{w}$ & $15^{\prime}$ & $\mathrm{b}$ \\
\hline 1975 & $\begin{array}{l}\text { Glauben Sie nicht, dass ich eine Amazone bin } \\
\text { - Aktionsdokumentation }\end{array}$ & NTSC, Farbe & 8 & d \\
\hline 1976 & Weiblicher Energieaustausch & NTSC, s/w & $15^{\prime}$ & $\mathrm{a}$ \\
\hline $1976 / 78$ & Reflektionen über die Geburt der Venus & Farbe & 15 , & $\mathrm{b}$ \\
\hline $1976 / 77$ & Zehntausend Jahre habe ich geschlafen & $\mathrm{s} / \mathrm{w}$ & $20{ }^{\prime}$ & $\mathrm{b}$ \\
\hline 1976 & Good Luck for a Better Art, mit K. v. Bruch & $\mathrm{s} / \mathrm{w}$ & 5 ' & $\mathrm{a}$ \\
\hline 1977 & Frauenkultur - Kontaktversuch & $\mathrm{s} / \mathrm{w}$ & $60^{\prime}$ & $\mathrm{b}$ \\
\hline $1977 / 81$ & $\begin{array}{l}\text { Frauenkultur - Kontaktversuch } \\
\text { - Aktionsdokumentation }\end{array}$ & NTSC, Farbe & 30 & $d$ \\
\hline 1977 & Maifrau & $\mathrm{s} / \mathrm{w}$ & 60 ' & $\mathrm{b}$ \\
\hline 1977 & Mutterliebe & Farbe & $4^{\prime}$ & a \\
\hline
\end{tabular}




\begin{tabular}{|c|c|c|c|c|}
\hline 1977 & Frau - Frau & NTSC, Far & $20^{\prime}$ & $\mathrm{c}$ \\
\hline 1977 & Herakles - Herkules - King Kong & Farbe, s/w & $30^{\prime}$ & $\mathrm{c}$ \\
\hline 1977 & Frauenlachen - Frauenzärtlichkeit mit Andrea & $\mathrm{s} / \mathrm{w}$ & $40^{\prime}$ & $\mathrm{b}$ \\
\hline 1977 & Venusdepression, Aktion mit fünf Frauen & $\mathrm{s} / \mathrm{w}$ & $40^{\prime}$ & $\mathrm{d}$ \\
\hline 1977 & Signale für Hausfrauen & $\mathrm{s} / \mathrm{w}$ & $15^{\prime}$ & $\mathrm{a}$ \\
\hline 1978 & Meine Verwandlung ist meine Befreiung & Farbe & $20^{\prime}$ & $\mathrm{c} / \mathrm{d}$ \\
\hline 1978 & Salto Mortale & $\mathrm{s} / \mathrm{w}$ & $20^{\prime}$ & $\mathrm{b}$ \\
\hline 1978 & Salto Mortale II & $\mathrm{s} / \mathrm{w}$ & $60^{\prime}$ & $\mathrm{b}$ \\
\hline 1978 & Meine Macht ist meine Ohnmacht & $\mathrm{s} / \mathrm{w}$ & $60^{\prime}$ & $\mathrm{b}$ \\
\hline 1979 & Kleine Stücke von/für? Julia & Farbe & $20^{\prime}$ & $\mathrm{a}$ \\
\hline 1979 & Tanz um einen Baum & Farbe, s/w & $30^{\prime}$ & $\mathrm{b} / \mathrm{d}$ \\
\hline 1979 & Jactatio & Farbe & $12^{\prime}$ & $\mathrm{a} / \mathrm{c}$ \\
\hline 1979 & Die Einsame Spaziergängerin & $\mathrm{s} / \mathrm{w}$ & $60^{\prime}$ & $\mathrm{b}$ \\
\hline 1980 & Lotusknospentöne & Farbe & $15^{\prime}$ & $\mathrm{a}$ \\
\hline 1980 & Keine Madame Pompadour & $\mathrm{s} / \mathrm{w}$ & $30^{\prime}$ & $\mathrm{b}$ \\
\hline 1980 & Requiem für Mütter & Farbe, s/w & $20^{\prime}$ & $\mathrm{d}$ \\
\hline 1980 & Psyche, aber sie irrte (gänzlich) umher & Farbe & $30^{\prime}$ & $\mathrm{c}$ \\
\hline 1981 & $\begin{array}{l}\text { Psyche, aber sie irrte (gänzlich) umher } \\
\text { - Aktionsdokumentation }\end{array}$ & $\begin{array}{l}\text { NTSC/PAL, } \\
\text { Farbe }\end{array}$ & $30^{\prime}$ & $\mathrm{d}$ \\
\hline 1981 & Psyche und Eros & Farbe & $15^{\prime}$ & $\mathrm{a} / \mathrm{c}$ \\
\hline 1981 & Wechselfrau im Rosenkranz & Farbe & $15^{\prime}$ & $\mathrm{a}$ \\
\hline 1981 & Wechselfrau im Wechselspiel & Farbe & $30^{\prime}$ & $\mathrm{c}$ \\
\hline 1981 & Großmutter - Dokumentation einer Begegnung & Farbe & $60^{\prime}$ & $\mathrm{c}$ \\
\hline 1981 & Judofrauen haben als Hilfe Boten & Farbe & $40^{\prime}$ & $\mathrm{c} / \mathrm{d}$ \\
\hline 1982 & Wer hat Angst vor der Schwarzen Frau? & Farbe, PAL & $10^{\prime}$ & \\
\hline 1982 & Schmelzprozesse & Farbe, PAL & $20^{\prime}$ & \\
\hline 1982 & Alles ist Schein & Farbe, PAL & $30^{\prime}$ & \\
\hline 1983 & Aufwärts zum Mount Everest & Farbe & $7^{\prime}$ & \\
\hline 1983 & Das Feenband/Visual Gong & $\begin{array}{l}\text { PAL/NTSC, } \\
\text { Farbe }\end{array}$ & $15{ }^{\prime}$ & \\
\hline $1983 / 84$ & Alle lieben Carmen & Farbe, PAL & $5^{\prime}$ & \\
\hline 1984 & Begegnung mit Ewa und Adam & Farbe, PAL & $30^{\prime}$ & \\
\hline 1984 & Inner Landscape-Insight Image & $\begin{array}{l}\text { NTSC, } \\
\text { Farbe }\end{array}$ & 25 & \\
\hline 1985 & Die Eulenspieglerin & Farbe, PAL & $20^{\prime}$ & \\
\hline 1985 & Im Zentrum des Zyklons & Farbe, PAL & 5 ' & \\
\hline 1985 & Eleven - Verstehen ist wie Hitze... & Farbe, PAL & $6^{\prime}$ & \\
\hline 1986 & Im Garten der Göttin & Farbe, PAL & $30^{\prime}$ & \\
\hline 1986 & Ana'l Haq, der Wind meiner Träume (?) & Farbe,PAL & $40^{\prime}$ & \\
\hline 1987 & Der Wind meiner Träume/ Dreamwind & Farbe, PAL & $8{ }^{\prime}$ & \\
\hline 1987 & Ama-Zonas & Farbe, PAL & $30^{\prime}$ & \\
\hline 1988 & Orphelia & Farbe, PAL & $30^{\prime}$ & \\
\hline 1988 & Orphelia, ein Transformationsstück & Farbe, PAL & $35^{\prime}$ & \\
\hline 1988 & Energetisches Phänomen - Zenkocher & Farbe, PAL & $30^{\prime}$ & \\
\hline 1989 & $\begin{array}{l}\text { Ein Moment im Leben des chinesischen Malers } \\
\text { HU EM AYe }\end{array}$ & Farbe, PAL & $70^{\prime}$ & \\
\hline 1989 & $\begin{array}{l}\text { Aus dem Leben des chinesischen Malers HU } \\
\text { EM AY }\end{array}$ & Farbe, PAL & $0^{13}$ & \\
\hline 1989 & Vier improvisierte Sequenzen & Farbe, PAL & $20^{\prime}$ & \\
\hline
\end{tabular}




\begin{tabular}{|l|l|l|l|l|}
\hline 1989 & Die Schlacht der Bäume & Farbe & $15^{\prime}$ & \\
\hline 1989 & Wie ein Phönix aus der Asche, Performanceband & Farbe, PAL & $60^{\prime}$ & \\
\hline 1990 & Osho-Samadhi & Farbe, PAL & $20^{\prime}$ & \\
\hline 1991 & Die Schlacht der Bäume & & $10^{\prime}$ & \\
\hline 1991 & Sonnenspiele & & $18^{\prime}$ & \\
\hline 1996 & Ëzengel (Computeranimation) & & & \\
\hline 1996 & Über den Tod & & $12^{\prime}$ & \\
\hline 1997 & Über die Kinder & & $8^{\prime}$ & \\
\hline 1998 & Über die Engel & & $15^{\prime}$ & \\
\hline
\end{tabular}

b) Videoaktionen/ Installationen

$\mathrm{I}=$ Videoinstallation

$\mathrm{P}=$ Performance

$\mathrm{S}=$ Videoskulptur

\begin{tabular}{|c|c|c|c|}
\hline 1972 & Naturkreisaktion & $\mathrm{P}$ & $\begin{array}{l}\text { Kunsthalle Düsseldorf/ "Between" - "1000 miles } \\
\text { from here", übernommen vom "Gallery House", } \\
\text { London, Sigi Kraus, Performance/aktion }\end{array}$ \\
\hline 1973 & $\begin{array}{l}\text { Videokonzert } \\
\text { Improvisation }\end{array}$ & $\mathrm{P}$ & $\begin{array}{l}\text { mit Konrad Schnitzler (Musik), Kunstmarkt } \\
\text { Köln, Aktion/Performance }\end{array}$ \\
\hline 1974 & Isolation is transparent & $\mathrm{P}, \mathrm{I}$ & $\begin{array}{l}\text { 112 Greene Street, New York, Willoughby Sharp, } \\
\text { übernommen vom Studio Oppenheim, Köln, } \\
\text { Performance und Installation }\end{array}$ \\
\hline 1974 & Five-Point Star & & Universitätszentrum Beograd \\
\hline 1974 & Sorry Mister & $P$ & Kunstverein Köln \\
\hline 1974 & $\begin{array}{l}\text { Der innere Widerstand } \\
\text { sind meine Füße }\end{array}$ & $P$ & Kunstverein Köln \\
\hline 1974 & Projekt Kinem & $P$ & $\begin{array}{l}\text { Kunstverein Köln, Projekt 74, Wulf Herzogenrath, } \\
\text { Aktion/Performance }\end{array}$ \\
\hline 1975 & The enchanted sea & $P$ & $\begin{array}{cccc}\text { Festival of } & \text { Expanded Media, Belgrad, } \\
\text { Aktion/Performance } & & & \\
\end{array}$ \\
\hline 1975 & $\begin{array}{l}\text { Glauben Sie nicht, daß } \\
\text { ich eine Amazone bin }\end{array}$ & $\mathrm{P}$ & \begin{tabular}{l}
\multicolumn{3}{c}{ Biennale des Jeunes, Paris, "Frauen und Kunst", } \\
Innsbruck, $\quad$ U. $\quad$ Krinzinger \\
Aktion/Performance
\end{tabular} \\
\hline 1976 & $\begin{array}{l}\text { Reflektionen über die } \\
\text { Geburt der Venus } \\
\text { (Reflections on the Birth } \\
\text { of Venus) }\end{array}$ & $\mathrm{P}, \mathrm{I}$ & $\begin{array}{l}\text { Institute of Contemporary Art, Los Angeles, } \\
\text { Womens Building, Los Angeles, "And/Or", Seattle, } \\
\text { Washington, USA, Anna Focke, Stichting "De Appel", } \\
\text { Amsterdam, Wis Smals, Aachen, Neue Galerie - } \\
\text { Sammlung Ludwig, Dr. W. Becker. Performance und } \\
\text { Installation }\end{array}$ \\
\hline 1977 & $\begin{array}{l}\text { Zehntausend Jahre } \\
\text { habe ich geschlafen }\end{array}$ & $\mathrm{P}, \mathrm{I}$ & $\begin{array}{l}\text { Neue Galerie Aachen - Sammlung Ludwig, Dr. } \\
\text { W. Becker, Performance und Installation, } \\
\text { "Künstlerinnen International", Berlin }\end{array}$ \\
\hline 1977 & $\begin{array}{l}\text { Frauenkultur } \\
\text { Kontaktversuch }\end{array}$ & $\mathrm{P}$ & $\begin{array}{l}\text { Folkwang Museum Essen, Dr. Z. Felix, Stichting } \\
\text { Amazone, Amsterdam, Aktion/Performance }\end{array}$ \\
\hline 1977 & Maifrau & $\mathrm{P}, \mathrm{I}$ & $\begin{array}{l}\text { Studio Galerie Mike Steiner, Berlin, Performance } \\
\text { und Installation }\end{array}$ \\
\hline 1977 & $\begin{array}{l}\text { Frauenkultur } \\
\text { Kontaktversuch }\end{array}$ & & Galerie Heike Curtze, Wien \\
\hline
\end{tabular}




\begin{tabular}{|c|c|c|c|}
\hline 1977 & $\begin{array}{l}\text { Reflektionen über die } \\
\text { Geburt der Venus }\end{array}$ & $P, I$ & $\begin{array}{l}\text { Galerie Oppenheim - Kunstmarkt Bologna, Performance } \\
\text { und Installation }\end{array}$ \\
\hline 1977 & $\begin{array}{l}\text { Venusdepression } \\
\text { Medusaimagination }\end{array}$ & $\mathrm{P}, \mathrm{I}$ & $\begin{array}{l}\text { mit fünf Frauen, Palazzo Strozzi, Florenz, } \\
\text { Performance und Installation } \\
\end{array}$ \\
\hline 1977 & $\begin{array}{l}\text { Köln - Florenz } 1 \text { : } \\
1000\end{array}$ & $\mathrm{P}$ & $\begin{array}{l}\text { Sabbataktion in der Villa Romana, Florenz, } \\
\text { Aktion/Performance }\end{array}$ \\
\hline 1977 & $\begin{array}{l}\text { Herakles - Herkules - } \\
\text { King Kong }\end{array}$ & $I$ & Documenta 6, Kassel, Installation \\
\hline 1977 & $\begin{array}{l}\text { Aktion mit Andrea } \\
\text { (Siebrasse): Frauenlachen }\end{array}$ & $\mathrm{P}$ & Kunstmarkt Köln, Aktion/Performance \\
\hline 1977 & $\begin{array}{l}\text { Aktion mit Andrea: } \\
\text { Frauenzärtlichkeit }\end{array}$ & $\mathrm{P}$ & $\begin{array}{ccc}\text { Galerie Jörg } & \text { Stummer, } & \text { Zürich, } \\
\text { Aktion/Performance } & & \\
\end{array}$ \\
\hline 1978 & $\begin{array}{l}\text { Meine Verwandlung } \\
\text { ist meine Befreiung }\end{array}$ & $\mathrm{P}, \mathrm{I}$ & $\begin{array}{l}\text { Forum Bremer Dom, Bremen, Performance und } \\
\text { Installation }\end{array}$ \\
\hline 1978 & Salto Mortale I & $\mathrm{P}$ & Pro Musica Nova, Bremen, Aktion/Performance \\
\hline 1978 & Salto Mortale & $\mathrm{P}$ & $\begin{array}{l}\text { Kunstverein Freiburg, "Performance by Artists", } \\
\text { Arnhem, Stichting "De Appel", Amsterdam, } \\
\text { Quadrum Galeria, Lissabon, Aktion/Performance }\end{array}$ \\
\hline 1978 & Salto Mortale II & $\mathrm{P}, \mathrm{I}$ & $\begin{array}{c}\text { Bonnefantenmuseum, } \\
\text { Aktion/Performance/Installation }\end{array}$ \\
\hline 1978 & $\begin{array}{l}\text { Meine Macht ist meine } \\
\text { Ohnmacht }\end{array}$ & $\mathrm{P}, \mathrm{I}$ & $\begin{array}{l}\text { Kunstmuseum Düsseldorf, Performance und } \\
\text { Installation }\end{array}$ \\
\hline 1978 & Belladonna & $I$ & Art Basel, Galerie Stampa, Installation \\
\hline 1979 & Tanz um einen Baum & $\mathrm{P}$ & Sydney, Australien, Aktion/Performance \\
\hline 1979 & $\begin{array}{l}\text { Frauenkultur } \\
\text { Kontaktversuch }\end{array}$ & $P$ & $\begin{array}{l}\text { Kunstverein Bonn, National Gallery of Victoria, } \\
\text { Melbourne, Institute of Contemporary Art, Brisbane, } \\
\text { Australien, Aktion/Performance }\end{array}$ \\
\hline 1979 & Konzert im Gewaltakt & $\mathrm{P}$ & $\begin{array}{l}\quad \text { Kunstverein Hamburg, Aktion/Performance, } \\
\text { Künstler Stuttgart (Katalog), Modern Art Galerie } \\
\text { Wien }\end{array}$ \\
\hline 1979 & $\begin{array}{cc}\text { Die } & \text { Einsame } \\
\text { Spaziergängerin } & \\
\end{array}$ & $\mathrm{P}$ & $\begin{array}{l}\text { Folkwang Museum, Essen, Stedelijk Museum, } \\
\text { Amsterdam, Performance }\end{array}$ \\
\hline 1980 & $\begin{array}{l}\text { Narzissen scheiden } \\
\text { weg }\end{array}$ & $\mathrm{P}$ & Frauentheaterfestival, Köln, Aktion/Performance \\
\hline 1980 & $\begin{array}{cc}\text { Keine } & \text { Madame } \\
\text { Pompadour } & \\
\end{array}$ & $\mathrm{P}$ & Centre Pompidou, Paris, Aktion/Performance \\
\hline 1980 & Im Haus der Frauen & $I$ & Kunstverein Bonn, Installation \\
\hline 1980 & Requiem für Mütter & & Wenkenpark Riehen, Basel - Galerie Stampa \\
\hline 1980 & $\begin{array}{l}\text { Psyche, aber sie irrte } \\
\text { gänzlich umher }\end{array}$ & $\mathrm{P}$ & $\begin{array}{cc}\text { Kulturwochen } & \text { Hamburg, } \\
\text { Aktion/Performance } & \\
\end{array}$ \\
\hline 1981 & a-space & & Toronto, Canada \\
\hline 1981 & Spiegelaktion mit Julia & $P$ & Museum Morsbroich, Köln \\
\hline 1981 & $\begin{array}{l}\text { Du bist kleiner - ich bin } \\
\text { größser }\end{array}$ & $P$ & $\begin{array}{l}\text { mit Klaus vom Bruch, Modern Art Galerie Grita } \\
\text { Insabm, Wien, Aktion/Performance }\end{array}$ \\
\hline 1981 & $\begin{array}{c}\text { Denkmal für eine } \\
\text { verzweifelte Frau }\end{array}$ & $I$ & Galerie Magers, Bonn, Installation \\
\hline 1981 & $\begin{array}{l}\text { Judofrauen haben als } \\
\text { Hilfe Boten }\end{array}$ & $\mathrm{P}, \mathrm{I}$ & $\begin{array}{l}\text { Moltkerei Köln, Installation und Performance } \\
\text { (Katalog) }\end{array}$ \\
\hline 1981 & Psyche und Eros & $I$ & $\begin{array}{l}\text { Galerie Stampa - "Art" 1981, Neue Galerie Aachen, } \\
\text { 1982, Videoinstallation }\end{array}$ \\
\hline
\end{tabular}




\begin{tabular}{|c|c|c|c|}
\hline 1981 & $\begin{array}{l}\text { Wechselfran } \quad \mathrm{im} \\
\text { Wechselspiel }\end{array}$ & $P$ & Galerie Grada, Zagreb, Aktion/Performance \\
\hline 1981 & Wechselfrau im Spiegelbild & $P$ & $\begin{array}{c}\text { Museum Schloß Morsbroich, Leverkusen, } \\
\text { Aktion/Performance }\end{array}$ \\
\hline 1982 & $\begin{array}{l}\text { Wer hat Angst vor der } \\
\text { Schwarzen Frau }\end{array}$ & $P$ & Kunstverein Freiburg, Aktion/Performance \\
\hline 1982 & $\begin{array}{l}\text { Begegnung mit Eva und } \\
\text { Adam }\end{array}$ & $P$ & $\begin{array}{l}\text { Westfälischer Kunstverein Münster, Kunstverein Köln, } \\
\text { Aktion/Performance }\end{array}$ \\
\hline 1982 & Schmelzprozesse & $I$ & Forum, Middelburg \\
\hline 1982 & Alles ist Schein & $I$ & Neue Nationalgalerie Berlin \\
\hline 1983 & $\begin{array}{l}\text { Aufwärts zum Mount } \\
\text { Everest }\end{array}$ & $\mathrm{P}, \mathrm{I}$ & Musée Communal des Beaux-Arts, Charleroi \\
\hline 1984 & Die Eulenspieglerin & $\mathrm{P}, \mathrm{I}$ & Kunstverein Hamburg \\
\hline 1984 & $\begin{array}{l}\text {...das Mädchen wächst } \\
\text { weiter }\end{array}$ & $\mathrm{I}$ & Musikfestival Köln \\
\hline 1985 & $\begin{array}{l}\text { Begegnung mit Ewa } \\
\text { und Adam, Part } 10\end{array}$ & $\mathrm{P}$ & Frauenkulturfestival Kopenhagen \\
\hline 1985 & $\begin{array}{l}\text {...das Mädchen wächst } \\
\text { weiter, Part } 2\end{array}$ & $P$ & Museum Weserburg, Bremen \\
\hline 1985 & $\begin{array}{l}\text { Die Eulenspieglerin, das } \\
\text { Mädchen wächst weiter }\end{array}$ & $P$ & Museum van Hedendaagse Kunst, Gent \\
\hline 1985 & Eleven & $P$ & Museum Ludwig, Köln \\
\hline 1985 & 3 Die Eulenspieglerin, Part & $I$ & Museo Gulbenkian, Lissabon \\
\hline 1985 & $\begin{array}{l}\text { Wer hat Angst vor der } \\
\text { Schwarzen Frau }\end{array}$ & $I$ & Nationalgalerie Berlin, Stockholm \\
\hline 1986 & Im Garten der Göttin & $\mathrm{P}, \mathrm{I}$ & Galerie Meier-Hahn, Düsseldorf \\
\hline 1986 & $\begin{array}{l}\text { Aufwärts zum Mount } \\
\text { Everest, Part } 2\end{array}$ & $\mathrm{P}, \mathrm{I}$ & Fachhochschule Köln, München \\
\hline 1986 & $\begin{array}{l}\text { Ana'l Haq - der Wind } \\
\text { meiner Träume }\end{array}$ & ,I,P & $\begin{array}{l}\text { Neue Galerie Sammlung Ludwig Aachen, Tel } \\
\text { Aviv }\end{array}$ \\
\hline 1987 & Alles ist Schein & $P$ & Nationalgalerie Berlin \\
\hline 1987 & Orphelia & $S$ & dokumenta 8, Kassel; London \\
\hline 1987 & Im Haus der Vesta & $P$ & dokumenta 8, Kassel \\
\hline 1987 & Nadabhrama & $I$ & Living Art Galerie, Köln \\
\hline 1987 & Performance-Improvisation & $P$ & Frauenmuseum Bonn \\
\hline 1987 & Ama-Zonas & $I$ & Stampa, Basel; Karlsrube \\
\hline 1988 & $\begin{array}{cc}\text { Or-phelia }- & \text { ein } \\
\text { Transformationsstück } & \\
\end{array}$ & $\mathrm{P}$ & Städtische Galerie im Prinz-Max-Palais, Karlsruhe \\
\hline 1988 & $\begin{array}{l}\text { Zenkocher - energetisches } \\
\text { Phänomen }\end{array}$ & $S$ & Made in Cologne, Blaue Halle, Köln \\
\hline 1988 & $\begin{array}{l}\text { The Image of } \\
\text { Madness/ Dance for a } \\
\text { mad House }\end{array}$ & $\mathrm{P}$ & Edge 88, St. John's Cathedral, London \\
\hline 1989 & $\begin{array}{l}\text { Ein Moment aus dem } \\
\text { Leben des chinesischen Malers } \\
\text { HUEM AY }\end{array}$ & $S$ & Galerie D. Bucbholy, Köln \\
\hline 1989 & $\begin{array}{l}\text { Anal Haq - der letzte } \\
\text { Part }\end{array}$ & $P$ & Moltkerei Köln \\
\hline 1989 & Or-phelia, III, das & $\mathrm{I}$ & St. Peter Kirche Köln \\
\hline
\end{tabular}




\begin{tabular}{|c|c|c|c|}
\hline & Osterstück & & \\
\hline 1989 & Der Matriarchenraum & $P$ & Frauenmuseum Bonn \\
\hline 1989 & $\begin{array}{l}\text { Wie ein Phönix aus der } \\
\text { Asche }\end{array}$ & $P, I$ & Art Gallery of Ontario, Toronto \\
\hline 1989 & $\begin{array}{r}\text { Vier improvisierte } \\
\text { Sequenzen }\end{array}$ & $P$ & HBK Münster \\
\hline 1989 & $\begin{array}{l}\text { Herzpendel - energetisches } \\
\text { Phänomen }\end{array}$ & $I$ & Ausstellung Andernorts, Nürnberg \\
\hline 1990 & $\begin{array}{l}\text { Wie ein Phoenix aus der } \\
\text { Asche }\end{array}$ & $P$ & \\
\hline 1990 & $\begin{array}{c}H U \quad E M \quad A Y \quad- \\
\text { Transformation }\end{array}$ & $I$ & Stadtgalerie Quakenbrück \\
\hline 1990 & Sonnenspiele & $P$ & Solarwochen Dillingen \\
\hline 1990 & Isabel im Wald & $S$ & \\
\hline 1990 & $\begin{array}{c}\text { Requiem für eine } \\
\text { Eiche (3-teilig) }\end{array}$ & $\mathrm{S}$ & \\
\hline 1990 & Isabel im Wald & $\mathrm{S}$ & Art Gallery of New South Wales, Sydney \\
\hline 1991 & Die Erdenfahrt & $\mathrm{P}$ & Stadtgalerie Saarbrücken \\
\hline 1991 & Zenkocher & $\mathrm{S}$ & \\
\hline 1992 & $\begin{array}{l}\text { Wie ein Phönix aus } \\
\text { der Asche }\end{array}$ & $\mathrm{P}$ & Toronto, Gallery of South Wales \\
\hline 1993 & Erdenlichter - Dim Lights & $S$ & \\
\hline 1993 & $\begin{array}{l}\text { Wie ein Phönix aus } \\
\text { der Asche }\end{array}$ & $\mathrm{P}$ & Barcelona, Santa Maria Kulturpalast \\
\hline 1994 & $\begin{array}{l}\text { Das Bild der Frau in } \\
\text { der } \\
\text { Version } 1\end{array}$ & $\mathrm{I}$ & Haus der Geschichte, Bonn \\
\hline 1994 & $\begin{array}{l}\text { Das Bild der Frau in } \\
\text { der Nachkriegszeit, } \\
\text { Version } 2\end{array}$ & $\mathrm{I}$ & \\
\hline 1994 & Hildegard Walk & $\mathrm{I}$ & Schloss, Bad Arolsen \\
\hline 1995 & Das Eiserne Zeitalter & $\mathrm{S}$ & \\
\hline 1995 & Über den Tod & $\mathrm{S}$ & St. Petri-Kirche Dortmund \\
\hline 1995 & Über die Engel 1 & $\mathrm{P}$ & Bollwerk Fribourg \\
\hline 1996 & $\begin{array}{l}\text { Über die Engel } 2 \\
\text { (Agora - Platz für Frauen) }\end{array}$ & $\mathrm{P}$ & Kreuzkirche Hannover \\
\hline 1996 & $\begin{array}{l}\text { Die Schlacht der } \\
\text { Bäume }\end{array}$ & $\mathrm{I}$ & Ehemaliges Militärgelände Oberolmer Wald \\
\hline 1996 & Last Call für Engel & $\mathrm{S}$ & $\begin{array}{l}\begin{array}{l}\text { Kunstmuseum Heidenheim, Kunstverein } \\
\text { Heilbronn }\end{array} \\
\end{array}$ \\
\hline 1997 & Über die Engel 3 & $\mathrm{P}$ & Martinskirche Nienburg Weser \\
\hline 1997 & $\begin{array}{c}\text { Im Palast der } \\
\text { Neugeborenen }\end{array}$ & I & Hamburger Bahnhof, Berlin \\
\hline 2000 & $\begin{array}{l}\text { Das Demeterprojekt - } \\
\text { Milleniumsfrauen }\end{array}$ & $\mathrm{P}$ & Deutscher Pavillon, Expo, Hannover \\
\hline 2001 & Die Reise ins Nirwana & $\mathrm{I}$ & \\
\hline
\end{tabular}


c) Fotoarbeiten

(Auswahl, der im Verlauf der Arbeit erwähnten Fotoarbeiten, für eine weitere Auflistung siehe

Glüher 2005, S. 231)

1972/73 Serie: Eine verheiratete Frau (A married woman)

A. Eine Frau in der Küche (Married Woman in her kitchen)

5 Fotoarbeiten $(30 x 40, \mathrm{~s} / \mathrm{w})$ Auflage 5

B. Eine verheiratete Frau (A married Woman)

1 Fotoarbeit (30x40, s/w) Auflage 15

C. Aspekte einer verheirateten Frau (Aspects of a married Woman)

8 Fotomontagen $(2 \times 30 / 40, \mathrm{~s} / \mathrm{w})$

D. Hauben für eine verheiratete Frau

20 Fotoarbeiten $(30 x 40, \mathrm{~s} / \mathrm{w})$ Auflage 3

E. Hauben - Fotoobjekte

4 Fotoarbeiten $(30 \times 40$, color) Auflage 2

1976 Female Energy Change (Weiblicher Energie-Austausch)

Venus, Minerva, Supergirl

3 Fotomontagen $(50 x 60, \mathrm{~s} / \mathrm{w})$ Auflage 3

1976 Tarot

9 Fotomontagen (30x40, color) Auflage 2

1976 Aphrodite TV

40 Fotoarbeiten $\&$ Text $(30 x 40$, s/w) Auflage 2

$1976 \quad$ Cal-Girls

16 Fotoarbeiten (30x40, color \&s/w) Auflage 2

1978 Titelfoto Emma 1978, Nr. 5

1978 Titelfoto Emma 1978, Nr. 8

$>$ Collage der Sterntitel

1978 Titelfoto Emma 1978, Nr. 12

$>$ Fotocollage s/w

1979 Titelfoto Emma 1979, Nr. 1 ?

$>$ Nina Hagen

1979 Titelfoto Emma 1979, Nr. 11

"Uns drückt der Schuh" > Frauenbeine mit roten Pumps

1980 Titelcollage Emma 1980, Nr. 1

$>$ "So denken Frauen heute"

1980 Titelfoto Emma 1980, Nr. 2

$>$ Paar 
1980 Titelfoto Emma 1980, Nr. 3

$>$ Tochter und Freundin in Florenz

$>$ kurzer Text zum Foto auf S. 2

1980 Titelfoto Emma 1980, Nr. 4

1980 Titelfoto Emma 1980, Nr. 6

$>$ Collage Gemüsekopf

1980 Titelfoto Emma 1980, Nr. 8

1980 Titelfoto Emma 1980, Nr. 9

1980 Titelfoto Emma 1980, Nr. 10

(zusammen mit Anne Kaute)

Fotoserien aus den 1990ern mit digitaler Überarbeitung:

1994 Das Bild der Frau in der Nachkriegszeit

1995 Über den Tod

1997 Dance in a House of Madness, Fotoobjekt 


\section{Literatur}

Nach AutorInnen:

Wenn bekannt 1. Autor, sonst 2. Herausgeber, sonst 3. Titel (Titel sind ohne Artikel alphabetisch einsortiert)

Adelman, Irene, Art Hats, Wiesbaden 1983

Aichmayr, Michael Josef, Der Symbolgehalt der Eulenspiegel-Figur im Kontext der europäischen Narren- und Schelmenliteratur. Göppingen 1991

Almhofer, Edith, Performance Art. Die Kunst zu leben. Wien 1986

Andernorts, Galerie Blauer und Bloessl, Ausst. 4. Mai - 24. Juni 1990, Nürnberg 1990

Anders, Ann (Hg.), Autonome Frauen. Schlüsseltexte der Neuen Frauenbewegung seit 1968. Frankfurt 1988

Alphen, von, Oscar u.a. (Hg.), Feministische Kunst internationaal, Den Haag 1978

Aureum vellus, oder, Guldin Schatz und Kunst-Kammer : darinnen der aller fürnemisten, fürtreffenlichsten, ausserlesenesten, herrlichisten und bewehrtesten Auctorum Schrifften und Bücher ... / von ... Salomone Trissmosino ... in sonderbare underschiedliche Tractätlein disponiert und in das Teutsch gebracht ... an Tag geben. Hamburg : Liebezeit, 1708. Mikrofilm von German baroque literature, Harold Jantz collection ; no. 285, reel 50. New Haven: Research Publications, 1973

Bagdadi, Nadja und Irene Bazinger (Hg.), Ewig lockt das Weib? Bestandsaufnahme und Perspektiven feministischer Theorie und Performance.

Baldessari: while something is happening here, something else is happening there; works 1988-1999. [Kat. Ausstellung Sprengelmuseum Hannover 26.9.1999 - 2.1.2000 etc.] mit Texten von Meg

Cranston, Diedrich Diedrichsen und Thomas Weski. Köln 1999

Barta, Ilsebill (Hg.) Frauen, Bilder, Männer, Mythen. Berlin 1987

Barthes, Roland, Die helle Kammer. Bemerkungen zur Photographie. Frankfurt am Main 1985

Barthes, Roland, Fragmente einer Sprache der Liebe. Auszüge. Frankfurt am Main 1984

Battcock, Gregory u.a., The Art of Performance: A critical Anthology. New York 1984

Battersby, Christine, Gender and Genius: Toward a Feminist Aesthetics. Southhampton 1989

Battistini, Matilde, Symbole und Allegorien. (Aus dem Ital. Suzanne Fischer). Bildlexikon der Kunst 3. Berlin 2003

Baudrillard, Jean, Videowelt und fraktales Subjekt (www.aec.ar/fest/fest88/baud/baud.rtf)

Baumgart, Silvia u.a. (Hg.), Denkräume zwischen Kunst und Wissenschaft. Berlin 1993

Beckers, Anita (Hg.), Life is art enough: Performance und erweiterte Kunstformen; eine Annäherung. [Vorträge, Diskussionen, Sonderbeiträge: bearb. von Inge Lorenz. Mit Beitr. von Elisabeth Jappe ...] (Symposion ; (Darmstadt) : 1994.11.10-12), Köln 1998

Benglis, Lynda, Female Sensibility. (VHS) Chicago 1974

Benjamin, Walter, Das Kunstwerk im Zeitalter seiner Reproduzierbarkeit. Drei Studien zur Kunstsoziologie. Frankfurt am Main 1966

Bellinger, Gerhard J., Knaurs Lexikon der Mythologie: 3100 Stichwörter zu den Mythen aller Völker von den Anfängen bis zur Gegenwart. München 1989

Below, Irene, Die Utopie der neuen Frau setzt die Archäologie der alten voraus: Frauenforschung in Kunstwissenschaft und künstlerischen Disziplinen. In: Frauen 
Kunstwissenschaft 11/1991, S. 24-40

Belting, Hans, Die Ausstellung von Kulturen. In: Wolf Lepenies (Hg.), Wissenschaftskolleg - Institute for Advanced Study Berlin. Berlin 1994/95

Belting, Hans, Gary Hill und das Alphabet der Bilder. In: Theodora Vischer (Hg.), Gary Hill. Arbeit am Video. Stuttgart 1995. S. 43-70

Belting, Hans, Das unsichtbare Meisterwerk. Die modernen Mythen der Kunst. München 1998

Berger, Renate, Malerinnen auf dem Weg ins 20. Jahrhundert. Köln 1982

Berger, Renate, Der Garten der Lüste. Köln 1985

Berger, Renate, Ikonoklasmus: Frauen oder Genusforschung in der Kunstwissenschaft. AG Interdisziplinäre Frauenforschung und -studie (Hg.). Pfaffenweiler 1990

Berger, Renate, Zwischen Leben und Tod: Zur Mutterimago bei Niki de St. Phalle, Ulrike Rosenbach, Mary Kelly und Annegret Soltau. In: Möhrmann, Renate (Hg.), Verklärt, verkitscht, vergessen: Die Mutter als ästhetische Figur. Stuttgart 1996

Bergier, Jean-Francois, Zwischen Wahn, Glaube und Wissenschaft. Magie, astrologie, Alchemie und Wissenschaftsgeschichte. Zürich 1988

Bermudez, Jose Luis, The Body and the Self. Cambridge 1995

Beuys, Barbara, Denn ich bin krank vor Liebe. Das Leben der Hildegard von Bingen. München 2001

Bhagwan Shree Rajneesh, Mein Weg: Der Weg der weißen Wolke. (Erstausgabe 1974) München 1988

Billeta, Erika (Hg.), Mythos und Ritual in der Kunst der 70er Jahre. Hamburg 1981

Börnreuter, Andrea und Peter Klaus Schuster (Hg.), Das XX. Jahrhundert. Kunst, Kultur, Politik und Gesellschaft in Deutschland. Köln 1999

Bovenschen, Silvia (Hg.), Aus der Zeit der Verzweiflung. Frankfurt 1977

Bovenschen, Silvia und Peter Gorsen, Frauen, Kunst und Kulturgeschichte. Institut für Kultur und Ästhetik (Hg.). Kronberg 1976

Breton 2001, Die Manifeste des Surrealismus. André Breton. (1. Auflage 1924). 10. Aufl. Reinbek bei Hamburg 2001

Bronfen, Elisabeth, Nur über ihre Leiche. Tod, Weiblichkeit und Ästhetik. München 1994

Brook, Barbara. Feminist Perspectives on the body. Essex 1999

Broude, Norma and Mary D. Garrard (Hg.), The power of feminist art : the American movement of the 1970s, history and impact. New York 1994

Büchner, Rainer, Grundsteine Kunst 3. Schülerarbeitsbuch für den Kunstunterricht der Klassen 9 und 10 an allgemeinbildenden Schulen. Stuttgart 1995.

Buschmann, Gerd, Call God: Gebetshaltungen in Werbeanzeigen. Materialien für einen alternativen Zugang zum Thema Gebet im Religionsunterricht (08.08.2002) http://www.theophil-online.de/praxis/mfpraxi6.htm

Buschmann, Renate, between in der Kunsthalle Düsseldorf zwischen 1969 und 1973. Die Chronik einer Nicht-Ausstellung. Köln 2002

Butin, Hubertus (Hg.), DuMonts Begriffslexikon zur zeitgenössischen Kunst. Köln 2002

Butler, Judith, Das Unbehagen der Geschlechter. Frankfurt am Main 199

Caianiello, Tiziana, Der Lichtraum (Hommage à Fontana) und das Creamcheese im museum kunst palast : zur Musealisierung der Düsseldorfer Kunstszene der 1960er Jahre. Bielefeld 2005

Carduff, Corinna und Joanna Pfaff-Czarnecke (Hg.), Rituale heute. Theorien Kontroversen - Entwürfe. Berlin 1999

Carlson, Marvin, Performance. A critical introduction. London, New York 1996

Chadwick, Whitney, Women, Art and Society. London 1991

Chicago, Judy, Beyond the Flower: The autobiography of a feminist artist. New York 1996 
Christiansen, Andrea, Mudras. München 2003

Claassen-Schmal, Barbara, Spekulum. Frauenkünste, Geburtstage, Krankheitsbilder. Ausstellung in der Weserburg Bremen 3.-30.10.1983. Berlin 1983

Clarke, Peter B., The New Evangelists: Recruitment, Method and Aims of New Religious Movements. London 1987

Cocalis, Susan, „Persönlicher Wirrwarr, fortdauernde Gefühle“: Performance-Kunst als weibliche Darstellungsform in Deutschland und den USA. In: Stephan, Inge und Sigrid Weigel (Hg.), Weiblichkeit und Avantgarde, Berlin/Hamburg 1987, S. 5-39

Cordes, Mechthild, Die ungelöste Frauenfrage. Eine Einführung in die feministische Theorie

Cottingham, Laura, How many bad Feminists does it take to change a light bulb, New York 1994

Dahm, Ulrike, Opfer und Ritus. Kommunikationstheoretische Untersuchungen. Marburg 2003.

Dammann, Ernst, Grundriß der Religionsgeschichte. (3. Aufl.) Stuttgart u.a. 1988

Daniels, Dieter und Rudolf Frieling, Medien Kunst Aktion. Die 60er und 70er Jahre in Deutschland. (Mit CD Rom) Wien/ New York 1997

Dech, Jula (Hg.), Frauen Künste: Kunst und Öffentlichkeit. Unna 1985

Decker, Edith, Von der Aktions- zur Videokunst. Die Ausweitung des Werkbegriffs. In: Funkkolleg Moderne Kunst, 26. Kollegstunde, Saarländischer Rundfunk Mai 1990

Decker, Edith und Wulf Herzogenrath (Hg.), Video Skulptur, Kunstverein Köln,1989

Dialogo, Sobre Arte Contemporanea. Kat. Museo Gulbenkian, (First exhibition - dialogue on contemporary art in Europe.Kat. Museum moderner Kunst Wien, Museum van hadendaagse Kunst Gand und staatliche Museen Berlin), Lissabon 1985

Dolff-Bonekämper, Gabi und Kirsten Fast, Annegret Friedrich, Der feministische Ansatz: Zur Korrektur des herrschenden Blicks. In: Funkkolleg Kunst, Studienbegleitbrief 12, Weinheim/Basel 1985, S. 121-138

Dünnebier, Anna und Gert v. Paczensky, Das bewegte Leben der Alice Schwarzer. München 1999

Durland, Steven (Hg.), The citizen Artist: 20 Years of Art in the Public Arena: An Anthology from High Performance Magazine 1978-1998. By Linda Friye Burnham, 1998

Duerr, Hans Peter, Traumzeit. Über die Grenze zwischen Wildnis und Zivilisation. Frankfurt am Main 1978

Dworkin, Andrea, Pornographie. Männer beherrschen Frauen. Köln 1987

Eco, Umberto, Über Spiegel und andere Phänomene. München 1988

Eco, Umberto, Das offene Kunstwerk, Frankfurt 1973

Eco, Umberto, Einführung in die Semiotik. Autorisierte dt. Ausgabe, 7. Aufl. (Erstveröffentlichung 1972). München 1991

Ecker, Gisela (Hg.), Feminist Aesthetics. London 1985

Eiblmayr, Silvia (Hg.), Die verletzte Diva: Hysterie und Körper, Technik in der Kunst des

20. Jahrhunderts. Köln 2000

Eiblmayr, Silvia, Die Frau als Bild: Der weibliche Körper in der Kunst des 20. Jahrhunderts. Berlin 1993

Eiblmayr, Silvia und Valie Export (Hg.), Kunst mit Eigen-Sinn: aktuelle Kunst von Frauen. München 1985

Eichenbaum, Luise und Susie Orbach, Feministische Psychotherapie. Auf der Suche nach einem neuen Selbstverständnis der Frau. München 1984

Eliade, Mircea, Mephistopheles und der Androgyn, Frankfurt am Main 1999

Eliade, Mircea, Ewige Bilder und Sinnbilder. Frankfurt am Main 1998

Eliade, Mircea und Ioan P. Culianu, Handbuch der Religionen. Frankfurt am Main 1995 
Engelbach, Barbara, Zwischen Body Art und Videokunst. Körper und Video in der Aktionskunst um 1970. München 2001

Erdheim, Mario, Ritual und Reflexion. In: Carduff/ Pfaff-Czarnecke, Rituale heute. Theorien - Kontroversen - Entwürfe. Berlin 1999, S. 165-178

Evans, Mary (Hg.), Feminism. Critical Concepts in literary and cultural studies. London 2001

Export, Valie, Das Reale und sein Double: der Körper. Bern 1987

Feldenkrais, Moshé, Bewußtheit durch Bewegung. Frankfurt/M 1978

Fine, Elsa Honig, Women \& Art. A History of Women Painters and Sculptors from the Renaissance to the 20th Century. Montclair/ London 1978

[The] First Generation: Women and Video, 1970-75. Essays by JoAnn Hanley and AnnSargent Wooster. New York 1993

Fischer, Konrad, Jürgen Harten und Hans Strelow, Prospect 71. Projection. Düsseldorf 1971

Fischer-Lichte, Erika, Ritualität und Grenze. In: Fischer-Lichte, Erika, Christian Horn u.a. (Hg), Ritualität und Grenze. Tübingen und Basel 2003, S. 11-30

Fischer, Konrad, Jürgen Harten und Hans Strelow, Prospekt 71: Projection. [Anläßl. d. Ausst. in d. Städt. Kunsthalle Düsseldorf]. Düsseldorf 1971

Fischer, Lothar, Max Ernst. Reinbek bei Hamburg 1969

Fisher Stoling, Susan, Künstlerinnen. The national Museum of Women in the Arts, München 1996

Florence, Penny und Dee Reynolds. Feminist subjects, multi-media: cultural methodologies. Manchester 1995

Folie, Dabine und Michael Glasmeier, Tableaux vivants - lebende Bilder und Attitüden in Fotographie, Film und Video. Katalog Kunsthalle Wien. Wien 2002

Förster, Jutta, Kunst von Frauen in Bremen. Bremen 1991

Franzen, Brigitte (Hg.), Himmel und Erde, Frauen in Gewaltverhältnissen, Marburg 1995

Frau - Raum - Zeit. Karl Hofer Symposion 1982. (Red.: Reiner E. Klemke). Berlin 1983

Frembgen, Jürgen, Derwische. Gelebter Sufismus. Wandernde Mystiker und Asketen im islamischen Orient. Köln 1993

Friedel, Helmut, Video-Narziss - Das Neue Selbstbildnis. In: Video by Artists 2. Toronto 1986; auch in: Herzogenrath 1982

Frieling, Rudolf und Wulf Herzogenrath (Hg.), 40jahrevideokunst.de - Teil 1. Digitales Erbe: Videokunst in Deutschland von 1963 bis heute. Ostfildern 2006

Frieling, Rudolf und Dieter Daniels, Medien, Kunst, Aktion. Die 60er und 70er Jahre in

Deutschland. Wien/ New York 1997

Frieling, Rudolf und Gerd Schwandner, Internationaler Videokunstpreis, ZKM Karlsruhe 1997

Frohne, Ursula (Hg.), Video cult-ures : multimediale Installationen der 90er Jahre ; [6.5. -

29.8.1999, eine Ausstellung des Museums für Neue Kunst, ZKM] Karlsruhe 1999

Froning, Hubertus, Museum Folkwang Essen. Braunschweig 1983

Frova, Antonio, La villa dei misteri a Pompei. Mailand 1965

Frutiger, Adrian, Der Mensch und seine Zeichen. Wiesbaden 2006

Gabriele Münter Preis: 40 Künstlerinnen. Preisträgerin Valie Export. Frauenmuseum Bonn 1997

Galerie Magers (Hg.), Frauen machen Kunst. 8. Dez. 1976 - 31. Jan. 1977, Bonn 1976

Garaudy, Roger, Der letzte Ausweg: Feminisierung der Gesellschaft, Olten 1982

Gasper, Hans (Hg.), Lexikon der Sekten, Sondergruppen und Weltanschauungen: Fakten, Hintergründe, Klärungen. Freiburg im Breisgau 1990

Gast, Wolfgang, Film und Literatur; Grundbuch; Einführung in Begriffe und Methoden der Filmanalyse. Frankfurt am Main 1993 
Gebelein, Helmut, Alchemie. München 1991

Geiss, Immanuel, Geschichte griffbereit. Dortmund 1988

Gieseke, Frank und Albert Markert, Flieger, Filz und Vaterland. Eine erweiterte BeuysBiografie. Berlin 1996

Glüher, Gerhard (Hg.), Ulrike Rosenbach. Wege zur Medienkunst 1969-2004. Köln 2005

Goldberg, RoseLee, Performance. Live Art since the 60s. London 1998

Goldberg, RoseLee, Performance Art. From Futurism to the Present. London 1988

Gombrich, Ernst, Die Geschichte der Kunst. Berlin 1992

Goldner, Colin, Die Psycho-Szene. Erw. und völlig überarb. Neuaufl., Lizenzausg. Aschaffenburg 2000

Gorsen, Peter, Das Bild Pygmalions. Kunstsoziologische Essays. Reinbek bei Hamburg 1969

Greer, Germaine, Das unterdrückte Talent. Die Rolle der Frauen in der bildenden Kunst. Berlin 1980

Grön, Ortrud, Pflück dir den Traum vom Baum der Erkenntnis.Träume im Spiegel von

Naturgesetzen; ein Lehrbuch für die Arbeit mit Träumen. Bergisch Gladbach 2007

Gröning, Karl, Body Decoration, a world survey of body art. New York 1998

Groos, Ulrike, Ready to shoot: Fernsehgalerie Gerry Schum, Videogalerie Schum. Köln 2003

Grosz, Elisabeth, Sexual subversions. St. Leonard 1989

Gruber, Bettina und Maria Vedder (Hg.), Kunst und Video, Köln 1983

Grün, Anselm, 50 Helfer in der Not. Die Heiligen für das Leben entdecken. Freiburg u.a. 2002

Grüterich, Marlies, Metamorphosen zwischen Natur- und Kulturkreisen. In: Romain, Lothar und Detlef Bluemler (Hg.), Künstler - Kritisches Lexikon der Gegenwartskunst, Ulrike Rosenbach, Ausgabe 6, München 1989

Guenter, Andrea, Politische Theorie und sexuelle Differenz. Feministische Praxis und Ordnung der Mutter. Königstein/Taunus 1998

Haage, Bernhard Dietrich, Alchemie im Mittelalter. Ideen und Bilder - von Zosimos bis Paracelsus. Zürich 1996

Haarmann, Harald, Universalgeschichte der Schrift. Frankfurt 1990

Haase, Amine, Gespräche mit Künstlern. Köln 1981

Hampe, Ruth, Metamorphosen des Bildlichen. Bremen 1999

Hanhardt, John G., Video Art - Expanded Forms. New York 1988

Hanhardt, John G., Video Culture. New York 1986

Haustein, Lydia, Videokunst. München 2003

HBKsaar (Hg.), 10 Jahre Medienkunst. Saarbrücken 2000

Heise, Gabriele, Ausgestiegen? Frankfurt am Main 1984

Heller, Nancy G., Künstlerinnen von der Renaissance bis zur Gegenwart. Dt. von Gisela Haßmann, Köln 1989

Heller, Nancy G., Women Artists. An illustrated History. New York 1987

Hering, Heide, Weibs-Bilder. Zeugnisse zum öffentlichen Ansehen der Frau. Reinbek bei Hamburg 1979

Herzogenrath, Wulf u.a. (Hg.), TV Kultur. Das Fernsehen in der Kunst seit 1879. Dresden 1997

Herzogenrath, Wulf, Videoskulptur in Deutschland seit 1963. Institut für Auslandsbeziehungen. Stuttgart 1995

Herzogenrath, Wulf, Videokunst. Kunsthalle Bremen 1995

Herzogenrath, Wulf, Mehr als Malerei. Vom Bauhaus zur Video-Skulptur. Regensburg 1994 
Herzogenrath, Wulf und Stephan von Wiese (Hg.), Rheingold, 40 Künstler aus Köln und Düsseldorf. Köln 1985

Herzogenrath, Wulf (Hg.), Videokunst in Deutschland 1963-1982, Kunstverein. Köln 1982

Herzogenrath, Wulf (Hg.), Videokunst. Ein neues Medium - aber kein neuer Stil. Stuttgart 1982 (a)

Herzogenrath, Wulf (Hg.), Künstler verwenden Fotografie - heute. Institut für Auslandsbeziehungen. Stuttgart 1982 (b)

Herzogenrath, Wulf, Video Art in West Germany. From reproduction to medium of concious creativity. In: Studio International 191. Mai/Juni 1976, S. 217-222

Hess, Thomas B. und E. Parker (Hg.), Women's Lib, Women Artists and AM History, in: Art News. Jan. 1971

Heubach, Wolfram, Die 60er Jahre. Kölns Weg zur Kunstmetropole. Vom Happening zum Kunstmarkt. Köln 1986

Hiebel, Hans H., Strukturale Psychoanalyse und Literatur (Jacques Lacan). In: KlausMichael Bogdal (Hg.) Neue Literaturtheorien. Eine Einführung. Opladen 1990, S.59

Hirner, René (Hg.), Vom Holzschnitt zum Internet. Kunstmuseum Heidenheim 1997

Hirschberg, Walter (Hg.), Neues Wörterbuch der Völkerkunde. Berlin 1988

Hoffmann-Curtis, Kathrin und Silke Wenk (Hg.), Mythen von Autorschaft und Weiblichkeit im 20. Jahrhundert. Marburg 1997

Hofmann, Werner, Die Moderne im Rückspiegel. Hauptwege der Kunstgeschichte.

München 1998

Hofmann, Werner (Hg.), Eva und die Zukunft. Das Bild der Frau seit der französischen Revolution. München 1986

Hohenberger, Eva und Karin Jurschik (Hg.), Blaue Wunder. Neue Filme und Videos von Frauen 1984 -1994. Hamburg 1994

Honisch, Dieter, 1945-1985: Kunst in der Bundesrepublik. Nationalgalerie Berlin. Berlin 1985

Honisch, Dieter, Junge Kunst in Deutschland, Kat. Nationalgalerie Berlin und Kölnischer Kunstverein. Berlin 1983

Honnef, Klaus (Hg.), Made in Cologne. Künstler aus Köln in der DuMont Kunsthalle. Ausstellung 10. Sept. - 16. Nov. 1988. Köln 1988

Hughes-Freeland, Felicia (Hg.), Ritual, Performance, Media. London und New York 1998

Hutcheon, Linda, A Poetics of Postmodernism. History, theory, fiction. New York 1988

Irigaray, Luce, Another Cause-Castration. In: Warhol, Robyn R. und Diane Price Herndl (Hg.), Feminism. An Anthology of literary theory and criticism. New Brunswick 1997

Irigary, Luce, Körper an Körper mit der Mutter. In: dies., Zur Geschlechterdifferenz. Interviews und Vorträge. Wien 1987

Irigary, Luce, Das Geschlecht, das nicht eins ist. Berlin 1979

Issak, Jo Anna, Feminism \& Contemporary Art. The Revolutionary Power of Women's Laughter. London/New York 1996

Jahn, Johannes, Wörterbuch der Kunst. Stuttgart 1983

Jappe, Elisabeth (Hg.), Performance Art, Köln 1995

Jappe, Elisabeth, Performance, Ritual, Prozess. Handbuch der Aktionskunst in Europa. New York 1993

Jappe, Georg, Ressource Kunst: Die Elemente neu gesehen, Akademie der Künste Berlin, Köln 1989

Jappe, Georg, Performance in Germany: An Introduction. In: Studio International 192, Juli-August 1976

Jászai, Geza, Veröffentlichungen des Landschaftsverband Westfalen Lippe, Münster 1983

Jensen, Jens Christian, Videokunst. Katalog der Sammlung Videokunst aus dem Besitz der 
Kunsthalle Kiel. Kiel 1988

Jochimsen, Margarethe, Frauenforschung und Kunst ... ; 1 ; Das Verhältnis der Geschlechter : Katalog zur Ausstellung ; [die Ausstellung "Das Verhältnis der Geschlechter findet anläßlich des Symposiums "Frauenforschung und Kunst von Frauen - Feministische Beiträge zu einer Erneuerung von Wissenschaft und Kunst", 16. - 18. Februar 1989, statt] Bonn 1990

Jones, Amelia, Body Art. Performing the subject. Mineapolis/ London 1998

Jung, Carl Gustav, Grundwerk. (hrsg. In 9 Bänden von Helmut Barz, Ursula Baumgardt u.a.), Bd. 6 Erlösungsvorstellungen in der Alchemie. Psychologie und Alchemie 2. Olten und Freiburg 1989

Jung, Carl Gustav, Psychologie und Alchemie. (1944) Zürich 1978

Jung, Carl Gustav und Karl Kerenyi, Einführung in das Wesen der Mythologie. Das göttliche Kind, das göttliche Mädchen (1941). Hildesheim 1980

Karow, Yvonne, Bhagwan-Bewegung und Vereinigungskirche. Religions- und selbstverständnis der Sannyasins und der Munies. Stuttgart u.a. 1990

Kat. Amsterdam 1980, Ulrike Rosenbach \& Valie Export. Ausstellung Stedelijk Museum

Amsterdam 1980

Kat. Arolsen 1997a, Made for Arolsen, Ulrike Rosenbach / (Museum Bad Arolsen und Museumsverein, Bad Arolsen. Mit einem Text von Gerhard Glüher. Katalog: Gerhard Glüher und Birgit Kümmel). Bad Arolsen 1997

Kat. Arolsen 1997b, Made for Arolsen, drei Künstlerinnen. Ausstellung 6. Sept. bis 26. Okt. 1997. Text: Gerhard Glüher. Katalog: Gerhard Glüher und Birgit Künel. Museum Schloss Arolsen. Bad Arolsen 1997

Kat. Berlin 2004, John Baldessari : [somewhere between almost right and not quite (with orange)] ; [anlässlich der Ausstellung „John Baldessari: Somewhere Between Almost Right and Not Quite (With Orange)“, Deutsche Guggenheim, 30. Oktober 2004 - 16. Januar 2005] / Deutsche Guggenheim. [Organisiert von Tracey Bashkoff] OstfildernRuit 2004

Kat. Berlin 2003a, Louise Bourgeois, - intime Abstraktionen. Stammer, Beatrice E.

(H.),[Anlässlich der Ausstellung „Louise Bourgeois - Intime Abstraktionen“ , 4. Juni bis 27. Juli 2003, Akademie der Künste Berlin] Berlin 2003

Kat. Berlin 2003b, Valie Export: mediale Anagramme. [Anlässlich der gleichnamigen Ausstellung „Mediale Anagramme Valie Export“, die von der NGBK in Kooperation mit der Akademie der Künste vom 18. Januar bis 9. März 2003 in der Akademie der Künste gezeigt wird] [Neue Gesellschaft für Bildende Kunst (NGBK) (Hg.). Katalogredaktion: Hildtrud Ebert] Berlin 2003

Kat. Berlin 1986, Androgyn: Sehnsucht nach Vollkommenheit / (Neuer Berliner

Kunstverein. Ausstellung und Katalog: Ursula Prinz. Mitarbeit: Tino Bierling) Berlin 1986

Kat. Berlin 1977, Künstlerinnen international 1877-1977. (Zusammengestellt und herausgegeben von AG Frauen in der Kunst) Berlin 1977

Kat. Bonn 2000, Rewind to the Future. Bonn, Berlin 2000

Kat. Bonn 1999, Zehnder, Frank Günter (Hg.), Ulrike Rosenbach, Last Call für Engel. Eine Ausstellung im rheinischen Landesmuseum Bonn, 26. August bis 31. Oktober 1999, Bonn 1999

Kat. Bonn 1987, Self. Neue Selbstbildnisse von Frauen. Fotografien. Frauenmuseum. Bonn 1987

Kat. Bonn 1976, Frauen machen Kunst (Ausstellung 8. Dezember 1976 - 31. Januar, Galerie Magers; Katalogred.: Philomene Magers und Margarethe Jochimsen), Bonn 1976

Kat. Charleroi 1983, Art Videos: retrospectives et perspectives. Konzeption und Katalog: 
Laurent Busine. Palais des Beaux-Arts, Charleroi 1983

Kat. Dortmund 1995, Ulrike Rosenbach. (hrsg. von Silke Konieczny und Michael Küstermann für „Kirche in der City“ und die „Arbeitsstelle Kirche und Kultur"). Dortmund 1995

Kat. Düsseldorf 2003, Laurie Anderson - the record of time: sound in the work of Laurie Anderson. (Redaktion Andreas Zeisig). Düsseldorf 2003

Kat. Göttingen 1998, Stadt Göttingen und Ursula Schönewald (Hg.), Ulrike Rosenbach: Die Einsame Spaziergängerin. Altes Rathaus Göttingen 1998, Göttingen 1998

Kat. Hannover 2000, Baldessari: while something is happening here, something else is happening there: works 1988-1999. Texte von Meg Cranston, Dietrich Diederichsen und Thomas Weski. Köln 1999

Kat. Hannover 1990, Joseph Beuys: Eine innere Mongolei. Dschingis Khan, Schamanen, Aktricen. Hannover u.a. 1990

Kat. Hannover 1982, Momentbild. Künstlerphotographie. Hannover 1982

Kat. Heidenheim 1996, Hirner, René (Hg.), Last Call für Engel, Kunstmuseum Heidenheim, Kunstverein Heilbronn 1996 (auch Rheinisches Landesmuseum Bonn 1999), Heidenheim 1996

Kat. Karlsruhe 1998, 14. Europäische Kulturtage Karlsruhe 1998: „1848“. Die Unruhe und die Zufriedenheit oder die Tragödie des Scheiterns. Badischer Kunstverein Karlsruhe (Hg.), Ausstellung und Katalog: Berit Böhm. Katalogred. Hark Irwin Kittel. Karlsruhe 1998

Kat. Karlsruhe 1996, Internationaler Videokunstpreis 1996. ZKM (Zentrum für Kunstund Medientechnologie) Karlsruhe, Kunsthalle Baden-Baden. Karlsruhe 1996

Kat. Kassel 2007, documenta 12, Katalog. Kassel 2007

Kat. Kassel 2002, Documenta 11_Platform 5: Ausstellung. Kurzführer. Redaktion: Gerti Fietzek. Kassel 2002

Kat. Kassel 1977, Documenta 6 ; Informationen Sonderheft documenta 6 : malerei, plastik, video, fotografie, film, performance, zeichnungen, bücher, utopisches design./ Redaktion: Manfred Schneckenburger. Kassel 1977

Kat. Kiel 1979, Umrisse. Bilder, Objekte, Videos, Filme von Künstlerinnen. 6.5. - 4.6.1979 Kunsthalle zu Kiel \& Schleswig-Holsteinischer Kunstverein zusammen mit der Künstlerinnengruppe Schleswig Holstein (GEDOK) und dem Filmclub Kiel. Kiel 1979

Kat. Köln 1991, Kölnischer Kunstverein (Hg.), Video im Kölnischen Kunstverein. Ulrike Rosenbach. Videos seit 1987. Köln 1991

Kat. Köln 1986, Wallraf-Richartz-Museum Köln: von Stefan Lochner bis Paul Cézanne ; 120 Meisterwerke der Gemäldesammlung / [Red.: Martina Schlagenhaufer]. Köln 1986

Kat. Köln 1979, Fünf in Köln. Buthe, Polke, Rosenbach, Rühen, Scher. Kölnischer Kunstverein. Köln 1979

Kat. Köln 1975, Video Katalog 1975, Oppenheim Studio Köln. Köln 1975

Kat. Köln 1974, Kunst bleibt Kunst, Aspekte internationaler Kunst am Anfang der 70er Jahre, Projekt '74. Kunstverein Köln. Köln 1974

Kat. Limoges 1993, William Wegman (mit Beiträgen von Frederic Paul). Limoges 1993

Kat. Linz 1996, Objekt Video. Ausstellung 10. Okt. bis 17. Nov. 1996. Oberösterreichische Landesgalerie Linz. Katalogred.: Gottfried Hattinger. Linz 1996

Kat. Liverpool 1989, Art from Köln. Tate Gallery 1989

Kat. Los Angeles 1998, Out of actions: zwischen Performance und Objekt 1949 - 1979; (Von Paul Schimmel. Mit Essays von Kristine Stiles. Hg. der dt. Ausg.: Peter Noever). Ostfildern 1998

Kat. Mainz 1996, CL III Storage Area GE 62E Oberolmerwald. 12.-19. Mai 1996. Mainz 1996 
Kat. München 1994, I Am You: Künstler gegen Gewalt. 20 Großflächenplakate gegen Intoleranz und Fremdenhass, Goethe-Institute, Zentralverwaltung, München 1994

Kat. München 1986, Beuys zu Ehren, Städtische Galerie im Lenbachhaus, München 1986

Kat. Nürnberg 1971, Albrecht Dürer 1471-1971, Ausstellung des Germanischen

Nationalmuseums. Nürnberg 1971

Kat. Ontario 1989, Ulrike Rosenbach: Video, Performance, Installation 1972-1989. Art

Gallery of York University und Art Gallery of Ontario. Ontario 1989

Kat. Osnabrück 1997, „Das Performancetraining an der HBKsaar“ von Ulrike Rosenbach anlässlich der Performance „Re-cordis: erinnern - zurückgeben durch’s Herz“ beim Student Forum des European Media Art Festivals Osnabrück 1997 (http://www.wallihoefinger.com/html/presse.html\#97f)

Kat. Paris 1995, Louise Bourgeois, Sculptures, environments, dessins 1938-1995. Musée d'Art Moderne de la ville de Paris 23.6. - 8.11.1995. Paris 1995

Kat. Quakenbrück 1990, Ulrike Rosenbach: Transformationen. Ausstellung Städtische Galerie. Quakenbrück. 1990

Kat. Saarbrücken 2000, HBKsaar (Hg.), mediasplit. Ein Medienkunstprojekt der HBKsaar unter Leitung von Prof. Ulrike Rosenbach. Saarbrücken 2000

Kat. Saarbrücken 1999, HBKsaar (Hg.), 10 Jahre Medienkunst. Saarbrücken 1999

Kat. Saarbrücken 1990, Ulrike Rosenbach: Arbeiten der 80er Jahre. Video, Installation,

Performance, Fotografie. AK Stadtgalerie Saarbrücken 1990 (Kat. und Ausst.: Ulrike

Rosenbach und Bernd Schulz, Texte: Dieter Daniels). Dillingen 1990

Kat. Schwerin 1999, Kornelia von Berswordt-Wallrabe (Hg.), Ulrike Rosenbach: Im Palast der neugeborenen Kinder. Ausstellung Staatliches Museum Schwerin. 25. März bis 24. Mai. 1999. Schwerin 1999

Kat. Stuttgart 2001, Joan Jonas: Performance, Video, Installation 1968 - 2000. Stuttgart 2001

Kat. Stuttgart 1993, Bright Light, International contemporary Art. Schloss Prestenik, Galerie Brigitte March, (Konzept: Brigitte March, Texte: René Lacombe) Stuttgart 1993

Kat. Stuttgart 1992, Force Sight, Internationale Kunst der Gegenwart. Schloss Prestenik, Galerie Brigitte March. Stuttgart 1992

Kat. Toronto 1989, Ulrike Rosenbach: Video, Performance, Installation 1972-1989. Ontario 1989

Kat. Venedig 1999, La Biennale di Venezia. 48a Esposizione Internationale d'Arte. DAPERTutto. Venedig 1999

Kat. Wien 1999, Jahrhundert der Frauen. Ausstellungskatalog Kunstforum Wien. Wien 1999

Kat. Wien 1975, Magna. Kunst und Kreativität. Ein Einblick über weibliche Sensibilität, Imagination, Projektion. Wien 1975

Kat. Würzburg 1999, Farblicht. Ausstellungskatalog Würzburg. Städtische Galerie.

Ostfildern 1999

Kent, Sarah und Jacqueline Morreau (Hg.), Women's images of men. London 1985

Kat. New York 1983, Ellsworth Kelly: Sculpture: (Patterson Sims und Emily Rauh Pulitzer (Hg.)) New York 1983

Kindler, Simone, Ophelia: der Wandel von Frauenbild und Bildmotiv. Berlin 2004

Kingsley, Rebecca, Body Art. Erlangen 1999

Kirves, Dietmar, Joseph Beuys \& Anatol Herzfeld : „Der Tisch“ ; [eine gemeinsame öffentliche 90minütige Aktion von Joseph Beuys mit seinen Schülern Anatol Herzfeld, Ulrich Meister, Joachim Duckwitz und Johannes Stüttgen am 23. Januar 1969 im Creamcheese in Düsseldorf, 1986 
Kobbert, Max J., Kunstpsychologie. Darmstadt 1986

Kölner Frauen Geschichtsverein (Hg.), 10 Uhr pünktlich Gürzenich. 100 Jahre bewegte Frauen in Köln. Zur Geschichte der Organisationen und Vereine, Münster 1995

Kölnischer Kunstverein (Hg.), Video im Kölnischen Kunstverein. Ulrike Rosenbach.

Video seit 1987. Köln 1991

Költzsch, Georg-Wilhelm, Phoenix Folkwang: die Meisterwerke. Museum Folkwang $<$ Essen>. Köln 2002

Kraus, Werner (Hg.), Die Heilkraft des Malens. Einführung in die Kunsttherapie. München 1996

Krauss, Rosalind, Video: The Aesthetics of Narcissism. In: October, Spring 1976

Kristeva, Julia, Die Revolution der poetischen Sprache. Frankfurt am Main 1978

Kristeva, Julia, Desire in language. Oxford 1980

Kubitza, Anette, Carolee Schneemanns. Körperkunst und die Avantgarde. Berlin 2002

Kuchenbuch, Thomas, Filmanalyse. Tehorien, Modelle, Kritik. Köln 1978

Kuh, Katharine, Die Kunst hat viele Gesichter. Wege zum Betrachten und Verstehen moderner Kunst. Hannover 1955

Kuhn, Annette (Hg.), Politeia. Bonn 1998

Kuhn, Annette und Marianne Pitzen (Hg.), Stadt der Frauen. Szenarien aus spätmittelalterlicher Geschichte und zeitgenössischer Kunst. Frauenmuseum Bonn. Bonn 1994

Kultermann, Udo, Das Erwachen der Frauen in der Kunst führt mit Verve in die Performance Szene. In: Du. Nr. 12, Dezember 1990

Kultermann, Udo, Geschichte der Kunstgeschichte: der Weg einer Wissenschaft. München 1996

Kuni, Verena, Bildstörung, in: Magazin der Kulturstiftung des Bundes, Nr. 7, Berlin 2006

Kunstfonds Bonn (Hg.), RAM, Realität, Anspruch, Medium, Katalog: Michaela Ebbinghaus. Bonn 1995

Kunsthalle Kiel (Hg.), Umrisse: Bilder, Objekte, Videos, Filme von Künstlerinnen. 6.5. 4.6.1979. Gesa Rautenberg (Bearb.), Kiel 1979

Kunst- und Ausstellungshalle der Bundesrepublik Deutschland (Hg.), Der elektronische Raum. 15 Positionen zur Medienkunst. Ostfildern 1998

Lacan, Jacques, Das Spiegelstadium als Bildner der Ich-Funktion. In: ders., Schriften I, Baden-Baden 1975

Lacan, Jacques, Das Spiegelstadium als Bildner der Ichfunktion, wie sie uns in der psychoanalytischen Erfahrung erscheint (1949), in: Haas, Norbert und Hans-Joachim Metzger

(Hg.), Das Werk von Jacques Lacan. Berlin 1986, Bd. 1, S. 61-70

Lacan, Jacques, Schriften (ausgew. und hg. von Norbert Haas). Olten 1973-1980

„Last call für Engel“. In: Artis. Das aktuelle Kunstmagazin. Bern 97, J. 49, Nr. 4., S. 58

Lengyel, Lancelot, Das geheime Wissen der Kelten, enträtselt aus druidisch-keltischer Mythik und Symbolik. Freiburg 1976

Lennox, Sara (Hg.), Auf der Suche nach den Gärten unserer Mütter. Feministische Kulturkritik. Darmstadt 1982

Levine, Les, Excerpts from a Tape: „Artistic“. In: Art Rite, Herbst 1974

Lewis, Clive Staples, Till we have Faces. A Myth Retold. (Erstveröffentlichung 1956) Glasgow 1978

Lexikon der christlichen Ikonographie, (hrsg. von Engelbert Kirschbaum. In Zsarb. mit Günter Bandmann), Rom 1974

Ley, Andreas, Hüte: von Kopf bis Hut; Kopfbedeckungen aus der Sammlung des Modemuseums im Münchner Stadtmuseum vom 18. Jahrhundert bis 2000. Wolfratshausen 2000 
Lindner, Ines (Hg.), Blick-Wechsel. Konstruktionen von Männlichkeit und Weiblichkeit in Kunst und Kunstgeschichte. S. 313-332. Berlin 1989

Lippard, Lucy R., Glauben Sie nicht, dass ich eine Amazone bin. In: Bronson, A A und Peggy Gale (Hg.), Performance by artists. Toronto 1979

Lippard, Lucy, From the Center. Feminist Essays on women's Art. New York 1976

Lippard, Lucy, Six Years: The Dematerialization of the art object. New York 1973

Lippard, Lucy R. (Hg.), Issue: Social Strategies by women Artists. An exibition. Institut of Contemporary arts, London 1980

Lischka, Gerhard Johann und Thomas Feuerstein (Hg.), Media-made. Wie kommen wir uns nahe? Köln 2001

Loeffler, Carl F. (Hg.), Performance Anthology. A Sourcebook for a Decade of California Performance Art. San Francisco 1980

Lorenz, Hilke, Kriegskinder. Das Schicksal einer Generation. Berlin 2005

Luca, Renate, Medien und weibliche Identitätsbildung. In: Zeitschrift für Medienpädagogik 1, 1999, S. 9 - 14

Lucie-Smith, Edward, Bildende Kunst im 20. Jahrhundert. Köln 1999

Lurker, Manfred, Wörterbuch der Symbolik. Stuttgart 1991

Lurker, Manfred, Symbol, Mythos und Legende in der Kunst. 1958

Macaire, Dominique und Wolfram Hosch, Bilder in der Landeskunde, Berlin 1996

Magnan, Nathalie, La vidéo entre art et communication. Guide de l'étudiant en art. Ecole nationale superieur des Beaux Arts, Paris 1997

Malsch, Friedemann und Dagmar Streckel, Künstler-Videos: Entwicklung und Bedeutung. Die Sammlung der Videobänder des Kunsthauses Zürich. Zürich 1996

Marsh, Anne, Body and Self. Performance Art in Australia 1969-92. Oxford 1993

Maus, Sibylle. Kunstlandschaft Bundesrepublik. Junge Kunst in deutschen Kunstvereinen. Hamburg 1984

McLuhan, Marshall, Die magischen Kanäle. Understanding Media. Düsseldorf u.a. 1992

Meyer-Denkmann, Gertrud, Performance Art von Frauen - eine feministische Kunst? In: Hoffmann Freia und Eva Rieger (Hg.), Von der Spielfrau zur Performance-Künstlerin: Auf der Suche nach einer Musikgeschichte der Frauen. Kassel 1992

Minnich, Elizabeth K., Von der halben zur ganzen Wahrheit. Einführung in feministisches Denken. Frankfurt 1994

Mirabai, Liebesnärrin. Die Verse der indischen Dichterin und Mystikerin. Kelkheim 2006

Mitgefangen - Mitgehangen. Perfomances und Medieninstallationen von Studentinnen der HBK Saar. CD-Rom Dokumentation zur Ausstellung im Wasserwerk in Scheidt. Saarbrücken 1997

Möhrmann, Renate, Verklärt, verkitscht, vergessen. In: Frauen Kunst Wissenschaft, Heft 20, Dez. 1993, S. $52 \mathrm{ff}$

Moeller, Bernd, Geschichte des Christentums in Grundzügen, Göttingen 1992

Monaco, James, Film verstehen: Kunst, Technik, Sprache, Geschichte und Theorie des

Films und der Medien; mit einer Einführung in Multimedia. Reinbek bei Hamburg 1995

Muecke, Nina und Angelika Sommer (Hg.), Rituale in der zeitgenössischen Kunst. Berlin 2003

Müller, Hedwig und Norbert Servos, Pina Bausch - Wuppertaler Tanztheater. Von Frühlingsopfer bis Kontakthof. Köln 1979

Museum Wiesbaden (Hg.), Künstlerinnen des 20. Jahrhunderts, Wiesbaden 1990

Nabakowski, Gislind, Interview mit Ulrike Rosenbach. In: Heute Kunst 16, OktoberDezember 1976

Nabakowski, Gislind und Helke Sander und Peter Gorsen, Frauen in der Kunst. 2 Bde. Frankfurt am Main 1980

Neue Galerie - Sammlung Ludwig (Hg.), Spuren des Heiligen in der Kunst heute, 
Ludwigforum Aachen 1986

Neue Galerie - Sammlung Ludwig (Hg.), Ulrike Rosenbach: Foto / Video / Aktion: 4. Dez. 1976 - 16. Jan. 1977. Mitarbeiter: Gislind Nabakowski und Peter Gorsen. Aachen 1976

Neumann, Erich, Die große Mutter. Phänomenologie der weiblichen Gestaltung des Unbewußten. (1. Aufl. 1974) 11. Aufl. Düsseldorf und Zürich 1997

Neumann, Erich, Amor und Psyche. Deutung eines Märchens. Ein Beitrag zur seelischen Entwicklung des Weiblichen. Mit dem Text des Märchens von Apuleius in der Übersetzung von A. Schaeffer, 2. Aufl.. Freiburg 1979

Neusüß, Floris (Hg.), Fotografie als Kunst. Kunst als Fotografie. Köln 1979

Nochlin, Linda, Women, art and Power and other essays, 1989

Noever, Peter (Hg.), Silent \& Violent. Zürich u.a. 1995

Noi altri - wir anderen. Künstlerische Aktivität und Selbsterfahrung im sozialen Raum. Ausstellungskatalog Regensburg städtische Galerie 1982

Nöring, Hermann (Hg.), European Media Art Festival. Osnabrück 1996

Nurbakhsh, Javad, Sufi Women. London 1990

O'Dell, Kathy, The Performance Artist as masochistic woman. In: Arts magazine 10. Sommer 1988

Öhlschläger, Claudia u.a. (Hg.), Körper - Gedächtnis - Schrift. Der Körper als Medium kultureller Erinnerung. Berlin 1987

Oppenheim, Ingrid (Hg.), Highlights: Rückblick Oppenheim Studio 1973 -1979. Kat. Sammlung Ingrid Oppenheim, Städtisches Kunstmuseum Bonn. Bonn 1983

[Das] orangene Buch, Die Meditationstechniken Oshos. Himberg 1998 (Erstersch. 1989)

Othmer, Regine (Hg.), Andere Orte - Überall. Agora-Platz für Frauen, Hannover 1995

Panofsky, Erwin, Sinn und Deutung in der bildenden Kunst. Köln 1978

Parker, Andrew und Eve Kososky Sedgwick (Hg.), Performativity and Performance. New York London 1995

Paul, Barbara, Mythos Mann. Ulrike Rosenbachs Videoinstallation „Herakles - Herkules King Kong (1977). In: Marburger Jahrbuch für Kunstwissenschaft 25. Marburg 1998

Petzinger, Renate, Über den Tod. Gespräch mit Ulrike Rosenbach. In: Zeitschrift für Gottesdienst und Predigt. Bd. 20. 2002/3, S. 27-28

Phelan, Peggy, Unmarked: The politics of Performance, London/New York 1993

Phillips, Lisa (Hg.), The american century: Art \& Culture, 1950-2000. New York 1999

Pichler, Cathrin (Hg.), Engel : Engel. Legenden der Gegenwart. Wien/New York 1997

Poeschel, Sabine, Handbuch der Ikonographie, Darmstedt 2005

Pohlen, Annelie (Hg.), Wechselströme. Kontemplation, Expression, Konstruktion. Deutsche Kunst heute. Kat. Bonner Kunstverein. Köln 1987

Pohlen, Annelie (Hg.), Zeichen und Mythen. Orte der Entfaltung. Joseph Beuys, Michael Buthe, Theo Lambertin, Rune Mields, Miralda, Ulrike Rosenbach. Bonn: Kunstverein, 29.11.1980-1.2.1981. Köln 1981

Pollock, Griselda, Die Räume der Weiblichkeit. In: Lindner, Ines (Hg.), Blick-Wechsel. Konstruktionen von Männlichkeit und Weiblichkeit in Kunst und Kunstgeschichte. S. 313-332. Berlin 1989

Pollock, Griselda und Roszika Parker (Hg.), Framing Feminism. Art and the Women's Movement 1970-85. New York/ London 1987

Popper, Frank. Art of the Electronic Age. London 1993

Preziosi, Donald (Hg.), The Art of Art History. A Critical Anthology. Oxford 1998

Puvogel, Renate, Brennpunkt Düsseldorf. Joseph Beuys, die Akademie, der allgemeine Aufbruch 1962 - 1987. In: Weltkunst: aktuelle Zeitschrift für Kunst und Antiquitäten. München 1987, Nr. 15, S. 2048-2049

Radio Bremen, Hauptabteilung Musik (Hg.), Pro Musica Nova 4. bis 10. Mai 1978. Bremen 1978 
[von] Ranke-Graves, Robert, Die weiße Göttin: Sprache des Mythos. (Ins Dt. übertr. von Thomas Lindquist) Berlin 1981

Rappaport, Roy A., Ritual and Religion in the Making of Humanity. Cambridge 2000

Reckitt, Helena (Hg.), Art and Feminism. London 2001

Reyer, Herbert, Kleine Geschichte der Stadt Hildesheim. Hildesheim 1999

Richter, Petra, Mit, neben, gegen. Die Schüler von Joseph Beuys. Düsseldorf 2000

Rituale. Kult, Kunst \& Heilung in Religion \& Alltag. In: Schneider, Wolf (Hg.) Connection special. Die Sonderhefte fürs Wesentliche. IV/03 Aug./Sept. 03

Robinson, Hilary (Hg), Visibly Female: Feminism and Art, an anthology, New York 1988

Romain, Lothar und Detlef Bluemler (Hrsg.), Ulrike Rosenbach, Künstler. Kritisches Lexikon der Gegenwartskunst. München 1989

Romain, Lothar (Hg.), Bis jetzt. Von der Vergangenheit zur Gegenwart. Plastik im Außenraum der BRD. München 1990

Rose, Barbara, Vaginal Ikonology, in: New York Magazine, 11. Februar 1974, S. 59

Rosenbach, Ulrike, „Das Performancetraining an der HBKsaar“ anlässlich der Performance

„Re-cordis: erinnern - zurückgeben durch's Herz" beim Student Forum des European Media Art Festivals Osnabrück. In: European Media Art Festival Osnabrück 1997. [Hermann Nöring (Hg.), Veranstalter: Experimentalfilm Workshop e.V.] Osnabrück 1997

Rosenbach, Ulrike, „Das Performancetraining an der HBKsaar“" anlässlich der Performance

Re-cordis: erinnern - zurückgeben durch's Herz beim Student Forum des European Media Art Festivals Katalog Osnabrück 1997

(http://www.wallihoefinger.com/html/presse.html\#97f)

Rosenbach, Ulrike, Feministische Kunst - und dann? In: Frauenforschung und Kunst von Frauen, hg. von d. Arbeitsgemeinschaft Interdisziplinäre Frauenforschung und studien. (Frauen in Geschichte und Gesellschaft; Bd. 15), Pfaffenweiler 1990, S. $141-145$

Rosenbach, Ulrike (Hg.), Videokunst, Foto, Aktionen/Performance, Feministische Kunst. St. Augustin 1982

Rosenbach, Ulrike u.a., Schule für kreativen Feminismus. Beispiel einer autonomen Kulturarbeit. Köln 1980

Rosler, Martha, The Private and the Public. Feminist Art in California. In: Artforum, September 1977

Roth, Moira, The amazing decade. Women and Performance Art in America 1970-80. A Sourcebook, Los Angeles 1983

Roth, Moira, About Time. London 1980

Rowell, Margit (Hg.), Skulptur im 20. Jahrhundert. Figur - Raumkonstruktion - Prozess. München 1986

Rühl, Anna Sarah, Ulrike Rosenbach. In: Kunst und Künstler im 20. Jahrhundert. Prestell Lexikon, München 1999

Rush, Michael, New Media in late 20th Century Art. London 1999

Salih, Sara, Judith Butler. London und New York 2002

Saunders, Ross, Die Frauen im Neuen Testament. Darmstadt 1999

Scharmann-Frank, Marion, Körper und Bild im Oeuvre Ulrike Rosenbachs. (Magisterarbeit) Heidelberg 2000

Saunders, Ross, Die Frauen im Neuen Testament. Darmstadt 1999

Schechner, Richard und Willa Appel (Hg.), By means of performance. Intercultural studies of theatre and ritual. Cambridge 1997

Scherer, Priska, Ulrike Rosenbach im Zeichen des Wandels unter besonderer 
Berücksichtigung der Aktion Begegnung mit Ewa und Adam. (Magisterarbeit) München 1996

Schlicher, Susanne, TanzTheater. Traditionen und Freiheiten. Pina Bausch, Gerhard Bohner,

Reinhild Hoffman, Hans Kresnik, Susanne Linke. Reinbek bei Hamburg 1987

Schmidt, Johann-Karl, Joan Jonas: Performance, Video, Installation 1968 - 2000. Ostfildern 2001

Schmidt, Katharina, To the People of New York, Palermo, 1. April - 16. Juli 1995, Museum für Gegenwartskunst, Basel 1995

Schmitz, Britta (Hg.), Hermann Nitsch. Orgien Mysterien Theater. Nationalgalerie im Martin-Gropius-Bau-Berlin. Köln 2006

Schneede, Uwe M., Joseph Beuys. Die Aktionen. Bonn 1994

Schneede, Uwe (Hg.), Expozitia de arte Plastika Contemporane. Kat. Mus. Coletior, (Joachim Sommermeier) Republica Romania/Bukarest 1985

Schneeman, Carolee, Bonnie Marranca und Bruce McPherson, Review of More than Meat

Joy: Complete Performance Works and Selected Writings by Carolee Schneeman. In:

Performing Arts Journal, 1980, vol. 4, no. 3, p. 160

Schneider, Pierre, Marc Chagall, Fast ein Jahrhundert, Stuttgart 1995

Schneider, Rebecca, The Explicit Body in Performance. London, New York 1997

Schöfer, Matthias, Mediennutzung und Zeitfaktor in der Aktionskunst. In: Kunstforum,

Bd. 151, Juli/September 2000, S. 106-116

Schoell-Glass, Charlotte, Aby Warburg und der Antisemitismus: Kulturwissenschaft als Geistespolitik. Frankfurt am Main 1998

Schröder, Johannes Lothar, Identität - Überschreitung/Verwandlung. Happenings, Aktionen und Performances von bildenden Künstlern. Münster 1990

Schubiger, Irene, Selbstdarstellung in der Videokunst. Zwischen Performance und Selfediting. Bonn 2003

Schulz-Hoffmann, Clara, Niki de Saint Phalle, Bonn 1987

Schwarz-Winklhofer, Inge (Hg.), Das Buch der Zeichen und Symbole. Graz 1994

Schwarzbauer, Georg F., Performance. Anmerkungen zum Themenbereich artifizieller Direktdarstellungen - Bilddokumentationen, Statements, Interviews. In: Kunstforum international Bd. 24, 1977, S. 39

Segal, Robert A. (Hg.), The Myth and Ritual Theory. An Anthology. Oxford 1998

Sichtermann, Siegfried (Hg.), Die Wandlungen des Till Eulenspiegel. Texte aus fünf Jahrhunderten Eulenspiegel-Dichtung. Köln 1982

Skrentny, Werner, New York. Köln 1993

Smith W.J., Ritual and the Ethology of Communicating. In: d'Aquili, E.G., Ch.D. Laughlin und J. McManus, The Spectrum of Ritual: A Biogenetic Structural Analysis. New York 1979, S. 51-79

Soerensen-Cassier, Dagmar, Transgenerationelle Prozesse von NS-Traumatisierungen. Ein Fallbericht. In: psychosozial 26. Jg. (2003) Heft II (Nr. 92), S.61-66

Spelman, Elizabeth V., Woman as Body: Ancient and Contemporary Views. In: Feminist Studies 1. Frühjahr 1982

Stachelhaus, Heiner, Joseph Beuys. München 2001

Stadt Marl (Hg.), Deutsche Videokunst 1994-96. Ausstellung zum 7. Marler Videokunstpreis. Skulpturenmuseum Glaskasten. Verantw.: Uwe Rüth. Marl 1996

Städtische Galerie Düsseldorf (Hg.), Ein anderes Klima: Künstlerinnen gebrauchen neue

Medien. 28. März - 11. Mai 1986. Düsseldorf 1986

Stephens, Chris und Katharina Stout (Hg.), Art \& the 60s. This was tomorrow. London 2004

Stiles, Kristine (Hg.), Theories and documents of Contemporary Art: A sourcebook of 
artist's writing. University of California Press, Berkely 1996

Strong, Roy, And when did you last see your father? The Victorian Painter and British History. London 1978

Stüber, Werner Jakob, Entwicklungsgeschichte des Modern Dance: Ansätze zur Selbsterfahrung und Körperaneignung im modernen Tanztheater. Wilhelmshaven 1984

Thomas, Karin, Kunst in Deutschland seit 1945, Köln 2002

Thomas, Karin, Bis heute. Stilgeschichte der bildenden Kunst im 20. Jahrhundert. 7. erw. Aufl., Köln 1986

Thomas, Karin, Zwei mal deutsche Kunst nach 1945. 40 Jahre Nähe und Ferne. Köln 1985

Thomas Jankowski, Angela, Ulrike Rosenbach. In: Du. Die Kunstzeitschrift, Hg.: Reto Conzett, Zürich 1/1981, S. 42

Tibetanische Totenbuch oder die Nachtod-Erfahrungen auf der Bardo-Stufe. (Hg. W.Y. Evans-Wentz). Freiburg 1987

Time based Arts. Videotape catalogue. Amsterdam 1985

Torcelli, Nicoletta, Video Kunst Zeit. Weimar 1996

Townsend, Chris (Hg.), The Art of Bill Viola. London 2004

Trier, Eduard (Hg), Zweihundert Jahre Kunstakademie Düsseldorf. Düsseldorf 1973

Tripp, Eduard, Reclams Lexikon der antiken Mythologie. Stuttgart 1981

Valstar, Arta und Dieter C. Schütz, Von Hildebrand bis Kricke. Bonn 1985

Vanags, Patricia, Glorreiches Pompeji. Herrsching 1983

van Assche. Christine, Vidéo et après : La collection vidéo du Musée national d'art moderne. Paris c1992

Vergine, Lea, Body Art and Performance. The body as language. Milano 2000

von Barloewen, Constantin (Hg.) Der Tod in den Weltkulturen und Weltreligionen. München 1996

von Ins, Jürg, Ekstase, Kult und Zeremonialisierung. Zürich 1979

Von Waberer, Keto, Das Nomadische spielt eine Rolle von Anfang. Interview mit Joseph Beuys aus dem Jahr 1979. In AK Hannover 1990, S. 197-221

von Wiese, Stephan, Brennpunkt Düsseldorf 1962 - 1987: Joseph Beuys, die Akademie,

der allgemeine Aufbruch, Kunstmuseum Düsseldorf 1987

Walker, Barbara, Die geheimen Symbole der Frauen. Lexikon der weiblichen Spiritualität. München 1997

Warhol, Robyn R. und Diane Price Herndl (Hg.), Feminism. An Anthology of literary theory and criticism. New Brunswick 1997

Warncke, Carsten-Peter, Symbol, Emblem, Allegorie. Die zweite Sprache der Bilder. Köln 2005

Wassermann, James und Gerda Bean, Kunst und Symbolik im Okkultismus. (Ins Dt. übertr. von Gerda Bean). Hanau 1995

Wehr, Gerhard, Der Urmensch und der Mensch der Zukunft, Freiburg 1964

Wehr, Gerhard, Heilige Hochzeit, Symbol und Erfahrung menschlicher Reifung. München 1986

Wehr, Gerhard, C. G. Jung. Reinbek bei Hamburg 1997

Weil, Kari, Androgyny and the Denial of Difference, Virginia 1992

Weissner, Carl und Walter Hartmann, Bob Dylan. Songtexte 1962-1985. Frankfurt am Main 1985

Wickham, Cynthia, Mit Zimmerpflanzen schöner wohnen. München 1978

Wilding, Faith, By our own Hands: The women Artist movement Southern California 1970-76. Santa Monica 1977

Willim, Bernd, Leitfaden der Computer Grafik : visuelle Informationsdarstellung mit dem 
Computer ; Grundlagen, Verfahren, Einsatzbereiche. Berlin 1989

Woman's Art, in: Neues Forum XX Januar. Wien 1973

Wulf, Christoph und Jörg Zirfas (Hg.), Die Kultur des Rituals. Inszenierungen - Praktiken - Symbole. München 2004

Wulf, Christoph und Jörg Zirfas, Einführung in die historische, systematische und methodische Dimension des Rituals. In: Wulf, Christoph und Jörg Zirfas (Hg.), Die Kultur des Rituals. Inszenierungen - Praktiken - Symbole. München 2004, S. 7-48

Wunder, Heide, Er ist die Sonn', sie ist der Mond. Frauen in der Frühen Neuzeit. München 1992

Zell, Andrea, Valie Export. Inszenierung von Schmerz. Berlin 2000

Zerbst, Marion und Werner Kafka, Das große Lexikon der Symbole. Zeichen-SchriftenMarken-Signale. (Hg. Rainer Dierkesmann), Leipzig 2003

Zerbst, Marion und Werner Waldmann, DuMonts Handbuch Zeichen und Symbole: Herkunft, Bedeutung, Verwendung. Köln 2003

Ziegler, Gerd, Tarot - Spiegel der Seele. Handbuch zum Crowley Tarot. Neuhausen $(\mathrm{CH})$ 1988

Ziesche, Angela, Das Schwere und das Leichte. Künstlerinnen des 20. Jahrhunderts. Köln 1995

Zizek, Slavoj, Liebe dein Symptom, wie dich selbst! Jacques Lacans Psychoanalyse und die Medien. Berlin 1991

Zurück zur Natur, aber wie? Kunst der letzten 20 Jahre. Städtische Galerie Prinz Max Palais, Karlsruhe 1988

Zweite, Armin (Hg.), Ich ist etwas Anderes: Kunst am Ende des 20. Jahrhunderts. (Mit Essays von Peter Bürger) Köln 2000

Zwick, Renate, Zu Problemen und Konsequenzen der Frauenkunst heute: Rebecca Horn, Friederike Pezold und Ulrike Rosenbach. Schriftliche Hausarbeit zur zweiten Dienstprüfung für das Lehramt an Realschulen. 1979 


\section{Verzeichnis der Bildquellen}

\section{Kapitel I:}

Abb. 1: Friedenspanzer vor dem Brandenburger Tor - Aktion von Ulrike Rosenbach und Michael

\section{Kapitel II:}

Fischer am 8. Mai 2007, Foto: Johannes Eisele, dpa

Abb. 2: Werbung für den Sony Portapak, (aus: Zielinski 1992, S. 232)

Abb. 3: Schematische Darstellung der Kathodenstrahlröhre

Abb. 4: Magnet TV: Nam June Paik, 1963, C Verlag der Kunst, Philo Fine Arts

Abb. 5-8: Nam June Paik: Global Groove, 1973, 4 Videostills, (C Nam June Paik

Abb. 9: Einstellungsgrößen

Abb. 10: Keith Sonnier: Animation I und Color Wipe, 1973, (c) VG Bild-Kunst Bonn 2011

Kapitel III:

Abb. 11-13: Ulrike Rosenbach: Einwicklung mit Julia, 1972, 3 Videostills, (C) VG Bild-Kunst Bonn 2011

Abb. 14-16: Ulrike Rosenbach: Videostills aus Das Brennesseltape, Zeichenhaube, 1972 und Eine Scheibe berühren, 1973, (C) VG Bild-Kunst Bonn 2011

Abb. 17-18: Ulrike Rosenbach: Videostills aus Das Kohltape und Der Mann sei das Haupt der Frau, 1973, (C) VG Bild-Kunst Bonn 2011

Abb. 19: James Ensor: Le Chou frisé, 1894, Öl/Leinwand, Folkwang Museum, Essen

Abb. 20: Bruce Nauman: Slow Angle Walk (Beckett Walk), 1968, Videostill, (C) VG Bild-Kunst Bonn 2011

Abb. 21: Dan Graham: Two Viewing Rooms, 1975, Installation 600 x 250 x 250 cm, C Sammlung Marc und José Gonsollen, Marseille

Abb. 22-24: Ulrike Rosenbach: Spielobjekte, 1967, Blei und Holz, C VG Bild-Kunst Bonn 2011

Abb. 25: Niki de Saint Phalle: Schwarze Nana, 1968-1969, Köln, Museum Ludwig, (C) VG Bild-

Kunst Bonn 2011

Abb. 26-27: Ulrike Rosenbach: Haubenobjekte, 1971, (Foto von Nic Tenwiggenhoern) (C) VG BildKunst Bonn 2011

Abb. 28-29: Ladies of the Rank of the 15th and 16th Century und Tafel VI bei Strutt „Honda Angelcynnan” (1774-6) aus: Strutt's „Dress and Habits“"

Abb. 30: Ulrike Rosenbach: Naturkreisaktion, 1973, (Foto von Nic Tenwiggenhoern), (C) VG BildKunst Bonn 2011

Abb. 31: Ulrike Rosenbach: Videoliveaktion mit Konrad Schnitzler auf dem Kölner Kunstmarkt, 1973, Aktionsfoto (von Hildegard Weber), (C) VG Bild-Kunst Bonn 2011

Abb 32-33: Ulrike Rosenbach: Sorry Mister, 1973, Aktionsfoto (von Hildegard Weber) und Videostill, (C) VG Bild-Kunst Bonn 2011

Abb. 34: Ulrike Rosenbach: Isolation is transparent, Aktionsfoto, 1974, C VG Bild-Kunst Bonn 2011

Abb. 35: Judy Chicago und Suzanne Lacy: Ablutions, Aktionsfoto, 1972, (C) VG Bild-Kunst Bonn 2011

Abb. 36-37: Ulrike Rosenbach: Der innere Widerstand sind meine Füße, Aktionsfotos (von Hildegard Weber) und Videostill, 1974, (C) VG Bild-Kunst Bonn 2011

Abb. 38: Szenenfoto aus „Kontakthof“" von Pina Bausch, (C) Francesco Carbone

Abb. 39-45: Ulrike Rosenbach: Glauben Sie nicht daß ich eine Amazone bin, 1975, Aktionsfoto (von Klaus vom Bruch) und 6 Videostills, (C) VG Bild-Kunst Bonn 2011, und

Abb. 46: Stephan Lochner: Madonna im Rosenhag, um 1450, Mischtechnik auf Holz, 51 x 40 cm, Köln, Wallraf-Richartz-Museum - Fondation Corboud 
Abb. 47: Niki de Saint Phalle: La mort du patriarche (Der Tod des Patriarchen (Schießbild)), 1962, Assemblage, 251 × 160 × $40 \mathrm{~cm}$, Gips, Farbe und verschiedene Objekte auf Holzplatte, Hannover, Sprengel Museum, (C) VG Bild-Kunst Bonn 2011

Abb. 48-49: Yoko Ono: Cut Piece, 1964, Performance, Yamaichi Concert Hall, Kyoto C Yoko Ono

Abb. 50: Gina Pane: Autoportrait(s), 1973, Performance Galerie Stadler, Paris, C VG Bild-Kunst Bonn 2011

Abb. 51: John Baldessari: Strobe Series: Futurist Girl with Flowers Falling from Her Mouth (For Botticelli) \#1, 1975, Farbfoto auf Tafel kaschiert, gerahmt 33,3 x 26,6 cm, New York, (C) John Baldessari und Marian Goodman Gallery New York

Abb. 52-54: John Baldessari: Thaumatrope Series - Horse with two Riders (Double Thaumatrope) 3 Schwarzweißfotos auf Tafel kaschiert, 1975, gerahmt 35,5 x $119 \mathrm{~cm}$, New York. C) John

Baldessari und Marian Goodman Gallery New York

Abb. 55-57: Rauminstallationen im Womanhouse, 1972, Los Angeles

Abb. 58-60: Ulrike Rosenbach: Female Energy Change -Venus, Minerva, Supergirl, 1975, 3

Schwarzweiß-Fotocollagen, (C) VG Bild-Kunst Bonn 2011

Abb. 61: Ulrike Rosenbach: Female Energy change - Venus, 1976, Farbfotocollage, (C) VG Bild-

Kunst Bonn 2011

Abb. 62: Sandro Botticelli: Geburt der Venus, um 1484, Tempera auf Leinwand, 172,5 x 278,5 cm, Florenz, Uffizien, Inventarnummer 1890 n. 878

Abb. 63: „The Fool“" aus dem Waite-Tarot

Abb. 64: Ulrike Rosenbach: Bilder zum Tarot: The Fool, 1976, Farbfotocollage, (C) VG Bild-Kunst Bonn 2011

Abb. 65: Schule von Fontainebleau: Diana als Jägerin, um 1550, 191 x 132 cm, Öl auf Leinwand, Paris, Musée du Louvre

Abb. 66: Ulrike Rosenbach: Bilder zum Tarot - The Fool, 1976, Farbfotocollage, (C) VG Bild-Kunst Bonn 2011

Abb. 67: William Holman Hunt: The Lady of Shalott (Die Dame von Shalott), 1886-1905, $188 \mathrm{~cm} x$ $146 \mathrm{~cm}$, Öl auf Leinwand, Hartford (Conn.), Wadsworth Atheneum

Abb. 68: Ulrike Rosenbach: Bilder zum Tarot - The Magicien, 1976, Fotocollage, (C) VG Bild-Kunst Bonn 2011

Abb. 69: Edward Burne-Jones: Merlin und Vivien (Die Verzauberung Merlins), 1873-74, 186,2 x $110,5 \mathrm{~cm}$, Öl auf Leinwand, National Museum Liverpool, Lady Lever Art Gallery)

Abb. 70: Ulrike Rosenbach: Reflexionen über die Geburt der Venus, 1976, Aktionsfoto (von Klaus vom Bruch), (C) VG Bild-Kunst Bonn 2011

Abb. 71: Titelfoto von Ulrike Rosenbach, Emma November 1979, Nr. 11

Abb. 72-73: Ulrike Rosenbach: 10000 Jahre habe ich geschlafen, 1977, Aktionsfotos (von Klaus vom Bruch), (C) VG Bild-Kunst Bonn 2011

Abb. 74-78: Ulrike Rosenbach: Maifrau, 1977, 3 Aktionsfotos (von Klaus vom Bruch) und 2 Videostills, (C) VG Bild-Kunst Bonn 2011

Abb. 79: Artemis von Ephesos, Kapitolinisches Museum Rom: Statue der Artemis von Ephesus römische Kopie eines Originals aus dem 2. Jahrhundert n. Chr., Marmor und Bronze, 115 $\mathrm{cm}$

Abb. 80: Louise Bourgeois mit selbstgestaltetem Kostüm, 1980, (erschienen in: Vogue, Oktober 1980), Foto: Duane Michals, (C) Louise Bourgeois Trust/ VG Bild-Kunst, Bonn 2011

Abb. 81: Anne Gauldin und Denise Yarlitz, The waitress godess Diana, 1978, Venice Beach, Foto: Maria Karras, (C) Anne Gauldin und Denise Yarlitz

Abb. 82: Ulrike Rosenbach: Venusdepression - Medusaimagination, (Foto von Antonio Sferlazzo), 1977, (C) VG Bild-Kunst Bonn 2011

Abb: 83-86: Sandro Botticelli: Nastagio degli Onesti Zyklus, 1482/83, Tempera auf Holz, $83 \mathrm{~cm} x$ $138 \mathrm{~cm}$, Begegnung mit der Verdammten im Pinienwald, Die infernalische Jagd, Bankett im Pinienwald, Prado, Madrid, Das Hochzeitsbankett, Privatbesitz 
Abb. 87: Ulrike Rosenbach: Hercules - Herakles - King Kong, 1978, C VG Bild-Kunst Bonn 2011

Abb. 88-89: Ulrike Rosenbach: Meine Verwandlung ist meine Befreiung, 1978, 2 Aktionsfotos, (C)

VG Bild-Kunst Bonn 2011

Abb. 90: Detail aus Albrecht Dürer: Die vier Apostel, 1526, Holz, 212,8 x 76,2 cm, Alte Pinakothek, München

Abb. 91-92: Ulrike Rosenbach: Salto Mortale, 1978, 2 Aktionsfotos, (C) VG Bild-Kunst Bonn 2011

Abb. 93-100: Standbilder aus ,Effi Briest' von Rainer Werner Fassbinder, 1974, (C) Tango-Film München

Abb. 101-103: Ulrike Rosenbach: Meine Macht ist meine Ohnmacht, 1978, 2 Aktionsfotos (von Erika Kiffl) und 1 Videostill, (C) VG Bild-Kunst Bonn 2011

Abb. 104-107: Klaus vom Bruch: Das Schleyer Band, 1978, 4 Videostills, C VG Bild-Kunst Bonn 2011

Abb. 108: Anselm Kiefer: Varus, 1976, Öl auf Leinwand, 200 x 270,5 cm, Collection Van Abbemuseum, Eindhoven, Niederlande, Foto von Peter Cox, (C) Anselm Kiefer

Abb. 109-111: Ulrike Rosenbach: Konzert im Gewaltakt, 1979, Aktionsfoto und 2 Videostills aus Jactatio, (C) VG Bild-Kunst Bonn 2011

Abb. 112-116: Ulrike Rosenbach: Tanz um einen Baum, 1979, 2 Aktionsfotos und 3 Videostills, C

VG Bild-Kunst Bonn 2011

Abb. 117-118: Ulrike Rosenbach: Die einsame Spaziergängerin, 1979, 2 Aktionsfotos (von Hildegard

Weber) und Videostills, (C) VG Bild-Kunst Bonn 2011

Abb. 119: Caspar David Friedrich: Gebirgslandschaft mit Regenbogen, 1809/10, Öl auf Leinwand,

\section{Kapitel IV}

70 x 103 cm, Museum Folkwang, Essen

Abb. 120: Ulrike Rosenbach: Wechselfrau im Spiegelbild, 1980, Aktionsfoto, (C) VG Bild-Kunst Bonn 2011

Abb. 121-122: Mary Kelly: Primapara, Bathing Series, Fotoserie, 1974, (C) Sammlung Generali Foundation, Wien

Abb. 123: Ulrike Rosenbach: Denkmal für eine verzweifelte Frau, 1981, Installation, C VG Bild-

Kunst Bonn 2011

Abb. 124-125: Ulrike Rosenbach: Requiem für Mütter, 1980, 2 Aktionsfotos (von Angela Thomas-

Jankowski), (C) VG Bild-Kunst Bonn 2011

Abb. 126: Ulrike Rosenbach: Requiem für Mütter, 1980, Aktionsfoto (von Angela Thomas-

Jankowski)

Abb. 127-128: Louise Bourgeois, Spiders, Objekt, 1994 und Zeichnung, 1944, (C) Louise Bourgeois

Trust/ VG Bild-Kunst, Bonn 2011

Abb. 129: Villa dei Misteri, Mysteriensaal, Pompeji, Fresken, 70-50 v. Chr.

Abb. 130-131: Ulrike Rosenbach: Narzissen scheiden weg, 1980, Aktionsfotos (von Hildegard Weber), (C) VG Bild-Kunst Bonn 2011

Abb. 132-133: Ulrike Rosenbach: Psyche, aber sie irrte gänzlich umher, 1980, 2 Aktionsfotos, (C VG Bild-Kunst Bonn 2011

Abb. 134: Ulrike Rosenbach: Keine Madame Pompadour, 1980, Aktionsfoto und Videostill, C VG

Bild-Kunst Bonn 2011

Abb. 135-137: Ulrike Rosenbach: Judofrauen haben als Hilfe Boten, 3 Aktionsfotos (von Hildegard

Weber), (C) VG Bild-Kunst Bonn 2011

Abb. 138: Ulrike Rosenbach: Wer hat Angst vor der schwarzen Frau, 1982, Aktionsfoto, (C) VG Bild-

Kunst Bonn 2011

Abb. 139: Ulrike Rosenbach: Das Feenband, 1983, Videostill, (C) VG Bild-Kunst Bonn 2011

Abb. 140-144: Ulrike Rosenbach: Lotus-Knospen-Töne, 1979, 5 Videostills, (C) VG Bild-Kunst Bonn 2011

Abb. 145: Ulrike Rosenbach: Eleven - es wurde eine Frage auf Leben und Tod, 1985, Aktionsfoto,

(C) VG Bild-Kunst Bonn 2011 
Abb. 146: Claude Lorrain, Einschiffung der Hl. Ursula, 1641, 113 x 149 cm, National Gallery, London

Abb. 147-148: Ulrike Rosenbach: Eleven - verstehen ist wie Hitze, 1985, 2 Videostills, (C) VG BildKunst Bonn 2011

Abb. 149-151: Ulrike Rosenbach: Inner Landscape - Insight Image, 1984, Videostill, (C) VG BildKunst Bonn 2011

Abb. 152-153: Ulrike Rosenbach: Aufwärts zum Mount Everest, 1983, 2 Aktionsfotos, (C) VG BildKunst Bonn 2011

Abb. 154: Ulrike Rosenbach: Ana l'haq, der Wind meiner Träume, 1986, Aktionsfoto, (C) VG BildKunst Bonn 2011

Abb. 155: Ulrike Rosenbach: Im Garten der Göttin, Aktionsfoto, 1986, (C) VG Bild-Kunst Bonn 2011

Abb. 156: Georges Mathieu: Dâna, 1958, Öl auf Leinwand, 65 x 100 cm, Museum Ludwig, Köln, (C) VG Bild-Kunst Bonn 2011

Abb. 157: Ulrike Rosenbach: Zenkocher - Energetisches Phänomen, 1988, Installation, (C) VG BildKunst Bonn 2011

Abb. 158: Ulrike Rosenbach: Ein Moment im Leben des chinesischen Malers HU EM AY, 1989, Installation, (C) VG Bild-Kunst Bonn 2011

Abb. 159: Ulrike Rosenbach: Begegnung mit Ewa und Adam, 1982, 2 Aktionsfotos, (C) VG BildKunst Bonn 2011

Abb. 160: Albrecht Dürer: Adam und Eva, 1501, 25 x 19,2 cm, Kupferstich,

Abb. 161: Retorte mit drei Vögeln aus dem Splendor Solis, 1531/32, Miniatur, Deckfarben auf Pergament, $33,1 \times 22,8 \mathrm{~cm}$

Abb. 162 : Aureum velus, Retorte mit drei Vögeln, 1708, Holzschnitt

Abb. 163: Max Ernst - La belle Jardinière, 1923, (C) VG Bild-Kunst Bonn 2011

Abb. 164: Ulrike Rosenbach: Schmelzprozesse, 1982, Installation, (C) VG Bild-Kunst Bonn 2011,

Abb. 165: Geflügelte Figur, Fresko aus der Villa dei Misteri, Pompeji, 70-50 v. Chr.

Abb. 166-167: Eulenspiegel-Darstellung und Die Eulenspieglerin, 1985, Aktionsfoto, C VG BildKunst Bonn 2011

Abb. 168-173: Ulrike Rosenbach: Die Eulenspieglerin, 1985, 6 Videostills, (C) VG Bild-Kunst Bonn 2011

Abb. 174: Ulrike Rosenbach: Die Eulenspieglerin, alchemistische Zeichnung mit Eulenspiegelmotiv, Videostill, 1985, (C) VG Bild-Kunst Bonn 2011

Abb. 175-176: Ulrike Rosenbach: Die Eulenspieglerin, 1985, 2 Videostills, (C) VG Bild-Kunst Bonn 2011

Abb. 177: Die Eulenspieglerin, alchemistische Zeichnung mit dem Motiv des Hermaphrodit, 1985, Videostill, (C) VG Bild-Kunst Bonn 2011

Abb. 178-181: Ulrike Rosenbach: Die Eulenspieglerin, Beispiele für elektronische Effekte, 1985, 4 Videostills, (C) VG Bild-Kunst Bonn 2011

Abb. 182: Ulrike Rosenbach: Die Eulenspieglerin, 1985, Videostill, (C) VG Bild-Kunst Bonn 2011

Abb. 183-184: Ulrike Rosenbach: Die Eulenspieglerin, alchemistische Zeichnung mit Darstellung Shivas, 1985, Videostill, (C) VG Bild-Kunst Bonn 2011, und traditionelle Darstellung des Shiva Nataraja

Abb. 185-187: Ulrike Rosenbach: Die Eulenspieglerin, alchemistische Zeichnung mit Hermaphrodit, 1985, Videostill, (C) VG Bild-Kunst Bonn 2011, und zwei Darstellungen des Hermaphrodit aus dem Buch der Heiligen Dreifaltigkeit, 15. Jh.

Abb. 188-189: Ulrike Rosenbach: Die Eulenspieglerin, alchemistische Zeichnung, 1985, Videostill, (C) VG Bild-Kunst Bonn 2011, und unterschiedliche Formen von Triskelen

Abb. 190-191: Ulrike Rosenbach: Die Eulenspieglerin, Spirale und Tau-Zeichen, Videostill, 1985, (C) VG Bild-Kunst Bonn 2011, und Louise Bourgeois: Spiral woman, 2003 
Abb. 192-193: Ulrike Rosenbach: Or-Phelia, 1987, Installation und Aktionsfoto, C VG Bild-Kunst Bonn 2011

Abb. 194-196: Ulrike Rosenbach: Or-Phelia, 1987, 3 Videostills, C VG Bild-Kunst Bonn 2011 Abb. 197-199: Ulrike Rosenbach: Or-Phelia, 1987, 3 Videostills, (C) VG Bild-Kunst Bonn 2011 Abb. 200-202: Ulrike Rosenbach: Or-Phelia, 1987, 3 Videostills, (C) VG Bild-Kunst Bonn 2011 Abb. 203-205: Ulrike Rosenbach: Or-Phelia, 1987, 3 Videostills, (C) VG Bild-Kunst Bonn 2011 Abb. 206-208: Ulrike Rosenbach: Or-Phelia, 1987, 3 Videostills, (C) VG Bild-Kunst Bonn 2011 Abb. 209-211: Ulrike Rosenbach: Or-Phelia, 1987, 3 Videostills, (C) VG Bild-Kunst Bonn 2011 Abb. 212-214: Ulrike Rosenbach: Or-Phelia, 1987, 3 Videostills, (C) VG Bild-Kunst Bonn 2011 Abb. 215-216: Ulrike Rosenbach: Or-Phelia, 1987, 2 Videostills, (C) VG Bild-Kunst Bonn 2011

Abb. 217: John Everett Millais: Ophelia, 1852, Öl auf Leinwand, 112 x $168 \mathrm{~cm}$, Tate Gallery of British Art, London

Abb. 218: Eugene Delacroix, Der Tod der Ophelia, 1844, Öl auf Leinwand, 55 x 64 cm, Sammlung Oskar Reinhart am Römerholz, Winterthur

Abb. 219-220: Ulrike Rosenbach: Or-Phelia, 1987, 2 Videostills, (C) VG Bild-Kunst Bonn 2011

Abb. 221: Lili Fischer: Besentanz, 1986, Aktionsfoto, C VG Bild-Kunst Bonn 2011

Abb. 222: Vesna Vesic: Wash me and I will be whiter than snow, 1998, VHS video production, 7',

Vladimir Zaric e CybeREX Belgrad (C) Vesna Vesic

Abb. 223: William Holman Hunt: The Lady of Shalott (Die Dame von Schalott), 1886-1905, Öl auf

Leinwand, 188 × $146 \mathrm{~cm}$, Hartford (Conn.), Wadsworth Atheneum

Abb. 224: Klaus vom Bruch: War Requiem, 1987, Installation, Foto von Lothar Schopf, (C) VG BildKunst, Bonn 2011

Abb. 225-227: Ulrike Rosenbach: Wie ein Phönix aus der Asche, 1989, 3 Aktionsfotos (von Art Gallery of Ontario Toronto, Canada), (C) VG Bild-Kunst, Bonn 2011

Abb. 228: Ingrid Mwangi: Coloured, 2001, Videostill, C VG Bild-Kunst Bonn 2011,

Abb. 229-230: Walli Höfinger: Hängen, 2 Aktionsfotos, (C) Walli Höfinger

Abb. 231-232: Ulrike Rosenbach: Clan Communication, 2000, Videostills, (C) VG Bild-Kunst, Bonn 2011

Abb. 233-234: Ulrike Rosenbach: Herzpendel, 1989, Installation, (C) VG Bild-Kunst, Bonn 2011

Abb. 235: Ulrike Rosenbach: Herzpendel, Detail, 1989, (C) VG Bild-Kunst, Bonn 2011

Abb. 236: Ulrike Rosenbach: Requiem für eine Eiche, 1990, Installation, (C) VG Bild-Kunst, Bonn 2011

Abb. 237: Ulrike Rosenbach: Die Schlacht der Bäume, 1991, Installation (Foto: Dietlinde Stroh), (C) VG Bild-Kunst, Bonn 2011

Abb. 238: Ulrike Rosenbach: Der Wind meiner Träume, 1986, Aktionsfoto, C VG Bild-Kunst, Bonn 2011

Abb. 239-240: Ulrike Rosenbach: Isabell im Wald, 1990, 2 Installationen, (C) VG Bild-Kunst Bonn 2011

Abb. 241: Ulrike Rosenbach: Das Bild der Frau in der Nachkriegszeit, 1994, Installation, Haus der

Geschichte, Bonn, (C) VG Bild-Kunst Bonn 2011

Abb. 242-243: Ulrike Rosenbach: Das Bild der Frau in der Nachkriegszeit, 1994, Videostills, (C) VG Bild-Kunst Bonn 2011

Abb. 244: Ulrike Rosenbach: Das Bild der Frau in der Nachkriegszeit, 1994, Fassung 2, Installation,

(C) VG Bild-Kunst Bonn 2011

Abb. 245-246: Ulrike Rosenbach: Hildegard Walk, 1994, Installation und Videostill, (C) VG BildKunst, Bonn 2011

Abb. 247-248: Ulrike Rosenbach: Spiegeleis, 1994, Installation und Videostill, (C) VG Bild-Kunst, Bonn 2011

Abb. 249: Ulrike Rosenbach: Das eiserne Zeitalter, 1995, Installation, (C) VG Bild-Kunst, Bonn 2011 Abb. 250-253: Ulrike Rosenbach: Über den Tod, 1995, Einladungskarte und 3 Installationsansichten, (C) VG Bild-Kunst, Bonn 2011 
Abb. 254: Tanzende Dakini, (C) Shah Jahan (Quelle: http://en.wikipedia.org/wiki/File:Varjayogini.jpg)

Abb. 255: Damien Hirst: Die physische Unmöglichkeit des Todes in den Gedanken eines Lebenden, 1991, (C) Damien Hirst and Science Ltd. All rights reserved/ VG Bild-Kunst, Bonn 2011

Abb. 256: Ulrike Rosenbach: Im Palast der neugeborenen Kinder, 1997, Installation, (C) VG BildKunst Bonn 2011

Abb. 257: Ulrike Rosenbach: Über die Kinder, 1997, Videostill, (C) VG Bild-Kunst Bonn 2011

Abb. 258: Ulrike Rosenbach: Nirwana, 2002, Installation, (C) VG Bild-Kunst Bonn 2011

Abb. 259: Ulrike Rosenbach: Last Call für Engel, 1996, Installation, Heidenheim, (C) VG Bild-Kunst Bonn 2011

Abb. 260: Katalogcover „Last Call für Engel“

Abb. 261-262: Ulrike Rosenbach: Über die Engel, Fribourg, 1995, Aktionsfoto (von Dietlinde Stroh), (C) VG Bild-Kunst Bonn 2011

Abb. 263: Ulrike Rosenbach: Über die Engel, Hannover, 1995, Aktionsfoto (von Dietlinde Stroh), (C) VG Bild-Kunst Bonn 2011

Abb. 264-267: Ulrike Rosenbach: Über die Engel, Nienburg, 1997, 4 Videostills, (C) VG Bild-Kunst Bonn 2011

Abb. 268-270: Ulrike Rosenbach: Protect the Mamas, 1990 und Baumengel (zweiteilig), 1985, Zeichnungen, (C) VG Bild-Kunst Bonn 2011

Abb. 271: Eija-Liisa Ahtila: The House, 2002, Videoinstallation, New York, Privatsammlung Gattung DVD-Projektion Datierung 2002. Urheberrechte: Finstral, (C) VG Bild-Kunst Bonn 2011

Abb. 272: John Baldessari, The Telephone Book (With Pearls), Schwarzweißfotocollage, 1988,

\section{Kapitel VI} (C) John Baldessari

Abb. 273-274: Ulrike Rosenbach: Ein geerdeter Engel braucht keine Flügel, 1985, und Über die Engel, Fribourg, 1995, Aktionsfoto (von Dietlinde Stroh), C VG Bild-Kunst Bonn 2011

Mein Dank gilt:

Thomas Baumgärtl

Derzsi Csongor

Joachim Fischer

Hans-Joachim Frese

FrauenMediaTurm, Köln

Prof. Dr. Ruth Hampe

Prof. Dr. Wulf Herzogenrath

Dr. Carsten Jöhnk

Elke Kaiser

Dr. Stefan Kraß

Gisela Meyer-Kaufmann

Niedersächsische Graduiertenförderung

Stephan Oertel

Prof. Ulrike Rosenbach

Andreas Vick

Prof. Dr. Carsten-Peter Warncke

Beate Zinke

und meiner Familie. 
D as Ouevre der international renommierten Künstlerin Ulrike Rosenbach ist facettenreich. Sie arbeitet hauptsächlich mit dem Medium Video, hat während der vergangenen vier Jahrzehnte ihres Schaffens zahlreiche Performances aufgeführt. Bereits Anfang der 1970er Jahre entwickelte sie ihre spezifische Form der Videoperformance. Auch gehören Fotografien und Zeichnungen zum weiterhin wachsenden Werkkonvolut. Die vorliegende Untersuchung zu ihrem künstlerischen Wirken fokussiert auf ikonographische Fragestellungen. Dabei werden besonders die Videound Performancearbeiten der Künstlerin in den Blick genommen, die an der Düsseldorfer Akademie studierte und bei Joseph Beuys Meisterschülerin war. Wenn Ulrike Rosenbach bisher hauptsächlich als feministische Künstlerin rezipiert wurde, so sind ihre frühen Arbeiten sicherlich durch feministische Fragestellungen und Motive bestimmt, doch verändern sich ihre Themen im Folgenden sukzessive. Zunehmend treten allgemeinmenschliche Fragestellungen in den Mittelpunkt ihres Schaffens und ihr Werk ist geprägt durch eine spezifische Bildsprache, die in eine Semantisierung der Materialien mündet. Zu dieser künstlerischen Welt bietet diese Analyse einen fundierten Zugang. 